\title{
GREENIDGE MULTI-POLLUTANT CONTROL PROJECT
}

Final Report of Work Performed May 19, 2006 - October 18, 2008

Principal Author Daniel P. Connell

April 2009

U.S. Department of Energy Cooperative Agreement DE-FC26-06NT41426

CONSOL Energy Inc.

Research \& Development

4000 Brownsville Road

South Park, PA 15129

AES Greenidge LLC

590 Plant Road

Dresden, NY 14441

Babcock Power Environmental Inc.

5 Neponset Street

Worcester, MA 01606 


\section{DISCLAIMER}

This report was prepared as an account of work sponsored by an agency of the United States Government. Neither the United States Government nor any agency thereof, nor any of their employees, makes any warranty, express or implied, or assumes any legal liability or responsibility for the accuracy, completeness, or usefulness of any information, apparatus, product, or process disclosed, or represents that its use would not infringe privately owned rights. Reference herein to any specific commercial product, process, or service by trade name, trademark, manufacturer, or otherwise does not necessarily constitute or imply its endorsement, recommendation, or favoring by the United States Government or any agency thereof. The views and opinions of authors expressed herein do not necessarily state or reflect those of the United States Government or any agency thereof.

\section{NOTICE}

The drawing titled "AES Greenidge \#4, Dresden, New York, NOxOUT Utility System, System Overview Sheet 1" in Appendix B is Copyright (C) 2009 Fuel Tech, Inc. This paper was written with the support of the U.S. Department of Energy under Contract No. DE-FC26-06NT41426. The Government reserves for itself and others acting on its behalf a royalty-free, nonexclusive, irrevocable, worldwide license for Governmental purposes to publish, distribute, translate, duplicate, exhibit, and perform this copyrighted paper. 


\section{ABSTRACT}

The Greenidge Multi-Pollutant Control Project was conducted as part of the U.S. Department of Energy's Power Plant Improvement Initiative to demonstrate an innovative combination of air pollution control technologies that can cost-effectively reduce emissions of $\mathrm{SO}_{2}, \mathrm{NO}_{\mathrm{x}}, \mathrm{Hg}$, acid gases $\left(\mathrm{SO}_{3}, \mathrm{HCl}\right.$, and $\left.\mathrm{HF}\right)$, and particulate matter from smaller coal-fired electric generating units (EGUs). There are about 400 units in the United States with capacities of 50-300 MW that currently are not equipped with selective catalytic reduction (SCR), flue gas desulfurization (FGD), or mercury control systems. Many of these units, which collectively represent more than $55 \mathrm{GW}$ of installed capacity, are difficult to retrofit for deep emission reductions because of space constraints and unfavorable economies of scale, making them increasingly vulnerable to retirement or fuel switching in the face of progressively more stringent environmental regulations. The Greenidge Project sought to confirm the commercial readiness of an emissions control system that is specifically designed to meet the environmental compliance requirements of these smaller coal-fired EGUs by offering a combination of deep emission reductions, low capital costs, small space requirements, applicability to high-sulfur coals, mechanical simplicity, and operational flexibility.

The multi-pollutant control system includes a $\mathrm{NO}_{x} \mathrm{OUT} \mathrm{CASCADE}^{\circledR}$ hybrid selective non-catalytic reduction (SNCR) / in-duct SCR system for $\mathrm{NO}_{x}$ control and a Turbosorp ${ }^{\circledR}$ circulating fluidized bed dry scrubbing system (with a new baghouse) for $\mathrm{SO}_{2}, \mathrm{SO}_{3}, \mathrm{HCl}, \mathrm{HF}$, and particulate matter control. Mercury removal is provided as a co-benefit of the in-duct SCR, dry scrubber, and baghouse, and by injection of activated carbon upstream of the scrubber, if required. The multi-pollutant control system was installed and tested on the 107-MW $\mathrm{MW}_{\mathrm{e}}$, 1953-vintage AES Greenidge Unit 4 by a team including CONSOL Energy Inc. as prime contractor, AES Greenidge LLC as host site owner, and Babcock Power Environmental Inc. as engineering, procurement, and construction contractor. About $44 \%$ of the funding for the project was provided by the U.S. Department of Energy, through its National Energy Technology Laboratory, and the remaining $56 \%$ was provided by AES Greenidge. Project goals included reducing high-load $\mathrm{NO}_{\mathrm{x}}$ emissions to $\leq 0.10 \mathrm{lb} / \mathrm{mmBtu}$; reducing $\mathrm{SO}_{2}, \mathrm{SO}_{3}, \mathrm{HCl}$, and $\mathrm{HF}$ emissions by at least $95 \%$; and reducing $\mathrm{Hg}$ emissions by at least $90 \%$ while the unit fired $2-4 \%$ sulfur eastern U.S. bituminous coal and co-fired up to $10 \%$ biomass.

This report details the final results from the project. The multi-pollutant control system was constructed in 2006 , with a total plant cost of $\$ 349 / \mathrm{kW}$ and a footprint of 0.4 acre - both substantially less than would have been required to retrofit AES Greenidge Unit 4 with a conventional SCR and wet scrubber. Start-up of the multi-pollutant control system was completed in March 2007, and the performance of the system was then evaluated over an approximately 18-month period of commercial operation. Guarantee tests conducted in March-June 2007 demonstrated attainment of all of the emission reduction goals listed above. Additional tests completed throughout the performance evaluation period showed $96 \% \mathrm{SO}_{2}$ removal, $98 \%$ mercury removal (with no activated carbon injection), $95 \% \mathrm{SO}_{3}$ removal, and $97 \% \mathrm{HCl}$ removal during longer-term operation. Greater than $95 \% \mathrm{SO}_{2}$ removal efficiency was observed even when the unit fired high-sulfur coals containing up to $4.8 \mathrm{lb} \mathrm{SO} / \mathrm{mmBtu}$. Particulate matter emissions were reduced by more than $98 \%$ relative to the emission rate observed prior to installation of the technology. The performance of the hybrid SNCR/SCR system was affected by problems with large particle ash, ammonia slip, and nonideal combustion characteristics, and high-load $\mathrm{NO}_{\mathrm{x}}$ emissions averaged $0.14 \mathrm{lb} / \mathrm{mmBtu}$ during long-term operation. Nevertheless, the system has reduced the unit's overall $\mathrm{NO}_{\mathrm{x}}$ emissions by $52 \%$ on a $\mathrm{lb} / \mathrm{mmBtu}$ basis.

The commercial viability of the multi-pollutant control system was demonstrated at AES Greenidge Unit 4. The system, which remains in service after the conclusion of the project, has enabled the unit to satisfy its permit requirements while continuing to operate profitably. As a result of the success at AES Greenidge Unit 4, three additional deployments of the Turbosorp ${ }^{\circledR}$ technology had been announced by the end of the project. 


\section{TABLE OF CONTENTS}

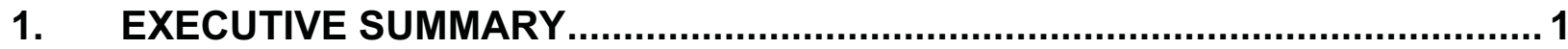

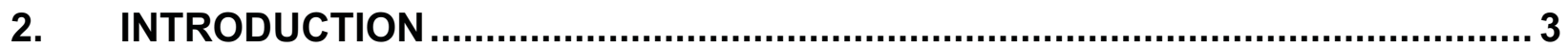

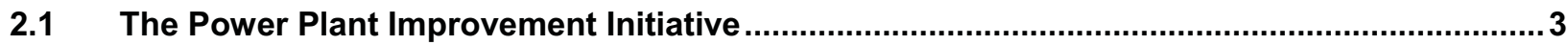

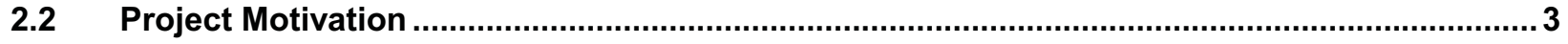

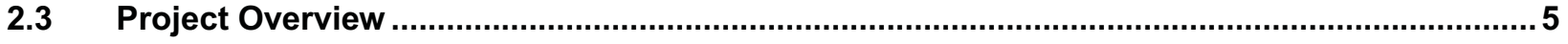

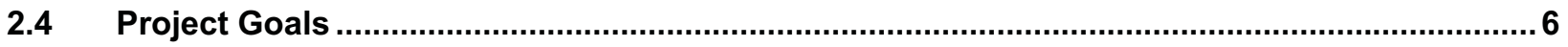

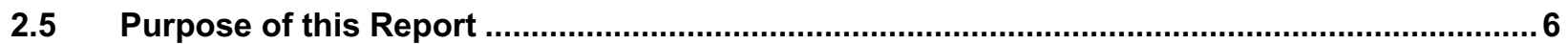

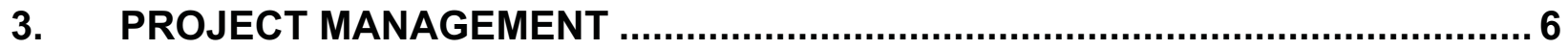

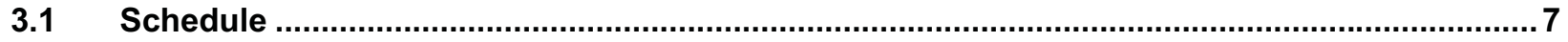

$3.2 \quad$ Budget

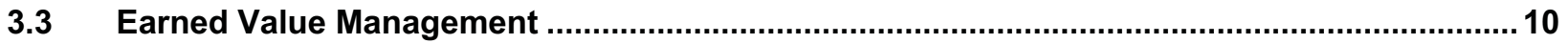

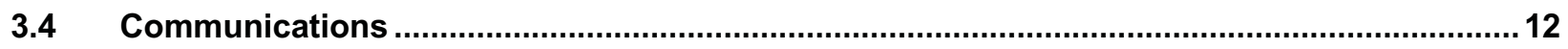

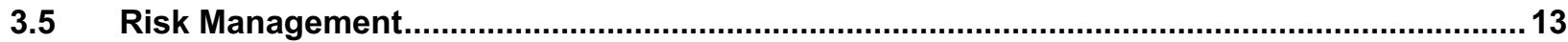

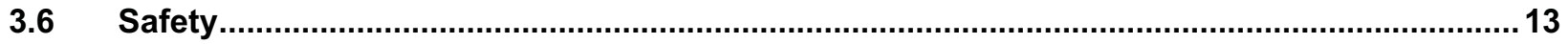

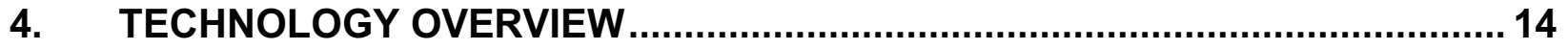

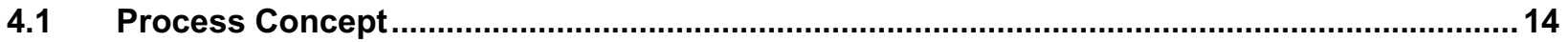

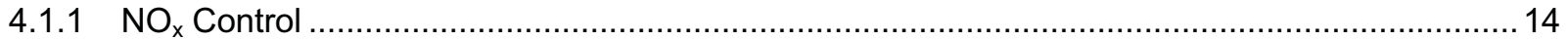

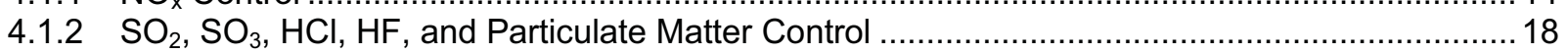

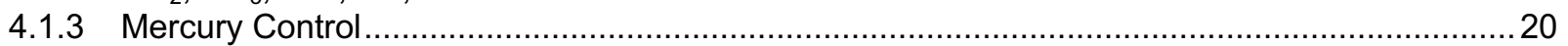

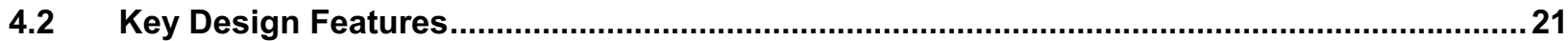

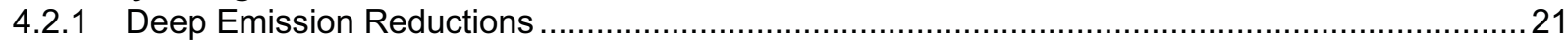

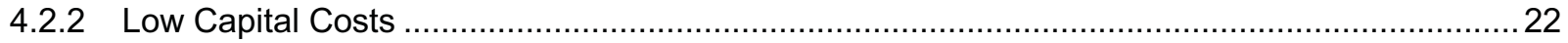

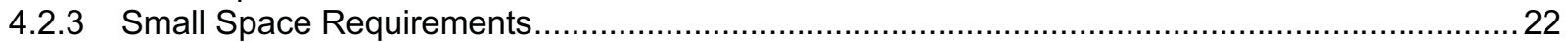

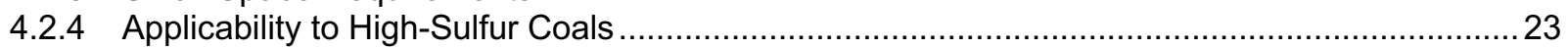

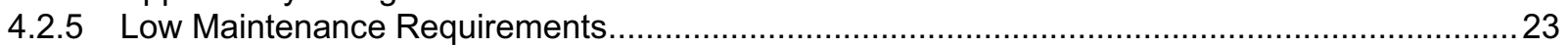

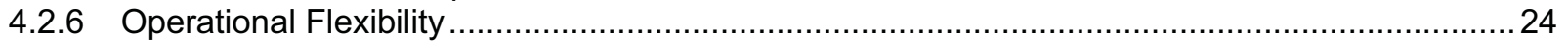

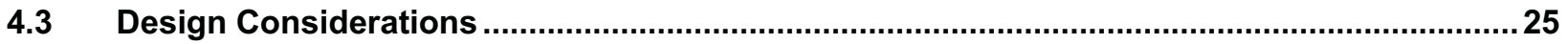

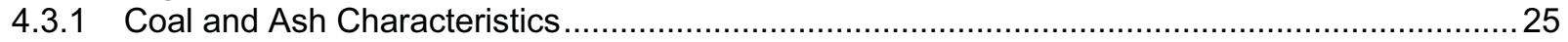

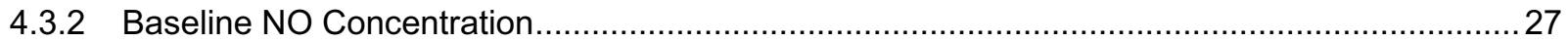

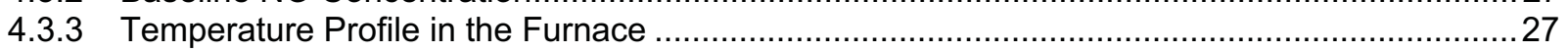

4.3.4 Flue Gas Residence Time and Flow Profile in the Furnace ..............................................2 27 


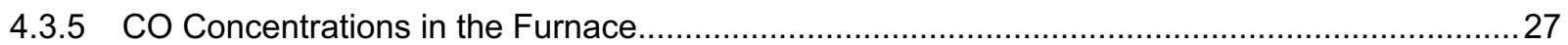

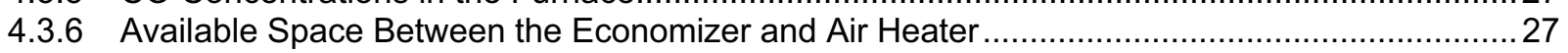

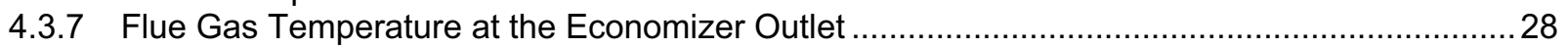

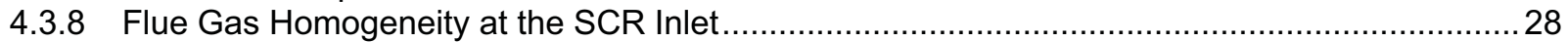

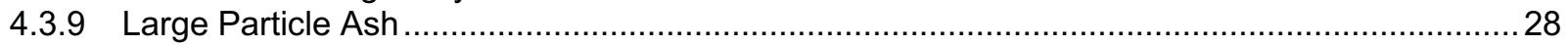

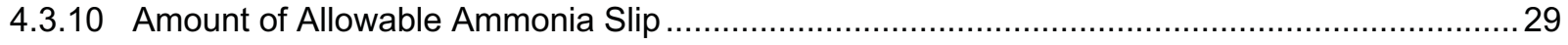

4.3.11 Approach to Adiabatic Saturation in the Absorber Vessel ...................................................29

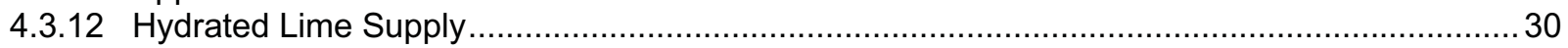

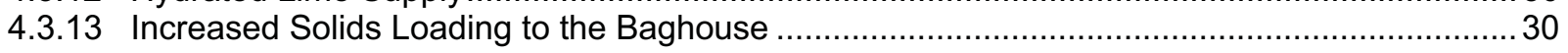

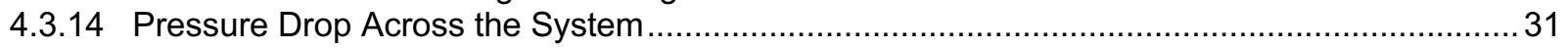

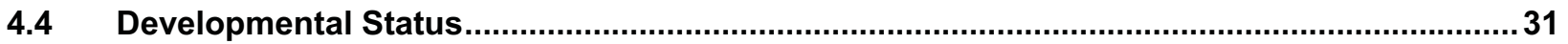

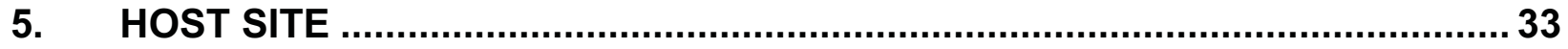

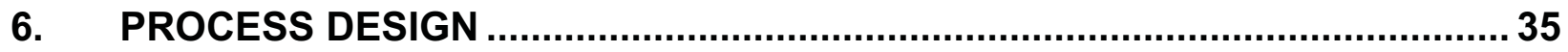

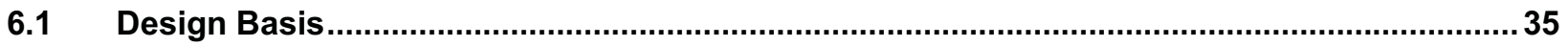

6.2 Description by Major Process Component …........................................................................ 36

6.2.1 Selective Non-Catalytic Reduction System................................................................. 36

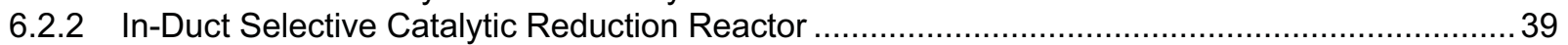

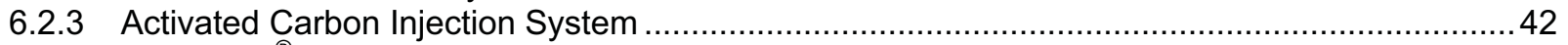

6.2.4 Turbosorp ${ }^{\circledR}$ Circulating Fluidized Bed Dry Scrubber ............................................................ 43

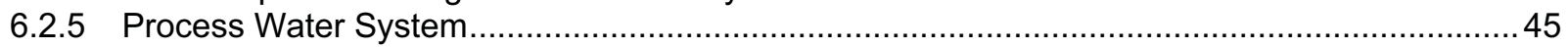

6.2.6 Lime Storage, Hydration, and Injection System ......................................................... 46

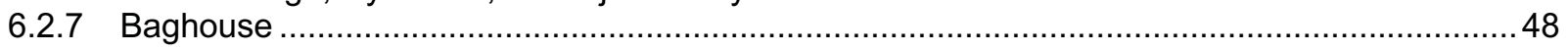

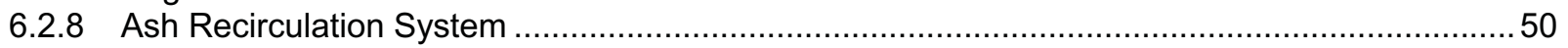

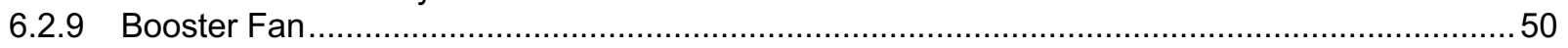

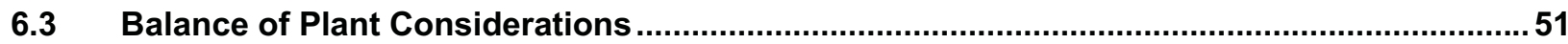

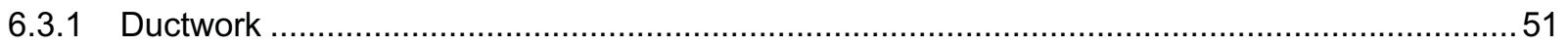

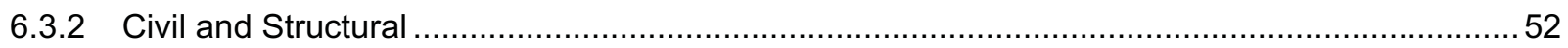

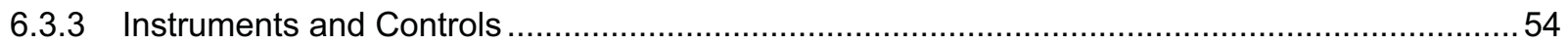

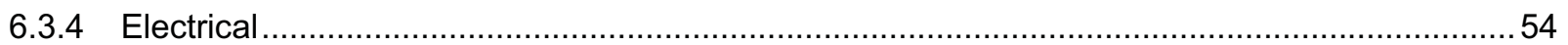

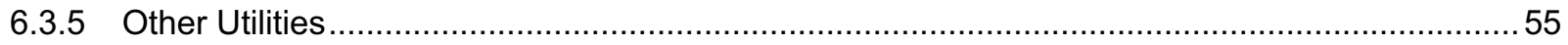

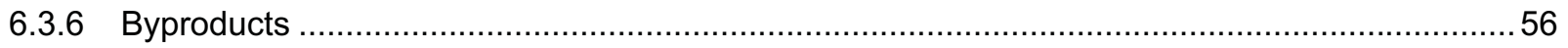

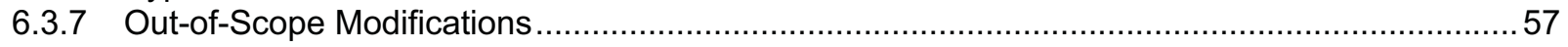

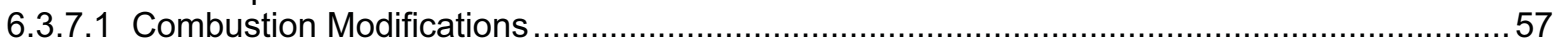

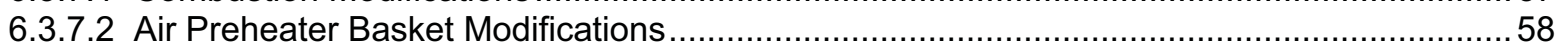

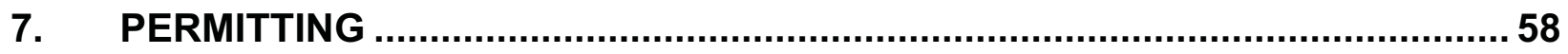

8. CONSTRUCTION, START-UP, AND COMMISSIONING ..................................60

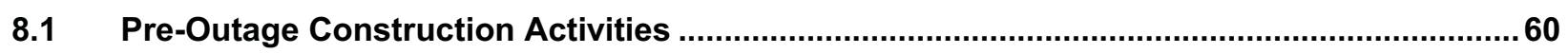

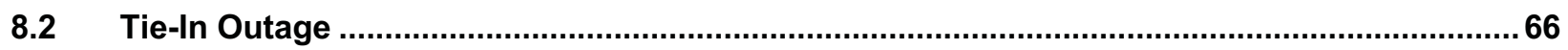

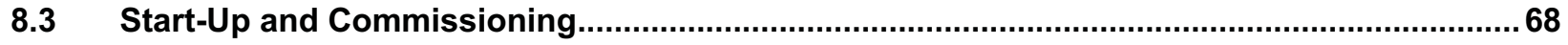

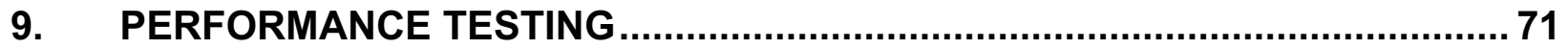




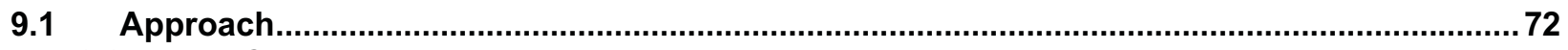

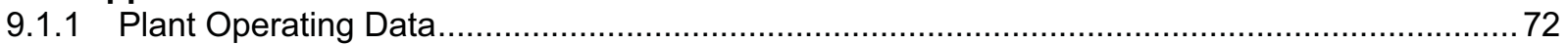

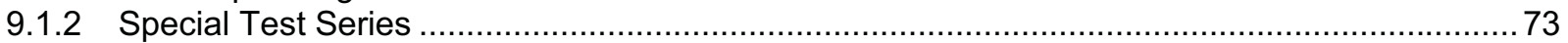

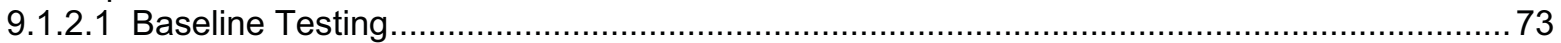

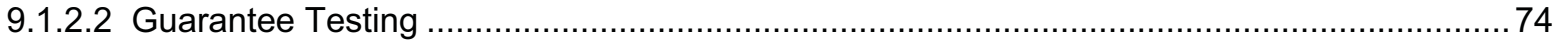

9.1.2.2.1 Sampling Campaign on March 28-30, 2007 .......................................................... 74

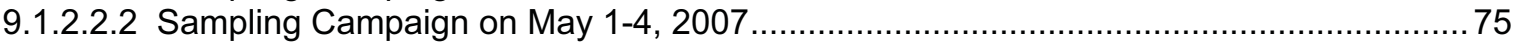

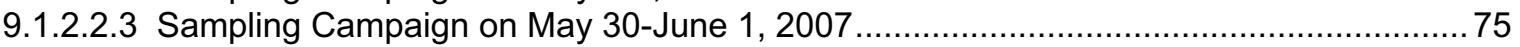

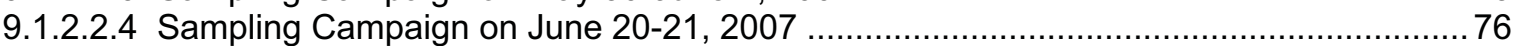

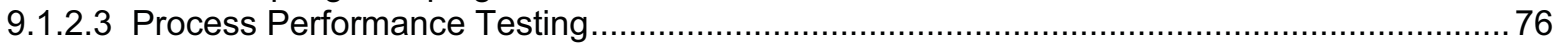

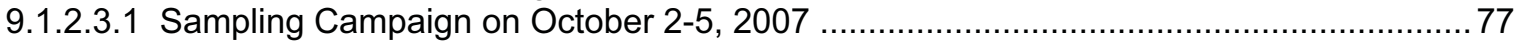

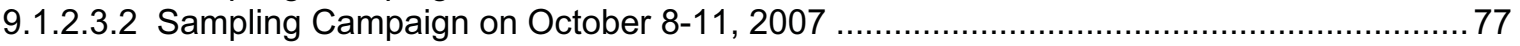

9.1.2.3.3 Sampling Campaign on November 13-16, 2007 .................................................. 78

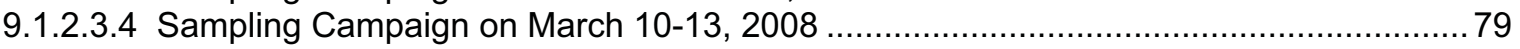

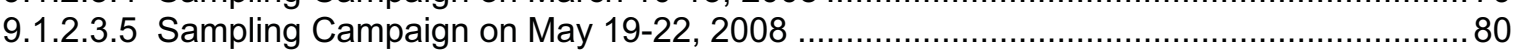

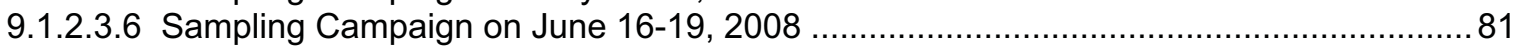

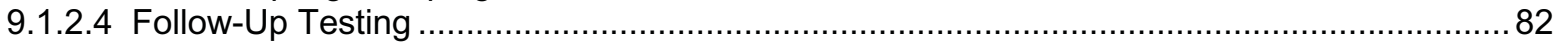

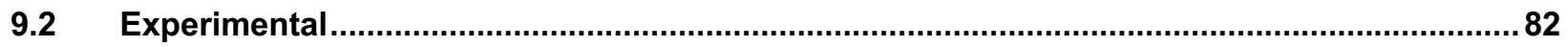

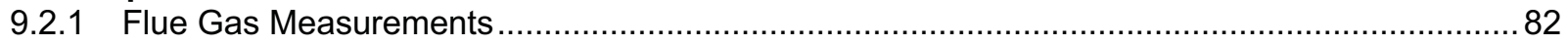

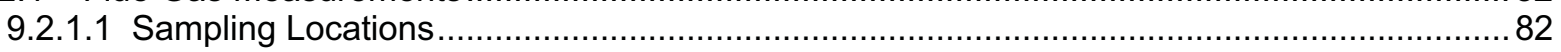

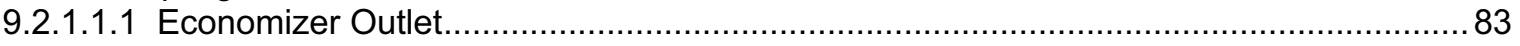

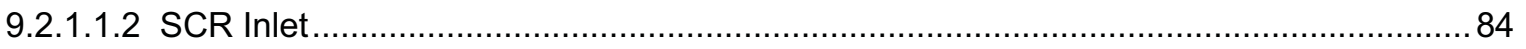

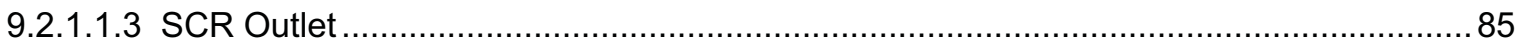

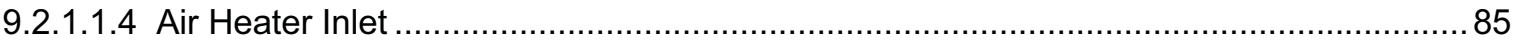

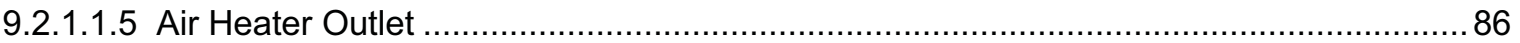

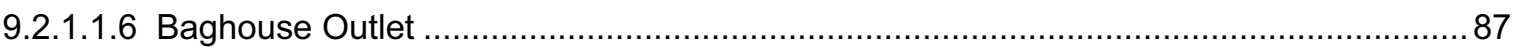

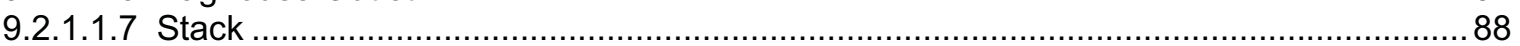

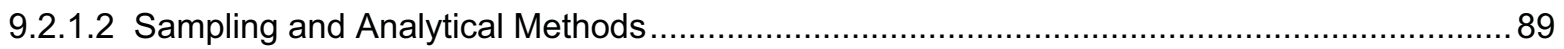

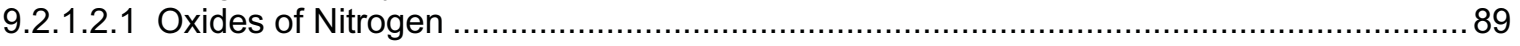

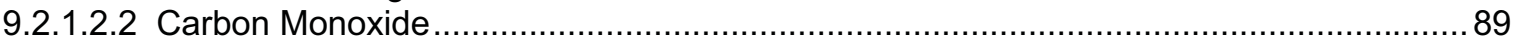

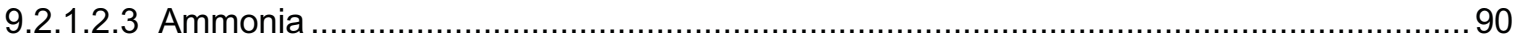

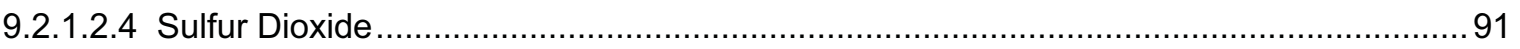

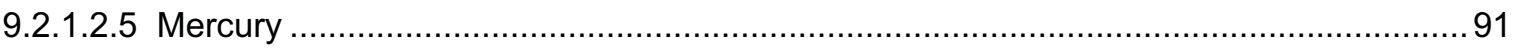

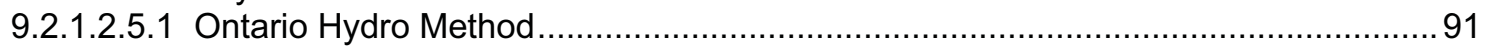

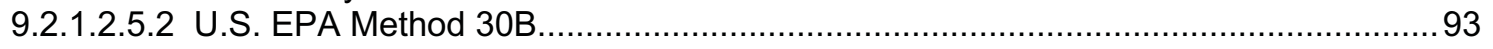

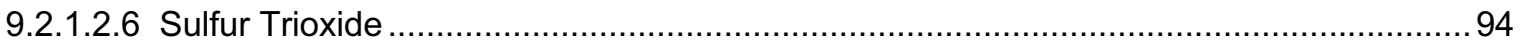

9.2.1.2.7 Hydrogen Chloride, Hydrogen Fluoride, and Particulate Matter .................................... 95

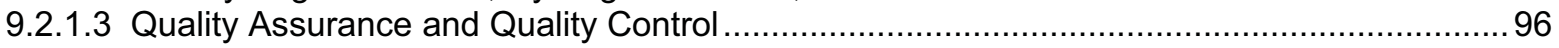

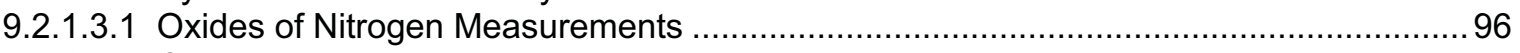

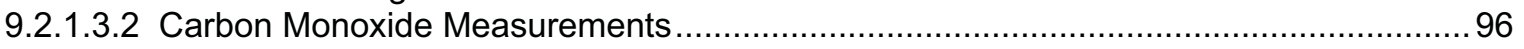

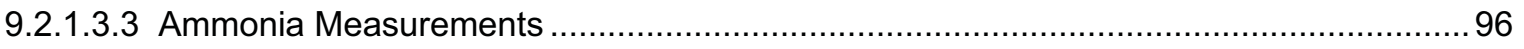

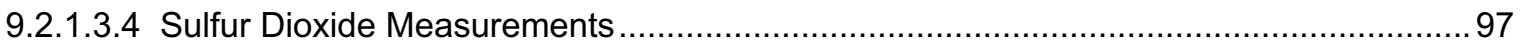

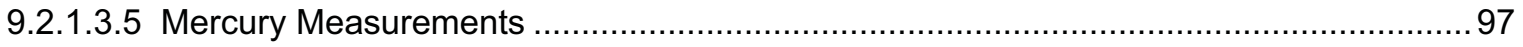

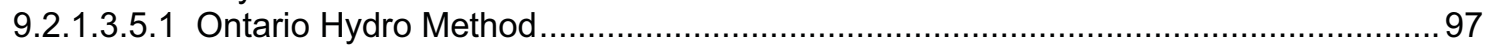

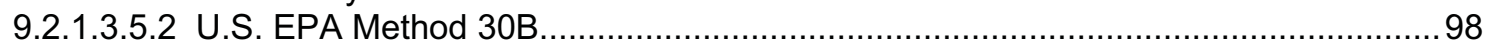

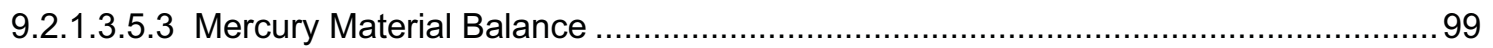

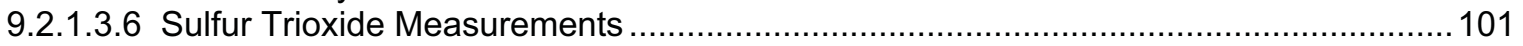

9.2.1.3.7 Hydrogen Chloride and Hydrogen Fluoride Measurements ...................................... 102

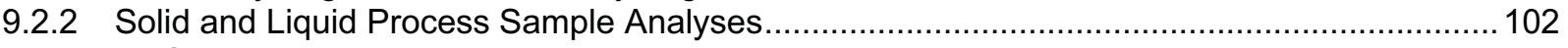

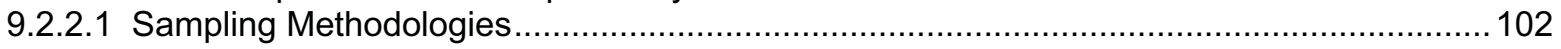

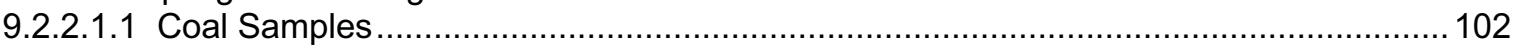

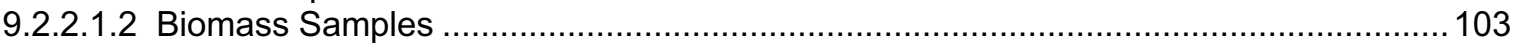

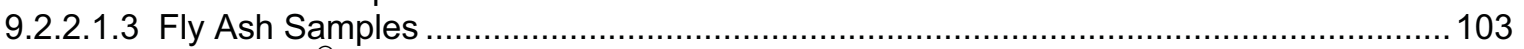

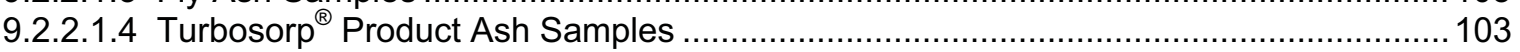

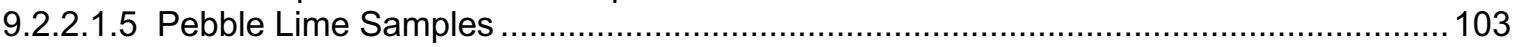




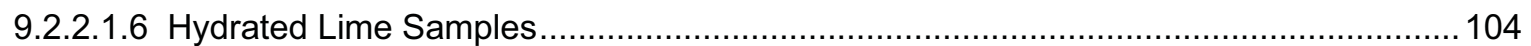

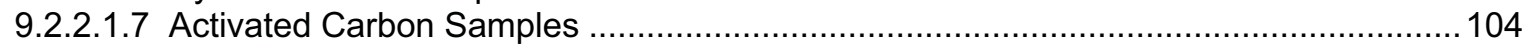

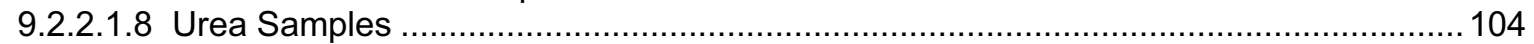

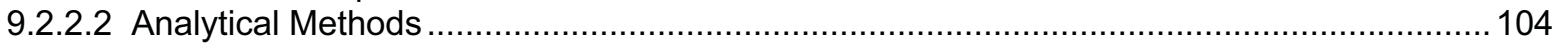

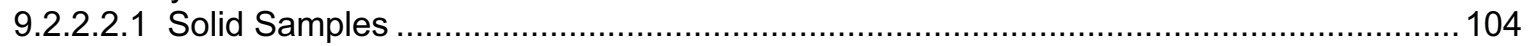

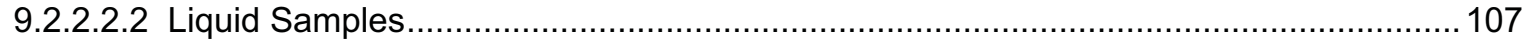

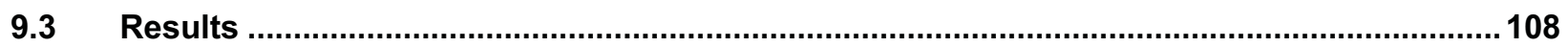

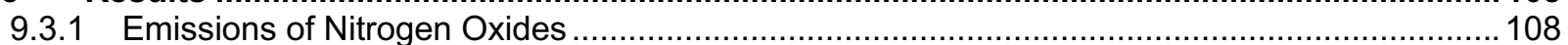

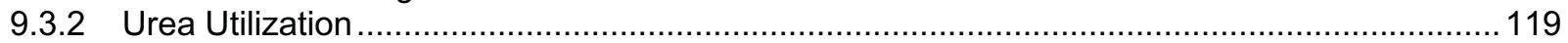

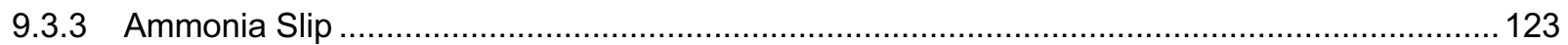

9.3.4 $\mathrm{SO}_{2}$-to-SO $\mathrm{SO}_{3}$ Conversion across the SCR Catalyst ..................................................... 131

9.3.5 Mercury Oxidation across the SCR Catalyst............................................................... 132

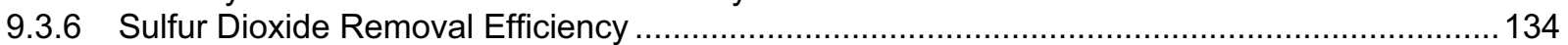

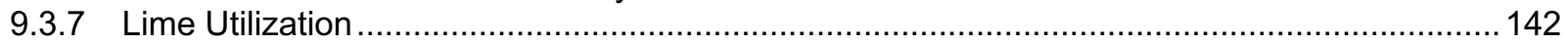

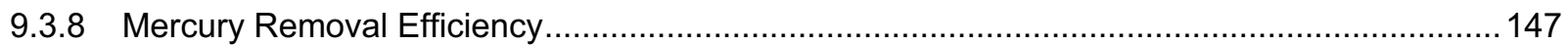

9.3.9 Sulfur Trioxide Removal Efficiency ................................................................................ 153

9.3.10 Hydrogen Chloride Removal Efficiency ....................................................................... 158

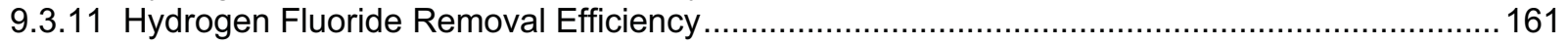

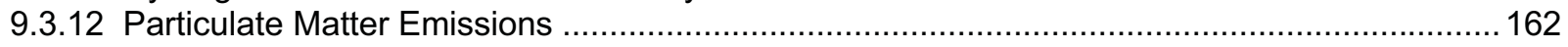

10. OPERATING AND MAINTENANCE EXPERIENCE .................................... 165

10.1 Routine Operating and Maintenance Requirements .....................................................165

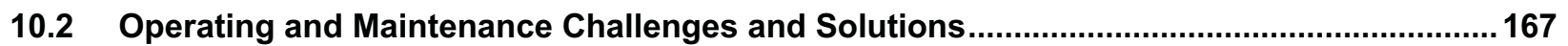

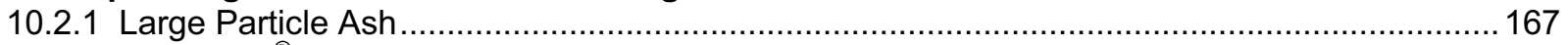

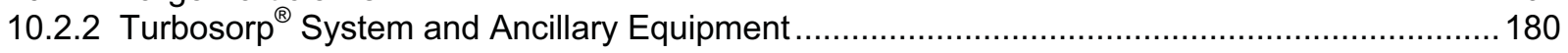

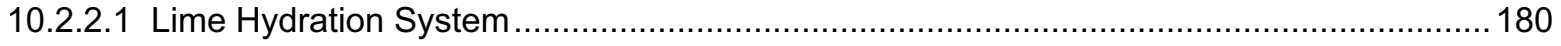

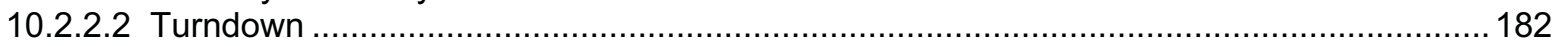

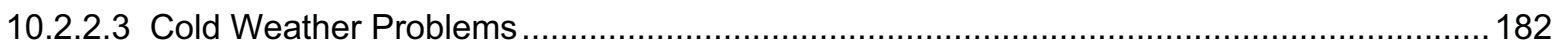

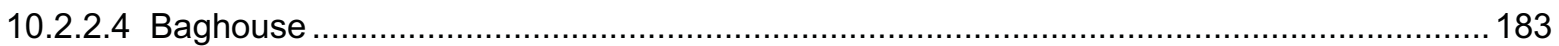

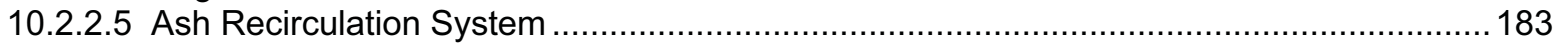

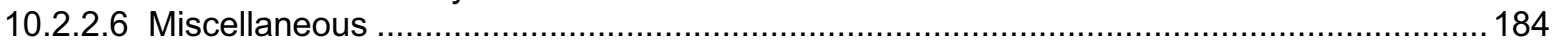

10.3 Operating and Maintenance Labor Requirements .......................................................... 185

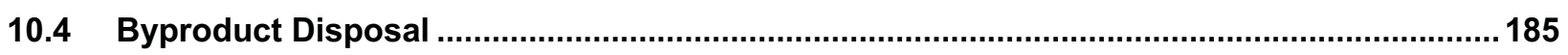

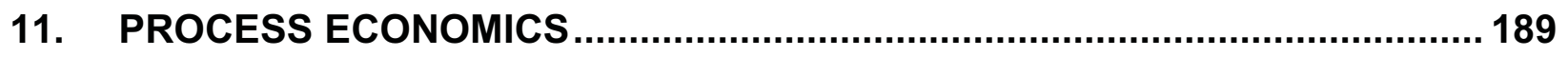

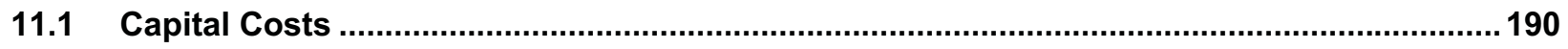

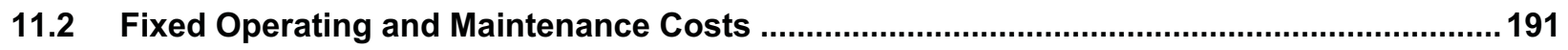

11.3 Variable Operating and Maintenance Costs ................................................................... 192

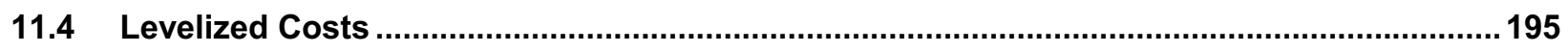

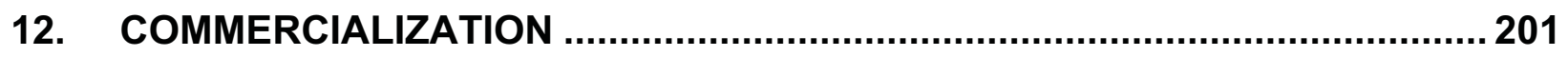

13. CONCLUSIONS AND RECOMMENDATIONS .............................................. 203 
REFERENCES

PROJECT BIBLIOGRAPHY

ACRONYMS AND ABBREVIATIONS

CHEMICAL SYMBOLS.

APPENDIX A - PROJECT SCHEDULE

APPENDIX B - ENGINEERING DRAWINGS

APPENDIX C - LIST OF MAJOR EQUIPMENT

APPENDIX D - PROJECT LOG

APPENDIX E - FLUE GAS SAMPLING SCHEDULES FROM SPECIAL TEST SERIES

APPENDIX F - PHOTOGRAPHS OF FLUE GAS SAMPLING LOCATIONS

APPENDIX G - CLEAN AIR ENGINEERING TESTING REPORTS

APPENDIX H - FIELD SAMPLING DATA SHEETS AND SAMPLING DATA REDUCTION WORKSHEETS

APPENDIX I - LABORATORY ANALYSIS RESULTS FOR FLUE GAS SAMPLES

APPENDIX J - SOLID AND LIQUID PROCESS SAMPLE ANALYSIS RESULTS

APPENDIX K - MERCURY MATERIAL BALANCES

APPENDIX L - BULK CHEMICAL ANALYSIS OF LPA AND ASH SAMPLES COLLECTED IN AND AROUND THE SCR REACTOR IN DECEMBER 2007 


\section{LIST OF FIGURES}

Figure 1. Map of operating coal-fired EGUs in the United States with capacities of $50-300 \mathrm{MW}_{\mathrm{e}} \ldots \ldots \ldots \ldots . . . .$.

Figure 2. Cumulative monthly Planned Value, Actual Cost, and Earned Value for the Greenidge Multi-Pollutant Control Project.

Figure 3. Cumulative monthly Schedule Performance Index and Cost Performance Index for the Greenidge Multi-Pollutant Control Project.

Figure 4. Schematic of the multi-pollutant control process that was demonstrated as part of the Greenidge Project.

Figure 5. Conceptual depiction of the effect of temperature on urea utilization and ammonia slip in SNCR, and the implications of this effect for hybrid SNCR/SCR design......

Figure 6. Conceptual illustration of the Delta Wing ${ }^{\mathrm{TM}}$ static mixing technology......

Figure 7. Schematic of the Turbosorp ${ }^{\circledR}$ circulating fluidized bed dry scrubbing system. Red, blue, and green arrows indicate the paths of solids, liquids, and gases, respectively, through the system.

Figure 8. Operating strategy for the hybrid $\mathrm{NO}_{\mathrm{x}}$ control system that was demonstrated as part of the Greenidge Project.

Figure 9. Aerial photograph of the AES Greenidge plant, as viewed from the south prior to the multi-pollutant control project.

Figure 10. Photograph showing several of the SNCR Zone 1 injectors at AES Greenidge Unit 4

Figure 11. Photograph showing one of the two multiple nozzle lances installed at AES Greenidge Unit 4.

Figure 12. Example of CFD modeling results used in the design of the hybrid $\mathrm{NO}_{x}$ control system for AES Greenidge Unit 4 (Boiler 6). Shown are temperature and velocity profiles for a case in which the unit is operating at $103 \%$ of its MCR.

Figure 13. Photograph showing the urea storage tank and HFD module at AES Greenidge Unit $4 \ldots \ldots \ldots . . .38$

Figure 14. Photograph showing the SNCR Zone 2 distribution module at AES Greenidge Unit 4.

Figure 15. Photograph of the physical flow model used to design the in-duct SCR reactor (courtesy of Ruscheweyh Consult $\mathrm{GmbH}$ )....

Figure 16. Schematic of the large particle ash removal system that was installed above the induct SCR reactor at AES Greenidge Unit 4.

Figure 17. Photograph of the in-duct SCR reactor at AES Greenidge Unit 4.

Figure 18. Photograph of the activated carbon injection system at AES Greenidge Unit 4.

Figure 19. Photograph of the Turbosorp ${ }^{\circledR}$ circulating fluidized bed dry scrubbing system, including ancillary equipment, at AES Greenidge Unit 4.

Figure 20. Process control schematic showing major control loops for the Turbosorp ${ }^{\circledR}$ circulating fluidized bed dry scrubber at AES Greenidge Unit 4. Lime injection control is shown in green; water injection control is shown in blue; solid product recycle control is shown in red; and solid product rejection control is shown in orange. 
Figure 21. Photograph showing the Turbosorp ${ }^{\circledR}$ water injection lance (in service). 46

Figure 22. Photograph of the lime hydrator at AES Greenidge. The chute in the foreground (with the red door) is used to convey hydrated lime from the cyclone to the hydrated lime silo.

Figure 23. Photograph showing part of the lime hydration system at AES Greenidge Unit 4. The hydrated lime classifier, cyclone, pebble lime weigh feeder, and bottom of the pebble lime storage silo are all visible.

Figure 24. Photograph showing the system that is used to feed hydrated lime to the Turbosorp ${ }^{\circledR}$ vessel at AES Greenidge Unit 4.

Figure 25. Photograph showing the inside of the baghouse penthouse at AES Greenidge Unit $4 \ldots \ldots \ldots . . .49$

Figure 26. Photograph of one of the air slide conveyers at AES Greenidge Unit 4. .50

Figure 27. Photograph of the booster fan at AES Greenidge Unit 4.

Figure 28. Photograph taken prior to the start of construction of the site for the outdoor portion of the multi-pollutant control system, as viewed from the southwest.

Figure 29. Photograph showing structural steel being erected for the baghouse support structure on April 6, 2006.

Figure 30. Photograph showing several baghouse modules and a partially assembled Turbosorp $^{\circledR}$ absorber section in the lay-down area in early May 2006.

Figure 31. Photograph showing one of the baghouse modules being lifted into place in mid-May 2006.

Figure 32. Photograph showing assembly of the Turbosorp ${ }^{\circledR}$ inlet and venturi sections in early June 2006.

Figure 33. Photograph showing installation of the roof of the Turbosorp ${ }^{\circledR}$ absorber during the first week of July 2006. The first pieces of structural steel for the baghouse penthouse are also visible......

Figure 34. Photograph showing one of the air slides being lifted into place on August 16, 2006.

Figure 35. Photograph showing the quicklime silo being set in place in September 2006. 65

Figure 36. Photograph taken on October 27, 2006, at the start of SCR reactor construction. 67

Figure 37. Photograph showing catalyst modules being loaded into the SCR reactor in November 2006.

Figure 38. Photograph showing the installation of the new ductwork used to transport the hydrator exhaust to the inlet of the Turbosorp ${ }^{\circledR}$ vessel.

Figure 39. Schematic showing the locations where flue gas sampling was performed during performance testing of the multi-pollutant control system at AES Greenidge Unit 4

Figure 40. Schematic of the stack sampling location at AES Greenidge Unit 4, including dimensions and traverse points.

Figure 41. Schematic of the Ontario Hydro Method sampling train in a Method 17 configuration. 92

Figure 42. Schematic of the U.S. EPA Method 30B sampling train. .93

Figure 43. $\mathrm{NO}_{\mathrm{x}}$ emission rate and total urea flow rate observed during guarantee testing of the multi-pollutant control system between 8:00 and 20:00 eastern standard time (EST) on 
March 28, 2007. The average unit load during this period was $105 \mathrm{MW}_{\mathrm{g}} . \mathrm{NO}_{\mathrm{x}}$ emissions were measured by the unit's stack CEM. The urea flow rate was measured by the SNCR system's flow meters and represents the flow of $50 \%(\mathrm{w} / \mathrm{w})$ urea solution.

Figure 44. $\mathrm{NO}_{\mathrm{x}}$ emission rate and total urea flow rate observed during guarantee testing of the multi-pollutant control system between 8:00 and 20:00 EST on May 1, 2007. The average unit load during this period was $106 \mathrm{MW}_{\mathrm{g}}$. $\mathrm{NO}_{\mathrm{x}}$ emissions were measured by the unit's stack CEM. The urea flow rate was measured by the SNCR system's flow meters and represents the flow of $50 \%(\mathrm{w} / \mathrm{w})$ urea solution.

Figure 45. $\mathrm{NO}_{\mathrm{x}}$ emission rate and total urea flow rate observed during guarantee testing of the multi-pollutant control system between 8:00 and 20:00 EST on June 20, 2007. The average unit load during this period was $106 \mathrm{MW}_{\mathrm{g}}$. $\mathrm{NO}_{\mathrm{x}}$ emissions were measured by the unit's stack CEM. The urea flow rate was measured by the SNCR system's flow meters and represents the flow of $50 \%(\mathrm{w} / \mathrm{w})$ urea solution.

Figure 46. Comparison of $\mathrm{NO}_{x}$ emissions from AES Greenidge Unit 4 measured during August 2007-September 2008, following installation of the multi-pollutant control system, with those measured during August 2004-September 2005, prior to installation of the system. Data were obtained from the unit's stack CEM. The average $\mathrm{NO}_{x}$ emission rate is plotted as a function of gross unit load. The percent $\mathrm{NO}_{x}$ reduction computed from these data for each unit load is also shown. Data are not shown for loads that have fewer than 10 observations in either period.

Figure 47. Thirty-day rolling average permit limits and $\mathrm{NO}_{x}$ emission rates for AES Greenidge Unit 4 from January 2008 through September 2008.

Figure 48. $\mathrm{NO}_{\mathrm{x}}$ emission rate and total urea flow rate observed between 7:19 and 10:09 EST on March 10, 2008. $\mathrm{NO}_{\mathrm{x}}$ emissions were measured by the unit's stack CEM. The urea flow rate was measured by the SNCR system's flow meters and represents the flow of $50 \%$ $(\mathrm{w} / \mathrm{w})$ urea solution

Figure 49. $\mathrm{NO}_{\mathrm{x}}$ emission rate and total urea flow rate observed between 14:55 and 18:27 EST on March 13, 2008. The drop in $\mathrm{NO}_{x}$ emissions around 16:40 occurred when biomass cofiring was discontinued, temporarily upsetting the system. $\mathrm{NO}_{x}$ emissions were measured by the unit's stack CEM. The urea flow rate was measured by the SNCR system's flow meters and represents the flow of $50 \%(\mathrm{w} / \mathrm{w})$ urea solution.

Figure 50. $\mathrm{NO}_{\mathrm{x}}$ emission rate and total urea flow rate observed between 8:01 and 10:31 EST on May 21, 2008. $\mathrm{NO}_{x}$ emissions were measured by the unit's stack CEM. The urea flow rate was measured by the SNCR system's flow meters and represents the flow of $50 \%$ $(\mathrm{w} / \mathrm{w})$ urea solution

Figure 51. $\mathrm{NO}_{\mathrm{x}}$ emission rate and total urea flow rate observed between 4:07 and 6:22 EST on May 22, 2008. $\mathrm{NO}_{\mathrm{x}}$ emissions were measured by the unit's stack CEM. The urea flow rate was measured by the SNCR system's flow meters and represents the flow of $50 \%$ $(\mathrm{w} / \mathrm{w})$ urea solution

Figure 52. Summary of $\mathrm{NO}_{x}$ removal efficiencies computed from $\mathrm{NO}_{x}$ concentrations measured at the SCR inlet and outlet sampling grids on March 28, 2007 (average of the three tests reported in Table 13). Each sampling grid consisted of 24 measurement points. The graph shows the $\mathrm{NO}_{x}$ removal achieved by the SCR as a function of location on the catalyst cross section. For purposes of this graph, any points with negative $\mathrm{NO}_{x}$ removal efficiencies were set equal to $0 \%$ removal efficiency.

Figure 53. Summary of $\mathrm{NO}_{x}$ removal efficiencies computed from $\mathrm{NO}_{x}$ concentrations measured at the SCR inlet and outlet sampling grids on June 20, 2007, between 20:00 and 20:47 Eastern Daylight Time (EDT). Each sampling grid consisted of 24 measurement points. 
The graph shows the $\mathrm{NO}_{x}$ removal achieved by the SCR as a function of location on the catalyst cross section.

Figure 54. Summary of $\mathrm{NO}_{x}$ removal efficiencies computed from $\mathrm{NO}_{x}$ concentrations measured at the SCR inlet and outlet sampling grids on May 21, 2008, between 7:12 and 9:59 EDT. Each sampling grid consisted of 24 measurement points. The graph shows the $\mathrm{NO}_{\mathrm{x}}$ removal achieved by the SCR as a function of location on the catalyst cross section. For purposes of this graph, any points with negative $\mathrm{NO}_{x}$ removal efficiencies were set equal to $0 \%$ removal efficiency. Invalid measurements were replaced with the average of surrounding valid measurements.

Figure 55. Summary of $\mathrm{NO}_{x}$ removal efficiencies computed from $\mathrm{NO}_{x}$ concentrations measured at the SCR inlet and outlet sampling grids on May 21, 2008, between 3:12 and 5:59 EDT. Each sampling grid consisted of 24 measurement points. The graph shows the $\mathrm{NO}_{\mathrm{x}}$ removal achieved by the SCR as a function of location on the catalyst cross section. For purposes of this graph, any points with negative $\mathrm{NO}_{x}$ removal efficiencies were set equal to $0 \%$ removal efficiency. Invalid measurements were replaced with the average of surrounding valid measurements.

Figure 56. Summary of $\mathrm{NO}_{x}$ removal efficiencies computed from $\mathrm{NO}_{x}$ concentrations measured at the SCR inlet and outlet sampling grids on May 22, 2008, between 0:48 and 5:35 EDT. Each sampling grid consisted of 24 measurement points. The graph shows the $\mathrm{NO}_{\mathrm{x}}$ removal achieved by the SCR as a function of location on the catalyst cross section. For purposes of this graph, any points with negative $\mathrm{NO}_{x}$ removal efficiencies were set equal to $0 \%$ removal efficiency. Invalid measurements were replaced with the average of surrounding valid measurements.

Figure 57. Total flow rate of $50 \% \mathrm{w} / \mathrm{w}$ urea solution (sum of all three SNCR zones) as a function of gross unit load between August 2007 and September 2008. Urea measurements were made by the SNCR system's online flow meters. The solid line indicates the mean flow rate at each load, and the dashed lines represent \pm 2 standard deviations from the mean. Computations were performed using hourly data.

Figure 58. $\mathrm{NH}_{3}$ concentrations measured at the air heater inlet sampling location between October 2007 and June 2008. The shading indicates the highest numbered (coolest temperature) zone of urea injection that was in operation during each test.

Figure 59. Ammonia slip as a function of gross unit load and urea injection regime at AES Greenidge Unit 4. Data were obtained during process performance testing at AES Greenidge in November 2007 and May 2008. The columns represent the mean ammonia concentration observed at each condition, and the error bars represent \pm 1 standard deviation. The relative flow rate of urea being injected into each zone of the SNCR system is also shown.

Figure 60. Scatter plot showing ammonia slip at the air heater inlet vs. the total flow rate of $50 \%$ w/w urea solution being injected into the SNCR system, with simple linear regression results. Data were taken from tests during October 2007-June 2008 that were conducted while urea was being injected into Zones 2 and 3 of the SNCR system and the pressure drop across the SCR catalyst was $\leq 2$ iwc.

Figure 61. Time series of the ammonia content of fly ash samples collected at the air heater outlet and the daily average pressure drop observed across the in-duct SCR catalyst at AES Greenidge Unit 4. The red arrows indicate the timing of outages during which the SCR catalyst was cleaned or replaced.

Figure 62. Scatter plot showing the ammonia content of fly ash samples collected at the air heater outlet vs. the daily average pressure drop measured across the SCR catalyst, with simple linear regression results. 
Figure 63. Scatter plot showing the ammonia content of fly ash samples collected at the air heater outlet vs. the daily average gross unit load, with simple linear regression results.

Figure 64. Scatter plot showing the ammonia content of fly ash samples collected at the air heater outlet vs. the daily average flow rate of $50 \% \mathrm{w} / \mathrm{w}$ urea solution to the SNCR system, with simple linear regression results.

Figure 65. Hourly $\mathrm{SO}_{2}$ rates $(\mathrm{lb} / \mathrm{mmBtu})$ determined at the air heater outlet (upstream of the Turbosorp $^{\circledR}$ system) and stack (downstream of the Turbosorp ${ }^{\circledR}$ system) during August 2007 - September 2008. $\mathrm{SO}_{2}$ was measured by the dilution extractive-type $\mathrm{SO}_{2}$ analyzer that is permanently installed at the air heater outlet and by the unit's stack CEM.

Figure 66. Five-minute average $\mathrm{SO}_{2}$ rates $(\mathrm{lb} / \mathrm{mmBtu})$ and gross unit load observed at AES Greenidge Unit 4 between 1000 and 2100 EST on October 3, 2007. $\mathrm{SO}_{2}$ was measured by the dilution extractive-type $\mathrm{SO}_{2}$ analyzer that is permanently installed at the air heater outlet (upstream of the Turbosorp ${ }^{\circledR}$ system) and by the unit's stack CEM (downstream of the Turbosorp ${ }^{\circledR}$ system).

Figure 67. Five-minute average Turbosorp ${ }^{\circledR}$ outlet temperatures, gross unit loads, and $\mathrm{SO}_{2}$ removal efficiencies observed at AES Greenidge Unit 4 between 0300 and 0900 EST on June 18, 2008. These data indicate the effect of interruptions in water injection on the performance of the Turbosorp ${ }^{\circledR}$ system. $\mathrm{SO}_{2}$ was measured by the dilution extractivetype $\mathrm{SO}_{2}$ analyzer that is permanently installed at the air heater outlet (upstream of the Turbosorp $^{\circledR}$ system) and by the unit's stack CEM (downstream of the Turbosorp ${ }^{\circledR}$ system).

Figure 68. Thirty-day rolling average $\mathrm{SO}_{2}$ emission rates and permit limit for AES Greenidge Unit 4 from January 2008 through September 2008.

Figure 69. Average $\mathrm{SO}_{2}$ removal efficiency and Turbosorp ${ }^{\circledR}$ outlet temperature as a function of gross unit load, based on hourly data collected during August 2007 - September 2008. $\mathrm{SO}_{2}$ was measured by the dilution extractive-type $\mathrm{SO}_{2}$ analyzer that is permanently installed at the air heater outlet (upstream of the Turbosorp ${ }^{\circledR}$ system) and by the unit's stack CEM (downstream of the Turbosorp ${ }^{\circledR}$ system).

Figure 70. Five-minute average gross unit loads, $\mathrm{SO}_{2}$ removal efficiencies, Turbosorp ${ }^{\circledR}$ outlet temperatures, and hydrated lime rotary feeder percent outputs observed at AES Greenidge Unit 4 between June 16, 2008, at 2030 EST and June 17, 2008, at 0230 EST. These data illustrate the performance of the Turbosorp ${ }^{\circledR}$ system in response to a load swing. $\mathrm{SO}_{2}$ was measured by the dilution extractive-type $\mathrm{SO}_{2}$ analyzer that is permanently installed at the air heater outlet (upstream of the Turbosorp ${ }^{\circledR}$ system) and by the unit's stack CEM (downstream of the Turbosorp ${ }^{\circledR}$ system).

Figure 71. Calcium-to-sulfur molar ratios determined during parametric testing of the Turbosorp ${ }^{\circledR}$ system at AES Greenidge Unit 4 in October 2007. Ratios were derived from process data and from the chemical analysis of Turbosorp ${ }^{\circledR}$ product ash samples using the procedures described in the text. Relevant plant operating conditions are also shown.

Figure 72. Calcium-to-sulfur molar ratios determined during parametric testing of the Turbosorp ${ }^{\circledR}$ system at AES Greenidge Unit 4 in June 2008. Ratios were derived from the chemical analysis of Turbosorp ${ }^{\circledR}$ product ash samples using the procedures described in the text. Relevant plant operating conditions are also shown.

Figure 73. Summary of coal-to-stack $\mathrm{Hg}$ removal efficiencies measured at AES Greenidge Unit 4 between March 2007 and June 2008. For bars labeled ">" the Hg concentration at the stack was below the method detection limit, and the removal efficiency was greater than the value shown. 
Figure 74. Scatter plot showing the coal-to-stack Hg removal efficiency vs. the carbon content of fly ash samples collected at the air heater outlet, with simple linear regression results. Data were collected during tests in October 2007-June 2008.

Figure 75. Scatter plot showing $\mathrm{Hg}$ removal efficiencies computed from $\mathrm{Hg}$ measurements at the air heater outlet and stack vs. $\mathrm{Hg}$ removal efficiencies computed from $\mathrm{Hg}$ measurements in the coal and at the stack. Measurements were conducted during tests in March, October, and November 2007.

Figure 76. Comparison of the average coal-to-stack $\mathrm{Hg}$ removal efficiency observed during baseline testing in November 2004, prior to installation of the multi-pollutant control system, with the average removal efficiency observed during performance testing in March 2007-June 2008, after installation of the system. Error bars represent \pm 1 standard deviation.

Figure 77. Scatter plot showing $\mathrm{SO}_{3}$ removal efficiencies vs. $\mathrm{SO}_{2}$ removal efficiencies observed across the Turbosorp ${ }^{\circledR}$ system during tests in May 2007 - June 2008, with simple linear regression results.

Figure 78. Scatter plot showing $\mathrm{SO}_{3}$ removal efficiencies across the Turbosorp ${ }^{\circledR}$ system vs. corresponding $\mathrm{SO}_{3}$ concentrations measured at the air heater outlet (Turbosorp ${ }^{\circledR}$ inlet) during tests in May 2007 - June 2008.

Figure 79. Scatter plot showing $\mathrm{HCl}$ removal efficiencies vs. $\mathrm{SO}_{2}$ removal efficiencies observed across the Turbosorp ${ }^{\circledR}$ system during tests in March 2007 - June 2008, with simple linear regression results.

Figure 80. Scatter plot showing $\mathrm{HCl}$ removal efficiencies vs. $\mathrm{SO}_{3}$ removal efficiencies observed across the Turbosorp ${ }^{\circledR}$ system during tests in March 2007 - June 2008, with simple linear regression results.

Figure 81. Summary of mean primary particulate matter emission rates measured at the AES Greenidge Unit 4 stack before and after installation of the multi-pollutant control system. The baseline testing emission rate is based on two measurements made using U.S. EPA Method 5 in November 2004. The performance testing emission rate is based on 59 measurements made using U.S. EPA Method 17 in March 2007 - June 2008. Error bars represent \pm 1 standard deviation.

Figure 82. Summary of mean primary particulate matter rates measured at the air heater outlet (upstream of the Turbosorp ${ }^{\circledR}$ system) and stack (downstream of the Turbosorp ${ }^{\circledR}$ system) during 43 tests in March 2007 - June 2008. Sampling was conducted simultaneously at the two locations using U.S. EPA Method 17. Data are presented on a logarithmic scale. Error bars represent +1 standard deviation.

Figure 83. Photograph taken on November 10, 2007, showing large particle ash accumulation in the in-duct SCR catalyst at AES Greenidge Unit 4.

Figure 84. Photograph from February 3, 2007, showing the accumulation of fly ash on top of the in-duct SCR reactor at AES Greenidge Unit 4. The buildup of fly ash appeared to be caused by pieces of LPA that blocked the catalyst channels.

Figure 85. Time series plot (EST) showing the average hourly pressure drops measured across the SCR catalyst and LPA screen at AES Greenidge Unit 4 between June 21, 2007, and September 30, 2008. The maximum gross unit load observed each day during this period is also plotted. 
Figure 86. Photograph of a partially plugged catalyst module (viewed from the inlet end) that was removed from the in-duct SCR reactor at AES Greenidge Unit 4 in late December 2007. A test catalyst element was removed near the center of the module.

Figure 87. Photograph of a portion of the outlet end of the SCR catalyst taken during the December 2007 outage at AES Greenidge Unit 4. Weak agglomerates of fly ash can be seen protruding from some of the catalyst channels.

Figure 88. Photograph of a portion of the catalyst screen taken during the November 2007 outage at AES Greenidge Unit 4. Small pieces of LPA (surrounded by fly ash) are visibly lodged in the screen. The white coloration is color "washout" from the photographic flash, and it does not represent the actual color of the ash.

Figure 89. Summary of results from the dissection of a catalyst element pulled from the in-duct SCR reactor during the November 9-12, 2007 outage. The catalyst element was cut into 18 sequentially numbered wafers, with wafer 1 taken from the outlet end and wafer 18 taken from the inlet end. The plot shows the number of plugged cells observed in each wafer (there were 324 total cells per wafer), as well as the cumulative number of LPA pieces found between the outlet end of the catalyst and each wafer.

Figure 90. Photograph comparing the original LPA screen that was installed in May 2007 (right) with the new, smaller-pitch LPA screen that was installed in May 2008.

Figure 91. Photograph showing one of the catalyst modules that was removed from the SCR reactor in May 2008. Catalyst erosion (likely caused by the rake soot blower) and some LPA plugging are evident in the picture.

Figure 92. Photograph from the May 2008 outage showing the new LPA screen (installed) and the new hinged seal connecting the two LPA screen sections.

Figure 93. Plot comparing the rates of increase in pressure drop across the SCR catalyst at AES Greenidge Unit 4 following the outages in August 2007 (navy blue), September 2007 (magenta), December 2007 (light blue), and May 2008 (red). For each case, the plot shows the high-load pressure drop across the SCR catalyst as a function of the cumulative MWh of operation since the conclusion of the outage. The high-load pressure drop includes all hourly average pressure drops measured when the unit was operating at $\geq 90 \mathrm{MW}_{\mathrm{g}}$......

Figure 94. Photograph of the product ash, including a mixture of scrubber byproduct and fly ash, produced by the Turbosorp ${ }^{\circledR}$ process at AES Greenidge Unit 4.

Figure 95. Scatter plot showing the mass flow rate of scrubber byproduct (excluding fly ash) produced by the Turbosorp process vs. the mass flow rate of $\mathrm{SO}_{2}$ removed by the process, with simple linear regression results. Data were derived from the material balances performed for each of the 34 mercury tests conducted at AES Greenidge between March 2007 and June 2008.

Figure 96. Projected effect of coal sulfur content on $\mathrm{SO}_{2}$ control costs for $95 \% \mathrm{SO}_{2}$ removal efficiency.

Figure 97. Effect of $\mathrm{SO}_{2}$ removal efficiency on $\mathrm{SO}_{2}$ control costs for a $3.6 \mathrm{lb} \mathrm{SO} / \mathrm{mmBtu}$ coal. Costs were derived from the results of parametric testing of the Turbosorp ${ }^{\circledR}$ system on June 16-18, 2008. 


\section{LIST OF TABLES}

Table 1. Summary of major project tasks. The organization with primarily responsibility for completing each task is indicated.

Table 2. Greenidge Project milestone plan showing planned and actual completion dates for critical path project milestones.

Table 3. Overall project budget and actual project cost through October 2008.

Table 4. Characteristics of existing Turbosorp ${ }^{\circledR}$ installations on coal-fired EGUs and of the AES Greenidge design.

Table 5. Assumed fuel characteristics (as fired) for the design case.

Table 6. Emission performance targets for the design case. 36

Table 7. Water requirements for operation of the multi-pollutant control system at AES Greenidge .55

Table 8. Projected composition of the fly ash / scrubber byproduct discharged from the baghouse. .56

Table 9. Permits required for construction and operation of the multi-pollutant control system at AES Greenidge Unit 4 .....

Table 10. Chemical composition of typical coal samples collected at AES Greenidge Unit 4 during the Operation and Testing Phase.

Table 11. Average $\mathrm{NO}_{x}$ emission rates measured during August 2004 - September 2005, prior to the installation of the multi-pollutant control system, and during August 2007 - September 2008, following installation of the system, for various unit load ranges. Averages are shown for all unit loads $\left(\geq 42 \mathrm{MW}_{\mathrm{g}}\right)$ and for three load ranges corresponding to the unit's current permit limits.

Table 12. Average $\mathrm{NO}_{x}$ emission rates observed with and without urea injection during tests on March 10, March 13, May 21, and May 22, 2008. These data were used to compute the $\mathrm{NO}_{x}$ removal efficiency achieved by the hybrid SNCR/SCR system.

Table 13. Average $\mathrm{NO}_{x}$ emission rates measured by Clean Air Engineering at the SCR inlet and SCR outlet sampling grids during tests in March 2007, May 2007, June 2007, and May 2008. The $\mathrm{NO}_{x}$ removal efficiencies computed from these data are also shown, as are relevant unit operating data.

Table 14. Estimated normalized stoichiometric ratio and urea utilization during the guarantee test periods on March 28, May 1, and June 20, 2007. Relevant process data are also summarized......

Table 15. Estimated normalized stoichiometric ratio and urea utilization during tests conducted on March 10, March 13, May 21, and May 22, 2008. Relevant process data are also summarized...

Table 16. Ammonia concentrations measured by CONSOL at the SCR outlet and air heater inlet sampling locations on March 28 and May 1, 2007. Relevant process data are also summarized......

Table 17. Ammonia concentrations measured by CONSOL and Clean Air Engineering at the air heater inlet sampling location on May 31 and June 1, 2007. Relevant process data are also summarized. 
Table 18. Ammonia concentrations measured by CONSOL at the air heater inlet sampling location on June $20-21,2007$. Relevant process data are also summarized.

Table 19. Ammonia concentrations measured by CONSOL at the air heater inlet sampling location during process performance testing and follow-up testing between October 2007 and June 2008. Relevant process data are also summarized.

Table 20. Summary of $\mathrm{SO}_{2}$-to- $\mathrm{SO}_{3}$ conversion rates determined from testing around the SCR reactor in October 2007, March 2008, and June 2008. Relevant process data are also summarized

Table 21. Summary of gas-phase mercury speciation determined from testing around the SCR reactor in October 2007, March 2008, May 2008, and June 2008. Relevant process data are also summarized.

Table 22. Average gas-phase mercury speciation around the SCR reactor, computed for three subsets of the measurements presented in Table 21. Paired t-tests were performed on each subset of measurements to assess the statistical significance of the change in mercury oxidation across the reactor.....

Table 23. Summary of the $\mathrm{SO}_{2}$ removal efficiency across the Turbosorp ${ }^{\circledR}$ system determined during guarantee testing on March 29, 2007.

Table 24. Summary of the long-term $\mathrm{SO}_{2}$ removal performance of the Turbosorp ${ }^{\circledR}$ system, based on hourly data collected from August 2007 through September 2008.

Table 25. $\mathrm{SO}_{2}$ concentrations, and implied removal efficiency across the Turbosorp ${ }^{\circledR}$ system, determined as part of $\mathrm{SO}_{3}$ tests conducted at the air heater outlet and stack using the controlled condensation method between October 2007 and June 2008.

Table 26. Average calcium-to-sulfur molar ratio estimated for the 14-month period from August 2007 through September 2008 using lime delivery (truck weight) data and $\mathrm{SO}_{2}$ data from the plant's online analyzers.

Table 27. Results of Hg tests performed at AES Greenidge Unit 4 during March 2007-June 2008. Relevant process conditions are also summarized.

Table 28. Summary of average mercury removal efficiencies observed during tests with and without activated carbon injection in March 2007 and October 2007.

Table 29. Mercury speciation determined as part of Ontario Hydro Method testing at the air heater outlet and stack in March, October, and November 2007. Speciation results at the air heater outlet were affected by a sampling artifact that leads to artificially high particlebound and/or oxidized mercury concentrations, and artificially low elemental and/or oxidized mercury concentrations.

Table 30. Results of $\mathrm{SO}_{3}$ tests performed around the Turbosorp ${ }^{\circledR}$ system at AES Greenidge Unit 4 during May 2007-June 2008. Relevant process conditions are also summarized.

Table 31. Results of $\mathrm{HCl}$ tests performed around the Turbosorp ${ }^{\circledR}$ system at AES Greenidge Unit 4 during March 2007-June 2008. Relevant process conditions are also summarized.

Table 32. Results of HF tests performed around the Turbosorp ${ }^{\circledR}$ system at AES Greenidge Unit 4 during March 2007-June 2008.

Table 33. Summary of outages at AES Greenidge Unit 4 during which actions were taken in and around the SCR reactor to address the LPA problem. 
Table 34. Synthetic Precipitation Leaching Procedure results for sixteen Turbosorp ${ }^{\circledR}$ product ash samples collected at AES Greenidge Unit 4 between November 2007 and June 2008.

Table 35. Average results from the chemical analysis of Turbosorp ${ }^{\circledR}$ product ash samples collected during follow-up testing at AES Greenidge Unit 4 on June 10-13, 2008.

Table 36. Base plant performance assumptions used in the economic analysis of the multipollutant control system at AES Greenidge Unit 4.

Table 37. Capital costs for the multi-pollutant control system at AES Greenidge Unit 4. Costs are expressed in 2005 dollars.

Table 38. Estimated fixed operating and maintenance costs for the multi-pollutant control system at AES Greenidge Unit 4.

Table 39. Unit prices used in variable O\&M cost calculations (as of early 2007). 193

Table 40. Performance assumptions used to compute the variable O\&M costs and levelized costs associated with the multi-pollutant control system at AES Greenidge Unit 4 ......

Table 41. Estimated variable operating and maintenance costs for the multi-pollutant control system at AES Greenidge Unit 4. 195

Table 42. Financial assumptions used for levelized capital cost calculations. 196

Table 43. Estimated levelized costs for the multi-pollutant control system at AES Greenidge Unit 4. Costs are expressed in constant 2005 dollars.

Table 44. Estimated levelized costs for the hybrid $\mathrm{NO}_{\mathrm{x}}$ control system (including the combustion modifications) at AES Greenidge Unit 4. Costs are expressed in constant 2005 dollars. 196

Table 45. Estimated levelized costs for the circulating fluidized bed dry scrubbing system at AES Greenidge Unit 4. Costs are expressed in constant 2005 dollars.

Table 46. Estimated levelized costs for the activated carbon injection system at AES Greenidge Unit 4. Costs are expressed in constant 2005 dollars.

Table 47. Turbosorp ${ }^{\circledR}$ projects at coal-fired electric generating units in the United States, as of October 2008. 


\section{Executive Summary}

As part of the Greenidge Multi-Pollutant Control Project, CONSOL Energy Inc. (CONSOL), AES Greenidge LLC, and Babcock Power Environmental Inc. (BPEI) installed and tested an innovative, integrated combination of air pollution control technologies on one of the nation's smaller existing coal-fired power plants - the 107-MW $\mathrm{AES}$ Greenidge Unit 4. The overall goal of the project, which was conducted in 2006-2008, was to demonstrate that this multi-pollutant control system, including a NO $\mathrm{NOUT}_{\mathrm{C}} \mathrm{CASCADE}^{\circledR}$ hybrid selective non-catalytic reduction (SNCR) / selective catalytic reduction (SCR) system and a Turbosorp ${ }^{\circledR}$ circulating fluidized bed dry scrubbing system, can cost-effectively reduce emissions of nitrogen oxides $\left(\mathrm{NO}_{\mathrm{x}}\right)$, sulfur dioxide, mercury, particulate matter (PM), and acid gases, including sulfur trioxide, hydrogen chloride, and hydrogen fluoride, from coal-fired electric generating units (EGUs) with capacities of $50 \mathrm{MW}_{\mathrm{e}}$ to $600 \mathrm{MW}_{\mathrm{e}}$. The project was conducted as part of the U.S. Department of Energy's (DOE's) Power Plant Improvement Initiative (PPII), which is managed by its National Energy Technology Laboratory (NETL).

Although the multi-pollutant control system at AES Greenidge is applicable to units with capacities of 50-600 $\mathrm{MW}_{\mathrm{e}}$, its potential benefits are greatest for units in the lower half of this size range. There are about 400 coalfired units operating in the United States with capacities of 50-300 MW or flue gas desulfurization (FGD) systems. These smaller units, which represent more than $55 \mathrm{GW}$ of installed generating capacity, are increasingly vulnerable to retirement or fuel switching as a result of progressively more stringent state and federal environmental regulations. The Greenidge Project sought to demonstrate the commercial readiness of an emissions control system that is particularly suited, because of its deep emission reduction capabilities, low capital and maintenance costs, small space demands, applicability to high-sulfur coal, and operational flexibility, to meet the requirements of this large group of existing electric generating units.

The Greenidge Multi-Pollutant Control Project was funded by the DOE and by AES Greenidge. The project aspired to be the first to demonstrate:

- Full-load $\mathrm{NO}_{x}$ emissions of $\leq 0.10 \mathrm{lb} / \mathrm{mmBtu}$ using a $\mathrm{NO}_{x} \mathrm{OUT}$ CASCADE ${ }^{\circledR}$ hybrid SNCR/SCR system, in combination with low- $\mathrm{NO}_{x}$ combustion technology, on a unit firing $>2 \%$-sulfur coal and biomass

- $\mathrm{SO}_{2}$ and acid gas $\left(\mathrm{SO}_{3}, \mathrm{HCl}, \mathrm{HF}\right)$ removal of $\geq 95 \%$ using a Turbosorp ${ }^{\circledR}$ circulating fluidized bed dry scrubber on a unit firing $>2 \%$-sulfur U.S. bituminous coal

- Mercury reduction of $\geq 90 \%$ via the co-benefits afforded by the in-duct SCR and Turbosorp ${ }^{\circledR}$ (with baghouse) systems and by activated carbon injection, if needed

$\mathrm{NO}_{x}$ control is the first step in the multi-pollutant control process and is accomplished using combustion modifications (installed outside of the scope of the DOE project) and urea-based SNCR in the furnace, followed by a single-layer SCR reactor that is installed in a modified section of the ductwork between the unit's economizer and air heaters. The SCR process is fed by ammonia slip from the SNCR process; static mixers located just upstream of the SCR are used to homogenize the flue gas before it enters the catalyst. Emissions of $\mathrm{SO}_{2}$ and other acid gases are reduced in the Turbosorp ${ }^{\circledR}$ circulating fluidized bed dry scrubbing system, which is installed downstream of the air heaters. In the Turbosorp ${ }^{\circledR}$ system, water and dry hydrated lime, which is supplied from an onsite hydrator installed as part of the project, are injected separately into a fluidized bed absorber, where the flue gas is evaporatively cooled and brought into intimate contact with the hydrated lime reagent in a fast fluidized bed. The hydrated lime reacts with the acidic constituents of the flue gas (i.e., $\mathrm{SO}_{2}$, $\mathrm{SO}_{3}, \mathrm{HCl}$, and $\mathrm{HF}$ ) to form dry solid products, which are separated from the flue gas in a new pulse-jet baghouse and recycled to the absorber via air slides at a high ratio to the inlet solids in order to maximize pollutant removal and lime utilization. Mercury removal is provided as a co-benefit of the in-duct SCR, dry scrubber, and baghouse, and by injection of activated carbon upstream of the scrubber, if required. A new booster fan was installed to overcome the pressure drop added by the multi-pollutant control equipment. The design includes turndown capabilities for the SNCR and Turbosorp ${ }^{\circledR}$ systems, enabling continued emissions reduction at reduced loads.

The multi-pollutant control system started up in early 2007, and its performance was then evaluated over an approximately 18-month period of commercial operation while AES Greenidge Unit 4 fired mid- or high-sulfur coal and co-fired up to $5 \%$ biomass (waste wood). Major conclusions of the project were as follows:

- The multi-pollutant control system achieved the performance target of $\geq 95 \% \mathrm{SO}_{2}$ removal efficiency during both short-term and long-term testing. The average $\mathrm{SO}_{2}$ removal efficiency observed during 14 months of 
commercial operation (August 2007 - September 2008) was 96.3\%. The inlet $\mathrm{SO}_{2}$ rate averaged 3.6 $\mathrm{lb} / \mathrm{mmBtu}$ during this period; however, $\mathrm{SO}_{2}$ removal efficiencies $\geq 95 \%$ were achieved for coals containing up to $4.8 \mathrm{Ib} \mathrm{SO}_{2} / \mathrm{mmBtu}$. Performance tests showed that the system required a calcium-to-sulfur $(\mathrm{Ca} / \mathrm{S}) \mathrm{molar}$ ratio of 1.6-1.7 to achieve $95 \% \mathrm{SO}_{2}$ removal efficiency under design conditions.

- The multi-pollutant control system achieved the performance target of $\geq 90 \% \mathrm{Hg}$ removal efficiency during both short-term and long-term testing. No activated carbon injection was required to achieve this removal efficiency. The average coal-to-stack $\mathrm{Hg}$ removal efficiency measured during 29 tests without activated carbon injection between March 2007 and June 2008 was 98\%.

- The multi-pollutant control system achieved the performance target of $\geq 95 \% \mathrm{SO}_{3}$ and $\mathrm{HCl}$ removal efficiency during both short-term and long-term testing. The average $\mathrm{SO}_{3}$ removal efficiency observed during 42 tests between May 2007 and June 2008 was 95.3\%, and the average $\mathrm{HCl}$ removal efficiency observed during 30 tests between March 2007 and June 2008 was 96.7\%. HF concentrations measured at the Turbosorp ${ }^{\circledR}$ inlet and stack were too low to demonstrate attainment of the performance target of $\geq 95 \%$ HF removal efficiency.

- Replacement of the unit's old electrostatic precipitator (ESP) with the Turbosorp ${ }^{\circledR}$ system, which includes a new baghouse, reduced its PM emissions by $98 \%$, to $<0.001 \mathrm{lb} / \mathrm{mmBtu}$.

- The multi-pollutant control system achieved the performance target for high-load $\mathrm{NO}_{\mathrm{x}}$ emissions of $\leq 0.10$ $\mathrm{lb} / \mathrm{mmBtu}$ during short-term (guarantee) testing, but it did not meet this goal during long-term operation. The average high-load $\mathrm{NO}_{x}$ emission rate observed during 14 months of commercial operation (August 2007 September 2008) was $0.14 \mathrm{lb} / \mathrm{mmBtu}$. The increase in $\mathrm{NO}_{\mathrm{x}}$ emissions between the guarantee tests and the long-term evaluation period occurred because AES Greenidge had to reduce the aggressiveness of low- $\mathrm{NO}_{x}$ firing in order to attain suitable combustion characteristics for routine operation. Nevertheless, overall $\mathrm{NO}_{x}$ emissions ( $\mathrm{lb} / \mathrm{mmBtu})$ were reduced by about $52 \%$ relative to the pre-project baseline.

- $\quad$ Operation of the multi-pollutant control system was hindered by the accumulation of large particle ash (LPA) in the in-duct SCR catalyst, which caused numerous outages for catalyst cleaning during the first year of operation. However, the severity of the problem was reduced by the installation of an LPA removal system (outside of the scope of the DOE project), including a screen, soot blowers, and vacuum ports. Additional operating experience is needed to confirm the long-term effectiveness of this system.

- Ammonia slip from the hybrid SNCR/SCR system was generally greater than expected during the first yearand-a-half of operation. Although the targeted ammonia slip of $\leq 2$ ppmvd @ $3 \% \mathrm{O}_{2}$ was demonstrated during guarantee testing, ammonia concentrations averaged 4.6 ppmvd over the course of 26 ammonia slip measurements that were performed at intermediate or high loads between October 2007 and June 2008. The higher-than-expected ammonia slip has not significantly affected plant operations, however.

- The retrofit difficulty associated with the installation of the multi-pollutant control system at AES Greenidge Unit 4 was low. The system required a footprint of only $\sim 0.4$ acre and was able to be integrated with the unit during a seven-week tie-in outage. No major problems were encountered during construction.

- The multi-pollutant control system affords lower capital costs in exchange for somewhat greater variable operating and maintenance (O\&M) costs relative to conventional technologies that are capable of achieving deep reductions in $\mathrm{NO}_{x}$ and $\mathrm{SO}_{2}$. The capital cost (\$2005) for the multi-pollutant control system at AES Greenidge Unit 4 (including the combustion modifications and LPA removal system, which were installed outside of the DOE scope) was $\sim \$ 349 / \mathrm{kW}_{\text {net }}$, which is about $40 \%$ less that the estimated cost to retrofit the unit with conventional SCR and wet FGD systems. Fixed and variable O\&M costs for the multi-pollutant control system total $\sim \$ 7.95 / \mathrm{MWh}$, and the costs for urea, lime, and waste disposal, which figure into the unit's dispatch calculations, are $\sim \$ 5.58 / \mathrm{MWh}$. Mercury, acid gas, and primary particulate matter control are co-benefits of the $\mathrm{NO}_{x}$ and $\mathrm{SO}_{2}$ control systems and add no incremental cost.

- Operation and maintenance of the multi-pollutant control system were handled by existing AES Greenidge plant personnel. AES is able to run Unit 4, including the multi-pollutant control system, with 3-4 operators per shift, as was the case prior to the project. Apart from the LPA problem, most of the maintenance requirements during the first year-and-a-half of operation involved the lime hydration system and the ash disposal and recirculation system. These were usually resolved without impacting operation of the Turbosorp $^{\circledR}$ system, and actions have been taken to minimize their recurrence.

- No major problems were encountered with byproduct disposal. The only significant byproduct from the multi-pollutant control system is the product ash from the Turbosorp ${ }^{\circledR}$ system. AES Greenidge generally disposes of the product ash at a landfill adjacent to the plant site, although 3,500 tons were provided for use as fill material in a local construction project.

The commercial viability of the multi-pollutant control system was demonstrated during more than a year-and-ahalf of routine operation at AES Greenidge Unit 4. The system, which remains in service after the conclusion of the project, has enabled the unit to satisfy its permit requirements while continuing to operate profitably. As a result of the success at AES Greenidge, three additional deployments of the Turbosorp ${ }^{\circledR}$ technology had been announced by the end of the project. 


\section{Introduction}

The Greenidge Multi-Pollutant Control Project was conducted under U.S. Department of Energy Cooperative Agreement No. DE-FC26-06NT41426 to demonstrate the full-scale, retrofit application of a multi-pollutant control system that is designed to reduce emissions of $\mathrm{NO}_{\mathrm{x}}, \mathrm{SO}_{2}$, $\mathrm{Hg}$, particulate matter, and acid gases, including $\mathrm{SO}_{3}, \mathrm{HCl}$, and $\mathrm{HF}$, from coal-fired units with capacities of 50-600 MW $\mathrm{MW}_{\mathrm{e}}$. The multi-pollutant control system, which includes the combination of a NO${ }_{x}$ OUT CASCADE ${ }^{\circledR}$ hybrid selective non-catalytic reduction / selective catalytic reduction system and a Turbosorp ${ }^{\circledR}$ circulating fluidized bed dry scrubbing system with baghouse ash recycling and activated carbon injection, was installed and tested on the coal-fired, $107 \mathrm{MW}_{\mathrm{e}}$ AES Greenidge Unit 4 (Boiler 6) in Dresden, New York. The project was part of the DOE's Power Plant Improvement Initiative, with an overall objective of demonstrating that the combination of technologies installed at AES Greenidge provides an affordable means for achieving deep reductions in the emissions of a number of pollutants from smaller coal-fired electric generating units, allowing these units to continue to produce low-cost, reliable electricity in an environment of increasingly stringent air emissions regulations.

\subsection{The Power Plant Improvement Initiative}

The Power Plant Improvement Initiative was established on October 11, 2000, under U.S. Public Law 106-291 to foster the commercial demonstration of coal-based technologies capable of improving the efficiency, cost-competitiveness, and environmental performance of new and existing electric generating facilities in the United States. A follow-on to the Clean Coal Technology Demonstration Program (CCTDP) that was implemented successfully in the 1980s and 1990s, the PPII is a cost-shared collaboration between government and industry, supported by $\$ 95$ million in federal funding transferred from the CCTDP program, that seeks to help ensure the reliability of the nation's energy supply. The Greenidge Multi-Pollutant Control Project was one of eight projects selected for negotiation under the PPII solicitation issued in February 2001, and one of five that were awarded cooperative agreements by the DOE. All of these projects focused on technologies that can be quickly commercialized and are applicable to energy systems that utilize at least $75 \%$ coal, and all included participant cost shares of $50 \%$ or greater. The DOE's National Energy Technology Laboratory manages the PPII projects.

\subsection{Project Motivation}

The Greenidge Multi-Pollutant Control Project responded to the objectives of the PPII by demonstrating a technology that is intended to help ensure the continued availability of reliable, low-cost electricity from the nation's large asset base of smaller existing coal-fired power plants. Although the technology being demonstrated at AES Greenidge is applicable to units with capacities of $50-600 \mathrm{MW}_{\mathrm{e}}$, its potential benefits are greatest for units in the lower half of this size range. Figure 1 presents a map showing all of the coal-fired electric generating units with capacities of 50-300 $\mathrm{MW}_{\mathrm{e}}$ that are currently operating in the United States. There are currently about 400 operating coal-fired EGUs in this size range that are equipped with neither flue gas desulfurization nor selective catalytic reduction technologies, and a majority of these units have not announced plans for air pollution control retrofits. These 400 smaller coal-fired units represent more than $55 \mathrm{GW}$ of installed electric generating capacity; hence, curtailment or loss 
of their generation would further exacerbate electricity and natural gas supply and distribution problems throughout the United States. However, these EGUs are subject to progressively more rigorous environmental regulations at the state and federal levels. Conventional control technologies being installed on newer, larger EGUs, such as selective catalytic reduction and wet flue gas desulfurization, are capable of achieving the emission rates set forth in these regulations, but entail large capital investments and large space requirements that make them unattractive for this fleet of older, smaller EGUs. Hence, there is a strong need to demonstrate and commercialize technologies specifically designed to meet the environmental compliance requirements of these smaller coal-fired units. The Greenidge Multi-Pollutant Control Project seeks to demonstrate the commercial readiness of an emissions control system that is particularly suited, because of its relatively low capital and maintenance costs and compact size, to satisfy these requirements.

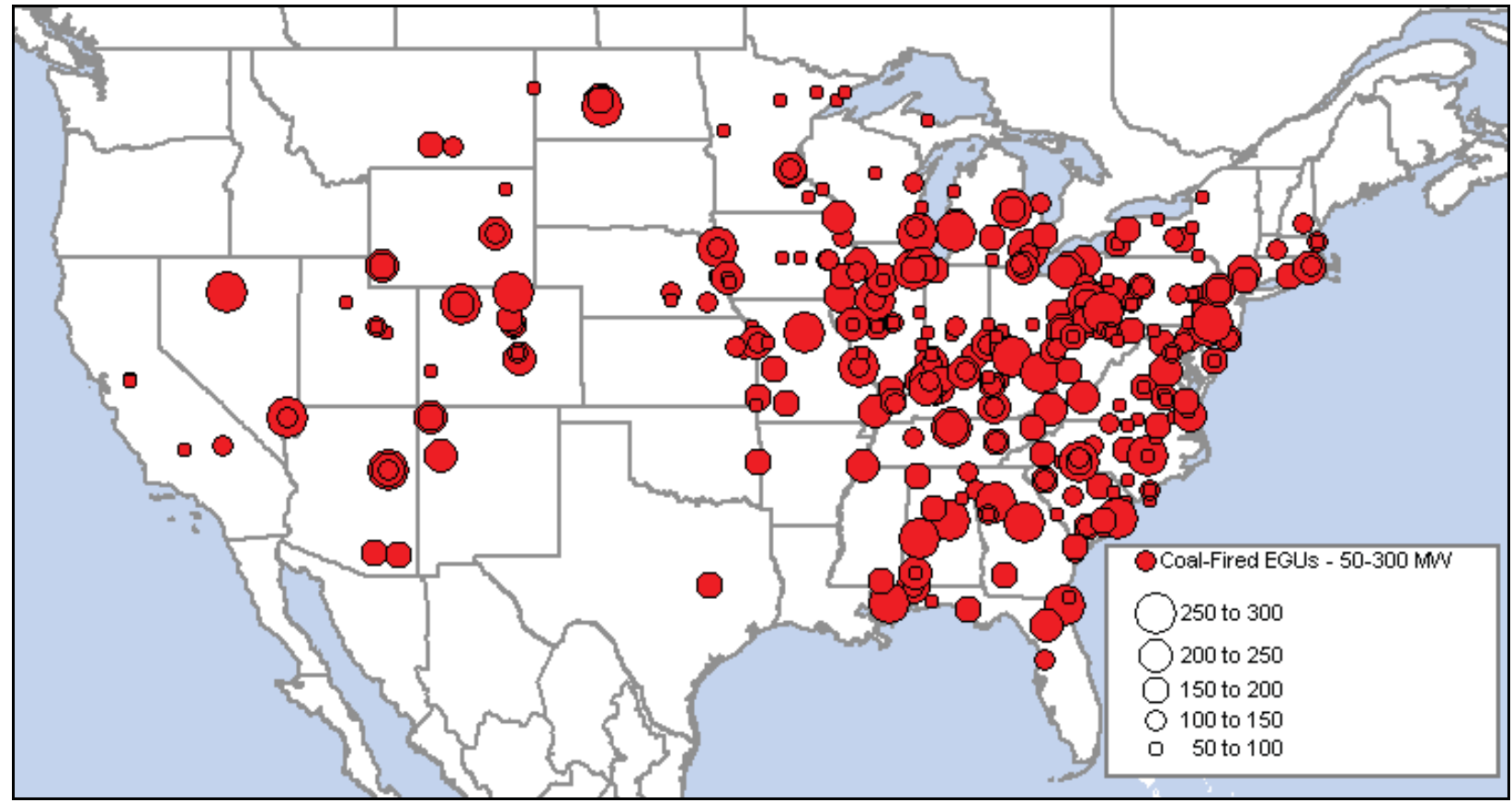

Figure 1. Map of operating coal-fired EGUs in the United States with capacities of $50-300 \mathrm{MW}_{\mathrm{e}}$.

As discussed above, the multi-pollutant control system being demonstrated as part of the Greenidge Project comprises an innovative, integrated combination of technologies, including a $\mathrm{NO}_{\mathrm{x}}$ OUT CASCADE ${ }^{\circledR}$ hybrid SNCR/SCR system and a Turbosorp ${ }^{\circledR}$ circulating fluidized bed dry scrubbing system with a new baghouse, solid product recycling system, and activated carbon injection system. Both of these technologies were developed and tested individually at a sufficient scale prior to the project to provide an adequate level of confidence concerning their mechanical operability. However, the Greenidge Project is unique in that it represents the first application in which a hybrid SNCR/SCR system and a circulating fluidized bed dry scrubbing system were combined to form an integrated multi-pollutant control system, as well as the first application of either of these technologies to a unit firing $>2 \%$-sulfur eastern U.S. bituminous coal. Demonstrating the cost and emissions reduction performance of the multi-pollutant control system when applied to a unit firing high-sulfur coal was an essential component of the project, as more than $80 \%$ of the 400 smaller coal-fired EGUs referenced above are located east of the Mississippi River, where eastern U.S. bituminous coal is a likely fuel source, and where it is often economically attractive for scrubbed units to fire high-sulfur coals. Moreover, the $\mathrm{NO}_{\mathrm{x}} \mathrm{OUT}$ CASCADE $^{\circledR}$ and Turbosorp ${ }^{\circledR}$ systems at AES Greenidge were designed to achieve greater $\mathrm{NO}_{\mathrm{x}}$ 
and $\mathrm{SO}_{2}$ removal efficiencies, respectively, than any previous installations of these technologies, enabling them to better satisfy the emission reduction needs of smaller coal-fired EGUs in the face of increasingly stringent environmental regulations.

Thus, the Greenidge Multi-Pollutant Control Project was motivated by the need to resolve uncertainties regarding the performance of the hybrid SNCR/SCR and Turbosorp ${ }^{\circledR}$ systems when combined in an integrated multi-pollutant control process, as well as the technical and economic performance of these systems when applied with ambitious performance targets to a unit firing eastern U.S. bituminous coals containing greater than $2 \%$ sulfur. It is hoped that, by resolving these uncertainties, the project will lead to wide commercial acceptance of the demonstration technology, which could significantly reduce emissions and help to extend the lives of many of the 400 smaller existing coal-fired EGUs identified above.

\subsection{Project Overview}

As part of the Greenidge Project, the multi-pollutant control system was retrofitted to AES Greenidge Unit 4, and its performance was demonstrated for more than a year-and-a-half of operation while the unit fired $>2 \%$-sulfur eastern U.S. bituminous coals in order to confirm its commercial viability. (The system continues to operate commercially at AES Greenidge following the conclusion of the DOE project). AES Greenidge Unit 4 is a $107 \mathrm{MW}_{\mathrm{e}}$ (Energy Information Administration net winter capacity), 1953-vintage, tangentially-fired, reheat unit that fires pulverized eastern U.S. bituminous coal as its primary fuel. As such, it is representative of many of the 400 smaller coal-fired units identified above. Unit 4 can also co-fire biomass at up to $10 \%$ heat input, and the demonstration program included an evaluation of the effect of biomass co-firing on the performance of the multi-pollutant control system. Prior to the installation of the multi-pollutant control system, AES entered into a consent decree with the State of New York in which it was mandated that AES Greenidge must install technology to reduce $\mathrm{NO}_{\mathrm{x}}$ and $\mathrm{SO}_{2}$ emissions from Unit 4, repower the unit, or retire the unit. Whereas the installation of conventional SCR and wet FGD technologies would have been cost-prohibitive for the $107-\mathrm{MW}_{\mathrm{e}}$ unit, the technologies installed as part of the Greenidge Multi-Pollutant Control Project provided AES with an affordable means for reducing emissions, enabling Unit 4 to continue to operate while reducing its environmental impact.

The scope of the Greenidge Project encompassed the design, permitting, procurement, construction, start-up, operation, and performance testing of the multi-pollutant control system. Design work commenced in 2005; the system started up in early 2007, and the testing and operation period concluded in October 2008. The project was conducted by a team including CONSOL Energy Inc., AES Greenidge LLC, and Babcock Power Environmental Inc. CONSOL was the prime contractor under the DOE Cooperative Agreement and was responsible for managing and administering the overall project, testing and evaluating the performance of the multi-pollutant control system, and reporting project results. AES Greenidge, the host site, was a subcontractor to CONSOL and was responsible for site management, environmental permitting, and operation of the demonstration facility. BPEI was a subcontractor to AES Greenidge and was responsible for engineering, procurement, and construction (EPC) of the multi-pollutant control facility. The NOxOUT CASCADE ${ }^{\circledR}$ hybrid SNCR/SCR technology was supplied by Fuel Tech under subcontract to BPEI; the SCR reactor was supplied by BPEI, and the Turbosorp ${ }^{\circledR}$ circulating fluidized bed dry scrubbing technology was supplied by BPEI under license from Austrian Energy and Environment. All funding for the project was provided by the DOE $(43.8 \%)$ and by AES Greenidge (56.2\%). 


\subsection{Project Goals}

As discussed above, the overall objective of the Greenidge Multi-Pollutant Control system was to demonstrate a multi-pollutant control system that can cost-effectively reduce emissions of $\mathrm{NO}_{x}, \mathrm{SO}_{2}, \mathrm{Hg}, \mathrm{SO}_{3}, \mathrm{HCl}, \mathrm{HF}$, and particulate matter from smaller coal-fired EGUs. The specific goals of the project were to:

- Demonstrate that the NO $\mathrm{NOUT}_{\mathrm{C}} \mathrm{CASCADE}^{\circledR}$ hybrid SNCR/SCR system, in combination with combustion modifications that were installed outside of the scope of the DOE cooperative agreement, can reduce high-load $\mathrm{NO}_{\mathrm{x}}$ emissions from the 107-MW $\mathrm{AES}$ Greenidge Unit 4 to $\leq 0.10 \mathrm{lb} / \mathrm{mmBtu}$ (a reduction of $\geq 60 \%$ following the combustion modifications) while the unit is firing $>2 \%$-sulfur coal and co-firing up to $10 \%$ biomass.

- Demonstrate that the Turbosorp ${ }^{\circledR}$ circulating fluidized bed dry scrubber can remove $\geq 95 \%$ of the $\mathrm{SO}_{2}$ emissions from AES Greenidge Unit 4 while the unit is firing $>2 \%$-sulfur coal and co-firing up to $10 \%$ biomass.

- Demonstrate $\geq 90 \%$ mercury removal via the co-benefits achieved by the SNCR/SCR and circulating fluidized bed dry scrubber (with baghouse) systems and, as required, carbon or other sorbent injection.

- Demonstrate $\geq 95 \%$ removal of acid gases $\left(\mathrm{SO}_{3}, \mathrm{HCl}\right.$, and $\left.\mathrm{HF}\right)$ by the Turbosorp ${ }^{\circledR}$ circulating fluidized bed dry scrubber.

- Evaluate process economics and performance to demonstrate the commercial readiness of an emission control system that is suitable for meeting the emission reduction requirements of boilers with capacities of $50 \mathrm{MW}_{\mathrm{e}}$ to $600 \mathrm{MW}_{\mathrm{e}}$.

\subsection{Purpose of this Report}

This final report is intended to serve as a stand-alone document that summarizes all of the publicly available information generated as part of the Greenidge Multi-Pollutant Control project. As such, it covers all facets of the project and incorporates information from the project's quarterly progress reports, public design reports, and other topical reports, as well as additional performance testing results and other data that have not been previously presented. The report culminates with the overall conclusions of the project, which assess the extent to which the project succeeded in meeting the goals set forth above.

\section{Project Management}

As discussed in Section 2.3, CONSOL Energy Inc. was responsible for the overall management and administration of the Greenidge Multi-Pollutant Control Project. Site operations were managed by AES Greenidge, a subcontractor to CONSOL, and the engineering, procurement, and construction of the multi-pollutant control system were managed by Babcock Power Environmental Inc., a subcontractor to AES Greenidge. The National Energy Technology Laboratory managed the project for the U.S. Department of Energy and oversaw all project activities. 
The project was organized into three phases and two budget periods. The first budget period included the Design and Procurement Phase (Phase 1) and the Construction Phase (Phase 2). The second budget period included the Operation and Testing Phase (Phase 3). Table 1 below summarizes the major project tasks under each phase and the organization primarily responsible for completing each task.

Table 1. Summary of major project tasks. The organization with primarily responsibility for completing each task is indicated.

\begin{tabular}{|ll|}
\hline Budget Period 1 & \\
Phase 1. Design and Procurement & \\
Pre-Award Activities & CONSOL, AES Greenidge, BPEI \\
Task 1.1 Phase 1 Project Management & CONSOL \\
Task 1.2 Total Process Definition and Design & BPEI \\
Task 1.3 Equipment Procurement & BPEI \\
Task 1.4 Environmental/Regulatory/Permitting & AES Greenidge \\
Task 1.5 Environmental Information Volume & CONSOL \\
Task 1.6 Baseline Testing & CONSOL \\
Phase 2. Construction & \\
Task 2.1 Phase 2 Project Management & CONSOL \\
Task 2.2 General Civil/Structural Construction & BPEI \\
Task 2.3 Process System Construction & BPEI \\
Task 2.4 Plant Start-Up and Commissioning & BPEI \\
& \\
Budget Period 2 & \\
Phase 3. Operation and Testing & \\
Task 3.1 Phase 3 Project Management & CONSOL \\
Task 3.2 Plant Operations & AES Greenidge \\
Task 3.3 Testing and Evaluation & CONSOL \\
Task 3.4 Final Reporting & CONSOL \\
\hline
\end{tabular}

A project kickoff meeting was held at NETL in Pittsburgh on July 27, 2006, shortly after the signing of the cooperative agreement, during which representatives from DOE, CONSOL, AES, and BPEI reviewed the project's work plan. Project status meetings were held at AES Greenidge periodically throughout the project performance periods to evaluate project progress and discuss any problems or changes in plans. These meetings included a review of important project management items, including schedule, budget, communications, and safety. Moreover, the project team employed earned value management and risk management methodologies, as required by $\mathrm{DOE}$, to objectify the project status evaluation process, inform project decisionmaking, and identify potential problems for mitigation. These project management topics are described in more detail in the following subsections.

\subsection{Schedule}

Appendix A presents the overall project schedule for the Greenidge Multi-Pollutant Control Project, which indicates both the baseline start and end dates and the actual start and end dates for major project tasks and selected subtasks. The schedule for design, procurement, and construction activities was driven largely by AES Greenidge's major outage in OctoberNovember 2006, during which tie-in of the multi-pollutant control system to the existing plant was completed. The timing of that outage was motivated by AES Greenidge's consent decree 
with the State of New York and by their dispatch obligations during peak power seasons. Hence, although the cooperative agreement between the U.S. Department of Energy and CONSOL Energy Inc. for the project was executed on May 19, 2006, a substantial amount of work was performed prior to the signing of that agreement in accordance with pre-award authorizations granted by the DOE. (These authorizations allowed the project team to incur costs associated with certain tasks under the cooperative agreement at its own risk, prior to the signing of the agreement, such that DOE would only reimburse those costs at the agreed-upon cost share if the parties succeeded in executing the agreement). This pre-award work included completion of environmental assessments required by the National Environmental Policy Act (NEPA), which culminated in the issuance of a Finding of No Significant Impact (FONSI) in December 2004, completion of baseline testing at AES Greenidge in November 2004, and commencement of design, procurement, and certain construction activities in 2005. As shown in Appendix A, site preparation work for the multi-pollutant control system began in late 2005, and process system construction began during the first quarter of 2006 . The tie-in outage was completed on schedule on November 18, 2006. However, start-up and commissioning of the multi-pollutant control system took longer than expected, delaying the start of performance testing by about 2.5 months (until March 26, 2007). The project's Testing and Evaluation task (Task 3.3) included three major test series: the Guarantee Tests (designed to evaluate whether the multi-pollutant control system satisfied its performance guarantees), the Process Performance Tests (designed to evaluate the performance of the multi-pollutant control system as a function of changes in unit operating conditions), and the Follow-Up Tests (designed to evaluate the performance of the multi-pollutant control system after a year of routine operation). The completion of the Guarantee Tests (and commencement of the Process Performance Tests) was further delayed when several re-tests were required to demonstrate attainment of the performance guarantee for ammonia slip, and the Process Performance Tests were delayed on several occasions by problems resulting from the accumulation of large particle ash in the induct SCR reactor. (These problems and their resolution are discussed in detail later in this report). Nevertheless, the delayed Process Performance Test campaigns were able to be completed during the approximately year-long period between the Guarantee Tests and FollowUp Tests, and field sampling for the Follow-Up Tests was completed in June 2008 as originally planned. The project concluded on October 18, 2008, according to schedule.

Prior to the signing of the cooperative agreement, six milestones (two per calendar year) were selected from the project's critical path to serve as a baseline for tracking overall project progress. These critical path project milestones are identified in Table 2. As shown in the table, all of the critical path project milestones were met on or ahead of schedule, leading to the timely completion of the project.

\subsection{Budget}

Table 3 summarizes the overall project budget for the Greenidge Project and the actual project cost through the end of October 2008. The total budgeted cost for Budget Period 1 (i.e., the Design and Procurement Phase and the Construction Phase) was $\$ 28,390,348$, and the total budgeted cost for Budget Period 2 (i.e., the Operation and Testing Phase) was $\$ 4,352,628$, for a total planned project cost of $\$ 32,742,976$. The U.S. Department of Energy contributed $43.8 \%$ of these costs, and AES Greenidge contributed the remaining $56.2 \%$.

As shown in the table, actual project expenditures through the end of October 2008 were $\$ 1,866,851$ greater than the total budgeted project cost. This variance arose largely because 
costs for consumables (i.e., lime and urea) during the Operation and Testing Phase substantially exceeded the originally budgeted cost, owing to significant price escalation that occurred after the baseline cost plan was developed. There was $\$ 4,371$ of available DOE funding remaining at the end of October 2008. These funds were reserved for completing the final report for the project.

Table 2. Greenidge Project milestone plan showing planned and actual completion dates for critical path project milestones.

\begin{tabular}{|c|c|c|c|c|c|c|c|c|c|c|c|c|c|c|}
\hline \multirow{3}{*}{$\begin{array}{l}\text { Critical Path } \\
\text { Project } \\
\text { Milestone }\end{array}$} & \multicolumn{8}{|c|}{ Project Duration - Start: 5/19/06 } & \multicolumn{4}{|c|}{ End: $10 / 18 / 08$} & \multirow{3}{*}{$\begin{array}{l}\text { Planned } \\
\text { Date }\end{array}$} & \multirow{3}{*}{$\begin{array}{c}\text { Actual } \\
\text { Date }\end{array}$} \\
\hline & \multicolumn{4}{|c|}{2006} & \multicolumn{4}{|c|}{2007} & \multicolumn{4}{|c|}{2008} & & \\
\hline & Q1 & Q2 & Q3 & Q4 & Q1 & Q2 & Q3 & Q4 & Q1 & Q2 & Q3 & Q4 & & \\
\hline $\begin{array}{l}\text { Initiate scrubber } \\
\text { system installation }\end{array}$ & & A & $\mathrm{P}$ & & & & & & & & & & $9 / 30 / 06$ & $5 / 30 / 06$ \\
\hline $\begin{array}{l}\text { Commence tie-in } \\
\text { outage }\end{array}$ & & & A & $\mathrm{P}$ & & & & & & & & & $12 / 31 / 06$ & $9 / 29 / 06$ \\
\hline $\begin{array}{l}\text { Begin guarantee / } \\
\text { performance testing }\end{array}$ & & & & & $\begin{array}{l}\mathrm{P} \\
\mathrm{A}\end{array}$ & & & & & & & & $3 / 31 / 07$ & $3 / 28 / 07$ \\
\hline $\begin{array}{l}\text { Begin routine plant } \\
\text { operation and data } \\
\text { collection for long- } \\
\text { term testing }\end{array}$ & & & & & & $\begin{array}{l}\mathrm{P} \\
\mathrm{A}\end{array}$ & & & & & & & 6/30/07 & $6 / 21 / 07$ \\
\hline $\begin{array}{l}\text { Begin follow-up } \\
\text { testing }\end{array}$ & & & & & & & & & & $\begin{array}{l}\mathrm{P} \\
\mathrm{A}\end{array}$ & & & $6 / 30 / 08$ & $6 / 10 / 08$ \\
\hline $\begin{array}{l}\text { Complete analyses } \\
\text { of process } \\
\text { performance and } \\
\text { economics }\end{array}$ & & & & & & & & & & & $\begin{array}{l}\mathrm{P} \\
\mathrm{A}\end{array}$ & & 9/30/08 & $9 / 30 / 08$ \\
\hline
\end{tabular}

NOTE: "A" indicates actual completion; "P" indicates planned completion.

Table 3. Overall project budget and actual project cost through October 2008.

\begin{tabular}{|l|c|c|c|c|}
\hline & \multicolumn{3}{|c|}{ Budgeted Cost } & Total Actual Cost \\
(through \\
\cline { 2 - 5 } & Budget Period 1 & Budget Period 2 & Total & 10/208) \\
\hline DOE Share & $\$ 12,434,972$ & $\$ 1,906,451$ & $\$ 14,341,423$ & $\$ 14,337,052$ \\
\hline AES Greenidge Share & $\$ 15,955,376$ & $\$ 2,446,177$ & $\$ 18,401,553$ & $\$ 20,272,775$ \\
\hline TOTAL & $\$ 28,390,348$ & $\$ 4,352,628$ & $\$ 32,742,976$ & $\$ 34,609,827$ \\
\hline
\end{tabular}

The budgeted cost for Budget Period 1, which included engineering, procurement, and construction of the multi-pollutant control system, is less than the total plant cost presented in the Process Economics section (Section 11) of this report. This discrepancy arose because certain costs (e.g., for the combustion modifications, large particle ash removal system, and several subcontracts) were excluded from the DOE budget but included in the reported capital cost because they were considered to be essential to the successful installation of the multipollutant control system. Hence, the process economics presented in Section 11 of this report are more indicative of the costs associated with the multi-pollutant control system at AES Greenidge than are the budget data presented in Table 3. 


\subsection{Earned Value Management}

The project's schedule and budget performance were evaluated routinely throughout the project using earned value management methodology. Earned value management is a project management tool that provides an objective, integrated means for measuring schedule and financial progress, as compared to the initial project plan. As such, it provides project managers with visibility into cost and schedule performance and enables them to more effectively measure and manage project performance. It is based on the following principles (U.S. DOE, 2005):

- All work is planned to completion.

- The work is broken down into finite product-oriented components that can be assigned to a responsible organization.

- The scope, schedule, and cost objectives are integrated into a plan by which progress can be measured.

- Actual costs are recorded.

- Performance is objectively measured.

- Variances and deviations are analyzed, impacts are forecasted, and estimates at completion are based on the actual performance to date.

- Changes to the performance measurement baseline are controlled.

- Earned Value information is employed in the organization's management process.

Earned value management practices were implemented soon after the cooperative agreement for the Greenidge Project was signed. The project's scope, schedule, and budget were integrated, such that the schedule set forth a plan for completing each task in the scope of work, and broke these tasks into measurable, product-oriented subtasks. (In many cases, milestones were used to provide measurable subtasks). The anticipated cost associated with each subtask - i.e., its Planned Value (PV) - was then determined, such that the sum of the PV for all subtasks equaled the total project budget. In this way, a baseline cost and schedule plan was developed that established the relationships between costs, time, and work products.

Each month during the project period, the Actual Cost $(A C)$ incurred during that month (i.e., the total of the funds actually spent for work that was completed) was determined from the participants' accounting systems. In addition, the Earned Value (EV) was derived by computing the originally budgeted value of the work actually accomplished during that month. (For example, envision a hypothetical scenario in which $\$ 10,000$ was originally budgeted for a particular subtask during the month of March. If the subtask was only $75 \%$ complete at the end of March, and $\$ 8,000$ was spent on that subtask during March, then that subtask would have a Planned Value of $\$ 10,000$, an Actual Cost of $\$ 8,000$, and an Earned Value of $\$ 7,500$ for March).

The project's cost performance and schedule performance were evaluated using the Planned Value, Actual Cost, and Earned Value data. The Schedule Performance Index (SPI) and Cost Performance Index (CPI) were computed as follows:

$$
\begin{aligned}
& \mathrm{SPI}=\mathrm{EV} / \mathrm{PV} \\
& \mathrm{CPI}=\mathrm{EV} / \mathrm{AC}
\end{aligned}
$$

By utilizing the concept of earned value, these indices are able to separate the effects of budget variances from the effects of schedule variances. If the SPI equals one, then the project is on schedule. An SPI greater than one indicates that the project is ahead of schedule, and an SPI less than one indicates that the project is behind schedule. Similarly, if the CPI equals one, 
then the project is on budget. A CPI greater than one indicates that the project is under budget, and a CPI less than one indicates that the project is over budget. (Hence, in the example above, the subtask's SPI for March would be $\$ 7,500 / \$ 10,000=0.75$, and the subtask's CPI for March would be $\$ 7,500 / \$ 8,000=0.94$, indicating that the subtask is progressing at only $75 \%$ of the planned rate and getting only $\$ 0.94$ of work accomplished for every $\$ 1.00$ spent).

Earned value management calculations were performed each month by CONSOL using a spreadsheet-based system. Trends and variances in the SPI and CPI were evaluated, and the results were reported to DOE. Figure 2 shows the project's cumulative monthly PV, AC, and EV for the entire project period, and Figure 3 shows its cumulative monthly SPI and CPI for the same period. (The earned value management system was implemented in July 2006 using May 2006 data; however, calculations were performed retrospectively through October 2005, when much of the design, procurement, and construction work under the EPC contract began).

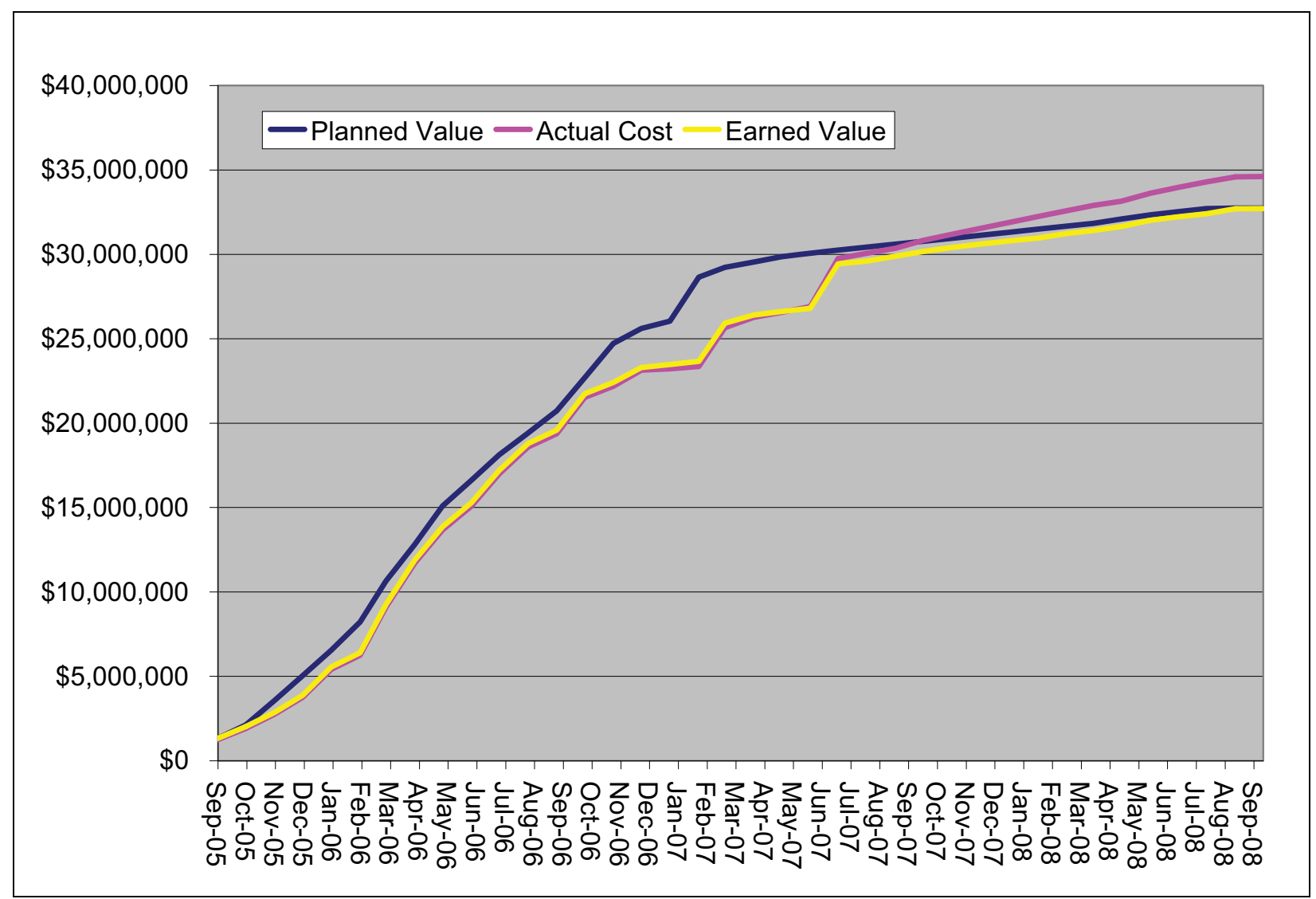

Figure 2. Cumulative monthly Planned Value, Actual Cost, and Earned Value for the Greenidge MultiPollutant Control Project.

As illustrated in these figures, the Greenidge Project fell behind schedule in late 2005 and early 2006, as the project participants were working to finalize the DOE cooperative agreement. The schedule performance improved during the spring and summer of 2006, when much of the construction work was completed, and it was about $96 \%$ on schedule during the heart of the tiein outage in October 2006. The project fell behind schedule again during the first half of 2007, when start-up and commissioning of the multi-pollutant control system took longer than expected and performance testing activities were delayed by the large particle ash and ammonia slip issues referenced in Section 3.1. The delayed activities were accomplished 
during 2007 and early 2008, however, and the SPI returned to 1.00 by September 2008, consistent with the on-schedule completion of the project in October 2008.

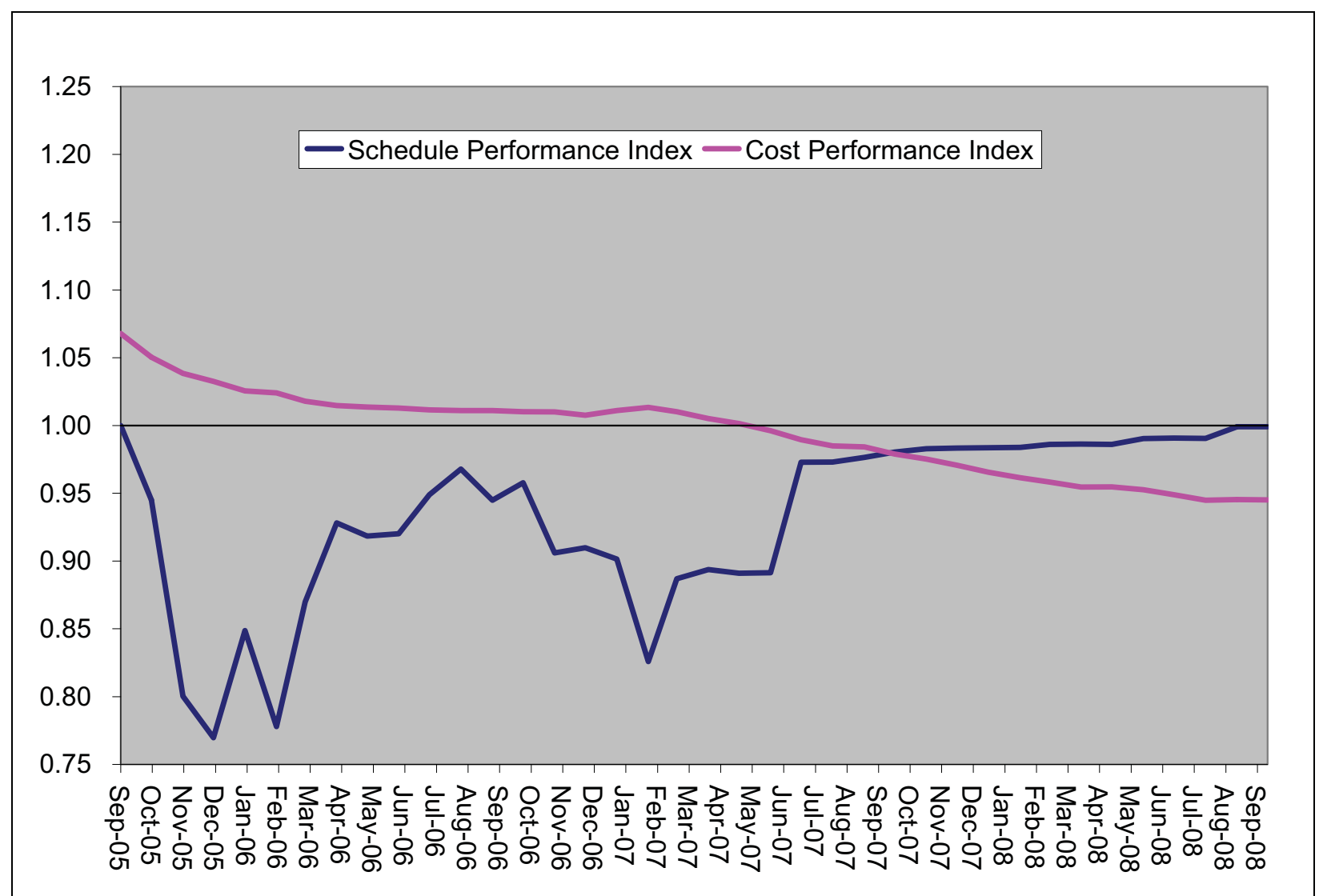

Figure 3. Cumulative monthly Schedule Performance Index and Cost Performance Index for the Greenidge Multi-Pollutant Control Project.

The cost performance index remained close to one throughout the project period, because the EPC contract, which represented a large portion of the total project cost, was paid on the basis of fixed price milestones. The project was slightly under budget during the design, procurement, and construction periods, but it ran slightly over budget during the operation and testing period in 2007 and 2008, owing to the cost overruns for consumables that were discussed in Section 3.2. The project was about $6 \%$ over budget when it concluded in October 2008.

\subsection{Communications}

The success of the Greenidge Project depended in part upon effective communication among the project team. The project's status, accomplishments, problems, and results were communicated to the DOE and to project team members by way of weekly, monthly, and quarterly reports. Moreover, as discussed above, earned value management results were communicated on a monthly basis, and project status meetings were held periodically to promote open dialogue among project participants.

Project results were also communicated to the public via several topical reports, including the Preliminary Public Design Report (issued in May 2007), Guarantee Testing Report (issued in 
March 2008), and Final Public Design Report (issued in November 2008). The project team published a magazine article on the project and presented project results at 12 technical conferences. These publications and conference proceedings are listed in the Project Bibliography included at the end of this report. Finally, press releases were issued to publicize the project; tours were conducted at AES Greenidge to showcase the project to parties with an interest in acquiring the demonstration technology, and technical presentations were given at several luncheon meetings to raise awareness of the project. This Final Report is the last and most comprehensive piece of the project's communication plan.

\subsection{Risk Management}

To identify and mitigate potential project problems, the project team employed risk management practices. The Project Risk Assessment was developed and maintained by the DOE Federal Project Manager, with input from DOE, CONSOL, and AES Greenidge. Specific project risks were identified in the following six areas:

1. Financial

2. Cost / schedule

3. Technical / scope

4. Management, planning, and oversight

5. Environmental, safety, and health

6. External influences

For each identified risk, the degree of risk (low, moderate, or high) was determined by considering the probability of occurrence and potential impact, and response and mitigation strategies were developed. An overall project risk potential was also determined by scoring the overall risk associated with each of the six areas listed above and aggregating these scores.

Project risks were identified and mitigation strategies were developed during meetings among DOE, CONSOL, and AES Greenidge in June 2006, September 2006, November 2006, February 2007, May 2007, September 2007, January 2008, and August 2008. (The frequency of these risk discussions decreased during the latter portion of the project, as the number, probability, and potential impact of project risks declined). This risk management framework helped to ensure that project risks and mitigation strategies were updated to reflect project progress and were transparent to the entire project team.

\subsection{Safety}

Safety was a top priority during the Greenidge Multi-Pollutant Control Project. Contractors were not permitted to work at the AES Greenidge site until they completed the plant's contractor safety training program. Annual renewal of this safety training was required. AES Greenidge monitored contractor safety performance throughout the construction period, and any deviations from the plant's safety policies were corrected immediately. In November 2007, BPEI trained all AES Greenidge personnel in the safe operation and maintenance of the multi-pollutant control system. Plant personnel reviewed project safety issues during weekly safety meetings that were held routinely throughout the project period. Prior to each field sampling campaign at AES Greenidge, CONSOL held a preparation meeting during which safety policies and procedures were reviewed with all members of the sampling team. 
During the construction period in 2006, there were two recordable incidents associated with the project, one of which was a lost time accident. The lost time accident occurred when a construction worker bumped his knee. The other recordable incident occurred when a welder, who was wearing all required safety equipment, was struck in the head by a pry bar and needed stitches. During the operation and testing period in 2007 and 2008, there were three recordable incidents associated with the project. None of these were lost time accidents. (The recordable incidents in 2007 and 2008 did not occur within the scope of the DOE funding, but all were related to the multi-pollutant control system). The first recordable incident during the Operation and Testing Phase occurred when a contractor hit his forehead on a steel lug while changing the catalyst in the SCR reactor. The second incident occurred when a worker's finger was pinched by an automatically operated air cylinder, resulting in a laceration that required stitches. The third incident occurred when a worker who was wearing proper eye protection sustained a possible eye laceration caused by a particle of lime that fell through the grating near the lime hydration system. All recordable incidents were properly reported; causes were identified, and corrective actions were implemented to prevent recurrence.

\section{Technology Overview}

As discussed in Section 2, the multi-pollutant control system that was demonstrated as part of the Greenidge Project comprises an innovative combination of technologies that were applied in a unique way and integrated for the first time at AES Greenidge Unit 4. This section provides a general, comprehensive overview the demonstration technology, covering important design features and considerations as well as the developmental status of the technology prior to the Greenidge Project. The specifics of the design for the AES Greenidge Unit 4 application are covered in Section 6 of this report.

\subsection{Process Concept}

Figure 4 presents a schematic of the multi-pollutant control process that was demonstrated as part of the Greenidge Multi-Pollutant Control Project. The process integrates three major components: $\mathrm{NO}_{x}$ control via a NO $\mathrm{NOUT} \mathrm{CASCADE}^{\circledR}$ hybrid SNCR/SCR system; $\mathrm{SO}_{2}, \mathrm{SO}_{3}, \mathrm{HCl}$, $\mathrm{HF}$, and particulate matter control via a Turbosorp ${ }^{\circledR}$ circulating fluidized bed dry scrubbing system with a baghouse and solid product recycling; and mercury control via activated carbon injection and the co-benefits afforded by the $\mathrm{NO}_{\mathrm{x}}$ control and Turbosorp ${ }^{\circledR}$ systems. General process chemistry and engineering concepts for each of these components are described below.

\subsection{1 $\mathrm{NO}_{\mathrm{x}}$ Control}

$\mathrm{NO}_{x}$ control is the first step in the multi-pollutant control process and is accomplished using urea-based, in-furnace selective non-catalytic reduction followed by a single-layer, in-duct selective catalytic reduction reactor that is fed by ammonia slip from the SNCR process. Although not an essential component of the multi-pollutant control process, for certain applications, such as that on AES Greenidge Unit 4, it may be advantageous to complement the 
hybrid SNCR/SCR system with combustion modifications designed to achieve further reductions in $\mathrm{NO}_{x}$ emissions and to improve the performance of the hybrid SNCR/SCR system.

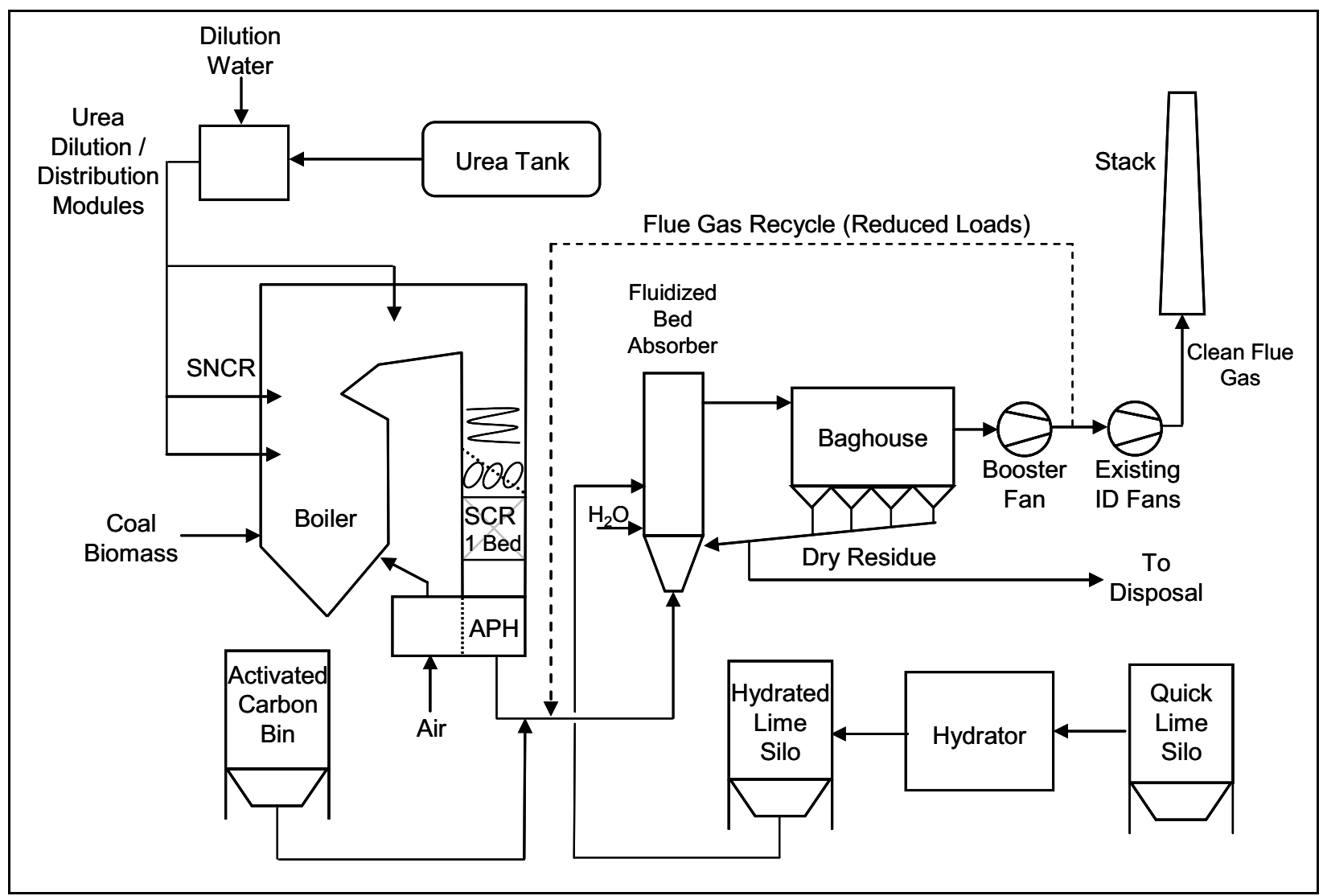

Figure 4. Schematic of the multi-pollutant control process that was demonstrated as part of the Greenidge Project.

In the SNCR process, aqueous urea $\left(\mathrm{CO}\left(\mathrm{NH}_{2}\right)_{2}\right)$ is atomized and injected into the furnace above the combustion zone. The relatively high temperatures in the furnace promote dissociation of the urea into reactive radicals (e.g., $\mathrm{NH}_{2}, \mathrm{NCO}$ ), which react with nitrogen oxide and oxygen to form molecular nitrogen, carbon dioxide, and water, according to the following overall reaction:

$$
\mathrm{CO}\left(\mathrm{NH}_{2}\right)_{2}+2 \mathrm{NO}+1 / 2 \mathrm{O}_{2} \rightarrow 2 \mathrm{~N}_{2}+\mathrm{CO}_{2}+2 \mathrm{H}_{2} \mathrm{O}
$$

The performance of a urea-based SNCR system can be quantified by computing its urea utilization, which is defined as:

$$
\text { Urea Utilization }(\%)=\left[\mathrm{NO}_{\mathrm{x}} \text { Reduction }(\%)\right] \div \mathrm{NSR} \text {, }
$$

where NSR is the normalized stoichiometric ratio, computed as:

$$
\mathrm{NSR}=2 \cdot[\text { moles urea }] \div\left[\text { moles inlet } \mathrm{NO}_{\mathrm{x}}\right]
$$

Hence, if the system achieves a $\mathrm{NO}_{x}$ reduction that is stoichiometrically equivalent to the amount of urea injected (i.e., if the number of moles of $\mathrm{NO}_{x}$ removed is twice the number of moles of urea injected), then the urea utilization is $100 \%$. If the $\mathrm{NO}_{\mathrm{x}}$ removal is less than 
stoichiometrically equivalent to the amount of urea injected, then the urea utilization is correspondingly less than $100 \%$.

In practice, urea utilization by SNCR systems is typically much less than $100 \%$ (e.g., $30-60 \%$, Albanese et al., 2005), in part because of restrictions on the amount of allowable ammonia slip from these systems. $\mathrm{NO}_{x}$ reduction according to reaction (3) occurs over a temperature range of approximately $1400^{\circ} \mathrm{F}$ to $2200^{\circ} \mathrm{F}$; however, the reaction is temperature-sensitive within this range, as illustrated in Figure 5. Ammonia is a byproduct of urea-based SNCR; the amount of ammonia produced by the process decreases as temperature increases. Because the amount of allowable $\mathrm{NH}_{3}$ slip is generally limited to 2-10 ppmv or less for coal-fired EGU applications, conventional stand-alone SNCR installations are typically designed to operate at relatively high temperatures that produce low amounts of ammonia slip. At these high temperatures, though, SNCR performance is adversely affected by competing reactions that consume the urea reagent or oxidize reagent to form additional $\mathrm{NO}_{\mathrm{x}}$, resulting in less-than-optimal urea utilization.

In a hybrid SNCR/SCR system, greater levels of ammonia slip from the SNCR process are actually desirable, as the ammonia produced via SNCR serves as the reagent to effectuate additional $\mathrm{NO}_{x}$ removal in the downstream SCR reactor. As a result, the SNCR system in a hybrid process can be designed to operate at lower temperatures (e.g., 1650-1900 ${ }^{\circ} \mathrm{F}$ ) than a stand-alone SNCR system would, resulting in improved urea utilization and greater $\mathrm{NO}_{\mathrm{x}}$ removal by the SNCR system, as well as sufficient $\mathrm{NH}_{3}$ slip to permit additional $\mathrm{NO}_{\mathrm{x}}$ reduction via SCR. Lower-temperature urea injection is accomplished in the hybrid SNCR/SCR system by including some injectors in upper sections of the furnace and in the convective pass.

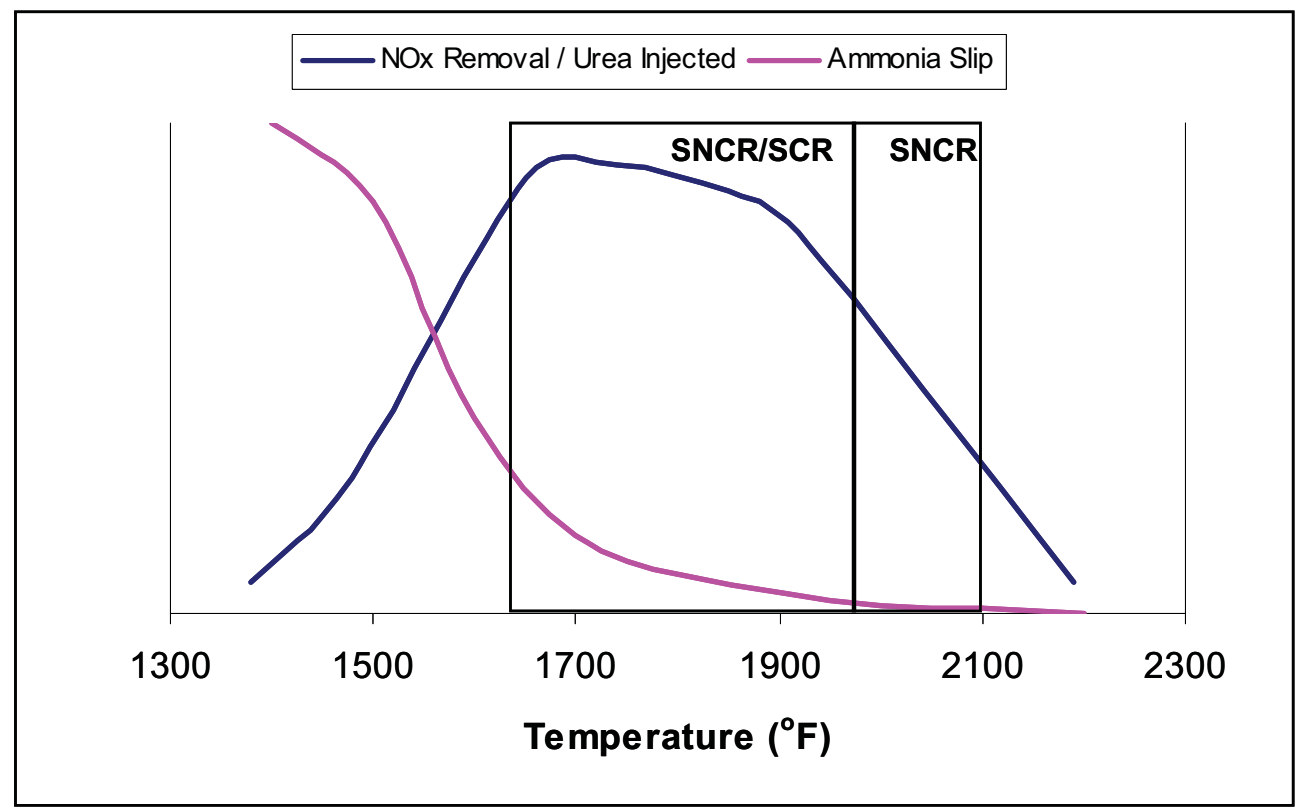

Figure 5. Conceptual depiction of the effect of temperature on urea utilization and ammonia slip in SNCR, and the implications of this effect for hybrid SNCR/SCR design.

The flue gas exiting the furnace, which contains unreacted $\mathrm{NO}_{x}$ (primarily $\mathrm{NO}$ ) and $\mathrm{NH}_{3}$ produced by the SNCR process, next flows through a compact SCR reactor containing a single catalyst layer that is installed in a modified section of the ductwork between the unit's economizer and air heater. The single-layer, in-duct SCR operates with the same process chemistry as a standard full-size SCR. Nitrogen oxides in the flue gas are reduced by ammonia 
(or by isocyanic acid, HNCO, which is also formed as part of the SNCR process) in the presence of a catalyst to form molecular nitrogen and water according to the following reactions:

$$
\begin{aligned}
& 4 \mathrm{NO}+4 \mathrm{NH}_{3}+\mathrm{O}_{2} \rightarrow 4 \mathrm{~N}_{2}+6 \mathrm{H}_{2} \mathrm{O} \\
& \mathrm{NO}+\mathrm{NO}_{2}+2 \mathrm{NH}_{3} \rightarrow 2 \mathrm{~N}_{2}+3 \mathrm{H}_{2} \mathrm{O} \\
& 4 \mathrm{NO}+4 \mathrm{HNCO}+\mathrm{O}_{2} \rightarrow 4 \mathrm{~N}_{2}+4 \mathrm{CO}_{2}+2 \mathrm{H}_{2} \mathrm{O}
\end{aligned}
$$

Because the SCR is fed by $\mathrm{NH}_{3}$ slip resulting from SNCR, it does not require the $\mathrm{NH}_{3}$ storage and handling system and $\mathrm{NH}_{3}$ injection grid that are typically needed for stand-alone SCR installations. Otherwise, the in-duct SCR utilizes the same technology as a standard full-size SCR, except that it is installed in a modified section of the ductwork between the unit's existing economizer and air heater(s), where flue gas temperatures (approximately $650{ }^{\circ} \mathrm{F}$ for the AES Greenidge Unit 4 application at full load) are in the optimum range for the SCR reactions to occur. Because of its small size, the amount of $\mathrm{NO}_{x}$ reduction achievable by the in-duct SCR is less than the amount achievable by a stand-alone SCR. However, unlike a stand-alone SCR, the purpose of the in-duct SCR in the hybrid system is to consume ammonia slip in order to permit enhanced $\mathrm{NO}_{x}$ reduction by the upstream SNCR, while also affording incremental $\mathrm{NO}_{x}$ reduction.

To maximize performance of the relatively small, in-duct SCR system, BPEl's Delta Wing ${ }^{\mathrm{TM}}$ static mixing technology is installed in the ductwork just upstream of the SCR reactor. As illustrated conceptually in Figure 6 , the Delta Wing ${ }^{\mathrm{TM}}$ technology utilizes stationary obstructions oriented at a slant to the direction of flow to create a zone of large, violent vortices that homogenize the velocity, temperature, and composition of the flue gas across the crosssectional area of the duct. For the in-duct SCR reactor, homogeneity in the distribution of $\mathrm{NO}_{\mathrm{x}}$ and $\mathrm{NH}_{3}$ throughout the flue gas is desired to maximize the utilization of the available catalyst surface, thereby maximizing $\mathrm{NO}_{x}$ reduction and minimizing $\mathrm{NH}_{3}$ slip. In addition, the static mixers are designed to maintain ash entrainment and distribution across the cross-sectional area of the reactor, minimizing catalyst deactivation and pressure drop via fly ash plugging. For units such as AES Greenidge Unit 4 that produce large particle ash, a screen and/or other LPA removal equipment is also required upstream of the SCR reactor in order to prevent LPA from accumulating in the catalyst.

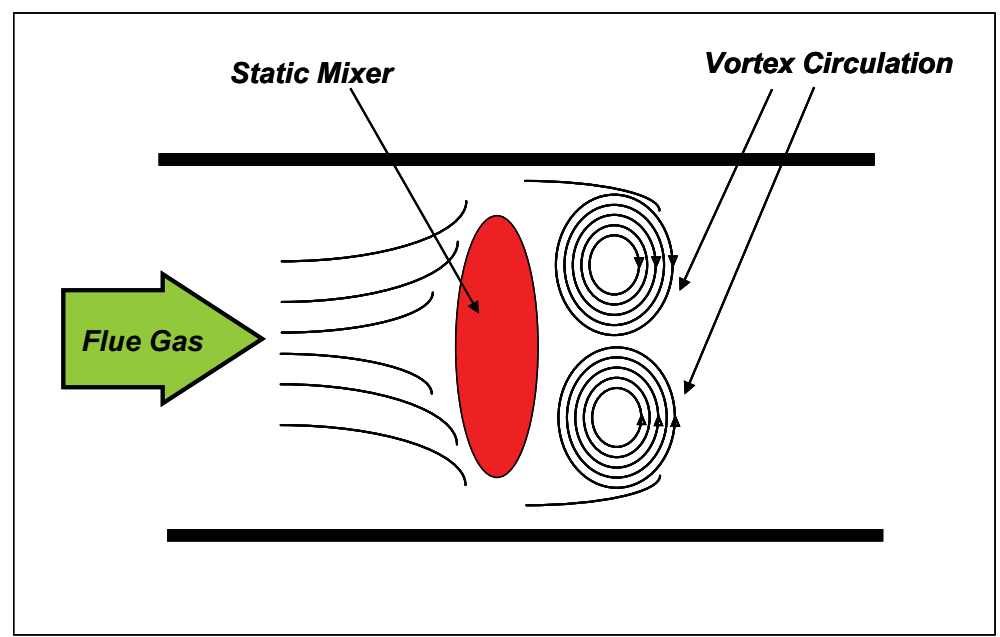

Figure 6. Conceptual illustration of the Delta Wing ${ }^{\mathrm{TM}}$ static mixing technology. 
Major process components for the hybrid SNCR/SCR system include urea storage equipment, urea delivery, metering, and distribution equipment, urea injection equipment, static mixers, LPA removal equipment (if required), SCR catalyst, duct modifications and catalyst support, and miscellaneous process control equipment. In addition, sonic horns and/or rake soot blowers are used to prevent ash buildup on top of the SCR catalyst. For the AES Greenidge Unit 4 installation, flue gas bypasses are not required around the economizer or the SCR catalyst, simplifying the design and operation of the system.

\subsection{2 $\mathrm{SO}_{2}, \mathrm{SO}_{3}, \mathrm{HCl}, \mathrm{HF}$, and Particulate Matter Control}

After exiting the SCR reactor and passing through the plant's existing air heater(s), the flue gas is sent to the Turbosorp ${ }^{\circledR}$ circulating fluidized bed dry scrubbing system for removal of $\mathrm{SO}_{2}, \mathrm{SO}_{3}$, $\mathrm{HCl}, \mathrm{HF}$, and particulate matter. In the Turbosorp ${ }^{\circledR}$ system, the flue gas first enters the absorber vessel through a venturi nozzle. (The inlet to the absorber vessel may contain either a single venturi nozzle or multiple venturi nozzles, depending upon the volume of flue gas being treated). Water and hydrated lime $\left(\mathrm{Ca}(\mathrm{OH})_{2}\right)$ are separately injected into the absorber above the venturi section.

In the absorber vessel, the pollutant-laden flue gas is cooled in a fast fluidized bed of moistened particles, which include the injected hydrated lime as well as fly ash and reaction products. As the flue gas passes through the bed of particles, intimate contact is provided between the alkaline particles of hydrated lime and the acid gases contained in the flue gas. The surface moisture of these lime particles provides for liquid phase diffusion of the acid gases and contact with the lime in solution. This is a quick absorption mechanism and the one mainly responsible for neutralization of the acid gases. The large surface area of the particles in the bed also provides for rapid heat transfer. Thus, the particles are quickly dried as the flue gas passes through the bed, and the flue gas is evaporatively cooled to within $45^{\circ} \mathrm{F}$ of its adiabatic saturation temperature.

The acid gas constituents of the flue gas $\left(\mathrm{SO}_{2}, \mathrm{SO}_{3}, \mathrm{HCl}, \mathrm{HF}\right.$, and to a lesser extent, $\left.\mathrm{CO}_{2}\right)$ are removed by reaction with hydrated lime. Each of these acid gas constituents produces a calcium-based salt and excess water when contacted with the alkaline $\mathrm{Ca}(\mathrm{OH})_{2}$ reagent. Sulfur dioxide and trioxide form calcium sulfite and sulfate hydrates. The halides, $\mathrm{HCl}$ and $\mathrm{HF}$, form calcium chloride and fluoride, respectively. Some $\mathrm{CO}_{2}$ reacts to form calcium carbonate. These reactions are summarized below:

$$
\begin{aligned}
& \mathrm{Ca}(\mathrm{OH})_{2}+\mathrm{SO}_{2} \leftrightarrow \mathrm{CaSO}_{3} \cdot 1 / 2 \mathrm{H}_{2} \mathrm{O}+1 / 2 \mathrm{H}_{2} \mathrm{O} \\
& \mathrm{Ca}(\mathrm{OH})_{2}+\mathrm{SO}_{3} \leftrightarrow \mathrm{CaSO}_{4} \cdot 1 / 2 \mathrm{H}_{2} \mathrm{O}+1 / 2 \mathrm{H}_{2} \mathrm{O} \\
& \mathrm{CaSO} \mathrm{C}_{3} \cdot 1 / 2 \mathrm{H}_{2} \mathrm{O}+1 / 2 \mathrm{O}_{2} \leftrightarrow \mathrm{CaSO}_{4} \cdot 1 / 2 \mathrm{H}_{2} \mathrm{O} \\
& \mathrm{Ca}(\mathrm{OH})_{2}+2 \mathrm{HCl} \leftrightarrow \mathrm{CaCl}_{2}+2 \mathrm{H}_{2} \mathrm{O} \\
& \mathrm{Ca}(\mathrm{OH})_{2}+2 \mathrm{HF} \leftrightarrow \mathrm{CaF}_{2}+2 \mathrm{H}_{2} \mathrm{O} \\
& \mathrm{Ca}(\mathrm{OH})_{2}+\mathrm{CO}_{2} \leftrightarrow \mathrm{CaCO}_{3}+\mathrm{H}_{2} \mathrm{O}
\end{aligned}
$$

After exiting the absorber vessel, the dry, solid products (i.e., fly ash, unreacted hydrated lime, $\mathrm{CaSO}_{3}, \mathrm{CaSO}_{4}, \mathrm{CaCO}_{3}, \mathrm{CaCl}_{2}$, and $\mathrm{CaF}_{2}$ ) are separated from the flue gas in a baghouse, which is an integral part of the Turbosorp ${ }^{\circledR}$ system. (Although water is injected into the absorber vessel and formed by the reactions in the absorber, the flue gas remains unsaturated). To maximize acid gas removal and reagent utilization, most (e.g., $\geq 95 \%$ ) of these solids are recycled via gravity to the absorber vessel using air slides. Upon reentering the absorber, the 
sulfite-coated surfaces of partially reacted $\mathrm{Ca}(\mathrm{OH})_{2}$ particles are moistened, causing the calcium sulfite to form needle-like crystals. This crystallization exposes fresh $\mathrm{Ca}(\mathrm{OH})_{2}$ surface, permitting additional reaction with acid gases and hence greater reagent utilization. Recycle of the baghouse solids provides ample residence time for sorbent reactivation and reaction with $\mathrm{Ca}(\mathrm{OH})_{2}$ according to this mechanism.

In addition to removing the acid gas constituents of the flue gas, the circulating fluidized bed dry scrubbing system enhances removal of particulate matter. For plants that are currently equipped with an electrostatic precipitator, installation of a baghouse is expected to improve fine particulate matter $\left(\mathrm{PM}_{2.5}\right)$ capture efficiency. Moreover, the fluidized particle bed in the absorber vessel promotes particle agglomeration via collisions among particles, resulting in larger particles that can be captured more easily in the baghouse. Agglomeration is further enhanced by the water that is injected for flue gas humidification, which tends to increase the cohesion of the particles.

Major components of the Turbosorp ${ }^{\circledR}$ system include the absorber vessel, hydrated lime storage and injection system, water storage and injection system, baghouse, solid product recycle and disposal system, and miscellaneous process control equipment. An onsite lime hydrator can be included as part of the installation to produce the required hydrated lime reagent from pebble lime, or the hydrated lime can be delivered to the site for direct use in the process. In addition, as shown in Figure 4, a flue gas recycle system may be included to provide sufficient flue gas flow to maintain a fluidized bed in the absorber at low load operation. Figure 7 presents a schematic of the Turbosorp ${ }^{\circledR}$ system highlighting the flow of solids, liquids, and gases through the process.

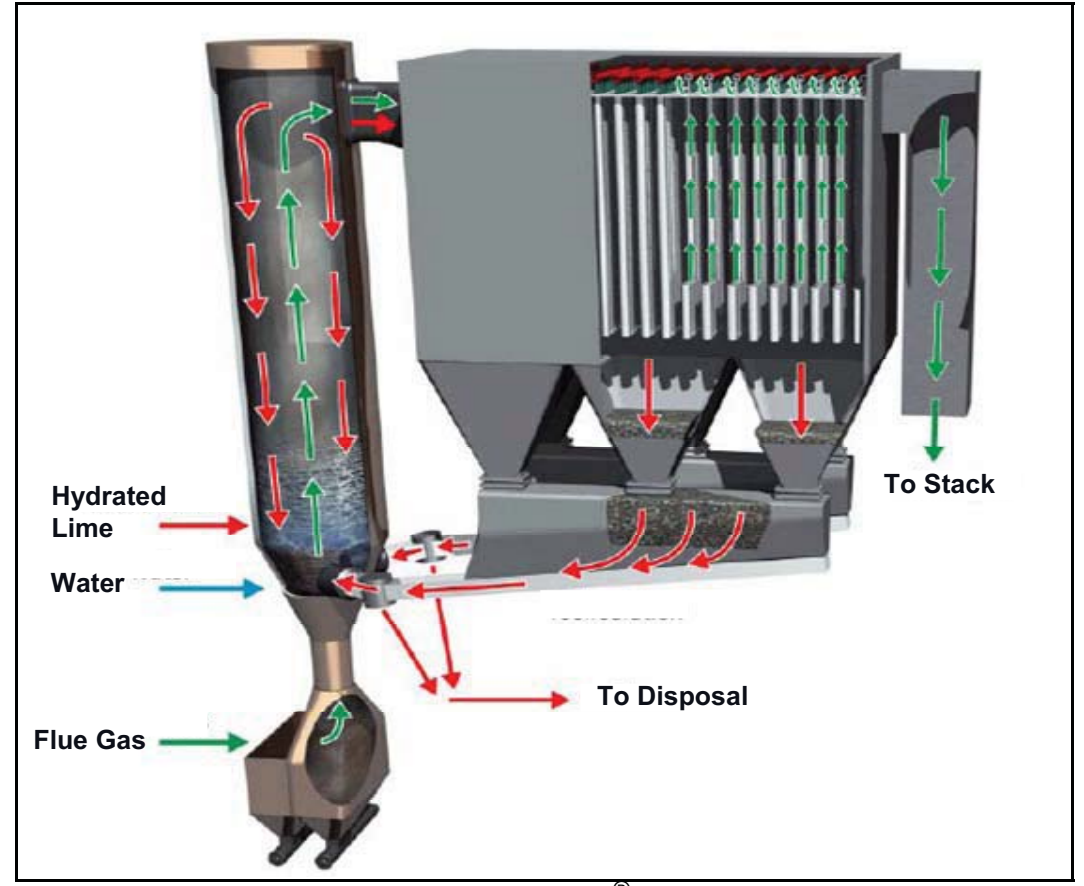

Figure 7. Schematic of the Turbosorp ${ }^{\circledR}$ circulating fluidized bed dry scrubbing system. Red, blue, and green arrows indicate the paths of solids, liquids, and gases, respectively, through the system.

The process is totally "dry", meaning that it introduces the reagent as a dry, free-flowing powder and produces a dry, free-flowing disposal product. The absorber operates not only as a 
chemical reactor but also as an evaporative cooler. Surface humidity of particles within the fluidized bed is held nearly constant by introducing the water independently from the recirculated solids and fresh hydrated lime. This reduces the potential for scaling relative to wet and semi-dry processes. Water injection, reagent injection, and bed recirculation are independent unit operations. Thus, the process allows reagent injection rates that are a function of pollutant loading and emission targets.

\subsubsection{Mercury Control}

Mercury control in the multi-pollutant control system is accomplished via the co-benefits afforded by the in-duct SCR, circulating fluidized bed dry scrubber, and baghouse and, if required, by the injection of activated carbon just upstream of the scrubber.

From a mercury control perspective, the Greenidge multi-pollutant control process is very similar to a conventional air pollution control configuration comprising an SCR, spray dryer, and baghouse. Measurements have demonstrated that this configuration, when applied to plants firing bituminous coal, achieves a high level of mercury removal (i.e., 89-99\%) without the need for any mercury-specific control technology (Withum, 2006; Miller et al., 2006). This high level of removal likely results from a combination of factors, including the conversion of elemental mercury $\left(\mathrm{Hg}^{0}\right)$ to oxidized mercury $\left(\mathrm{Hg}^{2+}\right)$ across the SCR catalyst (Presto and Granite, 2006), the removal of $\mathrm{Hg}^{2+}$ (a Lewis acid) via chemisorption by moistened, basic $\mathrm{Ca}(\mathrm{OH})_{2}$ particles in the scrubber (Lancia et al., 1993; Ghorishi and Gullett, 1998), and the removal of $\mathrm{Hg}^{2+}$ and possibly some $\mathrm{Hg}^{0}$ via adsorption onto carbon-containing fly ash and $\mathrm{Ca}(\mathrm{OH})_{2}$ at low temperatures in the baghouse (CEA, 2005), which facilitates contact between gaseous mercury and carbon or other sorbent contained in the "dust cake" that accumulates on its numerous filter bags. The Greenidge multi-pollutant control process includes all of these components, and hence, it is expected that its combination of an in-duct SCR, $\mathrm{Ca}(\mathrm{OH})_{2}$-based scrubber, and baghouse will generally result in high mercury removals without any activated carbon injection when applied to bituminous coal-fired units. Prior to the Greenidge Project, however, it was uncertain whether $\mathrm{Hg}^{0}$ would be oxidized effectively across the SCR catalyst at the abnormally high space velocities resulting from the single-layer, in-duct design. Determining the extent of $\mathrm{Hg}$ oxidation and its effect on overall $\mathrm{Hg}$ removal was one of the objectives of the project's testing program.

To ensure high mercury removal efficiencies, the multi-pollutant control system also includes an activated carbon injection system. Activated carbon, which adsorbs both $\mathrm{Hg}^{0}$ and $\mathrm{Hg}^{2+}(\mathrm{CEA}$, 2005), is injected into the flue gas just upstream of the Turbosorp ${ }^{\circledR}$ absorber vessel. Very effective utilization of the activated carbon and high mercury capture are expected to result from the long solids residence time provided by the circulating fluidized bed scrubbing system's high solids recycle ratio. The relatively low temperatures $\left(\sim 160^{\circ} \mathrm{F}\right)$ in the Turbosorp ${ }^{\circledR}$ system and the thorough contact facilitated by caking of the carbon sorbent on the baghouse filter bags are also expected to result in a high capacity for mercury capture by the activated carbon, as compared to simple duct injection. Moreover, the Turbosorp ${ }^{\circledR}$ system may help to promote mercury capture by removing $\mathrm{SO}_{3}$, which has been shown to compete with $\mathrm{Hg}$ for active binding sites on the activated carbon particles (Presto and Granite, 2007). The activated carbon injection system includes a carbon storage silo, carbon feed and injection system, and miscellaneous process control instrumentation. The baghouse is used to remove spent carbon from the flue gas. 


\subsection{Key Design Features}

As discussed in the Introduction, the multi-pollutant control system that was demonstrated as part of the Greenidge Project was designed with the overall goal of providing an integrated process that is well suited for reducing emissions of a number of pollutants from smaller (i.e., 50-300 $\mathrm{MW}_{\mathrm{e}}$ ) coal-fired EGUs. Therefore, the design included several key features that are consistent with the needs of these smaller units. These key design features, which are synonymous with the advantages of the multi-pollutant control system over technologies that have conventionally been applied to smaller coal-fired units, are identified and discussed in the subsections below.

\subsubsection{Deep Emission Reductions}

Conventional low-capital-cost air pollution control options for smaller coal-fired units, such as low- $\mathrm{NO}_{x}$ burners or stand-alone SNCR to reduce $\mathrm{NO}_{x}$ emissions and combustion of low-sulfur coal or use of sorbent injection in the furnace or ductwork to limit $\mathrm{SO}_{2}$ emissions, in most cases do not produce emission rates consistent with the low levels established in environmental regulations that recently have been promulgated or proposed. Hence, units employing these options are increasingly vulnerable to volatile allowance costs or even retirement as new regulations are enacted. Thus, it was essential that the Greenidge multi-pollutant control process be designed to achieve deeper emissions reductions than these conventional lowcapital-cost options and to meet or exceed applicable state and federal regulatory requirements for air emissions.

The process demonstrated at AES Greenidge is well suited for achieving $\mathrm{NO}_{\mathrm{x}}$ emission reductions of about $50-75 \%$, compared with the $20-35 \%$ reduction typically achievable by SNCR (Pfaff and Abrams, 2006). It also is designed to achieve greater than $95 \%$ removal of $\mathrm{SO}_{2}$, comparable to the $95-98 \%$ removals characteristic of today's best available wet scrubbing technologies for larger coal-fired units (DePriest and Gaikwad, 2003). Furthermore, the multipollutant control system is designed to achieve greater than $90 \%$ capture of mercury, meeting or exceeding the performance of state-of-the art mercury control technologies, and to reduce emissions of $\mathrm{SO}_{3}, \mathrm{HCl}$, and $\mathrm{HF}$ by at least $95 \% . \mathrm{NO}_{x}, \mathrm{SO}_{2}$, and mercury are the focus of many state and federal environmental actions. $\mathrm{SO}_{3}, \mathrm{HCl}$, and $\mathrm{HF}$ contribute to the formation of acid aerosols, and emissions of these compounds must be reported to the U.S. Environmental Protection Agency (EPA) as part of the national Toxics Release Inventory (TRI) program. Elevated concentrations of $\mathrm{SO}_{3}$ in flue gas can also result in the formation of visible emissions (i.e., "blue plumes"), which are often particularly problematic for coal-fired power plants with SCR systems because $\mathrm{SO}_{3}$ can be generated by oxidation of $\mathrm{SO}_{2}$ across the $\mathrm{SCR}$ catalyst. Although the Greenidge multi-pollutant control process includes an SCR reactor, the downstream circulating fluidized bed dry scrubber is designed for deep $\mathrm{SO}_{3}$ removal, eliminating the potential for plume visibility problems due to $\mathrm{SO}_{3}$. Finally, as discussed above, for plants currently using an ESP to control particulate matter emissions, installation of the circulating fluidized bed dry scrubber and baghouse is expected to afford a substantial improvement in PM control, especially for fine particles. 


\subsubsection{Low Capital Costs}

There are commercially-available conventional technologies, such as full-scale SCR systems and limestone forced oxidation wet scrubbers, that are capable of achieving or exceeding the deep emissions reductions targeted for the Greenidge multi-pollutant control process. However, operators of smaller coal-fired EGUs, which are penalized by economies of scale, often cannot afford the large capital costs associated with these technologies. Hence, the multi-pollutant control process that was demonstrated at AES Greenidge was designed to achieve deep emission reductions while offering substantially reduced capital costs compared to these conventional state-of-the-art technologies.

By using a compact, single-layer SCR reactor that is installed in a modified section of ductwork between the unit's economizer and air heater, the hybrid SNCR/SCR system avoids many of the capital costs associated with the multi-layer reactor, structural support steel, foundations, and new ductwork runs required for a conventional stand-alone SCR system. Also, unlike wet FGD systems, the Turbosorp ${ }^{\circledR}$ system does not produce saturated flue gas, and therefore is constructed from carbon steel rather than from the expensive corrosion-resistant materials required for wet scrubbers. For the same reason, use of the Turbosorp ${ }^{\circledR}$ system also does not entail the installation of a new corrosion-resistant stack (or flue gas reheat system), which is commonly required for wet scrubber retrofits. Because of these factors, as well as the mechanical simplicity of the Turbosorp ${ }^{\circledR}$ system relative to wet scrubbers, the capital cost of the multi-pollutant control system installed at the 107-MW $\mathrm{MW}_{\mathrm{e}} \mathrm{AES}$ Greenidge Unit 4 is estimated to be about $40 \%$ less than the capital cost would have been to retrofit the unit with a conventional system comprising a stand-alone SCR and wet limestone forced oxidation scrubber (as discussed in greater detail in Section 11).

In exchange for its substantially reduced capital costs, the Greenidge multi-pollutant control system has higher variable operating costs (because of its lower reagent utilization or use of more expensive reagent) and lower $\mathrm{NO}_{\mathrm{x}}$ removal efficiency (SCRs are capable of achieving 80$90 \%$ or greater $\mathrm{NO}_{x}$ reduction) relative to a conventional stand-alone SCR / wet FGD system. Whereas this tradeoff may be unattractive for large coal-fired EGUs, it is consistent with the needs of the owners of smaller units, which in many cases cannot justify or afford the large capital costs (per unit of electrical output) needed to retrofit with conventional technologies for deep emissions reductions.

\subsubsection{Small Space Requirements}

The relatively large amount of space required to install conventional SCR and wet FGD systems further prevents these technologies from being widely applied to smaller coal-fired EGUs. Many smaller coal-fired units are located in built-up areas and do not have sufficient physical space to easily accommodate both an SCR and wet scrubber; this increases the difficulty, and hence the capital cost, of retrofitting these technologies. Therefore, an objective in designing the Greenidge multi-pollutant control system was to minimize its required footprint.

The SNCR portion of the multi-pollutant control process requires only a small amount of space for a urea storage tank, a small shed containing the urea circulation module, and several small urea distribution skids located around the boiler. Unlike a conventional stand-alone SCR reactor, the single-layer SCR reactor requires essentially no new land area, as it is installed in a modified ductwork section between the economizer and air heater and needs only a few new 
support beams. The arrangement of the circulating fluidized bed dry scrubber, baghouse, and associated equipment is also compact. The various pieces of equipment are vertically tiered to permit gravity-assisted transport of solids where possible, and as a result, require less than 0.5 acre of land for a $110 \mathrm{MW}_{\mathrm{e}}$ installation. The layout of the multi-pollutant control system for the AES Greenidge Unit 4 installation is discussed in greater detail in Section 6.3.2 of this report.

\subsubsection{Applicability to High-Sulfur Coals}

As discussed in the Introduction, greater than $80 \%$ of the coal-fired units that are candidates for the demonstration technology are located east of the Mississippi River, where high-sulfur eastern U.S. bituminous coal is a candidate fuel source. The dispatch economics of these units can improve significantly with the installation of low-cost $\mathrm{SO}_{2}$ removal systems that allow the use of higher-Btu, higher-sulfur, less-expensive coals with a net reduction in $\mathrm{SO}_{2}$ emissions and a corresponding reduction in the need for purchasing allowances. Hence, an important design objective for the Greenidge multi-pollutant control system was that it be able to achieve deep $\mathrm{SO}_{2}$ emission reductions when applied to units firing high-sulfur (i.e., $>2 \%$-sulfur) coals.

Lime spray dryers provide a relatively low-capital-cost means for achieving deep reductions in $\mathrm{SO}_{2}$ emissions, as does the Turbosorp ${ }^{\circledR}$ circulating fluidized bed dry scrubber that was installed as part of the multi-pollutant control process at AES Greenidge. However, it is more difficult to treat high-sulfur flue gases and to achieve very high $\mathrm{SO}_{2}$ removal efficiencies with a spray dryer than with a circulating fluidized bed dry scrubber. In spray dryer systems, lime and water are injected into the absorber vessel together as a slurry, rather than separately as in the Turbosorp ${ }^{\circledR}$ system. As a result, increasing the lime injection rate (i.e., to accommodate a higher inlet $\mathrm{SO}_{2}$ loading or to increase the $\mathrm{SO}_{2}$ removal efficiency) may require a corresponding increase in the water injection rate to maintain the solids content of the slurry within acceptable limits. For sufficiently high $\mathrm{SO}_{2}$ loadings and removal efficiencies, the slurry injection scheme imposes a limit on the amount of lime that can be injected, because excess water could lead to scaling in the absorber vessel, plugging and binding of baghouse bags, and plugging of discharge feeders and conveyers. As a result, spray dryer installations are typically limited to applications that require $95 \%$ or lower $\mathrm{SO}_{2}$ removal efficiency and to units that fire coals with sulfur contents of about $2 \%(\sim 3 \mathrm{lb} \mathrm{SO} / \mathrm{mmBtu})$ or less. As discussed in Section 4.1 .2 above, in the Turbosorp ${ }^{\circledR}$ system, water injection and hydrated lime injection are carried out separately, such that the $\mathrm{Ca}(\mathrm{OH})_{2}$ injection rate is controlled solely by the pollutant loading and desired emission reduction, without being limited by the temperature or moisture content of the flue gas. As a result, the Turbosorp ${ }^{\circledR}$ system can be operated to achieve deep emission reductions (i.e., $98 \%$ or greater) for a wide range of fuels, including high-sulfur coals (i.e., up to $5 \mathrm{lb} \mathrm{SO} / \mathrm{mmBtu}$ or more).

\subsubsection{Low Maintenance Requirements}

Insofar as the PPII seeks to improve the reliability of the nation's energy supply, minimization of maintenance requirements was an objective in the design of the Greenidge multi-pollutant control system, such that system maintenance will not adversely affect unit availability. A drawback of both wet scrubbers and lime spray dryers is their use of slurries to introduce the limestone or lime into the system, resulting in high maintenance requirements and potential for operational problems. Problems arising from the use of slurries can include pipe plugging, nozzle plugging, solids build-up, and erosion and abrasion of pumps, pipes, and vessels. Wet 
scrubbers in particular are relatively complex, as they produce a slurry product and require pumps for slurry recirculation as well as maintenance-intensive dewatering equipment.

The Turbosorp ${ }^{\circledR}$ circulating fluidized bed dry scrubber that is part of the Greenidge multipollutant control system is expected to afford substantially reduced maintenance requirements compared to these more conventional FGD technologies. In the Turbosorp ${ }^{\circledR}$ process, lime is injected into the absorber as a dry hydrate rather than as a slurry. A blower is used to pneumatically convey the dry hydrated lime to the absorber for injection. The solids collected in the baghouse are also completely dry and are recycled to the absorber using air slides. Gravity provides the motive force for injection via the differential height between the bottom of the baghouse and the injection point on the absorber tower. Apart from the lime hydration system (if included), the system's only pump is used to inject liquid water into the absorber vessel. Hence, the process avoids the problems with plugging, erosion, abrasion, and scaling that can result from pumping and handling slurries in other types of scrubbing systems. The Turbosorp ${ }^{\circledR}$ system also includes comparatively few moving parts, and as implied in Section 4.2.4, is less likely to cause plugging and binding of fabric filter bags than a spray dryer is.

\subsubsection{Operational Flexibility}

Unlike larger baseload units, many smaller coal-fired EGUs routinely cycle their loads in response to electricity demand. Hence, a multi-pollutant control system designed for these smaller units should feature turndown capabilities to permit continued emissions reductions at reduced operating loads. The Greenidge multi-pollutant control system includes these capabilities.

For conventional SCR systems, low-load operation is constrained by reduced flue gas temperatures, which can cause incomplete ammonia consumption across the SCR catalyst, resulting in high ammonia slip and ammonium bisulfate fouling in the air heater (see Section 4.3.1). At sufficiently low temperatures, catalyst plugging and deactivation can also occur via the formation of salts in the SCR reactor. These constraints are particularly stringent for units that fire high-sulfur coals. Stand-alone SCR installations typically employ an economizer gas bypass and/or water flow circuit modifications to raise the flue gas temperature at the SCR inlet during low-load operation. However, because of the hybrid $\mathrm{NO}_{x}$ control strategy included as part of the Greenidge multi-pollutant control process, $\mathrm{NO}_{\mathrm{x}}$ removal capabilities are available to some extent at lower operating loads without the need for any such modifications. The operating strategy for the hybrid system is shown conceptually in Figure 8.

As illustrated in the figure, operation of the system varies with generator load, resulting in three distinct operating ranges: a high-load range in which $\mathrm{NO}_{x}$ reduction is accomplished via SCR, $\mathrm{SNCR}$, and low- $\mathrm{NO}_{\mathrm{x}}$ combustion (if applicable); an intermediate-load range in which $\mathrm{NO}_{\mathrm{x}}$ reduction is accomplished via SNCR and low-NO ${ }_{x}$ combustion (but not SCR), and a low-load range in which $\mathrm{NO}_{x}$ reduction is accomplished via low- $\mathrm{NO}_{x}$ combustion (but not SCR or SNCR). At generator loads that produce economizer outlet temperatures below the minimum operating temperature for the SCR reactor, urea injection into the upper (cooler) region of the furnace, which is used to generate ammonia slip for the SCR, is discontinued. However, the lower zones of urea injection continue to operate until the minimum SNCR operating temperature is reached, resulting in continued $\mathrm{NO}_{x}$ removal via SNCR. Below the minimum SNCR operating temperature, which is the minimum economizer outlet temperature at which it is safe to introduce very small amounts of ammonia into the SCR catalyst, urea injection into the furnace 
is discontinued. However, $\mathrm{NO}_{\mathrm{x}}$ emissions may continue to be controlled via the unit's low- $\mathrm{NO}_{\mathrm{x}}$ combustion system, if applicable. Hence, for smaller units that regularly cycle loads based upon peak and off-peak demands, the load following capabilities of the hybrid SNCR/SCR process can help to contribute to lower $\mathrm{NO}_{x}$ emission averages.

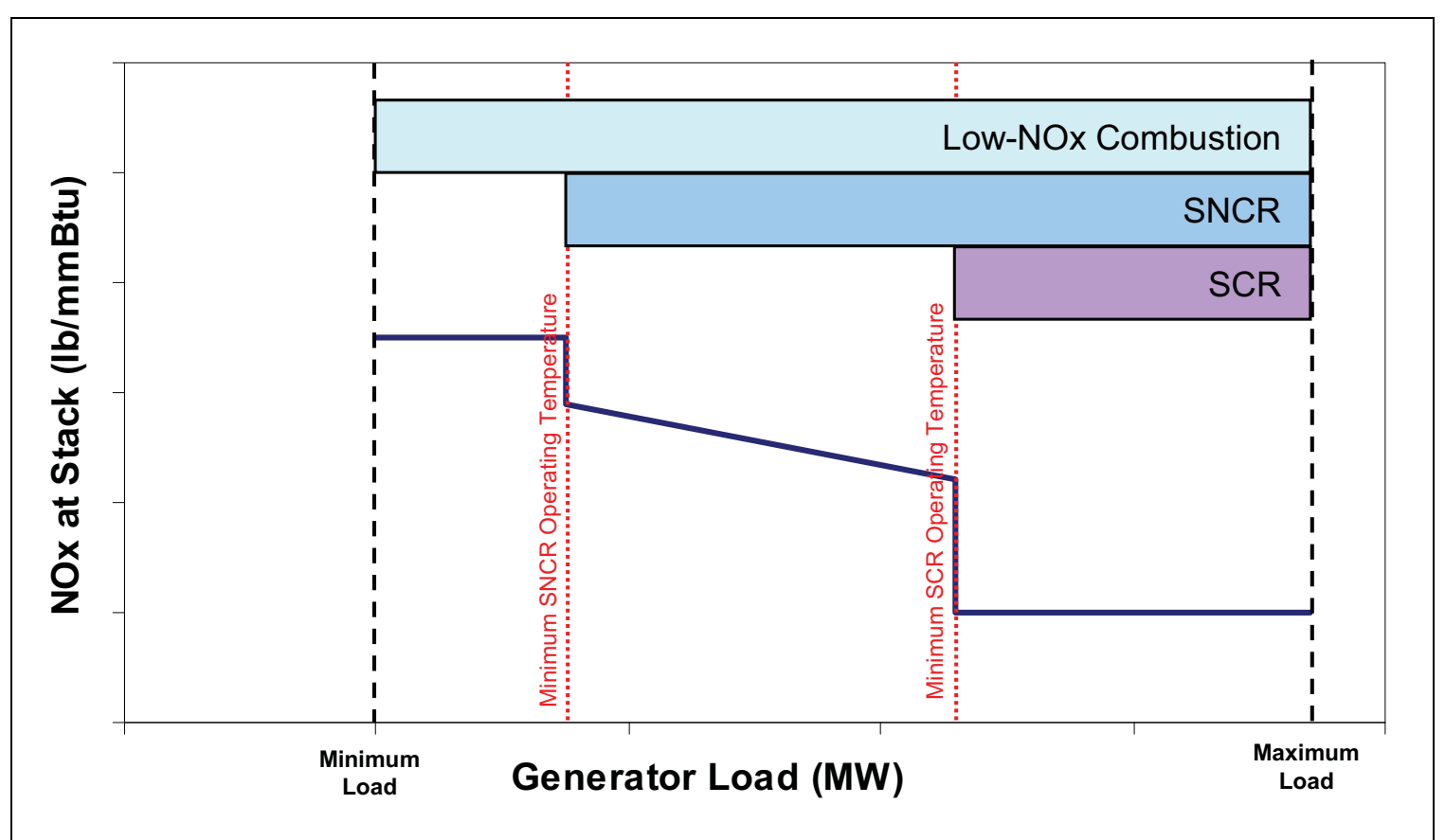

Figure 8. Operating strategy for the hybrid $\mathrm{NO}_{x}$ control system that was demonstrated as part of the Greenidge Project.

The circulating fluidized bed dry scrubber is also capable of operating at reduced loads. As discussed in Section 4.1.2, depending upon the extent of turndown that is desired, a flue gas recycle system may be required to provide sufficient flow to the absorber so that a fluidized bed can be maintained at the low end of the operating range.

\subsection{Design Considerations}

In addition to the overarching factors established in the preceding section, a number of unit- and application-specific factors affect the design of the multi-pollutant control process. Important design considerations for the process are discussed in the following subsections.

\subsubsection{Coal and Ash Characteristics}

Characteristics of a candidate unit's coal (and other secondary fuels if applicable) and the fly ash produced by its combustion impact the design of many aspects of the multi-pollutant control system.

Certain elemental chemical components of the coal, including arsenic and alkali metals, can poison the SCR catalyst by reacting with its active sites, causing deactivation (Wu, 2002). For 
an in-duct SCR reactor, which includes a limited catalyst volume, catalyst deactivation can have an appreciable impact on $\mathrm{NO}_{\mathrm{x}}$ removal performance.

Coal sulfur content can also affect the operation of the hybrid $\mathrm{NO}_{\mathrm{x}}$ control system. As mentioned in Section 4.2.1, the SCR catalyst promotes oxidation of a small percentage of $\mathrm{SO}_{2}$ in the flue gas to $\mathrm{SO}_{3}$, according to the following reaction:

$$
\mathrm{SO}_{2}+1 / 2 \mathrm{O}_{2} \rightarrow \mathrm{SO}_{3}
$$

This $\mathrm{SO}_{3}$ can then react with $\mathrm{Ca}$ to form $\mathrm{CaSO}_{4}$, which deactivates the catalyst by plugging its pores, or it can react with $\mathrm{NH}_{3}$ at sufficiently low temperatures to form $\mathrm{NH}_{4} \mathrm{HSO}_{4}$ or $\left(\mathrm{NH}_{4}\right)_{2} \mathrm{SO}_{4}$ according to the reactions below, causing catalyst plugging or air heater fouling.

$$
\begin{aligned}
& \mathrm{SO}_{3}+\mathrm{NH}_{3}+\mathrm{H}_{2} \mathrm{O} \rightarrow \mathrm{NH}_{4} \mathrm{HSO}_{4} \\
& \mathrm{NH}_{3}+\mathrm{NH}_{4} \mathrm{HSO}_{4} \rightarrow\left(\mathrm{NH}_{4}\right)_{2} \mathrm{SO}_{4}
\end{aligned}
$$

Hence, for mid- and high-sulfur coals, the $\mathrm{SO}_{2}$-to- $\mathrm{SO}_{3}$ conversion rate is an important consideration in the selection of an SCR catalyst.

The fly ash content of the flue gas must also be considered as part of the SCR system design, because greater ash loadings augment the potential for fly ash plugging, which causes catalyst deactivation and increased pressure drop. Thus, specification of a rake soot blower, sonic horn system, or other catalyst cleaning system is important to prevent deteriorations in SCR performance resulting from accumulation of fly ash in the catalyst.

For the circulating fluidized bed dry scrubbing system, the coal sulfur content affects the amount of hydrated lime reagent that must be injected to achieve a given level of $\mathrm{SO}_{2}$ removal. Although the Turbosorp ${ }^{\circledR}$ circulating fluidized bed dry scrubber is capable of achieving deep $\mathrm{SO}_{2}$ emission reductions across a wide range of coal sulfur contents, higher sulfur coals require greater hydrated lime injection rates than do lower sulfur coals for a given percentage of $\mathrm{SO}_{2}$ removal. This, in turn, increases the amount of solid byproduct generated by the process and affects the design of solids handling and storage equipment. Coal chlorine content also affects the performance of the circulating fluidized bed dry scrubber. $\mathrm{CaCl}_{2}$ is deliquescent. Hence, as the chlorine content increases, the process must be operated further from the adiabatic saturation temperature in order to avoid caking in the absorber vessel and plugging in the downstream equipment.

Finally, the composition of the coal and fly ash can affect the mercury removal performance of the system. For example, as coal chlorine content increases, the percentage of mercury in the flue gas that is present as $\mathrm{Hg}^{2+}$ (e.g., $\mathrm{HgCl}_{2}$ ) as opposed to $\mathrm{Hg}^{0}$ increases (CEA, 2005). Greater $\mathrm{Hg}^{2+}$ concentrations improve the potential for mercury removal as a co-benefit of the circulating fluidized bed dry scrubber and baghouse. This potential also increases as the amount of unburned carbon in the fly ash increases, because unburned carbon can adsorb gaseous mercury, especially at the low temperatures (Fenger and Winschel, 2006) afforded by the circulating fluidized bed dry scrubber, and can also serve as a mercury oxidation catalyst in the presence of sufficiently high chlorine concentrations (Niksa and Fujiwara, 2005; Presto and Granite, 2006). Hence, coal and ash characteristics may play a role in determining whether activated carbon injection is required for $\mathrm{Hg}$ control and, if so, what injection rate is needed. 


\subsubsection{Baseline NO Concentration}

The kinetics for $\mathrm{NO}_{x}$ reduction via SNCR are a function of the initial concentration of $\mathrm{NO}$, one of the reactants in the process and one of the products of the high-temperature reactions involving oxidation of reagent to form NO. Hence, the amount of $\mathrm{NO}_{x}$ removal achievable in the SNCR process depends on the concentration of NO leaving the combustion system. Baseline NO concentrations vary considerably from unit-to-unit, as they are a function of factors such as fuel nitrogen content, fuel volatile matter content, flame temperature, and combustion zone stoichiometry and residence time.

\subsubsection{Temperature Profile in the Furnace}

As discussed in Section 4.1.1, the performance of SNCR depends strongly on the temperature at which the process operates. Hence, the temperature profile in the furnace, which is specific to each application, strongly influences the design of the urea injection strategy. Computational fluid dynamics (CFD) are used to model the furnace temperature profile at various loads, and chemical kinetic modeling (CKM) is used to simulate the effect of temperature on the SNCR reactions. Modeling results form the basis for the design of the number, type, and placement of the urea injectors, as well as the urea injection strategy as a function of operating load.

\subsubsection{Flue Gas Residence Time and Flow Profile in the Furnace}

In order to optimize SNCR performance, a urea injection strategy must be developed that provides for thorough mixing of the reagent with the flue gas and sufficient residence time of urea and flue gas in the temperature regions of the furnace where the desired reactions between urea and NO occur. Reagent distribution and residence time are affected by the flue gas flow profile in the furnace. As with temperature, CFD and CKM are used to model the flow profile in the furnace and its effect on the SNCR reactions, and the results are used to inform the design of the urea injection strategy.

\subsubsection{CO Concentrations in the Furnace}

Carbon monoxide significantly impacts SNCR chemistry, with net effects of reducing ammonia slip, promoting the oxidation of reagent to form additional NO, and lowering the optimal temperature for NO reduction (Brouwer et al., 1996). Hence, local CO concentrations must be considered when modeling and designing the urea injection system.

\subsubsection{Available Space Between the Economizer and Air Heater}

The amount of incremental $\mathrm{NO}_{x}$ removal and ammonia slip control achievable by the SCR reactor is limited by the residence time of the flue gas in the catalyst. Residence time is the inverse of space velocity (flue gas volumetric flow rate $\div$ catalyst volume), and for a given flue gas flow rate, it increases with increasing catalyst volume. For the in-duct SCR reactor that is part of the Greenidge multi-pollutant control system, the volume of catalyst that can be installed, and hence the level of $\mathrm{NO}_{x}$ removal that can be achieved via SCR, is restricted by the amount 
of available space between the candidate unit's economizer and air heater. For a given catalyst, oxidation of $\mathrm{Hg}$, which is a desired co-benefit of SCR, and conversion of $\mathrm{SO}_{2}$ to $\mathrm{SO}_{3}$, which is undesired, are also expected to decrease with decreasing catalyst volume. The geometry between the economizer and air heater also affects the catalyst face velocities (flue gas volumetric flow rate $\div$ catalyst cross-sectional area) that can be achieved. High and low face velocities can each present problems; high face velocities contribute to increased catalyst erosion, whereas low face velocities can lead to ash deposition within the catalyst. For the retrofit application of an in-duct SCR reactor, the reactor cross-sectional area will often be limited by unit geometry, resulting in face velocities that are greater than normal. The effects of these elevated face velocities must be considered as part of the catalyst and reactor designs.

\subsubsection{Flue Gas Temperature at the Economizer Outlet}

Catalyst activity is a function of temperature, and within the acceptable temperature window for SCR operation, the rate of $\mathrm{NO}_{x}$ removal increases as temperature increases. Hence, the catalyst specification and the amount of $\mathrm{NO}_{x}$ removal achievable in the single-layer in-duct SCR reactor both depend on a unit's economizer outlet temperature. Variations in this temperature with unit load are a primary factor in establishing the turndown ranges for the SCR and SNCR systems, as illustrated in Figure 8. Per the discussion in Section 4.2.6, an economizer bypass can be installed to increase the temperature of the flue gas entering the SCR at reduced operating loads, increasing its turndown capability; however, the potential benefits afforded by this option must be weighed against its resultant effects on cost and operating complexity, and it was not selected for this project.

\subsubsection{Flue Gas Homogeneity at the SCR Inlet}

As discussed in Section 4.1.1, in order to maximize performance of the relatively small in-duct SCR reactor, it is essential that the temperature, composition, and velocity of the flue gas are homogeneous across the cross-sectional area of the catalyst. Localized deviations in composition (i.e., $\mathrm{NH}_{3} / \mathrm{NO}_{x}$ mole ratio), temperature, or velocity from target values can result in decreased $\mathrm{NO}_{x}$ removal efficiency and increased ammonia slip, and localized deviations in velocity from target values can also result in catalyst erosion or ash deposition. Hence, static mixers are used to homogenize the flue gas upstream of the in-duct SCR reactor. Because flue gas flows are unique to each candidate unit, physical flow modeling must be performed on a case-by-case basis to optimize the design of the static mixing system.

\subsubsection{Large Particle Ash}

If the candidate unit produces large particle ash (even if only in small quantities), then this LPA must be removed from the flue gas upstream of the SCR reactor in order to prevent it from plugging the catalyst. Large particle ash, which consists of pieces of slag that in many cases are too large to pass through the catalyst, poses a potential problem for many conventional SCR installations. If it is not captured ahead of the SCR, the LPA can become lodged in the catalyst and promote subsequent accumulation and bridging of fly ash, eventually plugging a substantial portion of the catalyst. This in turn causes an increase in the pressure drop across the SCR reactor (potentially straining downstream fans and ductwork), as well as decreased $\mathrm{NO}_{x}$ removal efficiency, increased ammonia slip, and increased catalyst erosion. In 
conventional installations, potential LPA problems are often easily mitigated by installing a screen and hopper at a $90^{\circ}$ bend in the ductwork upstream of the SCR reactor. However, physical constraints associated with the in-duct SCR design that is employed by the hybrid SNCR/SCR system can make the installation of an LPA removal system more challenging. The design of the LPA removal system varies by unit and is dependent upon factors such as the amount of available space between the economizer and SCR reactor, the presence or absence of a $90^{\circ}$ bend in the ductwork upstream of the reactor, the presence or absence of obstructions that could interfere with the screen, and the feasibility of utilizing hoppers to remove the captured LPA. The application at AES Greenidge Unit 4 was particularly challenging in that it involved vertically downward flow between the economizer and SCR, with obstructions (i.e., static mixers and an expansion joint), limited space, and no $90^{\circ}$ bends or hoppers. This required the development of a unique LPA removal system, which is described in Section 6.2.2. When selecting an LPA screen, important considerations include the pitch (which affects both the LPA capture efficiency and the pressure drop) and the material of construction (which affects the durability of the screen). The catalyst pitch can also be increased to reduce the likelihood of LPA accumulation, although this reduces the $\mathrm{NO}_{\mathrm{x}}$ removal efficiency achievable by the SCR system.

\subsubsection{Amount of Allowable Ammonia Slip}

In spite of its use of an in-duct SCR reactor to consume ammonia slip from the SNCR process, the design of the hybrid SNCR/SCR system is nevertheless constrained to some extent by ammonia slip. Obviously, the design level of ammonia slip from the SNCR process can be no greater than the sum of the amount of ammonia consumed in the SCR reactor and the amount of allowable ammonia slip from the overall hybrid system. As the SCR catalyst deactivates, its capacity to consume ammonia decreases; hence, limits on ammonia slip constrain the useful operating life of the catalyst. Moreover, at operating loads below the minimum SCR operating load, limits on ammonia slip restrict SNCR operation, resulting in less-than-optimal urea utilization and $\mathrm{NO}_{x}$ removal. Constraints on ammonia slip typically become more stringent as coal sulfur content increases, because the resultant greater concentrations of $\mathrm{SO}_{3}$ in the flue gas provide a greater driving force for the formation of ammonium bisulfate $\left(\mathrm{NH}_{4} \mathrm{HSO}_{4}\right)$ from any ammonia that is present. For units firing lower-sulfur coals, constraints may be also imposed by regulatory limits on $\mathrm{NH}_{3}$ emissions or concerns about $\mathrm{NH}_{3}$ contamination of the baghouse solids, which makes disposal or use of these solids more difficult.

\subsubsection{Approach to Adiabatic Saturation in the Absorber Vessel}

The Ca/S molar ratio (i.e., the number of moles of hydrated lime reagent injected per mole of inlet $\mathrm{SO}_{2}$ ) required to achieve a given level of $\mathrm{SO}_{2}$ removal in the circulating fluidized bed dry scrubber depends on the proximity of the temperature in the absorber vessel to the adiabatic saturation temperature of the flue gas. In general, for a given $\mathrm{Ca}(\mathrm{OH})_{2}$ injection rate, $\mathrm{SO}_{2}$ removal efficiencies improve as the operating temperature approaches the adiabatic saturation temperature. However, the approach to adiabatic saturation is limited by concerns about condensation, which can cause corrosion, deposition of solids in the absorber, binding and plugging of baghouse bags, and problems with the solids recirculation system. Hence, the absorber operating temperature must be carefully selected to maximize $\mathrm{SO}_{2}$ removal efficiency while avoiding any potential for condensation. Also, because the circulating fluidized bed dry scrubbing system operates at temperatures near the adiabatic saturation temperature of the flue 
gas, thorough insulation of the system is important, especially in colder climates, in order to minimize the potential for condensation. Per the discussion in Section 4.3.1, as the $\mathrm{Cl}$ content of the flue gas increases, the scrubber must be operated further from adiabatic saturation in order to avoid condensation. (The presence of $\mathrm{Cl}$ improves $\mathrm{SO}_{2}$ capture efficiency, however, approximately negating any effect of the higher operating temperature on the required $\mathrm{Ca} / \mathrm{S}$ molar ratio).

\subsubsection{Hydrated Lime Supply}

As discussed in Section 4.1.2, the multi-pollutant control system can be installed with or without a lime hydration system. Inclusion of a hydrator allows the plant to produce hydrated lime reagent onsite from purchased pebble lime. Otherwise, hydrated lime must be purchased for direct use in the process. On a mass basis, hydrated lime costs about $25 \%$ more (excluding delivery) and contains $24 \%$ less $\mathrm{Ca}$ than pebble lime. Hence, the cost per mole of $\mathrm{Ca}$ (excluding delivery) is about $65 \%$ greater for hydrated lime than for pebble lime, and the use of purchased hydrated lime substantially increases the multi-pollutant control system's variable operating and maintenance costs. Nevertheless, some operators may choose to purchase hydrated lime in order to avoid the capital investment and maintenance requirements associated with a lime hydration system. Even if a hydrator is included, the design should provide capability for accepting delivery of hydrated lime so that the hydrator can be taken offline for maintenance without affecting operation of the Turbosorp ${ }^{\circledR}$ scrubber.

\subsubsection{Increased Solids Loading to the Baghouse}

Because a large portion of the solids that are removed from the flue gas in the baghouse are recycled back to the Turbosorp ${ }^{\circledR}$ absorber vessel, the particle loading in the flue gas that is sent to the baghouse from the absorber vessel is substantially greater than it would have been with no circulating fluidized bed dry scrubber installed. As a result, the baghouse must be designed to accommodate this increased particle loading. Design modifications may include reducing the air-to-cloth ratio (i.e., $\mathrm{ft}^{3} / \mathrm{min}$ flue gas $\div \mathrm{ft}^{2}$ bag surface area), increasing the bag spacing, and increasing the baghouse inlet volume and depth of the drop-out zone beneath the bags.

The substantially increased particle loading resulting from solids recirculation is one reason why a unit's existing particulate control device typically cannot be used for PM removal in a circulating fluidized bed dry scrubber installation. (The existing particulate control device can be retained ahead of the scrubber to capture fly ash separately from the solid scrubber products. This arrangement may be economically attractive if the fly ash can be sold; however, a second particulate control device would still be required as part of the circulating fluidized bed dry scrubber). Conceptually, a new ESP could be used instead of a new baghouse with the Turbosorp ${ }^{\circledR}$ system; however, baghouses are preferred because the coating of sorbent material that accumulates on their filter bags promotes additional removal of $\mathrm{SO}_{2}$, acid gases, and mercury downstream of the absorber vessel, improving reagent utilization and overall pollutant removal efficiency.

Particle loading also affects the amount of compressed air required by the baghouse. A candidate unit's compressed air capacity must be assessed and increased if necessary in order to ensure that it is sufficient to satisfy the baghouse demand. 


\subsubsection{Pressure Drop Across the System}

Addition of the static mixing devices, LPA screen (if included), in-duct SCR catalyst, fluidized bed absorber, baghouse, and longer ductwork runs causes increased flue gas pressure drop. Hence, most applications of the multi-pollutant control system will require installation of a booster fan and/or modifications to the unit's existing ID fans to overcome this pressure drop. The amount of pressure drop and required modifications depend upon flue gas flow rate, equipment sizing and design, and existing ID fan capacity, and must be assessed on a case-bycase basis. The effect of increased pressure drop on the operating costs of the system must be considered as part of the design.

\subsection{Developmental Status}

As discussed in Section 2.2, all of the technologies that were demonstrated as part of the Greenidge Multi-Pollutant Control Project were developed and tested individually at a sufficient scale before the project to provide an adequate level of confidence concerning their mechanical operability. However, the Greenidge Project was unique in that it represented the first application in which a hybrid SNCR/SCR system and a circulating fluidized bed dry scrubbing system were combined to form an integrated multi-pollutant control system, as well as the first application of either of these technologies to a unit firing $>2 \%$-sulfur eastern U.S. bituminous coal.

Prior to the Greenidge Project, the Turbosorp ${ }^{\circledR}$ circulating fluidized bed dry scrubber had been applied to four European coal-fired power plants, but it had not been demonstrated on a coalfired EGU in the United States. Table 4 shows design targets for these European installations, as well as design capabilities for the AES Greenidge installation. As these data indicate, the Turbosorp ${ }^{\circledR}$ unit at AES Greenidge was designed for a greater flue gas $\mathrm{SO}_{2}$ concentration and greater level of $\mathrm{SO}_{2}$ removal than any previous installation. Circulating fluidized bed dry scrubbers similar to the Turbosorp ${ }^{\circledR}$ system were installed on two smaller coal-fired EGUs in the United States before the Greenidge Project (Westmoreland Energy's Roanoke Valley Unit 2 in North Carolina and Black Hills Power's Neil Simpson Unit 2 in Wyoming); however, both of these units fire less than $2 \%$-sulfur coal and are less than $100 \mathrm{MW}_{\mathrm{e}}$ in size.

Before the Greenidge Project, the hybrid SNCR/SCR system was tested on the equivalent of 80 $\mathrm{MW}_{\mathrm{e}}$ of flue gas from the PSE\&G Mercer Unit 2, which fired coal with a sulfur content of less than $1 \%$. The SCR configuration involved horizontal flow through two 5-foot-thick banks of plate catalyst. Relative to operation using only SNCR, the hybrid SNCR/SCR system improved overall $\mathrm{NO}_{x}$ reduction from $37 \%$ to $71 \%$ and overall urea utilization from $31 \%$ to $62 \%$ (for a constant urea feed rate) at full load, with less than $10 \mathrm{ppm}$ of ammonia slip (Albanese et al., 1995). Hybrid SNCR/SCR was also demonstrated at commercial scale on the former $147 \mathrm{MW}_{\mathrm{e}}$ GPU Generation Seward Unit 5, which fired bituminous coal containing about $1.5 \%$ sulfur. The system was designed to achieve $55 \% \mathrm{NO}_{x}$ reduction from a baseline of about $0.78 \mathrm{lb} / \mathrm{mmBtu}$, with the in-duct SCR contributing about $6 \%$ reduction at full load. The demonstration confirmed the feasibility of the hybrid SNCR/SCR concept, but its performance was limited by temperature stratification in the SCR and arsenic poisoning of the catalyst (Urbas, 1999). Hence, the Greenidge demonstration marked the greatest targeted $\mathrm{NO}_{\mathrm{x}}$ removal efficiency for a commercial-scale hybrid SNCR/SCR system on a coal-fired boiler in the United States, as well as the first application of the hybrid system to a unit firing $>2 \%$-sulfur eastern U.S. bituminous coal. It also marked the first installation of the hybrid SNCR/SCR system on a coal-fired unit in 
which the flue gas flows vertically downward through the in-duct SCR catalyst with no upstream economizer hopper or ductwork bend to capture large ash particles. (The Seward installation had vertical, downward flow through the catalyst, but it included a $90^{\circ}$ bend and an economizer hopper upstream of the reactor).

Table 4. Characteristics of existing Turbosorp ${ }^{\circledR}$ installations on coal-fired EGUs and of the AES Greenidge design.

\begin{tabular}{|c|c|c|c|c|c|c|c|c|}
\hline Plant & Country & Coal Type & $\begin{array}{c}\text { Flue gas } \\
\text { flow rate } \\
{\left[\mathrm{m}^{3} / \mathrm{h}\right]^{\mathrm{a}}}\end{array}$ & $\begin{array}{l}\text { Approx. } \\
\mathrm{SO}_{2} \\
\text { concentr. } \\
{\left[\mathrm{mg} / \mathrm{m}^{3}\right]^{\mathrm{b}}}\end{array}$ & $\begin{array}{c}\mathrm{SO}_{2} \\
\text { removal } \\
\text { efficiency } \\
{[\%]}\end{array}$ & $\begin{array}{c}\text { Approx. } \\
\mathrm{HCl} \\
\text { concentr. } \\
{\left[\mathrm{mg} / \mathrm{m}^{3}\right]^{\mathrm{b}}}\end{array}$ & $\begin{array}{c}\mathrm{HCl} \\
\text { removal } \\
\text { efficiency } \\
{[\%]}\end{array}$ & $\begin{array}{l}\text { Date } \\
\text { of } \\
\text { start- } \\
\text { up }\end{array}$ \\
\hline $\begin{array}{c}\text { Kraftwerk } \\
\text { Zeltweg }\end{array}$ & Austria & $\begin{array}{c}\text { lignite / } \\
\text { bituminous }\end{array}$ & 600,000 & 2,300 & 91 & 100 & $>90$ & 1994 \\
\hline $\begin{array}{l}\text { Kraftwerk } \\
\text { St. Andrä }\end{array}$ & Austria & $\begin{array}{c}\text { lignite / } \\
\text { bituminous }\end{array}$ & 450,000 & 2,500 & 92 & 100 & $>90$ & 1994 \\
\hline $\begin{array}{c}\text { Heiz-KW } \\
\text { Strakonice }\end{array}$ & $\begin{array}{c}\text { Czech } \\
\text { Republic }\end{array}$ & lignite & 261,000 & 4,200 & 85 & 30 & $>75$ & 1999 \\
\hline $\begin{array}{c}\text { REA } \\
\text { Siekierki }\end{array}$ & Poland & bituminous & 250,000 & 3,300 & 85 & 250 & $>95$ & 2002 \\
\hline $\begin{array}{c}\mathrm{AES} \\
\text { Greenidge }\end{array}$ & USA & bituminous & 450,000 & 5,000 & 95 & 100 & $>95$ & 2007 \\
\hline
\end{tabular}

${ }^{a}$ At standard temperature and pressure, wet; ${ }^{b}$ At standard temperature and pressure, dry

Thus, the principal uncertainties, and the motivation for the Greenidge Multi-Pollutant Control Project, included the performance of the hybrid SNCR/SCR and Turbosorp ${ }^{\circledR}$ systems when combined in an integrated multi-pollutant control process, as well as the technical and economic performance of these systems when applied with ambitious performance targets to a unit firing eastern U.S. bituminous coals containing greater than $2 \%$ sulfur. As discussed above, the demonstration program also included an evaluation of the effect of biomass co-firing on the performance of the multi-pollutant control system. Specific project uncertainties included:

- Control and performance of the combined combustion modifications, SNCR, and in-duct SCR, especially during load swings/cycling

- Catalyst performance, life, and replacement cost for an in-duct single catalyst layer installed on a unit firing greater than $2 \%$-sulfur eastern U.S. bituminous coal

- Extent of ash accumulation in the catalyst for an in-duct SCR reactor with vertical downward flow and no upstream hoppers or ductwork bends

- Effect of ammonia slip from the hybrid SNCR/SCR on unit operability for a unit firing greater than $2 \%$-sulfur coal

- Extent of $\mathrm{Hg}$ oxidation at high space velocities across the single catalyst layer and its effect on $\mathrm{Hg}$ removal performance

- $\mathrm{SO}_{2}$ capture and required $\mathrm{Ca} / \mathrm{S}$ ratio in the Turbosorp ${ }^{\circledR}$ for a high-sulfur U.S. bituminous coal

- Amount of $\mathrm{Hg}$ removal achievable in the Turbosorp ${ }^{\circledR}$ system and required activated carbon injection rate

- $\mathrm{SO}_{3}, \mathrm{HCl}$, and $\mathrm{HF}$ removal as a function of $\mathrm{SO}_{2}$ control conditions

- Effect of biomass co-firing on $\mathrm{NO}_{x}, \mathrm{Hg}$, and acid gas removal

- Effects of ammonia slip and carbon injection on solid waste management

- Economics of the combined system for a relatively small $\left(\sim 110 \mathrm{MW}_{\mathrm{e}}\right)$ unit firing greater than $2 \%$-sulfur eastern U.S. bituminous coal 
The Greenidge Project was conducted to resolve these uncertainties so that the technical and economic viability of the integrated multi-pollutant control process could be proven, thereby advancing commercial deployment of the technology.

\section{Host Site}

AES Greenidge served as the host site for demonstrating the multi-pollutant control system. Most major project activities, including installation, operation, and testing of the system, took place there. AES Greenidge is a $161-\mathrm{MW}_{\mathrm{e}}$ (Energy Information Administration net winter capacity) coal-fired electric power plant located in Dresden, Yates County, New York, along the western shore of Seneca Lake. It is a merchant plant that dispatches when its variable cost of producing electricity is less than the market price of electricity. (AES Greenidge sells its power into the New York Independent System Operator's day-ahead and hour-ahead markets). The plant, which is situated on a 153-acre site, currently comprises two electric generating units: the $54-\mathrm{MW}_{\mathrm{e}}$ (net) Unit 3 and the $107-\mathrm{MW}_{\mathrm{e}}$ (net) Unit 4 . Unit 4 is a reheat unit; Unit 3 is not. The Unit 3 steam turbine is served by Boilers 4 and 5 , each a pulverized coal-fired boiler having a maximum heat input of $380 \mathrm{mmBtu} / \mathrm{h}$. The Unit 4 steam turbine is served by Boiler 6 , a pulverized coal-fired boiler with a maximum heat input of $1,117 \mathrm{mmBtu} / \mathrm{h}$. Coal and other materials are delivered to the plant via train or truck. Fly ash generated by the facility is hauled to the 143-acre Lockwood Landfill, which is located just west-southwest of the plant site.

Figure 9 shows an aerial photograph of the AES Greenidge site, as viewed from the south prior to the commencement of the multi-pollutant control project. The plant's two original units, which were constructed for the New York State Electric \& Gas Corporation (NYSEG) in the late 1930s, were retired and removed from the plant in the 1980s; however, their idle stacks still stand adjacent to the boiler building. AES acquired the plant, including the still-operational Units 3 and 4, from NYSEG in 1999.

The multi-pollutant control system was installed on Unit 4 (Boiler 6), which was commissioned in 1953. As shown in Figure 9, the unit and its associated equipment are housed in or adjacent to the western end of the boiler building. Boiler 6 is a Combustion Engineering dry bottom, tangentially-fired, balanced draft, pulverized coal boiler designed for $780,000 \mathrm{lb} / \mathrm{h}$ steam flow at 1465 psig. Primary and reheat steam temperatures are $1005^{\circ} \mathrm{F}$. The boiler is served by two single-speed forced draft (FD) fans, two induced draft (ID) fans, and two Ljungstrom air preheaters. The Unit 4 turbine is a General Electric tandem compound reheat steam turbine, which drives a General Electric hydrogen-cooled electrical generator that is rated at 13,800 volts.

Eastern U.S. bituminous coal is the primary fuel for Boiler 6 . The furnace is equipped with four levels of pulverized coal burners, with four burners per level (one in each corner of the furnace). Boiler 6 is also permitted to fire clean, unadulterated wood as a supplement to bituminous coal (percent by weight of fuel is unrestricted) or waste wood from a particle board furniture manufacturing process (restricted to $30 \%$ by weight of the total fuel); this biomass fuel is prepared and fed to the boiler separately from the coal. AES Greenidge occasionally uses wood to provide up to $10 \%$ of the heat input to Boiler 6 . In addition to the potential economic benefits afforded by diversifying the plant's fuel portfolio, biomass co-firing can help to reduce emissions of $\mathrm{SO}_{2}$ and $\mathrm{NO}_{\mathrm{x}}$ as well as net emissions of $\mathrm{CO}_{2}$ (Fernando, 2002). In 1996, the boiler was outfitted with a natural gas reburn system that is capable of providing up to about $20 \%$ of its heat input; however, the reburn system currently is not in use. 
The 1996 combustion modifications to Boiler 6 included the installation of separated overfire air (SOFA) ports, which served as the boiler's primary means for $\mathrm{NO}_{\mathrm{x}}$ control. The system was capable of achieving full-load $\mathrm{NO}_{x}$ emissions of about $0.3 \mathrm{lb} / \mathrm{mmBtu}$. Prior to the installation of the multi-pollutant control system, an electrostatic precipitator was used to control particulate matter emissions from Boiler 6 , and the unit did not have any existing equipment for controlling $\mathrm{SO}_{2}$ emissions; fuel sulfur content was restricted (via the use of medium-sulfur coal and biomass co-firing) in order to meet its permitted limit of $3.8 \mathrm{lb} \mathrm{SO} / \mathrm{mmBtu}$.

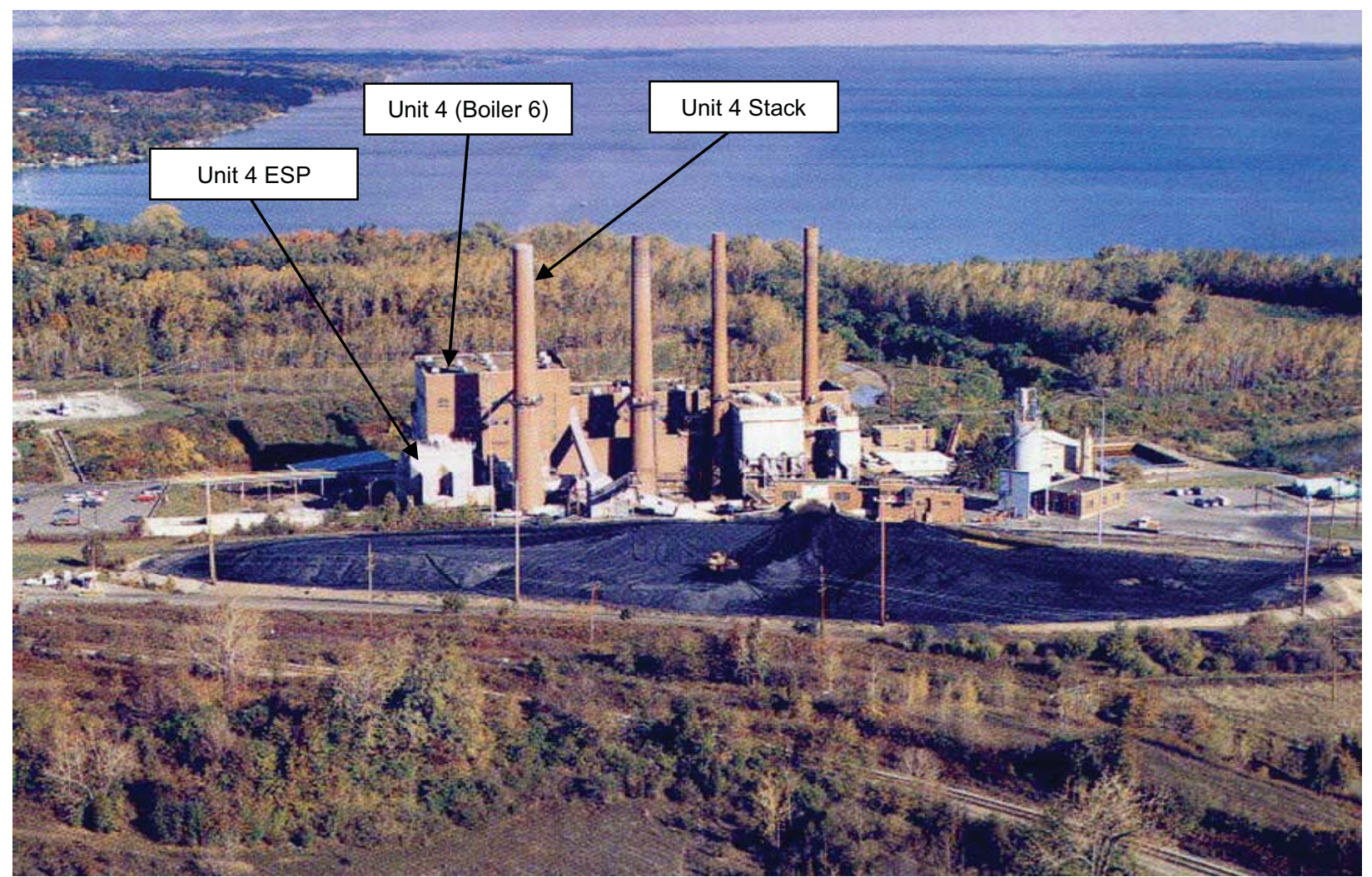

Figure 9. Aerial photograph of the AES Greenidge plant, as viewed from the south prior to the multipollutant control project.

In addition to installing the multi-pollutant control system that is the topic of this report, AES Greenidge undertook several other projects to help ensure a 20-30 year life extension for Unit 4. These included a major turbine overhaul, replacement of the unit's high-temperature superheater elements, miscellaneous boiler maintenance, and upgrades to the unit's distributed control system (DCS), air preheaters, and ash handling system. As mentioned above, modifications were also made to the combustion system for Boiler 6, including both its firing system and its SOFA system. Although these combustion modifications are not included in the scope of the DOE cooperative agreement, they are discussed in this report insofar as they helped to optimize the performance of the multi-pollutant control system that was demonstrated thereunder. 


\section{Process Design}

Having already reviewed the general concepts, key features, design considerations, and uncertainties associated with the multi-pollutant control technology in Section 4, this section focuses specifically on the system design for the AES Greenidge Unit 4 application. The project's detailed design and engineering tasks were led by Babcock Power Environmental Inc. As shown in the project schedule in Appendix A, process design work commenced in mid-2005, and it was largely complete by the summer of 2006.

Appendix B contains engineering drawings, including process flow diagrams, piping and instrument diagrams (P\&IDs), and general arrangement drawings, that summarize the design of the multi-pollutant control system at AES Greenidge Unit 4. Appendix C presents a list of the major equipment items required for the system. The design is described in the subsections below. The quantitative information concerning system performance that is presented in this section represents the expected performance at the time of design; actual performance results from the project's Operation and Testing Phase are presented in Section 9 of this report.

\subsection{Design Basis}

The multi-pollutant control system at AES Greenidge Unit 4 was designed to operate effectively while the unit fires eastern U.S. bituminous coals containing $2-4 \%$ sulfur and co-fires waste wood at $0-10 \%$ of the heat input to the furnace. The design case was based on the use of a $2.9 \%$-sulfur coal with approximately $10 \%$ biomass co-firing at the unit's maximum continuous rating (MCR). Design fuel characteristics are summarized in Table 5.

Table 5. Assumed fuel characteristics (as fired) for the design case.

\begin{tabular}{|l|c|c|c|}
\hline & Coal & Wood & Blended Fuel \\
\hline Higher Heating Value (Btu/lb) & 13,097 & 8,592 & 12,426 \\
\hline Carbon $(\% \mathrm{w} / \mathrm{w})$ & 72.17 & 45.13 & 68.14 \\
\hline Hydrogen $(\% \mathrm{w} / \mathrm{w})$ & 4.79 & 5.78 & 4.94 \\
\hline Nitrogen $(\% \mathrm{w} / \mathrm{w})$ & 1.36 & 2.8 & 1.57 \\
\hline Chlorine $(\% \mathrm{w} / \mathrm{w})$ & 0.1 & 0.22 & 0.12 \\
\hline Sulfur $(\% \mathrm{w} / \mathrm{w})$ & 2.9 & 0.2 & 2.5 \\
\hline Oxygen $(\% \mathrm{w} / \mathrm{w})$ & 5.04 & 38.72 & 10.05 \\
\hline Moisture $(\% \mathrm{w} / \mathrm{w})$ & 5.8 & 6.3 & 5.87 \\
\hline Ash $(\% \mathrm{w} / \mathrm{w})$ & 7.85 & 0.82 & 6.8 \\
\hline
\end{tabular}

The assumed chemical compositions of the quicklime and activated carbon reagents used by the process are summarized in the stream tables provided with the process flow diagrams in Appendix B. The NOxOUT ${ }^{\circledR}$ reagent used by the SNCR process is an aqueous solution containing approximately $50 \%(\mathrm{w} / \mathrm{w})$ urea, as well as additives to prevent scaling and corrosion.

Table 6 lists the emission performance targets for the design case. The targeted $\mathrm{NO}_{\mathrm{x}}$ emission rate of $\leq 0.10 \mathrm{lb} / \mathrm{mmBtu}$ at full load represents a $\mathrm{NO}_{x}$ removal efficiency by the combined combustion modifications, SNCR, and in-duct SCR of $\geq 67 \%$ relative to a pre-installation baseline $\mathrm{NO}_{\mathrm{x}}$ emission rate of approximately $0.30 \mathrm{lb} / \mathrm{mmBtu}$, or a removal efficiency by the hybrid SNCR/SCR system of $\geq 60 \%$ relative to the targeted rate of $0.25 \mathrm{lb} / \mathrm{mmBtu}$ leaving the new combustion system. 
Table 6. Emission performance targets for the design case.

\begin{tabular}{|l|l|}
\hline Parameter & Design Target \\
\hline $\mathrm{NO}_{\mathrm{x}}$ & $\leq 0.10 \mathrm{lb} / \mathrm{mmBtu}$ (full load) \\
\hline $\mathrm{NH}_{3}$ & $\leq 2 \mathrm{ppmvd} \mathrm{@} 3 \% \mathrm{O}_{2}$ (air heater inlet) \\
\hline $\mathrm{SO}_{2}$ & $\geq 95 \%$ removal \\
\hline $\mathrm{SO}_{3}$ & $\geq 95 \%$ removal \\
\hline $\mathrm{HCl}$ & $\geq 95 \%$ removal \\
\hline $\mathrm{HF}$ & $\geq 95 \%$ removal \\
\hline $\mathrm{Hg}$ & $\geq 90 \%$ removal \\
\hline
\end{tabular}

\subsection{Description by Major Process Component}

Major components of the multi-pollutant control process at AES Greenidge Unit 4 include the selective non-catalytic reduction system, in-duct selective catalytic reduction reactor, activated carbon injection system, Turbosorp ${ }^{\circledR}$ scrubber, process water system, lime hydration and injection system, baghouse, ash recirculation system, and booster fan.

\subsubsection{Selective Non-Catalytic Reduction System}

The urea-based SNCR system, which was supplied by Fuel Tech, is designed to operate synergistically with the in-duct SCR reactor to reduce $\mathrm{NO}_{x}$ emissions from AES Greenidge Unit 4. At full load operation, the SNCR system is designed to reduce $\mathrm{NO}_{\mathrm{x}}$ by about $42 \%$, from 0.25 $\mathrm{lb} / \mathrm{mmBtu}\left(190 \mathrm{ppmvd}\right.$, corrected to $3 \% \mathrm{O}_{2}$ ) leaving the combustion zone to $0.144 \mathrm{lb} / \mathrm{mmBtu}$ (110 ppmvd, corrected to $3 \% \mathrm{O}_{2}$ ) at the economizer outlet, and to supply a controlled amount of ammonia slip $\left(\sim 47 \mathrm{ppmvd}\right.$, corrected to $\left.3 \% \mathrm{O}_{2}\right)$ as a feed to the downstream in-duct SCR reactor to permit additional $\mathrm{NO}_{x}$ reduction there. Per the discussion in Section 4.2.6, for gross generator loads below about $86 \mathrm{MW}_{\mathrm{e}}$, which produce economizer outlet temperatures below the minimum SCR operating temperature of $600{ }^{\circ} \mathrm{F}$, the SNCR is designed to reduce $\mathrm{NO}_{\mathrm{x}}$ emissions by $20-25 \%$ while producing less than 2 ppmvd of ammonia slip. Because of concerns about formation of ammonium salts in the SCR catalyst, SNCR operation is discontinued when the economizer outlet temperature is less than $528{ }^{\circ} \mathrm{F}$, which occurs when the gross generator load falls below about $54 \mathrm{MW}_{\mathrm{e}}$.

The SNCR system design includes three separate zones of urea injection into the boiler, as illustrated in drawing No. 575P-M01-02 in Appendix B. In Zones 1 and 2, diluted urea reagent is injected via air-cooled wall injectors that are installed through penetrations in the waterwall. The Zone 1 injectors, which are located closest to the combustion zone, are mounted on retract mechanisms that allow them to be withdrawn from the furnace when not in use, preventing damage that could otherwise result from high furnace temperatures. In Zone 3, diluted urea reagent is injected through two $14-15 \mathrm{ft}$, retractable multiple nozzle lances (MNLs) into the superheater section. The MNLs are cooled using plant condensate water. Figure 10 shows several of the Zone 1 injectors at AES Greenidge Unit 4, and Figure 11 shows one of the MNLs. Because SNCR performance depends strongly on temperature and reagent distribution, as discussed in Sections 4.3.3 and 4.3.4, the optimal placement and spray patterns for injectors and lances were determined based on CFD and CKM results. Figure 12 provides an example of the CFD modeling results that were used in the design of the hybrid $\mathrm{NO}_{\mathrm{x}}$ control system for AES Greenidge Unit 4; both the temperature and velocity profiles (shown here for a case in 
which the unit is operating at $103 \%$ of its MCR) were utilized to inform the design of the urea injectors.

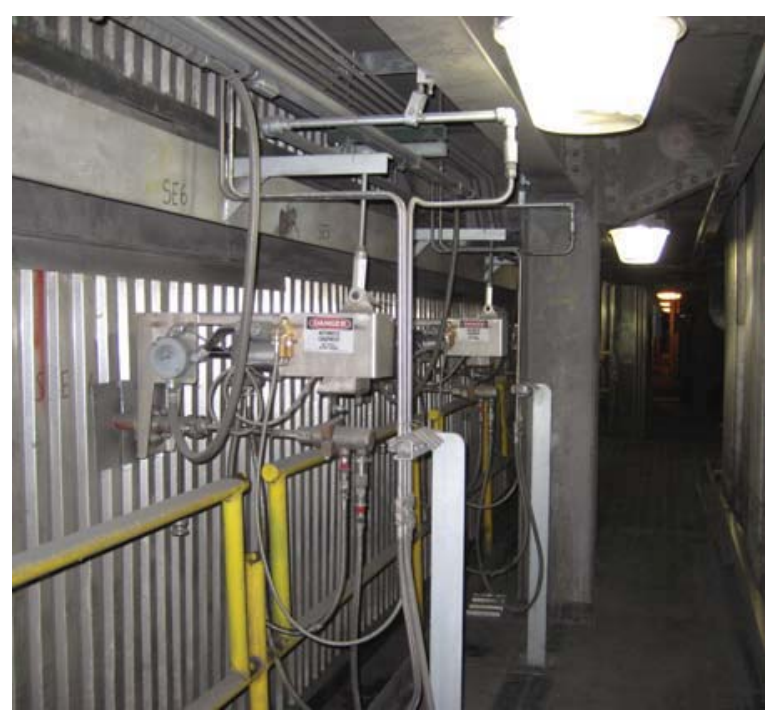

Figure 10. Photograph showing several of the SNCR Zone 1 injectors at AES Greenidge Unit 4.

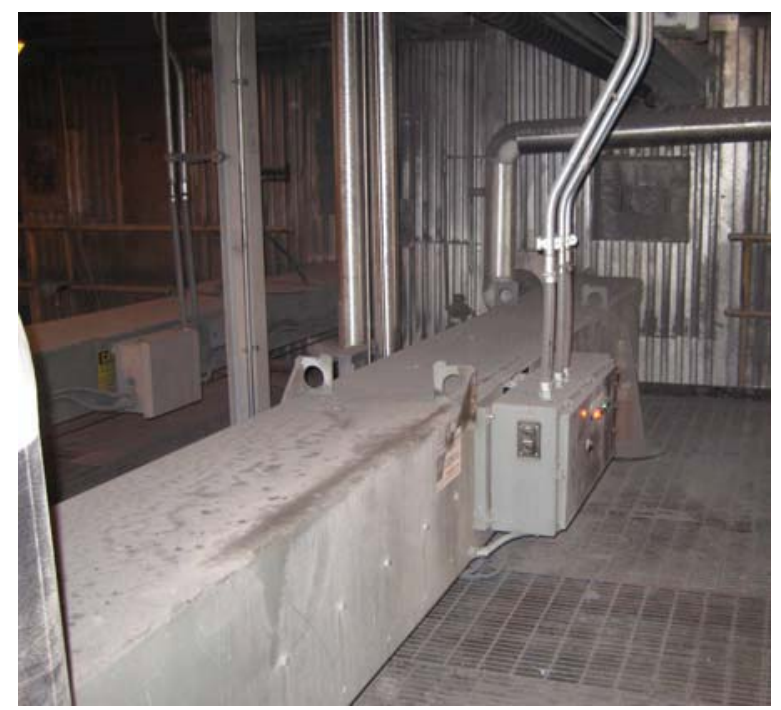

Figure 11. Photograph showing one of the two multiple nozzle lances installed at AES Greenidge Unit 4.

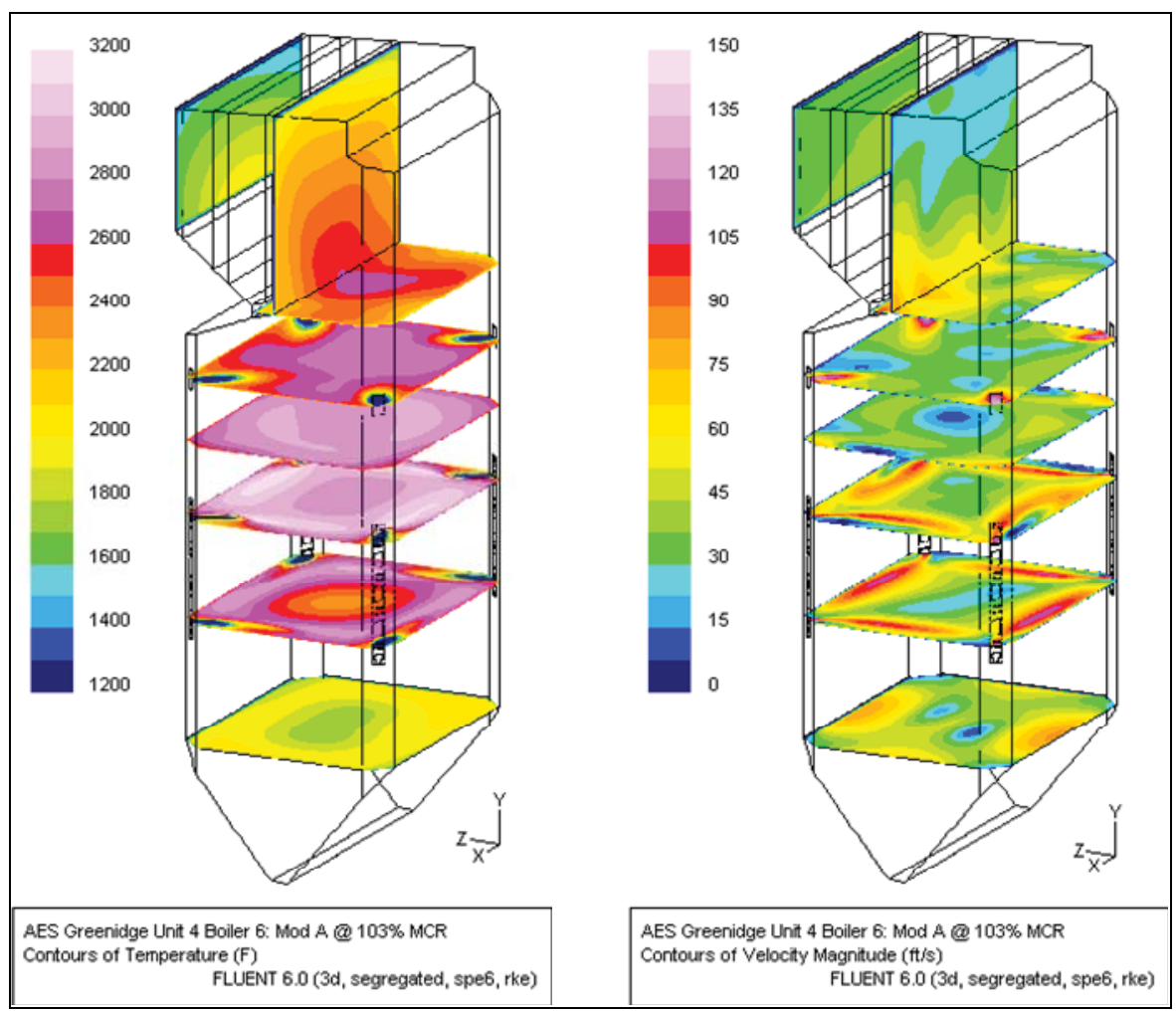

Figure 12. Example of CFD modeling results used in the design of the hybrid $\mathrm{NO}_{x}$ control system for AES Greenidge Unit 4 (Boiler 6). Shown are temperature and velocity profiles for a case in which the unit is operating at $103 \%$ of its MCR. 
The use of multiple urea injection zones is necessary to ensure thorough coverage of the reagent throughout the flue gas and to allow injection of urea into different temperature regions of the furnace, which is critical to the load-following capabilities of the hybrid SNCR/SCR system. At high load, when greater levels of ammonia slip are desired to feed the in-duct SCR reactor, urea can be injected into lower temperature regions of the furnace (i.e., by using the Zone 2 injectors and Zone $3 \mathrm{MNLs}$ ) that promote greater $\mathrm{NO}_{x}$ removal via SNCR and greater ammonia slip. At reduced loads, however, when ammonia slip from the SNCR is limited to $<2$ ppmvd, urea injection is restricted to higher temperature regions of the furnace (i.e., by using only the Zone 1 or Zone 2 injectors).

The liquid, urea-based $\mathrm{NO}_{\mathrm{x}} \mathrm{OUT}^{\circledR}$ reagent used by the SNCR process is delivered to site via tank truck and stored in a 15,000-gallon, fiberglass reinforced plastic tank. The tank is heated and insulated to maintain its temperature above $80^{\circ} \mathrm{F}$ in order to prevent the urea from crystallizing and precipitating out of the solution, and it is installed on a curbed concrete foundation for spill containment.

A high flow delivery and circulation (HFD) module is used to supply filtered urea-based reagent from the storage tank to the process. The HFD module includes two 100\% capacity, 5-hp centrifugal pumps (Pump 1A and Pump 1B in drawing No. 100276-SK081706-05) to circulate the urea solution and provide it to the injector zone metering (IZM) module, the next step in the urea injection process. The HFD module is contained in a heated enclosure located next to the urea storage tank; all piping interconnecting the SNCR system components is heat traced and insulated to prevent urea crystallization. Figure 13 presents a photograph of the urea storage tank and HFD module at AES Greenidge Unit 4.

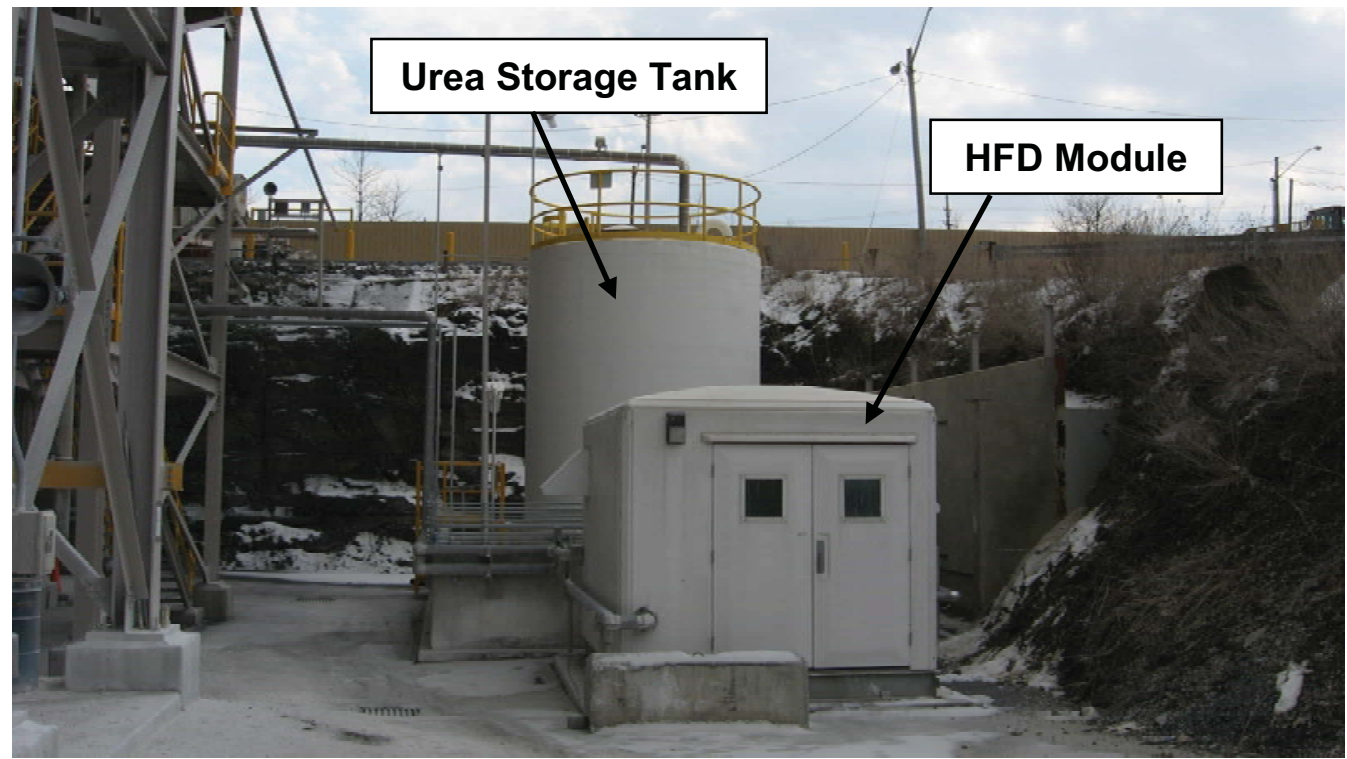

Figure 13. Photograph showing the urea storage tank and HFD module at AES Greenidge Unit 4.

Upon entering the IZM module, which is skid-mounted and installed inside the boiler building, the urea solution is diluted with water and distributed to the SNCR system's three injection zones. Dilution water is pressurized and provided to the IZM module by a dilution water pressure control module consisting of a pair of 5-hp, skid-mounted stainless steel pumps. The IZM module consists of pressure and flow control valves that independently meter the flow and concentration of urea solution sent to each injection zone. Four distribution modules, including 
two for Zone 1, one for Zone 2, and one for Zone 3 (the MNLs), are then used to meter the flow of diluted urea reagent and atomizing air to the individual injectors in response to the demands of the system. Figure 14 presents a photograph of the Zone 2 distribution module.

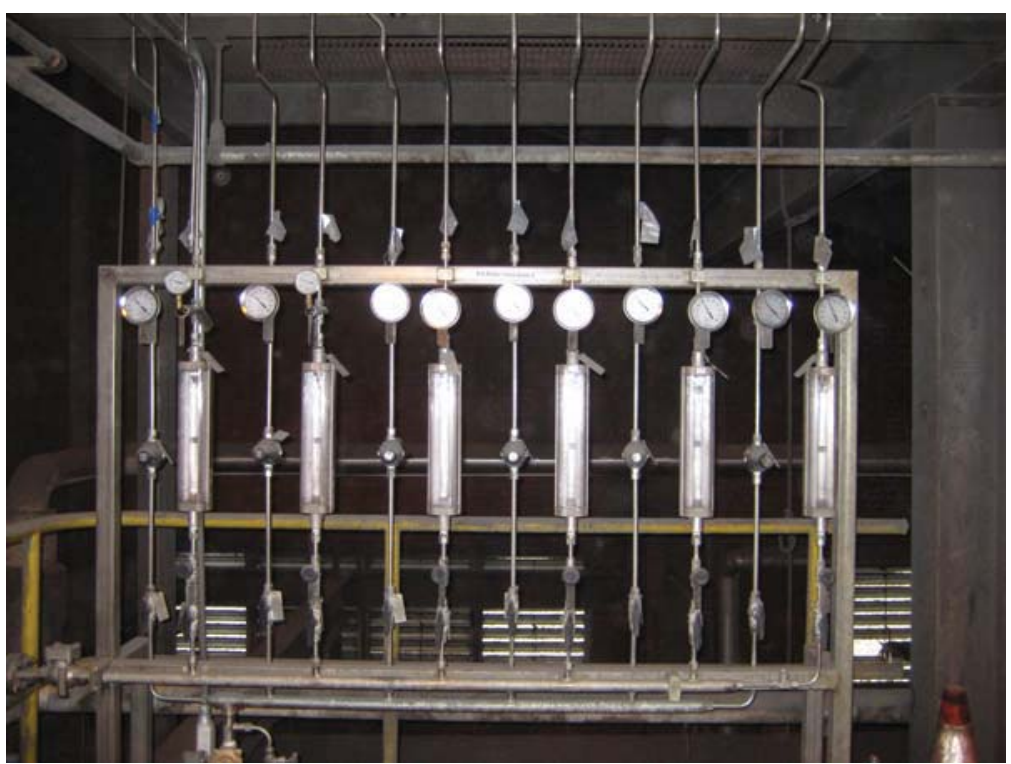

Figure 14. Photograph showing the SNCR Zone 2 distribution module at AES Greenidge Unit 4.

Urea injection by the SNCR system is controlled automatically based on the boiler load, furnace temperature, and $\mathrm{NO}_{x}$ emission rate at the stack. The primary control loop utilizes a feedforward boiler steam flow rate signal, which is fine-tuned as needed using the furnace temperature (measured using an air-cooled optical pyrometer supplied with the SNCR system). A feedback control loop is used to trim the SNCR system operation to achieve the desired $\mathrm{NO}_{\mathrm{x}}$ emission rate, which is measured by the stack continuous emission monitor (CEM).

\subsubsection{In-Duct Selective Catalytic Reduction Reactor}

Following the SNCR process, the flue gas flows to the in-duct SCR reactor, which is designed to further reduce $\mathrm{NO}_{x}$ emissions from AES Greenidge Unit 4 to $\leq 0.10 \mathrm{lb} / \mathrm{mmBtu}$ ( $\leq 76 \mathrm{ppmvd}$, corrected to $3 \% \mathrm{O}_{2}$ ), with $\leq 2$ ppmvd (corrected to $3 \% \mathrm{O}_{2}$ ) of ammonia slip, when the unit is operating at high load. A P\&ID of the SCR system is provided as drawing No. 100276SK4900050 in Appendix B. All ammonia reagent required for $\mathrm{NO}_{\mathrm{x}}$ reduction across the SCR catalyst is generated by the upstream SNCR process; hence, ammonia storage and injection systems are not required. As discussed in Section 6.2.1, the minimum operating temperature for the SCR catalyst is $600^{\circ} \mathrm{F}$. Because the SCR design for AES Greenidge does not include an SCR bypass, flue gas continues to flow through the catalyst even when temperatures are below this value. However, the amount of ammonia fed to the SCR reactor by the upstream SNCR process is restricted to $\leq 2$ ppmvd for economizer outlet temperatures between $528{ }^{\circ} \mathrm{F}$ and $600{ }^{\circ} \mathrm{F}$, and it is restricted to zero (i.e., SNCR operation is discontinued) for economizer outlet temperatures below $528{ }^{\circ} \mathrm{F}$, to prevent problems that could otherwise result from ammonia slip and ammonium bisulfate formation. 
Per the discussion in Section 4.3.6, the size of the in-duct SCR reactor, and hence the amount of catalyst that can be installed to effect $\mathrm{NO}_{x}$ removal, is constrained by the available space in the plant between the economizer outlet and the air heater inlet. As shown in drawings 100276GA200-01, 100276-GA100-01, and 100276-GA101-01 in Appendix B, the SCR system for AES Greenidge Unit 4 is designed to fit within the existing boiler building in a space with horizontal dimensions of 52' x 27' 2" and a vertical height of 23' 1/2". The design must account for an 8' 4$1 / 16$ " offset between the center of the economizer outlet and the center of the air heater inlet. This geometry allows for the installation of a single layer of catalyst in a reactor with a horizontal cross section measuring $45^{\prime} \times 14^{\prime}$. The flue gas flows vertically downward through the reactor, which is designed to accommodate a volumetric flow rate of about 490,000 acfm at full load.

The catalyst layer is $1330 \mathrm{~mm}(4.36 \mathrm{ft})$ deep and consists of 26 modules of honeycomb catalyst (Cormetech) in a $13 \times 2$ arrangement. The catalyst specified for AES Greenidge Unit 4 is a titanium/tungsten-based material that is formulated to provide $\geq 31 \% \mathrm{NO}_{x}$ removal efficiency, $\leq 2$ ppmvd $\mathrm{NH}_{3}$ slip, and $<1.0 \% \mathrm{SO}_{2}$-to- $\mathrm{SO}_{3}$ conversion over a 3-year operating life.

In addition to the SCR catalyst and new reactor ductwork, the SCR system includes Delta Wing $^{\mathrm{TM}}$ static mixers, a sonic horn system (see drawing No. 100276-SK4900065 in Appendix B), and a catalyst loading facility. Delta Wing ${ }^{\mathrm{TM}}$ static mixers are used by Riley Power Inc., a Babcock Power Inc. company, in domestic SCR installations under an exclusive license from Balcke-Durr, $\mathrm{GmbH}$. The previous demonstration of in-duct SCR at GPU Generation Seward Unit 5 highlighted the importance of achieving uniform distributions of temperature, velocity, composition, and fly ash loading across the reactor cross section (Urbas, 1999) in order to maximize $\mathrm{NO}_{x}$ reduction, minimize $\mathrm{NH}_{3}$ slip and ammonium bisulfate formation, and prevent fly ash plugging. Given these results, the in-duct SCR design for AES Greenidge Unit 4 includes a carefully designed system of Delta Wing ${ }^{\mathrm{TM}}$ static mixers to homogenize the flue gas before it enters the SCR reactor. The number, size, and orientation of the static mixers were determined on the basis of physical flow modeling, which was conducted by Ruscheweyh Consult $\mathrm{GmbH}$ using the physical model shown in Figure 15.

The four sonic horns are used to prevent ash buildup on top of the SCR catalyst. The catalyst loading facility is used for manual replacement of deactivated catalyst modules with new modules at the end of the catalyst's useful operating life. It includes a 2-ton electric hoist for raising and lowering catalyst modules to the loading platform, as well as a manual hoist, trolley, and catalyst loading cart for moving modules between the loading platform and the reactor.

The SCR system at AES Greenidge Unit 4 originally did not include a large particle ash removal system, because LPA was not expected to be a problem with this unit. However, soon after start-up, it became apparent that LPA was accumulating in the in-duct SCR catalyst, and the SCR was modified to include an LPA removal system, which is now considered to be an essential part of the system design. As discussed in Section 4.3.9, the development of an effective LPA removal system for AES Greenidge Unit 4 was particularly challenging, because the flue gas flows vertically downward between the economizer and SCR reactor, with no available $90^{\circ}$ bends or hoppers that can be used for inertial capture of the LPA. The LPA removal system was initially installed in May 2007, and several improvements have been made since then (most recently in May 2008). Figure 16 illustrates the final design. 


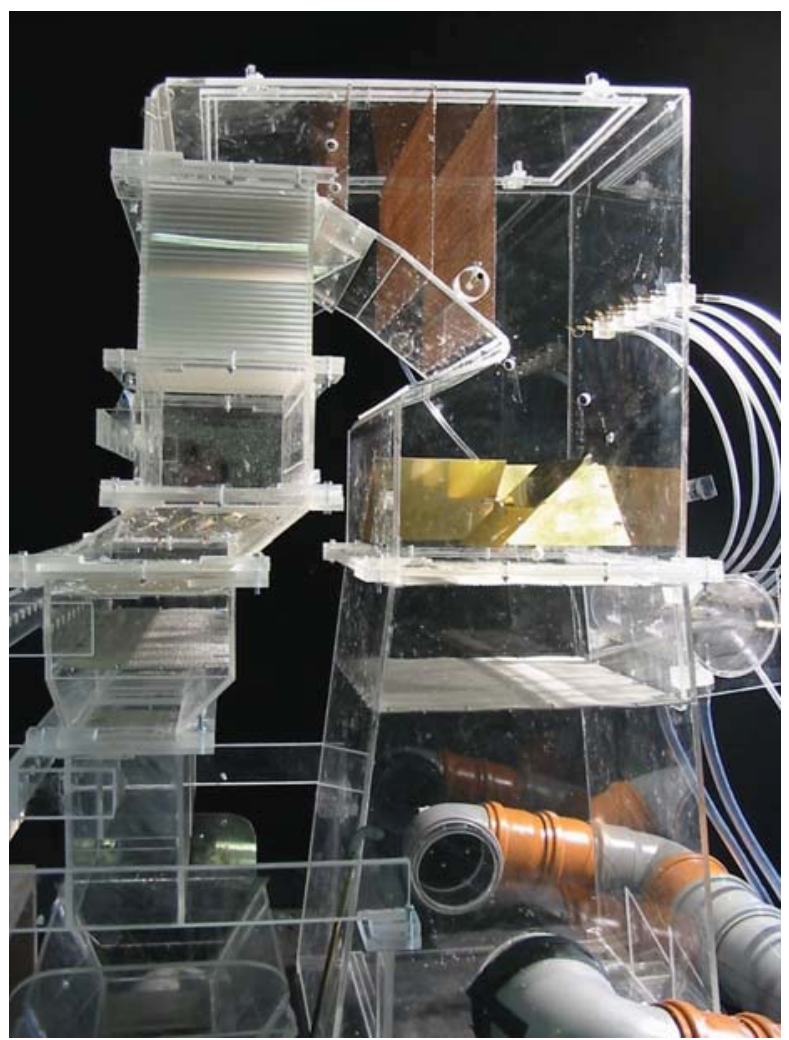

Figure 15. Photograph of the physical flow model used to design the in-duct SCR reactor (courtesy of Ruscheweyh Consult $\mathrm{GmbH}$ ).

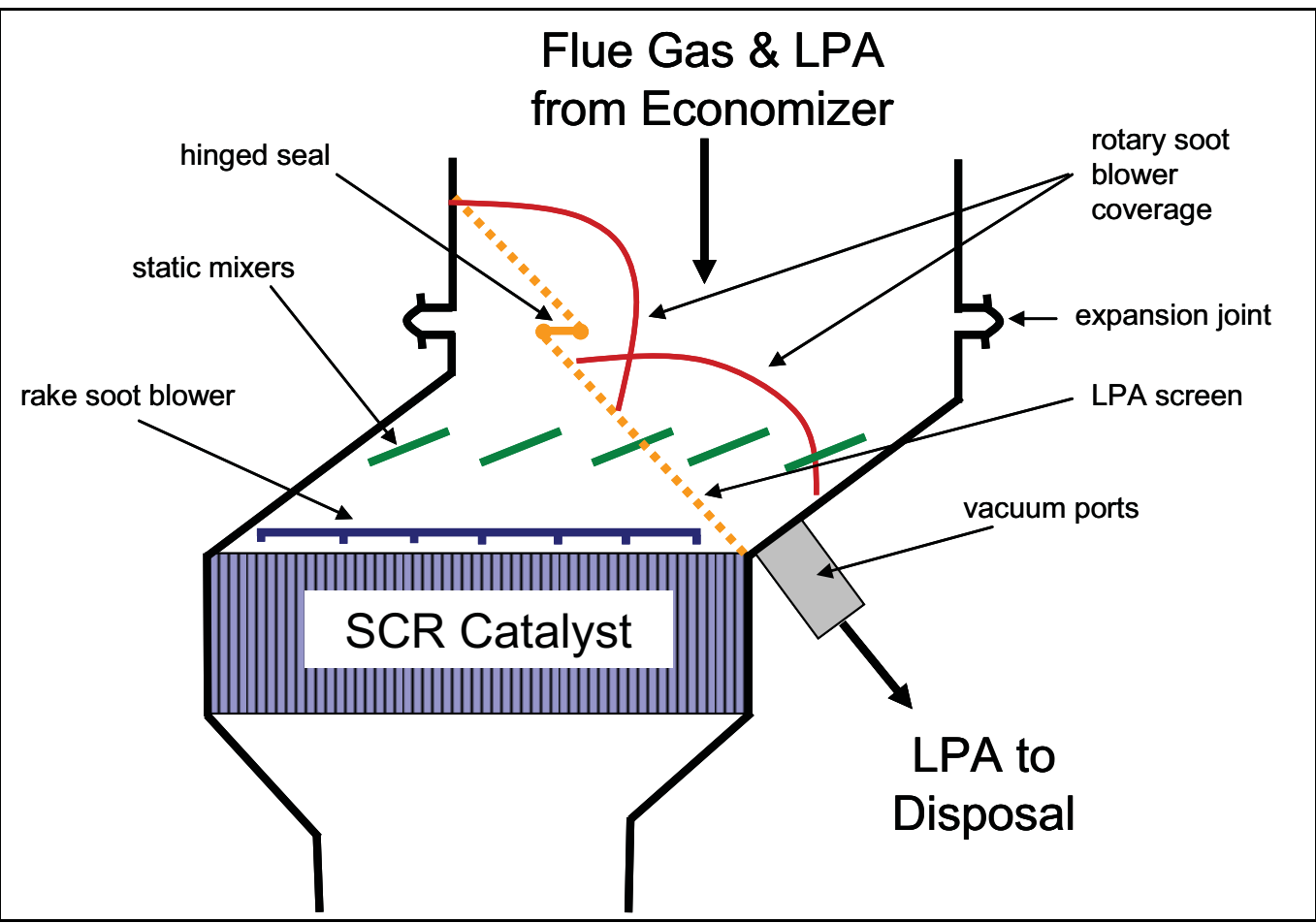

Figure 16. Schematic of the large particle ash removal system that was installed above the in-duct SCR reactor at AES Greenidge Unit 4. 
A sloped screen was installed in the ductwork between the economizer and the catalyst, intersecting the Delta Wing ${ }^{\mathrm{TM}}$ static mixers, to capture the LPA from the flue gas. The screen consists of perforated carbon steel sheets that are coated with a protective material. The perforations are hexagonal; opposing walls of each hexagon are separated by a distance of $4.00 \mathrm{~mm}$. The screen crosses an expansion joint, and it is therefore installed in two sections that are connected by a hinged seal so that it can move with the ductwork. Four rotary soot blowers are located beneath the screen to help transport the collected LPA to the base of the screen, where it is removed by eight vacuum ports. A rake soot blower was also installed above the SCR catalyst to aid the sonic horns in resuspending accumulated fly ash. The rake consists of $\sim 350$ blow holes that discharge steam at a $45^{\circ}$ angle relative to the catalyst surface. The operating pressure of the rake is adjustable, but it is typically operated at 60 psig.

Figure 17 shows a photograph of the in-duct SCR reactor at AES Greenidge Unit 4. The LPA removal system's vacuum ports are visible to the right of the reactor.

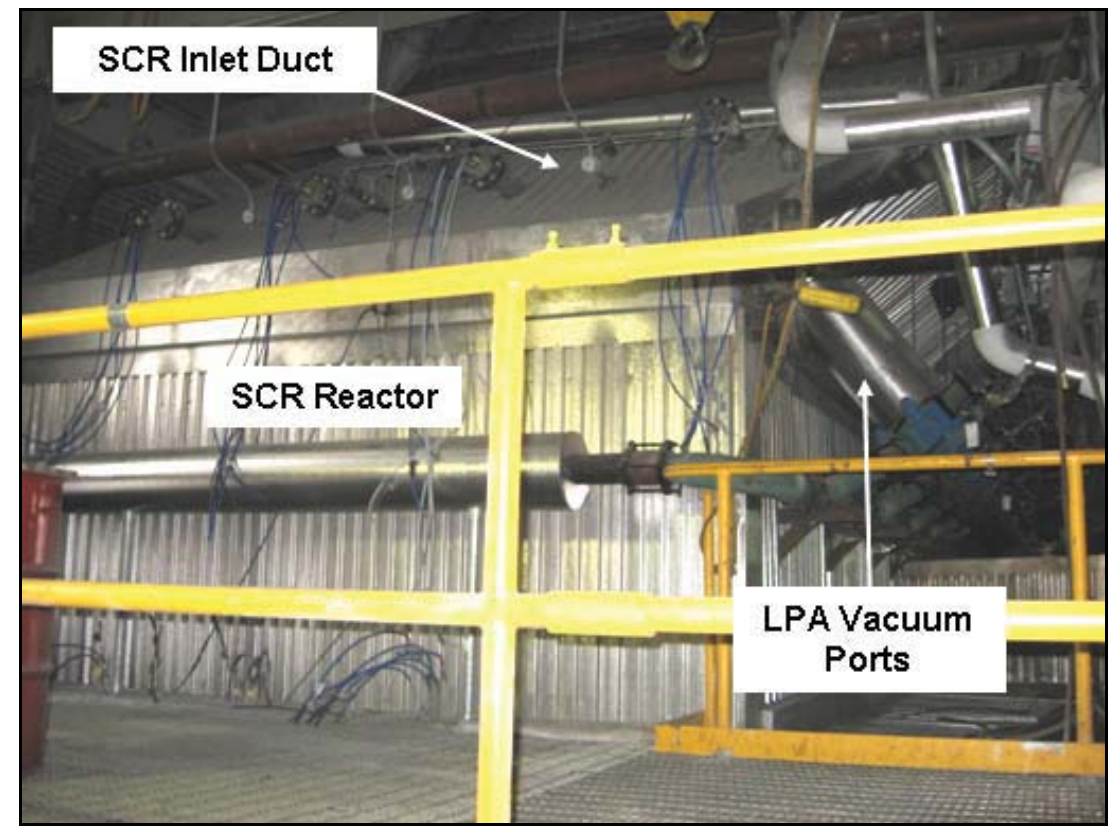

Figure 17. Photograph of the in-duct SCR reactor at AES Greenidge Unit 4.

\subsubsection{Activated Carbon Injection System}

Powdered activated carbon (PAC) can be injected into the flue gas downstream of the air heaters, before the Turbosorp ${ }^{\circledR}$ absorber vessel, to adsorb mercury. As discussed in Section 4.1.3, activated carbon injection is part of an overall mercury control strategy that also includes co-benefits afforded by the in-duct SCR, circulating fluidized bed dry scrubber, and baghouse. Very effective utilization of the activated carbon and high mercury capture are expected to result from the large solids recycle ratio, long residence time, and low temperatures provided by the circulating fluidized bed and baghouse. The activated carbon injection system is designed to inject $89.3 \mathrm{lb} / \mathrm{h}$ of PAC at full load, which corresponds to an injection rate of $3.5 \mathrm{lb}$ PAC / mmacf flue gas; however, as discussed in Section 9, performance tests conducted since start-up of the multi-pollutant control system have indicated that no PAC is required for $90 \% \mathrm{Hg}$ capture. 
The activated carbon injection system includes a PAC storage silo and a PAC feed system, as shown in drawing No. 100276-SK4900090 in Appendix B. The 750- $\mathrm{ft}^{3}$ storage silo discharges to a feed hopper, from which PAC is metered to an eductor via a screw feeder. An $80 \mathrm{scfm}$ blower is used to pneumatically convey the PAC to the duct for injection through a single port. The PAC injection rate is controlled based on the flue gas flow rate measured at the stack. Figure 18 presents a photograph of the activated carbon injection system at AES Greenidge Unit 4.

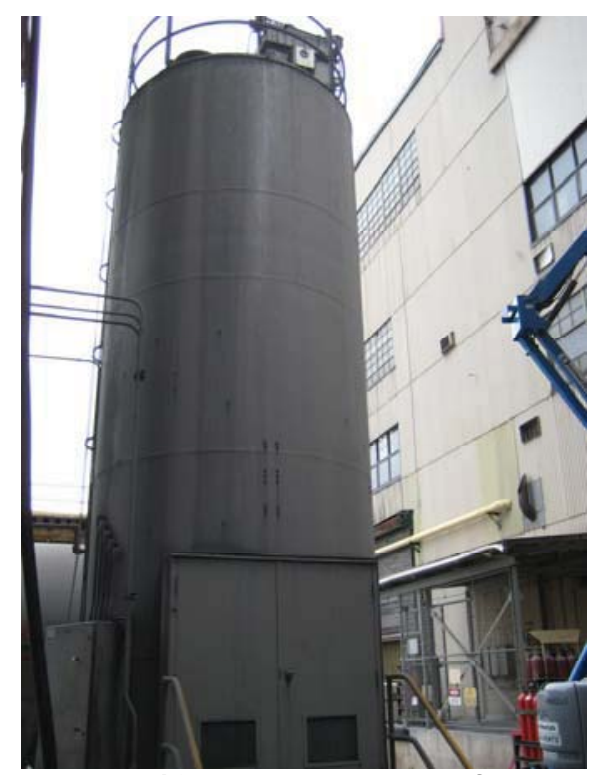

Figure 18. Photograph of the activated carbon injection system at AES Greenidge Unit 4.

\subsubsection{Turbosorp ${ }^{\circledR}$ Circulating Fluidized Bed Dry Scrubber}

The flue gas next flows to the Turbosorp ${ }^{\circledR}$ circulating fluidized bed dry scrubbing system, which is designed to remove $\geq 95 \%$ of the $\mathrm{SO}_{2}, \mathrm{SO}_{3}, \mathrm{HCl}$, and $\mathrm{HF}$ contained in the flue gas when the unit is firing the design fuel.

The Turbosorp ${ }^{\circledR}$ scrubber at AES Greenidge Unit 4 includes a single absorber vessel that is constructed from carbon steel. The vessel, which is 105' 9-1/2" tall, consists of a venturi inlet section and a cylindrical reaction chamber with a diameter of 23' 9-1/2". The reactor is designed to treat $277,807 \mathrm{scfm}(423,700 \mathrm{acfm})$ of incoming flue gas at $\sim 300^{\circ} \mathrm{F}$. At the inlet of the absorber vessel, the flue gas passes through a horizontal duct and a $90^{\circ}$ turn in the gas path (a hopper collects any ash that falls out of the gas at this bend). Once flowing in the vertical direction, the flue gas passes through a single venturi nozzle, which accelerates the gas just prior to the injection of water, hydrated lime, and recycled solids, thereby supporting the fluidized bed in the reaction chamber above. The entire vessel is thoroughly insulated to prevent condensation, per the discussion in Section 4.3.11.

The lime hydration and injection system, process water system, baghouse, and ash recirculation system, which are described in subsequent sections, are integral parts of the circulating fluidized bed dry scrubbing system. The interconnection among these systems is depicted in 
drawing No. 100276-SK4900095 in Appendix B. Dry hydrated lime reagent (containing 95\% $\mathrm{w} / \mathrm{w} \mathrm{Ca}(\mathrm{OH})_{2}$ ) is injected into the absorber at a rate of $\leq 8,623 \mathrm{lb} / \mathrm{h}$ (design conditions, full load) to react with the $\mathrm{SO}_{2}, \mathrm{SO}_{3}, \mathrm{HCl}$, and $\mathrm{HF}$ in the flue gas. (The projected $\mathrm{Ca} / \mathrm{S}$ molar ratio for the design fuel was $\sim 1.6-1.7$, based on the number of moles of $\mathrm{SO}_{2}$ entering the absorber). Water is separately injected to evaporatively cool the flue gas to $\sim 162^{\circ} \mathrm{F}$ and to moisten the surfaces of the particles in the absorber, enhancing the capture of $\mathrm{SO}_{2}, \mathrm{SO}_{3}, \mathrm{HCl}$, and $\mathrm{HF}$. Finally, $>95 \%$ of the solids captured in the baghouse are recycled to the absorber vessel via the ash recirculation system. These recycled solids enable a fast fluidized bed to be established in the absorber; the high recycle rate increases the hydrated lime utilization, helping to minimize the variable O\&M costs associated with the process. Figure 19 presents a photograph showing the Turbosorp $^{\circledR}$ absorber vessel and ancillary equipment at AES Greenidge Unit 4.

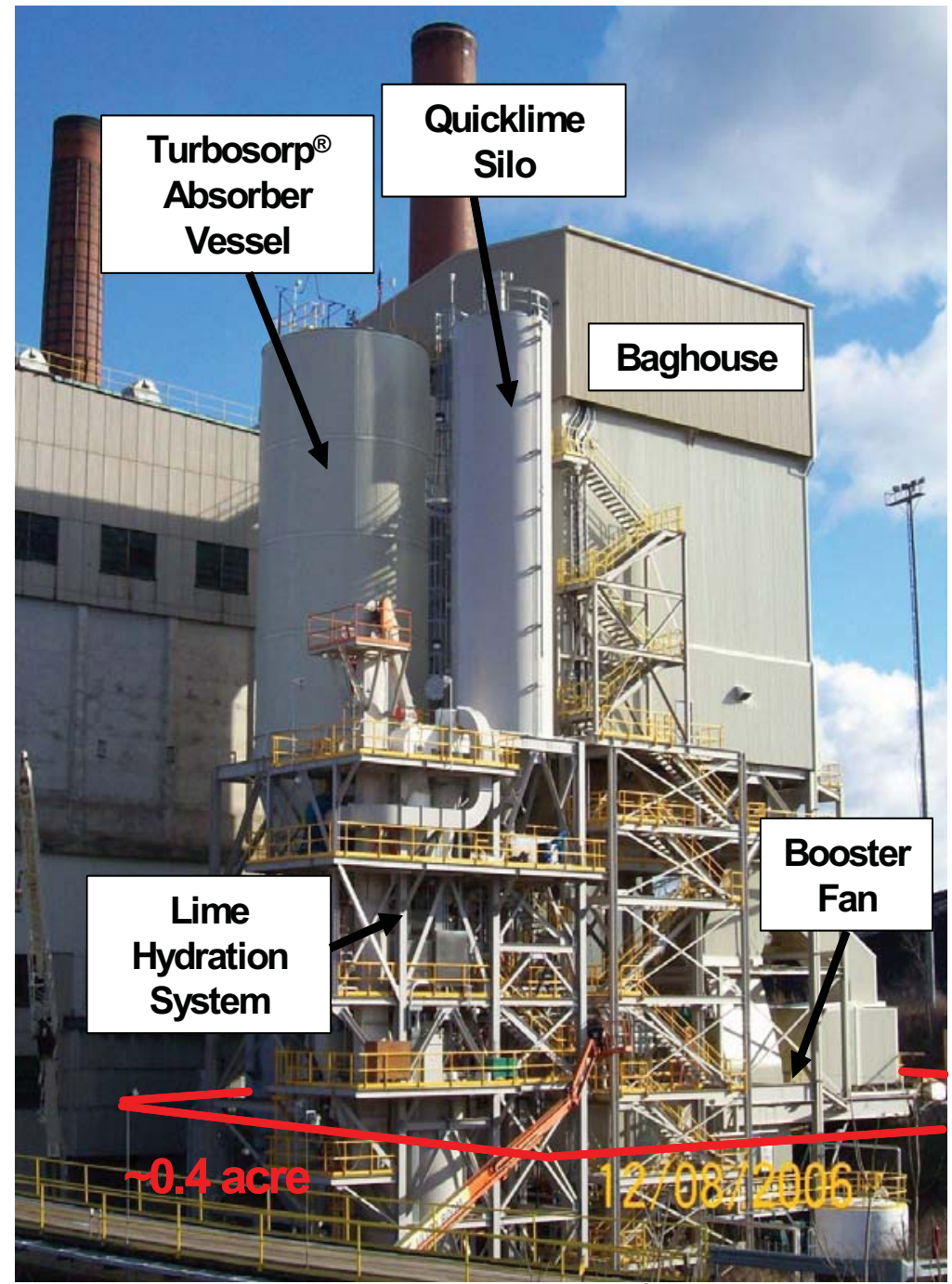

Figure 19. Photograph of the Turbosorp ${ }^{\circledR}$ circulating fluidized bed dry scrubbing system, including ancillary equipment, at AES Greenidge Unit 4.

Major control loops for the Turbosorp ${ }^{\circledR}$ process are shown in Figure 20. The control strategy includes separate PID (proportional-integral-derivative) control loops for each of the four major process operations: hydrated lime injection, water injection, solid product recycle, and solid product rejection. The hydrated lime injection rate is controlled on the basis of $\mathrm{SO}_{2}$ 
concentrations measured at the Turbosorp ${ }^{\circledR}$ system inlet and at the stack. Inlet $\mathrm{SO}_{2}$ concentrations are measured using a dilution extractive-type $\mathrm{SO}_{2}$ analyzer installed between the air heater outlet and the Turbosorp ${ }^{\circledR}$ absorber inlet; stack $\mathrm{SO}_{2}$ concentrations are measured using the unit's CEM. As inlet $\mathrm{SO}_{2}$ concentrations increase, more hydrated lime is added to the Turbosorp ${ }^{\circledR}$ absorber. The hydrated lime injection rate is fine-tuned by a feedback control loop based on the stack $\mathrm{SO}_{2}$ measurement. The temperature in the Turbosorp ${ }^{\circledR}$ absorber and the flue gas flow rate at the stack control the amount of cooling water that is injected into the absorber. The fluid bed density within the absorber (measured as the pressure drop across the absorber vessel) controls the amount of ash and scrubber reaction products that are recycled to the absorber vessel. Finally, the level of ash and reaction products in the air slides controls the rate at which these solids are rejected from the system for disposal.

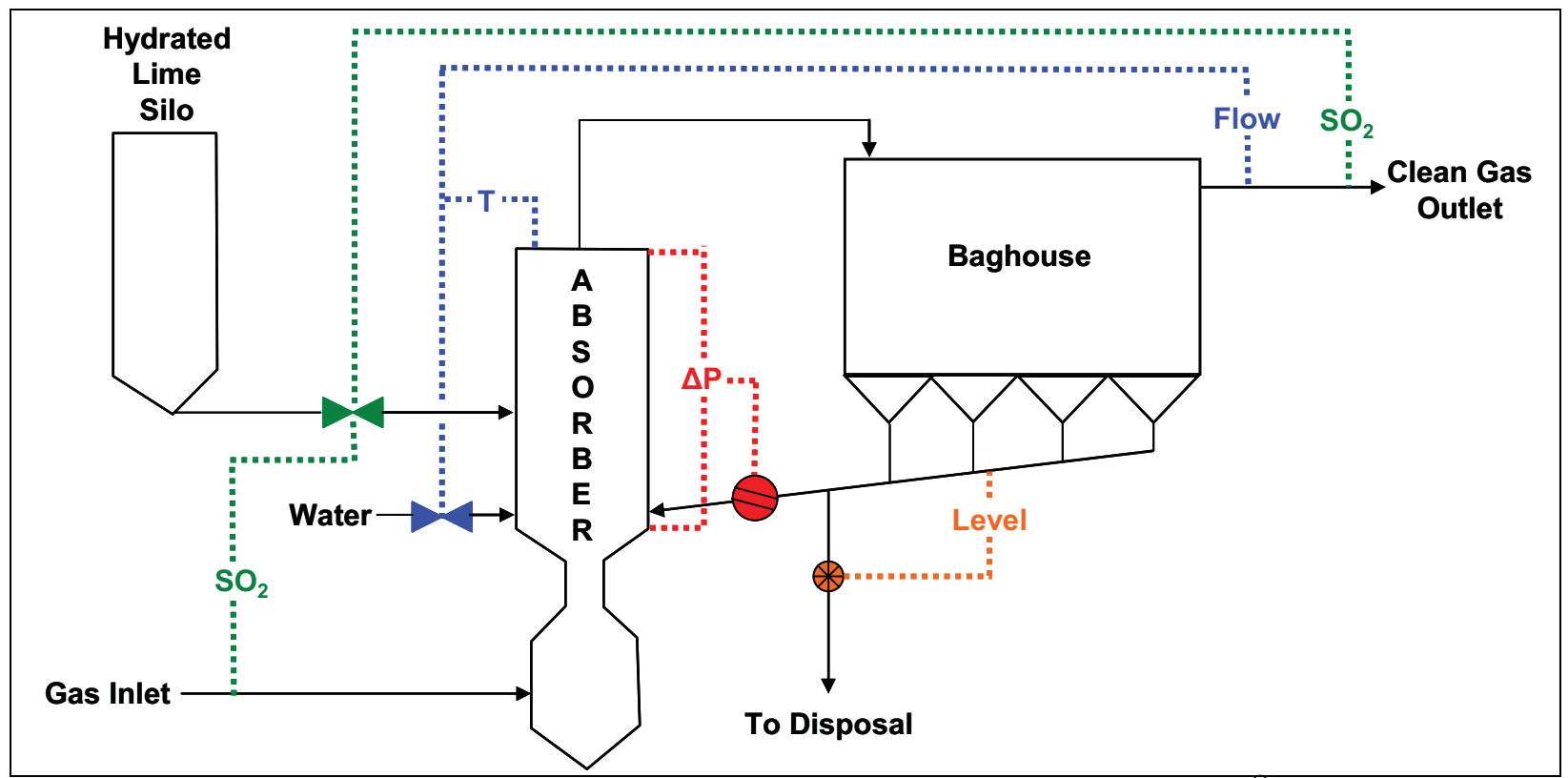

Figure 20. Process control schematic showing major control loops for the Turbosorp ${ }^{\circledR}$ circulating fluidized bed dry scrubber at AES Greenidge Unit 4. Lime injection control is shown in green; water injection control is shown in blue; solid product recycle control is shown in red; and solid product rejection control is shown in orange.

The Turbosorp ${ }^{\circledR}$ system at AES Greenidge also includes a flue gas recycle stream to enable turndown for continued operation at low generator loads. The system was designed to achieve $\geq 95 \%$ removal of $\mathrm{SO}_{2}, \mathrm{SO}_{3}, \mathrm{HCl}$, and $\mathrm{HF}$ when the unit is operating at any point between its minimum load (42 $\mathrm{MW}_{\mathrm{g}}$ ) and full load. As shown in drawing No. 100276-SK101206-03 in Appendix A, at minimum load, 43,766 scfm of flue gas is recycled from the booster fan outlet to the absorber inlet, increasing the gas flow to the absorber vessel from 136,808 scfm to 180,574 $\operatorname{scfm}(250,239 \mathrm{acfm})$. This flue gas flow rate, which is $65 \%$ of the full-load flow rate of 277,807 $\mathrm{scfm}$, is required to maintain a fluidized bed in the absorber vessel.

\subsubsection{Process Water System}

The process water system is designed to inject about $89 \mathrm{gpm}$ into the Turbosorp ${ }^{\circledR}$ absorber vessel at full load operation. Process water from the plant is supplied to a 6,300-gallon heated storage tank. This water is then fed to the absorber vessel by a 150-gpm capacity, high- 
pressure centrifugal pump and injected through a single lance. The pump and injection lance are provided in duplicate to ensure reliability. The P\&ID for the process water system is provided as drawing No. 100276-SK400093 in Appendix B. Figure 21 shows the process water injection lance installed in the Turbosorp ${ }^{\circledR}$ absorber vessel.

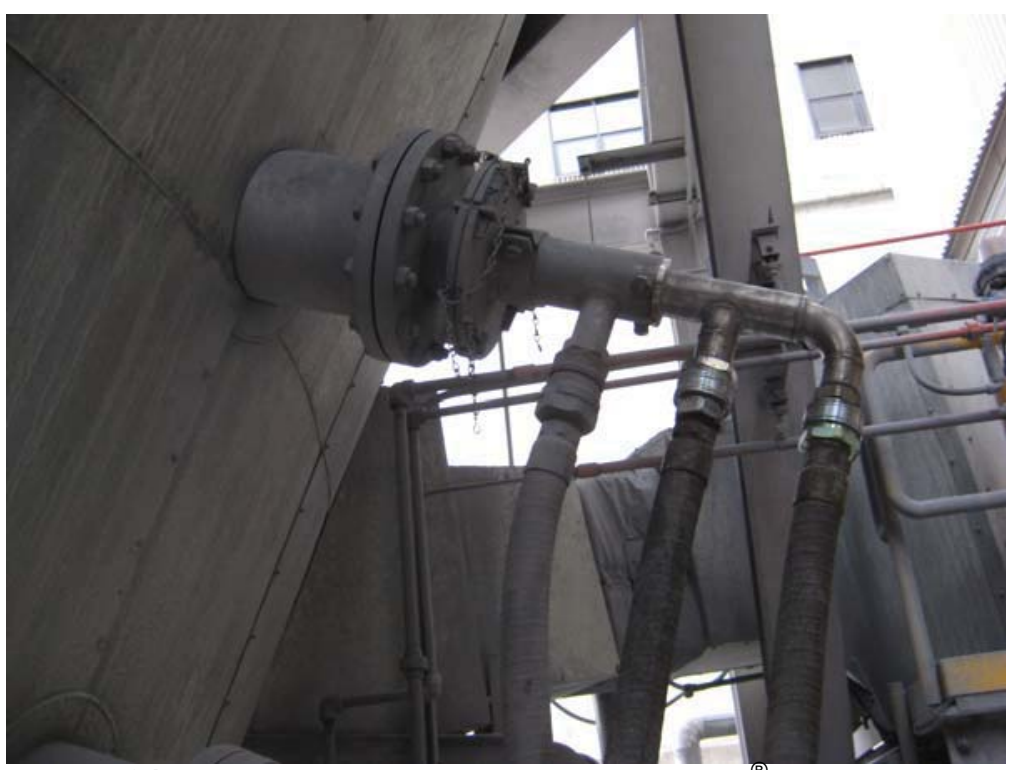

Figure 21. Photograph showing the Turbosorp ${ }^{\circledR}$ water injection lance (in service).

\subsubsection{Lime Storage, Hydration, and Injection System}

Because of the high cost of directly purchasing hydrated lime for use in the Turbosorp ${ }^{\circledR}$ system, the multi-pollutant control system at AES Greenidge includes a dedicated outdoor lime hydration system to produce hydrated lime from quicklime $(\mathrm{CaO})$. For AES Greenidge, the delivered cost of hydrated lime is $55-60 \%$ greater per mole of $\mathrm{Ca}$ than the delivered cost of quicklime. The lime hydration and injection system, which is depicted in drawing No. 100276-SK4900091 in Appendix B, consists of a quicklime storage silo, commercially available lime hydration system, hydrated lime classification and milling system, and hydrated lime storage silo and injection system.

Quicklime is delivered to the AES Greenidge site by truck and pneumatically unloaded into a $7,500-\mathrm{ft}^{3}$ storage silo. This silo is visible in Figure 19. A weigh feeder is used to supply quicklime $(\sim 6,600 \mathrm{lb} / \mathrm{h}$ at design conditions) from the silo to the hydrator, where it is mixed with water ( $~ 8 \mathrm{gpm}$ at design conditions) and agitated. The quicklime reacts exothermically with the water to form raw, dry hydrated lime. Figure 22 shows a photograph of the hydrator at AES Greenidge. The original design included a wet scrubber to treat the hydrator exhaust (which includes air, steam, and lime dust) and a milk of lime circuit that was partially fed by the wet scrubber and was used to supply water to the hydrator. However, these components have since been removed from the process (see Section 8.3); the hydrator exhaust is sent to the Turbosorp $^{\circledR}$ scrubber rather than to a separate wet scrubber for cleaning, thereby simplifying the process and eliminating the potential need to treat and dispose of alkaline milk of lime overflow. 
A bucket elevator is used to deliver the raw hydrated lime from the hydrator to an air classifier, which separates out coarse hydrated lime particles and sends them to a ball mill for grinding. About $3 \mathrm{gpm}$ of water is required to cool the ball mill bearings. The ground hydrated lime leaving the ball mill is returned to the classifier, which is shown in Figure 23. The hydrator, classifier, and ball mill are sized for a capacity of 10 short ton/h of solids. Operation of the lime hydration system is controlled using a programmable logic controller (PLC) with local operator interface units.

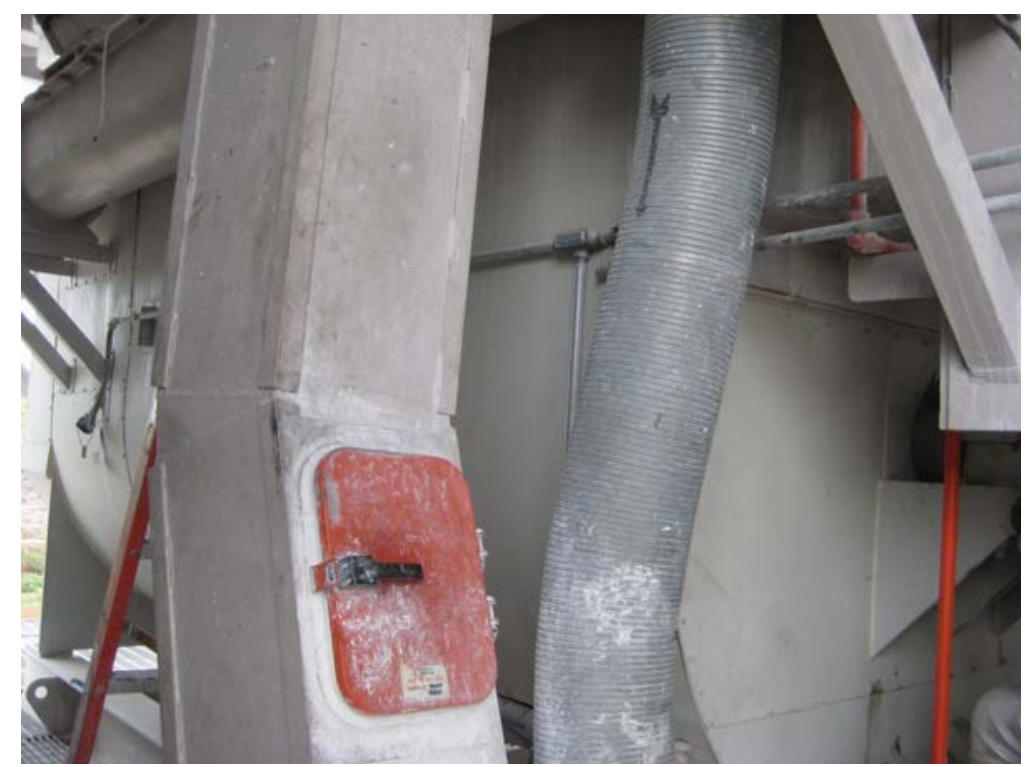

Figure 22. Photograph of the lime hydrator at AES Greenidge. The chute in the foreground (with the red door) is used to convey hydrated lime from the cyclone to the hydrated lime silo.

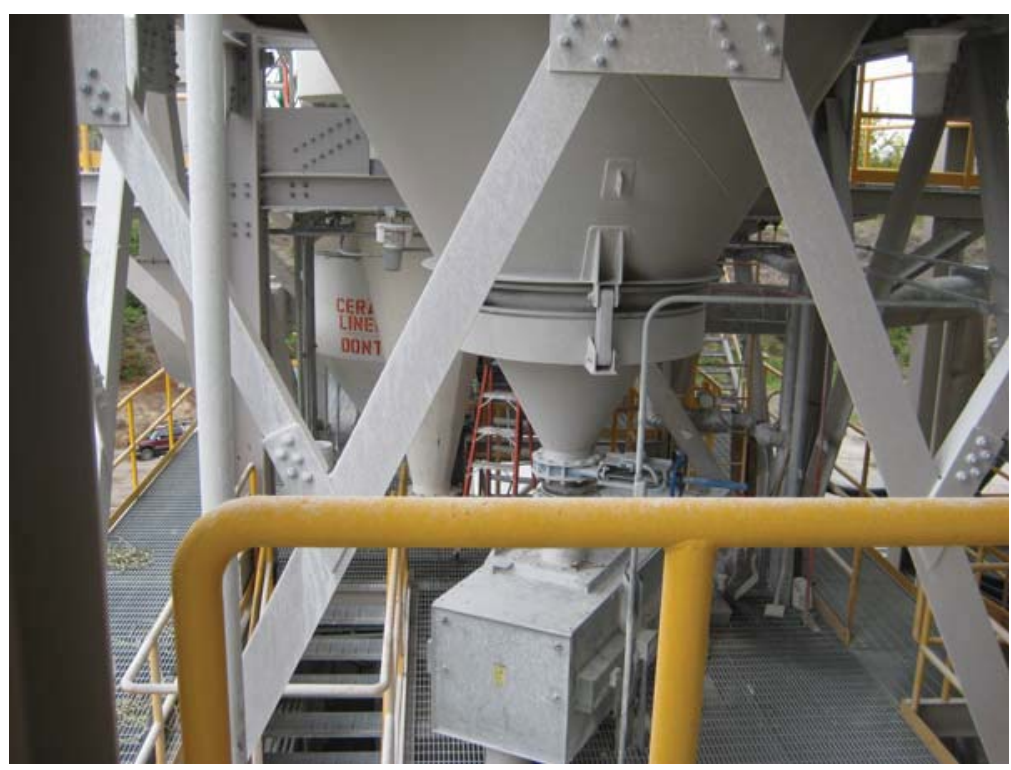

Figure 23. Photograph showing part of the lime hydration system at AES Greenidge Unit 4. The hydrated lime classifier, cyclone, pebble lime weigh feeder, and bottom of the pebble lime storage silo are all visible. 
The powdered hydrated lime leaving the classifier is captured using a cyclone and sent to a $2,200-\mathrm{ft}^{3}$ hydrated lime silo, where it is stored before being sent for injection into the Turbosorp ${ }^{\circledR}$ absorber vessel. As shown in drawing No. 100276-SK4900092 in Appendix B, a screw conveyer delivers hydrated lime from the silo to a distribution hopper, and a rotary feeder is used to meter the hydrated lime from the hopper to the Turbosorp ${ }^{\circledR}$ system. A 630-acfm blower pneumatically conveys the powdered hydrated lime from the silo to the absorber vessel. The hydrated lime feed system is shown in Figure 24. The design also includes the capability to accept hydrated lime directly from a delivery truck, enabling continued operation of the Turbosorp ${ }^{\circledR}$ system in the event of a problem with the hydrator.

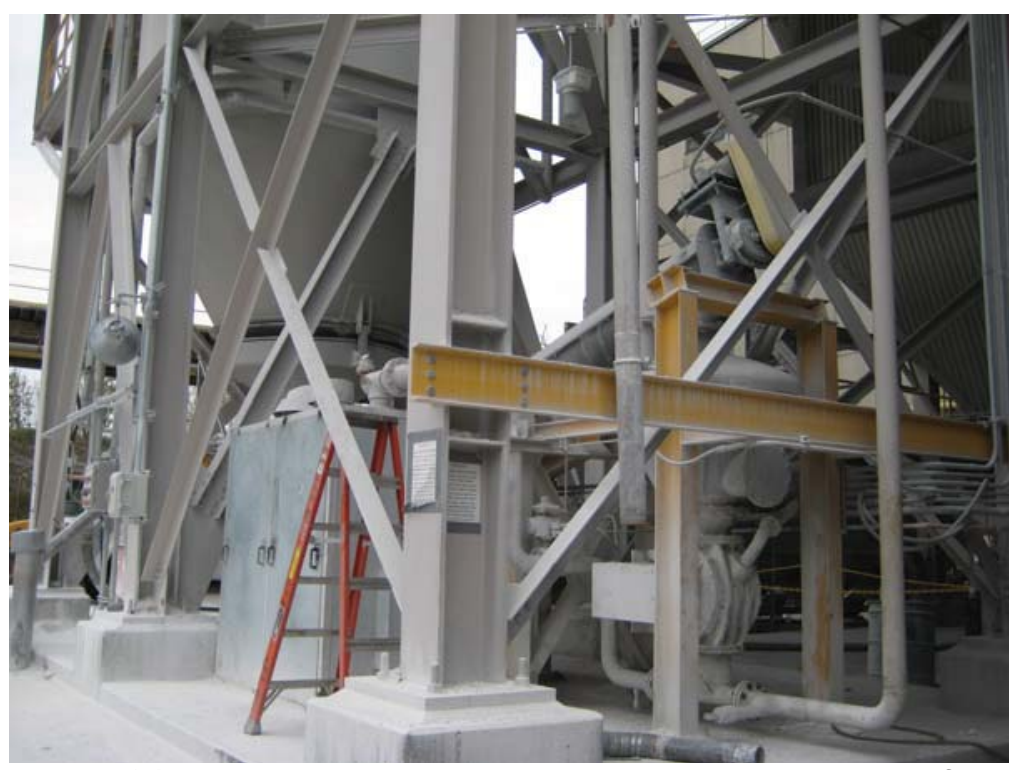

Figure 24. Photograph showing the system that is used to feed hydrated lime to the Turbosorp ${ }^{\circledR}$ vessel at AES Greenidge Unit 4.

\subsubsection{Baghouse}

The multi-pollutant control system includes a new pulsejet fabric filter (baghouse) to remove particulate matter from the flue gas after it exits the Turbosorp ${ }^{\circledR}$ absorber vessel. A new particulate control device was required for AES Greenidge Unit 4 because the unit's existing ESP was not capable of handling the increased particle loading in the flue gas that results from the solids recycling that is part of the circulating fluidized bed dry scrubbing process. The existing ESP was retired in place. A baghouse was selected for particulate control because it is expected to promote better removal efficiencies for $\mathrm{SO}_{2}$, acid gases, mercury, and fine particulate matter than an ESP would, as discussed in Section 4.3.13. Key design parameters are summarized below.

Inlet Flue Gas Flow Rate - 371,440 acfm (full load, normal operation)

Inlet Flue Gas Particle Loading - 244 gr/dscf (full load, normal operation)

Flue Gas Temperature $-162^{\circ} \mathrm{F}$ (full load, normal operation)

Flue Gas Temperature Range $-150^{\circ} \mathrm{F}$ to $350^{\circ} \mathrm{F}$

Number of Compartments -8

Number of Bags - 3168

Bag Material - Ryton ${ }^{\circledR}$ 


\section{Nominal Air-to-Cloth Ratio - $3\left(\mathrm{ft}^{3} / \mathrm{min}\right) / \mathrm{ft}^{2}$}

The baghouse is shown in drawing No. 100276-SK4900095 in Appendix B, and it is visible in the photograph in Figure 19. Dust laden flue gas from the Turbosorp ${ }^{\circledR}$ absorber enters the top of the baghouse and flows through the inlet plenum, vertically upward through the filter bags, and through the outlet plenum. Particulate matter is collected on the outside of the filter bags. The filter bags are cleaned on-line using pulsejets, which use high-pressure air to cause ash that has accumulated on the bags to fall into the hoppers at the bottom of the baghouse. Baghouse cleaning is controlled by a local PLC, which is capable of providing data to the plant's DCS. The baghouse design includes inlet baffling and extra space below the bags to improve flow distribution, as well as greater-than-normal bag spacing to reduce can velocity (the upward velocity component of the dust-laden flue gas as it passes between the filter bags). The reduced can velocity promotes settling of dust particles during bag cleaning. Although the temperature of the flue gas entering the baghouse is projected to be about $162{ }^{\circ} \mathrm{F}$ when the multi-pollutant control system is operating normally, temperatures as great as $350{ }^{\circ} \mathrm{F}$ may be encountered if the Turbosorp ${ }^{\circledR}$ scrubber is not in service. Ryton ${ }^{\circledR}$ bags were specified because of their ability to withstand flue gas temperatures of up to $400^{\circ} \mathrm{F}$ and their resistance to abrasion and acid attack. The entire baghouse is thoroughly insulated, and the baghouse hoppers are heated to prevent condensation, which could otherwise cause plugging and corrosion.

The baghouse is designed for continued operation with only seven of its eight compartments in service. Each compartment is equipped with inlet and outlet dampers that can be closed to isolate the compartment for on-line bag maintenance. Filter bags are accessed from the top of the baghouse. The baghouse structure includes a penthouse to accommodate the bag access area, valve actuators and cleaning air manifolds, and PLC. Figure 25 shows the inside of the baghouse penthouse.

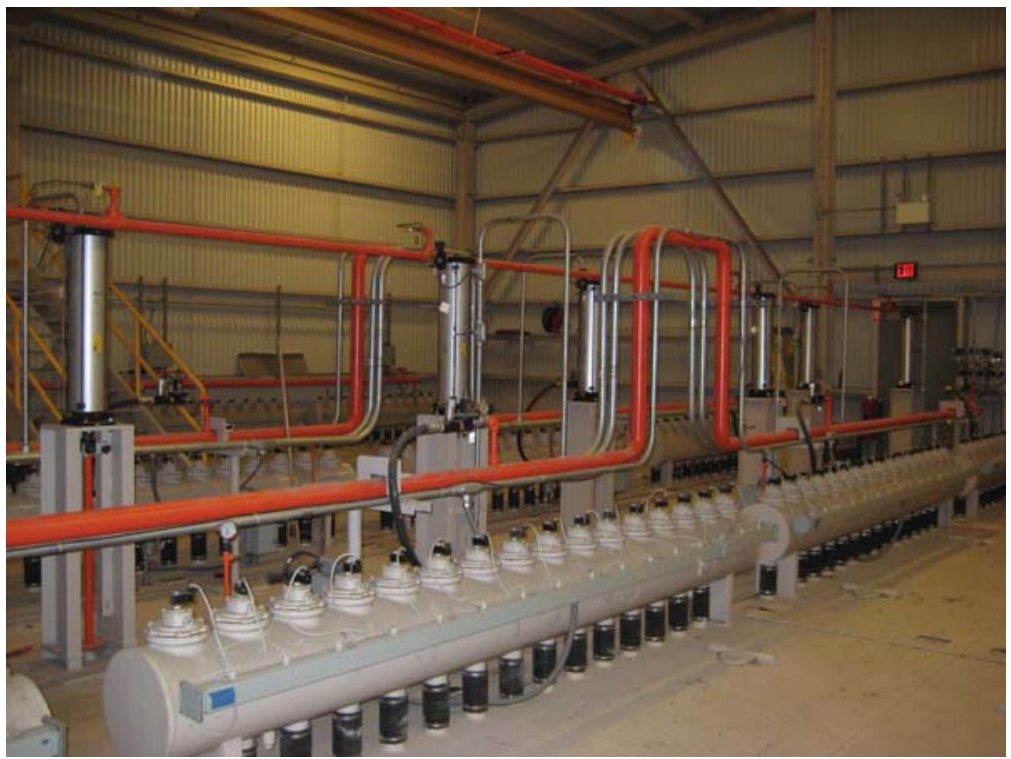

Figure 25. Photograph showing the inside of the baghouse penthouse at AES Greenidge Unit 4.

In spite of the increased particle loading arising from the multi-pollutant control system, the baghouse is designed to achieve particulate emission rates of about $0.01 \mathrm{gr} / \mathrm{dscf}$ across all generator operating loads. This is about $67 \%$ less than the emission rate of $0.03 \mathrm{gr} / \mathrm{dscf}$ measured from the existing ESP during baseline testing at AES Greenidge. 


\subsubsection{Ash Recirculation System}

The solids that are collected in the eight baghouse hoppers are fed into two air slide conveyers (one per set of four hoppers) that are collectively designed to process $517,658 \mathrm{lb} / \mathrm{h}$ of material at full load operation. P\&IDs for the air slides are provided as drawing No. 100276-SK4900097 and drawing No. 100276-SK4900098 in Appendix B. Each air slide conveyer consists of a sloped piece of ductwork with a thick fabric material dividing the upper portion of the duct from the lower portion. A blower provides air along the bottom portion of each air slide, thereby fluidizing the solids on top of the fabric and allowing them to flow by gravity back toward the Turbosorp $^{\circledR}$ absorber vessel. The design includes three $891 \mathrm{icfm}$ blowers, each sized to provide $100 \%$ of the fluidizing air flow required for a single slide. (Hence, at any given time, two of the blowers will be operating, with the third in standby). The air slides are heated and insulated to prevent moisture from condensing on the solids. Figure 26 presents a photograph showing one of the air slide conveyers at AES Greenidge Unit 4.

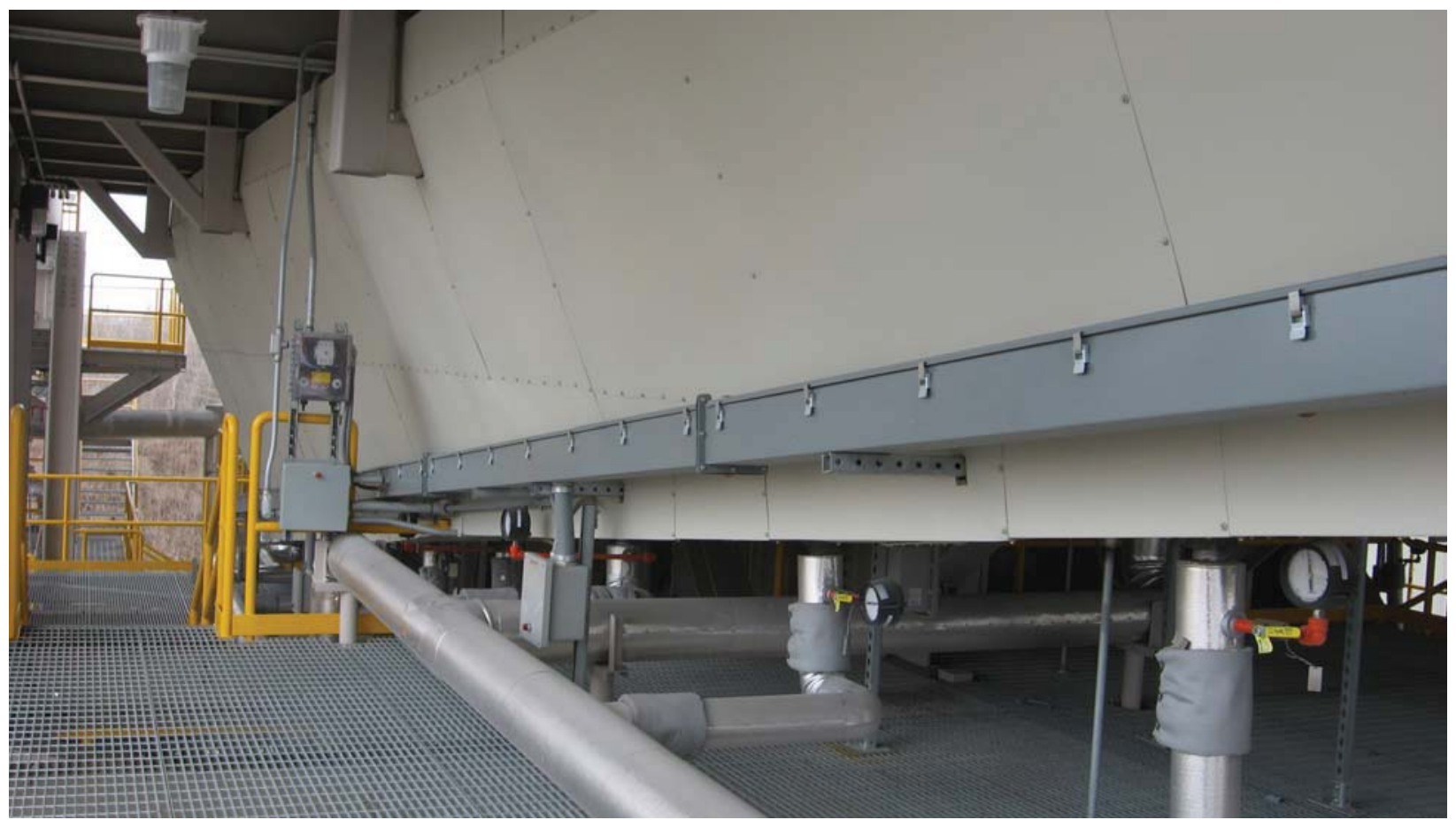

Figure 26. Photograph of one of the air slide conveyers at AES Greenidge Unit 4.

As discussed above, greater than $95 \%$ of the solids are recycled back into the absorber. Dosing valves are used to control the solids recycle rate, based on the pressure drop across the Turbosorp ${ }^{\circledR}$ reactor. Excess solids are fed through rotary feeders to a pair of ash disposal silos (one per air slide), each having a capacity of $720 \mathrm{ft}^{3}$, which are tied into the plant's existing pneumatic vacuum ash disposal system.

\subsubsection{Booster Fan}

The multi-pollutant control system at AES Greenidge includes a new flue gas booster fan and motor to overcome the increased pressure drop created by the addition of the static mixers, SCR catalyst, circulating fluidized bed dry scrubber, baghouse, and longer ductwork runs. The 
plant's existing ID fans do not afford sufficient capacity to overcome this pressure drop. The booster fan also provides the motive force for flue gas recirculation to the Turbosorp ${ }^{\circledR}$ inlet at low load operation, as required to maintain adequate fluidizing velocity. The 2068-bhp booster fan, which is shown in drawing No. 100276-SK4900096 in Appendix B and pictured in Figure 27 , is installed downstream of the baghouse; its discharge is connected to the suction of the existing ID fans. The flue gas recirculation duct is connected between the booster fan and ID fans; dampers are used to control the amount of flue gas (if any) that is returned to the absorber vessel. The design also includes a booster fan bypass system, consisting of a bypass duct with shut-off dampers and actuators, to aid in the plant start-up practice normally employed with the existing ID fans.

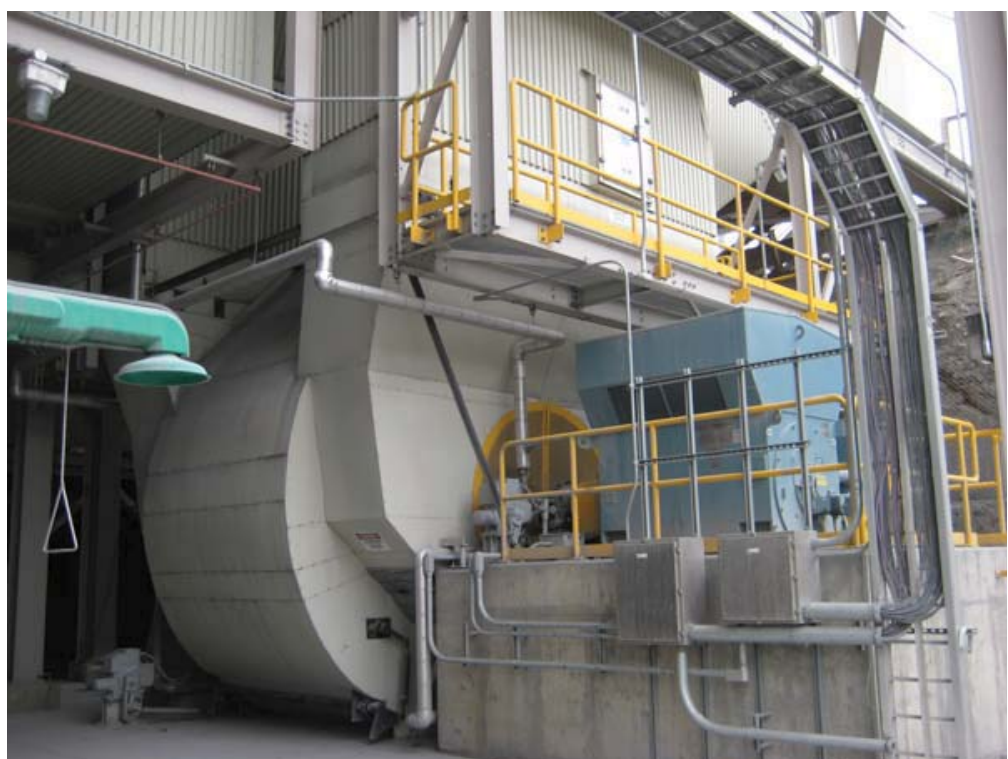

Figure 27. Photograph of the booster fan at AES Greenidge Unit 4.

\subsection{Balance of Plant Considerations}

\subsubsection{Ductwork}

To provide for interconnection among various components of the multi-pollutant control system and tie-in of the system to the existing plant, several existing sections of ductwork were demolished, and several new sections were installed. Specifically, the design required demolition of the section of existing ductwork connecting the economizer to the air heaters in order to accommodate the new in-duct SCR reactor, as well as demolition of the sections of existing ductwork connecting the air heaters to the ESP and the ESP to the ID fans to allow for tie-in of the Turbosorp ${ }^{\circledR}$ system and associated equipment to the existing plant. (As discussed in Section 6.2.7, the existing ESP was retired in place). Asbestos insulation had to be properly removed and disposed of prior to demolition; this was conducted outside of the scope of the DOE project. The general arrangement drawings included in Appendix B illustrate the ductwork layout for the AES Greenidge installation. New ductwork sections, which were fabricated from $1 / 4$ " carbon steel plate and were insulated and lagged in accordance with design standards, are as follows: 
- Economizer outlet to air heater inlet, including SCR reactor ductwork

- Air heater outlet to Turbosorp ${ }^{\circledR}$ absorber inlet

- Turbosorp ${ }^{\circledR}$ absorber outlet to baghouse inlet

- Baghouse outlet to booster fan inlet

- Booster fan bypass (from baghouse outlet duct to booster fan outlet duct)

- Booster fan outlet to ID fan inlet

- Flue gas recirculation duct (from booster fan outlet duct to absorber inlet duct)

All new ductwork was designed to limit loads imposed on new and existing equipment. Supports and expansion joints were included to limit stresses and movement to those specified by equipment suppliers and by good engineering practice.

\subsubsection{Civil and Structural}

The general arrangement drawings provided in Appendix B illustrate the layout and structural requirements for the multi-pollutant control system installation at AES Greenidge. Per the discussion in Section 4.2.3, a strength of the multi-pollutant control system is the relatively small amount of space required for its installation. As shown in drawing No. 100276-GA200-01 in Appendix B, for the AES Greenidge Unit 4 installation, most of the components of the multipollutant control system are located outdoors in an approximately $125^{\prime} \times 150^{\prime}$ plot just west of the boiler building. Figure 28 shows a photograph of this area taken prior to the start of construction. The area is constrained by the boiler building to the east, by a railroad bridge to the north, and by embankments to the south and west. The plant's existing pyrites silo and hydrogen dock are also visible in the photo. The system components installed in this area include the urea storage tank, urea HFD module, activated carbon injection system, Turbosorp ${ }^{\circledR}$ scrubber, process water system, lime storage, hydration, classification, and injection system, baghouse, ash recirculation system, and booster fan. Hence, only about 0.43 acre of land area was required outside of the boiler building to accommodate the multi-pollutant control system for the 107-MWe AES Greenidge Unit 4 installation.

The relatively small acreage required for the Greenidge multi-pollutant control system results from a combination of its use of a single-layer, in-duct SCR reactor rather than a full-size, standalone SCR reactor, and its use of a vertically-tiered arrangement for the Turbosorp ${ }^{\circledR}$ system, baghouse, and lime storage and hydration system to promote gravity-assisted transport of solids (e.g., for recycling baghouse solids to the Turbosorp ${ }^{\circledR}$ vessel, transporting solids from the recycle loop to the ash disposal silos, and transporting solids within the lime hydration process). This is evident in drawings 100276-GA100-01, 100276-GA101-01, 100-276-ISO100-01, and 100276-ISO101-01 in Appendix B, as well as in the photographs presented in Figures 17 and 19. As discussed in Section 6.2.2, the SCR system for AES Greenidge Unit 4 was designed to fit within the existing boiler building in a space with horizontal dimensions of $52^{\prime} \times 27^{\prime} 2^{\prime \prime}$ and a vertical height of $23^{\prime} 1 / 2$ ". The only other space required in the boiler building is for six SNCR dilution and distribution modules and for electrical equipment, which can be flexibly located, as well as for the catalyst loading facility and the retract mechanisms for the MNLs. The baghouse is elevated to allow for solids recirculation via the air slides; for the AES Greenidge Unit 4 installation, the bottoms of the baghouse hoppers are about 75' above ground level and the top of the baghouse penthouse is about 150' above ground level. 


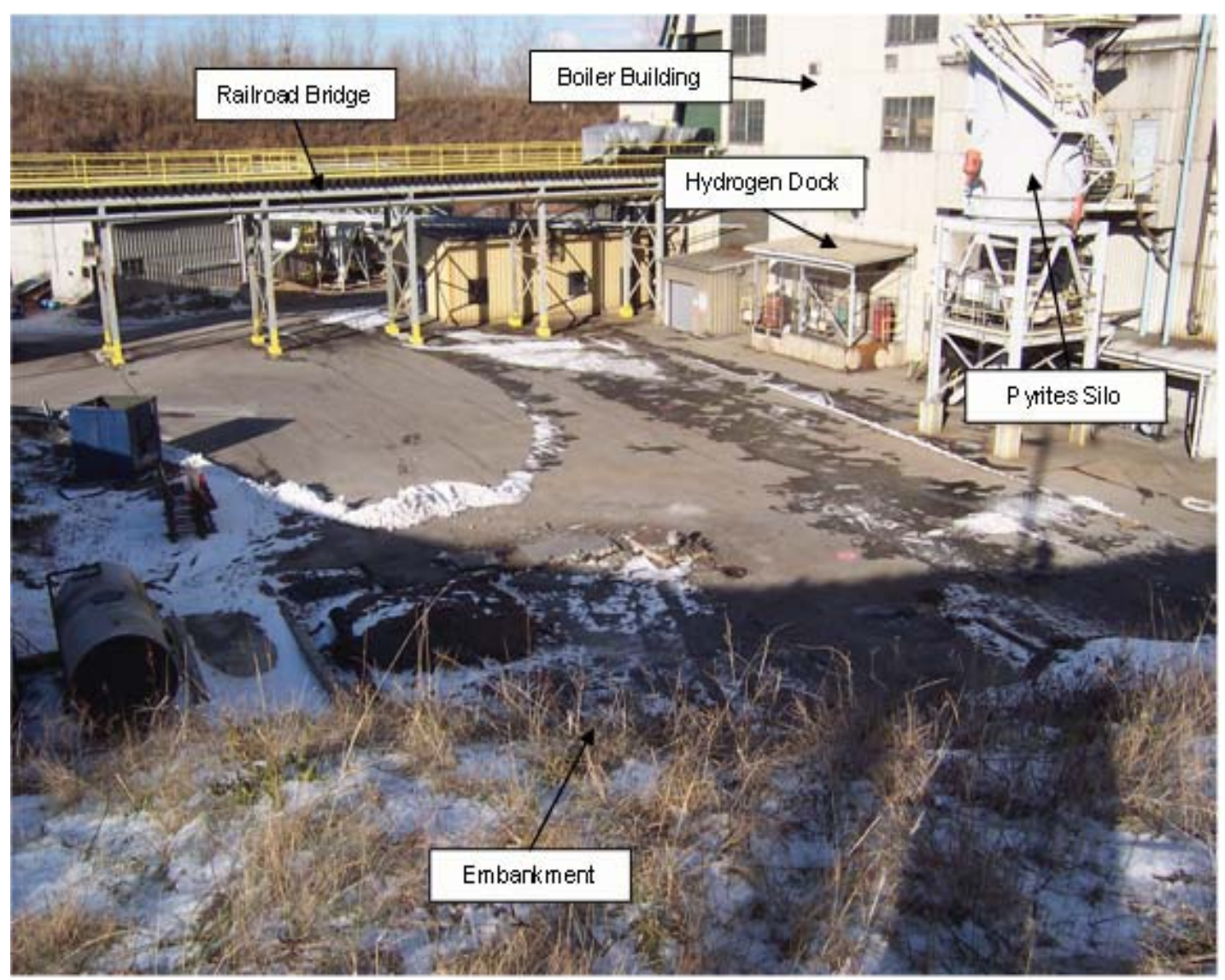

Figure 28. Photograph taken prior to the start of construction of the site for the outdoor portion of the multi-pollutant control system, as viewed from the southwest.

Equipment arrangement requirements dictated, to a great extent, the structural design for the multi-pollutant control system. Outside of the plant, foundations and structural steel were required for each of three primary support structures:

- Lime storage and hydration system support structure

- Turbosorp $^{\circledR}$ reactor support structure

- Baghouse support structure

These support structures were designed in accordance with all applicable codes and incorporate all necessary handrails, access stairs, ladders, floors, and platforms. The Turbosorp ${ }^{\circledR}$ reactor and baghouse support structures must be located adjacent to one another to facilitate solid product recycle via the air slides. Process constraints on the location of the lime storage and hydration system structure are less stringent; however, for the AES Greenidge retrofit, the lime structure was able to be situated immediately beside the Turbosorp ${ }^{\circledR}$ structure, $^{2}$ an ideal location for simplifying transport of the hydrated lime to the Turbosorp ${ }^{\circledR}$ vessel for injection.

Inside the plant, several new horizontal steel beams were required to construct a frame for supporting the SCR reactor. The frame was tied into the plant's existing support columns, which were reinforced as needed to accommodate the added load. A new access platform was also provided to facilitate catalyst loading and unloading. No new foundations were required for the SCR installation. 
A detailed discussion of the civil engineering design for the multi-pollutant control system installation at AES Greenidge is beyond the scope of this report. However, the design included the following:

- Site survey

- Geotechnical study

- Civil engineering demolition design, including plans for the removal and relocation of existing equipment and utilities

- Civil engineering site design, including site clearing, grubbing, grading, and drainage plans

- Erosion and sedimentation control design

- Underground utilities design

- Landscaping design

- Foundation engineering, including shallow foundations, slabs, or pads for equipment and components (e.g., water tank, water pumps, urea tank, HFD module, activated carbon silo, duct supports, piping, cable tray, stairway footings, etc.)

- Protective coatings for exposed structures

A new paved unloading facility was also provided south of the baghouse to accommodate receipt of urea and quicklime deliveries.

\subsubsection{Instruments and Controls}

Process control philosophies for major components of the multi-pollutant control process were discussed in Section 6.2. The multi-pollutant control system design included all field instrumentation required for operation and control of the system. Much of this instrumentation is shown in the P\&IDs that are included in Appendix B. In addition to standard temperature, pressure, level, and flow sensors and various control valves, this instrumentation includes the optical pyrometer required for control of the SNCR system (Section 6.2.1) and the dilution extractive-type $\mathrm{SO}_{2}$ analyzer that is used to measure absorber inlet $\mathrm{SO}_{2}$ concentrations for control of the Turbosorp ${ }^{\circledR}$ system (Section 6.2.4).

The SNCR system, lime hydration system, activated carbon injection system, and baghouse are each controlled locally by programmable logic controllers with local operator interface units. Input/output is hardwired to local junction boxes for interface with the plant's distributed control system. As discussed in Section 5, AES Greenidge upgraded its Unit 4 DCS simultaneously to, but outside of the scope of, the multi-pollutant control project. The DCS is an Emerson Ovation $^{\circledR}$ system. All other components of the multi-pollutant control system (i.e., sonic horns, Turbosorp ${ }^{\circledR}$ system, ash recirculation system, booster fan) are controlled through the DCS.

\subsubsection{Electrical}

The electrical design provided for tie-in of the new equipment to the plant's existing 2400V electrical system and included a new $2400 \mathrm{~V}$ motor control center (MCC), 2400V/480V transformer, and 480V MCC. $2400 \mathrm{VAC}$ power was required for the booster fan motor, and 480 VAC power was required for the SNCR system pumps, catalyst hoist, activated carbon blower, 
water booster pumps, hydrator, bucket elevator, air classifier, ball mill, hydrated lime blower, baghouse bridge crane, baghouse hopper heater panel, air slide blowers, etc. 120 VAC electrical connections were also required for instruments and controls, lighting, pipe heat tracing, etc.

Power is fed to the new $2400 \mathrm{~V} \mathrm{MCC}$ and to the new $2400 \mathrm{~V} / 480 \mathrm{~V}$ transformer and $480 \mathrm{~V}$ MCC from two existing 1200A breakers that previously were used for two of the plant's coal pulverizers. The new $2400 \mathrm{~V}$ MCC includes starters for these pulverizers as well as for the booster fan motor. The new 480V MCC includes starters for all other motors associated with the multi-pollutant control system.

The total estimated parasitic power requirement for full-load operation of the multi-pollutant control system at AES Greenidge Unit 4 is about $1875 \mathrm{~kW}$ (about $1.8 \%$ of the unit's net electrical output). The majority of this auxiliary load arises from the approximately $1475 \mathrm{~kW}$ net increase in fan power brought about by installation of the booster fan to supplement the unit's existing ID fans in overcoming the pressure drop created by installation of the multi-pollutant control system.

\subsubsection{Other Utilities}

Water and compressed air requirements for the multi-pollutant control system are summarized in drawing No. 100276-SK4900099 in Appendix B.

The multi-pollutant control system requires water for the SNCR system, hydrator, and Turbosorp ${ }^{\circledR}$ water injection system, as well as for cooling various pieces of equipment. Table 7 summarizes the water requirements for operation of the system. With the exception of the condensate that is used for MNL cooling, plant service water (i.e., filtered water obtained from Seneca Lake) is the source of all water consumed by the system. The plant's existing service water system had sufficient capacity to meet the demands of the multi-pollutant control system.

Table 7. Water requirements for operation of the multi-pollutant control system at AES Greenidge.

\begin{tabular}{|l|c|c|}
\hline Operation & Source of Water & Required Flow Rate (gpm) $^{\text {a }}$ \\
\hline Urea Dilution & Plant Service Water & 32 \\
\hline MNL Cooling & Condensate & 60 \\
\hline Turbosorp ${ }^{\circledR}$ Water Injection & Plant Service Water & 89 \\
\hline Lime Hydration & Plant Service Water & 8 \\
\hline Ball Mill Cooling & Plant Service Water & 3 \\
\hline Booster Fan Cooling & Plant Service Water & 16 \\
\hline
\end{tabular}

${ }^{a}$ At full-load operation.

Compressed air is also required throughout the multi-pollutant control system for actuators, as well as for various process operations, including:

- Urea atomization

- Sonic horns

- Baghouse pulsejet cleaning

Most of the compressed air demand results from baghouse cleaning. The plant's existing compressed air system originally was expected to afford sufficient capacity for satisfying the compressed air requirements added by the multi-pollutant control system. However, the 
compressed air demand for baghouse cleaning was greater than anticipated, forcing the plant to install additional compressor capacity (outside of the scope of the DOE project). The baghouse requires about $600 \mathrm{scfm}$ of compressed air during normal operation. During start-up, however, the compressed air demand can be as large as $1200 \mathrm{scfm}$.

\subsubsection{Byproducts}

The major byproduct generated by the multi-pollutant control system is the solid product resulting from the Turbosorp ${ }^{\circledR}$ process. As shown in drawing No. 100276-SK081706-05 in Appendix $B$, the solid reaction products and unreacted reagent resulting from the Turbosorp ${ }^{\circledR}$ system increase the amount of solids sent from the plant's particulate control device for disposal by a factor of about 3.8 , adding about $13,174 \mathrm{lb} / \mathrm{h}$ to the approximately $4,676 \mathrm{lb} / \mathrm{h}$ of fly ash produced when firing the design fuel at full load. (The mass added by activated carbon injection is very small, accounting in the original design for $\leq 89 \mathrm{lb} / \mathrm{h}$, or $\leq 0.7 \%$, of the $13,174 \mathrm{lb} / \mathrm{h}$ of new solid byproduct. No activated carbon was used in practice at AES Greenidge Unit 4). AES Greenidge modified its pneumatic ash handling system outside of the scope of the DOE-funded project to provide sufficient capacity (including a reasonable margin) for accommodating the extra solids produced by the multi-pollutant control process. The projected composition of the combined solid product is summarized in Table 8.

Table 8. Projected composition of the fly ash / scrubber byproduct discharged from the baghouse.

\begin{tabular}{|l|c|}
\hline Component & $\begin{array}{c}\text { Weight } \\
\text { Percent }\end{array}$ \\
\hline $\mathrm{CaSO}{ }_{3} \cdot 1 / 2 \mathrm{H}_{2} \mathrm{O}$ & 34.1 \\
\hline $\mathrm{Fly} \mathrm{Ash}$ & 26.2 \\
\hline $\mathrm{CaCO}$ & 13.3 \\
\hline $\mathrm{CaSO}_{4} \cdot 1 / 2 \mathrm{H}_{2} \mathrm{O}$ & 12.8 \\
\hline $\mathrm{Ca}(\mathrm{OH})_{2}$ & 9.5 \\
\hline $\mathrm{CaCl}$ & 1.0 \\
\hline $\mathrm{H}_{2} \mathrm{O}$ & 1.0 \\
\hline $\mathrm{CaO}$ & 0.3 \\
\hline $\mathrm{CaF}$ & 0.2 \\
\hline Other Solids & 1.6 \\
\hline
\end{tabular}

AES Greenidge landfills this byproduct in its Lockwood Landfill, located near the plant. However, as discussed further in Section 10.4, the composition of the material, which resembles spray dryer byproduct in that it is dry, has a moderate fly ash content, and contains unreacted hydrated lime $\left(\mathrm{Ca}(\mathrm{OH})_{2}\right)$, makes it a candidate for use as a structural or flowable fill, as a neutralizing agent, or as a feedstock for manufactured aggregate production. This may help to improve process economics in certain installations of the multi-pollutant control technology (i.e., if the plant is situated geographically near an application that can utilize the byproduct).

Gaseous and liquid waste streams from the multi-pollutant process are minimal. The only continuous sources of wastewater are the cooling water stream discharges from the ball mill and booster fan, which produce a combined $19 \mathrm{gpm}$ (maximum) of wastewater that is sent to drain. As shown in Table 6, the multi-pollutant control process is designed to reduce air emissions of a number of pollutants from AES Greenidge Unit 4. The hybrid SNCR/SCR process produces ammonia; however, the design limits emissions to $\leq 2$ ppmvd at all operating 
loads. Any $\mathrm{SO}_{3}$ formed from oxidation of $\mathrm{SO}_{2}$ across the $\mathrm{SCR}$ catalyst is removed from the flue gas in the Turbosorp ${ }^{\circledR}$ system. Also, although the Turbosorp ${ }^{\circledR}$ process and activated carbon injection increase the solids loading of the flue gas, the baghouse is expected to reduce the unit's overall particulate matter emission rate. The lime hydration system generates a new gaseous exhaust stream containing dust, steam, and lime; however, as discussed in Section 6.2.6, this stream is sent to the Turbosorp ${ }^{\circledR}$ scrubber and baghouse for cleaning, and it is not expected to have a measurable impact on air emissions.

\subsubsection{Out-of-Scope Modifications}

As discussed in Section 5, AES Greenidge undertook a number of projects outside of the scope of the DOE-funded multi-pollutant control project to help ensure a 20-30 year life extension for Unit 4. Several of these projects, although not included in the scope of the project covered by this report, nevertheless warrant coverage here because they were necessary to allow for installation of the multi-pollutant control system or to enable it to perform more optimally. These projects include the asbestos insulation removal discussed in Section 6.3.1, the DCS upgrade discussed in Section 6.3.3, the compressed air capacity expansion discussed in Section 6.3.5, and the ash handling system modifications discussed in Section 6.3.6, as well as combustion modifications and air preheater basket modifications, which are described in more detail below.

\subsubsection{Combustion Modifications}

The combustion modifications at AES Greenidge Unit 4 were designed to complement and enhance the performance of the hybrid SNCR/SCR system. Per the discussion in Section 6.1, the combustion modifications play an integral role in achieving the targeted $\mathrm{NO}_{\mathrm{x}}$ emission rate of $\leq 0.10 \mathrm{lb} / \mathrm{mmBtu}$, as they are expected to reduce $\mathrm{NO}_{\mathrm{x}}$ by $\sim 17 \%$ (to $\sim 0.25 \mathrm{lb} / \mathrm{mmBtu}$ ) from the plant's baseline $\mathrm{NO}_{x}$ emission rate of $\sim 0.30 \mathrm{lb} / \mathrm{mmBtu}$. Moreover, the combustion modifications are designed to enable the SNCR system to operate more optimally by affording more stable $\mathrm{NO}_{x}$ concentrations in the furnace and reducing $\mathrm{CO}$ concentrations in the furnace. As discussed in Section 4.3.5, CO concentrations significantly impact SNCR chemistry.

The combustion modifications include modified burner assemblies and modifications to the Boiler 6 SOFA system to improve furnace air staging. The boiler's existing coal nozzles, combustion air nozzles, and overfire air nozzles were replaced. The modified replacement combustion air nozzle tips provide an arrangement that offers internal main windbox air staging and maintains air penetration into the furnace when the SOFA ports are in use. Internal staging is accomplished by redesign of the air nozzle tips to increase the separation of the air streams around the fuel streams entering the boiler from each burner windbox. In addition, the design includes modified windbox compartment dampers to improve the control of secondary air flow. The SOFA system was modified to provide improved jet penetration, and it features nozzles with both tilt and yaw adjustment capability, which enable better mixing in the upper furnace and reduced $\mathrm{CO}$ concentrations during staged, low- $\mathrm{NO}_{x}$ firing, thereby creating more ideal conditions for SNCR. 


\subsubsection{Air Preheater Basket Modifications}

As discussed in Section 6.2.2, the in-duct SCR that was installed as part of the Greenidge multipollutant control system is designed to limit ammonia slip to $<2$ ppmvd (corrected to $3 \% \mathrm{O}_{2}$ ) and $\mathrm{SO}_{2}$-to- $\mathrm{SO}_{3}$ conversion to $<1.0 \%$ in order to minimize the potential for ammonium bisulfate fouling in the unit's air preheaters. In spite of these stringent performance targets, there remains some risk of ammonium bisulfate fouling, especially because the unit fires mid-to-high sulfur coals and because the multi-pollutant control system relies on a relatively shallow, single catalyst layer to consume almost all ammonia slipped from the SNCR. This risk increases as the catalyst ages and its activity decreases.

Prior to the multi-pollutant control project, the two Unit 4 air preheaters employed a three-layer basket configuration, consisting of hot end, intermediate, and cold end layers. This configuration is susceptible to ammonium bisulfate fouling, because there is a possibility that ammonium bisulfate deposits will bridge across the cold end and intermediate layers, rather than being limited to the cold end layer. Bridging of the deposits across layers decreases the effectiveness of on-line cleaning and enhances the rate of ammonium bisulfate accumulation.

As a result, AES Greenidge decided to replace and modify the configuration of the Unit 4 air preheater baskets while the multi-pollutant control system was being installed. The modifications entailed replacing the three-layer basket arrangement with a two-layer arrangement. The existing layer of cold end elements was replaced with a layer of deeper, enamel-coated, closed channel elements, and the existing layers of intermediate and hot end elements were replaced with a single layer of corrosion-resistant, low-alloy steel elements. This reconfiguration helps to ensure that any ammonium bisulfate formed is condensed on the coldend elements, which can be effectively cleaned via soot blowing. The enamel coating on these elements helps to prevent adhesion of ammonium bisulfate deposits, facilitate removal of these deposits, and resist corrosion. The modifications also included removal of the cold end element support screen to allow for more effective soot blowing.

\section{Permitting}

Several permits and permit modifications were required to allow the construction and operation of the multi-pollutant control system at AES Greenidge Unit 4. For this project, permit requirements were driven in part by the consent decree between AES Greenidge and the State of New York, as well as by local, state, and federal requirements. AES Greenidge oversaw the project's permitting tasks.

Table 9 summarizes the permits required for the project. All permits needed for construction of the multi-pollutant control system were obtained in 2005. AES Greenidge obtained a building permit for the multi-pollutant control facility from the Town of Torrey on August 10, 2005, and worked with the New York State Department of Environmental Conservation (DEC) to determine that a Storm Water Discharge Permit was not required for construction of the facility, given the size of the construction site. AES Greenidge's consent decree with the State of New York authorized them to proceed with construction and operation of the multi-pollutant control facility without a pre-construction permit from the State or any changes to their existing Title $\vee$ permit.

The Title $\mathrm{V}$ permit was modified as part of its regularly scheduled renewal process, however, in order to reflect the emission requirements set forth in the consent decree. The plant's existing 
Title $V$ permit expired on September 7, 2006, and it was renewed during the project period. AES Greenidge received a Notice of Complete Application for its Title V permit from the New York State DEC during the second calendar quarter of 2007, and the permit was issued in final form by the DEC on November 5, 2007. This newly renewed permit is valid through November 4, 2012. On February 28, 2008, the DEC approved the curve that establishes the permitted $\mathrm{NO}_{x}$ emission rate for AES Greenidge Unit 4 as a function of unit load.

Table 9. Permits required for construction and operation of the multi-pollutant control system at AES Greenidge Unit 4.

\begin{tabular}{|l|l|l|l|}
\hline Permit / Approval & $\begin{array}{l}\text { Approving } \\
\text { Authority }\end{array}$ & Responsible Party & Status \\
\hline Building Permit & $\begin{array}{l}\text { Town of } \\
\text { Torrey }\end{array}$ & AES Greenidge & Permit issued 8/10/05. \\
\hline $\begin{array}{l}\text { Consent Decree } \\
\text { Storm Water Discharge } \\
\text { Permit for Construction }\end{array}$ & $\begin{array}{l}\text { Sew York } \\
\text { State DEC }\end{array}$ & $\begin{array}{l}\text { Babcock Power } \\
\text { Environmental Inc. }\end{array}$ & $\begin{array}{l}\text { Not required because of size } \\
\text { of construction site. }\end{array}$ \\
\hline $\begin{array}{l}\text { Applicable Permits for } \\
\text { Material Transportation }\end{array}$ & Various & $\begin{array}{l}\text { Babcock Power } \\
\text { Environmental Inc. }\end{array}$ & Obtained as required. \\
\hline $\begin{array}{l}\text { Air Title V Facility (8-5763- } \\
\text { 00004/00013) }\end{array}$ & $\begin{array}{l}\text { New York } \\
\text { State DEC }\end{array}$ & AES Greenidge & Permit renewed 11/5/07. \\
\hline $\begin{array}{l}\text { SPDES NY0001325 - AES } \\
\text { Greenidge LLC }\end{array}$ & $\begin{array}{l}\text { New York } \\
\text { State DEC }\end{array}$ & AES Greenidge & $\begin{array}{l}\text { Permit expired 5/1/07. } \\
\text { submitted. }\end{array}$ \\
\hline $\begin{array}{l}\text { SPDES NY0107069 renewal } \\
\text { Lockwood Ash Disposal Site }\end{array}$ & $\begin{array}{l}\text { New York } \\
\text { State DEC }\end{array}$ & AES Greenidge & $\begin{array}{l}\text { Permit expires 11/30/10. } \\
\text { Application for renewal } \\
\text { submitted. }\end{array}$ \\
\hline $\begin{array}{l}\text { Solid Waste (8-5736- } \\
\text { 00005/00003) }\end{array}$ & $\begin{array}{l}\text { New York } \\
\text { State DEC }\end{array}$ & AES Greenidge & Permit renewed 9/5/08. \\
\hline
\end{tabular}

AES Greenidge also worked throughout the project period to complete all required renewals to the State Pollutant Discharge Elimination System (SPDES) permits for the plant and Lockwood Landfill (where AES Greenidge disposes its ash) and to the solid waste permit for the Lockwood Landfill. Any relevant modifications resulting from the installation of the multi-pollutant control system were incorporated during the renewal process. The SPDES permit for the AES Greenidge plant expired in May 2007; AES Greenidge submitted a Request for Information application to the New York State DEC for that permit in 2007 and is operating under an "administratively renewed" permit while the renewal process is completed. The solid waste permit for the Lockwood Landfill expired on March 12, 2007, and a renewed permit was issued on September 5, 2008. (This permit is valid through September 4, 2018). The existing SPDES permit for the Lockwood Landfill expires in November 2010, and AES Greenidge has applied for renewal.

In addition to the permitting requirements discussed above, the DOE cooperative agreement required that the project comply with the National Environmental Policy Act. CONSOL prepared an Environmental Information Volume for the project and submitted it to DOE on October 27, 2003. DOE prepared an Environmental Assessment (DOE/EA-1493) and issued a Finding of No Significant Impact for the project on December 3, 2004. This completed the NEPA process for the project. 


\section{Construction, Start-Up, and Commissioning}

As shown in Table 1, Babcock Power Environmental Inc. was responsible for the project's construction, start-up, and commissioning tasks. Much of the construction work was performed by Nicholson and Hall Corporation (Buffalo, New York), the project's mechanical contractor, and by O'Connell Electric Co. (Victor, New York), the project's electrical contractor.

The entire multi-pollutant control system was constructed in less than one year. Groundbreaking at AES Greenidge occurred in late December 2005, and the tie-in outage was completed on November 18, 2006. Much of the construction was able to be completed while Unit 4 was still online, such that the tie-in outage lasted for only about 7 weeks. As discussed in Section 3.1, the project's construction activities were completed on schedule. Start-up and commissioning of the system then took approximately 4.5 additional months to complete.

Per the discussion in Section 6.3.2, the multi-pollutant control system required only 0.43 acre of land area was outside of the boiler building to accommodate the Turbosorp ${ }^{\circledR}$ system (including all ancillary equipment), the booster fan, and the urea storage tank and HFD module, as well as a small amount of space inside the boiler building for the in-duct SCR reactor, SNCR skids and MNLs, and electrical equipment. During the construction period, additional space was needed for equipment lay-down, construction trailers, and cranes. Prior to the start of construction, Nicholson and Hall Corporation developed a site layout plan for the construction period. Two lots located west of the boiler building, adjacent to the construction site, were designated as laydown areas. These had a combined area of 0.55 acres. In addition, space was designated for two cranes (one to the north and one to the south of the site), as well as six office trailers, two tool trailers, and one toilet trailer.

The project schedule in Appendix A indicates the general progression of construction, start-up, and commissioning activities at AES Greenidge. These activities are further described in the Project Log, which is included as Appendix D (see the entries for January 2002 through March 2007). The project's construction, start-up, and commissioning activities occurred during three main stages: the pre-outage construction stage, the tie-in outage stage, and the start-up and commissioning stage. These stages are discussed in more detail below.

\subsection{Pre-Outage Construction Activities}

A large portion of the multi-pollutant control system was able to be constructed without interrupting operation of AES Greenidge Unit 4. Hence, a substantial amount of construction was completed prior to the start of the fall tie-in outage in September 2007. Construction activities that were wholly or partially completed prior to the outage included:

- Site excavation outside of the boiler building

- Construction of foundations and structural steel for the Turbosorp ${ }^{\circledR}$ reactor, baghouse, and lime storage and hydration system support structures

- Construction of ductwork foundations and piers

- Installation of the Turbosorp ${ }^{\circledR}$ absorber vessel (excluding tie-in to the air heater outlet)

- Installation of the baghouse

- Installation of the ash recirculation system

- Installation of the lime storage, hydration, and injection system 
- Installation of the process water system

- Installation of the activated carbon injection silo (excluding the injection pipe)

- Installation of the booster fan (excluding tie-in to the existing ID fans)

- Installation of the urea storage tank, HFD module, skid-mounted modules, and piping for the SNCR system (excluding penetrations into the boiler)

- Installation of grating and handrails in the Turbosorp ${ }^{\circledR}$, baghouse, and lime storage and hydration system support structures

- Installation of ductwork interconnecting new pieces of equipment (excluding tie-in ductwork)

- Installation of insulation, lagging, and cladding on outdoor pieces of equipment

- Assembly of the $2300 \mathrm{~V} / 480 \mathrm{~V}$ transformer and the $480 \mathrm{~V}$ and $2300 \mathrm{~V}$ motor control centers

- Installation of conduit, junction boxes, cable tray, and lighting

In October 2005, CONSOL received pre-award authorization from DOE to mobilize for construction and begin civil construction work. The civil subcontractor began mobilizing in late December 2007, and trenching and excavation of the site was completed by February 2006. DOE further authorized CONSOL in January 2006 to proceed with certain process system construction activities. Process system construction began with the installation of structural steel for the baghouse in March 2006. Figure 29 shows the progress that had been made as of early April 2006.

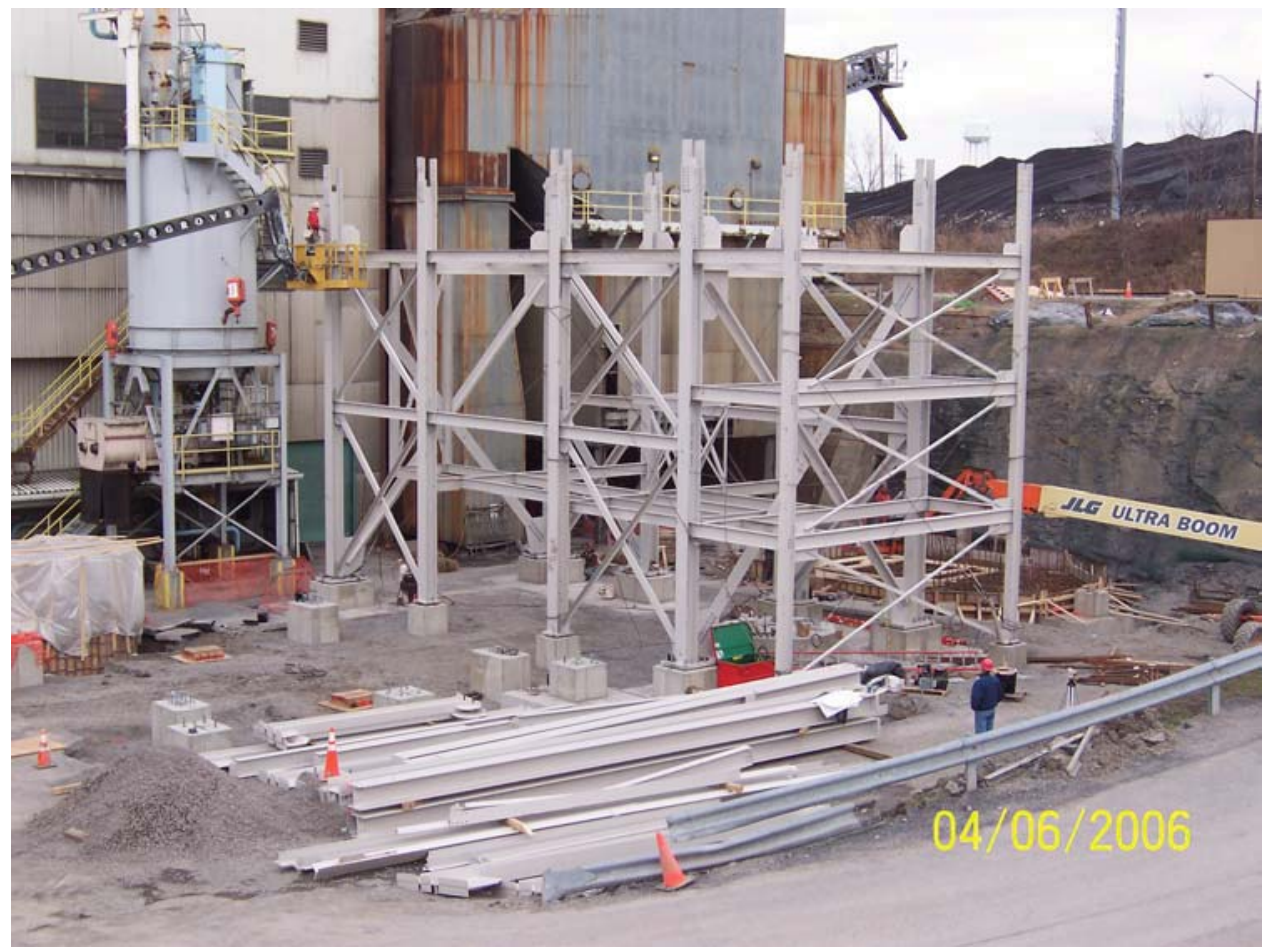

Figure 29. Photograph showing structural steel being erected for the baghouse support structure on April 6, 2006.

Much of the pre-outage construction work centered on the erection of the Turbosorp ${ }^{\circledR}$ system and its ancillary equipment. Figures 30-35 illustrate the progression of major construction activities related to the Turbosorp ${ }^{\circledR}$ system. Sections of the Turbosorp ${ }^{\circledR}$ absorber vessel and baghouse modules were delivered to site in April 2006 and partially assembled in the lay-down 
area (Figure 30). The baghouse modules and hoppers had been raised into place by the end of May 2006. The structural steel frame for the Turbosorp ${ }^{\circledR}$ was also erected in May, and the Turbosorp $^{\circledR}$ vessel was raised into place and welded in June (with the exception of the roof, which was installed during the first week of July, after work on the inside of the vessel was complete). Figure 31 shows one of the baghouse modules being set into place in mid-May. Figure 32 shows the assembly of the Turbosorp ${ }^{\circledR}$ inlet duct and venturi in early June, and Figure 33 shows the Turbosorp ${ }^{\circledR}$ absorber vessel roof being lifted into place in early July.

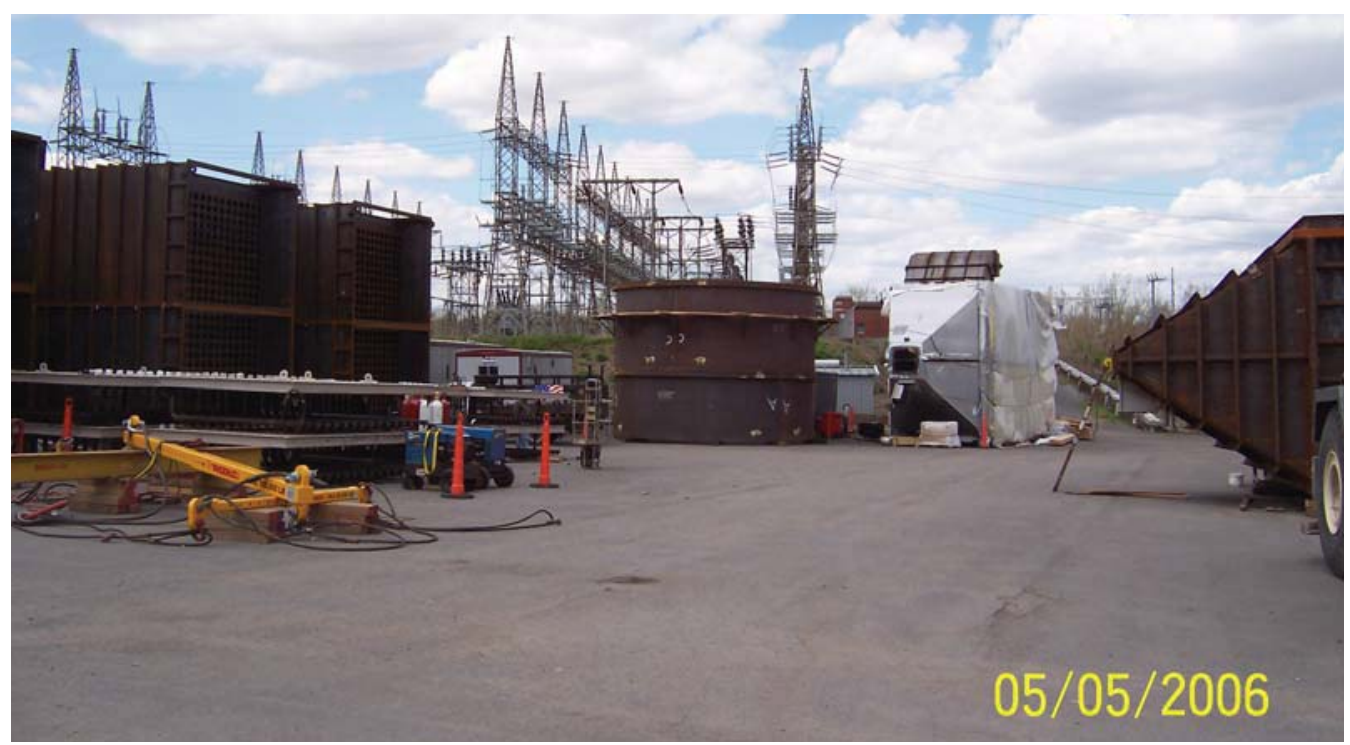

Figure 30. Photograph showing several baghouse modules and a partially assembled Turbosorp $^{\circledR}$ absorber section in the lay-down area in early May 2006.

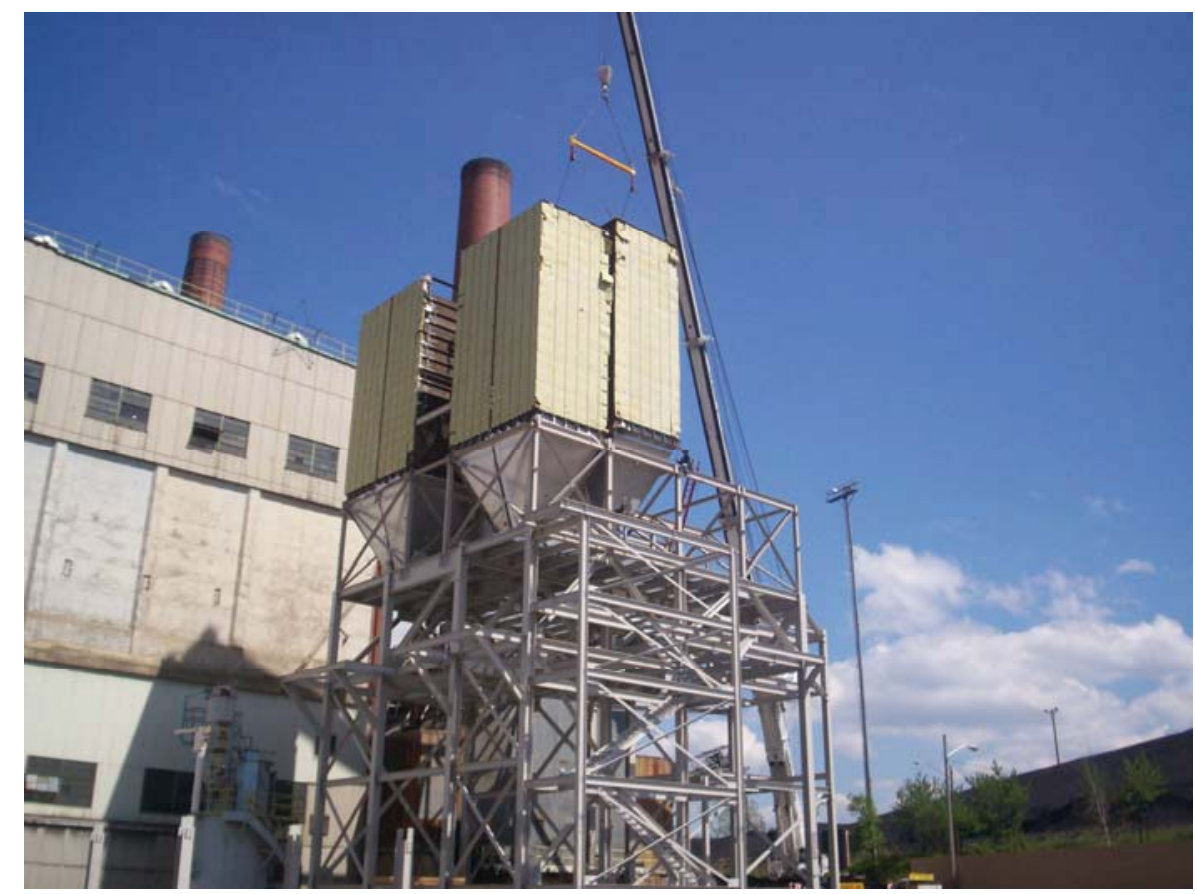

Figure 31. Photograph showing one of the baghouse modules being lifted into place in mid-May 2006. 
The water injection pump skid for the process water system was set in place in mid-August 2006, and both air slides for the ash recirculation system were lifted into place between August 18 and August 25. Figure 34 presents a photograph showing the installation of one of the air slides. Work on installing the penthouse atop the baghouse and on insulating, cladding, siding, and roofing the absorber vessel and baghouse continued into September 2006. Also, during September, contractors finished installing the approximately 3,200 baghouse bags and cages, and they installed the poppet valve actuators and cleaning air headers in the baghouse. The baghouse outlet duct was lifted into place during the week ending September 22.

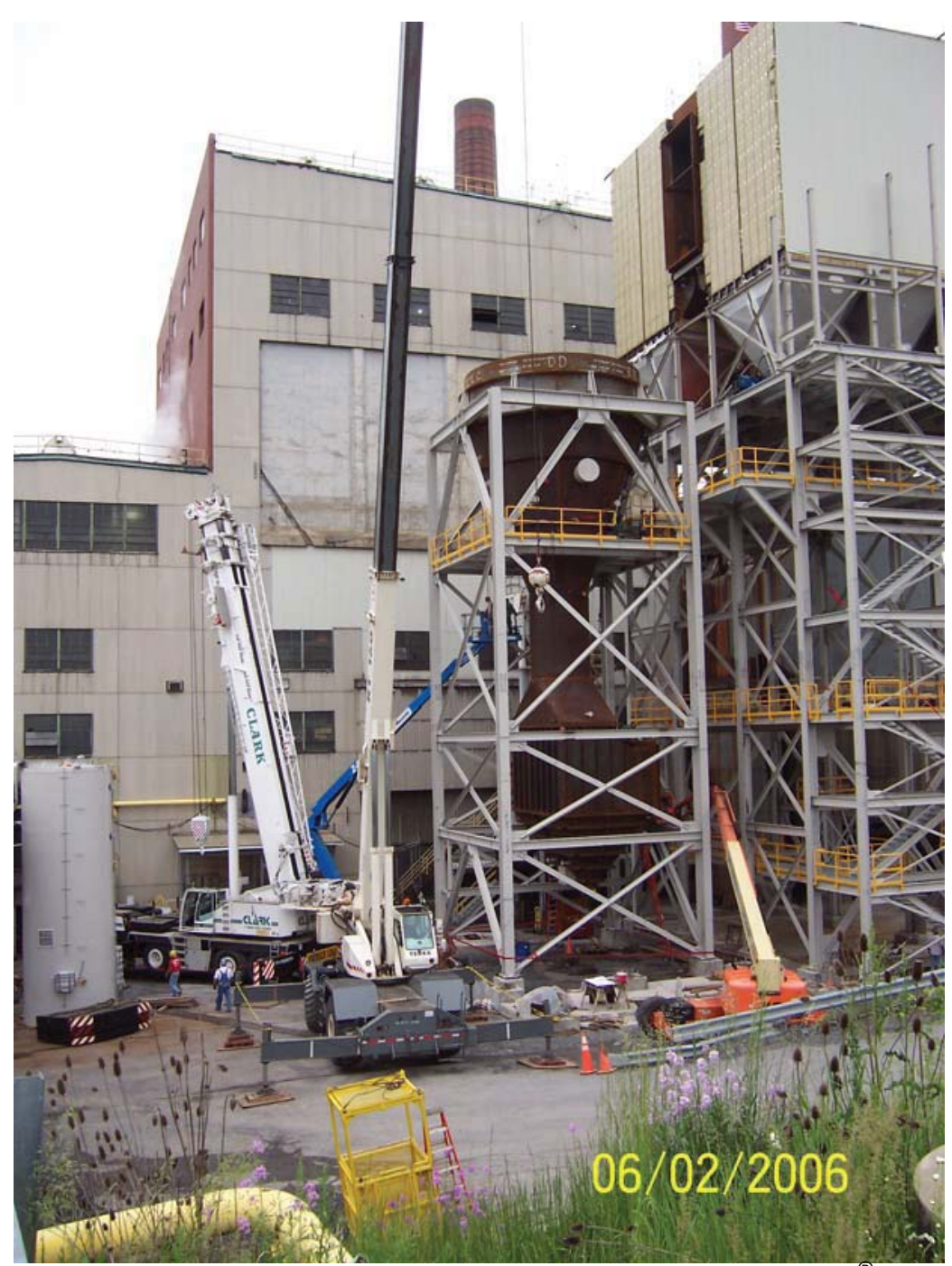

Figure 32. Photograph showing assembly of the Turbosorp ${ }^{\circledR}$ inlet and venturi sections in early June 2006. 


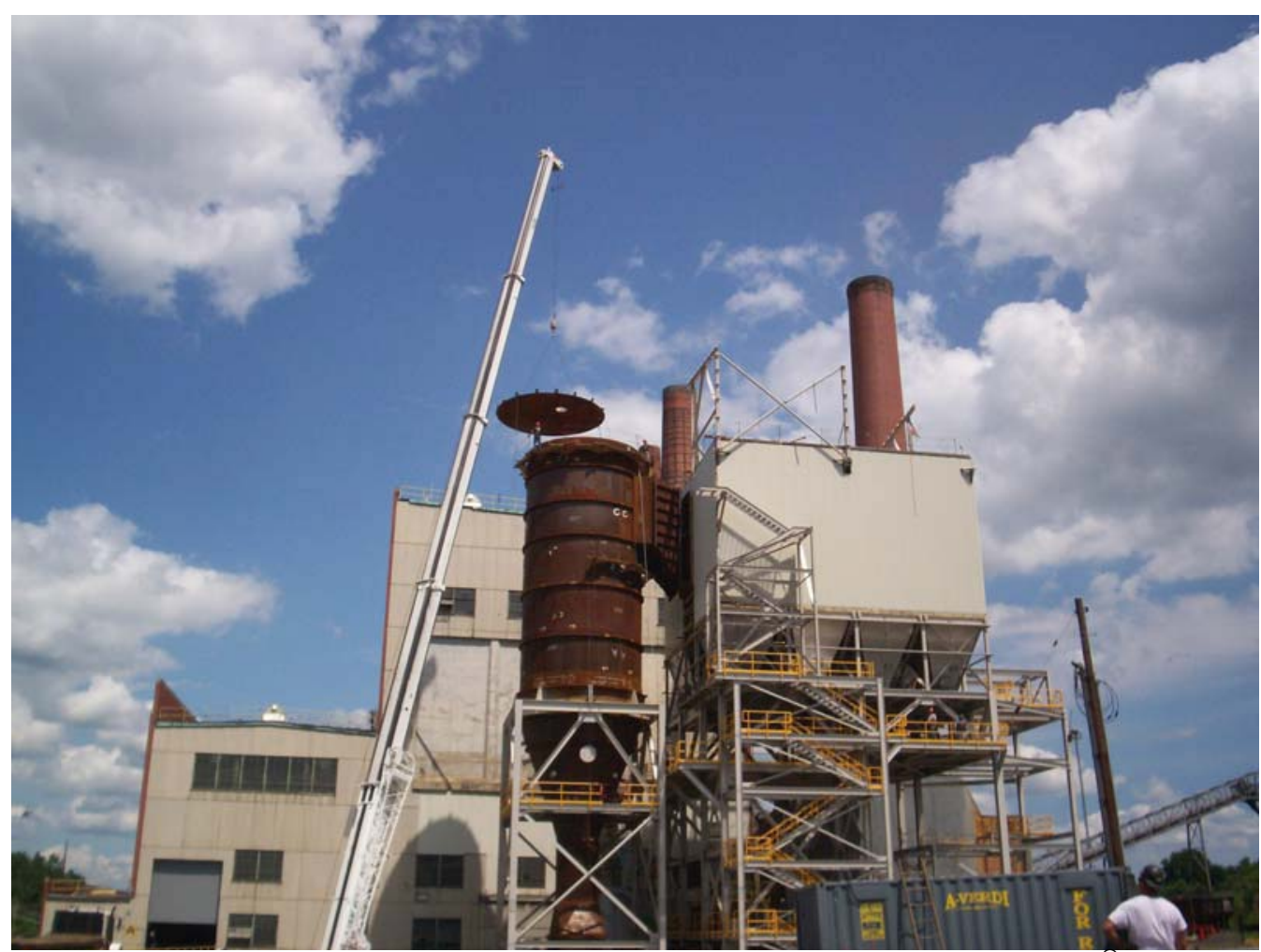

Figure 33. Photograph showing installation of the roof of the Turbosorp ${ }^{\circledR}$ absorber during the first week of July 2006. The first pieces of structural steel for the baghouse penthouse are also visible.

The lime storage, hydration, and injection system was constructed beside the Turbosorp ${ }^{\circledR}$ absorber vessel. First-tier structural steel for the system was erected in July 2006, and the hydrated lime silo and ball mill were set in place during that month. Second-tier steel erection for the system continued into August. The lime hydrator was lifted into place during the week ending August 4, and the quicklime silo was lifted into place on September 22, as shown in Figure 35. This was the last major component of the outdoor portion of the multi-pollutant control system to be set in place. Other work in the lime hydration structure during September included the installation of auxiliary equipment (e.g., bucket elevator, screw conveyer, etc.), grating, and handrails.

The number of contractors on site at AES Greenidge increased from about 35-40 in April 2006 to $160-170$ by the end of September 2006. (These numbers include some contractors who were performing work outside of the DOE scope on the projects described at the end of Section 5). Construction activities intensified significantly in August and September. In addition to the work being performed on the Turbosorp ${ }^{\circledR}$ system, lime hydration system, and baghouse, contractors worked throughout August and early September on assembling the booster fan for the multi-pollutant control system. In addition, several pre-outage construction tasks for the SNCR system were completed. Structural steel was installed for the six SNCR skid-mounted modules, and these modules were set in place in the boiler building. Installation of piping for the SNCR system (e.g., stainless steel tubing from the distribution modules, condensate cooling water line to the multiple nozzle lances) also commenced. Outside of the boiler building, the urea storage tank and HFD module were set in place during late August and early September. 


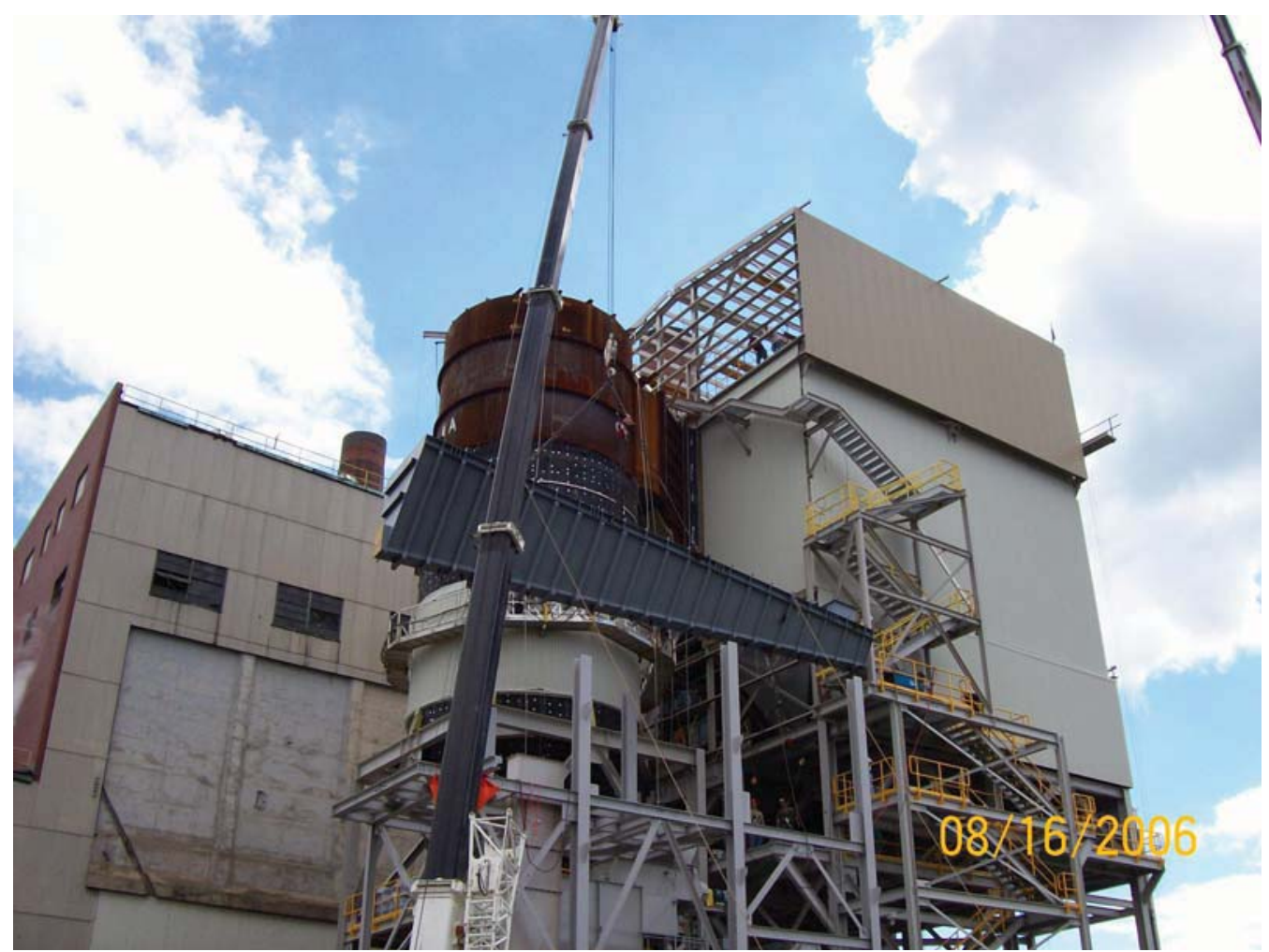

Figure 34. Photograph showing one of the air slides being lifted into place on August 16, 2006.

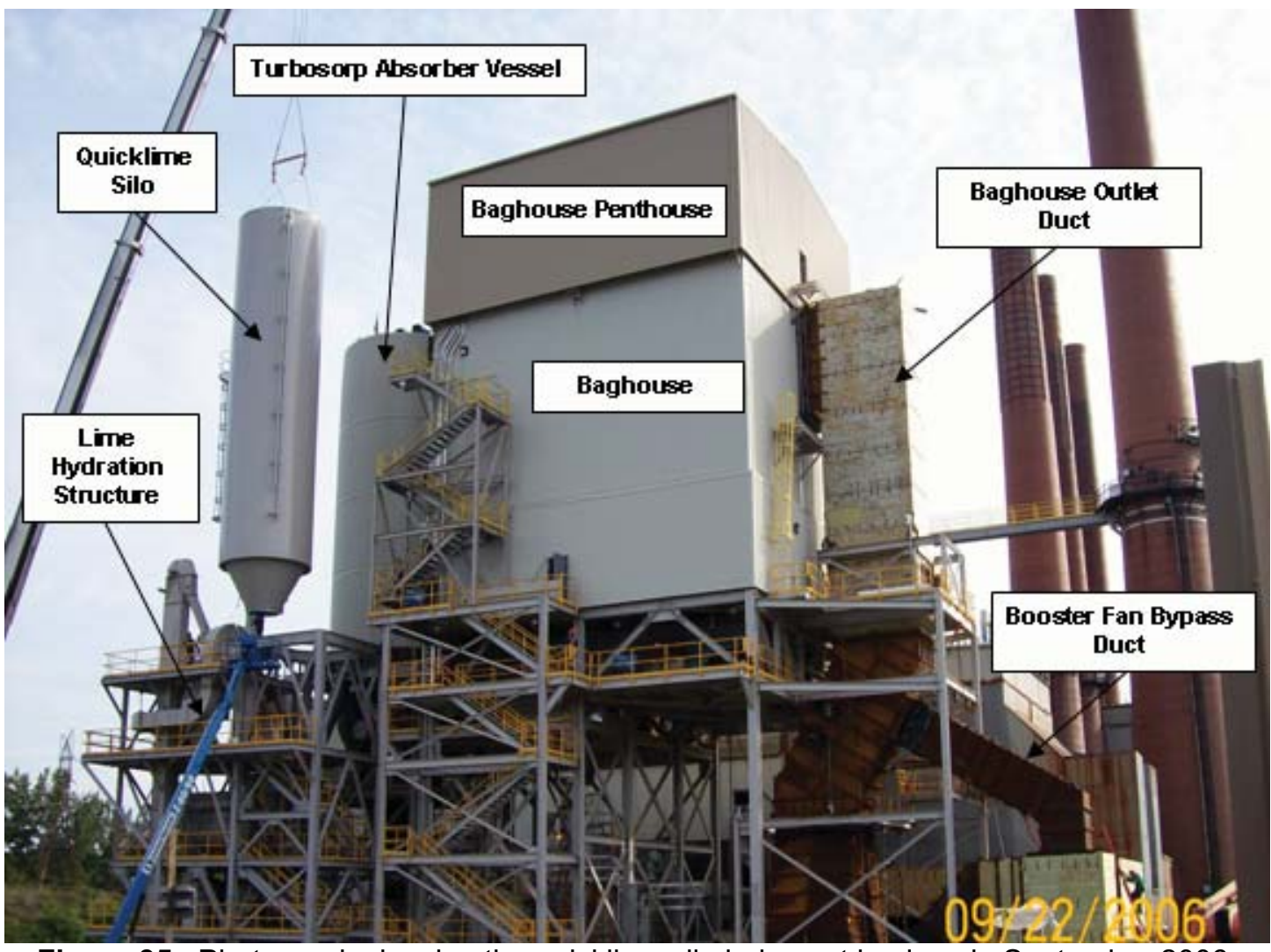

Figure 35. Photograph showing the quicklime silo being set in place in September 2006. 
Finally, substantial progress was made with the installation of electrical equipment. The $2300 \mathrm{~V} /$ $480 \mathrm{~V}$ transformer and the $480 \mathrm{~V}$ and $2300 \mathrm{~V}$ motor control centers were assembled and set in place in the plant by the beginning of September. During September, electricians finished installing cable tray in the plant and began pulling cable, including the feeder cables for the $2300 \mathrm{~V}$ transformer and $480 \mathrm{~V}$ motor control center and the cables for the booster fan motor. Electricians also worked during August and September on installing conduit, junction boxes, and lighting, especially in the baghouse structure.

No major problems were encountered during the pre-outage construction period. As of the end of September 2006, construction of the multi-pollutant control system had progressed sufficiently to allow the tie-in outage to begin.

\subsection{Tie-In Outage}

The tie-in outage began on September 29, 2006, one day ahead of schedule. Most remaining construction activities were completed during this outage, which lasted for 50 days. During the outage period, the number of contractors on site at AES Greenidge ranged from 210-250. (Again, this number includes some contractors who were performing work outside of the DOE scope on the projects described at the end of Section 5). Major construction activities during the outage included:

- Installation of the urea injectors and lances for the SNCR process

- Demolition of ductwork between the economizer and air heaters, between the air heaters and existing ESP, and between the existing ESP and ID fans

- Installation of the in-duct SCR reactor

- Tie-in of the Turbosorp ${ }^{\circledR}$ system, baghouse, ash recirculation system, and booster fan to the existing plant

- Completion of various electrical installation tasks

Demolition work was carried out during the first half of October 2006 to enable the SNCR injectors and the SCR reactor to be installed. Contractors erected scaffolding around Boiler 6 during the first week of October, and they removed lagging and insulation during that week from areas where the SNCR injectors would be installed. Demolition of ductwork between the economizer outlet and air heater inlet also was completed during the first two weeks of the month to allow for installation of the in-duct SCR reactor. By October 21, workers had finished modifying the Boiler 6 water wall to create penetrations for the multiple nozzle lances and urea injection nozzles for the SNCR system.

Installation of the SNCR injectors and multiple nozzle lances was completed by mid-November. All piping required for the SNCR system was in place by November 17, and workers finished reinstalling insulation and lagging on that day as well.

Installation of the in-duct SCR system, which was the critical path activity of the tie-in outage, was completed on schedule. During the month of October, support steel for the SCR reactor was erected in the boiler building; the expansion joint at the economizer outlet was installed, and construction of the SCR reactor casing commenced. Construction was completed during the first half of November. The Delta Wing static mixers had been installed by November 11, and workers loaded catalyst into the reactor and finished seal welding the reactor casing during the week of November 12 . The sonic horns, catalyst hoist, and access platforms were also 
installed, and the SCR reactor was insulated and lagged. Figure 36 presents a photograph taken on October 27, when construction of the SCR reactor was just beginning. Figure 37 shows the catalyst modules being loaded into the reactor on November 10.

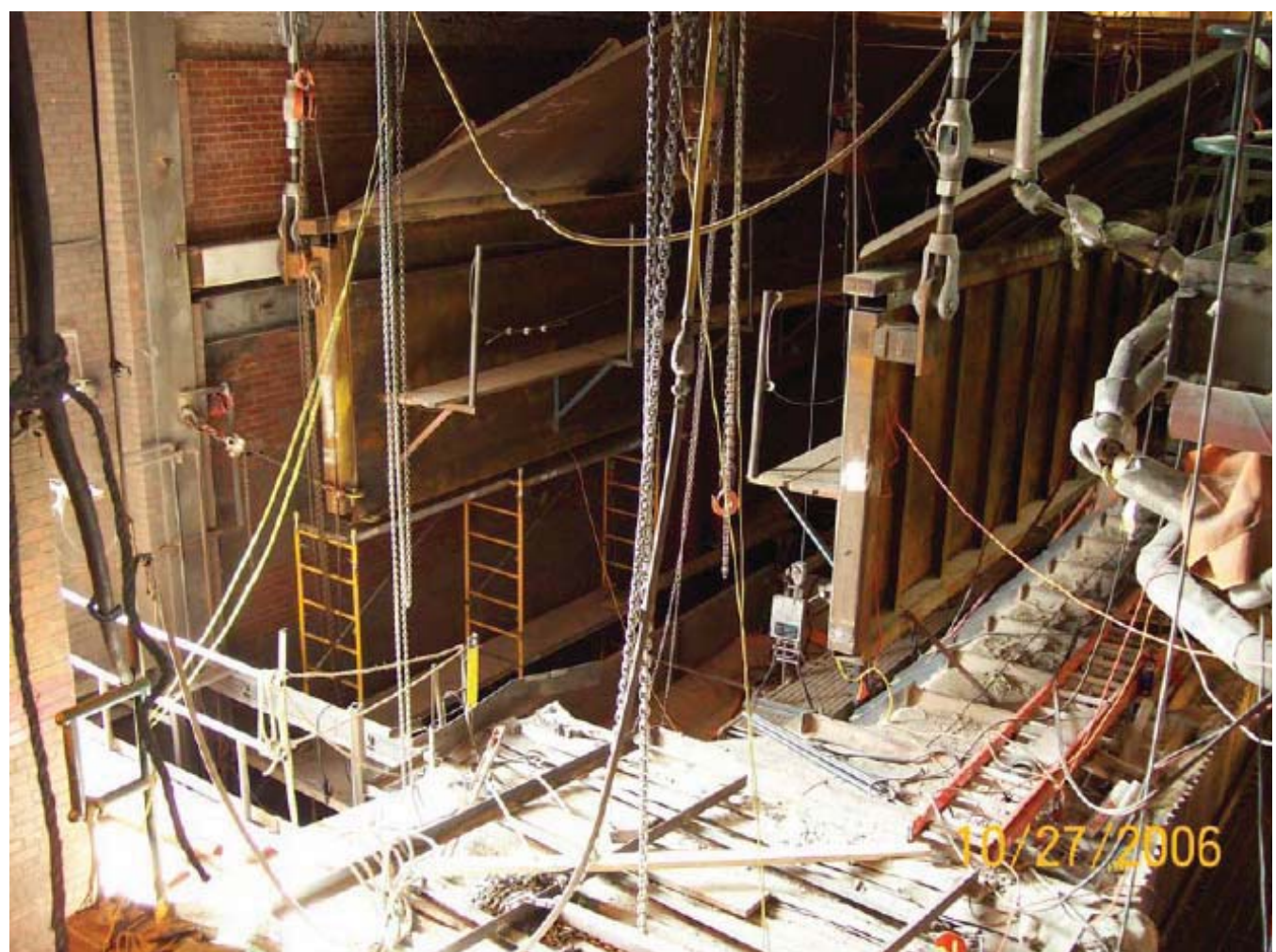

Figure 36. Photograph taken on October 27, 2006, at the start of SCR reactor construction.

Construction work during the outage also included tie-in of the Turbosorp ${ }^{\circledR}$ system and associated equipment into the existing plant. Demolition of ductwork from around the existing ESP was completed by October 17 to allow for tie-in of the Turbosorp ${ }^{\circledR}$ system, and installation of the ductwork (and associated expansion joints) connecting the air heater outlet duct to the inlet of the Turbosorp ${ }^{\circledR}$ vessel was completed during the week of November 12 . In addition, the last section of ductwork connecting the new booster fan to the existing ID fans was installed in mid-October.

All major electrical equipment wiring for the multi-pollutant control system had been completed by the end of October 2006. During that month, electricians set the control panel and variable frequency drive panel for the hydrator in place, pulled cable in the baghouse penthouse, modified the old $2400 \mathrm{~V}$ motor control centers to allow for connection of the new motor control centers, finished all remaining terminations for the 480V switchgear, completed hi-pot testing of the $2300 \mathrm{~V}$ feeder cables, and successfully energized the $2300 \mathrm{~V}$ transformer and bumped the booster fan motor. The $480 \mathrm{~V}$ motor control center was energized during the first week of November.

Also during the outage, miscellaneous remaining construction activities related to the Turbosorp ${ }^{\circledR}$ system, baghouse, lime hydration system, ash recirculation system, and activated carbon injection system were completed. For example, workers finished installing the activated carbon feed and injection system, the heating system for the ash recirculation air slides, the 
water spray nozzles for the Turbosorp ${ }^{\circledR}$ system, and the baghouse plenum doors. They also finished installing piping for the lime hydration system. The air slides and various ductwork sections were insulated and lagged, and piping tie-ins (e.g., for service air, instrument air, potable water, fire protection, etc.) were completed. The 200 -ton crane was disassembled and removed from the AES Greenidge site during the first half of November, and civil work for the quicklime and urea unloading area, which had been delayed until the demobilization of this crane, was completed.

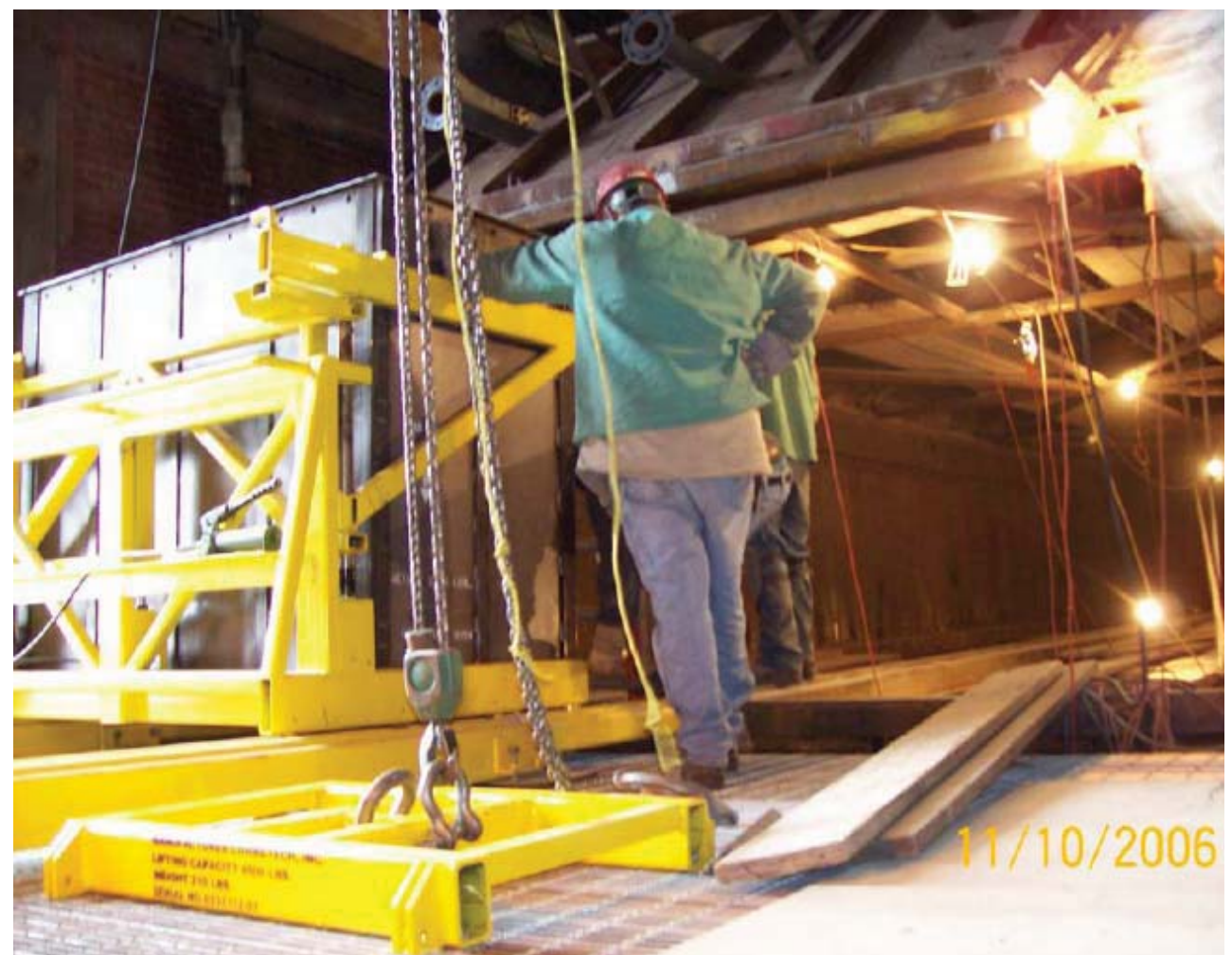

Figure 37. Photograph showing catalyst modules being loaded into the SCR reactor in November 2006.

The tie-in outage ended on schedule on November 18, when BPEI released Boiler 6 to AES Greenidge. As with the pre-outage construction activities, no significant problems were encountered during the tie-in outage.

\subsection{Start-Up and Commissioning}

Start-up and commissioning activities at AES Greenidge commenced during the summer of 2006, prior to the completion of construction. AES Greenidge and BPEI met during the week ending August 18, 2006, to begin planning for start-up and commissioning of the multi-pollutant control system. BPEl's start-up and commissioning manager arrived on site in late August to prepare the turnover and training packages. The operating and maintenance manuals for the multi-pollutant control system were completed in October 2006, and on November 2-3 and 6-7, BPEI held training sessions for AES Greenidge employees regarding operation and maintenance of the multi-pollutant control system. 
Most of the start-up and commissioning work, however, was completed between mid-November 2006 and late March 2007. Hence, it occurred during the winter months, which allowed cold weather-related problems (e.g., involving heat tracing, insulation, etc.) to be identified and resolved. Start-up and commissioning activities were finished about two months behind schedule, largely because of delays arising from the following issues:

- Late completion of the Unit 4 turbine outage (outside of the scope of the DOE project)

- Problem with the booster fan soft start

- Modification of the lime hydration system

- Accumulation of large particle ash in the in-duct SCR reactor

These issues, as well as other minor problems that were encountered and resolved during the start-up and commissioning period, are described in more detail in the paragraphs below.

As discussed above, BPEI released Boiler 6 to AES Greenidge for operation on November 18. However, two issues delayed start-up of Unit 4 and of the multi-pollutant control system.

First, the Unit 4 turbine outage, which was conducted by AES Greenidge simultaneously to the tie-in outage (but outside of the scope of the DOE project), ran several days behind schedule. The turbine was released to AES Greenidge on the evening of November 22, but problems with the turbine supervisory instrumentation and the hydraulic trip circuit delayed start-up by another week. These problems were resolved, however, and the Unit 4 generator was synchronized to the power grid on November 30.

Further delays arose from a problem with the soft start for the booster fan, which was within the scope of the DOE project. On November 24, an attempted start-up of the fan caused activation of the station service differential protection relay, blacking out the entire plant. Subsequent testing of the station service transformer and differential protection relay indicated no problems, and power to the plant was restored. AES Greenidge was able to operate Unit 4 at reduced load while bypassing the booster fan, but actual start-up of the multi-pollutant control system could not occur until the fan was operational. BPEI, Industry and Energy Associates, and Rockwell Automation worked throughout late November and early December to resolve the problem, and they succeeded in doing so on December 4, when workers discovered that the soft start controller was not properly grounded, corrected the problem, and started the fan.

While these problems were being resolved, the baghouse filter bags were pre-coated, and commissioning tasks were performed successfully for a number of equipment items (e.g., air slide blowers, various SNCR system components, process water pump, etc.) associated with the multi-pollutant control system. Start-up and commissioning activities proceeded normally throughout the rest of December. After synchronizing Unit 4 to the power grid on December 7, AES Greenidge gradually ramped up the unit's load while Babcock Power commissioned the new combustion system. Although it was conducted outside of the DOE scope, this combustion system work had to be completed before start-up of the hybrid SNCR/SCR system could occur. As of late December, Unit 4 was operating at full load, and the new low-NO $\mathrm{N}_{x}$ burners were achieving a $\mathrm{NO}_{x}$ emission rate of about $0.27 \mathrm{lb} / \mathrm{mmBtu}$, close to the target rate of 0.25 $\mathrm{lb} / \mathrm{mmBtu}$. Regarding pollution control equipment within the DOE scope, the baghouse was in service throughout the month of December, and various commissioning activities were completed for the SNCR system, Turbosorp ${ }^{\circledR}$ system, and lime hydration system, although none of these systems started up during the month. On December 15, workers established a fluidized bed in the Turbosorp ${ }^{\circledR}$ absorber using accumulated fly ash (no hydrated lime was 
injected) and successfully operated the Turbosorp ${ }^{\circledR}$ system for a time with water injection and baghouse ash recycling while Unit 4 was running at about $65 \mathrm{MW}$. On December 20, the first shipment of pebble lime was delivered to the Greenidge site; BPEI was working at the end of the month to improve the lime unloading system in response to several problems that were encountered while transporting the lime from the delivery truck to the storage silo.

Initial optimization of the combustion system was completed in January 2007, and Fuel Tech representatives returned to the AES Greenidge site during the week of January 22 to begin start-up of the SNCR system. The first load of urea was delivered to the site on January 23. Urea injection tests were performed beginning on January 26, and on February 6, the hybrid SNCR/SCR system was operated in "cascade" mode (i.e., such that the SNCR is used to generate ammonia slip for the SCR) for the first time. This initial, approximately three-hour test run was successful. The system was able to maintain stable emissions below the target rate of $0.10 \mathrm{lb} / \mathrm{mmBtu}$ throughout the test while Unit 4 was operating at $\sim 108 \mathrm{MW}_{\text {gross. }}$ Testing and optimization of the hybrid SNCR/SCR system at full load and at reduced load continued throughout the month of February. Tuning of the system was hindered in late February by high $\mathrm{CO}$ concentrations in the furnace, which are indicative of less-than-optimal combustion and can adversely affect SNCR performance. Adjustments were made to the unit's combustion system to correct this problem, and tuning of the system was completed during the first half of March.

Start-up of the lime hydration system commenced on January 12. However, it was quickly determined that modifications to the system were required to prevent excessive overflow of milk of lime. As discussed in Section 6.2.6, the system originally included a wet scrubber to remove particulate matter from the hydrator exhaust gas and a milk of lime circuit that was fed partially by the scrubber bottom liquid; the modifications involved eliminating the wet scrubber and milk of lime circuit from the process (although these pieces of equipment have not been physically removed from the lime hydration structure) and routing the hydrator exhaust to the Turbosorp ${ }^{\circledR}$ system. Figure 38 presents a photograph showing installation of the new ductwork used to transport the hydrator exhaust to the inlet of the Turbosorp ${ }^{\circledR}$ absorber vessel. The water required for lime hydration is now fed directly to the hydrator. BPEl completed these mechanical modifications during the second half of January, and they made corresponding required modifications to the control system for the lime hydration system during late January and the first half of February. The lime hydration system was successfully started up during the week of February 19.

While the modifications to the lime hydration system were being made, AES Greenidge purchased hydrated lime to allow start-up of the Turbosorp ${ }^{\circledR}$ system to proceed. Hydrated lime and water injection tests were performed beginning on January 13 . The Turbosorp ${ }^{\circledR}$ system was operated for short periods of time on January 15 and 16, and then it was operated during a series of tests throughout the rest of January as BPEl and Austrian Energy worked to tune its performance. $\mathrm{SO}_{2}$ removal efficiencies between $90 \%$ and $100 \%$ were achieved consistently during these optimization tests. Progress on optimization of the Turbosorp ${ }^{\circledR}$ system was hampered during early February by frigid temperatures and weather protection problems that caused frozen lines and valves. These problems were resolved by February 8 , and the Turbosorp $^{\circledR}$ system was operated occasionally during the next few weeks using purchased hydrated lime (at a limited injection rate to reduce cost).

The plant also experienced a problem during February with failing baghouse cleaning valve diaphragms. Dustex, the baghouse supplier, remedied the problem by replacing the failed diaphragms at no cost to AES, and the valves have since operated normally. 


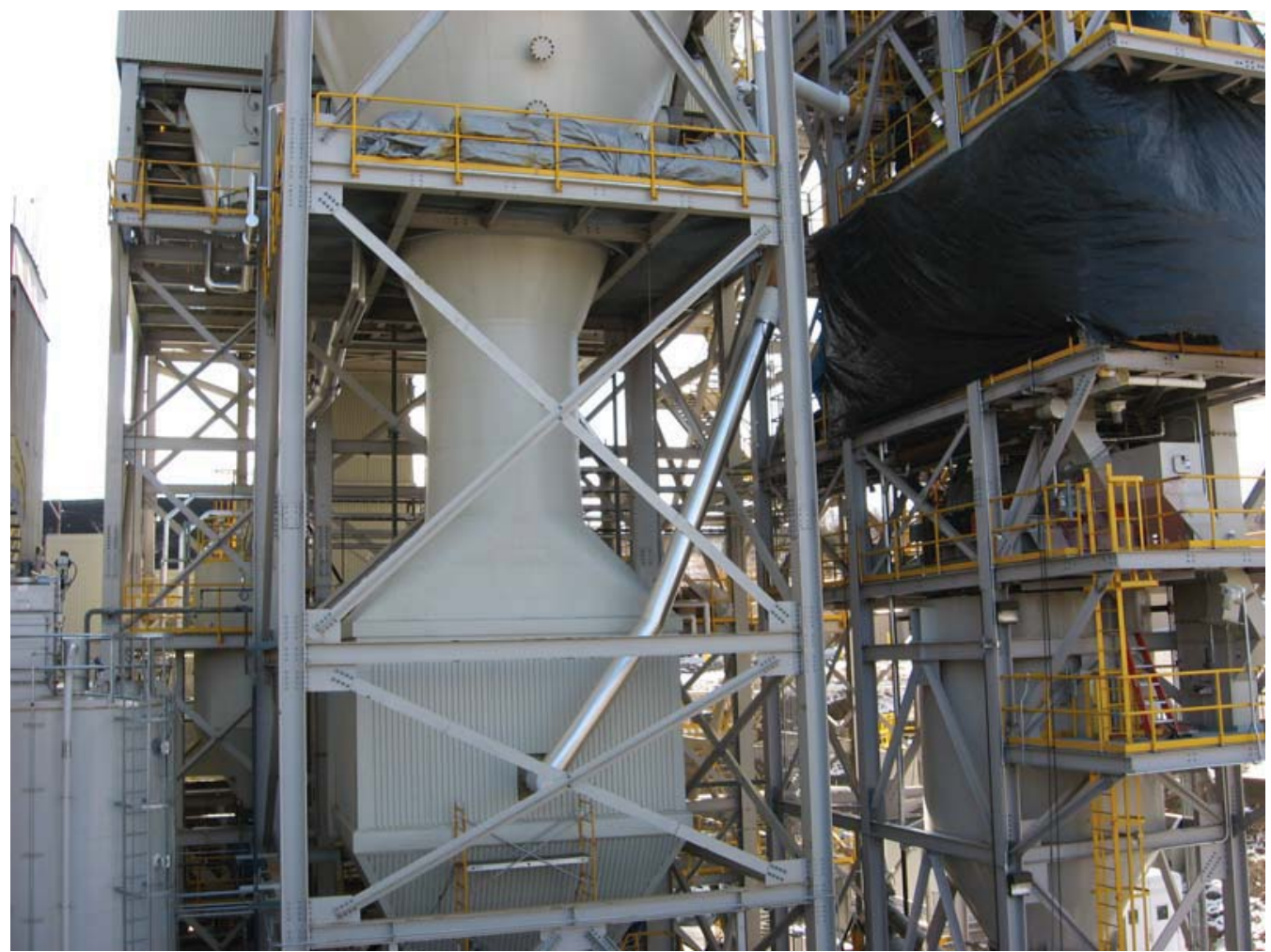

Figure 38. Photograph showing the installation of the new ductwork used to transport the hydrator exhaust to the inlet of the Turbosorp ${ }^{\circledR}$ vessel.

Finally, problems caused by large particle ash accumulation in the in-duct SCR reactor delayed start-up and commissioning activities. As a result of the LPA, Unit 4 had to be taken offline on February 2-4, March 2-4, and March 22-24 so that the SCR catalyst could be cleaned and inspected. (The catalyst was also cleaned during outages on January 3-7 and February 9-10 that were not directly caused by the LPA). These outages for catalyst cleaning interfered with start-up activities. The LPA problem is discussed in detail in Section 10 of this report.

On February 27, AES Greenidge successfully operated all of the components of the multipollutant control system, with the exception of the activated carbon injection system, while Unit 4 was running at about $91 \mathrm{MW}$. The activated carbon injection system was commissioned during the week of March 19. Hence, by the end of March 2007, all of the components of the multi-pollutant control system had been commissioned successfully and were ready for operation.

\section{Performance Testing}

Following the completion of start-up of the multi-pollutant control system in March 2007, the project entered an approximately 18-month operation and testing period during which the performance of the system was evaluated. The project's performance testing tasks were led by CONSOL Energy Inc. Research \& Development. This section details the design of the project's testing program, the sampling and analytical methods that were employed, and the performance testing results. 


\subsection{Approach}

The performance testing program was designed to evaluate both the short-term performance of the multi-pollutant control system while it operated under design conditions and the longer-term performance of the system while it ran under a range of conditions characteristic of routine commercial operation. The performance was evaluated using operating data that were collected routinely by the plant, as well as data that were collected during several special test series conducted by CONSOL at AES Greenidge. The design of the test program is described in more detail in the subsections below.

\subsubsection{Plant Operating Data}

Operating data from AES Greenidge Unit 4 and from the multi-pollutant control system were collected continuously throughout the 18-month performance evaluation period using the plant's online instrumentation. These data were used to evaluate the long-term, day-to-day performance of the multi-pollutant control system (e.g., for $\mathrm{NO}_{\mathrm{x}}$ emissions, urea consumption, $\mathrm{SO}_{2}$ removal efficiency, pressure drop across the SCR catalyst, etc.) and to provide information concerning plant operations during the special test series. CEM data, including $\mathrm{SO}_{2}$ and $\mathrm{NO}_{\mathrm{x}}$ emission rates, percent $\mathrm{CO}_{2}$ in the flue gas, stack flow rate, unit load, and heat input, were compiled using the CEM system's data acquisition and handling system (DAHS). Other plant data (i.e., data from the unit's DCS) were compiled using a PI system. These data included:

- Ambient conditions (temperature, pressure, relative humidity)

- Unit load (net, gross, station service)

- Coal feed rates

- Steam temperatures, pressures, and flow rate at multiple locations

- Combustion system data

- Urea flow rates

- Other SNCR system data

- Flue gas temperatures at the SCR inlet and outlet

- Pressure drop across the SCR reactor (catalyst and catalyst + LPA screen)

- Pressure drop across the air heaters

- $\mathrm{SO}_{2}$ concentration at the Turbosorp ${ }^{\circledR}$ inlet

- Temperature and pressure at the Turbosorp ${ }^{\circledR}$ inlet and outlet

- Lime hydration system operating conditions

- Process water system operating conditions

- Baghouse temperatures and pressures

- Booster fan data (e.g., amperage)

- $\quad$ CEM data $\left(\mathrm{SO}_{2}, \mathrm{NO}_{x}, \mathrm{CO}_{2}\right.$, stack flow rate)

Hourly average CEM data and PI data were provided to CONSOL by AES Greenidge on a monthly basis. CEM data were provided between January 2007 and September 2008. PI data were provided between June 2007 (when the PI system was implemented) and September 2008. During the special test series, data with a higher resolution (i.e., 1-, 2-, or 5-minute averages) were provided. (For test series conducted before June 2007, data were obtained directly from the plant's data historian). 
In addition to the continuously collected data, lime delivery tonnages were recorded by AES Greenidge and provided to CONSOL between January 2007 and September 2008 for use in tracking long-term sorbent utilization in the Turbosorp ${ }^{\circledR}$ system. AES Greenidge also determined the ammonia content of fly ash collected approximately once every three days (on average) between June 4, 2007, and September 29, 2008. These data were provided to CONSOL for use in evaluating the performance of the hybrid SNCR/SCR system.

Finally, CONSOL obtained 2005 CEM data from AES Greenidge Unit 4 for use in representing the unit's $\mathrm{NO}_{\mathrm{x}}$ and $\mathrm{SO}_{2}$ emissions prior to the project.

\subsubsection{Special Test Series}

The special test series were conducted to determine the performance of the multi-pollutant control system for pollutants (i.e., $\mathrm{Hg}, \mathrm{SO}_{3}, \mathrm{HCl}, \mathrm{HF}, \mathrm{NH}_{3}$, and particulate matter) that are not measured by the plant's CEM, and to enable an evaluation of the performance of the system under controlled conditions (e.g., fuel, unit load, scrubber operating conditions). Four special test series were conducted as part of the project: the baseline tests, the guarantee tests, the process performance tests, and the follow-up tests. Each test series consisted of one or more field sampling campaigns at AES Greenidge, during which flue gas and solid and liquid process samples were collected under a prescribed set of unit operating conditions. The samples were then submitted to the laboratory for chemical or physical analysis, and the resulting data were reduced and analyzed to determine the results of the test. The flue gas sampling schedules from all of the field sampling campaigns at AES Greenidge are provided in Appendix E. The objectives of the special test series, and the work performed during each sampling campaign, are described in more detail in the subsections below. The sampling locations, sampling and analytical methods, and quality control procedures that were employed for the tests are discussed in Section 9.2, and the results of the tests are presented in Section 9.3.

\subsubsection{Baseline Testing}

The baseline tests were conducted at AES Greenidge Unit 4 on November 17-18, 2004, prior to the installation of the multi-pollutant control system, in order to obtain data for use in designing the multi-pollutant control system and to establish a baseline against which the performance of the system could be compared. The tests were conducted while Unit 4 fired eastern U.S. bituminous coal containing 1.9-2.1\% (dry basis) sulfur (2.7-3.0 lb $\mathrm{SO}_{2} / \mathrm{mmBtu}$ ). With the exception of two $\mathrm{SO}_{3}$ tests at the air heater outlet, all tests were conducted while the unit was operating at or near full load. The following flue gas measurements were completed:

- Three Hg tests at the stack (full load)

- Three $\mathrm{SO}_{3}$ tests with simultaneous sampling at the air heater inlet, air heater outlet, and stack (full load)

- Two $\mathrm{SO}_{3}$ tests at the air heater outlet (low load)

- Three $\mathrm{HCl}$ and HF tests at the stack (full load)

- Three PM tests at the stack (full load, conducted as part of the $\mathrm{HCl}$ and $\mathrm{HF}$ tests)

Solid process samples, including coal, bottom ash, economizer hopper ash, and ESP hopper ash, were also collected for analysis during the sampling period in order to supplement the flue gas testing results. 


\subsubsection{Guarantee Testing}

Guarantee testing was conducted at AES Greenidge Unit 4 between March 2007 and June 2007. The purpose of the guarantee tests was to determine whether the multi-pollutant control system could achieve its performance targets while the unit operated at or near design conditions. The initial sampling campaign for guarantee testing occurred on March 28-30, 2007. This campaign was designed to evaluate all of the performance targets associated with the multi-pollutant control system. However, the testing results for ammonia slip, $\mathrm{SO}_{3}$ removal, $\mathrm{HCl}$ removal, and HF removal obtained during the March sampling campaign were either inconsistent with the performance targets or inconclusive. Hence, additional sampling campaigns were required on May 1-4 (for $\mathrm{SO}_{3}, \mathrm{HCl}, \mathrm{HF}$, and ammonia slip), May 30-June 1 (for ammonia slip), and June 20-21 (for ammonia slip) to demonstrate attainment of these performance targets. These sampling campaigns are described below.

\subsection{Sampling Campaign on March 28-30, 2007}

The tests on March 28-30, 2007, were designed to evaluate the performance targets for $\mathrm{NO}_{\mathrm{x}}$ emissions, $\mathrm{SO}_{2}$ removal efficiency, $\mathrm{Hg}$ removal efficiency, $\mathrm{SO}_{3}$ removal efficiency, $\mathrm{HCl}$ removal efficiency, HF removal efficiency, and ammonia slip. The tests were conducted while AES Greenidge Unit 4 operated at or near full load and fired eastern U.S. bituminous coal containing 2.5-2.8\% (dry basis) sulfur (3.6-4.0 $\mathrm{lb} \mathrm{SO}_{2} / \mathrm{mmBtu}$ ). The following flue gas measurements were completed:

- Three $\mathrm{NO}_{\mathrm{x}}$ tests with simultaneous sampling at the SCR inlet and outlet sampling grids

- Three ammonia slip tests at the SCR outlet

- Three $\mathrm{SO}_{2}$ tests with simultaneous sampling at the air heater outlet and baghouse outlet

- Three $\mathrm{Hg}$ tests with simultaneous sampling at the air heater outlet and stack (no activated carbon injection)

- Three Hg tests with simultaneous sampling at the air heater outlet and stack (with activated carbon injection)

- Three $\mathrm{SO}_{3}$ tests with simultaneous sampling at the air heater outlet and stack

- Three $\mathrm{SO}_{3}$ tests with simultaneous sampling at the SCR inlet and outlet

- Three $\mathrm{HCl}$ and $\mathrm{HF}$ tests with simultaneous sampling at the air heater outlet and stack

- Nine PM tests with simultaneous sampling at the air heater outlet and stack (conducted as part of the $\mathrm{Hg}$ tests and the $\mathrm{HCl}$ and $\mathrm{HF}$ tests)

The grid point $\mathrm{NO}_{\mathrm{x}}$ measurements at the SCR inlet and outlet and the $\mathrm{SO}_{2}$ measurements at the air heater outlet and baghouse outlet were performed by Clean Air Engineering (CAE); all other measurements were performed by CONSOL. In addition to the manual flue gas measurements, $\mathrm{NO}_{\mathrm{x}}$ and $\mathrm{SO}_{2}$ emissions were measured continuously throughout the testing period by the unit's stack CEM, and $\mathrm{SO}_{2}$ concentrations at the Turbosorp ${ }^{\circledR}$ inlet were measured using the dilution extractive-type $\mathrm{SO}_{2}$ analyzer that is permanently installed between the air heaters and Turbosorp ${ }^{\circledR}$ system.

Solid and liquid process samples, including coal, pebble lime, hydrated lime, Turbosorp ${ }^{\circledR}$ product ash, Turbosorp ${ }^{\circledR}$ hopper ash, activated carbon, and urea, were also collected throughout the testing period to allow for an assessment of system performance during the period and for the completion of $\mathrm{Hg}$ mass balances. Finally, AES Greenidge and BPEI monitored urea, lime, and carbon consumption rates and the pressure drop across system 
components to determine whether performance guarantees associated with these parameters were satisfied.

\subsection{Sampling Campaign on May 1-4, 2007}

The sampling campaign on May 1-4, 2008, was conducted to repeat the guarantee tests for ammonia slip, $\mathrm{SO}_{3}$ removal efficiency, $\mathrm{HCl}$ removal efficiency, and $\mathrm{HF}$ removal efficiency. (As discussed above, the results for these parameters obtained during the March sampling campaign were either inconsistent with the performance targets or inconclusive). Again, AES Greenidge Unit 4 operated at or near full load during the test period, and it fired eastern U.S. bituminous coal containing 3.1-3.4\% (dry basis) sulfur (4.4-4.9 $\mathrm{lb} \mathrm{SO}_{2} / \mathrm{mmBtu}$ ). The following flue gas measurements were completed:

- Four ammonia slip tests with simultaneous sampling at the SCR outlet and air heater inlet

- Three $\mathrm{SO}_{3}$ tests with simultaneous sampling at the air heater outlet and stack

- Two $\mathrm{HCl}$ and $\mathrm{HF}$ tests with simultaneous sampling at the air heater outlet and stack

The methods used to sample ammonia slip and $\mathrm{SO}_{3}$ were modified for the May tests in order to improve the representativeness and sensitivity of the measurements (see the discussion in Section 9.2). In addition to the manual flue gas measurements, $\mathrm{NO}_{\mathrm{x}}$ and $\mathrm{SO}_{2}$ emissions were measured continuously throughout the testing period by the unit's stack $\mathrm{CEM}$, and $\mathrm{SO}_{2}$ concentrations at the Turbosorp ${ }^{\circledR}$ inlet were measured using the dilution extractive-type $\mathrm{SO}_{2}$ analyzer that is permanently installed between the air heaters and Turbosorp ${ }^{\circledR}$ system. Various plant operating data and process samples (i.e., coal and fly ash from the air heater outlet) were also collected during the test period and analyzed to aid the interpretation of the flue gas sampling results.

\subsection{Sampling Campaign on May 30-June 1, 2007}

The ammonia slip tests performed during the May 1-4 testing campaign still did not demonstrate attainment of the performance target of $\leq 2$ ppmvd (corrected to $3 \% \mathrm{O}_{2}$ ) ammonia slip. As discussed in Section 10.2.1, AES Greenidge installed a new large particle ash removal system and a fresh SCR catalyst layer during an outage on May 17-25, 2008; it was suspected that LPA accumulation in the catalyst could have affected the ammonia slip testing results in early May.

Therefore, on May 30-June 1, following the outage, CONSOL and Clean Air Engineering performed additional ammonia slip, $\mathrm{NO}_{x}$, and $\mathrm{CO}$ testing around the in-duct SCR reactor. The objectives of this series of measurements were to determine the effects of the newly installed LPA screen on the $\mathrm{NO}_{x}$ removal performance of the in-duct SCR and to determine whether installation of the screen and replacement of the catalyst enabled the hybrid SNCR/SCR system to achieve its ammonia slip target. Unit 4 operated at or near full load and fired eastern U.S. bituminous coal containing 2.7-2.8\% (dry basis) sulfur (3.9-4.1 $\mathrm{lb} \mathrm{SO} \mathrm{SO}_{2} / \mathrm{mmBtu}$ ) during the test period.

Grid-point $\mathrm{NO}_{x}, \mathrm{CO}, \mathrm{CO}_{2}$, and $\mathrm{O}_{2}$ measurements at the SCR inlet and outlet sampling grids were performed throughout the day on May 30 and May 31 as personnel from BPEI and Fuel Tech worked to tune the Unit 4 combustion system and the SNCR system. CONSOL and Clean 
Air Engineering conducted side-by-side ammonia slip sampling at the air heater inlet on the evening of May 31 (1 test) and during the first half of the day on June 1 (2 tests). CONSOL also simultaneously sampled for ammonia at the economizer outlet during each test. Various plant operating and emissions data, including urea flow rates and $\mathrm{NO}_{\mathrm{x}}$ emissions measured by the stack CEM, were collected throughout the test period to aid with the interpretation of the ammonia slip results. The testing indicated that the system still was not meeting its performance target for ammonia slip.

\subsection{Sampling Campaign on June 20-21, 2007}

CONSOL performed additional ammonia slip sampling at AES Greenidge on June 20 and 21, 2008. The purpose of these tests, which were conducted after BPEI and Fuel Tech completed additional tuning of the hybrid SNCR/SCR system during the first half of June, was to determine whether this tuning enabled the multi-pollutant control system to satisfy its performance guarantee for ammonia slip. Unit 4 operated at or near full load and fired eastern U.S. bituminous coal containing $\sim 2.5 \%$ (dry basis) sulfur $(3.6 \mathrm{lb} \mathrm{SO} / \mathrm{mmBtu}$ ) during the test period. (Clean Air Engineering was also on site during the test period, outside of the scope of the DOE cooperative agreement, to perform $\mathrm{NO}_{\mathrm{x}}$ and $\mathrm{CO}$ grid point sampling. Data from two of the grid traverses on June 20 were provided by AES Greenidge for use in this report).

Three ammonia slip tests were completed at the air heater inlet on June 20; the third of these tests demonstrated attainment of the ammonia slip guarantee. Two additional ammonia slip tests were performed on June 21 while AES Greenidge, BPEI, and Fuel Tech worked to establish a set of acceptable boiler operating conditions for routine operation of the $\mathrm{NO}_{\mathrm{x}}$ control system. Various plant operating and emissions data, including urea flow rates and $\mathrm{NO}_{\mathrm{x}}$ emissions measured by the stack CEM, were also collected throughout the test period to aid with the interpretation of the ammonia slip results.

\subsubsection{Process Performance Testing}

The process performance tests were conducted to build upon the results of the guarantee tests by establishing the performance of the multi-pollutant control system as a function of changes in various plant operating conditions. The process performance test series included six sampling campaigns between October 2007 and June 2008. These sampling campaigns, which were conducted on October 2-5, October 8-11, November 13-16, March 10-13, May 19-22, and June 16-19, were designed to examine the effects of changes in unit load, fuel (e.g., coal sulfur content, biomass co-firing), urea injection scheme, and Turbosorp ${ }^{\circledR}$ process operating conditions (i.e., calcium-to-sulfur ratio, approach to adiabatic saturation temperature) on the performance of the system. In addition to pollutant removal efficiencies and emission rates, performance metrics such as reagent utilization, ammonia slip, $\mathrm{SO}_{2}$-to- $\mathrm{SO}_{3}$ conversion across the SCR catalyst, and $\mathrm{Hg}$ oxidation across the SCR catalyst were evaluated during the process performance tests. The six process performance test sampling campaigns are described in the subsections below. 


\subsection{Sampling Campaign on October 2-5, 2007}

The tests on October 2-5, 2007, were conducted to evaluate the performance of the multipollutant control system while AES Greenidge Unit 4 fired a higher-than-normal sulfur coal. During the test period, Unit 4 operated at or near full load, and it fired eastern U.S. bituminous coal containing $3.1-3.4 \%$ (dry basis) sulfur (4.4-4.9 lb $\mathrm{SO}_{2} / \mathrm{mmBtu}$ ). $\mathrm{NO}_{\mathrm{x}}$ and $\mathrm{SO}_{2}$ concentrations at the stack were measured continuously during the test period using the unit's CEM, and $\mathrm{SO}_{2}$ concentrations at the Turbosorp ${ }^{\circledR}$ inlet were measured using the dilution extractive-type $\mathrm{SO}_{2}$ analyzer that is permanently installed between the air heaters and Turbosorp $^{\circledR}$ system. The following manual flue gas measurements were also completed:

- Three Hg tests with simultaneous sampling at the SCR inlet, SCR outlet, air heater outlet, and stack (no activated carbon injection)

- Two $\mathrm{Hg}$ tests with simultaneous sampling at the air heater outlet and stack (with activated carbon injection)

- Two $\mathrm{SO}_{3}$ tests with simultaneous sampling at the air heater outlet and stack

- Four $\mathrm{SO}_{3}$ tests with simultaneous sampling at the SCR inlet and SCR outlet

- Two $\mathrm{HCl}$ and $\mathrm{HF}$ tests with simultaneous sampling at the air heater outlet and stack

- Seven PM tests with simultaneous sampling at the air heater outlet and stack (conducted as part of the $\mathrm{Hg}$ tests and the $\mathrm{HCl}$ and $\mathrm{HF}$ tests)

In addition to the flue gas measurements, various plant operating data and solid and liquid process samples (i.e., coal, bottom ash, fly ash from the air heater outlet, pebble lime, hydrated lime, Turbosorp ${ }^{\circledR}$ product ash, activated carbon, urea, and process water) were collected during the test period for use in evaluating the performance of the multi-pollutant control system.

As discussed in Section 10.2.2.1, the lime hydration system was often unable to keep up with the increased hydrated lime demand resulting from the higher-sulfur coal fired during the October 2-5 test period. The hydrated lime classifier plugged numerous times on October 3 and October 4, causing the lime hydration system to trip. This hindered the tests that were planned for those days; however, AES Greenidge was diligent in unplugging the hydrator and in taking deliveries of hydrated lime to allow the tests to proceed.

\subsection{Sampling Campaign on October 8-11, 2007}

The tests on October 8-11, 2007, were conducted to examine the effects of changes in the Ca/S molar ratio and approach to adiabatic saturation temperature on the multi-pollutant removal performance of the Turbosorp ${ }^{\circledR}$ system. During these tests, Unit 4 operated at or near full load and fired eastern U.S. bituminous coal containing 2.8-2.9\% (dry basis) sulfur (4.0-4.3 lb $\mathrm{SO}_{2} / \mathrm{mmBtu}$ ). $\mathrm{NO}_{x}$ and $\mathrm{SO}_{2}$ concentrations at the stack were measured continuously throughout the test period using the unit's $\mathrm{CEM}$, and $\mathrm{SO}_{2}$ concentrations at the Turbosorp ${ }^{\circledR}$ inlet were measured using the dilution extractive-type $\mathrm{SO}_{2}$ analyzer that is permanently installed between the air heaters and Turbosorp ${ }^{\circledR}$ system.

The Turbosorp ${ }^{\circledR}$ system was operated with a different targeted $\mathrm{Ca} / \mathrm{S}$ molar ratio on each of October 8, October 9, and October 10, while all other relevant set points were held constant. (The $\mathrm{Ca} / \mathrm{S}$ was changed by putting the $\mathrm{SO}_{2}$ trim control in manual mode and varying the trim multiplier setting). The Turbosorp ${ }^{\circledR}$ outlet temperature set point was maintained at $160{ }^{\circ} \mathrm{F}$ on these three test days. On each day, the following tests were completed: 
- One Hg test with simultaneous sampling at the air heater outlet and stack (no activated carbon injection)

- One $\mathrm{SO}_{3}$ test with simultaneous sampling at the air heater outlet and stack

- One $\mathrm{HCl}$ and $\mathrm{HF}$ test with simultaneous sampling at the air heater outlet and stack

- Two PM tests with simultaneous sampling at the air heater outlet and stack (conducted as part of the $\mathrm{Hg}$ test and the $\mathrm{HCl}$ and $\mathrm{HF}$ test)

(Coal mill problems on October 9 caused early termination of the $\mathrm{Hg}$ test on that day).

On October 11, the plan was to replicate the settings from October 8 and then increase the Turbosorp ${ }^{\circledR}$ outlet temperature set point by $5{ }^{\circ} \mathrm{F}$ (to $165^{\circ} \mathrm{F}$ ). However, the $\mathrm{SO}_{2}$ removal efficiency was lower on October 11 than on October 8 under these settings, and the temperature could not be raised by $5{ }^{\circ} \mathrm{F}$ while still maintaining $\mathrm{SO}_{2}$ emissions within the plant's permit limit. As a result, the tests on October 11 were conducted with a $165^{\circ} \mathrm{F}$ Turbosorp ${ }^{\circledR}$ outlet temperature set point, but with the hydrated lime injection set to control automatically to a $0.2 \mathrm{lb} / \mathrm{mmBtu} \mathrm{SO}_{2}$ emission rate. $\left(\mathrm{SO}_{2}\right.$ emissions on October 8 averaged $\left.<0.05 \mathrm{lb} / \mathrm{mmBtu}\right)$. One $\mathrm{Hg}$ and $\mathrm{PM}$ test and one $\mathrm{SO}_{3}$ test, each including simultaneous sampling at the air heater outlet and stack, were completed under these conditions.

Finally, during each day of testing between October 8 and October 11, an ammonia slip test was conducted at the air heater inlet. Various plant operating data and solid and liquid process samples (i.e., coal, bottom ash, fly ash from the air heater outlet, pebble lime, hydrated lime, Turbosorp ${ }^{\circledR}$ product ash, activated carbon, urea, and process water) were also collected throughout the test period for use in evaluating the performance of the system.

\subsection{Sampling Campaign on November 13-16, 2007}

The tests on November 13-16 were designed to evaluate the performance of the multi-pollutant control system when AES Greenidge Unit 4 operated at reduced loads (resulting in varied urea injection schemes) and when it co-fired biomass with coal. During the test period, the unit fired eastern U.S. bituminous coal containing 2.5-2.8\% (dry basis) sulfur (3.7-4.4 $\mathrm{lb} \mathrm{SO} \mathrm{SO}_{2} / \mathrm{mmBtu}$ ). Moreover, during the tests on November 16, it co-fired waste wood from a furniture manufacturing process, which had a higher heating value of 7500-7600 Btu/lb (as fired) and a sulfur content of $0.2-0.3 \mathrm{lb} \mathrm{SO}_{2} / \mathrm{mmBtu}$.

During the overnight period on November 13-14, Unit 4 operated at low load $\left(\sim 56 \mathrm{MW}_{\mathrm{g}}\right)$ and fired $100 \%$ coal. CONSOL completed three ammonia slip tests at the air heater inlet, three $\mathrm{SO}_{3}$ tests with simultaneous sampling at the air heater outlet and stack, and two $\mathrm{Hg}$ and PM tests at the stack under these conditions. All three ammonia slip tests were conducted while urea was only being injected into Zone 1 of the SNCR system.

During the overnight period on November 14-15, Unit 4 operated at intermediate loads ( 79-84 $\mathrm{MW}_{\mathrm{g}}$ ) and fired $100 \%$ coal. CONSOL completed four ammonia slip tests at the air heater inlet, three $\mathrm{SO}_{3}$ tests with simultaneous sampling at the air heater outlet and stack, and two $\mathrm{Hg}$ and PM tests at the stack under these conditions. One of the ammonia slip tests was conducted while urea was being injected into Zones 1 and 2 of the SNCR system; two ammonia slip tests were conducted while urea was being injected into Zones 2 and 3, and the final ammonia slip 
test was conducted while urea was injected into all three SNCR zones (the urea injection scheme changed partway through this test).

AES Greenidge Unit 4 began co-firing waste wood on November 15 in preparation for the tests on November 16; however, one of the hydrated lime classifier fan bearings failed that day, forcing the plant to take the hydrator offline. Biomass co-firing was discontinued, and the tests were delayed until sufficient deliveries of hydrated lime could be secured to enable full-load operation of the Turbosorp ${ }^{\circledR}$ system. Biomass co-firing resumed at about 10:30 am on November 16, and the unit operated near full load (102-103 $\mathrm{MW}_{\mathrm{g}}$ ) during the tests on that day. (The plant had no means for measuring the biomass feed rate, so it was estimated as $5 \%$ of the total heat input for purposes of this report). CONSOL completed three ammonia slip tests at the air heater inlet, two $\mathrm{SO}_{3}$ tests with simultaneous sampling at the air heater outlet and stack, and one $\mathrm{Hg}$ and $\mathrm{PM}$ test with simultaneous sampling at the air heater outlet and stack under these conditions. All three ammonia slip tests were conducted while urea was being injected into Zones 2 and 3 of the SNCR system.

As with the tests in October, $\mathrm{NO}_{\mathrm{x}}$ and $\mathrm{SO}_{2}$ concentrations at the stack were measured continuously throughout the November 13-16 test period using the unit's CEM, and $\mathrm{SO}_{2}$ concentrations at the Turbosorp ${ }^{\circledR}$ inlet were measured using the dilution extractive-type $\mathrm{SO}_{2}$ analyzer that is permanently installed between the air heaters and Turbosorp ${ }^{\circledR}$ system. Various plant operating data (e.g., load, urea flow rates) and solid and liquid process samples (i.e., coal, wood, fly ash from the air heater outlet, pebble lime, hydrated lime, Turbosorp ${ }^{\circledR}$ product ash, urea, and process water) also were collected for use in the performance evaluation.

\subsection{Sampling Campaign on March 10-13, 2008}

The tests on March 10-13, 2008, were designed to further evaluate the performance of the multi-pollutant control system while AES Greenidge Unit 4 co-fired biomass with coal. The biomass used during the March 2008 tests was waste wood from a sawmill. This waste wood had a lower heating content ( $5000-6900 \mathrm{Btu} / \mathrm{lb}$, as fired) than the furniture manufacturing waste wood used during the November 2007 process performance tests. During the tests on March 10-13, Unit 4 fired eastern U.S. bituminous coal containing $2.3-2.5 \%$ (dry basis) sulfur (3.4-3.6 lb SO $2 / \mathrm{mmBtu}$ ), and it co-fired the sawmill waste wood at $\sim 1.8-3.2 \%$ of the total heat input. (The waste wood feed rate was estimated from screw feeder data from the biomass processing system. These data were then multiplied by a correction factor derived by comparing long-term screw feeder data with delivery truck weigh slips). The unit operated at or near full load during the tests. $\mathrm{NO}_{\mathrm{x}}$ and $\mathrm{SO}_{2}$ concentrations at the stack were measured continuously during the test period using the unit's $\mathrm{CEM}$, and $\mathrm{SO}_{2}$ concentrations at the Turbosorp $^{\circledR}$ inlet were measured using the dilution extractive-type $\mathrm{SO}_{2}$ analyzer that is permanently installed between the air heaters and Turbosorp ${ }^{\circledR}$ system. The following manual flue gas measurements were also completed:

- Four $\mathrm{Hg}$ tests with simultaneous sampling at the economizer outlet, air heater inlet, air heater outlet, and stack (no activated carbon injection)

- Four $\mathrm{SO}_{3}$ tests with simultaneous sampling at the economizer outlet, air heater inlet, air heater outlet, and stack

- Four $\mathrm{HCl}$ and $\mathrm{HF}$ tests with simultaneous sampling at the air heater outlet and stack

- Eight PM tests at the stack (conducted as part of the $\mathrm{Hg}$ tests and the $\mathrm{HCl}$ and $\mathrm{HF}$ tests), and four PM tests at the air heater outlet (conducted as part of the $\mathrm{HCl}$ and $\mathrm{HF}$ tests) 
- Four ammonia slip tests at the air heater inlet

On March 10 and 13, several tests also were conducted without urea injection in order to establish the $\mathrm{NO}_{x}$ emission rate from the unit's low- $\mathrm{NO}_{x}$ combustion system, without the hybrid SNCR/SCR system in service. (No manual flue gas sampling was performed during these tests; $\mathrm{NO}_{\mathrm{x}}$ emissions were measured by the unit's stack $\mathrm{CEM}$ ).

In addition to the flue gas measurements, various plant operating data and solid and liquid process samples (i.e., coal, wood, bottom ash, fly ash from the air heater outlet, pebble lime, hydrated lime, Turbosorp ${ }^{\circledR}$ product ash, urea, and process water) were collected during the test period for use in evaluating the performance of the multi-pollutant control system.

\subsection{Sampling Campaign on May 19-22, 2008}

The tests on May 19-22, 2008, were designed to generate additional information about the performance of the multi-pollutant control system at reduced unit loads, and in particular, to thoroughly characterize the performance of the $\mathrm{NO}_{x}$ control system (i.e., ammonia slip, $\mathrm{NO}_{x}$ and CO concentration profiles around the SCR) as a function of load. During the test period, AES Greenidge Unit 4 fired eastern U.S. bituminous coal containing 2.0-2.4\% (dry basis) sulfur (3.0$3.6 \mathrm{lb} \mathrm{SO} / \mathrm{mmBtu})$.

During the overnight period on May 19-20, CONSOL completed two Hg tests at low unit load (56-57 $\mathrm{MW}_{\mathrm{g}}$ ), each of which included simultaneous sampling at the economizer outlet, air heater inlet, and stack. PM was also measured as part of the tests at the stack.

During the overnight period on May 20-21, CONSOL completed four ammonia slip tests at the air heater inlet at intermediate unit loads $\left(80-91 \mathrm{MW}_{\mathrm{g}}\right)$. Two of these tests were performed with urea injection into Zones 1 and 2 of the SNCR system, and two were performed with urea injection into Zones 2 and 3 of the SNCR system. In addition, two $\mathrm{SO}_{3}$ tests and two $\mathrm{HCl}, \mathrm{HF}$, and PM tests, each including simultaneous sampling at the air heater outlet and stack, were completed during this period. Clean Air Engineering measured $\mathrm{NO}_{\mathrm{x}}$ concentrations at the SCR inlet and outlet sampling grids and $\mathrm{CO}$ concentrations at the SCR inlet sampling grid while Zones 1 and 2 of the SNCR system were in operation.

On the morning of May 21, three additional ammonia slip tests were performed at the air heater inlet while Unit 4 operated at full load (108-110 $\mathrm{MW}_{\mathrm{g}}$ ). Urea was being injected into Zones 2 and 3 of the SNCR system during this period. Clean Air Engineering measured $\mathrm{NO}_{\mathrm{x}}$ concentrations at the SCR inlet and outlet sampling grids and CO concentrations at the SCR inlet sampling grid during these tests. Urea injection was briefly discontinued at the end of the test period in order to establish the $\mathrm{NO}_{\mathrm{x}}$ emission rate from the unit's low- $\mathrm{NO}_{\mathrm{x}}$ combustion system at full load, without the hybrid SNCR/SCR system in service.

Finally, during the overnight period on May 21-22, CONSOL completed three ammonia slip tests at the air heater inlet at low unit load $\left(56 \mathrm{MW}_{\mathrm{g}}\right)$, while urea was only being injected into SNCR Zone 1. Again, Clean Air Engineering measured $\mathrm{NO}_{x}$ concentrations at the SCR inlet and outlet sampling grids and CO concentrations at the SCR inlet sampling grid while these tests were being conducted. Urea injection was briefly discontinued at the end of the test period in order to establish the $\mathrm{NO}_{x}$ emission rate from the unit's low-NO $\mathrm{NO}_{\mathrm{x}}$ combustion system at low load, without the hybrid SNCR/SCR system in service. In addition, three $\mathrm{SO}_{3}$ tests and three $\mathrm{HCl}, \mathrm{HF}$, and 
PM tests, each including simultaneous sampling at the air heater outlet and stack, were completed while Unit 4 operated at low load.

$\mathrm{NO}_{\mathrm{x}}$ and $\mathrm{SO}_{2}$ concentrations at the stack were measured continuously throughout the May 1922 test period using the unit's $\mathrm{CEM}$, and $\mathrm{SO}_{2}$ concentrations at the Turbosorp ${ }^{\circledR}$ inlet were measured using the dilution extractive-type $\mathrm{SO}_{2}$ analyzer that is permanently installed between the air heaters and Turbosorp ${ }^{\circledR}$ system. Various plant operating data (e.g., load, urea flow rates) and solid and liquid process samples (i.e., coal, fly ash from the air heater outlet, pebble lime, hydrated lime, Turbosorp ${ }^{\circledR}$ product ash, and urea) also were collected for use in the performance evaluation.

\subsection{Sampling Campaign on June 16-19, 2008}

The tests on June 16-19, 2008, were designed to further evaluate the effects of changes in the $\mathrm{Ca} / \mathrm{S}$ molar ratio and approach to adiabatic saturation temperature on the multipollutant removal performance of the Turbosorp ${ }^{\circledR}$ system. During the test period, AES Greenidge Unit 4 operated at or near full load and fired eastern U.S. bituminous coal containing 2.5-2.6\% (dry basis) sulfur (3.5-3.7 lb SO $2 / \mathrm{mmBtu}$ ).

The Turbosorp ${ }^{\circledR}$ operating conditions were altered for each of the four test days. On June 16 , 17 , and 18, the scrubber was operated with $\mathrm{SO}_{2}$ emission rate set points of $0.28 \mathrm{lb} / \mathrm{mmBtu}, 0.17$ $\mathrm{lb} / \mathrm{mmBtu}$, and $0.066 \mathrm{lb} / \mathrm{mmBtu}$, respectively (corresponding to $\mathrm{SO}_{2}$ removal efficiencies of approximately $92 \%, 95 \%$, and $98 \%$ ), while its outlet temperature set point was maintained at $160^{\circ} \mathrm{F}$. Then, on June 19 , the $\mathrm{SO}_{2}$ emission rate set point was maintained at $0.18 \mathrm{lb} / \mathrm{mmBtu}$ (corresponding to $\sim 95 \%$ removal efficiency) while the outlet temperature set point was raised to $165{ }^{\circ} \mathrm{F}$. (The strategy of allowing the system to automatically control to a specified $\mathrm{SO}_{2}$ emission rate produced more stable, predictable data than the strategy employed during the October 8-11, 2007, sampling campaign, which attempted to specify the Ca/S molar ratio rather than the $\mathrm{SO}_{2}$ emission rate).

$\mathrm{NO}_{\mathrm{x}}$ and $\mathrm{SO}_{2}$ concentrations at the stack were measured continuously during the test period using the unit's CEM, and $\mathrm{SO}_{2}$ concentrations at the Turbosorp ${ }^{\circledR}$ inlet were measured using the dilution extractive-type $\mathrm{SO}_{2}$ analyzer that is permanently installed between the air heaters and Turbosorp $^{\circledR}$ system. The following manual flue gas measurements were also completed on each test day:

- One $\mathrm{Hg}$ test at the stack (no activated carbon injection)

- Three $\mathrm{SO}_{3}$ tests with simultaneous sampling at the air heater outlet and stack

- Two $\mathrm{HCl}$ and $\mathrm{HF}$ tests with simultaneous sampling at the air heater outlet and stack

- Two PM tests with simultaneous sampling at the air heater outlet and stack (conducted as part of the $\mathrm{HCl}$ and $\mathrm{HF}$ tests)

At the end of each day, after the system had been allowed to line out for at least 6.5 hours under the prescribed operating conditions, Turbosorp ${ }^{\circledR}$ product ash samples were collected in duplicate for use in determining the $\mathrm{Ca} / \mathrm{S}$ molar ratio. Other process samples (i.e., coal, fly ash from the air heater outlet, pebble lime, and hydrated lime) and plant operating data were also collected on each test day for use in this determination. 


\subsubsection{Follow-Up Testing}

The follow-up tests were designed to reevaluate the performance of the multi-pollutant control system under guarantee test conditions after it had operated commercially for more than one year. These tests were completed during a single sampling campaign on June 10-13, 2008. During the follow-up testing period, AES Greenidge Unit 4 operated at or near high load and fired eastern U.S. bituminous coal containing 2.4-2.6\% (dry basis) sulfur (3.3-3.7 lb $\mathrm{SO}_{2} / \mathrm{mmBtu}$ ). (The coal sulfur content during the follow-up testing period was slightly lower than it had been during the guarantee tests; however, CONSOL, DOE, and AES Greenidge agreed to proceed with the tests using this coal).

$\mathrm{NO}_{x}$ and $\mathrm{SO}_{2}$ concentrations at the stack were measured continuously during the test period using the unit's $\mathrm{CEM}$, and $\mathrm{SO}_{2}$ concentrations at the Turbosorp ${ }^{\circledR}$ inlet were measured using the dilution extractive-type $\mathrm{SO}_{2}$ analyzer that is permanently installed between the air heaters and Turbosorp ${ }^{\circledR}$ system. The following manual flue gas measurements were also completed:

- Four Hg tests with simultaneous sampling at the economizer outlet, air heater inlet, and stack (no activated carbon injection)

- Four $\mathrm{SO}_{3}$ tests with simultaneous sampling at the economizer outlet, air heater inlet, air heater outlet, and stack

- Four $\mathrm{HCl}$ and $\mathrm{HF}$ tests with simultaneous sampling at the air heater outlet and stack

- Eight PM tests at the stack (conducted as part of the $\mathrm{Hg}$ tests and the $\mathrm{HCl}$ and $\mathrm{HF}$ tests), and four PM tests at the air heater outlet (conducted as part of the $\mathrm{HCl}$ and $\mathrm{HF}$ tests)

- Four ammonia slip tests at the air heater inlet

In addition to the flue gas measurements, various plant operating data and solid and liquid process samples (i.e., coal, bottom ash, fly ash from the air heater outlet, pebble lime, hydrated lime, Turbosorp ${ }^{\circledR}$ product ash, and urea) were collected during the test period for use in evaluating the performance of the multi-pollutant control system.

\subsection{Experimental}

All flue gas sampling, solid and liquid process sample collection, laboratory analysis, and data reduction was conducted or overseen by CONSOL Energy Inc. Research \& Development. Samples were collected and analyzed using standard methods published by the U.S. Environmental Protection Agency or ASTM International (ASTM), whenever applicable. The methods and procedures used for sample collection, laboratory analysis, and quality assurance and quality control (QA/QC) are described in the subsections below.

\subsubsection{Flue Gas Measurements}

\subsubsection{Sampling Locations}

Figure 39 presents a schematic showing the locations where flue gas sampling was conducted during the guarantee tests, process performance tests, and follow-up tests at AES Greenidge Unit 4. These sampling locations are described below. Appendix F presents photographs showing the flue gas sampling locations. 
During the baseline tests, the stack sampling location was the same as described below. However, the air heater inlet and air heater outlet locations differed from those described below, owing to a different ductwork configuration prior the installation of the multi-pollutant control system. During the baseline tests, $\mathrm{SO}_{3}$ sampling at the air heater inlet was conducted at a single point in the "A" duct between the economizer and the air heater inlet, and $\mathrm{SO}_{3}$ sampling at the air heater outlet was conducted using two points: one in the "A" duct and one in the "B" duct between the air heater outlet and the ESP inlet. Samples were collected at a constant sampling rate for $30-36$ minutes at the air heater inlet, and for 40 minutes (20 minutes per point) at the air heater outlet.

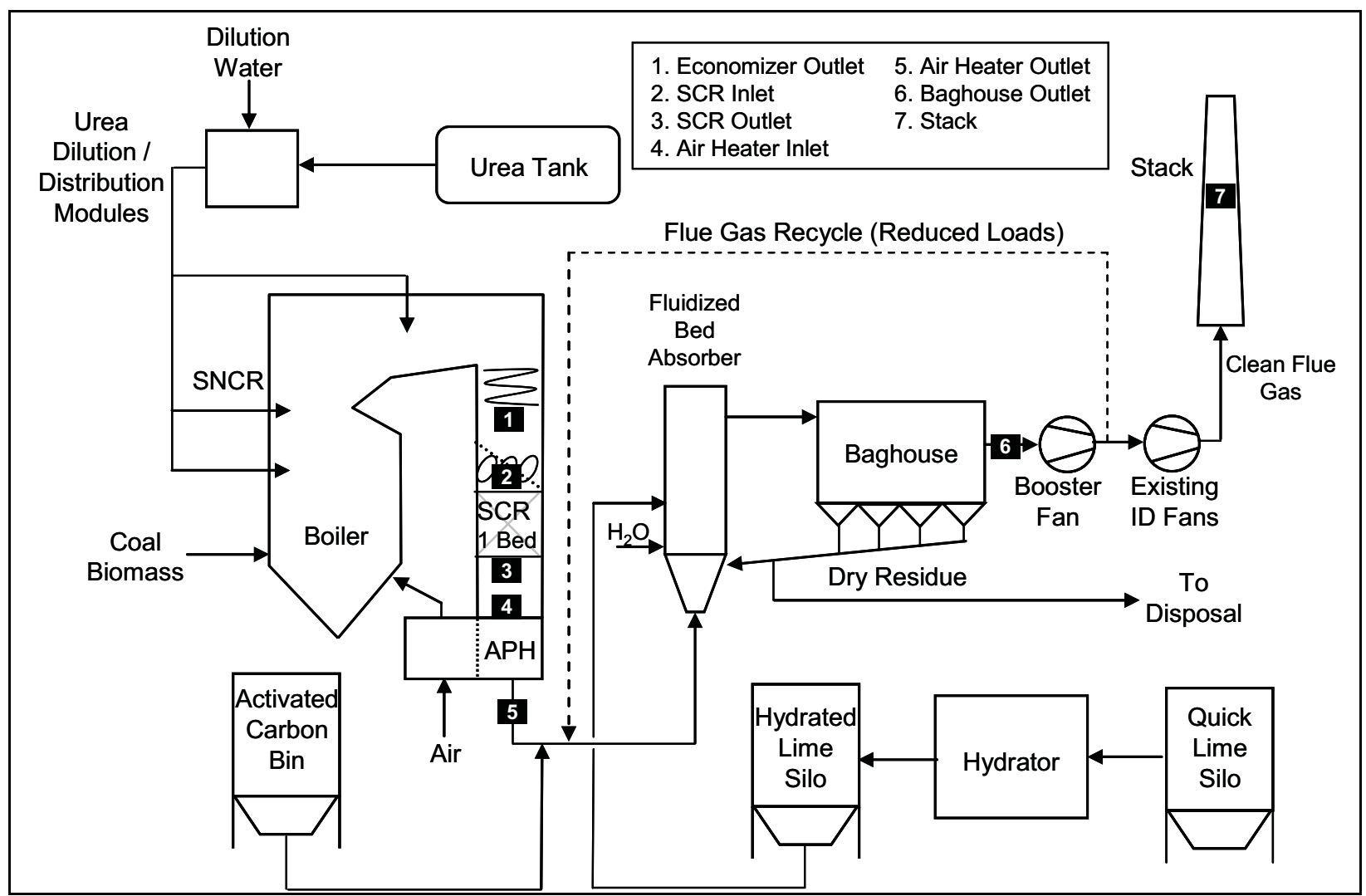

Figure 39. Schematic showing the locations where flue gas sampling was performed during performance testing of the multi-pollutant control system at AES Greenidge Unit 4.

\subsection{Economizer Outlet}

$\mathrm{NH}_{3}, \mathrm{Hg}$, and $\mathrm{SO}_{3}$ tests were conducted at the economizer outlet sampling location. This location consists of four, four-inch ports located downstream of the economizer but upstream of the in-duct SCR catalyst, static mixers, and large particle ash screen. Two of these ports (labeled E-1 and E-3) are located on the eastern wall of the economizer outlet duct, and the other two (labeled $\mathrm{W}-1$ and $\mathrm{W}-3$ ) are located on the western wall of the duct. On both the eastern and western sides of the economizer outlet, a support beam level with the sampling ports is located inside the duct at a depth of several feet. These support beams prevented the performance of isokinetic traverses of the economizer outlet duct. Hence, all sampling through the ports at the economizer outlet was conducted at a constant sampling rate (even if the 
method called for isokinetic sampling) at the deepest point that could be reached using a 10-12 foot probe. (In some instances, the probe was inserted at an angle to allow it to pass under the support beam).

During the $\mathrm{NH}_{3}$ tests on May 31-June 1, 2007, a composite sample was extracted from all four ports. During the 60-minute ammonia slip test on May 31, each of these ports was sampled for 15 minutes. During the 40-minute ammonia slip tests on June 1, each port was sampled for 10 minutes.

During the $\mathrm{Hg}$ tests on March 11, March 12, May 19-20, June 12, and June 13, 2008, a composite sample was extracted from all four ports. In general, each port was sampled for 30 minutes, resulting in a total test time of 120 minutes. (The first test on March 12 was 105 minutes long). Because the primary objective of the tests was to determine gas-phase $\mathrm{Hg}$ speciation, the sampling train nozzle was oriented away from the direction of flow to minimize the collection of particulate matter.

In general, during the $\mathrm{SO}_{3}$ tests on March 10, March 13, June 10, and June 11, 2008, a composite sample was extracted from all four ports. Each port was sampled for 15 minutes, resulting in a 60-minute total test. However, because of problems with leaks in the sample train during the June 2008 test period, only three ports were sampled during the first test on June 10 (one port was sampled for two 15-minute intervals), and only two ports were sampled during the second test on June 11 (each port was sampled for 25 minutes, for a total test time of 50 minutes).

\subsection{SCR Inlet}

$\mathrm{NO}_{\mathrm{x}}, \mathrm{CO}, \mathrm{Hg}$, and $\mathrm{SO}_{3}$ tests were conducted at the SCR inlet sampling location. The eastern wall of the SCR inlet duct is outfitted with four, four-inch flange ports, each of which contains six permanent sampling tubes. The six tubes installed through each of the four ports terminate at different depths in the duct, creating a 24-point grid of sample points covering the cross section of the duct. In addition, a single, four-inch port is located at approximately the center of the eastern wall of the SCR inlet duct (below the Delta Wing static mixers, but above the SCR catalyst). Manual flue gas sampling can be conducted through this port, although conventional probes can only cover about $20-25 \%$ of the 45 -foot duct width at this location.

Clean Air Engineering performed $\mathrm{NO}_{\mathrm{x}}$ testing on March 28, 2007, and $\mathrm{NO}_{\mathrm{x}}$ and $\mathrm{CO}$ testing on May 30-31, 2007, June 20, 2007, and May 21-22, 2008, using an automated sampling system that sequentially extracted samples from the 24-point permanent sampling grid at the SCR inlet. Each of the 24 grid points was sampled for a one-minute interval during each 24-minute test. A diagram showing the locations of the SCR inlet grid sampling points is provided in the CAE reports that are included in Appendix $G$ to this report.

During the $\mathrm{Hg}$ tests on October 2 and 3, 2007, sampling was conducted using a 10-foot probe inserted at a constant depth through the four-inch sampling port in the center of the eastern wall of the SCR inlet duct. The sampling was conducted at an isokinetic sampling rate; test times ranged from 100-120 minutes.

During the $\mathrm{SO}_{3}$ tests on March 30, October 4, and October 5, 2007, sampling was conducted using an 8- or 12-foot probe inserted at a constant depth through the four-inch sampling port in the center of the eastern wall of the SCR inlet duct. The sampling was conducted at a constant 
rate. Each test on March 30 was 40 minutes in duration. The test on October 4 was terminated early because the sampling train glassware failed. The tests on October 5 were each 60 minutes in duration.

\subsection{SCR Outlet}

$\mathrm{NO}_{x}, \mathrm{CO}, \mathrm{NH}_{3}, \mathrm{Hg}$, and $\mathrm{SO}_{3}$ tests were conducted at the SCR outlet sampling location. As with the SCR inlet duct, the eastern wall of the SCR outlet duct is outfitted with four, four-inch flange ports, each of which contains six permanent sampling tubes. The six tubes installed through each of the four ports terminate at different depths in the duct, creating a 24-point grid of sample points covering the cross section of the duct. In addition, two four-inch ports are located on the eastern wall of the SCR outlet duct, downstream of the SCR outlet sampling grid, which can be used for manual sampling. One of these ports is located closer to the northern side of the duct wall, and the other is located closer to the southern side.

Clean Air Engineering performed $\mathrm{NO}_{x}$ testing on March 28, 2007, and May 21-22, 2008, and $\mathrm{NO}_{x}$ and $\mathrm{CO}$ testing on May 30-31, 2007, and June 20, 2007, using an automated sampling system that sequentially extracted samples from the 24-point permanent sampling grid at the SCR outlet. Each of the 24 grid points was sampled for a one-minute interval during each 24minute test. A diagram showing the locations of the SCR outlet grid sampling points is provided in the CAE reports that are included in Appendix $G$ to this report.

During the $\mathrm{NH}_{3}$ tests on March 28, 2007, samples were drawn through the northernmost of the two four-inch ports downstream of the SCR outlet sampling grid; the port was traversed to a depth of approximately 10 feet using three sample points. Each test was 60 minutes in duration. During the $\mathrm{NH}_{3}$ tests on May 1, 2007, samples were drawn through both the northern and southern ports downstream of the SCR outlet sampling grid; each port was sampled for 30 minutes per test using a three-point traverse to a depth of approximately 10 feet. All ammonia samples at the SCR outlet were drawn at an isokinetic sampling rate.

During the $\mathrm{Hg}$ tests on October 2 and 3, 2007, samples were drawn isokinetically using a 10foot probe inserted through the northernmost of the two four-inch ports downstream of the SCR outlet sampling grid. Test times ranged from 90-120 minutes.

During the $\mathrm{SO}_{3}$ tests on March 30, October 4, and October 5, 2007, sampling was conducted using an 8- or 12-foot probe inserted at a constant depth through the northernmost of the two four-inch ports downstream of the SCR outlet sampling grid. Each test on March 30 was 40 minutes in duration, and each test on October 4-5 was 60 minutes in duration.

\subsection{Air Heater Inlet}

$\mathrm{NH}_{3}, \mathrm{Hg}$, and $\mathrm{SO}_{3}$ tests were conducted at the air heater inlet sampling location. All sampling at the air heater inlet was conducted through two ports located immediately upstream of the unit's two air heaters. One port is located at approximately the center (horizontal dimension) of the south wall of the eastern air heater inlet duct, and the other port is located at approximately the center of the south wall of the western air heater inlet duct. (These ports are downstream of the SCR outlet sampling ports described above). For all of the tests conducted at the air heater inlet as part of the project, the south wall of the boiler building prevented the use of a probe 
capable of reaching the exact center (in the north/south dimension) of the duct. Hence, samples were drawn from a point located as close as possible to the center of the duct.

During the $\mathrm{NH}_{3}$ tests on May 1, 2007, samples were drawn at a constant rate from a single point located near the center of each of the eastern and western ducts. Each 60-minute test consisted of 30 minutes of sampling in the eastern duct and 30 minutes of sampling in the western duct, resulting in a composite sample representing the average concentration in both ducts. During each $\mathrm{NH}_{3}$ test on May 31 and June 1, 2007, CONSOL and Clean Air Engineering simultaneously performed $\mathrm{NH}_{3}$ sampling through the air heater inlet ports. During the first half of each test, one group sampled the eastern duct while the other group sampled the western duct. The groups then exchanged positions for the second half of the test, such that each collected a composite sample representing the average concentration in both ducts. Both groups drew samples at a constant rate from a single point located near the center of each duct. The test on May 31 was 60 minutes in duration, and the tests on June 1 were each 40 minutes in duration. During each $\mathrm{NH}_{3}$ test on June 20 and 21, 2007, CONSOL used two sampling trains to simultaneously extract separate samples from the eastern and western air heater inlet ducts. Each sample was drawn at a constant rate from a single point located near the center of the duct. With the exception of the first test in the western duct, which lasted 50 minutes, all of the tests on June 20 and 21 were 40 minutes in duration. During all remaining $\mathrm{NH}_{3}$ tests (i.e., on October 8-11, 2007, November 13-16, 2007, March 10 and 13, 2008, May 20-22, 2008, and June 12-13, 2008), samples were drawn at a constant rate from a single point located near the center of each of the eastern and western ducts, resulting in a composite sample representing the average concentration in both ducts. Sampling was conducted for either 40 minutes (i.e., 20 minutes in each duct) or 60 minutes (i.e., 30 minutes in each duct), as indicated in the Field Sampling Data Sheets provided in Appendix $\mathrm{H}$.

During the $\mathrm{Hg}$ tests on March 11-12, May 19-20, and June 12-13, 2008, samples were drawn at a constant rate from a single point located near the center of each of the eastern and western ducts, resulting in a composite sample representing the average concentration in both ducts. All tests were 120 minutes in duration, with 60 minutes of sampling in each duct, except for the second test on March 12, which was 108 minutes long. Because the primary objective of the tests was to determine gas-phase $\mathrm{Hg}$ speciation, the sampling train nozzle was oriented away from the direction of flow to minimize the collection of particulate matter.

During the $\mathrm{SO}_{3}$ tests on March 10, March 13, and June 10-11, 2008, samples were drawn at a constant rate from a single point located near the center of each of the eastern and western ducts, resulting in a composite sample representing the average concentration in both ducts. All tests were 120 minutes in duration, with 60 minutes of sampling in each duct.

\subsection{Air Heater Outlet}

$\mathrm{SO}_{2}, \mathrm{Hg}, \mathrm{SO}_{3}, \mathrm{HCl}, \mathrm{HF}$, and $\mathrm{PM}$ tests were conducted at the air heater outlet sampling location. This location is situated along a stretch of horizontally-oriented ductwork (i.e., such that the flue gas flows parallel to the ground) between the air heater outlet and Turbosorp ${ }^{\circledR}$ inlet. The duct is rectangular with dimensions of approximately $12 \mathrm{ft}$ by $9.5 \mathrm{ft}$. Sampling was conducted through three vertically-oriented (i.e., positioned perpendicular to the ground) four-inch flange ports and through two vertically-oriented two-inch ports located just downstream of the four-inch ports. The dilution extractive-type $\mathrm{SO}_{2}$ analyzer that is permanently installed at the air heater outlet is located in line with the two-inch ports. 
During the $\mathrm{SO}_{2}$ tests on March 29, 2007, sampling was conducted by Clean Air Engineering using a CEM inserted through one of the two-inch ports described above. For the first two tests on that day, the sample was drawn from a single point in this port. For the third test, a threepoint traverse was performed through the same port. Each $\mathrm{SO}_{2}$ test was 60 minutes in duration. All other $\mathrm{SO}_{2}$ measurements at the air heater outlet were performed using the plant's dilution extractive-type $\mathrm{SO}_{2}$ analyzer.

During the $\mathrm{Hg}$ tests at the air heater outlet (i.e., on March 28 and 30, 2007, October 2-3, 2007, October 5, 2007, October 8-11, 2007, November 16, 2007, and March 11-12, 2008), samples were drawn by traversing the duct through all three four-inch flange ports. Each port was sampled at three points of varying depth, resulting in a nine-point traverse. (Several tests had to be terminated early, precluding the completion of all nine traverse points). With the exception of the test on October 9, 2007, which was discontinued when coal mill problems forced the unit to derate, all of the $\mathrm{Hg}$ tests at the air heater outlet were 100-126 minutes in duration. The tests on March 11-12, 2008, were conducted at a constant sampling rate, with the nozzle oriented away from the direction of flow to minimize the collection of particulate matter. All other $\mathrm{Hg}$ tests at the air heater outlet were conducted isokinetically and included simultaneous particulate matter sampling. (A cyclone was employed during the first test on October 3, 2007, in an attempt to minimize the amount of particulate matter that accumulated on the sampling train filter).

During the $\mathrm{SO}_{3}$ tests at the air heater outlet (i.e., on March 29, 2007, May 2, 2007, October 4-5, 2007, October 8-11, 2007, November 13-16, 2007, March 10 and 13, 2008, May 21-22, 2008, June 10-11, 2008, and June 16-19, 2008), sampling was conducted at one or more points through either the four-inch ports or the two-inch ports. For the testing on March 29, 2007, samples were drawn at a constant rate from a single point through one of the four-inch ports. For the testing on May 2, 2007, samples were drawn via a twelve-point traverse through the three four-inch flange ports. For all subsequent $\mathrm{SO}_{3}$ tests, samples were generally drawn from 1-3 points through each of the two two-inch ports. All $\mathrm{SO}_{3}$ sampling was performed at a constant rate. Test durations ranged from 40-70 minutes, although most tests were 60 minutes long.

During the $\mathrm{HCl}$ and $\mathrm{HF}$ tests at the air heater outlet (i.e., on March 29, 2007, May 4, 2007 , October 4-5, 2007, October 8-10, 2007, March 10 and 13, 2008, May 21-22, 2008, June 10-11, 2008, and June 16-19, 2008), samples were drawn by traversing the duct through all three fourinch flange ports. For the tests on May 4, 2007, each port was sampled at four points of varying depth, resulting in a twelve-point traverse. For all other tests, each port was sampled at three points of varying depth, resulting in a nine-point traverse. (Several tests had to be terminated early, precluding the completion of all traverse points). With the exception of the May 4, 2007, tests, all of the $\mathrm{HCl}$ and $\mathrm{HF}$ tests at the air heater outlet included simultaneous particulate matter measurements. Test durations ranged from 53-63 minutes. All sampling was performed isokinetically.

\subsection{Baghouse Outlet}

$\mathrm{SO}_{2}$ tests were conducted at the baghouse outlet sampling location. During the $\mathrm{SO}_{2}$ tests on March 29, 2007, sampling was conducted by Clean Air Engineering using a CEM inserted through a single port located in the vertically oriented ductwork between the baghouse outlet and the booster fan inlet. For the first two tests on that day, the sample was drawn from a 
single point in this port. For the third test, a three-point traverse was performed through the same port. Each $\mathrm{SO}_{2}$ test was 60 minutes in duration.

\subsection{Stack}

$\mathrm{NO}_{\mathrm{x}}, \mathrm{SO}_{2}, \mathrm{Hg}, \mathrm{SO}_{3}, \mathrm{HCl}, \mathrm{HF}$, and $\mathrm{PM}$ tests were conducted at the stack sampling location. All $\mathrm{NO}_{\mathrm{x}}$ and $\mathrm{SO}_{2}$ measurements at the stack were made using the unit's CEM. The manual sampling (i.e., for $\mathrm{Hg}, \mathrm{SO}_{3}, \mathrm{HCl}, \mathrm{HF}$, and $\mathrm{PM}$ ) was performed through some or all of the four four-inch ports located at the 83-ft level platform. The stack has an inner diameter of $13 \mathrm{ft}$; the four ports are located at 90-degree intervals about its circumference. Figure 40 presents a schematic showing the stack sampling location.

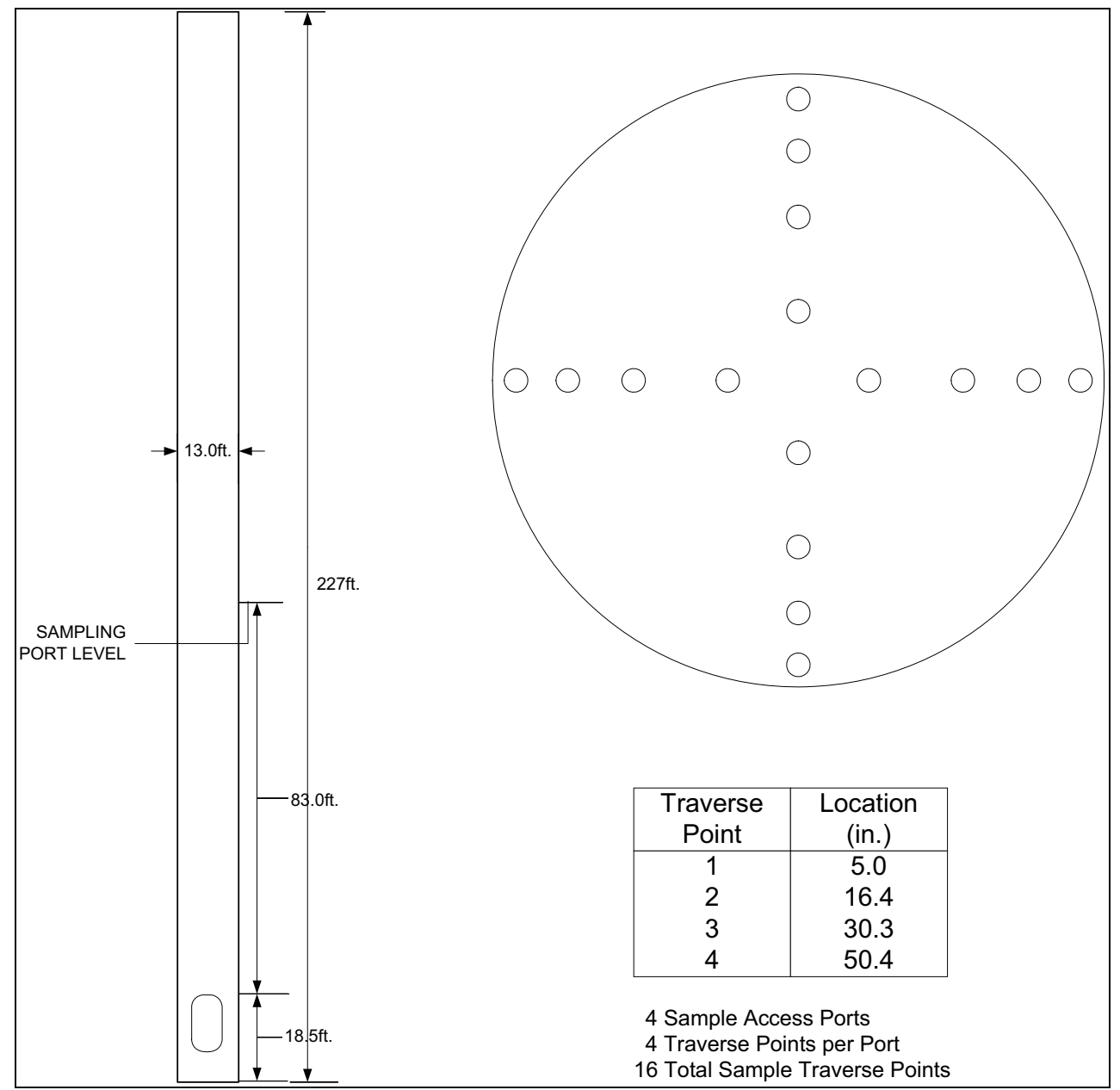

Figure 40. Schematic of the stack sampling location at AES Greenidge Unit 4, including dimensions and traverse points.

The $\mathrm{Hg}$ tests at the stack were performed using either the Ontario Hydro Method or U.S. EPA Method 30B. During the Ontario Hydro Method tests (i.e., on March 28 and 30, 2007, October 2-3, 2007, October 8-11, 2007, November 13-16, 2007, March 11-12, 2008, May 19-20, 2008, and June 12-13, 2008), samples were drawn by traversing the duct through all four ports. Each port was sampled at four points of varying depth, resulting in a sixteen-point traverse. With the exception of the test on October 9, 2007, which was discontinued when coal mill problems 
forced the unit to derate, all of the $\mathrm{Hg}$ tests at the stack were 116-128 minutes in duration (most were 120 minutes long). All of the Ontario Hydro tests at the stack were conducted isokinetically and included simultaneous particulate matter sampling. During the Method 30B tests (i.e., on June 12-13 and 16-19, 2008), samples were drawn from a single point through one of the four ports. The tests on June 12-13 were each 180 minutes in duration, and the tests on June 16-19 were each 360 minutes in duration. All of the Method 30B tests at the stack were conducted at a constant sampling rate.

During the $\mathrm{SO}_{3}$ tests at the stack (i.e., on March 29, 2007, May 2, 2007, October 4-5, 2007, October 8-11, 2007, November 13-16, 2007, March 10 and 13, 2008, May 21-22, 2008, June $10-11,2008$, and June 16-19, 2008), sampling was conducted at one or more points through the four-inch ports at the 83-ft level. For the testing on March 29, 2007, samples were drawn from a single point through one of the four ports. For the testing on May 2, 2007, samples were drawn via a sixteen-point traverse using all four ports. For all subsequent $\mathrm{SO}_{3}$ tests, samples were generally drawn from 1-4 points through one of the four ports at the 83-ft level. All $\mathrm{SO}_{3}$ sampling was performed at a constant rate. Each $\mathrm{SO}_{3}$ test at the stack on May 2 was 90 minutes in duration; all other $\mathrm{SO}_{3}$ tests at the stack were 60 minutes in duration.

During the $\mathrm{HCl}$ and $\mathrm{HF}$ tests at the stack (i.e., on March 29, 2007, May 4, 2007, October 4-5, 2007, October 8-10, 2007, March 10 and 13, 2008, May 21-22, 2008, June 10-11, 2008, and June 16-19, 2008), samples were drawn by traversing the duct through three or four of the sampling ports located at the 83-ft level platform. (For some tests, only three of the four ports were used in order to facilitate simultaneous $\mathrm{SO}_{3}$ sampling). Each port was sampled at four points of varying depth, resulting in a twelve- or sixteen-point traverse. With the exception of the May 4, 2007, tests, all of the $\mathrm{HCl}$ and $\mathrm{HF}$ tests at stack included simultaneous particulate matter measurements. Test durations ranged from 60-72 minutes (most tests were 64 minutes long). All $\mathrm{HCl}$ and $\mathrm{HF}$ sampling was performed isokinetically.

\subsubsection{Sampling and Analytical Methods}

\subsection{Oxides of Nitrogen}

$\mathrm{NO}_{x}$ measurements at the SCR inlet and SCR outlet were performed by Clean Air Engineering using U.S. EPA Method 7E, modified to incorporate the use of CAE's Multipoint Automated Sampling System (MASS). A complete description of the methodology is provided in the Clean Air Engineering reports that are included as Appendix $\mathrm{G}$ to this report. $\mathrm{NO}_{\mathrm{x}}$ measurements at the stack were made using the unit's stack CEM.

\subsection{Carbon Monoxide}

All CO measurements were performed by Clean Air Engineering using U.S. EPA Method 10, modified to incorporate the use of CAE's Multipoint Automated Sampling System. A complete description of the methodology is provided in the Clean Air Engineering reports that are included as Appendix $\mathrm{G}$ to this report. 


\subsection{Ammonia}

CONSOL and Clean Air Engineering both performed ammonia sampling using a modified version of U.S. EPA Conditional Test Method (CTM) 027. A complete description of the methodology followed by CAE is provided in Appendix $G$ to this report. The methodology followed by CONSOL is described below.

Because of space constraints at the sampling locations, complete isokinetic traverses could not be completed as specified in CTM 027 (as discussed above, sampling was conducted using an incomplete traverse at an isokinetic sampling rate at the SCR outlet and at a constant sampling rate at the air heater inlet and economizer outlet), and a heated Teflon sample line was required to connect the sampling probe to the impingers. Given the presence of $\mathrm{SO}_{2}$ and $\mathrm{SO}_{3}$ in the flue gas and the temperature of the heated line $\left(\sim 250^{\circ} \mathrm{F}\right)$, some of the collected ammonia was expected to condense out of the sample stream as ammonium bisulfate in the Teflon line, before reaching the impingers. Hence, the contents of line were collected by rinsing with deionized water or 0.1 normal $(\mathrm{N}) \mathrm{H}_{2} \mathrm{SO}_{4}$, and this line rinse was analyzed to account for the ammonia collected there. The sampling procedure is described in more detail below.

Samples were collected by pulling flue gas through an in-stack filter assembly containing a quartz fiber filter and a temperature-controlled quartz-lined probe that was heated to a temperature of $250^{\circ} \mathrm{F}$. Upon exiting the probe, the flue gas passed through a heated Teflon sample line (maintained at $\sim 250^{\circ} \mathrm{F}$ ) to the impinger train, where it flowed through a series of chilled impingers. The first two impingers were of Greenburg-Smith design, each containing $100 \mathrm{~mL}$ of a $0.1 \mathrm{~N} \mathrm{H}_{2} \mathrm{SO}_{4}$ solution. The third impinger, also containing $0.1 \mathrm{~N} \mathrm{H}_{2} \mathrm{SO}_{4}$, was a Greenburg-Smith type with the tip removed and was used to evaluate $\mathrm{NH}_{3}$ breakthrough. The final impinger, a Greenburg-Smith type without the tip, was filled with approximately $200 \mathrm{~g}$ of silica desiccant for moisture removal. After exiting the impingers, the gas sample passed through a dry test meter where its volume was measured. The $\mathrm{O}_{2}$ concentration in the gas exiting the meter was monitored using a Teledyne Max $\mathrm{V}$ portable electrochemical $\mathrm{O}_{2}$ analyzer.

Prior to sampling, the system was leak checked under a vacuum of approximately $10^{\prime \prime ~} \mathrm{Hg}$. The sample probe was placed at the proper location in the sample port; the sample port opening was sealed, and gas was sampled for 40-60 minutes. The following data were recorded: (1) starting gas volume, (2) interval gas volume, (3) final gas volume, (4) probe temperature, (5) heated line temperature, (6) meter differential pressure setting, (7) dry test meter temperature, (8) system vacuum, (9) exit gas $\mathrm{O}_{2}$ concentration, (10) barometric pressure, and (11) sampling time. Copies of the field data sheets are provided in Appendix $\mathrm{H}$. After sampling, the probe was removed from the duct and leak checked under a vacuum equal to or greater than the highest vacuum observed during testing, and the train components were disassembled for sample recovery. The sample train components were recovered in the following manner:

Sample Probe and In-Stack Filter Assembly - The quartz probe liner was rinsed with deionized water or $0.1 \mathrm{~N} \mathrm{H}_{2} \mathrm{SO}_{4}$, and the rinse was collected in an approved sample container. The filter was collected, but not analyzed, and the filter assembly was cleaned with deionized water. (The filter assembly rinse was not recovered). The probe rinse was diluted to a known volume and refrigerated until analysis.

Heated line - The heated Teflon line was rinsed with deionized water or $0.1 \mathrm{~N} \mathrm{H}_{2} \mathrm{SO}_{4}$, and the rinse was collected in an approved sample container. The rinse was then diluted to a known volume and refrigerated until analysis. 
Impingers - The contents of the first three impingers and connecting glassware (including rinses of these sample train components with deionized water) were collected in approved sample containers. These samples were then diluted to known volumes and refrigerated until analysis.

The samples were analyzed for ammonium ion by ion chromatography (IC), which is the method specified in CTM 027, or by ion selective electrode (ISE), which is not specified in CTM 027 but allows for the rapid, onsite determination of test results. Samples collected on March 28, 2007, May 1, 2007, October 8-11, 2007, November 13-16, 2007, March 10 and 13, 2008, May 20-22, 2008, and June 12-13, 2008, were analyzed by IC. Samples collected on May 31-June 1, 2007, were analyzed by both IC and ISE, and samples collected on June 20-21, 2007, were analyzed by ISE. The ISE analyses were performed in accordance with Standard Method (SM) $4500-\mathrm{NH}_{3}$ $\mathrm{D}$, using a Thermo Scientific Orion Model 95-12 ammonia gas-sensing ion specific electrode coupled with an Oakton model $\mathrm{pH} 2100 \mathrm{pH} /$ ion meter. The laboratory analysis results are provided in Appendix I.

For both the ISE and the IC analyses, the concentration of ammonia in the flue gas was calculated based on the mass of ammonium ion collected (sum of masses determined in the probe, heated line, and impingers) and the volume of flue gas sampled during the test.

\subsection{Sulfur Dioxide}

$\mathrm{SO}_{2}$ measurements performed by Clean Air Engineering at the air heater outlet and baghouse outlet were conducted using U.S. EPA Method 6C. A complete description of the methodology is provided in the CAE report that is included as Appendix $\mathrm{G}$ to this report. In addition, $\mathrm{SO}_{2}$ measurements were made at the air heater outlet using the plant's dilution extractive-type $\mathrm{SO}_{2}$ analyzer that is permanently installed there, and at the stack using the unit's stack CEM.

\subsection{Mercury}

Flue gas Hg measurements were performed using the Ontario Hydro Method (ASTM D6784-02) or U.S. EPA Method 30B. These methods are described below.

\subsection{Ontario Hydro Method}

With the exception of the U.S. EPA Method 30B tests at the stack on June 12-13 and 16-19, 2008, all Hg measurements performed as part of the project were conducted using the Ontario Hydro Method. (The tests at the stack on June 12-13 included side-by-side sampling via the Ontario Hydro Method and U.S. EPA Method 30B). During each Ontario Hydro Method test, gas was extracted from the flue gas stream through an in-stack filter assembly, heated glasslined probe, and heated sample line. (The baseline tests on November 17-18, 2004, used a heated, out-of-stack filter rather than the in-stack filter and heated sample line). Mercury collected in the filter was assumed to be particle-bound $\mathrm{Hg}\left(\mathrm{Hg}^{\text {part }}\right)$. The flue gas exited the sample line and passed through a series of chilled impingers. The first three impingers were filled with $100 \mathrm{~mL}$ of a $1 \mathrm{M}$ potassium chloride $(\mathrm{KCl})$ solution. Mercury captured in these impingers and in the probe and sample line, which were rinsed with $\mathrm{HNO}_{3}$ and $\mathrm{HCl}$, was reported as oxidized $\mathrm{Hg}\left(\mathrm{Hg}^{2+}\right)$. The next impinger was filled with $100 \mathrm{~mL}$ of $5 \%$ nitric acid and 
$10 \% \mathrm{H}_{2} \mathrm{O}_{2}$ solution to remove $\mathrm{SO}_{2}$ from the flue gas and preserve the oxidizing strength of the subsequent permanganate impingers. The next two impingers were filled with $100 \mathrm{~mL}$ of an acidic potassium permanganate $\left(\mathrm{KMnO}_{4}\right)$ solution. Mercury captured in the nitric acid impinger and the potassium permanganate impingers was reported as elemental mercury $\left(\mathrm{Hg}^{0}\right)$. The next impinger was blank to catch any excess moisture. The gas exited the impinger train through a silica gel-filled impinger that removed uncondensed moisture from the sample gas and then flowed through a vacuum pump and a dry gas meter. Oxygen readings were monitored at the outlet of the sampling train using a Teledyne Max $\mathrm{V}$ portable electrochemical $\mathrm{O}_{2}$ analyzer. Figure 41 presents a schematic of the Ontario Hydro Method sampling train. Copies of the field data sheets from the Ontario Hydro tests are provided in Appendix $\mathrm{H}$.

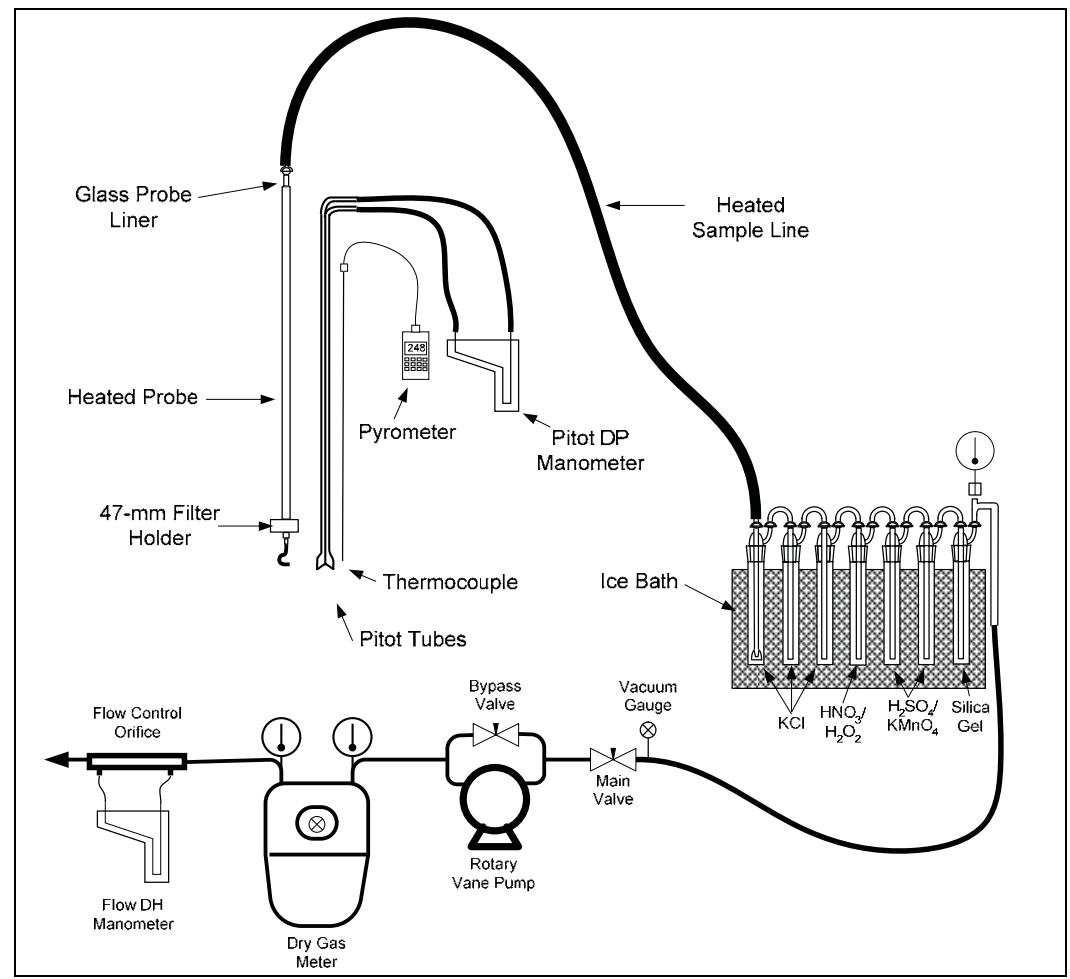

Figure 41. Schematic of the Ontario Hydro Method sampling train in a Method 17 configuration.

All of the Ontario Hydro Method tests at the stack, SCR inlet, and SCR outlet, and most of the tests at the air heater outlet, were conducted at an isokinetic sampling rate as specified in the method. In addition to measuring $\mathrm{Hg}$, the isokinetic tests at the air heater outlet and stack included the determination of particulate matter according to U.S. EPA Method 17. The Ontario Hydro Method was modified, however, for the tests at the air heater outlet on March 11-12 and for all of the tests at the economizer outlet and air heater inlet. Because the primary objective of these tests was to determine gas-phase $\mathrm{Hg}$ speciation (i.e., $\mathrm{Hg}^{0}$ and $\mathrm{Hg}^{2+}$ ), sampling was conducted at a constant, reduced rate, with the sampling train nozzle oriented away from the direction of flue gas flow, to minimize the collection of particulate matter. Hg speciation results determined using the Ontario Hydro Method can be biased in high-dust locations by adsorption of $\mathrm{Hg}$ onto the particulate (fly ash) that is collected on the sample filter or by reaction of $\mathrm{Hg}$ with that fly ash (Feeley et al., 2003). This can lead to artificially high particle-bound and/or oxidized mercury concentrations, and artificially low elemental and/or oxidized mercury concentrations. 
The $\mathrm{Hg}$ concentration of the individual impinger solutions and sampling component rinses was determined by cold vapor atomic absorption spectroscopy (CVAAS) or cold vapor atomic fluorescence spectroscopy (CVAFS) as specified in the Ontario Hydro Method. CVAAS was used for the tests on November 17-18, 2004, and March 28 and 30, 2007, and CVAFS was used for all subsequent tests in order to provide a lower method detection limit. The concentration of $\mathrm{Hg}$ on the filter solids was determined according to the procedures described in ASTM D6414 or ASTM D6722. The laboratory analysis results are provided in Appendix I.

\subsection{U.S. EPA Method 30B}

Hg measurements at the stack on June 12-13 and 16-19, 2008, were performed using U.S. EPA Method 30B "Determination of Total Vapor Phase Mercury Emissions from Coal-Fired Combustion Sources Using Carbon Sorbent Traps." (As discussed above, the tests at the stack on June 12-13 included side-by-side sampling via the Ontario Hydro Method and U.S. EPA Method 30B). The sorbent trap sampling train schematic is shown in Figure 42.

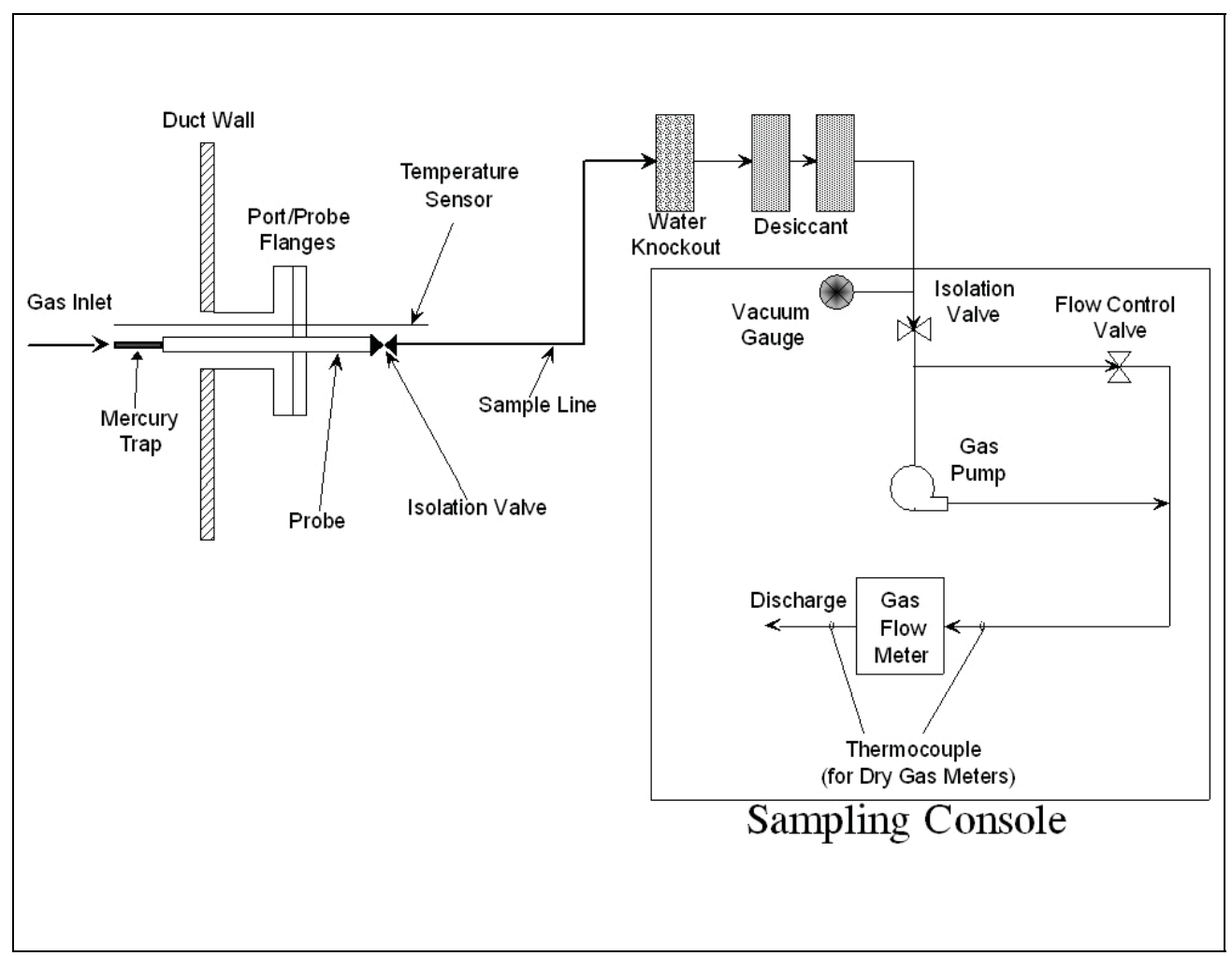

Figure 42. Schematic of the U.S. EPA Method 30B sampling train.

During each Method 30B test, flue gas was extracted from the stack through paired, in-stack, two-section, iodated carbon sorbent traps at a constant sampling rate. During the tests on June $12-13$, sampling was conducted for a period of 180 minutes at a sampling rate of approximately 1.85 dry standard liters per minute. During the tests on June 16-19, sampling was conducted for a period of 360 minutes at a sampling rate of either 1.85 or 0.95 dry standard liters per minute. The sorbent trap temperature was maintained at stack temperature. After exiting the sorbent traps, the flue gas passed through a series of chilled impingers (used to dry the flue gas) and a dry gas meter. 
Prior to each test, the sampling train was assembled, pre-heated, and checked for leaks. After passing the leak-check procedure, the sampling probe was inserted into the stack and sampling was initiated. Oxygen readings were monitored at the outlet of the sampling train using a Teledyne Max $\mathrm{V}$ portable electrochemical $\mathrm{O}_{2}$ analyzer to verify continued leak-free sample train operation. At regular intervals during the sampling period, the following data were recorded: (1) time, (2) sample flow rate, (3) gas meter reading, (4) stack temperature, (5) gas meter temperatures, (6) sampling system vacuum readings, and (7) temperature of the last impinger. Copies of the field data sheets are provided in Appendix $\mathrm{H}$.

The sampling flow rate was adjusted as necessary to maintain it within $20 \%$ of the targeted flow rate. At the completion of the sampling period, the sample train was checked for leaks and then disassembled.

The mercury concentration in the individual trap beds was determined by cold vapor atomic fluorescence spectroscopy as specified in Method 30B. The laboratory analysis results are provided in Appendix I.

\subsection{Sulfur Trioxide}

Flue gas $\mathrm{SO}_{3}$ concentrations were determined using a controlled condensation method originally developed by the U.S. EPA and modified by CONSOL (DeVito and Smith, 1991; Oda and DeVito, 1998). In this method, flue gas is pulled through a temperature-controlled quartzlined probe that is fitted with a quartz wool plug to remove particulate matter. The probe temperature is maintained at $\sim 550^{\circ} \mathrm{F}$ to minimize $\mathrm{SO}_{3}$ condensation and $\mathrm{SO}_{2}$ oxidation. After exiting the probe, the gas sample passes through a $140^{\circ} \mathrm{F}$, temperature-controlled condenser that is loosely packed with glass wool. Essentially all of the $\mathrm{SO}_{3}$ is collected in the condenser. The sample gas exits the condenser and enters a series of miniature impingers. The first two impingers contain a $3 \% \mathrm{H}_{2} \mathrm{O}_{2}$ solution, which captures the $\mathrm{SO}_{2}$. The gas next passes through an empty impinger, and finally through a silica gel-filled impinger for moisture removal. The gas is then conveyed through a rotameter, a vacuum pump, and a dry test meter. The $\mathrm{O}_{2}$ concentration in the gas exiting the dry test meter is monitored using a Teledyne Max $\mathrm{V}$ portable electrochemical $\mathrm{O}_{2}$ analyzer.

Prior to sampling, the system is leak checked under a vacuum of 10 " of $\mathrm{Hg}$. The sample probe is then positioned at the proper location and gas is sampled for at least 30 minutes. The following data are recorded: (1) starting gas volume, (2) interval gas volume, (3) final gas volume, (4) probe temperature, (5) condenser temperature, (6) water bath temperature, (7) flue gas duct temperature, (8) dry test meter temperature, (9) flow meter setting, (10) system vacuum, (11) exit gas $\mathrm{O}_{2}$ concentration, (12) barometric pressure, and (13) sampling time. Copies of the field data sheets are provided in Appendix $\mathrm{H}$. After sampling, the probe is removed from the duct, leak checked under a vacuum of 10" of $\mathrm{Hg}$, and purged with ambient air for 10 minutes, and the train components are disassembled for sample recovery.

During the $\mathrm{SO}_{3}$ tests on November 17-18, 2004, and March 29 and 30, 2007, the sample train contents were recovered using isopropyl alcohol (IPA) rinses and analyzed by $\mathrm{BaCl}_{2}$ titration. The quartz plug was removed from the probe tip, placed in a glass bottle, and extracted with 20 $\mathrm{mL}$ of isopropyl alcohol. The solids were filtered and the filtrate was diluted to a known volume prior to analysis. The quartz probe liner was rinsed with IPA into a glass bottle and diluted to a known volume. The condenser interior was also rinsed (via three complete rinses) with IPA into a glass bottle and the rinses were diluted to a known volume prior to analysis. Each of these 
samples was analyzed for sulfate by a $\mathrm{BaCl}_{2}$ titration to a thorin endpoint as described in EPA Method 6. The quartz plug contains $\mathrm{SO}_{3}$ that was absorbed onto the solid particles prior to collection in the sampling train. The gas-phase $\mathrm{SO}_{3}$ value is the sum of the probe and condenser rinses. In most cases, the majority of the gas-phase $\mathrm{SO}_{3}$ is found in the condenser rinse. The $\mathrm{SO}_{3}$ values are reported in ppmvd at duct conditions and at $3 \%$ oxygen.

Ammonia resulting from the SNCR system likely interfered with the $\mathrm{BaCl}_{2}$ titration results for the tests on March 29 and 30, 2007, as discussed in EPA Method 8. To avoid possible $\mathrm{NH}_{3}$ interference and improve the sensitivity of the method for determining the low-level $\mathrm{SO}_{3}$ concentrations encountered at the stack, all subsequent $\mathrm{SO}_{3}$ samples were analyzed for sulfate by ion chromatography rather than by $\mathrm{BaCl}_{2}$ titration. IPA poses a problem for the IC analysis; hence, the filter plug extraction, probe rinse, and condenser rinse were performed using deionized water instead of IPA. All other aspects of the method remained unchanged. The laboratory analysis results are provided in Appendix I.

The concentration of $\mathrm{SO}_{2}$ in the flue gas can also be determined from the controlled condensation train by analyzing the $\mathrm{H}_{2} \mathrm{O}_{2}$ impinger solutions (and rinse of the tubing connecting the condenser to the impingers) for sulfate by ion chromatography or $\mathrm{BaCl}_{2}$ titration. This was done for most of the $\mathrm{SO}_{3}$ tests at AES Greenidge Unit 4, and results were used in the data analyses whenever no other $\mathrm{SO}_{2}$ measurements were available (e.g., at the SCR inlet and SCR outlet sampling locations).

\subsection{Hydrogen Chloride, Hydrogen Fluoride, and Particulate Matter}

Flue gas $\mathrm{HCl}, \mathrm{HF}$, and particulate matter measurements were conducted using a combined U.S. EPA Method 17/26A sampling train or a combined U.S. EPA Method 5/26A sampling train. The Method 5/26A train was used for the baseline tests on November 17-18, 2004, and the Method $17 / 26$ A train was used for all other measurements. (As discussed above, particulate matter measurements were also conducted during many of the Ontario Hydro Hg tests using a U.S. EPA Method 17 configuration. Particulate matter was not determined during the $\mathrm{HCl}$ and $\mathrm{HF}$ tests on May 4, 2007). In the Method 17/26A configuration, gas is extracted isokinetically from the flue gas stream through an in-stack filter assembly, heated glass-lined probe, and heated sample line. In the Method 5/26A configuration, gas is extracted isokinetically from the flue gas stream through a heated glass-lined probe and heated quartz filter. Probe, line, and filter temperatures (where applicable) are maintained at $\sim 250^{\circ} \mathrm{F}$.

The flue gas exits the sample line and passes through a series of chilled impingers. The first two impingers are Greenburg-Smith design, each containing $100 \mathrm{~mL}$ of a $0.1 \mathrm{~N} \mathrm{H}_{2} \mathrm{SO}_{4}$ solution that collects the hydrogen halide portion of the sample, which is solubilized in the acidic solution and forms chloride $\left(\mathrm{Cl}^{-}\right)$and fluoride $\left(\mathrm{F}^{-}\right)$ions. Because emissions of $\mathrm{Cl}_{2}$ were not targeted in the program at AES Greenidge, the Method 26A impinger train was altered to exclude the impingers specified for capturing that compound. The next impinger is initially empty to catch any excess moisture. The gas exits the impinger train through a silica gel-filled impinger that removes uncondensed moisture from the sample gas, and it then flows through a vacuum pump and a dry gas meter.

The sampling train design results in the following collection sequence: 


\section{Sampling Train Component}

Filter

Probe and Sample Line Rinse

Impingers
Species Measured

Particulate Matter

$\mathrm{HCl} \& \mathrm{HF}$

$\mathrm{HCl} \& \mathrm{HF}$

Sampling was performed isokinetically. Oxygen readings were monitored at the outlet of the sampling train using a Teledyne Model Max 5 portable electrochemical $\mathrm{O}_{2}$ analyzer. Copies of the field data sheets are provided in Appendix $\mathrm{H}$. The $\mathrm{Cl}^{-}$and $\mathrm{F}^{-}$concentrations of the impinger solutions were determined by ion chromatography as specified in EPA Method 26A. The laboratory analysis results are provided in Appendix I.

\subsubsection{Quality Assurance and Quality Control}

The CONSOL field sampling team used standard EPA-type sampling equipment that conformed to all applicable test codes. Most of the equipment used in the manual sampling methods was obtained from Thermo-Andersen (formerly known as Andersen Instruments, Graseby-Nutech, and Nutech). CONSOL used a Mettler electronic balance for pre- and post-test dust weights. This balance was checked daily with class "S" calibration weights.

All sampling trains were leak checked prior to each test and again at the end of each test. All sample trains, with the exception of CTM 027 sample trains, were purged with air for ten minutes and then disassembled and transported to the lab trailer for recovery.

A Teledyne Max $\mathrm{V}$ portable gas analyzer was used for determining flue gas composition at the sample train discharge. The meter operator used the readings to assess the operation of the sampling train and the unit operation. Past experience has indicated that the accuracy of the oxygen determination by this analyzer is equal to or better than that of a manual Orsat analyzer.

\subsection{Oxides of Nitrogen Measurements}

Quality assurance / quality control information for the $\mathrm{NO}_{\mathrm{x}}$ measurements at the SCR inlet and outlet is provided in the Clean Air Engineering reports that are included in Appendix $G$ to this report.

\subsection{Carbon Monoxide Measurements}

Quality assurance / quality control information for the CO measurements at the SCR inlet and outlet is provided in the Clean Air Engineering reports that are included in Appendix $G$ to this report.

\subsection{Ammonia Measurements}

As discussed above, CONSOL and Clean Air Engineering both performed ammonia sampling at AES Greenidge Unit 4. Quality assurance / quality control information for the $\mathrm{NH}_{3}$ 
measurements made by CAE is provided in Appendix $\mathrm{G}$ to this report. The quality assurance / quality control procedures followed by CONSOL are described below.

For the ISE analyses, at the beginning of each analytical day, fresh calibration standards with concentrations of $0.1,1.0,10$, and $100 \mathrm{mg} / \mathrm{L}$ ammonia as nitrogen $\left(\mathrm{NH}_{3}-\mathrm{N}\right)$ were prepared. These were used to develop a standard semilogarithmic curve relating concentrations of $\mathrm{NH}_{3}-\mathrm{N}$ to the ion meter's millivolt readings. Blank samples of the deionized water and $0.1 \mathrm{~N} \mathrm{H}_{2} \mathrm{SO}_{4}$ reagents used for sample recovery were run to confirm that they were not contaminated.

For the ion chromatography analyses, although not required by method, randomly selected samples were run in duplicate. The average result for each sample was reported. In all cases, the duplicate results had a relative percent difference (RPD) of $\leq 10 \%$. An independent quality control standard with a concentration of approximately the midpoint of the calibration curve range was run immediately after calibration and after every 10 samples. In all cases, recovery of the quality control standard was between $90 \%$ and $110 \%$. Randomly selected samples from each batch were spiked at $2 \mathrm{mg} / \mathrm{L} \mathrm{NH} \mathrm{NH}_{3} \mathrm{~N}$ to assess any possible matrix issues; none were discovered. Blank samples of the deionized water and $0.1 \mathrm{~N} \mathrm{H}_{2} \mathrm{SO}_{4}$ reagents used for sample recovery were also run to confirm that they were not contaminated.

In addition to the standard QA/QC procedures specified in CTM 027, blank samples were obtained after one of the tests on each of June 1, June 20, October 10, November 13, and November 15 by performing a second rinsing of the probe and line that were used for sampling at the air heater inlet. This was done to ensure that: (1) the initial rinses succeeded in recovering all of the ammonia collected in the probe and line, and (2) there was no residual ammonia from the test that could affect the results of a subsequent test. The blank rinses were analyzed for ammonium. The ammonium concentrations in the probe rinse blanks were less than or equal to the ammonium concentrations in blank deionized water or $\mathrm{H}_{2} \mathrm{SO}_{4}$ solutions that were used to perform the rinses, and the amount of ammonium recovered in the line rinse blanks was $\leq 12 \%$ of the amount recovered in the original line rinses (or below the detection limit). Moreover, during the May 31-June 1 testing period, the impingers from a blank CTM 027 train were recovered in the field and analyzed for ammonium; ammonium concentrations in all three field blank impingers were less than the IC limit of detection $\left(0.1 \mathrm{mg} / \mathrm{L} \mathrm{NH}_{3}-\mathrm{N}\right)$.

\subsection{Sulfur Dioxide Measurements}

Quality assurance / quality control information for the $\mathrm{SO}_{2}$ measurements at the air heater outlet and baghouse outlet is provided in the Clean Air Engineering Report that is included as Appendix $\mathrm{G}$ to this report.

\subsection{Mercury Measurements}

\subsection{Ontario Hydro Method}

Samples were prepared and analyzed as outlined in ASTM D6784-02 (Ontario Hydro Method). The samples from November 2004 and March 2007 were analyzed using a Thermo Unicam 969 CVAAS, which had a detection limit of $0.14 \mu \mathrm{g} / \mathrm{L}$. All subsequent samples were analyzed using a Tekran 2600 CVAFS, which had a detection limit of $0.1 \mathrm{ng} / \mathrm{L}$. $\mathrm{R}^{2}$ values for all instrument calibration curves were $>0.999$. A sample of National Institute of Standards and Technology 
(NIST) Standard Reference Material (SRM) 1641D was analyzed immediately after calibration. If recovery of $\mathrm{Hg}$ in the NIST standard was not within $100 \pm 10 \%$, then the analyzer was recalibrated before proceeding. An independent calibration verification (ICV) sample was analyzed at the beginning of each run and after every $10^{\text {th }}$ sample; if recovery of $\mathrm{Hg}$ in the ICV was not within $100 \pm 10 \%$, then the run was stopped, the analyzer was recalibrated, and the affected samples were reanalyzed. All samples were run in duplicate with an acceptance criterion of $10 \%$ relative percent difference. (Four samples were slightly above 10\% RPD). One in 10 samples was analyzed in triplicate with an acceptance criterion of $10 \%$ relative standard deviation (RSD). Matrix spikes were included at a 1-in-10 sample frequency with an acceptance criterion of $100 \pm 10 \%$ spike recovery. Although not required by ASTM D6784-02, digestion duplicates and digestion spikes also were included periodically to assess the efficiency of the digestions.

Particulate-impregnated filters and blank filter thimbles were digested according to ASTM D6414 and then analyzed in duplicate with an acceptance criterion of $10 \%$ relative percent difference. Matrix spikes were included at a 1-in-10 sample frequency, with an acceptance criterion of $100 \pm 10 \%$ spike recovery. NIST SRM 1633B was digested and analyzed with the batch of filters; recovery of $\mathrm{Hg}$ in the SRM was required to be $100 \pm 10 \%$. Loose particulate from filter thimbles was analyzed according to ASTM D6722. One out of every ten samples was analyzed in duplicate with an acceptance criterion of $10 \%$ relative percent difference. Again, a sample of NIST SRM 1633B was analyzed with the batch of samples; $100 \pm 10 \%$ recovery of $\mathrm{Hg}$ in the SRM was required.

\subsection{U.S. EPA Method 30B}

Samples were prepared and analyzed as outlined in U.S. EPA Method 30B. (Although specified in the method, the field recovery test was not performed as part of the sampling at AES Greenidge). The samples were analyzed using a Tekran 2600 CVAFS, which had a detection limit of $0.1 \mathrm{ng} / \mathrm{L}$. $R^{2}$ values for all instrument calibration curves were $>0.99$, and all calibration standards were recovered to within $10 \%$ of their true values. An ICV standard was analyzed at the beginning of each run, and a continuing calibration verification (CCV) standard was analyzed after every $10^{\text {th }}$ sample. Recoveries for the ICV and CCV were required to be $100 \pm 10 \%$; if this criterion was not satisfied, then the run was stopped, the analyzer was recalibrated, and the affected samples were reanalyzed. Blanks, duplicates, matrix spikes, and digestion spikes were also included as part of the analytical run (at a frequency of approximately one out of every ten samples) in order to assess the performance of the method. The acceptance criterion for spike recovery was $100 \pm 10 \%$, and the acceptance criterion for duplicates was $\leq 10 \%$ relative percent difference.

As discussed in Section 9.2.1.2.5.2, each Method 30B sampling train contained paired sorbent traps. Each trap contained two sections; the second section is used to assess $\mathrm{Hg}$ breakthrough. Method 30B requires that the paired sorbent trap agreement is $\leq 10 \%$ relative deviation (RD) for $\mathrm{Hg}$ concentrations $>1 \mu \mathrm{g} / \mathrm{dscm}$ and $\leq 20 \% \mathrm{RD}$ (or $\leq 0.2 \mu \mathrm{g} / \mathrm{dscm}$ absolute difference) for $\mathrm{Hg}$ concentrations $\leq 1 \mu \mathrm{g} / \mathrm{dscm}$. All eight test runs performed at AES Greenidge Unit 4 satisfied this criterion. The method also requires that the $\mathrm{Hg}$ breakthrough in the second sorbent trap section is $\leq 10 \%$ of the section $1 \mathrm{Hg}$ mass for $\mathrm{Hg}$ concentrations $>1 \mu \mathrm{g} / \mathrm{dscm}$ and $\leq 20 \%$ of the section $1 \mathrm{Hg}$ mass for $\mathrm{Hg}$ concentrations $\leq 1 \mu \mathrm{g} / \mathrm{dscm}$. Eleven of the sixteen sorbent traps analyzed as part of the eight Method 30B tests at AES Greenidge did not satisfy this criterion. However, the mass of $\mathrm{Hg}$ determined in the first and second sections of these traps, which ranged from 1.05-14.1 ng, was on the same order as the mass of $\mathrm{Hg}$ determined in 
blank sorbent trap sections, which ranged from 1.6-4.5 ng. Hence, the failure to satisfy the breakthrough criterion likely resulted from extremely low flue gas $\mathrm{Hg}$ concentrations (i.e., 0.01 $0.05 \mu \mathrm{g} / \mathrm{dscm}$ ) rather than from actual breakthrough, and test results are reported as valid results in this report even if the breakthrough criterion was not satisfied.

\subsection{Mercury Material Balance}

Mercury material balances were performed to confirm the quality of all coal-to-stack mercury removal efficiencies determined during the project. These material balances, which were performed independently for each test run, compare the total amount of mercury leaving the process during the test with the total amount of mercury entering the process during the test. The mercury material balance closure is the total mercury output from the process divided by the total mercury input, expressed as a percentage.

During the baseline tests, which were conducted prior to installation of the multi-pollutant control system, mercury entered the process in the coal. Potential mercury output streams included the bottom ash, ESP ash, and stack flue gas. (The methodologies used to collect and analyze solid and liquid process samples are described in Section 9.2.2, and analytical results for these samples are presented in Appendix J).

For all other tests, which were conducted after installation of the multi-pollutant control system, potential mercury input streams included the coal, urea, activated carbon (on March 30 and October 5, 2007), process water, and hydrated lime. Potential mercury output streams included the bottom ash, Turbosorp ${ }^{\circledR}$ hopper ash, Turbosorp ${ }^{\circledR}$ product ash, and stack flue gas.

For purposes of the $\mathrm{Hg}$ material balances, the amount of mercury entering or exiting the process via the urea, activated carbon, process water, bottom ash, and Turbosorp ${ }^{\circledR}$ hopper ash streams was assumed to be negligible. Based on mercury concentrations determined in the urea samples that were collected during the tests in March 2007, October 2007, November 2007, March 2008, May 2008, and June 2008 (all less than the analytical detection limit of 0.35 $\mu \mathrm{g} / \mathrm{L})$, the average urea feed rate recorded by the plant during these test ( $53 \mathrm{gal} / \mathrm{h}$, or $201 \mathrm{~L} / \mathrm{h}$ ), and the average total $\mathrm{Hg}$ input computed for these tests $(0.00745 \mathrm{lb} / \mathrm{h}$, or $3.38 \mathrm{~g} / \mathrm{h})$, the urea contributed less than $0.01 \%$ of the total $\mathrm{Hg}$ input to the process. The activated carbon also contributed less than $0.01 \%$ of the total $\mathrm{Hg}$ input, based on the $\mathrm{Hg}$ concentration of $0.005 \mathrm{ppm}$ determined in activated carbon samples collected during testing in March 2007 and October 2007 and on the design carbon injection rate of $89 \mathrm{lb} / \mathrm{h}$. Process water samples were collected during the test series in October 2007, November 2007, March 2008, and June 2008; the mercury concentration determined in every process water sample collected as part of the project was less than the analytical detection limit of $0.35 \mu \mathrm{g} / \mathrm{L}$. Hence, assuming the design process water flow rate of $121 \mathrm{gpm}$ (combination of urea dilution water and water injected into the Turbosorp ${ }^{\circledR}$ system), the process water contributed less than $0.3 \%$ of the total $\mathrm{Hg}$ input to the process. Bottom ash samples were collected during the baseline testing at AES Greenidge in November 2004, and it was determined that the bottom ash contained less than $0.1 \%$ of the total $\mathrm{Hg}$ output from the unit. Bottom ash samples collected during the test series in October 2007, March 2008, and June 2008 had mercury concentrations that were less than or equal to the average concentration observed in the bottom ash during the baseline tests. Hence, mercury output in the bottom ash during the guarantee tests, process performance tests, and follow-up tests was assumed to be negligible. Finally, the flow rate of ash leaving the Turbosorp $^{\circledR}$ hopper (beneath the inlet to the absorber vessel) is not known, but it is insignificant 
relative to the flow rate of Turbosorp ${ }^{\circledR}$ product ash leaving the process. The concentration of $\mathrm{Hg}$ in the Turbosorp ${ }^{\circledR}$ hopper ash was also only about $35 \%$ as great as that in the Turbosorp ${ }^{\circledR}$ product ash during the March 2007 guarantee tests. Hence, it is reasonable to assume that the urea, activated carbon, process water, bottom ash, and Turbosorp ${ }^{\circledR}$ hopper ash were not significant sources or sinks of mercury.

Methods used to measure or estimate the amount of mercury fed to or removed from the system via the remaining process streams are summarized below.

\section{Mercury Input from Coal}

Coal feed rates during the tests were recorded and provided by the plant. Coal samples were collected at approximately the beginning and middle of each test; the samples from each test were composited and analyzed for mercury. The mercury input from coal was computed as the product of the coal feed rate and the mercury concentration in the coal.

Mercury Input from Hydrated Lime (Guarantee, Process Performance, and Follow-Up Tests)

The mass flow rate of hydrated lime being fed to the Turbosorp ${ }^{\circledR}$ absorber vessel was estimated for each test by performing a calcium balance around the Turbosorp ${ }^{\circledR}$ system. The mass flow rate of Ca entering the Turbosorp ${ }^{\circledR}$ system via the fly ash was estimated from the coal feed rate, coal ash content, and coal ash composition; per the assumptions made during baseline testing, which were based on historic plant data, it was assumed that $90.5 \%$ of the coal ash is converted to fly ash. The mass flow rate of $\mathrm{Ca}$ exiting the Turbosorp ${ }^{\circledR}$ system via the product ash was estimated from the product ash mass flow rate (estimated as described below) and the $\mathrm{Ca}$ content of the product ash sample(s) collected during the test. The required mass flow rate of $\mathrm{Ca}$ in the hydrated lime stream was then calculated by subtracting the flow rate of $\mathrm{Ca}$ in the fly ash stream from the flow rate of $\mathrm{Ca}$ in the product ash stream, and the total mass flow rate of hydrated lime was computed by dividing this result by the weight percentage of Ca determined in the hydrated lime sample collected during the test. To compute the mercury input from hydrated lime, the mercury concentration determined in the hydrated lime sample was multiplied by the estimated hydrated lime mass flow rate.

\section{Mercury Output via Bottom Ash and ESP Ash (Baseline Tests)}

The mass flow rates of bottom ash and ESP ash leaving the plant were calculated based on data collected by the U.S. Department of Energy, Energy Information Administration (EIA). During 2001, 2002, and 2003, the EIA data indicate that $9.5 \%$ of the total ash produced at AES Greenidge was bottom ash, and $90.5 \%$ of the total ash produced there was ESP ash. (As discussed above, there are two coal-fired units at Greenidge; it was assumed that the split between the bottom ash and ESP ash generated from both units was similar). The mass flow rates of bottom ash and ESP ash were calculated based on the coal firing rates provided by the plant, the ash content of the coal, the moisture, carbon, and ash contents of the bottom ash and ESP ash, and the split between the bottom ash and the ESP ash. The ESP hoppers were sampled individually; the ash production split was assumed to be $90 \%$ in the first hopper row and $10 \%$ in the second hopper row, based on information from plant operating personnel. The ESP ash analyses for moisture, ash, carbon, and mercury represent a weighted average based on this split. To compute the mercury output from the bottom ash or ESP ash, the mercury concentration determined in the bottom ash or ESP ash sample was multiplied by the estimated bottom ash or ESP ash mass flow rate.

Mercury Output via Product Ash (Guarantee, Process Performance, and Follow-Up Tests)

The mass flow rate of Turbosorp ${ }^{\circledR}$ product ash being discharged from the process was estimated for each test by performing a sulfur balance around the Turbosorp ${ }^{\circledR}$ system. The 
mass flow rate of sulfur entering the Turbosorp ${ }^{\circledR}$ system was estimated from the coal feed rate and coal sulfur content measured during the test, and the mass flow rate of sulfur exiting the system via the stack flue gas was calculated using the average stack flue gas flow rate and $\mathrm{SO}_{2}$ concentration measured during the test. $\left(\mathrm{SO}_{2}\right.$ concentrations were obtained from the plant's stack CEM, and flue gas flow rates were computed as the average of values measured by the stack CEM and by CONSOL. Plant flow rate measurements were converted to a dry basis using flue gas moisture concentrations determined by CONSOL during each test). The required mass flow rate of sulfur in the product ash stream was then calculated by subtracting the flow rate of sulfur in the stack flue gas stream from the flow rate of sulfur entering the Turbosorp ${ }^{\circledR}$ system, and the total mass flow rate of product ash was computed by dividing this result by the weight percentage of sulfur determined in the product ash sample(s) collected during the test. To compute the mercury output via product ash, the mercury concentration determined in the product ash sample(s) was multiplied by the estimated product ash mass flow rate.

\section{Mercury Output via Stack Flue Gas}

The mercury output via the stack flue gas was measured using the Ontario Hydro Method or U.S. EPA Method 30B. For cases in which the concentration of mercury in the flue gas was less than the method detection limit (i.e., the tests on March 28 and 30, 2007), the $\mathrm{Hg}$ concentration was assumed to be equal to the detection limit value.

Appendix $\mathrm{K}$ summarizes the $\mathrm{Hg}$ material balance results for each test. CONSOL's QA/QC criterion for material balance closure for a single test is $100 \pm 30 \%$. The first test on November 17,2004 , had a material balance closure of $145 \%$, owing largely to an abnormally high measured stack gas mercury content; that test is considered to be invalid. The other two $\mathrm{Hg}$ tests from the baseline testing series had material balance closures of $87 \%$ and $102 \%$, satisfying the QA/QC criterion. All 34 tests conducted during the guarantee, process performance, and follow-up testing series satisfied the $100 \pm 30 \%$ criterion. Mercury material balance closures for these tests ranged from $73-123 \%$, with a mean closure of $105 \%$.

Material balances were also completed for $\mathrm{SiO}_{2}$ and $\mathrm{Al}_{2} \mathrm{O}_{3}$ for each test to further validate the results of the $\mathrm{Hg}$ material balances. The methodology was the same as described above for the $\mathrm{Hg}$ material balances. For the two valid tests from the baseline testing series, material balance closures were $101 \%$ and $100 \%$ for $\mathrm{SiO}_{2}$ and $95 \%$ (both tests) for $\mathrm{Al}_{2} \mathrm{O}_{3}$. For the 34 tests conducted during the guarantee, process performance, and follow-up testing series, the material balance closures for $\mathrm{SiO}_{2}$ ranged from $73-125 \%$, with a mean closure of $102 \%$, and the material balance closures for $\mathrm{Al}_{2} \mathrm{O}_{3}$ ranged from $76-125 \%$, with a mean closure of $102 \%$. Hence, all of the $\mathrm{SiO}_{2}$ and $\mathrm{Al}_{2} \mathrm{O}_{3}$ material balances also satisfied the $100 \pm 30 \%$ QA/QC criterion, supporting the validity of the methodology that was used to perform the $\mathrm{Hg}$ material balances.

\subsection{Sulfur Trioxide Measurements}

For the IC analyses, immediately after calibration of the ion chromatograph, an independent calibration verification sample was analyzed in duplicate. Sample analysis proceeded only if recovery of the ICV sample was $100 \pm 10 \%$ and the duplicate results had a RPD of $\leq 5 \%$. An independent, secondary QC standard was analyzed in duplicate after every $10^{\text {th }}$ sample. In all cases, recovery of the secondary QC standard was $100 \pm 10 \%$, and replicate results agreed within $5 \%$. All samples were run in duplicate. If duplicate results were within $5 \%$ of each other, then the average of the duplicates was reported. If results did not agree within $5 \%$, the samples were run again in duplicate and the average of the four replicates was reported. Blank samples 
of the $\mathrm{H}_{2} \mathrm{O}_{2}$ impinger solution and the deionized water used for sample recovery were also analyzed to verify that background $\mathrm{SO}_{4}{ }^{2-}$ concentrations were low.

For the $\mathrm{BaCl}_{2}$ titrations, a blank $3 \% \mathrm{H}_{2} \mathrm{O}_{2}$ solution and a blank IPA sample were titrated with each batch using the same $\mathrm{BaCl}_{2}$ titrant used for sample analysis. Blanks required $0.05 \mathrm{~mL}$ (the smallest increment readable with the microburette) to cause a color change.

\subsection{Hydrogen Chloride and Hydrogen Fluoride Measurements}

$\mathrm{HCl}$ and $\mathrm{HF}$ samples were analyzed per EPA Method 26A. Immediately after calibration of the ion chromatograph, an ICV sample was analyzed in duplicate. The analysis proceeded only if recovery was $100 \pm 10 \%$ for both $\mathrm{Cl}^{-}$and $\mathrm{F}^{-}$, and the duplicate results had relative percent differences of $\leq 5 \%$ for both species. An independent, secondary QC sample was analyzed in duplicate after every 10 samples. Results were accepted if the recovery of $\mathrm{Cl}^{-}$and $\mathrm{F}^{-}$in the secondary QC standard was $100 \pm 10 \%$ and the duplicate results agreed within $5 \%$. All samples were run in duplicate. If duplicate results agreed within $5 \%$, then the average of the duplicates was reported. If results were not within $5 \%$ of one another, the samples were run again in duplicate and the average of the 4 replicates was reported, per Method 26A. Although not required by method, randomly selected samples were spiked at $2 \mathrm{mg} / \mathrm{L} \mathrm{Cl}^{-}$and $2 \mathrm{mg} / \mathrm{L} \mathrm{F}^{-}$to assess any possible matrix issues. Blank samples of the $0.1 \mathrm{~N} \mathrm{H}_{2} \mathrm{SO}_{4}$ impinger solution were also analyzed by ion chromatography to confirm that this solution was not contaminated; blank values in excess of the detection limit $\left(0.2 \mathrm{mg} / \mathrm{L}\right.$ for both $\mathrm{Cl}^{-}$and $\left.\mathrm{F}^{-}\right)$were subtracted from the $\mathrm{HCl}$ and $\mathrm{HF}$ analysis results, as permitted by EPA Method $26 \mathrm{~A}$.

\subsubsection{Solid and Liquid Process Sample Analyses}

\subsubsection{Sampling Methodologies}

Samples of coal, biomass, fly ash, Turbosorp ${ }^{\circledR}$ product ash, pebble lime, hydrated lime, activated carbon, and urea were routinely collected during the guarantee tests, process performance tests, and follow-up tests. The methods used to collect these samples are described in the subsections below. In addition to the routinely collected samples, AES Greenidge occasionally provided samples of bottom ash, ESP hopper ash (baseline tests only), Turbosorp $^{\circledR}$ hopper ash, and process water for use in the $\mathrm{Hg}$ material balances described in Section 9.2.1.3.5.3.

\subsection{Coal Samples}

Coal samples were collected from the unit's four coal mill feeders. Each coal sample collected during the project was a composite sample containing an approximately equal portion of coal from each feeder that was in operation during the time of sample collection. Each composite sample had a total volume of approximately five gallons. Samples were stored and transported in plastic buckets with lids that contained o-ring seals to limit contact with outside air. During most of the Ontario Hydro Method testing periods, in order to improve the representativeness of the coal samples, each mill feeder was sampled twice - once at the beginning of the test and a second time after one hour of testing - and these sub-samples were combined to form a five- 
gallon composite sample. (During several Ontario Hydro tests, however, separate five-gallon composite samples were collected at the beginning and middle of the test).

\subsubsection{Biomass Samples}

Biomass (waste wood) samples were collected during the test series in November 2007 and March 2008 that included biomass co-firing. Samples were taken from the metering bin located downstream of the biomass hammer mill, and hence they represented the processed waste wood that was being sent to the boiler. Between two and five gallons of waste wood were collected for each sample. Samples were stored and transported in plastic buckets with lids that contained o-ring seals to limit contact with outside air.

\subsection{Fly Ash Samples}

Fly ash samples were generally collected using the plant's CEGRIT Automatic Flyash Sampler that is permanently installed at a fixed position in the ductwork between the air heater outlet and Turbosorp ${ }^{\circledR}$ inlet. The fly ash was collected isokinetically during a several-hour sampling period, resulting in a total sample volume of approximately $250-500 \mathrm{~mL}$. Each sample was then transferred from the glass sampling jar to a plastic sample bottle (polyethylene / polypropylene) for transport and storage.

In several instances (e.g., the guarantee tests in March 2007), fly ash samples were not available from the CEGRIT sampler. In these cases, fly ash samples were obtained from the particulate collected as part of Ontario Hydro Method or Method 17/26A sampling at the air heater outlet.

\subsection{Turbosorp ${ }^{\circledR}$ Product Ash Samples}

During the guarantee tests in March 2007, samples of product ash from the Turbosorp ${ }^{\circledR}$ process were collected from ports located at the interconnection of the air slides and the Turbosorp ${ }^{\circledR}$ absorber vessel. To facilitate sample collection, all subsequent samples were collected from ports installed at the base of the product ash silos. Between two and five gallons of product ash were collected for each sample. Samples were stored and transported in plastic buckets with lids that contained o-ring seals to limit contact with outside air.

\subsection{Pebble Lime Samples}

Pebble lime samples were collected from the weigh belt that feeds the pebble lime to the hydrator. Between one and two gallons of pebble lime were collected for each sample. In most cases, samples were first sealed in plastic zip-lock bags, and the bags were then stored and transported in plastic buckets with lids that contained o-ring seals, in order to limit contact with outside air. (If proper precautions are not taken, lime can react with $\mathrm{CO}_{2}$ and moisture in the air, altering its composition). 


\subsection{Hydrated Lime Samples}

Hydrated lime samples were collected from the chute that transports the hydrated lime from the cyclone to the hydrated lime storage silo. Between one and two gallons of hydrated lime were collected for each sample. In most cases, samples were first sealed in plastic zip-lock bags, and the bags were then stored and transported in plastic buckets with lids that contained o-ring seals, in order to limit contact with outside air. (If proper precautions are not taken, lime can react with $\mathrm{CO}_{2}$ and moisture in the air, altering its composition).

\subsection{Activated Carbon Samples}

Activated carbon samples were collected during the tests that included activated carbon injection - i.e., on March 30, 2007, and October 5, 2007. Samples were drawn from the PAC feed system. Each sample had a total volume of approximately $250-500 \mathrm{~mL}$. Samples were transferred to plastic sample bottles (polyethylene / polypropylene) for transport and storage.

\subsection{Urea Samples}

Urea samples were collected from a valve in the SNCR system's HFD module. Samples were drawn directly into $500 \mathrm{~mL}$ plastic sample bottles (polyethylene / polypropylene) for transport and storage.

\subsubsection{Analytical Methods}

\subsection{Solid Samples}

Most solid process samples analyses were performed by the CONSOL Energy Inc. Research \& Development analytical laboratory. Solid samples were analyzed using the following methods, as applicable:

ASTM D2013: Preparing Coal Samples for Analysis. This standard practice covers the reduction and division of gross or divided samples up to and including the individual portions used for laboratory analysis.

ASTM D5142: Proximate Analysis of the Analysis Sample of Coal and Coke by Instrumental Procedures. Moisture, volatile matter, and ash are determined sequentially in a single instrumental procedure by establishing the loss in mass of the analysis specimen when heated under rigidly controlled conditions of temperature, time, atmosphere, and specimen mass.

ASTM D5373: Instrumental Determination of Carbon, Hydrogen, and Nitrogen in Laboratory Samples of Coal and Coke. Carbon, Hydrogen, and Nitrogen are determined concurrently in a single instrumental procedure. The conversion of the subject materials in each sample occurs during combustion of the sample at an elevated temperature in an atmosphere of purified oxygen. For pebble lime, hydrated lime, and product ash samples, the instrument was calibrated using NIST SRM 88B (dolomitic limestone) rather than with ethylenediaminetetraacetic acid (EDTA), which is typically used. 
ASTM D4239: Sulfur in the Analysis Sample of Coal and Coke Using High-Temperature Combustion and Infrared Absorption. The test specimen is heated in a tube furnace in a stream of oxygen to oxidize the sulfur to sulfur dioxide. The gas stream containing the sulfur dioxide is passed through a cell where it is measured at a precise wavelength by an infrared absorption detector.

ASTM D5865: Gross Calorific Value of Coal and Coke. A weighed sample of coal is burned under controlled conditions in an oxygen bomb calorimeter. The higher heating value is calculated from the temperature rise of the water in the calorimeter vessel and the effective heat capacity of the system. Corrections are made for the heat released by the ignition of the fuse and the thermochemical reactions forming nitric and sulfuric acids.

ASTM D6721: Determination of Chlorine by Oxidative Hydrolysis Microcoulometry. A weighed sample is combusted with tungsten accelerator in a humidified oxygen gas flow, at $900{ }^{\circ} \mathrm{C}$. Halogens are oxidized and converted to hydrogenated halides, which are flushed into a titration cell where they accumulate. Chlorine is converted to hydrochloric acid. Once the chloride is captured in the electrolyte of the titration cell, it can be quantitatively determined by microcoulometry.

ASTM D6349: Determination of Major and Minor Elements in Coal, Coke, and Solid Residues from Combustion of Coal and Coke by Inductively Coupled Plasma-Atomic Emission Spectrometry. The sample to be analyzed is ashed under standard conditions and ignited to a constant weight. The ash is digested in a mixture of hydrofluoric, nitric, and hydrochloric acids. The solution is then analyzed by ICP-AES, in which characteristic line emission spectra are produced by a radio-frequency inductively coupled plasma. The intensity of these emissions is proportional to the concentration of analyte in the sample. For pebble lime, hydrated lime, and product ash samples, which contain substantially more calcium than coal samples, the instrument was calibrated using NIST SRM 88B (dolomitic limestone) rather than with NIST SRM 1633A (coal fly ash), which is typically used.

ASTM D3302: Standard Test Method for Total Moisture in Coal. All of the moisture in and on a sample of coal is determined based on the loss of weight in a coal sample in an air atmosphere under rigidly controlled conditions of temperature, time, and air flow.

ASTM D5987: Total Fluorine in Coal and Coke by Pyrohydrolytic Extraction and Ion Chromatography. A weighed sample is subjected to pyrohydrolytic combustion conditions. Fluorine is quantitatively released from the sample matrix and retained in the pyrohydrolysate that is gravimetrically processed. The total concentration in the sample is then determined by ion chromatography.

ASTM D6722: Total Mercury in Coal and Coal Combustion Residues by Direct Combustion Analysis. The analysis sample is heated under oxidative conditions and chemically decomposed. Flowing oxygen carries the decomposition products to a gold amalgamator that selectively traps mercury. The amalgamator is rapidly heated, releasing mercury vapor that is carried through an atomic absorption spectrophotometer. Mercury concentration is measured as a function of absorbance peak area.

ASTM D5967 Digestion with ASTM D6357 Analysis for the Determination of Se. A weighed sample is subjected to pyrohydrolytic combustion conditions. Selenium is quantitatively released from the sample matrix and subsequently analyzed by inductively coupled plasma-mass spectrometry (ICP-MS). 
ASTM C25, Section 19: Loss on Ignition. The sample is ignited at $1000^{\circ} \mathrm{C}$ to a constant weight. The release of free moisture, bound water, carbon dioxide, sulfur dioxide, and volatile pyrolytic products of any organic material that may be present results in a sample weight loss, or loss on ignition.

ASTM C25, Section 20: Free Moisture in Hydrated Lime. The sample is heated to $115^{\circ} \mathrm{C}$ under an atmosphere of $\mathrm{CO}_{2}$-free air until the sample reaches a constant weight. The weight loss of the sample is the free moisture, or the water released at $115^{\circ} \mathrm{C}$.

ASTM C25, Section 28: Available Lime Index. An aliquot of sample is slaked and dispersed with water. The lime is solubilized by reaction with sugar to form calcium sucrate, which is then determined by titration against hydrochloric acid using a phenolphthalein indicator. The available calcium is calculated as $\mathrm{CaO}$ for pebble lime and as $\mathrm{Ca}(\mathrm{OH})_{2}$ for hydrated lime.

ASTM C110, Section 19: Apparent Loose Density of Hydrated Lime, Pulverized Quicklime, and Limestone. A sample of lime is sifted through a five-inch diameter flour sifter equipped with mesh openings of $1 \mathrm{~mm}$ into a density cup of known volume. The sifting continues until the cup has been overfilled and a cone of excess material remains. The excess material is removed by sliding the edge of a spatula over the density cup. The loose density is then calculated as the ratio of the weight sample remaining to the volume of the density cup.

ASTM C110, Section 20: Apparent Packed Density of Hydrated Lime, Pulverized Quicklime, and Limestone. Twenty-five grams of lime are transferred to a graduated cylinder and the initial volume is recorded. The cylinder is gently tapped on a desktop one hundred times and the volume is recorded. The tapping continues until the compaction volume change is less than $0.5 \mathrm{~mL}$ per one hundred repetitions. The packed density is then calculated as the ratio of the initial sample weight to the final sample volume.

EPA Method 1312: Synthetic Precipitation Leaching Procedure. An extraction fluid is prepared by adding a 60/40 weight percent mixture of sulfuric/nitric acids to reagent-grade water until the solution has reached a $\mathrm{pH}$ of 4.2. The sample and extraction fluid are placed in a zero headspace leaching vessel, secured in a rotary extractor device, and rotated at $30 \mathrm{rpm}$ for a period of 18 hours. The extraction fluid is then separated from the sample by filtration through a glass fiber filter. The filtrate is analyzed for mercury by cold vapor atomic absorption spectroscopy or cold vapor atomic fluorescence spectroscopy.

CONSOL In-House Method: Ammonia in Fly Ash. A five-gram sample is placed in a volumetric digestion vessel. The digestion vessel is filled to $50 \mathrm{~mL}$ with reagent grade water, closed, and gently agitated for a period of one hour. The liquid portion is subsequently analyzed using an ammonia ion-selective electrode. Using the sample weight, the ammonia concentration is converted from units of ppm in solution to units of ppm in the ash.

CONSOL In-House Method: Paste $\mathrm{pH}$. A five-gram sample is placed in a $50 \mathrm{~mL}$ beaker. Reagent grade water is slowly added to the sample until a thick paste is formed. A handheld $\mathrm{pH}$ meter is immersed in the resulting paste and the $\mathrm{pH}$ measurement is recorded.

In addition to the solid sample analyses performed by CONSOL, selected hydrated lime samples from the October 2007 and November 2007 test series were analyzed by RJ Lee Group, Inc., for BET surface area (nitrogen physisorption, single point), and selected hydrated 
lime, pebble lime, and product ash samples from the March 2007, March 2008, and June 2008 test series were analyzed by CTL Group using the following methods:

Pebble Lime

Available $\mathrm{CaO}$

Slaking Rate/Residue

Hydrated Lime

Density

Particle Size Distribution

Surface Area

Product Ash

Particle Size Distribution

Surface Area
ASTM C25, Section 28

ASTM C110-05, Section 11

ASTM C110, Sections 19 and 20

Laser Diffraction (wet dispersion in isopropanol)

$\operatorname{BET}\left(\mathrm{N}_{2}\right.$, single point)

Laser Diffraction (wet dispersion in isopropanol)

$\operatorname{BET}\left(\mathrm{N}_{2}\right.$, single point)

Additional details regarding these analyses can be found in the RJ Lee Group and CTL Group reports that are included in Appendix $\mathrm{J}$ to this report.

\subsection{Liquid Samples}

Liquid process samples (i.e., urea and process water) were analyzed by CONSOL using the following methods, as applicable:

SM 4500-H B for the Determination of $\mathrm{pH}$. The activity of hydrogen ions is determined by potentiometric measurement using a standard hydrogen electrode and a reference electrode.

SM 2540D for the Determination of Total Suspended Solids. A well mixed sample is filtered through a weighed standard glass-fiber filter and the residue retained on the filter is dried to a constant weight. The increase in the weight of the filter represents the total suspended solids.

SM 4500-NH3 E for the Determination of Ammonia. An ammonia selective electrode equipped with a hydrophobic gas permeable membrane separates the sample solution from an electrode internal solution of ammonium chloride. Ammonia diffuses through the membrane and potentiometric measurements are subsequently made by an ion selective electrode.

SM 3112B for the Determination of Mercury. The mercury in an aqueous sample is reduced to vaporous elemental mercury and is determined by cold vapor atomic absorption or by cold vapor atomic fluorescence.

SM 4110B for the Determination of Anions by lon Chromatography. Phosphate in a portion of test solution is determined by ion chromatography with chemical suppression of eluent conductivity.

Density using the Paar Digital Density Meter DMA35. The sample is passed through a vibrating tube. The sample density is proportional to the period of vibration in the tube. 


\subsection{Results}

The plant operating data and special test series data were analyzed by CONSOL to evaluate the performance of the multi-pollutant control system during the Operation and Testing Phase. The evaluation determined whether the performance targets for pollutant emission rates and removal efficiencies (see Section 2.4) were satisfied, and it also included an assessment of important performance indicators such as urea utilization, lime utilization, ammonia slip, $\mathrm{SO}_{2}$-to$\mathrm{SO}_{3}$ conversion across the SCR catalyst, and $\mathrm{Hg}$ oxidation across the SCR catalyst. Key results are presented and discussed in the subsections below. (Complete results for the flue gas measurements conducted during the special test series can be found in Appendices $G, H$, and I, and complete results for the solid and liquid process sample analyses conducted during these tests can be found in Appendix J).

Throughout the Operation and Testing Phase, AES Greenidge Unit 4 generally fired eastern U.S. bituminous coals containing $2-4 \%$ sulfur (although it also co-fired Powder River Basin coal at up to $25 \%$ by weight of the total fuel for a time during September 2008 and co-fired biomass at less than $5 \%$ of the total heat input at times during November 2007 and February-April 2008). Table 10 presents chemical analysis results for representative coal samples collected during the special test series. (Complete results for all of the coal samples collected during the project are included in Appendix J). Other relevant operating conditions during the Operation and Testing Phase are discussed where appropriate in the subsections below.

\subsubsection{Emissions of Nitrogen Oxides}

The hybrid $\mathrm{NO}_{x}$ control system significantly reduced the $\mathrm{NO}_{x}$ emissions from AES Greenidge Unit 4 , but it fell slightly short of the project's performance target for $\mathrm{NO}_{\mathrm{x}}$ during long-term operation.

As discussed in Section 9.1.2.2, guarantee testing of the multi-pollutant control system at AES Greenidge Unit 4 was completed in March-June 2007. During the guarantee testing campaigns, the combustion system and SNCR system were configured to operate as closely as possible to design conditions, and the project team demonstrated on several occasions that the hybrid $\mathrm{NO}_{\mathrm{x}}$ control system could maintain high-load $\mathrm{NO}_{x}$ emissions below the targeted emission rate of 0.10 $\mathrm{lb} / \mathrm{mmBtu}$. Figures 43,44 , and 45 provide examples of this. These figures show the $\mathrm{NO}_{\mathrm{x}}$ emission rates measured by the unit's stack CEM during 12-hour periods on March 28, 2007, May 1, 2007, and June 20, 2007, respectively. (The total flow rate of $50 \% \mathrm{w} / \mathrm{w}$ urea solution being fed to the SNCR system is also plotted on each graph). The performance guarantee for $\mathrm{NO}_{x}$ emissions $(\leq 0.10 \mathrm{lb} / \mathrm{mmBtu}$ at high load) was officially satisfied on March 28,2007 , when the hybrid $\mathrm{NO}_{x}$ control system attained an average $\mathrm{NO}_{x}$ emission rate of $0.096 \mathrm{lb} / \mathrm{mmBtu}$ over 12 hours while the unit was operating at approximately $105 \mathrm{MW}_{\mathrm{g}}$. Similar performance was observed on May 1 and June 20, when the system achieved 12-hour average $\mathrm{NO}_{\mathrm{x}}$ emission rates of $0.097 \mathrm{lb} / \mathrm{mmBtu}$ and $0.096 \mathrm{lb} / \mathrm{mmBtu}$, respectively, while the unit operated at about 106 $\mathrm{MW}_{\mathrm{g}}$. Hence, the project's goal for $\mathrm{NO}_{\mathrm{x}}$ emissions was achieved reproducibly during short-term operation under design conditions.

AES Greenidge was unable to achieve the targeted emission rate in the long term, however, while also maintaining acceptable combustion characteristics, sufficiently high steam temperatures, and sufficiently low ammonia slip for routine operation. During the guarantee test periods, a substantial amount of overfire air was required in order to achieve a $\mathrm{NO}_{\mathrm{x}}$ emission 
rate of $\leq 0.10 \mathrm{lb} / \mathrm{mmBtu}$. As a result, the unit did not have sufficient windbox pressure to avoid flame attachments, and several burners were damaged by flame attachments during the testing. The low pressure also increased the risk for a windbox fire, although none occurred. Moreover, steam temperatures were lower than desired during the guarantee tests. Hence, after the ammonia slip guarantee was satisfied on June 20, 2007 (see Section 9.3.3), plant personnel reduced the aggressiveness of low- $\mathrm{NO}_{x}$ firing in order to achieve more suitable combustion characteristics and sufficiently high steam temperatures for routine, long-term operation. The change in turn caused boiler conditions to deviate from the design basis for the SNCR system, promoting less-than-optimal performance of that system. Tuning of the combustion system and SNCR system for long-term operation continued through July 2007 . The $\mathrm{NO}_{\mathrm{x}}$ control problems were exacerbated by the accumulation of large particle ash in the in-duct SCR catalyst (see Section 10.2.1), which caused periodic deteriorations in the performance of the SCR reactor, making it more difficult to achieve the performance target for $\mathrm{NO}_{x}$ emissions while maintaining sufficiently low ammonia slip. As a result, the unit generally has operated with high-load $\mathrm{NO}_{\mathrm{x}}$ emissions of $0.10-0.15 \mathrm{lb} / \mathrm{mmBtu}$ since the guarantee testing period.

Table 10. Chemical composition of typical coal samples collected at AES Greenidge Unit 4 during the Operation and Testing Phase.

\begin{tabular}{|c|c|c|c|c|c|c|}
\hline Sample Collection Date & $3 / 28 / 2007$ & $10 / 4 / 2007$ & $11 / 16 / 2007$ & $3 / 10 / 2008$ & $5 / 20 / 2008$ & $6 / 11 / 2008$ \\
\hline Analytical Number & 20071797 & 20076586 & 20077319 & 20081017 & 20082479 & 20083362 \\
\hline Total Moisture (\%) & 6.54 & 5.63 & 7.89 & 7.21 & 5.71 & 4.46 \\
\hline $\begin{array}{l}\text { As Determined Moisture } \\
(\%)\end{array}$ & 1.43 & 1.70 & 1.41 & 1.44 & 1.24 & 1.45 \\
\hline Volatile Matter (\% dry) & 39.92 & 40.81 & 34.39 & 35.73 & 29.80 & 38.71 \\
\hline $\begin{array}{l}\text { Ash (\% dry, ignited @ } \\
\left.750^{\circ} \mathrm{C}\right)\end{array}$ & 7.99 & 8.50 & 13.46 & 9.61 & 12.06 & 7.45 \\
\hline Carbon (\% dry) & 75.86 & 75.97 & 71.57 & 75.77 & 74.61 & 77.20 \\
\hline Hydrogen (\% dry) & 5.01 & 5.29 & 5.36 & 5.14 & 4.60 & 5.40 \\
\hline Nitrogen (\% dry) & 1.44 & 1.40 & 1.45 & 1.57 & 1.78 & 1.67 \\
\hline Sulfur (\% dry) & 2.57 & 3.27 & 2.84 & 2.43 & 2.03 & 2.56 \\
\hline Chlorine (\% dry) & 0.074 & 0.069 & 0.096 & 0.100 & 0.088 & 0.084 \\
\hline Mercury (ppm dry) & 0.097 & 0.102 & 0.262 & 0.117 & 0.102 & 0.076 \\
\hline Fluorine (ppm dry) & 70.6 & 54.1 & & 70.8 & 72.6 & 42.2 \\
\hline $\begin{array}{l}\text { Higher Heating Value } \\
\text { (Btu/lb dry) }\end{array}$ & 13916 & 13768 & 13028 & 13704 & 13340 & 14107 \\
\hline \multicolumn{7}{|c|}{ Major Ash Elements (\% of ash, dry) } \\
\hline $\mathrm{SiO}_{2}$ & 44.62 & 39.90 & 48.59 & 47.82 & 49.82 & 41.93 \\
\hline $\mathrm{Al}_{2} \mathrm{O}_{3}$ & 22.46 & 20.78 & 24.78 & 23.00 & 27.56 & 22.50 \\
\hline $\mathrm{TiO}_{2}$ & 0.99 & 0.84 & 1.05 & 1.05 & 2.13 & 1.01 \\
\hline $\mathrm{Fe}_{2} \mathrm{O}_{3}$ & 20.52 & 24.30 & 18.60 & 18.04 & 11.32 & 21.15 \\
\hline $\mathrm{CaO}$ & 4.59 & 5.63 & 2.05 & 3.16 & 2.81 & 5.76 \\
\hline $\mathrm{MgO}$ & 0.92 & 0.97 & 0.97 & 0.74 & 0.70 & 1.14 \\
\hline $\mathrm{Na}_{2} \mathrm{O}$ & 0.81 & 0.89 & 0.40 & 0.63 & 0.53 & 1.14 \\
\hline $\mathrm{K}_{2} \mathrm{O}$ & 1.57 & 1.33 & 2.41 & 1.54 & 1.62 & 1.26 \\
\hline $\mathrm{P}_{2} \mathrm{O}_{5}$ & 0.48 & 0.25 & 0.35 & 0.43 & 0.34 & 0.28 \\
\hline $\mathrm{SO}_{3}$ & 3.78 & 4.62 & 1.99 & 3.14 & 2.46 & 6.53 \\
\hline
\end{tabular}




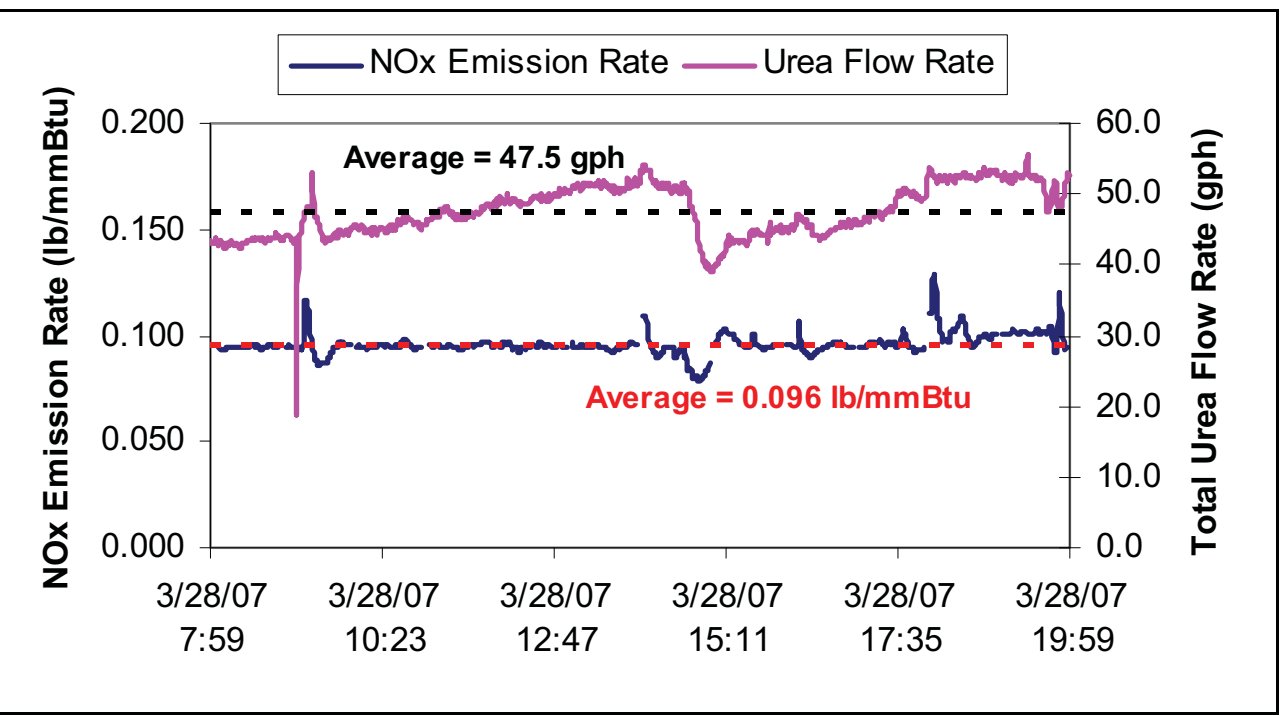

Figure 43. $\mathrm{NO}_{x}$ emission rate and total urea flow rate observed during guarantee testing of the multi-pollutant control system between 8:00 and 20:00 eastern standard time (EST) on March 28, 2007. The average unit load during this period was $105 \mathrm{MW}_{\mathrm{g}}$. $\mathrm{NO}_{\mathrm{x}}$ emissions were measured by the unit's stack CEM. The urea flow rate was measured by the SNCR system's flow meters and represents the flow of $50 \%(w / w)$ urea solution.

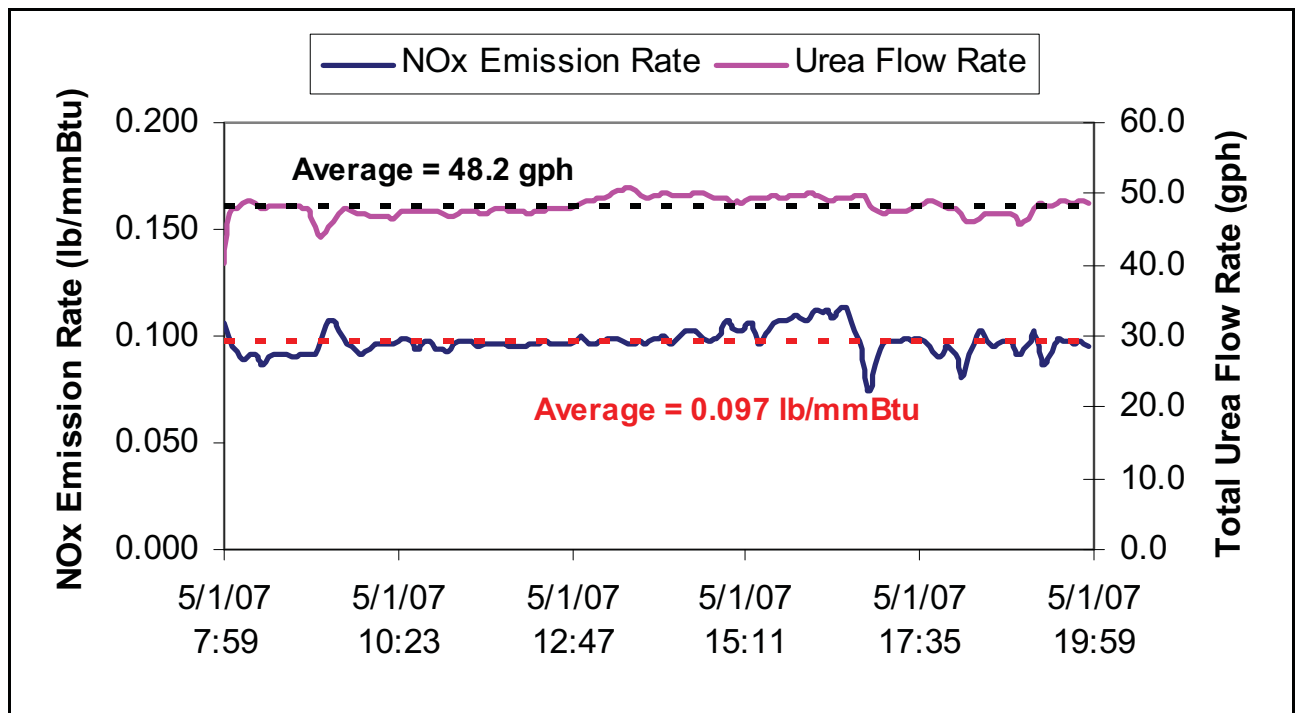

Figure 44. $\mathrm{NO}_{\mathrm{x}}$ emission rate and total urea flow rate observed during guarantee testing of the multi-pollutant control system between 8:00 and 20:00 EST on May 1, 2007. The average unit load during this period was $106 \mathrm{MW}_{\mathrm{g}} . \mathrm{NO}_{\mathrm{x}}$ emissions were measured by the unit's stack CEM. The urea flow rate was measured by the SNCR system's flow meters and represents the flow of $50 \%(\mathrm{w} / \mathrm{w})$ urea solution. 


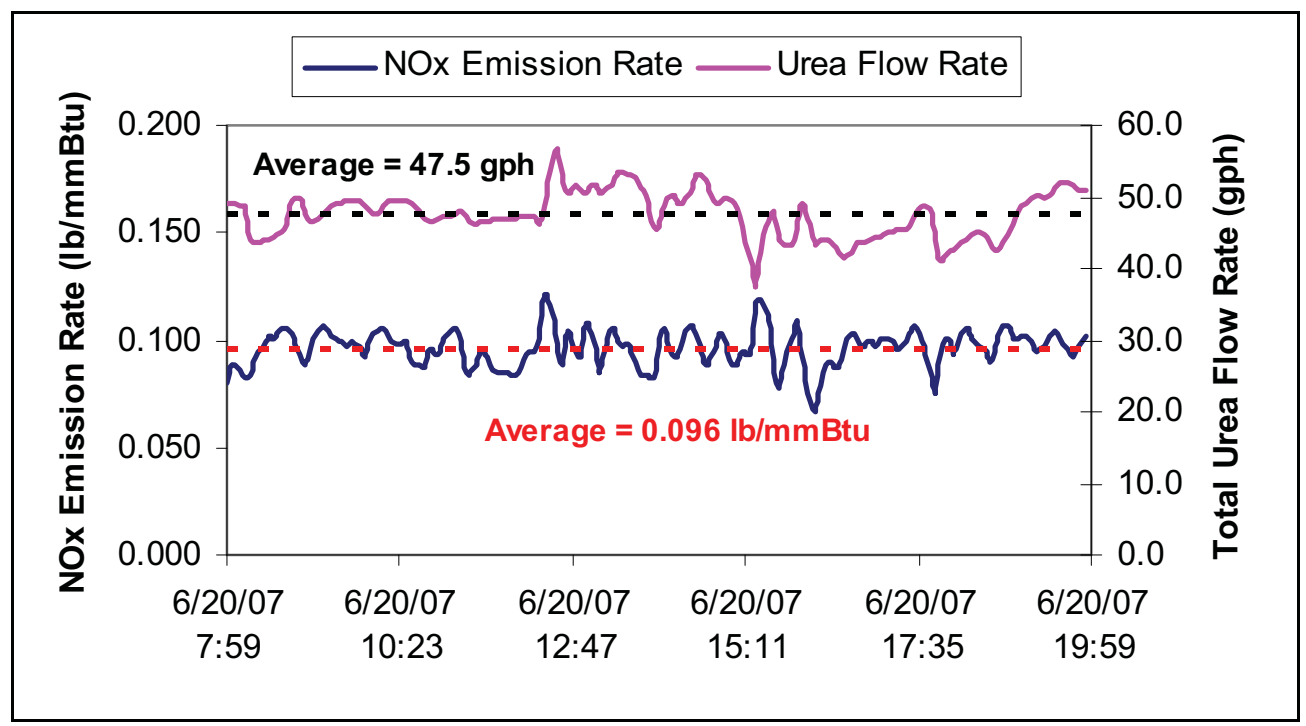

Figure 45. $\mathrm{NO}_{\mathrm{x}}$ emission rate and total urea flow rate observed during guarantee testing of the multi-pollutant control system between 8:00 and 20:00 EST on June 20, 2007. The average unit load during this period was $106 \mathrm{MW}_{\mathrm{g}} . \mathrm{NO}_{\mathrm{x}}$ emissions were measured by the unit's stack CEM. The urea flow rate was measured by the SNCR system's flow meters and represents the flow of $50 \%(\mathrm{w} / \mathrm{w})$ urea solution.

Figure 46 shows average $\mathrm{NO}_{x}$ emissions from AES Greenidge Unit 4 as a function of gross generator load during August 2007 - September 2008, following installation of the multipollutant control system, and compares these with average $\mathrm{NO}_{x}$ emissions measured during August 2004 - September 2005, prior to installation of the system. Table 11 summarizes the overall average $\mathrm{NO}_{x}$ emission rates measured during each of these periods, as well as the average $\mathrm{NO}_{x}$ emission rates computed for several load ranges defined in the unit's current permit. These data illustrate the $\mathrm{NO}_{x}$ control performance of the multi-pollutant control system during routine, long-term operation. As illustrated in Figure 46, installation of the multi-pollutant control system reduced the unit's $\mathrm{NO}_{x}$ emission rate by $\sim 25-50 \%$ at low generator loads and by $\sim 50-60 \%$ at mid and high generator loads. As discussed in Sections 4.1.1 and 4.2.6, greater $\mathrm{NO}_{x}$ removal is expected at high generator loads than at low generator loads, because injection of urea into low-temperature regions of the furnace and operation of the SCR reactor must be discontinued at low load. (Low-temperature urea injection and operation of the SCR system both promote improved $\mathrm{NO}_{x}$ removal efficiency). The average high-load $\mathrm{NO}_{x}$ emission rate measured between August 2007 and September 2008 was $0.14 \mathrm{lb} / \mathrm{mmBtu}$. Hence, the hybrid $\mathrm{NO}_{x}$ control system did not achieve the project's performance target for $\mathrm{NO}_{x}$ emissions during long-term operation. Nevertheless, the multi-pollutant control system significantly reduced the unit's $\mathrm{NO}_{x}$ emissions. The overall $\mathrm{NO}_{x}$ emission rate of $0.15 \mathrm{lb} / \mathrm{mmBtu}$ measured during August 2007 - September 2008 represents a $52 \%$ reduction from the overall emission rate of 0.32 $\mathrm{lb} / \mathrm{mmBtu}$ measured prior to the project in August 2004 - September 2005.

As shown in Table 11, the $\mathrm{NO}_{x}$ emission limit specified in the permit for AES Greenidge Unit 4 varies according to the turndown strategy for the hybrid $\mathrm{NO}_{x}$ control system. The permitted $\mathrm{NO}_{\mathrm{x}}$ emission rate is $0.15 \mathrm{lb} / \mathrm{mmBtu}$ for gross generator loads above $68 \mathrm{MW}$, but it increases to 0.28 $\mathrm{lb} / \mathrm{mmBtu}$ when the gross generator load is between 53 and $68 \mathrm{MW}$ and to $0.35 \mathrm{lb} / \mathrm{mmBtu}$ when the gross generator load is between 43 and $52 \mathrm{MW}$. Compliance with the permit is determined on a 30-day rolling average basis. The limit for a given day is computed as the heat-inputweighted average of the permit limits applicable to each hour of that day (based on the load ranges defined above), and the 30 -day rolling average permit limit is computed as the heat- 
input-weighted average of the limits for the most recent 30 days. Hence, the permit limit varies from day-to-day, depending upon the unit's load profile. The 30-day rolling average $\mathrm{NO}_{\mathrm{x}}$ emission rate is computed similarly from hourly $\mathrm{NO}_{x}$ emission and heat input data. Figure 47 shows the 30-day rolling average permit limits and 30-day rolling average $\mathrm{NO}_{x}$ emission rates for AES Greenidge Unit 4 from January 2008 through September 2008. As illustrated in the figure, the combustion modifications and hybrid SNCR/SCR system have enabled AES Greenidge Unit 4 to satisfy its permit limit for $\mathrm{NO}_{x}$, despite falling short of the project's $\mathrm{NO}_{\mathrm{x}}$ emission performance target during long-term operation.

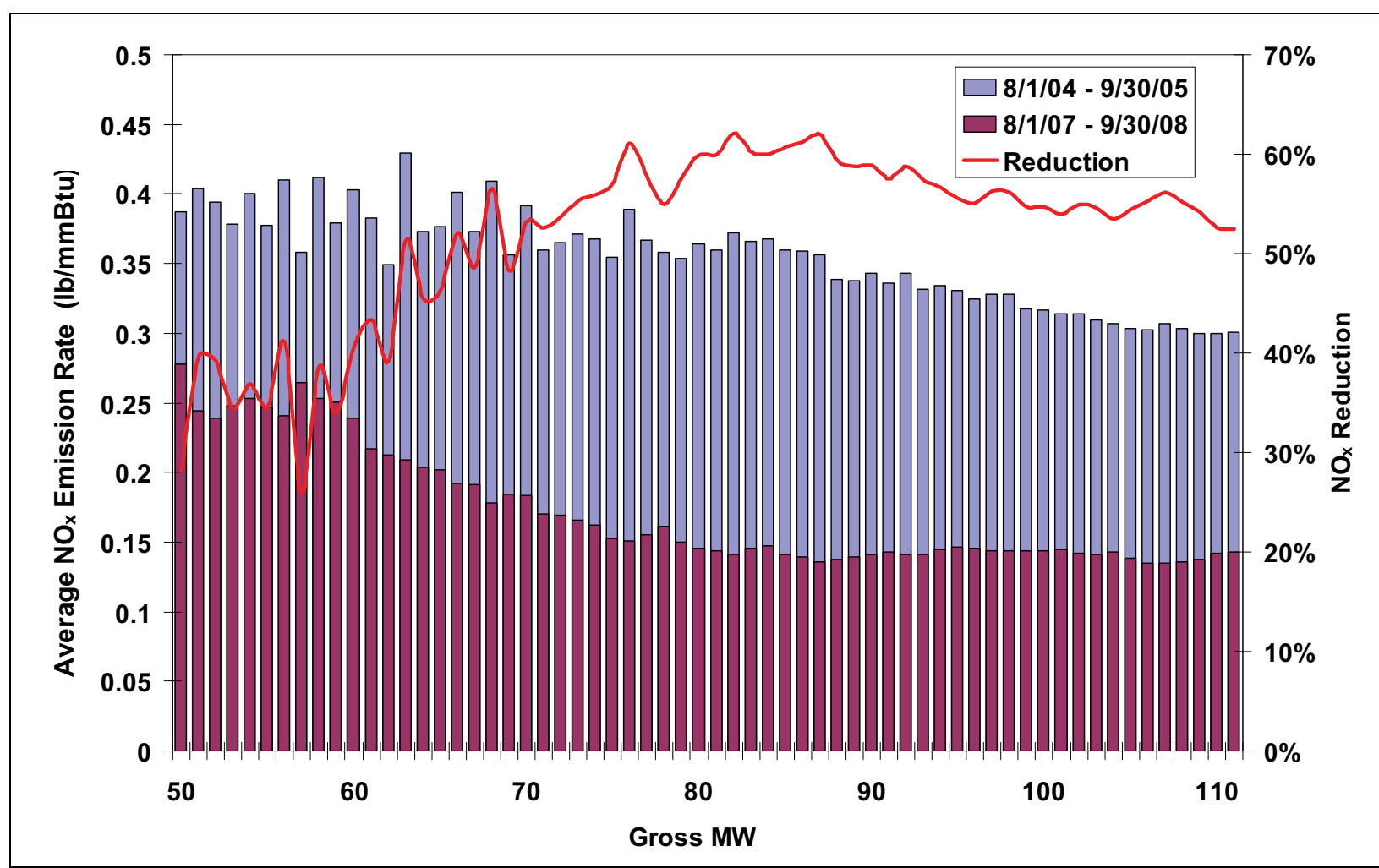

Figure 46. Comparison of $\mathrm{NO}_{\mathrm{x}}$ emissions from AES Greenidge Unit 4 measured during August 2007September 2008, following installation of the multi-pollutant control system, with those measured during August 2004-September 2005, prior to installation of the system. Data were obtained from the unit's stack CEM. The average $\mathrm{NO}_{x}$ emission rate is plotted as a function of gross unit load. The percent $\mathrm{NO}_{\mathrm{x}}$ reduction computed from these data for each unit load is also shown. Data are not shown for loads that have fewer than 10 observations in either period.

Table 11. Average $\mathrm{NO}_{x}$ emission rates measured during August $2004-$ September 2005, prior to the installation of the multi-pollutant control system, and during August 2007 - September 2008, following installation of the system, for various unit load ranges. Averages are shown for all unit loads $\left(\geq 42 \mathrm{MW}_{\mathrm{g}}\right)$ and for three load ranges corresponding to the unit's current permit limits.

\begin{tabular}{|c|c|c|c|c|}
\hline Load Range & $\begin{array}{c}\mathrm{NO}_{\mathrm{x}} \text { Emission Rate } \\
\text { August } 2004- \\
\text { September } 2005 \\
\text { (Ib/mmBtu) }\end{array}$ & $\begin{array}{c}\mathrm{NO}_{\mathrm{x}} \text { Emission Rate } \\
\text { August } 2007- \\
\text { September } 2008 \\
\text { (lb/mmBtu) }\end{array}$ & $\begin{array}{c}\text { Reduction in } \\
\text { NO }_{x} \text { Emission } \\
\text { Rate } \\
(\%)\end{array}$ & $\begin{array}{c}\text { Current } \\
\text { Applicable } \\
\text { Permit Limit }^{\mathrm{a}} \\
\text { (lb/mmBtu) }\end{array}$ \\
\hline All & 0.322 & 0.153 & 52.4 & \\
\hline$\geq 69 \mathrm{MW}_{\mathrm{g}}$ & 0.311 & 0.142 & 54.4 & 0.15 \\
\hline $53-68 \mathrm{MW}_{\mathrm{q}}$ & 0.388 & 0.234 & 39.6 & 0.28 \\
\hline $43-52 \mathrm{MW}_{\mathrm{g}}$ & 0.410 & 0.255 & 37.7 & 0.35 \\
\hline
\end{tabular}

${ }^{a}$ Compliance with the permit limits is assessed on a 30-day rolling average basis, as described in the text. 
As discussed earlier, the reduction in $\mathrm{NO}_{x}$ emissions arising from the multi-pollutant control system includes reductions contributed by the combustion modifications, SNCR system, and SCR system. The combustion modifications were designed to reduce $\mathrm{NO}_{\mathrm{x}}$ emissions to 0.25 $\mathrm{lb} / \mathrm{mmBtu}$ at high load; the SNCR system was designed to reduce $\mathrm{NO}_{\mathrm{x}}$ by $\sim 42 \%$ from the emission rate leaving the combustion system, and the SCR system was designed to further reduce $\mathrm{NO}_{\mathrm{x}}$ by $\sim 31 \%$ from the emission rate leaving the SNCR system. (Hence, the hybrid SNCR/SCR system was expected to reduce $\mathrm{NO}_{x}$ emissions by $60 \%$ relative to the emission rate achieved by the new combustion modifications).

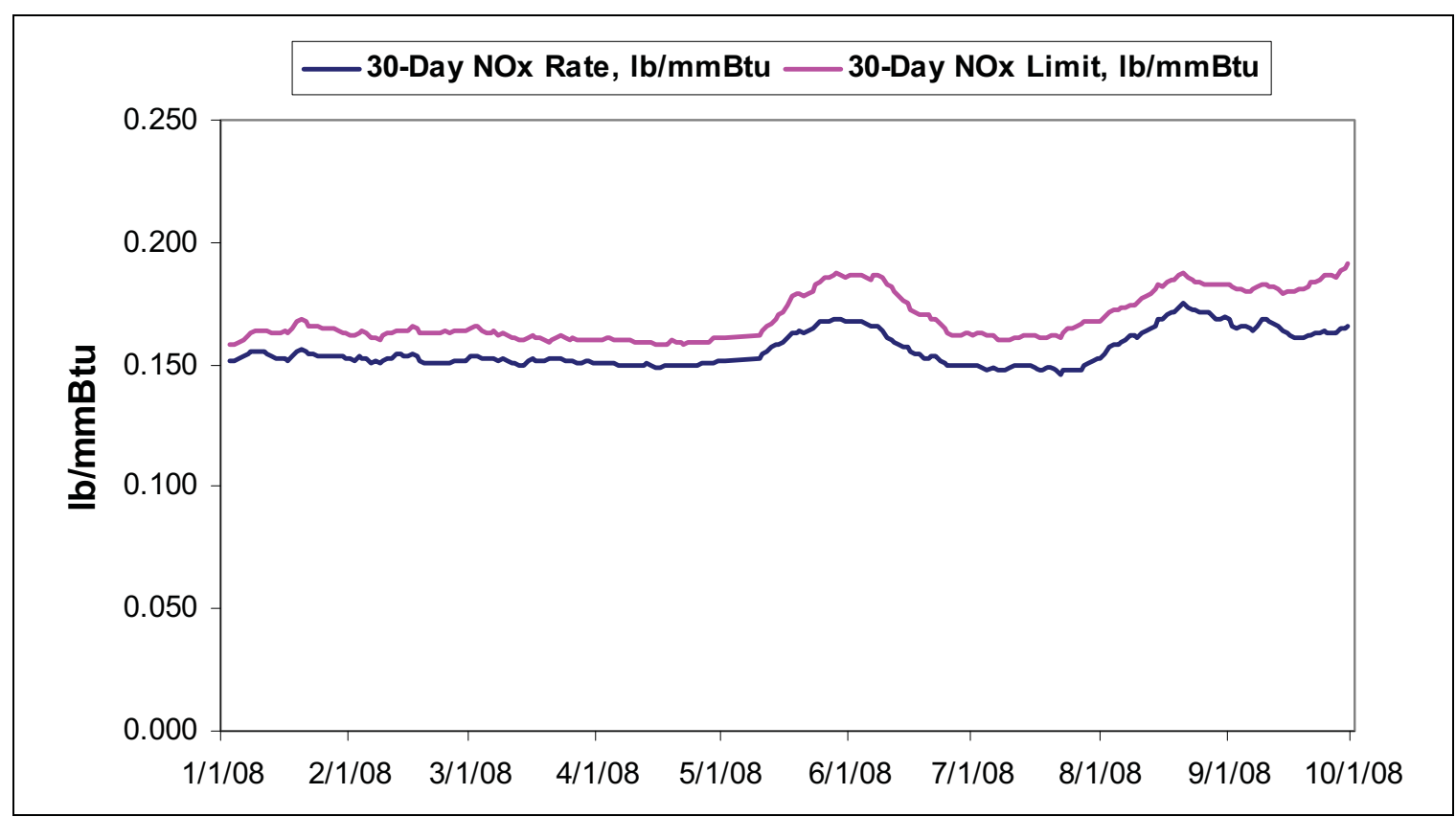

Figure 47. Thirty-day rolling average permit limits and $\mathrm{NO}_{\mathrm{x}}$ emission rates for AES Greenidge Unit 4 from January 2008 through September 2008.

Several tests were conducted in an effort to isolate the performance of the individual components of the hybrid $\mathrm{NO}_{x}$ control system. On March 10, March 13, and May 21, 2008, urea injection was temporarily shut off while Unit 4 operated at or near full load (106-110 $\mathrm{MW}_{\mathrm{g}}$ ) in order to determine the baseline $\mathrm{NO}_{x}$ emission rate being achieved by the combustion system and the percent reduction in $\mathrm{NO}_{x}$ emissions contributed by the hybrid SNCR/SCR system. (Biomass was being co-fired with coal during the first half of the test on March 13). Figures 4850 show the $\mathrm{NO}_{x}$ emission rates and urea flow rates measured during the tests on these three days. (When in service, urea injection occurred in Zones 2 and 3 of the SNCR system). Table 12 summarizes the $\mathrm{NO}_{x}$ emission rates observed with and without urea injection for each test and the percent $\mathrm{NO}_{x}$ removal efficiency determined from these data for the hybrid SNCR/SCR system. $\left(\mathrm{NO}_{x}\right.$ emission rates were computed using one-minute average data. The emission rate with urea injection is based on data from the one-hour period immediately before the urea was shut off, and the emission rate without urea injection is based on data from the period of stable $\mathrm{NO}_{x}$ emissions that occurred while the urea injection system was not in service. Biomass co-firing was discontinued about 30 minutes after the urea was shut off on March 13; only data collected while biomass was being co-fired are included in the averages for that day's test).

During all three tests, $\mathrm{NO}_{\mathrm{x}}$ emissions from the combined combustion modifications, SNCR system, and SCR system averaged greater than the performance target of $0.10 \mathrm{lb} / \mathrm{mmBtu}$. As 
shown in Table 12, this resulted in part because the combustion system was unable to attain its targeted emission rate of $0.25 \mathrm{lb} / \mathrm{mmBtu}$. $\mathrm{NO}_{\mathrm{x}}$ emissions from the combustion system, without the hybrid SNCR/SCR system in service, were 0.26-0.27 lb/mmBtu. (Although it did not meet the target, this emission rate nevertheless represents an improvement over the average $\mathrm{NO}_{\mathrm{x}}$ emission rate of $0.30 \mathrm{lb} / \mathrm{mmBtu}$ observed at loads of 106 and $110 \mathrm{MW}_{\mathrm{g}}$ between August 2004 and September 2005, prior to the installation of the multi-pollutant control system). The hybrid SNCR/SCR system also fell short of its target of $60 \% \mathrm{NO}_{\mathrm{x}}$ removal efficiency. That system contributed $51 \% \mathrm{NO}_{\mathrm{x}}$ removal on March 10, 52\% removal on March 13, and $42 \%$ removal on May 21.

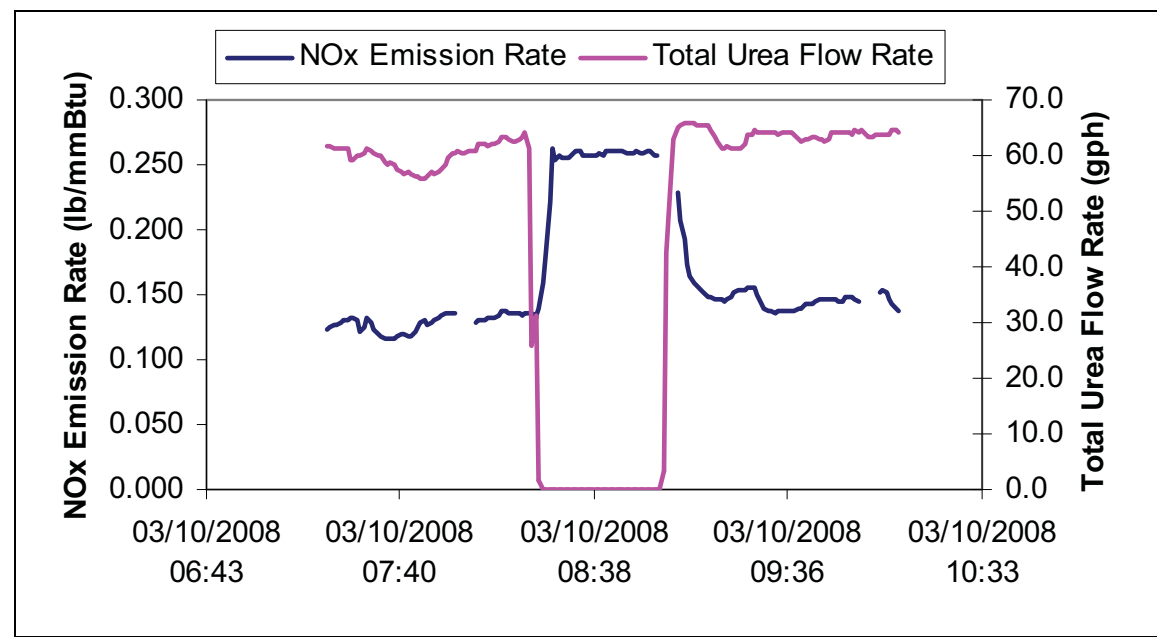

Figure 48. $\mathrm{NO}_{\mathrm{x}}$ emission rate and total urea flow rate observed between 7:19 and 10:09 EST on March 10, 2008. $\mathrm{NO}_{x}$ emissions were measured by the unit's stack CEM. The urea flow rate was measured by the SNCR system's flow meters and represents the flow of $50 \%(\mathrm{w} / \mathrm{w})$ urea solution.

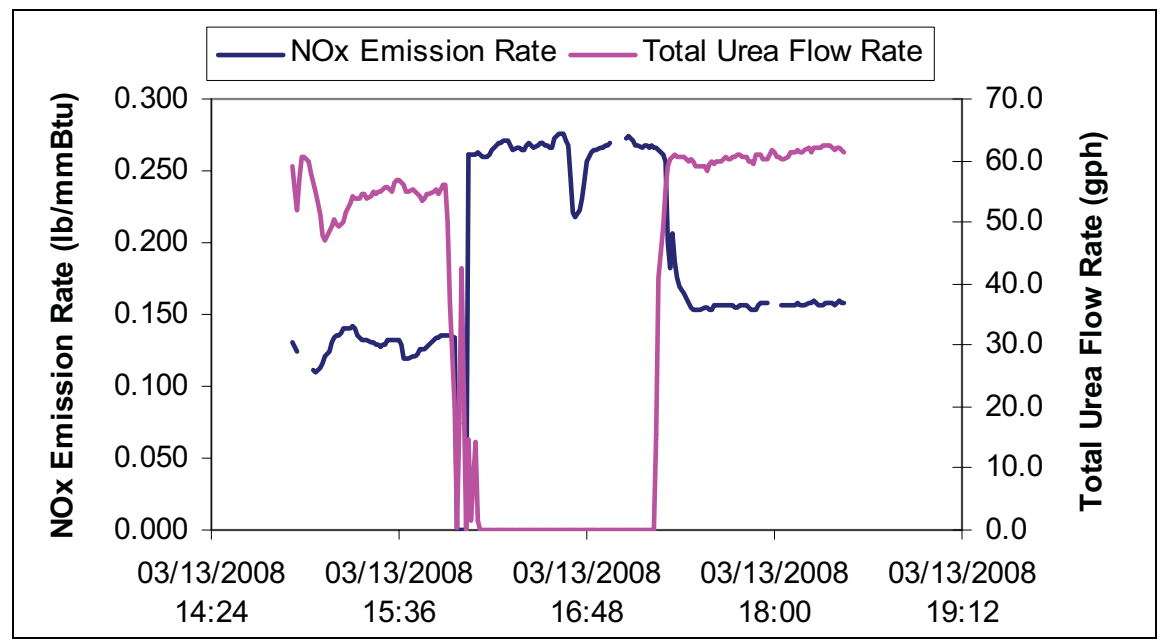

Figure 49. $\mathrm{NO}_{\mathrm{x}}$ emission rate and total urea flow rate observed between 14:55 and 18:27 EST on March 13, 2008. The drop in $\mathrm{NO}_{x}$ emissions around 16:40 occurred when biomass co-firing was discontinued, temporarily upsetting the system. $\mathrm{NO}_{\mathrm{x}}$ emissions were measured by the unit's stack CEM. The urea flow rate was measured by the SNCR system's flow meters and represents the flow of $50 \%(\mathrm{w} / \mathrm{w})$ urea solution. 
To evaluate the performance of the combustion modifications and SNCR system at low load, urea injection was temporarily shut off on May 22, 2008, while Unit 4 was operating at 56 MW $_{\mathrm{g}}$. Figure 51 shows the $\mathrm{NO}_{x}$ emission rates and urea flow rates measured during this test. (When in service, urea injection occurred in Zone 1 of the SNCR system). The average $\mathrm{NO}_{x}$ emission rates observed with and without urea injection are shown in Table 12. (These averages were computed using the same methodology that is described above for the full-load tests). The combustion modifications alone achieved a baseline $\mathrm{NO}_{x}$ emission rate of $0.366 \mathrm{lb} / \mathrm{mmBtu}$ during the test, which is slightly lower than the average emission rate of $0.41 \mathrm{lb} / \mathrm{mmBtu}$ observed at $56 \mathrm{MW}_{\mathrm{g}}$ between August 2004 and September 2005, prior to the project. The SNCR system further reduced $\mathrm{NO}_{x}$ emissions by $37.5 \%$, surpassing the $20-25 \%$ removal efficiency that was expected at low load operation.

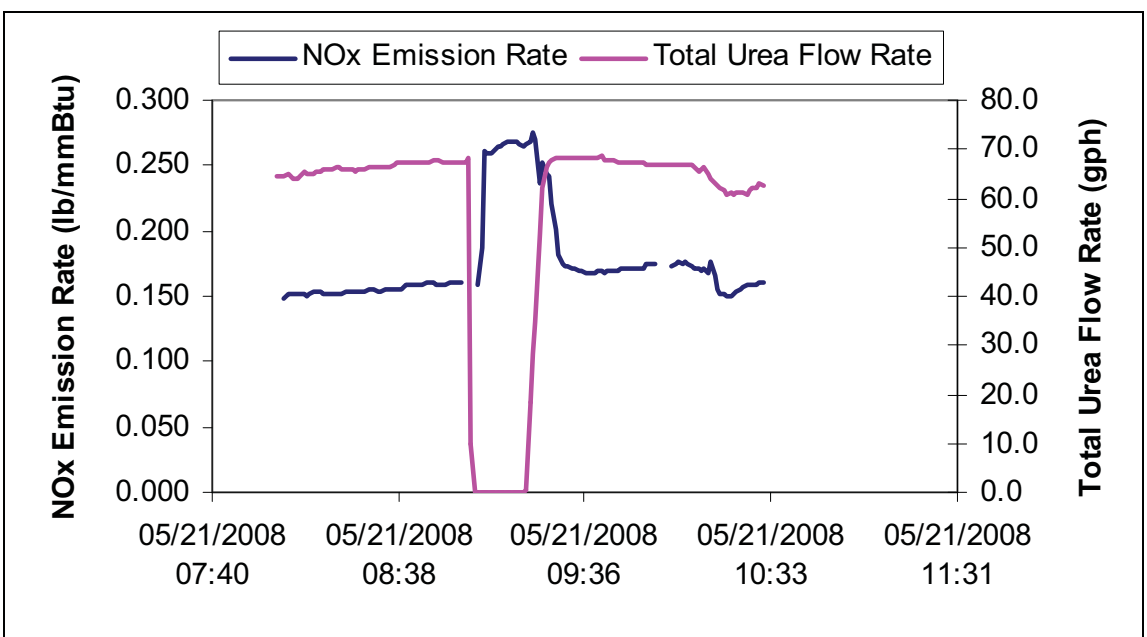

Figure 50. $\mathrm{NO}_{\mathrm{x}}$ emission rate and total urea flow rate observed between 8:01 and 10:31 EST on May 21, 2008. $\mathrm{NO}_{x}$ emissions were measured by the unit's stack CEM. The urea flow rate was measured by the SNCR system's flow meters and represents the flow of $50 \%(\mathrm{w} / \mathrm{w})$ urea solution.

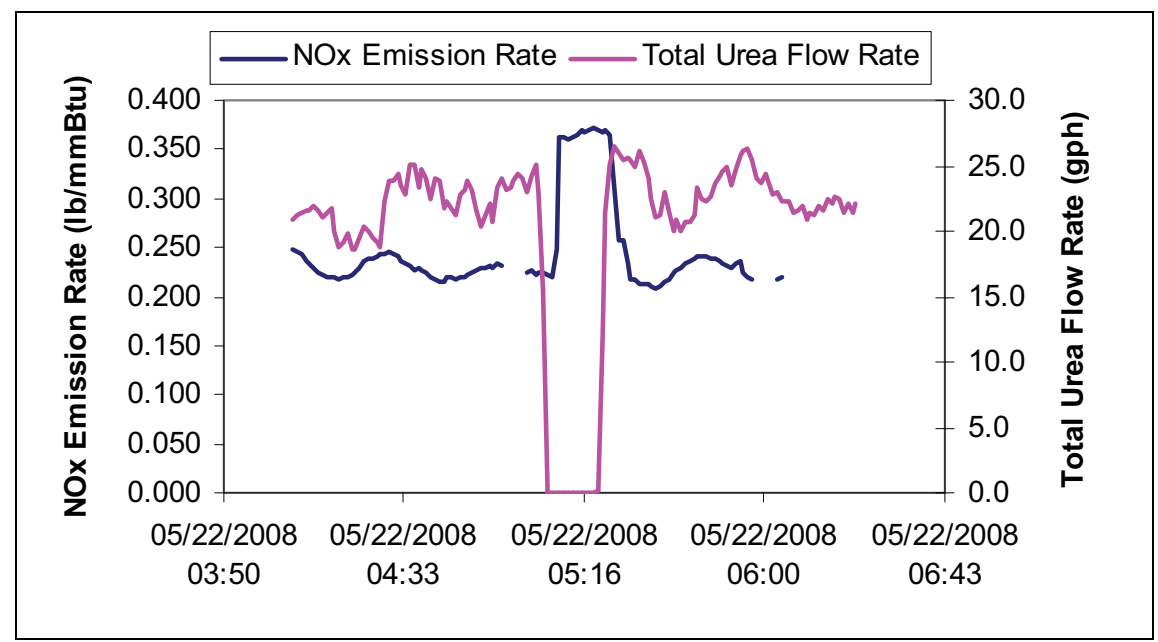

Figure 51. $\mathrm{NO}_{\mathrm{x}}$ emission rate and total urea flow rate observed between 4:07 and 6:22 EST on May 22, 2008. $\mathrm{NO}_{\mathrm{x}}$ emissions were measured by the unit's stack CEM. The urea flow rate was measured by the SNCR system's flow meters and represents the flow of $50 \%(\mathrm{w} / \mathrm{w})$ urea solution. 
Table 12. Average $\mathrm{NO}_{x}$ emission rates observed with and without urea injection during tests on March 10 , March 13, May 21, and May 22, 2008. These data were used to compute the $\mathrm{NO}_{\mathrm{x}}$ removal efficiency achieved by the hybrid SNCR/SCR system.

\begin{tabular}{|c|c|c|c|c|}
\hline $\begin{array}{l}\text { Date / Time } \\
\text { (EST) }\end{array}$ & $\begin{array}{l}\text { Unit Load } \\
\left(\mathrm{MW}_{\mathrm{g}}\right)\end{array}$ & $\begin{array}{c}\text { Average } \mathrm{NO}_{\mathrm{x}} \\
\text { Emission Rate } \\
\text { Without Urea } \\
\text { Injection } \\
\text { (Ib/mmBtu) }\end{array}$ & $\begin{array}{c}\text { Average } \mathrm{NO}_{\mathrm{x}} \\
\text { Emission Rate } \\
\text { With Urea } \\
\text { Injection } \\
\text { (Ib/mmBtu) }\end{array}$ & $\begin{array}{c}\text { NO }_{\mathrm{x}} \text { Removal } \\
\text { Efficiency by } \\
\text { Hybrid } \\
\text { SNCR/SCR } \\
(\%)\end{array}$ \\
\hline $3 / 10 / 080719-0858$ & 106 & 0.259 & 0.128 & 50.5 \\
\hline $3 / 13 / 08$ 1455-1636 & 106 & 0.267 & 0.129 & 51.7 \\
\hline 5/21/08 0801-0917 & 110 & 0.265 & 0.155 & 41.5 \\
\hline $5 / 22 / 080407-0519$ & 56 & 0.366 & 0.229 & 37.5 \\
\hline
\end{tabular}

As discussed in Section 9.1.2, Clean Air Engineering performed $\mathrm{NO}_{\mathrm{x}}$ measurements at the SCR inlet and SCR outlet sampling grids on March 28, 2007, May 30-June 1, 2007, June 20, 2007, and May 21-22, 2008, to evaluate the performance of the in-duct SCR reactor. Table 13 summarizes the average $\mathrm{NO}_{x}$ emission rates measured at the SCR inlet and SCR outlet during each test, as well as the apparent SCR NO removal efficiencies computed from these data. (A more complete presentation of the SCR grid point sampling results is included in the Clean Air Engineering reports in Appendix G). The data in Table 13 suggest that the SCR reactor met or exceeded its targeted $\mathrm{NO}_{\mathrm{x}}$ removal efficiency of $\geq 31 \%$ during all but two of the full-load tests conducted in March 2007-May 2008. Those tests had apparent removal efficiencies of about $27 \%$ across the SCR reactor.

Table 13. Average $\mathrm{NO}_{x}$ emission rates measured by Clean Air Engineering at the SCR inlet and SCR outlet sampling grids during tests in March 2007, May 2007, June 2007, and May 2008. The $\mathrm{NO}_{x}$ removal efficiencies computed from these data are also shown, as are relevant unit operating data.

\begin{tabular}{|c|c|c|c|c|c|}
\hline $\begin{array}{l}\text { Test Date / Time } \\
\text { (EDT) }\end{array}$ & $\begin{array}{l}\text { Unit Load } \\
\left(\mathrm{MW}_{\mathrm{g}}\right)\end{array}$ & $\begin{array}{c}\text { Mean NO }_{\mathrm{x}} \\
\text { Emission } \\
\text { Rate at } \\
\text { SCR Inlet } \\
\text { (lb/mmBtu) }\end{array}$ & $\begin{array}{c}\text { Mean NO }_{\mathrm{x}} \\
\text { Emission } \\
\text { Rate at SCR } \\
\text { Outlet }^{\mathrm{b}} \\
\text { (Ib/mmBtu) }\end{array}$ & $\begin{array}{c}\text { Apparent } \\
\text { SCR NO } \\
\text { Removal } \\
\text { Efficiency } \\
(\%)\end{array}$ & $\begin{array}{c}\mathrm{NO}_{\mathrm{x}} \\
\text { Emission } \\
\text { Rate from } \\
\text { Stack CEM } \\
\text { (Ib/mmBtu) }\end{array}$ \\
\hline $3 / 28 / 07$ 0912-1023 & 105 & 0.126 & 0.072 & $43.1 \%$ & 0.096 \\
\hline $3 / 28 / 07$ 1112-1223 & 105 & 0.118 & 0.072 & $38.9 \%$ & 0.095 \\
\hline $3 / 28 / 07$ 1248-1359 & 106 & 0.115 & 0.068 & $40.8 \%$ & 0.095 \\
\hline 3/30/07 1112-1135 & 108 & 0.126 & 0.073 & $41.9 \%$ & 0.104 \\
\hline $5 / 31 / 07$ 1736-1759 & 104 & 0.142 & 0.069 & $51.3 \%$ & 0.086 \\
\hline $5 / 31 / 07$ 1800-1911 & 105 & 0.146 & 0.078 & $46.4 \%$ & 0.103 \\
\hline $6 / 1 / 07$ 1024-1111 & 108 & 0.130 & 0.079 & $39.6 \%$ & 0.100 \\
\hline $6 / 1 / 07$ 1200-1247 & 108 & 0.128 & 0.093 & $26.8 \%$ & 0.103 \\
\hline $6 / 20 / 07$ 2000-2047 & 104 & 0.141 & 0.080 & $42.9 \%$ & 0.099 \\
\hline 5/21/08 0312-0559 & 81 & 0.153 & 0.104 & $31.9 \%$ & 0.151 \\
\hline $5 / 21 / 080712-0959$ & 109 & 0.133 & 0.097 & $27.3 \%$ & 0.144 \\
\hline $5 / 22 / 080048-0535$ & 56 & 0.178 & 0.172 & $3.4 \%$ & 0.239 \\
\hline
\end{tabular}

${ }^{a}$ Each complete traverse of the SCR sampling grids took 24 minutes to complete. For tests with durations longer than 24 minutes, data represent the average of multiple traverses. ${ }^{\mathrm{b}} \mathrm{Clean}$ Air Engineering reported the average $\mathrm{NO}_{x}$ concentration at each grid point, corrected to $3 \% \mathrm{O}_{2}$. To compute the mean $\mathrm{NO}_{x}$ emission rate, all valid grid point $\mathrm{NO}_{x}$ concentrations measured during the time period of interest were arithmetically averaged, and the average concentration was converted to a heat input basis using an oxygen-based fuel factor $\left(F_{d}\right)$ of $9780 \mathrm{scf} / \mathrm{mmBtu}$. 
The validity of these SCR grid sampling results is called into question, however, by the appreciable disparity between the average $\mathrm{NO}_{x}$ emission rates computed from the grid point measurements at the SCR outlet and the $\mathrm{NO}_{x}$ emission rates reported by the unit's continuous emissions monitor. As shown in Table 13, the mean $\mathrm{NO}_{x}$ emission rates at the SCR outlet were consistently $9-33 \%$ lower than the emission rates reported by the CEM. The cause of this discrepancy is unknown. Possible causes include measurement error or flow stratification at the SCR outlet. Measurement error is unlikely, because both the Clean Air Engineering $\mathrm{NO}_{\mathrm{x}}$ analyzer and the unit's stack CEM were calibrated during the test periods. Regarding possible flow stratification, all grid point measurements were weighted equally when computing the average $\mathrm{NO}_{x}$ concentrations at the SCR outlet. $\mathrm{NO}_{x}$ concentrations were inhomogeneous across the SCR outlet grid, though (see Appendix G). Hence, if significant flow stratification existed, the use of unweighted average $\mathrm{NO}_{x}$ concentrations at the SCR outlet could have caused the mean $\mathrm{NO}_{x}$ emission rates determined there to be biased relative to the emission rates measured at the stack. The direction of the bias suggests that areas of low $\mathrm{NO}_{\mathrm{x}}$ concentration at the SCR outlet were given too much weight in the averages and that areas of high $\mathrm{NO}_{\mathrm{x}}$ concentration were given too little weight. Space limitations around the SCR reactor prevented the performance of a manual traverse to determine the velocity profile at the SCR outlet in order to confirm or refute this explanation. Any flow stratification would likely also bias the average $\mathrm{NO}_{\mathrm{x}}$ removal efficiencies computed from the $\mathrm{NO}_{\mathrm{x}}$ grid point measurements; therefore, the data presented in Table 13 must be interpreted cautiously.

The $\mathrm{NO}_{x}$ tests at the SCR inlet and outlet sampling grids enabled an evaluation of the spatial distribution of $\mathrm{NO}_{x}$ removal efficiencies over the cross section of the reactor. As discussed in Section 4.1.1, the SCR reactor includes static mixers to homogenize the velocity, composition, and temperature of the flue gas across the catalyst. If such homogeneity is achieved, then $\mathrm{NO}_{\mathrm{x}}$ removal should be relatively uniform across the catalyst cross section (assuming uniform catalyst activity). However, the SCR grid sampling results suggested significant stratification in the $\mathrm{NO}_{\mathrm{x}}$ removal efficiency across the cross section of the SCR reactor. This was particularly evident during the tests on March 28, 2007, as shown in Figure 52. During those tests, very high $\mathrm{NO}_{x}$ removal efficiencies (>90\%) were observed in the northeastern and northwestern corners of the reactor, while much lower removal efficiencies $(<20 \%)$ were observed in the center of the reactor, particularly toward the south wall.

This stratification in $\mathrm{NO}_{x}$ removal efficiencies could have resulted from the flow stratification contemplated above. Areas of high flow would have relatively low flue gas residence time in the reactor, promoting low $\mathrm{NO}_{x}$ removal efficiency, whereas areas of low flow would have relatively high flue gas residence time, allowing greater $\mathrm{NO}_{x}$ removal efficiency (assuming an even distribution of $\mathrm{NO}_{x}$ and $\mathrm{NH}_{3}$ entering the reactor). Alternatively, it could have resulted from unevenness in the $\mathrm{NH}_{3}$-to- $\mathrm{NO}_{x}$ ratio at the SCR inlet. Regions with more $\mathrm{NH}_{3}$ would have greater $\mathrm{NO}_{x}$ removal efficiencies, and regions with less $\mathrm{NH}_{3}$ would have comparatively lower $\mathrm{NO}_{x}$ removal efficiencies. Either of these scenarios could result in high ammonia slip (i.e., because the residence time was too low to allow all of the ammonia to react, or because ammonia was fed in excess of the amount that could be consumed by reaction with $\mathrm{NO}_{\mathrm{x}}$ across the reactor), and high ammonia slip was observed during the tests on March 28 (see Section 9.3.3). Tuning was conducted throughout the rest of the guarantee test period in an effort to lessen ammonia slip by reducing deviations in flow and composition across the SCR reactor. Figure 53 shows the $\mathrm{NO}_{x}$ removal profile measured across the reactor on June 20, 2007, when the ammonia slip guarantee was satisfied, and Figure 54 shows the profile measured on May 21,2008 , after more than a year of routine commercial operation of the hybrid SNCR/SCR system. These figures indicate some improvement in the distribution of $\mathrm{NO}_{\mathrm{x}}$ removal efficiencies across the reactor cross section, although stratification is still evident. 


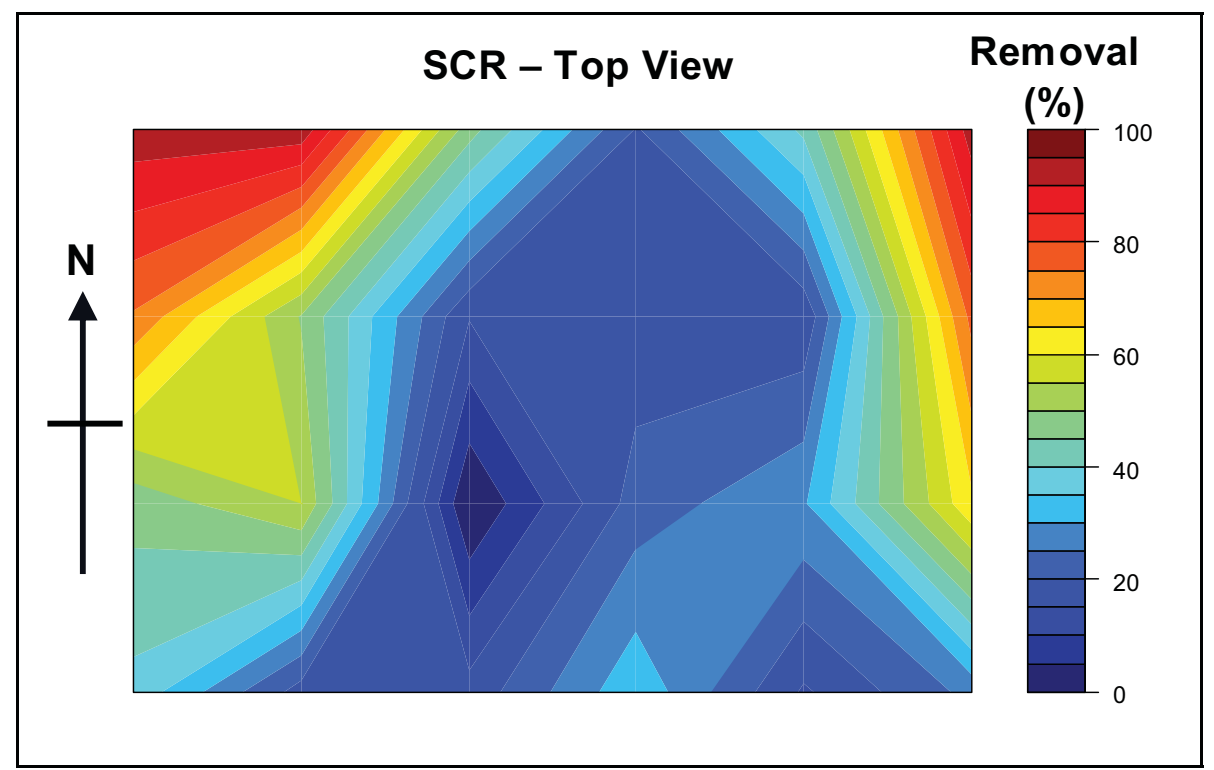

Figure 52. Summary of $\mathrm{NO}_{x}$ removal efficiencies computed from $\mathrm{NO}_{\mathrm{x}}$ concentrations measured at the SCR inlet and outlet sampling grids on March 28, 2007 (average of the three tests reported in Table 13). Each sampling grid consisted of 24 measurement points. The graph shows the $\mathrm{NO}_{x}$ removal achieved by the SCR as a function of location on the catalyst cross section. For purposes of this graph, any points with negative $\mathrm{NO}_{x}$ removal efficiencies were set equal to $0 \%$ removal efficiency.

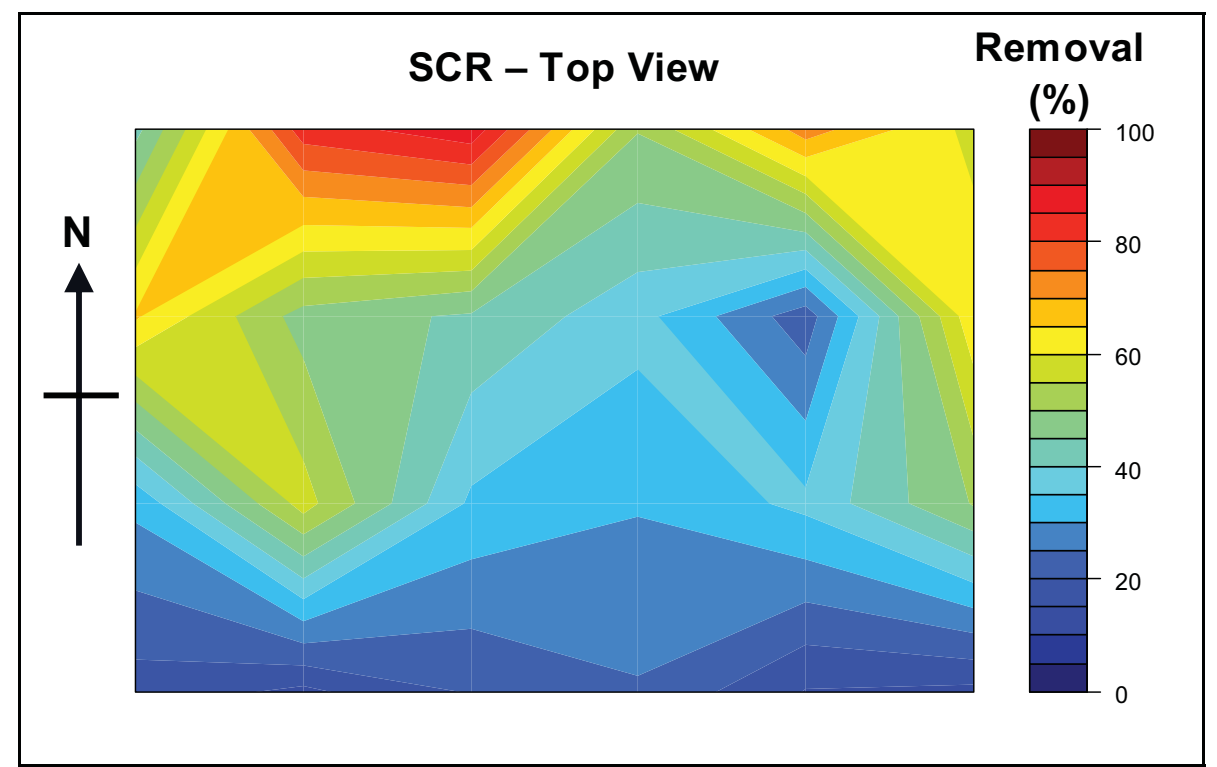

Figure 53. Summary of $\mathrm{NO}_{x}$ removal efficiencies computed from $\mathrm{NO}_{x}$ concentrations measured at the SCR inlet and outlet sampling grids on June 20, 2007, between 20:00 and 20:47 Eastern Daylight Time (EDT). Each sampling grid consisted of 24 measurement points. The graph shows the $\mathrm{NO}_{x}$ removal achieved by the SCR as a function of location on the catalyst cross section. 


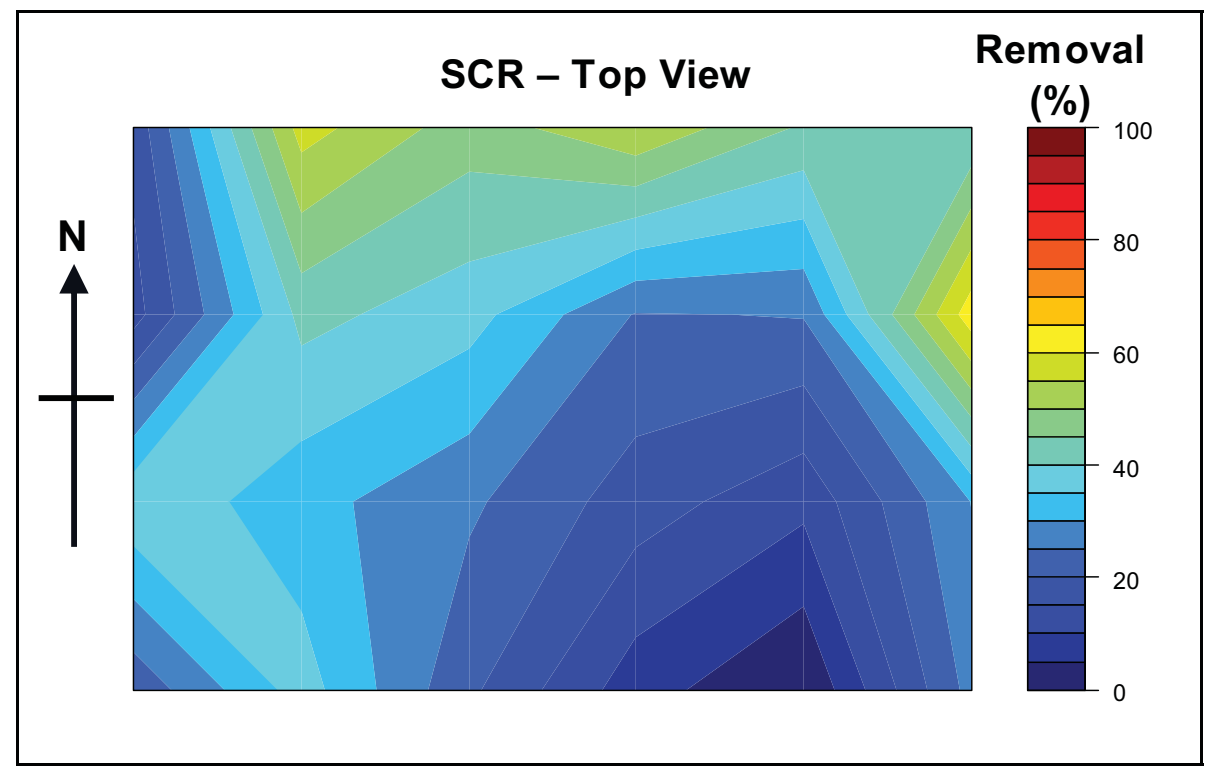

Figure 54. Summary of $\mathrm{NO}_{x}$ removal efficiencies computed from $\mathrm{NO}_{x}$ concentrations measured at the SCR inlet and outlet sampling grids on May 21, 2008, between 7:12 and 9:59 EDT. Each sampling grid consisted of 24 measurement points. The graph shows the $\mathrm{NO}_{x}$ removal achieved by the SCR as a function of location on the catalyst cross section. For purposes of this graph, any points with negative $\mathrm{NO}_{x}$ removal efficiencies were set equal to $0 \%$ removal efficiency. Invalid measurements were replaced with the average of surrounding valid measurements.

Figures 55 and 56 show the $\mathrm{NO}_{x}$ removal profiles measured in May 2008 when AES Greenidge Unit 4 was operating at intermediate load $\left(81 \mathrm{MW}_{\mathrm{g}}\right)$ and at low load $\left(56 \mathrm{MW}_{\mathrm{g}}\right)$, respectively. During the intermediate load test on May 21, urea was being injected into Zones 1 and 2 of the SNCR system, rather than into Zones 2 and 3, and the flue gas temperature at the SCR inlet was about $60^{\circ} \mathrm{F}$ cooler than it was during the full load test (109 $\mathrm{MW}_{\mathrm{g}}$ ) performed later that day. In spite of this, the $\mathrm{NO}_{x}$ removal efficiency across the SCR reactor did not decrease at intermediate load. (The areas of high and low removal efficiency in the $\mathrm{NO}_{x}$ removal profile shifted, however). As expected, $\mathrm{NO}_{x}$ removal efficiencies were near-zero across the entire SCR cross section when the unit operated at low load $\left(56 \mathrm{MW}_{\mathrm{g}}\right)$ and no urea was injected into the zones of the SNCR system (i.e., Zones 2 and 3) that are designed to generate ammonia slip for the SCR reactor.

\subsubsection{Urea Utilization}

The variable operating costs of the hybrid SNCR/SCR system depend strongly upon the amount of urea that is required to achieve a given level of $\mathrm{NO}_{x}$ removal. As discussed in Section 4.1.1, urea consumption is normally expressed in terms of the normalized stoichiometric ratio (Equation 5) and the urea utilization (Equation 4). The normalized stoichiometric ratio compares the amount of urea actually being injected with the amount that would be required to stoichiometrically react with all of the $\mathrm{NO}_{x}$ at the SNCR inlet. The urea utilization is the percentage of injected urea that is actually consumed by reaction with $\mathrm{NO}_{\mathrm{x}}$. As discussed by Albanese et al. (2005), in commercial practice, stand-alone SNCR systems typically operate with an NSR of $0.6-2.0$ and a urea utilization of $30-60 \%$. 


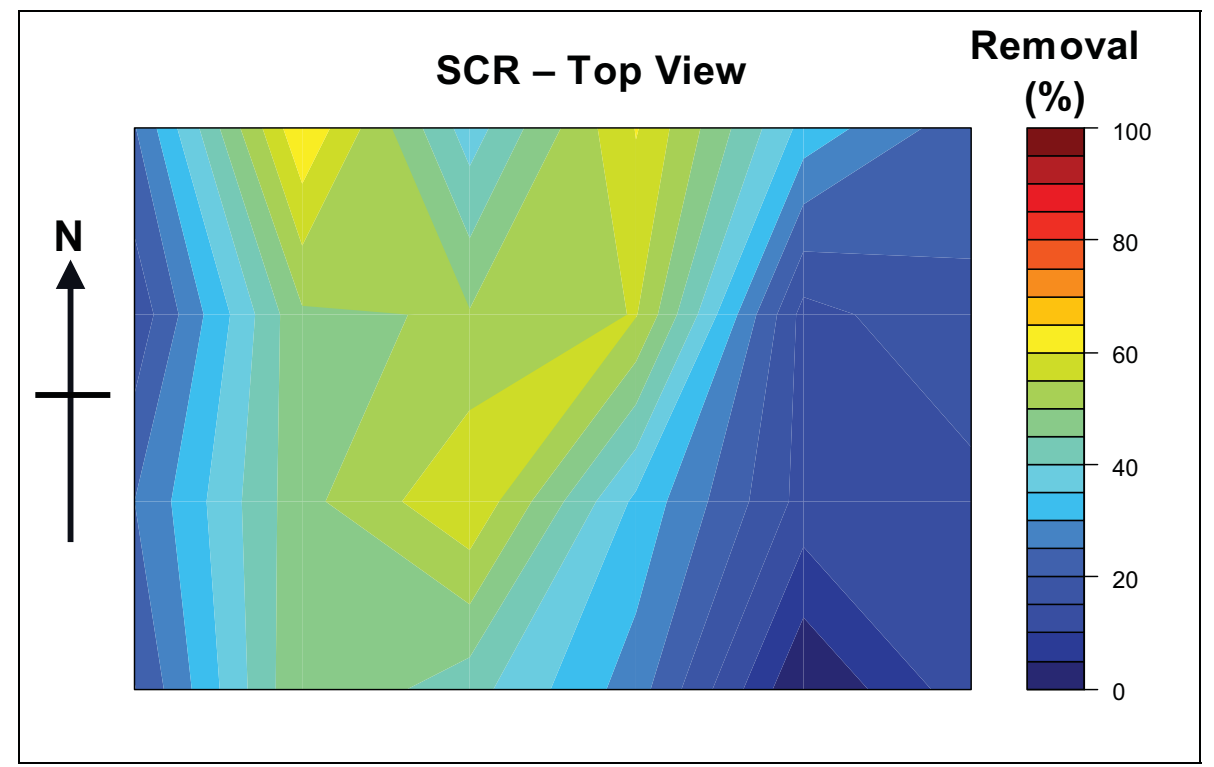

Figure 55. Summary of $\mathrm{NO}_{x}$ removal efficiencies computed from $\mathrm{NO}_{x}$ concentrations measured at the SCR inlet and outlet sampling grids on May 21, 2008, between 3:12 and 5:59 EDT. Each sampling grid consisted of 24 measurement points. The graph shows the $\mathrm{NO}_{x}$ removal achieved by the SCR as a function of location on the catalyst cross section. For purposes of this graph, any points with negative $\mathrm{NO}_{x}$ removal efficiencies were set equal to $0 \%$ removal efficiency. Invalid measurements were replaced with the average of surrounding valid measurements.

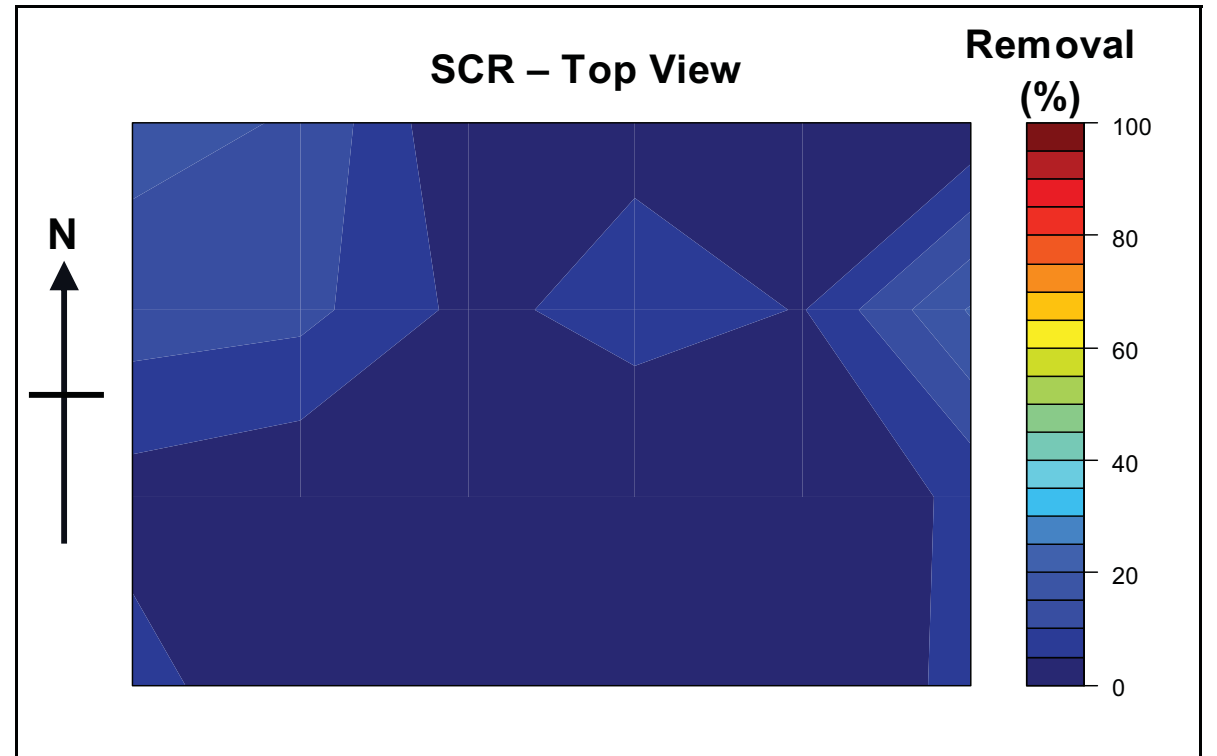

Figure 56. Summary of $\mathrm{NO}_{x}$ removal efficiencies computed from $\mathrm{NO}_{\mathrm{x}}$ concentrations measured at the SCR inlet and outlet sampling grids on May 22, 2008, between 0:48 and 5:35 EDT. Each sampling grid consisted of 24 measurement points. The graph shows the $\mathrm{NO}_{\mathrm{x}}$ removal achieved by the SCR as a function of location on the catalyst cross section. For purposes of this graph, any points with negative $\mathrm{NO}_{x}$ removal efficiencies were set equal to $0 \%$ removal efficiency. Invalid measurements were replaced with the average of surrounding valid measurements. 
The NSR and urea utilization were estimated using data collected during the 12-hour guarantee test periods on March 28, May 1, and June 20, 2007. The $\mathrm{NO}_{x}$ emission rates and urea flow rates (50\% w/w solution) observed during these test periods are shown in Figures 43-45. The NSR and urea utilization estimated for each period, as well as key process data used in the derivation of these metrics, are presented in Table 14. The average unit load, average heat input, and $\mathrm{NO}_{\mathrm{x}}$ emission rate were computed using one-minute or five-minute average data from the unit's CEM and DCS. The baseline $\mathrm{NO}_{x}$ emission rate leaving the new combustion system was not measured during the March 28, May 1, or June 20 test periods; hence, the design rate of $0.25 \mathrm{lb} / \mathrm{mmBtu}$ was assumed in the NSR and urea utilization calculations. The density of urea was assumed to be $9.5 \mathrm{lb} / \mathrm{gal}$, consistent with the measured density of urea samples collected during the March 2007 tests.

Table 14. Estimated normalized stoichiometric ratio and urea utilization during the guarantee test periods on March 28, May 1, and June 20, 2007. Relevant process data are also summarized.

\begin{tabular}{|c|c|c|c|c|c|c|c|}
\hline $\begin{array}{l}\text { Date/Time } \\
\text { (EST) }\end{array}$ & $\begin{array}{c}\text { Average } \\
\text { Unit } \\
\text { Load }^{\mathrm{a}} \\
\left.\text { (MW }_{\mathbf{g}}\right)\end{array}$ & $\begin{array}{c}\text { Average } \\
\text { Heat } \\
\text { Input }^{\mathrm{a}} \\
\text { (mmBtu/h) }^{\mathrm{mm}}\end{array}$ & $\begin{array}{c}\text { Assumed } \\
\text { NO } \text { Rate } \\
\text { at SNCR } \\
\text { Inlet } \\
\text { (Ib/mmBtu) }\end{array}$ & $\begin{array}{c}\text { Flow } \\
\text { Rate of } \\
50 \% \text { Urea } \\
\text { Solution } \\
\text { (gph) }\end{array}$ & $\begin{array}{c}\mathrm{NO}_{\mathrm{x}} \\
\text { Removal } \\
\text { by } \\
\text { SNCR/SCR } \\
(\%) \\
\end{array}$ & NSR & $\begin{array}{c}\text { Urea } \\
\text { Utilization } \\
(\%)\end{array}$ \\
\hline $\begin{array}{l}3 / 28 / 07 \\
0800-2000\end{array}$ & 105 & 1020 & 0.25 & 47.5 & 61.6 & 1.36 & 45.4 \\
\hline $\begin{array}{l}5 / 1 / 07 \\
0800-2000\end{array}$ & 106 & 1023 & 0.25 & 48.2 & 61.1 & 1.37 & 44.5 \\
\hline $\begin{array}{l}6 / 20 / 07 \\
0800-2000\end{array}$ & 106 & 1027 & 0.25 & 47.5 & 61.6 & 1.35 & 45.7 \\
\hline
\end{tabular}

${ }^{a}$ Computed using one-minute or five-minute CEM data provided by AES Greenidge. ${ }^{b}$ Computed using one-minute or five-minute DCS data provided by AES Greenidge. ${ }^{\circ}$ Computed from the assumed $\mathrm{NO}_{x}$ rate at the SNCR inlet and the average $\mathrm{NO}_{x}$ rate measured by the unit's stack CEM.

As shown in the table, the SNCR performance was very consistent across the three guarantee test periods. The average flow rate of $50 \% \mathrm{w} / \mathrm{w}$ urea solution was about $48 \mathrm{gph}$ during all three periods. The estimated normalized stoichiometric ratio ranged from 1.35-1.37, and the estimated urea utilization ranged from $44.5-45.7 \%$ during these tests. These values are all near the middle of the typical ranges cited above for SNCR systems.

This performance was not sustained during long-term operation of the system, however. Figure 57 summarizes the urea flow rates observed between August 2007 and September 2008, following the completion of guarantee testing. These flow rates, which represent the combined flow of $50 \% \mathrm{w} / \mathrm{w}$ urea solution to all three SNCR injection zones, were derived from hourly average measurements made by the SNCR system's online flow meters. The data are plotted as a function of gross unit load; the mean urea flow rate at each load is indicated by the solid line, and the interval representing \pm 2 standard deviations from the mean is indicated by the dashed lines. Approximately $95 \%$ of the hourly urea flow rates fell within this interval.

As shown in Figure 57, the total urea flow rate increased with increasing unit load. This is the expected trend, because the number of moles of $\mathrm{NO}_{x}$ leaving the combustion system and the desired $\mathrm{NO}_{x}$ removal efficiency both increase as load increases. However, the long-term average urea flow rates were considerably greater than the flow rates observed during guarantee testing. During the period from August 2007 through September 2008, the total urea injection rate averaged 60.1-60.8 gph (with a standard deviation of 5.6-5.8 gph) when the unit operated at 105-106 $\mathrm{MW}_{\mathrm{g}}$. Hence, urea consumption was about $20-25 \%$ greater than it was during the tests in March-June 2007. As shown in Section 9.3.1, the average $\mathrm{NO}_{x}$ removal 
efficiency at 105-106 $\mathrm{MW}_{\mathrm{g}}$ was also substantially lower in August 2007 - September 2008 than it was during the guarantee tests. These data suggest that the changes made to the combustion system and SNCR system after guarantee testing caused a significant decrease in the urea utilization of the hybrid SNCR/SCR system.

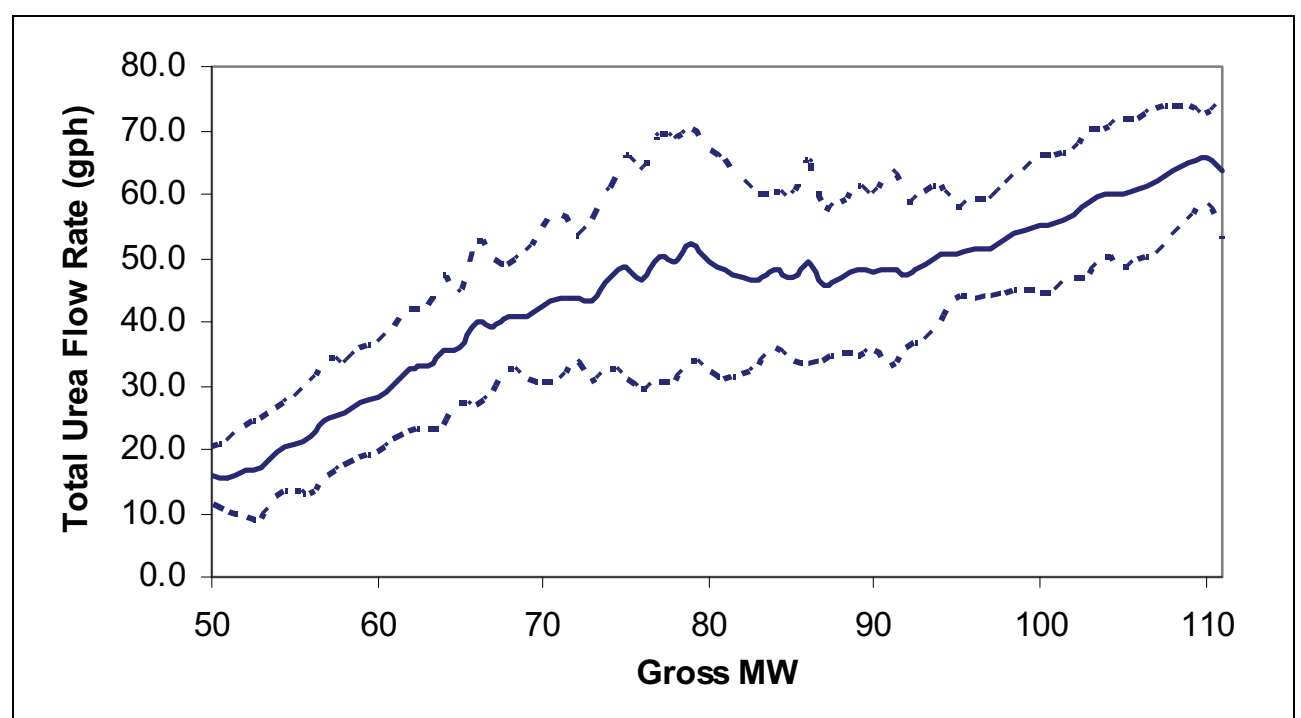

Figure 57. Total flow rate of $50 \% \mathrm{w} / \mathrm{w}$ urea solution (sum of all three SNCR zones) as a function of gross unit load between August 2007 and September 2008. Urea measurements were made by the SNCR system's online flow meters. The solid line indicates the mean flow rate at each load, and the dashed lines represent \pm 2 standard deviations from the mean. Computations were performed using hourly data.

The tests conducted on March 10, March 13, May 21, and May 22, 2008, were used to quantify the NSR and urea utilization achieved by the SNCR system during the period of long-term operation following the guarantee tests. As discussed in the preceding section, the baseline $\mathrm{NO}_{\mathrm{x}}$ emission rate from the combustion system was measured during these tests by temporarily discontinuing the flow of urea to the SNCR system and observing the resulting emission rate measured by the unit's stack CEM (see Figures 48-51 and Table 12). The $\mathrm{NO}_{\mathrm{x}}$ emission rate with the hybrid SNCR/SCR system in service and the urea injection rate required to achieve this $\mathrm{NO}_{x}$ emission rate were computed from data collected during the one-hour period immediately before the urea was shut off. Again, the average unit load, average heat input, and $\mathrm{NO}_{\mathrm{x}}$ emission rates were computed using one-minute average data from the unit's CEM and DCS, and the density of urea ( $50 \% \mathrm{w} / \mathrm{w}$ solution) was assumed to be $9.5 \mathrm{lb} / \mathrm{gal}$.

Table 15 shows the NSR and urea utilization estimated for the four tests in March and May 2008. The urea flow rates observed during these tests were generally similar to the long-term average flow rates shown in Figure 57 at the corresponding unit loads. The full-load tests on March 10, March 13, and May 21, 2008, had substantially greater normalized stoichiometric ratios and lower urea utilization than the tests in March-May 2007, indicating a decline in the performance of the hybrid SNCR/SCR system following the guarantee test period. The urea utilization determined at full load in March and May 2008 ranged from $24.6-36.9 \%$, near or below the bottom of the 30-60\% range referenced above for typical stand-alone SNCR systems. By contrast, the SNCR system performed commendably at low load operation (56 $\mathrm{MW}_{\mathrm{g}}$ ), achieving a urea utilization of 50.3\% during the test on May 22, 2008. 
Table 15. Estimated normalized stoichiometric ratio and urea utilization during tests conducted on March 10, March 13, May 21, and May 22, 2008. Relevant process data are also summarized.

\begin{tabular}{|c|c|c|c|c|c|c|c|}
\hline $\begin{array}{l}\text { Date/Time } \\
\text { (EST) }\end{array}$ & $\begin{array}{c}\text { Average } \\
\text { Unit } \\
\text { Load }^{\mathrm{a}} \\
\left(\mathbf{M W}_{\mathrm{g}}\right)\end{array}$ & $\begin{array}{c}\text { Average } \\
\text { Heat } \\
\text { Input }^{\mathrm{a}} \\
\text { (mmBtu/h) }\end{array}$ & $\begin{array}{c}\mathrm{NO}_{\mathrm{x}} \text { Rate } \\
\text { at SNCR } \\
\text { Inlet }^{\mathrm{b}} \\
\text { (lb/mmBtu) }\end{array}$ & $\begin{array}{c}\text { Flow } \\
\text { Rate of } \\
50 \% \text { Urea } \\
\text { Solution } \\
\text { (gph) }\end{array}$ & $\begin{array}{c}\mathrm{NO}_{\mathrm{x}} \\
\text { Removal by } \\
\text { SNCR/SCR } \\
(\%)\end{array}$ & NSR & $\begin{array}{c}\text { Urea } \\
\text { Utilization } \\
(\%)\end{array}$ \\
\hline $\begin{array}{l}3 / 10 / 08 \\
0719-0858\end{array}$ & 106 & 1061 & 0.259 & 60.0 & 50.5 & 1.59 & 31.7 \\
\hline $\begin{array}{l}3 / 13 / 08 \\
1455-1636\end{array}$ & 106 & 1058 & 0.267 & 54.3 & 51.7 & 1.40 & 36.9 \\
\hline $\begin{array}{l}5 / 21 / 08 \\
0801-0917\end{array}$ & 110 & 1077 & 0.265 & 66.3 & 41.5 & 1.69 & 24.6 \\
\hline $\begin{array}{l}5 / 22 / 08 \\
0407-0519\end{array}$ & 56 & 592 & 0.366 & 22.1 & 37.5 & 0.75 & 50.3 \\
\hline
\end{tabular}

${ }^{a}$ Computed using one-minute CEM data provided by AES Greenidge. ${ }^{\circ}$ Computed from one minute CEM data collected after urea injection was discontinued during the second portion of the test. ${ }^{\circ}$ Computed using one-minute DCS data provided by AES Greenidge. ${ }^{\mathrm{d}}$ Computed from the average $\mathrm{NO}_{\mathrm{x}}$ rates measured by the unit's stack CEM during the periods with and without urea injection.

\subsubsection{Ammonia Slip}

Ammonia slip from the hybrid SNCR/SCR system at AES Greenidge Unit 4 was generally greater than the target of 2 ppmvd @ 3\% $\mathrm{O}_{2}$ during the first year-and-a-half of operation.

As discussed in Section 9.1.2.2, several attempts were required before attainment of the ammonia slip guarantee could be demonstrated, and even then, the guarantee was just narrowly satisfied. During guarantee testing on March 28, 2007, ammonia slip measurements were conducted at the SCR outlet sampling location. All three measurements that day indicated ammonia concentrations greater than 2 ppmvd @ $3 \% \mathrm{O}_{2}$. It was hypothesized that the greaterthan-expected ammonia slip might have arisen because sampling was conducted close to the northeastern wall of the SCR reactor, near the region of locally high $\mathrm{NO}_{x}$ removal efficiency (and potential excess ammonia) that is visible in Figure 52. As a result, on May 1, 2007, ammonia slip sampling was conducted at the air heater inlet location, as well as at the SCR outlet location, in an effort to improve the representativeness of the measurements. (The differences between these sampling locations are detailed in Sections 9.2.1.1.3 and 9.2.1.1.4). Although neither location allowed for a complete traverse of the ductwork downstream of the SCR reactor, the air heater inlet location enabled points to be sampled near the center of the ductwork on both the eastern and western sides of the reactor, likely resulting in samples that were more characteristic of the average conditions across the reactor. Results from the ammonia slip tests on March 28 and May 1, 2007, are shown in Table 16. The ammonia concentrations measured at the air heater inlet on May 1 were consistently lower than the corresponding concentrations measured at the SCR outlet, although all were still greater than the performance target of 2 ppmvd @ $3 \% \mathrm{O}_{2}$.

All subsequent ammonia slip measurements performed as part of the project were conducted at the air heater inlet sampling location. The next round of ammonia slip tests occurred on May 31-June 1, 2007. During those tests, CONSOL and Clean Air Engineering simultaneously sampled for ammonia at the air heater inlet while BPEI and Fuel Tech worked to tune the combustion system and SNCR system. As stated in Section 9.2.1.1.4, during the first half of each test, one group sampled the eastern air heater inlet duct while the other group sampled 
the western duct. The groups then exchanged positions for the second half of the test, such that each collected a composite sample representing the average concentration in both ducts. Each group also analyzed the collected samples using both an ion selective electrode in the field and ion chromatography in the laboratory. Results are summarized in Table 17 . With the exception of two ammonia concentrations determined by Clean Air Engineering using ion chromatography, all of the ammonia concentrations measured during the tests exceeded 2 ppmvd @ 3\% $\mathrm{O}_{2}$. Whereas the IC and ISE results determined by CONSOL exhibited reasonable agreement for all three tests (the relative percent difference between the two methods was less than $25 \%$ for each test), the IC and ISE results determined by Clean Air Engineering exhibited poor agreement (the relative percent difference between the two methods was greater than $120 \%$ in all cases). Moreover, neither the CAE IC results nor the CAE ISE results agreed well with the CONSOL IC and ISE results. Some disparity between the CONSOL and Clean Air Engineering measurements may be expected to result from random error and from minor methodological differences, including the fact that the groups sampled the eastern and western ducts at different points in time and that CONSOL used a slightly longer probe than CAE, allowing CONSOL to extract samples from deeper points in the duct (closer to the center). However, the large unexplained disparity between the Clean Air Engineering IC and ISE results, which bracket the CONSOL IC and ISE results, call the validity of these CAE results into question. The Clean Air Engineering report (included in Appendix $G$ ) identifies exceptions to QA/QC guidelines, including the guidelines for sample hold time and sample storage temperature, that might have contributed to the discrepancies among the results. Because of these exceptions and the inconsistency between the ISE and IC results, the Clean Air Engineering ammonia slip measurements from May 31 and June 1 were considered to be invalid. The ammonia slip guarantee was not achieved during the May 31-June 1 test period.

Table 16. Ammonia concentrations measured by CONSOL at the SCR outlet and air heater inlet sampling locations on March 28 and May 1, 2007. Relevant process data are also summarized.

\begin{tabular}{|c|c|c|c|c|}
\hline \multirow[b]{2}{*}{ Date/Time (local) } & \multirow{2}{*}{$\begin{array}{l}\text { Unit Load } \\
\left(\mathrm{MW}_{\mathrm{q}}\right)\end{array}$} & \multirow{2}{*}{$\begin{array}{c}\mathrm{NO}_{\mathrm{x}} \text { Emissions } \\
(\mathrm{lb} / \mathrm{mmBtu})\end{array}$} & \multicolumn{2}{|c|}{$\mathrm{NH}_{3}$ Concentration (ppmvd @ 3\% $\mathrm{O}_{2}$ ) } \\
\hline & & & SCR Outlet & Air Heater Inlet \\
\hline 3/28/07 0914-1014 & 105 & 0.095 & 4.6 & - \\
\hline 3/28/07 1115-1215 & 105 & 0.095 & 11.4 & - \\
\hline $3 / 28 / 07$ 1300-1400 & 105 & 0.095 & 13.5 & - \\
\hline 5/1/07 0903-1006 & 106 & 0.092 & 11.6 & 3.6 \\
\hline $5 / 1 / 071121-1235$ & 106 & 0.096 & 9.7 & 5.1 \\
\hline $5 / 1 / 07$ 1335-1438 & 106 & 0.097 & 14.3 & 4.0 \\
\hline 5/1/07 1530-1635 & 106 & 0.102 & 9.8 & 4.2 \\
\hline
\end{tabular}

Table 17. Ammonia concentrations measured by CONSOL and Clean Air Engineering at the air heater inlet sampling location on May 31 and June 1, 2007. Relevant process data are also summarized.

\begin{tabular}{|c|c|c|c|c|c|c|}
\hline \multirow{2}{*}{$\begin{array}{l}\text { Date/Time } \\
\text { (local) }\end{array}$} & \multirow{2}{*}{$\begin{array}{c}\text { Unit Load } \\
\left(\mathrm{MW}_{\mathrm{g}}\right)\end{array}$} & \multirow{2}{*}{$\begin{array}{c}\mathrm{NO}_{\mathrm{x}} \\
\text { Emissions } \\
\text { (lb/mmBtu) }\end{array}$} & \multirow{2}{*}{$\begin{array}{l}\text { Sampling } \\
\text { Group }\end{array}$} & \multicolumn{2}{|c|}{$\begin{array}{l}\mathrm{NH}_{3} \text { Concentration } \\
\left(\mathrm{ppmvd} @ 3 \% \mathrm{O}_{2} \text { ) }\right.\end{array}$} & \multirow{2}{*}{$\begin{array}{l}\operatorname{RPD}^{\mathrm{a}} \\
(\%)\end{array}$} \\
\hline & & & & IC & ISE & \\
\hline \multirow{2}{*}{$\begin{array}{l}5 / 31 / 07 \\
1804-1914\end{array}$} & \multirow{2}{*}{105} & \multirow{2}{*}{0.103} & CONSOL & $>2.5^{b}$ & $>2.5^{b}$ & 0.0 \\
\hline & & & $\mathrm{CAE}$ & 1.4 & 6.2 & 126 \\
\hline \multirow{2}{*}{$\begin{array}{l}6 / 1 / 07 \\
1020-1108\end{array}$} & \multirow{2}{*}{108} & \multirow{2}{*}{0.099} & CONSOL & 4.9 & 4.2 & 15 \\
\hline & & & $\mathrm{CAE}$ & 2.0 & 8.1 & 122 \\
\hline \multirow{2}{*}{$\begin{array}{l}6 / 1 / 07 \\
1205-1252\end{array}$} & \multirow{2}{*}{108} & \multirow{2}{*}{0.103} & CONSOL & 4.7 & 3.8 & 21 \\
\hline & & & CAE & 2.4 & 10.9 & 128 \\
\hline
\end{tabular}

${ }^{a} \mathrm{RPD}=100 \times|\mathrm{IC}-\mathrm{ISE}| /((\mathrm{IC}+\mathrm{ISE}) / 2){ }^{\mathrm{b}} \mathrm{A}$ portion of the sample line rinse was spilled during sample recovery. Hence, the actual amount of $\mathrm{NH}_{3}$ present in the flue gas was greater than the amount determined from the recovered sample. 
CONSOL conducted additional ammonia slip testing at the air heater inlet on June 20 and 21, 2007, after BPEl and Fuel Tech completed further tuning of the hybrid $\mathrm{NO}_{\mathrm{x}}$ control system. As discussed in Section 9.2.1.1.4, for each of these tests, the eastern and western air heater inlet ducts were sampled independently using separate trains for the full duration of each test, thereby generating data regarding the distribution of ammonia between the two ducts. Table 18 summarizes the results. Measured ammonia concentrations decreased throughout the day on June 20 as BPEI tuned the combustion system and SNCR system. The third test performed on that day indicated 2 ppmvd $\mathrm{NH}_{3} @ 3 \% \mathrm{O}_{2}$ (to one significant digit) while the Unit $4 \mathrm{NO}_{\mathrm{x}}$ emission rate was $\leq 0.10 \mathrm{lb} / \mathrm{mmBtu}$, consistent with the performance target for ammonia slip. The testing on June 21 was performed to support tuning activities focused on establishing a set of acceptable boiler operating conditions for routine operation of the $\mathrm{NO}_{x}$ control system under its permitted high-load $\mathrm{NO}_{x}$ emission rate of $0.15 \mathrm{lb} / \mathrm{mmBtu}$. Hence, $\mathrm{NO}_{\mathrm{x}}$ emissions during the $\mathrm{NH}_{3}$ slip tests on June 21 were greater than $0.10 \mathrm{lb} / \mathrm{mmBtu}$. The average ammonia slip measured at the air heater inlet during the two tests on June 21 was 2.3 ppmvd @ $3 \% \mathrm{O}_{2}$.

Table 18. Ammonia concentrations measured by CONSOL at the air heater inlet sampling location on June 20-21, 2007. Relevant process data are also summarized.

\begin{tabular}{|c|c|c|c|c|c|}
\hline \multirow[b]{2}{*}{ Date / Time (local) } & \multirow{2}{*}{$\begin{array}{l}\text { Unit } \\
\text { Load } \\
\left(\mathrm{MW}_{\mathrm{g}}\right)\end{array}$} & \multirow{2}{*}{$\begin{array}{c}\mathrm{NO}_{\mathrm{x}} \\
\text { Emissions } \\
\text { (Ib/mmBtu) }\end{array}$} & \multicolumn{3}{|c|}{$\mathrm{NH}_{3}$ Concentration (ppmvd @ 3\% $\mathrm{O}_{2}$ ) } \\
\hline & & & East Duct & West Duct & Average \\
\hline 6/20/07 0935-1035 & 108 & 0.101 & 3.4 & 7.8 & 5.6 \\
\hline $6 / 20 / 071755-1836$ & 104 & 0.100 & 3.9 & 2.9 & 3.4 \\
\hline $6 / 20 / 072002-2047$ & 104 & 0.099 & 1.6 & 3.1 & 2.4 \\
\hline $6 / 21 / 071109-1150$ & 108 & 0.161 & 1.3 & 3.0 & 2.1 \\
\hline 6/21/07 1517-1557 & 108 & 0.138 & 1.6 & 3.4 & 2.5 \\
\hline
\end{tabular}

All of the ammonia slip tests performed during the guarantee test period occurred while Unit 4 was firing $100 \%$ coal and operating at or near full load, with urea being injected into Zones 2 and 3 of the SNCR system. In order to track ammonia slip from the hybrid SNCR/SCR system during longer-term operation, and to evaluate the effects of changes in operating conditions on the amount of ammonia slip, ammonia measurements were performed at the air heater inlet during the process performance tests and follow-up tests in October 2007, November 2007, March 2008, May 2008, and June 2008. A total of 32 additional ammonia slip tests were completed during these periods. Figure 58 shows the ammonia concentrations measured during these tests. Table 19 provides additional detail about the tests, including a summary of relevant process conditions observed during each measurement period. With the exception of tests conducted at low load, when urea was only being injected through Zone 1 of the SNCR system, the measured ammonia slip was generally greater than the target of 2 ppmvd @ $3 \% \mathrm{O}_{2}$ regardless of unit operating conditions. Of the 26 tests conducted at intermediate and high load, when urea was being injected into Zone 2 of the SNCR system (as well as either Zone 1 or Zone 3), only two had ammonia slip concentrations below 2 ppmvd @ 3\% $\mathrm{O}_{2}$. Both of these occurred on May 21, 2008. Ammonia concentrations measured during the 26 tests ranged from 1.6 to 7.3 ppmvd @ 3\% $\mathrm{O}_{2}$, with a mean concentration of 4.6 ppmvd @ 3\% $\mathrm{O}_{2}$. Hence, the hybrid SNCR/SCR system fell short of its performance target for ammonia slip during long-term operation. 
Table 19. Ammonia concentrations measured by CONSOL at the air heater inlet sampling location during process performance testing and follow-up testing between October 2007 and June 2008. Relevant process data are also summarized.

\begin{tabular}{|c|c|c|c|c|c|c|c|}
\hline $\begin{array}{l}\text { Test Date/Time } \\
\text { (local) }\end{array}$ & $\begin{array}{c}\mathrm{NH}_{3} \\
\text { Concentration } \\
(p p m v d \\
\left.@ 3 \% \mathrm{O}_{2}\right) \\
\end{array}$ & $\begin{array}{l}\text { Unit } \\
\text { Load } \\
\left(\mathrm{MW}_{\mathrm{g}}\right)\end{array}$ & $\begin{array}{l}\text { Biomass } \\
\text { Co-Firing }\end{array}$ & $\begin{array}{l}\text { Active } \\
\text { Urea } \\
\text { Injection } \\
\text { Zones }\end{array}$ & $\begin{array}{c}\text { SCR } \\
\text { Inlet } \\
\text { Temp } \\
\left({ }^{\circ} \mathrm{F}\right) \\
\end{array}$ & $\begin{array}{c}\text { SCR } \\
\text { dP } \\
\text { (iwc) }\end{array}$ & $\begin{array}{c}\mathrm{NO}_{\mathrm{x}} \\
\text { Emissions } \\
\text { (lb/mmBtu) }\end{array}$ \\
\hline 10/8/07 0840-0940 & 3.5 & 107 & No & $2 / 3$ & 672 & 1.8 & 0.126 \\
\hline 10/9/07 0807-0909 & 2.6 & 109 & No & $2 / 3$ & 670 & 2.0 & 0.128 \\
\hline 10/10/07 0802-0904 & 4.0 & 109 & No & $2 / 3$ & 668 & 1.9 & 0.127 \\
\hline 10/11/07 0812-0912 & 4.8 & 108 & No & $2 / 3$ & 669 & 2.1 & 0.127 \\
\hline $11 / 13 / 07$ 2323-0027 & 0.3 & 56 & No & 1 & 572 & 1.1 & 0.214 \\
\hline $11 / 14 / 07$ 0117-0221 & 0.2 & 56 & No & 1 & 581 & 1.1 & 0.232 \\
\hline $11 / 14 / 07$ 0356-0500 & 0.2 & 56 & No & 1 & 583 & 1.3 & 0.230 \\
\hline $11 / 14 / 07$ 2311-2355 & 4.1 & 84 & No & $2 / 3$ & 627 & 1.6 & 0.130 \\
\hline $11 / 15 / 07$ 0052-0135 & 6.5 & 84 & No & $2 / 3$ & 636 & 1.5 & 0.146 \\
\hline $11 / 15 / 07$ 0347-0430 & 4.2 & 79 & No & $1 / 2$ & 632 & 1.5 & 0.131 \\
\hline 11/15/07 0502-0545 & 4.9 & 80 & No & $1 / 2 / 3$ & 635 & 1.5 & 0.141 \\
\hline 11/16/07 1240-1326 & 6.6 & 102 & Yes & $2 / 3$ & 698 & 2.0 & 0.161 \\
\hline $11 / 16 / 07$ 1412-1457 & 5.6 & 103 & Yes & $2 / 3$ & 702 & 2.0 & 0.162 \\
\hline $11 / 16 / 07$ 1642-1726 & 6.4 & 102 & Yes & $2 / 3$ & 685 & 2.0 & 0.141 \\
\hline $3 / 10 / 08$ 1440-1550 & 5.5 & 108 & Yes & $2 / 3$ & 678 & 2.3 & 0.133 \\
\hline $3 / 13 / 08$ 0900-1005 & 6.4 & 107 & Yes & $2 / 3$ & 660 & 2.6 & 0.130 \\
\hline $3 / 13 / 08$ 1150-1255 & 6.3 & 108 & Yes & $2 / 3$ & 673 & 2.6 & 0.143 \\
\hline $3 / 13 / 2008$ 1420-1525 & 5.4 & 108 & Yes & $2 / 3$ & 673 & 2.6 & 0.155 \\
\hline $5 / 20 / 082313-0011$ & 3.2 & 90 & No & $2 / 3$ & 638 & 0.7 & 0.172 \\
\hline $5 / 21 / 080100-0145$ & 3.6 & 91 & No & $2 / 3$ & 649 & 1.0 & 0.200 \\
\hline $5 / 21 / 080328-0416$ & 2.8 & 80 & No & $1 / 2$ & 617 & 1.1 & 0.143 \\
\hline $5 / 21 / 080453-0545$ & 1.9 & 81 & No & $1 / 2$ & 626 & 1.2 & 0.161 \\
\hline $5 / 21 / 080708-0753$ & 4.4 & 108 & No & $2 / 3$ & 676 & 1.2 & 0.126 \\
\hline $5 / 21 / 080801-0856$ & 1.6 & 109 & No & $2 / 3$ & 682 & 1.2 & 0.142 \\
\hline 5/21/08 0912-0957 & 3.1 & 110 & No & $2 / 3$ & 686 & 1.2 & 0.156 \\
\hline $5 / 22 / 08$ 0103-0158 & 0.2 & 56 & No & 1 & 563 & 0.9 & 0.240 \\
\hline $5 / 22 / 08$ 0207-0258 & 0.2 & 56 & No & 1 & 565 & 0.8 & 0.246 \\
\hline $5 / 22 / 080458-0555$ & 0.1 & 55 & No & 1 & 555 & 0.7 & 0.230 \\
\hline $6 / 12 / 08$ 1010-1115 & 6.1 & 107 & No & $2 / 3$ & 642 & 1.6 & 0.137 \\
\hline $6 / 12 / 08$ 1355-1510 & 7.3 & 106 & No & $2 / 3$ & 642 & 1.6 & 0.144 \\
\hline $6 / 13 / 08$ 1030-1135 & 4.4 & 109 & No & $2 / 3$ & 651 & 1.8 & 0.141 \\
\hline 6/13/08 1505-1615 & 5.5 & 108 & No & $2 / 3$ & 648 & 1.8 & 0.131 \\
\hline
\end{tabular}

The amount of ammonia slip observed at the air heater inlet appeared to depend strongly upon the zones through which urea was being injected and upon the pressure drop across the in-duct SCR catalyst. The process performance tests in November 2007 and May 2008 included parametric tests to determine the relationships among unit load, urea injection scheme, and ammonia slip for the hybrid SNCR/SCR system. The results of these tests are summarized in Figure 59. 


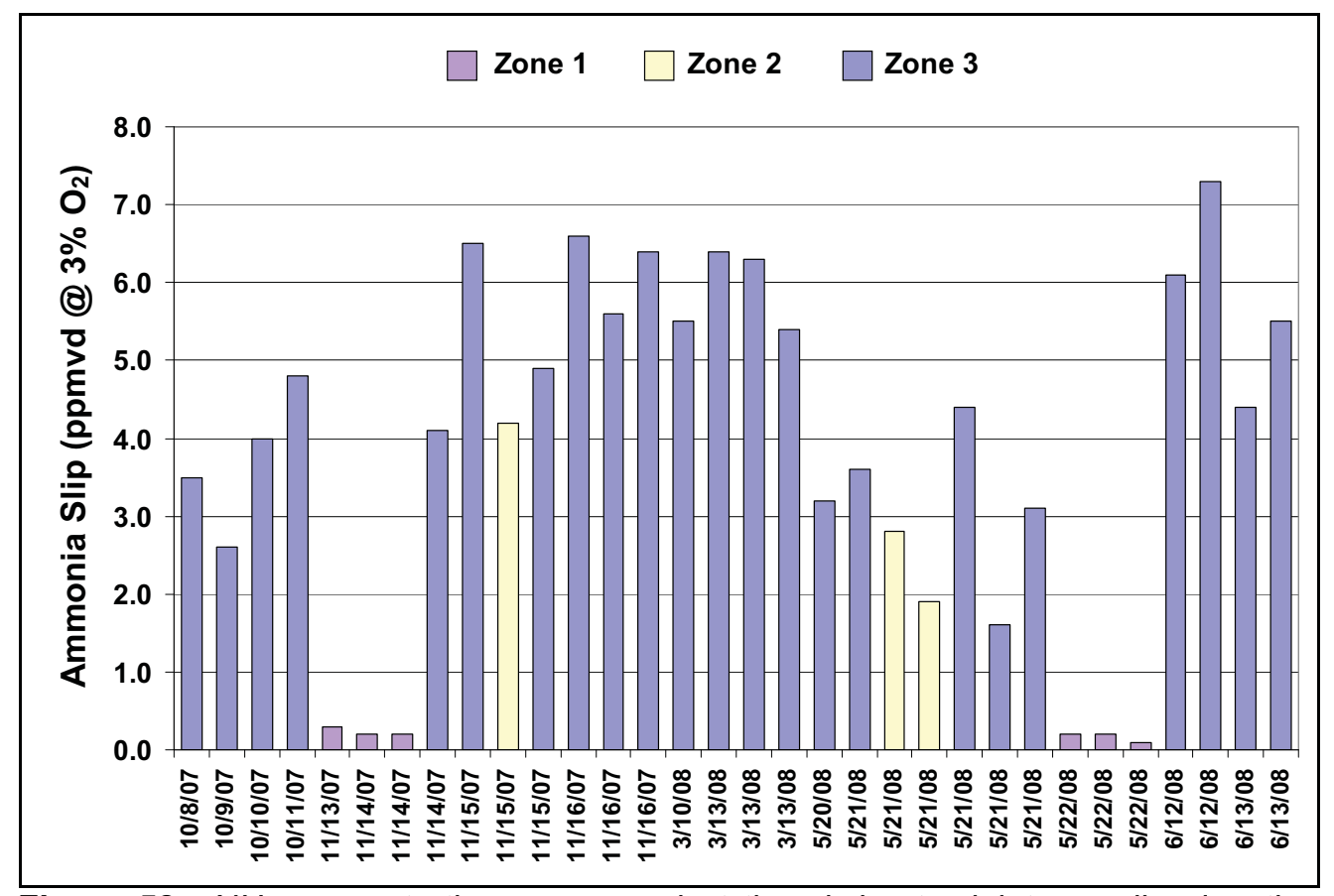

Figure 58. $\mathrm{NH}_{3}$ concentrations measured at the air heater inlet sampling location between October 2007 and June 2008. The shading indicates the highest numbered (coolest temperature) zone of urea injection that was in operation during each test.

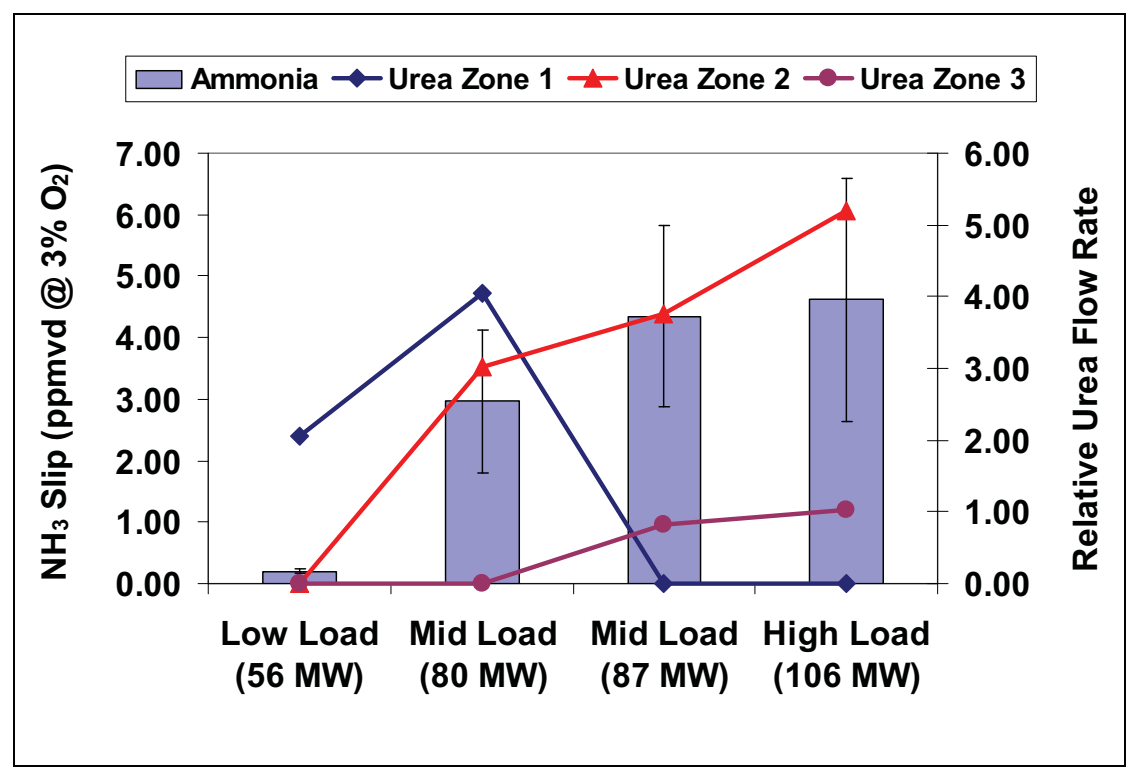

Figure 59. Ammonia slip as a function of gross unit load and urea injection regime at AES Greenidge Unit 4. Data were obtained during process performance testing at AES Greenidge in November 2007 and May 2008. The columns represent the mean ammonia concentration observed at each condition, and the error bars represent \pm 1 standard deviation. The relative flow rate of urea being injected into each zone of the SNCR system is also shown.

As shown in the figure, the ammonia slip was well within the 2 ppmvd target at low unit load, when urea was only being injected into Zone 1 of the SNCR system, but it increased rapidly 
upon introduction of urea into Zone 2 (cooler-temperature zone) at intermediate load. A less pronounced rise in ammonia slip was observed as urea was introduced into Zone 3 (coolest temperature zone). Ammonia slip concentrations observed at both mid and high loads averaged greater than the target of 2 ppmvd @ 3\% $\mathrm{O}_{2}$. Figure 59 combines data from the November 2007 and May 2008 test series. However, the ammonia concentrations measured in November were greater than those measured in May. In May 2008, the average ammonia slip at the air heater inlet was 2.3-3.4 ppmvd at intermediate loads and 3.0 ppmvd at high load, whereas in November 2007, the average ammonia slip was 4.2-5.3 ppmvd at intermediate loads and $6.2 \mathrm{ppmvd}$ at full load. The difference in ammonia concentrations likely resulted from the fact that the SCR catalyst was cleaner in May than it was in November.

While the amount of ammonia slip at the air heater inlet appeared to depend upon which SNCR injection zones were in operation, no association was observed between the flow rate of urea and the ammonia slip for a given injection scheme. This is evident in Figure 60, which shows ammonia slip plotted against the total flow rate of $50 \% \mathrm{w} / \mathrm{w}$ urea solution for tests conducted when urea was being injected through Zones 2 and 3 of the SNCR system and the pressure drop across the SCR catalyst was $\leq 2$ iwc.

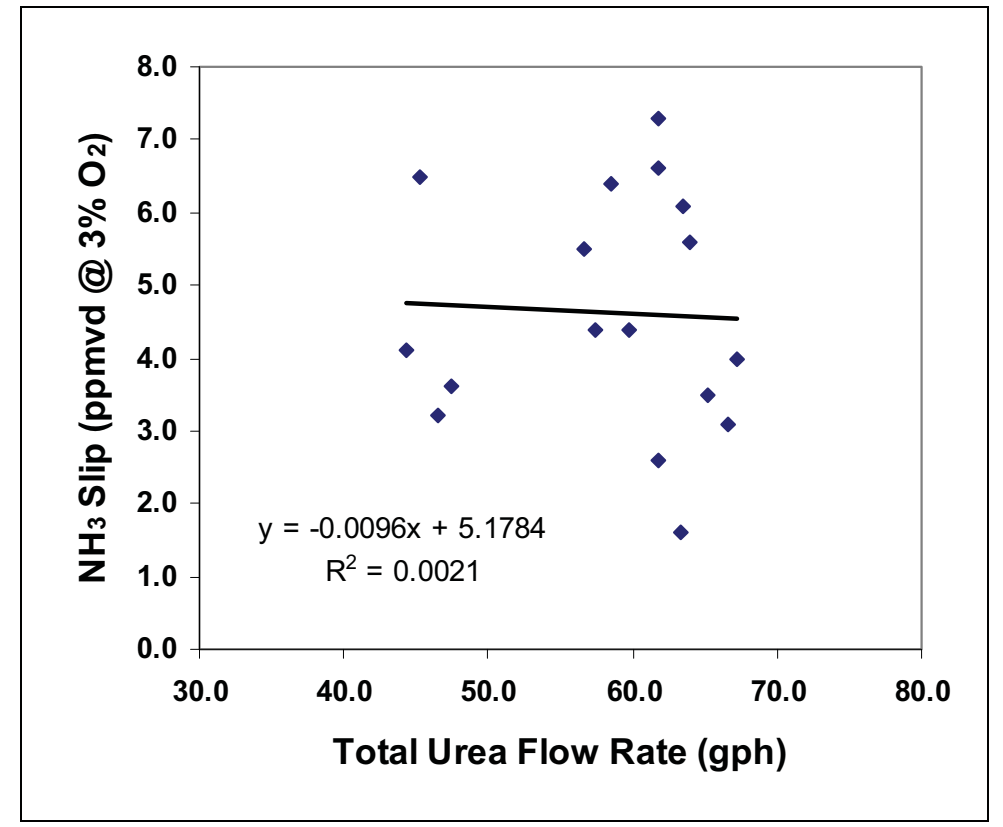

Figure 60. Scatter plot showing ammonia slip at the air heater inlet vs. the total flow rate of $50 \% \mathrm{w} / \mathrm{w}$ urea solution being injected into the SNCR system, with simple linear regression results. Data were taken from tests during October 2007-June 2008 that were conducted while urea was being injected into Zones 2 and 3 of the SNCR system and the pressure drop across the SCR catalyst was $\leq 2$ iwc.

The data presented in Table 19 suggest some association between the ammonia slip at the air heater inlet and the pressure drop across the in-duct SCR catalyst. This association is much clearer, however, using the fly ash ammonia concentrations determined by AES Greenidge throughout the Operation and Testing Phase. The fly ash samples were collected using the CEGRIT sampler in the ductwork downstream of the air heaters (see Section 9.2.2.1.3) on an approximately 1-in-3 day frequency; the ammonia content of this fly ash was used as a surrogate for ammonia slip. Figure 61 shows the fly ash ammonia concentrations over time, as 
well as the 24-hour average pressure drops observed across the in-duct SCR catalyst. As shown in the figure, the ammonia content of the ash tended to increase as the pressure drop across the catalyst increased. The increase in pressure drop occurred because of large particle ash accumulation in the catalyst (see Section 10.2.1). This promotes ammonia slip by decreasing both the effective surface area of the catalyst and the flue gas residence time in unplugged catalyst channels, thereby decreasing the conversion of $\mathrm{NH}_{3}$ and $\mathrm{NO}_{x}$ across the catalyst. Both the pressure drop and the ammonia content of the fly ash decreased abruptly after outages were conducted to clean or replace the catalyst, as indicated by the red arrows in Figure 61. Figure 62 presents a scatter plot showing the daily ammonia-in-ash and pressure drop data. For a given level of catalyst plugging, the pressure drop across the catalyst varies with unit load. The urea injection scheme and urea injection rate are also related to unit load, as discussed above. To ensure that the association between pressure drop and the ammonia content of the fly ash did not arise from collinearity with unit load or urea injection rate, the associations between these variables were also explored. Results are shown in Figures 63-64; no significant associations were found. Hence, these data suggest that the high ammonia slip observed throughout the project arose in part from the large particle ash problem that affected the in-duct SCR reactor. This was not the sole cause, though, because ammonia concentrations $>2$ ppmvd @ 3\% $\mathrm{O}_{2}$ were observed even when the unit was operating with a clean catalyst (e.g., during the process performance tests in May 2008).

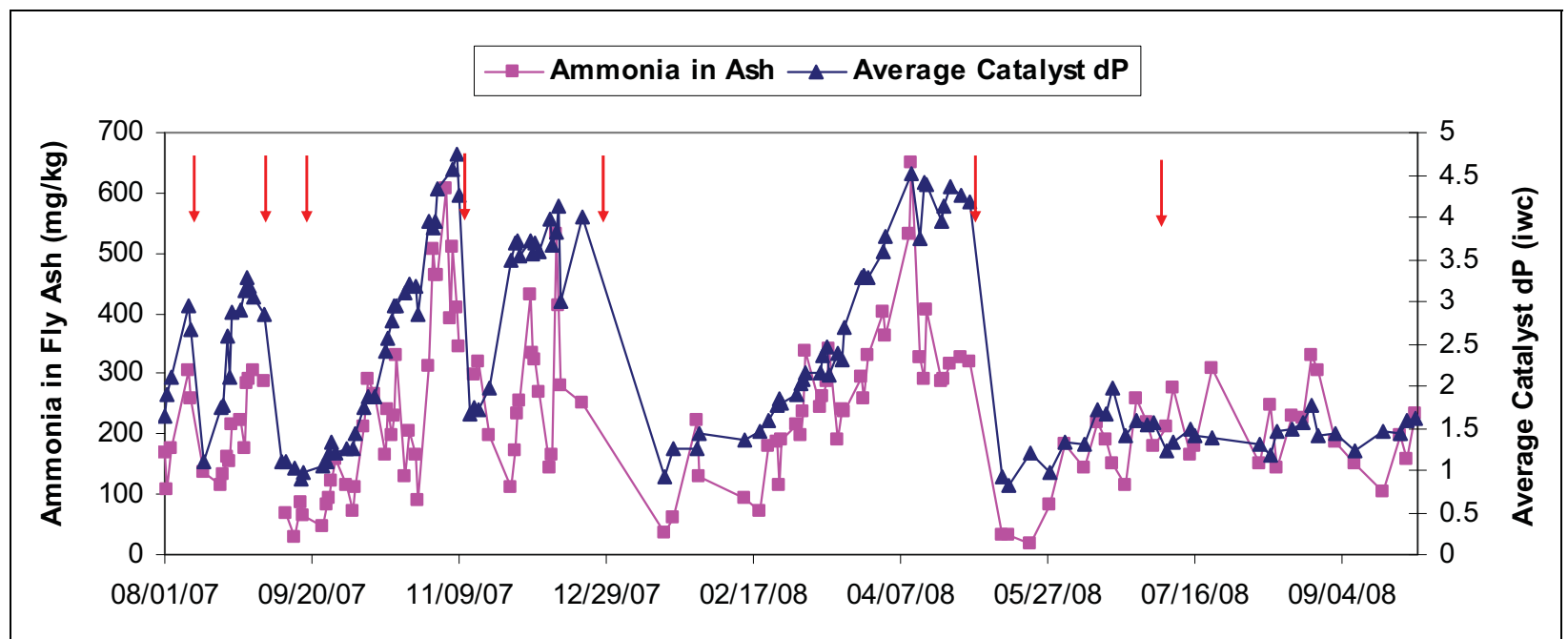

Figure 61. Time series of the ammonia content of fly ash samples collected at the air heater outlet and the daily average pressure drop observed across the in-duct SCR catalyst at AES Greenidge Unit 4. The red arrows indicate the timing of outages during which the SCR catalyst was cleaned or replaced.

The higher-than-expected ammonia slip has not significantly affected unit operations. Ammonium bisulfate fouling promoted by ammonia slip has likely added to the normal rate of increase in pressure drop across the air heaters. Plant personnel reported that they have had to soot blow the air heaters more frequently since the multi-pollutant control system was installed in order to prevent the pressure drop from increasing too rapidly. AES Greenidge also washed the air heater baskets during several outages in 2007 and 2008, although air heater fouling was never the cause of an outage. The air heater basket modifications described in Section 6.3.7.2 have likely helped to minimize the extent of ammonium bisulfate accumulation in the air heaters. The ammonia slip also has not affected byproduct handling. AES Greenidge will continue to monitor ammonia slip after the conclusion of the project (via the ammonia content of the fly ash) to look for possible effects of decreasing catalyst activity. 


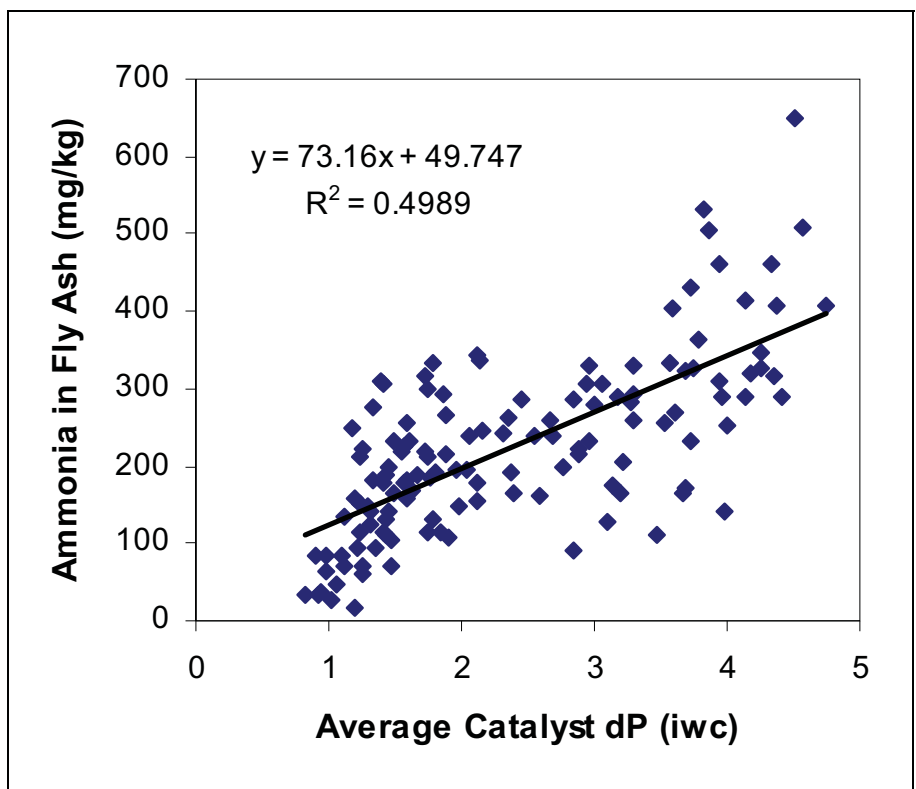

Figure 62. Scatter plot showing the ammonia content of fly ash samples collected at the air heater outlet vs. the daily average pressure drop measured across the SCR catalyst, with simple linear regression results.

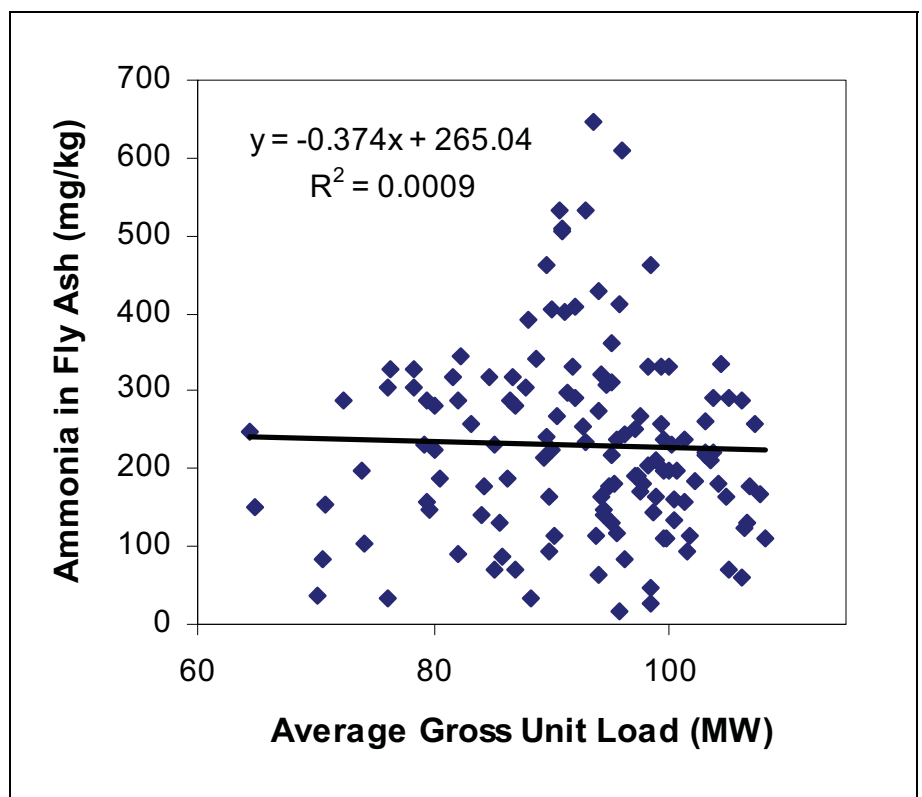

Figure 63. Scatter plot showing the ammonia content of fly ash samples collected at the air heater outlet vs. the daily average gross unit load, with simple linear regression results. 


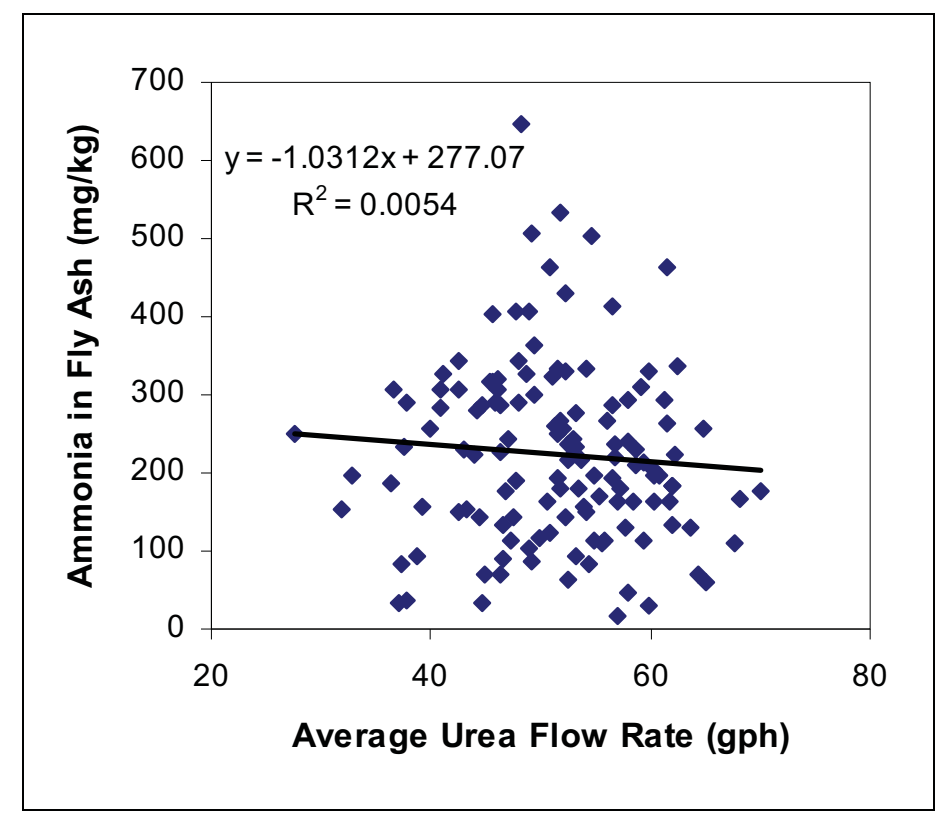

Figure 64. Scatter plot showing the ammonia content of fly ash samples collected at the air heater outlet vs. the daily average flow rate of $50 \% \mathrm{w} / \mathrm{w}$ urea solution to the SNCR system, with simple linear regression results.

\subsection{4 $\mathrm{SO}_{2}$-to- $\mathrm{SO}_{3}$ Conversion across the SCR Catalyst}

As discussed in Section 4.3.1, the catalyst in the hybrid SNCR/SCR system fosters the oxidation of a small portion of flue gas $\mathrm{SO}_{2}$ to $\mathrm{SO}_{3}$. The catalyst installed at AES Greenidge Unit 4 was designed to limit the $\mathrm{SO}_{2}$-to- $\mathrm{SO}_{3}$ conversion rate to less than $1 \%$. This target was established in an effort to minimize ammonium bisulfate fouling in the air heaters, because high $\mathrm{SO}_{3}$ concentrations, when coupled with ammonia slip, promote ammonium bisulfate formation.

To determine the $\mathrm{SO}_{2}$-to- $\mathrm{SO}_{3}$ conversion rate, $\mathrm{SO}_{2}$ and $\mathrm{SO}_{3}$ concentrations were measured just upstream and just downstream of the SCR reactor (at either the SCR inlet and SCR outlet sampling locations or the economizer outlet and air heater inlet sampling locations) during performance testing of the multi-pollutant control system on March 30, 2007, October 4-5, 2007, March 10 and 13, 2008, and June 10-11, 2008. All of the tests were performed while Unit 4 was operating at or near full load, when the conversion rate is expected to be maximal. The tests on March 30, 2007, were invalid because of possible ammonia interference with the analytical results, and the test on October 4, 2007, was invalid because the sampling train glassware broke partway through the test. In addition, the second test on October 5, 2007, and the first test on June 11, 2008, were considered to be invalid because $\mathrm{SO}_{2}$ concentrations determined as part of the controlled condensation train were dramatically lower than the concentrations expected from the coal, indicating a probable sampling problem. Results from the valid tests are summarized in Table 20. The average $\mathrm{SO}_{2}$-to- $\mathrm{SO}_{3}$ conversion rate measured during these tests was $0.54 \%$, which satisfies the performance target of $\leq 1.0 \%$. All but one of the nine individual tests met this target. No strong associations were observed between the $\mathrm{SO}_{2}$-to- $\mathrm{SO}_{3}$ conversion rate and SCR operating conditions (e.g., SCR operating temperature, pressure drop across the catalyst). 
Table 20. Summary of $\mathrm{SO}_{2}$-to- $\mathrm{SO}_{3}$ conversion rates determined from testing around the SCR reactor in October 2007, March 2008, and June 2008. Relevant process data are also summarized.

\begin{tabular}{|c|c|c|c|c|c|c|c|}
\hline \multirow{2}{*}{$\begin{array}{l}\text { Test } \\
\text { Date/Time } \\
\text { (local) }\end{array}$} & \multirow{2}{*}{$\begin{array}{l}\text { Unit } \\
\text { Load } \\
\left(\mathrm{MW}_{\mathrm{g}}\right)\end{array}$} & \multirow{2}{*}{$\begin{array}{c}\text { Average } \mathrm{SO}_{2} \\
\text { Concentration } \\
\left.\text { (ppmvd @ } 3 \% \mathrm{O}_{2}\right)\end{array}$} & \multicolumn{2}{|c|}{ 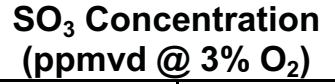 } & \multirow{2}{*}{$\begin{array}{c}\mathrm{SO}_{2} \text {-to-SO } \mathrm{SO}_{3} \\
\text { Conversion } \\
\text { (\%) }\end{array}$} & \multirow{2}{*}{$\begin{array}{l}\mathrm{SCR} \\
\mathrm{dP} \\
\text { (iwc) }\end{array}$} & \multirow{2}{*}{$\begin{array}{c}\text { SCR } \\
\text { Inlet } \\
\text { Temp } \\
\left({ }^{\circ} \mathrm{F}\right)\end{array}$} \\
\hline & & & $\begin{array}{r}\text { SCR } \\
\text { Inlet }^{\text {b }}\end{array}$ & $\begin{array}{c}\text { SCR } \\
\text { Outlet }^{\mathrm{b}}\end{array}$ & & & \\
\hline $\begin{array}{l}10 / 5 / 07 \\
0840-0950\end{array}$ & 108 & 2079 & 11.0 & 21.8 & $0.52 \%$ & 1.6 & 662 \\
\hline $\begin{array}{l}10 / 5 / 07 \\
1405-1505\end{array}$ & 108 & 2162 & 10.2 & 14.5 & $0.20 \%$ & 1.7 & 679 \\
\hline $\begin{array}{l}3 / 10 / 08 \\
1440-1604\end{array}$ & 108 & 1572 & 8.5 & 20.8 & $0.78 \%$ & 2.3 & 677 \\
\hline $\begin{array}{l}3 / 13 / 08 \\
0900-1026\end{array}$ & 107 & 1543 & 11.2 & 19.5 & $0.54 \%$ & 2.6 & 663 \\
\hline $\begin{array}{l}3 / 13 / 08 \\
1149-1308\end{array}$ & 108 & 1531 & 12.2 & 18.6 & $0.42 \%$ & 2.6 & 672 \\
\hline $\begin{array}{l}3 / 13 / 08 \\
1420-1539\end{array}$ & 108 & 1641 & 8.6 & 14.7 & $0.37 \%$ & 2.6 & 674 \\
\hline $\begin{array}{l}6 / 10 / 08 \\
1325-1541\end{array}$ & 105 & 2107 & 9.4 & 34.4 & $1.19 \%$ & 1.5 & 640 \\
\hline $\begin{array}{l}6 / 11 / 08 \\
1149-1320\end{array}$ & 107 & 1733 & 12.9 & 20.7 & $0.45 \%$ & 1.6 & 639 \\
\hline $\begin{array}{l}6 / 11 / 08 \\
1502-1705\end{array}$ & 105 & 2048 & 15.8 & 23.0 & $0.35 \%$ & 1.6 & 637 \\
\hline
\end{tabular}

${ }^{a}$ Computed from the $\mathrm{SO}_{2}$ concentrations determined as part of the controlled condensation measurements upstream and downstream of the SCR reactor. ${ }^{\mathrm{b}}$ Sampling on October 5, 2007, was conducted at the SCR inlet and SCR outlet locations; sampling on all subsequent dates was conducted at the economizer outlet and air heater inlet locations. ${ }^{\circ} \mathrm{Computed}$ from the $\mathrm{SO}_{3}$ concentrations measured at the SCR inlet (or economizer outlet) and SCR outlet (or air heater inlet) and the average $\mathrm{SO}_{2}$ concentration measured at these locations.

For eight of the nine tests shown in Table 20, $\mathrm{SO}_{3}$ concentration measurements were also made just downstream of the air heater. On average during these tests, the $\mathrm{SO}_{3}$ concentration decreased from 21.7 ppmvd @ 3\% $\mathrm{O}_{2}$ to 10.7 ppmvd @ 3\% $\mathrm{O}_{2}$ across the air heater. The significant decrease in the measured $\mathrm{SO}_{3}$ concentration between the SCR outlet and air heater outlet may reflect the formation of ammonium bisulfate in the air heaters, especially since the ammonia slip from the SCR reactor has generally been greater than the target of 2 ppmvd @ $3 \% \mathrm{O}_{2}$. It may also result simply from the condensation of $\mathrm{SO}_{3}$ as sulfuric acid on the air heater baskets, which can lead to corrosion, and its subsequent loss to the incoming combustion air. In any event, the appreciable loss of $\mathrm{SO}_{3}$ across the air heater illustrates the importance of maintaining a low $\mathrm{SO}_{2}$-to- $\mathrm{SO}_{3}$ conversion rate in the SCR reactor.

\subsubsection{Mercury Oxidation across the SCR Catalyst}

Per the discussion in Section 4.1.3, in addition to reducing $\mathrm{NO}_{\mathrm{x}}$ emissions, the in-duct SCR reactor is expected to contribute to the $\mathrm{Hg}$ removal performance of the multi-pollutant control system by converting some of the elemental mercury in the flue gas to oxidized mercury, which is more easily captured downstream in the circulating fluidized bed dry scrubber and baghouse. $\mathrm{Hg}$ oxidation is often observed across conventional SCR reactors, but the extent to which $\mathrm{Hg}$ would be oxidized across the comparatively small in-duct SCR at AES Greenidge Unit 4 was uncertain when the process was being designed. 
To investigate $\mathrm{Hg}$ oxidation across the in-duct SCR catalyst, concentrations of $\mathrm{Hg}^{0}$ and $\mathrm{Hg}^{2+}$ were measured just upstream and just downstream of the SCR reactor (at either the SCR inlet and SCR outlet sampling locations or the economizer outlet and air heater inlet sampling locations) during performance testing on October 2-3, 2007, March 11-12, 2008, May 19-20, 2008, and June 12-13, 2008. The tests in May 2008 were performed while Unit 4 was operating at low load $\left(56 \mathrm{MW}_{\mathrm{g}}\right.$ ), and all of the other tests were performed while Unit 4 was operating at or near full load (106-109 $\mathrm{MW}_{\mathrm{g}}$ ). The first test on October 3, 2007, was invalid because of a back-flush in the sampling train at the SCR outlet, which prevented the determination of $\mathrm{Hg}$ speciation at that location.

As discussed in Section 9.2.1.2.5.1, all of the mercury speciation measurements around the SCR reactor were conducted using the Ontario Hydro Method. Several methodological issues must be understood when interpreting these measurements. First, $\mathrm{Hg}$ speciation results determined using the Ontario Hydro Method can be biased in high-dust locations by adsorption of $\mathrm{Hg}$ onto the fly ash that is collected on the sample filter. The fly ash can also promote $\mathrm{Hg}$ oxidation. These artifacts are expected to be minimal, however, at the high temperatures around the SCR. To further reduce the likelihood of bias, during the tests in March, May, and June 2008, sampling was performed at a constant, reduced flow rate, with the nozzle oriented away from the direction of flow to reduce the uptake of particulate matter. Mercury concentrations in the fly ash collected during sampling at the economizer outlet, SCR inlet, SCR outlet, and air heater inlet were very low, ranging from 0.003 to $0.034 \mu \mathrm{g} / \mathrm{g}$. (By contrast, $\mathrm{Hg}$ concentrations in the fly ash collected in October 2007 and March 2008 during sampling at the air heater outlet, where temperatures are considerably cooler, ranged from 0.53 to $1.28 \mu \mathrm{g} / \mathrm{g}$ ). Hence, the fly ash did not appear to interfere with the $\mathrm{Hg}$ measurements around the SCR reactor. Second, the Ontario Hydro Method has not been validated for high-temperature testing; however, flue gas conditions were similar at the SCR inlet and outlet, reducing the probability of relative measurement bias between those locations. Finally, physical constraints prevented the performance of complete traverses of the ductwork upstream and downstream of the SCR reactor, introducing some possibility of error if $\mathrm{Hg}$ speciation was stratified over the cross section of the reactor.

Results from the valid tests are summarized in Table 21. For ten of the twelve tests, the proportion of mercury present as $\mathrm{Hg}^{2+}$ was greater at the SCR outlet than at the SCR inlet. This was true even for one of the two tests conducted at low load, when the SCR inlet temperature $\left(564^{\circ} \mathrm{F}\right)$ was less than the minimum operating temperature for the SCR catalyst $\left(600^{\circ} \mathrm{F}\right)$. The other low-load test showed no change in mercury oxidation across the catalyst, and the full-load test on October 2 showed a decrease in mercury oxidation across the catalyst. A significant disparity between the total Hg concentrations at the SCR inlet and SCR outlet was observed for several of the tests, indicating possible measurement error (such as that which could result from stratification of $\mathrm{Hg}$ concentration across the reactor).

Table 22 summarizes average mercury oxidation results for three cases: one in which all of the tests from Table 21 are included, one in which only the results of the full-load tests $\left(>100 \mathrm{MW}_{\mathrm{g}}\right)$ are included, and one in which only the results of the full-load tests with less than $20 \%$ RPD between the total gas-phase Hg concentration at the SCR inlet and SCR outlet are included. As shown in the table, the proportion of $\mathrm{Hg}$ present in oxidized form increased, on average, from $64-69 \%$ at the SCR inlet to $87-90 \%$ at the SCR outlet. Paired t-tests performed on each of the three subsets of measurements all indicated a statistically significant increase in the percentage of oxidized mercury across the SCR reactor. These results strongly suggest that the single- 
layer, in-duct SCR reactor was effective in oxidizing mercury, although this conclusion must be interpreted in the context of the methodological limitations discussed above.

Table 21. Summary of gas-phase mercury speciation determined from testing around the SCR reactor in October 2007, March 2008, May 2008, and June 2008. Relevant process data are also summarized.

\begin{tabular}{|c|c|c|c|c|c|c|c|c|c|}
\hline \multirow[b]{2}{*}{$\begin{array}{l}\text { Test Date / } \\
\text { Time } \\
\text { (local) }\end{array}$} & \multirow[b]{2}{*}{$\begin{array}{l}\text { Unit } \\
\text { Load } \\
\left(\mathrm{MW}_{\mathrm{g}}\right)\end{array}$} & \multicolumn{4}{|c|}{$\mathrm{Hg}\left(\mu \mathrm{g} / \mathrm{dscm} @ 3 \% \mathrm{O}_{2}\right)$} & \multirow{2}{*}{$\begin{array}{c}\mathrm{Hg}^{2+} / \mathrm{Hg}^{\mathrm{TOT}} \\
\text { SCR } \\
\text { Inlet } \\
(\%)\end{array}$} & \multirow{2}{*}{$\begin{array}{c}\mathrm{Hg}^{2+} / \mathrm{Hg}^{\mathrm{TOT}} \\
\text { SCR } \\
\text { Outlet } \\
(\%)\end{array}$} & \multirow[b]{2}{*}{$\begin{array}{c}\text { SCR } \\
\text { dP } \\
\text { (iwc) }\end{array}$} & \multirow{2}{*}{$\begin{array}{c}\text { SCR } \\
\text { Inlet } \\
\text { Temp } \\
\left({ }^{\circ} \mathrm{F}\right) \\
\end{array}$} \\
\hline & & $\begin{array}{l}\mathrm{Hg}^{2+} \\
\text { SCR } \\
\text { Inlet }^{\mathrm{a}} \\
\end{array}$ & $\begin{array}{l}\mathrm{Hg}^{\mathrm{TO}} \\
\text { SCR } \\
\text { Inlet }^{\mathrm{a}} \\
\end{array}$ & $\begin{array}{c}\text { Hg }^{2+} \\
\text { SCR } \\
\text { Outlet }^{\mathrm{a}}\end{array}$ & $\begin{array}{c}\text { Hg } \\
\text { SCR } \\
\text { Outlet }^{\mathrm{a}}\end{array}$ & & & & \\
\hline $\begin{array}{l}10 / 2 / 07 \\
1505-1715\end{array}$ & 109 & 2.74 & 4.98 & 2.31 & 6.54 & $55.0 \%$ & $35.3 \%$ & 1.5 & 673 \\
\hline $\begin{array}{l}10 / 3 / 07 \\
1555-1756\end{array}$ & 107 & 3.43 & 4.85 & 3.32 & 4.30 & $70.7 \%$ & $77.2 \%$ & 1.5 & 661 \\
\hline $\begin{array}{l}3 / 11 / 08 \\
0928-1157\end{array}$ & 107 & 5.69 & 6.89 & 7.49 & 7.83 & $82.6 \%$ & $95.7 \%$ & 2.4 & 666 \\
\hline $\begin{array}{l}3 / 11 / 08 \\
1325-1628\end{array}$ & 107 & 4.07 & 6.42 & 8.69 & 8.93 & $63.4 \%$ & $97.3 \%$ & 2.4 & 667 \\
\hline $\begin{array}{l}3 / 12 / 08 \\
0945-1147\end{array}$ & 109 & 5.05 & 6.95 & 7.58 & 7.96 & $72.7 \%$ & $95.2 \%$ & 2.5 & 673 \\
\hline $\begin{array}{l}3 / 12 / 08 \\
1350-1616\end{array}$ & 107 & 4.54 & 7.44 & 5.89 & 6.27 & $61.0 \%$ & $93.9 \%$ & 2.5 & 674 \\
\hline $\begin{array}{l}5 / 19 / 08 \\
2331-0143\end{array}$ & 56 & 10.09 & 12.20 & 13.13 & 13.65 & $82.7 \%$ & $96.2 \%$ & 0.9 & 564 \\
\hline $\begin{array}{l}5 / 20 / 08 \\
0305-0517\end{array}$ & 56 & 9.21 & 11.24 & 10.21 & 12.41 & $81.9 \%$ & $82.3 \%$ & 0.8 & 572 \\
\hline $\begin{array}{l}6 / 12 / 08 \\
0940-1145\end{array}$ & 106 & 2.39 & 3.46 & 5.71 & 6.11 & $69.1 \%$ & $93.5 \%$ & 1.6 & 641 \\
\hline $\begin{array}{l}6 / 12 / 08 \\
1330-1538\end{array}$ & 106 & 2.42 & 3.62 & 5.55 & 5.88 & $66.9 \%$ & $94.4 \%$ & 1.6 & 642 \\
\hline $\begin{array}{l}6 / 13 / 08 \\
1000-1211\end{array}$ & 109 & 4.10 & 5.28 & 6.09 & 6.39 & $77.7 \%$ & $95.3 \%$ & 1.8 & 651 \\
\hline $\begin{array}{l}6 / 13 / 08 \\
1441-1657\end{array}$ & 108 & 2.49 & 7.92 & 6.03 & 7.17 & $31.4 \%$ & $84.1 \%$ & 1.8 & 648 \\
\hline
\end{tabular}

${ }^{a}$ Sampling on October 2-3, 2007, was conducted at the SCR inlet and SCR outlet locations; sampling on all subsequent dates was conducted at the economizer outlet and air heater inlet locations. $\mathrm{Hg}^{\text {TOT }}$ is the total gas-phase mercury concentration, defined as the sum of $\mathrm{Hg}^{0}$ and $\mathrm{Hg}^{2+}$.

\subsubsection{Sulfur Dioxide Removal Efficiency}

The Turbosorp ${ }^{\circledR}$ system at AES Greenidge Unit 4 consistently met or exceeded its performance target for $\mathrm{SO}_{2}$ removal efficiency during the Operation and Testing Phase of the project.

Guarantee testing for $\mathrm{SO}_{2}$ removal efficiency was completed on March 29, 2007 . Three approximately 60-minute-long tests were performed while AES Greenidge Unit 4 fired eastern U.S. bituminous coal containing about $2.7 \%$ sulfur (dry basis), or about $3.8 \mathrm{lb} \mathrm{SO} / \mathrm{mmBtu}$, and operated near full load. $\mathrm{SO}_{2}$ concentrations at the air heater outlet were determined by Clean Air Engineering using U.S. EPA Method $6 \mathrm{C}$, and $\mathrm{SO}_{2}$ emissions at the stack were determined by the unit's CEM. Results are summarized in Table 23. The average $\mathrm{SO}_{2}$ removal efficiency observed during the three tests was $96.0 \%$, achieving the performance target of $\geq 95 \%$. (Clean Air Engineering also measured $\mathrm{SO}_{2}$ concentrations at the baghouse outlet sampling location during the tests on March 29. Results of those measurements are provided in Appendix $G$. The 
average emission rate measured at the baghouse outlet was slightly higher than that measured by the stack CEM, resulting in an average $\mathrm{SO}_{2}$ removal efficiency of $94.1 \%$ calculated from the air heater outlet to the baghouse outlet. The cause of the discrepancy is unknown. However, because the unit's permit limit for $\mathrm{SO}_{2}$ and the controls for the Turbosorp ${ }^{\circledR}$ system are both based on the $\mathrm{SO}_{2}$ emission rate measured by the stack CEM, this emission rate was used to determine attainment of the performance target for $\mathrm{SO}_{2}$ emissions).

Table 22. Average gas-phase mercury speciation around the SCR reactor, computed for three subsets of the measurements presented in Table 21. Paired t-tests were performed on each subset of measurements to assess the statistical significance of the change in mercury oxidation across the reactor.

\begin{tabular}{|c|c|c|c|c|c|c|c|c|}
\hline \multirow[b]{2}{*}{ Case $^{a}$} & \multicolumn{4}{|c|}{ Average $\mathrm{Hg}\left(\mu \mathrm{g} / \mathrm{dscm} @ 3 \% \mathrm{O}_{2}\right)$} & \multirow{2}{*}{$\begin{array}{c}\mathrm{Hg}^{2+} / \mathrm{Hg}^{\mathrm{TOT}} \\
\text { SCR } \\
\text { Inlet } \\
(\%)\end{array}$} & \multirow{2}{*}{$\begin{array}{c}\mathrm{Hg}^{2+} / \mathrm{Hg}^{\mathrm{TOT}} \\
\text { SCR } \\
\text { Outlet } \\
(\%)\end{array}$} & \multicolumn{2}{|c|}{ Paired t-test } \\
\hline & $\begin{array}{l}\mathrm{Hg}^{2+} \\
\text { SCR } \\
\text { Inlet }^{\text {b }}\end{array}$ & $\begin{array}{l}\mathrm{Hg}^{\mathrm{TO}} \\
\text { SCR } \\
\text { Inlet }^{\mathrm{b}}\end{array}$ & $\begin{array}{l}\mathrm{Hg}^{2+} \\
\text { SCR } \\
\text { Outlet }^{\mathrm{b}}\end{array}$ & $\begin{array}{c}\mathrm{Hg}^{\text {IOT }} \\
\text { SCR } \\
\text { Outlet }^{\mathrm{b}}\end{array}$ & & & $\begin{array}{c}\text { Mean } \\
\text { Difference }\end{array}$ & p-value ${ }^{d}$ \\
\hline $\begin{array}{l}\text { All } \\
\text { measurements } \\
(\mathrm{N}=12)\end{array}$ & 4.69 & 6.77 & 6.83 & 7.79 & 69.2 & 87.8 & 18.8 & 0.005 \\
\hline $\begin{array}{l}\text { Full-load } \\
\text { measurements } \\
(\mathrm{N}=10)\end{array}$ & 3.69 & 5.78 & 5.87 & 6.74 & 63.9 & 87.1 & 21.1 & 0.007 \\
\hline $\begin{array}{l}\text { Full-load } \\
\text { measurements } \\
\text { with }<20 \% \\
\text { RPD between } \\
\text { Inlet and } \\
\text { Outlet Hg } \mathrm{Hg}^{\text {TOT }} \\
(\mathrm{N}=6)\end{array}$ & 4.22 & 6.56 & 6.07 & 6.65 & 64.3 & 91.2 & 24.2 & 0.016 \\
\hline
\end{tabular}

${ }^{a} \mathrm{~N}$ is the number of observations. ${ }^{\mathrm{b}}$ The SCR inlet includes measurements made at the economizer outlet and SCR inlet sampling locations, and the SCR outlet includes measurements made at the SCR outlet and air heater inlet sampling locations. $\mathrm{Hg}^{\mathrm{TOT}}$ is the total gas-phase mercury concentration, defined as the sum of $\mathrm{Hg}^{0}$ and $\mathrm{Hg}^{2+}$. ${ }^{\mathrm{C}}$ Mean of the differences between $\mathrm{Hg}^{2+} / \mathrm{Hg}^{\text {TOT }}$ (\%) at the SCR outlet and $\mathrm{Hg}^{2+} / \mathrm{Hg}^{\text {TOT }}(\%)$ at the SCR inlet for the individual tests. ${ }^{\mathrm{d}} \mathrm{A}$ p-value less than 0.05 indicates that the mean difference was significantly different from zero at the $95 \%$ confidence level.

Table 23. Summary of the $\mathrm{SO}_{2}$ removal efficiency across the Turbosorp ${ }^{\circledR}$ system determined during guarantee testing on March 29, 2007.

\begin{tabular}{|c|c|c|c|c|c|c|}
\hline \multirow[b]{2}{*}{$\begin{array}{l}\text { Test } \\
\text { Date/Time } \\
\text { (local) }\end{array}$} & \multirow[b]{2}{*}{$\begin{array}{l}\text { Unit } \\
\text { Load } \\
\left(\mathrm{MW}_{\mathrm{g}}\right)\end{array}$} & \multicolumn{3}{|c|}{ Air Heater Outlet ${ }^{a}$} & \multirow{2}{*}{$\begin{array}{c}\text { Stack } \\
\mathrm{SO}_{2} \\
\text { Rate }^{\mathrm{b}} \\
\text { (lb/mmBtu) }\end{array}$} & \multirow{2}{*}{$\begin{array}{c}\mathrm{SO}_{2} \\
\text { Removal } \\
\text { Efficiency } \\
(\%)\end{array}$} \\
\hline & & $\begin{array}{c}\mathrm{SO}_{2} \\
\text { Concentration } \\
\text { (ppmvd) }\end{array}$ & $\begin{array}{c}\mathrm{CO}_{2} \\
\text { Concentration } \\
(\%, \text { dry }) \\
\end{array}$ & $\begin{array}{c}\mathrm{SO}_{2} \\
\text { Rate } \\
\text { (Ib/mmBtu) }\end{array}$ & & \\
\hline $\begin{array}{l}3 / 29 / 07 \\
0959-1100\end{array}$ & 105 & 1410 & 11.54 & 3.65 & 0.137 & 96.2 \\
\hline $\begin{array}{l}3 / 29 / 07 \\
1216-1317\end{array}$ & 105 & 1398 & 11.61 & 3.60 & 0.128 & 96.4 \\
\hline $\begin{array}{l}3 / 29 / 07 \\
1513-1613\end{array}$ & 106 & 1381 & 11.52 & 3.58 & 0.173 & 95.2 \\
\hline AVERAGE & 105 & 1396 & 11.56 & 3.61 & 0.146 & 96.0 \\
\hline
\end{tabular}

${ }^{\mathrm{a}}$ Measurements made by Clean Air Engineering. ${ }^{\mathrm{b}}$ Measured by the unit's stack CEM. 
The Turbosorp ${ }^{\circledR}$ system continued to exhibit a high level of performance during longer-term operation. To illustrate the long-term $\mathrm{SO}_{2}$ removal efficiency of the system, Figure 65 shows the hourly $\mathrm{SO}_{2}$ rates measured at the air heater outlet (Turbosorp ${ }^{\circledR}$ inlet) by the unit's online dilution extractive-type $\mathrm{SO}_{2}$ analyzer and the hourly $\mathrm{SO}_{2}$ rates measured at the stack (Turbosorp ${ }^{\circledR}$ outlet) by the unit's CEM during August 2007 through September 2008. $\left(\mathrm{SO}_{2}\right.$ concentrations at the air heater outlet are measured on a wet basis. However, moisture and $\mathrm{CO}_{2}$ are not continuously measured at the air heater outlet. Hence, for purposes of expressing the $\mathrm{SO}_{2}$ concentrations on a heat input basis, the moisture at the air heater outlet was assumed to equal $8.4 \%$, and the $\mathrm{CO}_{2}$ concentration at the air heater outlet was assumed to equal 1.062 times the stack $\mathrm{CO}_{2}$ concentration. These assumptions are based on the average moisture and $\mathrm{CO}_{2}$ concentrations measured by $\mathrm{CONSOL}$ during mercury, $\mathrm{HCl}$, and $\mathrm{HF}$ testing between March 2007 and June 2008). During this 14-month period, AES Greenidge Unit 4 primarily fired eastern U.S. bituminous coals, although it fired a blend of eastern bituminous coal and Powder River Basin (PRB) coal (at up to $25 \%$ by weight of the total fuel) for a time during September 2008 and co-fired biomass (at less than 5\% of the total heat input) at times during November 2007 and February-April 2008. Table 24 summarizes the average long-term performance of the Turbosorp $^{\circledR}$ system. Between August 1, 2007, and September 30, 2008, the system reduced $\mathrm{SO}_{2}$ emissions from $3.62 \mathrm{lb} / \mathrm{mmBtu}$ to $0.13 \mathrm{lb} / \mathrm{mmBtu}$, resulting in an average removal efficiency of $96.3 \%$. This surpassed the project's performance target of $95 \% \mathrm{SO}_{2}$ removal efficiency.

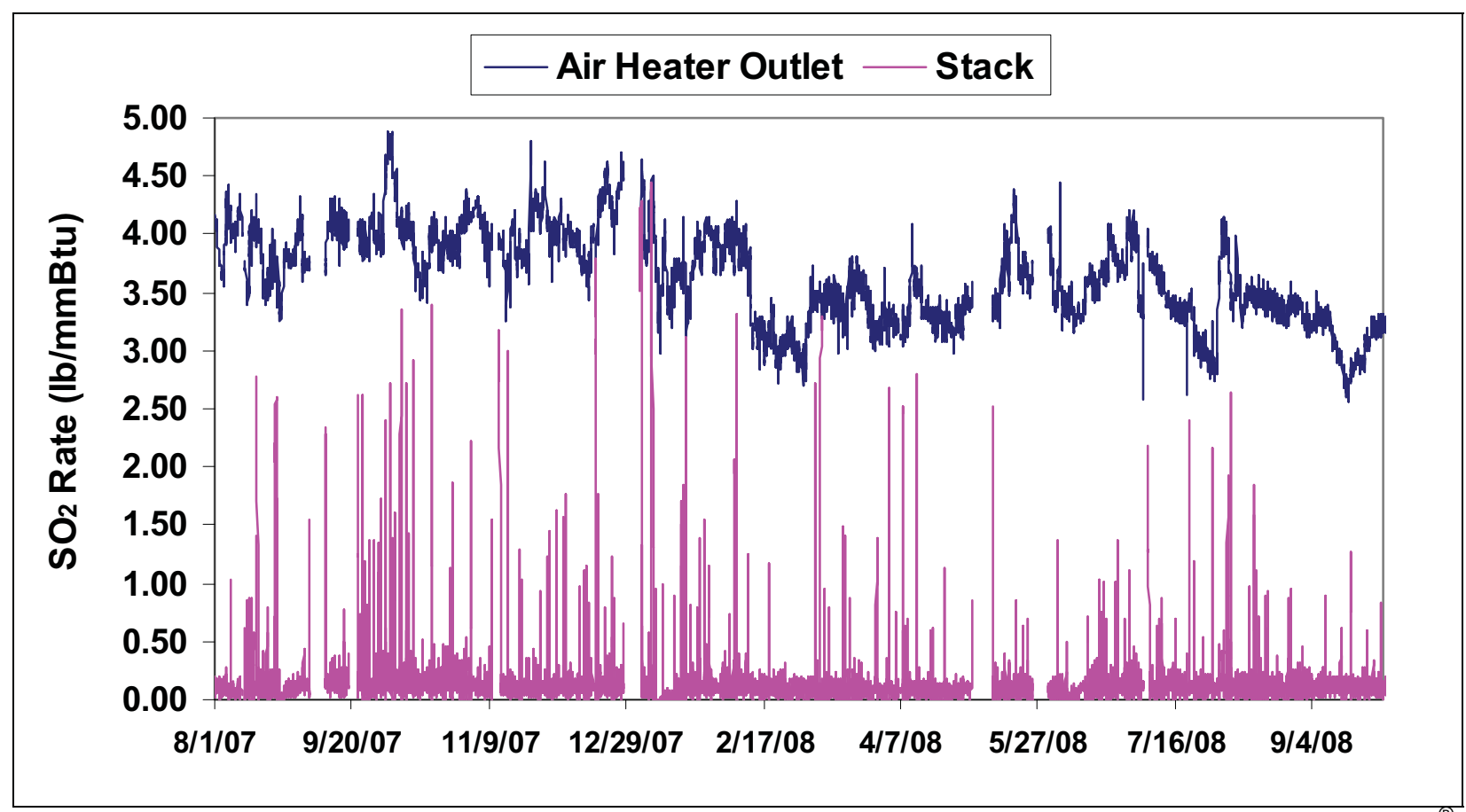

Figure 65. Hourly $\mathrm{SO}_{2}$ rates $(\mathrm{lb} / \mathrm{mmBtu})$ determined at the air heater outlet (upstream of the Turbosorp ${ }^{\circledR}$ system) and stack (downstream of the Turbosorp ${ }^{\circledR}$ system) during August 2007 - September $2008 . \mathrm{SO}_{2}$ was measured by the dilution extractive-type $\mathrm{SO}_{2}$ analyzer that is permanently installed at the air heater outlet and by the unit's stack CEM. 
Table 24. Summary of the long-term $\mathrm{SO}_{2}$ removal performance of the Turbosorp ${ }^{\circledR}$ system, based on hourly data collected from August 2007 through September 2008.

\begin{tabular}{|l|c|c|}
\hline & Mean $^{\mathbf{a}}$ & Range $^{\mathbf{b}}$ \\
\hline $\mathrm{SO}_{2}$ at Air Heater Outlet (Ib/mmBtu) & 3.62 & $2.56-4.88$ \\
\hline $\mathrm{SO}_{2}$ at Stack (Ib/mmBtu) & 0.134 & $0.000-4.407$ \\
\hline $\mathrm{SO}_{2}$ Removal Efficiency (\%) & 96.3 & $-3.7-100.0$ \\
\hline
\end{tabular}

${ }^{a}$ Computed as the heat input-weighted mean of hourly average $\mathrm{SO}_{2}$ rates. ${ }^{6}$ Represents the minimum and maximum hourly average values observed during the period.

$\mathrm{SO}_{2}$ concentrations determined as part of $\mathrm{SO}_{3}$ testing at the air heater outlet and stack provide an independent measure of the $\mathrm{SO}_{2}$ removal performance of the Turbosorp ${ }^{\circledR}$ system. As discussed in Section 9.2.1.2.6, the concentration of $\mathrm{SO}_{2}$ in the flue gas can be determined by analyzing the $\mathrm{H}_{2} \mathrm{O}_{2}$ impingers from the controlled condensation sampling train that is used for $\mathrm{SO}_{3}$ measurements. $\mathrm{SO}_{2}$ concentrations were determined in this way as part of $39 \mathrm{SO}_{3}$ tests conducted between October 2007 and June 2008. Results are summarized in Table 25. The average $\mathrm{SO}_{2}$ removal efficiency computed from these test results was $95.1 \%$, again satisfying the performance target. (During several of the controlled condensation tests, the Turbosorp ${ }^{\circledR}$ system was intentionally being operated to achieve $\mathrm{SO}_{2}$ removal efficiencies above or below $95 \%)$.

As discussed in Sections 2.2, 2.4, and 4.2.4, an important objective of the Greenidge MultiPollutant Control Project was to prove that the Turbosorp ${ }^{\circledR}$ system could achieve high $\mathrm{SO}_{2}$ removal efficiencies while AES Greenidge Unit 4 fired high-sulfur (i.e., $>2 \%$-sulfur) coal. This objective was demonstrated during guarantee testing, when $96 \% \mathrm{SO}_{2}$ removal was achieved with a $2.7 \%$ sulfur coal, as well as during long-term testing, when $96 \%$ removal was achieved over a 14-month period with a similar average sulfur loading. (The average $\mathrm{SO}_{2}$ rate at the Turbosorp $^{\circledR}$ inlet was $3.61 \mathrm{lb} / \mathrm{mmBtu}$ during the guarantee tests and $3.62 \mathrm{lb} / \mathrm{mmBtu}$ during the August 2007-September 2008 period). Hourly average $\mathrm{SO}_{2}$ rates at the Turbosorp ${ }^{\circledR}$ inlet ranged from 2.56 to $4.88 \mathrm{lb} / \mathrm{mmBtu}$ between August 2007 and September 2008; high $\mathrm{SO}_{2}$ removal efficiencies were observed even when the inlet $\mathrm{SO}_{2}$ was at the top end of this range. Figure 66 shows five-minute average $\mathrm{SO}_{2}$ rates measured upstream and downstream of the Turbosorp ${ }^{\circledR}$ system on October 3, 2007, when the greatest inlet $\mathrm{SO}_{2}$ loadings were observed. This day occurred within the October 2-5, 2007, process performance testing campaign, which was designed to evaluate the performance of the multi-pollutant control system while AES Greenidge Unit 4 fired higher-than-normal sulfur coal (see Section 9.1.2.3.1). The coal sulfur content on October 3 averaged $3.3 \%\left(4.8 \quad \mathrm{lb} \mathrm{SO}_{2} / \mathrm{mmBtu}\right)$, and the Turbosorp ${ }^{\circledR}$ system succeeded in reducing $\mathrm{SO}_{2}$ emissions by $96.5 \%$ over an 11-hour period of full-load (108 $\mathrm{MW}_{\mathrm{g}}$ ) operation with this fuel. Similarly high removal efficiencies were observed during the other days of the testing campaign. Hence, the project succeeded in confirming the applicability of the Turbosorp ${ }^{\circledR}$ system to units that fire high-sulfur coal.

AES Greenidge routinely operates the Turbosorp ${ }^{\circledR}$ system with an $\mathrm{SO}_{2}$ emission rate set point of $0.10 \mathrm{lb} / \mathrm{mmBtu}$, which is below its permitted emission rate of $0.19 \mathrm{lb} / \mathrm{mmBtu}$, in order to provide a margin for transient upsets in system performance. These upsets, which are evidenced by the occasional spikes in stack $\mathrm{SO}_{2}$ emission rate in Figure 65 , can be caused either by routine operating and maintenance activities or by unexpected equipment problems. 
Table 25. $\mathrm{SO}_{2}$ concentrations, and implied removal efficiency across the Turbosorp ${ }^{\circledR}$ system, determined as part of $\mathrm{SO}_{3}$ tests conducted at the air heater outlet and stack using the controlled condensation method between October 2007 and June 2008.

\begin{tabular}{|c|c|c|c|}
\hline Test Date / Time (local) & $\begin{array}{c}\mathrm{SO}_{2} \text { at Air Heater } \\
\text { Outlet } \\
\text { (ppmvd @ } 3 \% \mathrm{O}_{2} \text { ) }\end{array}$ & $\begin{array}{c}\mathrm{SO}_{2} \text { at Stack } \\
\left(\mathrm{ppmvd} @ 3 \% \mathrm{O}_{2}\right)\end{array}$ & $\begin{array}{c}\mathrm{SO}_{2} \text { Removal } \\
\text { Efficiency } \\
(\%)\end{array}$ \\
\hline 10/4/2007 1520-1641 & 1819 & 85 & 95.3 \\
\hline $10 / 5 / 20070840-0950$ & 1899 & 44 & 97.7 \\
\hline $10 / 8 / 2007$ 1530-1634 & 1349 & 21 & 98.4 \\
\hline $10 / 9 / 2007$ 1040-1150 & 1363 & 157 & 88.5 \\
\hline $10 / 10 / 2007$ 1040-1144 & 1809 & 162 & 91.1 \\
\hline $10 / 11 / 2007$ 1230-1335 & 1793 & 145 & 91.9 \\
\hline $11 / 13 / 20072325-0047$ & 1885 & 69 & 96.3 \\
\hline $11 / 14 / 20070135-0240$ & 2122 & 48 & 97.8 \\
\hline $11 / 14 / 20070405-0510$ & 1989 & 106 & 94.7 \\
\hline $11 / 14 / 20072305-0010$ & 2075 & 59 & 97.2 \\
\hline $11 / 15 / 20070105-0210$ & 2196 & 35 & 98.4 \\
\hline $11 / 15 / 20070430-0535$ & 1991 & 114 & 94.3 \\
\hline $11 / 16 / 2007$ 1215-1328 & 1963 & 16 & 99.2 \\
\hline $11 / 16 / 2007$ 1427-1533 & 2139 & 53 & 97.5 \\
\hline $3 / 10 / 2008$ 1440-1622 & 1673 & 86 & 94.9 \\
\hline $3 / 13 / 20080902-1017$ & 1543 & 84 & 94.6 \\
\hline $3 / 13 / 2008$ 1148-1254 & 1426 & 86 & 94.0 \\
\hline $3 / 13 / 2008$ 1420-1534 & 1631 & 76 & 95.4 \\
\hline $5 / 21 / 20080040-0146$ & 1820 & 41 & 97.8 \\
\hline $5 / 21 / 20080350-0535$ & 2120 & 95 & 95.5 \\
\hline $5 / 21 / 20082300-0010$ & 1920 & 296 & 84.6 \\
\hline $5 / 22 / 20080125-0225$ & 2132 & 38 & 98.2 \\
\hline $5 / 22 / 20080410-0510$ & 2146 & 84 & 96.1 \\
\hline $6 / 10 / 2008$ 1325-1535 & 2048 & 27 & 98.7 \\
\hline $6 / 11 / 2008$ 0900-1003 & 2150 & 73 & 96.6 \\
\hline $6 / 11 / 2008$ 1149-1251 & 2056 & 83 & 96.0 \\
\hline $6 / 11 / 2008$ 1502-1637 & 2039 & 59 & 97.1 \\
\hline $6 / 16 / 2008$ 1132-1232 & 2205 & 167 & 92.4 \\
\hline $6 / 16 / 2008$ 1415-1515 & 2224 & 178 & 92.0 \\
\hline $6 / 16 / 2008$ 1620-1721 & 2093 & 193 & 90.8 \\
\hline $6 / 17 / 2008$ 1130-1230 & 1995 & 130 & 93.5 \\
\hline $6 / 17 / 2008$ 1350-1450 & 1828 & 94 & 94.9 \\
\hline $6 / 17 / 2008$ 1545-1645 & 2015 & 104 & 94.8 \\
\hline $6 / 18 / 2008$ 1210-1312 & 1553 & 51 & 96.7 \\
\hline $6 / 18 / 2008$ 1400-1500 & 1787 & 40 & 97.7 \\
\hline $6 / 18 / 2008$ 1555-1655 & 2151 & 78 & 96.4 \\
\hline $6 / 19 / 2008$ 1150-1250 & 2233 & 136 & 93.9 \\
\hline $6 / 19 / 2008$ 1356-1458 & 2191 & 145 & 93.4 \\
\hline $6 / 19 / 2008$ 1540-1646 & 2024 & 107 & 94.7 \\
\hline AVERAGE & 1933 & 94 & 95.1 \\
\hline
\end{tabular}




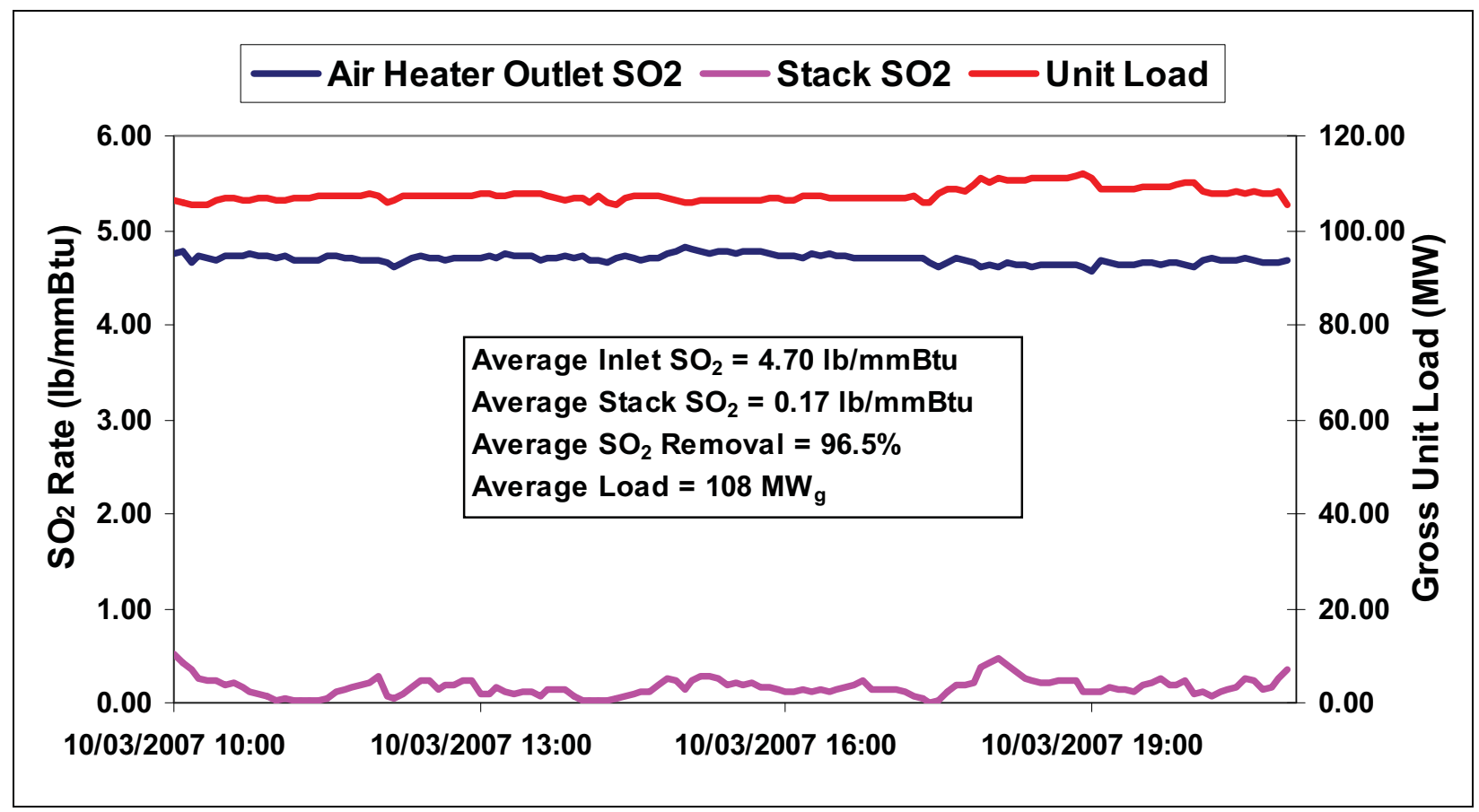

Figure 66. Five-minute average $\mathrm{SO}_{2}$ rates $(\mathrm{lb} / \mathrm{mmBtu})$ and gross unit load observed at AES Greenidge Unit 4 between 1000 and 2100 EST on October 3, 2007. $\mathrm{SO}_{2}$ was measured by the dilution extractivetype $\mathrm{SO}_{2}$ analyzer that is permanently installed at the air heater outlet (upstream of the Turbosorp ${ }^{\circledR}$ system) and by the unit's stack CEM (downstream of the Turbosorp ${ }^{\circledR}$ system).

Figure 67 provides an example of each type of cause. This figure shows 5-minute average $\mathrm{SO}_{2}$ removal efficiencies, gross unit loads, and Turbosorp ${ }^{\circledR}$ outlet temperatures observed between 3:00 and 9:00 EST on June 18, 2008. During this period, plant personnel changed the Turbosorp $^{\circledR}$ water injection lance at about 5:10 EST, temporarily interrupting the supply of water to the absorber vessel. Later, at about 7:05 EST, the water injection pump tripped, again causing a short interruption in the water supply. In both cases, the discontinuation of water injection into the absorber vessel caused the temperature at the Turbosorp ${ }^{\circledR}$ outlet to rise from about $160^{\circ} \mathrm{F}$ (its normal operating point) to about $230^{\circ} \mathrm{F}$. As a result, $\mathrm{SO}_{2}$ removal efficiency, which depends strongly upon the proximity of the temperature in the absorber to the adiabatic saturation temperature of the flue gas (see Section 4.3.11), decreased dramatically from more than $95 \%$ to less than $30 \%$, causing a spike in $\mathrm{SO}_{2}$ emissions. The $\mathrm{SO}_{2}$ removal efficiency returned to normal (i.e., >95\%) about 45 minutes after water injection resumed. As discussed in Section 10.1, plant personnel change the water injection lance about once every week as part of their routine maintenance regimen, accounting for a number of the spikes in stack $\mathrm{SO}_{2}$ emissions observed in Figure 65. The other spikes are generally attributable to unexpected equipment problems, such as interruptions in water or hydrated lime injection (possibly resulting from problems with the lime hydration system), freezing of valves or pressure transmitters during periods of cold weather, etc. (See Section 10.2.2 for additional details). 


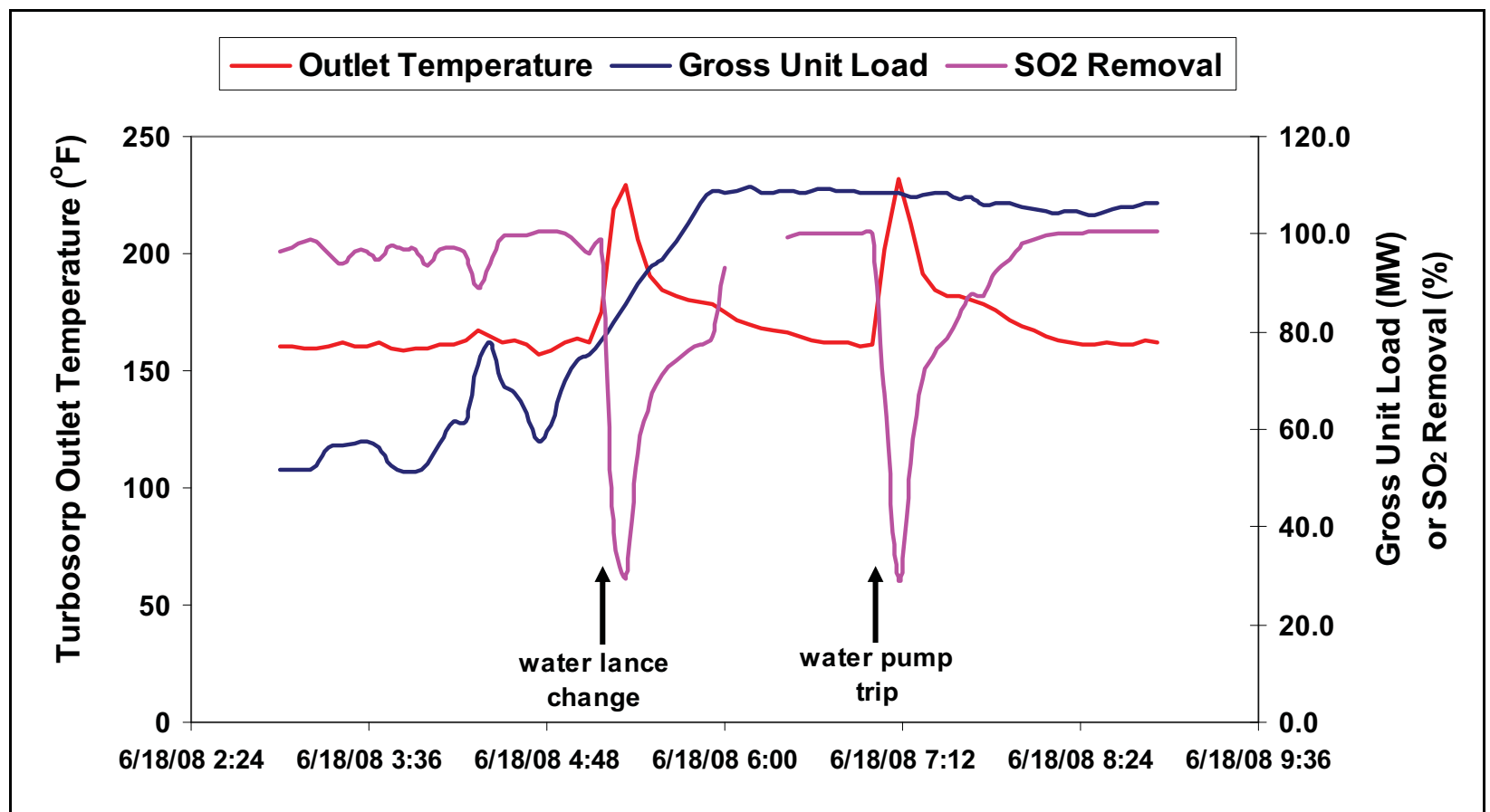

Figure 67. Five-minute average Turbosorp $\left.{ }^{(}\right)$outlet temperatures, gross unit loads, and $\mathrm{SO}_{2}$ removal efficiencies observed at AES Greenidge Unit 4 between 0300 and 0900 EST on June 18, 2008. These data indicate the effect of interruptions in water injection on the performance of the Turbosorp ${ }^{\circledR}$ system. $\mathrm{SO}_{2}$ was measured by the dilution extractive-type $\mathrm{SO}_{2}$ analyzer that is permanently installed at the air heater outlet (upstream of the Turbosorp ${ }^{\circledR}$ system) and by the unit's stack CEM (downstream of the Turbosorp ${ }^{\circledR}$ system).

Such upsets occurred infrequently, however, and the Turbosorp ${ }^{\circledR}$ system proved capable of maintaining $\mathrm{SO}_{2}$ emissions within the unit's permit limit during long-term operation. This is exemplified in Figure 68. As with the permit limit for $\mathrm{NO}_{x}$ emissions, compliance with the permit limit for $\mathrm{SO}_{2}$ emissions is determined on a 30-day rolling average basis. Unlike the $\mathrm{NO}_{x}$ permit limit, however, the $\mathrm{SO}_{2}$ permit limit remains constant at $0.19 \mathrm{lb} / \mathrm{mmBtu}$ over the entire range of normal unit operating loads. As shown in Figure 68, with the exception of a few days at the beginning of January when the 30-day rolling average $\mathrm{SO}_{2}$ emission rate was near 0.19 $\mathrm{lb} / \mathrm{mmBtu}$, the Turbosorp ${ }^{\circledR}$ system maintained $\mathrm{SO}_{2}$ emissions well below the permit limit during the first nine months of 2008, achieving 30-day rolling average $\mathrm{SO}_{2}$ emission rates as low as $0.09 \mathrm{lb} / \mathrm{mmBtu}$.

Figure 69 shows the average $\mathrm{SO}_{2}$ removal efficiency across the Turbosorp ${ }^{\circledR}$ system as a function of gross unit load. Averages were computed for 10-MW load ranges using the hourly data collected during the August 2007 - September 2008 time period. As shown in the figure, the $\mathrm{SO}_{2}$ removal efficiency averaged greater than $95 \%$ when the unit operated above $60 \mathrm{MW}_{\mathrm{g}}$, and it averaged close to $97 \%$ for unit loads greater than $90 \mathrm{MW}_{\mathrm{g}}$. Somewhat lower removal efficiencies were observed at the bottom end of the unit's operating range, with an average of $93 \%$ removal for loads below $60 \mathrm{MW}_{\mathrm{g}}$. The slight decline in $\mathrm{SO}_{2}$ removal efficiency at lower unit loads likely reflects the fact that plant personnel tended to derate the unit when problems arose with the Turbosorp ${ }^{\circledR}$ system in order to minimize the impact of the resulting elevated $\mathrm{SO}_{2}$ emissions on the 30-day rolling average emission rate. $\mathrm{SO}_{2}$ removal was highly variable at low unit loads, consistent with the prevalence of upsets in system performance at those loads. Although not depicted in Figure 69, the relative standard deviation among hourly $\mathrm{SO}_{2}$ removal efficiencies was $15.3 \%$ for unit loads below $60 \mathrm{MW}_{\mathrm{g}}$, versus only $1.4 \%$ for unit loads above 110 
$\mathrm{MW}_{\mathrm{g}}$. The variation in $\mathrm{SO}_{2}$ removal efficiency with unit load was also strongly correlated with the Turbosorp ${ }^{\circledR}$ outlet temperature, as shown in Figure 69. As expected, lower average $\mathrm{SO}_{2}$ removal efficiencies were observed at loads with higher average Turbosorp ${ }^{\circledR}$ outlet temperatures. These higher temperatures are indicative of water lance changes (typically conducted at reduced load) and other upsets involving water injection and temperature control in the Turbosorp ${ }^{\circledR}$ system.

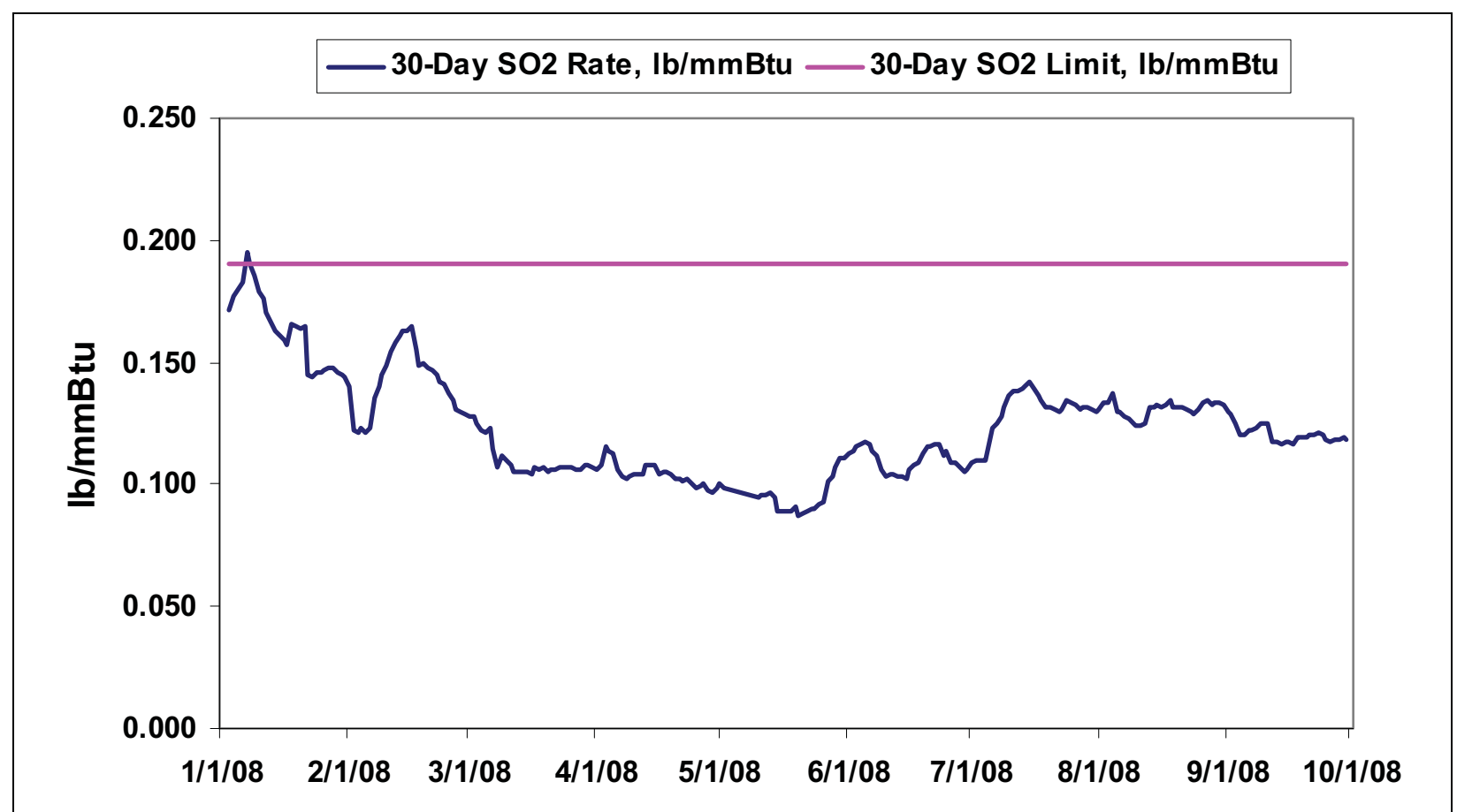

Figure 68. Thirty-day rolling average $\mathrm{SO}_{2}$ emission rates and permit limit for AES Greenidge Unit 4 from January 2008 through September 2008.

Load swings had only a minimal impact on the $\mathrm{SO}_{2}$ removal performance of the Turbosorp ${ }^{\circledR}$ system. This is illustrated in Figure 70 , which summarizes system performance during a relatively extreme load swing that occurred on June 16-17, 2008. As shown in the figure, the gross unit load increased from about $50 \mathrm{MW}_{\mathrm{g}}$ to about $105 \mathrm{MW}_{\mathrm{g}}$ between $2300 \mathrm{EST}$ on June 16 and 0000 EST on June 17, and it then returned to around $50 \mathrm{MW}_{\mathrm{g}}$ by $0100 \mathrm{EST}$ on June 17. As the unit load began to increase, the quantity and temperature of flue gas being fed to the Turbosorp ${ }^{\circledR}$ absorber vessel also increased. This caused an approximately $10^{\circ} \mathrm{F}$ rise in the temperature at the Turbosorp ${ }^{\circledR}$ outlet, leading to a drop in $\mathrm{SO}_{2}$ removal efficiency from about $96 \%$ to about $87 \%$ as the approach to adiabatic saturation in the absorber vessel widened. The hydrated lime feed increased in response to the rising $\mathrm{SO}_{2}$ emissions, as evidenced by the increase in rotary feeder output, and the water injection rate also increased to counteract the rising flue gas temperature. As a result, when the unit load abruptly began to drop at 0000 EST on June 17, bringing about a corresponding drop in the quantity and temperature of flue gas to be treated, the Turbosorp ${ }^{\circledR}$ system was left with an excess of hydrated lime and water injection. The Turbosorp ${ }^{\circledR}$ outlet temperature quickly fell to $155^{\circ} \mathrm{F}$, and the $\mathrm{SO}_{2}$ removal increased to $100 \%$. This extremely high removal efficiency continued for about an hour while the drop in load was completed and the hydrated lime and water injection rates adjusted to the new set of conditions. Overall, the load swing had little impact on the unit's $\mathrm{SO}_{2}$ emissions. In spite of the relatively rapid changes in process conditions, the Turbosorp ${ }^{\circledR}$ system was able to maintain an average $\mathrm{SO}_{2}$ removal efficiency of $95 \%$ during the two-hour period containing the load swing. 


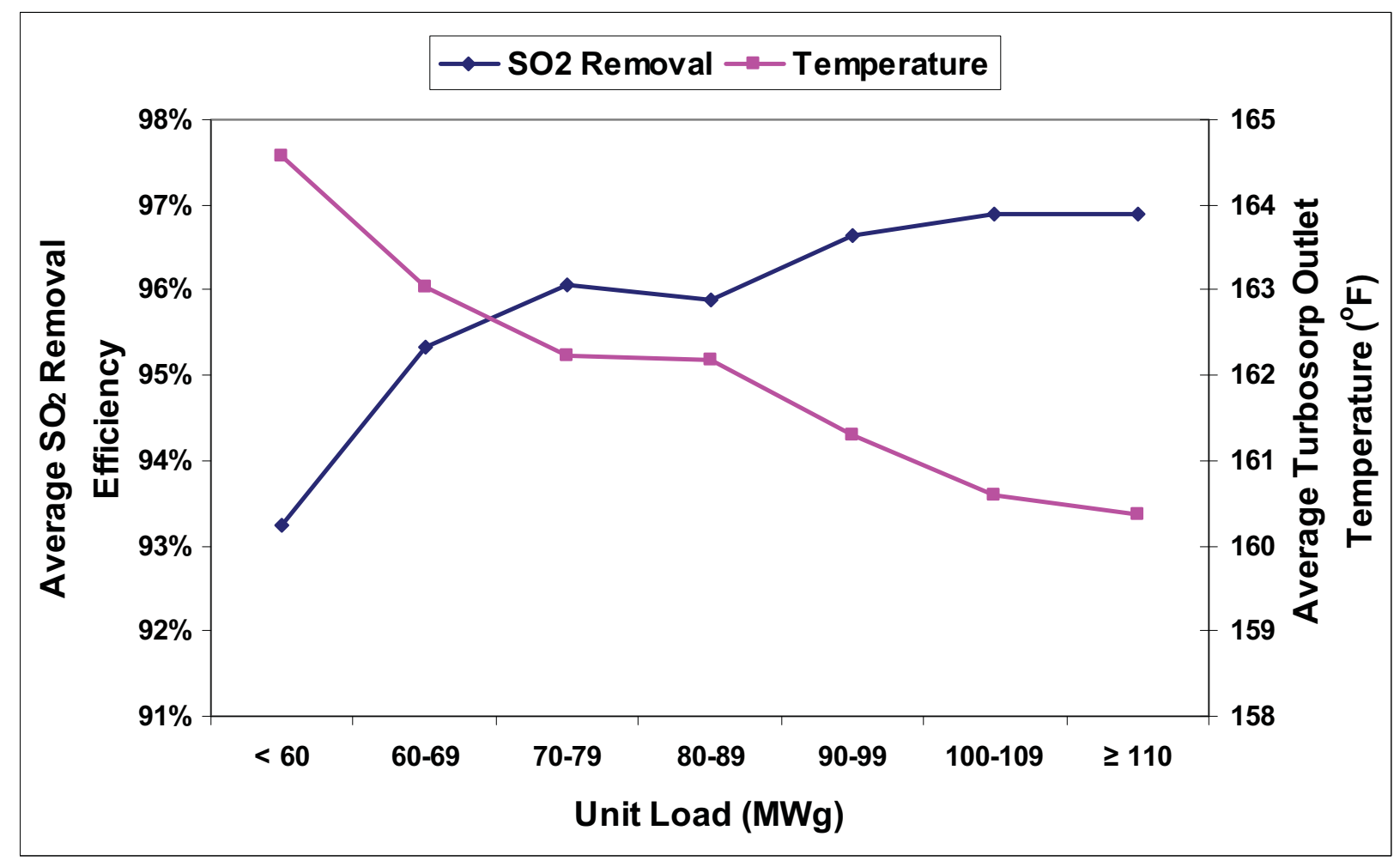

Figure 69. Average $\mathrm{SO}_{2}$ removal efficiency and Turbosorp ${ }^{\circledR}$ outlet temperature as a function of gross unit load, based on hourly data collected during August 2007 - September 2008. $\mathrm{SO}_{2}$ was measured by the dilution extractive-type $\mathrm{SO}_{2}$ analyzer that is permanently installed at the air heater outlet (upstream of the Turbosorp $^{\circledR}$ system) and by the unit's stack CEM (downstream of the Turbosorp ${ }^{\circledR}$ system).

\subsubsection{Lime Utilization}

The variable operating costs of the Turbosorp ${ }^{\circledR}$ process depend strongly on the amount of hydrated lime that is required to achieve a given level of $\mathrm{SO}_{2}$ removal. Lime utilization in the Turbosorp ${ }^{\circledR}$ process is typically expressed in terms of the calcium-to-sulfur molar ratio, defined as the number of moles of available $\mathrm{CaO}$ being fed to the scrubber divided by the number of moles of sulfur present as $\mathrm{SO}_{2}$ or $\mathrm{SO}_{3}$ in the flue gas at the inlet to the scrubber. Per the discussion in Section 4.3, the $\mathrm{Ca} / \mathrm{S}$ molar ratio is expected to vary with several other operating conditions, including the $\mathrm{SO}_{2}$ removal efficiency and approach to adiabatic saturation temperature in the absorber vessel. In general, greater $\mathrm{Ca} / \mathrm{S}$ molar ratios are expected as the $\mathrm{SO}_{2}$ removal efficiency or scrubber operating temperature increases. The projected $\mathrm{Ca} / \mathrm{S}$ molar ratio for AES Greenidge Unit 4 under design conditions (4.0 lb SO $\mathrm{SO}_{2} / \mathrm{mmBtu}$ fuel, $95 \% \mathrm{SO}_{2}$ removal efficiency, $\sim 160{ }^{\circ} \mathrm{F}$ scrubber operating temperature) was $1.6-1.7$, as cited in Section 6.2.4. 


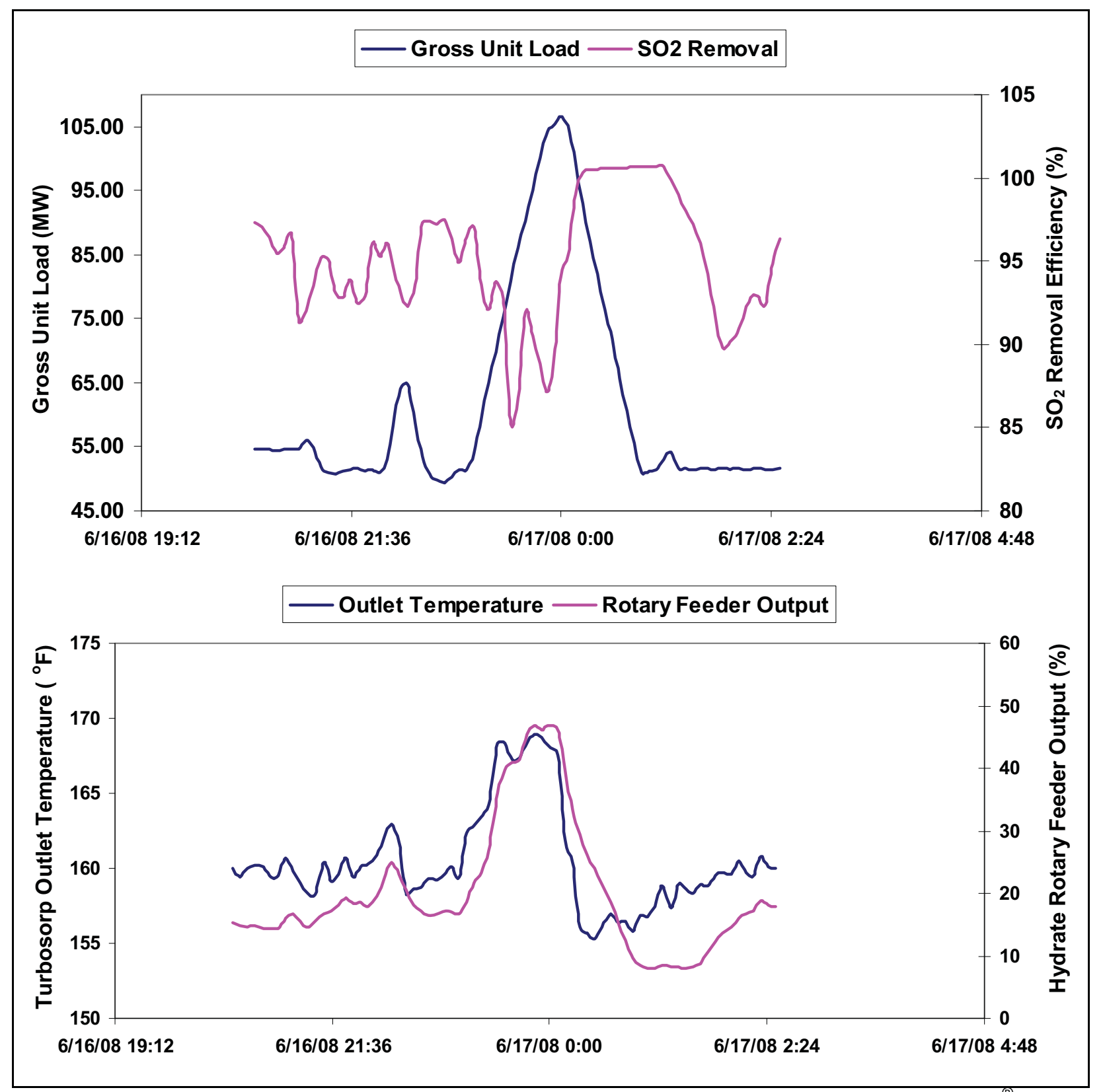

Figure 70. Five-minute average gross unit loads, $\mathrm{SO}_{2}$ removal efficiencies, Turbosorp ${ }^{\circledR}$ outlet temperatures, and hydrated lime rotary feeder percent outputs observed at AES Greenidge Unit 4 between June 16, 2008, at 2030 EST and June 17, 2008, at 0230 EST. These data illustrate the performance of the Turbosorp ${ }^{\circledR}$ system in response to a load swing. $\mathrm{SO}_{2}$ was measured by the dilution extractive-type $\mathrm{SO}_{2}$ analyzer that is permanently installed at the air heater outlet (upstream of the Turbosorp $^{\circledR}$ system) and by the unit's stack CEM (downstream of the Turbosorp ${ }^{\circledR}$ system).

Per the discussion in Sections 9.1.2.3.2 and 9.1.2.3.6, the process performance testing campaigns on October 8-11, 2007, and June 13-16, 2008, were designed to enable an evaluation of the $\mathrm{Ca} / \mathrm{S}$ molar ratios required for various scrubber operating conditions (i.e., for changes in $\mathrm{SO}_{2}$ removal efficiency and operating temperature). Operating conditions were varied each day during these testing campaigns. For the tests in October 2007, the $\mathrm{Ca} / \mathrm{S}$ ratios were calculated from the pebble lime feed rate, change in hydrated lime silo level, and $\mathrm{SO}_{2}$ loading at the scrubber inlet, and they also were determined independently by chemically 
analyzing samples of the product ash produced by the Turbosorp ${ }^{\circledR}$ system. (The hydrated lime injection rate is not directly measured at AES Greenidge Unit 4). The hydrated lime silo level monitor malfunctioned during the June 2008 tests; hence, $\mathrm{Ca} / \mathrm{S}$ molar ratios could only be determined from the product ash analysis for those tests.

When process data were used to determine the Ca/S molar ratio, the number of moles of calcium was computed by multiplying the estimated hydrated lime feed rate by the available $\mathrm{Ca}(\mathrm{OH})_{2}$ content of hydrated lime samples collected on that day, and dividing by the molecular weight of $\mathrm{Ca}(\mathrm{OH})_{2}$. The hydrated lime feed rate was estimated using the pebble lime feed rate and hydrated lime silo level data recorded by the unit's PI system, as well as chemical composition and density results from pebble and hydrated lime samples collected that day. Available $\mathrm{Ca}(\mathrm{OH})_{2}$ was determined in accordance with ASTM C25, as described in Section 9.2.2.2.1. The number of moles of sulfur was computed as $95 \%$ of the sulfur fed with the coal (U.S. EPA, 1995), which was determined from the coal feed rates reported by the plant and the sulfur content of coal samples collected that day.

When Turbosorp ${ }^{\circledR}$ product ash samples were used to determine the $\mathrm{Ca} / \mathrm{S}$ molar ratio, samples of product ash, coal, hydrated lime, and fly ash (drawn upstream of the scrubber) were collected during the test period for use in the determination. These samples were analyzed for $\mathrm{Ca}, \mathrm{S}, \mathrm{Al}$, and $\mathrm{Si}$ by inductively coupled plasma-atomic emission spectroscopy. The hydrated lime samples were also analyzed for available $\mathrm{Ca}(\mathrm{OH})_{2}$ (per ASTM C25). Ca/S molar ratios were then computed from the concentrations of $\mathrm{Ca}$ and $\mathrm{S}$ determined in the product ash samples. Finally, these ratios were corrected to remove the $\mathrm{Ca}$ and $\mathrm{S}$ that are attributable to coal fly ash (the $\mathrm{Ca}, \mathrm{S}, \mathrm{Al}$, and $\mathrm{Si}$ data from the product ash and fly ash samples were used to perform these corrections), to adjust for the available $\mathrm{Ca}(\mathrm{OH})_{2}$ content of the hydrated lime being used in the process, and to base them on moles of inlet sulfur as opposed to moles of sulfur removed. (For this final correction, inlet sulfur was estimated as $95 \%$ of the sulfur fed with the coal, and sulfur removal was computed by subtracting the sulfur emissions determined by the stack CEM from the estimated inlet sulfur).

Figure 71 shows the $\mathrm{Ca} / \mathrm{S}$ molar ratios determined during the October 8-12, 2007, testing campaign. Data are also shown for two days from the preceding week (October 2 and 5, 2007), during which testing was performed with higher-sulfur coal. (The $\mathrm{Ca} / \mathrm{S}$ ratios for these two additional days were computed using the same methods described above). As shown in the figure, the ratios determined from the product ash analysis exhibited less variability than those computed from process data, likely owing to the long residence time of solids in the system and the relatively short periods of stable operation under the desired conditions (as little as 4 hours on some days), which made it difficult to obtain representative samples. Hence, the processdata-based $\mathrm{Ca} / \mathrm{S}$ ratios are likely more reflective of day-to-day variations in hydrated lime consumption for the October tests, although it is important to recognize that these ratios depend upon a number of measurements and therefore are susceptible to several sources of error. The process-data-based $\mathrm{Ca} / \mathrm{S}$ ratios generally varied according to expectation. Process conditions on October 9 and 10 (coal sulfur content $=4.1 \mathrm{lb} \mathrm{SO} / \mathrm{mmBtu}_{2} \mathrm{SO}_{2}$ removal efficiency $=95 \%$, Turbosorp $^{\circledR}$ outlet temperature $=160^{\circ} \mathrm{F}$ ) were very similar to the design specification for AES Greenidge Unit 4; the average $\mathrm{Ca} / \mathrm{S}$ molar ratio computed from process data on these days was 1.68 , consistent with the projected range of 1.6-1.7 referenced above. Higher $\mathrm{Ca} / \mathrm{S}$ molar ratios (average $=2.0$ ) were required on October 2 and 5 , when the $\mathrm{SO}_{2}$ removal efficiency (average = $97 \%$ ) and coal sulfur content (average $=4.6 \mathrm{lb} \mathrm{SO} / \mathrm{mmBtu}$ ) were greater than design conditions, and on October 12 , when the scrubber outlet temperature was raised by $5{ }^{\circ} \mathrm{F}$ from its typical set point of $160{ }^{\circ} \mathrm{F}$. The estimated approach to adiabatic saturation temperature in the Turbosorp ${ }^{\circledR}$ absorber vessel on this last day of testing was $45^{\circ} \mathrm{F}$, which is at least $6^{\circ} \mathrm{F}$ 
greater than the approach temperatures of 34-39 ${ }^{\circ} \mathrm{F}$ estimated for the other five days. Although the scrubber outlet temperature remained constant at $160^{\circ} \mathrm{F}$ on October 8-10, the estimated approach temperature on October 8 was about $3{ }^{\circ} \mathrm{F}$ less than the estimated approach temperatures on October 9 and 10 , possibly explaining why such a high $\mathrm{SO}_{2}$ removal efficiency was observed with a relatively low $\mathrm{Ca} / \mathrm{S}$ molar ratio on that day.

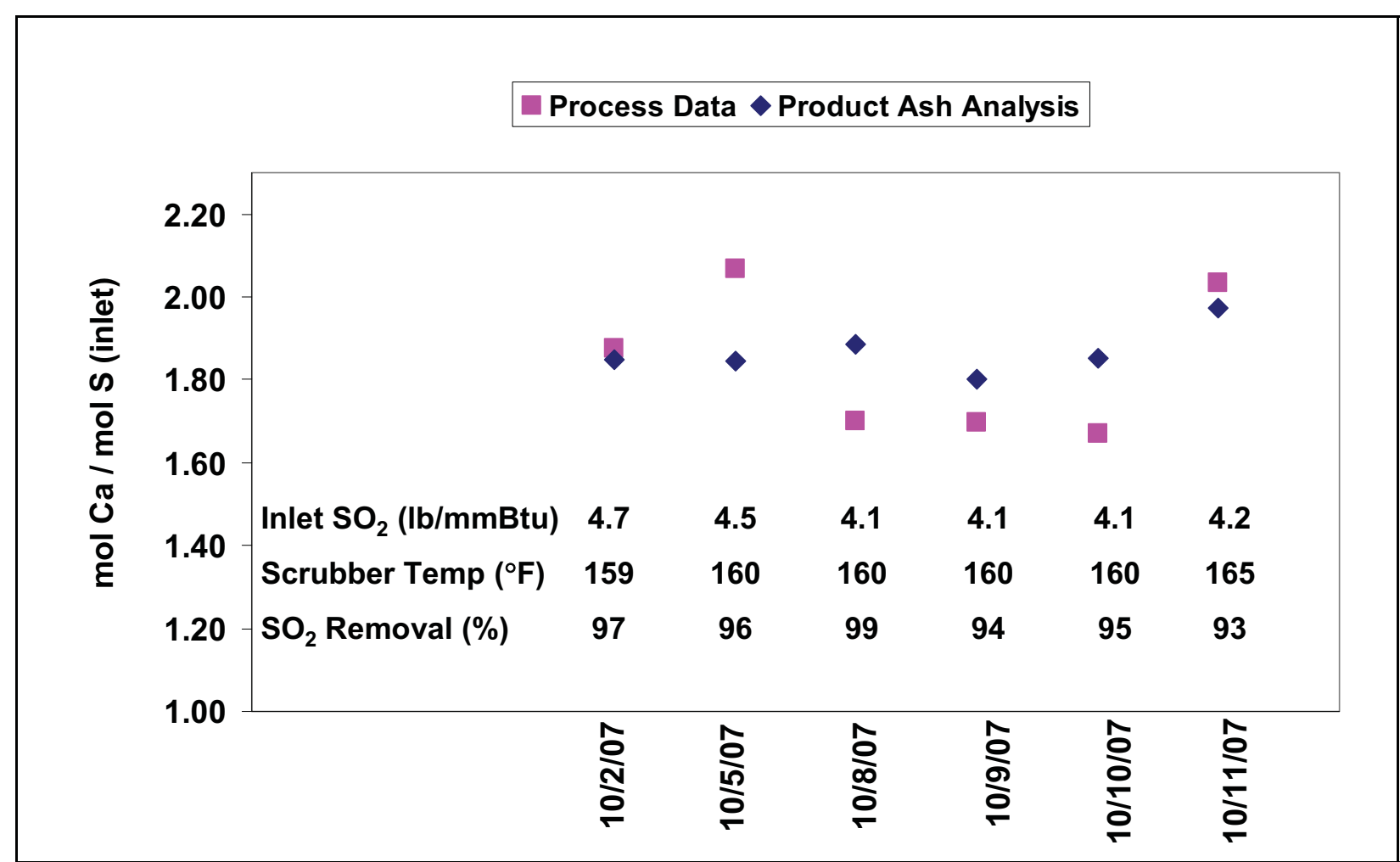

Figure 71. Calcium-to-sulfur molar ratios determined during parametric testing of the Turbosorp ${ }^{\circledR}$ system at AES Greenidge Unit 4 in October 2007. Ratios were derived from process data and from the chemical analysis of Turbosorp ${ }^{\circledR}$ product ash samples using the procedures described in the text. Relevant plant operating conditions are also shown.

As discussed in Section 9.1.2.3.6, scrubber operating conditions were more stable and predictable during the June 16-19, 2008, testing campaign than they were during the October 812, 2007, campaign, providing a better scenario for parametrizing the performance of the Turbosorp $^{\circledR}$ system. In the absence of hydrated lime silo level data for use in computing process-data-based $\mathrm{Ca} / \mathrm{S}$ molar ratios, extra care was taken to ensure that representative product ash samples could be obtained to determine these ratios. On the morning of each test day, after the unit reached full load, the desired set points were established, and the system was allowed to approach steady state. It was then operated at apparent steady state for at least 6.5 hours. Product ash samples were not collected until the end of the period of steady-state operation, in order to ensure that they would be mostly comprised of material generated during that period. (In contrast, during the October 2007 tests, product ash samples were collected throughout the period of steady-state operation). Moreover, to verify the representativeness of the samples, the first five gallons of product ash drawn from the system was discarded, and five-gallon samples were then drawn in duplicate for analysis. In all cases, the concentrations of $\mathrm{Ca}$ and $\mathrm{S}$ determined in the duplicate samples from a given test day agreed within 5\% (relative percent difference). Figure 72 shows the $\mathrm{Ca} / \mathrm{S}$ molar ratios that were determined from the product ash samples collected during the June 16-19 tests, as well as relevant scrubber 
operating data from each test day. The coal sulfur content during the June 16-19 test period was 3.5-3.7 $\mathrm{lb} \mathrm{SO}_{2} / \mathrm{mmBtu}$. During the first three test days, the Turbosorp ${ }^{\circledR}$ operating temperature was held constant at $160^{\circ} \mathrm{F}$ while the $\mathrm{SO}_{2}$ removal efficiency was increased from $92 \%$ to $98 \%$. As expected, the $\mathrm{Ca} / \mathrm{S}$ ratio increased with increasing $\mathrm{SO}_{2}$ removal efficiency, varying from about 1.3 at $92 \% \mathrm{SO}_{2}$ removal to about 1.9 at $98 \% \mathrm{SO}_{2}$ removal. The $\mathrm{Ca} / \mathrm{S}$ molar ratio was 1.60 for $95 \% \mathrm{SO}_{2}$ removal efficiency with a $160{ }^{\circ} \mathrm{F}$ scrubber operating temperature. This is consistent with the projected range of $1.6-1.7$ for $95 \%$ removal efficiency under design conditions. On the last day of testing, the $\mathrm{SO}_{2}$ removal efficiency was held at $95 \%$ while the Turbosorp $^{\circledR}$ operating temperature was raised by $5^{\circ} \mathrm{F}$ to $165^{\circ} \mathrm{F}$. (The estimated approach to adiabatic saturation temperature in the Turbosorp ${ }^{\circledR}$ absorber vessel on this last day was $42^{\circ} \mathrm{F}$, about $5{ }^{\circ} \mathrm{F}$ greater than the estimated approach temperature of $37^{\circ} \mathrm{F}$ on June 17). As anticipated, increasing the operating temperature (and, hence, moving further from the adiabatic saturation temperature in the fluidized bed absorber) caused an increase in the $\mathrm{Ca} / \mathrm{S}$ ratio that was required to achieve $95 \% \mathrm{SO}_{2}$ removal.

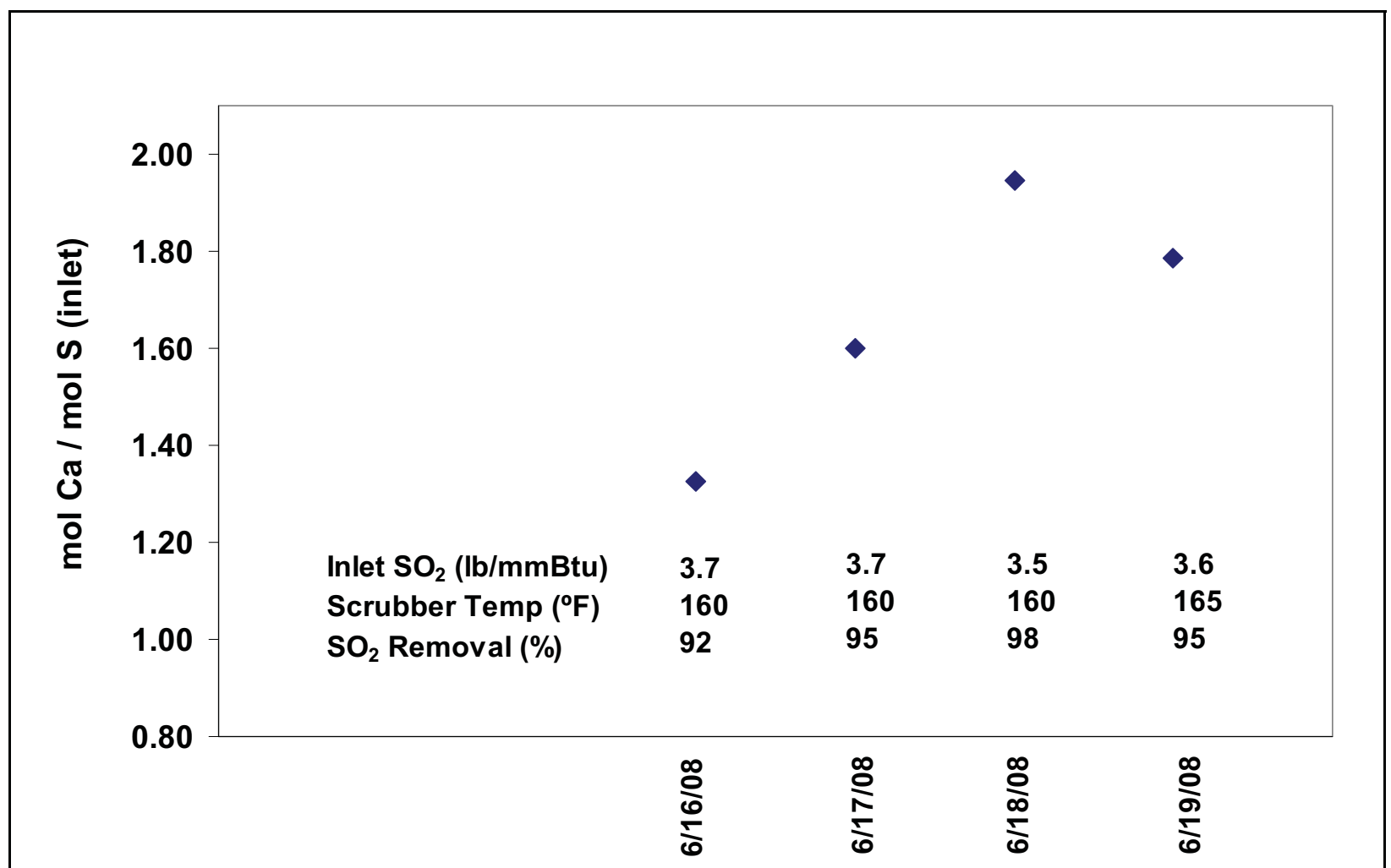

Figure 72. Calcium-to-sulfur molar ratios determined during parametric testing of the Turbosorp ${ }^{\circledR}$ system at AES Greenidge Unit 4 in June 2008. Ratios were derived from the chemical analysis of Turbosorp ${ }^{\circledR}$ product ash samples using the procedures described in the text. Relevant plant operating conditions are also shown.

The parametric tests in October 2007 and June 2008 provided an indication of the short-term lime utilization in the Turbosorp ${ }^{\circledR}$ system under controlled operating conditions. To assess the longer-term performance of the system, sorbent utilization was analyzed independently over the fourteen-month period between August 1, 2007, and September 30, 2008, using lime delivery data (i.e., truck weights) and $\mathrm{SO}_{2}$ data from the plant's online analyzers. Results are summarized in Table 26. As discussed in Section 9.3.6, during this period, the average inlet $\mathrm{SO}_{2}$ rate was $3.62 \mathrm{lb} / \mathrm{mmBtu}$, and the average $\mathrm{SO}_{2}$ removal efficiency was $96.3 \%$. The temperature at the outlet of the Turbosorp ${ }^{\circledR}$ absorber vessel averaged $161.7^{\circ} \mathrm{F}$, just slightly 
above the normal set point of $160^{\circ} \mathrm{F}$. Lime consumption (measured as available $\mathrm{CaO}$ ) totaled 22,969 tons, and the amount of $\mathrm{SO}_{2}$ fed to the scrubber totaled 15,148 tons, resulting in an average $\mathrm{Ca} / \mathrm{S}$ molar ratio of 1.73 . (For purposes of this calculation, any missing values in the inlet $\mathrm{SO}_{2}$ concentration data were replaced with values obtained by linear interpolation from the nearest valid concentrations). This is slightly greater than the design ratio of 1.6-1.7; however, some deviation from the design might be expected, because the fourteen-month lime total includes excess lime that was wasted during periods when $\mathrm{SO}_{2}$ emissions were over-controlled (16.5\% of the one-hour periods during August 2007 - September 2008 had $\mathrm{SO}_{2}$ removal efficiencies of $\geq 99 \%$ ) or when lime was overfed to the scrubber to compensate for temperature upsets resulting from load swings or maintenance activities (e.g., change-out of the water injection lance). The calculation is also susceptible to a number of sources of measurement error, including errors in the truck weights, stack flow rate measurements, available $\mathrm{CaO}$ measurements, and $\mathrm{SO}_{2}$ measurements.

Table 26. Average calcium-to-sulfur molar ratio estimated for the 14-month period from August 2007 through September 2008 using lime delivery (truck weight) data and $\mathrm{SO}_{2}$ data from the plant's online analyzers.

\begin{tabular}{|c|c|}
\hline \multicolumn{2}{|l|}{ Average Process Conditions } \\
\hline $\mathrm{SO}_{2}$ Rate at Turbosorp ${ }^{\circledR}$ Inlet $(\mathrm{lb} / \mathrm{mmBtu})^{\mathrm{a}}$ & 3.62 \\
\hline Turbosorp $^{\circledR}$ Outlet Temperature $\left({ }^{\circ} \mathrm{F}\right)$ & 161.7 \\
\hline $\mathrm{SO}_{2}$ Removal Efficiency (\%) & 96.3 \\
\hline \multicolumn{2}{|l|}{ Lime Consumption } \\
\hline Total Pebble Lime Deliveries (tons) ${ }^{b}$ & 24,683 \\
\hline Total Hydrated Lime Deliveries (tons) ${ }^{\mathrm{b}}$ & 1,593 \\
\hline Average Pebble Lime Available $\mathrm{CaO}(\% \mathrm{w} / \mathrm{w})^{\mathrm{c}}$ & 88.6 \\
\hline Average Hydrated Lime Available $\mathrm{CaO}(\% \mathrm{w} / \mathrm{w})^{\mathrm{c}}$ & 68.8 \\
\hline Total Available $\mathrm{CaO}$ Consumed (tons) & 22,969 \\
\hline Total Available CaO Consumed (Ibmol) & 820,311 \\
\hline \multicolumn{2}{|l|}{ Sulfur Fed to Turbosorp ${ }^{\circledR}$ System } \\
\hline Total $\mathrm{SO}_{2}$ Fed to Turbosorp ${ }^{\circledR}$ System (tons) ${ }^{a}$ & 15,148 \\
\hline Total $\mathrm{SO}_{2}$ Fed to Turbosorp System (lbmol) ${ }^{\mathrm{a}}$ & 473,364 \\
\hline Estimated Ca/S Molar Ratio & 1.73 \\
\hline
\end{tabular}

${ }^{a} \mathrm{SO}_{2}$ was measured by the dilution extractive-type $\mathrm{SO}_{2}$ analyzer that is permanently installed at the air heater outlet (upstream of the Turbosorp ${ }^{\circledR}$ system). Concentrations were converted to a mass basis using the assumptions described in Section 9.3.6. Any missing values were replaced with values obtained by linear interpolation from the nearest valid data. ' Sum of delivery truck weights between July 31, 2007, and September 29, 2008. ${ }^{\mathrm{C}} \mathrm{Based}$ on the available $\mathrm{CaO}$ (or available $\mathrm{Ca}(\mathrm{OH})_{2} \times 56 / 74$ ) content of pebble lime or hydrated lime samples collected during the sampling campaigns in October 2007 - June 2008. Available $\mathrm{CaO}$ and available $\mathrm{Ca}(\mathrm{OH})_{2}$ were determined according to ASTM C25.

Nevertheless, these long-term data, coupled with the results of the process performance tests on October 9-10, 2007, and June 17, 2008, provide strong evidence that the Turbosorp ${ }^{\circledR}$ system at AES Greenidge achieved the targeted sorbent utilization during more than a year of commercial operation. The October 2007 and June 2008 parametric tests also confirmed that the required $\mathrm{Ca} / \mathrm{S}$ ratio generally varied as expected with changes in scrubber operating conditions.

\subsubsection{Mercury Removal Efficiency}

The multi-pollutant control system at AES Greenidge Unit 4 consistently exceeded its performance target of $\geq 90 \% \mathrm{Hg}$ removal efficiency on a coal-to-stack basis. A total of 34 tests 
were conducted between March 2007 and June 2008 as part of the guarantee tests, process performance tests, and follow-up tests to determine the coal-to-stack mercury removal efficiency achieved by the multi-pollutant control system. As discussed in Section 9.2, for each test, $\mathrm{Hg}$ concentrations at the stack were determined using the Ontario Hydro Method (ASTM D 678402) or U.S. EPA Method 30B, and $\mathrm{Hg}$ concentrations in the coal were determined by ASTM D 6722. Results are summarized in Figure 73 and in Table 27. (The tests on June 12-13, 2008, included simultaneous sampling via the Ontario Hydro Method and Method 30B. The Hg removal efficiencies determined from the Ontario Hydro Method measurements were less than those determined from the $30 \mathrm{~B}$ measurements. Hence, the Ontario Hydro Method results are shown to be conservative). Attainment of the performance target for $\mathrm{Hg}$ removal was officially demonstrated during the tests on March 28 and 30, 2007. Greater than 90\% coal-to-stack removal efficiency was observed during each of the six tests conducted on those two days, with a six-test average removal efficiency of $>94.6 \%$. (For the guarantee tests on March 28 and 30 , $\mathrm{Hg}$ was determined in the Ontario Hydro Method samples using cold vapor atomic absorption spectroscopy, and all $\mathrm{Hg}$ concentrations at the stack were below the method detection limit. Cold vapor atomic fluorescence spectroscopy was employed for subsequent tests so that stack $\mathrm{Hg}$ concentrations could be detected). Very high $\mathrm{Hg}$ removal efficiency continued to be observed during all subsequent tests conducted as part of the project. Coal-to-stack removal efficiencies ranged from $92.7 \%$ to $99.8 \%$ for the $28 \mathrm{Hg}$ measurements completed as part of process performance and follow-up testing between October 2007 and June 2008. The overall average removal efficiency during these tests was $98.6 \%$. As discussed in section 9.2.1.3.5.3, mercury material balances were performed for all $34 \mathrm{Hg}$ tests conducted during the project's Operation and Testing Phase, and all of these balances had closures of $100 \pm 30 \%$, giving credence to the test results. Thus, the performance target for mercury removal efficiency was satisfied without exception.

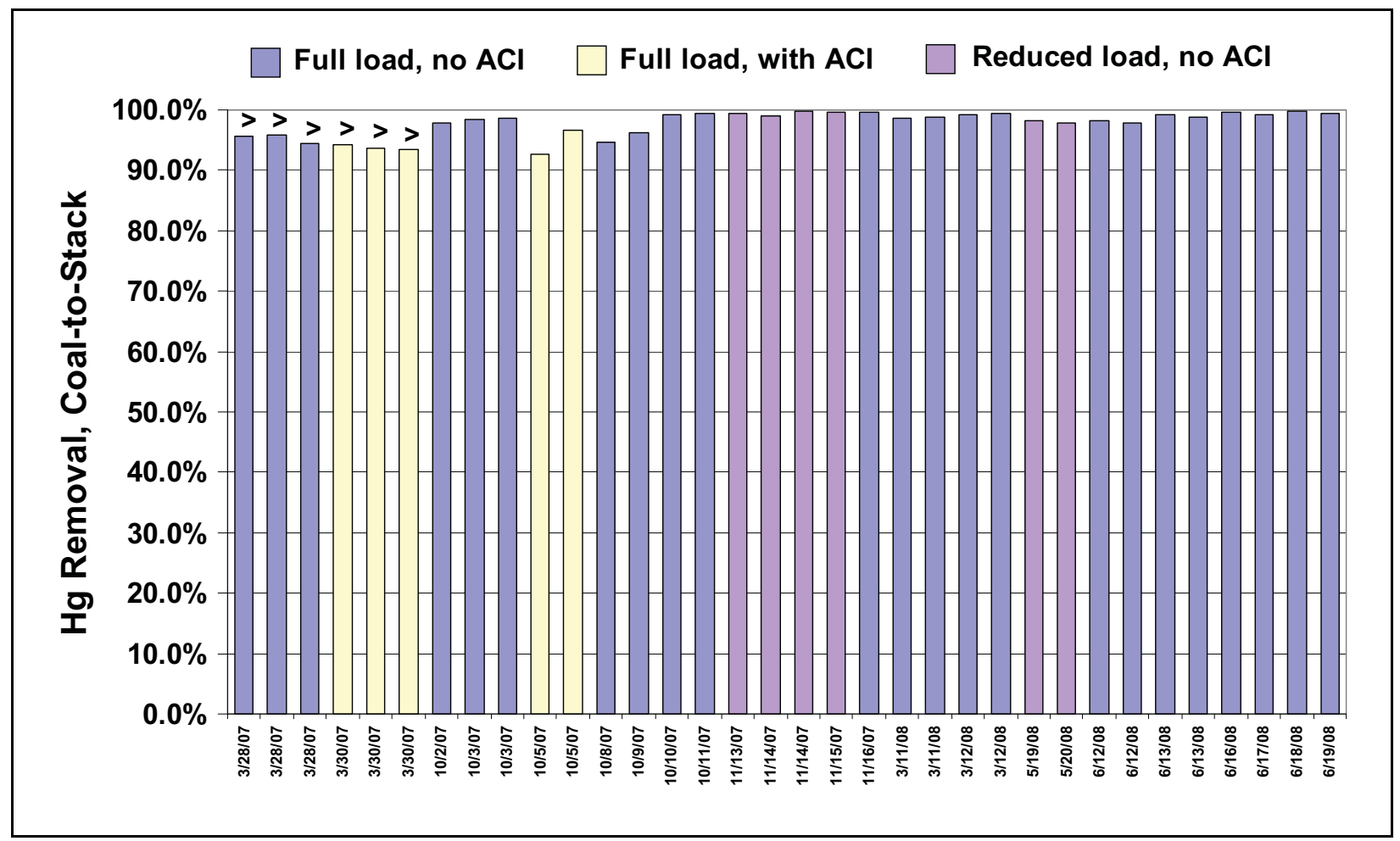

Figure 73. Summary of coal-to-stack $\mathrm{Hg}$ removal efficiencies measured at AES Greenidge Unit 4 between March 2007 and June 2008. For bars labeled ">" the Hg concentration at the stack was below the method detection limit, and the removal efficiency was greater than the value shown. 


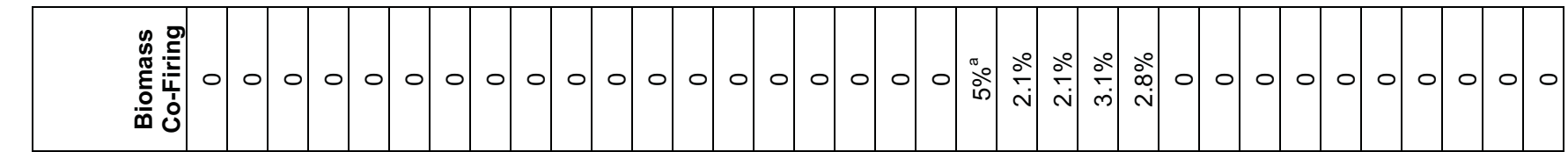

:

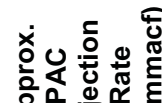

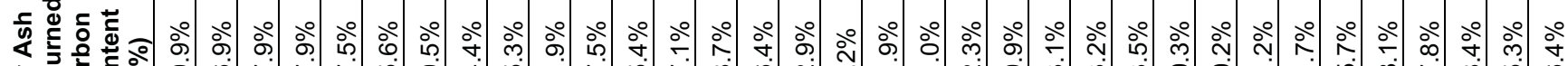

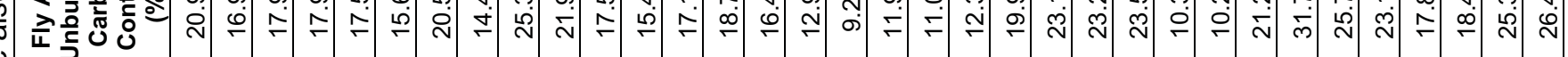

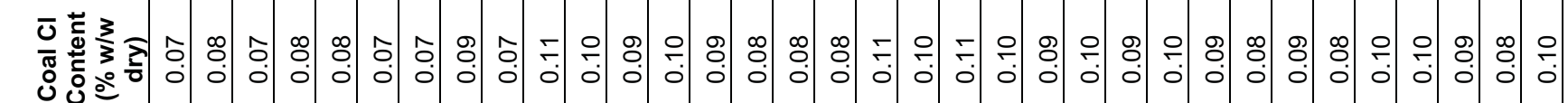

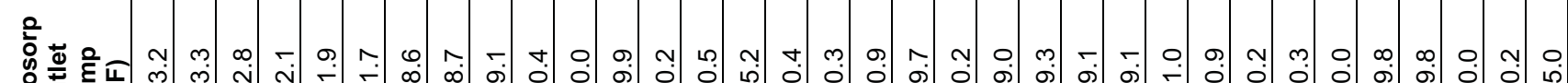

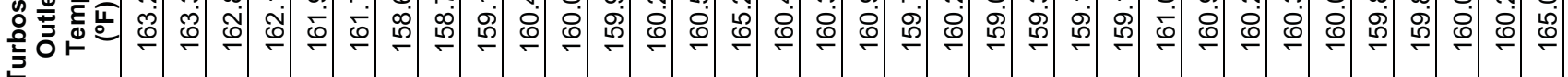

일

華

$\frac{\overrightarrow{0}}{\mathscr{Q}}$

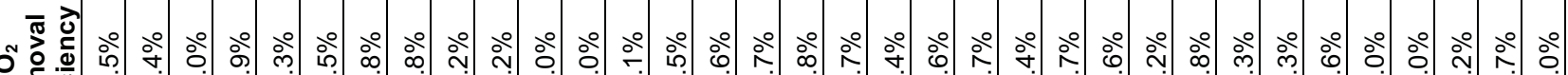

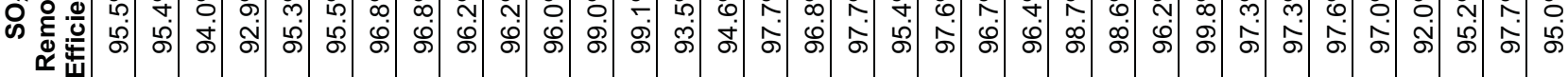

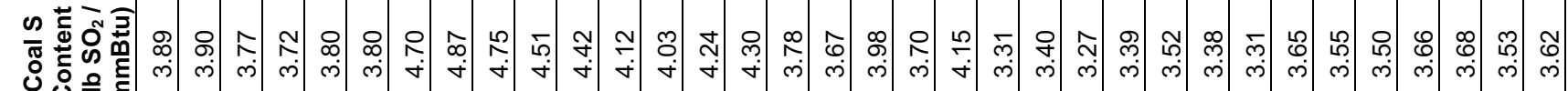

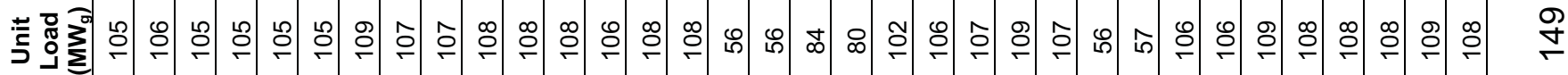

ه

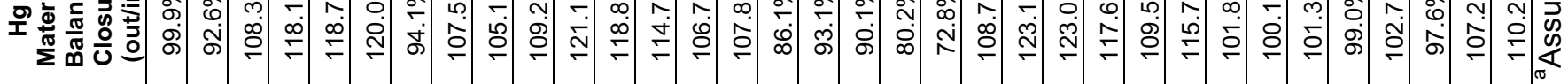

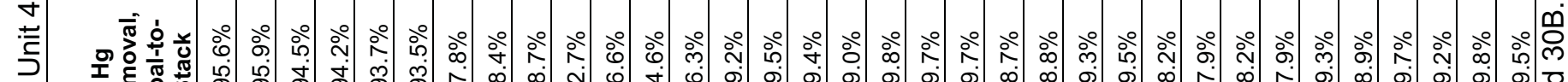

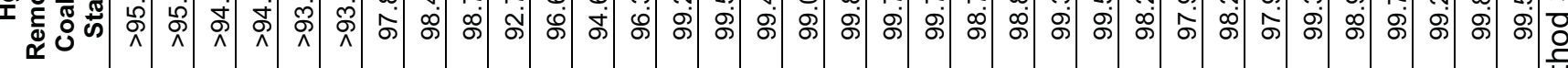

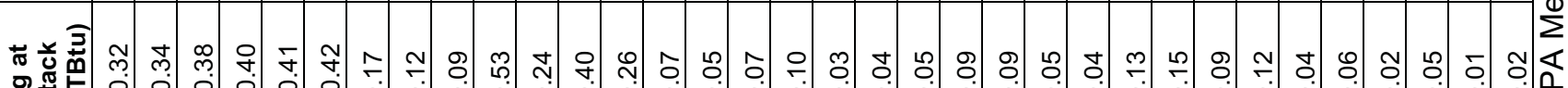

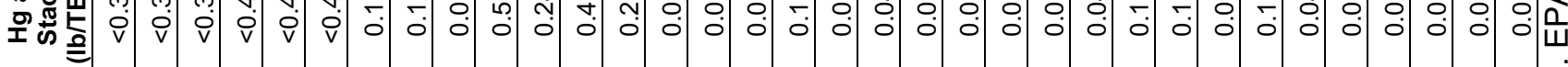

$\oplus$

तั

$=5$ 三

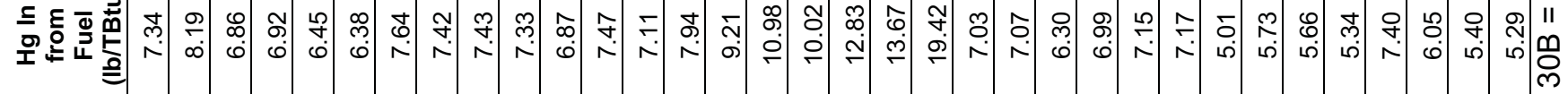

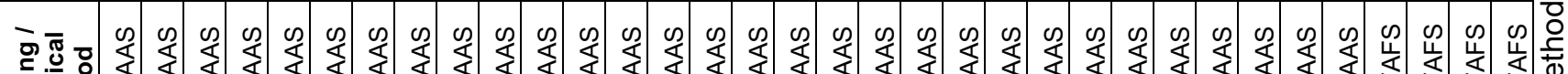

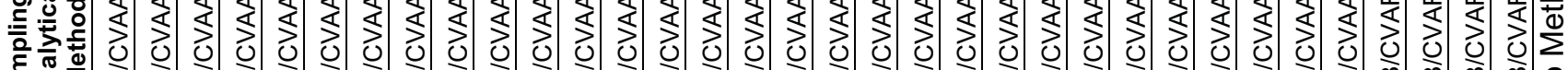

心

오

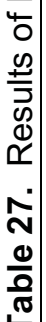

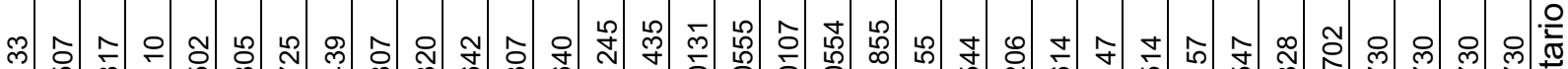

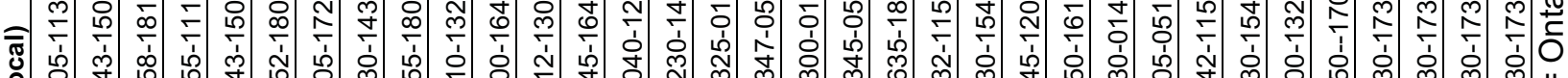

。

ล̃.

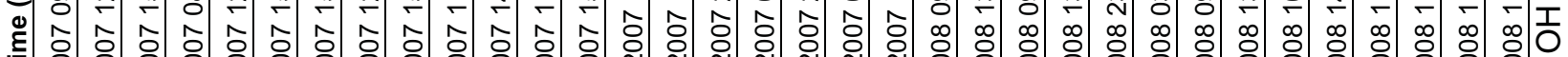

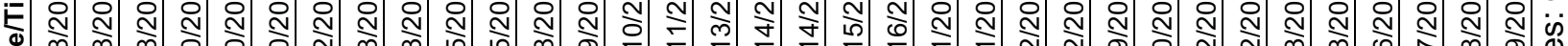

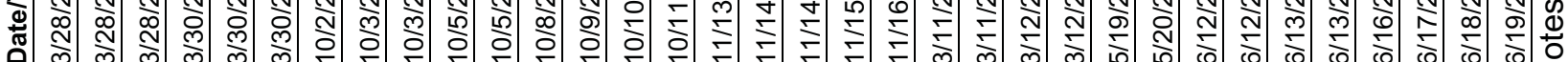


As discussed earlier, the multi-pollutant control system at AES Greenidge Unit 4 includes an activated carbon injection $(\mathrm{ACl})$ system that can be used, if necessary, to promote mercury capture in the Turbosorp ${ }^{\circledR}$ scrubber and baghouse. To evaluate the effect of activated carbon injection on the mercury removal performance of the multi-pollutant control system, the guarantee testing campaign on March 28-30, 2007, and the process performance testing campaign on October 2-5, 2007, included $\mathrm{Hg}$ tests both with and without ACl. For the tests with activated carbon injection, a relatively low-cost, untreated, lignite-derived, powdered activated carbon sorbent (Super HOK) was injected at a nominal rate of $3 \mathrm{lb} / \mathrm{mmacf}$ of flue gas. The results are summarized in Table 28. During both test campaigns, the measurements conducted while activated carbon was being injected ahead of the Turbosorp ${ }^{\circledR}$ system exhibited a lower average coal-to-stack $\mathrm{Hg}$ removal efficiency than the measurements conducted with no ACl. It is unlikely that the activated carbon inhibited mercury removal. Rather, the apparent discrepancy probably resulted from several factors, including the lower coal Hg content during the tests with activated carbon injection (as shown in Table 28), variations in operating conditions between the tests with carbon injection and the tests without carbon injection (these tests were conducted on different days during both the March and October campaigns), and measurement error, which is especially likely at the low $\mathrm{Hg}$ concentrations observed at the stack. As illustrated in Table 28, the average mercury material balance closure was closer to $100 \%$ for the tests without $\mathrm{ACl}$ than it was for the tests with $\mathrm{ACl}$, suggesting greater error in the results of the latter tests. In any event, the project definitively confirmed that the multi-pollutant control system at AES Greenidge Unit 4 can achieve $>90 \% \mathrm{Hg}$ removal efficiency without any activated carbon injection. Twenty-nine of the 34 mercury tests shown in Figure 73 were conducted while the activated carbon injection system was not in service; the average coal-tostack mercury removal efficiency observed during these tests was $98.4 \%$. The tests performed in March and October 2007 suggest that activated carbon injection cannot contribute any additional, measurable $\mathrm{Hg}$ removal efficiency to the already-high level achieved by the other components of the multi-pollutant control system. Hence, apart from these two test periods, AES Greenidge has operated the multi-pollutant control system without any activated carbon injection.

Table 28. Summary of average mercury removal efficiencies observed during tests with and without activated carbon injection in March 2007 and October 2007.

\begin{tabular}{|l|c|c|c|c|c|}
\hline & $\begin{array}{c}\text { Number } \\
\text { of } \\
\text { Tests }\end{array}$ & $\begin{array}{c}\text { Average Hg in } \\
\text { Coal } \\
\text { (Ib/TBtu) }\end{array}$ & $\begin{array}{c}\text { Average Hg at } \\
\text { Stack } \\
\text { (Ib/TBtu) }\end{array}$ & $\begin{array}{c}\text { Average Hg } \\
\text { Material } \\
\text { Balance } \\
\text { Closure } \\
\text { (\%) }\end{array}$ \\
\hline $\begin{array}{l}\text { March 28-30, 2007 } \\
\text { No ACl }\end{array}$ & 3 & 7.46 & $<0.35$ & $>95.4$ & 100 \\
With ACl & 3 & 6.58 & $<0.41$ & $>93.8$ & 119 \\
\hline $\begin{array}{l}\text { October 2-5, 2007 } \\
\text { No ACl } \\
\text { With ACl }\end{array}$ & 3 & 7.50 & 0.13 & 98.3 & 102 \\
\hline
\end{tabular}

Table 27 summarizes relevant plant operating conditions observed during each of the 34 mercury tests that were conducted during the Operation and Testing Phase of the project. High mercury removal efficiency was observed irrespective of these operating conditions. During all of the test periods, AES Greenidge Unit 4 fired typical eastern U.S. bituminous coals containing $5.0-19.4 \mathrm{lb} \mathrm{Hg} / \mathrm{TBtu}, 3.3-4.9 \mathrm{lb} \mathrm{SO} / \mathrm{mmBtu}$, and $0.07-0.11 \% \mathrm{Cl}$. For the five tests on November 16, 2007, and March 11-12, 2008, it also co-fired waste wood at less than $5 \%$ of the total heat input. The gross generator load during the reduced-load tests on November 13-15, 2007, and May 19-20, 2008, ranged from 56 to $84 \mathrm{MW}$; during the other 28 tests, the unit 
operated between 102 and $109 \mathrm{MW}_{\mathrm{g}}$. The $\mathrm{SO}_{2}$ removal efficiency across the Turbosorp ${ }^{\circledR}$ system varied between $92 \%$ and $100 \%$ during the tests, and the Turbosorp ${ }^{\circledR}$ outlet temperature varied between 159 and $165^{\circ} \mathrm{F}$. None of these variables had an observable effect on the coalto-stack mercury removal efficiency over the range of conditions encountered during the tests.

AES Greenidge Unit 4 produces fly ash with appreciable amounts of unburned carbon. The carbon content of fly ash samples collected at the air heater outlet, upstream of the Turbosorp ${ }^{\circledR}$ system, during each of the 34 mercury tests was in all cases greater than $9 \%$. The average fly ash carbon content observed during these tests was $18.6 \%$. As discussed in Section 4.3.1, unburned carbon in the fly ash can adsorb gaseous mercury, especially at low temperatures such as those encountered in the Turbosorp ${ }^{\circledR}$ system. (Based on coal and fly ash chemical composition data from the tests in October 2007 - June 2008, the ash had already captured about $23 \%$ of the coal $\mathrm{Hg}$ by the time it reached the air heater outlet, upstream of the Turbosorp ${ }^{\circledR}$ system). Hence, it is possible that the high mercury removal efficiencies observed at AES Greenidge Unit 4 were in part attributable to the high unburned carbon content of the fly ash. The tests conducted during the Operation and Testing Phase of the project were unable to confirm or refute this possibility. As shown in Figure 74, no association was observed between the mercury removal efficiencies and fly ash unburned carbon contents measured during these tests. (The tests in March 2007, which had stack Hg concentrations below the detection limit, are excluded from the plot). However, the fly ash unburned carbon content at AES Greenidge may have been too high throughout the tests to enable such an association to be discovered. (Assuming that there is an association between mercury removal efficiency and fly ash carbon content, once sufficient carbon is present to achieve $90-100 \% \mathrm{Hg}$ capture, any further increase in carbon content might not be expected to bring about a measurable improvement). Alternatively, the high level of mercury removal observed at AES Greenidge could have resulted largely from another mechanism, such as capture by $\mathrm{Ca}(\mathrm{OH})_{2}$ in the scrubber and baghouse. Thus, it is unclear whether the multi-pollutant control system would be able to achieve high $\mathrm{Hg}$ removal efficiencies without any activated carbon injection when applied to units having lower fly ash unburned carbon contents (e.g., <4\%). The $\mathrm{Hg}$ removal performance of the system is especially uncertain for units that fire PRB coal, as these units have lower fly ash unburned carbon content and lower coal $\mathrm{Cl}$ concentrations than bituminous coal-fired units. (As discussed in Section 4.3.1, coal $\mathrm{Cl}$ helps to oxidize $\mathrm{Hg}$, making it easier to capture). Additional testing is recommended to elucidate these uncertainties.

As discussed in Section 9.3.5, the in-duct SCR catalyst at AES Greenidge Unit 4 was effective in converting some of the $\mathrm{Hg}^{0}$ in the flue gas to $\mathrm{Hg}^{2+}$, potentially making this mercury easier to capture in the downstream Turbosorp ${ }^{\circledR}$ system. On average, the mercury at the SCR outlet was about $90 \%$ oxidized. The air heater can contribute additional $\mathrm{Hg}$ oxidation. Mercury measurements were performed at the air heater outlet during the guarantee tests in March 2007 and the process performance tests in October 2007 and November 2007 using the Ontario Hydro Method. (Measurements were also performed at the air heater outlet during the March 2008 testing campaign, but particle-bound mercury concentrations were not determined for those tests). Mercury removal efficiencies computed from the air heater outlet to the stack agreed well with those measured from the coal to the stack, as shown in Figure 75 . However, mercury speciation measurements at the air heater outlet were affected by the aforementioned artifact by which fly ash collected on the sampling train filter adsorbs and/or oxidizes $\mathrm{Hg}$. This leads to artificially high particle-bound and/or oxidized mercury concentrations, and artificially low elemental and/or oxidized mercury concentrations. (The direction of the bias in the oxidized mercury results depends upon the extent to which mercury is adsorbed as opposed to oxidized by the fly ash). Table 29 shows the mercury speciation results at the air heater outlet and stack for the 16 tests in March-November 2007 that included simultaneous sampling at these 
locations. The particle-bound mercury at the air heater outlet, which averaged $53 \%$ of the total mercury at that location, was definitely biased high by adsorption of gas-phase mercury as it passed through the particulate on the sampling train filter. During the tests in October November 2007, the mercury concentration in the particulate catch from the sampling train (average $=0.86 \mathrm{ppm}$ ) was about three times as great as the mercury concentration in particulate samples collected by the plant's online fly ash sampler at the air heater outlet (average $=0.27 \mathrm{ppm}$ ). (Fly ash samples were not available at the air heater outlet during the March 2007 tests). The Turbosorp ${ }^{\circledR}$ system was very effective in removing oxidized mercury, given the greater-than $90 \%$ coal-to-stack removal efficiency observed during all of the $\mathrm{Hg}$ tests and the fact that at least $90 \%$ of the mercury going into the scrubber was present as $\mathrm{Hg}^{2+}$ or $\mathrm{Hg}^{\text {part }}$ (based on the results of the mercury speciation measurements at the SCR outlet). The data in Table 29 also suggest that the system removed elemental mercury. Given the nature of the sampling artifact at the air heater outlet, the $\mathrm{Hg}^{0}$ concentrations at that location were at least as great as the values reported in Table 29. Concentrations of $\mathrm{Hg}^{0}$ (expressed on a standard oxygen basis of $3 \%$ ) decreased across the Turbosorp ${ }^{\circledR}$ system for all 14 tests that had detectable concentrations at the air heater outlet. (Concentrations of $\mathrm{Hg}^{0}$ at the air heater outlet were below the detection limit for the first two tests on March 30, 2007). However, this finding must be interpreted cautiously in light of the low $\mathrm{Hg}^{0}$ concentrations observed at both the air heater outlet and stack and the possibility that even a small amount of measurement error could significantly impact results at these low concentrations.

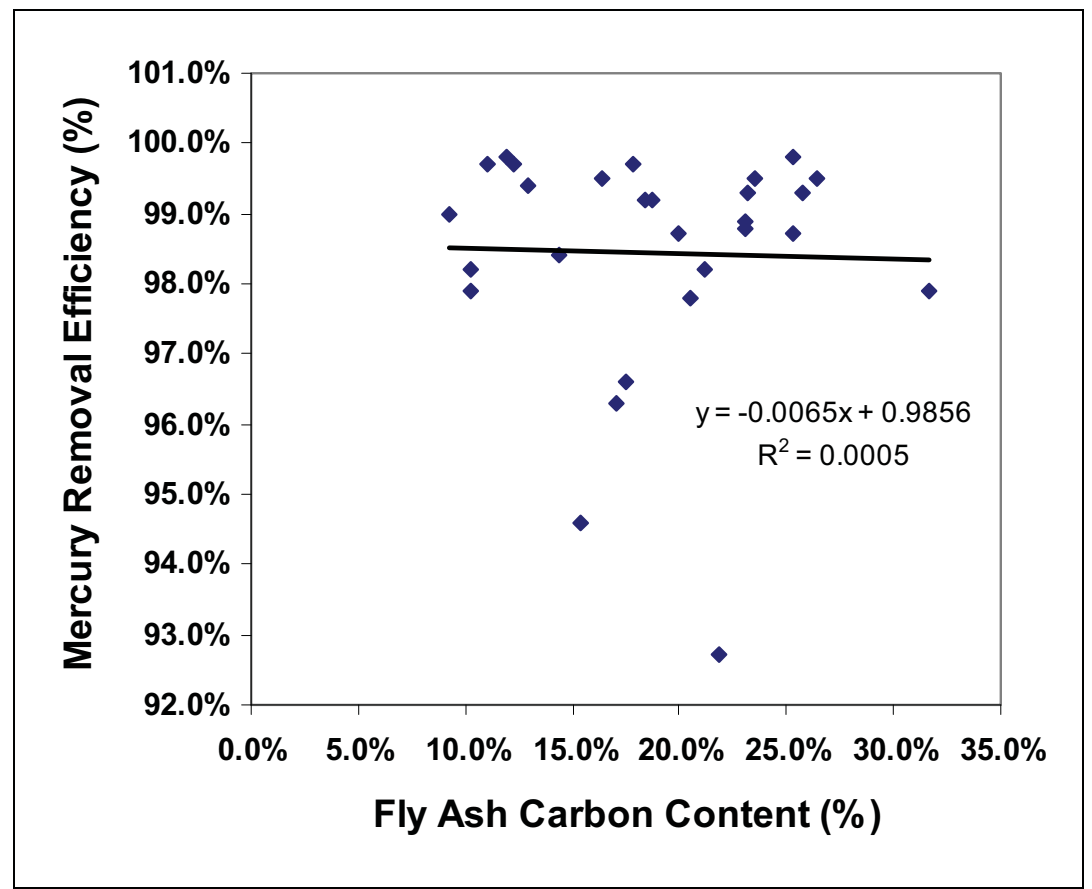

Figure 74. Scatter plot showing the coal-to-stack $\mathrm{Hg}$ removal efficiency vs. the carbon content of fly ash samples collected at the air heater outlet, with simple linear regression results. Data were collected during tests in October 2007-June 2008.

In addition to reducing $\mathrm{Hg}$ by $>90 \%$ on a coal-to-stack basis, the multi-pollutant control system at AES Greenidge Unit 4 achieved more than $90 \%$ mercury capture over and above the baseline removal efficiency that had been achieved prior to the project by the unit's ESP. As shown in Figure 76, during baseline testing at AES Greenidge in November 2004, mercury was reduced from an average of $9.82 \mathrm{lb} /$ TBtu in the coal to $6.89 \mathrm{lb} /$ TBtu at the stack, suggesting 
about $30 \%$ capture in the ESP. (As discussed in Section 9.2.1.3.5.3, the first test on November 17,2004 , was invalid, because it did not satisfy the quality control criterion for mercury material balance closure. That test is not included in the results shown in Figure 76). This $\mathrm{Hg}$ removal likely resulted from adsorption of some $\mathrm{Hg}$ onto unburned carbon in the fly ash, as discussed above, and its subsequent removal in the particulate collection device. The carbon content of the fly ash during the baseline tests averaged $12.4 \%$. In light of the baseline testing results, the $98 \% \mathrm{Hg}$ removal achieved by the multi-pollutant control system represents a $97 \%$ reduction from the mercury emissions that could be achieved prior to the project by the unit's existing ESP. (That is, for a given fuel, the mercury emission rate after installation of the multi-pollutant control system was about $97 \%$ less than the emission rate before installation of the system). Hence, the system succeeded in all respects from a mercury control perspective.

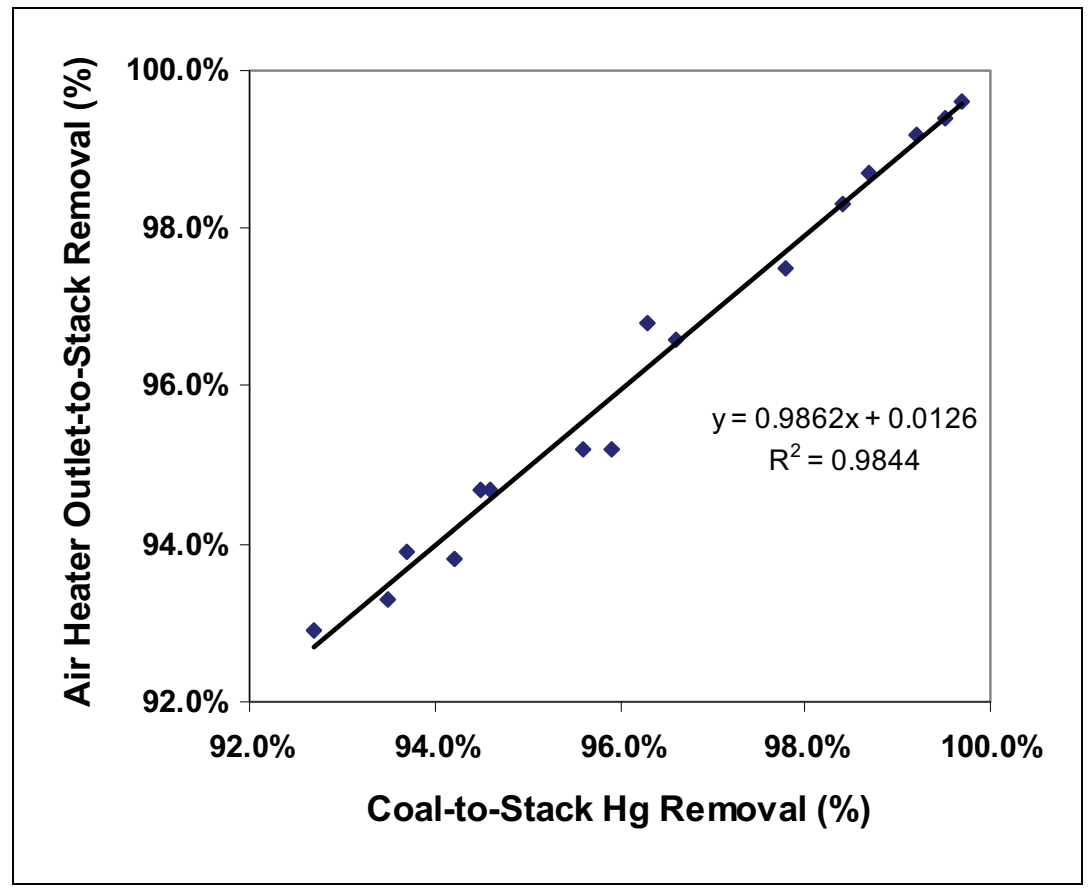

Figure 75. Scatter plot showing $\mathrm{Hg}$ removal efficiencies computed from $\mathrm{Hg}$ measurements at the air heater outlet and stack vs. $\mathrm{Hg}$ removal efficiencies computed from $\mathrm{Hg}$ measurements in the coal and at the stack. Measurements were conducted during tests in March, October, and November 2007.

\subsubsection{Sulfur Trioxide Removal Efficiency}

The Turbosorp ${ }^{\circledR}$ system demonstrated attainment of its performance target for sulfur trioxide removal efficiency during the Operation and Testing Phase of the project. A total of 42 valid $\mathrm{SO}_{3}$ tests, each including simultaneous sampling at the air heater outlet (upstream of the Turbosorp $^{\circledR}$ system) and stack (downstream of the Turbosorp ${ }^{\circledR}$ system) were completed at AES Greenidge Unit 4 between May 2007 and June 2008. (As discussed in Section 9.2.1.2.6, additional $\mathrm{SO}_{3}$ tests were performed on March 29, 2007, but those tests were invalid because of probable ammonia interference with the analytical results). Table 30 summarizes the results of these tests. On average, the Turbosorp ${ }^{\circledR}$ scrubber and baghouse reduced $\mathrm{SO}_{3}$ in the flue gas from 14.1 ppmvd @ 3\% $\mathrm{O}_{2}$ to 0.7 ppmvd @ 3\% $\mathrm{O}_{2}$, resulting in an overall removal efficiency of $95.3 \%$. This satisfied the performance target of $\geq 95 \%$ removal efficiency. 
Table 29. Mercury speciation determined as part of Ontario Hydro Method testing at the air heater outlet and stack in March, October, and November 2007. Speciation results at the air heater outlet were affected by a sampling artifact that leads to artificially high particlebound and/or oxidized mercury concentrations, and artificially low elemental and/or oxidized mercury concentrations.

\begin{tabular}{|c|c|c|c|c|c|c|}
\hline \multirow[b]{2}{*}{ Date/Time (local) } & \multicolumn{3}{|c|}{$\begin{array}{c}\text { Concentration at } \\
\text { Air Heater Outlet } \\
\left(\mu \mathrm{g} / \mathrm{dscm} @ 3 \% \mathrm{O}_{2}\right)\end{array}$} & \multicolumn{3}{|c|}{$\begin{array}{c}\text { Concentration at } \\
\text { Stack } \\
\left(\mu \mathrm{g} / \mathrm{dscm} @ 3 \% \mathrm{O}_{2}\right)\end{array}$} \\
\hline & $\mathrm{Hg}^{\text {part }}$ & $\mathrm{Hg}^{2+}$ & $\mathrm{Hg}^{0}$ & $\mathrm{Hg}^{\text {part }}$ & $\mathrm{Hg}^{2+}$ & $\mathrm{Hg}^{0}$ \\
\hline 3/28/2007 0905-1133 & 5.32 & 3.72 & 0.63 & $<0.00$ & $<0.21$ & $<0.25$ \\
\hline $3 / 28 / 2007$ 1243-1507 & 3.72 & 6.12 & 0.40 & $<0.00$ & $<0.23$ & $<0.25$ \\
\hline $3 / 28 / 2007$ 1558-1817 & 4.89 & 4.79 & 0.60 & $<0.00$ & $<0.27$ & $<0.26$ \\
\hline 3/30/2007 0855-1110 & 4.41 & 4.77 & $<0.41$ & $<0.00$ & $<0.30$ & $<0.29$ \\
\hline $3 / 30 / 2007$ 1243-1502 & 4.83 & 4.36 & $<0.43$ & $<0.00$ & $<0.30$ & $<0.29$ \\
\hline 3/30/2007 1552-1805 & 4.13 & 4.11 & 0.70 & $<0.00$ & $<0.32$ & $<0.28$ \\
\hline $10 / 2 / 2007$ 1505-1725 & 4.10 & 5.00 & 0.46 & 0.00 & 0.17 & 0.07 \\
\hline $10 / 3 / 2007$ 1230-1439 & 2.58 & 7.10 & 0.15 & 0.00 & 0.09 & 0.07 \\
\hline $10 / 3 / 2007$ 1555-1807 & 5.89 & 3.65 & 0.18 & 0.00 & 0.09 & 0.04 \\
\hline $10 / 5 / 20071110-1320$ & 6.56 & 3.95 & 0.16 & 0.00 & 0.67 & 0.08 \\
\hline $10 / 5 / 2007$ 1400-1642 & 5.43 & 4.14 & 0.25 & 0.00 & 0.29 & 0.05 \\
\hline $10 / 8 / 2007$ 1112-1307 & 4.55 & 6.18 & 0.12 & 0.04 & 0.49 & 0.04 \\
\hline $10 / 9 / 2007$ 1545-1640 & 5.99 & 5.57 & 0.14 & 0.00 & 0.26 & 0.10 \\
\hline $10 / 10 / 2007$ 1040-1245 & 7.76 & 3.95 & 0.11 & 0.00 & 0.07 & 0.02 \\
\hline $10 / 11 / 2007$ 1230-1435 & 8.59 & 3.12 & 0.12 & 0.00 & 0.05 & 0.01 \\
\hline $11 / 16 / 2007$ 1635-1855 & 14.00 & 5.64 & 0.33 & 0.00 & 0.04 & 0.02 \\
\hline
\end{tabular}

The performance guarantee for $\mathrm{SO}_{3}$ removal efficiency was officially satisfied on the basis of the three tests conducted on May 2, 2008. The average removal efficiency observed during those tests was $97.1 \%$. Similar performance was observed more than a year later during the followup tests on June 10-11, 2008, when the $\mathrm{SO}_{3}$ removal efficiency averaged $96.1 \%$. During both of these test series, the unit was operating near full load (105-109 $\mathrm{MW}_{\mathrm{g}}$ ); however, the coal sulfur content and $\mathrm{SO}_{3}$ concentration at the Turbosorp ${ }^{\circledR}$ inlet were greater during the guarantee tests than during the follow-up tests.

$\mathrm{SO}_{3}$ removal efficiencies measured during the process performance tests, which were conducted in October 2007 - June 2008, varied considerably. The minimum $\mathrm{SO}_{3}$ removal efficiency observed during these tests was $78.8 \%$, and the maximum $\mathrm{SO}_{3}$ removal efficiency was $99.4 \%$. Changes in $\mathrm{SO}_{3}$ removal efficiency hypothetically could result from changes in the performance of the Turbosorp ${ }^{\circledR}$ system. Scrubber operating conditions varied during the course of the process performance tests. For example, as shown in Table 30, the Turbosorp ${ }^{\circledR}$ outlet temperature ranged from $159^{\circ} \mathrm{F}$ to $170^{\circ} \mathrm{F}$. As discussed earlier, during the tests on October 811,2007 , and June 16-19, 2008, conditions in the Turbosorp ${ }^{\circledR}$ system were intentionally altered to determine their effect on its pollutant removal performance. However, no associations were discovered between scrubber operating conditions and $\mathrm{SO}_{3}$ removal efficiency. As shown in Figure 77, $\mathrm{SO}_{3}$ removal efficiency did not correlate with $\mathrm{SO}_{2}$ removal efficiency, which is expected to be a good surrogate for the overall performance of the Turbosorp ${ }^{\circledR}$ system. (During the Turbosorp ${ }^{\circledR}$ parametric tests on June 16-19, 2008, $\geq 95 \% \mathrm{SO}_{3}$ removal efficiency was observed for all four sets of scrubber operating conditions that were studied. However, contrary 
to expectation, the greatest $\mathrm{SO}_{3}$ removal efficiency was observed under the set of conditions that produced the lowest $\mathrm{SO}_{2}$ removal efficiency, and vice versa).

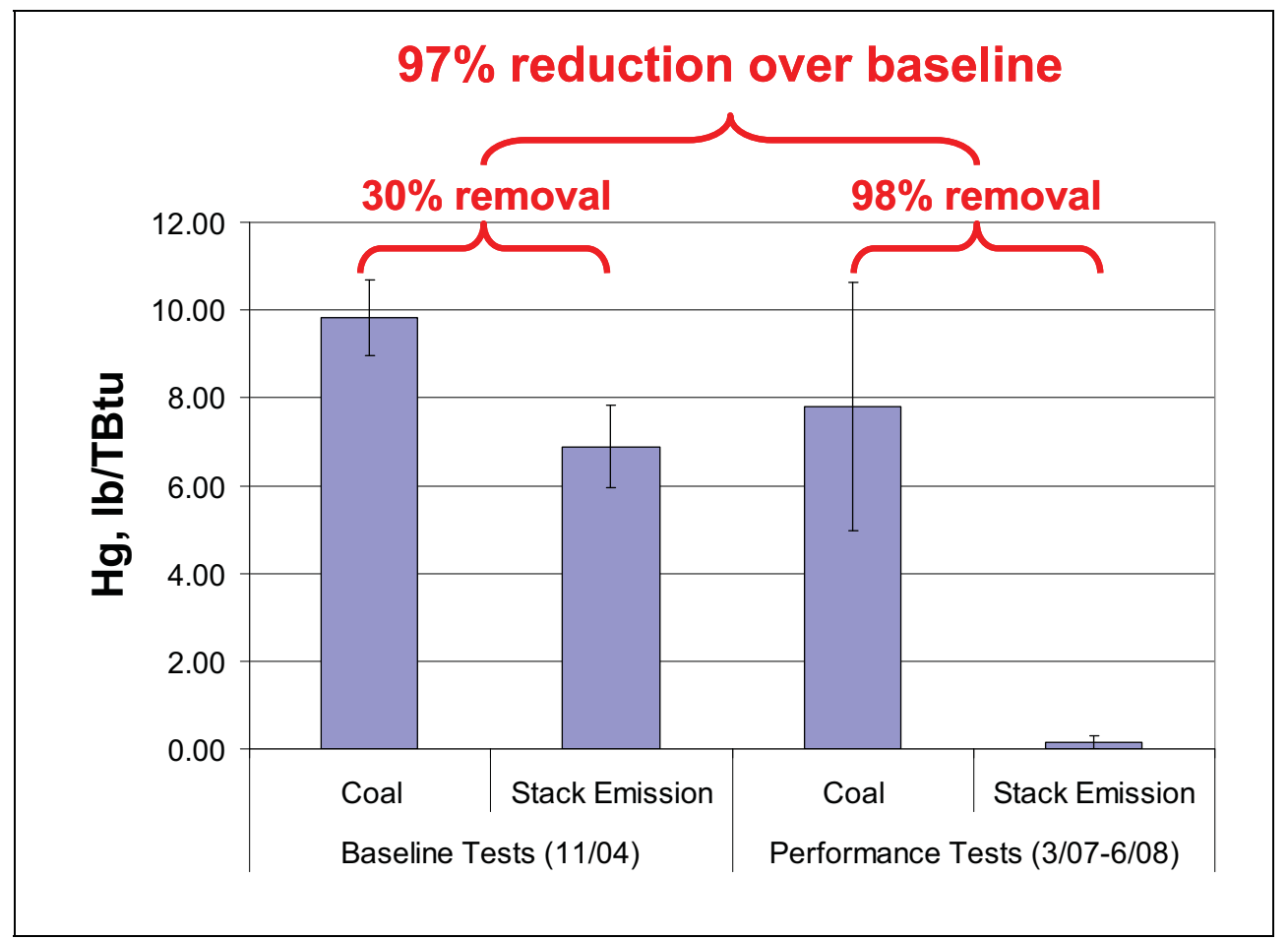

Figure 76. Comparison of the average coal-to-stack $\mathrm{Hg}$ removal efficiency observed during baseline testing in November 2004, prior to installation of the multi-pollutant control system, with the average removal efficiency observed during performance testing in March 2007-June 2008, after installation of the system. Error bars represent \pm 1 standard deviation.

It is more likely that the variation in $\mathrm{SO}_{3}$ removal efficiency resulted from changes in the $\mathrm{SO}_{3}$ concentrations at the inlet to the Turbosorp ${ }^{\circledR}$ system and from random error in the $\mathrm{SO}_{3}$ measurements at the stack. $\mathrm{SO}_{3}$ concentrations at the Turbosorp ${ }^{\circledR}$ inlet ranged from 4.7 to 28.7 ppmvd @ 3\% $\mathrm{O}_{2}$ during the course of the 42 tests shown in Table 30. Such variation can arise from a number of factors, including fluctuations in fuel sulfur content, boiler operating conditions, $\mathrm{SO}_{2}$-to- $\mathrm{SO}_{3}$ conversion across the SCR catalyst, and $\mathrm{SO}_{3}$ removal across the air heater (either by condensation of $\mathrm{SO}_{3}$ on the air heater baskets and its subsequent loss to the incoming combustion air, or by reaction of $\mathrm{SO}_{3}$ with ammonia slip to form ammonium bisulfate, as discussed in Section 9.3.4). As shown in Figure 78, there was some correlation between the $\mathrm{SO}_{3}$ removal efficiency and the $\mathrm{SO}_{3}$ concentration measured just upstream of the Turbosorp ${ }^{\circledR}$ system. Removal efficiencies of $<93 \%$ were only observed when the inlet $\mathrm{SO}_{3}$ concentration was relatively low $\left(<11\right.$ ppmvd @ $3 \% \mathrm{O}_{2}$ ). Demonstrating $\geq 95 \%$ removal efficiency from such a low starting concentration would require the ability to accurately measure very small concentrations of $\mathrm{SO}_{3}$ at the stack. For example, 95\% removal from an inlet concentration of 11 ppmvd gives a stack concentration of $0.55 \mathrm{ppmvd}$, and $95 \%$ removal from an inlet concentration of 4.7 ppmvd gives a stack concentration of 0.24 ppmvd (all concentrations expressed on a $3 \%$ $\mathrm{O}_{2}$ basis). These stack concentrations are near or below the detection limit for the controlled condensation method (0.15-1.5 ppm or more; Wiza, 2008). All 42 stack $\mathrm{SO}_{3}$ concentrations measured during the Operation and Testing Phase of the project were $\leq 1.7$ ppmvd @ $3 \% \mathrm{O}_{2}$, and 38 of the 42 stack concentrations were $\leq 1.0$ ppmvd @ 3\% $\mathrm{O}_{2}$. Hence, these measurements are expected to contain substantial random error, likely affecting the calculated 
$\mathrm{SO}_{3}$ removal efficiencies across the Turbosorp ${ }^{\circledR}$ system. Nevertheless, the $\mathrm{SO}_{3}$ measurements presented in Table 30 show that installation of the Turbosorp ${ }^{\circledR}$ system has resulted in very low $\mathrm{SO}_{3}$ emissions from AES Greenidge Unit 4.

Table 30. Results of $\mathrm{SO}_{3}$ tests performed around the Turbosorp ${ }^{\circledR}$ system at AES Greenidge Unit 4 during May 2007-June 2008. Relevant process conditions are also summarized.

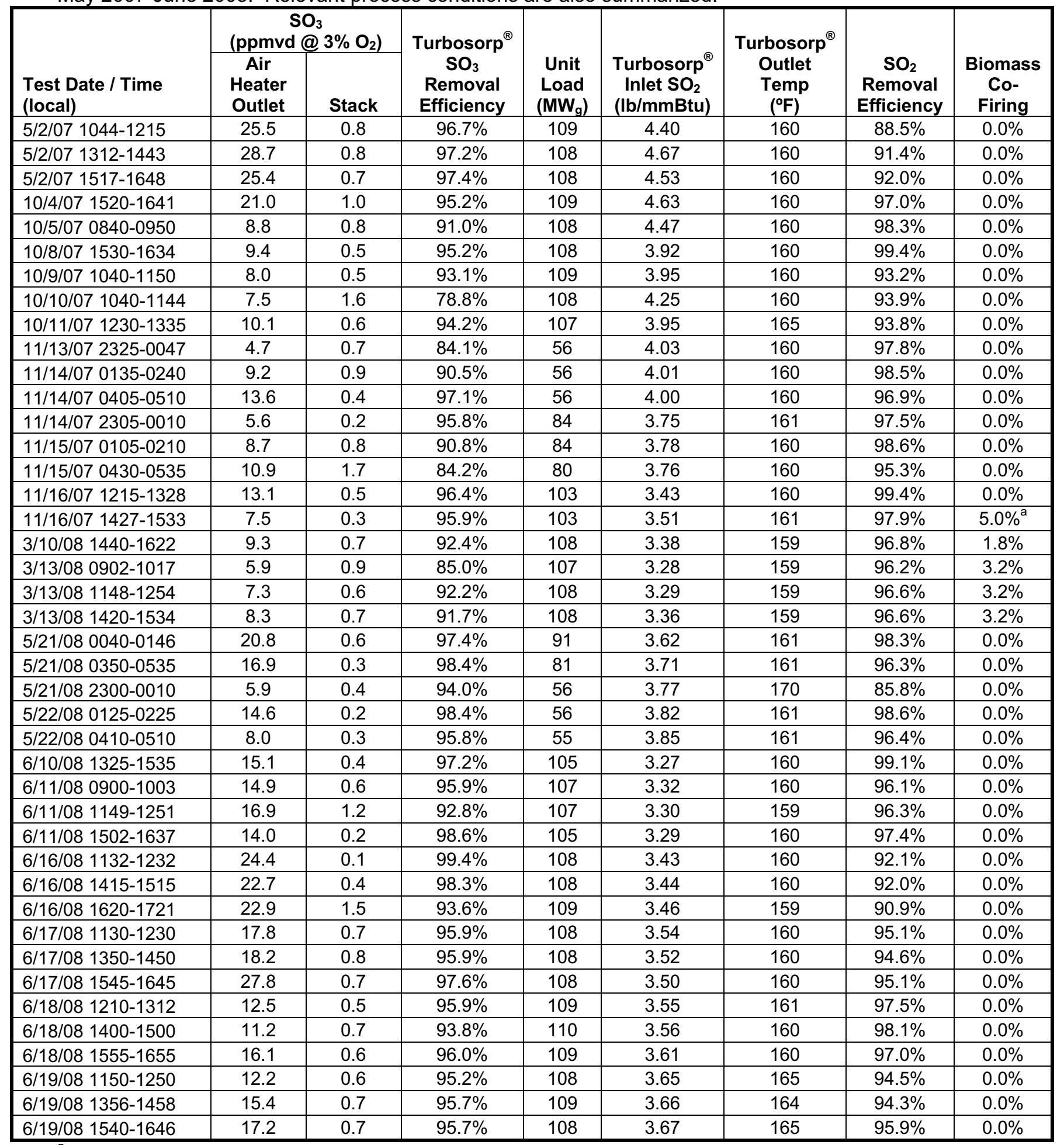

${ }^{\mathrm{a} A s s u m e d .}$ 


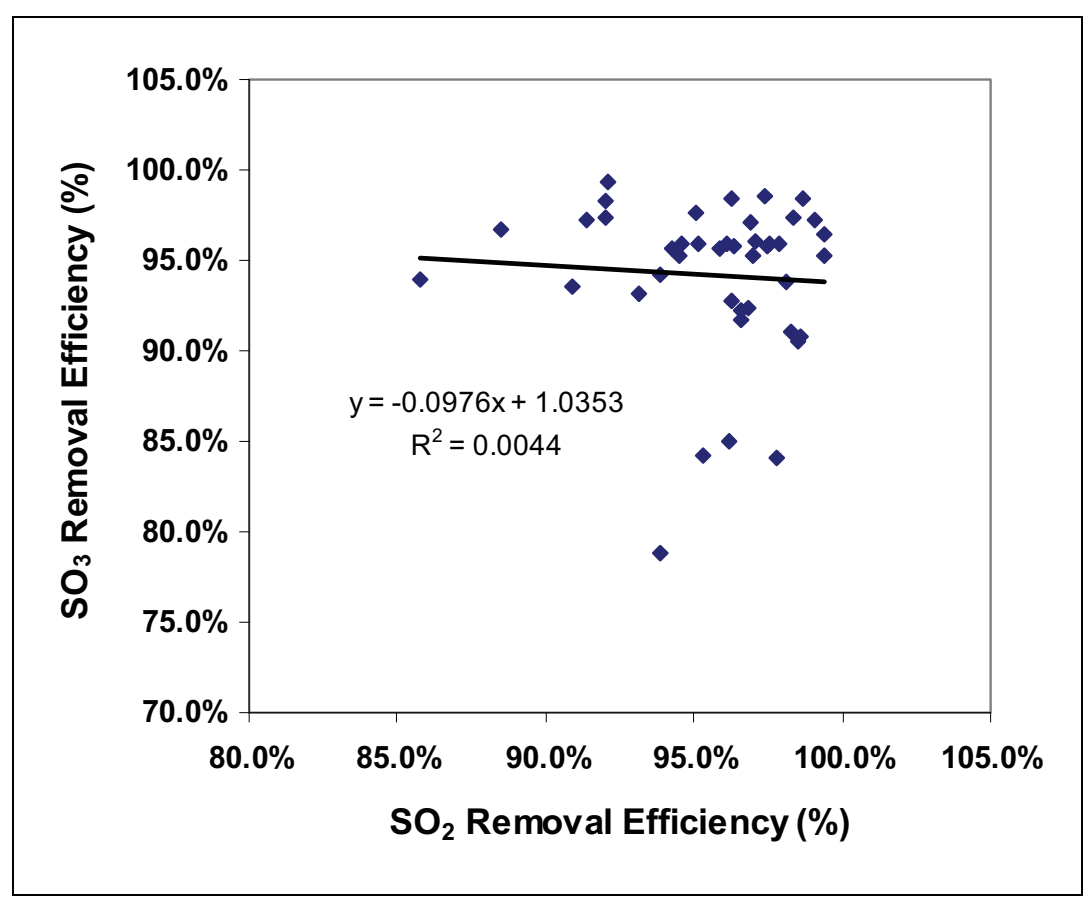

Figure 77. Scatter plot showing $\mathrm{SO}_{3}$ removal efficiencies vs. $\mathrm{SO}_{2}$ removal efficiencies observed across the Turbosorp ${ }^{\circledR}$ system during tests in May 2007 - June 2008, with simple linear regression results.

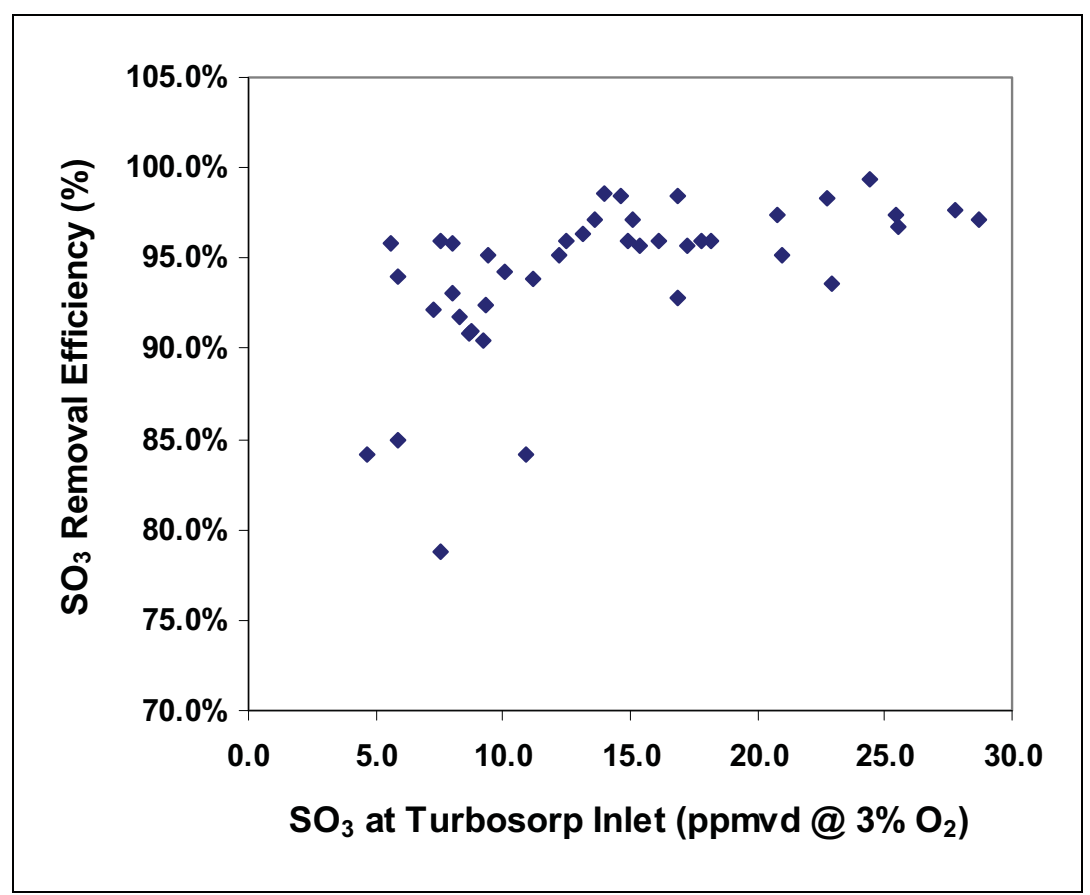

Figure 78. Scatter plot showing $\mathrm{SO}_{3}$ removal efficiencies across the Turbosorp ${ }^{\circledR}$ system vs. corresponding $\mathrm{SO}_{3}$ concentrations measured at the air heater outlet (Turbosorp ${ }^{\circledR}$ inlet) during tests in May 2007 June 2008. 


\subsubsection{Hydrogen Chloride Removal Efficiency}

The Turbosorp ${ }^{\circledR}$ system also demonstrated attainment of its performance target for hydrogen chloride removal efficiency during tests performed in 2007 and 2008 . Thirty valid $\mathrm{HCl}$ tests were completed at AES Greenidge Unit 4 between March 2007 and June 2008. (One additional test on March 29, 2007, was considered to be invalid because of chloride contamination in the sampling trains). Each test included simultaneous sampling at the air heater outlet (upstream of the Turbosorp ${ }^{\circledR}$ system) and stack (downstream of the Turbosorp ${ }^{\circledR}$ system). The results are summarized in Table 31. On average, the Turbosorp ${ }^{\circledR}$ scrubber and baghouse reduced $\mathrm{HCl}$ in the flue gas from 38.4 ppmvd @ $3 \% \mathrm{O}_{2}$ to 1.3 ppmvd @ $3 \% \mathrm{O}_{2}$, resulting in an overall removal efficiency of $96.7 \%$. This satisfied the performance target of $\geq 95 \% \mathrm{HCl}$ removal efficiency.

Table 31. Results of $\mathrm{HCl}$ tests performed around the Turbosorp ${ }^{\circledR}$ system at AES Greenidge Unit 4 during March 2007-June 2008. Relevant process conditions are also summarized.

\begin{tabular}{|c|c|c|c|c|c|c|c|c|}
\hline \multirow[b]{2}{*}{$\begin{array}{l}\text { Test Date / Time } \\
\text { (local) }\end{array}$} & \multicolumn{2}{|c|}{$\begin{array}{c}\mathrm{HCl} \\
\left(p p m v d @ 3 \% \mathrm{O}_{2}\right)\end{array}$} & \multirow{2}{*}{$\begin{array}{c}\text { Turbosorp }^{\circledR} \\
\text { HCI } \\
\text { Removal } \\
\text { Efficiency }\end{array}$} & \multirow[b]{2}{*}{$\begin{array}{l}\text { Unit } \\
\text { Load } \\
\left(\mathrm{MW}_{\mathrm{g}}\right)\end{array}$} & \multirow[b]{2}{*}{$\begin{array}{l}\text { Coal Cl } \\
\text { Content } \\
(\%, \text { dry) }\end{array}$} & \multirow{2}{*}{$\begin{array}{c}\text { Turbosorp }^{\circledR} \\
\text { Outlet } \\
\text { Temp } \\
\left({ }^{\circ} \mathrm{F}\right)\end{array}$} & \multirow[b]{2}{*}{$\begin{array}{c}\mathrm{SO}_{2} \\
\text { Removal } \\
\text { Efficiency }\end{array}$} & \multirow[b]{2}{*}{$\begin{array}{c}\text { Biomass } \\
\text { Co- } \\
\text { Firing }\end{array}$} \\
\hline & $\begin{array}{l}\text { Air } \\
\text { Heater } \\
\text { Outlet }\end{array}$ & Stack & & & & & & \\
\hline 03/29/07 1220-1344 & 36.0 & 2.8 & $92.4 \%$ & 107 & 0.073 & 163 & $95.2 \%$ & $0.0 \%$ \\
\hline 03/29/07 1515-1637 & 38.6 & 1.1 & $97.1 \%$ & 106 & 0.076 & 163 & $94.8 \%$ & $0.0 \%$ \\
\hline $05 / 04 / 07$ 0831-0940 & 40.4 & 1.3 & $96.8 \%$ & 107 & 0.066 & 161 & $95.9 \%$ & $0.0 \%$ \\
\hline $05 / 04 / 07$ 1015-1130 & 39.9 & 1.0 & $97.5 \%$ & 103 & 0.096 & 159 & $97.1 \%$ & $0.0 \%$ \\
\hline $10 / 04 / 07$ 1520-1637 & 32.7 & 2.2 & $93.2 \%$ & 109 & 0.069 & 161 & $97.1 \%$ & $0.0 \%$ \\
\hline $10 / 05 / 07$ 0840-0959 & 29.0 & 0.3 & $99.1 \%$ & 108 & 0.085 & 160 & $98.1 \%$ & $0.0 \%$ \\
\hline $10 / 08 / 07$ 1530-1640 & 33.8 & 2.6 & $92.2 \%$ & 108 & 0.090 & 160 & $99.4 \%$ & $0.0 \%$ \\
\hline $10 / 09 / 07$ 1040-1150 & 31.9 & 0.7 & $98.0 \%$ & 109 & 0.097 & 160 & $93.2 \%$ & $0.0 \%$ \\
\hline $10 / 10 / 07$ 1440-1553 & 33.2 & 1.4 & $95.9 \%$ & 109 & 0.089 & 160 & $94.1 \%$ & $0.0 \%$ \\
\hline $03 / 10 / 08$ 1443-1610 & 44.8 & 2.1 & $95.3 \%$ & 108 & 0.098 & 159 & $96.7 \%$ & $1.8 \%$ \\
\hline 03/13/08 0902-1042 & 39.0 & 1.3 & $96.6 \%$ & 107 & 0.100 & 159 & $96.3 \%$ & $3.2 \%$ \\
\hline $03 / 13 / 08$ 1147-1304 & 45.5 & 0.7 & $98.4 \%$ & 108 & 0.100 & 159 & $96.5 \%$ & $3.2 \%$ \\
\hline $03 / 13 / 08$ 1417-1533 & 48.6 & 0.7 & $98.5 \%$ & 108 & 0.100 & 159 & $96.7 \%$ & $3.2 \%$ \\
\hline $05 / 21 / 080044-0230$ & 40.9 & 2.4 & $94.1 \%$ & 89 & 0.085 & 161 & $98.8 \%$ & $0.0 \%$ \\
\hline $05 / 21 / 080350-0547$ & 41.3 & 1.6 & $96.2 \%$ & 81 & 0.085 & 161 & $96.3 \%$ & $0.0 \%$ \\
\hline $05 / 21 / 082300-0017$ & 35.4 & $<0.2$ & $>99.4 \%$ & 56 & 0.090 & 169 & $86.4 \%$ & $0.0 \%$ \\
\hline $05 / 22 / 08$ 0129-0250 & 26.1 & $<0.2$ & $>99.3 \%$ & 56 & 0.090 & 161 & $98.8 \%$ & $0.0 \%$ \\
\hline $05 / 22 / 080410-0527$ & 27.9 & 2.9 & $89.5 \%$ & 55 & 0.090 & 161 & $96.9 \%$ & $0.0 \%$ \\
\hline 06/10/08 1327-1528 & 37.5 & $<0.1$ & $>99.7 \%$ & 105 & 0.078 & 160 & $99.1 \%$ & $0.0 \%$ \\
\hline 06/11/08 0902-1025 & 41.6 & $<0.1$ & $>99.8 \%$ & 107 & 0.083 & 160 & $96.4 \%$ & $0.0 \%$ \\
\hline $06 / 11 / 08$ 1145-1300 & 42.4 & $<0.1$ & $>99.8 \%$ & 107 & 0.083 & 159 & $96.3 \%$ & $0.0 \%$ \\
\hline 06/11/08 1455-1610 & 40.3 & $<0.1$ & $>99.8 \%$ & 105 & 0.083 & 160 & $97.0 \%$ & $0.0 \%$ \\
\hline 06/16/08 1130-1250 & 44.1 & 4.0 & $91.0 \%$ & 108 & 0.098 & 160 & $92.3 \%$ & $0.0 \%$ \\
\hline $06 / 16 / 08$ 1415-1533 & 45.1 & 2.0 & $95.7 \%$ & 108 & 0.098 & 160 & $92.1 \%$ & $0.0 \%$ \\
\hline $06 / 17 / 08$ 1129-1242 & 45.2 & 1.4 & $97.0 \%$ & 108 & 0.085 & 160 & $95.1 \%$ & $0.0 \%$ \\
\hline $06 / 17 / 08$ 1349-1515 & 35.1 & 1.1 & $96.8 \%$ & 108 & 0.085 & 160 & $94.9 \%$ & $0.0 \%$ \\
\hline $06 / 18 / 08$ 1135-1242 & 37.8 & 1.7 & $95.5 \%$ & 108 & 0.083 & 160 & $97.0 \%$ & $0.0 \%$ \\
\hline $06 / 18 / 08$ 1350-1500 & 40.0 & 0.9 & $97.8 \%$ & 110 & 0.083 & 160 & $98.2 \%$ & $0.0 \%$ \\
\hline $06 / 19 / 08$ 1148-1255 & 39.0 & 0.7 & $98.2 \%$ & 108 & 0.100 & 165 & $94.5 \%$ & $0.0 \%$ \\
\hline 06/19/08 1450-1557 & 38.4 & 0.7 & $98.2 \%$ & 109 & 0.100 & 165 & $94.7 \%$ & $0.0 \%$ \\
\hline
\end{tabular}

The performance guarantee for $\mathrm{HCl}$ removal efficiency was officially satisfied on the basis of the four valid tests conducted on March 29 and May 4, 2008. The average removal efficiency observed during those tests was $96.0 \%$. Even better performance was observed more than a 
year later during the follow-up tests on June $10-11,2008$, when the $\mathrm{HCl}$ removal efficiency averaged $96.1 \%$. During both the guarantee tests and the follow-up tests, AES Greenidge Unit 4 operated at an average load of $106 \mathrm{MW}_{\mathrm{g}}$ and fired eastern U.S. bituminous coal containing about $0.08 \% \mathrm{w} / \mathrm{w} \mathrm{Cl}$.

$\mathrm{HCl}$ removal efficiency was measured across a variety of scrubber and unit operating conditions during process performance testing of the multi-pollutant control system in October 2007 - June 2008. During these tests, the unit load ranged from 55 to $110 \mathrm{MW}_{\mathrm{g}}$; the fuel $\mathrm{Cl}$ content ranged from 0.07 to $0.10 \%$; the Turbosorp ${ }^{\circledR}$ outlet temperature ranged from 159 to $169{ }^{\circ} \mathrm{F}$, and the $\mathrm{SO}_{2}$ removal efficiency across the Turbosorp ${ }^{\circledR}$ system ranged from 86.4 to $99.4 \%$. The average $\mathrm{HCl}$ removal efficiency measured during the process performance tests under these varying conditions was $96.2 \%$, about the same as the removal efficiency observed during guarantee testing. As with $\mathrm{SO}_{3}$ removal efficiency, $\mathrm{HCl}$ removal efficiency showed no apparent association with scrubber operating conditions and did not correlate with $\mathrm{SO}_{2}$ removal efficiency (Figure 79). Moreover, as shown in Figure $80, \mathrm{HCl}$ removal efficiency did not correlate with $\mathrm{SO}_{3}$ removal efficiency, based on the results of 24 tests during which $\mathrm{SO}_{3}$ sampling was conducted simultaneously with $\mathrm{HCl}$ sampling.

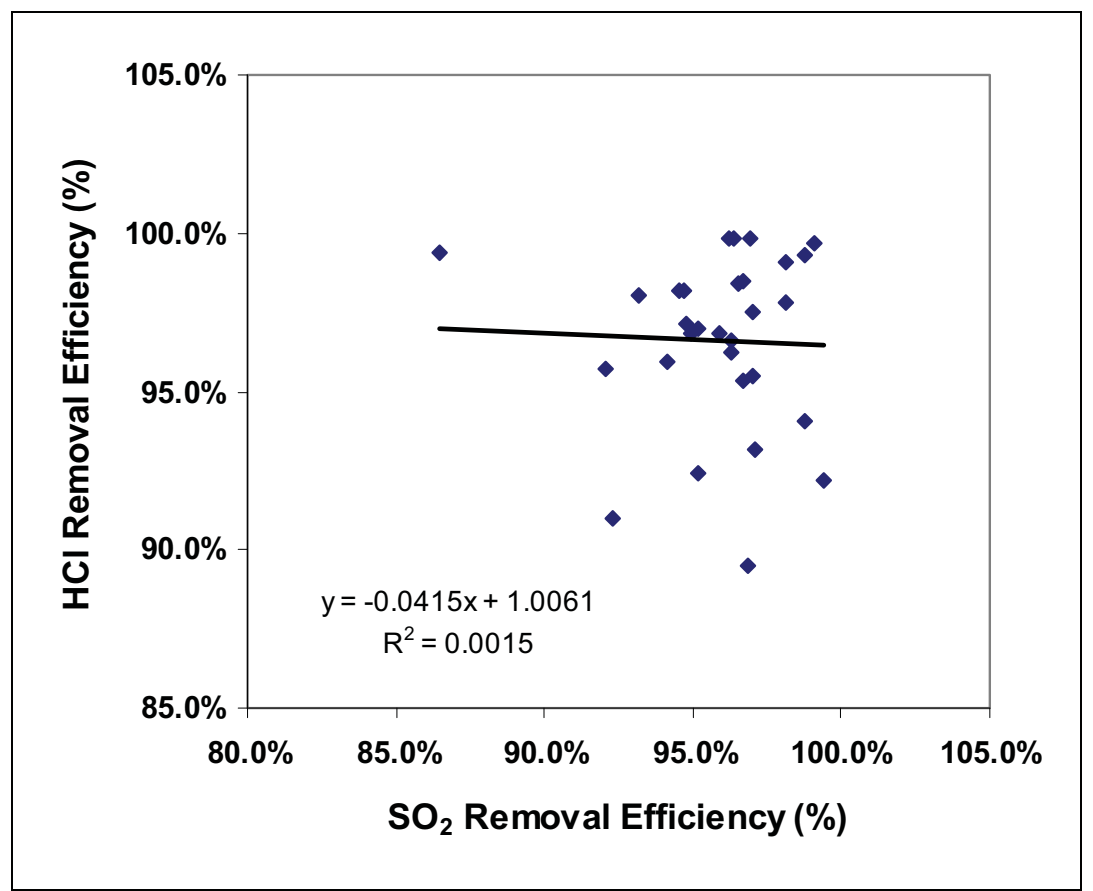

Figure 79. Scatter plot showing $\mathrm{HCl}$ removal efficiencies vs. $\mathrm{SO}_{2}$ removal efficiencies observed across the Turbosorp ${ }^{\circledR}$ system during tests in March 2007 - June 2008, with simple linear regression results.

$\mathrm{HCl}$ removal efficiencies ranged from $89.5 \%$ to $99.8 \%$ during the 30 tests reported in Table 31 . Given the lack of an association with scrubber operating conditions, the variability in these removal efficiencies likely resulted from measurement error at the stack. In some cases, the same sampling train components that were used for Ontario Hydro Method sampling, which utilizes an $\mathrm{HCl}$ rinse, had to be used for subsequent $\mathrm{HCl}$ sampling. Although the components were thoroughly rinsed, it was difficult to avoid a small amount of chloride contamination. While this background concentration is insignificant at the relatively large flue gas $\mathrm{HCl}$ concentrations (26-49 ppmvd @ 3\% $\mathrm{O}_{2}$ ) observed at the air heater outlet, it can introduce significant error (on a 
percentage basis) at the low flue gas concentrations $\left(0.1-4\right.$ ppmvd @ 3\% $\left.\mathrm{O}_{2}\right)$ encountered at the stack. The coefficient of variation (mean $\div$ standard deviation, expressed as a percentage), which provides a metric for quantifying the variability of data, was $77.5 \%$ for the $30 \mathrm{HCl}$ concentration measurements at the stack, versus only $14.3 \%$ for the $30 \mathrm{HCl}$ concentration measurements at the air heater outlet. (For comparison, the coefficient of variation for the 42 $\mathrm{SO}_{3}$ concentrations measured at the stack was $52.8 \%$, and the coefficient of variation for the 42 $\mathrm{SO}_{3}$ concentrations measured at the air heater outlet was $46.5 \%$ ). During several tests, the probe and line rinses at the air heater outlet and stack were checked for the presence of residual chloride by precipitation with silver nitrate. In general, several additional rinses were required to reduce the chloride concentration below a detectable level, indicating low-level contamination. A small amount of chloride background would be expected to cause a slight downward bias in the removal efficiencies reported in Table 31. Such bias would not detract from the conclusion that the Turbosorp ${ }^{\circledR}$ system attained its performance target for $\mathrm{HCl}$ removal efficiency.

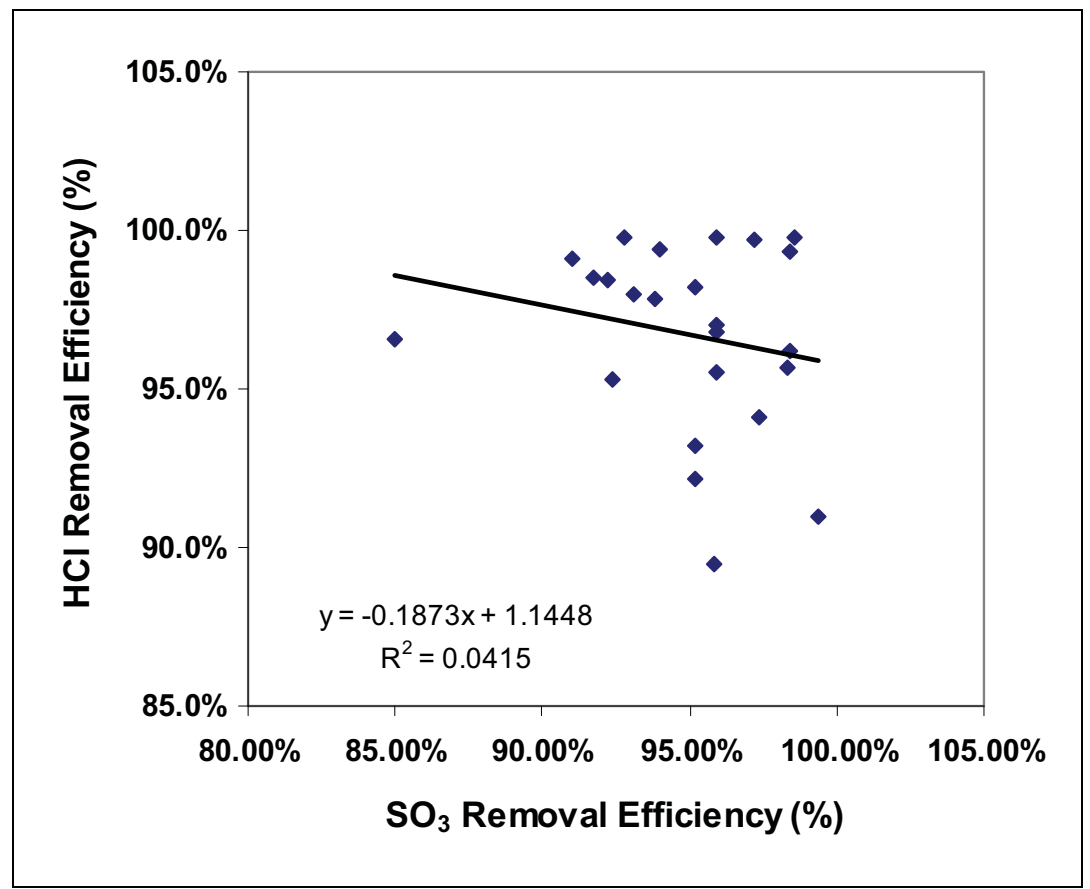

Figure 80. Scatter plot showing $\mathrm{HCl}$ removal efficiencies vs. $\mathrm{SO}_{3}$ removal efficiencies observed across the Turbosorp ${ }^{\circledR}$ system during tests in March 2007 - June 2008, with simple linear regression results.

It is also noteworthy that the amount of $\mathrm{HCl}$ measured at the air heater outlet was less than the amount that would be expected under the assumption that all of the coal chlorine forms $\mathrm{HCl}$. Based on the coal feed rate and chlorine content measured during the 30 valid $\mathrm{HCl}$ tests, about $63.9 \mathrm{lb} / \mathrm{h}$ of $\mathrm{HCl}$ would be anticipated at the air heater outlet, on average, under this assumption. However, the flue gas measurements at the air heater outlet indicated an average of just 38.6 $\mathrm{lb} / \mathrm{h}$ of $\mathrm{HCl}$. Fly ash samples were collected at the air heater outlet during 25 of the 30 tests and analyzed for $\mathrm{Cl}$; these samples accounted for only $1.3 \mathrm{lb} / \mathrm{h}$ of the additional $25 \mathrm{lb} / \mathrm{h}$ of expected $\mathrm{HCl}$. The bottom ash contained even less $\mathrm{Cl}(\mathrm{lb} / \mathrm{h})$ than the fly ash, based on five samples collected between October 2007 and June 2008. (A similar, but smaller, bias was observed during the baseline tests in November 2004, prior to installation of the multi-pollutant control system. During those tests, the average $\mathrm{HCl}$ emission rate at the stack was $61 \mathrm{lb} / \mathrm{h}$, and the 
$\mathrm{HCl}$ emission rate predicted from the coal feed rate and chlorine content was $72 \mathrm{lb} / \mathrm{h}$. Again, the amount of $\mathrm{Cl}$ in the ESP ash and bottom ash was insufficient to account for the $11 \mathrm{lb} / \mathrm{h}$ discrepancy). The reason for the inconsistency between the coal chlorine and the $\mathrm{HCl}$ measured at the air heater outlet is unknown. Such an inconsistency could result if gaseous $\mathrm{Cl}$ was present in a form other than $\mathrm{HCl}\left(\right.$ e.g., $\left.\mathrm{Cl}_{2}\right)$ at the air heater outlet, if $\mathrm{Cl}$ was accumulating somewhere in the system, or if the measurements at the air heater outlet were biased (e.g., because of failure to collect a representative flue gas or fly ash sample). The second potential cause (accumulation of $\mathrm{Cl}$ ) is improbable. The first potential cause would not impact that data presented in Table 31. In the case of the third potential cause, assuming that the stack $\mathrm{HCl}$ measurements were not subject to a similar bias, the $\mathrm{HCl}$ removal efficiency across the Turbosorp ${ }^{\circledR}$ system would be at least as great as the values reported in Table 31 (and possibly greater if the bias was present in the flue gas $\mathrm{HCl}$ concentration measurements rather than in the fly ash measurements).

\subsubsection{Hydrogen Fluoride Removal Efficiency}

As discussed in Section 2.4, the Greenidge Project sought to demonstrate $\geq 95 \%$ removal of hydrogen fluoride across the Turbosorp ${ }^{\circledR}$ system. However, the HF tests conducted as part of the Operation and Testing Phase of the project were inconclusive with respect to this performance target. Table 32 summarizes the results of the $31 \mathrm{HF}$ tests that were completed at AES Greenidge Unit 4 between March 2007 and June 2008. Each test included simultaneous sampling at the air heater outlet (upstream of the Turbosorp ${ }^{\circledR}$ system) and stack (downstream of the Turbosorp ${ }^{\circledR}$ system). (As discussed in Section 9.2.1.2.7, $\mathrm{HF}$ and $\mathrm{HCl}$ were determined from a common sampling train by U.S. EPA Method 26A). For 30 of the 31 tests, the HF concentration determined in the flue gas at the stack was below the detection limit. However, all HF concentrations measured at the air heater outlet were also near or below the detection limit. HF was detectable at the air heater outlet during 15 tests. HF concentrations during these tests averaged 1.07 ppmvd @ 3\% $\mathrm{O}_{2}$ at the air heater outlet and $<0.18$ ppmvd @ 3\% $\mathrm{O}_{2}$ at the stack, resulting in an average removal efficiency of $>83.5 \%$ across the Turbosorp ${ }^{\circledR}$ system. The greatest removal efficiency observed during a single test was $>91.8 \%$. (Because of the low concentration upstream of the Turbosorp ${ }^{\circledR}$ system and the limitation imposed by the method detection limit at the stack, it was impossible to demonstrate 95\% HF removal efficiency). During the remaining 16 tests, the HF concentration at the air heater outlet was below the method detection limit, precluding the calculation of a removal efficiency. Hence, the HF removal performance of the Turbosorp ${ }^{\circledR}$ system was indeterminate.

The amount of HF measured at the air heater outlet was appreciably less than the amount expected from the coal fluorine content. As shown in Table 32, if it is assumed that all of the coal fluorine forms HF, then about 3.5 to $5.4 \mathrm{lb} / \mathrm{h}$ of HF would be anticipated upstream of the Turbosorp ${ }^{\circledR}$ system. However, HF mass flow rates determined at the air heater outlet during the tests in March 2007 through May 2008 averaged $<10 \%$ of the expected amount, ranging from $<0.12 \mathrm{lb} / \mathrm{h}$ to $1.2 \mathrm{lb} / \mathrm{h}$. This discrepancy is similar to the one described in Section 9.3.10 between the coal chlorine content and the $\mathrm{HCl}$ measured at the air heater outlet. Again, the cause of the discrepancy is unknown. Possible causes include measurement error or the presence of gas-phase fluorine in a form other than HF. In addition to the coal and flue gas measurements, fluorine concentrations were determined in fly ash and Turbosorp ${ }^{\circledR}$ product ash samples collected during 20 of the $31 \mathrm{HF}$ tests. All of these tests were conducted while the unit was operating near full load (i.e., 105-110 $\mathrm{MW}_{\mathrm{g}}$ ). On average during these 20 tests, the HF measured in the flue gas at the air heater outlet accounted for $<11.2 \%$ of the fluorine fed with 
the coal, and the fluorine in the fly ash at that location accounted for an additional $8.5 \%$, leaving an $80.3 \%$ gap in the material balance closure. Moreover, the sum of the mass flow rates of fluorine in the product ash and stack flue gas (from HF) was more than twice as great as the mass flow rate of fluorine at the air heater outlet (from HF and fly ash), but only about half as much as the mass flow rate of fluorine in the coal. (In the absence of actual product ash flow rate measurements, the design flow rate of $17,850 \mathrm{lb} / \mathrm{h}$ was assumed for the purpose of this comparison). These disparities indicate substantial uncertainty in the HF testing results.

Table 32. Results of HF tests performed around the Turbosorp ${ }^{\circledR}$ system at AES Greenidge Unit 4 during March 2007-June 2008.

\begin{tabular}{|c|c|c|c|c|c|c|c|}
\hline \multirow[b]{2}{*}{$\begin{array}{l}\text { Test Date / Time } \\
\text { (local) }\end{array}$} & \multicolumn{2}{|c|}{$\begin{array}{c}\text { HF } \\
\text { (ppmvd @ 3\% O O })\end{array}$} & \multirow{2}{*}{$\begin{array}{c}\text { Turbosorp }^{\circledR} \\
\text { HF Removal } \\
\text { Efficiency }\end{array}$} & \multirow[b]{2}{*}{$\begin{array}{l}\text { Unit } \\
\text { Load } \\
\left(\mathrm{MW}_{\mathrm{g}}\right)\end{array}$} & \multirow{2}{*}{$\begin{array}{c}\text { Coal F } \\
\text { Content } \\
\text { (ppm, } \\
\text { dry) }\end{array}$} & \multirow{2}{*}{$\begin{array}{l}\text { HF Mass } \\
\text { Flow } \\
\text { Predicted } \\
\text { from Coal } \\
\text { (lb/h) }\end{array}$} & \multirow{2}{*}{$\begin{array}{c}\text { HF Mass } \\
\text { Flow at } \\
\text { Air Heater } \\
\text { Outlet } \\
(\mathrm{lb} / \mathrm{h})\end{array}$} \\
\hline & $\begin{array}{l}\text { Heater } \\
\text { Outlet }\end{array}$ & Stack & & & & & \\
\hline $3 / 29 / 07$ 1000-1125 & $<0.34$ & $<0.20$ & Indeterminate & 105 & 63.51 & 5.08 & $<0.21$ \\
\hline $3 / 29 / 07$ 1220-1344 & $<0.34$ & $<0.23$ & Indeterminate & 107 & 63.83 & 5.09 & $<0.21$ \\
\hline $3 / 29 / 07$ 1515-1637 & $<0.35$ & $<0.21$ & Indeterminate & 106 & 66.23 & 5.29 & $<0.21$ \\
\hline $5 / 4 / 07$ 0831-0940 & $<0.25$ & $<0.16$ & Indeterminate & 107 & & & $<0.14$ \\
\hline $5 / 4 / 07$ 1015-1130 & $<0.21$ & $<0.16$ & Indeterminate & 103 & & & $<0.12$ \\
\hline $10 / 4 / 07$ 1520-1637 & 1.31 & $<0.17$ & $>87.0 \%$ & 109 & 54.10 & 4.35 & 0.87 \\
\hline 10/5/07 0840-0959 & 1.23 & $<0.15$ & $>87.8 \%$ & 108 & 53.60 & 4.30 & 0.77 \\
\hline $10 / 8 / 07$ 1530-1640 & 0.87 & $<0.16$ & $>81.6 \%$ & 108 & 59.10 & 4.75 & 0.50 \\
\hline 10/9/07 1040-1150 & 1.05 & $<0.17$ & $>83.8 \%$ & 109 & 55.70 & 4.53 & 0.63 \\
\hline 10/10/07 1440-1553 & 1.55 & $<0.15$ & $>90.3 \%$ & 109 & 48.50 & 3.93 & 0.92 \\
\hline $3 / 10 / 08$ 1443-1610 & 1.87 & $<0.19$ & $>89.8 \%$ & 108 & 69.03 & 5.39 & 1.09 \\
\hline 3/13/08 0902-1042 & 1.16 & $<0.15$ & $>87.1 \%$ & 107 & 67.58 & 5.20 & 0.68 \\
\hline $3 / 13 / 08$ 1147-1304 & 1.95 & $<0.17$ & $>91.3 \%$ & 108 & 67.58 & 5.20 & 1.13 \\
\hline $3 / 13 / 08$ 1417-1533 & 2.07 & $<0.17$ & $>91.8 \%$ & 108 & 67.58 & 5.23 & 1.20 \\
\hline $5 / 21 / 080044-0230$ & 0.97 & $<0.38$ & $>60.8 \%$ & 89 & 74.45 & 4.89 & 0.41 \\
\hline $5 / 21 / 080350-0547$ & 0.48 & $<0.24$ & $>50.0 \%$ & 81 & 74.45 & 4.62 & 0.21 \\
\hline $5 / 21 / 082300-0017$ & $<0.72$ & $<0.35$ & Indeterminate & 56 & 82.15 & 3.68 & $<0.22$ \\
\hline $5 / 22 / 08$ 0129-0250 & $<0.66$ & 0.41 & Indeterminate & 56 & 82.15 & 3.70 & $<0.21$ \\
\hline $5 / 22 / 08$ 0410-0527 & $<0.56$ & $<0.34$ & Indeterminate & 55 & 82.15 & 3.72 & $<0.18$ \\
\hline $6 / 10 / 08$ 1327-1528 & $<0.44$ & $<0.20$ & Indeterminate & 105 & 42.20 & 3.24 & $<0.24$ \\
\hline $6 / 11 / 08$ 0902-1025 & $<0.28$ & $<0.17$ & Indeterminate & 107 & 42.35 & 3.31 & $<0.16$ \\
\hline $6 / 11 / 08$ 1145-1300 & $<0.26$ & $<0.17$ & Indeterminate & 107 & 42.35 & 3.30 & $<0.14$ \\
\hline $6 / 11 / 08$ 1455-1610 & $<0.26$ & $<0.19$ & Indeterminate & 105 & 42.35 & 3.30 & $<0.15$ \\
\hline $6 / 16 / 08$ 1130-1250 & $<0.27$ & $<0.18$ & Indeterminate & 108 & 50.75 & 4.04 & $<0.16$ \\
\hline $6 / 16 / 08$ 1415-1533 & 0.42 & $<0.14$ & $>66.7 \%$ & 108 & 50.75 & 4.02 & 0.24 \\
\hline $6 / 17 / 08$ 1129-1242 & 0.47 & $<0.13$ & $>72.3 \%$ & 108 & 44.60 & 3.55 & 0.28 \\
\hline $6 / 17 / 08$ 1349-1515 & 0.37 & $<0.15$ & $>59.5 \%$ & 108 & 44.60 & 3.51 & 0.22 \\
\hline $6 / 18 / 08$ 1135-1242 & 0.31 & $<0.13$ & $>58.1 \%$ & 108 & 45.85 & 3.66 & 0.18 \\
\hline $6 / 18 / 08$ 1350-1500 & $<0.32$ & $<0.14$ & Indeterminate & 110 & 45.85 & 3.66 & $<0.19$ \\
\hline 6/19/08 1148-1255 & $<0.33$ & $<0.12$ & Indeterminate & 108 & 48.65 & 3.91 & $<0.19$ \\
\hline $6 / 19 / 08$ 1450-1557 & $<0.23$ & $<0.15$ & Indeterminate & 109 & 48.65 & 3.87 & $<0.13$ \\
\hline
\end{tabular}

\subsubsection{Particulate Matter Emissions}

Installation of the Turbosorp ${ }^{\circledR}$ system, including a new baghouse, at AES Greenidge Unit 4 resulted in a substantial reduction in primary (non-condensable) particulate matter emissions from the unit. 
As discussed earlier, prior to the installation of the multi-pollutant control system, an electrostatic precipitator was used to control PM emissions from Unit 4. The particulate matter emission rate achieved by the ESP was characterized during baseline testing in November 2004. As shown in Figure 81, the average emission rate observed during two valid tests conducted using U.S. EPA Method 5 was $0.063 \mathrm{lb} / \mathrm{mmBtu}$. (A third test was performed using Method 5 on November 17, 2004. However, an unusually high grain loading was observed for that test, and the sample filter contained a large amount of very coarse, carbon-like particulate matter that was not present during any of the other baseline tests at the stack. Hence, the results of the test were considered to be invalid).

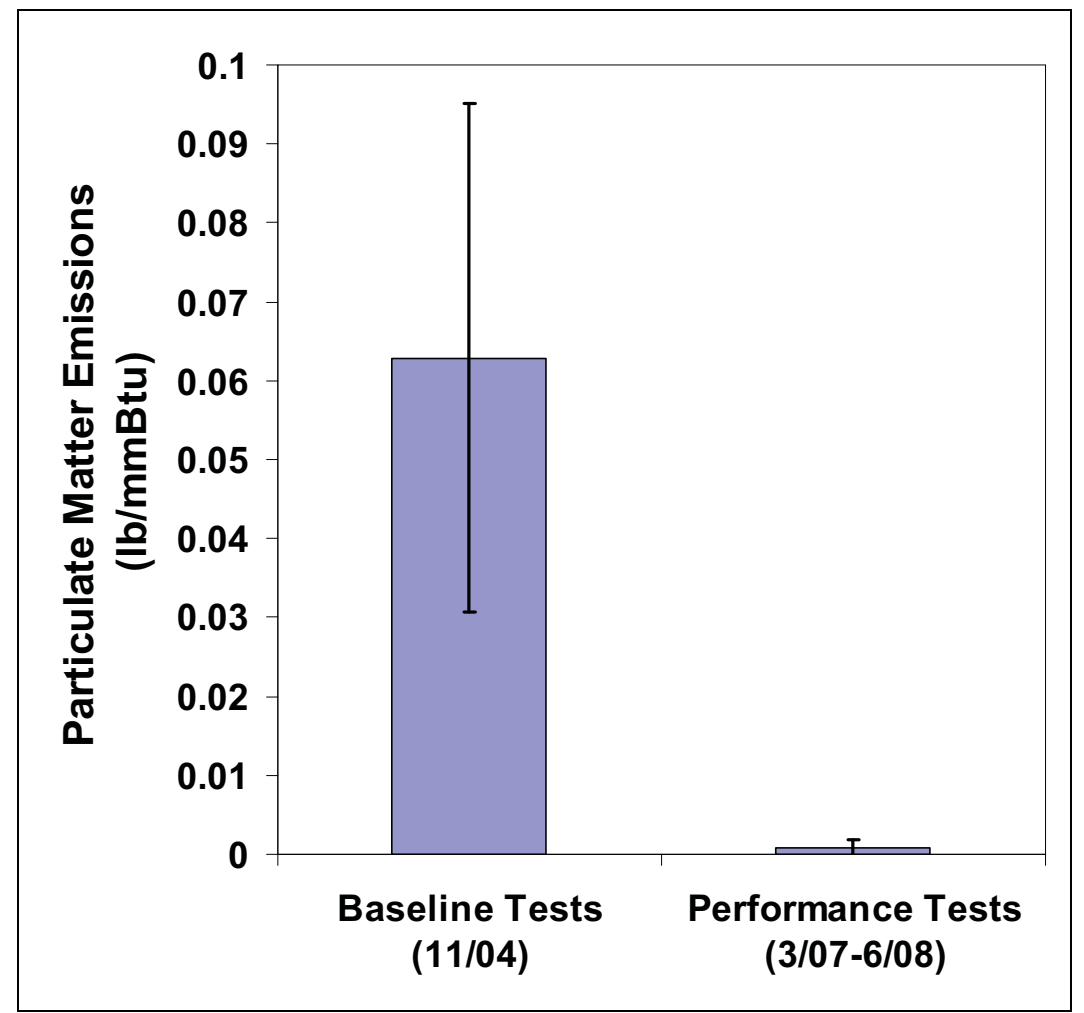

Figure 81. Summary of mean primary particulate matter emission rates measured at the AES Greenidge Unit 4 stack before and after installation of the multi-pollutant control system. The baseline testing emission rate is based on two measurements made using U.S. EPA Method 5 in November 2004. The performance testing emission rate is based on 59 measurements made using U.S. EPA Method 17 in March 2007 - June 2008. Error bars represent \pm 1 standard deviation.

Following the installation of the multi-pollutant control system, particulate matter emission rates were determined as part of all of the tests conducted at the stack using the Ontario Hydro Method or U.S. EPA Method 26A. (In both methods, sampling was performed using a U.S. EPA Method 17 configuration for the particulate matter determination). Fifty-eight valid PM measurements were completed between March 2007 and June 2008. (One additional measurement on October 5, 2007, was invalid because the particle filter broke during sampling). The average PM emission rate ascertained from these measurements was $<0.001 \mathrm{lb} / \mathrm{mmBtu}$, as shown in Figure 81. This represents a more-than $98 \%$ reduction over the PM emission rate observed during baseline testing. The improvement in PM emissions occurred in spite of the 
substantial increase in flue gas particulate loading brought about by the hydrated lime, reaction products, and high solids recycle rate in the Turbosorp ${ }^{\circledR}$ system. (No PM measurements were performed between the Turbosorp ${ }^{\circledR}$ absorber vessel and baghouse. However, design calculations projected that the Turbosorp ${ }^{\circledR}$ system would increase the particulate loading from 2 $\mathrm{gr} / \mathrm{dscf}$ at the absorber vessel inlet to $244 \mathrm{gr} / \mathrm{dscf}$ at the baghouse inlet). It resulted largely from the superior performance of the baghouse relative to the unit's old electrostatic precipitator. Particle agglomeration in the fluidized bed absorber may also have contributed to the improved PM capture efficiency, although no tests were performed to confirm or refute this hypothesis.

A number of the particulate matter tests included simultaneous sampling at the air heater outlet and stack. (In several cases, the Ontario Hydro Method sampling train at the air heater outlet was altered such that it did not enable a valid particulate matter measurement). These tests produced 43 pairs of valid PM measurements upstream and downstream of the Turbosorp ${ }^{\circledR}$ system. The results are summarized in Figure 82 (notice the logarithmic y-axis scale). On average, the PM rate was reduced from $5.81 \mathrm{lb} / \mathrm{mmBtu}$ at the air heater outlet to $<0.001$ $\mathrm{lb} / \mathrm{mmBtu}$ at the stack, indicating $>99.9 \%$ removal efficiency across the Turbosorp ${ }^{\circledR}$ system. (Again, the actual removal efficiency across the baghouse was even greater than this, given the substantial increase in particle loading across the fluidized bed absorber). Hence, the Greenidge Project demonstrated that the Turbosorp ${ }^{\circledR}$ system, when installed with a new baghouse, is a highly effective particulate control device.

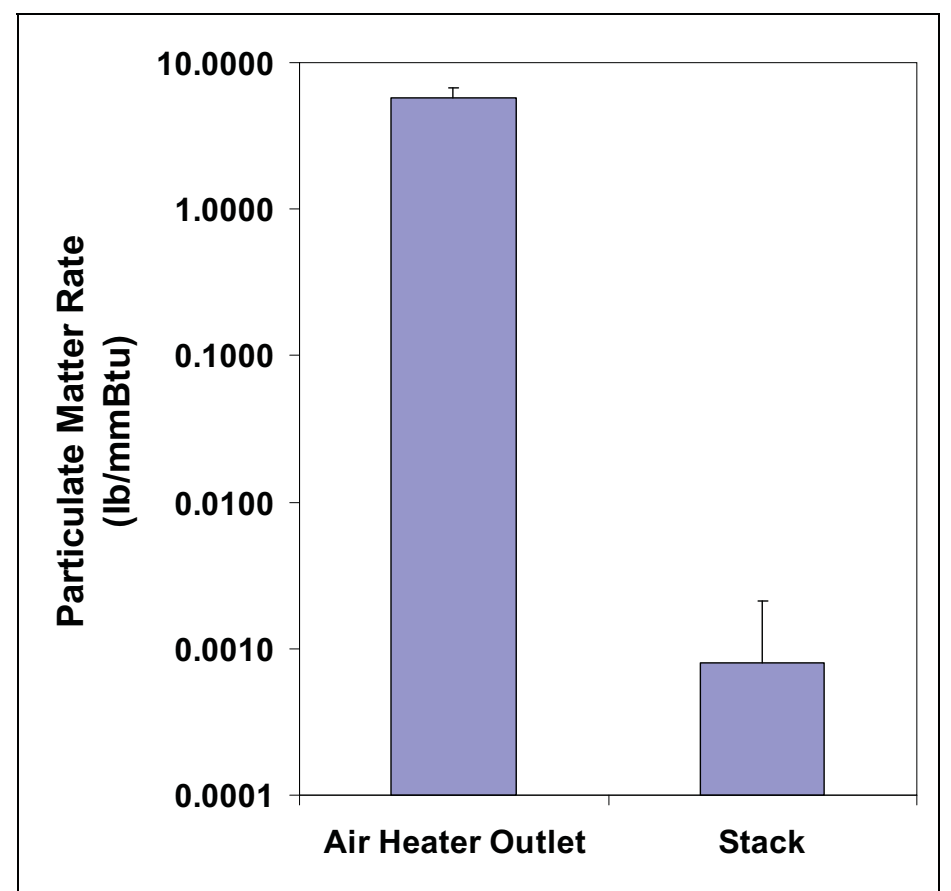

Figure 82. Summary of mean primary particulate matter rates measured at the air heater outlet (upstream of the Turbosorp $^{\circledR}$ system) and stack (downstream of the Turbosorp ${ }^{\circledR}$ system) during 43 tests in March 2007 - June 2008. Sampling was conducted simultaneously at the two locations using U.S. EPA Method 17. Data are presented on a logarithmic scale. Error bars represent +1 standard deviation. 


\section{Operating and Maintenance Experience}

During the Operation and Testing Phase of the Greenidge Project, AES Greenidge gained more than a year-and-a-half of commercial operating experience with the multi-pollutant control system. Throughout this time, plant personnel developed an understanding of the routine operating and maintenance requirements associated with the system. As expected with a demonstration project, they also encountered unexpected challenges related to the operation of the system and worked to resolve these. The subsections below summarize the key O\&M lessons learned during the project. (Certain aspects of system operations, including requirements for electricity, water, compressed air, urea, and lime, have already been discussed in Sections 6.3.4, 6.3.5, 9.3.2, and 9.3.7, and are not covered further in this section). Additional details concerning O\&M can be found in the Project Log in Appendix D, which provides a history of the monthly operating experience at AES Greenidge Unit 4.

\subsection{Routine Operating and Maintenance Requirements}

The day-to-day operating and maintenance requirements associated with the multi-pollutant control system were able to be satisfied by the plant's existing staff, with little added burden. As discussed in Section 6.3.3, a number of the components of the multi-pollutant control system were integrated into the unit's distributed control system. These components are monitored and controlled by the same control room operator who is responsible for Unit 4 . (Hence, a single control room operator is able to control the entire unit, including the multi-pollutant control system). Two-to-three auxiliary operators are staffed at all times to monitor equipment and operate manual controls associated with Unit 4; these operators have also been able to accommodate all additional routine operating requirements resulting from the multi-pollutant control system (e.g., operation of equipment items that are controlled by programmable logic controllers with local interface units). In addition, plant operations personnel perform the following duties on a regular basis to monitor for problems and prevent interruptions in system performance:

- Walk down the system and visually check equipment (2-4 times per day)

- Make miscellaneous adjustments to the multi-pollutant control system (1 time per day)

- Clean the vents on the Turbosorp ${ }^{\circledR}$ product ash disposal silos (2-6 times per day)

- Clean the ball mill magnets (2 times per day)

- Clean the butterfly vent valve at the hydrator exhaust (2-4 times per day)

- Operate the LPA vacuum ports (1 time per day)

- Accept pebble lime deliveries (2 times per day)

- Accept urea deliveries (1-2 times per week)

- Change out and clean the Turbosorp ${ }^{\circledR}$ process water injection lance (1 time per week)

- Change out and clean the process water strainers (1 time per week)

- Shut down and restart the lime hydrator (1 time per week)

- Clean the weir box at the entrance to the premixer of the lime hydrator (1 time per week)

- Clean the hydrated lime classifier fan (1 time per week)

AES Greenidge also routinely hires a vacuum truck to remove ash from the hopper at the Turbosorp $^{\circledR}$ inlet (beneath the venturi nozzle) and to clean fugitive ash and lime from the area around the Turbosorp ${ }^{\circledR}$, lime hydration, and ash disposal systems. The Turbosorp ${ }^{\circledR}$ inlet hopper is vacuumed about twice per month, and the other vacuuming is performed as needed. 
In addition to the O\&M activities that are performed regularly while Unit 4 is operating, certain routine and preventative maintenance activities are performed during outages, when plant personnel can access the internals of the multi-pollutant control system and safely service equipment items. Some or all of the following tasks are typically performed during planned and unplanned outages:

- Inspect and service the SNCR urea injectors (to repair damaged tips, heat shields, etc.)

- Vacuum fly ash and large particle ash from the SCR catalyst, catalyst screen, and LPA screen

- Clean the SCR catalyst using an air lance

- Inspect equipment items (e.g., internals of SCR reactor, Turbosorp ${ }^{\circledR}$ absorber vessel, and baghouse)

- Service miscellaneous equipment items (e.g., pumps, valves, motors, etc.), as needed

The amount of work performed during a given outage depends upon the duration of the outage, the amount of time that has passed since the previous outage, and the nature of any problems affecting the multi-pollutant control system prior to the outage.

Finally, it is anticipated that the SCR catalyst and the baghouse bags and cages will have to be replaced every several years. This work will also be performed during outages, when the unit is offline.

As discussed in Section 6.2.2, the SCR catalyst at AES Greenidge was designed for a 3-year operating life. This life expectancy was based upon the anticipated decline in catalyst activity over time and the effect of this decreased activity on the ability of the catalyst to continue meet its performance targets for $\mathrm{NO}_{x}$ removal and $\mathrm{NH}_{3}$ slip. However, during the Operation and Testing Phase of the Greenidge Project, it was discovered that the operating life of the catalyst was constrained predominantly by plugging and erosion that resulted from the LPA problem discussed in Section 10.2.1, rather than by decreasing activity. Once sufficient large particle ash and fly ash have accumulated in the catalyst channels, it becomes too difficult to clean the catalyst in place using a vacuum and air lance, and the catalyst modules must be sent offsite for professional cleaning. Hence, to avoid prolonged outages, AES Greenidge has found it necessary to always keep a spare catalyst layer, so that one layer can be sent for cleaning while the other is in service. In addition to the limitation imposed by declining catalyst activity, erosion (resulting from the rake soot blower and from areas of high flue gas velocity) may limit the number of times that the catalyst can be cleaned and reused. During the approximately 22month period between December 2006 and October 2008, the catalyst was changed out three times (in May 2007, December 2007, and May 2008). (The in-duct SCR reactor was in service during the start-up and commissioning period as well as during the Operation and Testing Phase). The original catalyst layer, which was in service from December 2006-May 2007 and from January 2008-May 2008, was too severely damaged after its second period of service to be cleaned and reused. However, this catalyst was subjected to relatively harsh operating conditions before the LPA mitigation system was fully implemented in May 2008, and AES Greenidge anticipates a longer catalyst life and less frequent need for catalyst cleanings going forward. As of the end of the project in October 2008, plant personnel were working to develop a catalyst management plan based on the experience gained during the Operation and Testing Phase. They currently anticipate that they will have to replace the catalyst with a new or rejuvenated layer every two years. (Additional operating time is required to determine whether the catalyst can be rejuvenated for reuse after two years in service). Based on the experience 
gained during the project, the catalyst can be completely changed out (including removal of the old catalyst layer and installation of the new catalyst layer) during a 2-to-3-day outage.

The baghouse bags and cages are expected to last for approximately 5 years before failing from mechanical wear. The Operation and Testing Phase of the Greenidge Project was not long enough to enable an evaluation of the actual operating lives of the bags and cages. However, no bags or cages had to be replaced during the approximately 22-month period of operation between December 2006 and October 2008. (As with the in-duct SCR reactor, the baghouse was in service throughout both the start-up and commissioning period and the Operation and Testing Phase, resulting in 22 months of operating experience).

\subsection{Operating and Maintenance Challenges and Solutions}

For the most part, the multi-pollutant control system at AES Greenidge Unit 4 ran without problem during its first year-and-a-half of commercial operation. However, as expected with a first-of-a-kind installation, the project team encountered several unanticipated challenges that periodically hindered the operation and performance of the system. These challenges, and the solutions that were devised to address them, are discussed in the subsections below. (Certain operating challenges that were specific to the project's performance targets, including the challenges associated with maintaining high-load $\mathrm{NO}_{x}$ emissions below $0.10 \mathrm{lb} / \mathrm{mmBtu}$ and ammonia slip below 2 ppmvd @ 3\% $\mathrm{O}_{2}$, have already been covered in Sections 9.3.1 and 9.3.3 and are not addressed any further in this section).

\subsubsection{Large Particle Ash}

The most troublesome problem encountered during operation of the multi-pollutant control system at AES Greenidge was the accumulation of large particle ash in the in-duct SCR reactor. Figure 83 presents a photograph showing LPA that collected on the surface and in the channels of the SCR catalyst during a portion of the Operation and Testing Phase of the project. LPA consists of porous slag pieces of varying shape and size that are likely formed in the upper furnace or on heat exchange surfaces in the convective pass (Ryan and St. John, 2003). In many cases, these LPA pieces are too large to pass through the honeycomb catalyst. Hence, unless the LPA is captured upstream of the SCR, it will accumulate on the top (inlet) of the catalyst and become lodged in the catalyst channels. This can then promote subsequent accumulation of fly ash within and on top of the catalyst, as illustrated in Figure 84. Plugging of the in-duct SCR catalyst in this way led to various operational problems at AES Greenidge Unit 4 , as discussed below.

The effect of large particle ash on the operation of the multi-pollutant control system began to be realized in early January 2007, less than a month after the in-duct SCR reactor entered service. On January 2, plant personnel reported concerns about increasing pressure drop across the SCR catalyst. As a result, they decided to take Unit 4 offline for its steam turbine screen outage on January 3 , several days earlier than planned, to enable an inspection of the SCR internals. This inspection indicated that the buildup in pressure drop was caused by refractory and miscellaneous construction debris that remained in the boiler after the tie-in outage and had blocked portions of the catalyst surface, as well as by LPA that had accumulated on the catalyst. The debris and ash were removed, and the unit returned to service on January 7 . It operated normally until January 30 , when plant personnel again observed an increase in 
pressure drop across the catalyst. The catalyst was cleaned and inspected on February 2-4; LPA was identified as the cause of the increase in pressure drop.

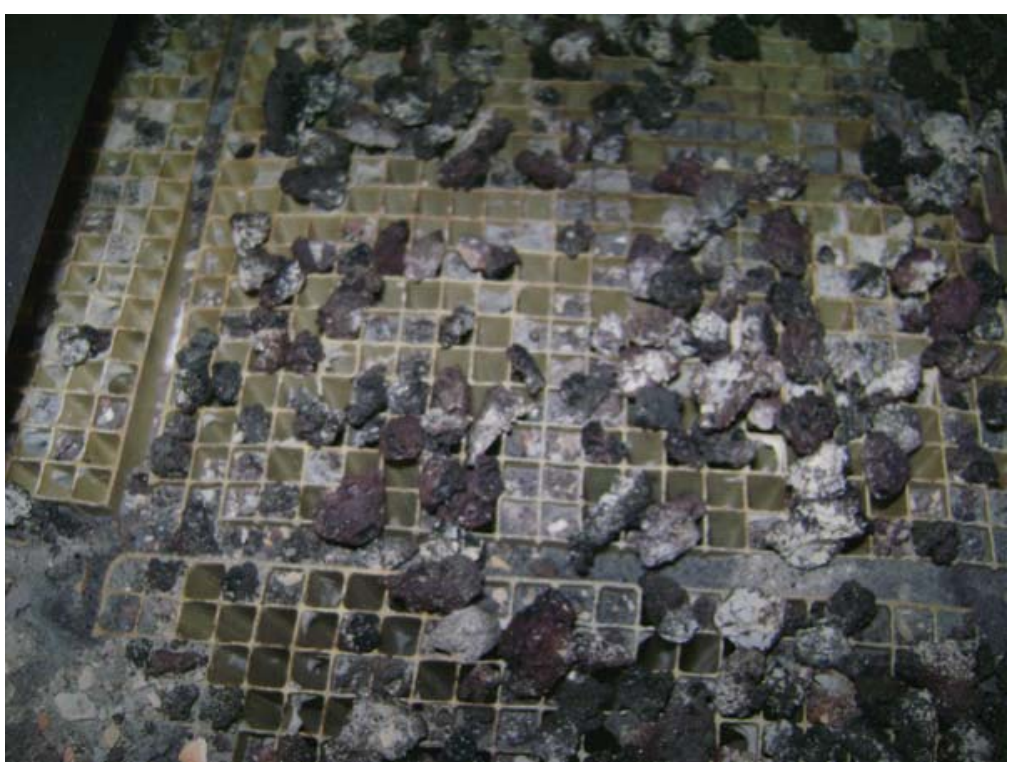

Figure 83. Photograph taken on November 10, 2007, showing large particle ash accumulation in the in-duct SCR catalyst at AES Greenidge Unit 4.

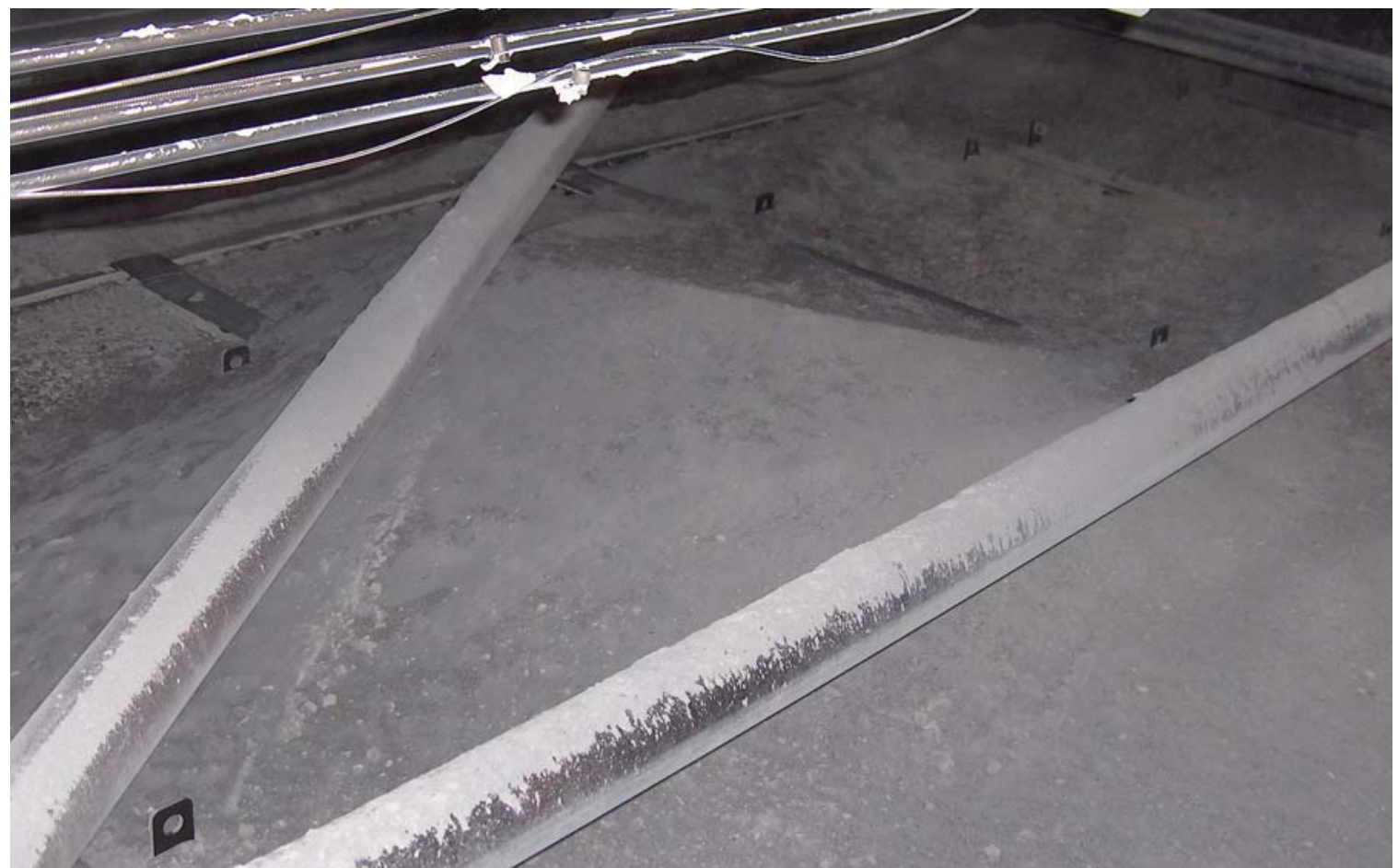

Figure 84. Photograph from February 3, 2007, showing the accumulation of fly ash on top of the in-duct SCR reactor at AES Greenidge Unit 4 . The buildup of fly ash appeared to be caused by pieces of LPA that blocked the catalyst channels.

The large particle ash problem affected the operation of AES Greenidge Unit 4 throughout much of the project's Operation and Testing Phase. As shown in Table 33, the in-duct SCR reactor 
was inspected, cleaned, or modified because of LPA accumulation during 17 outages between January 2007 and October 2008. The LPA problem was the primary cause of nine of these outages. Per the discussion in Section 4.3.9, accumulation of large particle ash in the SCR catalyst may cause a deterioration in SCR performance, including decreased $\mathrm{NO}_{x}$ removal efficiency and increased ammonia slip. The association between increased catalyst plugging (presumably caused by LPA) and increased ammonia slip at AES Greenidge was illustrated in Section 9.3.3. (No association was discovered between catalyst plugging and $\mathrm{NO}_{\mathrm{x}}$ emissions, likely owing to the importance of other factors such as the performance of the combustion system and SNCR system in determining the $\mathrm{NO}_{x}$ emission rate). LPA accumulation in the SCR catalyst can also pose other problems for unit operations, including increased pressure drop that strains downstream ductwork and requires an increase in fan power.

Table 33. Summary of outages at AES Greenidge Unit 4 during which actions were taken in and around the SCR reactor to address the LPA problem.

\begin{tabular}{|l|l|l|}
\hline Outage Dates & Outage Cause & Actions Taken in/around SCR Reactor \\
\hline January 3-7, 2007 & Steam turbine screen & $\begin{array}{l}\text { LPA, fly ash, and construction debris cleaned } \\
\text { from SCR }\end{array}$ \\
\hline February 2-4, 2007 & SCR cleaning & LPA and fly ash cleaned from SCR \\
\hline February 9-10, 2007 & Superheater tube leak & LPA and fly ash cleaned from SCR \\
\hline March 2-4, 2007 & SCR cleaning & LPA and fly ash cleaned from SCR \\
\hline March 22-24, 2007 & SCR cleaning & LPA and fly ash cleaned from SCR \\
\hline April 19-22, 2007 & SCR cleaning & LPA and fly ash cleaned from SCR \\
\hline May 17-25, 2007 & $\begin{array}{l}\text { Catalyst change / LPA } \\
\text { removal system } \\
\text { installation }\end{array}$ & $\begin{array}{l}\text { Catalyst layer changed; LPA screen, eight } \\
\text { vacuum ports, and two soot blowers installed to } \\
\text { capture and remove LPA upstream of the SCR }\end{array}$ \\
\hline June 15-17, 2007 & Tube leak & LPA and fly ash cleaned from SCR \\
\hline July 12-14, 2007 & ID fan cable failure & LPA and fly ash cleaned from SCR \\
\hline August 10-12, 2007 & SCR cleaning & LPA and fly ash cleaned from SCR \\
\hline September 4-10, 2007 & $\begin{array}{l}\text { LPA removal system } \\
\text { modification }\end{array}$ & $\begin{array}{l}\text { Two LPA soot blowers replaced with four rotary } \\
\text { soot blowers; spring seal installed to close gap } \\
\text { between LPA screen sections; rake soot blower } \\
\text { installed above catalyst; LPA and fly ash cleaned } \\
\text { from SCR }\end{array}$ \\
\hline September 18-21, 2007 & Oil leak & LPA and fly ash (minimal) cleaned from SCR \\
\hline November 9-12, 2007 & SCR cleaning & $\begin{array}{l}\text { LPA and fly ash cleaned from SCR; spring seal } \\
\text { repaired }\end{array}$ \\
\hline $\begin{array}{l}\text { December 27, 2007 - } \\
\text { January 3, 2008 }\end{array}$ & Catalyst change & $\begin{array}{l}\text { Catalyst layer changed; gaps in LPA screen } \\
\text { patched; samples collected for evaluation }\end{array}$ \\
\hline May 2-10, 2008 & Planned spring outage & $\begin{array}{l}\text { LPA screen replaced with smaller-pitch screen; } \\
\text { LPA screen spring seal replaced with hinged seal; } \\
\text { catalyst layer changed; catalyst test modules } \\
\text { installed; rake soot blower discharge angle } \\
\text { changed from 90 to 45 }\end{array}$ \\
\hline July 4-6, 2008 & LPA and fly ash cleaned from SCR \\
\hline October 3-6, 2008 & Damaged coal burners & LPA and fly ash cleaned from SCR \\
\hline
\end{tabular}

During the first half of 2007, the timing of outages for SCR cleaning was driven by the need to maintain a clean catalyst for purposes of guarantee testing. Hence, outages were held whenever the pressure drop across the SCR catalyst reached $\sim 2.5$ iwc at full load. The baseline pressure drop across the catalyst is $\sim 1.1$ iwc at full load. 
After the guarantee tests were completed, however, it became less important to achieve optimal SCR performance as the unit was able to satisfy its permit limit for $\mathrm{NO}_{x}$ emissions even when the catalyst was partially plugged. Hence, AES Greenidge began to tolerate larger pressure drops across the SCR reactor in order to avoid the undesirable economic consequences of frequent outages. The amount of tolerable pressure drop was then limited by the need to maintain less than 18 iwc of vacuum downstream of the air preheaters in order to avoid the risk of ductwork collapse. (As discussed in Section 9.3.3, increases in the pressure drop across the air preheaters, possibly resulting from ammonium bisulfate fouling, also contribute to the vacuum present in the downstream ductwork. LPA accumulation may promote ammonium bisulfate fouling by causing increased ammonia slip from the SCR reactor). Figure 85 shows the hourly average pressure drops measured across the SCR catalyst between June 2007 and September 2008, following the completion of guarantee testing, as well as the hourly average gross unit loads during this period. As illustrated in the figure, AES Greenidge was able to tolerate up to nearly 5 iwc of pressure drop across the catalyst before taking an outage to clean the SCR reactor. At times (i.e., prior to the outages beginning on September 4, 2007, November 9, 2007, December 27, 2007, and May 2, 2008), plant personnel also derated the unit to reduce the pressure drop and extend the period of operation between outages.

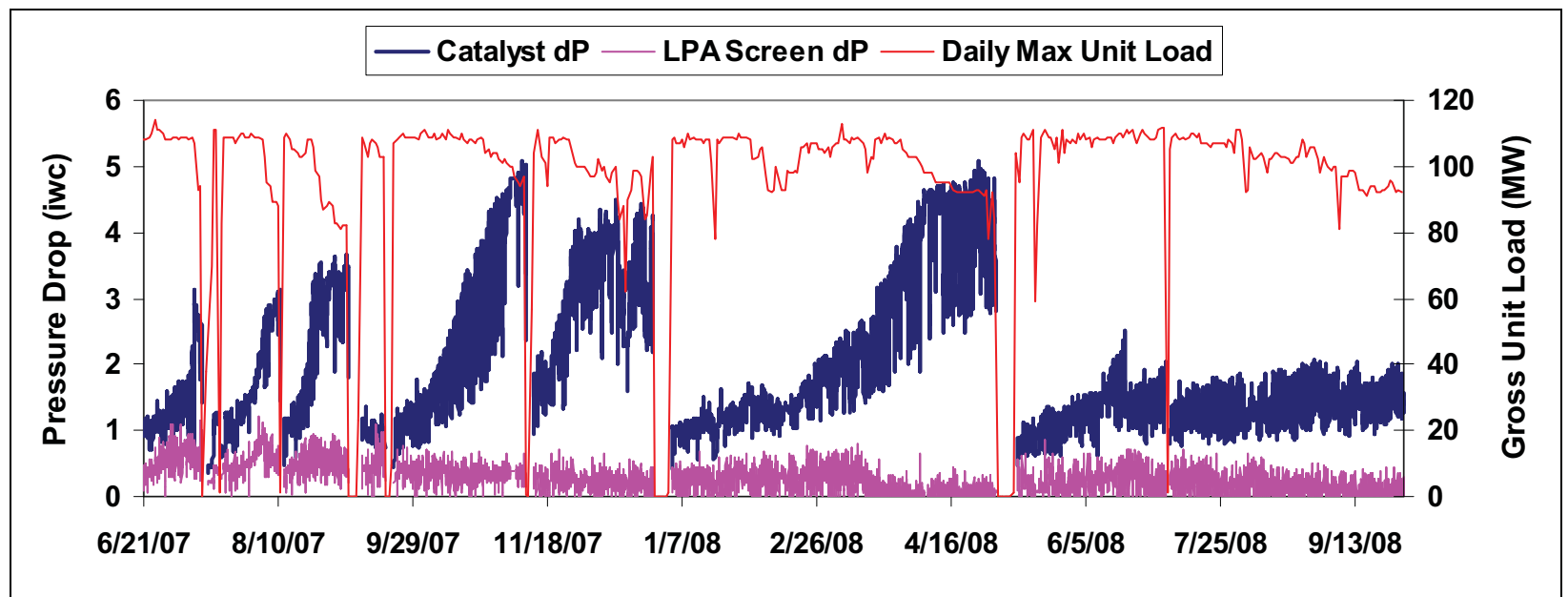

Figure 85. Time series plot (EST) showing the average hourly pressure drops measured across the SCR catalyst and LPA screen at AES Greenidge Unit 4 between June 21, 2007, and September 30, 2008. The maximum gross unit load observed each day during this period is also plotted.

The frequency of outages for SCR cleaning also decreased as a result of the implementation of a large particle ash removal system. (The LPA removal system was installed outside of the scope of the DOE cooperative agreement, but it is discussed here because it was essential to the successful operation of the multi-pollutant control system). The final design of that system, and the challenges associated with installing it in the tight ductwork configuration upstream of the in-duct SCR reactor, have already been described in Section 6.2.2. The development of an effective LPA removal system required several iterations between May 2007 and May 2008, however. The operating experience that led to the final design is discussed here.

The large particle ash removal system was originally installed during an outage on May 17-25, 2007. The initial design included a sloped screen above the SCR catalyst to capture LPA from the flue gas, eight vacuum ports (visible in Figure 17) to remove captured LPA from the base of the screen, and two soot blowers beneath the screen to aid in transporting the LPA to the vacuum ports. As with the final screen design described in Section 6.2.2, the original screen consisted of coated carbon steel sheets with hexagonal perforations. However, the perforations 
were considerably larger than those in the final design; opposing walls of each hexagon were separated by a distance of $5.83 \mathrm{~mm}$. Also during the May 2007 outage, the original SCR catalyst, which had been in service since start-up of the in-duct SCR reactor in December 2006, was removed from the reactor and replaced with a new catalyst layer. The original layer was too severely plugged to continue in service without first being sent offsite for professional cleaning.

After returning to service, the system operated for less than a month before plant personnel observed increasing pressure drop across both the LPA screen and the SCR catalyst. The SCR reactor was inspected during a tube leak outage on June 15-17, 2007; the inspection indicated that the soot blowers were missing several areas of the LPA screen, allowing LPA to accumulate in those areas. Another inspection during an ID fan cable failure outage in July confirmed that the soot blowers were not affording adequate coverage to keep the LPA screen clean. Figure 85 includes a plot of the pressure drop across just the LPA screen (excluding the catalyst). Small increases in the pressure drop across the screen are evident during JuneAugust 2007, coinciding with this less-than-optimal soot blower performance. Moreover, in spite of the presence of the screen, AES Greenidge observed that some LPA was still reaching the catalyst, presumably by passing through the small gap between the two sections of the LPA screen. (As described in Section 6.2.2, because the top of the screen is affixed to the ductwork above an expansion joint, the screen was installed in two sections to allow it to move with the duct as furnace temperatures change - e.g., during start-up and shut-down). A short outage was held on August 10-11, 2007, to allow for the removal of LPA that had accumulated on the screen and catalyst. The pressure drop across the SCR (including both the catalyst and the screen) returned to normal following the outage, but it was again increasing as of the end of August, eventually forcing AES Greenidge to derate Unit 4.

AES Greenidge completed an outage in early September 2007 to modify the large particle ash removal system in response to the problems identified in June-August. During the outage, which lasted from September 4 through September 10, the two soot blowers that had been installed in May to clean the LPA screen were replaced with four rotary soot blowers to provide improved cleaning coverage, and a spring seal was installed to close the gap between the two sections of the LPA screen. The plant also installed a rake soot blower containing $\sim 350$ blow points immediately above the catalyst to aid in resuspending any fly ash that accumulates on its surface. (The rake was expected to keep the catalyst cleaner than the existing sonic horns).

The new rotary soot blowers proved to be effective in preventing LPA from accumulating on the LPA screen. As shown in Figure 85, the increases in pressure drop that had been observed across the screen during June-August 2007 were not observed during September 2007Septemeber 2008, and inspections conducted during this latter period did not indicate any appreciable buildup of LPA on the screen.

The pressure drop across the SCR catalyst began to increase again soon after the September 2007 outage, however. The plant took several actions in October 2007 to try to alleviate this problem, including increasing the discharge pressure and frequency of operation of the rake soot blower above the catalyst and resuming operation of the sonic horn system (which had initially been discontinued after the installation of the rake), but these were unsuccessful in reversing the trend. As of the end of October, Unit 4 was derated in order to maintain sufficient pressure downstream of the reactor to avoid risk of ductwork collapse. The unit was further derated in early November to allow it to continue to operate while AES completed an outage at another of its New York power plants. 
Then, on November 9-12, 2007, AES Greenidge held an outage to inspect and clean the in-duct SCR reactor. Upon entering the reactor, plant personnel discovered a substantial amount of modestly sized large particle ash distributed relatively evenly over the surface of the catalyst. (They did not observe mounding of ash as they had during previous outages, likely owing to the effect of the rake soot blower). Some of the LPA was small enough to have passed directly through the mesh of the LPA screen, and some LPA also likely reached the catalyst by passing through gaps where the screen meets the duct walls. In addition, the spring seal that was installed in September to close the gap between the upper and lower sections of LPA screen did not flex as it was designed to, creating another gap for LPA to penetrate. Large particle ash was vacuumed from the surface of the catalyst, and a temporary fix for the spring seal was installed. When the unit returned to service, the pressure drop across the SCR catalyst was greater than the normal baseline, likely because some LPA was lodged deep within the catalyst and could not be removed as part of the cleaning.

The pressure drop across the SCR catalyst increased relatively rapidly following the midNovember 2007 outage, and Unit 4 was derated for much of December in order to maintain sufficient pressure downstream of the reactor. At the end of December, AES Greenidge held another outage to inspect and clean the SCR reactor. Plant personnel thoroughly patched gaps in the LPA screen while the unit was offline. Also during this outage, the existing, plugged SCR catalyst layer was replaced with the original catalyst layer, which had been removed from the reactor in May 2007 (as discussed above) and professionally cleaned. Figure 86 presents a photograph of one of the plugged catalyst modules that was removed from the SCR reactor in December 2007. The outage began on December 27, and the work in the SCR reactor was completed successfully by December 30 , but a problem with the unit's distributed control system (unrelated to the multi-pollutant control system) prevented it from returning to service until January 3, 2008.

The pressure drop across the SCR catalyst returned to its baseline value of $\sim 1.1$ iwc in early January 2008, following the outage. However, this pressure drop again increased throughout January-April, consistent with LPA and fly ash accumulation in the catalyst. The rate of increase in pressure drop was slower than the rate observed after previous outages; we suspect that AES's efforts to thoroughly patch gaps in the LPA screen during the December 2007 outage, along with the installation of freshly cleaned catalyst during that outage, helped to slow the rate of catalyst plugging. Moreover, Unit 4 was derated because of coal quality issues for a time in February and early March 2008, which may have helped to reduce the rate of LPA accumulation in the catalyst. At the end of March, however, the pressure drop across the SCR catalyst was nearly 4 iwc, and plant personnel had to derate Unit 4 to avoid the risk of ductwork collapse downstream of the air heaters. The unit continued to be derated throughout April 2008 so that it could continue to operate until its planned spring outage in early May. Elevated pressure drop across the air heaters, possibly resulting in part from ammonium bisulfate formation on the air heater baskets, also contributed to this derate. 


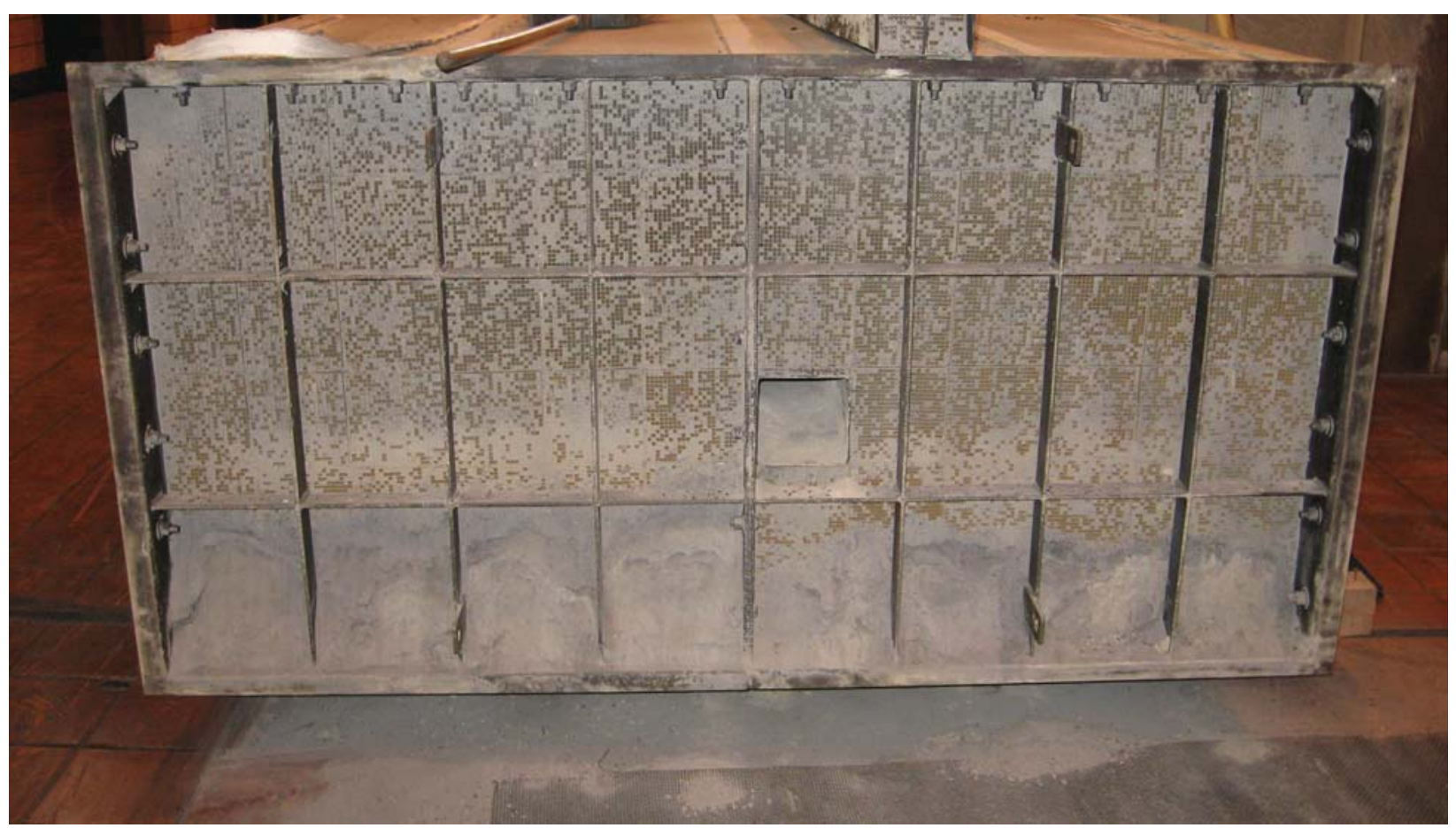

Figure 86. Photograph of a partially plugged catalyst module (viewed from the inlet end) that was removed from the in-duct SCR reactor at AES Greenidge Unit 4 in late December 2007. A test catalyst element was removed near the center of the module.

Meanwhile, the project team worked to diagnose the cause of the catalyst plugging problem and to develop a solution for overcoming the problem. Upon inspecting the SCR reactor in late December 2007, plant personnel observed weak agglomerates of fine ash adhering to structures above the catalyst and protruding from the bottom of the catalyst (see Figure 87). Some of the catalyst channels also appeared to be plugged by "sticky" fly ash. These observations led the project team to hypothesize that a chemical mechanism could be contributing to ash accumulation in the catalyst. To investigate this possibility, samples of the various types of ash and other deposits found in and around the SCR reactor were collected during the December outage and sent to CONSOL for bulk chemical analysis and to Lehigh University for X-ray diffraction (XRD) analysis.

Results of the bulk chemical analyses were discussed during a project status review meeting including representatives from CONSOL, AES Greenidge, and DOE on January 17, 2008, and results of the bulk chemical analyses and XRD analyses were discussed during a meeting including representatives from Lehigh, AES Greenidge, DOE, CONSOL, Fuel Tech, and Cormetech on February 19, 2008. The bulk chemical analysis results, which are included in Appendix $L$ to this report, did not indicate any chemical mechanisms of plugging, although several interesting observations were noted with respect to the sulfur, ammonia, iron, and carbon content of the samples. Apart from typical ash components (e.g., $\mathrm{Fe}_{2} \mathrm{O}_{3}, \mathrm{Al}_{2} \mathrm{O}_{3}, \mathrm{SiO}_{2}$ ), XRD analysis identified calcium sulfate, sodium nitrate, and calcium urate hexahydrate (a possible product of urea decomposition) in some of the samples from the SCR reactor; however, the abundance of these components was small relative to the ash components, and no clear evidence of a chemical mechanism of catalyst plugging was discovered. 


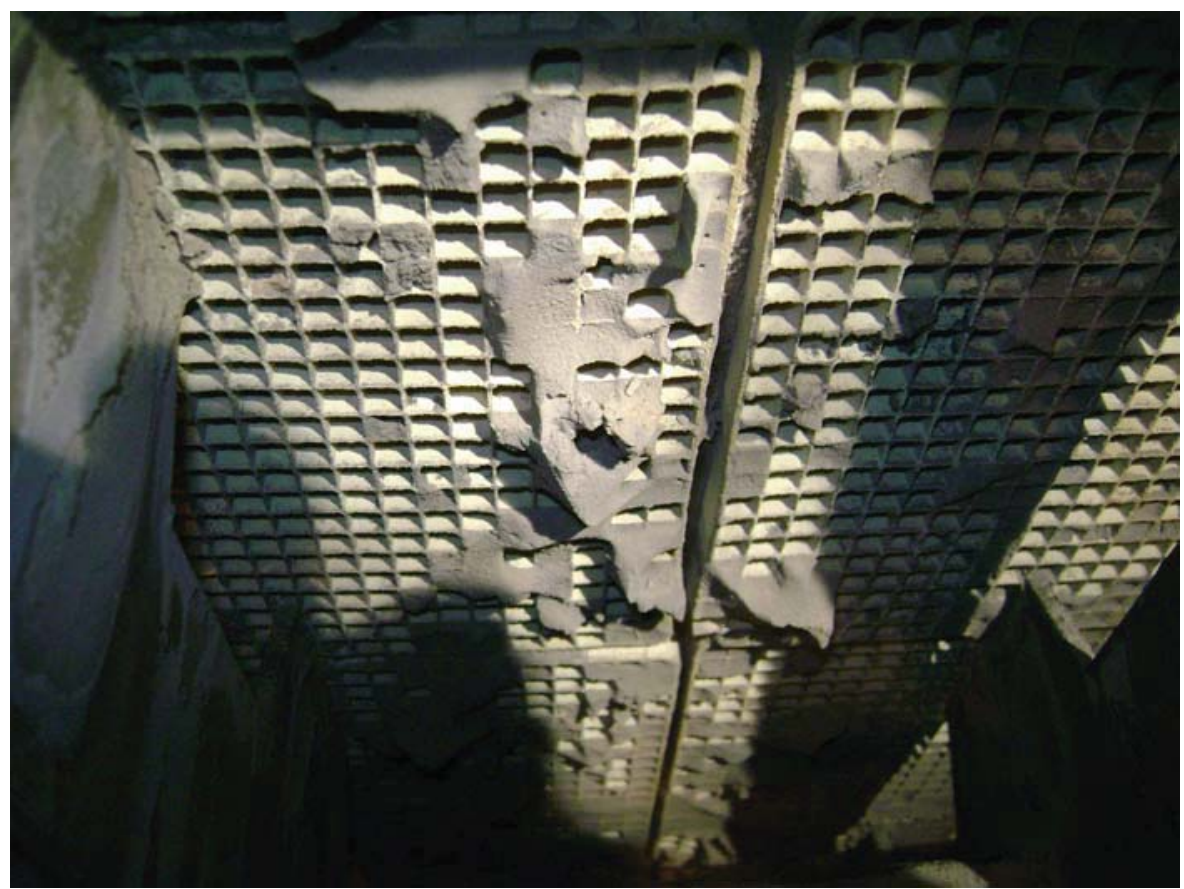

Figure 87. Photograph of a portion of the outlet end of the SCR catalyst taken during the December 2007 outage at AES Greenidge Unit 4. Weak agglomerates of fly ash can be seen protruding from some of the catalyst channels.

Hence, the team concluded that the continued catalyst plugging was likely being caused predominantly by pieces of LPA that were small enough to pass through the LPA screen but large enough to lodge in the catalyst. The LPA in the catalyst channels would then promote subsequent accumulation and bridging of fly ash, especially in areas of reduced flue gas velocity. (Accumulation of LPA and/or fly ash also contributes to an altered velocity profile across the catalyst). This physical mechanism of plugging was supported by observations of LPA lodged in the catalyst and catalyst screen during the November and December 2007 outages, as shown in Figures 83 and 88. (The catalyst screen is located below the LPA screen, just above and parallel to the surface of the catalyst). It was also supported by BPEl's dissection of a catalyst element that was pulled from the SCR reactor during the outage in November 2007. As part of this dissection, the catalyst element, which was $53 \%$ plugged, was cut into eighteen sequentially numbered wafers of approximately equal thickness, such that the first wafer was taken from the outlet end of the catalyst and the eighteenth was taken from the inlet end. Each wafer was probed to determine the number of plugged channels and the number of LPA particles (defined by visual inspection or as any particle not passing a $3.4 \mathrm{~mm}$ screen) contained within the channels. As illustrated in Figure 89, analysis of the resulting data indicated a strong correspondence between the number of plugged cells in any given wafer and the cumulative total number of LPA pieces found in all wafers between the given wafer and the outlet end of the catalyst. This observation is consistent with the hypothesis that LPA was the root cause of the catalyst plugging. It suggests that as relatively large pieces of LPA became lodged within the catalyst channels, they provided a foundation for the accumulation of fly ash and smaller LPA particles in the space above, thereby plugging these channels. In some cases, hardened fly ash was discovered at the inlet end of the catalyst channels. It is believed that this hardened ash, which was distinctly different from LPA, may have resulted from the compaction and wetting of fly ash that had already accumulated in these channels as a result of downstream LPA. 


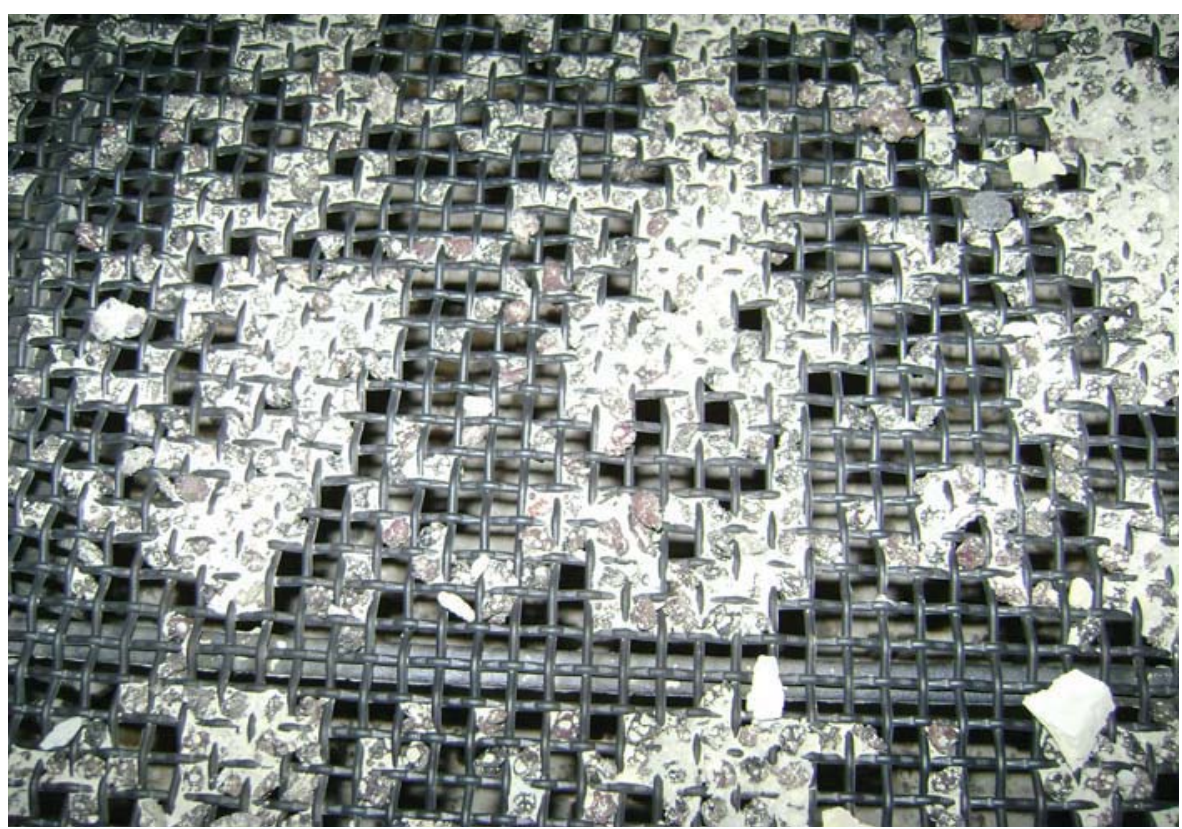

Figure 88. Photograph of a portion of the catalyst screen taken during the November 2007 outage at AES Greenidge Unit 4. Small pieces of LPA (surrounded by fly ash) are visibly lodged in the screen. The white coloration is color "washout" from the photographic flash, and it does not represent the actual color of the ash.

Based on the analyses performed in early 2008, AES Greenidge decided to address the catalyst plugging problem mechanically (i.e., by taking further action to prevent LPA from penetrating the screen and lodging in the catalyst), and they implemented additional modifications to the LPA removal system during the unit's planned spring outage on May 2-10, 2008. These modifications resulted in the final LPA removal system design described in Section 6.2.2. The May 2008 outage marked the first time that Unit 4 was out of service since January 3, 2008. Upon inspecting the SCR reactor at the start of the outage, plant personnel reported that the catalyst was plugged with substantial amounts of LPA and fly ash, and the catalyst was also severely eroded in places, presumably because of the rake soot blower. It also appeared that one of the rotary soot blowers on the western side of the LPA screen and one of the LPA vacuum ports were not functioning properly prior to the outage, based on observations of accumulated LPA near those pieces of equipment. These issues were attended to.

During the outage, the existing LPA screen above the in-duct SCR reactor was removed and replaced with a new, smaller-pitch LPA screen, in order to improve the capture efficiency for small pieces of LPA. Figure 88 presents a side-by-side comparison of the new screen and the original screen. In addition, the existing catalyst modules, which were severely eroded and plugged with fly ash and LPA, were removed and replaced with clean catalyst modules. Figure 89 illustrates the condition of one of the catalyst modules that was taken out of the SCR reactor during the May 2008 outage. Most of the replacement modules had been in service at AES Greenidge Unit 4 prior to its late December 2007 outage, and they were sent for professional cleaning before being reinstalled in the reactor. However, eight of the 26 modules were refitted with larger-pitch catalyst (seven were refitted with honeycomb catalyst, and one was refitted with corrugated catalyst) so that the performance of this catalyst (i.e., its susceptibility to plugging) could be evaluated. Also during the outage, the rake soot blower was modified so that it blows at a 45-degree angle rather than perpendicularly to the catalyst surface (the discharge pressure of the rake was also reduced to lessen catalyst erosion), and a new seal 
was installed to close the gap between the two sections of the LPA screen. The seal, which is shown in Figure 92, consists of a plate that is attached with hinges to each of the two screen sections; this design was expected to perform better than the spring seal that was installed previously.

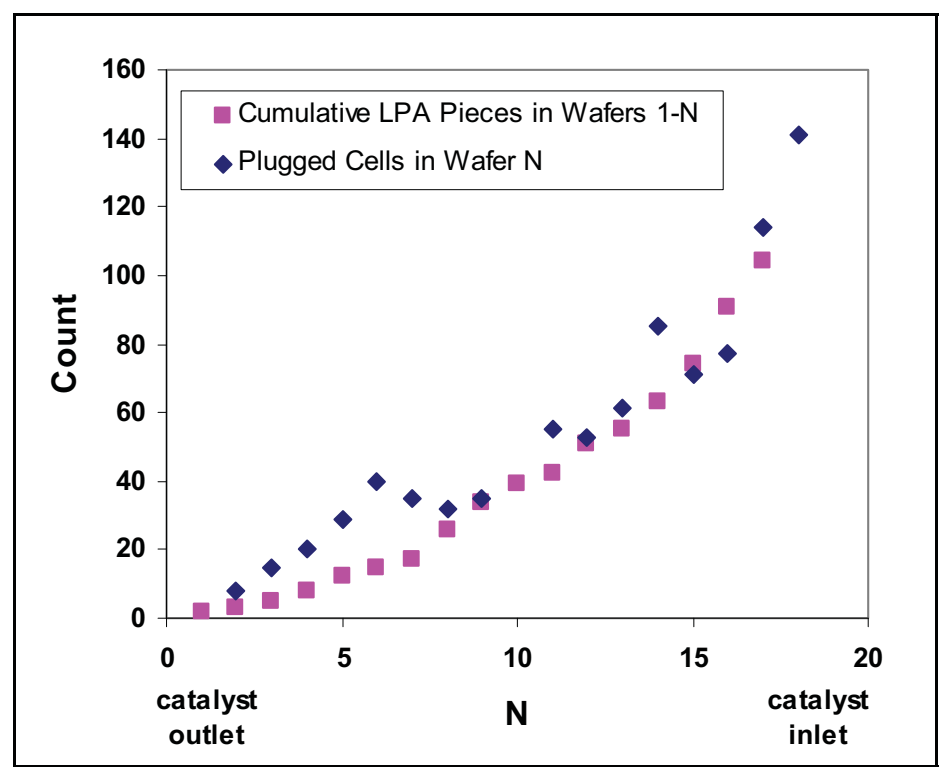

Figure 89. Summary of results from the dissection of a catalyst element pulled from the in-duct SCR reactor during the November 9-12, 2007 outage. The catalyst element was cut into 18 sequentially numbered wafers, with wafer 1 taken from the outlet end and wafer 18 taken from the inlet end. The plot shows the number of plugged cells observed in each wafer (there were 324 total cells per wafer), as well as the cumulative number of LPA pieces found between the outlet end of the catalyst and each wafer.

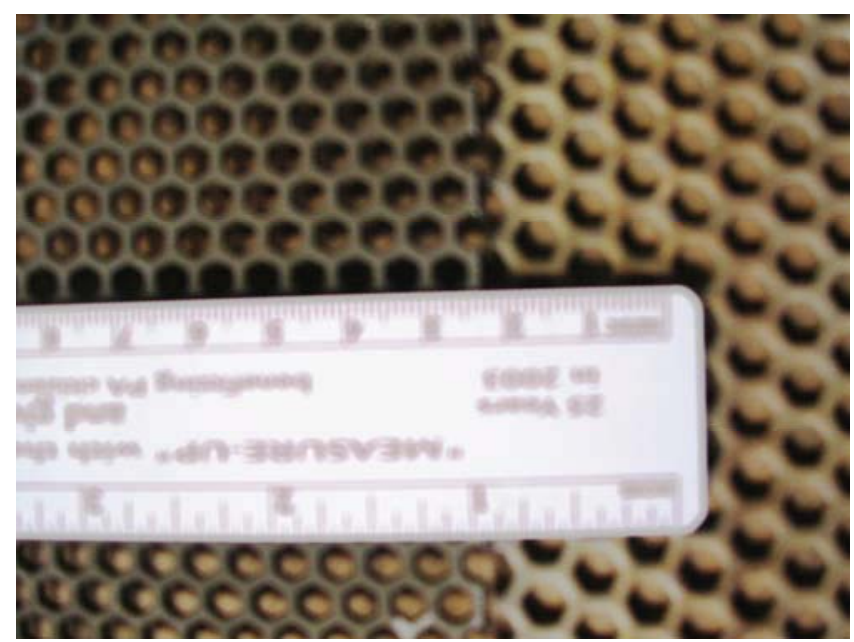

Figure 90. Photograph comparing the original LPA screen that was installed in May 2007 (right) with the new, smaller-pitch LPA screen that was installed in May 2008. 


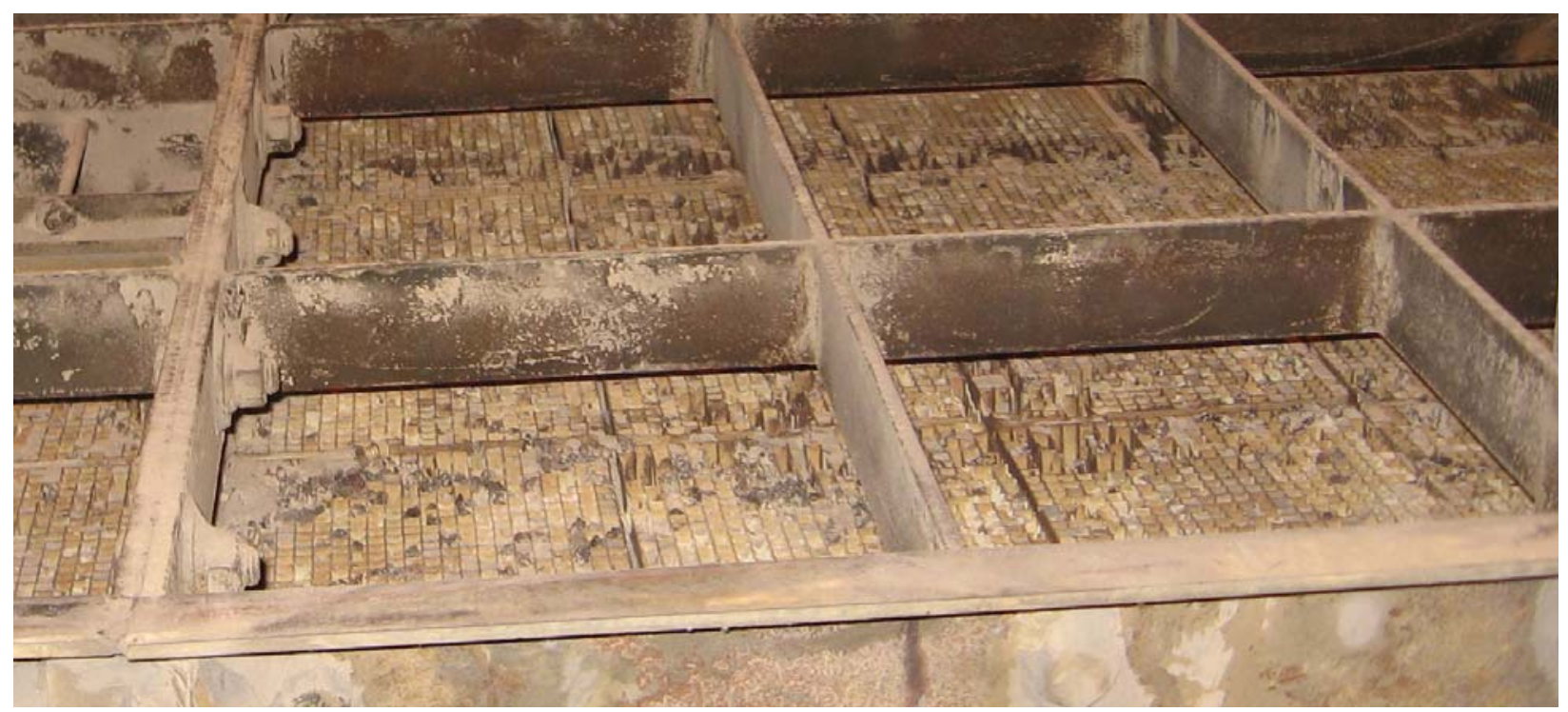

Figure 91. Photograph showing one of the catalyst modules that was removed from the SCR reactor in May 2008. Catalyst erosion (likely caused by the rake soot blower) and some LPA plugging are evident in the picture.

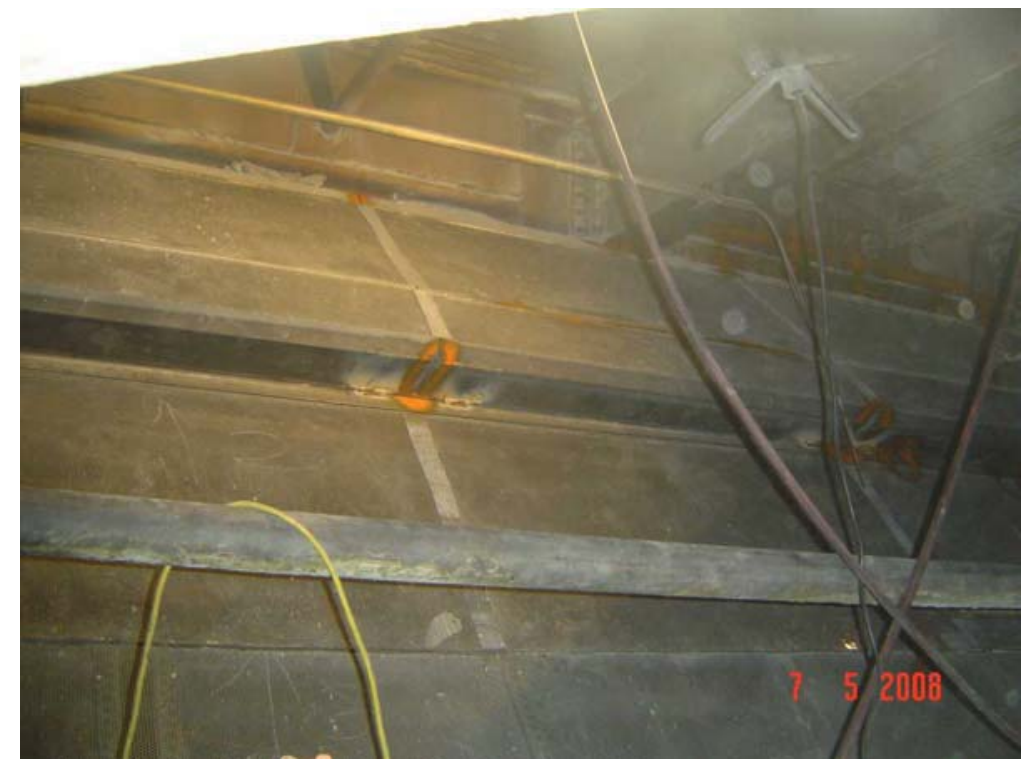

Figure 92. Photograph from the May 2008 outage showing the new LPA screen (installed) and the new hinged seal connecting the two LPA screen sections.

Immediately following the May 2008 outage, the full-load pressure drop across the SCR catalyst returned to its normal, clean catalyst baseline value of $\sim 1.1$ iwc. This pressure drop then began to increase gradually at the end of May, and by June 19, it had risen to $\sim 2.4$ iwc. That day, plant personnel realized that the operating pressure of the rake soot blower had been set to just $20 \mathrm{psi}$ rather than the desired $60 \mathrm{psi}$. Upon increasing the pressure and operating the soot blower, the pressure drop across the SCR catalyst decreased to 1.4-1.5 iwc, illustrating the importance of the rake soot blower in keeping the catalyst clean. (The abrupt decrease in pressure drop across the catalyst on June 19 is clearly visible in Figure 85). Plant personnel were able to maintain a relatively constant pressure drop across the SCR catalyst for the rest of June by operating the rake soot blower four times per day at 60 psi. 
On the evening of July 4, 2008, AES Greenidge unexpectedly had to take Unit 4 offline to repair an economizer tube leak. Although unrelated to the multi-pollutant control system, the outage gave plant personnel an opportunity to inspect the in-duct SCR reactor and gauge the performance of the LPA removal system. Just prior to the outage, the pressure drop across the SCR catalyst rose to about $1.7 \mathrm{iwc}$ at full load. Upon inspecting the reactor, plant personnel found that the large particle ash screen and catalyst screen were partially plugged with wet fly ash and some LPA. It is unclear how much the tube leak contributed to this plugging. Some catalyst channels were plugged, but these were fairly well distributed across the cross section of the catalyst. There were no piles of fly ash on top of the catalyst screen, as had been observed during some previous outages, and the extent of catalyst plugging appeared to be less than it would have been in the past after $\sim 8$ weeks of operation. Plant personnel vacuumed the LPA screen and catalyst screen (they did not remove the catalyst screen to vacuum the catalyst directly), and the unit returned to service on the morning of July 6.

The high-load pressure drop across the SCR catalyst remained relatively constant at 1.5-2.0 iwc through the end of September 2008. (AES Greenidge generally continued to operate the rake soot blower four times per day at $60 \mathrm{psi}$, although they raised the operating pressure several times in late August in order to correct an apparent slight increase in pressure drop). AES Greenidge Unit 4 was derated by several megawatts throughout much of August and September 2008, because two coal burners were damaged by flame attachments and had to be taken out of service. The unit was further derated by about 3-7 MW during several weeks in September while it co-fired Powder River Basin coal with Northern Appalachian coal. (The derate was required because of the high moisture content of the PRB coal). These derates may have contributed to a slower rate of LPA accumulation in the catalyst.

AES Greenidge held an outage on October 3-6, 2008, to repair the damaged coal burners. During the outage, plant personnel inspected the in-duct SCR reactor. Although some LPA had accumulated in the LPA screen, catalyst screen, and catalyst, the amount of accumulation appeared to be much less than was typically observed prior to May 2008, when the original, larger-pitch LPA screen was in service. Based on a visual inspection, the larger-pitch honeycomb catalyst test modules appeared to be less plugged than the smaller-pitch honeycomb catalyst modules or the corrugated catalyst test module. Plant personnel vacuumed LPA from the catalyst screen (they did not remove the screen to access the catalyst directly) and cleaned the catalyst from above using an air lance. The pressure drop across the SCR catalyst was about 1.7 iwc at high loads following the outage.

The improvements made to the LPA removal system during the outages in September 2007, December 2007, and May 2008 all appeared to be effective in reducing the severity of the catalyst plugging problem. This is illustrated in Figure 93, which shows the rate of increase in the high-load pressure drop across the SCR reactor following each of these outages. The pressure drop data are plotted as a function of cumulative megawatt-hours of operation after each outage. Data collected after the August 2007 SCR cleaning outage are also included to provide a baseline for comparison.

As shown in the figure, the rate of increase in pressure drop across the SCR catalyst became less severe with each successive improvement to the LPA removal system. Following the August 10-12, 2007, outage, which occurred prior to the installation of the rake soot blower, the high-load pressure drop across the catalyst increased from 1.1 iwc to 3 iwc after only 25,000 MWh of operation. The rake soot blower was installed during the outage on September 4-10, 2007, as were the spring seal and rotary soot blowers for the LPA screen. Following that 
outage, $\sim 80,000 \mathrm{MWh}$ of operation were logged before the pressure drop across the SCR catalyst reached 3 iwc. The SCR catalyst was not changed out during the August 10-12 or September 4-10 outages. A fresh catalyst layer was installed during the outage on December 27, 2007 - January 3, 2008, though, and plant personnel thoroughly patched gaps in the LPA screen during that outage. This substantially slowed the rate of increase in pressure drop across the SCR reactor. As shown in Figure 93, 170,000 MWh of operation were logged before the pressure drop reached 3 iwc. Finally, during the May 2-10, 2008, outage, the catalyst was again changed, and the smaller-pitch LPA screen and hinged seal were installed. The pressure drop across the SCR catalyst never reached 3 iwc during about 290,000 MWh of operation following this outage. However, the change in soot blowing pressure in June, the economizer tube leak (and associated SCR cleaning) in July, and the derates in August and September make it difficult to ascertain the extent of improvement in performance afforded by the smaller-pitch LPA screen. Nevertheless, the pressure drop across the catalyst remained below 2 iwc during more than 170,000 MWh of continuous operation between early July and late September 2008, without any indication of an exponentially increasing trend. (By comparison, in all previous cases, the pressure drop had surpassed 3 iwc after $\leq 170,000 \mathrm{MWh}$ of uninterrupted operation). This suggests that the smaller-pitch LPA screen brought about some reduction in the severity of the SCR plugging problem.

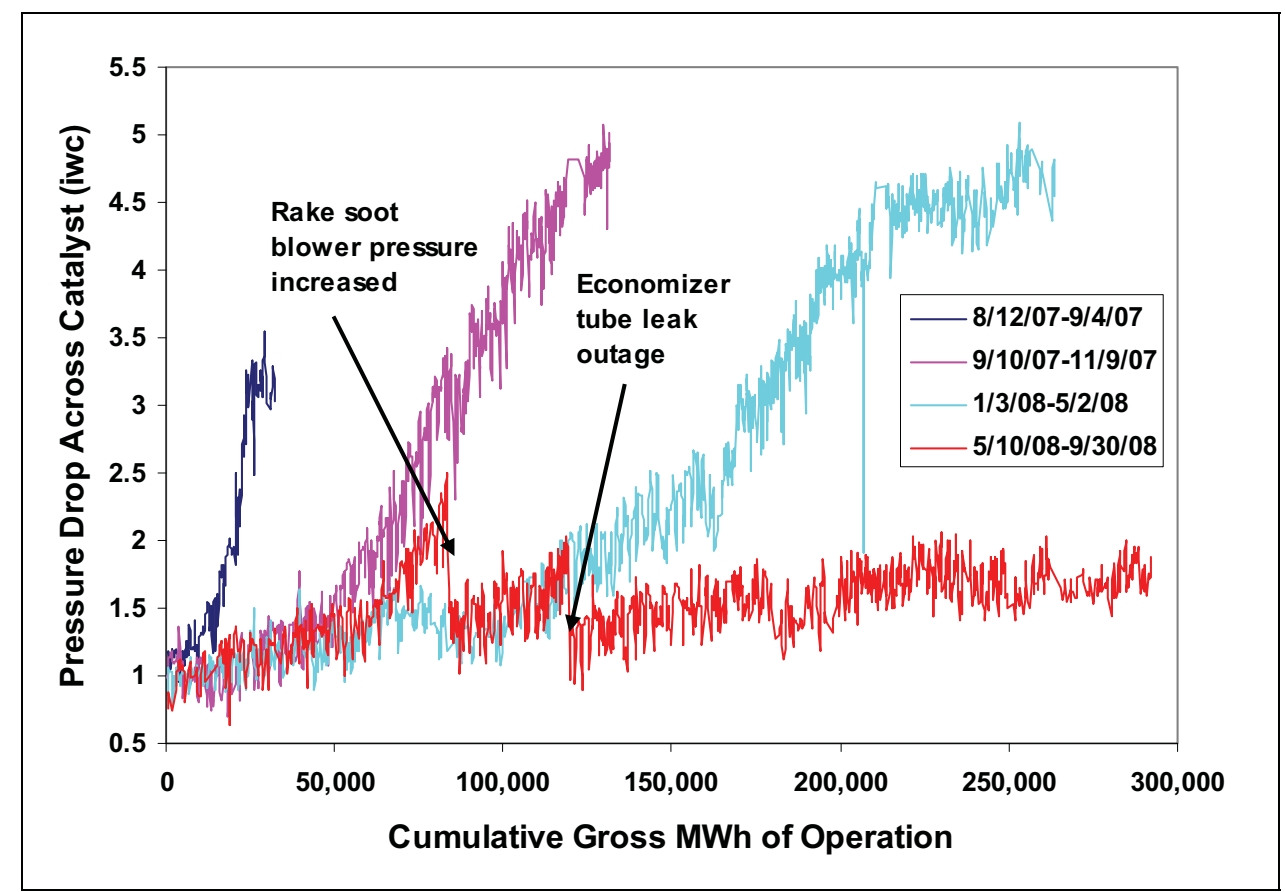

Figure 93. Plot comparing the rates of increase in pressure drop across the SCR catalyst at AES Greenidge Unit 4 following the outages in August 2007 (navy blue), September 2007 (magenta), December 2007 (light blue), and May 2008 (red). For each case, the plot shows the high-load pressure drop across the SCR catalyst as a function of the cumulative MWh of operation since the conclusion of the outage. The high-load pressure drop includes all hourly average pressure drops measured when the unit was operating at $\geq 90 \mathrm{MW}_{\mathrm{g}}$.

In summary, the project team made substantial progress in mitigating the large particle ash problem during the Operation and Testing Phase of the project. The data presented above indicate that, while the LPA screen was clearly a central part of the solution, the rake soot blower also played a very important role in reducing catalyst plugging. Additional operating 
experience is required to confirm the rate of catalyst plugging with the smaller-pitch LPA screen and to determine the long-term durability of the screen in the hot, particle-laden environment upstream of the SCR reactor. In the meantime, AES Greenidge continues to explore options for further mitigation of the LPA problem. As of the end of the project, they were evaluating the possibility of using alternative catalyst designs (e.g., plate-type catalyst) that may be less susceptible to plugging.

\subsubsection{Turbosorp ${ }^{\circledR}$ System and Ancillary Equipment}

As discussed in Section 4.2.5, the Turbosorp ${ }^{\circledR}$ system is mechanically simple relative to many alternative FGD technologies, and therefore, it is expected to afford low maintenance requirements. This was generally true at AES Greenidge during the Operation and Testing Phase of the project. All of the challenges encountered with the Turbosorp ${ }^{\circledR}$ process had significantly less impact on the operation of the multi-pollutant control system than the LPA problem discussed above. Nevertheless, the Turbosorp ${ }^{\circledR}$ system and its ancillary equipment at times required non-routine O\&M attention, and the lessons learned from this O\&M experience may help to improve the design of future installations of the Turbosorp ${ }^{\circledR}$ technology.

\subsubsection{Lime Hydration System}

The majority of the O\&M requirements associated with the Turbosorp ${ }^{\circledR}$ process during its first year-and-a-half of operation involved the lime hydration system, which is the most mechanically complex part of the process.

Most of the problems occurred in the hydrated lime milling and classification system. During August-November 2007, plant personnel endured several episodes of plugging in the hydrated lime classification loop. The most noteworthy episode occurred in early October, when Unit 4 was firing a higher-than-normal sulfur coal (i.e., containing approximately $4.4-4.9 \mathrm{lb}$ $\mathrm{SO}_{2} / \mathrm{mmBtu}$ ) for performance testing, resulting in increased hydrated lime demand for the scrubber. Although this demand was well within the design limits for the lime hydration system, the hydrated lime classifier plugged numerous times on October 3 and 4, causing the lime hydration system to trip. AES Greenidge personnel were diligent in unplugging the lime hydration system and in taking deliveries of hydrated lime to allow the unit to continue to operate during this period, and the problems subsided when the unit returned to firing coal with more typical sulfur content (i.e., $4.0-4.3 \mathrm{Ib} \mathrm{SO}_{2} / \mathrm{mmBtu}$ ). After additional sporadic plugging in November, plant personnel slowed the speed of one of the rotary feeders in the classification system, because they believed that the feeder previously was operating too rapidly to allow its pockets to fill, causing fines to build up in the system. This modification reduced the severity of the problem. In addition, since the end of the project in October 2008, AES Greenidge installed a new soft start on the classifier fan, which has significantly improved the reliability of the lime hydration system.

Another recurring problem involved the escape of balls from the ball mill. This first occurred in July 2007, when several escaped balls caused minor damage to the lime hydration system, forcing it offline for repair. Similar problems were encountered during the first quarter of 2008. On several occasions, balls escaped from the ball mill and jammed the rotary feeder that removes heavies from the hydrated lime classifier. Moreover, in mid-March 2008, an escaped ball caused the screw conveyer at the classifier outlet to fail, again forcing the lime hydration 
system offline. Plant personnel installed magnets at the inlet and outlet of the bucket elevator to capture escaped balls before they can reach the classifier, and this has helped to mitigate the problem. They also recently recharged the ball mill with less-brittle balls, because the original balls were breaking too frequently, allowing metal fragments to escape the mill and interfere with operation of the system.

Other non-routine problems encountered with the lime hydration system, and the actions taken to solve them, were as follows:

- On May 3, 2007, the water feed rate to the lime hydrator was out of limits, causing the hydrator to plug and require cleaning. The control logic for the hydrator was modified to prevent this problem from occurring again in the future.

- During the week of August 20, 2007, the lime hydration system had to be taken offline because the bucket elevator shaft failed. Plant maintenance personnel repaired the problem, and the system returned to service.

- In mid-November 2007, one of the hydrated lime classifier fan bearings failed. The lime hydration system was taken offline while the problem was repaired.

- On January 15, 2008, a bolt fell out of the ball mill, allowing balls to spill on the ground. The lime hydration system was taken offline while the problem was addressed.

- The original hydrated lime classifier eroded severely during the first year of operation. A new, ceramic-lined classifier was installed during the unit's May 2008 outage to provide resistance to erosion.

- On June 19, 2008, the hydrated lime silo level transmitter failed, causing the hydrator (which is controlled automatically based on the silo level) to produce hydrated lime at a slower rate than required to keep up with demand. The level transmitter was not able to be repaired onsite, and the lime hydration system was operated for several days by taking periodic, manual hydrate silo level measurements and adjusting the hydrator output accordingly. The level transmitter was repaired and returned to service the following week; however, the problem recurred in mid-July. The silo level measurements also appeared to be affected by dust interferences. As of the end of the project, plant personnel were evaluating options for improving the reliability of these measurements.

- The hydrator mixer plugged soon after returning to service following the Unit 4 outage on October 3-6, 2008. Plant personnel cleared the hydrator and worked through problems with lime buildup in the pebble lime belt feeder, and the lime hydration system returned to service on the evening of October 7.

Many of the problems with the lime hydration system required that it be taken out of service for maintenance or repair. This can be accomplished without impacting operation of the Turbosorp ${ }^{\circledR}$ process if there is a sufficient inventory of hydrated lime available to satisfy the demand from the scrubber. However, the hydrated lime storage silo that was installed as part of the multi-pollutant control system, which has a capacity of $2,200 \mathrm{ft}^{3}$, only holds enough hydrated lime for about six hours of operation at full load, assuming design conditions. For longer hydrator outages, this inventory can be replenished by taking deliveries of hydrated lime, 
allowing continued operation of the Turbosorp ${ }^{\circledR}$ system. Deliveries often required greater than six hours to arrive, though, and Unit 4 had to be derated during several of the hydrator outages because of insufficient hydrated lime supply. During the fourth quarter of 2007, AES Greenidge began renting a temporary storage tanker to enable them to maintain a larger onsite inventory of hydrated lime. As of the end of the project, they were procuring a $10,000 \mathrm{ft}^{3}$ silo to significantly increase their hydrate storage capacity. This will afford much more flexibility for performing offline maintenance on the hydrator without adversely affecting the operation of Unit 4.

\subsubsection{Turndown}

Per the discussion in Section 6.2.4, the Turbosorp ${ }^{\circledR}$ system at AES Greenidge Unit 4 was installed with a flue gas recirculation system to preserve the unit's turndown capability. The recirculation system was designed to recycle flue gas from the booster fan outlet duct (upstream of the ID fans) to the Turbosorp ${ }^{\circledR}$ inlet duct in order to maintain sufficient fluidizing velocity in the absorber vessel at low unit loads. In practice, however, the flue gas recirculation system has behaved unstably when it is operated in automatic control mode. At times, this has resulted in adverse pressure gradients that create the potential for reverse flow through the recirculation duct (i.e., such that flue gas could potentially bypass the Turbosorp ${ }^{\circledR}$ system by traveling through this duct).

Thus, AES has generally operated Unit 4 so that the flue gas flow rate upstream of the Turbosorp $^{\circledR}$ system is adequate to maintain a fluidized bed in the absorber vessel without having to use the flue gas recirculation system. This has reduced the unit's maximum turndown by about $8 \mathrm{MW}_{\mathrm{n}}$, increasing its minimum operating load from about $37 \mathrm{MW}_{\mathrm{n}}$ prior to the project to about $45 \mathrm{MW}_{\mathrm{n}}$ after the project. AES is able to operate the flue gas recirculation system in manual mode when necessary, such as during start-up of the unit.

The problems with automatic control of the flue gas recirculation system likely could have been avoided if the recycle stream was taken from the discharge of the ID fans rather than from the discharge of the booster fan. This approach was not taken at AES Greenidge, because it would have been necessary to move the ID fans to accommodate tie-in of the recirculation duct. In retrospect, given the loss of turndown, it may have been better to replace the two existing ID fans with two larger-capacity fans, rather than installing the booster fan, and to take the flue gas recycle stream from the discharge of these new ID fans. This option should be considered in future installations of the Turbosorp ${ }^{\circledR}$ technology.

\subsubsection{Cold Weather Problems}

As discussed earlier, the Turbosorp ${ }^{\circledR}$ system at AES Greenidge is located in an open structure outside of the boiler building, and it is therefore exposed to ambient weather conditions. AES Greenidge generally experiences cold winters (ambient temperatures as low as $1{ }^{\circ} \mathrm{F}$ were observed at the plant during the winter of 2007-2008), and these cold temperatures at times caused problems with operation of the Turbosorp ${ }^{\circledR}$ system. As discussed in Section 8.3, frozen lines and valves resulting from frigid weather hampered start-up of the Turbosorp ${ }^{\circledR}$ system in February 2007. The following year, in February 2008, plant personnel again encountered problems with freezing lines and valves in the lime hydration system and with freezing and clogging of the dosing valves in the Turbosorp ${ }^{\circledR}$ system during periods of cold weather. They succeeded in overcoming these problems by cleaning, heating, and/or insulating the problem 
areas, and they were able to operate the Turbosorp ${ }^{\circledR}$ system with a low set point for $\mathrm{SO}_{2}$ emissions to make up for the higher-than-normal emissions encountered during the problem period. In early March 2008, AES Greenidge encountered problems with frozen pressure transmitters in the Turbosorp ${ }^{\circledR}$ system, which caused them to lose the fluidized bed in the absorber vessel several times. Plant personnel thawed the transmitters, and the scrubber returned to normal operation.

Harsh weather conditions, including cold temperatures, wind, and icing, also made it more difficult for plant O\&M personnel to service the Turbosorp ${ }^{\circledR}$ equipment at times during winter. In light of these experiences, consideration should be given to enclosing the Turbosorp ${ }^{\circledR}$ system in locations that commonly experience cold weather.

As discussed in Section 4.3.11, because the Turbosorp ${ }^{\circledR}$ system operates near the adiabatic saturation temperature of the flue gas, there is a potential for condensation and ash deposition if the absorber vessel is not well insulated. This potential increases in cold climates. The inside of the Turbosorp ${ }^{\circledR}$ vessel was inspected during an outage in May 2008, following more than a year of operation, and no evidence of any significant ash deposition was discovered. Plant personnel again inspected the absorber vessel internals in October 2008 and reported that while the inlet cone was clean, there appeared to be some small deposits higher in the vessel. These deposits were too minor to warrant further action, however. Hence, in spite of cold weather conditions, no major condensation issues were encountered in the Turbosorp ${ }^{\circledR}$ absorber vessel at AES Greenidge.

\subsubsection{Baghouse}

As discussed in Section 6.3.5, the compressed air demand from the baghouse exceeded expectations. It was originally anticipated that the baghouse would require about $300 \mathrm{scfm}$ of compressed air; however, the actual demand was about $600 \mathrm{scfm}$ during normal operation and as much as $1200 \mathrm{scfm}$ during start-up. As a result, AES Greenidge had to install additional compressor capacity (outside of the scope of the DOE project) to handle the excess demand.

In addition, the valves at the inlet to the baghouse modules did not work properly, preventing plant personnel from being able to isolate the individual modules for online maintenance. An inspection of the baghouse near the end of the project in October 2008 revealed significant ash accumulation around these valves, suggesting that some condensation had occurred. Plant personnel cleaned the ash from one of the eight modules, and they planned to clean the other seven modules during a future outage. The valves should be exercised frequently as part of normal operating practice to maintain their mobility.

No other problems were encountered with operation of the baghouse. As stated in Section 10.1, no baghouse bags or cages failed during the Operation and Testing Phase of the project. In addition, no problems were encountered with plugging or binding of the bags.

\subsubsection{Ash Recirculation System}

On a few occasions, short-lived problems with the ash recirculation system required non-routine maintenance and/or hindered operation of the Turbosorp ${ }^{\circledR}$ system. These minor problems included the following: 
- During the weekend of January $19-20,2008$, Unit 4 had to be derated for several hours when one side of the ash disposal system plugged. The problem appeared to result from the control strategy for disposing ash from the ash recirculation system, which biased the entire ash disposal to one of the air slides. AES considered modifications to the control scheme for the ash disposal system to prevent this problem from recurring.

- During April 2008, plugging occurred around the rotary air locks and in the ash disposal lines that are located between the air slides and the product ash silos. On at least one occasion, the plugging appeared to be caused by rain leakage around the knife gate valves downstream of the air slides. Plant personnel were able to resolve all of the plugging issues without having to derate Unit 4.

- On June 15 and 16, 2008, concrete-like deposits formed in one side of the ash disposal system, forcing one of the ash silos out of service. Plant personnel were able to continue to operate the Turbosorp ${ }^{\circledR}$ system using the other silo while they cleared the deposits.

- In September 2008, plant personnel found it difficult for a time to maintain an inventory of product ash in one of the air slides, but they overcame this problem by adjusting set points associated with the air slide level control.

An important design feature of the ash recirculation and disposal system is the ability for either side of the system (i.e., either of the two air slides or either of the two ash disposal silos) to handle $100 \%$ of the required throughput of product ash. This significantly reduced the severity of impact from problems that involved only one side of the system. To improve the performance of the ash recirculation system, AES Greenidge installed larger motors on the air slide blowers in May 2008. These new, 30-hp motors were expected to reduce the likelihood that the system would trip because of high air slide ash levels. They also now operate the rotary air locks above the ash disposal silos on a regular basis (at least once every 15 minutes) to prevent them from plugging.

\subsubsection{Miscellaneous}

Other minor problems encountered with the Turbosorp ${ }^{\circledR}$ process during the Operation and Testing Phase of the project included the following:

- In May 2008, the $\mathrm{SO}_{2}$ analyzer upstream of the absorber vessel malfunctioned. This analyzer, which provides one of the inputs to the control loop that governs how much hydrated lime is injected into the absorber, was out of service for several days while AES Greenidge waited for a replacement part. During that time, plant personnel had to operate the Turbosorp ${ }^{\circledR}$ scrubber with the hydrated lime injection control system in manual mode. (They had trouble scaling back the hydrated lime injection rate during drops in load, and they likely overfed hydrate in trying to ensure that the unit's $\mathrm{SO}_{2}$ emissions remained within its permit limit). The inlet $\mathrm{SO}_{2}$ analyzer was repaired, and the hydrated lime injection control system returned to normal, automatic operation.

- In September 2008, AES Greenidge experienced some minor problems with plugging in the hydrated lime feed pipe. The Turbosorp ${ }^{\circledR}$ system was able to continue to operate in spite of this plugging. The timing of the problem coincided with misty weather conditions 
at the plant. Plant personnel took advantage of the unit's outage on October 3-6, 2008, to thoroughly clean the feed pipe.

\subsection{Operating and Maintenance Labor Requirements}

AES Greenidge was able to operate and maintain the multi-pollutant control system without adding any new O\&M personnel. As discussed in Section 10.1, AES is able to run Unit 4, including the multi-pollutant control system, with three-to-four operators per shift (one control room operator plus two-to-three auxiliary operators). This is the same level of staffing that was required prior to installation of the multi-pollutant control system. Maintenance staffing per shift also did not change as a result of the installation of the multi-pollutant control system.

Quantification of the O\&M labor requirements associated with the multi-pollutant control system was complicated, however, by the fact that the plant's other unit - Unit 3-operated much less frequently in 2007 and 2008 than it did prior to installation of the multi-pollutant control system. As a result, O\&M time that would have been spent on Unit 3 could instead be spent attending to the multi-pollutant control system, with no net increase in staffing requirement. Plant personnel estimate that, if Unit 3 had continued its pre-project level of operation, four additional full-time positions (two operators and two maintenance personnel) would have been required to accommodate the increase in O\&M work arising from the multi-pollutant control system. This estimate appears to be conservative based on experience during the first year-and-a-half of operation. For example, plant operations personnel tracked their hours by task during MarchOctober 2008, and on average, only six operator hours per day (as opposed to the 12 hours per day implied by the estimate above) were spent on the multi-pollutant control system. However, much of the additional time in the estimate is intended to account for the occasional overtime and increased staffing needed to handle non-routine O\&M requirements such as those described in the preceding section. Moreover, O\&M labor requirements are expected to increase over the life of the system as the multi-pollutant control equipment ages and requires more attention.

\subsection{Byproduct Disposal}

As discussed in Section 6.3.6, the only major solid or liquid byproduct produced by the multipollutant control system is the product ash from the Turbosorp ${ }^{\circledR}$ system. The product ash, which is pictured in Figure 94, is a fine, dry, powdery material consisting of a mixture of fly ash and scrubber byproduct (i.e., reaction products and unreacted hydrated lime). AES Greenidge does not directly measure the mass flow rate of product ash that is discharged from the Turbosorp ${ }^{\circledR}$ process; however, this flow rate was estimated as part of the material balances that were performed for each of the 34 mercury tests conducted between March 2007 and June 2008 (see Section 9.2.1.3.5.3 and Appendix K). The material balances indicated that, on average, about $20,540 \mathrm{lb} / \mathrm{h}$ of product ash (including fly ash) was produced at full load. (This is based on the results of the 28 tests conducted when the unit was operating at greater than $100 \mathrm{MW}_{\mathrm{g}}$ ). If the mass contributed by fly ash is excluded, about $13,260 \mathrm{lb} / \mathrm{h}$ of scrubber byproduct was produced on average. This compares closely with the projected rate of $13,174 \mathrm{lb} / \mathrm{h}$ discussed in Section 6.3.6. Figure 95 shows the relationship between the mass of scrubber byproduct generated in the Turbosorp ${ }^{\circledR}$ process and the mass of $\mathrm{SO}_{2}$ removed by the process, based on the results of the 34 material balances. On average, about $3.4 \mathrm{lb}$ of scrubber byproduct (excluding fly ash) was produced for every $\mathrm{lb}$ of $\mathrm{SO}_{2}$ removed. 


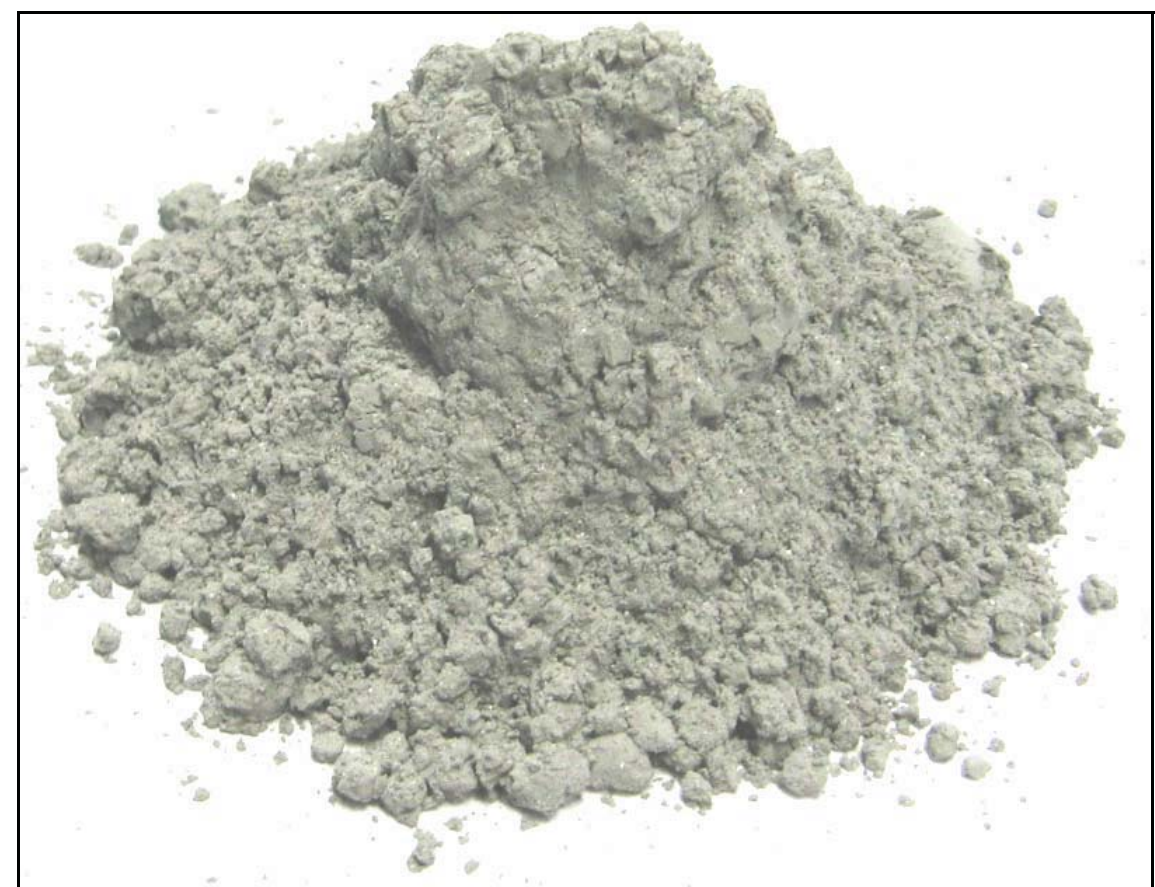

Figure 94. Photograph of the product ash, including a mixture of scrubber byproduct and fly ash, produced by the Turbosorp ${ }^{\circledR}$ process at AES Greenidge Unit 4.

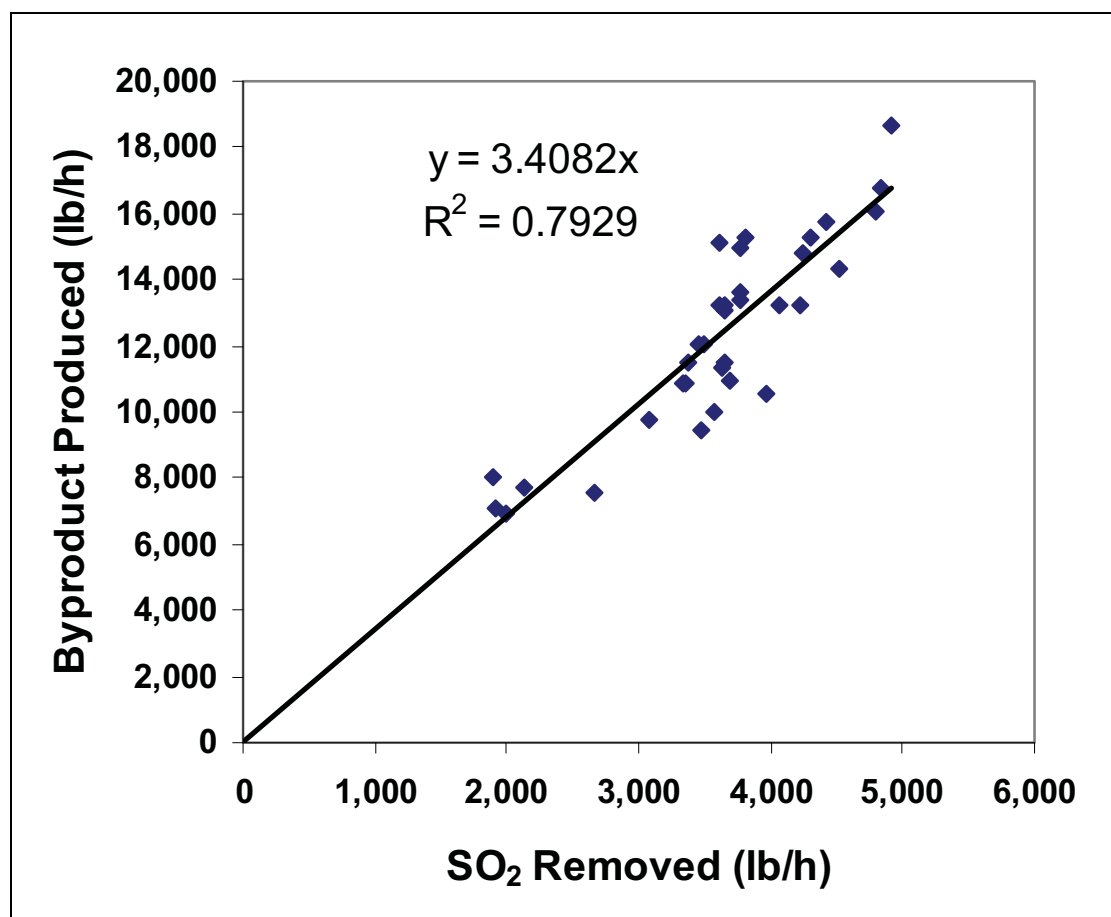

Figure 95. Scatter plot showing the mass flow rate of scrubber byproduct (excluding fly ash) produced by the Turbosorp ${ }^{\circledR}$ process vs. the mass flow rate of $\mathrm{SO}_{2}$ removed by the process, with simple linear regression results. Data were derived from the material balances performed for each of the 34 mercury tests conducted at AES Greenidge between March 2007 and June 2008. 
As discussed earlier, AES Greenidge disposes of the Turbosorp ${ }^{\circledR}$ product ash in a landfill located near the plant. The product ash is transported from the plant to the landfill via truck. Installation of the Turbosorp ${ }^{\circledR}$ system has caused a significant increase in the quantity of material that must be transported and the rate at which the landfill is occupied. In addition, plant personnel reported that the product ash is more difficult to condition with the plant's paddle mixer and results in more fugitive dust than pure fly ash. Overall, however, no major problems have been encountered with disposal of the product ash.

The mercury that is captured by the Turbosorp ${ }^{\circledR}$ process resides in the product ash. To determine the potential for leaching of this mercury, sixteen product ash samples collected during the testing campaigns in November 2007, March 2008, May 2008, and June 2008 were analyzed by the Synthetic Precipitation Leaching Procedure (SPLP), as described in Section 9.2.2.2.1. This procedure is designed to evaluate the mobility of metals in properly engineered landfills that do not include municipal waste. It uses leaching solution with a $\mathrm{pH}$ of 4.2 to simulate the type of acid precipitation that may be encountered east of the Mississippi River. Results are shown in Table 34. The leachates from the November 2007 samples were analyzed for $\mathrm{Hg}$ by cold vapor atomic absorption spectroscopy, and the leachates from all subsequent samples were analyzed for $\mathrm{Hg}$ by cold vapor atomic fluorescence spectroscopy, which has a lower detection limit. All of the SPLP tests indicated a very low potential for Hg leaching from the product ash. For the three tests that used CVAAS, the concentration of $\mathrm{Hg}$ in the leachate was below the analytical detection limit of $0.35 \mu \mathrm{g} / \mathrm{L}$. For the remaining 13 tests that used CVAFS, the mean concentration of $\mathrm{Hg}$ in the leachate was $0.036 \mu \mathrm{g} / \mathrm{L}$. (By comparison, the U.S. EPA drinking water standard for $\mathrm{Hg}$ is $2 \mu \mathrm{g} / \mathrm{L}$ ). These tests indicated that, on average, only $0.13 \%$ of the $\mathrm{Hg}$ in the product ash was leached.

Table 34. Synthetic Precipitation Leaching Procedure results for sixteen Turbosorp ${ }^{\circledR}$ product ash samples collected at AES Greenidge Unit 4 between November 2007 and June 2008.

\begin{tabular}{|l|c|c|cc|}
\hline $\begin{array}{l}\text { Sample Collection } \\
\text { Date / Time (local) }\end{array}$ & $\begin{array}{c}\text { Hg Concentration } \\
\text { in Leachate } \\
(\boldsymbol{\mu g} / \mathbf{L})\end{array}$ & $\begin{array}{c}\text { Total Hg in } \\
\text { Product Ash } \\
(\boldsymbol{\mu g} / \mathbf{g})\end{array}$ & $\begin{array}{c}\text { Hg Leached from } \\
\text { Product Ash } \\
(\boldsymbol{\mu g} / \mathbf{g})\end{array}$ & $\begin{array}{c}\text { Hg Leached } \\
\text { from Product } \\
\text { Ash } \\
\mathbf{( \% )}\end{array}$ \\
\hline $11 / 14 / 070145$ & $<0.35$ & 0.469 & $<0.01$ & $<1.49 \%$ \\
\hline $11 / 15 / 070600$ & $<0.35$ & 0.608 & $<0.01$ & $<1.15 \%$ \\
\hline $11 / 16 / 071945$ & $<0.35$ & 0.673 & $<0.01$ & $<1.04 \%$ \\
\hline $03 / 10 / 081530$ & 0.008 & 0.439 & 0.0002 & $0.04 \%$ \\
\hline $03 / 11 / 081645$ & 0.011 & 0.458 & 0.0002 & $0.05 \%$ \\
\hline $03 / 12 / 081630$ & 0.019 & 0.422 & 0.0004 & $0.09 \%$ \\
\hline $03 / 13 / 081600$ & 0.032 & 0.453 & 0.0006 & $0.14 \%$ \\
\hline $05 / 20 / 080520$ & 0.073 & 0.357 & 0.0004 & $0.10 \%$ \\
\hline $05 / 21 / 080500$ & 0.065 & 0.369 & 0.0003 & $0.09 \%$ \\
\hline $05 / 22 / 080200$ & 0.047 & 0.355 & 0.0002 & $0.07 \%$ \\
\hline $06 / 12 / 081700$ & 0.032 & 0.312 & 0.0006 & $0.21 \%$ \\
\hline $06 / 13 / 081700$ & 0.042 & 0.337 & 0.0008 & $0.25 \%$ \\
\hline $06 / 16 / 081730$ & 0.053 & 0.486 & 0.0011 & $0.22 \%$ \\
\hline $06 / 17 / 081745$ & 0.026 & 0.356 & 0.0005 & $0.14 \%$ \\
\hline $06 / 18 / 081800$ & 0.025 & 0.314 & 0.0005 & $0.16 \%$ \\
\hline $06 / 19 / 081800$ & 0.037 & 0.320 & 0.0007 & $0.23 \%$ \\
\hline
\end{tabular}

NOTE: The SPLP leachates from November 2007 were analyzed using CVAAS; all other leachates were analyzed using CVAFS. 
The chemical composition of the Turbosorp ${ }^{\circledR}$ product ash was determined throughout the Operation and Testing Phase of the Greenidge Project by analyzing samples collected during the special test series in March 2007 through October 2008. The results from all of these analyses are included in Appendix J. Table 35 shows the average chemical composition of product ash samples collected during follow-up testing on June 10-13, 2008, when Unit 4 and the multi-pollutant control system were operating near design conditions. Noteworthy characteristics of the product ash include the low moisture content $(<1 \%)$, the moderate concentration of fly ash, and the presence of unreacted lime. Moreover, product ash samples from March 2007 and June 2008 were analyzed to determine physical properties, including particle size distribution and surface area. These analyses indicated that the product ash has a median particle diameter of $\sim 6-7 \mu \mathrm{m}$ and a surface area of $\sim 6 \mathrm{~m}^{2} / \mathrm{g}$.

Table 35. Average results from the chemical analysis of Turbosorp $^{\circledR}$ product ash samples collected during follow-up testing at AES Greenidge Unit 4 on June 10-13, 2008.

\begin{tabular}{|c|c|}
\hline Moisture (\%) & 0.92 \\
\hline Ash (\% dry, ignited @ $\left.750^{\circ} \mathrm{C}\right)$ & 82.81 \\
\hline Carbon (\% dry) & 11.51 \\
\hline Chlorine (\% dry) & 0.34 \\
\hline Mercury (ppm dry) & 0.322 \\
\hline Fluorine (ppm dry) & 90.90 \\
\hline Ammonia (ppm dry) & 28.75 \\
\hline Paste $\mathrm{pH}$ & 12.80 \\
\hline Available $\mathrm{Ca}(\mathrm{OH})_{2}(\%)$ & 4.15 \\
\hline \multicolumn{2}{|c|}{ Major Ash Elements (\% of total sample, dry) ${ }^{a}$} \\
\hline $\mathrm{SiO}_{2}$ & 13.61 \\
\hline $\mathrm{Al}_{2} \mathrm{O}_{3}$ & 6.90 \\
\hline $\mathrm{TiO}_{2}$ & 0.31 \\
\hline $\mathrm{Fe}_{2} \mathrm{O}_{3}$ & 4.87 \\
\hline $\mathrm{CaO}$ & 32.12 \\
\hline $\mathrm{MgO}$ & 0.61 \\
\hline $\mathrm{Na}_{2} \mathrm{O}$ & 0.39 \\
\hline $\mathrm{K}_{2} \mathrm{O}$ & 0.40 \\
\hline $\mathrm{P}_{2} \mathrm{O}_{5}$ & 0.09 \\
\hline $\mathrm{SO}_{3}$ & 24.93 \\
\hline
\end{tabular}

${ }^{\mathrm{a}}$ Elemental results are reported in oxide form by convention.

The chemical and physical properties of the Turbosorp ${ }^{\circledR}$ product ash, which are similar to those of spray dryer ash, make it a candidate for use in several commercial applications. According to the most recent statistics available from the American Coal Ash Association (ACAA), about 8\% of the byproduct generated by dry scrubbers (e.g., spray dryers) in the United States is utilized in various engineering, construction, and agricultural applications (ACAA, 2008). These applications typically take advantage of the acid neutralization capability and cementitious characteristics of the byproduct. Mining applications are the largest consumer of dry scrubber byproduct, accounting for $74 \%$ of the total utilization. The byproduct is typically used for mine reclamation and can be used to fill surface mine voids, fill underground voids to prevent subsidence, or prevent and neutralize acid mine drainage. Dry scrubber byproduct is also used in concrete products ( $14 \%$ of the total utilization), as flowable fill $(8 \%)$, in agricultural applications $(2 \%)$, in waste stabilization/solidification $(1 \%)$, as structural fill $(<1 \%)$, and in soil 
modification/stabilization ( $<1 \%)$. In addition to the uses identified in the ACAA survey, CONSOL and Universal Aggregates, LLC, demonstrated the viability of producing manufactured aggregates (e.g., for use in masonry block or roadway construction) from spray dryer scrubbing byproducts (Wu et al., 2005; Wu and Yuran, 2007). Given the similarities between Turbosorp ${ }^{\circledR}$ product ash and spray dryer byproduct, the Turbosorp ${ }^{\circledR}$ product ash could potentially be used in any of these applications. The composition of the product ash is expected to vary from unit to unit, based on differences in factors such as the coal ash content and composition, the coal sulfur content, the fly ash unburned carbon content, and the $\mathrm{SO}_{2}$ removal efficiency. Hence, the suitability of the product ash for reuse will have to be evaluated on a unit- and applicationspecific basis.

During the Operation and Testing Phase of the Greenidge Project, AES actively pursued opportunities for beneficial reuse of the Turbosorp ${ }^{\circledR}$ product ash. They succeeded in supplying 3,500 tons of product ash for use as fill material in a nearby construction project, thereby avoiding the cost associated with landfilling this ash. In most cases, however, potential users of the product ash were located at a significant distance from the plant, and high transportation costs prevented utilization of the ash. This is consistent with the relatively low rate of dry scrubber byproduct utilization identified in the ACAA survey, and suggests that beneficial reuse of the Turbosorp ${ }^{\circledR}$ product ash will be limited to niche applications having attractive economics.

\section{Process Economics}

As discussed earlier, the multi-pollutant control system that was demonstrated at AES Greenidge Unit 4 was designed to provide an affordable emissions control option for smaller coal-fired EGUs. As such, the system was expected to offer lower capital costs and fixed O\&M costs (in exchange for somewhat higher variable O\&M costs) than conventional emissions control retrofit technologies, consistent with the needs of these smaller units.

This section summarizes the estimated capital costs and fixed and variable O\&M costs associated with the multi-pollutant control system at AES Greenidge Unit 4. Process economics were derived using common cost estimating practices as well as design, performance, and cost information from the AES Greenidge installation. In the absence of project-specific information, cost estimating and financing assumptions were generally taken from NETL's Quality Guidelines for Energy System Studies (McGurl et al., 2004). Costs are expressed in constant 2005 dollars, consistent with the start of construction at AES Greenidge Unit 4.

Assumptions regarding the performance of the base plant were taken from the design basis for AES Greenidge Unit 4. Key assumptions are highlighted in Table 36. A capacity factor of $80 \%$ was assumed in accordance with the NETL Quality Guidelines for Energy System Studies. (For the estimates presented here, all of the unit's operating time was assumed to be at full load, such that turndown of the hybrid SNCR/SCR system was not modeled). Capital costs were based on the actual cost to install the multi-pollutant control system at AES Greenidge Unit 4. Fixed operating and maintenance costs were based on the O\&M experience described in Section 10 and on common cost estimating assumptions. Variable O\&M costs were computed in two ways: first using the projected performance at the time of design (as described in Section 6 ), and then using the actual performance observed during the Operation and Testing Phase of the project (as described in Section 9). 
The estimated capital costs, fixed O\&M costs, variable O\&M costs, and levelized costs associated with the multi-pollutant control system are presented in the following subsections.

Table 36. Base plant performance assumptions used in the economic analysis of the multi-pollutant control system at AES Greenidge Unit 4.

\begin{tabular}{|l|c|}
\hline Maximum capacity $\left(\mathrm{MW}_{\mathrm{e}}, \mathrm{net}\right)$ & 107 \\
\hline Fuel feed rate $(\mathrm{lb} / \mathrm{h})$ & 85,692 \\
\hline Fuel HHV (Btu/lb) & 12,426 \\
\hline Fuel sulfur content $(\%, \mathrm{w} / \mathrm{w})$ & 2.5 \\
\hline Fuel Hg content $(\mathrm{ppmw})$ & 0.1 \\
\hline Baseline NO $\mathrm{N}_{\mathrm{x}}$ emission rate $(\mathrm{lb} / \mathrm{mmBtu})$ & 0.30 \\
\hline Flue gas flow rate at air heater outlet $(\mathrm{acfm})$ & 423,700 \\
\hline Annual capacity factor $(\%)$ & 80 \\
\hline
\end{tabular}

\subsection{Capital Costs}

Table 37 summarizes the capital costs for the multi-pollutant control system at AES Greenidge Unit 4. Costs are summarized for the overall plant, and they are also broken down by major project subsystem. Costs for the hybrid $\mathrm{NO}_{x}$ control system include the costs for the combustion modifications, SNCR system, in-duct SCR system, static mixers, sonic horns, large particle ash removal system, and all supporting equipment. (Even though the combustion modifications and large particle ash removal system were not part of the scope of the DOE project, they are included in this cost estimate because they are essential to the performance and operability of the installation at AES Greenidge Unit 4. The costs for the LPA removal system reflect the final design as of May 2008.) Costs for the circulating dry scrubbing system include the costs for the absorber vessel, process water system, lime storage, hydration, and injection system, baghouse, ash recirculation system, booster fan, and all supporting equipment. (The entire booster fan cost was included with the circulating dry scrubbing system because this system accounts for a majority of the pressure drop added by the multi-pollutant control system).

Table 37. Capital costs for the multi-pollutant control system at AES Greenidge Unit 4. Costs are expressed in 2005 dollars.

\begin{tabular}{|l|c|c|c|c|c|c|}
\hline & \multicolumn{2}{|c|}{$\begin{array}{c}\text { Total Plant } \\
\text { Cost }\end{array}$} & \multicolumn{2}{c|}{$\begin{array}{c}\text { Total Plant } \\
\text { Investment }\end{array}$} & \multicolumn{2}{c|}{$\begin{array}{c}\text { Total Capital } \\
\text { Requirement }\end{array}$} \\
\hline & $\$ \mathbf{M M}$ & $\mathbf{\$} / \mathbf{k W}_{\text {net }}$ & $\mathbf{\$ M M}$ & $\mathbf{\$} / \mathbf{k W}_{\text {net }}$ & $\mathbf{\$ M M}$ & $\mathbf{\$} / \mathbf{k W}_{\text {net }}$ \\
\hline Hybrid $\mathrm{NO}_{\mathbf{x}}$ Control System & 12.2 & 114 & 12.5 & 117 & 12.9 & 120 \\
\hline Circulating Dry Scrubber System & 24.5 & 229 & 25.1 & 234 & 26.1 & 244 \\
\hline Activated Carbon Injection System & 0.6 & 6 & 0.6 & 6 & 0.6 & 6 \\
\hline TOTAL & 37.3 & 349 & 38.2 & 357 & 39.6 & 370 \\
\hline
\end{tabular}

Capital costs are expressed as total plant cost (TPC), total plant investment (TPI), and total capital requirement (TCR). The total plant costs presented in Table 37 are the EPC capital costs for the AES Greenidge Unit 4 installation and include the costs to design, procure, fabricate, deliver, install, and commission the multi-pollutant control system. TPI was computed by multiplying TPC by a factor of 1.0235 to account for interest during the construction period. The allowance for funds used during construction (AFUDC) of $2.35 \%$ was derived using the pretax weighted cost of capital presented in Table 42 and a construction period of 1.67 years, consistent with the amount of time required for engineering, procurement, construction, and start-up at AES Greenidge Unit 4. The total capital requirement was calculated as the sum of 
the TPI, pre-production cost, and inventory capital. Pre-production (start-up) costs were computed as $2 \%$ of the TPI plus one month of fixed and variable O\&M costs. Inventory capital was computed as $0.5 \%$ of the TPC.

The TPC for the multi-pollutant control system at AES Greenidge Unit 4 was $\$ 349 / \mathrm{kW}_{\text {net. }}$. This is about $40 \%$ less than it would have cost to retrofit AES Greenidge Unit 4 with conventional SCR and wet FGD systems, based on quotes and cost estimates that were obtained prior to the start of the project.

Published cost data also confirm the higher cost of conventional SCR and wet FGD systems relative to the Greenidge multi-pollutant control system. For example, Hoskins (2003) reported an average installed cost of $\sim \$ 125 / \mathrm{kW}$ (\$2002) for SCR retrofits on units with capacities between 150 and $200 \mathrm{MW}$, based on data from four actual installations. Assuming that the average unit capacity was at the midpoint of the cited range, this equates to an installed cost of $\sim 21,900,000$ for a $175 \mathrm{MW}$ unit, in year 2002 dollars. According to the Power Capital Costs Index $(\mathrm{PCCl})$ that is published by Cambridge Energy Research Associates (CERA), the capital cost of power plant construction projects (excluding nuclear) was about $21.6 \%$ higher in 2005 than it was in 2002 (CERA, 2008). If the SCR retrofit cost reported by Hoskins is escalated by this factor and scaled to a 107-MW unit size using the six-tenths rule (i.e., via multiplication by a factor of $[107 / 175]^{0.6}$ ), it becomes $\$ 19,800,000$, or about $\$ 185 / \mathrm{kW}$. The total plant cost for the hybrid SNCR/SCR system at AES Greenidge Unit 4 was about $38 \%$ less than this amount.

Similarly, Sargent and Lundy (2003) reported an estimated EPC capital cost of $\$ 85,539,000$, in year 2002 dollars, for a wet limestone forced oxidation scrubber retrofit on a $500 \mathrm{MW}$ unit firing Appalachian high-sulfur coal. (The reported total plant cost of $\$ 77,763,000$ was multiplied by a factor of 1.1 to convert it to an EPC basis, as recommended by the authors). If this cost is escalated to year 2005 dollars and scaled to a $107 \mathrm{MW}$ plant size using the same methodology set forth above, it becomes $\$ 41,250,000$, or about $\$ 386 / \mathrm{kW}$. The EPC capital cost for the Turbosorp $^{\circledR}$ system at AES Greenidge Unit 4 was about $41 \%$ less than this amount.

\subsection{Fixed Operating and Maintenance Costs}

Fixed operating and maintenance costs include operating labor costs, maintenance labor and materials costs, and administrative and support labor costs.

As discussed in Section 10.3, plant personnel estimated that, in the absence of any other changes at the plant, installation of the multi-pollutant control system would have increased operating labor requirements by the equivalent of two full-time operators, or about 11.4 manhours per day. Hence, the estimate presented here assumes 12 hours per day of additional operating labor (at $\$ 45 /$ hour) to run the multi-pollutant control system.

Maintenance labor and materials costs from the Operation and Testing Phase of the Greenidge Project are not expected to reflect the actual long-term operation of the multi-pollutant control system. Certain maintenance costs incurred during the first year-and-a-half of operation at AES Greenidge, such as the costs related to the LPA problem, arose as part of the learning process associated with this first-of-a-kind installation. These costs, which generally led to design improvements, are not expected to be incurred in subsequent years at AES Greenidge or in subsequent installations of the multi-pollutant control system. Moreover, excluding these "onetime" costs, first-year maintenance costs are expected to underrepresent the actual 
maintenance costs over the life of the system, because the multi-pollutant control equipment will likely require more attention as it ages. Hence, given the uncertainty associated with interpreting first-year maintenance cost data, maintenance labor and materials costs were estimated as $1.5 \%$ of the total plant cost for purposes of this analysis. This is less than the general guidance provided by the NETL Quality Guidelines for Energy System Studies (2.2\% of TPC), consistent with the mechanical simplicity afforded by the multi-pollutant control system relative to conventional technologies. The fixed maintenance costs estimated in this way do not include the costs associated with change-out of the SCR catalyst and change-out of the baghouse bags and cages, which are categorized as variable O\&M costs. Forty percent of the fixed maintenance costs were assigned to labor, and sixty percent were assigned to materials, in accordance with common cost estimating practices. The maintenance labor cost estimated by this method was about $20 \%$ greater than the cost associated with adding two new maintenance personnel (@ \$45/hour) per the discussion in Section 10.3. The maintenance materials cost was about twice as great as the plant's estimate of $\$ 145,000$ for routine maintenance materials and services, based on first-year operating experience. Additional experience is required before the maintenance costs associated with the multi-pollutant control system can be accurately quantified.

Administrative and support labor costs were estimated as $30 \%$ of total operating and maintenance labor costs, per the guidance provided by the NETL Quality Guidelines for Energy System Studies.

Table 38 summarizes the fixed O\&M costs that were estimated in this way. (Costs were converted to a $\$ / \mathrm{MWh}$ basis using the $107 \mathrm{MW}$ net capacity and $80 \%$ capacity factor shown in Table 36). Overall fixed O\&M costs are estimated to be approximately $\$ 880,000$ per year, or about \$1.18/MWh.

Table 38. Estimated fixed operating and maintenance costs for the multi-pollutant control system at AES Greenidge Unit 4.

\begin{tabular}{|l|c|c|}
\hline & \$MM/year & \$/MWh \\
\hline Operating Labor & 0.20 & 0.26 \\
\hline Maintenance Labor & 0.22 & 0.30 \\
\hline Maintenance Materials & 0.34 & 0.45 \\
\hline Administrative \& Support Labor & 0.13 & 0.17 \\
\hline TOTAL & 0.88 & 1.18 \\
\hline
\end{tabular}

\subsection{Variable Operating and Maintenance Costs}

The variable operating and maintenance costs associated with the multi-pollutant control system include costs for pebble lime, urea, activated carbon, waste disposal, electricity, water, compressed air, replacement catalyst, and replacement baghouse bags and cages.

Table 39 summarizes the unit prices that were used in the variable O\&M cost calculations. Costs for reagents (e.g., urea, lime, and powdered activated carbon) reflect approximate market prices during start-up of the multi-pollutant control system in early 2007. 
Table 39. Unit prices used in variable O\&M cost calculations (as of early 2007).

\begin{tabular}{|l|c|c|}
\hline Item & Unit & Price per Unit \\
\hline Aqueous urea $-50 \% \mathrm{w} / \mathrm{w}$ & gal (delivered) & $\$ 1.35$ \\
\hline Pebble lime & ton (delivered) & $\$ 115$ \\
\hline Powdered activated carbon & $\mathrm{Ib}$ (delivered) & $\$ 0.35$ \\
\hline Electricity & MWh & $\$ 40$ \\
\hline Plant service water & $1000 \mathrm{gal}$ & $\$ 0.20$ \\
\hline Compressed air & $1000 \mathrm{scf}$ & $\$ 0.25$ \\
\hline Replacement catalyst & layer & $\$ 380,000$ \\
\hline Baghouse bags & bag & $\$ 80$ \\
\hline Baghouse cages & cage & $\$ 60$ \\
\hline Waste disposal & ton & $\$ 17$ \\
\hline
\end{tabular}

As discussed above, the actual performance of the multi-pollutant control system observed during the Operation and Testing Phase of the Greenidge Project was not always consistent with its expected performance. To illustrate the effect of these deviations in performance on the economics of the multi-pollutant control system, variable O\&M costs and levelized costs (discussed in the next section) were computed on the basis of both the projected performance at the time of design ("design case") and the actual performance observed during the first yearand-a-half of commercial operation of the system ("actual performance case"). Table 40 summarizes the differences in the assumptions used for these two cases.

Table 40. Performance assumptions used to compute the variable O\&M costs and levelized costs associated with the multi-pollutant control system at AES Greenidge Unit 4.

\begin{tabular}{|c|c|c|}
\hline & $\begin{array}{c}\text { Design } \\
\text { Case }\end{array}$ & $\begin{array}{c}\text { Actual } \\
\text { Performance } \\
\text { Case }\end{array}$ \\
\hline \multicolumn{3}{|l|}{ Hybrid NOx Control System } \\
\hline $\mathrm{NO}_{\mathrm{x}}$ rate following combustion modifications ( $\left.\mathrm{lb} / \mathrm{mmBtu}\right)$ & 0.25 & 0.26 \\
\hline $\mathrm{NO}_{x}$ rate at SCR outlet $(\mathrm{lb} / \mathrm{mmBtu})$ & 0.10 & 0.14 \\
\hline SNCR normalized stoichiometric ratio & 1.35 & 1.56 \\
\hline Catalyst life (years) & 3 & 2 \\
\hline \multicolumn{3}{|l|}{ Circulating Fluidized Bed Dry Scrubber } \\
\hline $\mathrm{SO}_{2}$ removal efficiency (\%) & 95 & 95 \\
\hline $\mathrm{Ca} / \mathrm{S}$ molar ratio & 1.65 & 1.66 \\
\hline Pebble lime available $\mathrm{CaO}(\% \mathrm{w} / \mathrm{w})$ & 95 & 89 \\
\hline $\mathrm{CaO}$ hydration efficiency (\%) & 99 & 99 \\
\hline Number of baghouse bags and cages & 3,168 & 3,168 \\
\hline Baghouse bag and cage life (years) & 5 & 5 \\
\hline Solid byproduct production (lb/h, excluding fly ash) & 12,972 & 13,459 \\
\hline \multicolumn{3}{|l|}{ Activated Carbon Injection System } \\
\hline Mercury removal efficiency (\%) & 90 & 98 \\
\hline Activated carbon feed rate (lb/mmacf) & 3.5 & 0 \\
\hline \multicolumn{3}{|l|}{ Utilities } \\
\hline Power consumption $\left(\%\right.$ of net $\left.\mathrm{MW}_{\mathrm{e}}\right)$ & 1.8 & 1.8 \\
\hline Water consumption (gpm) & 139 & 139 \\
\hline Compressed air consumption (scfm) & 600 & 600 \\
\hline
\end{tabular}


The assumptions for the design case were generally derived from the information presented in Section 6 and in drawing No. 100276-SK081706-05 in Appendix B. (The normalized stoichiometric ratio of 1.35 and $\mathrm{Ca} / \mathrm{S}$ molar ratio of 1.65 are consistent with original performance expectations but slightly lower than the values represented in drawing No. 100276-SK08170605. Hence, the water and byproduct flow rates indicated in the drawing were adjusted in the cost estimate so that they correspond to these lower values).

The assumptions for the actual performance case were derived from the results presented in Sections 9 and 10. (In the absence of any compelling evidence suggesting a change in performance from the design case, the same value was assumed for both cases). The $\mathrm{NO}_{\mathrm{x}}$ rate following the combustion modifications, $\mathrm{NO}_{x}$ rate at the SCR outlet, and SNCR normalized stoichiometric ratio represent the average values observed during testing of the hybrid $\mathrm{NO}_{\mathrm{x}}$ control system on March 10, March 13, and May 21, 2008. These results, which are representative of the long-term performance of the hybrid $\mathrm{NO}_{x}$ control system, were summarized in Table 15 and discussed in Section 9.3.2. The assumed 2-year catalyst life is consistent with the catalyst management plan being developed as of the end of the project, per the discussion in Section 10.1. The $\mathrm{Ca} / \mathrm{S}$ molar ratio of 1.66 is the average value observed during the Turbosorp ${ }^{\circledR}$ system tests on October 9-10, 2007, and June 17, 2008, as discussed in Section 9.3.7. During those tests, the average coal sulfur content was $4.0 \mathrm{lb} \mathrm{SO} / \mathrm{mmBtu}$, and the average $\mathrm{SO}_{2}$ removal efficiency was $95 \%$, consistent with design conditions. The average available $\mathrm{CaO}$ content of pebble lime samples collected at AES Greenidge between March 2007 and June 2008 was substantially less than the $95 \%$ value assumed in the design case; this difference is also reflected in Table 40. (The byproduct flow rates for the design case and the actual performance case were estimated using the same equation, which was derived from the projected product ash composition in the design case. The larger flow rate for the actual performance case reflects the slightly higher $\mathrm{Ca} / \mathrm{S}$ molar ratio and lower pebble lime available $\mathrm{CaO}$ content for that case). Finally, the actual performance case assumes $98 \% \mathrm{Hg}$ removal efficiency with no activated carbon injection, per the results presented in Section 9.3.8.

Table 41 summarizes the estimated variable O\&M costs for the multi-pollutant control system at AES Greenidge Unit 4. (Annual costs were computed using an $80 \%$ capacity factor, per the assumptions set forth above). The total estimated variable O\&M cost is $\$ 6.55$ per MWh (\$4.91 million per year) for the design case and $\$ 6.77$ per MWh ( $\$ 5.08$ million per year) for the actual performance case. The $\$ 0.22 / \mathrm{MWh}$ increase in cost from the design case to the actual performance case represents the net effect of increased pebble lime consumption, increased waste disposal, increased urea consumption, decreased activated carbon consumption, and more frequent catalyst purchases. Pebble lime and waste disposal costs, which both depend on the amount of hydrated lime required in the Turbosorp ${ }^{\circledR}$ system, collectively account for about $70 \%$ of the variable O\&M cost associated with the multi-pollutant control system. (Waste disposal costs only include the incremental costs associated with the solid byproduct added by the multi-pollutant control system, and do not include the costs associated with fly ash disposal). Hence, the economics of the multi-pollutant control process are particularly sensitive to changes in coal sulfur content, $\mathrm{SO}_{2}$ removal efficiency, and lime quality, which affect hydrated lime consumption. The effect of lime quality on process economics is evident in the difference between the design case, which assumed $95 \%$ available $\mathrm{CaO}$ in the pebble lime, and the actual performance case, which assumed $89 \%$ available $\mathrm{CaO}$. The effects of coal sulfur content and $\mathrm{SO}_{2}$ removal efficiency are explored in Section 11.4.

As stated earlier, the variable O\&M costs associated with the multi-pollutant control system are somewhat greater than those for conventional stand-alone SCR and wet FGD systems. The greater costs arise largely because of less efficient reagent utilization in the multi-pollutant 
control system relative to these conventional technologies. Wet FGD systems typically operate with a Ca/S molar ratio close to 1.0 to achieve $>95 \% \mathrm{SO}_{2}$ removal efficiency (Sarget and Lundy, 2003) and, therefore, require considerably fewer moles of calcium reagent than the Turbosorp ${ }^{\circledR}$ system, which uses a $\mathrm{Ca} / \mathrm{S}$ molar ratio of $\sim 1.7$ to achieve $95 \%$ removal. Moreover, many wet FGD systems use limestone reagent, which is significantly (e.g., more than $50 \%$ ) less expensive per mole of calcium than pebble lime. The gypsum byproduct produced by some wet FGD systems also can be sold for a credit, further reducing variable O\&M costs. (Wet FGDs have greater auxiliary power and water costs than the Turbosorp ${ }^{\circledR}$ system, but these are not sufficient to compensate for the difference in reagent costs). Similarly, the hybrid SNCR/SCR system consumes more moles of nitrogen (from either urea or ammonia reagent), and achieves less $\mathrm{NO}_{x}$ reduction, than a conventional SCR system. Whereas the hybrid SNCR/SCR system at AES Greenidge has a reagent utilization of $30 \%$ (actual performance case) to $45 \%$ (design case), reagent utilization in conventional SCR systems approaches 100\% (Albanese et al., 1995). For a given reagent (e.g., urea), this equates to greater reagent costs for the hybrid SNCR/SCR relative to a conventional SCR. (Many SCR systems use aqueous or anhydrous ammonia reagents rather than urea, and reagent costs are therefore application-specific).

Table 41. Estimated variable operating and maintenance costs for the multipollutant control system at AES Greenidge Unit 4.

\begin{tabular}{|c|c|c|c|c|}
\hline & \multicolumn{2}{|c|}{$\begin{array}{l}\text { Design } \\
\text { Case } \\
\end{array}$} & \multicolumn{2}{|c|}{$\begin{array}{c}\text { Actual Performance } \\
\text { Case }\end{array}$} \\
\hline & \$MM/year & $\$ / M W h$ & \$MM/year & $\$ / M W h$ \\
\hline Pebble lime & 2.62 & 3.50 & 2.81 & 3.75 \\
\hline Waste disposal & 0.77 & 1.03 & 0.80 & 1.07 \\
\hline Electricity & 0.54 & 0.72 & 0.54 & 0.72 \\
\hline Urea & 0.47 & 0.62 & 0.57 & 0.76 \\
\hline Powdered activated carbon & 0.22 & 0.29 & 0.00 & 0.00 \\
\hline Catalyst & 0.13 & 0.17 & 0.19 & 0.25 \\
\hline Baghouse bags and cages & 0.09 & 0.12 & 0.09 & 0.12 \\
\hline Compressed air & 0.06 & 0.08 & 0.06 & 0.08 \\
\hline Process water & 0.01 & 0.02 & 0.01 & 0.02 \\
\hline TOTAL & 4.91 & 6.55 & 5.08 & 6.77 \\
\hline
\end{tabular}

\subsection{Levelized Costs}

The capital costs (TCR) presented in Section 11.1 were annualized using a fixed charge factor of $13.05 \%$, which was derived according to the economic assumptions shown in Table 42 . The financial structure is consistent with the guidance for high-risk projects set forth in the NETL Quality Guidelines for Energy System Studies.

The total levelized cost associated with the multi-pollutant control system was computed by combining the levelized capital cost with the annual fixed and variable O\&M costs presented in Sections 11.2 and 11.3, and dividing the result by the unit's annual net electric output (again, an $80 \%$ capacity factor was assumed). Table 43 summarizes the derivation of this cost for both the design case and the actual performance case. Overall, based on the capital cost to install the system at AES Greenidge and the actual performance observed during the Operation and Testing Phase of the project, it is estimated that the multi-pollutant control system increased the 
unit's levelized cost of electricity by about $\$ 14.85 / \mathrm{MWh}$. Capital charges and variable O\&M costs each account for about $46 \%$ of this cost, and fixed O\&M costs account for the remaining $8 \%$.

Table 42. Financial assumptions used for levelized capital cost calculations.

\begin{tabular}{|l|c|}
\hline Constant / current dollars & 2005 constant \\
\hline Plant life & 20 years \\
\hline Discount rate (before tax) & $7.09 \%$ \\
\hline Percent debt & $45 \%$ \\
\hline Percent preferred stock & $10 \%$ \\
\hline Percent common stock & $45 \%$ \\
\hline Nominal cost of debt & $9 \%$ \\
\hline Nominal cost of preferred stock & $8.5 \%$ \\
\hline Nominal cost of common stock & $12 \%$ \\
\hline Inflation rate & $3 \%$ \\
\hline Federal tax rate & $35 \%$ \\
\hline State tax rate & $4 \%$ \\
\hline Property tax rate & $2 \%$ \\
\hline Investment tax credit & $0 \%$ \\
\hline Fixed charge factor & $13.05 \%$ \\
\hline
\end{tabular}

Table 43. Estimated levelized costs for the multi-pollutant control system at AES Greenidge Unit 4. Costs are expressed in constant 2005 dollars.

\begin{tabular}{|l|c|c|c|c|}
\hline \multirow{2}{*}{} & \multicolumn{2}{|c|}{ Design Case } & \multicolumn{2}{c|}{ Actual Performance Case } \\
\cline { 2 - 5 } & $\mathbf{\$ M M} / \mathbf{y e a r}$ & $\mathbf{\$ M W h}$ & $\mathbf{\$ M M} / \mathbf{y e a r}$ & $\mathbf{\text { MWh }}$ \\
\hline Annualized capital cost & 5.17 & 6.89 & 5.17 & 6.90 \\
\hline Annual fixed O\&M cost & 0.88 & 1.18 & 0.88 & 1.18 \\
\hline Annual variable O\&M cost & 4.91 & 6.55 & 5.08 & 6.77 \\
\hline Total levelized cost & 10.97 & 14.62 & 11.13 & 14.85 \\
\hline
\end{tabular}

Levelized costs were also computed separately for the hybrid $\mathrm{NO}_{\mathrm{x}}$ control system, circulating fluidized bed dry scrubbing system, and activated carbon injection system, so that they could be expressed in terms of the cost per mass of pollutant removed. Tables 44-46 summarize the levelized costs for each of these major subsystems associated with the multi-pollutant control process.

Table 44. Estimated levelized costs for the hybrid $\mathrm{NO}_{\mathrm{x}}$ control system (including the combustion modifications) at AES Greenidge Unit 4. Costs are expressed in constant 2005 dollars.

\begin{tabular}{|l|c|c|c|c|}
\hline \multirow{2}{*}{} & \multicolumn{2}{|c|}{ Design Case } & \multicolumn{2}{c|}{ Actual Performance Case } \\
\cline { 2 - 5 } & $\mathbf{\$} \mathbf{M W h}$ & $\begin{array}{c}\mathbf{\$} \text { /ton } \mathbf{N O}_{\mathbf{x}} \\
\text { removed }\end{array}$ & $\mathbf{\$} \mathbf{M W h}$ & $\begin{array}{c}\mathbf{\$} \text { /ton } \mathbf{N O}_{\mathbf{x}} \\
\text { removed }\end{array}$ \\
\hline Annualized capital cost & 2.24 & 2,251 & 2.24 & 2,771 \\
\hline Annual fixed O\&M cost & 0.37 & 372 & 0.37 & 457 \\
\hline Annual variable O\&M cost & 0.85 & 853 & 1.07 & 1,322 \\
Urea & 0.62 & 626 & 0.76 & 937 \\
Replacement catalyst & 0.17 & 170 & 0.25 & 313 \\
Electricity & 0.05 & 55 & 0.05 & 67 \\
Water & 0.00 & 3 & 0.00 & 4 \\
\hline Total levelized cost & 3.46 & 3,476 & 3.68 & 4,550 \\
\hline
\end{tabular}


Table 45. Estimated levelized costs for the circulating fluidized bed dry scrubbing system at AES Greenidge Unit 4. Costs are expressed in constant 2005 dollars.

\begin{tabular}{|l|c|c|c|c|}
\hline \multirow{2}{*}{} & \multicolumn{2}{|c|}{ Design Case } & \multicolumn{2}{c|}{ Actual Performance Case } \\
\cline { 2 - 5 } & $\mathbf{\$} / \mathbf{M W h}$ & $\begin{array}{c}\mathbf{\$} \text { /ton } \mathbf{S O}_{\mathbf{2}} \\
\text { removed }\end{array}$ & $\mathbf{\$} \mathbf{\text { MWh }}$ & $\begin{array}{c}\mathbf{\$} \text { /ton } \mathbf{S O}_{\mathbf{2}} \\
\text { removed }\end{array}$ \\
\hline Annualized capital cost & 4.54 & 241 & 4.54 & 241 \\
\hline Annual fixed O\&M cost & 0.79 & 42 & 0.79 & 42 \\
\hline Annual variable O\&M cost & 5.41 & 287 & 5.70 & 303 \\
Lime & 3.50 & 186 & 3.75 & 199 \\
Waste disposal & 1.03 & 55 & 1.07 & 57 \\
Electricity & 0.67 & 35 & 0.67 & 35 \\
Baghouse bags and cages & 0.12 & 6 & 0.12 & 6 \\
Compressed air & 0.08 & 4 & 0.08 & 4 \\
Water & 0.01 & 1 & 0.01 & 1 \\
\hline Total levelized cost & 10.74 & 570 & 11.03 & 586 \\
\hline
\end{tabular}

Table 46. Estimated levelized costs for the activated carbon injection system at AES Greenidge Unit 4. Costs are expressed in constant 2005 dollars.

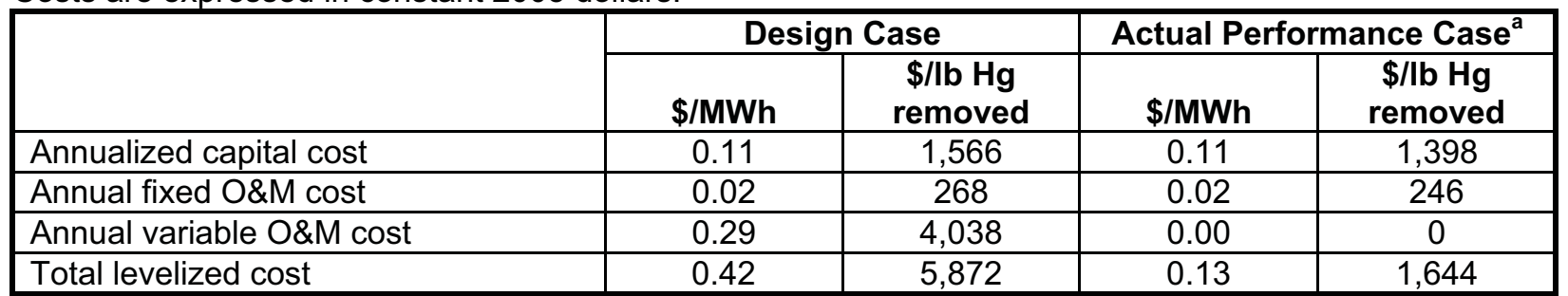

${ }^{a}$ Although activated carbon injection is not needed at AES Greenidge Unit 4, AES must still incur the capital and fixed charges for the $\mathrm{ACl}$ system that was installed as part of the project. However, based on the results from AES Greenidge, future applications of the multi-pollutant control system may not require the installation of an activated carbon injection system to achieve $>90 \% \mathrm{Hg}$ removal. Those applications would have a total levelized $\mathrm{Hg}$ control cost of zero.

Hence, $\mathrm{SO}_{2}$ control accounts for about three-fourths of the total levelized cost associated with the multi-pollutant control system, and $\mathrm{NO}_{x}$ control accounts for about one-fourth of the total levelized cost. The overall levelized costs (including annualized capital, fixed O\&M, and variable O\&M costs) for $\mathrm{NO}_{\mathrm{x}}$ and $\mathrm{SO}_{2}$ control are about $\$ 3.68 / \mathrm{MWh}\left(\sim 4,550 /\right.$ ton of $\mathrm{NO}_{\mathrm{x}}$ removed) and about $\$ 11.03 / \mathrm{MWh}\left(\sim 586 /\right.$ ton of $\mathrm{SO}_{2}$ removed), respectively, based on the actual performance case. The cost for $\mathrm{SO}_{2}$ control also covers $\mathrm{SO}_{3}, \mathrm{HCl}$, and improved primary particulate matter control, which are co-benefits of the Turbosorp ${ }^{\circledR}$ system and which add no incremental cost. As discussed in Section 5, AES Greenidge is a merchant plant that dispatches when its variable cost of producing electricity is less than the market price of electricity. The $\mathrm{NO}_{x}$ and $\mathrm{SO}_{2}$ control costs that figure into the economic dispatch calculations for Unit 4 are the costs for urea, lime, and waste disposal. Hence, the hybrid $\mathrm{NO}_{\mathrm{x}}$ control system adds about $\$ 0.76 / \mathrm{MWh}$ to the unit's dispatch cost, and the circulating fluidized bed dry scrubbing system adds about $\$ 4.82 / \mathrm{MWh}$ to the dispatch cost.

As shown in Table 44, the hybrid $\mathrm{NO}_{x}$ control system at AES Greenidge is now estimated to cost about $\$ 0.22 / \mathrm{MWh}$ more to operate than expected at the time of design. About $64 \%$ of this cost increase is attributable to the higher-than-anticipated urea consumption (NSR) observed during long-term operation, and the remaining $36 \%$ is attributable to the more frequent catalyst replacements that will likely be required because of plugging and erosion. Whereas the increase in $\mathrm{NO}_{x}$ control costs is relatively modest $(6 \%)$ when expressed on a megawatt-hour 
basis, it is much more dramatic when expressed per ton of $\mathrm{NO}_{\mathrm{x}}$ removed. As discussed in Section 9.3.1 and shown in Table 40, in addition to requiring more urea than expected, the hybrid $\mathrm{NO}_{\mathrm{x}}$ control system fell short of its targeted $\mathrm{NO}_{\mathrm{x}}$ removal efficiency. As a result, the capital costs and fixed and variable O\&M costs are spread out over fewer tons of $\mathrm{NO}_{\mathrm{x}}$, inflating the $\mathrm{NO}_{\mathrm{x}}$ removal cost. As shown in Table 44, the cost per ton of $\mathrm{NO}_{\mathrm{x}}$ removed is about $31 \%$ greater for the actual performance case than for the design case.

The cost per ton of $\mathrm{NO}_{\mathrm{x}}$ removed becomes even larger when the $\mathrm{NO}_{\mathrm{x}}$ removal contributed by the combustion modifications is excluded from the calculation. For purposes of computing the $\mathrm{NO}_{x}$ control costs in Table 44, the $\mathrm{NO}_{x}$ removal was taken as the total removal contributed by both the combustion modifications and the hybrid SNCR/SCR system (i.e., such that the total $\mathrm{NO}_{x}$ reduction was $0.20 \mathrm{lb} / \mathrm{mmBtu}$ for the design case and $0.16 \mathrm{lb} / \mathrm{mmBtu}$ for the actual performance case). This was necessary in order to derive the total levelized cost (including capital and fixed costs) associated with the overall $\mathrm{NO}_{x}$ control system. However, the variable O\&M costs shown in Table 44 are associated solely with the hybrid SNCR/SCR system and not with the combustion modifications. Hence, these costs might be more appropriately expressed on the basis of the $\mathrm{NO}_{x}$ reduction contributed by only that system (i.e., $0.15 \mathrm{lb} / \mathrm{mmBtu}$ for the design case and $0.12 \mathrm{lb} / \mathrm{mmBtu}$ for the actual performance case). When the $\mathrm{NO}_{\mathrm{x}}$ reduction arising from the combustion modifications is excluded, the total variable O\&M cost associated with the hybrid SNCR/SCR system is $\$ 1,136$ / ton of $\mathrm{NO}_{\mathrm{x}}$ removed for the design case and $\$ 1,702$ / ton of $\mathrm{NO}_{x}$ removed for the actual performance case. The cost for urea, which figures into the unit's dispatch calculations, is $\$ 834$ / ton of $\mathrm{NO}_{\mathrm{x}}$ removed for the design case and $\$ 1,207$ / ton of $\mathrm{NO}_{\mathrm{x}}$ removed for the actual performance case.

Unlike the hybrid $\mathrm{NO}_{x}$ control system, the circulating fluidized bed dry scrubbing system met the performance expectations for both $\mathrm{SO}_{2}$ removal efficiency and reagent utilization. Nevertheless, the estimated cost to operate the scrubber increased by about $3 \%$ as a result of experience gained during the Operation and Testing Phase of the project. This increase arose because the average available $\mathrm{CaO}$ content of the pebble lime delivered to AES Greenidge (89\%) was less than the available $\mathrm{CaO}$ content assumed in the design case $(95 \%)$. As a result of the poorer lime quality, AES Greenidge had to purchase about $7 \%$ more pebble lime than expected in order to obtain a given amount of available $\mathrm{CaO}$.

As discussed in Section 11.3, in addition to being dependent on lime quality, the variable O\&M costs for the Turbosorp ${ }^{\circledR}$ system are particularly sensitive to changes in the coal sulfur content or required $\mathrm{SO}_{2}$ removal efficiency. Both of these factors affect the amount of hydrated lime required in the circulating fluidized bed dry scrubber and the amount of byproduct generated by the scrubber.

The multi-pollutant control system at AES Greenidge Unit 4 was designed for coals containing $2-4 \%$ sulfur ( 3-6 lb SO $2 / \mathrm{mmBtu}$ ); hence, variations in coal sulfur content are anticipated during operation of the system. Figure 96 illustrates the effect of these changes on $\mathrm{SO}_{2}$ control costs, assuming that $\mathrm{SO}_{2}$ removal efficiency is held constant at $95 \%$. (When calculating these $\mathrm{SO}_{2}$ control costs, the pebble lime available $\mathrm{CaO}$ content was assumed to be $89 \%$ ). The total levelized cost (including capital and operating costs) and the cost for lime and waste disposal are each plotted in order to show the effects on overall control costs and dispatch costs, respectively. As the coal sulfur content increases, more $\mathrm{SO}_{2}$ must be removed per unit of electric output, and $\mathrm{SO}_{2}$ control costs increase accordingly on a $\$ / \mathrm{MWh}$ basis. (It is important to recognize that, with respect to the unit's overall variable operating cost, this increase in $\mathrm{SO}_{2}$ control costs may be offset by a decrease in fuel costs, because higher-sulfur coals tend to be less expensive than lower-sulfur coals). This effect is eliminated if costs are levelized based on 
the mass of $\mathrm{SO}_{2}$ removed rather than the net electric output from the unit. When expressed on this basis, the total $\mathrm{SO}_{2}$ control cost decreases with increasing coal sulfur content, because the capital costs and fixed O\&M costs are spread over a greater number of tons of $\mathrm{SO}_{2}$.

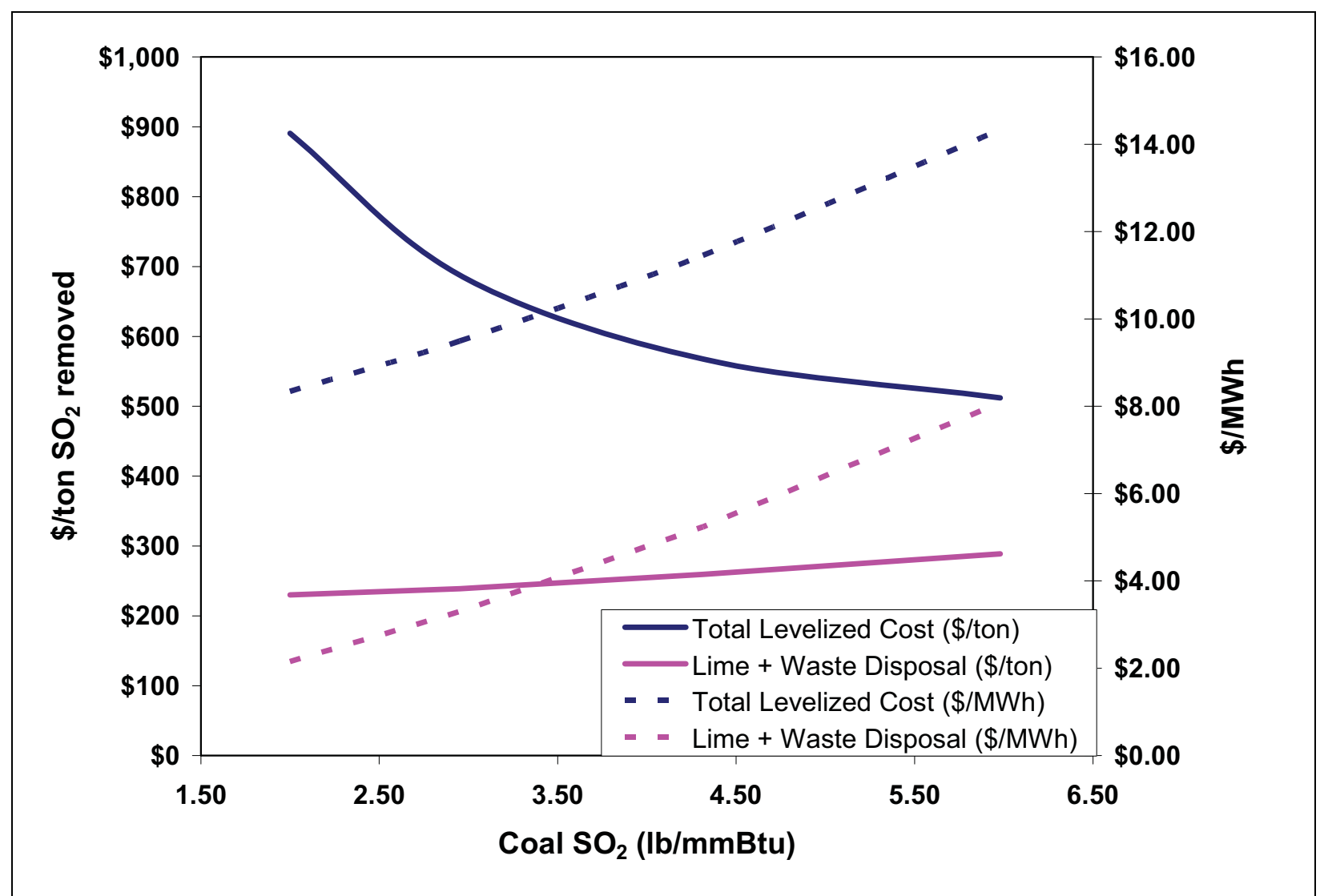

Figure 96. Projected effect of coal sulfur content on $\mathrm{SO}_{2}$ control costs for $95 \% \mathrm{SO}_{2}$ removal efficiency.

As discussed in Section 9.3.7 and shown in Figure 72, parametric tests were conducted in June 2008 to determine the effect of variations in $\mathrm{SO}_{2}$ removal efficiency on the required $\mathrm{Ca} / \mathrm{S}$ molar ratio in the Turbosorp ${ }^{\circledR}$ process. The data collected during these tests were used to derive the sensitivity of $\mathrm{SO}_{2}$ control costs to changes in $\mathrm{SO}_{2}$ removal efficiency. Results are plotted in Figure 97, using the same four cost metrics shown in Figure 96. All of the costs in Figure 97 are for a $3.6 \mathrm{lb} \mathrm{SO} / \mathrm{mmBtu}$ coal, consistent with the coal used during the June tests. As shown in the figure, all four measures of cost increased with increasing $\mathrm{SO}_{2}$ removal efficiency. When expressed on a $\$ / \mathrm{MWh}$ basis, the cost for lime and waste disposal increased by $43 \%$ as $\mathrm{SO}_{2}$ removal increased from $92 \%$ to $98 \%$, and the total levelized cost for $\mathrm{SO}_{2}$ control increased by $16 \%$ over the same increment of $\mathrm{SO}_{2}$ removal efficiencies. Costs rose more slowly when expressed per ton of $\mathrm{SO}_{2}$ removed, owing to the increase in the divisor with increasing $\mathrm{SO}_{2}$ removal efficiency. The June 2008 tests also examined the effect of the scrubber operating temperature on the required $\mathrm{Ca} / \mathrm{S}$ ratio. Based on the test results, for $95 \% \mathrm{SO}_{2}$ removal efficiency with a $3.6 \mathrm{lb} \mathrm{SO} / \mathrm{mmBtu}$ coal, raising the operating temperature by $5{ }^{\circ} \mathrm{F}$ (e.g., to reduce the risk of condensation) causes the lime and waste disposal costs to increase by $\$ 0.47 / \mathrm{MWh}$ (\$28/ton of $\mathrm{SO}_{2}$ removed), or about $11 \%$.

All of the costs presented thus far for the Turbosorp ${ }^{\circledR}$ system and the overall multi-pollutant control system have assumed that AES Greenidge must pay $\$ 17 /$ ton to landfill the solid byproduct generated in the circulating fluidized bed dry scrubber. However, as discussed in 
Sections 6.3.6 and 10.4, process economics would improve if an opportunity for beneficial reuse of this byproduct could be identified. Using the actual performance case as an example (Tables 41, 43, and 44), if waste disposal costs were eliminated (e.g., by providing the scrubber byproduct for beneficial reuse at zero net cost), then the costs associated with the multipollutant control system, including its contribution to the unit's dispatch cost, would decrease by $\$ 57$ / ton of $\mathrm{SO}_{2}$ removed (\$1.07/MWh).

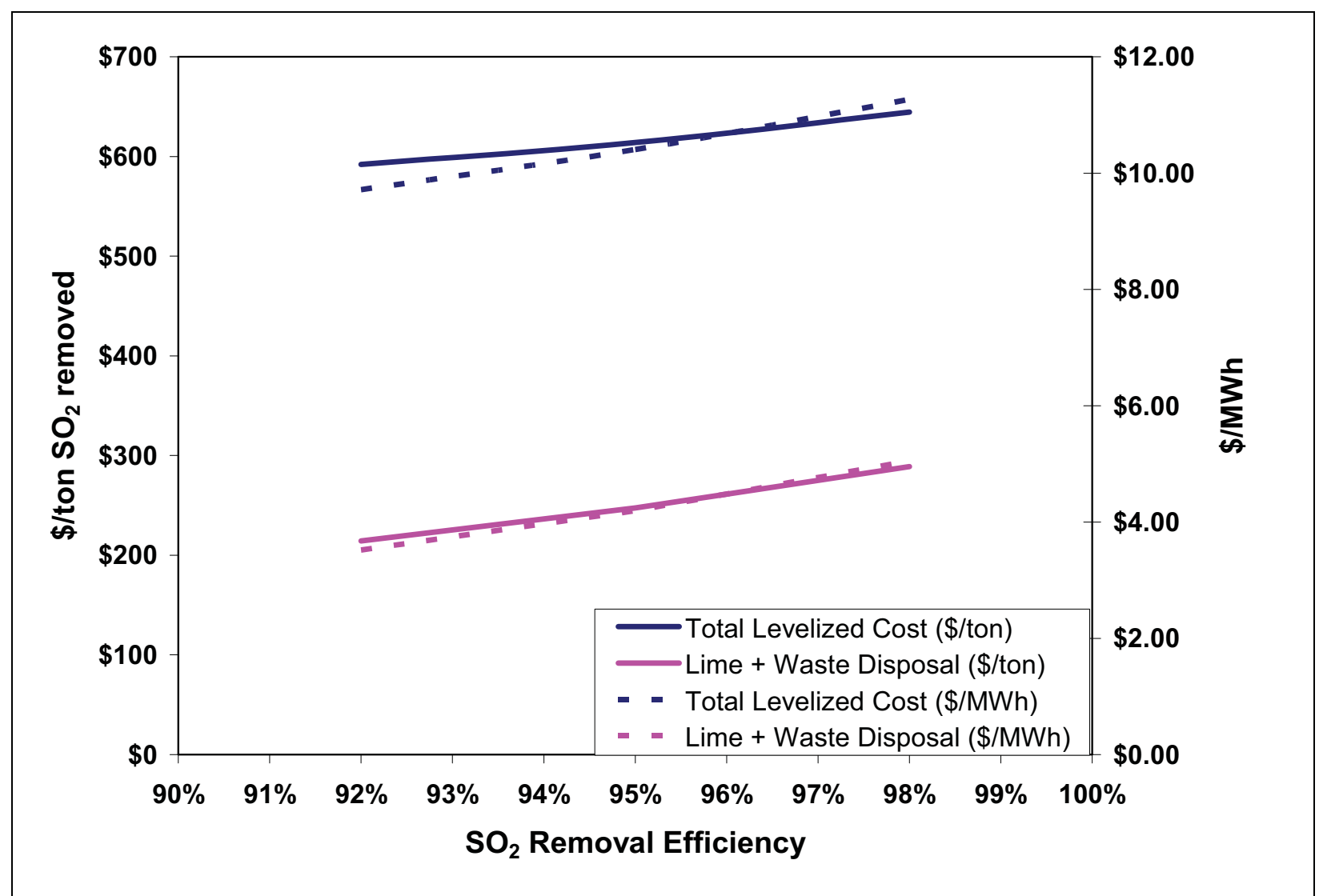

Figure 97. Effect of $\mathrm{SO}_{2}$ removal efficiency on $\mathrm{SO}_{2}$ control costs for a $3.6 \mathrm{lb} \mathrm{SO} / \mathrm{mmBtu}$ coal. Costs were derived from the results of parametric testing of the Turbosorp ${ }^{\circledR}$ system on June 16-18, 2008.

Finally, as shown in Table 46, it was originally anticipated that the $\mathrm{Hg}$ control costs associated with the multi-pollutant control system could be as great as $\$ 0.42 / \mathrm{MWh}$, or $\$ 5,872 / \mathrm{lb}$ of $\mathrm{Hg}$ removed, owing to the potential need for up to $3.5 \mathrm{lb} / \mathrm{mmacf}$ of activated carbon injection in order to achieve $90 \% \mathrm{Hg}$ removal efficiency. However, the tests conducted at AES Greenidge in March 2007 through June 2008 proved that $>90 \% \mathrm{Hg}$ removal efficiency can be achieved consistently without any activated carbon injection. Hence, there are no variable O\&M costs associated with $\mathrm{Hg}$ control at AES Greenidge (i.e., $\mathrm{Hg}$ control is accomplished as a co-benefit of the other components of the multi-pollutant control system), resulting in a savings of $\$ 0.29 / \mathrm{MWh}$. Although it is not used, AES Greenidge must continue to incur the capital and fixed costs associated with the activated carbon injection system that was installed as part of the project, which amount to $\$ 0.13 / \mathrm{MWh}$, or $\$ 1,644 / \mathrm{lb}$ of $\mathrm{Hg}$ removed. However, these costs can also be avoided in future installations that do not require activated carbon injection. 
In short, installation of the multi-pollutant control system has enabled AES Greenidge Unit 4 to satisfy its air emissions requirements while remaining profitable, thereby extending the life of the unit. This is indicative of the economic viability of the system.

\section{Commercialization}

The Greenidge Multi-Pollutant Control Project, as a major demonstration project under the Power Plant Improvement Initiative, was conducted to resolve any remaining technical and economic uncertainties regarding the multi-pollutant control technology so as to enable and promote its commercial deployment. Babcock Power Environmental Inc. is responsible for marketing the technology.

The Greenidge Project has already succeeded in spurring commercialization of the Turbosorp ${ }^{\circledR}$ technology. As of the end of the project in October 2008, three additional projects were underway to retrofit Turbosorp ${ }^{\circledR}$ circulating fluidized bed dry scrubbers to coal-fired EGUs in the United States. Key features of these additional projects are summarized in Table 47. (Key features of the AES Greenidge application are also included for comparison). The performance specifications for all three projects resemble those at AES Greenidge. All are designed to achieve $\mathrm{SO}_{2}$ removal efficiencies of $95 \%$ or more, with fuel sulfur contents ranging from 2.3 to $4.6 \mathrm{Ib} \mathrm{SO} / \mathrm{mmBtu}$.

Table 47. Turbosorp ${ }^{\circledR}$ projects at coal-fired electric generating units in the United States, as of October 2008.

\begin{tabular}{|c|c|c|c|c|}
\hline & $\begin{array}{c}\text { AES } \\
\text { Greenidge 4 }\end{array}$ & $\begin{array}{c}\text { AES } \\
\text { Westover 8 }\end{array}$ & $\begin{array}{c}\text { GRU } \\
\text { Deerhaven 2 }\end{array}$ & $\begin{array}{c}\text { FirstLight } \\
\text { Mt. Tom 1 }\end{array}$ \\
\hline $\begin{array}{c}\text { Unit Capacity } \\
\mathrm{MW}_{\mathrm{e}}\end{array}$ & 107 (net) & 84 (net) & 248 (gross) & 155 (gross) \\
\hline $\begin{array}{c}\text { Turbosorp } \\
\text { Start-Up }\end{array}$ & Spring 2007 & Fall 2008 & Spring 2009 & Fall 2009 \\
\hline Fuel & $\begin{array}{c}\text { Bituminous } \\
\text { Pulverized Coal }\end{array}$ & $\begin{array}{c}\text { Bituminous } \\
\text { Pulverized Coal }\end{array}$ & $\begin{array}{c}\text { Bituminous } \\
\text { Pulverized Coal }\end{array}$ & $\begin{array}{c}\text { Bituminous } \\
\text { Pulverized Coal }\end{array}$ \\
\hline $\begin{array}{c}\text { Inlet SO }{ }_{2} \\
\text { Ib/mmBtu }\end{array}$ & 4.0 & 3.4 & $2.3-3.9$ & $2.7-4.6$ \\
\hline $\begin{array}{c}\text { Outlet SO } \\
\text { lb/mmBtu }\end{array}$ & $\leq 0.2$ & $\leq 0.17$ & $\leq 0.10$ & $0.14-0.23$ \\
\hline $\begin{array}{c}\text { SO }{ }_{2} \text { Removal } \\
\%\end{array}$ & $1 \times 95$ & $\geq 95$ & $\geq 95.6-97.4$ & $\geq 95$ \\
\hline Hydrator & $\begin{array}{c}\text { Cold Side } \\
\text { Abandon }\end{array}$ & $\begin{array}{c}\text { Cold Side } \\
\text { Abandon }\end{array}$ & $\begin{array}{c}\text { Hot Side } \\
\text { Retain }\end{array}$ & $\begin{array}{c}\text { Cold Side } \\
\text { Retain }\end{array}$ \\
\hline $\begin{array}{c}\text { Existing ESP } \\
\text { New Baghouse }\end{array}$ & Yes & Yes & Yes & Yes \\
\hline Activated Carbon Injection & Yes & No & Provisions & Yes \\
\hline System & Compact/Hybrid & Yes & Yes & Existing \\
\hline SCR & & &
\end{tabular}


The projects at AES Westover Unit 8, GRU Deerhaven Unit 2, and FirstLight Mt. Tom Unit 1 include several noteworthy variations in the application of the Turbosorp ${ }^{\circledR}$ technology, illustrating some of the design options available to candidate units.

As discussed earlier, the particulate control device is an integral part of the Turbosorp ${ }^{\circledR}$ process. Although it is possible to install a Turbosorp ${ }^{\circledR}$ system with an ESP to remove the reaction products and spent sorbent from the flue gas, baghouses are generally preferred because they provide for deeper emission reductions. All of the projects in Table 47 include a new baghouse as part of the Turbosorp ${ }^{\circledR}$ system. The existing particulate control device can be either retired (as it was at AES Greenidge) or retained (because of economic and/or operating considerations). At AES Westover Unit 8, as at AES Greenidge Unit 4, the existing cold-side ESP was abandoned, with fly ash being collected along with the spent sorbent and reaction products in the new baghouse. At these sites, both the booster fan and the existing ID fans are located downstream of the Turbosorp ${ }^{\circledR}$ reactor and baghouse. The hot-side ESP at GRU Deerhaven Unit 2 will be retained, allowing the new SCR reactor and the existing air heater to operate with low dust loading. The cold-side ESP at Mt. Tom will also be retained. Retaining the ESP allows the fly ash to be disposed or sold separately from the scrubber product, if desired. However, the ESP can be operated at reduced power, because the baghouse provides supplemental particulate emission control. At Deerhaven, the Turbosorp ${ }^{\circledR}$ system will be located downstream of the unit's two existing ID fans, but upstream of two new booster fans that are being installed as part of the project. At Mt. Tom, the Turbosorp ${ }^{\circledR}$ system will be installed upstream of the two existing ID fans, and a single new booster fan will be installed ahead of the Turbosorp ${ }^{\circledR}$ absorber vessel. To enable low-load operation of the Turbosorp ${ }^{\circledR}$ system, both of these installations will include a flue gas recirculation stream taken downstream of the final fan; the recycled flue gas will be introduced downstream of the ID fans (but upstream of the Turbosorp ${ }^{\circledR}$ absorber vessel) at Deerhaven, and upstream of the booster fan at Mt. Tom.

The hydrated lime required by the Turbosorp ${ }^{\circledR}$ system can be produced from pebble lime in an onsite hydrator, as it is at AES Greenidge, or it can be purchased and delivered to site for direct use in the process. The Turbosorp ${ }^{\circledR}$ installations at AES Westover and FirstLight Mt. Tom do not include hydrators; both of these applications are designed to use hydrated lime that is delivered by truck. At GRU Deerhaven, two complete hydration trains will provide fully redundant, on-site hydration capacity, while allowing for delivery of both pebble lime and hydrated lime. The lime hydration system specified for the Deerhaven project includes an improved hydrator design that eliminates the need for post-hydrator milling and classification. This design is expected to avoid many of the problems discussed in Section 10.2.2.1, likely resulting in a significant reduction in maintenance requirements relative to those at AES Greenidge. Each hydration train will also require appreciably less equipment than the lime hydration system that was installed as part of the Greenidge Project.

The Turbosorp ${ }^{\circledR}$ system at Mt. Tom Unit 1 will include an activated carbon injection system; the system at Deerhaven Unit 2 includes provisions for an $\mathrm{ACl}$ system, and the system at Westover Unit 8 does not include an $\mathrm{ACl}$ system. The decision to include or exclude activated carbon injection capabilities for a given installation depends upon the required amount of $\mathrm{Hg}$ reduction and the amount of $\mathrm{Hg}$ removal that can be reasonably expected as a co-benefit of the Turbosorp ${ }^{\circledR}$ system and any other pollution controls that are installed. As discussed in Section 9.3.8, the Turbosorp ${ }^{\circledR}$ system at AES Greenidge Unit 4 was able to achieve $98 \% \mathrm{Hg}$ removal without any activated carbon injection. However, it is uncertain whether this high level of removal will be observed for units that produce fly ash with low unburned carbon content, fire low-chlorine coal, or capture fly ash upstream of the Turbosorp ${ }^{\circledR}$ process. 
None of the three additional announced deployments of the Turbosorp ${ }^{\circledR}$ system are being installed in combination with the hybrid SNCR/SCR system that was included at AES Greenidge. However, all of these deployments will include a conventional SCR upstream of the Turbosorp $^{\circledR}$ system. Two of the projects include SCR as part of the retrofit; BPEI recently installed an SCR system at Mt. Tom Unit 1, and this SCR will continue in service.

The Turbosorp ${ }^{\circledR}$ projects at Westover, Deerhaven, and Mt. Tom are consistent with the population of smaller, existing coal-fired EGUs targeted by the Greenidge Project. As shown in Section 2.2, there are a number of additional, similar units that remain candidates for the demonstration technology. Babcock Power Environmental continues to market the technology to these units. In addition to conventional applications involving mid- or high-sulfur coal, such as those presented in Table 47, BPEI is pursuing application of the Turbosorp ${ }^{\circledR}$ process to lowsulfur coals, to opportunity fuels such as petroleum coke and biomass, and as a polishing scrubber to achieve very low emissions from fluidized bed boilers. The successful commercialization of the demonstration technology is the greatest indicator of the success of the Greenidge Project.

\section{Conclusions and Recommendations}

As part of the Greenidge Project, an integrated multi-pollutant control system including a $\mathrm{NO}_{\mathrm{x}}$ OUT CASCADE ${ }^{\circledR}$ hybrid SNCR/SCR system and a Turbosorp ${ }^{\circledR}$ circulating fluidized bed dry scrubbing system was successfully installed, tested, and operated commercially for more than a year-and-a-half at AES Greenidge Unit 4. The project represented the first application in which these technologies were combined to form an integrated multi-pollutant control system, as well as the first application of either of these technologies to a unit firing $>2 \%$-sulfur eastern U.S. bituminous coal. It also included more ambitious performance targets for both technologies than any prior application. The testing results and experience gained from the Greenidge Project resolved uncertainties related to the technical and economic performance of the multipollutant control system, helping to establish its commercial viability. Major conclusions of the project are as follows:

- The multi-pollutant control system achieved the performance target of $\geq 95 \% \mathrm{SO}_{2}$ removal efficiency during both short-term and long-term testing while AES Greenidge Unit 4 fired eastern U.S. bituminous coals containing $>2 \%$ sulfur. The average $\mathrm{SO}_{2}$ removal efficiency observed during 14 months of commercial operation (August 2007 September 2008) was $96.3 \%$. The inlet $\mathrm{SO}_{2}$ rate averaged $3.62 \mathrm{lb} / \mathrm{mmBtu}$ during this period, and $\mathrm{SO}_{2}$ removal efficiencies greater than $95 \%$ were achieved for coals containing up to $3.3 \%$ sulfur $(4.8 \mathrm{lb} \mathrm{SO} / \mathrm{mmBtu})$. Performance tests showed that the system required a calcium-to-sulfur molar ratio of 1.6-1.7 to achieve $95 \% \mathrm{SO}_{2}$ removal efficiency under design conditions; however, the required $\mathrm{Ca} / \mathrm{S}$ ratio is sensitive to the $\mathrm{SO}_{2}$ removal efficiency and proximity to the adiabatic saturation temperature in the absorber vessel.

- The multi-pollutant control system achieved the performance target of $\geq 90 \% \mathrm{Hg}$ removal efficiency (coal-to-stack) during both short-term and long-term testing. No activated carbon injection was required to achieve this removal efficiency. The average coal-tostack $\mathrm{Hg}$ removal efficiency measured during 29 tests without activated carbon injection between March 2007 and June 2008 was 98\%. This represents a 97\% reduction from the baseline removal efficiency that had been achieved by the unit's ESP prior to the 
project. Hg removal efficiencies of $>90 \%$ were observed irrespective of plant operating conditions. The high mercury removal efficiency may be attributable in part to the high unburned carbon content of the fly ash at AES Greenidge Unit 4; it is unclear whether activated carbon would be required for units that produce fly ash containing less unburned carbon. Tests conducted around the single-layer SCR suggested that it increases the proportion of mercury that is present in oxidized form; this may contribute to better capture efficiency in the downstream scrubber.

- The multi-pollutant control system achieved the performance target of $\geq 95 \% \mathrm{SO}_{3}$ and $\mathrm{HCl}$ removal efficiency during both short-term and long-term testing. The average $\mathrm{SO}_{3}$ removal efficiency observed during 42 tests between May 2007 and June 2008 was $95.3 \%$, and the average $\mathrm{HCl}$ removal efficiency observed during 30 tests between March 2007 and June 2008 was 96.7\%. Routine variations in process conditions (e.g., fuel, load, scrubber operating conditions) did not have a discernible effect on the $\mathrm{SO}_{3}$ and $\mathrm{HCl}$ removal performance of the system. Attainment of the performance target of $\geq 95 \% \mathrm{HF}$ removal efficiency could not be determined, because HF concentrations measured at the Turbosorp ${ }^{\circledR}$ scrubber inlet and stack were too low to demonstrate $95 \%$ removal.

- Primary (non-condensable) particulate matter emissions from AES Greenidge Unit 4 were significantly reduced by replacing the unit's existing ESP with the Turbosorp ${ }^{\circledR}$ system, which includes a new baghouse. The average PM emission rate measured during 58 tests between March 2007 and June 2008, following the installation of the multi-pollutant control system, was $<0.001 \mathrm{lb} / \mathrm{mmBtu}$. This represents a more-than $98 \%$ reduction over the baseline full-load PM emission rate of $0.063 \mathrm{lb} / \mathrm{mmBtu}$ measured in November 2004, prior to the installation of the system. The improvement in PM emissions occurred in spite of the substantial increase in flue gas particulate loading brought about by the hydrated lime, reaction products, and high solids recycle rate in the Turbosorp $^{\circledR}$ system.

- The multi-pollutant control system achieved the performance target for high-load $\mathrm{NO}_{\mathrm{x}}$ emissions of $\leq 0.10 \mathrm{lb} / \mathrm{mmBtu}$ during short-term (guarantee) testing, but it did not meet this goal during long-term operation. The average high-load $\mathrm{NO}_{\mathrm{x}}$ emission rate observed during 14 months of commercial operation (August 2007 - September 2008) was $0.14 \mathrm{lb} / \mathrm{mmBtu}$. Urea consumption was also greater during routine, long-term operation than it was during guarantee testing. The increase in $\mathrm{NO}_{\mathrm{x}}$ emissions between the guarantee tests and the long-term performance evaluation period occurred because AES Greenidge had to reduce the aggressiveness of low- $\mathrm{NO}_{x}$ firing in order to attain suitable combustion characteristics for routine operation. This caused the $\mathrm{NO}_{\mathrm{x}}$ emissions from the combustion zone to exceed the target of $0.25 \mathrm{lb} / \mathrm{mmBtu}$, and it caused boiler conditions to deviate from the design basis for the SNCR system, likely resulting in less-than-optimal performance of that system. Nevertheless, installation of the combustion modifications and hybrid SNCR/SCR system reduced $\mathrm{NO}_{\mathrm{x}}$ emissions from AES Greenidge Unit 4 by $\sim 25-50 \%$ at low generator loads and by $\sim 50-60 \%$ at mid and high generator loads. Overall, $\mathrm{NO}_{x}$ emissions were reduced by about $52 \%$ relative to the pre-project baseline. The success of the hybrid $\mathrm{NO}_{x}$ control system in achieving $\mathrm{NO}_{x}$ emissions of $\leq 0.10 \mathrm{lb} / \mathrm{mmBtu}$ during guarantee testing suggests that future installations may be able to achieve this level of performance if they incorporate appropriate design improvements. 
- Biomass (waste wood) co-firing did not have any discernible effect on the performance of the multi-pollutant control system. However, the extent $(<5 \%$ of total heat input) and duration of co-firing were too limited to permit a thorough evaluation of its impact on the system.

- Operation of the multi-pollutant control system was hindered by the accumulation of large particle ash in the in-duct SCR catalyst, but the severity of the problem was reduced by the installation of a large particle ash removal system. Numerous outages and derates were required during the first year of operation of the multi-pollutant control system to clean LPA from the SCR reactor. An LPA removal system, including a sloped screen, soot blowers, and vacuum ports, was installed in May 2007 and modified in September 2007 and May 2008 to mitigate the problem. The development of an effective LPA removal system for the in-duct SCR at AES Greenidge Unit 4 was very challenging because of space constraints, the vertically downward flow through the SCR reactor, and the lack of any ductwork bends or hoppers upstream of the reactor. The LPA removal system has significantly reduced the frequency of outages and derates, although additional operating experience is needed to confirm its effectiveness. The September 2007 outage also included the installation of a rake soot blower above the SCR catalyst; this has helped to reduce the rate of catalyst plugging.

- Ammonia slip from the hybrid SNCR/SCR system was generally greater than expected during the first year-and-a-half of operation. The system was designed to limit the ammonia concentration at the SCR outlet to $\leq 2$ ppmvd @ $3 \% \mathrm{O}_{2}$. Ammonia slip was demonstrated at 2 ppmvd during guarantee testing in June 2007, while the hybrid $\mathrm{NO}_{\mathrm{x}}$ control system achieved a $\mathrm{NO}_{x}$ emission rate of $0.10 \mathrm{lb} / \mathrm{mmBtu}$. This level of performance was not sustained during long-term operation, however. Ammonia concentrations ranged from 1.6 to $7.3 \mathrm{ppmvd}$ (mean = $4.6 \mathrm{ppmvd}$ ) over the course of 26 ammonia slip measurements that were performed at intermediate or high loads between October 2007 and June 2008. The greater-than-expected ammonia slip likely resulted from several factors, including stratification of the flue gas flow and/or composition at the inlet to the SCR reactor and decreased SCR performance arising from LPA accumulation in the catalyst. The ammonia slip has not significantly affected plant operations, however. Air heater basket modifications implemented outside of the scope of the DOE project appear to have been effective in reducing the impact of ammonium bisulfate fouling on air heater performance. Also, $\mathrm{SO}_{2}$-to- $\mathrm{SO}_{3}$ conversion across the SCR catalyst was less than 1\% (based on 9 tests performed between October 2007 and June 2008), helping to limit the driving force for ammonium bisulfate formation.

- The retrofit difficulty associated with the installation of the multi-pollutant control system at AES Greenidge Unit 4 was low. The multi-pollutant control system required a footprint of only $\sim 0.4$ acre and was able to be integrated with the unit during a seven-week tie-in outage. No major problems were encountered during construction of the system.

- The multi-pollutant control system affords lower capital costs in exchange for somewhat greater variable O\&M costs relative to conventional technologies that are capable of achieving deep reductions in $\mathrm{NO}_{x}$ and $\mathrm{SO}_{2}$. The EPC capital cost $(\$ 2005)$ for the multipollutant control system at AES Greenidge Unit 4 (including the combustion modifications and LPA screen, which were installed outside of the DOE scope) was $\sim \$ 349 / \mathrm{kW}_{\text {net }}$, which is about $40 \%$ less than the estimated cost to retrofit the unit with conventional SCR and wet FGD systems. Fixed and variable O\&M costs for the multi- 
pollutant control system total $\sim \$ 7.95 / \mathrm{MWh}$, and the costs for urea, lime, and waste disposal, which figure into the unit's dispatch calculations, are $\sim \$ 5.58 / \mathrm{MWh}$. The tradeoff between capital costs and variable O\&M costs is consistent with the needs of many operators of older, smaller units. Mercury control, acid gas control, and improved primary particulate matter control are co-benefits of the $\mathrm{NO}_{\mathrm{x}}$ and $\mathrm{SO}_{2}$ control systems and add no incremental cost.

- Operation and maintenance of the multi-pollutant control system were handled by existing AES Greenidge plant personnel. During periods of routine operation, AES is able to run Unit 4, including the multi-pollutant control system, with 3-4 operators per shift, as was the case prior to the project. Apart from the LPA problem, most of the maintenance requirements during the first year-and-a-half of operation involved the lime hydration system and the ash disposal and recirculation system. These were usually resolved without impacting operation of the Turbosorp ${ }^{\circledR}$ system, and actions have been taken to minimize their recurrence. The multi-pollutant control system has, however, caused the loss of $8 \mathrm{MW}$ of turndown capability for Unit 4, owing to problems with automatic control of the flue gas recirculation system in the Turbosorp ${ }^{\circledR}$ process. Firstyear maintenance requirements are expected to be less than maintenance requirements in subsequent years; hence, the maintenance requirements associated with the system cannot be fully quantified on the basis of data collected during this project.

- No major problems were encountered with byproduct disposal. The only significant byproduct from the multi-pollutant control system is the product ash from the Turbosorp ${ }^{\circledR}$ process; approximately 3.4 tons of scrubber byproduct (excluding fly ash) are produced for each ton of $\mathrm{SO}_{2}$ removed. AES Greenidge generally disposes of the product ash at a landfill adjacent to the plant site. Process economics can be improved if a beneficial reuse for the product ash can be identified. During the project period, 3,500 tons of product ash were sent for use as fill material in a local construction project; however, transportation costs severely limit opportunities for beneficial reuse of the ash. The mercury captured by the multi-pollutant control system resides in the product ash; tests confirmed that very little $(0.1 \%)$ of this $\mathrm{Hg}$ is leachable. Ammonia slip from the hybrid SNCR/SCR system has not affected byproduct handling. Liquid discharges from the multi-pollutant control system consist solely of $19 \mathrm{gpm}$ (maximum) of once-through cooling water.

- The commercial viability of the multi-pollutant control system was demonstrated at AES Greenidge Unit 4. The system, which will remain in service after the conclusion of the project, has enabled the unit to satisfy its permit requirements while continuing to operate profitably. Performance has been established over more than a year-and-a-half of routine operation. As a result of the success at AES Greenidge Unit 4, three additional deployments of the Turbosorp ${ }^{\circledR}$ technology had been announced by the end of the project.

Lessons learned during the Greenidge Multi-Pollutant Control Project can be used to improve upon the design of the multi-pollutant control system and provide for greater ease of operation in future installations. The project team offers the following recommendations based upon the experience acquired at AES Greenidge:

1. The hybrid $\mathrm{NO}_{\mathrm{x}}$ control system should be designed on the basis of less optimistic assumptions about the combustion system (i.e., without assuming overly aggressive 
low- $\mathrm{NO}_{\mathrm{x}}$ firing), so that the SNCR system can be designed to operate optimally under these realistic conditions.

2. Large particle ash should be considered as part of the SCR reactor design, even if it is only produced in very small amounts. A large particle ash removal system should be installed upstream of the SCR reactor unless it is known with certainty that the unit will not generate LPA. The design of the LPA removal system will vary by unit. However, if it is integrated upfront as part of the overall design of the hybrid $\mathrm{NO}_{\mathrm{x}}$ control system, then it may be able to incorporate desirable features (e.g., one-piece screen design, hoppers, ductwork bends, etc.) that would be difficult or impossible to implement after the SCR reactor has been installed. LPA should also be considered when selecting the catalyst for the SCR reactor. Important considerations include the geometry of the catalyst (i.e., pitch, honeycomb vs. plate vs. corrugated design), which might affect its susceptibility to plugging, and the durability (resistance to erosion) of the catalyst.

3. A rake soot blower should be installed in addition to, or in place of, the sonic horns in order to prevent fly ash accumulation in the SCR catalyst. The placement of the sonic horns, which are located above the static mixers at AES Greenidge Unit 4, should be reconsidered in order to improve their effectiveness.

4. Plant personnel should consider implementing a catalyst management plan in conjunction with the installation of the multi-pollutant control system in order to maximize the useful operating life of the catalyst and minimize costs associated with catalyst replacement or rejuvenation. To reduce the risk of prolonged downtime, it is recommended that a spare catalyst layer always be kept on site in the event that the catalyst must be replaced because of plugging or damage (e.g., from LPA accumulation or an economizer tube leak).

5. The design should provide a system for removing ash from the hopper at the inlet to the Turbosorp $^{\circledR}$ absorber vessel, thereby eliminating the need to hire a vacuum truck for this purpose.

6. For plants located in cold climates, consideration might be given to enclosing the Turbosorp $^{\circledR}$ and lime hydration structures in order to reduce the risk of weather-induced plugging or freezing of equipment, and to facilitate wintertime maintenance. If exposure to cold temperatures is anticipated, the ash disposal chutes should be heated to prevent condensation and plugging.

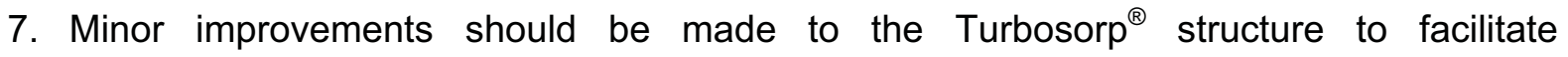
maintenance. Specific recommendations include the addition of cable ports to the roof of the absorber vessel for maintenance access and the addition of a hoist rail to aid in change-out of the water injection lance.

8. If possible, the design should provide for change-out of the Turbosorp ${ }^{\circledR}$ water injection lance without interrupting the supply of water to the absorber vessel. This would eliminate the transient spikes in $\mathrm{SO}_{2}$ emissions that occur when the lance is changed, and it might be particularly important for units with permit limits that are based on short averaging periods.

9. The Turbosorp ${ }^{\circledR}$ system should include some means for continuously estimating the approach to adiabatic saturation in the absorber vessel, so that the operating 
temperature can be adjusted to maximize lime utilization while avoiding the risk of condensation.

10. The design of the lime hydration system should be modified to eliminate or improve the milling and classification system. (As discussed in Section 12, an improved hydrator design that avoids post-hydrator milling and classification will be implemented at GRU Deerhaven Unit 2). Further tests should be conducted to establish the effect of the hydrated lime particle size on the performance of the Turbosorp ${ }^{\circledR}$ system.

11. The design should provide sufficient onsite hydrated lime storage capacity ( $\sim 1-2$ days) to allow for offline maintenance of the lime hydration system without upsetting the Turbosorp ${ }^{\circledR}$ process.

12. The relatively large compressed air demand arising from the baghouse should be considered as part of the initial design, and the plant's compressed air capacity should be increased as necessary to accommodate this demand.

13. The baghouse compartment isolation valves should be exercised routinely (when the unit is operating at reduced load) in order to maintain their operability and retain the ability to perform online maintenance on the baghouse.

14. If possible, the flue gas recirculation duct should be tied into the ID fan discharge rather than the booster fan discharge to provide for improved control of the flue gas recirculation system and to avoid the potential for reverse flow through the system (i.e., bypassing the Turbosorp ${ }^{\circledR}$ scrubber and baghouse). This will help to ensure that the unit's full original turndown capability is retained. In some cases, it might make sense to replace the existing ID fans with larger fans, rather than installing a separate booster fan, in order to simplify the system.

15. Additional testing should be conducted to elucidate the fate of HF in the system.

16. Additional testing should be conducted to determine the $\mathrm{Hg}$ removal performance of the multi-pollutant control system (and the amount of activated carbon injection required, if any) for units that produce fly ash with low unburned carbon content, fire low-chlorine coal, or capture fly ash upstream of the Turbosorp ${ }^{\circledR}$ process. 


\section{REFERENCES}

Albanese, V.; Boyle, J.; Huhmann, A.; Wallace, A. Evaluation of Hybrid SNCR/SCR for $\mathrm{NO}_{x}$ Abatement on a Utility Boiler; Presented at Power-Gen '95, Anaheim, CA, December 1995.

Albanese, V.; Boyle, J.; Sun, W.; Abrams, R. Hybridization of Urea-SNCR with SCR: A Fit for the Future; Presented at ICAC's Clean Air Technologies \& Strategies Conference, Baltimore, MD, March 7-10, 2005.

American Coal Ash Association; 2007 Coal Combustion Product (CCP) Production \& Use Survey Results (Revised); September 2008; Available: http://www.acaa-usa.org/associations/ 8003/files/2007_ACAA_CCP_Survey_Report_Form\%2809-15-08\%29.pdf

Brouwer, J.; Heap, M.P.; Pershing, D.W.; Smith, P.J. A Model for Prediction of Selective Noncatalytic Reduction of Nitrogen Oxides by Ammonia, Urea, and Cyanuric Acid with Mixing Limitations in the Presence of CO; In Proceedings of the Twenty-Sixth Symposium (International) on Combustion; The Combustion Institute: Pittsburgh, PA, 1996.

Cambridge Energy Research Associates; IHS-CERA Power Capital Costs Index; December 2008; Available: http://ihsindexes.com/pcci-graph.htm.

Canadian Electricity Association (CEA); Mercury Information Clearinghouse, Quarter 5 Mercury Fundamentals; January 2005.

DePriest, W.; Gaikwad, R.P. Economics of Lime and Limestone for Control of Sulfur Dioxide; Presented at the Fourth Mega Symposium on Power Plant Air Pollutant Control, Washington, D.C., May 19-22, 2003.

DeVito, M.S.; Smith, D.L. Controlled Condensation Method: New Option for $\mathrm{SO}_{3}$ Sampling; Power 1991, 135(2), 41-44.

Feeley, T.J.; Brickett, L.A.; Murphy, J.T. Evaluation of the Effect of SCR NO $\mathrm{N}_{\mathrm{x}}$ Control Technology on Mercury Speciation; U.S. Department of Energy, National Energy Technology Laboratory: Pittsburgh, PA, 2003. Available: http://www.netl.doe.gov/technologies/coalpower/ ewr/pubs/SCRHgPaperFinal030503.pdf.

Fenger, M.L.; Winschel, R.A. Multi-Pollutant Emissions Control: Pilot Plant Study of Technologies for Reducing $\mathrm{Hg}, \mathrm{SO}_{3}, \mathrm{NO}_{\mathrm{x}}$ and $\mathrm{CO}_{2}$ Emissions; Final Report of Work Performed Under U.S. DOE-NETL Cooperative Agreement No. DE-FC26-01NT41181, CONSOL Energy Inc. Research \& Development: South Park, PA, 2006.

Fernando, R. Experience of Indirect Cofiring of Biomass and Coal; IEA Clean Coal Centre: London, 2002; Report No. CCC/64.

Ghorishi, B.; Gullett, B.K. Sorption of Mercury Species by Activated Carbons and CalciumBased Sorbents: Effect of Temperature, Mercury Concentration and Acid Gases; Waste Manage. Res. 1998, 16, 582-593. 
Hoskins, B. Uniqueness of SCR Retrofits Translates into Broad Cost Variations; Power Engineering, May 2003. Available: http://pepei.pennnet.com/display_article/176832/6/ARTCL/ none/none/1/Uniqueness-of-SCR-Retrofits-Translates-into-Broad-Cost-Variations/

Lancia, A.; Musmarra, D.; Pepe, F.; Volpicelli, G. Adsorption of Mercuric Chloride Vapours from Incinerator Flue Gases on Calcium Hydroxide Particles; Combust. Sci. Technol. 1993, 93, 277289.

McGurl, G.V.; James, R.E.; Parsons, E.L.; Ruether, J.A.; Wimer, J.G. Quality Guidelines for Energy System Studies; Prepared by Office of Systems and Policy Support, U.S. Department of Energy, National Energy Technology Laboratory, February 24, 2004. Available: http://www.netl.doe.gov/publications/others/quality_guidelines/main.html.

Miller, C.E.; Feeley, T.J.; Aljoe, W.W.; Lani, B.W.; Schroeder, K.T.; Kairies, C.; McNemar, A.T.; Jones, A.P.; Murphy, J.T. Mercury Capture and Fate Using Wet FGD at Coal-Fired Power Plants; DOE/NETL Mercury and Wet FGD R\&D: Pittsburgh, PA, 2006. Available: http://www.netl.doe.gov/technologies/coalpower/ewr/coal_utilization_byproducts/pdf/mercury_\% 20FGD\%20white\%20paper\%20Final.pdf.

Niksa, S.; Fujiwara, N. Predicting Extents of Mercury Oxidation in Coal-Derived Flue Gases; $J$. Air \& Waste Manage. Assoc. 2005, 55, 930-939.

Oda, R.L.; DeVito, M.S. Controlled Condensation for Flue Gas $\mathrm{SO}_{3}$ Measurements, Presented at the U.S. DOE/FETC Conference on Formation, Distribution, Impact, and Fate of $\mathrm{SO}_{3}$ in Utility Gas Streams, Pittsburgh, PA, March 30-31, 1998.

Pfaff, D.; Abrams, R. Hybrid SNCR/In-Duct SCR System; Presented at the 2006 DOE/NETL Environmental Control Conference, Pittsburgh, PA, May 16-18, 2006.

Presto, A.A.; Granite, E.J. Survey of Catalysts for Oxidation of Mercury in Flue Gas; Environ. Sci. Technol. 2006, 40, 5601-5609.

Presto, A.A.; Granite, E.J. Impact of Sulfur Oxides on Mercury Capture by Activated Carbon; Environ. Sci. Technol. 2007, 41, 6579-6584.

Ryan, A.; St. John, B. SCR System Design Considerations for "Popcorn" Ash; In Proceedings of the Power Plant Air Pollutant Control "Mega" Symposium, Washington, DC, May 19-22, 2003.

Sargent \& Lundy; Wet Flue Gas Desulfurization Technology Evaluation: Project Number 11311000; Prepared for the National Lime Association, Sargent \& Lundy LLC: Chicago, IL, 2003.

Urbas, J.B. Hybrid Selective Non-Catalytic Reduction (SNCR) / Selective Catalytic Reduction (SCR) Demonstration for the Removal of NOx from Boiler Flue Gases; Final Technical Report of Work Performed Under U.S. DOE Agreement No. DE-FG22-96PC96256, GPU Generation, Inc.: Johnstown, PA, 1999.

U.S. Department of Energy (DOE); Earned Value Management Application Guide - Version 1.6; January 1, 2005. 
U.S. Environmental Protection Agency (EPA); Compilation of Air Pollutant Emission Factors, AP-42, Fifth Edition, Volume 1: Stationary Point and Area Sources; Office of Air Quality

Planning and Standards, Office of Air and Radiation: Research Triangle Park, NC, 1995.

Withum, J.A. Evaluation of Mercury Emissions from Coal-Fired Facilities with SCR and FGD Systems; Final Report of Work Performed Under U.S. DOE-NETL Cooperative Agreement No. DE-FC26-02NT41589, CONSOL Energy Inc. Research \& Development: South Park, PA, 2006. Available: http://www.netl.doe.gov/technologies/coalpower/ewr/mercury/control-tech/pubs/ DOE\%20SCR-FGD\%20FINAL\%20REPORT.pdf.

Wiza, C. Precise $\mathrm{SO}_{3}$ Measurements: What we Know and Need to Know; In Proceedings of the EUEC Energy \& Environment Conference, Tucson, AZ, January 28-30, 2008.

Wu, M.M.; Winschel, R.A.; Wasson, G.E. Composition Effects on Durability of Aggregates Made from Coal Combustion By-Products; Presented at the 1995 International Ash Utilization Symposium, Lexington, KY, October 23-25, 1995.

Wu, M.; Yuran, P. Commercial Demonstration of the Manufactured Aggregate Processing Technology Utilizing Spray Dryer Ash; Final Report of Work Performed Under U.S. DOE-NETL Cooperative Agreement No. DE-FC26-02NT41421, Universal Aggregates, LLC: West Mifflin, PA, 2007. Available: http://www.netl.doe.gov/technologies/coalpower/cctc/PPII/bibliography/ demonstration/industrial/aggregate/Universal\%20Aggregates\%20LLC\%20Final\%20Technical\% 20Report\%20_DE-FC26-02N.pdf

Wu, Z. $\mathrm{NO}_{x}$ Control for Pulverized Coal Fired Power Stations; IEA Clean Coal Centre: London, 2002; Report No. CCC/69. 


\section{PROJECT BIBLIOGRAPHY}

1. Connell, D.P.; Roll, D.J.; Rady, W.B.; Abrams, R.F. Design of an Integrated Multi-Pollutant Control System for Reducing Emissions of $\mathrm{SO}_{2}, \mathrm{NO}_{\mathrm{x}}, \mathrm{Hg}$, Acid Gases, and Particulate Matter from Smaller Coal-Fired Power Plants; In Proceedings of the 2006 American Filtration and Separations Society Conference on Separations Processes for the Power Generation Industry, Pittsburgh, PA, October 16-18, 2006.

2. Connell, D.P.; Roll, D.J.; Rady, W.B.; Abrams, R.F.; Huber, W.P. Initial Cost and

Performance Results from the Greenidge Multi-Pollutant Control Project; In Proceedings of the 2007 Electric Power Conference \& Exhibition, Rosemont, IL, May 1-3, 2007.

3. Connell, D.P.; Roll, D.J.; Rady, W.B.; Abrams, R.F.; Huber, W.P. The Greenidge MultiPollutant Control Project: Key Technical and Economic Features of a New Approach for Reducing Emissions from Smaller Coal-Fired Units; In Proceedings of the Air \& Waste Management Association's $100^{\text {th }}$ Annual Conference \& Exhibition, Pittsburgh, PA, June 2629, 2007.

4. Connell, D.P.; Locke, J.E.; Roll, D.J.; Rady, W.B.; Huber, W.P. Preliminary Performance Testing Results from the Greenidge Multi-Pollutant Control Project; In Proceedings of COAL-GEN, Milwaukee, WI, August 1-3, 2007.

5. Roll, D.J.; Abrams, R.F.; Connell, D.P. Follow-on Turbosorp Testing Results from the Greenidge Multi-Pollutant Control Project; In Proceedings of POWER-GEN International, New Orleans, LA, December 11-13, 2007.

6. Connell, D.P.; Locke, J.E.; Roll, D.J. Mercury Capture in a Circulating Fluidized Bed Dry Scrubber at AES Greenidge Unit 4; In Proceedings of the DOE-NETL Mercury Control Technology Conference, Pittsburgh, PA, December 11-13, 2007.

7. Connell, D.P.; Locke, J.E.; Roll, D.J.; Huber, W.P.; Abrams, R.F. Mercury Removal Performance of the Greenidge Multi-Pollutant Control System; In Proceedings of the EUEC Energy \& Environment Conference, Tucson, AZ, January 28-30, 2008.

8. Connell, D.P.; Roll, D.J.; Huber, W.P. Multi-Pollutant Control and the Smaller Unit: Greenidge One Year On; Modern Power Systems 2008, 28(5), 18-23.

9. Roll, D.J.; Connell, D.P.; Huber W.P. Results from the First Year of Operation of a Circulating Fluidized Bed Dry Scrubber with High-Sulfur Coal at AES Greenidge Unit 4; In Proceedings of the 2008 Electric Power Conference \& Exhibition, Baltimore, MD, May 6-8, 2008.

10. Connell, D.P.; Roll, D.J.; Huber, W.P. First-Year Operating Experience from the Greenidge Multi-Pollutant Control Project; In Proceedings of the $33^{\text {rd }}$ International Technical Conference on Coal Utilization and Fuel Systems, Clearwater, FL, June 1-5, 2008. 
11. Connell, D.P.; Locke, J.E.; Roll, D.J.; Abrams, R.F.; Beittel, R.; Huber, W.P. The Greenidge Multi-Pollutant Control Project: Performance and Cost Results from the First Year of Operation; In Proceedings of the Power Plant Air Pollutant Control "Mega" Symposium, Baltimore, MD, August 25-28, 2008.

12. Connell, D.P.; Roll, D.J.; Abrams, R.F.; Beittel, R.; Huber, W.P. The Greenidge MultiPollutant Control Project: Demonstration Results and Deployment of Innovative Technology for Reducing Emissions from Smaller Coal-Fired Power Plants; In Proceedings of the $25^{\text {th }}$ Annual International Pittsburgh Coal Conference, Pittsburgh, PA, September 29-October 2, 2008.

13. Connell, D.P.; Roll, D.J.; Huber, W.P. The Greenidge Multi-Pollutant Control Project: Demonstration of Innovative Technology for Reducing Air Emissions from Smaller CoalFired Units; Presented at the 2008 Joint Meeting of the Pittsburgh Coal Mining Institute of America / Society for Mining, Metallurgy, and Exploration, Inc., Canonsburg, PA, October 30-31, 2008. 


\section{ACRONYMS AND ABBREVIATIONS}

\begin{tabular}{|c|c|c|}
\hline${ }^{\circ} \mathrm{C}$ & - & degrees Celsius \\
\hline${ }^{\circ} \mathrm{F}$ & - & degrees Fahrenheit \\
\hline A & - & ampere \\
\hline$A C$ & - & actual cost \\
\hline ACAA & - & American Coal Ash Association \\
\hline acfm & - & actual cubic feet per minute \\
\hline $\mathrm{ACl}$ & - & activated carbon injection \\
\hline AFUDC & - & allowance for funds used during construction \\
\hline ASTM & - & $\begin{array}{l}\text { ASTM International (formerly American Society for } \\
\text { Testing and Materials) }\end{array}$ \\
\hline BET & - & Brunauer-Emmett-Teller \\
\hline bhp & - & brake horsepower \\
\hline BPEI & - & Babcock Power Environmental Inc. \\
\hline Btu & - & British thermal unit \\
\hline CAE & - & Clean Air Engineering \\
\hline $\mathrm{Ca} / \mathrm{S}$ & - & calcium-to-sulfur molar ratio \\
\hline CCTDP & - & Clean Coal Technology Demonstration Program \\
\hline CCV & - & continuing calibration verification \\
\hline CEM & - & continuous emission monitor \\
\hline CERA & - & Cambridge Energy Research Associates \\
\hline CFD & - & computational fluid dynamics \\
\hline CKM & - & chemical kinetic modeling \\
\hline CONSOL & - & CONSOL Energy Inc. \\
\hline $\mathrm{CPI}$ & - & cost performance index \\
\hline СТМ & - & Conditional Test Method \\
\hline CVAAS & - & cold vapor atomic absorption spectroscopy \\
\hline CVAFS & - & cold vapor atomic fluorescence spectroscopy \\
\hline DAHS & - & data acquisition and handling system \\
\hline DCS & - & distributed control system \\
\hline DEC & - & Department of Environmental Conservation \\
\hline
\end{tabular}




\begin{tabular}{|c|c|c|}
\hline DOE & - & U.S. Department of Energy \\
\hline $\mathrm{dP}$ & - & pressure drop \\
\hline dscf & - & dry standard cubic foot \\
\hline dscm & - & dry standard cubic meter \\
\hline EDT & - & Eastern Daylight Time (United States) \\
\hline EGU & - & electric generating unit \\
\hline EIA & - & U.S. Energy Information Administration \\
\hline EPA & - & U.S. Environmental Protection Agency \\
\hline EPC & - & engineering, procurement, and construction \\
\hline ESP & - & electrostatic precipitator \\
\hline EST & - & Eastern Standard Time (United States) \\
\hline EV & - & earned value \\
\hline$F_{d}$ & - & oxygen-based fuel factor \\
\hline FD & - & forced draft \\
\hline FGD & - & flue gas desulfurization \\
\hline FONSI & - & Finding of No Significant Impact \\
\hline $\mathrm{ft}$ & - & foot \\
\hline g & - & gram \\
\hline gal & - & gallon \\
\hline gph & - & gallons per hour \\
\hline gpm & - & gallons per minute \\
\hline gr & - & grain \\
\hline GW & - & gigawatt \\
\hline h & - & hour \\
\hline HFD & - & high flow delivery and circulation \\
\hline HHV & - & higher heating value \\
\hline hp & - & horsepower \\
\hline $\mathrm{Hg}^{0}$ & - & elemental mercury \\
\hline $\mathrm{Hg}^{2+}$ & - & oxidized mercury \\
\hline $\mathrm{Hg}^{\text {part }}$ & - & particle-bound mercury \\
\hline $\mathrm{Hg}^{\mathrm{TOT}}$ & - & total gas-phase mercury \\
\hline IC & - & ion chromatography \\
\hline
\end{tabular}




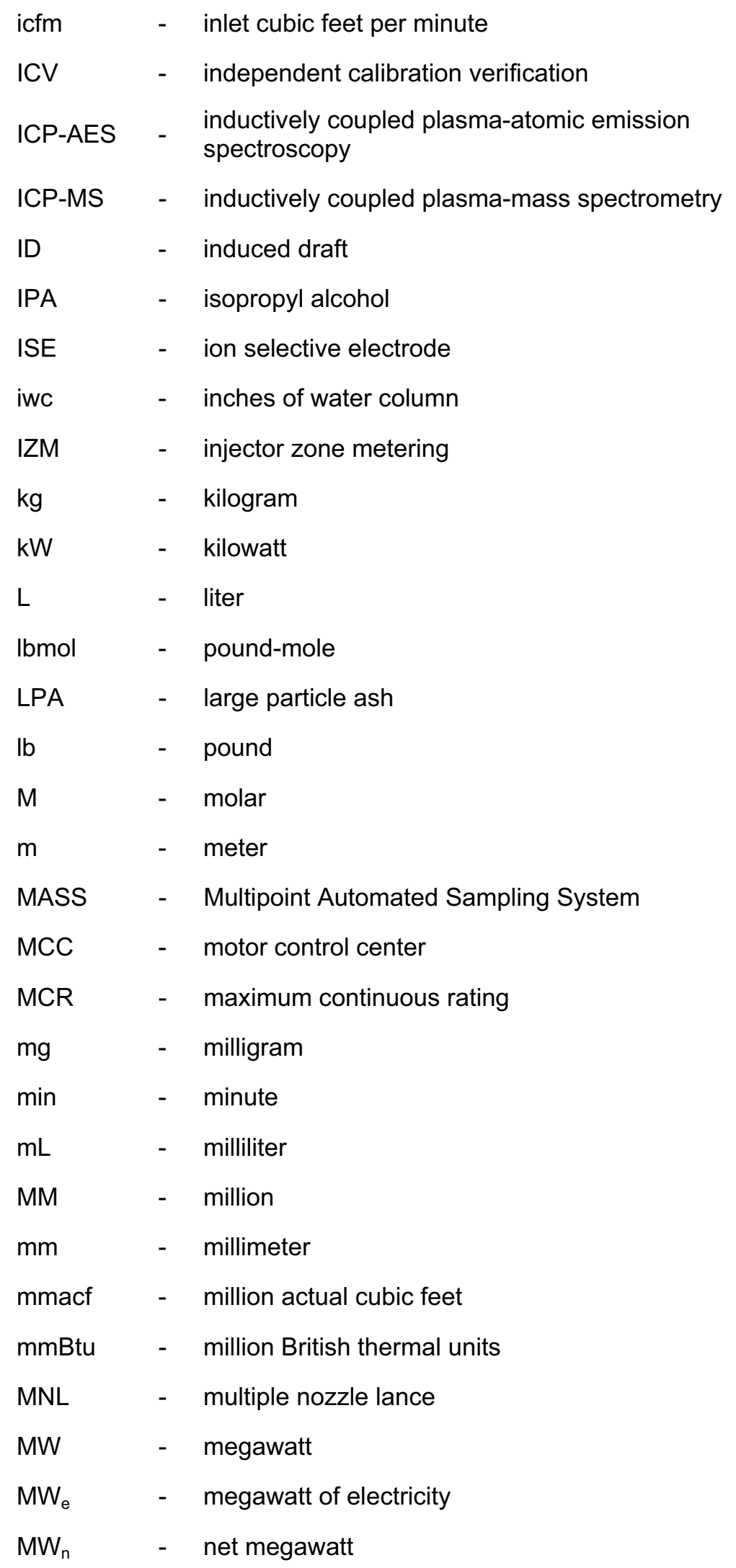




\begin{tabular}{|c|c|c|}
\hline $\mathrm{MW}_{\mathrm{g}}$ & - & gross megawatt \\
\hline MWh & - & megawatt hour \\
\hline N & - & normal \\
\hline NEPA & - & National Environmental Policy Act \\
\hline NETL & - & National Energy Technology Laboratory \\
\hline ng & - & nanogram \\
\hline $\mathrm{NH}_{3}-\mathrm{N}$ & - & ammonia as nitrogen \\
\hline NIST & - & National Institute of Standards and Technology \\
\hline $\mathrm{NO}_{\mathrm{x}}$ & - & nitrogen oxides \\
\hline NSR & - & normalized stoichiometric ratio \\
\hline NYSEG & - & New York State Electric \& Gas Corporation \\
\hline O\&M & - & operating and maintenance \\
\hline PAC & - & powdered activated carbon \\
\hline $\mathrm{PCCl}$ & - & Power Capital Costs Index \\
\hline $\mathrm{pH}$ & - & $\begin{array}{l}\text { measurement of the acidity or alkalinity of an } \\
\text { aqueous solution }\end{array}$ \\
\hline P\&ID & - & piping and instrument diagram \\
\hline PID & - & proportional-integral-derivative \\
\hline PLC & - & programmable logic controller \\
\hline PM & - & particulate matter \\
\hline $\mathrm{PM}_{2.5}$ & - & $\begin{array}{l}\text { fine particulate matter }(<2.5 \mu \mathrm{m} \text { aerodynamic } \\
\text { diameter) }\end{array}$ \\
\hline PPII & - & Power Plant Improvement Initiative \\
\hline ppm & - & parts per million \\
\hline ppmvd & - & parts per million by volume, dry basis \\
\hline ppmw & - & parts per million by weight \\
\hline PRB & - & Powder River Basin \\
\hline psig & - & pounds per square inch gauge \\
\hline PV & - & planned value \\
\hline QA/QC & - & quality assurance and quality control \\
\hline $\mathrm{R}^{2}$ & - & coefficient of determination \\
\hline RD & - & relative deviation \\
\hline RPD & - & relative percent difference \\
\hline
\end{tabular}




\begin{tabular}{|c|c|c|}
\hline RSD & - & relative standard deviation \\
\hline scf & - & standard cubic feet \\
\hline scfm & - & standard cubic feet per minute \\
\hline SCR & - & selective catalytic reduction \\
\hline SM & - & Standard Method \\
\hline SNCR & - & selective non-catalytic reduction \\
\hline SOFA & - & separated overfire air \\
\hline SPDES & - & State Pollutant Discharge Elimination System \\
\hline SPI & - & schedule performance index \\
\hline SPLP & - & Synthetic Precipitation Leaching Procedure \\
\hline SRM & - & Standard Reference Material \\
\hline STPH & - & short tons per hour \\
\hline TBtu & - & trillion British Thermal Units \\
\hline TCR & - & total capital requirement \\
\hline TPC & - & total plant cost \\
\hline TPI & - & total plant investment \\
\hline TRI & - & Toxics Release Inventory \\
\hline U.S. & - & United States \\
\hline V & - & volt \\
\hline VAC & - & volts alternating current \\
\hline$w / w$ & - & by weight \\
\hline XRD & - & X-ray diffraction \\
\hline$\mu g$ & - & microgram \\
\hline$\mu \mathrm{m}$ & - & micrometer \\
\hline
\end{tabular}




\section{CHEMICAL SYMBOLS}

\begin{tabular}{|c|c|c|}
\hline $\mathrm{Al}_{2} \mathrm{O}_{3}$ & - & aluminum oxide \\
\hline $\mathrm{BaCl}_{2}$ & - & barium chloride \\
\hline C & - & carbon \\
\hline $\mathrm{Ca}$ & - & calcium \\
\hline $\mathrm{CaCl}_{2}$ & - & calcium chloride \\
\hline $\mathrm{CaCO}_{3}$ & - & calcium carbonate \\
\hline $\mathrm{CaF}_{2}$ & - & calcium fluoride \\
\hline $\mathrm{CaO}$ & - & calcium oxide (or quicklime) \\
\hline $\mathrm{Ca}(\mathrm{OH})_{2}$ & - & calcium hydroxide \\
\hline $\mathrm{CaSO}_{3} \cdot 1 / 2 \mathrm{H}_{2} \mathrm{O}$ & - & calcium sulfite hemihydrate \\
\hline $\mathrm{CaSO}_{4}$ & - & calcium sulfate \\
\hline $\mathrm{CaSO}_{4} \cdot 1 / 2 \mathrm{H}_{2} \mathrm{O}$ & - & calcium sulfate hemihydrate \\
\hline $\mathrm{Cl}$ & - & chlorine \\
\hline $\mathrm{Cl}^{-}$ & - & chloride \\
\hline $\mathrm{Cl}_{2}$ & - & molecular chlorine \\
\hline $\mathrm{CO}$ & - & carbon monoxide \\
\hline $\mathrm{CO}_{2}$ & - & carbon dioxide \\
\hline $\mathrm{CO}\left(\mathrm{NH}_{2}\right)_{2}$ & - & urea \\
\hline$F$ & - & fluorine \\
\hline $\mathrm{F}^{-}$ & - & fluoride \\
\hline $\mathrm{F}_{2}$ & - & molecular fluorine \\
\hline $\mathrm{Fe}_{2} \mathrm{O}_{3}$ & - & iron (III) oxide (or ferric oxide) \\
\hline $\mathrm{H}$ & - & hydrogen \\
\hline $\mathrm{HCl}$ & - & hydrogen chloride (or hydrochloric acid) \\
\hline $\mathrm{Hg}$ & - & mercury \\
\hline $\mathrm{Hg}^{0}$ & - & elemental mercury \\
\hline $\mathrm{Hg}^{2+}$ & - & oxidized mercury \\
\hline $\mathrm{Hg}^{\text {part }}$ & - & particle-bound mercury \\
\hline $\mathrm{Hg}^{\text {TOT }}$ & - & total gas-phase mercury \\
\hline $\mathrm{HgCl}_{2}$ & - & mercury (II) chloride (or mercuric chloride) \\
\hline
\end{tabular}




\begin{tabular}{|c|c|c|}
\hline HF & - & hydrogen fluoride (or hydrofluoric acid) \\
\hline HNCO & - & isocyanic acid \\
\hline $\mathrm{HNO}_{3}$ & - & nitric acid \\
\hline $\mathrm{H}_{2} \mathrm{O}$ & - & water \\
\hline $\mathrm{H}_{2} \mathrm{O}_{2}$ & - & hydrogen peroxide \\
\hline $\mathrm{H}_{2} \mathrm{SO}_{4}$ & - & sulfuric acid \\
\hline $\mathrm{KCl}$ & - & potassium chloride \\
\hline $\mathrm{KMnO}_{4}$ & - & potassium permanganate \\
\hline $\mathrm{K}_{2} \mathrm{O}$ & - & potassium oxide \\
\hline $\mathrm{MgO}$ & - & magnesium oxide \\
\hline N & - & nitrogen \\
\hline $\mathrm{N}_{2}$ & - & molecular nitrogen \\
\hline $\mathrm{Na}_{2} \mathrm{O}$ & - & sodium oxide \\
\hline NCO & - & isocyanate radical \\
\hline $\mathrm{NH}_{2}$ & - & amido radical \\
\hline $\mathrm{NH}_{3}$ & - & ammonia \\
\hline $\mathrm{NH}_{3}-\mathrm{N}$ & - & ammonia as nitrogen \\
\hline $\mathrm{NH}_{4} \mathrm{HSO}_{4}$ & - & ammonium bisulfate \\
\hline$\left(\mathrm{NH}_{4}\right)_{2} \mathrm{SO}_{4}$ & - & ammonium sulfate \\
\hline NO & - & nitric oxide \\
\hline $\mathrm{NO}_{2}$ & - & nitrogen dioxide \\
\hline $\mathrm{NO}_{\mathrm{x}}$ & - & oxides of nitrogen \\
\hline $\mathrm{O}_{2}$ & - & oxygen \\
\hline $\mathrm{P}_{2} \mathrm{O}_{5}$ & - & phosphorus pentoxide \\
\hline$S$ & - & sulfur \\
\hline Se & - & selenium \\
\hline $\mathrm{SiO}_{2}$ & - & silicon dioxide \\
\hline $\mathrm{SO}_{2}$ & - & sulfur dioxide \\
\hline $\mathrm{SO}_{3}$ & - & sulfur trioxide \\
\hline $\mathrm{SO}_{4}{ }^{2-}$ & - & sulfate \\
\hline $\mathrm{TiO}_{2}$ & - & titanium dioxide \\
\hline
\end{tabular}




\section{APPENDIX A \\ PROJECT SCHEDULE}




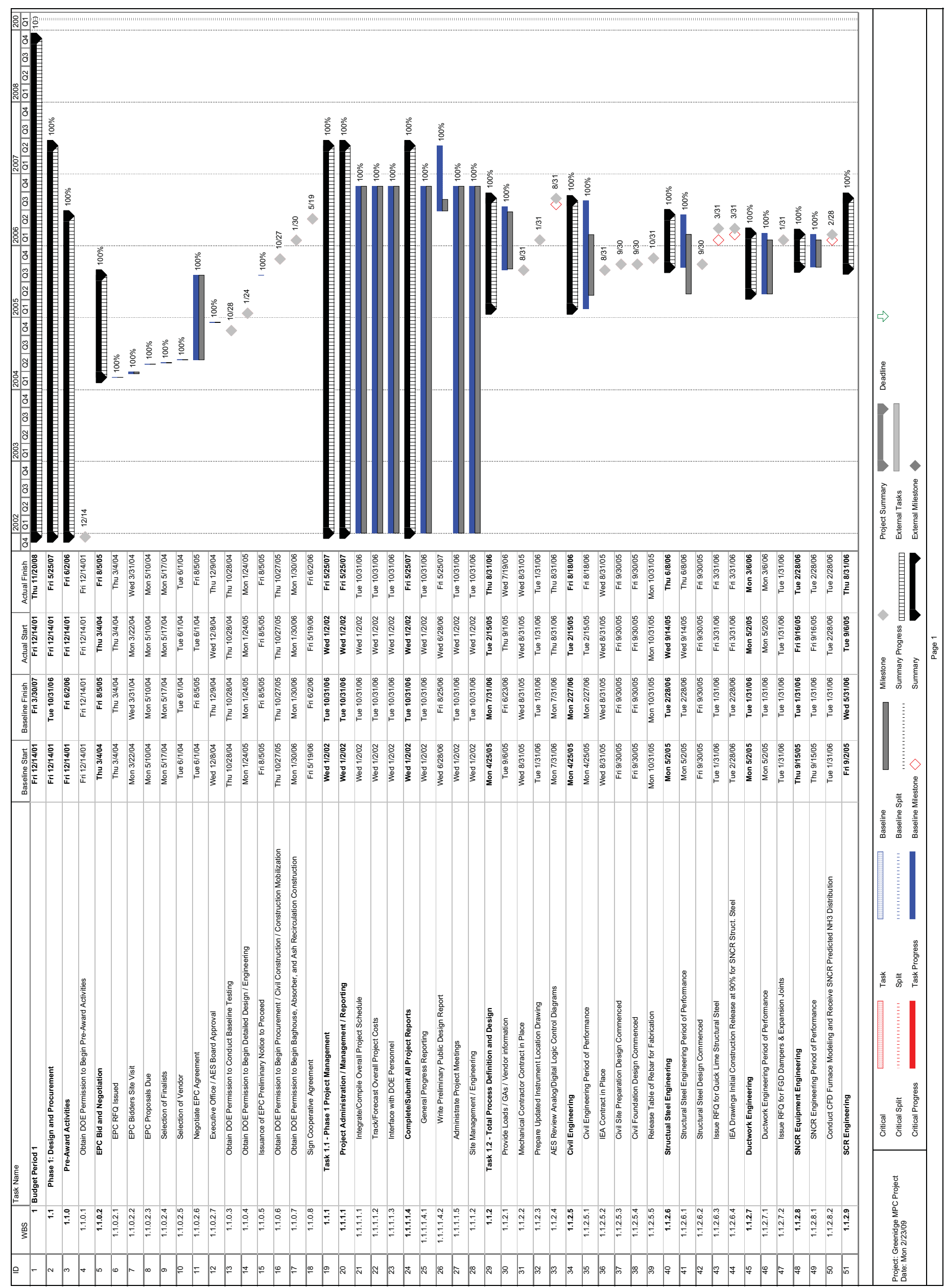




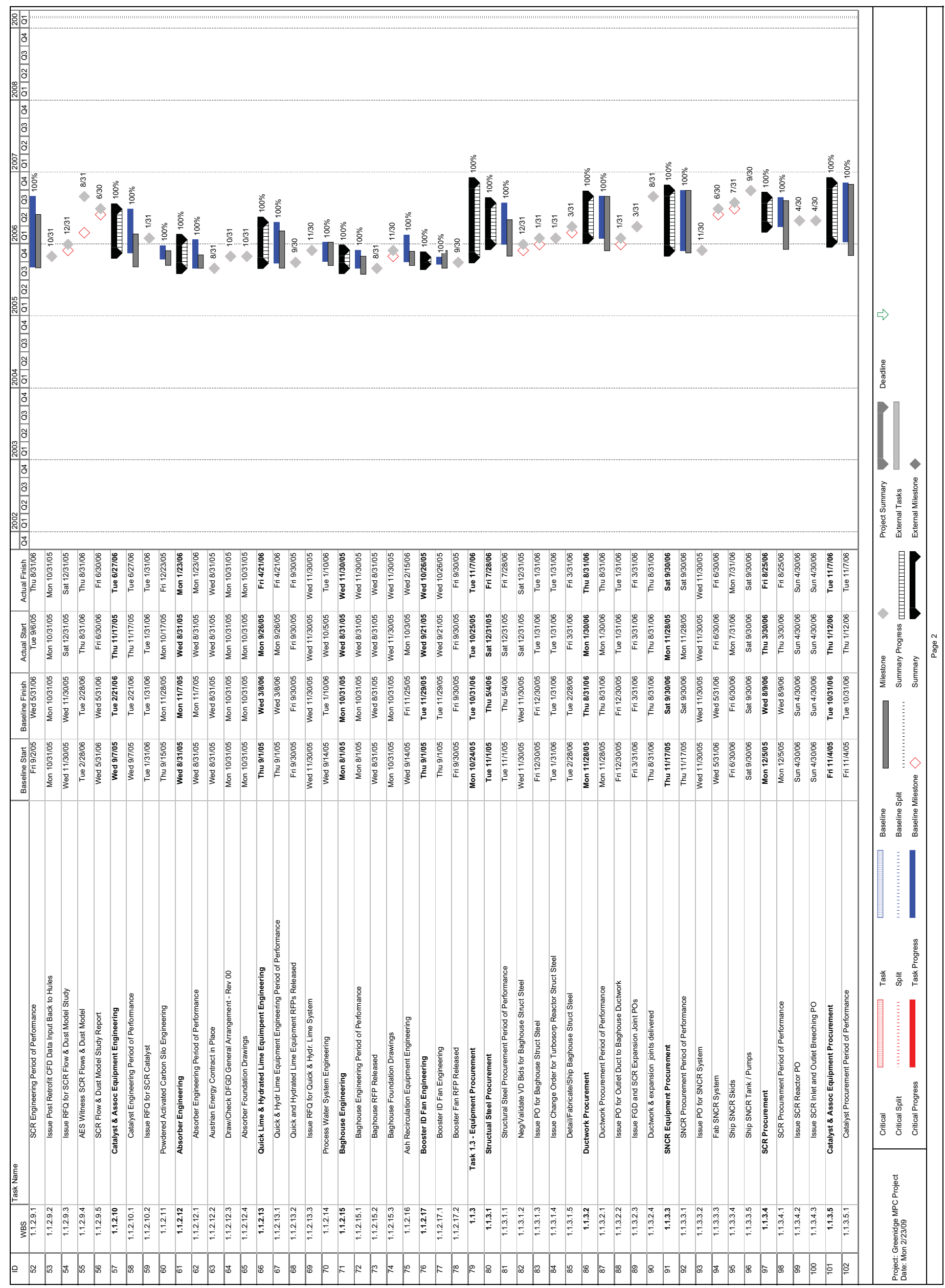









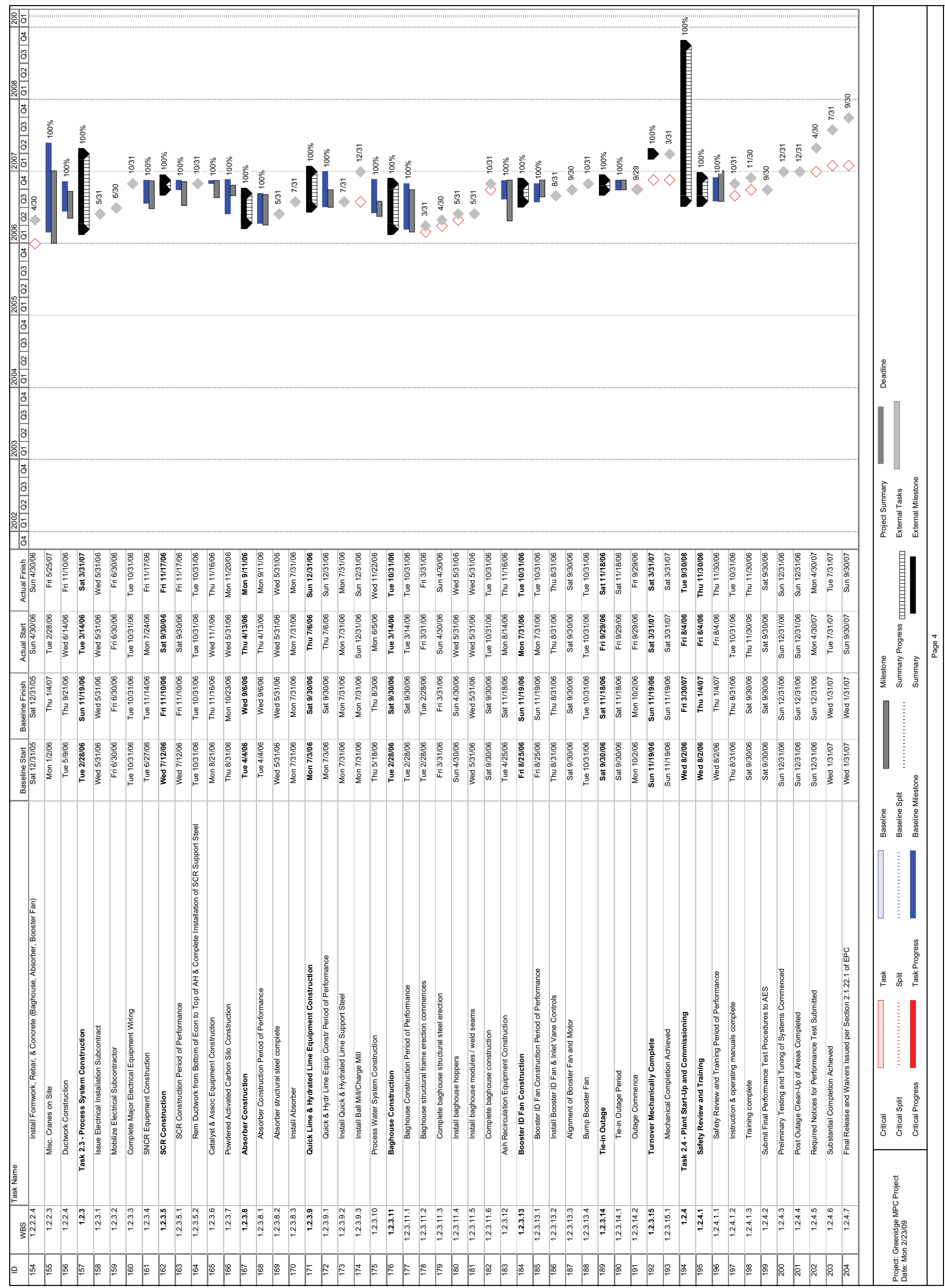




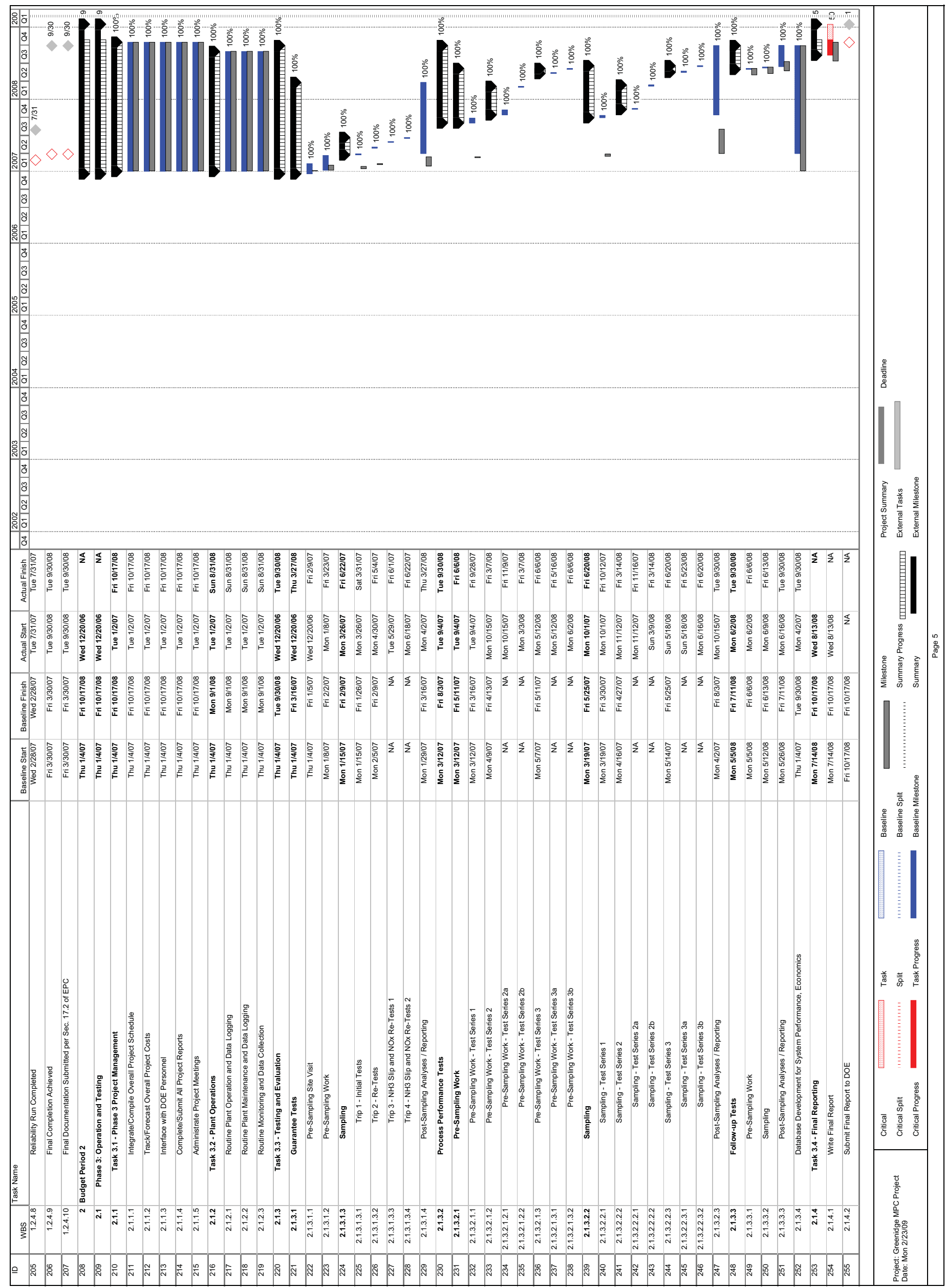




\section{APPENDIX B \\ ENGINEERING DRAWINGS}




\section{CONTENTS}

Drawing

100276-SK081706-05

100276-SK101206-03

Fuel Tech (not numbered)

100276-SK4900050

100276-SK4900065

100276-SK4900090

100276-SK4900091

100276-SK4900092

100276-SK4900093

100276-SK4900095

100276-SK4900096

100276-SK4900097

100276-SK4900098

100276-SK4900099

100276-GA200-01

100276-GA100-01

100276-GA101-01

100276-ISO100-01

100276-ISO101-01
Description

Process Flow Diagram - Design Load

Process Flow Diagram - Low Load

AES Greenidge \#4, Dresden, New York, NOxOUT

Utility System, System Overview Sheet 1

Selective Catalytic Reactor System

Sonic Horn System

Powdered Activated Carbon System

Lime Preparation System

Hydrated Lime Transport System

Process Water System

$\mathrm{SO}_{2}$ Reduction System (Turbosorp ${ }^{\circledR}$ System and

Baghouse)

Booster Fan

Air Slide 1

Air Slide 2

Plant Air, Plant Water, and Potable Water

Plan View

Elevation View Looking North

Elevation View Looking East

Isometric View Looking Northwest

Isometric View Looking Southeast 


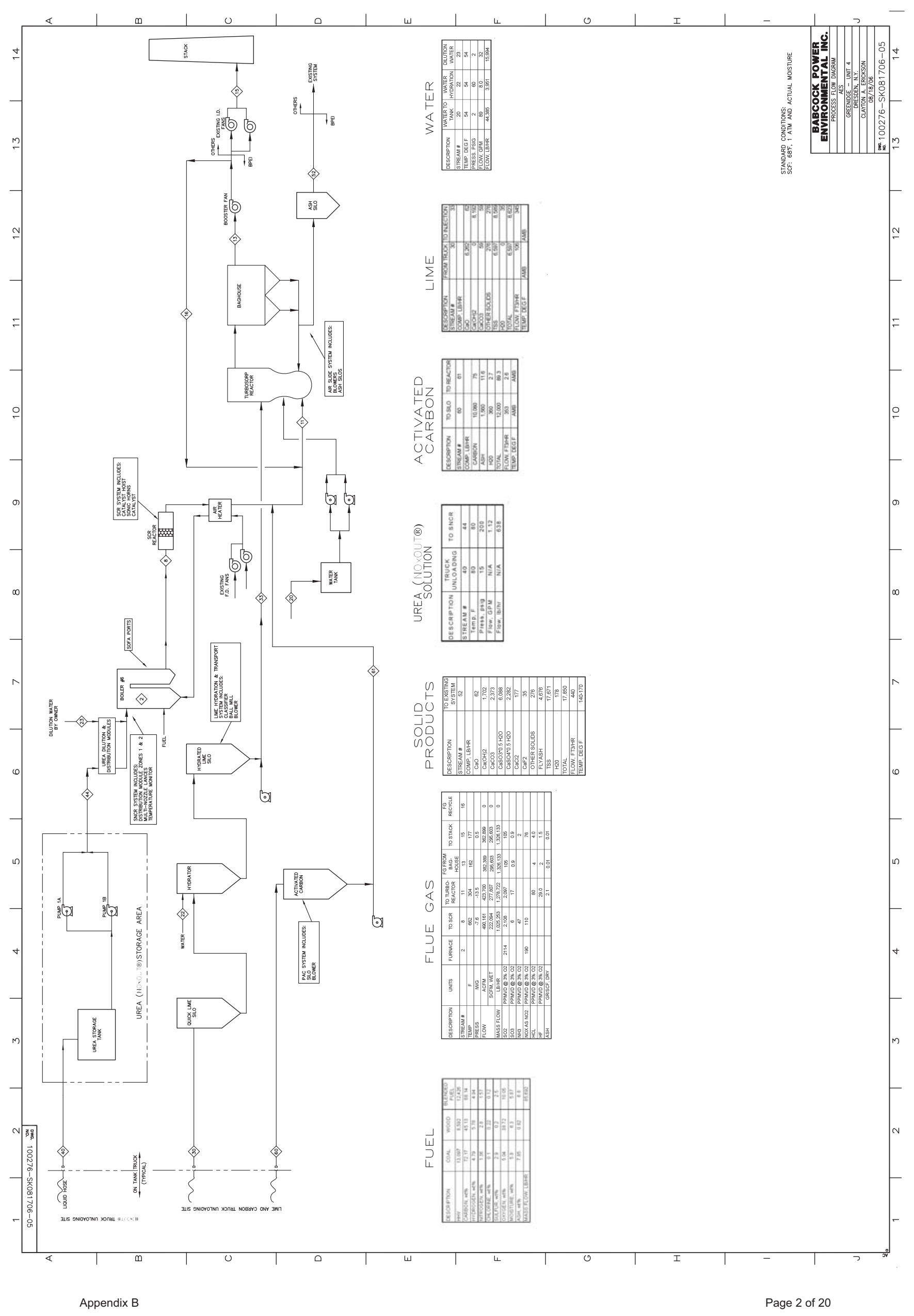




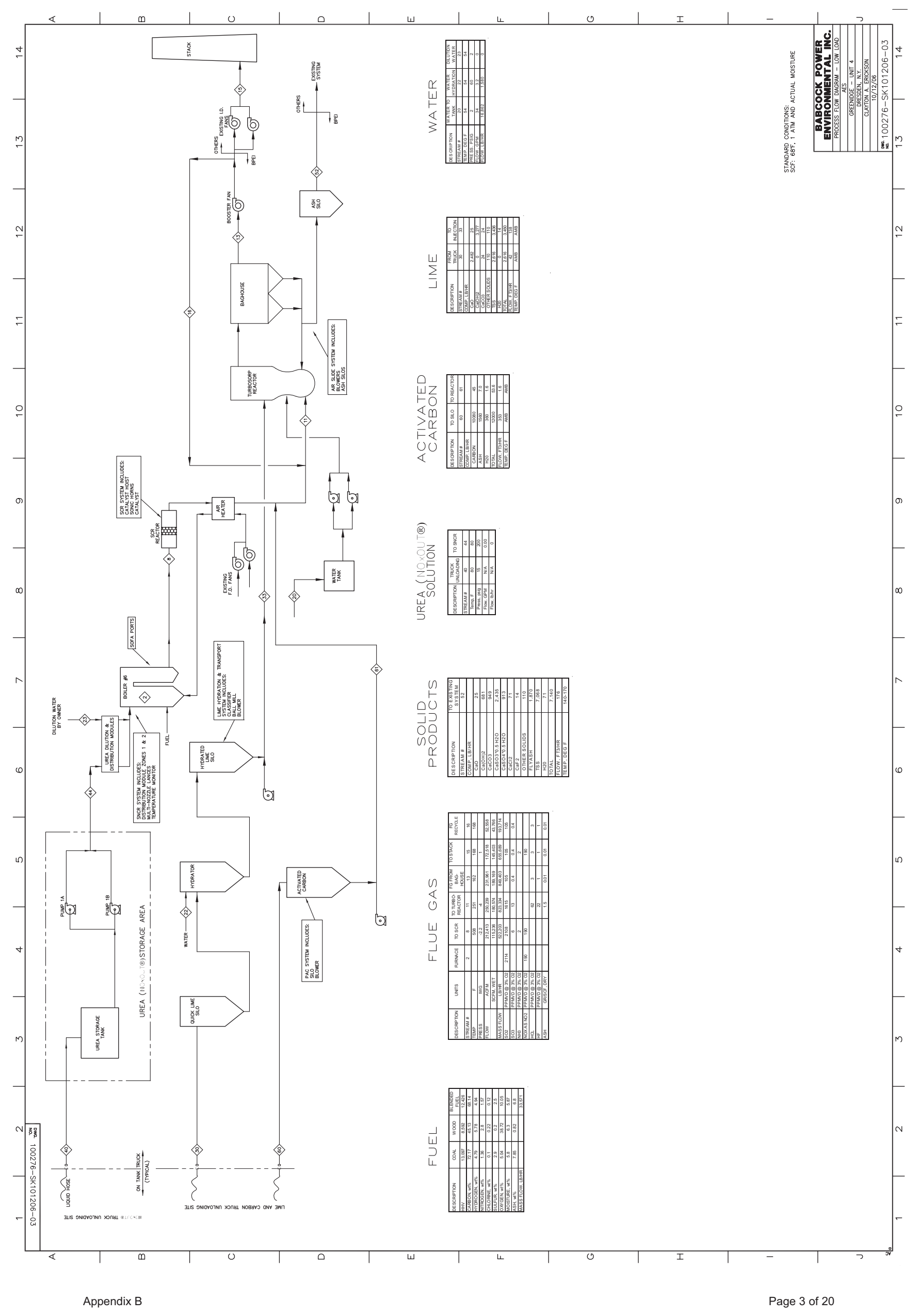




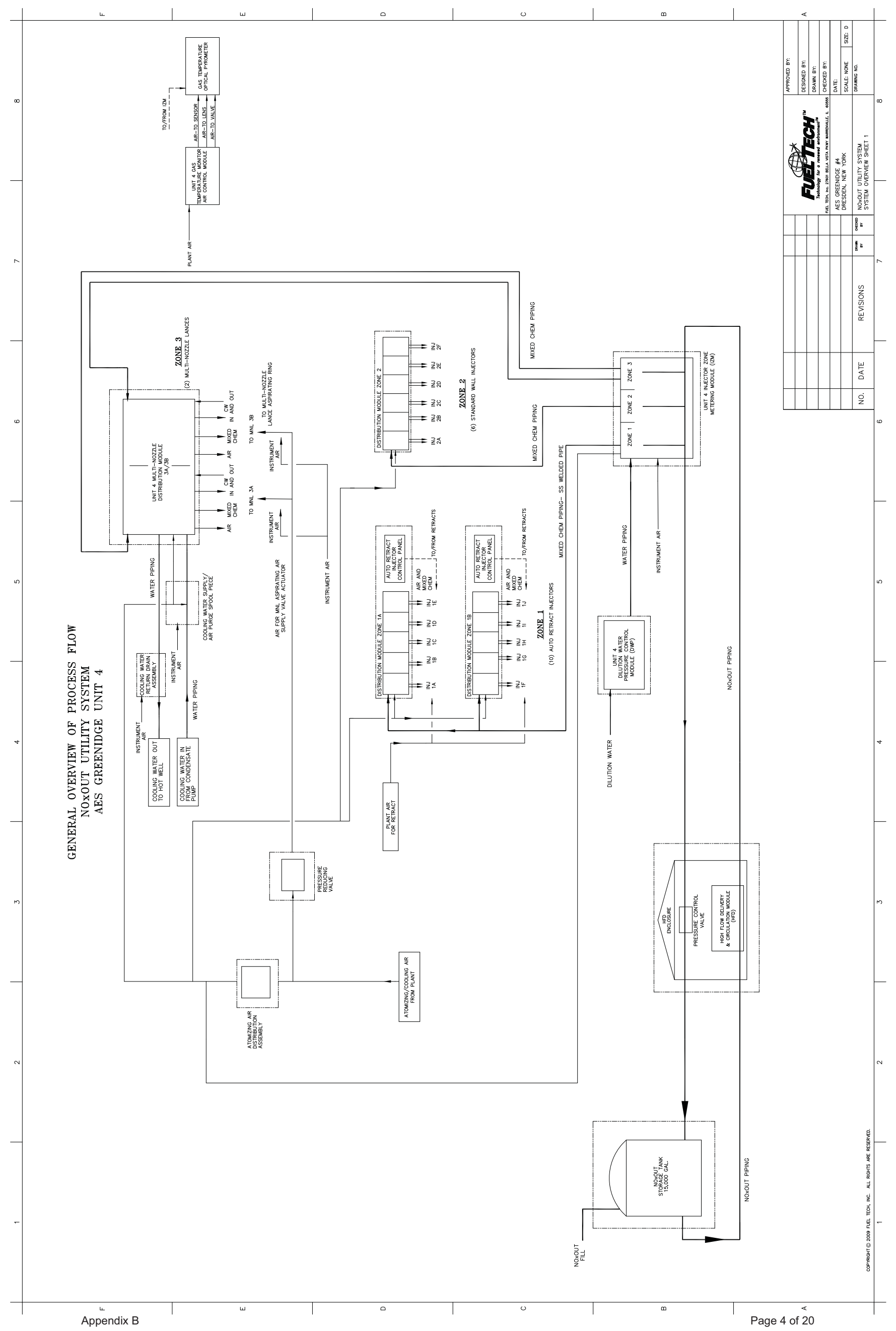




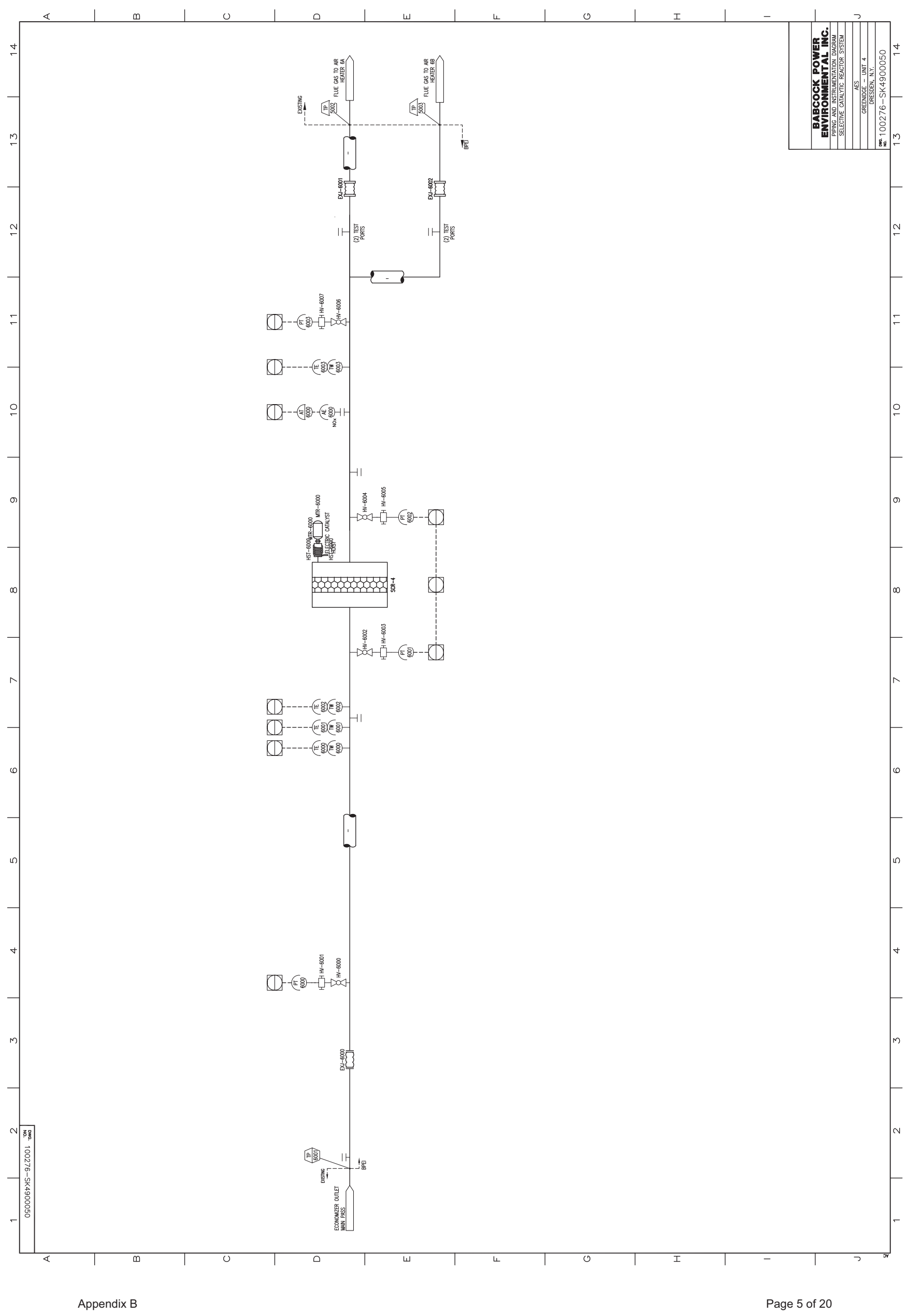




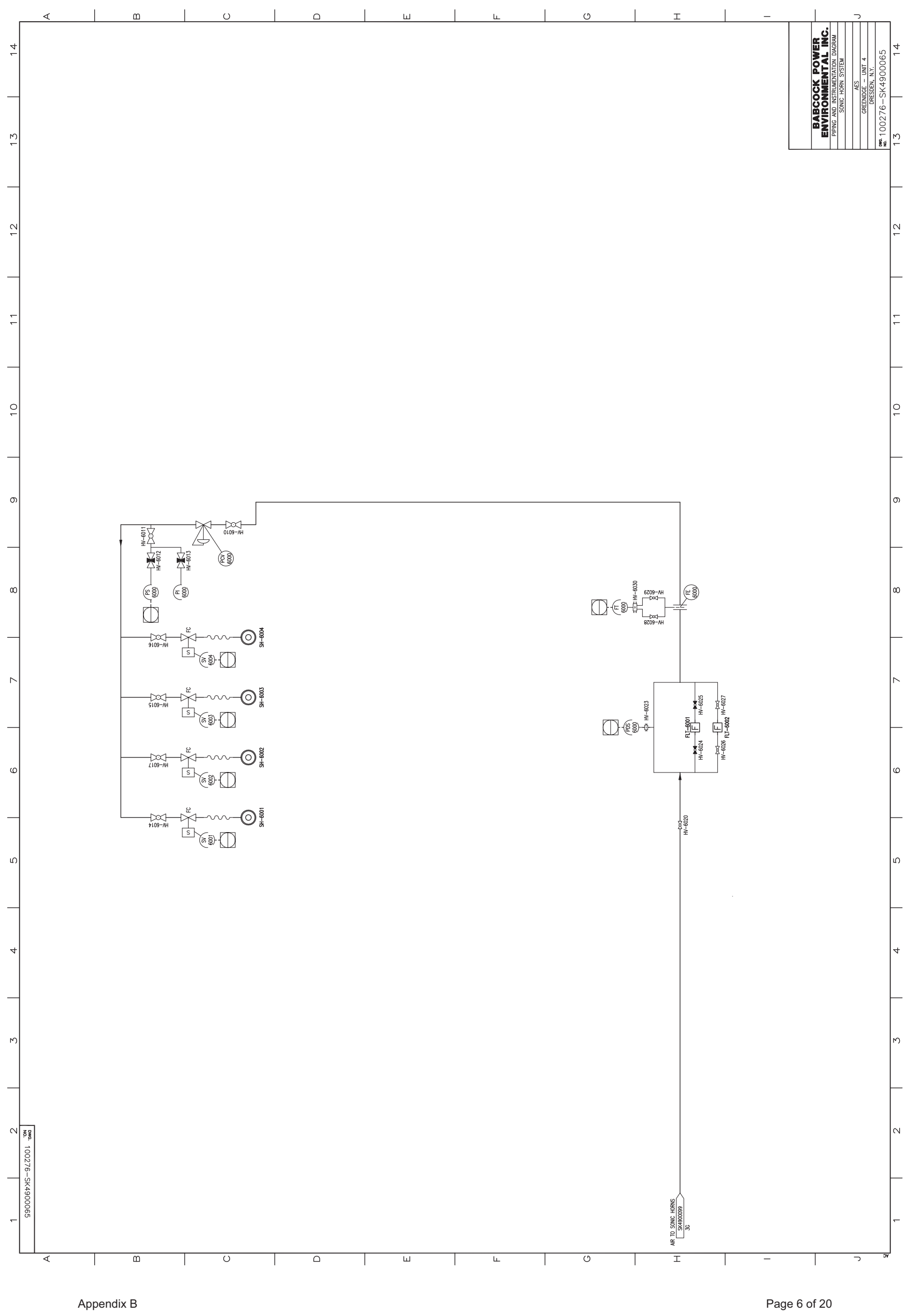




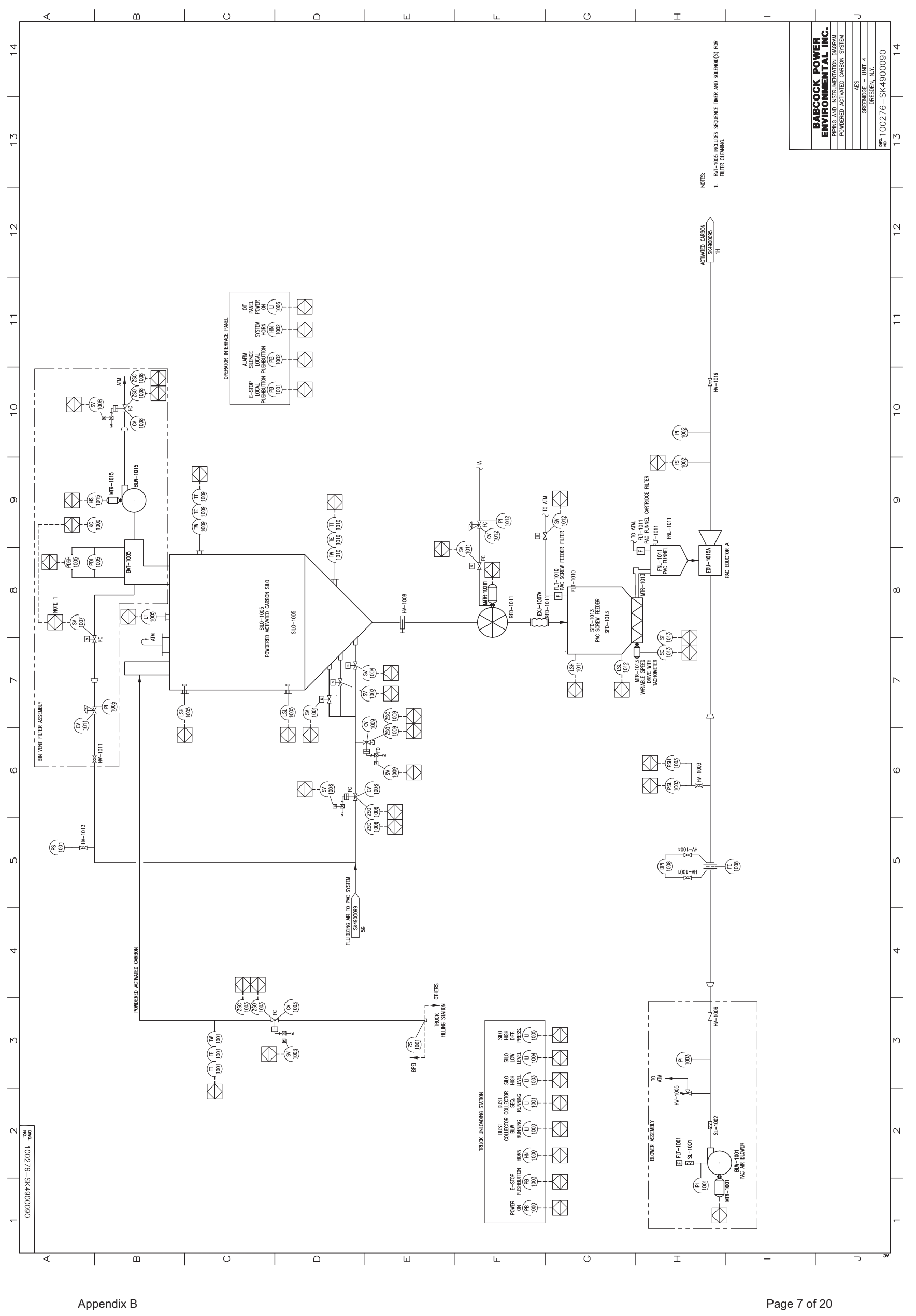




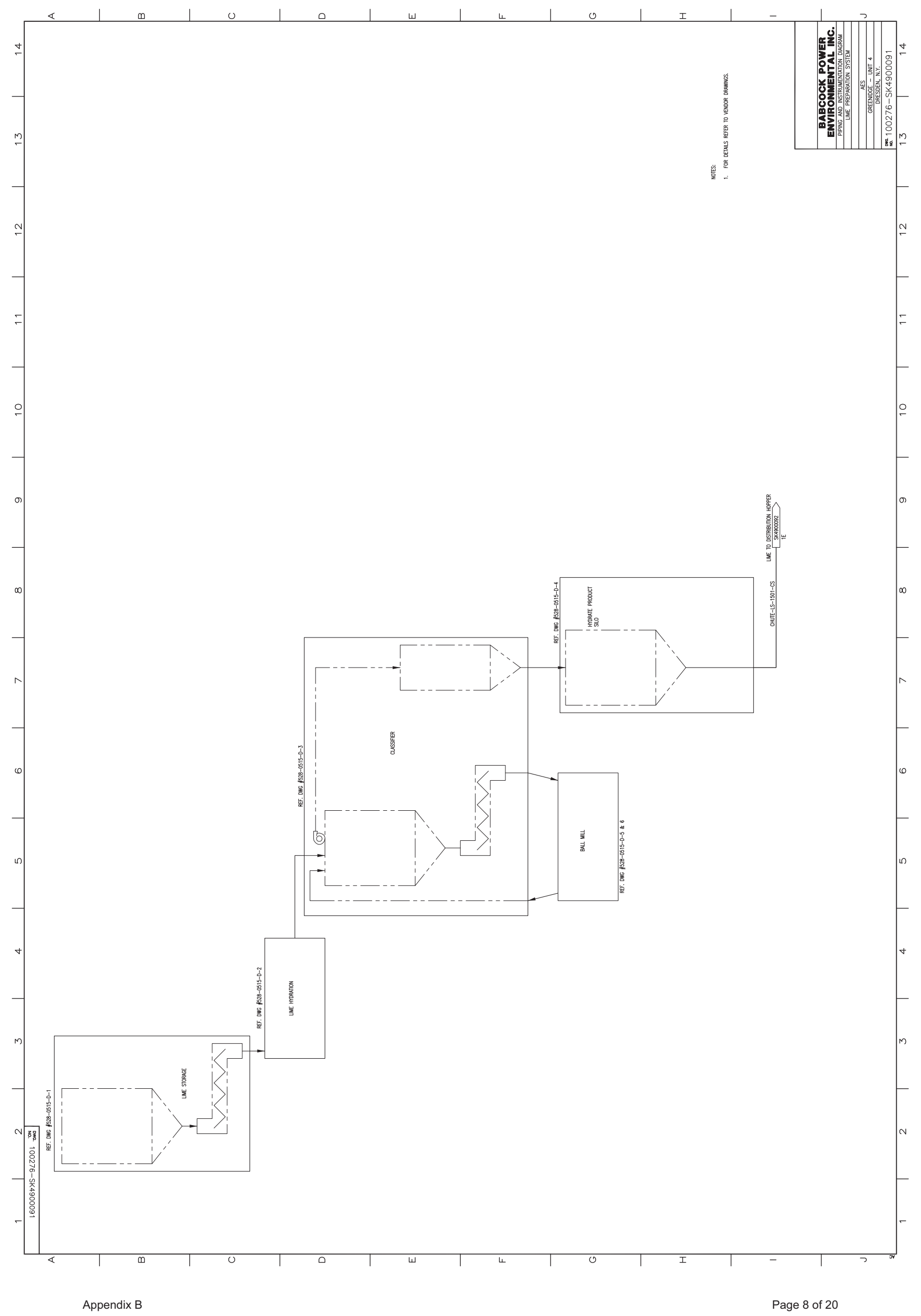




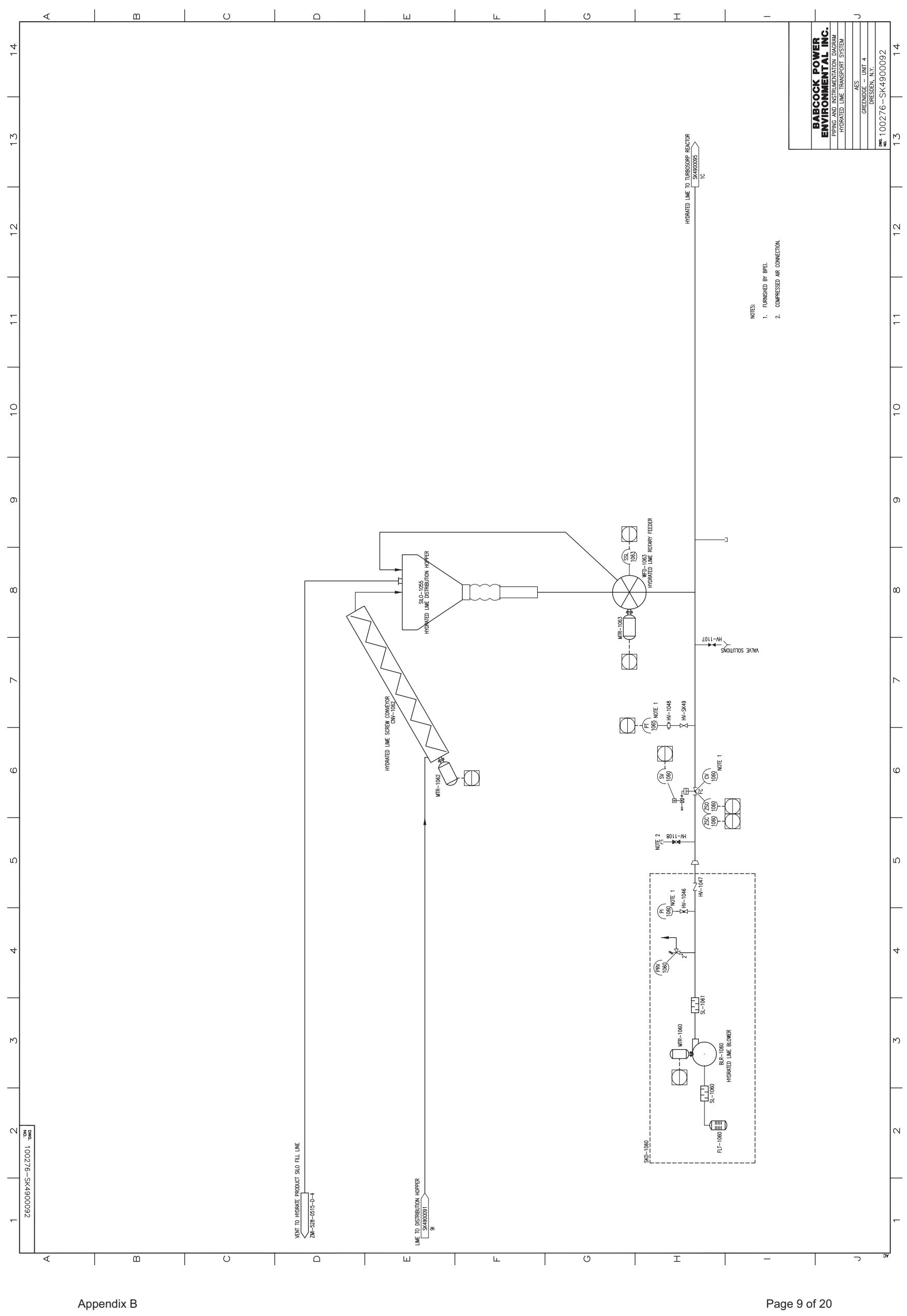




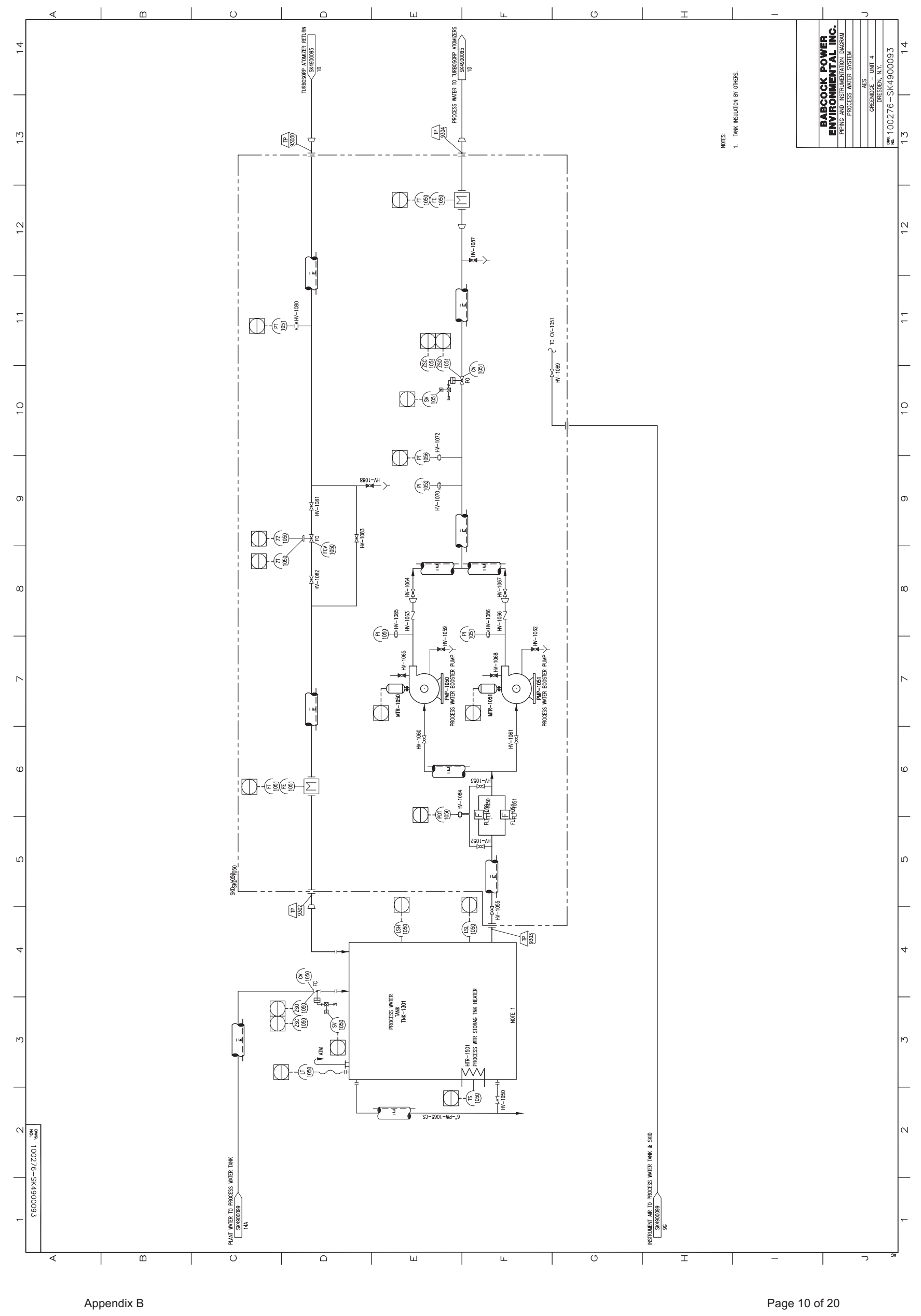




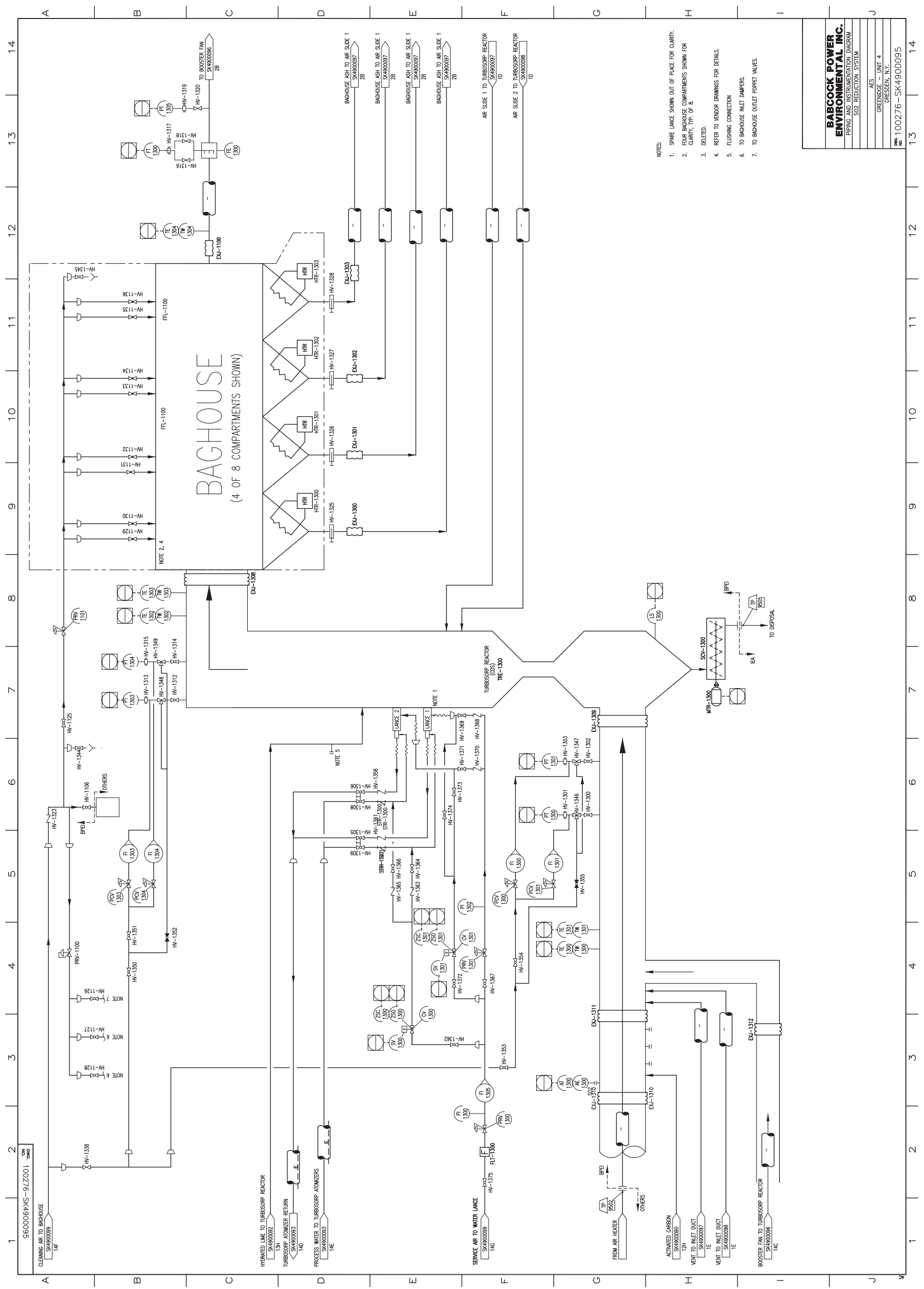




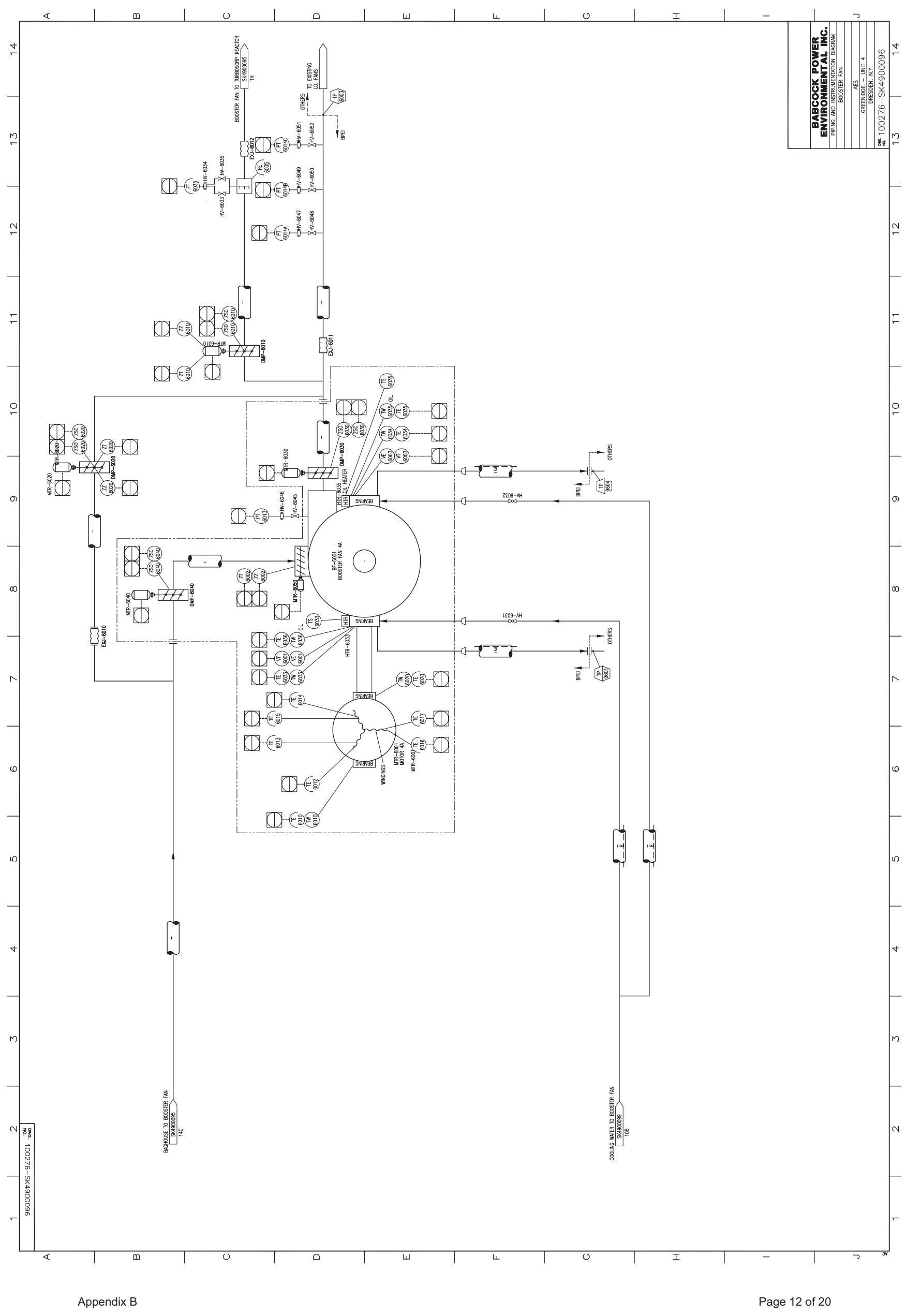




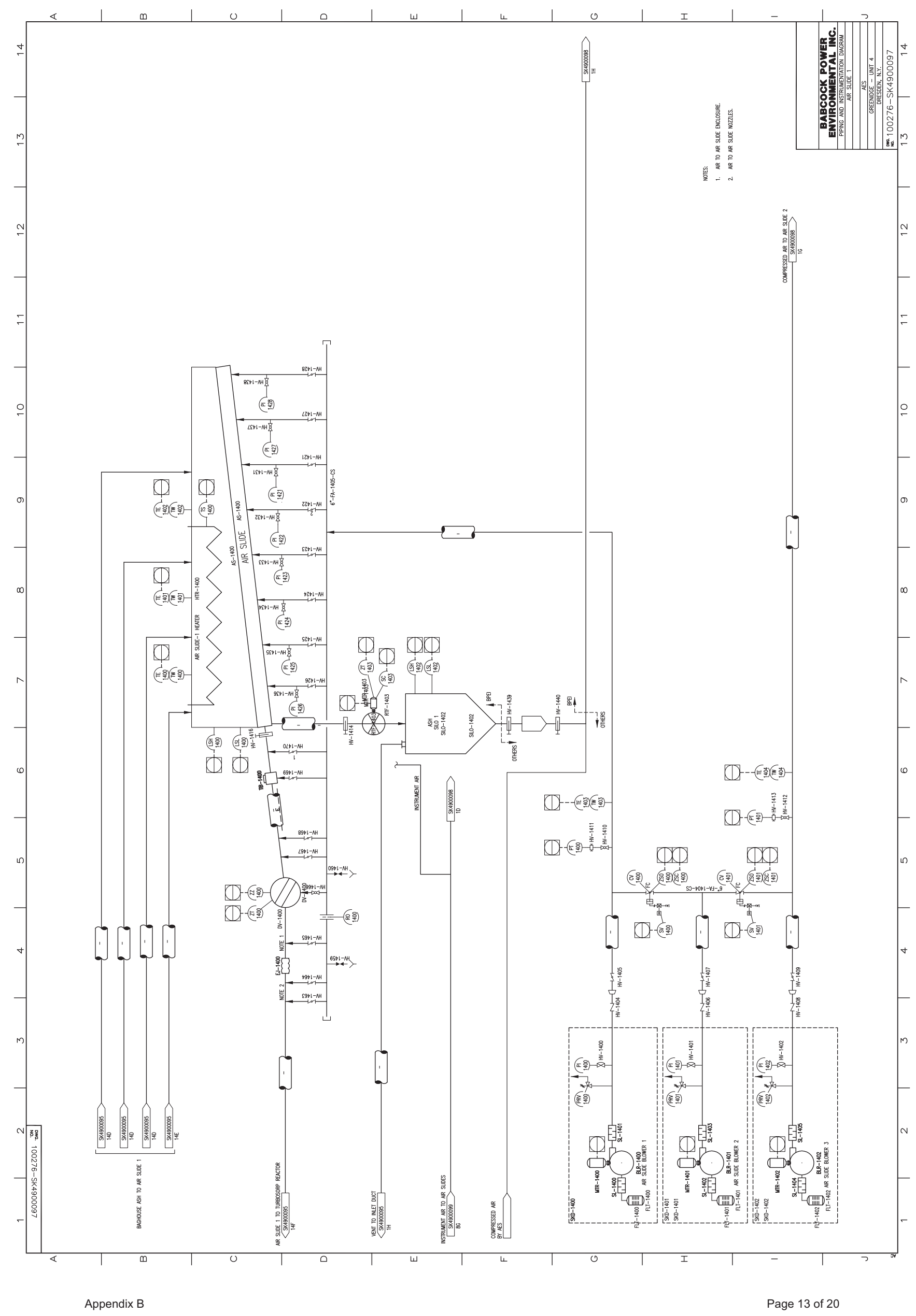




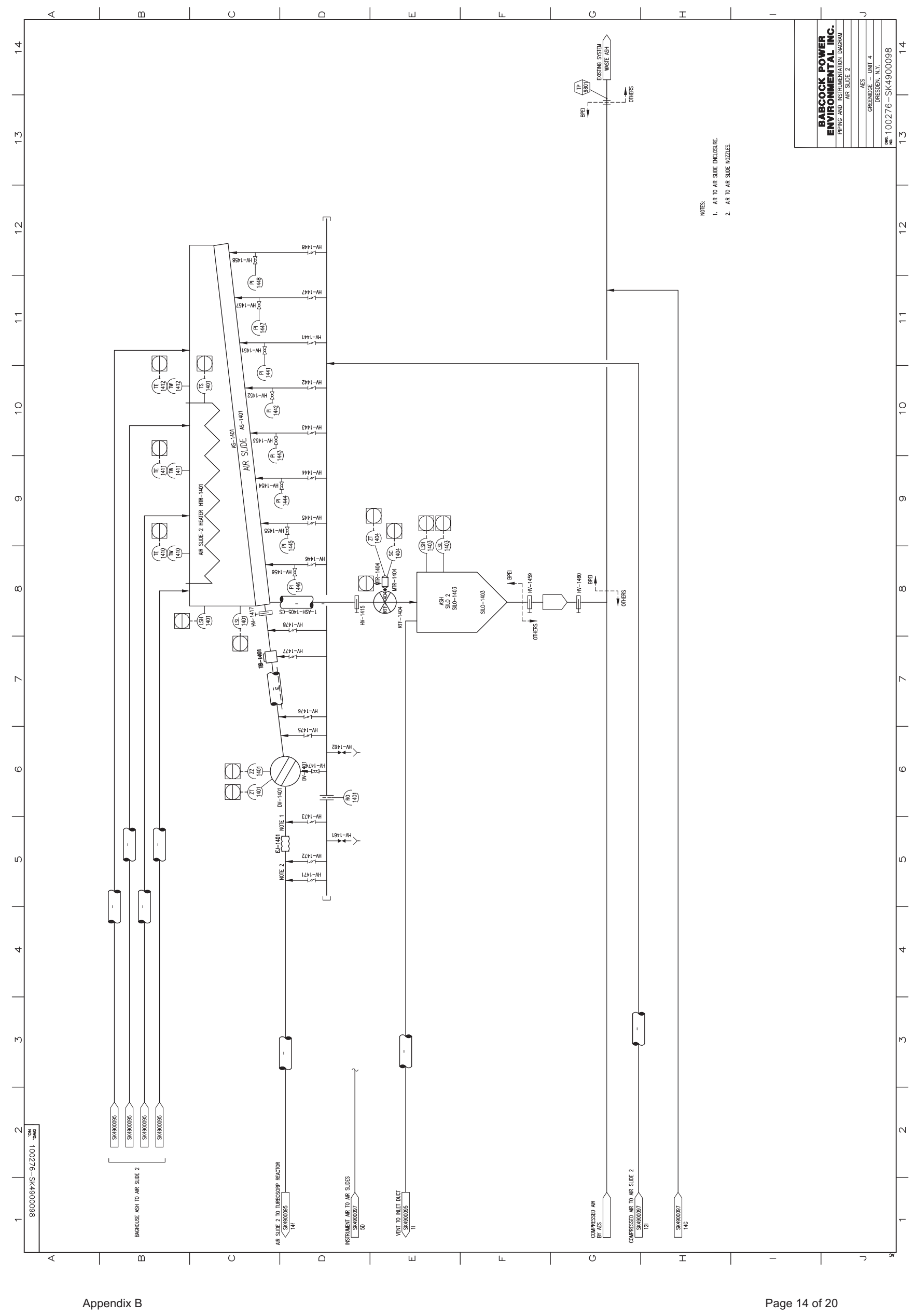




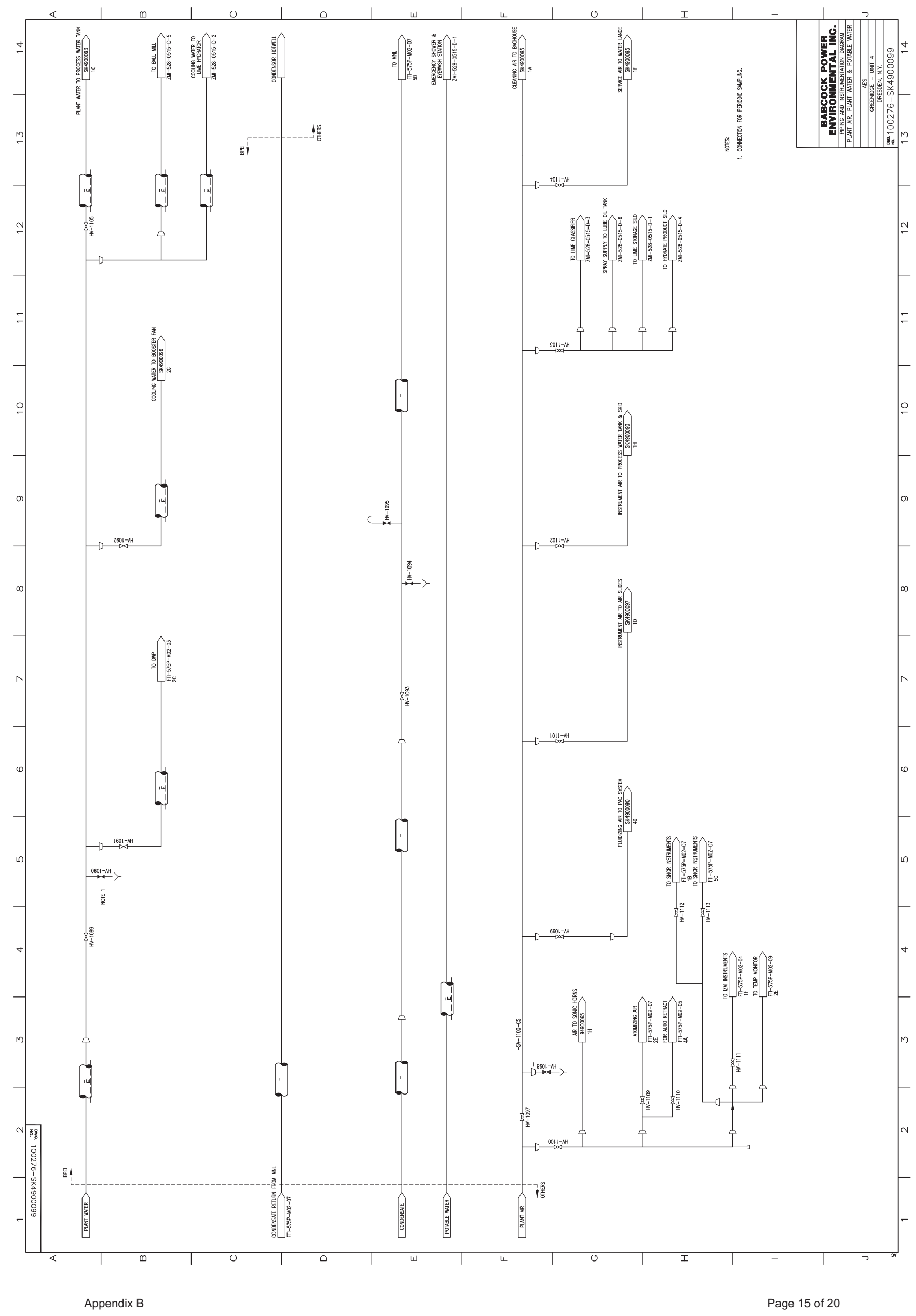




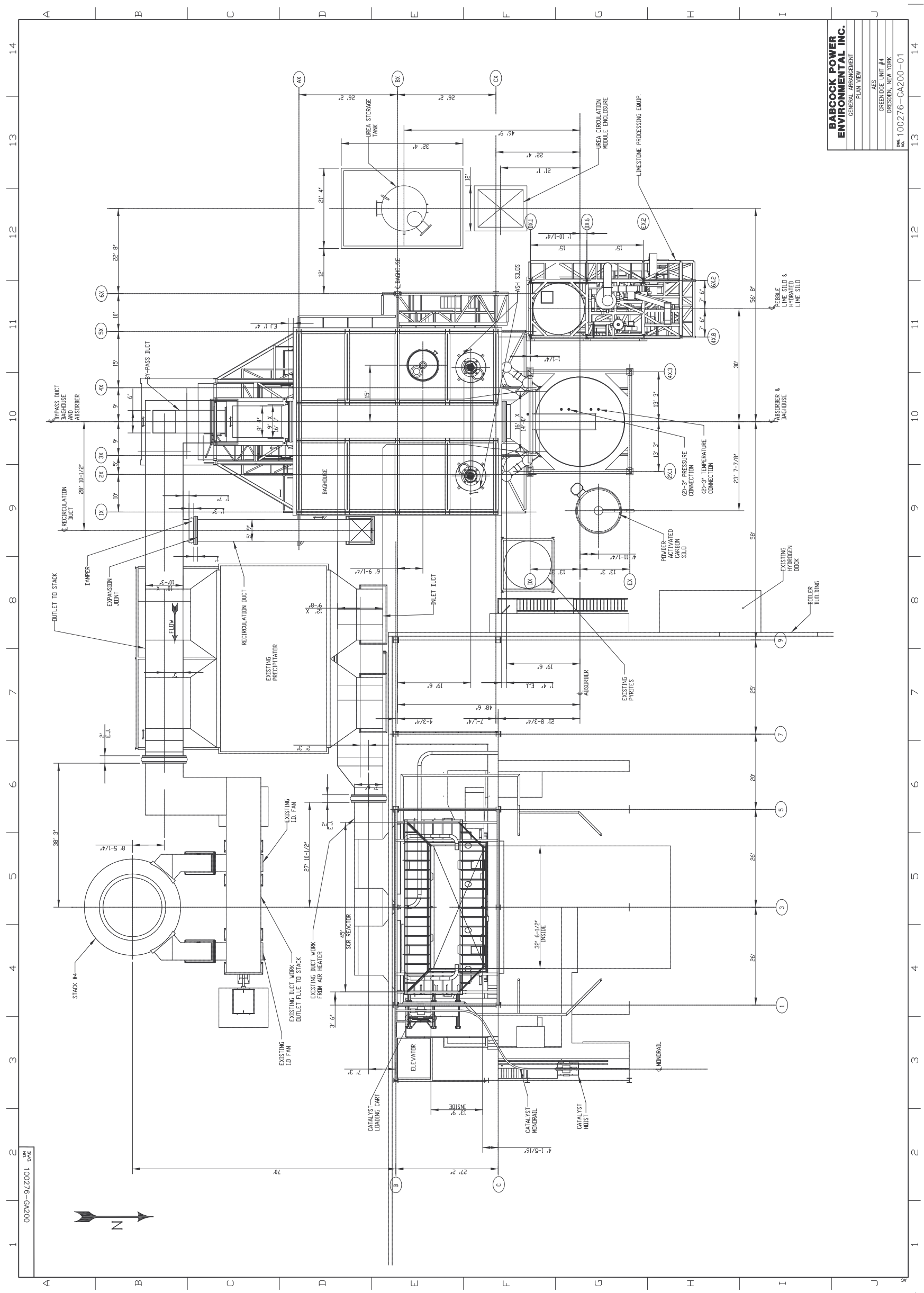

Appendix B

Page 16 of 20 


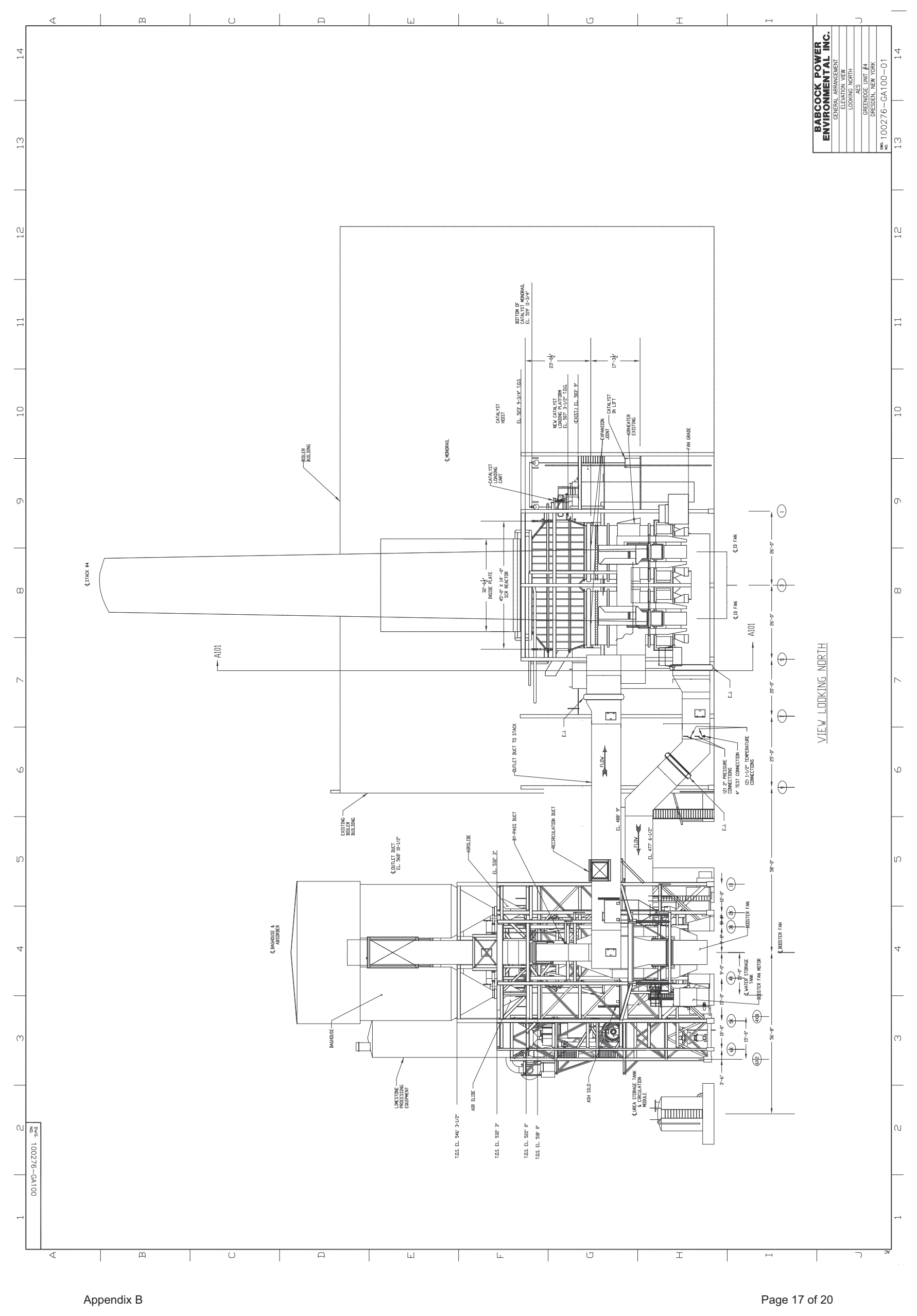




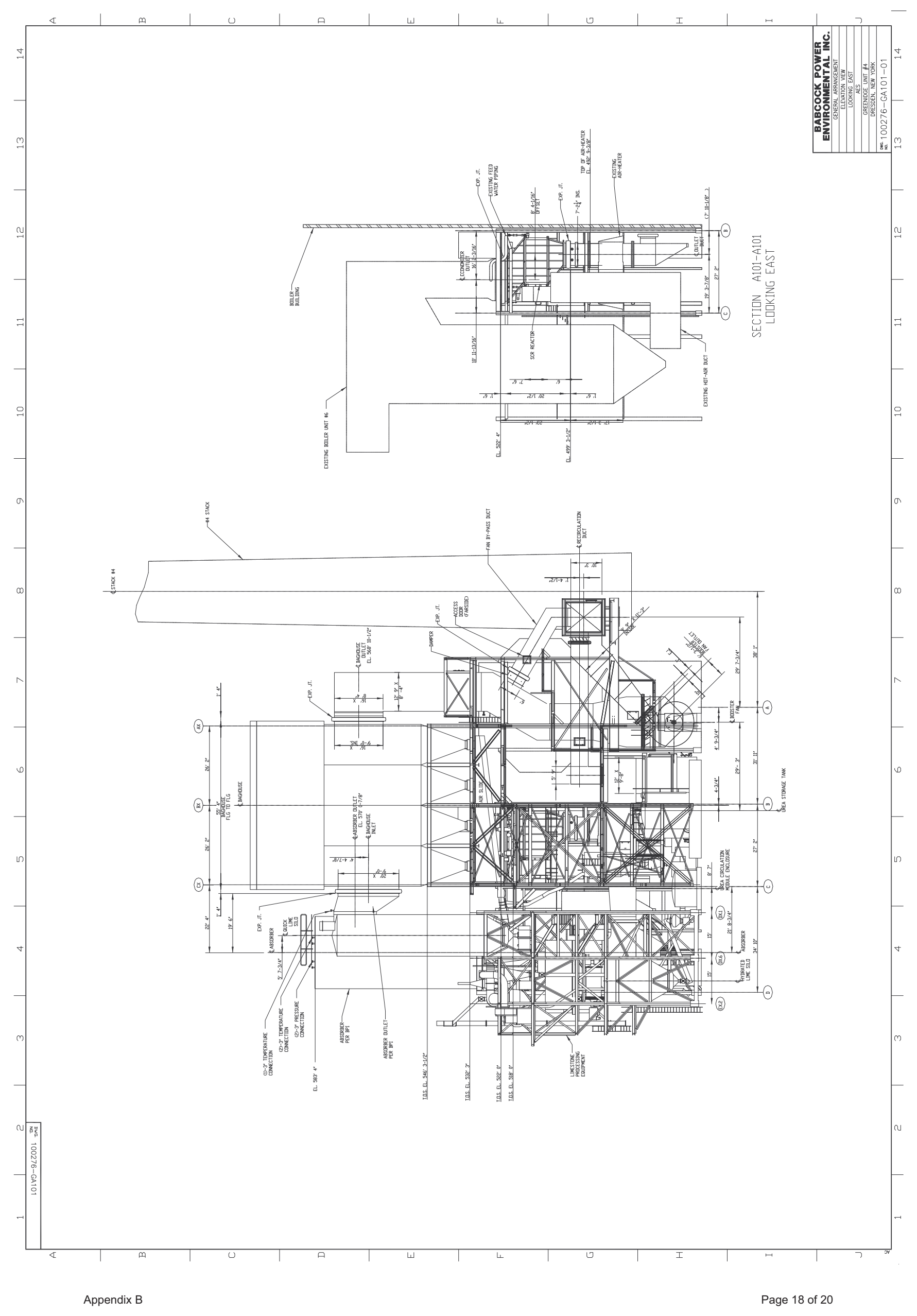




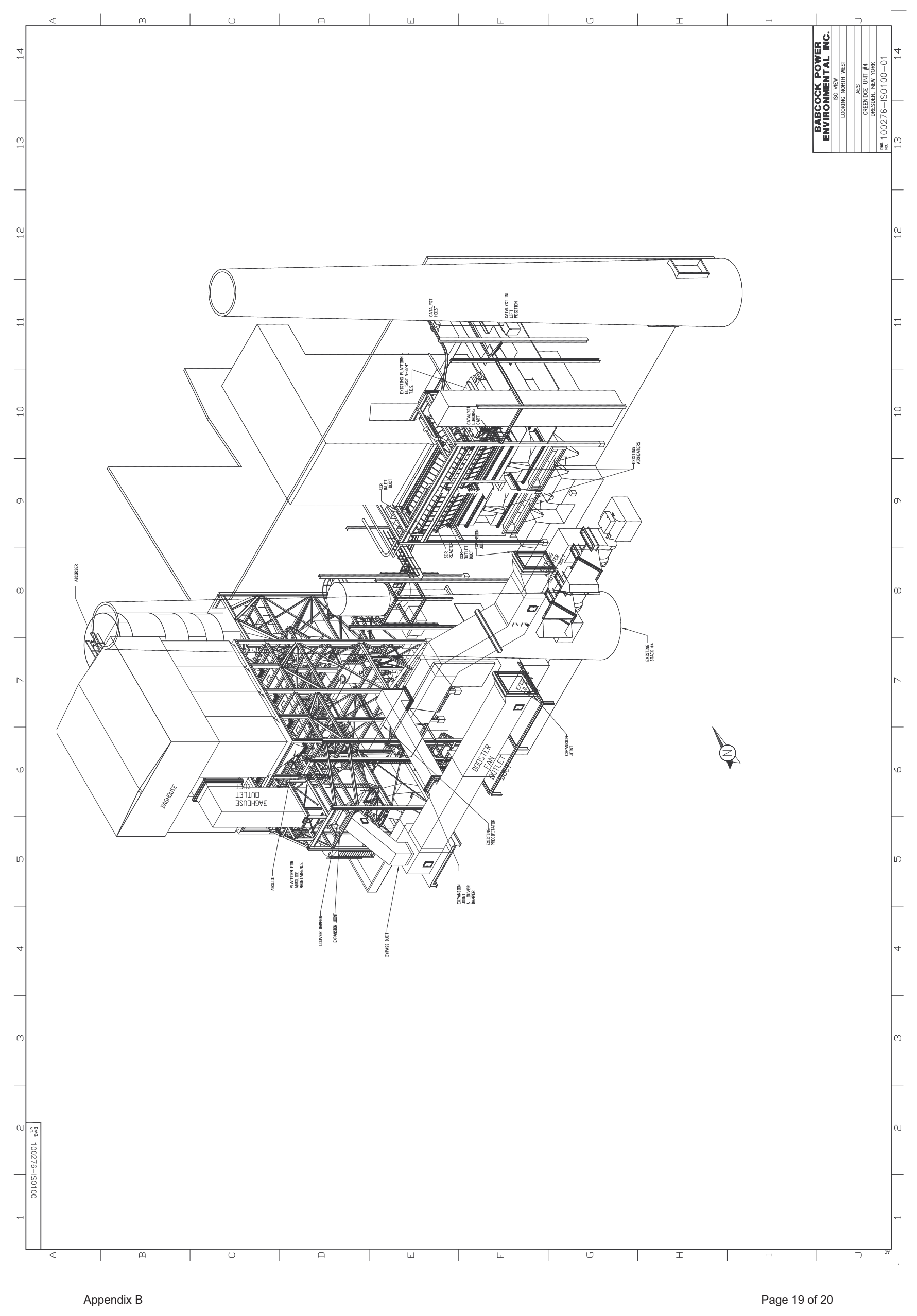




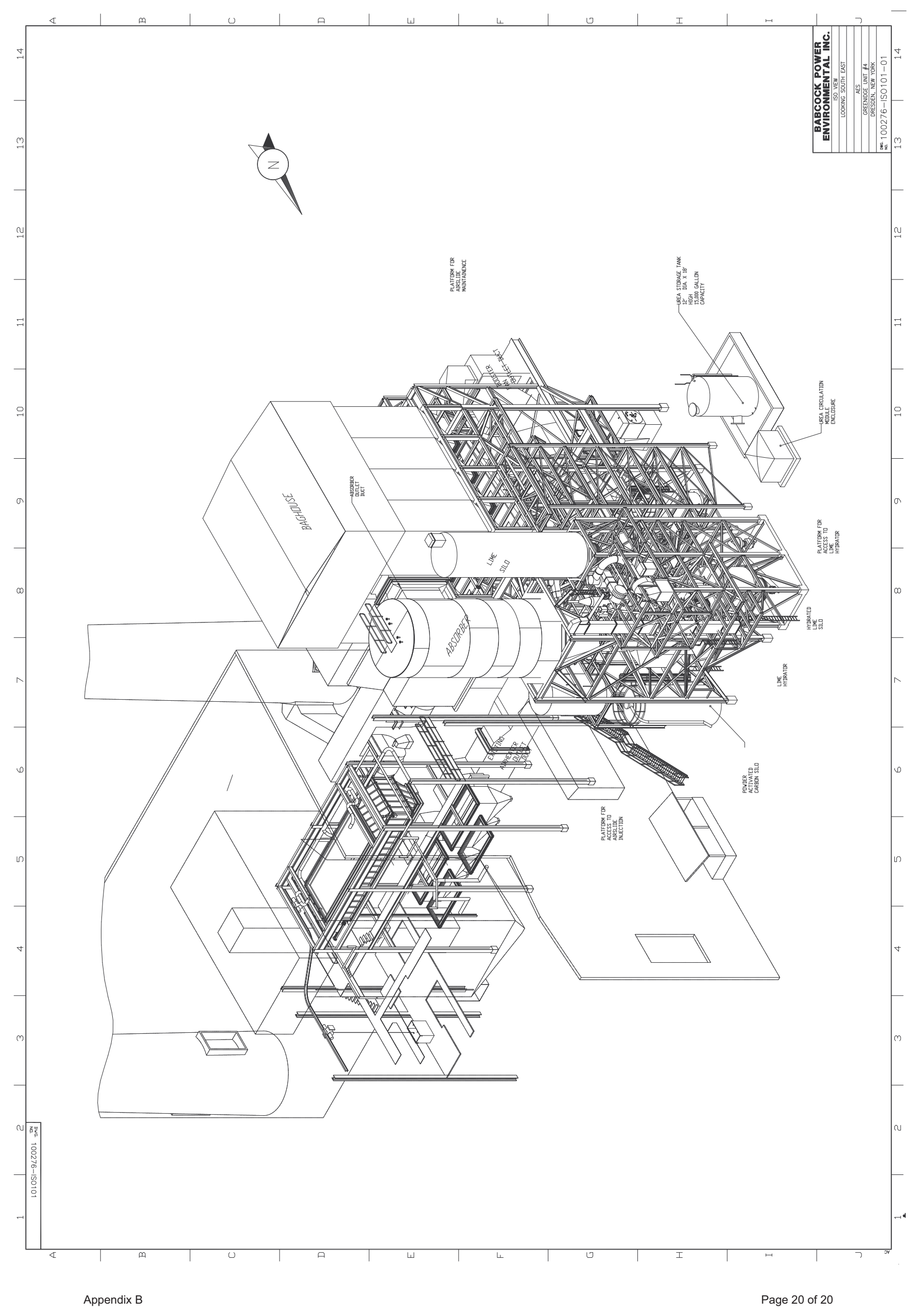




\section{APPENDIX C LIST OF MAJOR EQUIPMENT}




\begin{tabular}{|c|c|c|c|}
\hline Item & Quantity & Size & Manufacturer \\
\hline SNCR System & 1 & N/A & Fuel Tech \\
\hline Urea Storage Tank & 1 & $15,000 \mathrm{gal}$ & Fuel Tech \\
\hline High Flow Delivery Module & 1 & $96 " \times 48 " \times 30 "(h)$ & Fuel Tech \\
\hline Centrifugal Pump & 2 & $5 \mathrm{hp} / \mathrm{pump}$ & Fuel Tech \\
\hline Dilution Water Pressure Control Module & 1 & $96 " \times 48 " \times 78 "(h)$ & Fuel Tech \\
\hline Centrifugal Pump & 2 & $5 \mathrm{hp} / \mathrm{pump}$ & Fuel Tech \\
\hline Injector Zone Metering Module & 1 & $144^{\prime \prime} \times 48 " \times 78 "(h)$ & Fuel Tech \\
\hline Distribution Module & 2 & $67^{\prime \prime} \times 24^{\prime \prime} \times 72^{\prime \prime}(\mathrm{h})$ & Fuel Tech \\
\hline Distribution Module & 1 & $80 " \times 24 " x \times 72^{\prime \prime}(h)$ & Fuel Tech \\
\hline MNL Distribution Module & 1 & $84 " \times 41^{\prime \prime} \times 84^{\prime \prime}(\mathrm{h})$ & Fuel Tech \\
\hline Wall Injector & 6 & $3 \mathrm{ft}$ & Fuel Tech \\
\hline Auto Retract Injector & 10 & $3 \mathrm{ft}$ & Fuel Tech \\
\hline Multiple Nozzle Lance & 2 & $14-15 \mathrm{ft}$ & Fuel Tech \\
\hline SCR Reactor System & 1 & $490,161 \mathrm{acfm}$ & BPEI \\
\hline SCR Reactor & 1 & $27^{\prime}-2 "$ x 45'-5/8" & BPEI \\
\hline Electric Catalyst Hoist & 1 & 2 ton & American Crane \\
\hline Catalyst Layer & 1 & $1330 \mathrm{~mm}$ thick & Cormetech \\
\hline Sonic Horn & 4 & N/A & BHA \\
\hline Powdered Activated Carbon System & 1 & $89.3 \mathrm{lb} / \mathrm{h}$ & Chemco \\
\hline PAC Storage Silo & 1 & $750 \mathrm{ft}^{3}$ & Chemco \\
\hline PAC Blower & 1 & $80 \mathrm{scfm}$ & Chemco \\
\hline Lime Hydration and Injection System & 1 & $8623 \mathrm{lb} / \mathrm{h}$ & ZMI Portec \\
\hline Lime Storage Silo & 1 & $7500 \mathrm{ft}^{3}$ & ZMI Portec \\
\hline Lime Hydrator & 1 & $10 \mathrm{STPH}$ & ZMI Portec \\
\hline
\end{tabular}




\begin{tabular}{|c|c|c|c|}
\hline Item & Quantity & Size & Manufacturer \\
\hline Bucket Elevator & 1 & $20 \mathrm{STPH}$ & ZMI Portec \\
\hline Hydrated Lime Classifier & 1 & 10 STPH & ZMI Portec \\
\hline Hydrated Lime Fines Cyclone & 1 & $10 \mathrm{STPH}$ & ZMI Portec \\
\hline Hydrated Lime Ball Mill & 1 & $10 \mathrm{STPH}$ & ZMI Portec \\
\hline Hydrate Product Silo & 1 & $2200 \mathrm{ft}^{3}$ & ZMI Portec \\
\hline Hydrated Lime Blower & 1 & 630 acfm & FL Smidth \\
\hline Process Water System & 1 & N/A & BPEI \\
\hline Process Water Tank & 1 & $6300 \mathrm{gal}$ & Goodheart Sons \\
\hline Process Water Booster Pump & $2 \times 100 \%$ & 150 gpm / pump & Lechler \\
\hline Water Injection Lance & $2 \times 100 \%$ & $85 \mathrm{gpm} /$ lance & Lechler \\
\hline Turbosorp $^{\circledR}$ System & 1 & $423,700 \mathrm{acfm}$ & BPEI \\
\hline Turbosorp ${ }^{\circledR}$ Reactor & 1 & $\begin{array}{l}23 \text { '-9 1/2" dia. } x \\
105^{\prime}-9 \text { 1/2" height }\end{array}$ & BPEI \\
\hline Baghouse & 1 & 371,440 acfm & Dustex \\
\hline Booster Fan & 1 & $2,068 \mathrm{bhp}$ & TLT Co-Vent \\
\hline Air Slides & 2 & $517,658 \mathrm{lb} / \mathrm{h}$ total & FL Smidth \\
\hline Air Slide Blower & $3 \times 50 \%$ & $891 \mathrm{icfm} /$ blower & FL Smidth \\
\hline Ash Silo & 2 & $720 \mathrm{ft}^{3} /$ silo & Goodheart Sons \\
\hline
\end{tabular}


APPENDIX D PROJECT LOG 


\section{January 2002 - May 2006 (Pre-Award Period)}

The cooperative agreement for the Greenidge Multi-Pollutant Control Project was executed on May 19, 2006. However, in order to keep the project on pace to meet AES Greenidge's scheduled fall 2006 tie-in outage, the timing of which was driven by their Consent Decree with the State of New York and by their dispatch obligations during the peak power season, a substantial amount of Budget Period 1 work was performed prior to the signing of the cooperative agreement in accordance with pre-award authorizations granted by the Department of Energy. This pre-award work began in January 2002.

CONSOL prepared an Environmental Information Volume for the project and submitted it to DOE on October 27, 2003. DOE prepared an Environmental Assessment (DOE/EA-1493) and issued a Finding of No Significant Impact (FONSI) for the project on December 3, 2004.

CONSOL performed baseline testing at AES Greenidge Unit 4 on November 17-18, 2004, in order to obtain data for use in designing the multi-pollutant control facility and to establish a baseline against which the performance of the multi-pollutant controls could be compared.

AES Greenidge obtained a building permit for the multi-pollutant control facility from the Town of Torrey on August 10, 2005, and worked with the New York State Department of Environmental Conservation to determine that a Storm Water Discharge Permit was not required for construction of the facility, given the size of the construction site. AES Greenidge's Consent Decree with the State of New York, which was executed on January 11, 2005, authorized them to proceed with construction of the multi-pollutant control facility without a pre-construction permit from the State or any changes to their existing Title $\mathrm{V}$ permit.

CONSOL received authorization from DOE on January 24, 2005, to begin incurring pre-award costs associated with detailed design and engineering work. In August 2005, AES issued Babcock Power Environmental Inc. a Preliminary Notice to Proceed on the project, and BPEI began detailed schedule development and detailed process design activities. Detailed civil and structural design had commenced by the end of September 2005. The design of the multipollutant control process, including the development of process flow diagrams, piping and instrumentation diagrams, general arrangement drawings, equipment and material specifications, etc., was largely complete when the cooperative agreement was executed in May 2006.

Procurement of the multi-pollutant control system began in October 2005 under pre-award authorization from DOE. As of the signing of the cooperative agreement in May 2006, purchase orders had been issued for all major equipment items, including the SNCR system, SCR reactor, SCR catalyst, activated carbon system, Turbosorp reactor, lime hydration system, baghouse, and booster fan. Major purchase orders for structural steel and ductwork were also issued. The baghouse modules were delivered to the site beginning in March 2006, and the Turbosorp reactor was shipped in April 2006.

In October 2005, CONSOL received pre-award authorization from DOE to mobilize for construction and begin civil construction work. Trenching and excavation of the site for the new multi-pollutant control equipment were completed in February 2006, and formwork, rebar, and concrete were installed for the Turbosorp absorber, baghouse, and booster fan. The containment wall for the urea tank was also poured in late May 2006. 
CONSOL received further authorization from DOE in January 2006 to begin certain process system construction activities. Consistent with this authorization, installation of structural steel for the baghouse began in March 2006, and the baghouse modules and hoppers had been raised into place by the end of May 2006. The structural steel frame for the Turbosorp was also erected in May.

\section{June 2006}

Design, procurement, and construction activities continued during June 2006 in preparation for the project's September 30 - November 18, 2006, tie-in outage. SCR flow modeling continued, and AES Greenidge and BPEI met to begin developing the control philosophy for the Turbosorp and baghouse so that it could be integrated into the plant's existing control logic.

Purchase orders for thermocouples, thermowells, pressure switches, pressure gauges, pressure and level transmitters, and $\mathrm{NO}_{\mathrm{x}}$ and $\mathrm{SO}_{2}$ monitors were finalized. The Turbosorp water tank, water injection pump skid, and ash silos were delivered, as were conduit, cable tray, and several sections of ductwork for the Turbosorp inlet and baghouse outlet. Issues regarding delays in the delivery of structural steel and of low- and medium-voltage switchgear were resolved with no anticipated effect on the project schedule.

Construction activities during June 2006 included installation and welding of the Turbosorp vessel (with the exception of the roof, which could not be installed until work on the inside of the vessel is complete). The concrete pad beneath the Turbosorp vessel was poured, and concrete was also poured for ductwork foundations and piers beneath the existing precipitator. The baghouse inlet duct and two sections of the Turbosorp inlet duct were lifted into place, and installation of the baghouse penthouse commenced. Work on insulating and lagging the baghouse and on installing structural steel, grating, and handrails proceeded throughout the month. The electrical subcontractor began mobilizing in preparation for the installation of conduit for baghouse lighting. Heavy rains in the northeastern U.S. resulted in one day of lost work on site during June; overall, however, site work was on track to meet the scheduled fall tiein outage.

A project status review meeting including representatives from DOE, CONSOL, and AES Greenidge was held at AES Greenidge on June 7.

\section{July 2006}

Construction activities during July 2006 included installation of the roof of the Turbosorp vessel; installation of the expansion joint at the Turbosorp outlet; erection of structural steel for the lime hydration system, SNCR system, and baghouse penthouse; insulation of the Turbosorp vessel, ash silos, and baghouse; rigging and welding of ductwork around the Turbosorp and baghouse; completion of ductwork foundations; and installation of conduit, cable tray, junction boxes, and piping (e.g., condensate cooling water line to the multiple nozzle lance of the SNCR system and water and air lines to the Turbosorp vessel). Problems were encountered with fit-up of the baghouse penthouse such that all of the roof trusses had to be coped; however, these problems were resolved by the end of the month. Pieces of the lime hydration system (e.g., lime hydrator, quicklime storage silo, second-tier structural steel) and SNCR system (e.g., multiple nozzle lances, skid-mounted modules) were delivered to the site, and the hydrated lime silo and ball mill for the lime hydration system were lifted into place. Other deliveries during the month included the booster fan housing, the air slide blowers, and the low-voltage motor control center. 
The National Energy Technology Laboratory in Pittsburgh hosted a project kickoff meeting on July 27. In addition, the Department of Energy's Office of Fossil Energy issued a Techline and CONSOL, AES, and Babcock Power Environmental Inc. each issued press releases on the project near the end of July.

\section{August 2006}

Construction activities at the Greenidge site intensified during the month of August as the project's fall tie-in outage drew nearer. The two ash recirculation slides that will be used to recycle solids from the baghouse to the Turbosorp absorber vessel were delivered to the Greenidge site, and these slides, as well as the lime hydrator, flue gas recirculation duct, and water injection pump skid for the Turbosorp system, were set into place. Contractors began assembling the booster fan and installing the booster fan outlet ductwork. Substantial progress was made in the delivery and installation of electrical equipment, which had been areas of concern because of their potential to cause schedule delays. The $480 \mathrm{~V}$ motor control center was assembled; the $2300 \mathrm{~V}$ motor control center was delivered to the site and positioned on the turbine floor, and the $2300 \mathrm{~V} / 480 \mathrm{~V}$ transformer was set into place in the plant. Electricians continued to install cable tray in the plant and conduit and lighting in the baghouse structure, and ironworkers completed the erection of structural steel for the pipe and cable bridge. Further progress was made in insulating the Turbosorp vessel, Turbosorp inlet duct, baghouse inlet elbows, and ash silos; erecting second-tier structural steel for the lime hydration system; installing piping for the SNCR and Turbosorp systems; and siding and roofing the baghouse penthouse. AES Greenidge and Babcock Power Environmental Inc. began working on plans for start-up and commissioning of the multi-pollutant control system; BPEl's start-up and commissioning manager arrived on site.

\section{September 2006}

The tie-in outage for the multi-pollutant control system began at about 7:00 p.m. on Friday, September 29. In the days leading up to the outage, a substantial amount of construction work was accomplished. The urea tank was delivered to the Greenidge site and set into place, and the baghouse outlet duct, quick lime silo, and booster fan bypass duct were also lifted into place. Contractors completed the installation of all 3,200 baghouse bags, as well as the installation of poppet valve actuators and cleaning air headers in the baghouse. Electricians finished installing cable tray in the plant and began pulling cable, including the feeder cables for the $2300 \mathrm{~V}$ transformer and $480 \mathrm{~V}$ motor control center and the cables for the booster fan motor. Pipefitters continued to install large bore pipe to the Turbosorp vessel, to the air slides, and inside the plant; more than 1,400 of the 1,750 feet of large bore pipe have been installed. Contractors also continued assembling the booster fan, installing ductwork at the booster fan outlet, insulating and lagging various pieces of ductwork, installing grating and handrails in the lime hydration structure, and installing cable tray, conduit, and lighting. Moreover, they finished insulating and cladding the Turbosorp vessel and siding and roofing the baghouse penthouse. As of the end of September, mechanical installation of the Turbosorp system, lime hydration system, baghouse, and ash recirculation system was largely complete. Remaining construction work for these pieces of equipment predominantly consisted of electrical installation (especially in the lime hydration structure, where electrical work was just beginning), installation of insulation and lagging in various places, and tie-in to the existing plant. Inside the boiler building, work continued to focus on installing the SNCR and SCR systems.

A project status review meeting including representatives from DOE, CONSOL, and AES Greenidge was held at AES Greenidge on September 12. 


\section{October 2006}

The tie-in outage continued throughout the month of October. Work at the Greenidge site in October focused primarily on installing the in-duct SCR reactor, installing the urea injection system for the SNCR process, tying the Turbosorp system and associated systems into the existing plant, and completing various electrical installation tasks. Contractors erected scaffolding around Boiler 6 and removed insulation in the areas where the SNCR and SCR systems were being installed. Demolition of ductwork at the economizer outlet was completed to allow for construction of the in-duct SCR reactor. The expansion joint at the economizer outlet was installed, and erection of support steel and casing for the reactor commenced. The SCR installation, which was the critical path activity of the tie-in outage, progressed without any major problems. Contractors also finished removing tubes and modifying the Boiler 6 water wall to permit installation of the multiple nozzle lances and urea injection nozzles for the SNCR system. Tubing was installed for the front wall injectors. Demolition of ductwork from around the existing ESP was completed to allow for tie-in of the Turbosorp system, and installation of the ductwork connecting the Turbosorp inlet to the existing plant commenced. The section of ductwork connecting the booster fan to the existing ID fans was also installed. Finally, electricians set the control panel and variable frequency drive panel for the hydrator in place, pulled cable in the baghouse penthouse, modified the old $2400 \mathrm{~V}$ motor control centers to allow for connection of the new motor control centers, finished all remaining terminations for the 480V switchgear, completed hi-pot testing of the $2300 \mathrm{~V}$ feeder cables, and successfully energized the $2300 \mathrm{~V}$ transformer and bumped the booster fan motor.

On October 17, Dan Connell (CONSOL) gave a presentation on the project at the American Filtration and Separations Society's 2006 fall conference on Separations Processes for the Power Generation Industry, which was held in Pittsburgh, PA.

\section{November 2006}

The tie-in outage for the multi-pollutant control system at AES Greenidge was completed in midNovember, according to schedule. The Delta Wing static mixers were installed in the ductwork upstream of the SCR reactor in early November, and the SCR catalyst was delivered to the Greenidge site on November 6 . By November 14, installation of the catalyst and of the SCR reactor casing had been completed. Contractors installed the urea injectors and multiple nozzle lances in Boiler 6 for the SNCR system, and successfully completed hydrostatic pressure testing of the boiler. The last section of ductwork connecting the Turbosorp inlet to the existing plant was also installed. Various pieces of equipment and ductwork, including the SCR reactor, Turbosorp inlet ductwork, and air slides, were insulated and lagged. The 200-ton crane was disassembled and removed from the site, and civil work for the urea and quicklime unloading area, which had been delayed until the demobilization of this crane, was completed. The tie-in outage ended at about 10:00 pm on Saturday, November 18, when Babcock Power released Boiler 6 to AES Greenidge for operation.

Two issues delayed start-up of Unit 4 and of the multi-pollutant control system, however. The Unit 4 turbine outage, which was conducted by AES outside of the scope of the DOE project, ran several days behind schedule. General Electric released the turbine to AES Greenidge on the evening of Wednesday, November 22. Problems with the turbine supervisory instrumentation and the hydraulic trip circuit delayed start-up of the turbine by another week. 
These problems were resolved, though, and the generator was synchronized on Thursday, November 30.

In addition, there was a problem with the soft start for the booster fan. On Friday, November 24, an attempted start-up of the fan caused operation of the station service differential protection relay, blacking out the entire plant. Subsequent testing of the station service transformer and differential protection relay indicated no problems, and power to the plant was restored. As of the end of November, however, Babcock Power Environmental, IEA, and Rockwell Automation were still working to resolve the problem with the soft start. AES Greenidge was able to operate Unit 4 at reduced load while bypassing the booster fan, but actual start-up of the multi-pollutant control system could not occur until the booster fan was operational. In the meantime, commissioning activities were performed successfully for a number of equipment items (e.g., air slide blowers, various SNCR system components, process water pump, etc.) associated with the multi-pollutant control system. The baghouse filter bags were pre-coated on November 17 and 18.

A project status review meeting including representatives from DOE, CONSOL, and AES Greenidge was held at the Greenidge site on November 2. On November 2-3 and 6-7, Babcock Power Environmental conducted training sessions for AES Greenidge employees regarding operation and maintenance of the multi-pollutant control system.

\section{December 2006}

During December 2006, start-up and commissioning activities progressed at AES Greenidge. The problem with the booster fan soft start that had delayed start-up of the multi-pollutant control system was resolved in early December. On December 4, workers discovered that the soft start controller was not properly grounded and successfully corrected the problem and started the fan. Start-up and commissioning activities proceeded normally throughout the rest of the month. After synchronizing Unit 4 to the power grid on December 7, AES gradually ramped up the unit's load while Babcock Power commissioned the new combustion system. This work was conducted outside of the DOE scope, but had to be completed before start-up of the hybrid SNCR/SCR system could occur. As of late December, Unit 4 was operating at full load, and the new low- $\mathrm{NO}_{\mathrm{x}}$ combustion system was achieving a $\mathrm{NO}_{\mathrm{x}}$ emission rate of about 0.27 $\mathrm{lb} / \mathrm{mmBtu}$, close to the target rate of $0.25 \mathrm{lb} / \mathrm{mmBtu}$. Combustion system optimization was scheduled to be completed in early January 2007. Regarding pollution control equipment within the DOE scope, the baghouse was in service throughout the month of December, and various commissioning activities were completed for the SNCR system, Turbosorp system, and lime hydration system, although none of these systems started up during the month. On December 15 , workers established a fluidized bed in the Turbosorp absorber using accumulated fly ash (no hydrated lime was injected) and successfully operated the Turbosorp system for a time with water injection and baghouse ash recycling while Unit 4 was running at about $65 \mathrm{MW}$. On December 20, the first shipment of pebble lime was delivered to the Greenidge site; Babcock Power Environmental modified the lime unloading system in response to several problems that were encountered while transporting the lime from the delivery truck to the storage silo.

DOE approved continuation into the project's second budget period and issued a cooperative agreement modification authorizing funding for the balance of the project. On December 13, Bill Rady (AES Greenidge) gave a presentation on the project at the December luncheon of the Air \& Waste Management Association's Genesee Finger Lakes Chapter, which was held in Rochester, NY. On December 20, CONSOL, AES Greenidge, and Babcock Power 
Environmental met at the Greenidge site to plan for guarantee testing of the multi-pollutant control system.

\section{January 2007}

Start-up and commissioning activities continued at AES Greenidge throughout January 2007. On Tuesday, January 2, plant personnel reported concerns about increasing pressure drop across the in-duct SCR catalyst. As a result, they decided to take the unit off line for its steam turbine screen outage on January 3 , rather than on January 11 as originally scheduled, so that BPEI could inspect the SCR internals and determine the cause of the problem. This inspection indicated that the buildup in pressure drop was caused by refractory and miscellaneous construction debris that remained in the boiler after the tie-in outage and had blocked portions of the catalyst surface, as well as by large particle ash that had accumulated in the catalyst. The debris and ash were removed, and the unit returned to service on January 7 . It operated normally until January 30, when plant personnel again observed an increase in pressure drop across the catalyst.

Start-up of the lime hydration system commenced on January 12. However, it was quickly determined that major modifications to the system were required to prevent excessive overflow of milk of lime. BPEI completed these modifications, which involved eliminating the hydrator's wet scrubber and milk of lime circuit and routing the hydrator exhaust to the Turbosorp system, during the second half of the month. As of the end of January, they were working to complete modifications to the control system for the hydrator. In the meantime, AES Greenidge purchased hydrated lime to allow start-up of the Turbosorp system to proceed. Hydrated lime and water injection tests were performed beginning on January 13. The system was operated for short periods of time on January 15 and 16, and then it was operated during a series of tests throughout the rest of the month as BPEI and Austrian Energy worked to tune its performance. $\mathrm{SO}_{2}$ removal efficiencies between $90 \%$ and $100 \%$ were achieved consistently during these optimization tests.

Combustion system optimization was completed successfully in January. Fuel Tech representatives returned to the AES Greenidge site during the week of January 22 to begin start-up of the SNCR system, and the first load of urea was delivered to site on January 23. Urea injection tests were performed beginning on January 26.

\section{February 2007}

February was marked by continued progress with start-up and commissioning of the multipollutant control system.

On February 6, the hybrid SNCR/SCR system was operated in "cascade" mode (i.e., such that the SNCR is used to generate ammonia slip for the SCR) for the first time. This initial, approximately 3-hour test run was successful. The system was able to maintain stable emissions below the target rate of $0.10 \mathrm{lb} / \mathrm{mmBtu}$ throughout the test while Unit 4 was operating at $108 \mathrm{MW}_{\text {gross. }}$. Testing and optimization of the hybrid SNCR/SCR system at full load and at reduced load continued throughout the month. Tuning of the system was hindered in late February by high $\mathrm{CO}$ concentrations in the furnace, which are indicative of less-than-optimal combustion and can adversely affect SNCR performance. Adjustments were made to the unit's combustion system to correct this problem. 
Progress on start-up of the lime hydration system and optimization of the Turbosorp system was hampered during early February by frigid temperatures and weather protection problems that caused frozen lines and valves. These problems were resolved by February 8 , and the Turbosorp system was operated occasionally during the next few weeks using purchased hydrated lime (at a limited injection rate to reduce cost). The plant also experienced problems during the month with failing baghouse cleaning valves. A temporary air compressor was brought in to satisfy the increased demand caused by air leakage from the failed valves, and the design flaw that caused the valves to fail was corrected. Following the cold weather problems in early February, workers encountered and resolved several additional process control problems with the lime hydration system. That system was successfully started up during the week of February 19.

On February 27, AES Greenidge successfully operated all of the components of the multipollutant control system, with the exception of the activated carbon injection system, while Unit 4 was running at about $91 \mathrm{MW}_{\text {gross. }}$.

The accumulation of large particle ash in the in-duct SCR catalyst continued to affect operation of Unit 4. The unit was taken off line on February 2-4 so that the catalyst could be cleaned and inspected. The catalyst was cleaned another time during a primary superheater tube leak outage on February 9-10. The plant again reported increasing pressure drop across the SCR at the end of February. The project team began working to develop a solution to this problem. Babcock Power Environmental Inc. proposed a solution consisting of a sloped screen passing through the static mixers above the SCR catalyst, and they began modeling this design to assess its feasibility.

A project status review meeting including representatives from DOE and CONSOL was held at NETL in Pittsburgh on February 15.

\section{March 2007}

During March 2007, all major remaining start-up and commissioning activities were completed at AES Greenidge. The Turbosorp ${ }^{\circledR}$ system, lime hydration system, and baghouse operated regularly throughout the month of March while AES Greenidge Unit 4 was in service. Tuning of the hybrid SNCR/SCR system was completed during the first half of the month. As of March 13, all components of the multi-pollutant control system, with the exception of the activated carbon injection system, were operating normally. The activated carbon injection system was commissioned during the week of March 19.

AES Greenidge continued to experience problems with large particle ash accumulation in the induct SCR catalyst; this forced several outages for catalyst cleaning in March. Unit 4 was taken off line on the evening of Friday, March 2, so that LPA could be removed from the catalyst. This was the first catalyst cleaning since the superheater tube leak outage on February 9-10. The unit returned to service on Sunday, March 4. Unit 4 was derated during the week of March 19 because of high pressure drop across the in-duct SCR; the unit was taken off line again at the end of that week so that the catalyst could be cleaned in preparation for guarantee testing. AES Greenidge and Babcock Power Environmental Inc. met on March 15 regarding the LPA problem and agreed conceptually to a solution consisting of a sloped screen to capture the LPA, soot blowers to clean the screen, and vacuum ports to remove the captured LPA from the base of the screen. 
CONSOL conducted field sampling for guarantee testing of the multi-pollutant control system at AES Greenidge during the week of March 26. All sampling was carried out while the plant was operating at full load and firing coal similar to the design coal. Flue gas sampling included gridpoint $\mathrm{NO}_{x}$ measurements at the SCR inlet and SCR outlet (March 28), $\mathrm{SO}_{3}$ measurements at the SCR inlet and SCR outlet (March 30), $\mathrm{NH}_{3}$ measurements at the SCR outlet (March 28), $\mathrm{SO}_{2}, \mathrm{SO}_{3}, \mathrm{HCl}, \mathrm{HF}$, and particulate measurements at the air heater outlet and stack (March 29), and $\mathrm{Hg}$ measurements at the air heater outlet and stack, including a set of three measurements on March 28 with no activated carbon injection and a set of three measurements on March 30 with activated carbon injection. $\left(\mathrm{NO}_{\mathrm{x}}\right.$ and $\mathrm{SO}_{2}$ measurements were performed by Clean Air Engineering). Solid and liquid process samples were collected throughout the testing period to allow for an assessment of system performance during the period and for the completion of $\mathrm{Hg}$ mass balances. AES Greenidge and BPEI also monitored urea, lime, and carbon consumption rates and pressure drop across the system components to determine whether performance guarantees associated with these parameters were satisfied.

\section{April 2007}

The multi-pollutant control system operated regularly throughout the month of April. However, AES Greenidge Unit 4 was derated during the week of April 16 because of increasing pressure drop across the SCR reactor. An outage was held on April 19-22 so that large particle ash could be removed from the surface of the in-duct SCR catalyst and the unit's air heater baskets could be cleaned. This was the first outage for catalyst cleaning since March 22-24. Pressure drops across the in-duct SCR reactor and air heater returned to acceptable levels following the outage.

Preliminary results from the guarantee tests on March 28-30 became available by April 18. The March tests demonstrated attainment of the performance guarantees for $\mathrm{NO}_{\mathrm{x}}, \mathrm{SO}_{2}$, and $\mathrm{Hg}$, but the results for ammonia slip, $\mathrm{SO}_{3}, \mathrm{HCl}$, and $\mathrm{HF}$ were either inconsistent with the guarantees or inconclusive. A small CONSOL sampling crew traveled to AES Greenidge on April 23-27 to perform continuous $\mathrm{CO}, \mathrm{NO}_{x}, \mathrm{O}_{2}$, and $\mathrm{CO}_{2}$ measurements at the SCR inlet sampling grid (actual sampling was performed on April 24-26) for use in tuning the combustion system and hybrid SNCR/SCR system.

\section{May 2007}

On May 1-4, CONSOL repeated the guarantee tests for $\mathrm{NH}_{3}$ slip at the SCR outlet and for $\mathrm{SO}_{3}$, $\mathrm{HCl}$, and $\mathrm{HF}$ removal across the Turbosorp system. Modifications were made to the methods used to sample $\mathrm{NH}_{3}$ and $\mathrm{SO}_{3}$ in an effort to improve the representativeness and sensitivity of the measurements. The re-tests confirmed attainment of the guarantees for $\mathrm{SO}_{3}$ and $\mathrm{HCl}$. However, the measured ammonia slip was still too high to satisfy the performance guarantee, and the HF removal efficiency across the Turbosorp system was indeterminate because of low measured concentrations at the Turbosorp inlet.

On May 3, the water feed to the lime hydrator was out of limits, causing the hydrator to plug and require cleaning. The control logic for the hydrator was modified to prevent this problem from occurring again in the future.

On May 4, several burners were affected by flame attachments, forcing them out of service. As a result, AES Greenidge Unit 4 was derated until these burners could be repaired during the large particle ash screen installation outage. 
The large particle ash screen installation outage began on May 17. During the outage, a sloped screen was installed in the ductwork above the SCR catalyst (intersecting the Delta Wing static mixers) to capture LPA from the flue gas and prevent it from accumulating on the surface of the catalyst. Eight vacuum ports were installed through the wall of the SCR inlet duct at the base of the screen to remove the captured LPA from the system; two soot blowers were also installed below the screen to aid in transporting the LPA to the vacuum ports. In addition, during the outage, AES replaced the existing SCR catalyst layer with a new layer so that the existing layer could be professionally cleaned. (The cleaned layer was then stored on site as a spare). Moreover, the plant took advantage of the screen installation outage to complete various routine maintenance activities so that they would not have to hold their usual outage in September for these activities. The outage was completed on May 25.

On May 30-June 1, crews from CONSOL and Clean Air Engineering performed $\mathrm{NH}_{3}, \mathrm{NO}_{x}, \mathrm{CO}$, $\mathrm{CO}_{2}$, and $\mathrm{O}_{2}$ sampling at the inlet and outlet of the in-duct SCR. These measurements were required to determine the effects of the LPA screen on the performance of the SCR, and in particular to determine whether installation of the screen and fresh catalyst layer enabled the hybrid SNCR/SCR process to meet its ammonia slip guarantee. Personnel from Babcock Power and Fuel Tech worked to tune the Unit 4 combustion system and SNCR system during the test period. The tests showed that the $\mathrm{NO}_{x}$ control system still was not meeting the ammonia slip guarantee.

Dan Connell (CONSOL) presented project results at the Electric Power Conference \& Exhibition in Rosemont, IL, on May 3. A project status review meeting including representatives from DOE, CONSOL, and AES was held at AES Greenidge on May 22. The Preliminary Public Design Report for the project was submitted to DOE on May 25.

\section{June 2007}

During the first two weeks of June, Babcock Power and Fuel Tech continued to make adjustments to the hybrid $\mathrm{NO}_{x}$ control system in an effort to reduce the ammonia slip. CONSOL and Clean Air Engineering returned to AES Greenidge on the week of June 18 to perform additional ammonia slip testing and SCR grid point testing. These tests demonstrated attainment of the performance guarantee for ammonia slip, (although the measured ammonia slip exceeded the value that had been predicted for this stage of the SCR catalyst's life) thereby concluding the project's guarantee tests. Having satisfied the ammonia slip guarantee, AES, $\mathrm{BPEI}$, and Fuel Tech worked on June 21 to establish a set of boiler operating conditions for routine operation. CONSOL and Clean Air Engineering provided ammonia slip and SCR grid point measurements to support this effort. As of the end of the day, Unit 4 was operating with $\mathrm{NO}_{x}$ emissions below $0.15 \mathrm{lb} / \mathrm{mmBtu}$ (thereby satisfying its permitted $\mathrm{NO}_{\mathrm{x}}$ emission rate) and with $\sim 2$ ppmv of ammonia slip. Additional combustion system tuning and SCR grid point measurements were completed during the week of June 25.

The Turbosorp ${ }^{\circledR}$ system operated smoothly throughout the month of June and consistently achieved deep $\mathrm{SO}_{2}$ removal efficiencies (e.g., >95\%). The large particle ash screen that was installed above the SCR reactor in May generally operated without problem, although a small increase in pressure drop across the screen was observed in mid-June. The screen was inspected during an economizer tube leak outage on June 15-17; the inspection indicated that the soot blowers installed below the screen were missing several areas of the screen, allowing large particle ash to accumulate in those areas. 
On June 27, Dan Connell (CONSOL) gave a presentation on the project at the Air \& Waste Management Association's $100^{\text {th }}$ Annual Conference \& Exhibition, which was held in Pittsburgh.

\section{July 2007}

The multi-pollutant control system at AES Greenidge continued to operate within its permit limits for $\mathrm{SO}_{2}$ and $\mathrm{NO}_{x}$ during July 2007. The plant continued to work on characterizing and optimizing the performance of the hybrid $\mathrm{NO}_{x}$ control system; AES, Babcock Power, and Fuel Tech completed another round of combustion system and SNCR/SCR tuning during the week of July 23. The process was informed by $\mathrm{NO}_{x}$ and $\mathrm{CO}$ grid point measurements performed by Clean Air Engineering at the SCR inlet and outlet. During the tuning period, the plant developed a set of full-load combustion and SNCR operating conditions that allowed them to achieve their desired steam temperatures and an acceptable $\mathrm{NO}_{x}$ removal distribution across the SCR catalyst (i.e., such that there were no areas of extremely high $\mathrm{NO}_{x}$ removal efficiency that would tend to indicate high $\mathrm{NH}_{3}$ slip) while maintaining a $\mathrm{NO}_{x}$ emission rate of $\sim 0.13-0.14 \mathrm{lb} / \mathrm{mmBtu}$. These conditions required that zone two of the SNCR system was operated at its maximum capacity. Tuning and characterization of the combustion and SNCR/SCR systems were also completed at intermediate loads that produced economizer outlet temperatures near or just below the minimum operating temperature for the in-duct SCR. This work indicated that the system was capable of better-than-expected $\mathrm{NO}_{x}$ removal performance at moderate loads of around $70 \mathrm{MW}$.

AES Greenidge personnel continued to observe increasing pressure drop across the large particle ash screen. The screen was inspected and cleaned during an outage brought about by an ID fan cable failure; the inspection again indicated that the soot blowers installed beneath the screen were not affording adequate coverage to keep it clean. AES ordered four new rotary soot blowers to provide improved cleaning coverage.

AES Greenidge encountered some problems with the lime hydration system at the end of the month, as several balls escaped from the ball mill and caused minor damage to the system. As a result, they had to operate the Turbosorp system using purchased hydrated lime while the lime hydration system was repaired.

CONSOL and AES met on July 18 to develop plans for process performance testing of the multi-pollutant control system.

\section{August 2007}

In general, the multi-pollutant control system operated routinely during August 2007, although minor problems were encountered with the lime hydration system and with increasing pressure drop across the large particle ash screen and in-duct SCR reactor.

The ball mill and classifier again required maintenance in mid-August to overcome some minor operational problems. Also, during the week of August 20, the lime hydration system had to be taken offline because the bucket elevator shaft failed. The plant continued to operate the Turbosorp system using purchased hydrated lime while the shaft was replaced.

A short outage was held on August 10-11 to allow the plant to remove large particle ash that had accumulated on the LPA screen and in-duct SCR catalyst; the pressure drop across the SCR (including the screen) returned to normal following the outage, but was again increasing as 
of the end of the month. The four new rotary soot blowers for the LPA removal system were delivered to the plant.

On August 2, Dan Connell (CONSOL) presented a paper on the project at the COAL-GEN conference in Milwaukee, WI.

\section{September 2007}

During September 2007, AES Greenidge completed an outage to modify the large particle ash (LPA) removal system that was installed above the in-duct SCR reactor in May. During the outage, which began on the evening of September 4, the two soot blowers that had been installed in May to clean the LPA screen were replaced with four rotary soot blowers to provide improved cleaning coverage, and a spring seal was installed to close the gap between the two sections of the LPA screen. (Because the top of the screen is affixed to the ductwork above an expansion joint, the screen was installed in two sections to allow it to move with the duct as furnace temperatures change - e.g., during start-up and shut-down. Based on the plant's observations during previous outages for LPA screen cleaning, it appeared that some LPA was traveling through the gap between the screen sections and accumulating on the surface of the catalyst. Hence, the seal was installed to prevent this from occurring in the future). The plant also installed a rake containing $\sim 350$ blow points immediately above the catalyst to aid in resuspending any fly ash that accumulates on its surface. (The rake is expected to keep the catalyst cleaner than the existing sonic horns). The outage ended at around 12:00 a.m. on September 10, and the plant successfully completed troubleshooting of a cam problem with the new soot blowers during the next several days.

The plant did not observe any increase in the pressure drop across the LPA screen during the first week of operation after the outage. Unit 4 was then taken offline again on September 1821 so that plant personnel could find and repair the source of an oil leak that was unrelated to the multi-pollutant control system. An inspection of the in-duct SCR during this outage confirmed that only a minor amount of LPA was present on the LPA screen.

The Turbosorp scrubber and ancillary equipment operated routinely during September 2007, with no major problems reported by the plant.

A project status review meeting including representatives from DOE, CONSOL, and AES was held at AES Greenidge on September 5.

\section{October 2007}

CONSOL completed the first series of process performance tests at AES Greenidge on October $1-12,2007$. The tests during the week of October 1 were conducted to evaluate the performance of the multi-pollutant control system while AES Greenidge Unit 4 was firing a higher-than-normal sulfur coal. (The sulfur content of the coal was $\sim 4.5-5.0 \mathrm{lb} \mathrm{SO} \mathrm{S}_{2} / \mathrm{mmBtu}$ during these tests). The Turbosorp scrubber proved capable of consistently achieving $>95 \%$ $\mathrm{SO}_{2}$ removal efficiency during the test period; however, the lime hydration system was often unable to keep up with the increased hydrated lime demand resulting from the higher-sulfur coal. The hydrated lime classifier plugged numerous times on October 3 and October 4, causing the lime hydration system to trip. This hindered the tests that were planned for those days; however, AES Greenidge was diligent in unplugging the hydrator and in taking deliveries of hydrated lime to allow the tests to proceed. Representatives from DOE-NETL visited AES Greenidge on October 3 to observe the testing. The tests during the week of October 8 were 
conducted to examine the effects of changes in $\mathrm{Ca} / \mathrm{S}$ ratio and approach temperature on the multi-pollutant removal performance of the Turbosorp system. (During these tests, Unit 4 fired coal with a sulfur content of $\sim 4.0-4.3 \mathrm{lb} \mathrm{SO}_{2} / \mathrm{mmBtu}$ ).

Routine commercial operation of the multi-pollutant control system continued during October 2007. Early in the month, however, AES Greenidge began to observe an increase in the pressure drop across the in-duct SCR catalyst (but not the large particle ash screen). The plant took several actions to try to alleviate this problem, including increasing the discharge pressure and frequency of operation of the rake soot blower that is installed above the catalyst and resuming operation of the sonic horn system, but these were unsuccessful in reversing the trend. As of the end of October, the plant was derated to about $95 \mathrm{MW}_{\text {net }}$ in order to maintain sufficient pressure downstream of the reactor to avoid risk of ductwork collapse.

\section{November 2007}

The trend of increasing pressure drop across the in-duct SCR reactor at AES Greenidge Unit 4 continued into early November 2007. The unit was further derated in early November to allow it to continue to operate while AES completed an outage at another of its New York power plants. Then, on November 9-12, AES Greenidge held an outage to inspect and clean the in-duct SCR catalyst. Upon entering the SCR reactor, plant personnel discovered a substantial amount of modestly sized large particle ash distributed relatively evenly over the surface of the catalyst. (They did not observe mounding of the LPA as they had during previous outages). Some of the LPA was small enough to pass directly through the LPA screen's mesh, and some also likely reached the catalyst by passing through gaps where the screen meets the duct walls. In addition, the spring seal that was installed in September to close the gap between the two sections of LPA screen did not flex as it was designed to. The new rotary soot blowers that were installed in September to clean LPA from the LPA screen appeared to be working effectively. AES vacuumed the LPA from the surface of the catalyst, collected samples for evaluation, and installed a temporary fix for the spring seal. When the unit returned to service, the pressure drop across the SCR was greater than its normal baseline, likely because some LPA was lodged deep within the catalyst and could not be removed as part of the cleaning.

Apart from the SCR pressure drop problem and several minor issues with the lime hydration system, the multi-pollutant control system operated regularly throughout November. In late November, plant personnel slowed down the rotation speed of one of the rotary feeders in the lime hydration system in order to help prevent the system from plugging. They believed that the feeder had been rotating too rapidly to allow its pockets to fill, allowing fines to build up in the system.

Also during November, CONSOL completed a second round of process performance testing of the multi-pollutant control system at AES Greenidge. This round of tests, which was conducted on November 13-16 (just after the catalyst cleaning outage), was designed to evaluate the performance of the multi-pollutant control system when Unit 4 operates at reduced loads and when it co-fires biomass (waste wood from a furniture manufacturing process) with coal.

AES Greenidge Unit 4 began co-firing waste wood on November 15; however, one of the hydrated lime classifier fan bearings failed that day, forcing the plant to take the hydrator offline.

AES continued to operate Unit 4 using hydrated lime from their onsite inventory, but waste wood co-firing was discontinued and the unit eventually had to be derated when the onsite supply of hydrate was depleted and the truck en route to replenish it broke down. The start of testing on November 16 was delayed until hydrated lime deliveries resumed. 


\section{December 2007}

During December 2007, AES Greenidge continued to experience elevated pressure drop across the in-duct SCR reactor, which hampered operation of Unit 4. The unit was derated throughout the month in order to maintain sufficient pressure downstream of the reactor to avoid risk of ductwork implosion. At the end of the month, AES Greenidge held an outage to inspect and clean the SCR reactor and to replace the current SCR catalyst layer with the original catalyst layer (which had been removed from the reactor in May 2007 and sent for professional cleaning in early December). The outage began on December 27, and the work in the SCR reactor was completed successfully by December 30, but a problem with the unit's distributed control system (unrelated to the multi-pollutant control system) prevented it from returning to service by year's end.

Meanwhile, the project team continued to work on diagnosing the catalyst plugging problem so that a solution could be developed to overcome it. AES met with Dr. Carlos Romero from Lehigh University to solicit his ideas; Babcock Power dissected catalyst samples that were collected during the unit's November outage to evaluate the extent and mechanism of plugging, and CONSOL held a brainstorming session to discuss mechanisms that may be contributing to the problem. Upon inspecting the SCR reactor during the December outage, plant personnel reported that the SCR catalyst was plugged with small pieces of large particle ash and with substantial amounts of seemingly sticky fly ash. They collected samples of the various types of ash and other deposits found in the SCR reactor; these were sent to CONSOL for chemical analysis and to Lehigh University for X-ray diffraction analysis.

Apart from the SCR pressure drop problem, the multi-pollutant control system operated normally during December.

Dan Connell (CONSOL) presented a poster on the project at DOE/NETL's Mercury Control Technology Conference, which was held in Pittsburgh, PA, on December 11-13, and Rich Abrams (Babcock Power) presented a paper on the project at the POWER-GEN conference, which was held in New Orleans, LA, on the same dates.

\section{January 2008}

The DCS problem that was encountered at the end of the catalyst cleaning outage in December 2007 was resolved in early January 2008, and Unit 4 returned to service on the morning of January 3. AES decreased the intensity of the rake soot blower above the in-duct SCR catalyst to reduce catalyst erosion, which was observed during the outage, and they closely monitored the pressure drop across the catalyst to track the rate of plugging. As of January 28, about 3.5 weeks after the conclusion of the outage, the pressure drop across the SCR reactor had increased by only about 0.2 i.w.c. from its full-load baseline of 1.1 i.w.c.

CONSOL chemically analyzed 10 samples of large particle ash, fly ash, and other deposits that were collected in the SCR reactor and ductwork by AES Greenidge personnel during the late December outage. The results were discussed with DOE and AES Greenidge during a project status review meeting at the plant on January 17 . The results did not immediately indicate any chemical mechanisms of plugging, although several interesting observations were noted with respect to the sulfur, ammonia, iron, and carbon content of the samples. AES Greenidge sent a similar set of samples to Lehigh University for X-ray diffraction (XRD) analysis. Notwithstanding any possible chemical mechanisms, it appeared that the catalyst plugging was due at least in 
part to LPA that was small enough to pass through the LPA screen but large enough to lodge in the catalyst. This physical mechanism of plugging was supported by observations of LPA lodged in the catalyst and catalyst screen during the late December outage and by a Babcock Power Environmental report describing the dissection of a catalyst element that was pulled from the SCR reactor during the unit's November 2007 outage.

Routine commercial operation of the multi-pollutant control system continued in January 2008. Apart from several short-lived problems with the lime hydration system and air slides, the Turbosorp scrubber and ancillary equipment operated normally throughout the month. The lime hydration system required maintenance on January 15-16 and was offline for a time (among other things, a bolt fell out of the ball mill, allowing balls to spill out); AES continued to operate the Turbosorp system during this period using hydrated lime from its onsite inventory and purchased hydrated lime. The plant later encountered some problems with the air slides during the weekend of January 19-20. The problems appeared to result from the control strategy for disposing ash from the system, which biased the entire ash disposal to one of the air slides, causing the ash removal system on that side to plug. The unit had to be derated to about $50 \mathrm{MW}$ for several hours while the blockage was cleared.

On January 30, Dan Connell (CONSOL) gave a presentation on the project at the EUEC Energy \& Environment Conference in Tucson, AZ.

\section{February 2008}

The multi-pollutant control system at AES Greenidge Unit 4 operated routinely throughout February, although the unit was derated for much of the month due to coal quality issues. Unit 4 fired a lower-sulfur, lower-Btu coal than normal during part of February, and for a time, it had trouble maintaining a $\mathrm{NO}_{x}$ emission rate near the setpoint of $0.125 \mathrm{lb} / \mathrm{mmBtu}$ with this fuel. However, plant personnel succeeded in improving $\mathrm{NO}_{\mathrm{x}}$ emissions by adjusting the burner tilts. Some problems were also encountered with freezing lines and valves in the lime hydration system and with freezing and clogging of the dosing valves in the Turbosorp system during periods of cold weather. Plant personnel succeeded in overcoming these problems by cleaning, heating, and/or insulating the problem areas, and they then operated the Turbosorp scrubber with a very low setpoint for $\mathrm{SO}_{2}$ emissions to make up for the higher-than-normal emissions encountered during the problem period. AES found it to be relatively easy to achieve very low $\mathrm{SO}_{2}$ emissions with the lower-sulfur coal (e.g., $2.8 \mathrm{lb} \mathrm{SO}_{2} / \mathrm{mmBtu}$ ) that they fired at times in February.

The pressure drop across the in-duct SCR catalyst at AES Greenidge increased very gradually throughout February. As of February 27, the pressure drop across the catalyst was approximately 1.8-2.0 i.w.c. when Unit 4 was operating just below full load. (This represents an increase of about 0.7-0.9 i.w.c. during the 8 weeks of operation since the clean catalyst layer was installed).

Results became available from Lehigh University's X-ray diffraction (XRD) analysis of samples that were collected in and around the in-duct SCR reactor during the December 2007 outage.

On February 19, Dr. Carlos Romero from Lehigh met with personnel from AES, DOE, CONSOL, Fuel Tech, and Cormetech to discuss these results. Apart from typical ash components (e.g., $\mathrm{Fe}_{2} \mathrm{O}_{3}, \mathrm{Al}_{2} \mathrm{O}_{3}, \mathrm{SiO}_{2}$ ), XRD analysis identified calcium sulfate, sodium nitrate, and calcium urate hexahydrate (a possible product of urea decomposition) in some of the samples; however, the abundance of these components was small relative to the ash components, and no clear evidence of a chemical mechanism of catalyst plugging was discovered. Hence, AES decided 
to proceed with modifications to the LPA screen to address the catalyst plugging problem mechanically (i.e., by preventing large particle ash from penetrating the LPA screen and lodging in the catalyst).

\section{March 2008}

During March 2008, CONSOL completed a fourth week of process performance testing of the multi-pollutant control system at AES Greenidge Unit 4. This test series, which was conducted on March 10-13, was designed to evaluate the performance of the system while the unit co-fired biomass (sawmill waste wood) with coal.

The pressure drop across the in-duct SCR reactor at AES Greenidge Unit 4 continued to increase gradually throughout March 2008. At the beginning of the month, the pressure drop was approximately 2 i.w.c. when Unit 4 was operating just below full load. (The unit was derated by several megawatts in early March because of coal quality issues). By the end of March, the pressure drop across the SCR had increased to nearly 4 i.w.c., and plant personnel had to derate the unit to $95 \mathrm{MW}_{\text {net }}$ to avoid the risk of ductwork collapse downstream of the air heaters. (Pressure drop arising from air heater fouling also contributed to the negative static pressure downstream of the air heaters, and hence, to the derate). Plant personnel sent the catalyst layer that was removed from the SCR in December 2007 for professional cleaning so that it could be installed during the May 2008 outage.

The Turbosorp scrubber and ancillary equipment generally operated routinely during March. Early in the month, AES Greenidge encountered some problems with frozen pressure transmitters in the Turbosorp system, which caused them to lose the fluidized bed several times. Plant personnel succeeded in thawing the transmitters, and the scrubber returned to normal operation. In addition, in early March, the plant experienced problems with balls escaping from the lime hydration system's ball mill and ultimately jamming the rotary feeder that removes heavies from the hydrated lime classifier. In mid-March, an escaped ball caused a screw conveyer failure, forcing the lime hydration system offline for repair. Plant personnel were able to continue to operate the Turbosorp scrubber using hydrated lime from their onsite storage tanker while the repairs were completed. They added magnets at the inlet and outlet of the bucket elevator to capture escaped balls and prevent them from damaging the system.

On March 20, Dan Connell (CONSOL) gave a presentation on the project to the Energy Technology Group of the American Chemical Society, Pittsburgh Section. A report and an addendum describing the results of the 2007 guarantee tests at AES Greenidge were submitted to DOE.

\section{April 2008}

AES Greenidge Unit 4 was derated throughout April 2008 because of elevated pressure drop across the in-duct SCR reactor and air preheaters. The derate was required to avoid the risk of collapse of the ductwork between the air preheaters and Turbosorp scrubber. The high pressure drop across the SCR likely resulted from the accumulation of large particle ash in the catalyst, and the high pressure drop across the air preheaters likely resulted from ammonium bisulfate formation on the air preheater baskets. As of Monday, April 28, Unit 4 was derated to about $85 \mathrm{MW}_{\text {net }}$ because of the elevated pressure drop. (It was then further derated to $72 \mathrm{MW}_{\text {net }}$ so that plant personnel could overhaul one of the coal mills; this was unrelated to the multipollutant control system). AES Greenidge worked throughout April to prepare for the unit's planned spring outage in May. 
The Turbosorp system generally operated routinely throughout the month, although AES Greenidge experienced some problems with plugging in the ash recirculation and disposal system. The plugging occurred around the rotary air locks located downstream of the air slides and in the ash disposal lines that transport product ash to the ash silos. On at least one occasion, the plugging appeared to be caused by rain leakage around the knife gate valves downstream of the air slides. Plant personnel were able to resolve all of the plugging issues without having to derate the unit. They planned to install an enclosure around the gate valves to prevent recurrence of the rain leakage problem. AES Greenidge also raised the Turbosorp outlet temperature setpoint by one degree Fahrenheit to reduce the risk of condensation.

CONSOL R\&D, AES Greenidge, and Babcock Power Environmental met on April 28 and 29 to plan for the project's remaining process performance tests and follow-up tests.

\section{May 2008}

AES Greenidge commenced its planned spring outage for Unit 4 on the evening of May 2, and the outage concluded during early afternoon on May 10. (The unit was derated in the days leading up to the outage because of elevated pressure drop across the SCR reactor and air heaters). Upon inspecting the SCR reactor at the start of the outage, plant personnel reported that the catalyst was plugged with substantial amounts of LPA and fly ash, and the catalyst was also severely eroded in places, presumably because of the rake soot blower. It also appeared that one of the rotary soot blowers on the western side of the LPA screen and one of the LPA vacuum ports were not functioning properly prior to the outage, based on observations of accumulated LPA near those pieces of equipment. Plant personnel attended to these issues.

During the outage, the existing LPA screen above the in-duct SCR reactor was removed and replaced with a new, smaller-pitch LPA screen. In addition, the existing catalyst modules were removed and replaced with clean catalyst modules. Most of these replacement modules had been in service at AES Greenidge Unit 4 prior to its late December 2007 outage, and they were sent for professional cleaning before being reinstalled in the reactor. However, eight modules were refitted with larger-pitch catalyst (seven were refitted with honeycomb catalyst, and one was refitted with corrugated catalyst) so that the performance of this catalyst (i.e., its susceptibility to plugging) could be evaluated. Also during the outage, the rake soot blower was modified so that it blows at a 45-degree angle rather than perpendicularly to the catalyst surface (the discharge pressure of the rake was also reduced to lessen catalyst erosion), and a new seal was installed to close the gap between the two sections of the LPA screen. The new seal consists of a plate that is attached with hinges to each of the two screen sections.

In addition to the work performed in the in-duct SCR reactor, AES Greenidge washed the air heater baskets, removed ash from the Turbosorp hopper, and inspected the Turbosorp system during the outage. Plant personnel did not observe any evidence of significant ash deposition, scaling, or erosion in the Turbosorp absorber vessel. Several improvements were made to the Turbosorp system and ancillary equipment. AES installed a new, ceramic-lined hydrated lime classifier to replace the existing one, and they installed new 30-hp motors on the air slide blowers to replace the existing smaller motors. (The larger motors are expected to reduce the likelihood that the ash recirculation system will trip because of high air slide ash levels). Finally, plant personnel attended to immobile valves and painted corroded areas in the baghouse.

The multi-pollutant control system generally operated normally after returning to service on May 10. Immediately following the outage, the full-load pressure drop across the SCR catalyst bed 
was about 1.0 - 1.2 i.w.c., and the pressure drop across the combined LPA screen and catalyst bed was about 1.3 - 1.5 i.w.c.. The pressure drop across the catalyst bed increased slightly by the end of the month.

The only noteworthy problem encountered with the Turbosorp system during May occurred when the $\mathrm{SO}_{2}$ analyzer at the inlet to the absorber vessel malfunctioned. This analyzer, which provides one of the inputs to the control loop that governs how much hydrated lime is injected into the absorber, was out of service for several days while AES Greenidge waited for a replacement part. During that time, plant personnel had to operate the Turbosorp scrubber with the hydrated lime injection control system in manual mode, and they believe that they significantly overfed hydrated lime to the scrubber. (They had trouble scaling back the hydrated lime injection rate during load swings, and they were also erring on the cautious side to ensure that the unit's $\mathrm{SO}_{2}$ emissions remained within its permit limits). The inlet $\mathrm{SO}_{2}$ analyzer was repaired and reinstalled.

During May 19-22, CONSOL and Clean Air Engineering completed a fifth week of process performance testing of the multi-pollutant control system at AES Greenidge Unit 4. The test series was designed to generate additional information about the performance of the multipollutant control system at reduced unit loads, and in particular, to thoroughly characterize the performance of the $\mathrm{NO}_{\mathrm{x}}$ control system (i.e., ammonia slip, $\mathrm{NO}_{\mathrm{x}}$ and $\mathrm{CO}$ concentration profiles around the SCR) as a function of load.

On May 8, Doug Roll (AES Greenidge) gave a presentation on the project at the Electric Power Conference in Baltimore, MD. In addition, Modern Power Systems magazine published an article on the project in its May 2008 edition.

\section{$\underline{\text { June } 2008}$}

During June 2008, CONSOL completed two weeks of performance testing of the multi-pollutant control system at AES Greenidge Unit 4. Follow-up testing was completed on the week of June 9 , and parametric testing of the Turbosorp system was completed on the week of June 16 . The follow-up tests were designed to reevaluate the performance of the multi-pollutant control system under guarantee test conditions after more than a year of operation. (The coal sulfur content during the follow-up testing period was slightly lower than it had been during the guarantee tests; however, CONSOL, DOE, and AES agreed to proceed with the tests as scheduled). The Turbosorp parametric tests were designed to evaluate the relationship between $\mathrm{SO}_{2}$ removal efficiency, calcium-to-sulfur ratio, and approach to adiabatic saturation temperature in the Turbosorp system.

The multi-pollutant control system operated routinely during June 2008 . The full-load pressure drop across the in-duct SCR reactor increased throughout the first half of the month, reaching $\sim 2.4$ i.w.c. on June 19. That day, plant personnel decided to manually operate the rake soot blower several times during the middle of day shift (they previously had been operating the soot blower only once per shift), and they realized that the rake's operating pressure was set to just 20 psi rather than the desired 60 psi. Upon increasing the pressure and operating the soot blower, the pressure drop across the SCR catalyst decreased to 1.4-1.5 i.w.c. (not far from the clean catalyst baseline pressure drop of $\sim 1.1$ i.w.c.). After attending to some problems with the rake's poppet valves, plant personnel resumed routine soot blowing at 60 psi. They were able to maintain the full-load pressure drop across the catalyst at $\sim 1.5$ i.w.c. during the rest of the month by operating the rake soot blower four times per day at this pressure. 
The Turbosorp ${ }^{\circledR}$ system generally operated well throughout the month. Its performance was particularly commendable during the parametric tests on June $16-19$, as it maintained $\mathrm{SO}_{2}$ emission rates and temperatures that closely mirrored the set points while the unit operated at steady state. Two minor problems were encountered during the test period, however. On June 15 and 16, concrete-like deposits formed in one side of the ash disposal system, forcing one of the ash silos out of service. Plant personnel were able to continue to operate the Turbosorp system using the other silo while they cleared the deposits. Then, on June 19, the hydrated lime silo level transmitter failed, causing the hydrator (which is controlled automatically based on the silo level) to produce hydrated lime at a slower rate than required to keep up with demand. Upon realizing the problem, plant personnel had to fill the silo with hydrate from their onsite storage tanker to avoid running out of hydrated lime for the scrubber. The level transmitter was not able to be repaired onsite, and the lime hydration system was operated for several days by taking periodic, manual hydrate silo level measurements and adjusting the hydrator output accordingly. AES Greenidge received replacement electronics for the level transmitter during the following week, and the transmitter was repaired.

On June 4, Dan Connell (CONSOL) presented a paper on the project at the 2008 Clearwater Coal Conference in Clearwater, FL.

\section{July 2008}

Routine commercial operation of the multi-pollutant control system at AES Greenidge continued throughout July 2008.

On the evening of July 4, AES unexpectedly had to take Unit 4 offline to repair an economizer tube leak. Although unrelated to the multi-pollutant control system, the outage gave plant personnel an opportunity to inspect the in-duct SCR reactor. Just prior to the outage, the pressure drop across the SCR catalyst (excluding the large particle ash screen) had risen to about 1.7 i.w.c. at full load. Upon inspecting the reactor, plant personnel found that the large particle ash screen and catalyst screen were partially plugged with wet fly ash and some LPA. It was unclear how much the tube leak contributed to this plugging. Some catalyst channels were plugged, but these were fairly well distributed across the cross section of the catalyst. There were no piles of fly ash on top of the catalyst screen, as had been observed during some previous outages, and the extent of catalyst plugging appeared to be less than it would have been in the past after $\sim 8$ weeks of operation. Plant personnel vacuumed the LPA screen and catalyst screen (they did not remove the catalyst screen to vacuum the catalyst directly), and the unit returned to service on the morning of July 6 . No discernible increase in the pressure drop across the in-duct SCR catalyst was observed for the rest of the month. As of July 28 , the pressure drop across the catalyst (excluding the LPA screen) was 1.5-1.6 i.w.c. when Unit 4 was operating at about $109 \mathrm{MW}_{\text {gross. }}$.

The only noteworthy problem encountered with the hybrid $\mathrm{NO}_{\mathrm{x}}$ control system in July occurred on July 26, when the SNCR system tripped out of service while the urea tank was being filled.

(The trip was triggered by the high level indicator on the urea tank). The system remained offline for several hours before plant personnel could restart it. (There was a problem with one of the set points in the control system, and it took several hours to diagnose this issue). The unit was operating at low load while the problem was being resolved, however, and its $\mathrm{NO}_{\mathrm{x}}$ emission average was therefore impacted only minimally.

Apart from typical maintenance requirements, the Turbosorp system operated without problem during July 2008. In the lime hydration system, however, the hydrated lime silo level monitor 
continued to perform less-than-optimally. Once during the month, a level monitor malfunction caused the hydrated lime silo level to drop to zero. Plant personnel were able to overcome the problem by increasing the rate of hydrated lime production to rebuild the silo inventory, without having to introduce any hydrated lime from their onsite storage tanker.

\section{August 2008}

The multi-pollutant control system at AES Greenidge operated routinely throughout August. Apart from typical maintenance requirements, no problems were encountered with the Turbosorp system or its ancillary equipment. Unit 4 experienced periodic problems with burner flame attachments, and it was derated by several megawatts throughout most of the month because 1-2 damaged burners had to be taken out of service. The pressure drop across the induct SCR reactor increased slightly during the month. As of August 2, the pressure drop across the SCR catalyst (excluding the LPA screen) was 1.6-1.7 i.w.c. when the unit was operating at $\sim 108 \mathrm{MW}_{\text {gross. }}$ By August 25, the pressure drop had increased to 1.8-2.0 i.w.c. when the unit was operating at only $\sim 105 \mathrm{MW}_{\text {gross. }}$ Near the end of the month, plant personnel blew the rake soot blower above the catalyst several times at a higher-than-normal pressure in an effort to reverse the increasing trend in pressure drop. Although it is more difficult to track the full-load pressure drop when the unit is derated, operating the rake in this way appeared to have some effect. As of the beginning of September, the pressure drop across the SCR catalyst was $\sim 1.5$ i.w.c. when the unit was operating at $100 \mathrm{MW}_{\text {gross. }}$

On August 14, a project status review meeting including representatives from DOE, CONSOL, and AES was held at AES Greenidge. On August 6, Dan Connell (CONSOL) and Rod Beittel (Babcock Power) gave a presentation on the project at a WorleyParsons "Lunch and Learn" meeting in Reading, PA. On August 28, Dan Connell (CONSOL) presented project results at the 2008 Power Plant Air Pollutant Control "MEGA" Symposium in Baltimore, MD.

\section{September 2008}

The multi-pollutant control system at AES Greenidge Unit 4 operated routinely throughout September. Unit 4 was derated throughout the month to $\sim 92 \mathrm{MW}_{\text {net }}$ because two coal burners were out of service. These burners were damaged by flame attachments in August. AES Greenidge began co-firing Powder River Basin (PRB) coal with Northern Appalachian coal during mid-September, and Unit 4 was further derated to $\sim 85-89 \mathrm{MW}_{\text {net }}$ for the rest of the month because of the high moisture content of this PRB coal. Although it is more difficult to track the pressure drop across the in-duct SCR catalyst when the unit is derated, this pressure drop appeared to increase only slightly during September. On September 2, the pressure drop was $\sim 1.5$ i.w.c. when the unit was operating at $\sim 92 \mathrm{MW}_{\text {net, }}$ and on September 29, it was $\sim 1.7$ i.w.c. when the unit was operating at $\sim 85 \mathrm{MW}_{\text {net. }}$

The Turbosorp system continued to perform commendably during the month. Apart from typical maintenance requirements, only two minor issues were encountered with operation of the system. Once during the month, plant personnel found it difficult to maintain an inventory of product ash in one of the air slides, but they easily overcame this problem by adjusting set points associated with the air slide level control. (The problem was encountered for the first time after PRB co-firing began, leading to speculation that it may have been associated with changes in the quantity and/or composition of the product ash resulting from this co-firing). Later, AES Greenidge experienced some minor problems with plugging in the hydrated lime

feed pipe to the Turbosorp system, which may have been promoted by very misty weather conditions that were experienced at the plant. 
A draft of the project's Final Public Design Report was submitted to DOE for review on September 25, and a draft of CONSOL's process performance and cost evaluations was submitted to DOE on September 30.

\section{October 2008}

AES Greenidge held an outage to repair the damaged coal burners that had caused Unit 4 to be derated in August and September. The outage began on the evening October 3 and ended on the morning of October 6. During the outage, plant personnel inspected the in-duct SCR reactor. Although some LPA had accumulated in the LPA screen, catalyst screen, and catalyst, the amount of accumulation appeared to be much less than was typically observed prior to May 2008, when the original, larger-pitch LPA screen was in service. Based on a visual inspection, the larger-pitch test catalyst modules appeared to have fewer plugged channels than the smaller-pitch catalyst modules. Plant personnel vacuumed LPA from the catalyst screen (they did not remove the screen to access the catalyst directly) and cleaned the catalyst from above using an air lance. The pressure drop across the SCR catalyst averaged about 1.7 i.w.c. (at high loads) following the outage.

Also during the outage, AES cleaned out the hydrated lime feed pipe and inspected the Turbosorp system and baghouse. The Turbosorp inlet cone was clean, but there appeared to be some small deposits higher in the absorber vessel. Significant ash accumulation was observed around the valves at the inlet to the baghouse modules, suggesting that some condensation had occurred in the baghouse. Plant personnel cleaned the ash from one of the eight modules; they will clean the other seven modules during a future outage.

Soon after Unit 4 returned to service on October 6, the hydrator mixer plugged, forcing the lime hydration system offline. Unit 4 was derated for a time to conserve hydrated lime, and AES took deliveries of hydrated lime so that the Turbosorp system could continue to operate while the mixer was cleaned. Plant personnel unplugged the hydrator and worked through problems with lime buildup in the lime belt feeder, and the lime hydration system returned to service on the evening of October 7.

On October 2, Dan Connell (CONSOL) presented project results at the 25th Annual International Pittsburgh Coal Conference in Pittsburgh, PA. On Friday, October 3, CONSOL, AES, and BPEI met at AES Greenidge to mark the conclusion of BPEl's EPC contract for the project and to discuss project close-out and final reporting.

The period of performance under the DOE cooperative agreement ended on October 18, as originally scheduled. During the rest of October, the project team focused on completing the final report and other project close-out requirements. Representatives from DOE, CONSOL, and AES met at AES Greenidge on October 24 to formulate the project's conclusions. 


\section{APPENDIX E}

FLUE GAS SAMPLING SCHEDULES

FROM SPECIAL TEST SERIES 


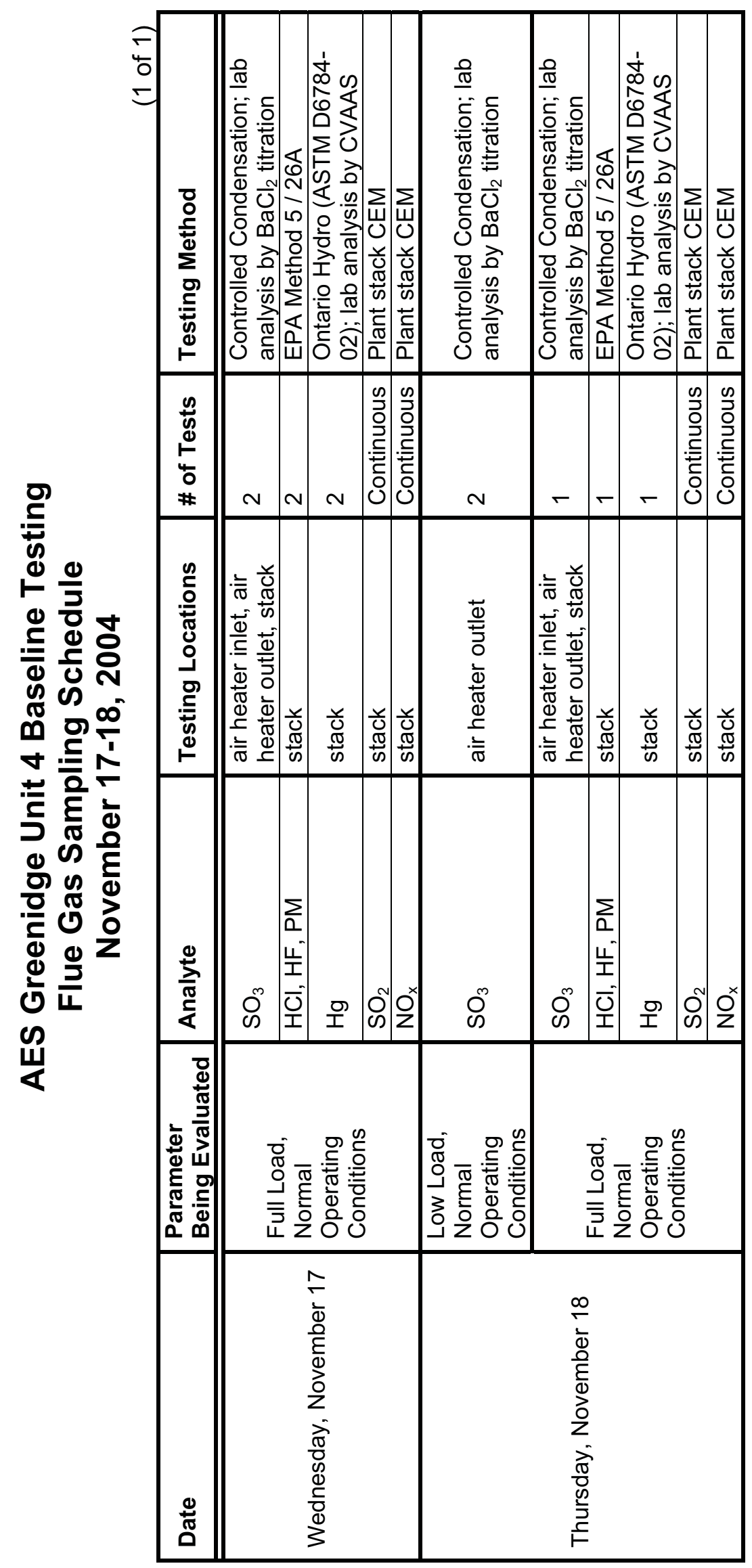




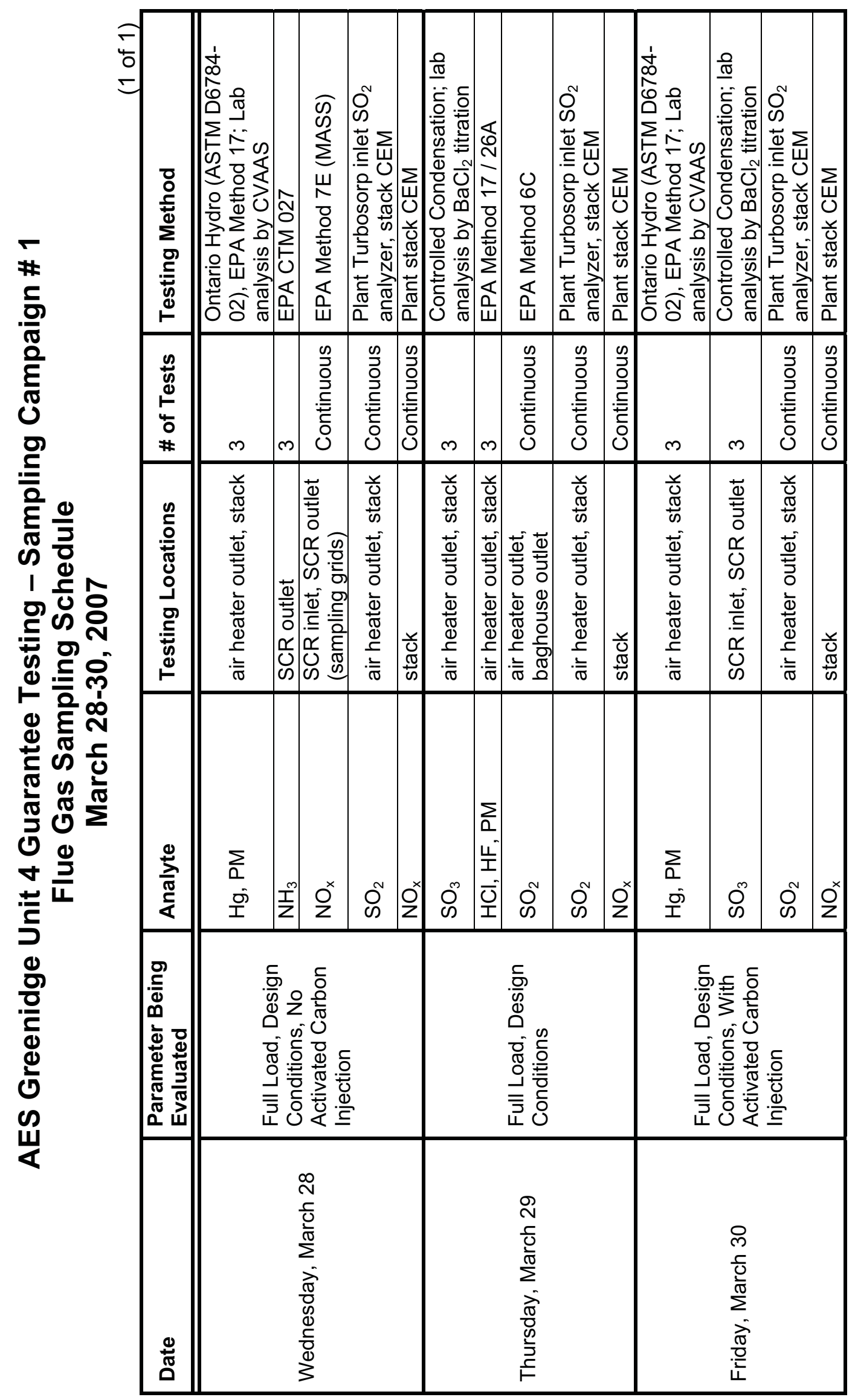




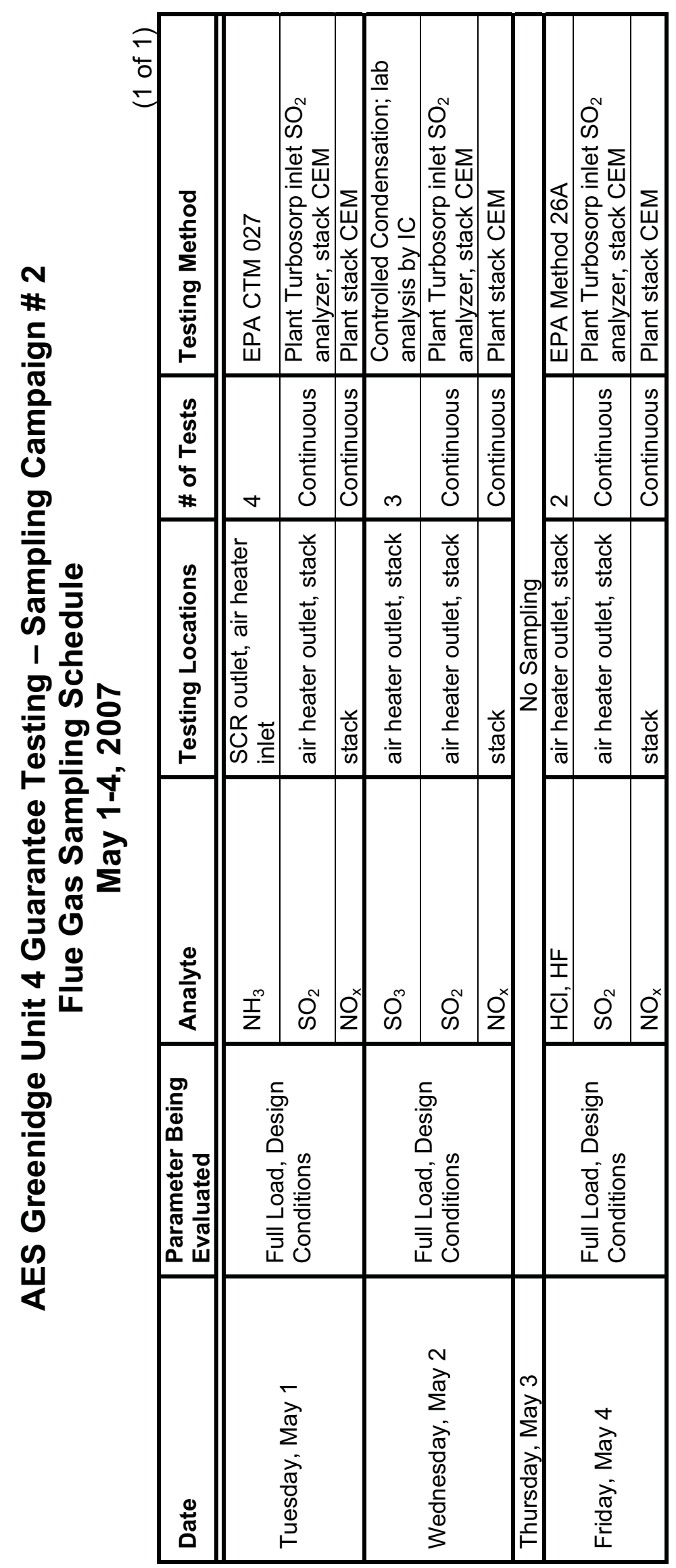




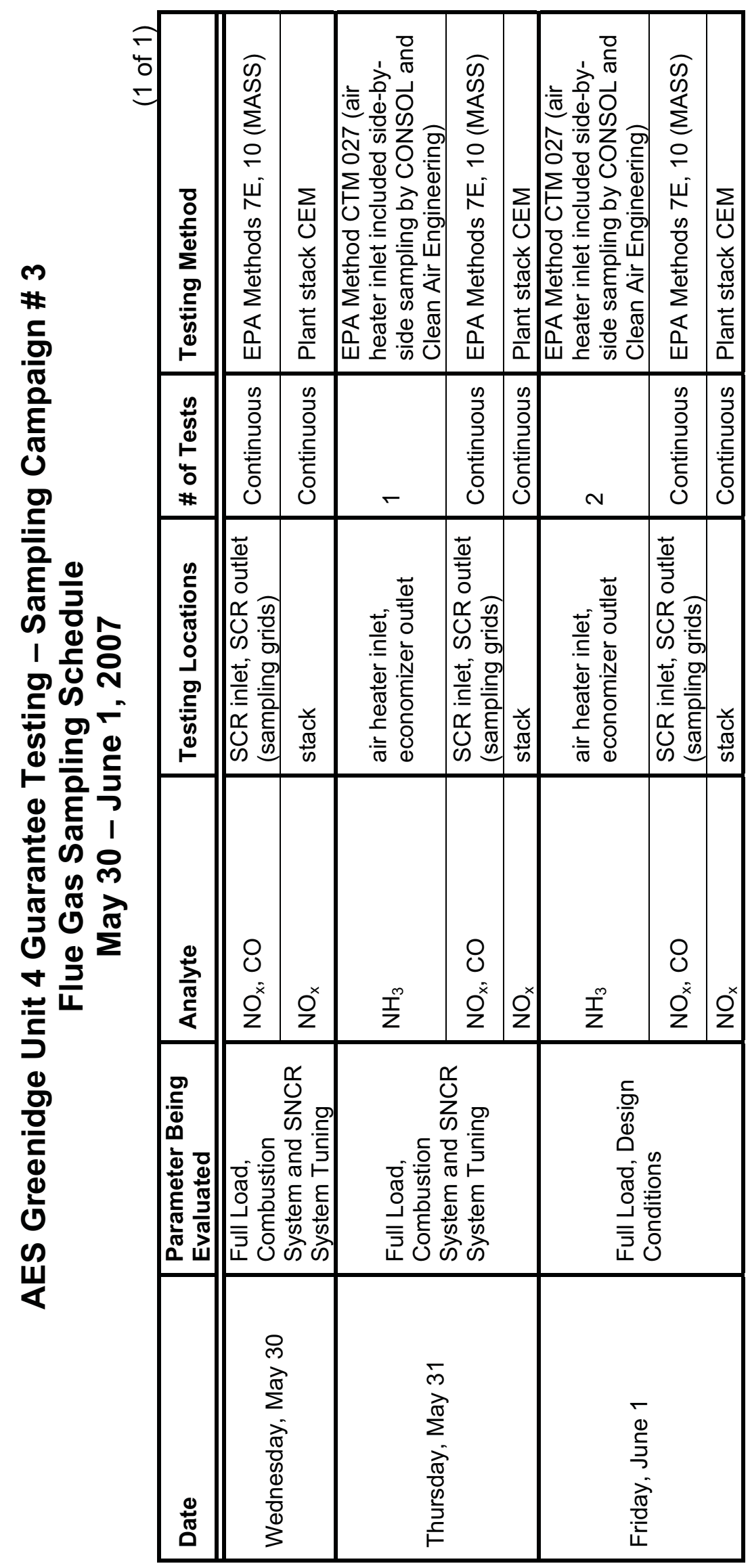




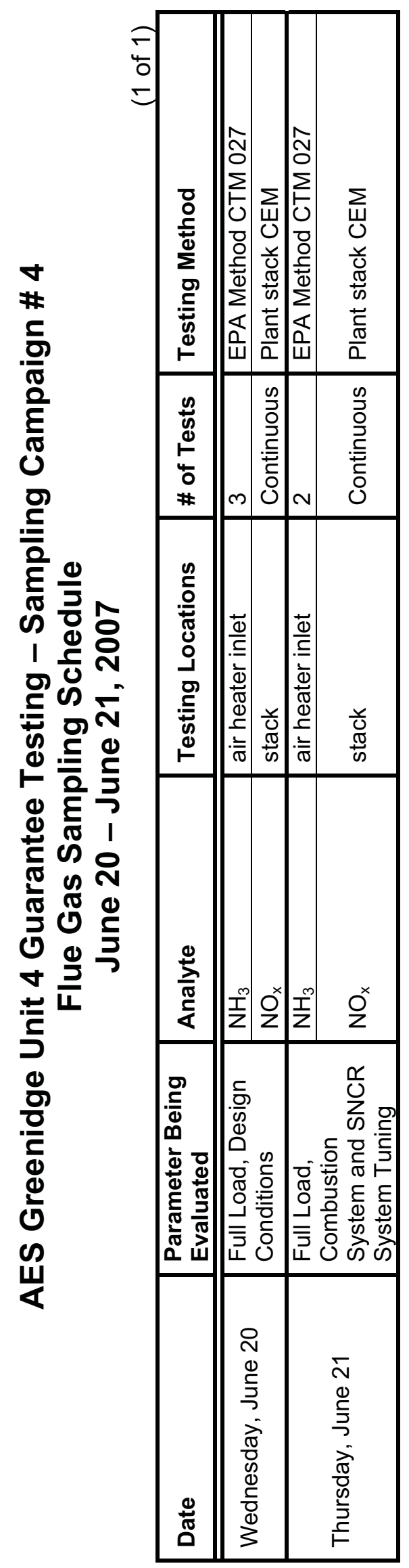




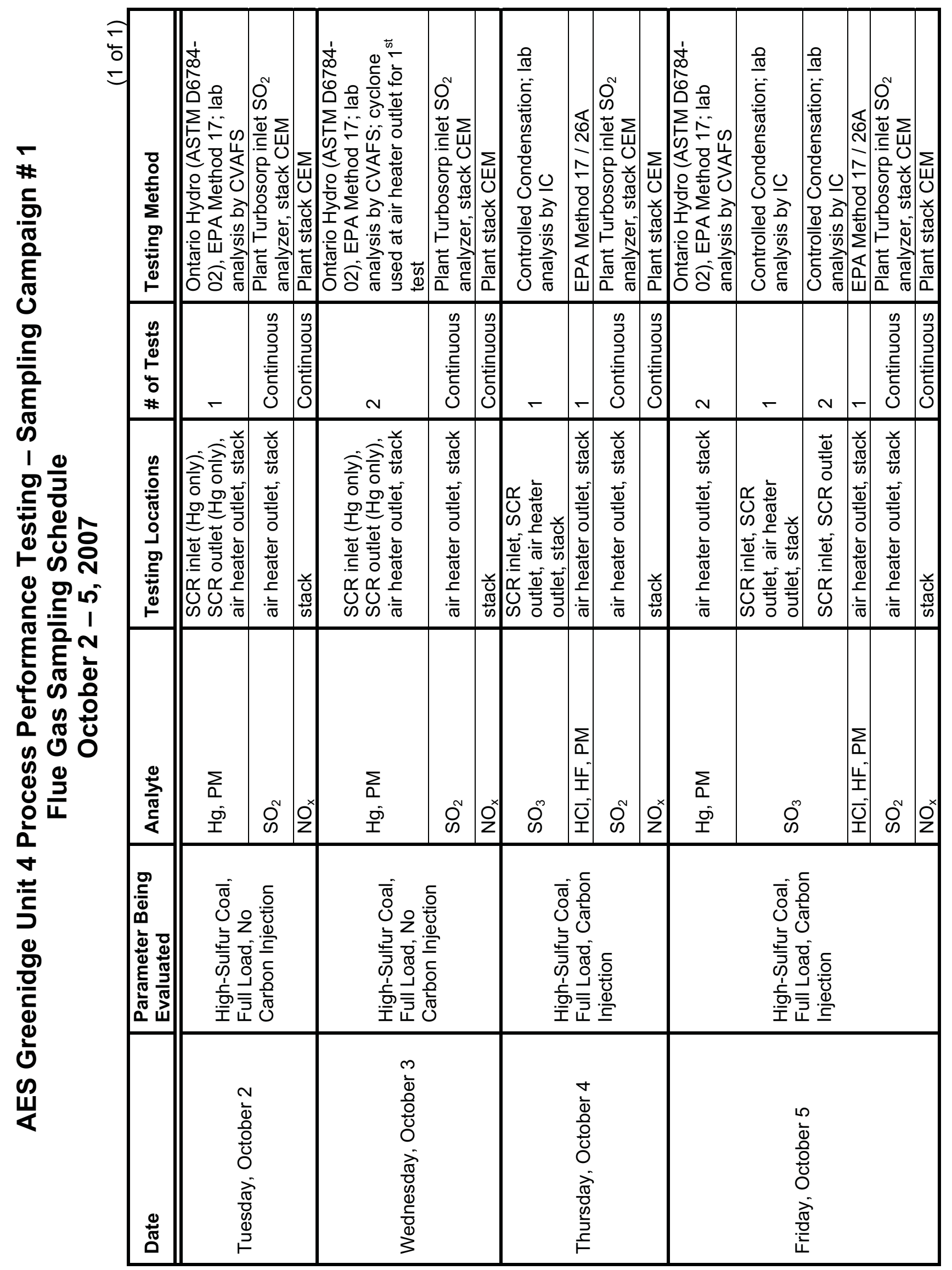




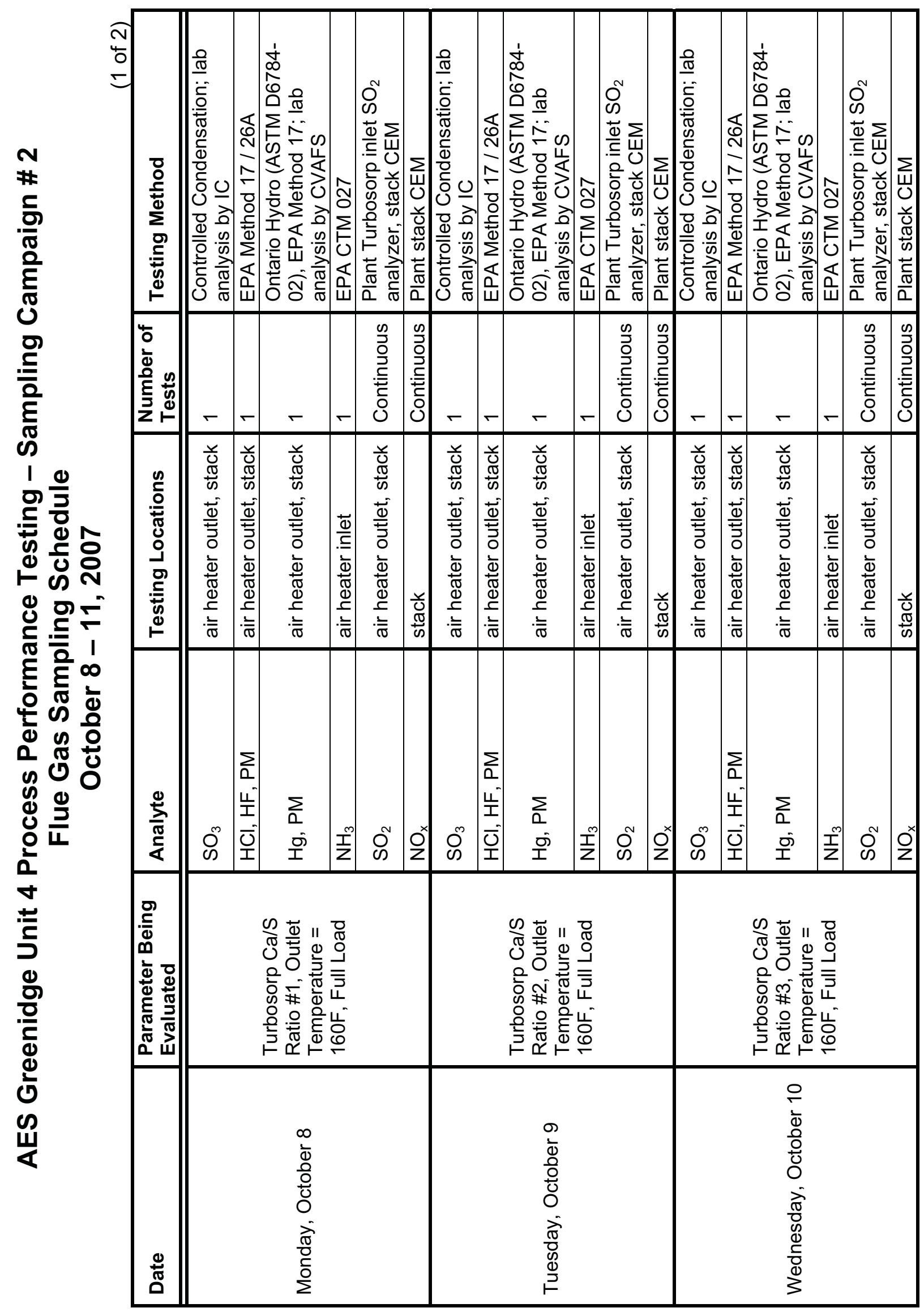




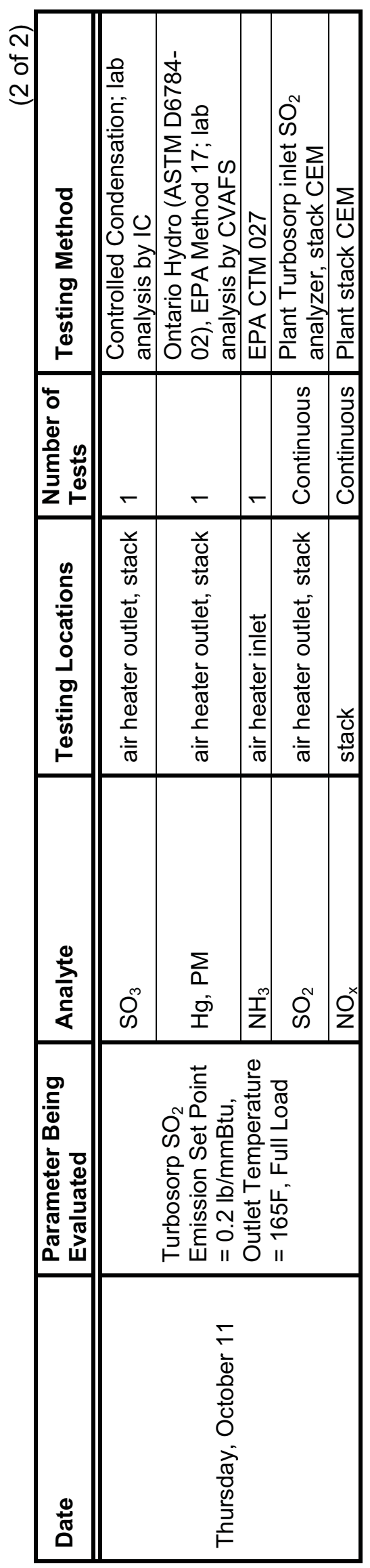

Appendix E 


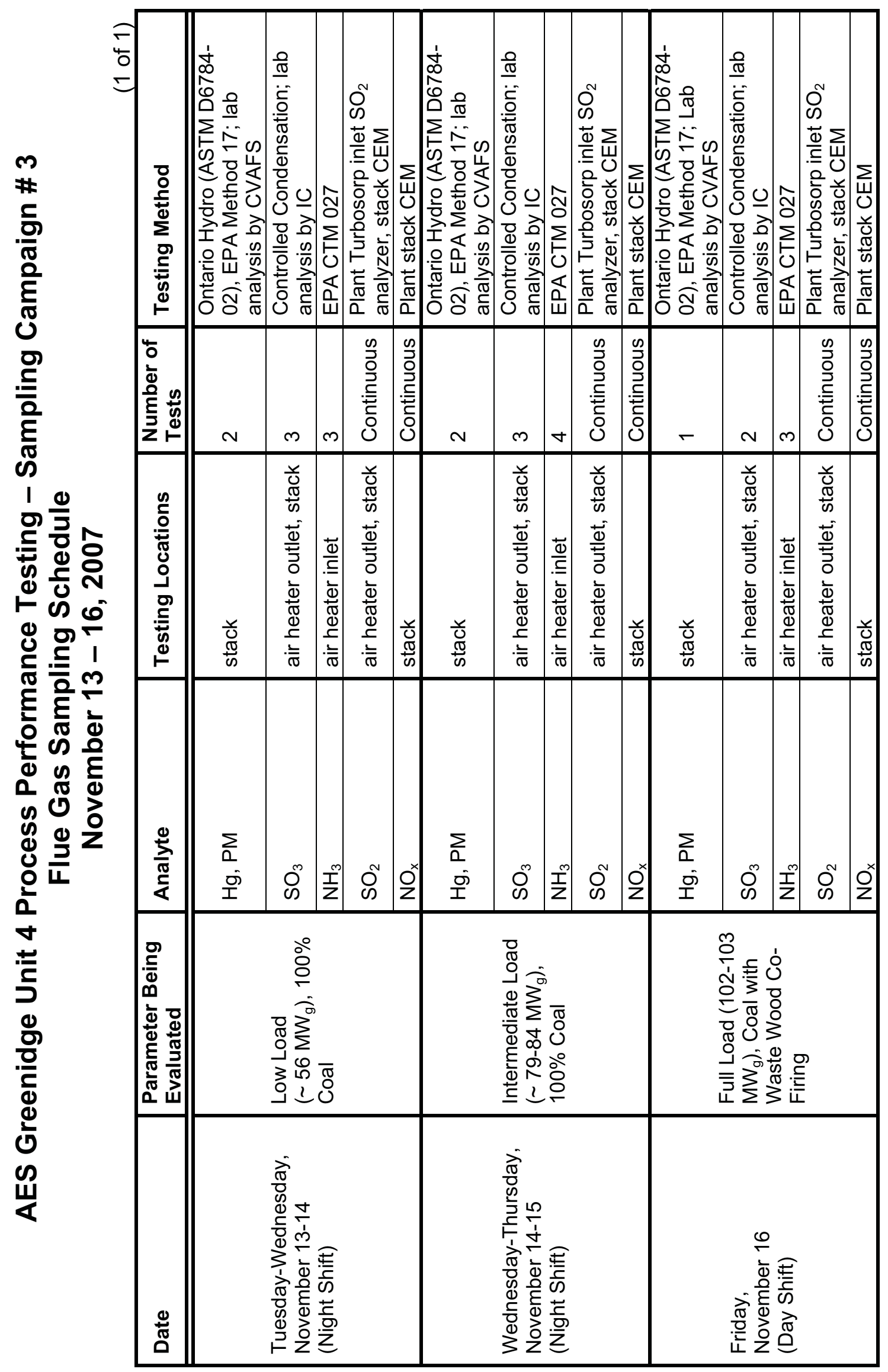




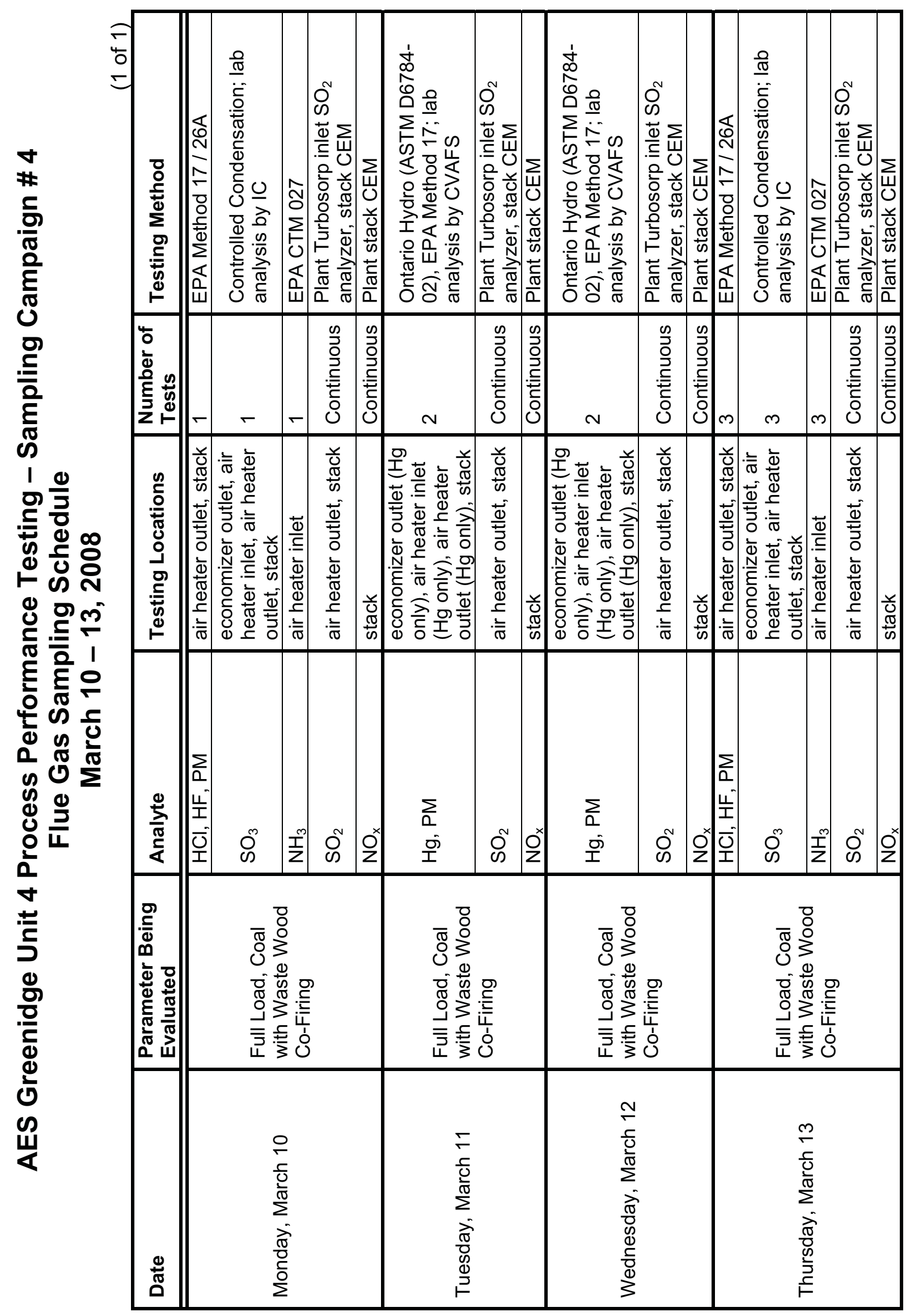




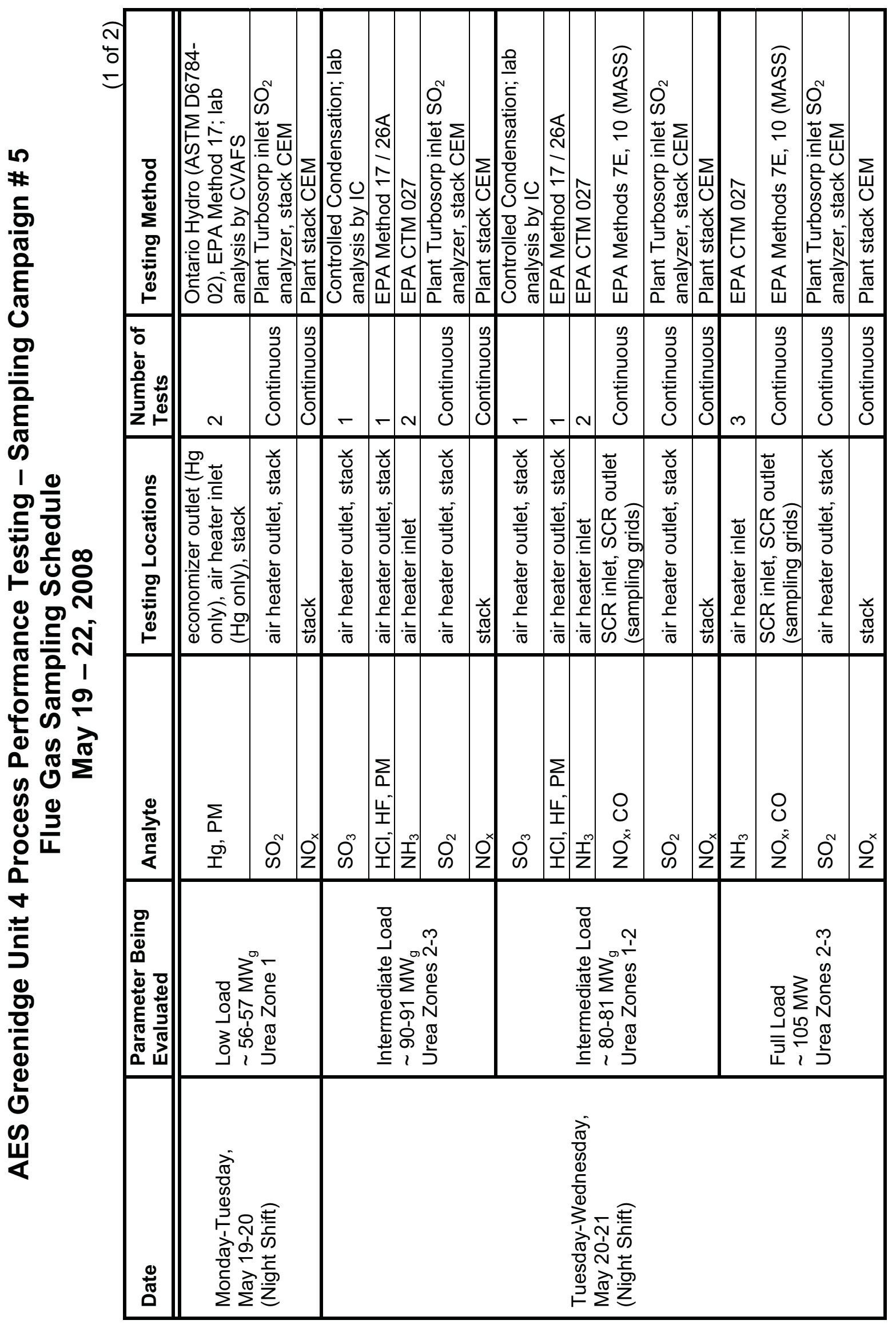




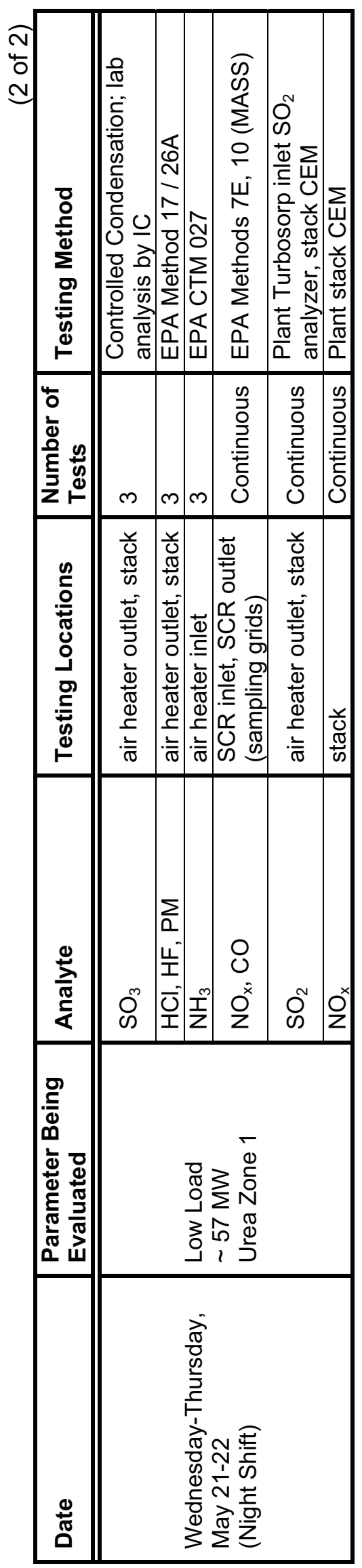

Appendix E 


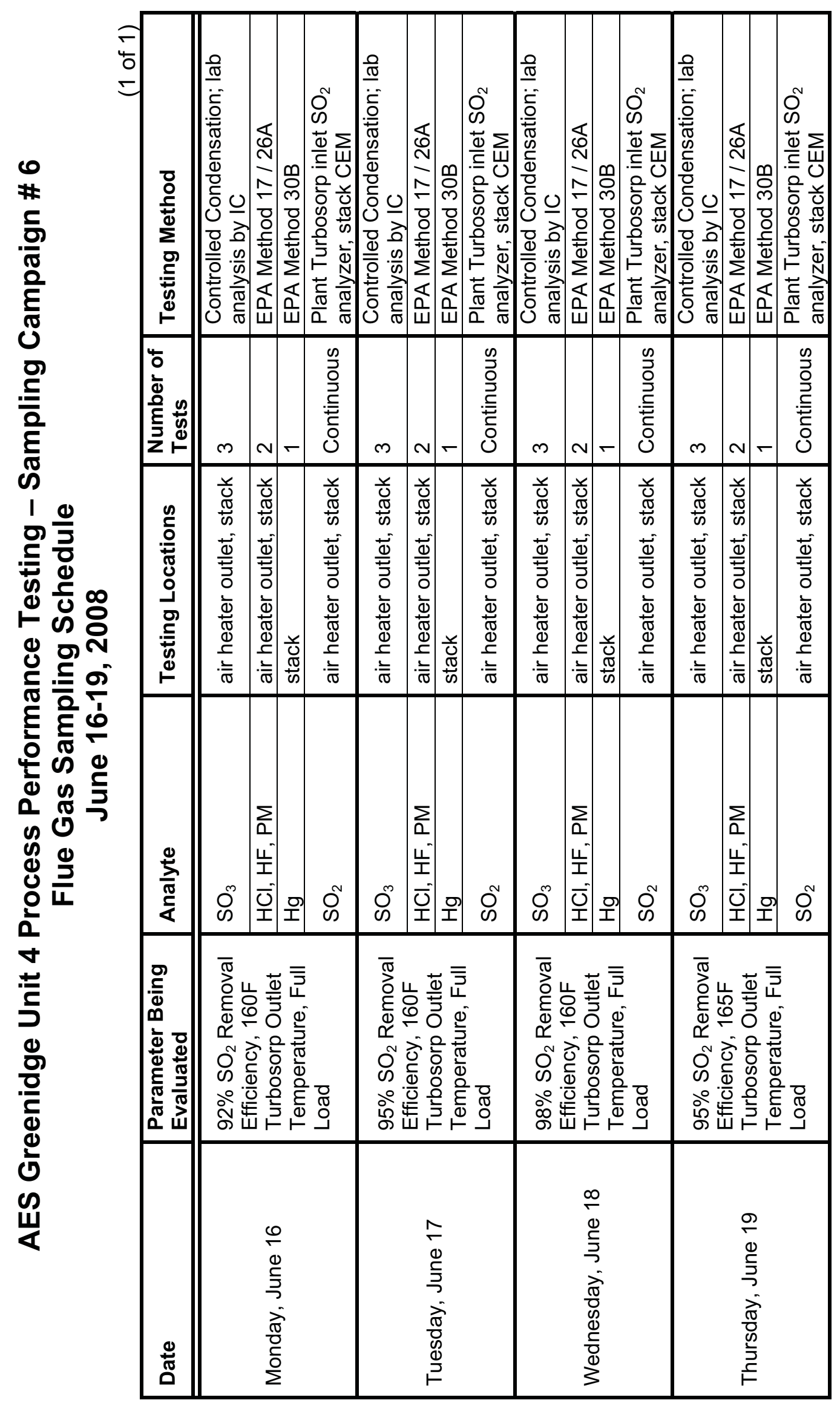




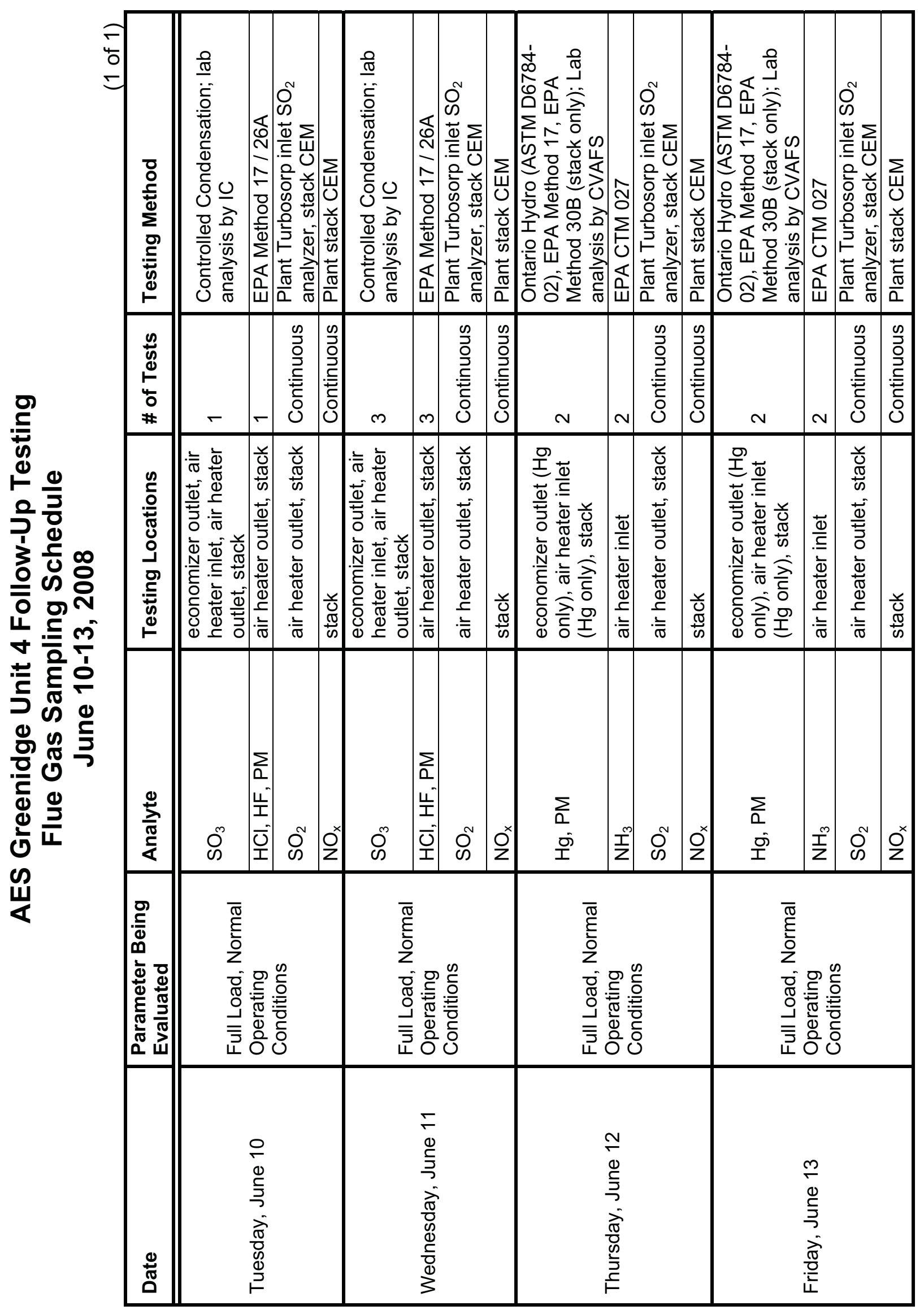




\section{APPENDIX F PHOTOGRAPHS OF FLUE GAS SAMPLING LOCATIONS}




\section{Economizer Outlet Sampling Location}
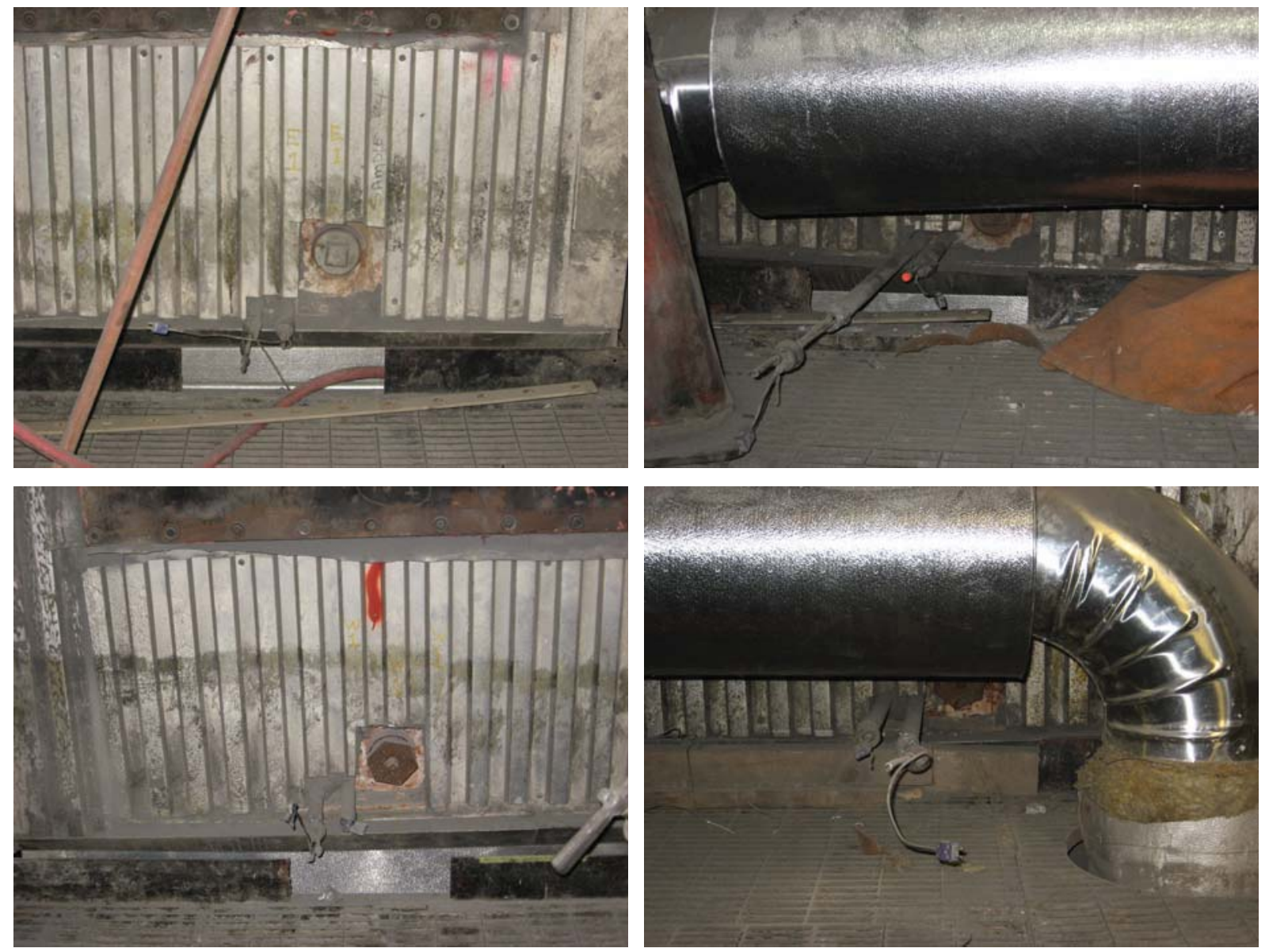


\section{SCR Inlet Sampling Location}
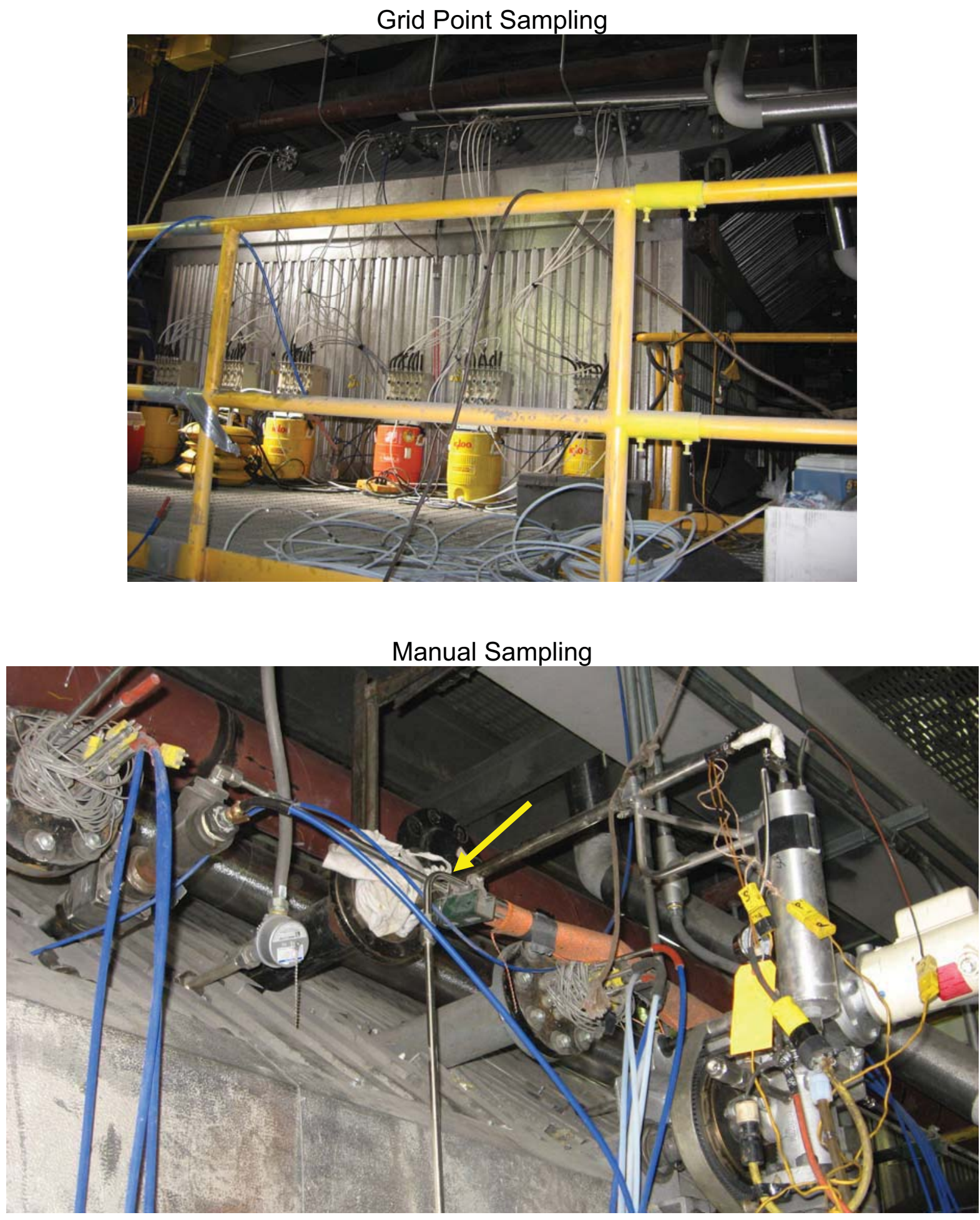


\section{SCR Outlet Sampling Location}

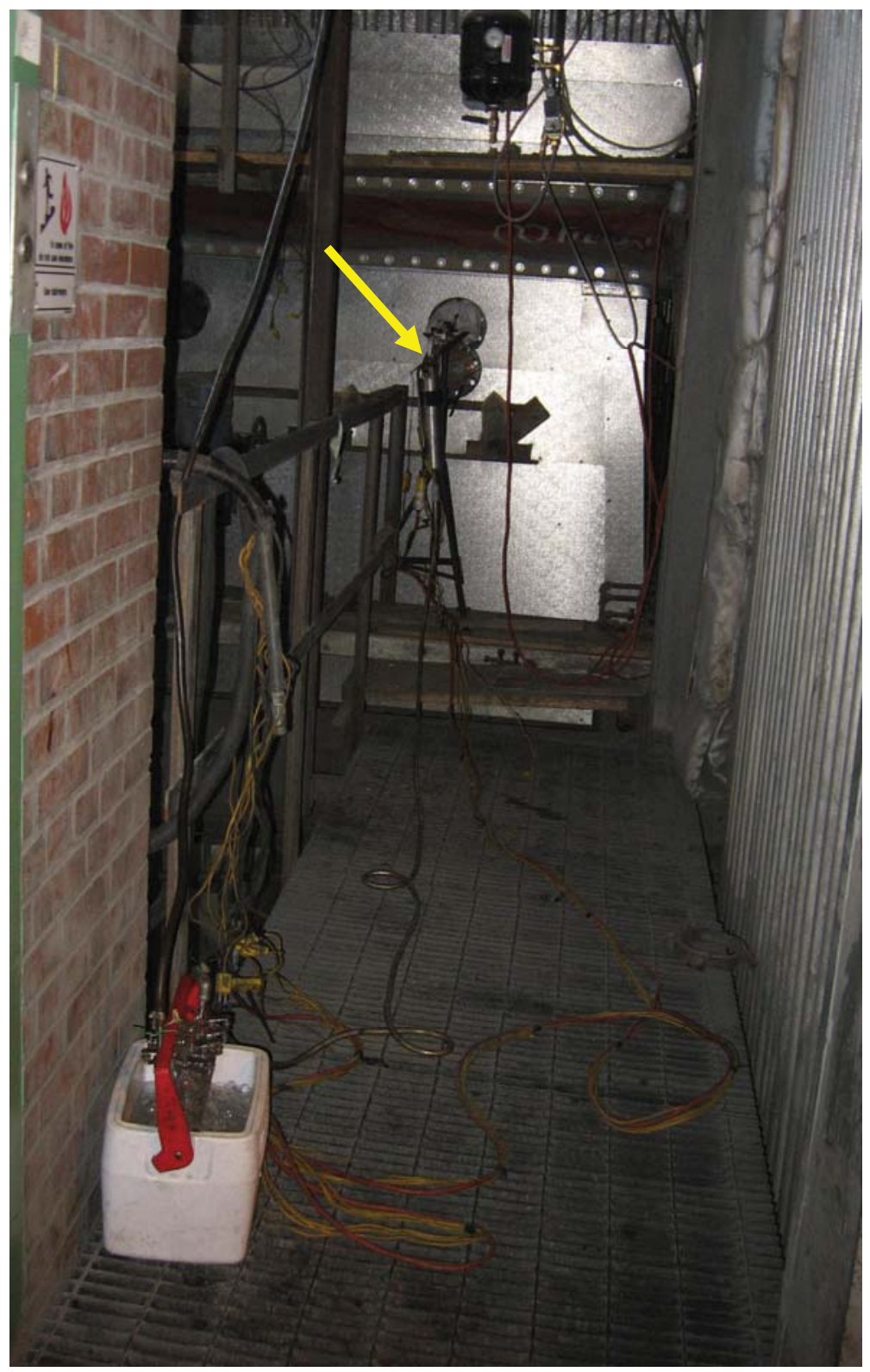




\section{Air Heater Inlet Sampling Location}

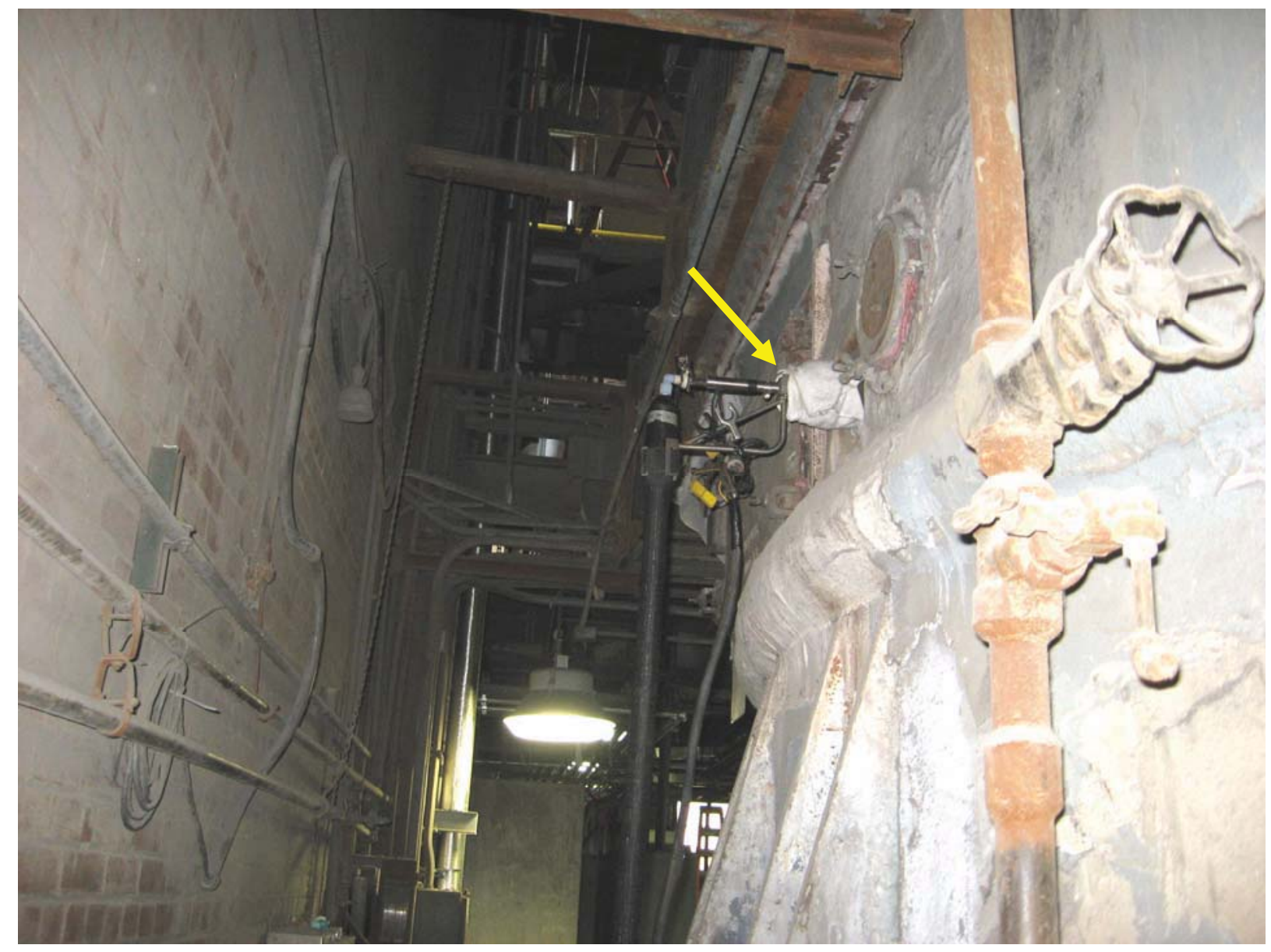




\section{Air Heater Outlet Sampling Location}

Two-Inch Ports and Plant $\mathrm{SO}_{2}$ Analyzer

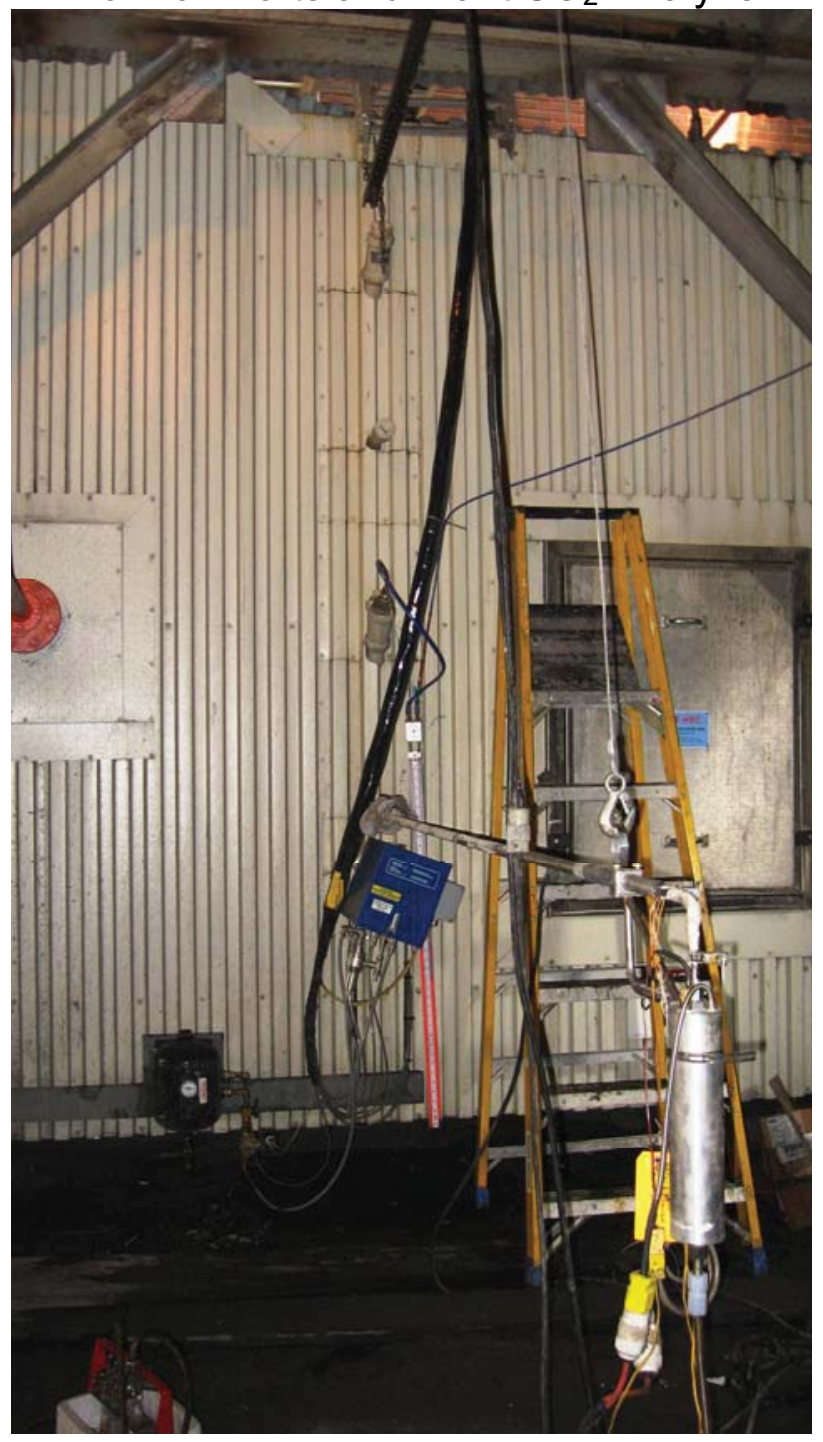

Four-Inch Ports

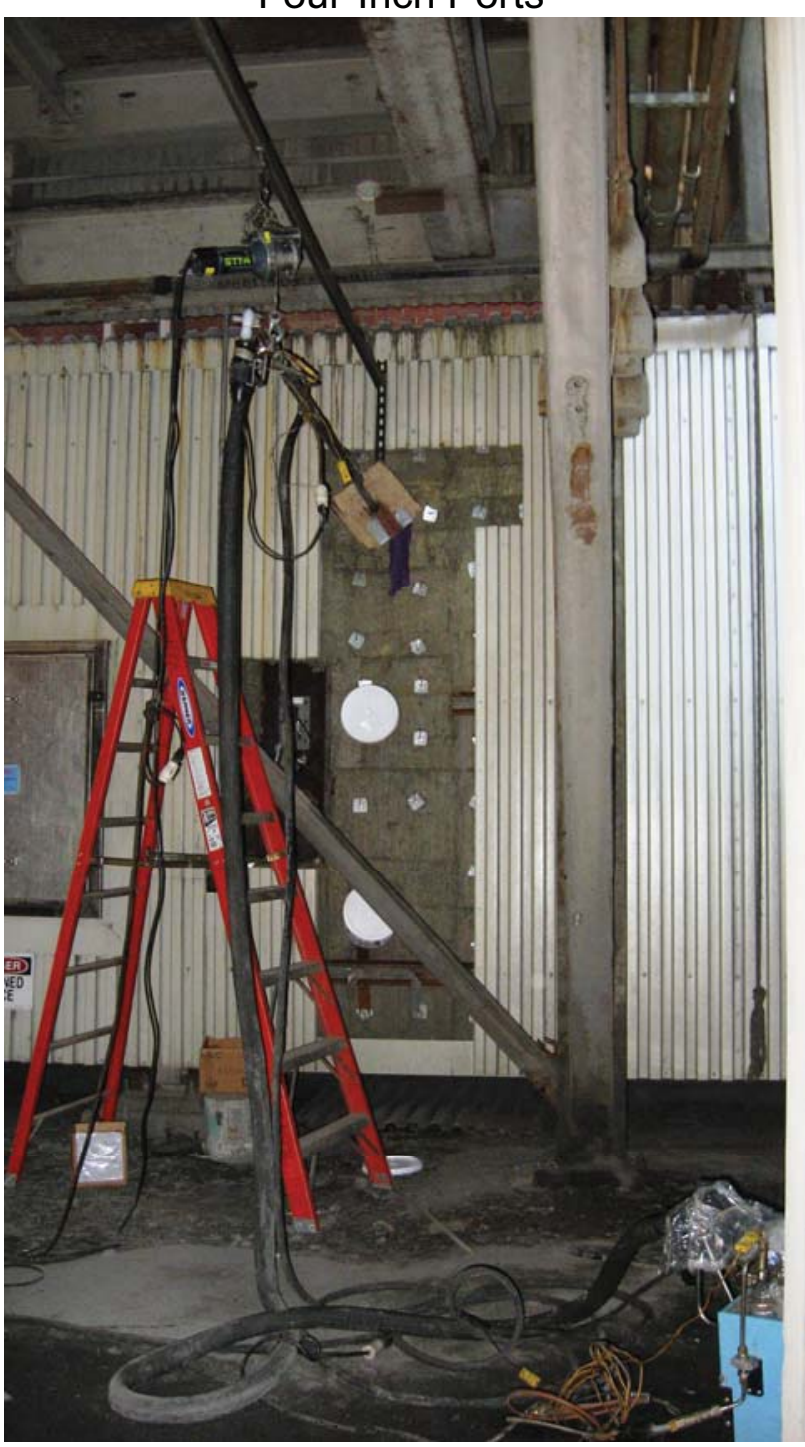




\section{Baghouse Outlet Sampling Location}

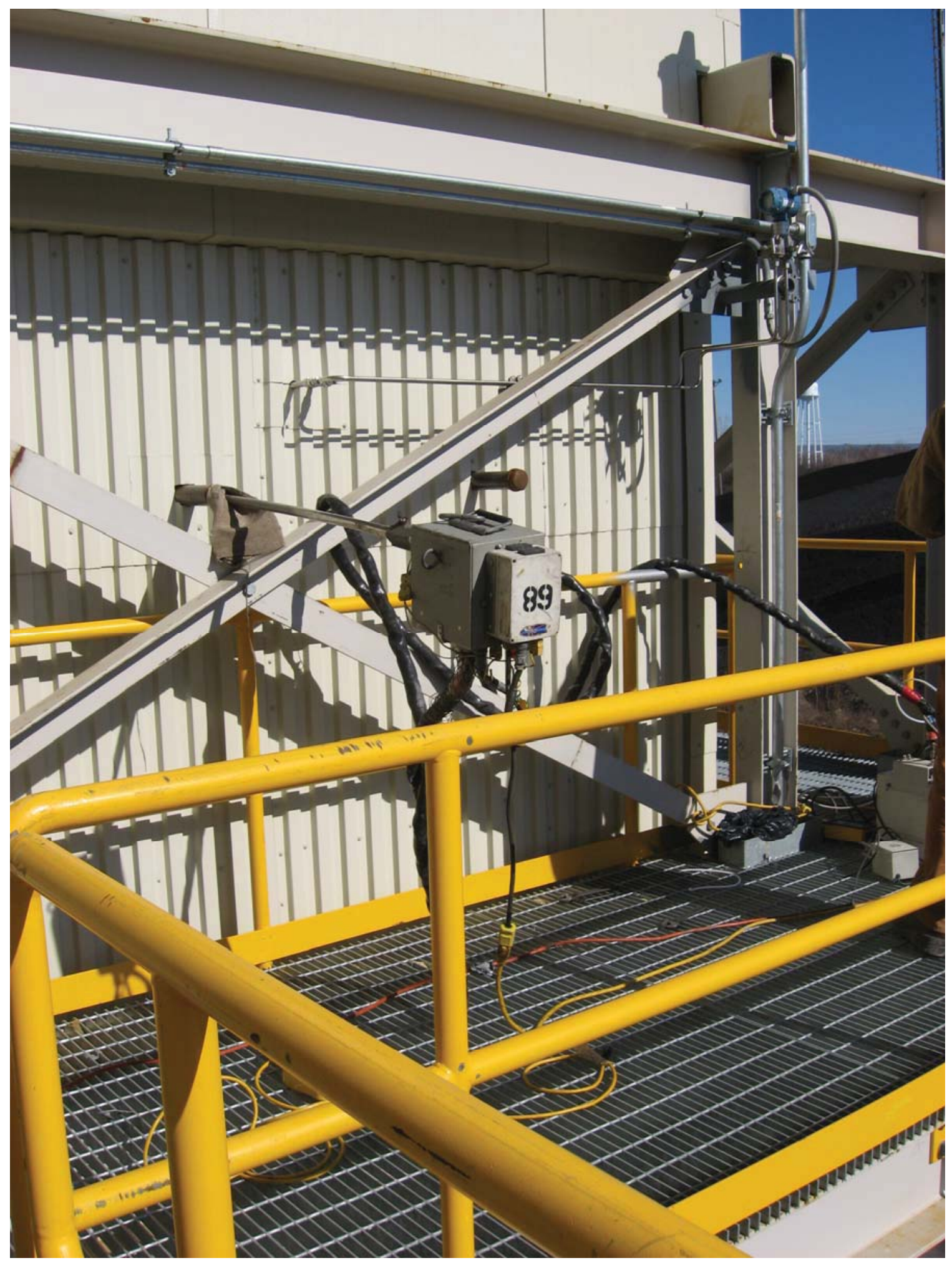




\section{Stack Sampling Location}

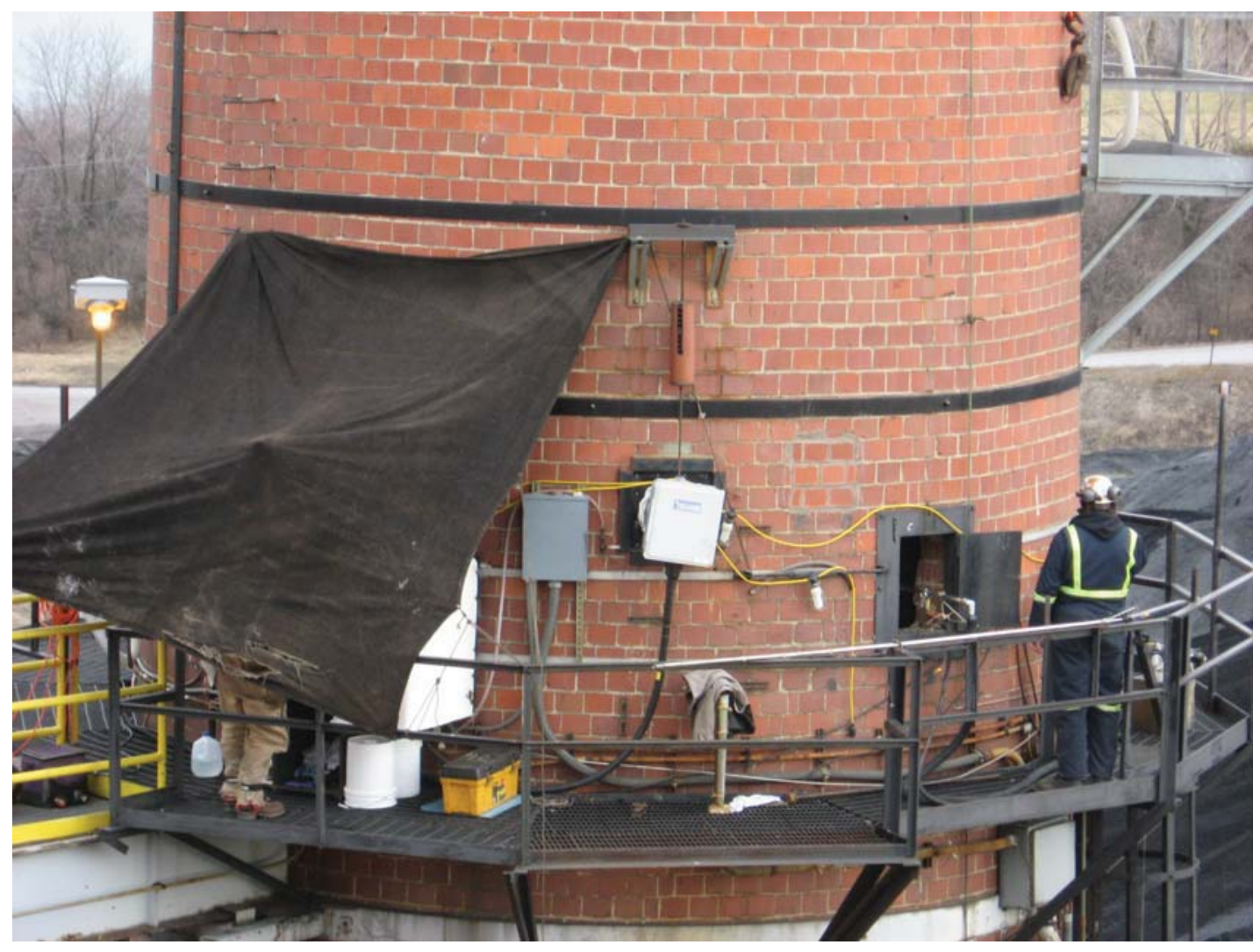




\section{APPENDIX G \\ CLEAN AIR ENGINEERING TESTING REPORTS}




\section{CONTENTS}

Test Dates

March 28-29, 2007

May 30 - June 1, 2007

June 20, 2007

May 21-22, 2008
Report Title

"Report on Performance Testing Performed for CONSOL Energy Inc., Unit 4 SCR Outlet, SCR Inlet, Air Heater Outlet, and Baghouse Outlet at the AES Greenidge Station"

"Report on Pollutant Emission Characterization Performed for CONSOL Energy Inc., Air Heater Inlet and Unit 4 SCR Inlet \& Outlet, AES Greenidge Station, Dresden, New York"

Clean Air Engineering $\mathrm{NO}_{\mathrm{x}}, \mathrm{CO}, \mathrm{O}_{2}$, and $\mathrm{CO}_{2}$ Sampling Results, SCR Inlet and Outlet Sampling Grids, June 20, 2007, 20:00-20:47

"Report on Flue Gas Characterization Performed for CONSOL Energy Inc., Unit 4 SCR Inlet \& SCR Outlet, AES Greenidge Station"
Report Date

July 9, 2007

November 16, 2007

June 20, 2007

(raw data sheets)

September 29, 2008 
Consol Energy Inc. 1800 Washington Road

Pittsburgh, PA 15241

\section{REPORT ON PERFORMANCE TESTING}

\section{Performed for: \\ CONSOL ENERGY INC. \\ UNIT 4 SCR OUTLET, SCR INLET, AIR HEATER OUTLET, AND \\ BAGHOUSE OUTLET AT THE \\ AES GREENIDGE STATION}

Client Reference No: 4700140111

CleanAir Project No: 10192

Revision 0: May 18, 2007

Revision 1: July 9, 2007

To the best of our knowledge, the data presented in this report are accurate, complete, error free, legible and representative of the actual emissions during the test program.

Submitted by,

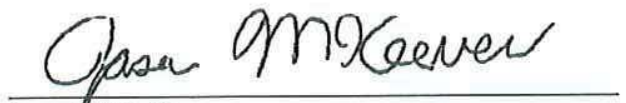

Jasof McKeever

Project Engineer

jmckeever@cleanair.com

(800) 632-1619 ext. 249
Reviewed by,

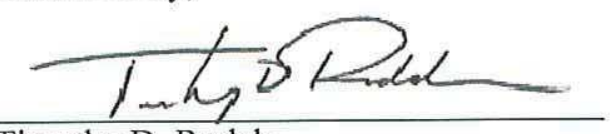

Timothy D. Rodak Leader, Eastern Engineering Group trodak@cleanair.com

(800) 632-1619 ext. 225 


\section{CleanAir}

CONSOL ENERGY INC.

Client Reference No: 4700140111

AES GREENIDGE STATION

CleanAir Project No: 10192

REVISION HISTORY

ii

\section{REPORT ON PERFORMANCE TESTING}

Revision History

\begin{tabular}{|c|c|c|l|}
\hline Revision No: & Date & Pages & Comments \\
\hline 0 & $05 / 18 / 07$ & All & Original version of document. \\
\hline 1 & $7 / 9 / 07$ & All & Comments revision \\
\hline
\end{tabular}

Revision 1 


\section{CleanAir}

CONSOL ENERGY INC.

Client Reference No: 4700140111

AES GREENIDGE STATION

CleanAir Project No: 10192

\section{CONTENTS}

iii

1 PROJECT OVERVIEW

1-1

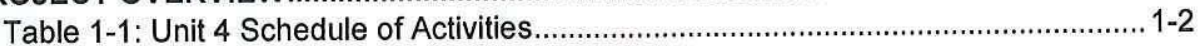

Table 1-2: Summary of Nitrogen Oxides Test Results ........................................... 1-3

Table 1-3: Summary of Nitrogen Oxides Test Result in (Ib/MMBtu) ........................ 1-3

Table 1-4: Summary of Sulfur Dioxide Test Results ............................................. 1-4

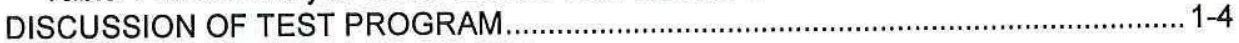

Figure 1-1: MASS ${ }^{\circledR}$ System ............................................................................ 1-5

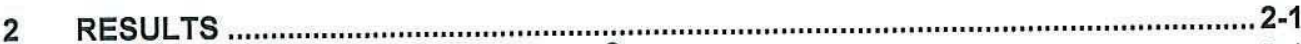

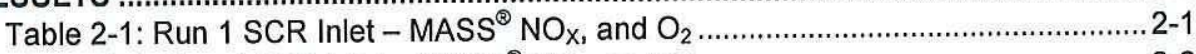

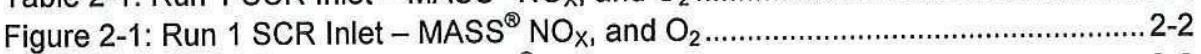

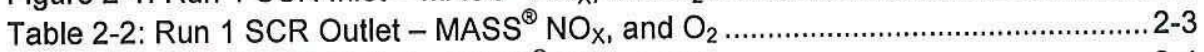

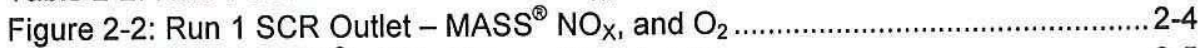

Table 2-3: Run 1 MASS $^{\circledR}-\mathrm{NO}_{x}$ Removal Efficiency ................................................. 2-5

Figure 2-3: Run $1 \mathrm{MASS}^{\circledR}-\mathrm{NO}_{x}$ Removal Efficiency................................................. 2-5

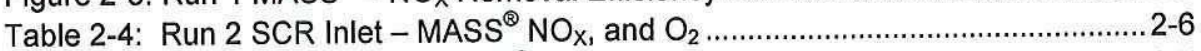

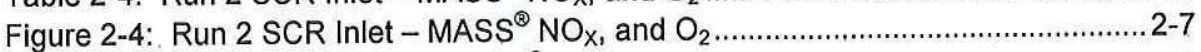

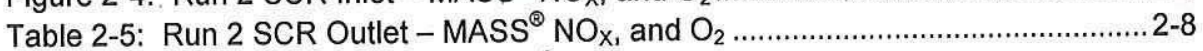

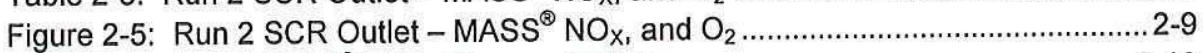

Table 2-6: Run 2 MASS $^{\circledR}$ - NOx Removal Efficiency ................................................ 2-10

Figure 2-6: Run 2: MASS ${ }^{\circledR}$ - NOx Removal Efficiency.............................................. 2-10

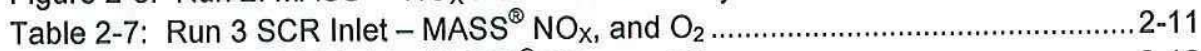

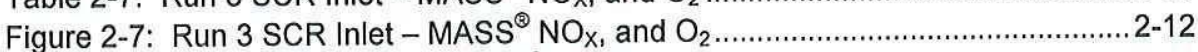

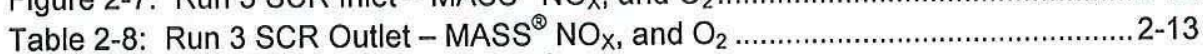

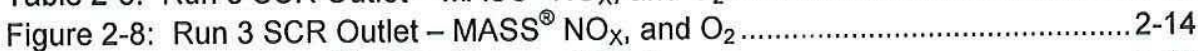

Table 2-9: Run 3 MASS $^{\circledR}-\mathrm{NO}_{x}$ Removal Efficiency ............................................ 2-15

Figure 2-9: Run 3 MASS $^{\circledR}$ - Removal Effiency ................................................... 2-15

Table 2-10: Sulfur Dioxide Reduction Efficiency Results .................................... 2-16

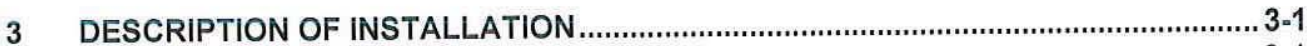

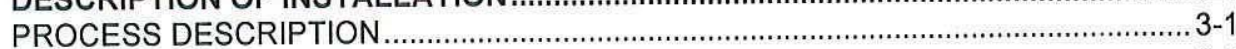

DESCRIPTION OF SAMPLING LOCATION(S) …............................................... 3-1

Table 3-1: Sampling Points ............................................................................... 3-1

Figure 3-1: SCR Inlet - Sampling Point Determination (EPA Method 1).................... 3-2

Figure 3-2: SCR Outlet - Sampling Point Determination (EPA Method 1) ................. 3-3

4

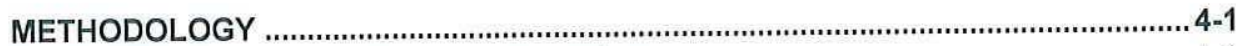

Table 4-1: Summary of Sampling Procedures ………….......................................... 4-1

5 APPENDIX

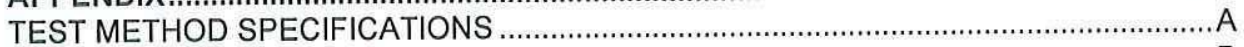

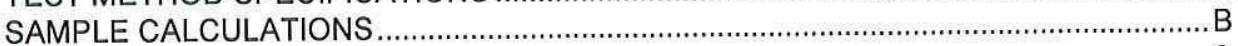

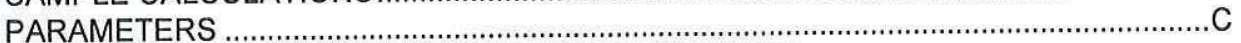

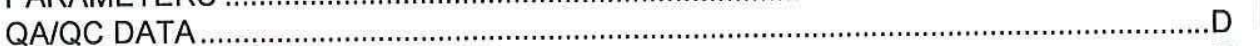

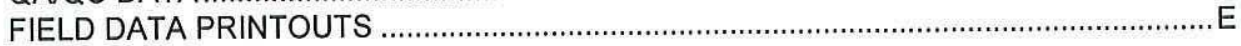

Revision 1 


\section{CleanAir}

CONSOL ENERGY INC. AES GREENIDGE STATION
Client Reference No: 4700140111

CleanAir Project No: 10192

\section{PROJECT OVERVIEW}

Consol Energy Inc. (Consol) contracted Clean Air Engineering (CleanAir) to perform guarantee testing at the AES Greenidge Station in Dresden, NY. The testing was conducted in order to demonstrate a cost effective emission control technology.

All testing was performed in accordance with regulations set forth by the United States Environmental Protection Agency (USEPA).

The test included the following constituents:

$\underline{\text { SCR Inlet and Outlet }}$

- nitrogen oxides $\left(\mathrm{NO}_{\mathrm{x}}\right)$

- flue gas composition $\left(\mathrm{O}_{2}, \mathrm{CO}_{2}\right)$

Air Heater Outlet and Baghouse Outlet

- sulfur dioxide $\left(\mathrm{SO}_{2}\right)$

- flue gas composition $\left(\mathrm{O}_{2}, \mathrm{CO}_{2}\right)$

The testing took place on Greenidge Unit 4 on March 28 and 29, 2007. Coordinating the field testing were:
J. Locke - Consol Energy Inc.
D. Connell - Consol Energy Inc.
S. Lehmann - Clean Air Engineering
J. McKeever - Clean Air Engineering

Table 1-1 outlines the schedule adhered to during the test program. Tables 1-2 and 1-3 summarize the results of the test program. A more detailed presentation of the test conditions and results of analysis are shown on tables 2-1 through 2-10 and Figures 2-1 through 2-9. 


\section{CleanAir}

CONSOL ENERGY INC.

Client Reference No: 4700140111

AES GREENIDGE STATION

CleanAir Project No: 10192

\section{PROJECT OVERVIEW}

$1-2$

Table 1-1:

Unit 4 Schedule of Activities

\begin{tabular}{|c|c|c|c|c|c|c|}
\hline $\begin{array}{c}\text { Run } \\
\text { Number }\end{array}$ & Location & Method & Analyte & Date & $\begin{array}{l}\text { Start } \\
\text { Time }\end{array}$ & $\begin{array}{l}\text { End } \\
\text { Time }\end{array}$ \\
\hline 1 & Unit 4 SCR Inlet/Outlet & USEPA Method 3A, 7E & $\mathrm{O}_{2}, \mathrm{CO}_{2}, \mathrm{NO}_{\mathrm{X}}$ & $03 / 28 / 07$ & 09:12 & $10: 23$ \\
\hline 2 & Unit 4 SCR Inlet/Outlet & USEPA Method $3 A, 7 E$ & $\mathrm{O}_{2}, \mathrm{CO}_{2}, \mathrm{NO}_{\mathrm{X}}$ & $03 / 28 / 07$ & $11: 12$ & $12: 23$ \\
\hline 3 & Unit 4 SCR InlevOutlet & USEPA Method $3 A, 7 E$ & $\mathrm{O}_{2}, \mathrm{CO}_{2}, \mathrm{NO}_{\mathrm{X}}$ & $03 / 28 / 07$ & $12: 48$ & $13: 59$ \\
\hline 1 & Unit 4 AH Outlet/ BH Outlet & USEPA Method $3 \mathrm{~A}, 6 \mathrm{C}$ & $\mathrm{O}_{2}, \mathrm{CO}_{2}, \mathrm{SO}_{2}$ & $03 / 29 / 07$ & $09: 59$ & $11: 00$ \\
\hline 2 & Unit $4 \mathrm{AH}$ Outlet/ $\mathrm{BH}$ Outlet & USEPA Method $3 A, 6 C$ & $\mathrm{O}_{2}, \mathrm{CO}_{2}, \mathrm{SO}_{2}$ & $03 / 29 / 07$ & $12: 16$ & $13: 17$ \\
\hline 3 & Unit 4 AH Outlet/ $\mathrm{BH}$ Outlet & USEPA Method $3 \mathrm{~A}, 6 \mathrm{C}$ & $\mathrm{O}_{2}, \mathrm{CO}_{2}, \mathrm{SO}_{2}$ & $03 / 29 / 07$ & $15: 13$ & $16: 13$ \\
\hline
\end{tabular}

Revision 1 


\section{CleanAir}

CONSOL ENERGY INC.

\section{PROJECT OVERVIEW}

Table 1-2:

Summary of Nitrogen Oxides Test Results

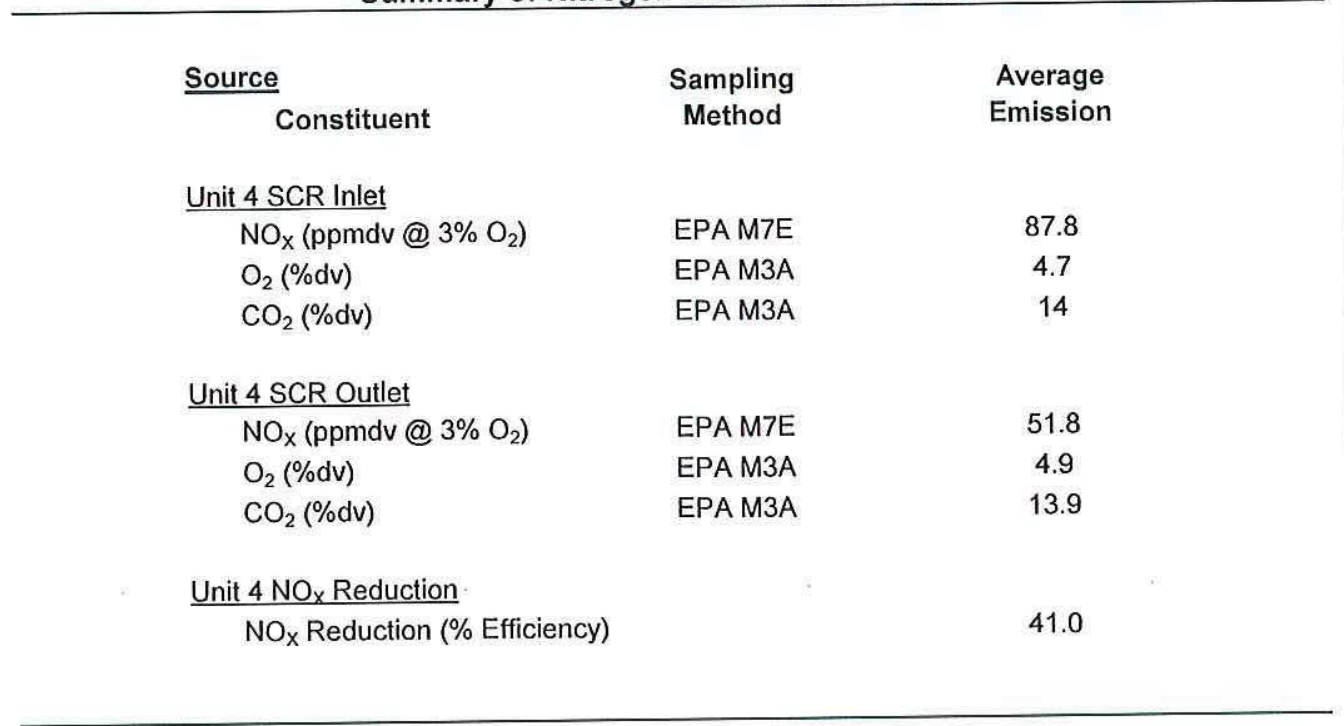

Table 1-3:

Summary of Nitrogen Oxides Test Result in (Ib/MMBtu)

\begin{tabular}{|c|c|c|c|c|}
\hline Source & & & & Average \\
\hline Constituent & Run 1 & Run 2 & Run 3 & \\
\hline Unit 4 SCR Outlet & & & & \\
\hline $\mathrm{NO}_{\mathrm{x}}\left(\mathrm{ppmdv} @ 3 \% \mathrm{O}_{2}\right)$ & 52.7 & 52.7 & 50.1 & 51.8 \\
\hline Fd Factor (dscf/MMBtu) & 9737 & 9618 & 9535 & \\
\hline $\mathrm{NO}_{\mathrm{x}}\left(\mathrm{Ib} / \mathrm{MMBtu} @ 3 \% \mathrm{O}_{2}\right)$ & 0.0711 & 0.0709 & 0.0674 & 0.0698 \\
\hline
\end{tabular}

Note: Fd factor was determined by short prox/ultimate analysis (provided by Consol Energy Inc.)

Revision 1 


\section{PROJECT OVERVIEW}

\begin{tabular}{|c|c|c|}
\hline $\begin{array}{l}\text { Source } \\
\text { Constituent }\end{array}$ & Sampling & $\begin{array}{l}\text { Average } \\
\text { Emission }\end{array}$ \\
\hline \multicolumn{3}{|l|}{ Unit 4 Air Heater Outlet } \\
\hline $\mathrm{SO}_{2}\left(\mathrm{ppmdv} @ 3 \% \mathrm{O}_{2}\right.$ ) & EPA M6C & 1840.8 \\
\hline $\mathrm{O}_{2}(\% \mathrm{dv})$ & EPA M3A & 7.32 \\
\hline $\mathrm{CO}_{2}(\% \mathrm{dv})$ & EPA M3A & 11.56 \\
\hline \multicolumn{3}{|l|}{ Unit 4 Baghouse Outlet } \\
\hline $\mathrm{SO}_{2}\left(\mathrm{ppmdv} @ 3 \% \mathrm{O}_{2}\right)$ & EPA M6C & 108.9 \\
\hline $\mathrm{O}_{2}(\% \mathrm{dv})$ & EPA M3A & 7.30 \\
\hline $\mathrm{CO}_{2}(\% \mathrm{dv})$ & EPA M3A & 11.57 \\
\hline Unit $4 \mathrm{SO}_{2}$ Reduction & & \\
\hline
\end{tabular}

\section{DISCUSSION OF TEST PROGRAM}

Testing on AES Greenidge Unit 4 consisted of several USEPA methods and conformed to Part 60 of the Code of Federal Regulations. The testing at all four locations was conducted using extractive methods. These tests were performed with the units running at full load.

The $\mathrm{SO}_{2}$ testing was based on a modified Method 6C. USEPA Code of Federal Regulations part 60 was followed with the following exceptions. During the sampling a single test point was used during the first two runs, this point was chosen by selecting a point in the center of the duct. For the third $\mathrm{SO}_{2}$ run a single port was traversed using 3 points across the duct.

To collect $\mathrm{NO}_{x}, \mathrm{CO}_{2}$, and $\mathrm{O}_{2}$ emissions data, Clean Air used its Multipoint Automated Sampling Systems (MASS). Using the MASS, Clean Air was able to establish a sampling grid and develop a detailed $\mathrm{NO}_{\mathrm{X}}$, and $\mathrm{O}_{2}$ profile for both the inlet and outlet ducts. This proprietary system allows a large number of sample points to be individually analyzed in a short amount of time giving a more complete view of the gas profile within the duct. Not only are overall concentrations in the duct discovered, but also spatial stratification or temporal variation.

This tool takes much of the wait out of boiler or SCR tuning and optimization by creating an efficient method of data collection. Decision making time is reduced and 


\section{PROJECT OVERVIEW}

enhanced with expedient, accurate, and reliable data. The expanded data capacity allows for increased analytical ability and a better "big picture" of unit operation.

\section{Description of the MASS ${ }^{\circledR}$}

The Clean Air Engineering's MASS ${ }^{\circledR}$ (Multi-Point Automated Sampling System) uses a series of automated 8-point sample modules with integrated programmable logic controllers (PLC's) to sequentially and rapidly cycle through a multi-point test grid. For this program, a 24-point permanent outlet grid was tested using an 8 module system. Using a bank of two (2) $\mathrm{O}_{2} / \mathrm{CO}_{2}$ monitors and (2) $\mathrm{NO}_{\mathrm{X}}$ monitors, the 24-point traverse was completed in 24 minutes. This is a considerable time savings over the typical 2 hour manual traverse.

The MASS ${ }^{\circledR}$ has been programmed to automatically cycle through and analyze each point on the grid. The key is the dynamic switching which allows for a vented "prepurge" prior the actual analysis allowing for zero wasted analyzer time. This modular and expandable system is capable of analyzing 128 individual sample points in 32 minutes or less. A diagram of the system can be seen in Figure 1-1 below. This shows a general arrangement process flow diagram for a "typical" 64-point MASS ${ }^{\circledR}$ system arrangement.

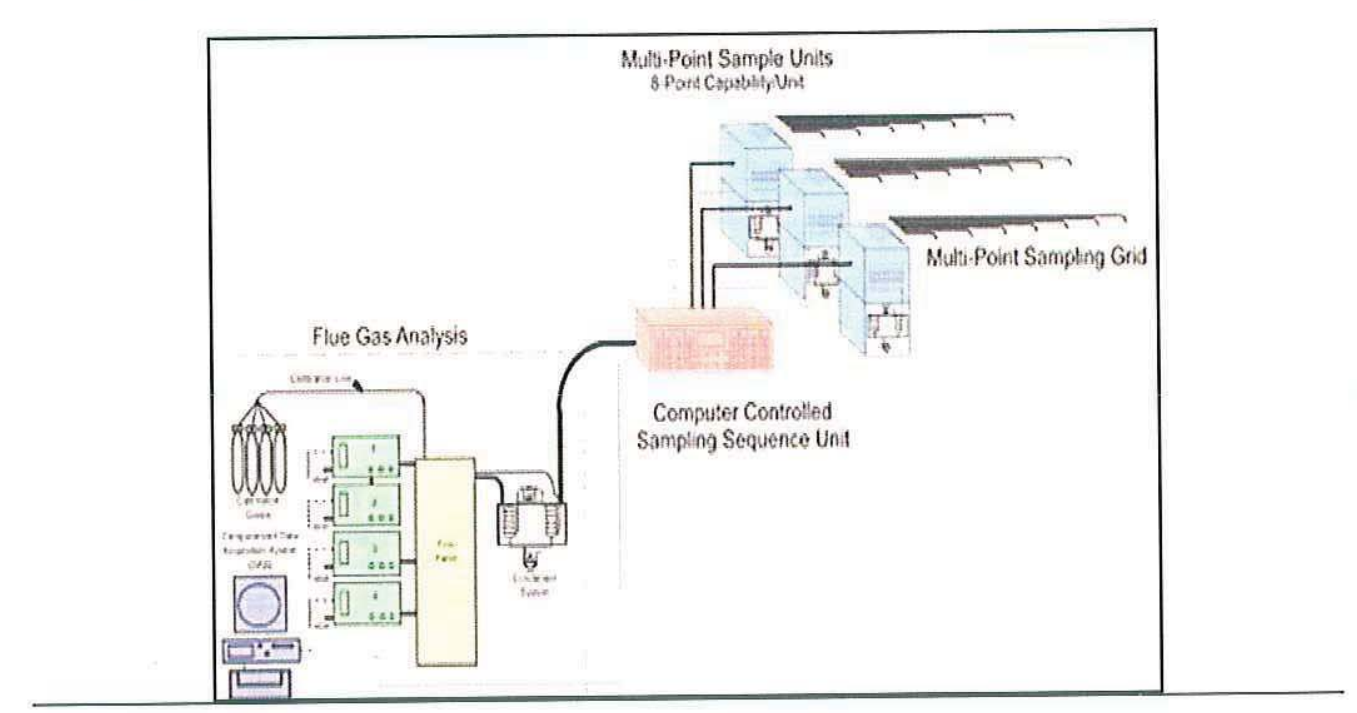

Figure 1-1: MASS ${ }^{\circledR}$ System

Revision 1 


\section{CleanAir}

CONSOL ENERGY INC.

Client Reference No: 4700140111

AES GREENIDGE STATION

CleanAir Project No: 10192

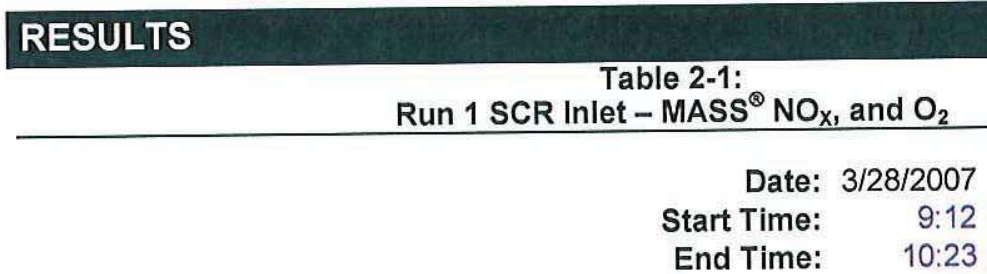

2-1

\begin{tabular}{|c|c|c|c|c|c|}
\hline \multicolumn{6}{|c|}{ Inlet - Nitrogen Oxides (ppmdv @ $3 \% \mathrm{O}_{2}$ ) } \\
\hline AVG & 98.0 & 91.4 & 93.7 & 87.1 & \\
\hline 6 & 108.9 & 107.0 & 107.7 & 87.7 & 102.8 \\
\hline 5 & 80.4 & 72.8 & 77.5 & 69.5 & 75.1 \\
\hline 4 & 89.0 & 82.4 & 84.7 & 82.2 & 84.6 \\
\hline 3 & 100.5 & 100.5 & 104.2 & 97.8 & 100.8 \\
\hline 2 & 105.5 & 85.9 & 86.9 & 87.4 & 91.5 \\
\hline 1 & 103.8 & 99.7 & 101.4 & 98.2 & 100.8 \\
\hline & 1 & 2 & 3 & 4 & 92.6 \\
\hline
\end{tabular}

\begin{tabular}{|c|c|c|c|c|}
\hline \multicolumn{5}{|c|}{ Inlet - Oxygen (\%dv) } \\
\hline AVG & 5.5 & 4.9 & 4.1 & 4.4 \\
\hline 6 & 8.6 & 6.8 & 6.3 & 6.6 \\
\hline 5 & 4.8 & 4.5 & 4.5 & 4.5 \\
\hline 4 & 4.4 & 3.9 & 3.7 & 3.7 \\
\hline 3 & 5.0 & 5.3 & 3.3 & 3.2 \\
\hline 2 & 2.9 & 3.0 & 2.9 & 2.5 \\
\hline 1 & 7.5 & 6.0 & 4.0 & 5.7 \\
\hline & 1 & 2 & 3 & 4 \\
\hline
\end{tabular}

Revision 1 


\section{CleanAir}

CONSOL ENERGY INC.

AES GREENIDGE STATION

Client Reference No: 4700140111

CleanAir Project No: 10192

\section{RESULTS}

Figure 2-1:

Run 1 SCR Inlet - MASS ${ }^{\circledR} \mathrm{NO}_{\mathrm{X}}$, and $\mathrm{O}_{2}$

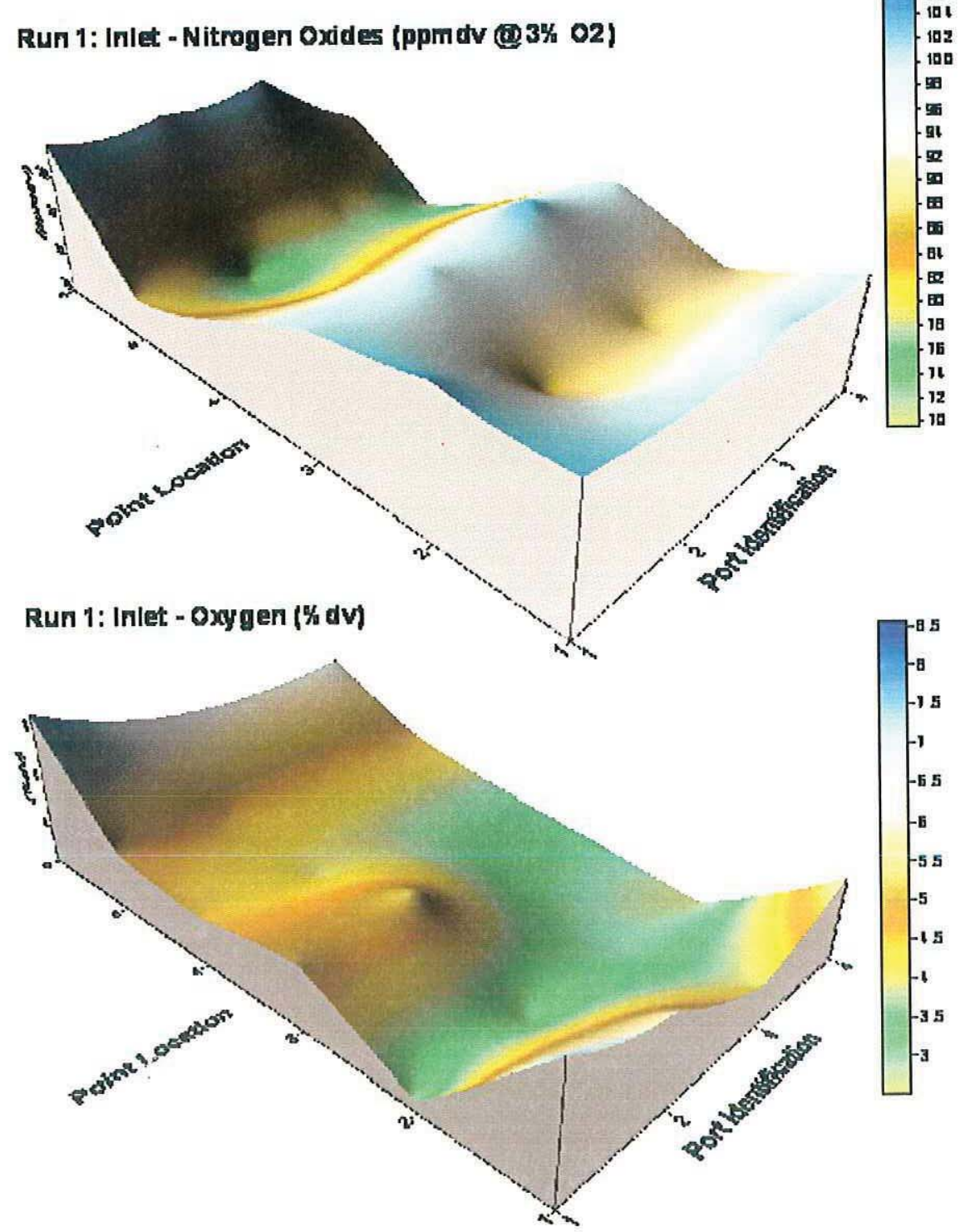

Revision 1 


\section{CleanAir}

CONSOL ENERGY INC.

Client Reference No: 4700140111

AES GREENIDGE STATION

CleanAir Project No: 10192

\section{RESULTS}

$2-3$

Table 2-2:

Run 1 SCR Outlet - MASS ${ }^{\circledast} \mathrm{NO}_{\mathrm{X}}$, and $\mathrm{O}_{2}$

Date: $3 / 28 / 2007$

Start Time: $\quad 9: 12$

End Time: $\quad 10: 23$

Outlet - Nitrogen Oxides (ppmdv @ 3\% O

\begin{tabular}{|c|c|c|c|c|}
\multicolumn{1}{c}{ AVG } & 69.9 & 58.2 & 52.0 & 30.9 \\
\hline $\mathbf{6}$ & 55.9 & 59.0 & 28.1 & 6.2 \\
\hline $\mathbf{5}$ & 61.7 & 27.3 & 32.8 & 4.8 \\
\hline $\mathbf{4}$ & 68.8 & 85.8 & 67.2 & 39.4 \\
\hline $\mathbf{3}$ & 65.2 & 77.2 & 85.0 & 75.3 \\
\hline $\mathbf{2}$ & 91.8 & 62.3 & 73.4 & 51.8 \\
\hline $\mathbf{1}$ & 75.9 & 37.4 & 25.4 & 7.8 \\
\hline & $\mathbf{1}$ & $\mathbf{2}$ & $\mathbf{3}$ & $\mathbf{4}$ \\
\hline
\end{tabular}

Outlet - Oxygen (\%dv)

\begin{tabular}{|c|c|c|c|c|c|}
\hline AVG & 5.7 & 5.3 & 4.5 & 4.0 & \\
\hline 6 & 7.7 & 6.7 & 5.5 & 5.6 & 6.4 \\
\hline 5 & 6.3 & 4.9 & 4.3 & 4.0 & 4.9 \\
\hline 4 & 4.7 & 5.9 & 4.9 & 4.5 & 5.0 \\
\hline 3 & 5.3 & 4.7 & 4.4 & 3.5 & 4.5 \\
\hline 2 & 5.6 & 4.6 & 4.3 & 2.7 & 4.3 \\
\hline 1 & 4.9 & 5.0 & 3.7 & 3.5 & 4.3 \\
\hline & 1 & 2 & 3 & 4 & 4.9 \\
\hline
\end{tabular}

Revision 1 


\section{CleanAir}

CONSOL ENERGY INC.

Client Reference No: 4700140111

AES GREENIDGE STATION

CleanAir Project No: 10192

\section{RESULTS}

$2-4$

Figure 2-2:

Run 1 SCR Outlet - MASS ${ }^{\circledR} \mathrm{NO}_{\mathrm{X}}$, and $\mathrm{O}_{2}$

Run 1: Outlet - Nitrogen Oxides (ppmedv (0) 3\% 02)
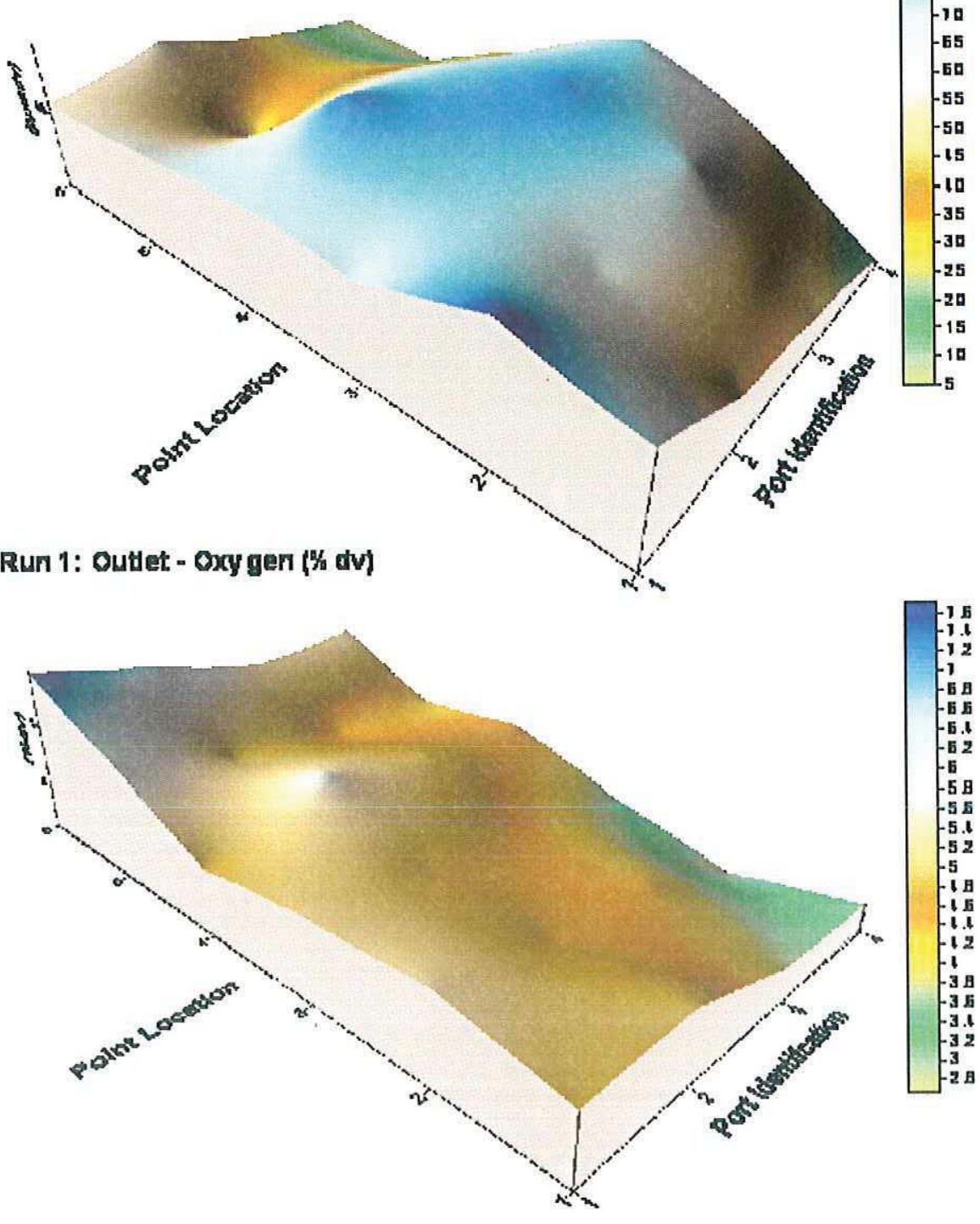

Revision 1 


\section{CleanAir}

CONSOL ENERGY INC.

AES GREENIDGE STATION
Client Reference No: 4700140111

CleanAir Project No: 10192

\section{RESULTS}

$2-5$

Table 2-3:

Run $1 \mathrm{MASS}^{\circledR}$ - $\mathrm{NO}_{\mathrm{X}}$ Removal Efficiency

Date: $3 / 28 / 2007$

Start Time: $\quad 9: 12$

End Time: $\quad 10: 23$

\begin{tabular}{|c|c|c|c|c|}
\hline \multicolumn{5}{|c|}{ Removal Efficiency (@ 3\% $\mathrm{O}_{2}$ ) } \\
\hline AVG & $28.3 \%$ & $36.1 \%$ & $43.6 \%$ & $65.6 \%$ \\
\hline 6 & $48.7 \%$ & $44.8 \%$ & $73.9 \%$ & $92.9 \%$ \\
\hline 5 & $23.3 \%$ & $62.5 \%$ & $57.7 \%$ & $93.1 \%$ \\
\hline 4 & $22.8 \%$ & $-4.1 \%$ & $20.7 \%$ & $52.0 \%$ \\
\hline 3 & $35.1 \%$ & $23.2 \%$ & $18.4 \%$ & $23.0 \%$ \\
\hline 2 & $13.0 \%$ & $27.5 \%$ & $15.6 \%$ & $40.8 \%$ \\
\hline 1 & $26.8 \%$ & $62.5 \%$ & $75.0 \%$ & $92.1 \%$ \\
\hline & 1 & 2 & 3 & 4 \\
\hline
\end{tabular}

$65.1 \%$

$59.1 \%$

$22.8 \%$

$24.9 \%$

$24.2 \%$

$64.1 \%$

$43.4 \%$

Run 1: NOx Removal Efficieney (Co 3\% O2)

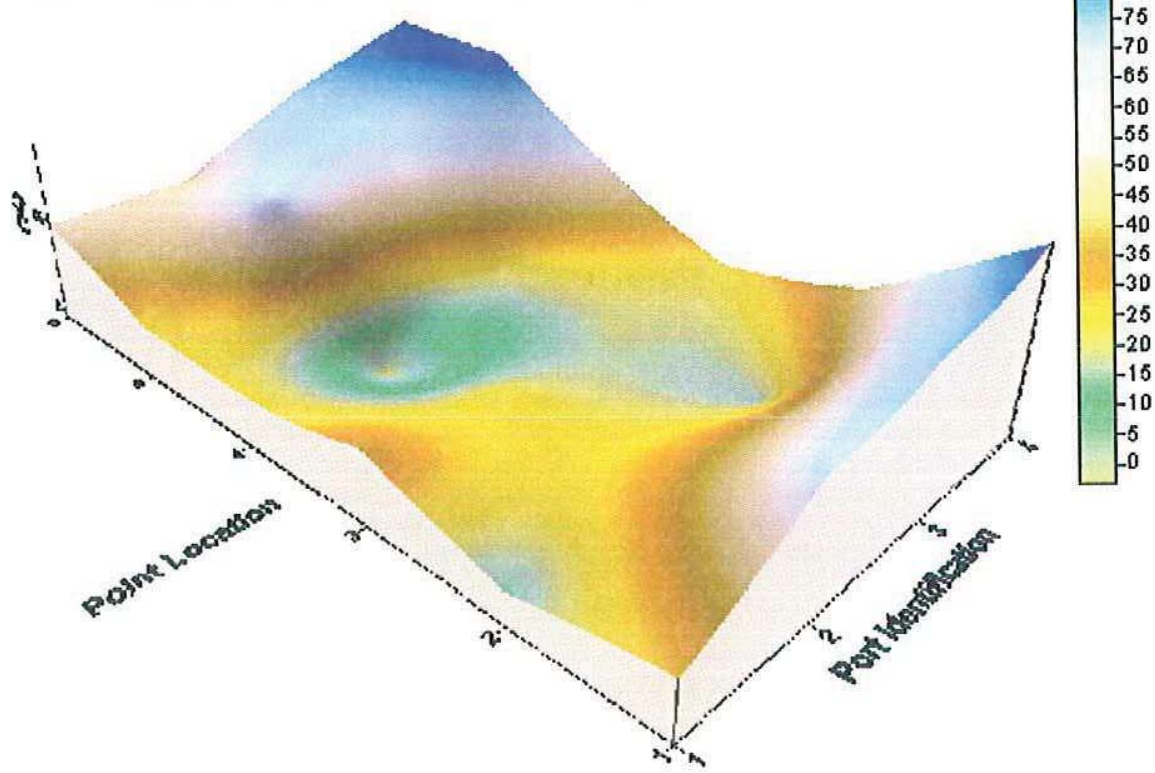

Figure 2-3:

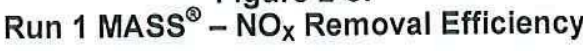

Revision 1 


\section{CleanAir}

CONSOL ENERGY INC. AES GREENIDGE STATION
Client Reference No: 4700140111

CleanAir Project No: 10192

\section{RESULTS \\ Table 2-4: \\ Run 2 SCR Inlet - MASS ${ }^{\circledR} \mathrm{NO}_{\mathrm{X}}$, and $\mathrm{O}_{2}$}

Date: $3 / 28 / 2007$

Start Time: $\quad 11: 12$

End Time: $12: 23$

Inlet - Nitrogen Oxides (ppmdv @ 3\% $\mathrm{O}_{2}$ )

\begin{tabular}{|c|c|c|c|c|}
\multicolumn{1}{c|}{ AVG } & 93.4 & 84.7 & 86.7 & 80.3 \\
\hline $\mathbf{6}$ & 102.6 & 96.6 & 98.2 & 77.2 \\
\hline $\mathbf{5}$ & 73.5 & 63.0 & 69.9 & 61.7 \\
\hline $\mathbf{4}$ & 86.3 & 77.6 & 80.4 & 77.5 \\
\hline $\mathbf{3}$ & 96.1 & 95.6 & 99.5 & 94.5 \\
\hline $\mathbf{2}$ & 99.6 & 80.1 & 78.6 & 78.3 \\
\hline $\mathbf{1}$ & 102.3 & 95.4 & 93.6 & 92.8 \\
\hline & $\mathbf{1}$ & $\mathbf{2}$ & $\mathbf{3}$ & $\mathbf{4}$ \\
\hline
\end{tabular}

Inlet - Oxygen (\%dv)

\begin{tabular}{|c|c|c|c|c|}
\multicolumn{1}{c|}{ AVG } & 5.5 & 4.9 & 4.1 & 4.4 \\
\hline 6 & 8.6 & 6.8 & 6.3 & 6.4 \\
\hline 5 & 4.6 & 4.3 & 4.4 & 4.3 \\
\hline 4 & 4.3 & 3.8 & 3.6 & 3.5 \\
\hline 3 & 5.0 & 5.4 & 3.3 & 3.1 \\
\hline 2 & 3.1 & 3.2 & 3.0 & 2.7 \\
\hline 1 & 7.6 & 6.1 & 4.2 & 6.3 \\
\hline & 1 & 2 & 3 & 4 \\
\hline
\end{tabular}




\section{CleanAir}

CONSOL ENERGY INC.

AES GREENIDGE STATION

Client Reference No: 4700140111

CleanAir Project No: 10192

\section{RESULTS}

$2-7$

Figure 2-4:

Run 2 SCR Inlet - MASS ${ }^{\circledR} \mathrm{NO}_{\mathrm{x}}$, and $\mathrm{O}_{2}$

Run 2: Inlet - Nitrogen Oxides (ppm dv (1) 3\% 02)

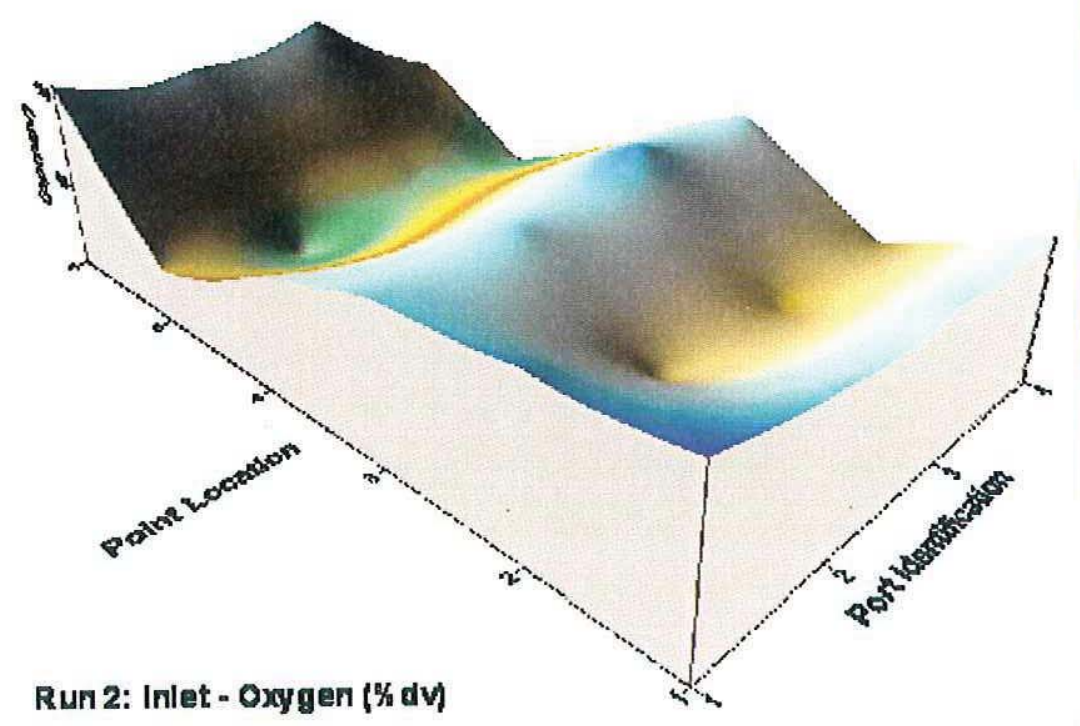

Rur 2: Inlet - Oxygen (\% dV)

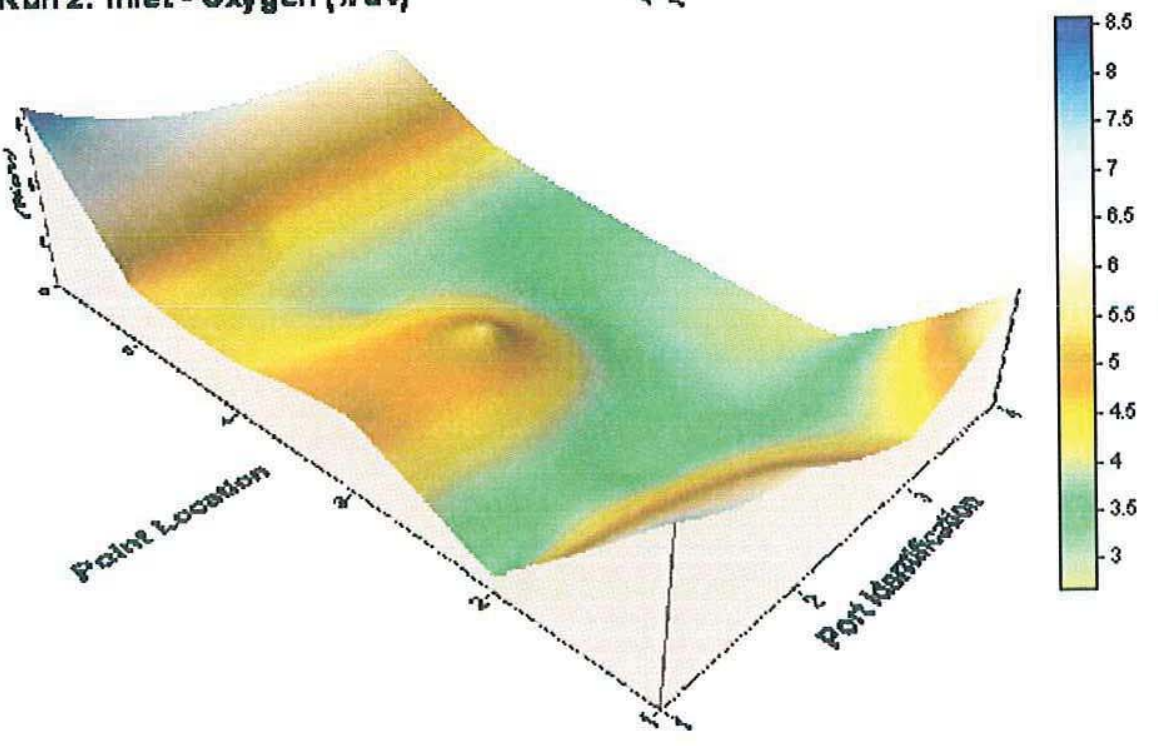

Revision 1 


\section{CleanAir}

CONSOL ENERGY INC.

Client Reference No: 4700140111

AES GREENIDGE STATION

CleanAir Project No: 10192

\section{RESULTS}

$2-8$

Table 2-5:

Run 2 SCR Outlet - MASS ${ }^{\circledR} \mathrm{NO}_{\mathrm{X}}$, and $\mathrm{O}_{2}$

Date: $3 / 28 / 2007$

Start Time: $\quad 11: 12$

End Time: $12: 23$

\begin{tabular}{|c|c|c|c|c|c|}
\hline \multicolumn{6}{|c|}{ Outlet - Nitrogen Oxides (ppmdv @ 3\% O } \\
\hline AVG & 73.0 & 56.2 & 51.4 & 30.0 & \\
\hline 6 & 67.3 & 52.8 & 24.9 & 5.1 & 37.5 \\
\hline 5 & 60.4 & 24.7 & 31.7 & 4.2 & 30.3 \\
\hline 4 & 74.0 & 87.3 & 69.9 & 42.5 & 68.4 \\
\hline 3 & 66.5 & 78.9 & 86.2 & 76.5 & 77.0 \\
\hline 2 & 92.1 & 58.5 & 72.6 & 45.1 & 67.1 \\
\hline 1 & 78.0 & 35.3 & 23.2 & 6.8 & 35.8 \\
\hline & 1 & 2 & 3 & 4 & 52.7 \\
\hline
\end{tabular}

Outlet - Oxygen (\%dv)

\begin{tabular}{|c|c|c|c|c|c|}
\hline AVG & 5.7 & 5.3 & 4.5 & 3.9 & \\
\hline 6 & 8.0 & 6.7 & 5.7 & 5.4 & 6.5 \\
\hline 5 & 6.1 & 4.8 & 4.2 & 3.9 & 4.7 \\
\hline 4 & 4.4 & 5.8 & 4.8 & 4.4 & 4.8 \\
\hline 3 & 5.2 & 4.8 & 4.3 & 3.3 & 4.4 \\
\hline 2 & 5.7 & 4.6 & 4.3 & 2.7 & 4.3 \\
\hline 1 & 4.8 & 5.0 & 3.8 & 3.8 & 4.3 \\
\hline & 1 & 2 & 3 & 4 & 4.9 \\
\hline
\end{tabular}

Revision 1 


\section{CleanAir}

CONSOL ENERGY INC.

AES GREENIDGE STATION
Client Reference No: 4700140111

CleanAir Project No: 10192
RESULTS
$2-9$

Figure 2-5:

Run 2 SCR Outlet - MASS ${ }^{\circledR} \mathrm{NO}_{\mathrm{X}}$, and $\mathrm{O}_{2}$

Run 2: Outlet - Nitrogen Oxides (ppm dv (3)3\% 02)

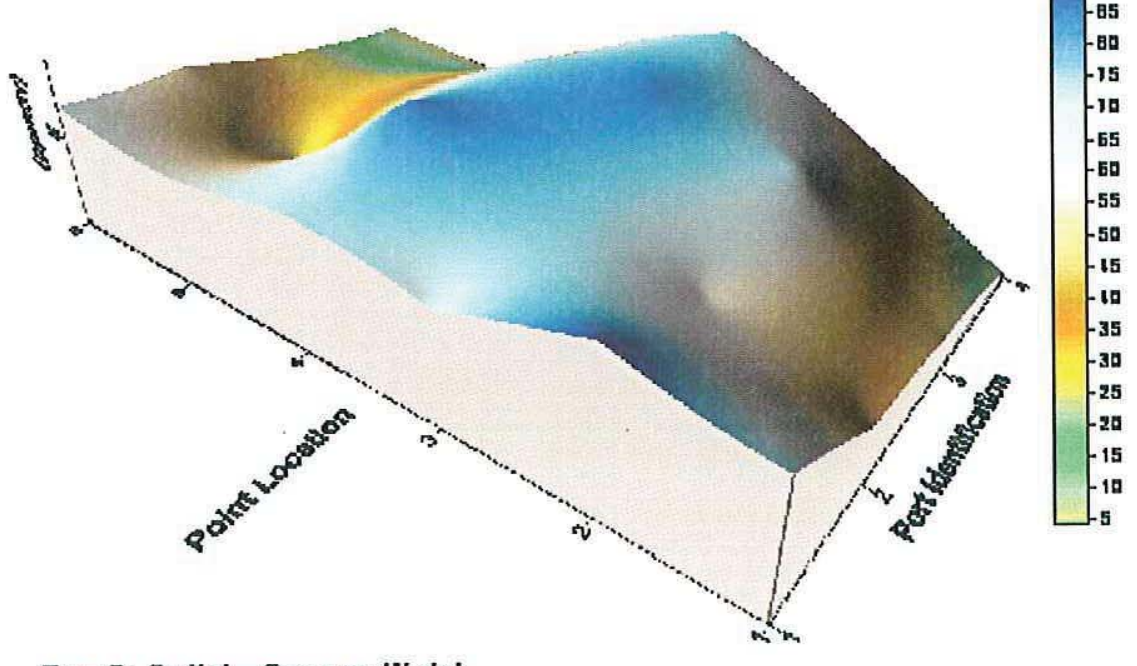

Rur 2: Outter - Oxygen (\% dv)

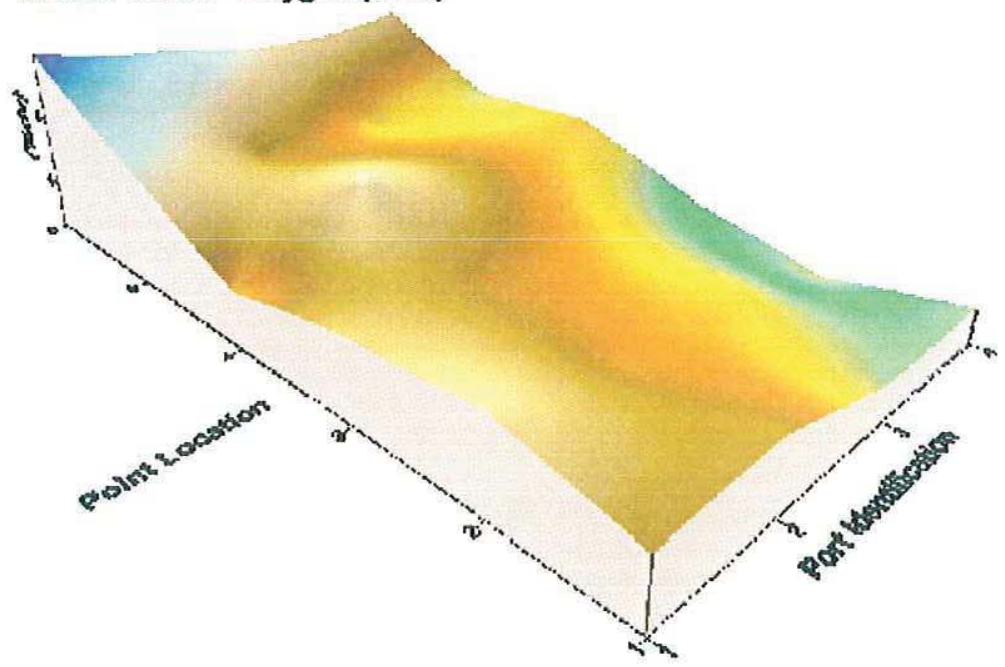




\section{CleanAir}

CONSOL ENERGY INC.

Client Reference No: 4700140111

AES GREENIDGE STATION

CleanAir Project No: 10192

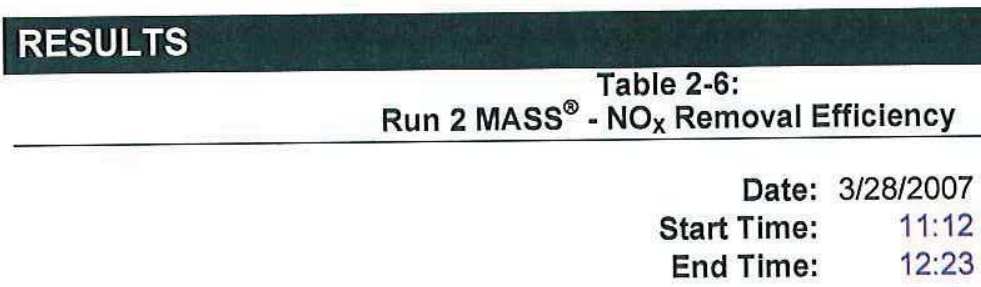

Removal Efficiency (ppmdv @ 3\% $\mathrm{O}_{2}$ )

\begin{tabular}{|c|c|c|c|c|}
\multicolumn{1}{c|}{ AVG } & $21.4 \%$ & $33.5 \%$ & $39.8 \%$ & $64.3 \%$ \\
\hline $\mathbf{6}$ & $34.5 \%$ & $45.3 \%$ & $74.6 \%$ & $93.4 \%$ \\
\hline $\mathbf{5}$ & $17.8 \%$ & $60.9 \%$ & $54.7 \%$ & $93.1 \%$ \\
\hline $\mathbf{4}$ & $14.2 \%$ & $-12.5 \%$ & $13.1 \%$ & $45.1 \%$ \\
\hline $\mathbf{3}$ & $30.8 \%$ & $17.5 \%$ & $13.4 \%$ & $19.0 \%$ \\
\hline $\mathbf{2}$ & $7.5 \%$ & $27.0 \%$ & $7.6 \%$ & $42.4 \%$ \\
\hline $\mathbf{1}$ & $23.8 \%$ & $63.0 \%$ & $75.3 \%$ & $92.7 \%$ \\
\hline & $\mathbf{1}$ & $\mathbf{2}$ & $\mathbf{3}$ & $\mathbf{4}$ \\
\hline
\end{tabular}

Run 2: NOx Removal Effieiency (@ 3\% 02)

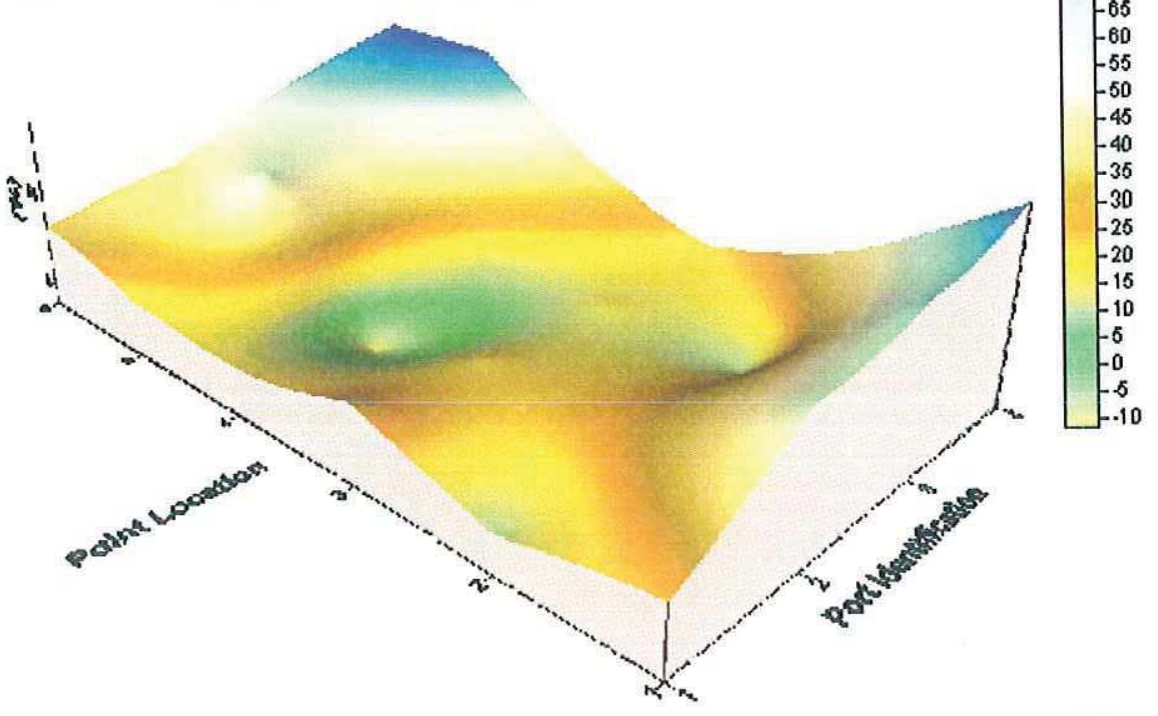

Figure 2-6:

Run 2: MASS ${ }^{\circledR}$ - NOx Removal Efficiency

Revision 1 


\section{CleanAir}

CONSOL ENERGY INC.

Client Reference No: 4700140111

AES GREENIDGE STATION

CleanAir Project No: 10192

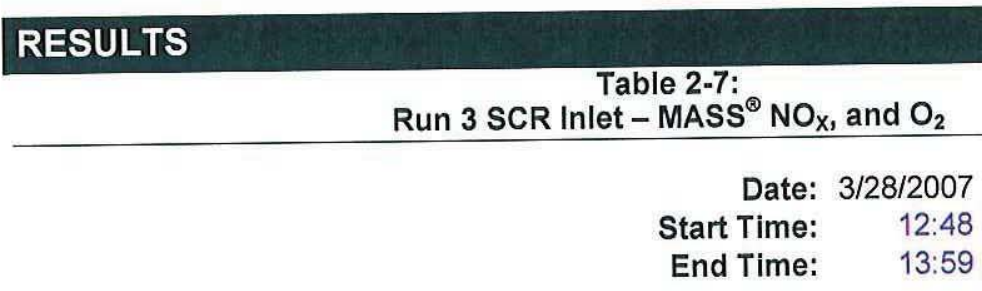

\begin{tabular}{|c|c|c|c|c|c|}
\hline \multicolumn{6}{|c|}{ Inlet - Nitrogen Oxides (ppmdv @ 3\% $\mathrm{O}_{2}$ ) } \\
\hline AVG & 91.1 & 83.7 & 85.0 & 78.5 & \\
\hline 6 & 100.5 & 97.8 & 96.0 & 74.8 & 92.3 \\
\hline 5 & 68.8 & 59.5 & 66.6 & 58.8 & 63.4 \\
\hline 4 & 81.5 & 74.1 & 78.7 & 75.4 & 77.4 \\
\hline 3 & 94.1 & 96.1 & 98.3 & 94.4 & 95.7 \\
\hline 2 & 101.6 & 77.9 & 76.4 & 76.5 & 83.1 \\
\hline 1 & 100.1 & 96.5 & 93.8 & 91.1 & 95.4 \\
\hline & 1 & 2 & 3 & 4 & 84.6 \\
\hline
\end{tabular}

Inlet - Oxygen (\%dv)
\begin{tabular}{|c|c|c|c|c|}
\hline AVG & 5.6 & 4.9 & 4.1 & 4.3 \\
\hline 6 & 8.6 & 6.9 & 6.3 & 6.3 \\
\hline 5 & 4.5 & 4.2 & 4.3 & 4.1 \\
\hline 4 & 4.3 & 3.6 & 3.5 & 3.4 \\
\hline 3 & 5.0 & 5.2 & 3.3 & 3.1 \\
\hline 2 & 3.2 & 3.3 & 3.2 & 2.8 \\
\hline 1 & 7.8 & 6.2 & 4.3 & 6.1 \\
\hline & 1 & 2 & 3 & 4 \\
\hline
\end{tabular}

7.0
4.2
3.7
4.2
3.1
6.1
4.7

Revision 1 


\section{CleanAir}

CONSOL ENERGY INC. AES GREENIDGE STATION
Client Reference No: 4700140111

CleanAir Project No: 10192

\section{RESULTS}

Figure 2-7:

Run 3 SCR Inlet - MASS ${ }^{\circledR} \mathrm{NO}_{\mathrm{X}}$, and $\mathrm{O}_{2}$

Run 3: Inlet - Nitrogen Oxdes (ppm dv (1)3\% 02)

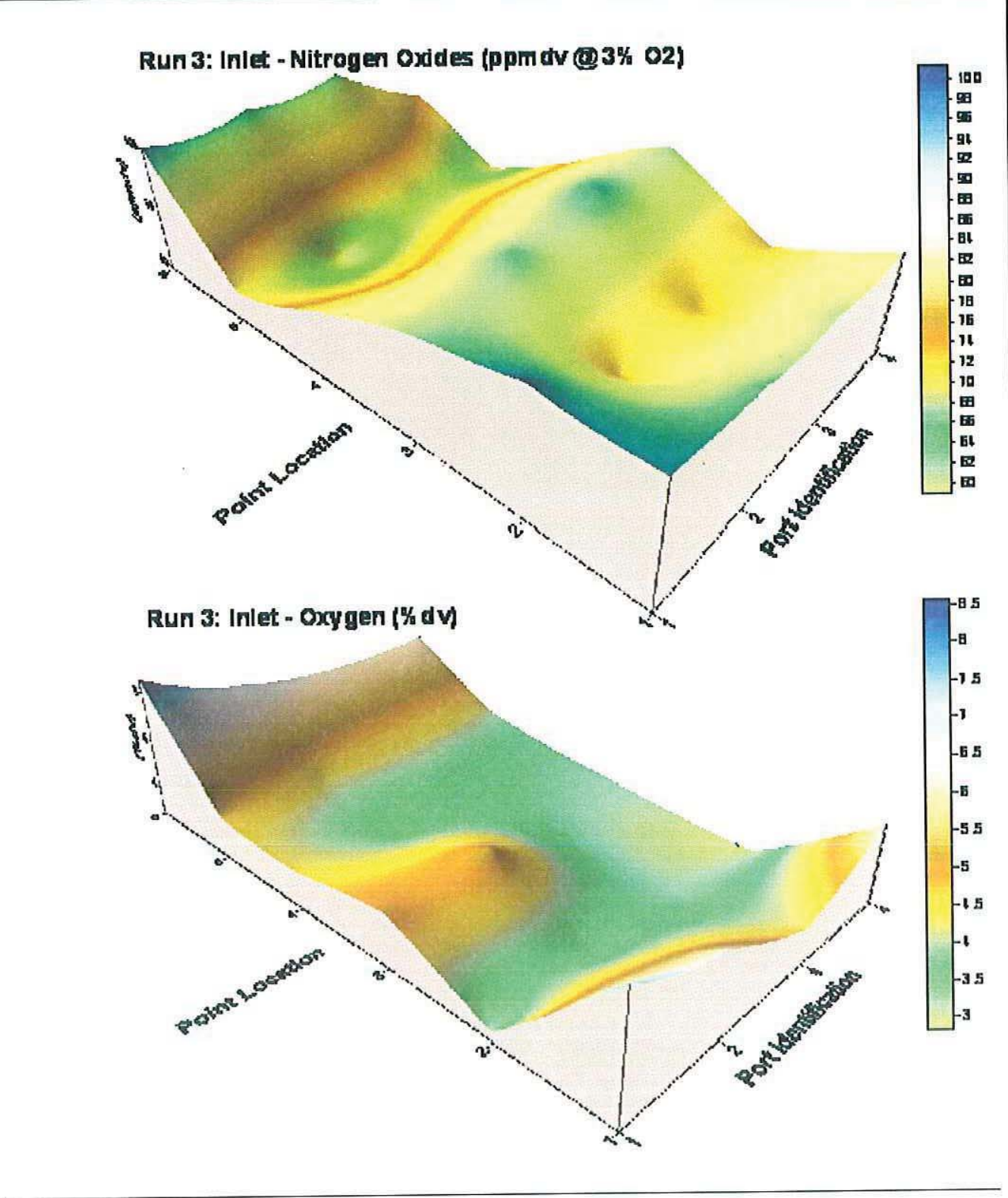

Revision 1 


\section{CleanAir}

CONSOL ENERGY INC.

Client Reference No: 4700140111

AES GREENIDGE STATION

CleanAir Project No: 10192

\section{RESULTS}

Table 2-8:

Run 3 SCR Outlet - MASS ${ }^{\circledR} \mathrm{NO}_{\mathrm{X}}$, and $\mathrm{O}_{2}$

Date: $3 / 28 / 2007$

Start Time: $\quad 12: 48$

End Time: $\quad 13: 59$

\begin{tabular}{|c|c|c|c|c|c|}
\hline \multicolumn{6}{|c|}{ Outlet - Nitrogen Oxides (ppmdv @ 3\% O } \\
\hline AVG & 68.3 & 53.1 & 48.6 & 30.2 & \\
\hline 6 & 68.5 & 48.2 & 24.6 & 4.8 & 36.5 \\
\hline 5 & 60.3 & 34.8 & 42.3 & 3.7 & 35.3 \\
\hline 4 & 70.3 & 80.4 & 69.1 & 42.0 & 65.5 \\
\hline 3 & 60.8 & 71.3 & 79.6 & 78.5 & 72.6 \\
\hline 2 & 78.7 & 51.5 & 57.1 & 45.7 & 58.3 \\
\hline 1 & 71.3 & 32.5 & 18.9 & 6.4 & 32.3 \\
\hline & 1 & 2 & 3 & 4 & 50.1 \\
\hline
\end{tabular}

AVG
\begin{tabular}{|c|c|c|c|c|}
\hline AVtlet - Oxygen (\%dv) \\
\hline $\mathbf{6}$ & 5.9 & 5.3 & 4.5 & 3.9 \\
\hline $\mathbf{5}$ & 5.9 & 6.6 & 5.4 & 5.3 \\
\hline $\mathbf{4}$ & 4.9 & 5.0 & 4.4 & 3.7 \\
\hline $\mathbf{3}$ & 5.4 & 5.7 & 4.7 & 4.3 \\
\hline $\mathbf{2}$ & 5.4 & 4.0 & 4.6 & 3.4 \\
\hline $\mathbf{1}$ & 5.6 & 5.3 & 3.9 & 2.8 \\
\hline & $\mathbf{1}$ & $\mathbf{2}$ & $\mathbf{3}$ & 3.9 \\
\hline
\end{tabular}

Revision 1 


\section{CleanAir}

CONSOL ENERGY INC.

Client Reference No: 4700140111

AES GREENIDGE STATION

CleanAir Project No: 10192

\section{RESULTS}

Figure 2-8:

Run 3 SCR Outlet - MASS ${ }^{\circledR} \mathrm{NO}_{\mathrm{X}}$, and $\mathrm{O}_{2}$

Run 3: Outlet - Nitrogen Oxides (ppmdv@3\% 02)

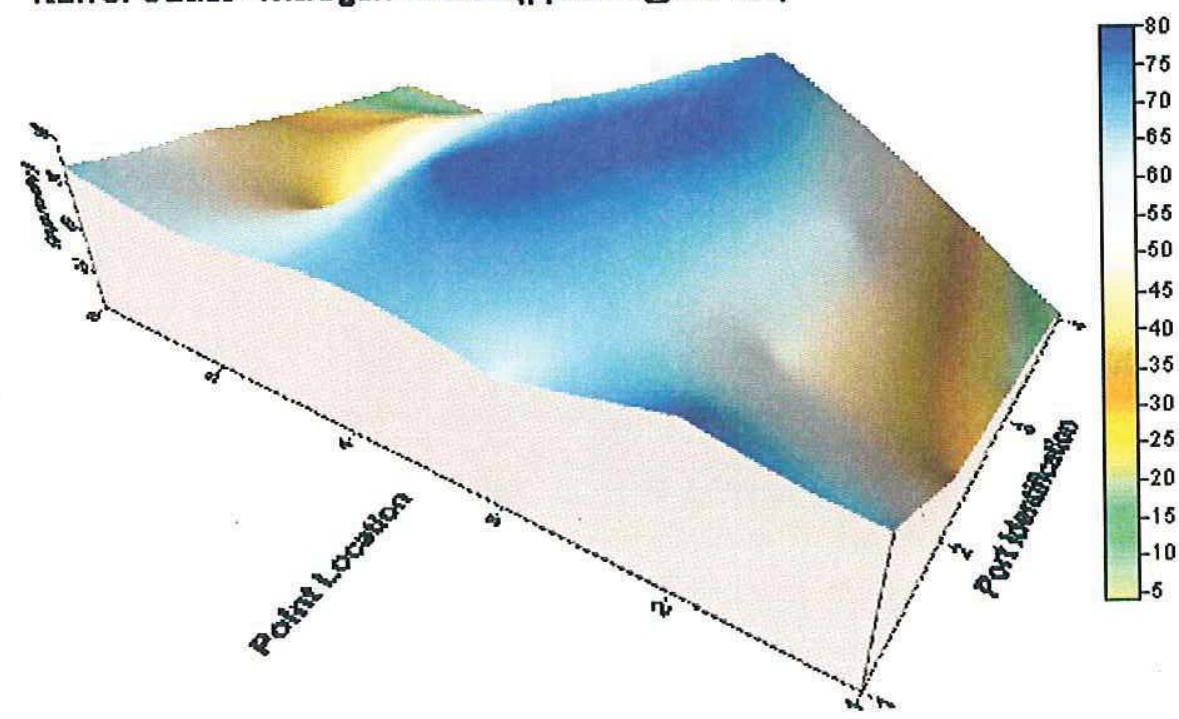

Run 3: Outlet - Oxygen (\% dV)

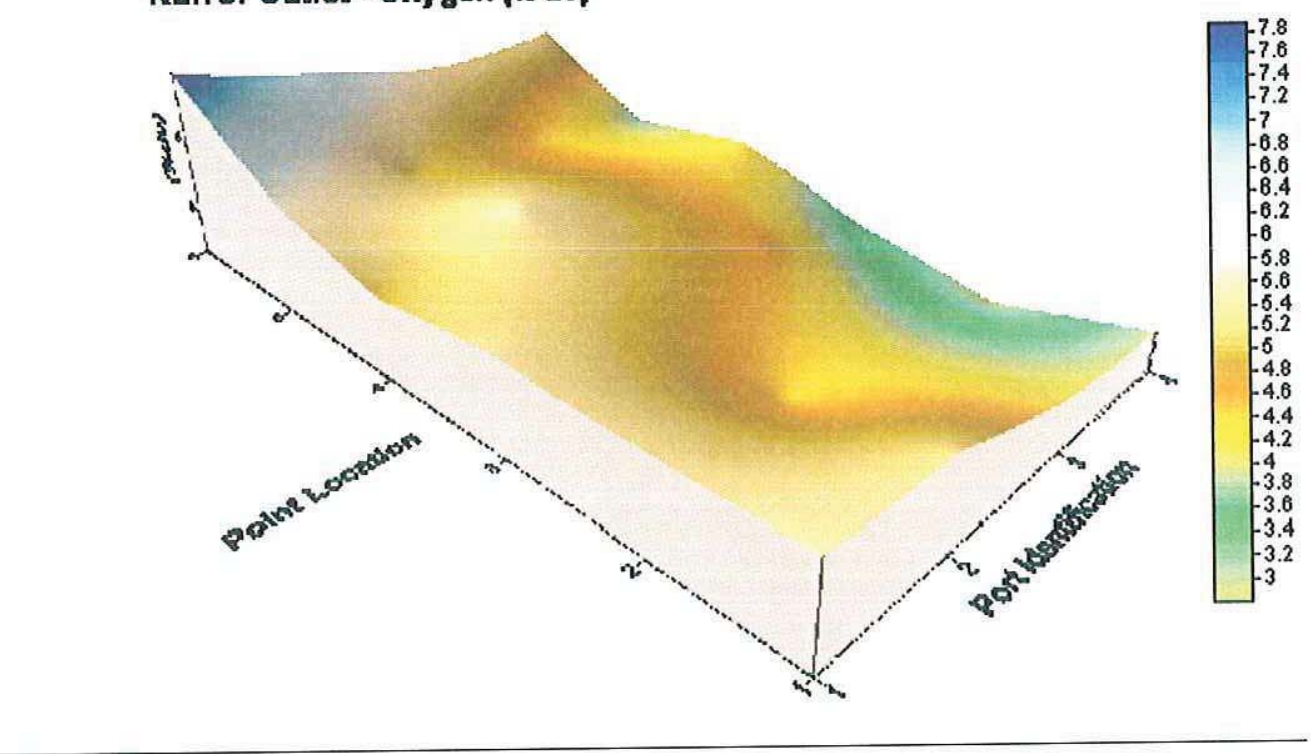

Revision 1 


\section{CleanAir}

CONSOL ENERGY INC.

Client Reference No: 4700140111

AES GREENIDGE STATION

CleanAir Project No: 10192

\section{RESULTS}

Run 3 MASS $^{\circledR}$ - NOx Removal Efficiency

Date: $3 / 28 / 2007$

Start Time: $\quad 12: 48$

End Time: $\quad 13: 59$

\begin{tabular}{c|c|c|c|c|}
\multicolumn{5}{c}{ Removal Efficiency (ppmdv @ $3 \% \mathrm{O}_{2}$ ) } \\
\multicolumn{1}{c|}{ AVG } & $24.1 \%$ & $35.0 \%$ & $41.2 \%$ & $63.6 \%$ \\
\hline $\mathbf{6}$ & $31.9 \%$ & $50.8 \%$ & $74.4 \%$ & $93.6 \%$ \\
\hline $\mathbf{5}$ & $12.4 \%$ & $41.6 \%$ & $36.4 \%$ & $93.6 \%$ \\
\hline $\mathbf{4}$ & $13.7 \%$ & $-8.5 \%$ & $12.2 \%$ & $44.3 \%$ \\
\hline $\mathbf{3}$ & $35.3 \%$ & $25.8 \%$ & $19.0 \%$ & $16.8 \%$ \\
\hline $\mathbf{2}$ & $22.5 \%$ & $34.0 \%$ & $25.2 \%$ & $40.2 \%$ \\
\hline $\mathbf{1}$ & $28.8 \%$ & $66.3 \%$ & $79.9 \%$ & $92.9 \%$ \\
\hline & $\mathbf{1}$ & $\mathbf{2}$ & $\mathbf{3}$ & $\mathbf{4}$ \\
\hline
\end{tabular}

\section{Run 3: NOx Ren oval Effieieney (e) 3\% 02)}

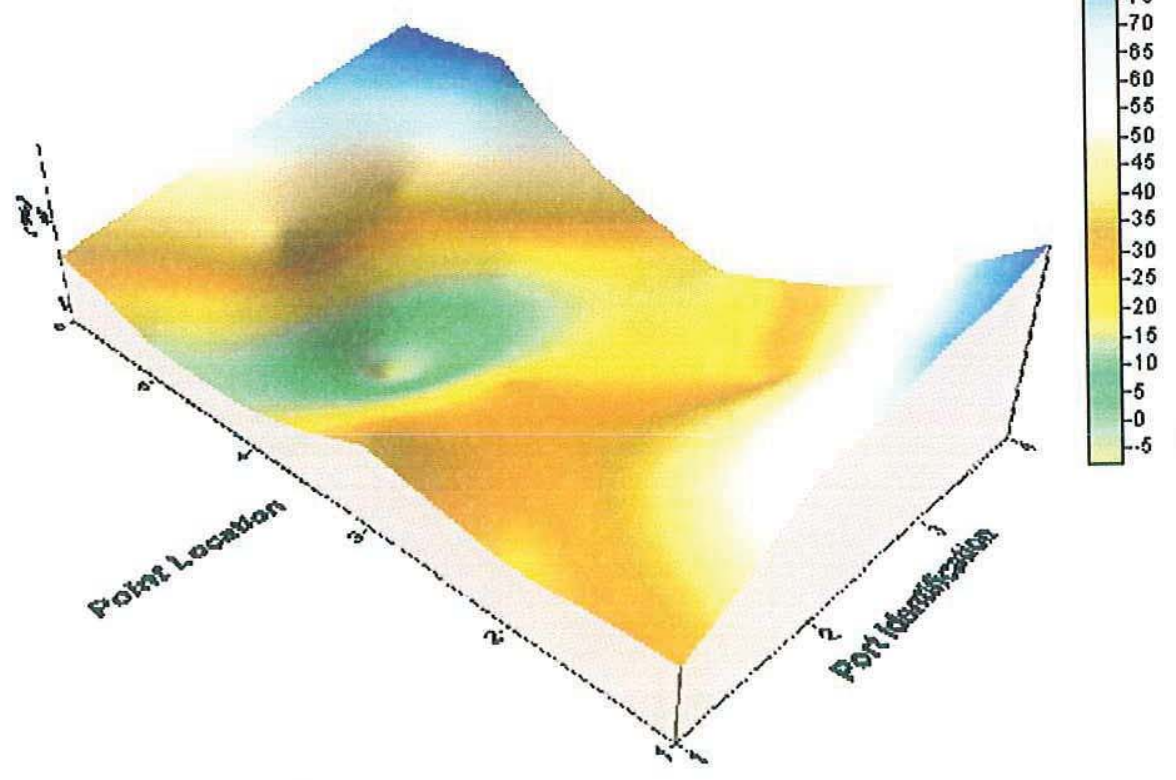

Figure 2-9:

Run 3 MASS $^{\odot}-$ Removal Effiency

Revision 1 


\section{CleanAir}

CONSOL ENERGY INC.

Client Reference No: 4700140111

AES GREENIDGE STATION

CleanAir Project No: 10192

\section{RESULTS}

2-16

Sulfur Dioxide Reduction Efficiency Results

Run

Date (2007)

Start Time

Stop Time

Air Heater Outlet

$\mathrm{SO}_{2}$ (ppmdv@3\% O

$\mathrm{O}_{2}$ (\%dv)

$\mathrm{CO}_{2}(\% \mathrm{dv})$

Baghouse Outlet

$\mathrm{SO}_{2}$ (ppmdv@3\% $\mathrm{O}_{2}$ )

$\mathrm{O}_{2}$ (\%dv)

$\mathrm{CO}_{2}(\% \mathrm{dv})$

Reduction Efficiency

$\begin{array}{ccc}1 & \mathbf{2} & \mathbf{3} \\ & & \\ 29-\text { Mar } & 29-\text { Mar } & 29-\text { Mar } \\ \text { 9:59 } & 12: 16 & 15: 13 \\ 11: 00 & 13: 17 & 16: 13\end{array}$

Average

$\begin{array}{llll}1854.76 & 1829.81 & 1837.92 & 1840.83\end{array}$

$\begin{array}{llll}7.30 & 7.22 & 7.45 & 7.32\end{array}$

$\begin{array}{llll}11.54 & 11.61 & 11.52 & 11.56\end{array}$

$\mathrm{SO}_{2}(\%)$

94.40

95.04

92.81

94.08

Revision 1 


\section{CleanAir}

CONSOL ENERGY INC.

Client Reference No: 4700140111

AES GREENIDGE STATION

CleanAir Project No: 10192

\section{DESCRIPTION OF INSTALLATION}

\section{PROCESS DESCRIPTION}

AES Greenidge Unit 4 is representative of 492 coal-fired electricity generating units in the United States with capacities of 50-300 MWe. AES Greenidge Unit 4 is a 104-MW coal-fired unit. The unit had an integrated multipollutant control system installed on it, which is going to reduce emissions in an economically viable way. This new technology utilizes a hybrid selective non-catalytic reduction / selective catalytic reduction system for $\mathrm{NO}_{\mathrm{x}}$ reduction and a circulating fluidized-bed dry scrubber for $\mathrm{SO}_{2}$ and Mercury Reduction.

The testing was performed at the SCR inlet and outlet for $\mathrm{NO}_{\mathrm{x}}$ and $\mathrm{O}_{2} / \mathrm{CO}_{2}$. Testing was also conducted at the Air Heater Outlet and Baghouse Outlet for $\mathrm{SO}_{2}$ and $\mathrm{O}_{2} / \mathrm{CO}_{2}$.

\section{DESCRIPTION OF SAMPLING LOCATION(S)}

Sampling points for the MASS system were located on a grid at both the SCR Inlet and SCR Outlet location. The grid consisted of four ports with six points per port from which $\mathrm{NO}_{\mathrm{x}}, \mathrm{O}_{2}$, and $\mathrm{CO}_{2}$ were measured.

Sampling points for the $\mathrm{SO}_{2}$ testing were selected at a central location in the duct of the Air Heater Outlet and Baghouse Outlet for the first two runs. The third $\mathrm{SO}_{2}$ run consisted of a three point traverse of that same port.

Table 3-1 outlines the sampling point configurations. Figure 3-1 through 3-2 illustrates the sampling points and orientation of sampling ports for each of the sources tested in the program.

Table 3-1:

Sampling Points

\begin{tabular}{|c|c|c|c|c|c|c|c|c|}
\hline Location & Constituent & Method & $\begin{array}{l}\text { Run } \\
\text { No. }\end{array}$ & Ports & $\begin{array}{l}\text { Points } \\
\text { per Port }\end{array}$ & $\begin{array}{l}\text { Minutes } \\
\text { per Point }\end{array}$ & $\begin{array}{c}\text { Total } \\
\text { Minutes }\end{array}$ & Figure \\
\hline SCR Inlet & $\mathrm{NO}_{\mathrm{X}}, \mathrm{O}_{2}, \mathrm{CO}_{2}$ & $3 \mathrm{~A}, 7 \mathrm{E}$ & $1-3$ & 4 & 6 & 1 & $72^{1}$ & $3-1$ \\
\hline SCR Outlet & $\mathrm{NO}_{x}, \mathrm{O}_{2}, \mathrm{CO}_{2}$ & $3 \mathrm{~A}, 7 \mathrm{E}$ & $1-3$ & 4 & 6 & 1 & $72^{1}$ & $3-2$ \\
\hline Air Heater Outlet & $\mathrm{SO}_{2}, \mathrm{O}_{2}, \mathrm{CO}_{2}$ & $3 \mathrm{~A}, 6 \mathrm{C}$ & $1-2$ & 1 & 1 & 60 & 60 & N/A \\
\hline Air Heater Outlet & $\mathrm{SO}_{2}, \mathrm{O}_{2}, \mathrm{CO}_{2}$ & $3 \mathrm{~A}, 6 \mathrm{C}$ & 3 & 1 & 3 & 20 & 60 & $N / A$ \\
\hline Baghouse Outlet & $\mathrm{SO}_{2}, \mathrm{O}_{2}, \mathrm{CO}_{2}$ & $3 \mathrm{~A}, 6 \mathrm{C}$ & $1-2$ & 1 & 1 & 60 & 60 & N/A \\
\hline Baghouse Outlet & $\mathrm{SO}_{2}, \mathrm{O}_{2}, \mathrm{CO}_{2}$ & $3 A, 6 C$ & 3 & 1 & 3 & 20 & 60 & N/A \\
\hline
\end{tabular}

\footnotetext{
${ }^{1}$ Each cycle of the MASS took 24 minutes, 3 cycles were combined for each run.
} 


\section{CleanAir}

CONSOL ENERGY INC.

Client Reference No: 4700140111

AES GREENIDGE STATION

CleanAir Project No: 10192

\section{DESCRIPTION OF INSTALLATION}

3-2

DESCRIPTION OF SAMPLING LOCATION (CONTINUED)
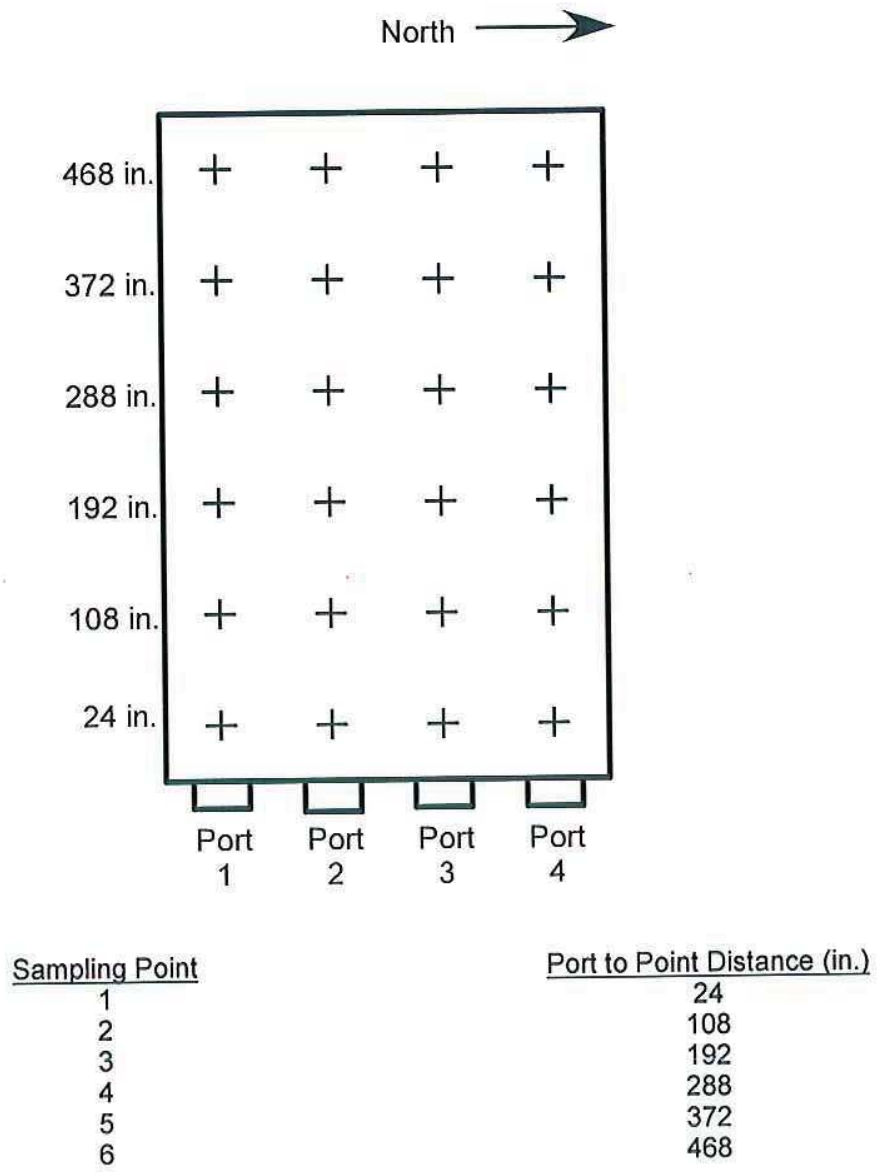

Figure 3-1: SCR Inlet - Sampling Point Determination (EPA Method 1)

Revision 1 


\section{CleanAir}

CONSOL ENERGY INC.

Client Reference No: 4700140111

AES GREENIDGE STATION

CleanAir Project No: 10192

\section{DESCRIPTION OF INSTALLATION}

3-3

DESCRIPTION OF SAMPLING LOCATION (CONTINUED)

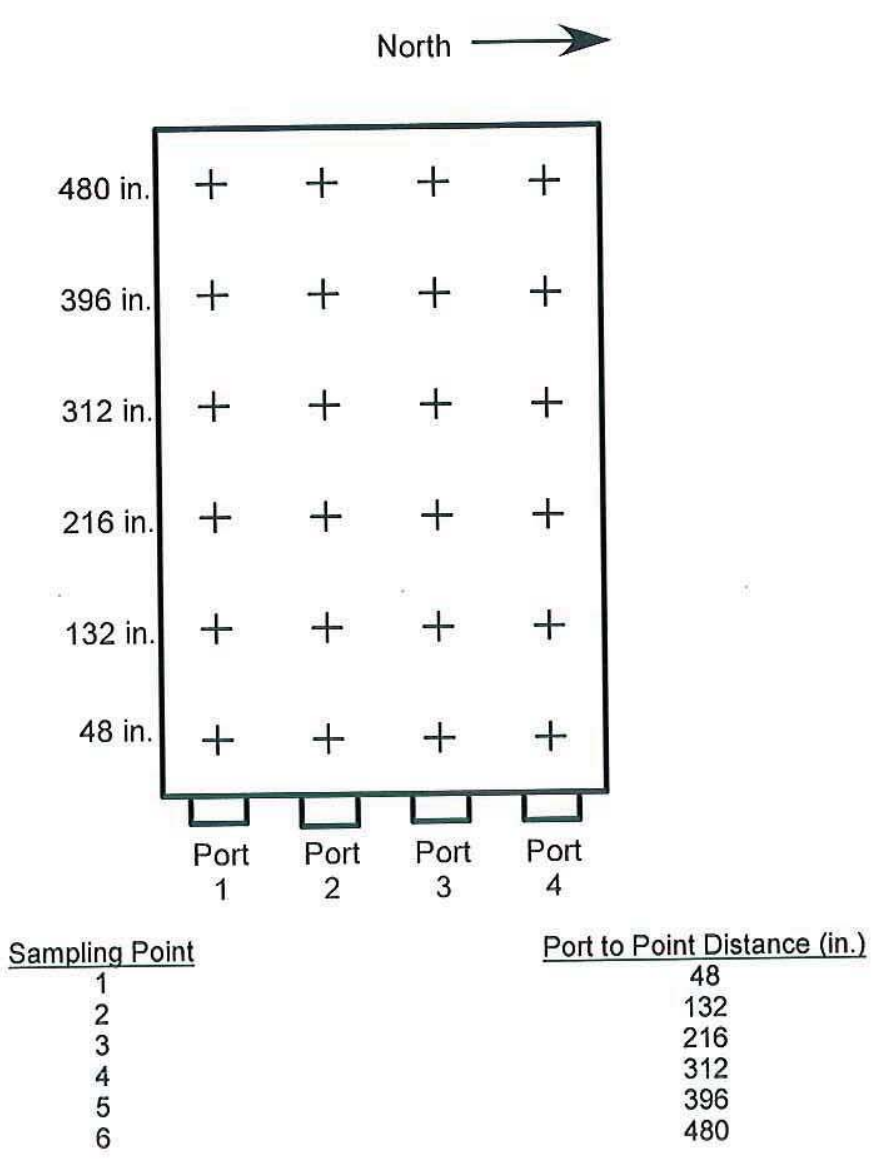

Figure 3-2: SCR Outlet - Sampling Point Determination (EPA Mlethod 1)

Revision 1 


\title{
CleanAir
}

CONSOL ENERGY INC.

AES GREENIDGE STATION

Client Reference No: 4700140111

CleanAir Project No: 10192

\section{METHODOLOGY}

Clean Air Engineering followed procedures as detailed in U.S. Environmental

Protection Agency (EPA) Methods 3A, 6C, 7E, as well as Clean A Proprietary Method

MASS $^{\circledR}$. The following table summarizes the methods and their respective sources.

Table 4-1:

Summary of Sampling Procedures

\author{
Title 40 CFR Part 60 Appendix A \\ Method 3A "Determination of Oxygen and Carbon Dioxide Concentrations in Emissions from \\ Stationary Sources (Instrumental Analyzer Procedure)" \\ Method 6C "Determination of Sulfur Dioxide Emissions from Stationary Sources (Instrumental \\ Analyzer Procedure)" \\ Method 7E "Determination of Nitrogen Oxides Emissions from Stationary Sources (Instrumental \\ Analyzer Procedure)" \\ CleanAir Proprietary Methods \\ MASS $^{\circledast} \quad$ "Multipoint Automated Sampling System for Stationary Grid Gas Analysis"
}

These methods appear in detail in Title 40 of the Code of Federal Regulations (CFR) and on the World Wide Web at http://www.cleanair.com.

Diagrams of the sampling apparatus and major specifications of the sampling, recovery and analytical procedures are summarized for each method in Appendix A.

Clean Air Engineering followed specific quality assurance and quality control (QA/QC) procedures as outlined in the individual methods and in USEPA "Quality Assurance Handbook for Air Pollution Measurement Systems: Volume III Stationary Source-Specific Methods", EPA/600/R-94/038C. Additional QA/QC methods as prescribed in Clean Air's internal Quality Manual were also followed. Results of all QA/QC activities performed by Clean Air Engineering are summarized in Appendix D. 


\section{CleanAir}

CONSOL ENERGY INC.

Client Reference No: 4700140111

AES GREENIDGE STATION

CleanAir Project No: 10192

\section{APPENDIX}

$5-1$

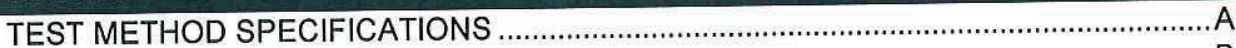

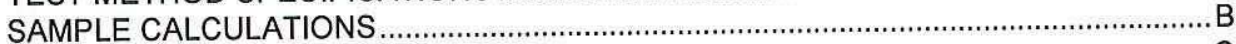

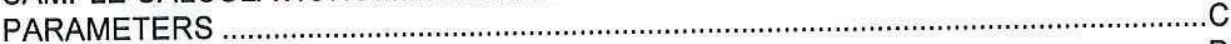

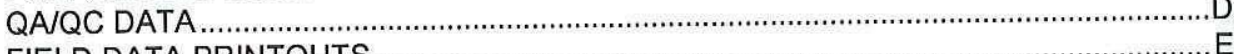

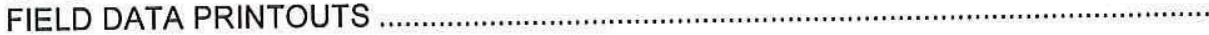

Revision 1 
CONSOL ENERGY INC.

AES GREENIDGE STATION
Client Reference No: 4700140111

CleanAir Project No: 10192

\section{TEST METHOD SPECIFICATIONS}

A

Revision 1 
This Page Intentionally Left Blank 


\section{Specification Sheet for}

Source Location Name(s)
Pollutant(s) to be Determined
Other Parameters to be Determined from Train

\section{Pollutant Sampling Information}

Duration of Run

No. of Sample Traverse Points

Sample Time per Point.

Sampling Rate

\section{Sampling Probe}

Nozzle Material

Nozzle Design

Probe Liner Material

Effective Probe Lenglh

Probe Temperature Set-Point

\section{Particulate Filter}

In-Stack Filter

In-Stack Filter Material

External Filter

External Filter Material

External Filter Set-Point

\section{Sample Delivery System \\ Heated Sample Line Material \\ Heated Sample Line Set-Point \\ Healed Sample Line Connections \\ Moisture Removal System \\ Sample Pump Type \\ Sample Pump Material \\ Sample Flow Control \\ Non-Heated Sample Line Material \\ Non-Heated Sample Line Connections \\ Additional Filters \\ Additional Filter Type \\ Additional Filter Location \\ Filter Material}

\section{Analyzer Description}

Oxygen $\left(\mathrm{O}_{2}\right)$

Carbon Dioxide $\left(\mathrm{CO}_{2}\right)$

Sulfur Dioxide $\left(\mathrm{SO}_{2}\right)$

Nitrogen Oxides (NO ${ }_{x}$ )

Carbon Monoxide (CO)

Total Hydrocarbon (THC)

Hydrogen Chloride $(\mathrm{HCl})$

Ammonia $\left(\mathrm{NH}_{3}\right)$

\section{EPA Method 6C}

Air Heater Outlet

Sulfur Dioxide $\left(\mathrm{SO}_{2}\right)$

2 and $\mathrm{CO} 2$ (EPA Method 3A)

Actual Specification Used

$\begin{array}{ll}\text { N/A } & 60 \text { minutes } \\ \text { N/A } & 1 \\ \text { N/A } & 60 \text { minutes } \\ \text { Constant Rate } & \text { Constant Rate }\end{array}$

NIA

N/A

Stainless Steel or Pyrex Glass

Sufficient to Traverse Points

Prevent Condensation

None

N/A

Stainless Steel

8 feet

$248^{\circ} \mathrm{F} \pm 25^{\circ} \mathrm{F}$

Yes

Non-reactive to gas

Yes

Borosilicate, Quartz Glass Wool or Fiber Mat

Prevent Condensation

Stainless Steel or Teflon

Prevent Condensation

Probe Exit to Moisture Removal System

Refrigerator-type condenser or similar

Leak-Free, minimal response time

Non-reactive to sample gases

Constant Rate

Stainless Steel or Teflon

Moisture Removal to Sample Gas Manifold

Optional

N/A

Optional

Non-reactive to sample gases

EPA Method 3A (Paramagnetic)

EPA Method 3A (NDII)

EPA Method 6C (UV, NDIR or Fluorescence)

N/A

N/A

N/A

N/A

N/A
Yes

Fritted Stainless Steel

Yes

Borosilicate Glass Fiber Mat

$248^{\circ} \mathrm{F} \pm 25^{\circ} \mathrm{F}$

Teflon

$248^{\circ} \mathrm{F} \pm 25^{\circ} \mathrm{F}$

Probe to Moislure Removal System

Refrigerator-type condenser

Diaphragm

Teflon

Constant Rate $( \pm 10 \%)$

Teflon

Moisture Removal to Sample Gas Manifold

Yes

Particulate Removal

Entrance to Sample Manifold

Glass Fiber

EPA Method 3A (Paramagnetic)

EPA Method 3A (NDIR)

EPA Method 6C (UV Absorption) 


\section{Specification Sheet for}

\author{
Instrument Span Range \\ Oxygen $\left(\mathrm{O}_{2}\right)$ \\ Carbon Dioxide $\left(\mathrm{CO}_{2}\right)$ \\ Sulfur Dioxide $\left(\mathrm{SO}_{2}\right)$ \\ Nitrogen Oxides $\left(\mathrm{NO}_{\mathrm{x}}\right)$ \\ Carbon Monoxide (CO) \\ Total Hydrocarbon (THC) \\ Hydrogen Chloride $(\mathrm{HCl})$
}

Ammonia $\left(\mathrm{NH}_{3}\right)$

\section{Data Acquisition \\ Data Recorder \\ Recorder Resolution \\ Data Storage \\ Measurement Freq. $<60 \mathrm{~min}$. Sample Time \\ Recording Freq. $<60 \mathrm{~min}$. Sample Time \\ Measurement Freq. $>60 \mathrm{~min}$. Sample Time \\ Recording Freq. $>60 \mathrm{~min}$. Sample Time}

Calibration Gas Specifications

Oxygen $\left(\mathrm{O}_{2}\right)$

Carbon Dioxide $\left(\mathrm{CO}_{2}\right)$

Sulfur Dioxide $\left(\mathrm{SO}_{2}\right)$

Nitrogen Oxides $\left(\mathrm{NO}_{\mathbf{x}}\right)$

Carbon Monoxide (CO)

Total Hydrocarbon (THC)

Hydrogen Chloride $(\mathrm{HCl})$

Ammonia $\left(\mathrm{NH}_{3}\right)$

\section{EPA Method 6C}

Standard Method Specification

Actual Specification Used

$\begin{array}{ll}\leq 1.33 \times \text { Expected Maximum } & 0-15 \% \\ \leq 1.33 \times \text { Expected Maximum } & 0-15 \% \\ \leq 1.33 \times \text { Expected Maximum } & 0-5,000 \mathrm{ppm} \\ \text { N/A } & \text { N/A } \\ \text { N/A } & \text { N/A } \\ \text { N/A } & \text { N/A } \\ \text { N/A } & \text { N/A } \\ \text { NIA } & \text { N/A }\end{array}$

$\begin{array}{ll}\text { Strip chart, Analog Computer or Digital Recorder } & \text { Analog Computer } \\ 0.5 \text { Percent of Span } & 0.1 \text { Percent of Span } \\ \text { Manually or Automatic } & \text { Manually }\end{array}$

1-min intervals or 30 measurements (less restrictive) One reading per second

1 -min. intervals or 30 measurements (less restrictive) One Minute Average $(60,1$ second readings)

2-min, intervals or 96 measurements (less restrictive) N/A

2-min. intervals or 96 measurements (less restrictive) N/A

EPA Protocol 1
EPA Protocol 1
EPA Protocol 1
N/A
N/A
N/A
N/A
N/A

EPA Protocol 1

EPA Protocol 1

EPA Protocol 1 


\section{Specification Sheet for}

\author{
Source Location Name(s) \\ Pollutant(s) to be Determined \\ Other Parameters to be Determined from Train $\mathrm{O} 2$ and $\mathrm{CO} 2$ (EPA Method 3A) \\ Baghouse Outlet \\ Sulfur Dioxide $\left(\mathrm{SO}_{2}\right)$
}

Standard Method Specification

Pollutant Sampling Information

Duration of Run

No. of Sample Traverse Points

Sample Time per Point

Sampling Rate

\section{Sampling Probe}

Nozzle Material

Nozzle Design

Probe Liner Material

Effective Probe Length

Probe Temperature Set-Point

Particulate Filter

In-Stack Filter

In-Stack Filter Material

External Filter

Extemal Filter Material

Extemal Filter Set-Point

\section{Sample Delivery System}

Heated Sample Line Material

Heated Sample Line Set-Point

Heated Sample Line Connections

Moisture Removal System

Sample Pump Type

Sample Pump Material

Sample Flow Control

Non-Heated Sample Line Material

Non-Heated Sample Line Connections

Additional Filters

Additional Filter Type

Additional Filter Location

Filter Material

\section{Analyzer Description}

Oxygen $\left(\mathrm{O}_{2}\right)$

Carbon Dioxide $\left(\mathrm{CO}_{2}\right)$

Sulfur Dioxide $\left(\mathrm{SO}_{2}\right)$

Nitrogen Oxides $\left(\mathrm{NO}_{x}\right)$

Carbon Monoxide (CO)

Total Hydrocarbon (THC)

Hydrogen Chloride ( $\mathrm{HCl})$

Ammonia $\left(\mathrm{NH}_{3}\right)$
N/A

N/A

N/A

Constant Rate

NIA

N/A

Stainless Steel or Pyrex Glass

Sufficient to Traverse Points

Prevent Condensation

Yes

Non-reactive to gas

Yes

Borosilicate, Quartz Glass Wool or Fiber Mat

Prevent Condensation

Stainless Steel or Teflon

Prevent Condensation

Probe Exit to Moisture Removal System

Refrigerator-type condenser or similar

Leak-Free, minimal response time

Non-reactive to sample gases

Constant Rate

Stainless Steel or Teflon

Moisture Removal to Sample Gas Manifold

Optional

N/A

Optional

Non-reactive to sample gases

EPA Method 3A (Paramagnetic)

EPA Method 3A (NDIR)

EPA Method 6C (UV, NDIR or Fluorescence)

N/A

N/A

N/A

N/A

N/A
Actual Specification Used

\author{
60 minutes \\ 1 \\ 60 minutes \\ Constant Rate \\ None \\ N/A \\ Stainless Steel \\ 8 feet \\ $248^{\circ} \mathrm{F} \pm 25^{\circ} \mathrm{F}$
}

Yes

Fritted Stainless Steel

Yes

Borosilicate Glass Fiber Mat

$248^{\circ} \mathrm{F} \pm 25^{\circ} \mathrm{F}$

Teflon

$248^{\circ} \mathrm{F} \pm 25^{\circ} \mathrm{F}$

Probe to Moisture Removal System

Refrigerator-type condenser

Diaphragm

Teflon

Constant Rate $( \pm 10 \%)$

Teflon

Moisture Removal to Sample Gas Manifold

Yes

Particulate Removal

Entrance to Sample Manifold

Glass Fiber

EPA Method 3A (Paramagnetic)

EPA Method 3A (NDIR)

EPA Method 6C (UV Absorption) 
Specification Sheet for

Instrument Span Range

Oxygen $\left(\mathrm{O}_{2}\right)$

Carbon Dioxide $\left(\mathrm{CO}_{2}\right)$

Sulfur Dioxide $\left(\mathrm{SO}_{2}\right)$

Nitrogen Oxides $\left(\mathrm{NO}_{x}\right)$

Carbon Monoxide (CO)

Total Hydrocarbon (THC)

Hydrogen Chloride ( $\mathrm{HCl})$

Ammonia $\left(\mathrm{NH}_{3}\right)$

Calibration Gas Specifications

Oxygen $\left(\mathrm{O}_{2}\right)$

Carbon Dioxide $\left(\mathrm{CO}_{2}\right)$

Sulfur Dioxide $\left(\mathrm{SO}_{2}\right)$
EPA Method 6C

Standard Method Specification

Actual Specification Used

$\begin{array}{ll}\leq 1.33 \times \text { Expected Maximum } & 0-15 \% \\ \leq 1.33 \times \text { Expected Maximum } & 0-15 \% \\ \leq 1.33 \times \text { Expected Maximum } & 0-150 \mathrm{ppm} \\ \text { N/A } & \text { N/A } \\ \text { N/A } & \text { N/A } \\ \text { N/A } & \text { N/A } \\ \text { N/A } & \text { N/A } \\ \text { N/A } & \text { N/A } \\ & \\ & \\ \text { EPA Protocol 1 } & \text { EPA Protocol 1 } \\ \text { EPA Protocol 1 } & \text { EPA Protocol 1 } \\ \text { EPA Protocol 1 } & \text { EPA Protocol 1 }\end{array}$




\section{EPA Methods 3A, 6C Sampling Train Configuration Air Heater Outlet \& Baghouse Outlet}

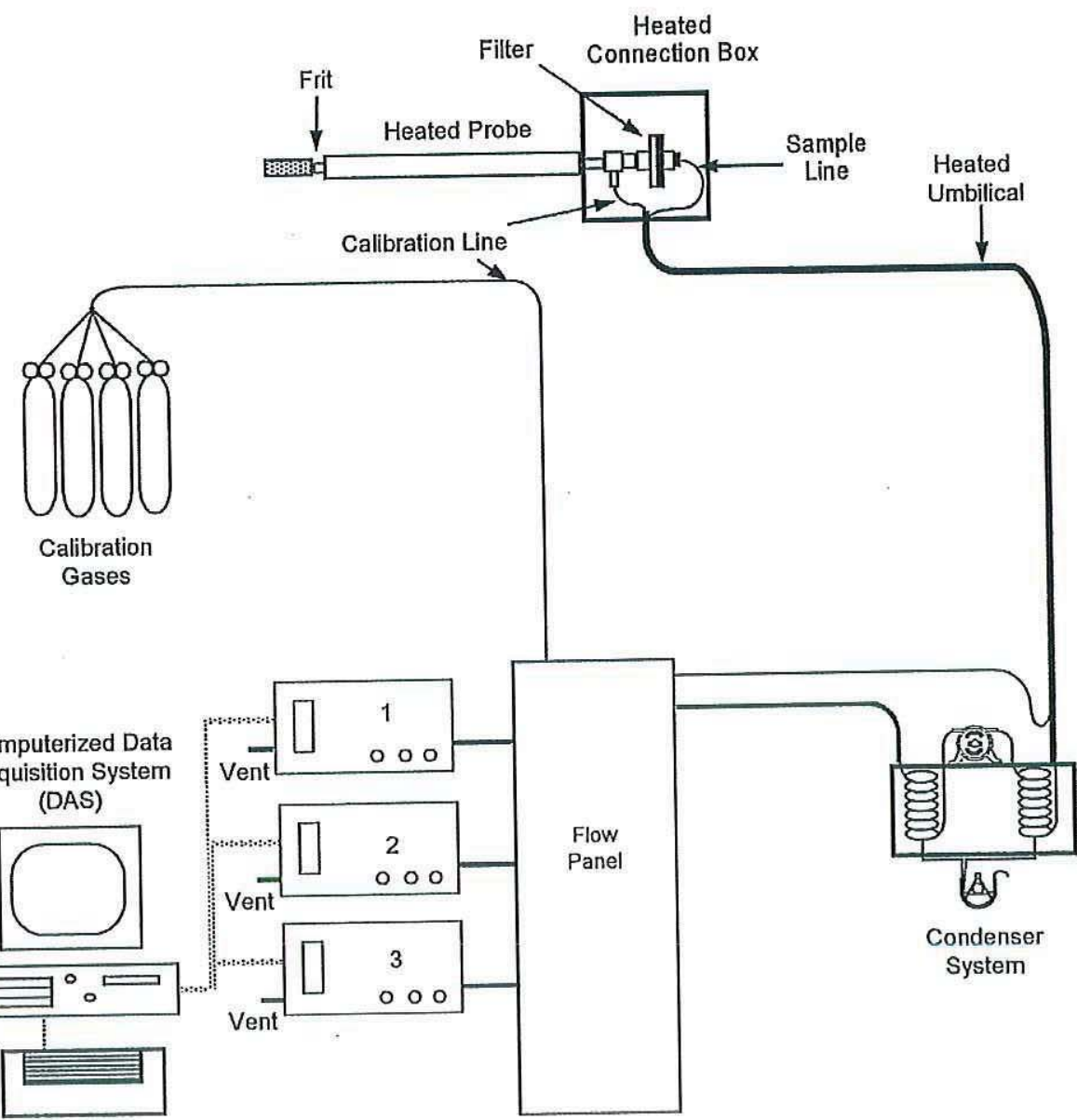

Printer

\begin{tabular}{|c|c|c|c|c|}
\hline Number & Gas & Monitor & Range Used & $\begin{array}{c}\text { Calibration Gas } \\
\text { Concentrations }\end{array}$ \\
\hline 1 Air Heater Outlet & $\mathrm{O}_{2}$ & Servomex 1420B Paramanetic & $0-15 \%$ & $6.04 \%, 14.1 \%$ \\
\hline 2 Air Heater Outlet & $\mathrm{CO}_{2}$ & Servomex 1415 NDIR & $0-15 \%$ & $6.02,13.98 \%$ \\
\hline 3 Air Heater Outlet & $\mathrm{SO}_{2}$ & Western Research 921 UV & $0-5000 \mathrm{ppm}$ & $121.6 \mathrm{ppm}, 2479 \mathrm{ppm}$ \\
\hline 1 Baghouse Outlet & $\mathrm{O}_{2}$ & Servomex 1420B Paramanetic & $0-15 \%$ & $6.04 \%, 14.1 \%$ \\
\hline 2 Baghouse Outlet & $\mathrm{CO}_{2}$ & Servomex 1415 NDIR & $0-15 \%$ & $6.02,13.98 \%$ \\
\hline 3 Baghouse Outlet & $\mathrm{SO}_{2}$ & Western Research 921 UV & $0-150 \mathrm{ppm}$ & $49.35 \mathrm{ppm}, 121.6 \mathrm{ppm}$ \\
\hline
\end{tabular}


Specification Sheet for

Source Location Name(s)

Pollutant(s) to be Determined

Other Parameters to be Determined from Train

\section{Pollutant Sampling Information}

Duration of Run

No. of Sample Traverse Points

Sample Time per Point

Sampling Rate

\section{Sampling Probe \\ Nozzle Material \\ Nozzle Design \\ Probe Liner Material \\ Effective Probe Length \\ Probe Temperature Set-Point \\ Particulate Filter \\ In-Stack Filter \\ In-Stack Filter Material \\ External Filter \\ External Filler Material}

External Filter Set-Point

\section{Sample Delivery System}

Heated Sample Line Material

Heated Sample Line Set-Point

Heated Sample Line Connections

Moisture Removal System

Sample Pump Type

Sample Pump Material

Sample Flow Control

Non-Heated Sample Line Material

Non-Heated Sample Line Connections

Additional Filters

Addilional Filter Type

Additional Filter Location

Filter Material

\section{Analyzer Description}

Oxygen $\left(\mathrm{O}_{2}\right)$

Carbon Dioxide $\left(\mathrm{CO}_{2}\right)$

Sulfur Dioxide $\left(\mathrm{SO}_{2}\right)$

Nitrogen Oxides $\left(\mathrm{NO}_{x}\right)$

Carbon Monoxide (CO)

Total Hydrocarbon (THC)

Hydrogen Chloride $(\mathrm{HCl})$

Ammonia $\left(\mathrm{NH}_{3}\right)$

\section{EPA Method 3A and 7E with MASS}

SCR Inlet/Outlet Test Grid

Determination of Nitrogen Oxides $\left(\mathrm{NO}_{x}\right)$ Emissions

O2 (EPA Method 3A)

Standard Method Speciflcation

Actual Specification Used

$\begin{array}{ll}\text { N/A } & 72 \text { minutes } \\ \text { N/A } & 24 \text { (3 cycles per run) } \\ \text { N/A } & 1 \text { minute } \\ \text { Constant Rate } & \text { Constant Rate }\end{array}$

N/A None

N/A N/A

Stainless Steel or Pyrex Glass Test Grid

Sufficient to Traverse Points See Report Section 3 for point localions

Prevent Condensation Stack Temp

Yes

No

Non-reactive to gas N/A

Yes . Yes

Borosilicate, Quartz Glass Wool or Fiber Mat Borosilicate Glass Fiber Mat

Prevent Condensation

Ambient

Stainless Steel or Teflon Teflon

Prevent Condensation Ambient

Probe Exit to Moisture Removal System N/A

Refrigerator-type condenser or similar Coil - Condenser Type

Leak-Free, minimal response time Piston

Non-reactive to sample gases Teflon

Constant Rate

Stainless Steel or Teflon

Moisture Removal to Sample Gas Manifold

Constant Rate $( \pm 10 \%)$

Teflon

Probe to Sample Gas Manifold

Yes

Particulate Removal

N/A

Optional

Non-reactive to sample gases

Entrance to Sample Manifold

Glass Fiber

N/A
N/A
N/A
EPA Method 7E (Chemiluminescent)
N/A
N/A
N/A
N/A

EPA Method 3A (Paramagnetic)

N/A

N/A

EPA Method 7E (Chemiluminescent)

N/A

N/A

N/A

N/A 


\section{Specification Sheet for}

\author{
Instrument Span Range \\ Oxygen $\left(\mathrm{O}_{2}\right)$ \\ Carbon Dioxide $\left(\mathrm{CO}_{2}\right)$ \\ Sulfur Dioxide $\left(\mathrm{SO}_{2}\right)$ \\ Nitrogen Oxides $\left(\mathrm{NO}_{x}\right)$ \\ Carbon Monoxide (CO) \\ Total Hydrocarbon (THC) \\ Hydrogen Chloride $(\mathrm{HCl})$ \\ Ammonia $\left(\mathrm{NH}_{3}\right)$
}

\section{Data Acquisition}

Data Recorder

Recorder Resolution

Data Storage

Measurement Freq. $<60 \mathrm{~min}$. Sample Time

Recording Freq. $<60 \mathrm{~min}$. Sample Time

Measurement Freq. $>60 \mathrm{~min}$. Sample Time

Recording Freq. $>60 \mathrm{~min}$. Sample Time

\section{Calibration Gas Specifications}

Oxygen $\left(\mathrm{O}_{2}\right)$

Carbon Dioxide $\left(\mathrm{CO}_{2}\right)$

Sulfur Dioxide $\left(\mathrm{SO}_{2}\right)$

Nitrogen Oxides $\left(\mathrm{NO}_{x}\right)$

Carbon Monoxide (CO)

Total Hydrocarbon (THC)

Hydrogen Chloride $(\mathrm{HCl})$

Ammonia $\left(\mathrm{NH}_{3}\right)$

\section{EPA Method 3A and 7E with MASS}

Standard Method Specification

Actual Specification Used

$\begin{array}{ll}\leq 1.33 \times \text { Expected Maximum } & 0-15 \% \\ \leq 1.33 \times \text { Expected Maximum } & 0-15 \% \\ & \text { N/A } \\ \leq 1.33 \times \text { Expected Maximum } & 0-250 \mathrm{ppm} \\ \leq 1.33 \times \text { Expected Maximum } & \text { N/A } \\ \text { N/A } & \text { N/A } \\ \text { N/A } & \text { N/A } \\ \text { N/A } & \text { N/A }\end{array}$

Strip chart, Analog Computer or Digital Recorder

Analog Computer

0.5 Percent of Span

0.1 Percent of Span

Manually or Automatic

Automatic

1-min. intervals or 30 measurements (less restriclive) One reading per second

1 -min. intervals or 30 measurements (less restrictive) One Minute Average $(60,1$ second readings)

2-min. intervals or 96 measurements (less restriclive) N/A

2-min. intervals or 96 measurements (less restrictive) N/A

EPA Protocol 1
N/A
N/A
EPA Protocol 1
N/A
N/A
N/A
N/A

EPA Protocol 1

EPA Protocol 1

EPA Protocol 1 


\section{CONSOL ENERGY INC. AES GREENIDGE STATION}

\section{Client Reference Number: $\mathbf{4 7 0 0 1 4 0 1 1 1}$ \\ Clean Air Project Number: 10192}

\section{Multi-Point Automated Sampling System}

The NOx and $\mathrm{O}_{2}$ distributions at the SCR Inlet and Outlet were measured simultaneously using an extractive continuous emission monitoring (CEM) package contained in a mobile emission laboratory. The system is comprised of three basic subsystems, including; 1) a flue gas sample acquisition and conditioning system, 2) a calibration gas system, and 3) the electronic gas analyzers.

In order to assess local NOx reductions, CleanAir has developed a proprietary flue gas profiling system called the Multi-Point Automated Sampling System (MASS). The MASS system allows duct emission profiles to be characterized in a matter of minutes, as opposed much longer sampling times for traditional duct emission traverses using "manual" traversing techniques.

Clean Air Engineering's MASS system uses a series of automated 8-point sample modules with integrated programmable logic controllers (PLC's) to sequentially and rapidly cycle through a multi-point sample grid. A diagram of the sampling system is provided in Figure 1.

\section{Figure 1:}

CleanAir's Multi-Point Automated Sampling System

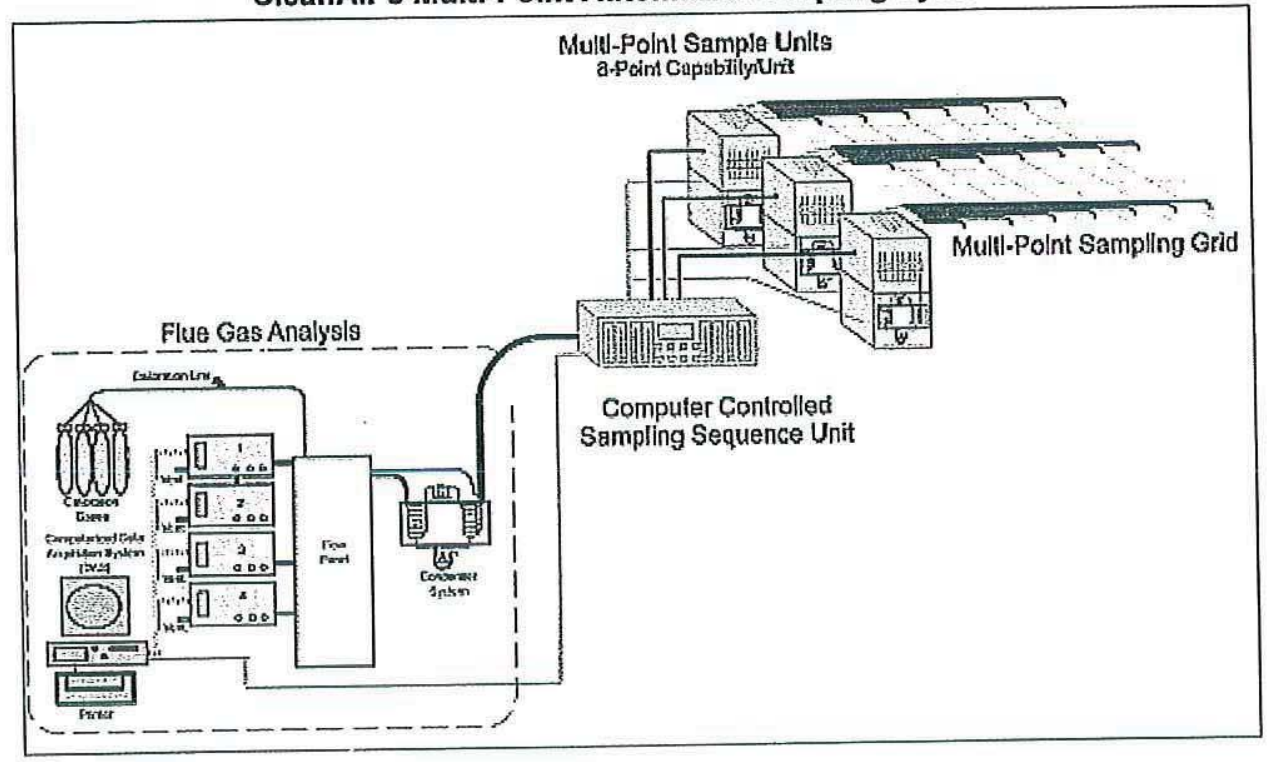

Based on a 24 point grid system (Inlet and Outlet) for the reactor module, three (3) cycles were performed to obtain a test duration of 72 minutes. A total of three test runs were performed concurrently at both the SCR Inlet and Outlet test grid locations. 
CONSOL ENERGY INC. AES GREENIDGE STATION
Client Reference No: 4700140111

CleanAir Project No: 10192

SAMPLE CALCULATIONS

B

Revision 1 


\section{This Page Intentionally Left Blank}


Consol Energy

CleanAir Project No. 10192

Dresden, New York

Stack, AH Outlet

\section{CEM Field Sample Calculations for SO2 AH Outlet}

Sample data taken from Run 1 and

and Channel 2

Note: The tables presenting the results are generated electronically from raw data. It may not be possible to exactly duplicate these results using a calculator. The reference method data, results and all calculations are carried to sixteen decimal places throughout. The final table is formatted to an appropriate number of significant figures.

051507140613

1. Average of a calibration series
$C_{\text {nice }}$
$=\frac{\left(C_{1}+C_{2}+C_{3}\right)}{3}$
Where:
$\mathrm{C}_{1}, \mathrm{C}_{2}, \mathrm{C}_{3} \quad=$ concentrations of 3 conseculive gas samples that are
representative of the calibration gas
$\mathrm{C}_{\text {mce }}=$ average concentration of a calibration series
$=133.235 \quad \mathrm{ppmdv}$

2a. Calibration Error Check for Hydrocarbons ( $5 \%$ of actual calibration gas value error allowed by Method $25 \mathrm{~A}$ )

$$
\begin{aligned}
& \underset{H C}{E_{H C}}=a b s\left|\frac{C_{m c e}-C_{m a}}{C_{m a}}\right| \leq l_{c a l} \\
& \begin{aligned}
\mathrm{C}_{\text {mce }} \quad= & \text { average concentration of a calibration series } \\
& \text { In this case the low cal series for channel } 2
\end{aligned} \\
& \mathrm{C}_{\mathrm{ma}} \quad=\text { concentration of aclual calibration gas value } \\
& \text { Ical = limit for calibration error for hydrocarbons } \\
& \text { E }=\text { calibration error check value }
\end{aligned}
$$

$\begin{array}{lcc}= & 133.235 & \text { ppmdv } \\ = & 121.600 & \text { ppmdv } \\ = & 5.0 \% & \\ = & \text { NA } & \end{array}$

2b. Calibration Error Check for non-Hydrocarbons ( $2 \%$ of Instrument Span)

$$
\begin{array}{ll}
E & =a b s\left|\frac{C_{m c c}-C_{m a}}{\text { Span }}\right| \leq l_{c a l} \\
\begin{array}{cl}
\text { Where: } & =\text { average concentration of a calibration series } \\
\mathrm{C}_{\text {mea }} & \text { In this case the low cal series for channel } 2 \\
& =\text { concentration of aclual calibration gas value }
\end{array} \\
\begin{array}{cl}
\mathrm{C}_{\mathrm{ma}} & =\text { instrument span value } \\
\text { Span } & =\text { limit for calibration error for non-hydrocarbons } \\
\mathrm{I}_{\text {cal }} & =\text { calibration error check value }
\end{array} \\
\mathrm{E} &
\end{array}
$$$$
\begin{array}{lcc}
= & 133.235 & \text { ppmdv } \\
& & \\
= & 121.600 & \text { ppmdv } \\
= & 2479.000 & \\
& 2.0 \% &
\end{array}
$$

3. System Bias as Percent of Span Value (5\% is allowed)

$$
E_{\text {Bias }}=a b s\left|\frac{C_{m f}-C_{m c e}}{\operatorname{Span}}\right| \leq l_{\text {bias }}
$$

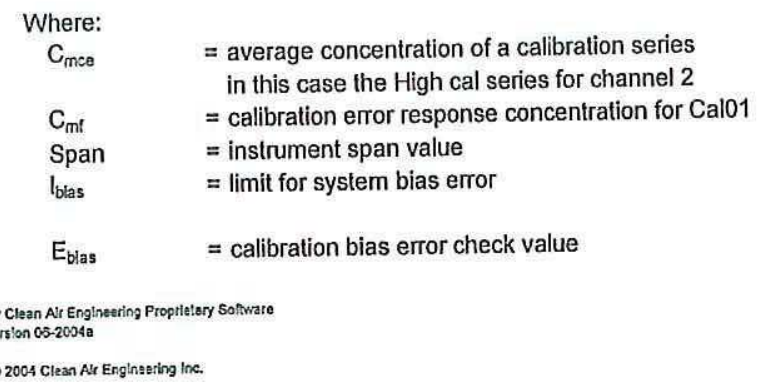

$\begin{array}{lll}= & 2482.035 & \text { ppmdv } \\ & & \\ = & 2411.901 & \text { ppmdv } \\ = & 5479.000 & \text { ppmdv } \\ & & \\ & 2.83 \% & \text { Pass }\end{array}$


Consol Energy

CleanAir Project No. 10192

Dresden, New York

Stack, AH Outlet

4. System Drift as Percent of Span Value (3\%)

$$
E_{\text {Drif }}=a b s\left|\frac{C_{m f}-C_{m i}}{S p a n}\right| \leq l_{d r i n}
$$

$\begin{array}{ll}\text { Where: } & \text { = calibration error response concentration for Cal01 (final) } \\ \mathrm{C}_{\mathrm{mI}} & =\text { calibration error response concentration for Cal00 (initial) } \\ \mathrm{C}_{\mathrm{mi}} & =\text { instrument span value } \\ \text { Span } & =\text { limit for system drift error } \\ \text { I drift } & =\text { calibration drift error check value }\end{array}$

$\begin{array}{lcl}= & 2411.901 & \text { ppmdv } \\ = & 2432.641 & \text { ppmdv } \\ = & 2479.000 & \text { ppmdv } \\ = & 3.0 \% & \\ =\quad 0.84 \% & \text { Pass }\end{array}$

5. Average Concentration for an entire Run

$$
\begin{aligned}
& C=\frac{\sum_{i=1}^{N}{ }^{C} i}{N} \\
& \text { Where: } \quad=\text { All concentration readings for the entirely of Run } 1 \\
& \mathrm{C}_{\mathrm{i}} \quad=\text { All concentration readings for the entirely of } 2 \\
& \mathrm{~N} \quad=\text { total number of readings in Run } 1 \\
& \text { C } \quad=\text { average } \mathrm{SO} 2 \text { concentration for Run } 1
\end{aligned}
$$

\begin{tabular}{|c|c|c|c|c|}
\hline $\mathrm{C}_{\mathrm{ma}}$ & $=$ concentration of actual calibration gas value & $=$ & 2479.000 & ppmdv \\
\hline C & $=$ average $\mathrm{SO} 2$ concentration for Run 1 & $=$ & 1384.546 & ppmdv \\
\hline$C_{m !}$ & = calibration error response concentration for Cal01 (final) & $=$ & 2411.901 & ppmdv \\
\hline$C_{m i}$ & $=$ calibration error response concentration for Cal00 (initial) & $=$ & 2432.641 & ppmdv \\
\hline $\mathrm{C}_{01}$ & $\begin{aligned}= & \text { calibration error response concentration for Cal01 (final) } \\
& \text { for zero gas }\end{aligned}$ & $=$ & 13.789 & ppmdv \\
\hline $\mathrm{C}_{01}$ & $\begin{aligned}= & \text { calibration error response concentration for Cal00 (initial) } \\
& \text { for zero gas }\end{aligned}$ & $=$ & 19.829 & ppmdv \\
\hline $\mathrm{C}_{D C}$ & $=$ drift corrected average concentration for Run 1 & $=$ & 1409.550 & ppmdv \\
\hline
\end{tabular}

6. Drift-Corrected Average Concentration for an entire Run

$C_{D C}=\left(C-\frac{C_{o i}+C_{o f}}{2}\right)\left(\frac{C_{m a}}{\frac{C_{m i}+C_{m f}}{2}-\frac{C_{o i}+C_{o f}}{2}}\right)$ 


\title{
CEM Emissions Sample Calculations for $\mathrm{SO} 2 \mathrm{AH}$ Outlet
}

\author{
Sample data taken from Run 1 \\ and Channel 2
}

Note: The tables presenting the results are generated electronically from raw data. It may not be possible to exactly duplicate these results using a calculator. The reference method data, results and all calculations are carried to sixteen decimal places throughout. The final table is formatted to an appropriate number of significant figures.

051507143419

1. SO2 concentration (ppmdv)
$C(p p m d v)$
$=k_{1} \times C_{D C}$
if dry gas
$C(p p m d v)$
$=\frac{k_{1} \times C_{D C}}{\left(1-B_{W} / 100\right)}$
if wet gas
Where:
$\mathrm{C}_{D C} \quad=$ drift corrected average concentration
$\mathrm{B}_{\mathrm{w}} \quad=$ actual water vapor in gas $(\% \mathrm{v} / \mathrm{v})$
$100=$ conversion factor to change percentage to decimal
$\mathrm{k}_{1} \quad=\mathrm{ppm} / \%$ to $\mathrm{ppm}$ conversion factor for diluent gases
if wet gas
$C($ ppmdv) $=\mathrm{SO} 2$ concentration (ppmdv)
$\begin{array}{lcl}= & 1409.550 & \mathrm{ppmdv} \\ = & 0.000 & \% \mathrm{v} / \mathrm{v} \\ = & 100 & \\ = & 1 & \end{array}$
$=\quad 1409.550 \mathrm{ppmdv}$

2. SO2 concentration (ppmwv)
$C($ ppmwr)
$=k_{1} \times C_{D C}$
if wet gas
$C(p p m w r)$
$=k_{1} \times C_{D C} \times\left(1-B_{W} / 100\right)$
if $\quad d r y$ gas

$$
\begin{array}{lcl}
= & 1409.550 & \text { ppmdv } \\
= & 0.000 & \% \text { v/v } \\
= & 100 & \\
= & 1 & \\
& & \\
& 1409.550 & \text { ppmwv }
\end{array}
$$

3. $\mathrm{SO} 2$ concentration (lb/dscf)

$$
C(l b / d s c f)=\frac{C(p p m d v) \times M W(g a s)}{10^{6} p p m \times 385.3}
$$

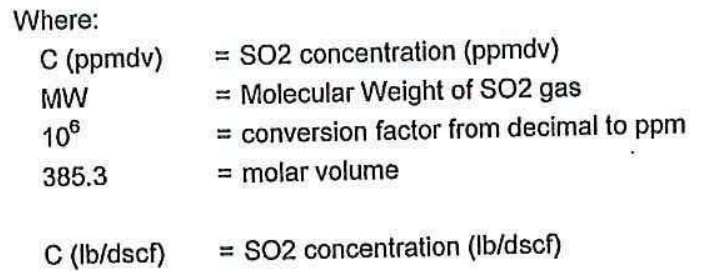

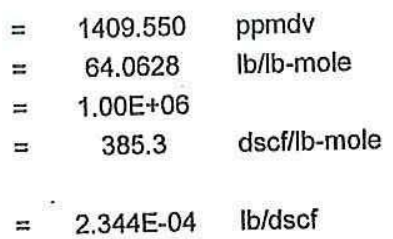

$=1409.550$ ppmdv

$=64.0628 \quad \mathrm{lb} / \mathrm{lb}-\mathrm{mole}$

$=1.00 \mathrm{E}+06$

$=2.344 \mathrm{E}-04 \mathrm{lb} / \mathrm{dscf}$ 
CleanAir Project No. 10192

Dresden, New York

Stack, $\mathrm{AH}$ Outlet

4. $\mathrm{SO} 2$ concentration (Ib/scf)

$$
C(l b / s c f)=C(l b / d s c f) \times \frac{Q_{s l d}}{Q_{s}}
$$

$\begin{array}{lllcl}\text { Where: } & & =2.344 \mathrm{E}-04 & \mathrm{lb} / \mathrm{dscf} \\ \mathrm{C}(\mathrm{lb} / \mathrm{dscf}) & =\mathrm{SO} 2 \text { concentration }(\mathrm{lb} / \mathrm{dscf}) & 0 & \mathrm{dscf} / \mathrm{min} \\ Q_{\text {sld }} & =\text { volumetric flow rate at standard conditions, dry basis }(\mathrm{dscfm}) & = & \mathrm{scf} / \mathrm{min} \\ \mathrm{Q}_{\mathrm{s}} & =\text { volumetric flow rate (standard cubic feet/min) } & = & \\ \mathrm{C}(\mathrm{lb} / \mathrm{scf}) & =\mathrm{SO} 2 \text { concentration }(\mathrm{lb} / \mathrm{scf}) & = & \mathrm{N} / \mathrm{A} & \mathrm{lb} / \mathrm{scf}\end{array}$

5. $\mathrm{SO} 2$ concentration (Ib/acf)

$$
C(l b / a c f)=C(l b / d s c f) \times \frac{Q_{s l d}}{Q_{a}}
$$

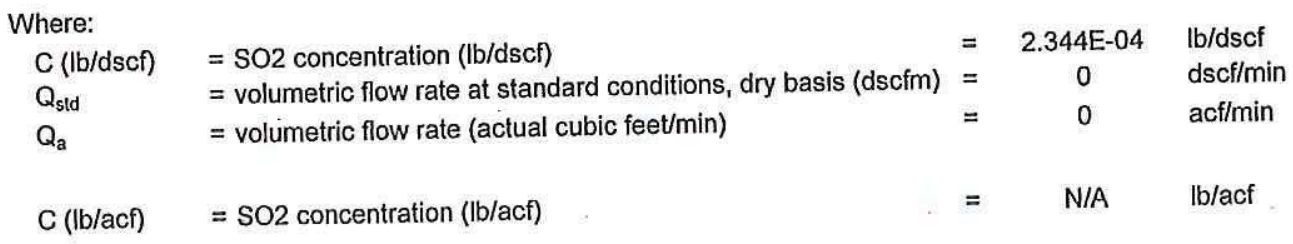

6. $\mathrm{SO} 2$ concentration (\%dv)

$$
C(\% d v)=C(p p m d v) \times \frac{100}{10^{6}}
$$

$\begin{array}{llll}\text { Where: } & & =1409.550 \mathrm{ppmdv} \\ C(\mathrm{ppmdv}) & =\text { SO2 concentration (ppmdv) } & =1.00 \mathrm{E}+02 \\ 100 & =\text { conversion factor from decimal to percentage } & =1.00 \mathrm{E}+06 \\ 10^{6} & =\text { conversion factor from decimal to ppm } & =0.1410 \% \% \mathrm{dv}\end{array}$

7. $\mathrm{SO} 2$ concentration $(\mathrm{mg} / \mathrm{dscm})$

$$
C(\mathrm{mg} / \mathrm{dscm})=C(\mathrm{lb} / \mathrm{dscf}) \times k_{2} \times 35.31
$$

$$
\begin{array}{ll}
\text { Where: } & \\
\begin{array}{ll}
\mathrm{C}(\mathrm{lb} / \mathrm{dscf}) & =\mathrm{SO} 2 \text { concentration (Ib/dscf) } \\
\mathrm{k}_{2} & =\text { conversion factor from } \mathrm{lb} \text { to } \mathrm{mg} \\
35.31 & =\text { conversion factor from dscf to } \mathrm{dscm}
\end{array}
\end{array}
$$

$\mathrm{C}(\mathrm{mg} / \mathrm{dscm})=\mathrm{SO} 2$ concentration $(\mathrm{mg} / \mathrm{dscm})$

$\begin{array}{lcl}= & 2.344 \mathrm{E}-04 & \mathrm{lb} / \mathrm{dscf} \\ = & 453515 & \mathrm{mg} / \mathrm{lb} \\ = & 35.31 & \mathrm{ft}^{3} / \mathrm{m}^{3} \\ & & \\ & 3752.982 & \mathrm{mg} / \mathrm{dscm}\end{array}$


CleanAir Project No. 10192

\section{Dresden, New York}

Stack, AH Outlet

8. $\mathrm{SO} 2$ concentration ( $\mathrm{mg} / \mathrm{Nm} 3 \mathrm{dry}$ )

$$
C \quad\left(m g / \mathrm{Nm}^{3} d r y\right) \quad=C(\mathrm{lb} / d s c f) \times k_{2} \times 35.31 \times\left(\frac{68+460}{32+460}\right)
$$

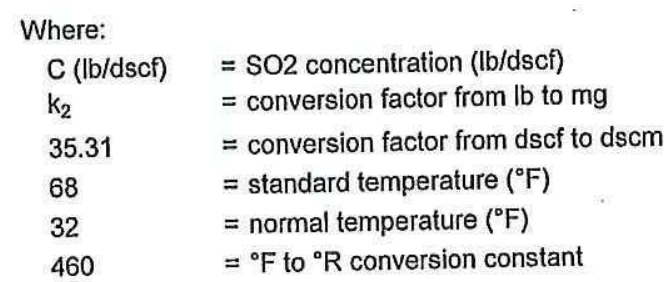

$\mathrm{C}(\mathrm{mg} / \mathrm{Nm} 3 \mathrm{dr} \cdot=\mathrm{SO} 2$ concentration $(\mathrm{mg} / \mathrm{Nm} 3 \mathrm{dry})$

$\begin{array}{lcl}= & 2.344 \mathrm{E}-04 & \mathrm{lb} / \mathrm{dscf} \\ = & 453515 & \mathrm{mg} / \mathrm{lb} \\ = & 35.31 & \mathrm{ft}^{3} / \mathrm{m}^{3} \\ = & 68 & { }^{\circ} \mathrm{F} \\ = & 32 & { }^{\circ} \mathrm{F} \\ = & 460 & \\ =4027.591 & \mathrm{mg} / \mathrm{Nm}^{3} \mathrm{dry}\end{array}$

9. SO2 concentration corrected to $3 \% \mathrm{O} 2$ (ppmdv example)

$C(p p m d v @ x \% 02)=C(p p m d v) \times\left(\frac{20.9-x}{20.9-O_{2}}\right)$

Where:

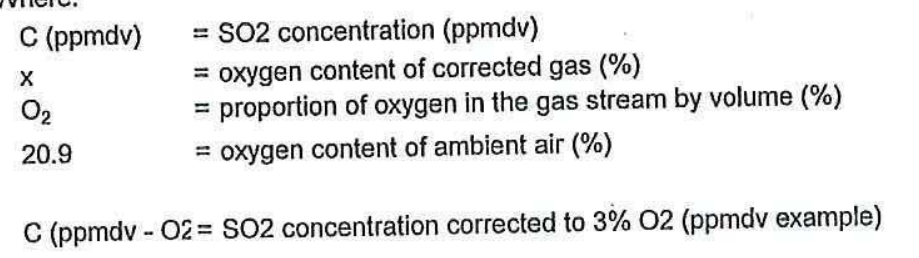

$\begin{array}{lcl}= & 1409.550 & \text { ppmdv } \\ = & 3.00 & \% \\ = & 7.201 & \% \\ = & 20.9 & \%\end{array}$

$=1841.848$ ppmdv @ 3\%O2

10. SO2 concentration corrected to $12 \% \mathrm{CO} 2$ (ppmdv example)

$C\left(p p m d v @ y \% C 0_{2}\right)=C(p p m d v) \times\left(\frac{y}{C_{2}}\right)$
Where:
$\mathrm{C}(\mathrm{ppmdv}) \quad=\mathrm{SO} 2$ concentration (ppmdv)
y $\quad=$ carbon dioxide content of corrected gas (\%)
$=1409.550 \quad$ ppmdv
$\mathrm{CO}_{2}$
$=$ proportion of carbon dioxide in the gas stream by volume $(\%)=$
$=12.00 \%$
C (ppmdv $-\mathrm{CO}=\mathrm{SO} 2$ concentration corrected to $12 \% \mathrm{CO} 2$ (ppmdv example)
$11.491 \%$

11. SO2 Removal Efficiency\% (no data on this channel for example)
$R E$

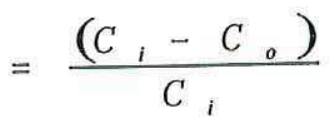
$\begin{aligned} & \text { Where: } \\ & \text { RC }\end{aligned} \quad=$ Removal Channel Number
UI $=$ Unit Index Number
$\mathrm{C}_{\mathrm{l}} \quad=$ Initial concentration
$\mathrm{C}_{0} \quad=$ Final concentration
RE = Recovery Efficiency (\%)

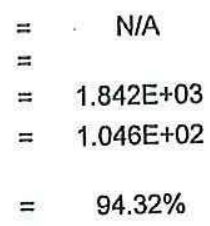




\section{CEM Emissions Sample Calculations for NOX 0}

\section{Sample data taken from Run 1} and Channel 2

Note: The tables presenting the results are generated electronically from raw data. It may not be possible to exactly duplicate these results using a calculator. The reference method data, results and all calculations are carried to sixeen final table is formatted to an appropriate number of significant figures.

070607080138

1. NOX concentration corrected to $3 \% \mathrm{O} 2$ (ppmdv example)

$$
C(p p m d v @ x \% 02)=C(p p m d v) \times\left(\frac{20.9-x}{20.9-O_{2}}\right)
$$

Where:

$\begin{array}{lllll}\text { Where: } & = & 46.900 & \mathrm{ppmdv} \\ \mathrm{C}(\mathrm{ppmdv}) & =\text { NOX concentration (ppmdv) } & = & 3.00 & \% \\ \mathrm{x} & =\text { oxygen content of corrected gas (\%) } & = & 4.900 & \% \\ \mathrm{O}_{2} & =\text { proportion of oxygen in the gas stream by volume (\%) } & =20.9 & \% \\ 20.9 & =\text { oxygen content of ambient air (\%) } & & \\ & & & \end{array}$

2. NOX concentration corrected to $12 \% \mathrm{CO} 2$ (ppmdv example)

$C\left(p p m d v @ y \% C 0_{2}\right)=C(p p m d v) \times\left(\frac{y}{C O_{2}}\right)$

\begin{tabular}{|c|c|c|c|c|}
\hline \multicolumn{5}{|l|}{ Where: } \\
\hline C (ppmdv) & $=$ NOX concentration (ppmdv) & $=$ & 46.900 & \\
\hline $\begin{array}{l}\mathrm{y} \\
\mathrm{CO}_{2}\end{array}$ & $\begin{array}{l}=\text { carbon dioxide content of corrected gas }(\%) \\
=\text { proportion of carbon dioxide in the gas stream by volume }(\%)\end{array}$ & $\begin{array}{l}= \\
=\end{array}$ & $\begin{array}{c}12.00 \\
13.900\end{array}$ & $\begin{array}{l}\% \\
\%\end{array}$ \\
\hline$d v$ & $=$ NOX concentration corrected to $12 \% \mathrm{CO} 2$ (ppmdv example) & $=$ & 40.500 & ppmdv@12\%CO2 \\
\hline
\end{tabular}

3. NOX Fd-based emission rate (Ib/MMBtu)

$$
E_{F d}=C(l b / d s c f) \times F_{d} \times\left(\frac{20.9}{20.9-O_{2}}\right)
$$

Where:

$$
\begin{array}{ll}
\mathrm{C}(\mathrm{lb} / \mathrm{dscf}) & =\text { NOX concentration (Ib/dscf) } \\
\mathrm{F}_{\mathrm{d}} & =\text { ratio of gas volume to heat content of fuel (dscf/MMBtu) } \\
\mathrm{O}_{2} & =\text { proportion of oxygen in the gas stream by volume }(\%) \\
20.9 & =\text { oxygen content of ambient air }(\%) \\
\mathrm{E}_{\mathrm{Fd}} & =\text { NOX Fd-based emission rate (Ib/MMBtu) }
\end{array}
$$

$\begin{array}{lcl}= & 5.600 \mathrm{E}-06 & \mathrm{Ib} / \mathrm{dscf} \\ = & 9737 & \mathrm{dscf} / \mathrm{MMBtu} \\ = & 4.900 & \% \\ = & 20.9 & \% \\ = & 0.0711 & \text { Ib/MMBtu }\end{array}$




\section{Consol Energy}

CleanAir Project No. 10192

Dresden, New York

SCR Inlet, SCR Outlet

\section{CEM Field Sample Calculations}

for NOX 0

$$
\text { Sample data taken from Ruñ 1 }
$$

and Channel 2

Note: The tables presenting the results are generated electronically from raw data. It may not be possible to exactly duplicate Note: The reference method data, results and all calculations are camied to these results using a calculator. The reference method data, results and all calculations are caignificant figures.

sixteen decimal places throughout. The final table is formatted to an approprialo number of significant figures.

1. Average Concentration for an entire Run

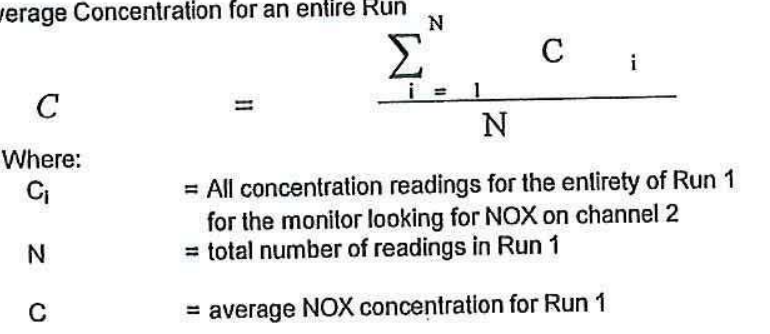

$\begin{array}{lll} & \begin{array}{c}\mathrm{i}=1 \\ 140.600\end{array} & \text { ppmdv } \\ = & 3 & \\ = & 46.900 & \text { ppmdv }\end{array}$




\section{This Page Intentionally Left Blank}


CONSOL ENERGY INC. AES GREENIDGE STATION
Client Reference No: 4700140111

CleanAir Project No: 10192

\section{PARAMETERS}

C

Revision 1 


\section{This Page Intentionally Left Blank}




\section{TEST LOG}

Client: Consol Energy Dresden, New York

CleanAir Project No. 10192

\begin{tabular}{|c|c|c|c|c|c|c|c|c|}
\hline $\begin{array}{c}\text { Run } \\
\text { Number }\end{array}$ & Location & Method & Analyte & Date & & $\begin{array}{l}\text { Start } \\
\text { Time }\end{array}$ & End Time & Notes \\
\hline 1 & SCR Inlet & MASS: $3 A, 7 E$ & $\mathrm{O}_{2} / \mathrm{CO}_{2}, \mathrm{NO}_{\mathrm{x}}$ & $3 / 28 / 07$ & & $09: 12$ & $10: 23$ & \\
\hline 2 & SCR Inlet & MASS: $3 A, 7 E$ & $\mathrm{O}_{2} / \mathrm{CO}_{2}, \mathrm{NO}_{\mathrm{x}}$ & $3 / 28 / 07$ & & $11: 12$ & $12: 23$ & \\
\hline 3 & SCR Inlet & MASS: $3 A, 7 E$ & $\mathrm{O}_{2} / \mathrm{CO}_{2}, \mathrm{NO}_{\mathrm{x}}$ & $3 / 28 / 07$ & & $12: 48$ & $13: 59$ & \\
\hline 1 & SCR Outlet & MASS: $3 A, 7 E$ & $\mathrm{O}_{2} / \mathrm{CO}_{2}, \mathrm{NO}_{\mathrm{x}}$ & $3 / 28 / 07$ & - & 09:12 & $10: 23$ & \\
\hline 2 & SCR Outlet & MASS: $3 A, 7 E$ & $\mathrm{O}_{2} / \mathrm{CO}_{2}, \mathrm{NO}_{\mathrm{x}}$ & $3 / 28 / 07$ & & $11: 12$ & $12: 23$ & \\
\hline 3 & SCR Outlet & MASS: $3 A, 7 E$ & $\mathrm{O}_{2} / \mathrm{CO}_{2}, \mathrm{NO}_{\mathrm{x}}$ & $3 / 28 / 07$ & & $12: 48$ & $13: 59$ & \\
\hline
\end{tabular}


Clean Air Engineering Project \#10192

Consol Energy

AES Dresden

Date:

Start Time:

3/28/2007

Run \# (Cycle \#) 1 (Avg)

End Time:

10:23

\begin{tabular}{|c|c|c|c|c|c|c|c|}
\hline $\begin{array}{l}\text { Inlet } \\
\text { Point }\end{array}$ & Time Sampled & $\begin{array}{c}\text { NOx } \\
\text { ppmdv }\end{array}$ & $\begin{array}{l}\text { PPM Dev } \\
\text { from Avg. }\end{array}$ & $\begin{array}{c}\mathrm{O} 2 \\
\% \mathrm{dv}\end{array}$ & $\begin{array}{l}\mathrm{CO2} \\
\% \mathrm{dv} \\
\end{array}$ & $\begin{array}{c}\text { NOx } \\
@ 3 \% 02 \\
\end{array}$ & $\begin{array}{l}\text { PPM Dev } \\
\text { from Avg. }\end{array}$ \\
\hline $1-1$ & & 77.6 & -5.6 & 7.5 & 11.6 & 103.8 & 11.2 \\
\hline $1-2$ & & 105.9 & 22.7 & 2.9 & 15.4 & 105.5 & 12.9 \\
\hline $1-3$ & & 89.1 & 5.9 & 5.0 & 13.7 & 100.5 & 8.0 \\
\hline 1.4 & & 82.2 & -1.0 & 4.4 & 14.3 & 89.0 & -3.5 \\
\hline 1.5 & & 72.5 & -10.7 & 4.8 & 13.9 & 80.4 & -12.1 \\
\hline 1.6 & & 75.0 & -8.2 & 8.6 & 10.7 & 108.9 & 16.3 \\
\hline $2-1$ & & 83.3 & 0.1 & 6.0 & 12.9 & 99.7 & 7.1 \\
\hline $2-2$ & & 86.2 & 3.0 & 3.0 & 15.5 & 85.9 & -6.6 \\
\hline $2-3$ & & 87.4 & 4.2 & 5.3 & 13.5 & 100.5 & 8.0 \\
\hline $2-4$ & & 78.4 & -4.8 & 3.9 & 14.7 & 82.4 & -10.1 \\
\hline $2-5$ & & 66.5 & -16.7 & 4.5 & 14.1 & 72.8 & -19.8 \\
\hline $2-6$ & & 84.1 & 0.9 & 6.8 & 12.2 & 107.0 & 14.4 \\
\hline $3-1$ & & 95.7 & 12.5 & 4.0 & 14.5 & 101.4 & 8.8 \\
\hline $3-2$ & & 87.4 & 4.2 & 2.9 & 15.5 & 86.9 & -5.6 \\
\hline $3-3$ & & 102.4 & 19.2 & 3.3 & 15.1 & 104.2 & 11.7 \\
\hline $3-4$ & & 81.5 & -1.7 & 3.7 & 14.9 & 84.7 & -7.9 \\
\hline $3-5$ & & 70.9 & -12.3 & 4.5 & 14.1 & 77.5 & -15.1 \\
\hline $3-6$ & & 87.7 & 4.5 & 6.3 & 12.6 & 107.7 & 15.1 \\
\hline $4-1$ & & 83.4 & 0.2 & 5.7 & 13.1 & 98.2 & 5.6 \\
\hline $4-2$ & & 89.7 & 6.5 & 2.5 & 15.8 & 87.4 & -5.1 \\
\hline $4-3$ & & 96.9 & 13.7 & 3.2 & 15.3 & 97.8 & 5.2 \\
\hline 4-4 & & 79.0 & -4.2 & 3.7 & 14.8 & 82.2 & -10.4 \\
\hline 4-5 & & 63.6 & -19.6 & 4.5 & 14.2 & 69.5 & -23.1 \\
\hline 4.6 & & 70.2 & -13.0 & 6.6 & 12.4 & 87.7 & -4.9 \\
\hline t Ave & & 83.2 & & 4.7 & 13.9 & 92.6 & \\
\hline
\end{tabular}

\begin{tabular}{|c|c|c|c|c|c|c|c|c|c|}
\hline $\begin{array}{l}\text { Outlet } \\
\text { Point }\end{array}$ & Time Sampled & $\begin{array}{c}\text { NOx } \\
\text { ppmdv }\end{array}$ & $\begin{array}{l}\text { PPM Dev } \\
\text { from Avg. }\end{array}$ & $\begin{array}{c}\mathrm{O} 2 \\
\% \mathrm{dv}\end{array}$ & $\begin{array}{l}\mathrm{CO} 2 \\
\% \mathrm{dv} \\
\end{array}$ & $\begin{array}{c}\mathrm{NOx} \\
\text { @ } 3 \% \mathrm{O} 2 \\
\end{array}$ & $\begin{array}{l}\text { PPM Dev } \\
\text { from Avg. } \\
\end{array}$ & $\begin{array}{c}\text { Removal } \\
\text { Efficiency }\end{array}$ & $\begin{array}{c}\text { Removal Eff } \\
\text { w/ O2 correction }\end{array}$ \\
\hline $1-1$ & & 68.0 & 21.1 & 4.9 & 13.9 & 75.9 & 23.2 & 9.7 & 24.6 \\
\hline $1-2$ & & 78.6 & 31.8 & 5.6 & 13.3 & 91.8 & 39.1 & 25.4 & 12.5 \\
\hline $1-3$ & & 56.9 & 10.1 & 5.3 & 13.6 & 65.2 & 12.5 & 33.6 & 33.1 \\
\hline $1-4$ & & 62.2 & 15.4 & 4.7 & 14.0 & 68.8 & 16.0 & 31.1 & 29.2 \\
\hline $1-5$ & & 50.4 & 3.5 & 6.3 & 12.7 & 61.7 & 9.0 & 29.8 & 23.4 \\
\hline $1-6$ & & 40.7 & -6.2 & 7.7 & 10.3 & 55.9 & 3.1 & 66.8 & 70.0 \\
\hline $2-1$ & & 33.3 & -13.5 & 5.0 & 13.8 & 37.4 & -15.3 & 60.0 & 62.4 \\
\hline $2-2$ & & 56.7 & 9.8 & 4.6 & 14.1 & 62.3 & 9.6 & 31.9 & 25.1 \\
\hline $2-3$ & & 69.7 & 22.8 & 4.7 & 14.0 & 77.2 & 24.5 & 18.2 & 21.3 \\
\hline $2-4$ & & 71.9 & 25.0 & 5.9 & 13.0 & 85.8 & 33.1 & 5.6 & -7.1 \\
\hline $2-5$ & & 24.4 & -22.4 & 4.9 & 13.9 & 27.3 & -25.4 & 63.5 & 62.9 \\
\hline $2-6$ & & 46.9 & 0.0 & 6.7 & 12.3 & 59.0 & 6.3 & 36.4 & 37.2 \\
\hline $3-1$ & & 24.4 & -22.5 & 3.7 & 14.9 & 25.4 & -27.4 & 75.2 & 75.6 \\
\hline $3-2$ & & 68.1 & 21.3 & 4.3 & 14.4 & 73.4 & 20.7 & 18.8 & 12.8 \\
\hline $3-3$ & & 78.6 & 31.7 & 4.4 & 14.3 & 85.0 & 32.3 & 20.5 & 15.6 \\
\hline $3-4$ & & 59.9 & 13.0 & 4.9 & 13.9 & 67.2 & 14.4 & 26.0 & 20.2 \\
\hline $3-5$ & & 30.5 & -16.4 & 4.3 & 14.4 & 32.8 & -19.9 & 56.1 & 57.0 \\
\hline 3.6 & & 24.1 & -22.7 & 5.5 & 13.4 & 28.1 & -24.7 & 70.3 & 71.9 \\
\hline $4-1$ & & 7.6 & -39.3 & 3.5 & 15.1 & 7.8 & -44.9 & 91.0 & 92.2 \\
\hline $4-2$ & & 52.8 & 5.9 & 2.7 & 15.9 & 51.8 & -0.9 & 38.5 & 38.1 \\
\hline $4-3$ & & 73.3 & 26.5 & 3.5 & 15.2 & 75.3 & 22.6 & 24.0 & 22.6 \\
\hline 4-4 & & 36.1 & -10.8 & 4.5 & 14.2 & 39.4 & -13.3 & 53.6 & 50.9 \\
\hline 4.5 & & 4.5 & -42.3 & 4.0 & 14.6 & 4.8 & -47.9 & 92.7 & 92.9 \\
\hline 4-6 & & 5.3 & -41.5 & 5.6 & 13.3 & 6.2 & -46.5 & 91.7 & 92.2 \\
\hline \multirow{2}{*}{\multicolumn{2}{|c|}{ Outlet Averages }} & 46.9 & 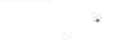 & 4.9 & 13.9 & 52.7 & & 44.9 & 43.4 \\
\hline & & 9737.0 & Fd & & & & & & \\
\hline
\end{tabular}


Clean Air Engineering Project \#10192

Consol Energy

AES Dresden

$\begin{array}{lrrr}\text { Date: } & 3 / 28 / 2007 & \text { Run \# (Cycle \#) } & 2 \text { (Avg) } \\ \text { Start Time: } & 11: 12 & \\ \text { End Time: } & 12: 23 & \end{array}$

\begin{tabular}{|c|c|c|c|c|c|c|c|}
\hline $\begin{array}{l}\text { Inlet } \\
\text { Point }\end{array}$ & Time Sampled & $\begin{array}{c}\text { NOx } \\
\text { ppmdv }\end{array}$ & $\begin{array}{l}\text { PPM Dev } \\
\text { from Avg. }\end{array}$ & $\begin{array}{c}02 \\
\% d v\end{array}$ & $\begin{array}{l}\mathrm{CO2} \\
\% \mathrm{dv}\end{array}$ & $\begin{array}{c}\text { NOx } \\
@ 3 \% 02 \\
\end{array}$ & $\begin{array}{l}\text { PPM Dev } \\
\text { from Avg. }\end{array}$ \\
\hline $1-1$ & & 76.3 & -1.1 & 7.6 & 11.6 & 102.3 & 16.0 \\
\hline $1-2$ & & 99.0 & 21.5 & 3.1 & 15.3 & 99.6 & 13.3 \\
\hline $1-3$ & & 85.4 & 8.0 & 5.0 & 13.8 & 96.1 & 9.8 \\
\hline $1-4$ & & 79.9 & 2.4 & 4.3 & 14.3 & 86.3 & 0.0 \\
\hline 1.5 & & 66.9 & -10.5 & 4.6 & 14.1 & 73.5 & -12.8 \\
\hline $1-6$ & & 70.6 & -6.8 & 8.6 & 10.7 & 102.6 & 16.4 \\
\hline $2-1$ & & 79.1 & 1.7 & 6.1 & 12.8 & 95.4 & 9.1 \\
\hline $2-2$ & & 79.2 & 1.8 & 3.2 & 15.3 & 80.1 & -6.2 \\
\hline $2-3$ & & 82.8 & 5.4 & 5.4 & 13.4 & 95.6 & 9.3 \\
\hline $2-4$ & & 74.1 & -3.3 & 3.8 & 14.7 & 77.6 & -8.7 \\
\hline $2-5$ & & 58.4 & -19.1 & 4.3 & 14.3 & 63.0 & -23.2 \\
\hline $2-6$ & & 75.9 & -1.5 & 6.8 & 12.2 & 96.6 & 10.3 \\
\hline $3-1$ & & 87.5 & 10.0 & 4.2 & 14.4 & 93.6 & 7.3 \\
\hline $3-2$ & & 78.4 & 1.0 & 3.0 & 15.4 & 78.6 & -7.7 \\
\hline $3-3$ & & 98.0 & 20.6 & 3.3 & 15.2 & 99.5 & 13.2 \\
\hline $3-4$ & & 77.7 & 0.2 & 3.6 & 14.9 & 80.4 & -5.8 \\
\hline 3.5 & & 64.4 & -13.0 & 4.4 & 14.3 & 69.9 & -16.4 \\
\hline $3-6$ & & 79.8 & 2.4 & 6.3 & 12.6 & 98.2 & 11.9 \\
\hline $4-1$ & & 75.7 & -1.7 & 6.3 & 12.6 & 92.8 & 6.5 \\
\hline $4-2$ & & 79.7 & 2.3 & 2.7 & 15.7 & 78.3 & -8.0 \\
\hline $4-3$ & . & 94.2 & 16.7. & 3.1 & 15.4 & 94.5 & 8.2 \\
\hline $4-4$ & & 75.5 & -2.0 & 3.5 & 15.0 & 77.5 & -8.8 \\
\hline 4.5 & & 57.3 & -20.1 & 4.3 & 14.4 & 61.7 & -24.5 \\
\hline 4-6 & & 62.5 & -15.0 & 6.4 & 12.5 & 77.2 & -9.0 \\
\hline
\end{tabular}

Inlet Averages

77.4

$\begin{array}{lll}4.7 & 14.0 & 86.3\end{array}$

\begin{tabular}{|c|c|c|c|c|c|c|c|c|c|}
\hline $\begin{array}{l}\text { Outlet } \\
\text { Point }\end{array}$ & Time Sampled & $\begin{array}{c}\text { NOx } \\
\text { ppmdv }\end{array}$ & $\begin{array}{l}\text { PPM Dev } \\
\text { from Avg. }\end{array}$ & $\begin{array}{l}\mathrm{O} 2 \\
\% \mathrm{dv}\end{array}$ & $\begin{array}{l}\mathrm{CO2} \\
\% \mathrm{dv}\end{array}$ & $\begin{array}{c}\text { NOx } \\
\text { @ } 3 \% 02 \\
\end{array}$ & $\begin{array}{l}\text { PPM Dev } \\
\text { from Avg. }\end{array}$ & $\begin{array}{l}\text { Removal } \\
\text { Efficiency }\end{array}$ & $\begin{array}{c}\text { Removal Eff } \\
\text { WI O2 correction }\end{array}$ \\
\hline $1-1$ & & 69.9 & 23.1 & 4.8 & 13.9 & 78.0 & 25.3 & 9.7 & 24.6 \\
\hline $1-2$ & & 78.4 & 31.5 & 5.7 & 13.3 & 92.1 & 39.4 & 25.4 & 12.5 \\
\hline $1-3$ & & 58.2 & 11.3 & 5.2 & 13.6 & 66.5 & 13.8 & 33.6 & 33.1 \\
\hline $1-4$ & & 68.4 & 21.6 & 4.4 & 14.4 & 74.0 & 21.4 & 31.1 & 29.2 \\
\hline 1.5 & & 49.8 & 3.0 & 6.1 & 12.8 & 60.4 & 7.7 & 29.8 & 23.4 \\
\hline 1.6 & & 48.5 & 1.7 & 8.0 & 11.1 & 67.3 & 14.6 & 66.8 & 70.0 \\
\hline $2-1$ & & 31.4 & -15.4 & 5.0 & 13.8 & 35.3 & -17.4 & 60.0 & 62.4 \\
\hline $2-2$ & & 53.1 & 6.3 & 4.6 & 14.1 & 58.5 & 5.8 & 31.9 & 25.1 \\
\hline $2-3$ & & 71.1 & 24.3 & 4.8 & 14.0 & 78.9 & 26.2 & 18.2 & 21.3 \\
\hline $2-4$ & & 73.4 & 26.6 & 5.8 & 13.1 & 87.3 & 34.6 & 5.6 & -7.1 \\
\hline $2-5$ & & 22.2 & -24.6 & 4.8 & 14.0 & 24.7 & -28.0 & 63.5 & 62.9 \\
\hline $2-6$ & & 41.7 & -5.1 & 6.7 & 12.2 & 52.8 & 0.1 & 36.4 & 37.2 \\
\hline $3-1$ & & 22.1 & -24.7 & 3.8 & 14.9 & 23.2 & -29.5 & 75.2 & 75.6 \\
\hline $3-2$ & & 67.2 & 20.4 & 4.3 & 14.4 & 72.6 & 19.9 & 18.8 & 12.8 \\
\hline $3-3$ & & 79.7 & 32.9 & 4.3 & 14.4 & 86.2 & 33.5 & 20.5 & 15.6 \\
\hline $3-4$ & & 63.1 & 16.3 & 4.8 & 14.0 & 69.9 & 17.2 & 26.0 & 20.2 \\
\hline $3-5$ & & 29.6 & -17.2 & 4.2 & 14.5 & 31.7 & -21.0 & 56.1 & 57.0 \\
\hline 3.6 & & 21.2 & -25.6 & 5.7 & 13.2 & 24.9 & -27.7 & 70.3 & 71.9 \\
\hline $4-1$ & & 6.5 & -40.3 & 3.8 & 14.9 & 6.8 & -45.9 & 91.0 & 92.2 \\
\hline $4-2$ & & 45.7 & -1.1 & 2.7 & 15.8 & 45.1 & -7.6 & 38.5 & 38.1 \\
\hline $4-3$ & & 75.0 & 28.2 & 3.3 & 15.3 & 76.5 & 23.8 & 24.0 & 22.6 \\
\hline 4-4 & & 39.1 & -7.7 & 4.4 & 14.3 & 42.5 & -10.2 & 53.6 & 50.9 \\
\hline $4-5$ & & 4.0 & -42.8 & 3.9 & 14.8 & 4.2 & .48 .4 & 92.7 & 92.9 \\
\hline 4-6 & & 4.4 & -42.4 & 5.4 & 13.4 & 5.1 & -47.6 & 91.7 & 92.2 \\
\hline \multirow{3}{*}{\multicolumn{2}{|c|}{ Outlet Averages }} & 46.8 & & 4.9 & 13.9 & 52.7 & & 41.2 & 39.7 \\
\hline & & 9737.0 & $F d$ & & & & & & \\
\hline & & 0.0709 & $\mathrm{lb} / \mathrm{Mbtu}$ & & & & & & \\
\hline
\end{tabular}


Clean Air Engineering Project \#10192

Consol Energy

AES Dresden

$\begin{array}{lrrr}\text { Date: } & 3 / 28 / 2007 & \text { Run \# (Cycle \#) } & 3 \text { (Avg) } \\ \text { Start Time: } & 12: 48 & \\ \text { End Time: } & 13: 59 & \end{array}$

\begin{tabular}{|c|c|c|c|c|c|c|c|}
\hline $\begin{array}{l}\text { Inlet } \\
\text { Point }\end{array}$ & Time Sampled & $\begin{array}{c}\text { NOX } \\
\text { ppmdv }\end{array}$ & $\begin{array}{l}\text { PPM Dev } \\
\text { from Avg. }\end{array}$ & $\begin{array}{c}\mathrm{O} 2 \\
\% \mathrm{dv}\end{array}$ & $\begin{array}{l}\mathrm{CO} 2 \\
\% \mathrm{dv} \\
\end{array}$ & $\begin{array}{c}\text { NOx } \\
\text { @ } 3 \% 02 \\
\end{array}$ & $\begin{array}{l}\text { PPM Dev } \\
\text { from Avg. }\end{array}$ \\
\hline $1-1$ & & 73.3 & -2.6 & 7.8 & 11.4 & 100.1 & 15.5 \\
\hline $1-2$ & & 100.6 & 24.7 & 3.2 & 15.2 & 101.6 & 17.0 \\
\hline $1-3$ & & 83.5 & 7.6 & 5.0 & 13.7 & 94.1 & 9.5 \\
\hline $1-4$ & & 75.6 & -0.3 & 4.3 & 14.3 & 81.5 & -3.0 \\
\hline $1-5$ & & 63.1 & -12.8 & 4.5 & 14.2 & 68.8 & -15.7 \\
\hline 1.6 & & 69.3 & -6.6 & 8.6 & 10.7 & 100.5 & 16.0 \\
\hline $2-1$ & & 79.3 & 3.4 & 6.2 & 12.7 & 96.5 & 11.9 \\
\hline $2-2$ & & 76.5 & 0.6 & 3.3 & 15.2 & 77.9 & -6.6 \\
\hline $2-3$ & & 84.1 & 8.2 & 5.2 & 13.6 & 96.1 & 11.6 \\
\hline $2-4$ & & 71.5 & -4.4 & 3.6 & 14.9 & 74.1 & -10.5 \\
\hline $2-5$ & & 55.6 & -20.3 & 4.2 & 14.5 & 59.5 & -25.1 \\
\hline $2-6$ & & 76.6 & 0.7 & 6.9 & 12.1 & 97.8 & 13.3 \\
\hline $3-1$ & & 87.3 & 11.4 & 4.3 & 14.4 & 93.8 & 9.3 \\
\hline $3-2$ & & 75.5 & -0.4 & 3.2 & 15.3 & 76.4 & -8.2 \\
\hline $3-3$ & & 96.7 & 20.8 & 3.3 & 15.2 & 98.3 & 13.7 \\
\hline $3-4$ & & 76.4 & 0.5 & 3.5 & 15.0 & 78.7 & -5.9 \\
\hline $3-5$ & & 61.9 & -14.0 & 4.3 & 14.4 & 66.6 & -18.0 \\
\hline 3-6 & & 78.6 & 2.7 & 6.3 & 12.7 & 96.0 & 11.5 \\
\hline $4-1$ & & 75.5 & -0.4 & 6.1 & 12.8 & 91.1 & 6.6 \\
\hline $4-2$ & & 77.2 & 1.3 & 2.8 & 15.6 & 76.5 & -8.1 \\
\hline $4-3$ & & 94.1 & 18.2 & 3.1 & 15.4 & 94.4 & 9.9 \\
\hline $4-4$ & & 73.8 & -2.1 & 3.4 & 15.1 & 75.4 & -9.2 \\
\hline 4.5 & & 55.3 & -20.6 & 4.1 & 14.6 & 58.8 & -25.7 \\
\hline 4-6 & & 60.9 & -15.0 & 6.3 & 12.6 & 74.8 & -9.8 \\
\hline
\end{tabular}

Inlet Averages

$\begin{array}{llll}75.9 & 4.7 & 14.0 & 84.6\end{array}$

\begin{tabular}{|c|c|c|c|c|c|c|c|c|c|}
\hline $\begin{array}{l}\text { Outlet } \\
\text { Point }\end{array}$ & Time Sampled & $\begin{array}{c}\text { NOx } \\
\text { ppmdv }\end{array}$ & $\begin{array}{l}\text { PPM Dev } \\
\text { from Avg. }\end{array}$ & $\begin{array}{l}\mathrm{O} 2 \\
\% \mathrm{dv}\end{array}$ & $\begin{array}{l}\mathrm{CO} 2 \\
\% \mathrm{dv} \\
\end{array}$ & $\begin{array}{c}\text { NOx } \\
\text { @ } 3 \% \text { O2 }\end{array}$ & $\begin{array}{l}\text { PPM Dev } \\
\text { from Avg. }\end{array}$ & $\begin{array}{l}\text { Removal } \\
\text { Efficiency }\end{array}$ & $\begin{array}{c}\text { Removal Eff } \\
\text { W/ O2 correction } \\
\end{array}$ \\
\hline $1-1$ & & 61.3 & 17.0 & 5.6 & 13.2 & 71.3 & 21.2 & 9.7 & 24.6 \\
\hline $1-2$ & & 67.6 & 23.2 & 5.4 & 13.5 & 78.7 & 28.7 & 25.4 & 12.5 \\
\hline $1-3$ & & 52.3 & 8.0 & 5.4 & 13.5 & 60.8 & 10.8 & 33.6 & 33.1 \\
\hline $1-4$ & & 62.9 & 18.6 & 4.9 & 13.9 & 70.3 & 20.3 & 31.1 & 29.2 \\
\hline $1-5$ & & 50.8 & 6.4 & 5.8 & 13.1 & 60.3 & 10.3 & 29.8 & 23.4 \\
\hline 1.6 & & 49.8 & 5.5 & 7.9 & 11.2 & 68.5 & 18.4 & 66.8 & 70.0 \\
\hline $2-1$ & & 28.2 & -16.1 & 5.3 & 13.5 & 32.5 & -17.6 & 60.0 & 62.4 \\
\hline $2-2$ & & 47.4 & 3.0 & 4.3 & 14.4 & 51.5 & 1.4 & 31.9 & 25.1 \\
\hline $2-3$ & & 63.5 & 19.1 & 5.0 & 13.8 & 71.3 & 21.2 & 18.2 & 21.3 \\
\hline $2-4$ & & 68.4 & 24.1 & 5.7 & 13.2 & 80.4 & 30.3 & 5.6 & -7.1 \\
\hline $2-5$ & & 30.8 & -13.6 & 5.0 & 13.8 & 34.8 & -15.3 & 63.5 & 62.9 \\
\hline $2 \cdot 6$ & & 38.5 & -5.8 & 6.6 & 12.4 & 48.2 & -1.9 & 36.4 & 37.2 \\
\hline $3-1$ & & 17.6 & -26.7 & 4.2 & 14.5 & 18.9 & -31.2 & 75.2 & 75.6 \\
\hline $3-2$ & & 54.2 & 9.8 & 3.9 & 14.8 & 57.1 & 7.1 & 18.8 & 12.8 \\
\hline $3-3$ & & 72.4 & 28.0 & 4.6 & 14.1 & 79.6 & 29.5 & 20.5 & 15.6 \\
\hline $3-4$ & & 62.7 & 18.3 & 4.7 & 14.1 & 69.1 & 19.1 & 26.0 & 20.2 \\
\hline $3-5$ & & 38.7 & -5.6 & 4.4 & 14.3 & 42.3 & -7.7 & 56.1 & 57.0 \\
\hline $3-6$ & & 21.2 & -23.2 & 5.4 & 13.4 & 24.6 & -25.5 & 70.3 & 71.9 \\
\hline $4-1$ & & 6.1 & -38.2 & 3.9 & 14.8 & 6.4 & -43.6 & 91.0 & 92.2 \\
\hline $4-2$ & & 46.2 & 1.9 & 2.8 & 15.8 & 45.7 & -4.3 & 38.5 & 38.1 \\
\hline $4-3$ & & 77.0 & 32.6 & 3.4 & 15.3 & 78.5 & 28.5 & 24.0 & 22.6 \\
\hline $4-4$ & & 38.9 & -5.4 & 4.3 & 14.4 & 42.0 & -8.0 & 53.6 & 50.9 \\
\hline $4-5$ & & 3.6 & -40.8 & 3.7 & 15.0 & 3.7 & -46.3 & 92.7 & 92.9 \\
\hline $4-6$ & & 4.1 & -40.2 & 5.3 & 13.6 & 4.8 & -45.3 & 91.7 & 92.2 \\
\hline \multirow{3}{*}{\multicolumn{2}{|c|}{ Outlet Averages }} & 44.4 & & 4.9 & 13.9 & 50.1 & & 42.6 & 41.0 \\
\hline & & 9737.0 & Fd & & & & & & \\
\hline & & 0.0674 & Ib/Mbtu & & & & & & \\
\hline
\end{tabular}




\section{TEST LOG}

Client: Consol Energy Dresden, New York

CleanAir Project No. 10192

\begin{tabular}{|c|c|c|c|c|c|c|c|}
\hline $\begin{array}{c}\text { Run } \\
\text { Number }\end{array}$ & Location & Method & Analyte & Date & $\begin{array}{l}\text { Start } \\
\text { Time }\end{array}$ & End Time & Notes \\
\hline 1 & AH Outlet & $3 \mathrm{~A}, 6 \mathrm{C}$ & $\mathrm{O} 2 / \mathrm{CO} 2, \mathrm{SO} 2$ & $3 / 29 / 07$ & $09: 59$ & $11: 00$ & \\
\hline 2 & AH Outlet & $3 A, 6 C$ & $\mathrm{O} 2 / \mathrm{CO} 2, \mathrm{SO} 2$ & $3 / 29 / 07$ & $12: 16$ & $13: 17$ & \\
\hline 3 & AH Outlet & $3 A, 6 C$ & $\mathrm{O} 2 / \mathrm{CO} 2, \mathrm{SO} 2$ & $3 / 29 / 07$ & $15: 13$ & $16: 13$ & \\
\hline 1 & BH Outlet & $3 \mathrm{~A}, 6 \mathrm{C}$ & $\mathrm{O} 2 / \mathrm{CO} 2, \mathrm{SO} 2$ & $3 / 29 / 07$ & $09: 59$ & $11: 00$ & \\
\hline 2 & BH Outlet & $3 \mathrm{~A}, 6 \mathrm{C}$ & $\mathrm{O} 2 / \mathrm{CO} 2, \mathrm{SO} 2$ & $3 / 29 / 07$ & $12: 16$ & $13: 17$ & \\
\hline 3 & BH Outlet & $3 \mathrm{~A}, 6 \mathrm{C}$ & $\mathrm{O} 2 / \mathrm{CO} 2, \mathrm{SO} 2$ & $3 / 29 / 07$ & $15: 13$ & $16: 13$ & \\
\hline
\end{tabular}

Notes:

None

061407143432

Prepared by Clean Air Engineering Proprielary Soltware

SS CEM Version 06-2004a

Copyright ๑ 2004 Clean Air Engineering Inc. 
Consol Energy

CleanAir Project No. 10192

Dresden, New York

BH Outlet, AH Outlet

Run Number

Date (2007)

Start Time

End Time

Elapsed Time (hh:mm)

Channel

Parameter

Location

Measurement Units

Measured Average (drift-corrected)

Concentration (ppmdv)

Concentration (\%dv)

Concentration @3\%02 (ppm)

Concentration @12\%CO2 (ppm)

Concentration @3\%O2 (lb/scf)

Concentration @12\%CO2 (lb/scf)

Concentration @3\%O2 (\%v)

Concentration @12\%CO2 (\%v)

Concentration @3\%O2 (mg/scm)

Concentration @12\%CO2 (mg/scm)

Concentration @3\%O2 (mg/Nm3).

Concentration @12\%CO2 (mg/Nm3)

Removal Efficiency (\%)

Consol Energy

Clean Air Project No. 10192

Dresden, New York

BH Outlet, AH Outlet

\author{
Run Number \\ Date (2007) \\ Start Time \\ End Time \\ Elapsed Time (hh:mm) \\ Channel \\ Parameter \\ Location \\ Measurement Units \\ Measured Average (drift-corrected) \\ Concentration (ppmdv) \\ Concentration (\%dv) \\ Concentration @3\%O2 (ppm) \\ Concentration @12\%CO2 (ppm) \\ Concentration @3\%O2 (Ib/scf) \\ Concentration @12\%CO2 (b/scf) \\ Concentration @3\%O2 (\%v) \\ Concentration @12\%CO2 (\%v) \\ Concentration @3\%O2 (mg/scm) \\ Concentration @12\%CO2 (mg/scm) \\ Concentration @3\%O2 (mg/Nm3) \\ Concentration @12\%CO2 (mg/Nm3) \\ Removal Efficiency (\%)
}

Continuous Emissions Monitoring Parameters

1
Mar 29
$9: 59$
$11: 00$
$01: 01$

\begin{tabular}{|c|c|c|c|c|c|}
\hline $\begin{array}{c}2 \\
\text { SO2 } \\
\text { AH Oullet } \\
\text { ppmdv }\end{array}$ & $\begin{array}{c}4 \\
\text { O2 } \\
\text { AH Outlet } \\
\% d v\end{array}$ & $\begin{array}{c}5 \\
\text { CO2 } \\
\text { AH Oullet } \\
\% d v\end{array}$ & $\begin{array}{c}7 \\
\text { SO2 } \\
\text { BH Outlet } \\
\text { ppmdv }\end{array}$ & $\begin{array}{c}8 \\
\text { O2 } \\
\text { BH Outlet } \\
\% d v\end{array}$ & $\begin{array}{c}9 \\
\mathrm{CO} 2 \\
\text { BH Outlet } \\
\% \text { dv }\end{array}$ \\
\hline 1409.55 & 7.30 & 11.54 & 79.50 & 7.20 & 11.49 \\
\hline $\begin{array}{c}1409.55 \\
0.141\end{array}$ & 7.297 & 11.538 & $\begin{array}{l}79.50 \\
0.008\end{array}$ & 7.201 & 11.491 \\
\hline $\begin{array}{l}1854.76 \\
1466.04\end{array}$ & & & 103.89 & & \\
\hline $3.084 E-04$ & & & $\begin{array}{c}83.03 \\
1.727 E-05\end{array}$ & & \\
\hline $2.438 \mathrm{E}-04$ & & & 1.380E-05 & & \\
\hline 0.185 & & & 0.010 & & \\
\hline 0.147 & & & 0.008 & & \\
\hline 4938.36 & & & 276.60 & & \\
\hline 3903.40 & & & 221.06 & & \\
\hline 5299.71 & . & & 296.84 & . & \\
\hline 4189.01 & & & 237.24 & & \\
\hline & & & $94.40 \%$ & & \\
\hline
\end{tabular}

Continuous Emissions Monitoring Parameters

2
Mar 29
$12: 16$
$13: 17$
$01: 01$

\begin{tabular}{|c|c|c|c|c|c|c|}
\hline & $\begin{array}{c}2 \\
\text { SO2 } \\
\text { AH Outlet } \\
\text { ppmdv }\end{array}$ & $\begin{array}{c}4 \\
\text { O2 } \\
\text { AH Outlet } \\
\% d v\end{array}$ & $\begin{array}{c}5 \\
\mathrm{CO} 2 \\
\text { AH Outlet } \\
\% \text { dv }\end{array}$ & $\begin{array}{c}7 \\
\text { SO2 } \\
\text { BH Outlet } \\
\text { ppmdv }\end{array}$ & $\begin{array}{c}8 \\
\text { O2 } \\
\text { BH Oullet } \\
\% d v\end{array}$ & $\begin{array}{c}9 \\
\text { CO2 } \\
\text { BH Outlet } \\
\% d v\end{array}$ \\
\hline & 1398.11 & 7.22 & 11.61 & 69.70 & 7.16 & 11.71 \\
\hline & 1398.11 & & & 69.70 & 7164 & 11711 \\
\hline & $\begin{array}{c}0.140 \\
1829.81\end{array}$ & 7.223 & 17.010 & 90.83 & 1.104 & 11.81 \\
\hline - & 1445.01 & & & 71.42 & & \\
\hline & $\begin{array}{l}3.042 E-04 \\
2.403 E-04\end{array}$ & & & $\begin{array}{l}1.510 \mathrm{E}-05 \\
1.187 \mathrm{E}-05\end{array}$ & & \\
\hline & 0.183 & & & $\begin{array}{c}1.187 \mathrm{E}-05 \\
0.009\end{array}$ & & \\
\hline & 0.145 & & & $\begin{array}{l}0.009 \\
0.007\end{array}$ & & \\
\hline & 4871.95 & & & $\begin{array}{c}0.007 \\
241.83\end{array}$ & & \\
\hline & 3847.40 & & & $\begin{array}{l}241.83 \\
190.16\end{array}$ & & \\
\hline & 5228.43 & & & $\begin{array}{l}190.16 \\
259.52\end{array}$ & & \\
\hline & 4128.92 & & & $\begin{array}{l}259.52 \\
204.07\end{array}$ & & \\
\hline & & & & $\begin{array}{l}204.07 \\
95.04 \%\end{array}$ & & \\
\hline
\end{tabular}

Prepared by Clean Ait Enghneering Proprielary Soltware SS CEM Verston 05-2004a

Coppright 02004 Clean Att Enginnering Inc. 
Consol Energy

Clean Air Project No. 10192

Dresden, New York

BH Outlet, AH Outlet

Run Number

Date (2007)

Start Time

End Time

Elapsed Time (hh:mm)

Channel

Parameter

Location

Measurement Units

Measured Average (drift-corrected)

Concentration (ppmdv)

Concentration (\%dv)

Concentration @3\%O2 (ppm)

Concentration @12\%CO2 (ppm)

Concentration @3\%O2 (lb/sct)

Concentration @12\%CO2 (Ib/scf)

Concentration @3\%O2 (\%v)

Concentration @12\%CO2 (\%v)

Concentration @3\%O2 (mg/scm)

Concentration @12\%CO2 (mg/scm)

Concentration @3\%O2 (mg/ $/ \mathrm{Nm} 3$ )

Concentration @12\%CO2 (mg/Nm3)

Removal Efficiency (\%)
Continuous Emissions Monitoring Parameters

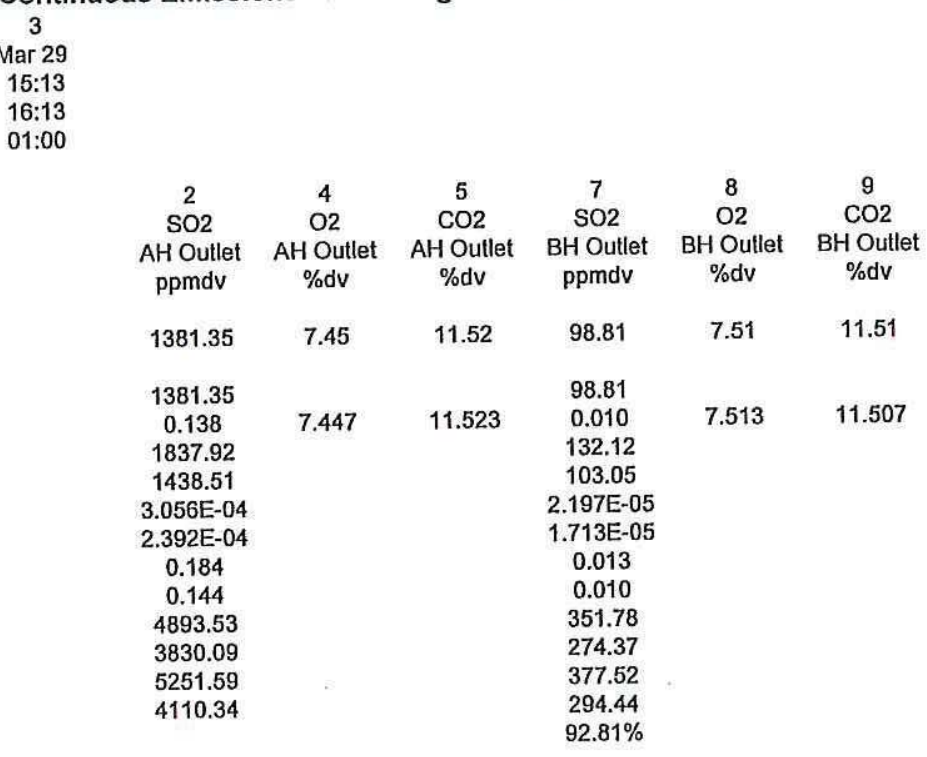




\section{This Page Intentionally Left Blank}


CONSOL ENERGY INC.

AES GREENIDGE STATION
Client Reference No: 4700140111

CleanAir Project No: 10192

QA/QC DATA

D

Revision 1

Appendix G

Page 61 of 537 
This Page Intentionally Left Blank 
Registered Labs Application

Page 1 of 1

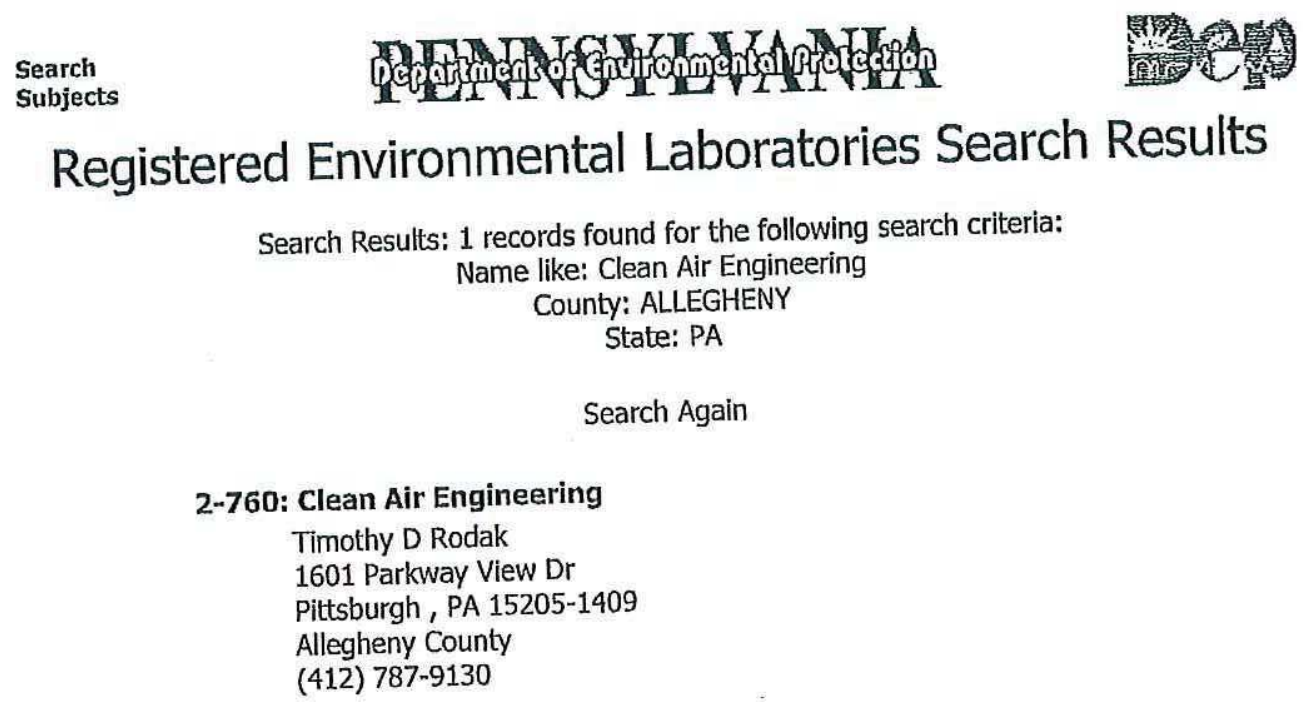

Search Again

PA Home Site | Ask DEP | Plug-Ins | Home Page

http://www.dep.state.pa.us/labs/registered/default.asp 


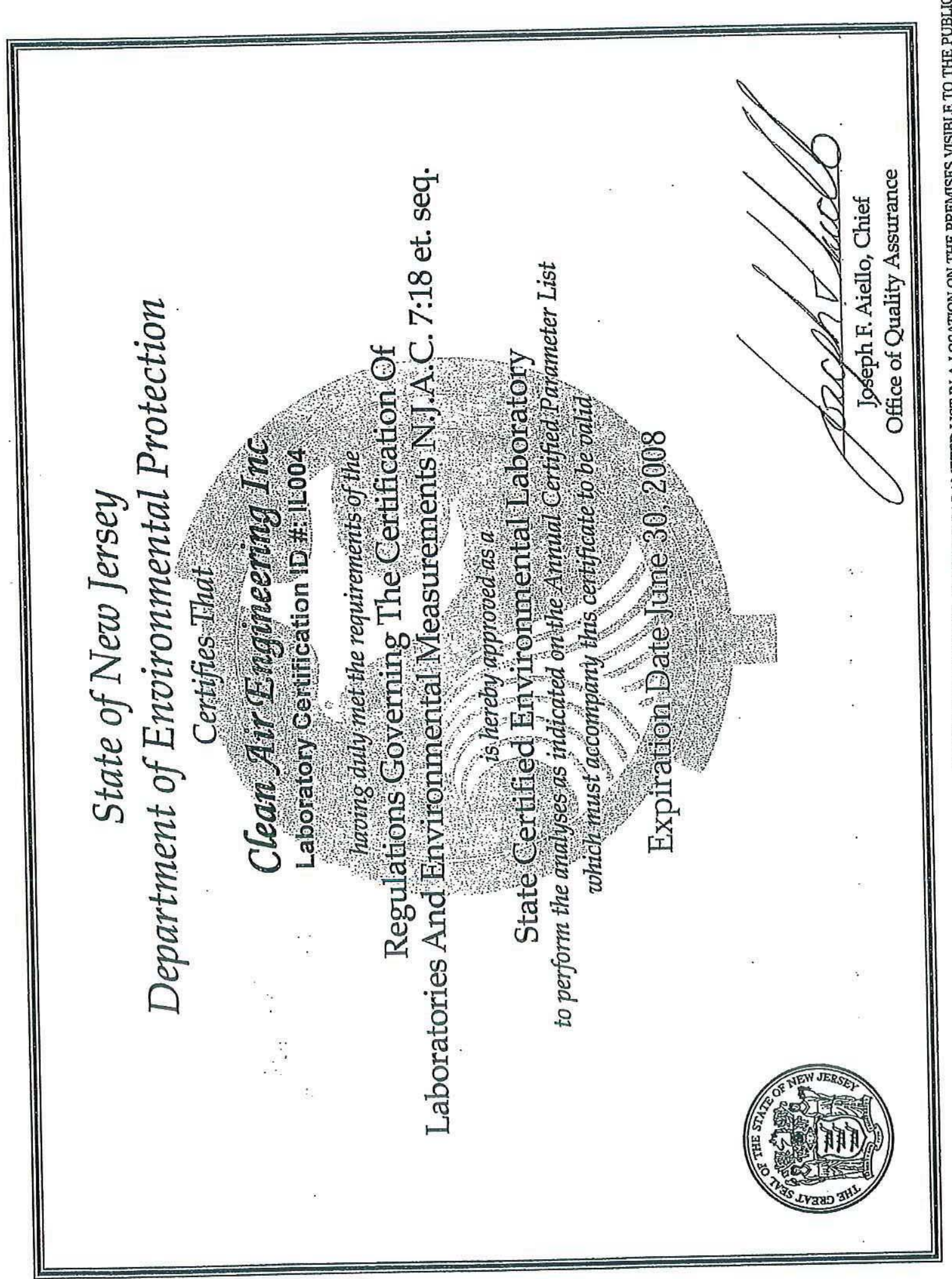

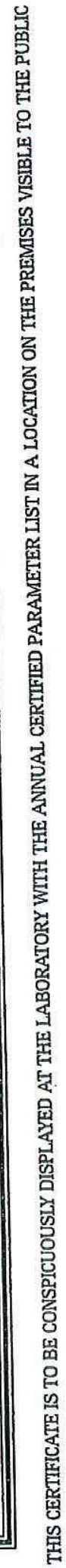




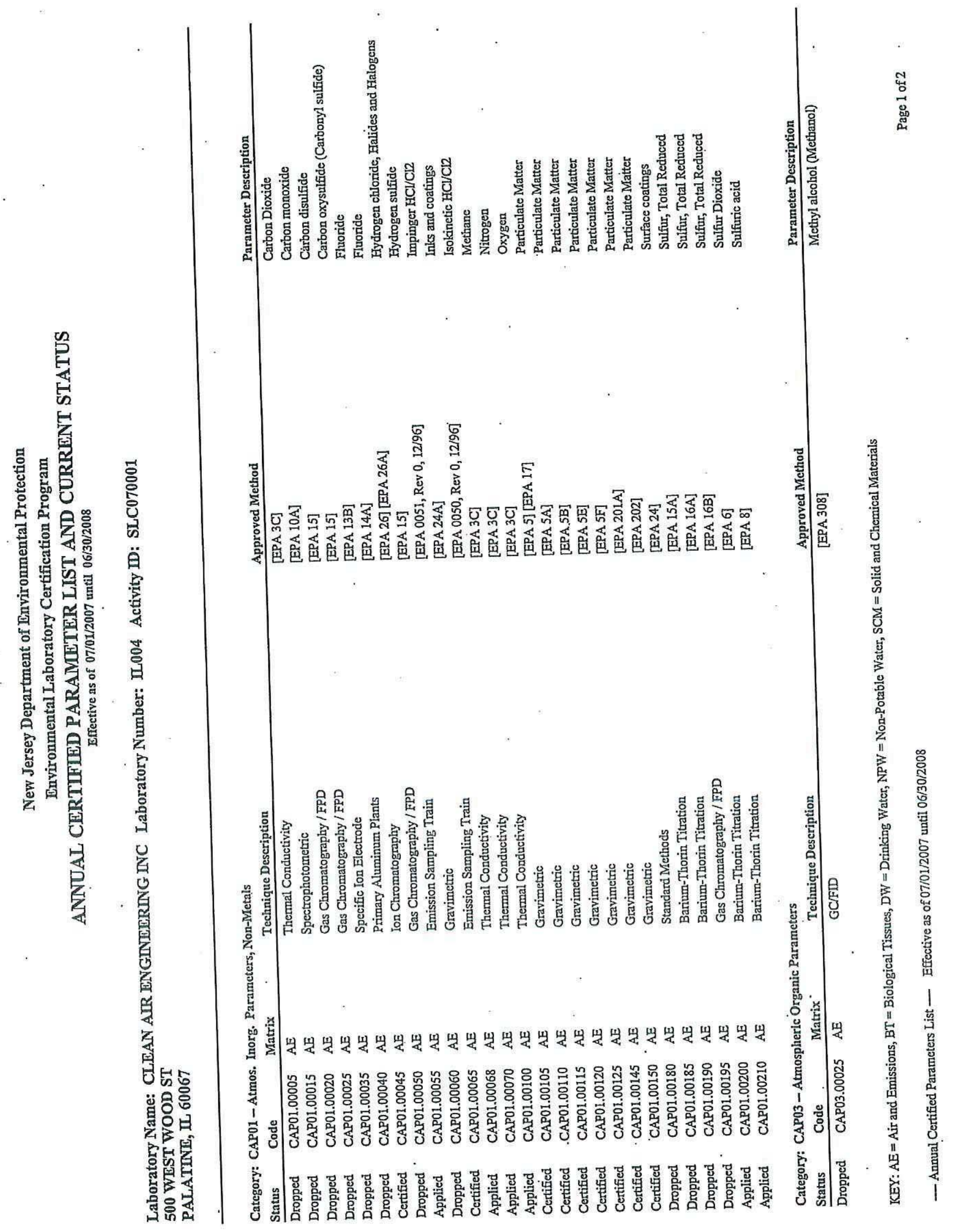




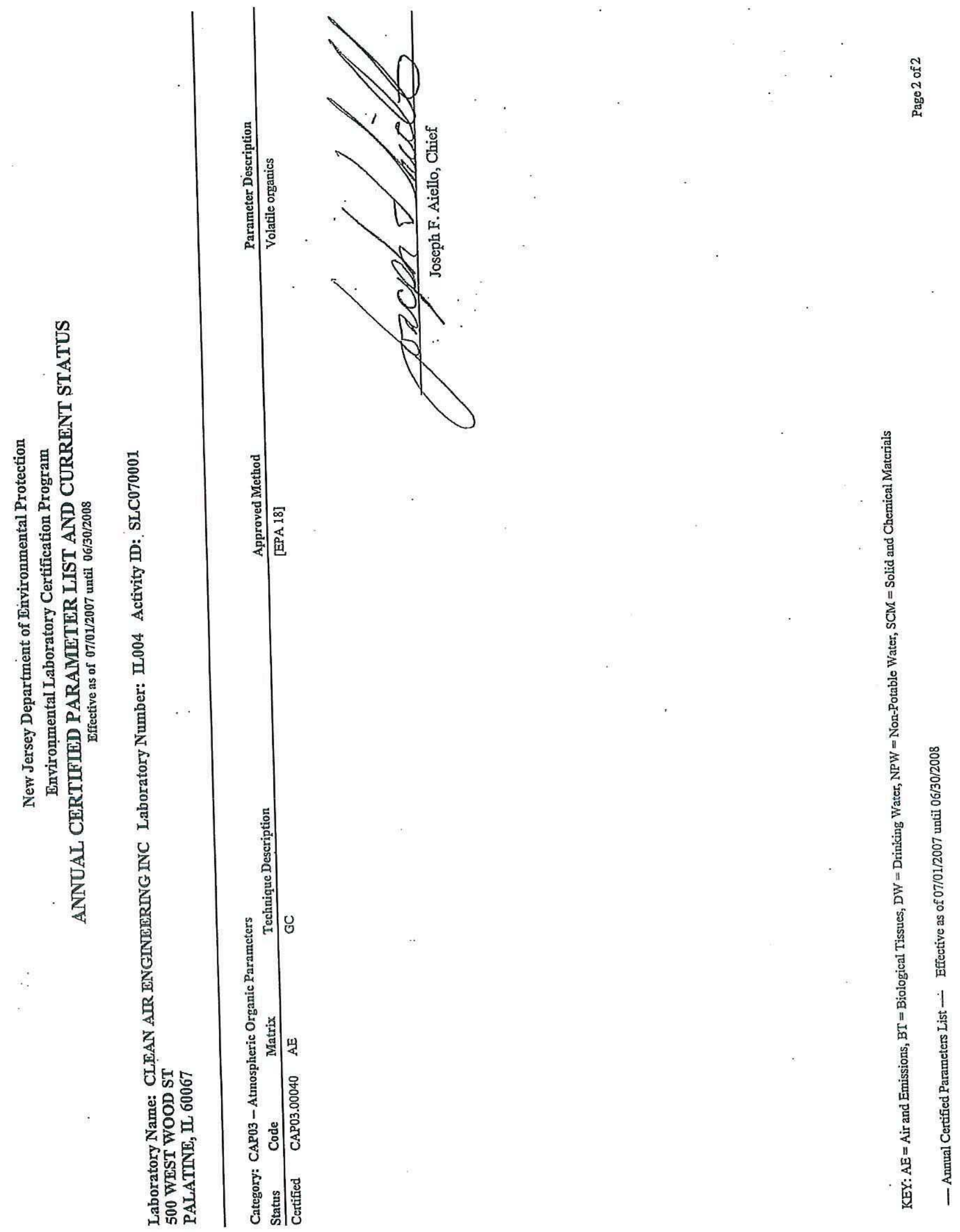




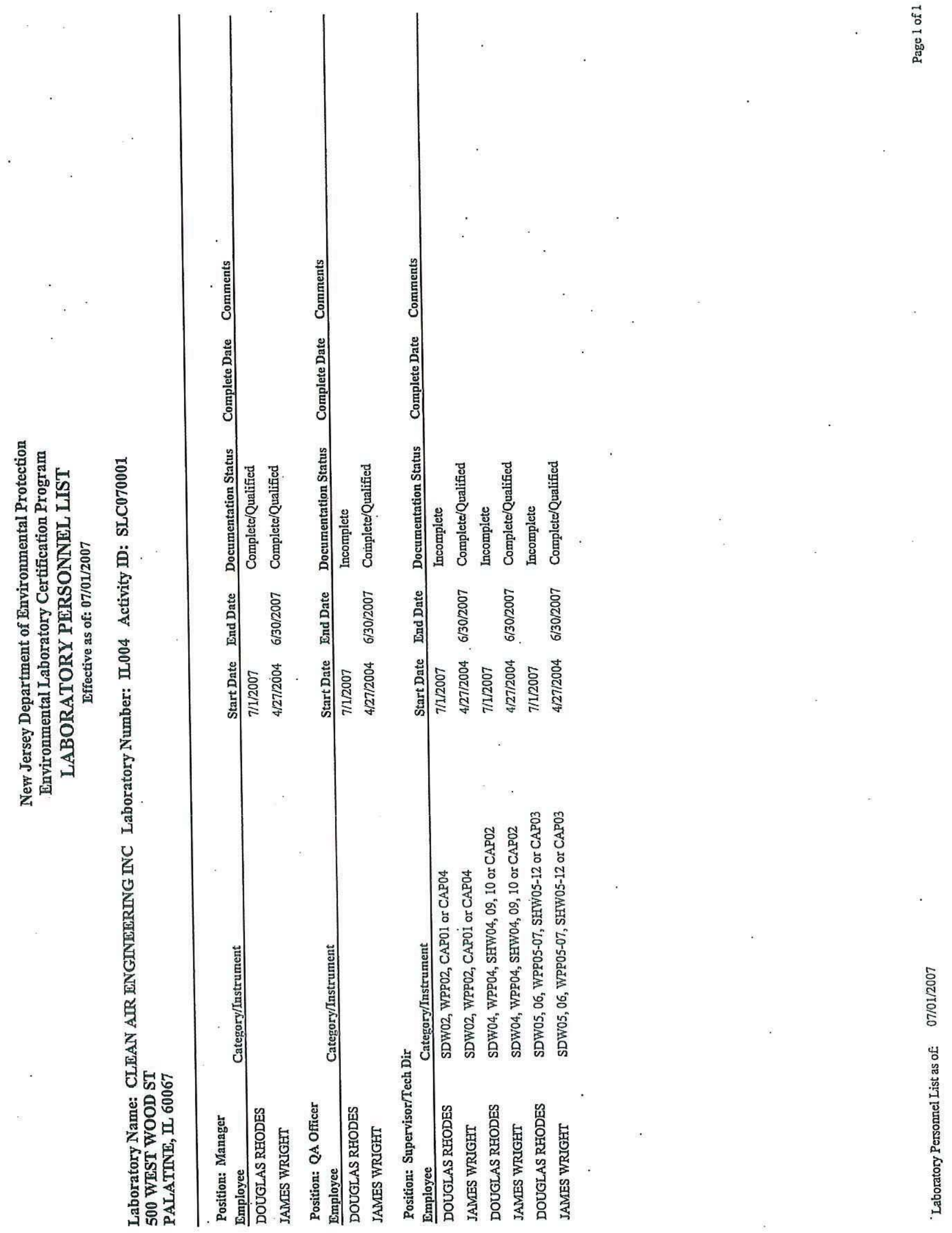




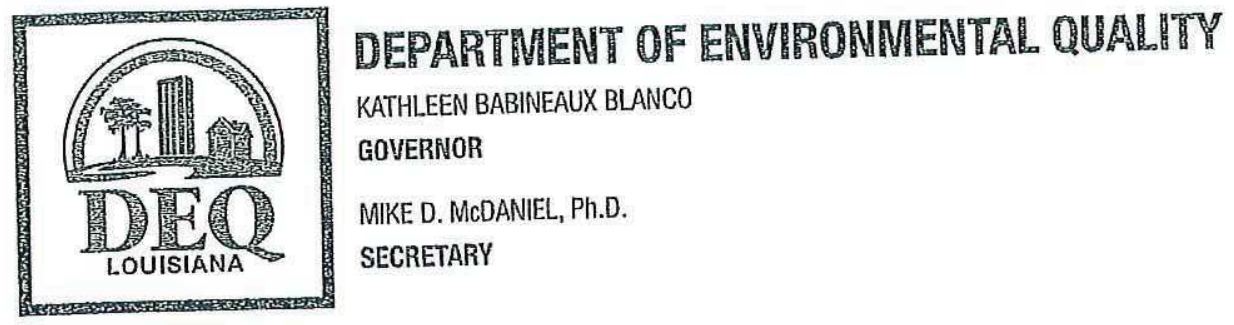

CERTIFIED MAIL \#7007 0710000561081458

Return Receipt Requested

June 30, 2007

AI \#85668

LELAP Certificate \#03099

Mr. Robert Doran

Clean Air Engineering

321 Century Plaza \#130

Houston, TX 77073

\section{RE: Accreditation Certificate}

Dear Mr. Doran:

In accordance with Louisiana Administrative Code, Title 33, Part I, Subpart 3, Laboratory Accreditation, the State of Louisiana formally recognizes that this laboratory has successfully completed the accreditation process and is technically competent to perform the environmental analyses listed on the scope of accreditation detailed in the attachment. Accreditation does not constitute an endorsement of the suitability of the listed methods for any specific purpose. Parameters or analytes that the laboratory has applied for accreditation not included in the scope of accreditation attachment are not accredited.

NELAP accreditation is granted only for those methods/analytes for which "NELAP" is indicated as the type of accreditation. "STATE" is indicated as the type of accreditation for those methods/analytes for which NELAP accreditation is not available. Accreditation is dependent on the laboratory's successful ongoing compliance with regulations as outlined in the Louisiana Administrative Code, Title 33, Part I, Subpart 3, Laboratory Accreditation.

The enclosed accreditation certificate is property of the State of Louisiana. Should a change in accreditation status occur, the Department may recall the original accreditation certificate and attachments. The recalled certificate and attachments should be returned

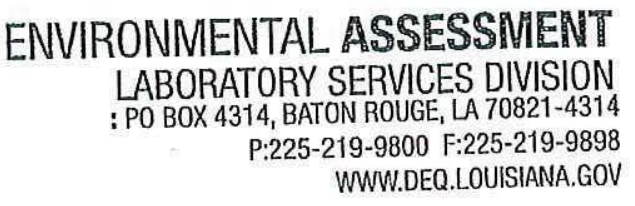


Re: Accreditation Certificate

June 30, 2007

Page 2 of 2

to: Office of Environmental Assessment, Louisiana Environmental Laboratory Accreditation Program, P.O. Box 4314, Baton Rouge, LA 70821-4314, Attention: Dr. David L. Boucher.

LAC 33:I.5313.A requires that the laboratory report must include all relevant information. Therefore, the certificate number shall be placed in the upper right corner of all laboratory reports. If the test report includes results of any test for which the laboratory is not accredited, the unaccredited results must be clearly identified as such.

Please be advised that it is your responsibility to examine the scope of accreditation attachment for accuracy and completeness. If you find that an analyte for which you expected to be accredited is not listed, please examine your records to ensure that:

1. You have met the requirements for successful participation in proficiency test studies as outlined in LAC 33:I.4711 and in the NELAC Standard 2.7.2.

2. In the case of accreditation by recognition, the requested analyte must be listed for the requested method and matrix on both the certificate issued by the Primary AA and on the Louisiana application form.

If you have any questions, please contact the Louisiana Environmental Laboratory Accreditation Program at (225) 219-9800.

Sincerely,

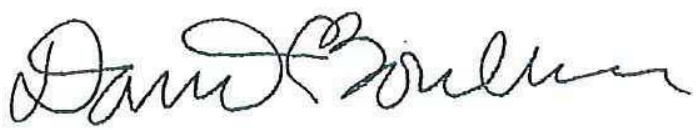

Dr. David L. Boucher, Acting Supervisor

Louisiana Environmental Laboratory Accreditation Program

$\mathrm{db}$

Enclosure 


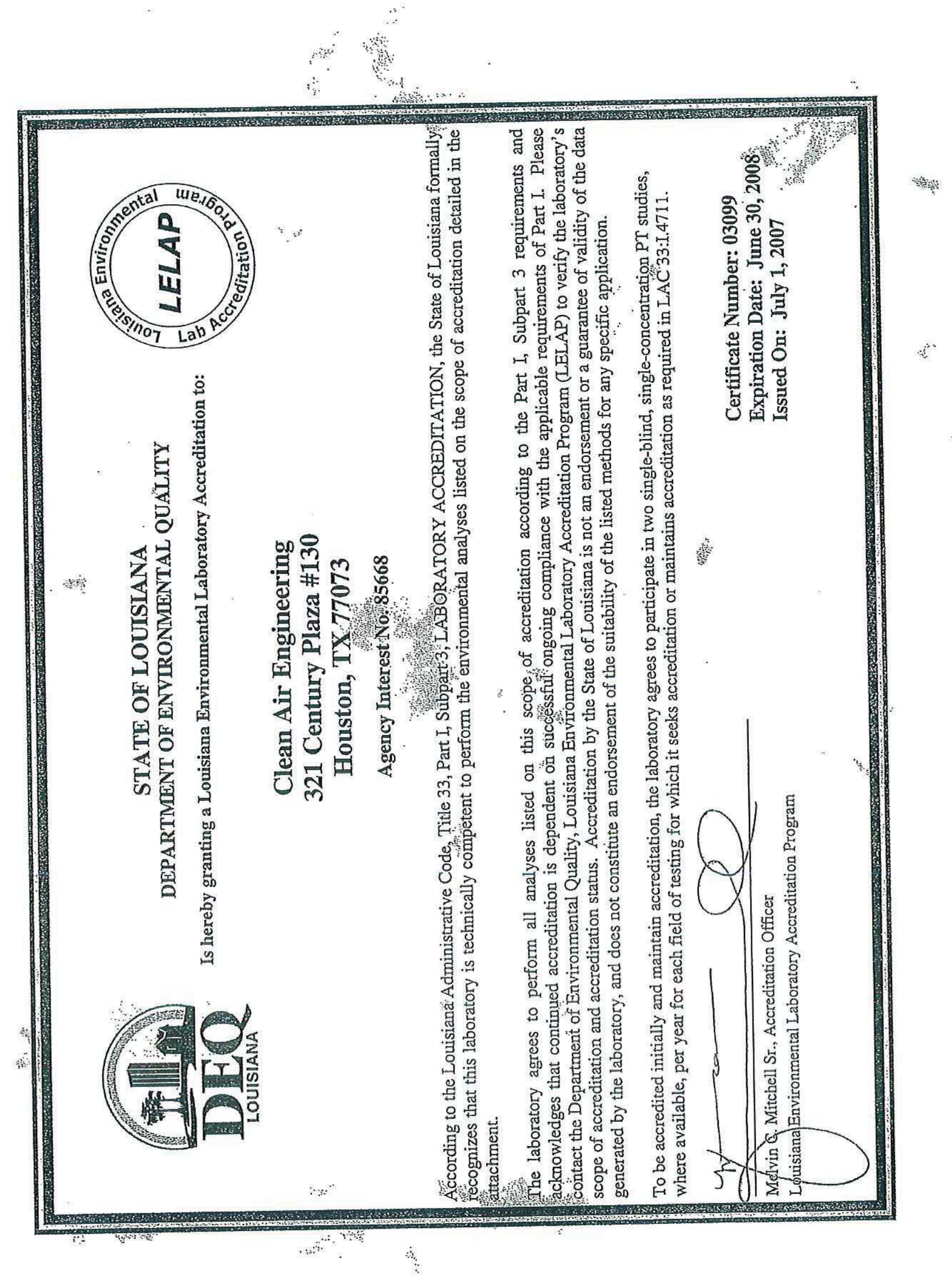




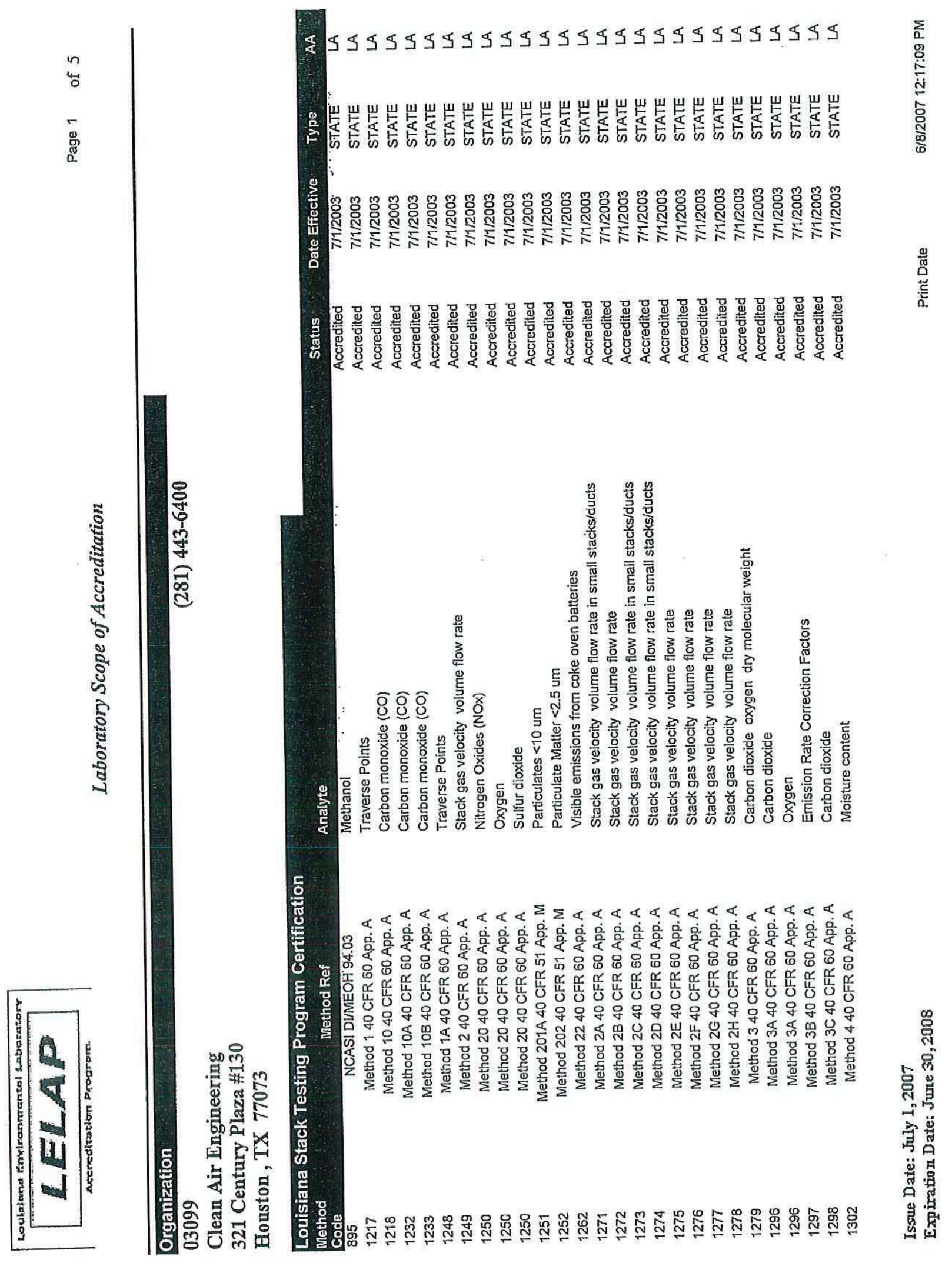




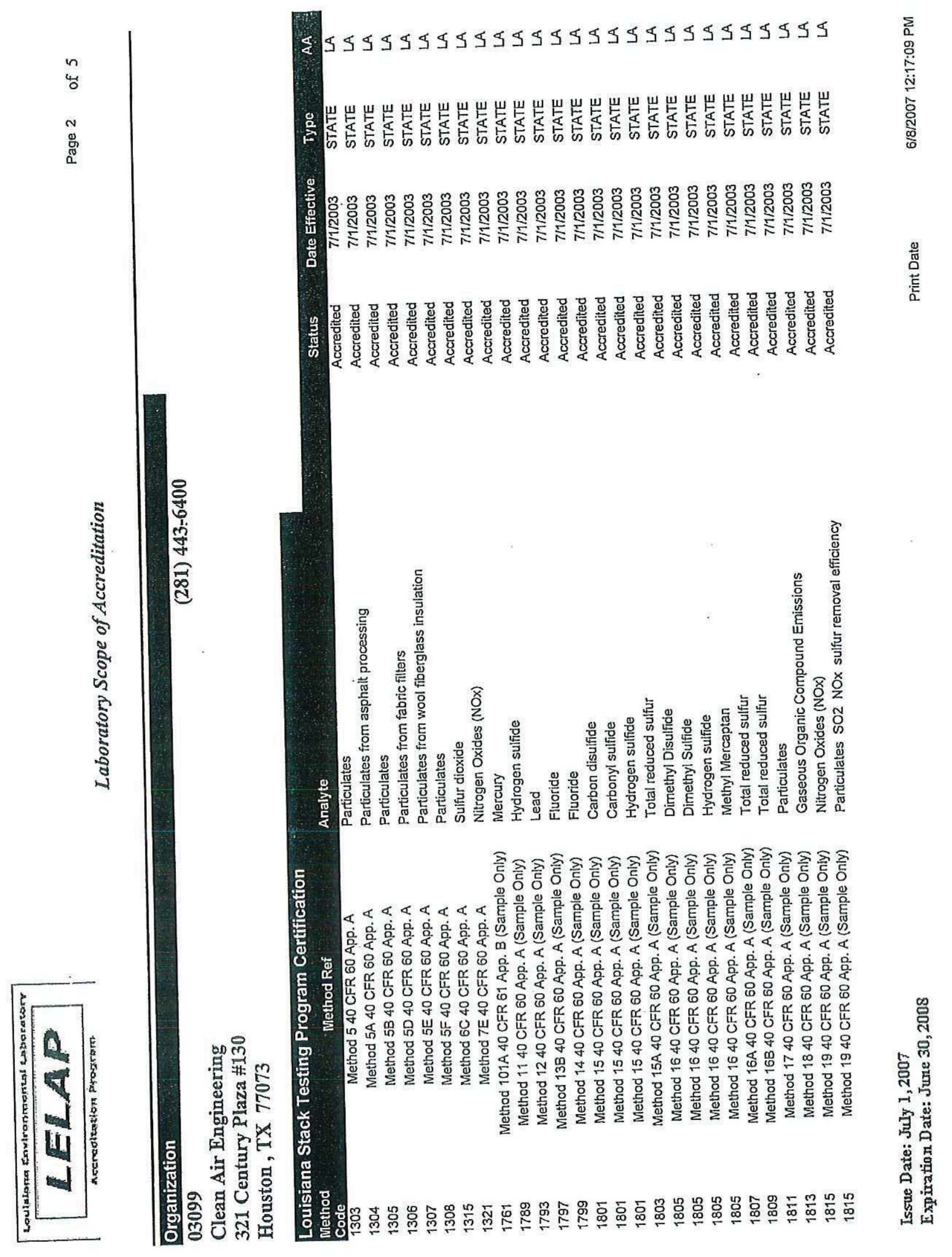




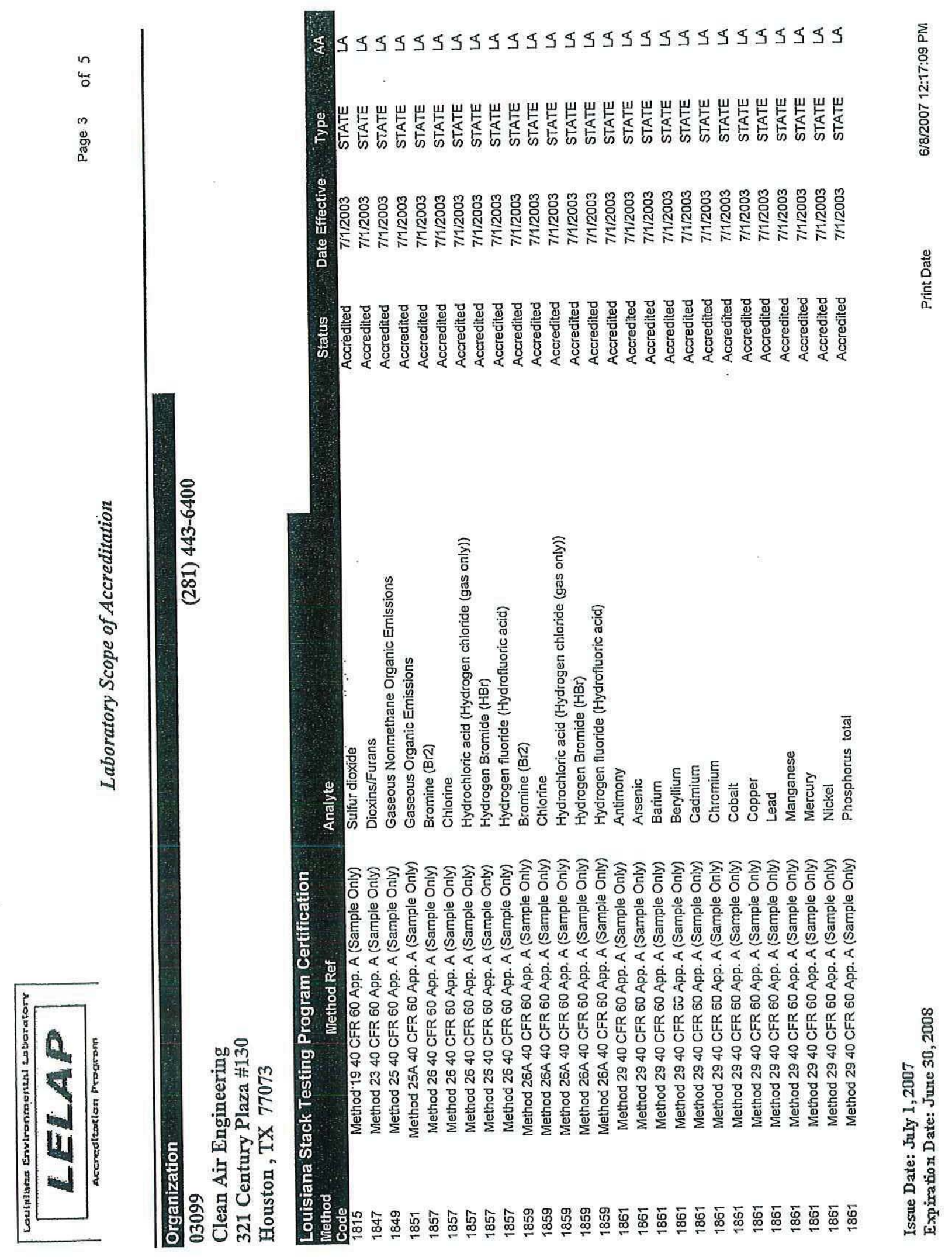




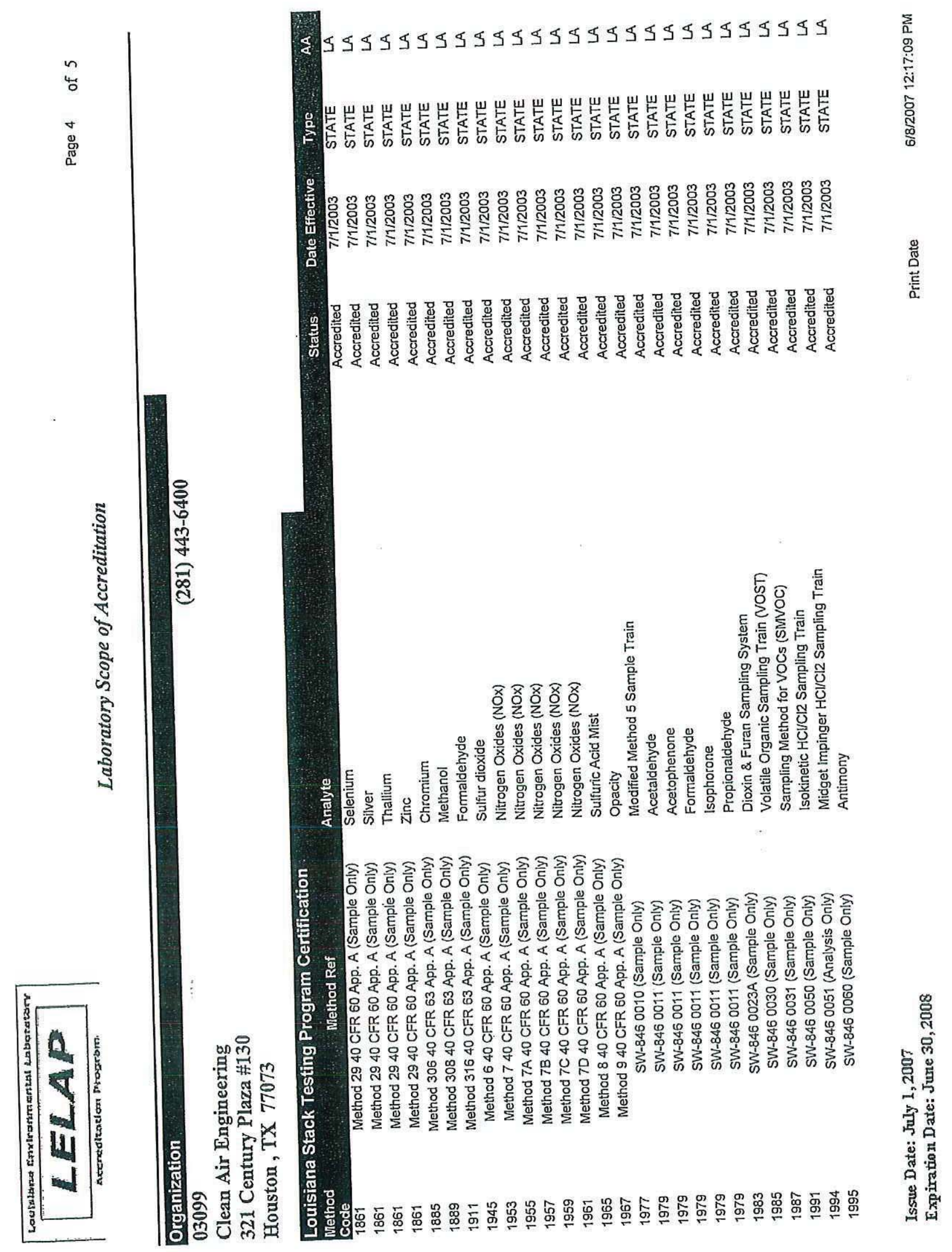




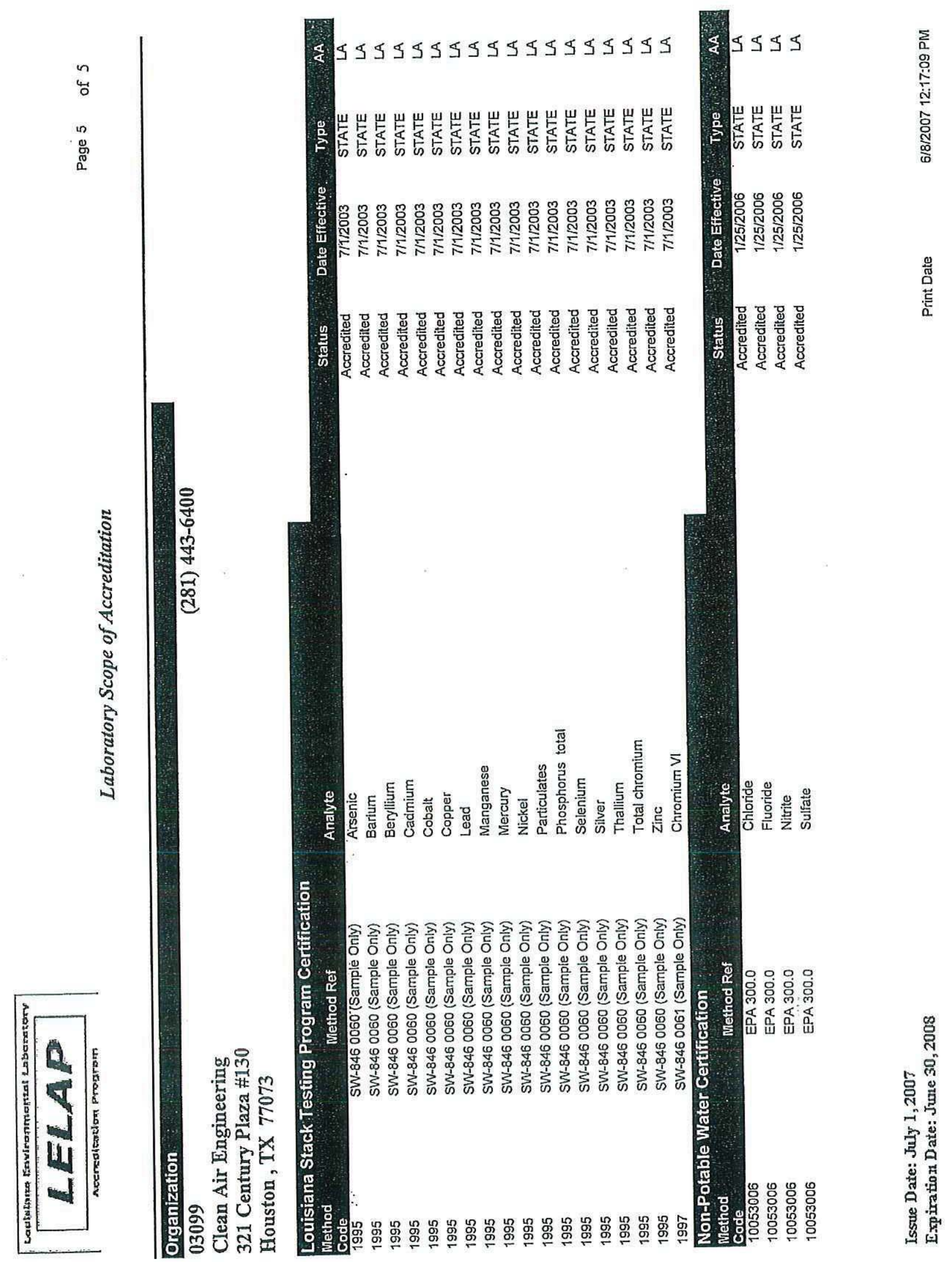




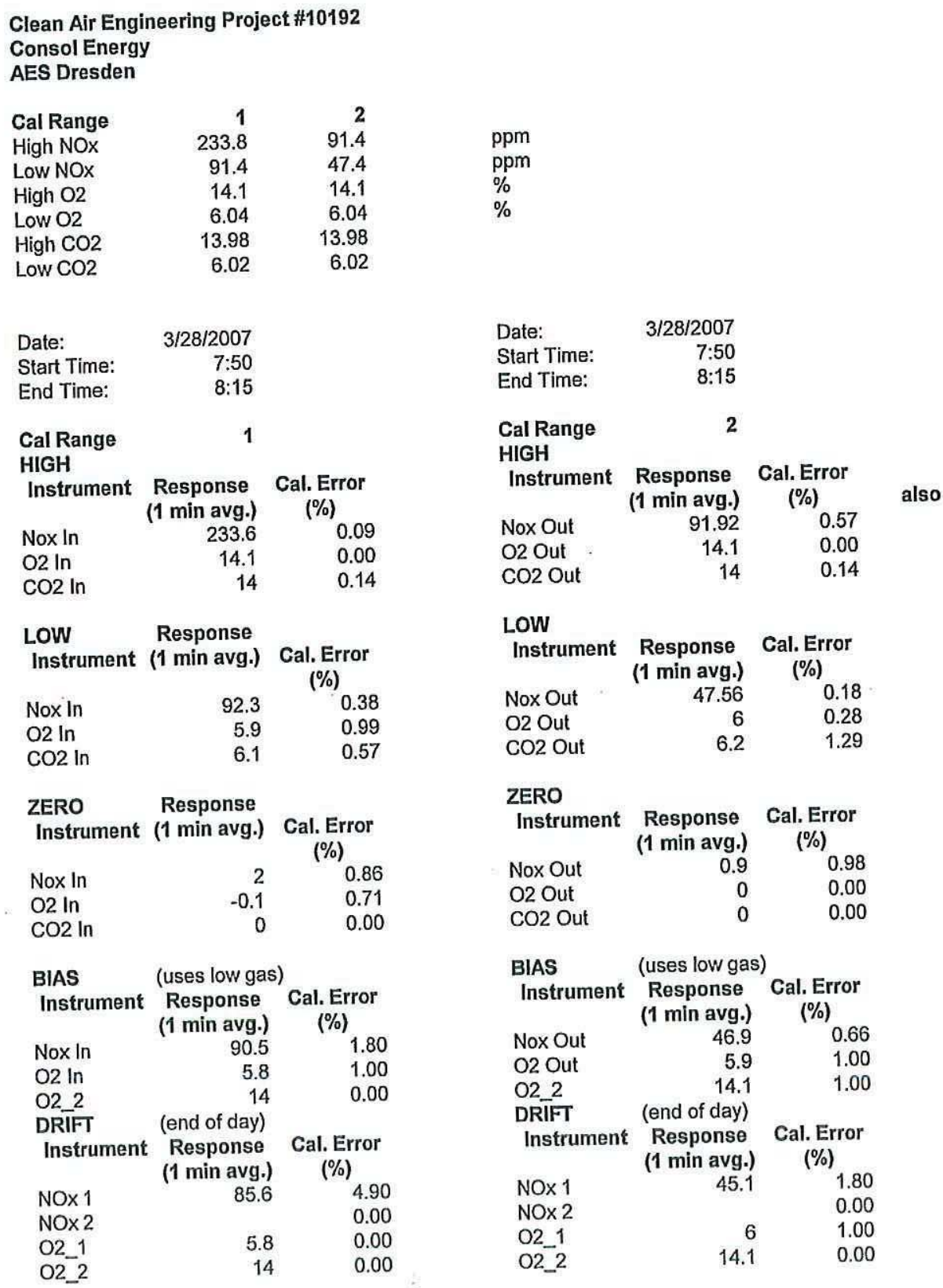


Consol Energy

CleanAIr Project No. 10192

Dresden, New York

BH Outlet, AH Outlet

$$
\begin{array}{rrr}
\text { Date: } & & \text { March 29, } 2007 \\
\text { Start Time } & 8: 39 & \\
\text { Stop Time } & 9: 01
\end{array}
$$

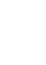

CALIBRATION ERROR

Channel 7
CALIBRATION ERROR

Channel 2
SO2

02

$\begin{array}{r}\mathrm{CO} 2 \\ \hline\end{array}$

SO2

AH Outlet

AH Outlet

BH Outlet

ppmov

Instrument Information

ppmdv

Manufacturer: Wstrn Rsrch

Model:

Detection:

921NMP

UV Photo.

204589 68-B
Servomex
$1420 \mathrm{~B}$
Paramagn.

Servomex Wstrn Rsrch 1415B 921 NMP
NDIR UVPhoto.

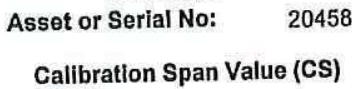

2479.000

System Response Time (seconds)

60

Manufacturer Certified Cylinder Value $\left(\mathbf{C}_{v}\right)$

$\begin{array}{lrr}\text { Zero } & 0.000 & 0.000 \\ \text { Low } & 121.600 & 6.040 \\ \text { Mld } & & \\ \text { High } & 2479.000 & 14.100\end{array}$

Actual gas to be used for blas checks

$$
2479.000
$$

6.040

68-B

14.100

60

$60 \quad 60$

$0.000 \quad 0.000$

49.350

121.600

13.980

13.980

49.350

6.040

\begin{tabular}{|c|c|c|c|c|c|c|}
\hline Zero & 3.452 & -0.010 & 0.148 & -0.056 & 0.002 & 0.003 \\
\hline Low & 133.235 & 6.061 & 6.041 & 48.630 & 6.050 & 5.940 \\
\hline Mid & & & 0.209 & & & \\
\hline High & 2482.035 & 14.189 & 14.059 & 121.848 & 14.140 & 13.966 \\
\hline
\end{tabular}

\begin{tabular}{rr}
$\begin{array}{r}\text { Channel } 8 \\
\text { O2 }\end{array}$ & $\begin{array}{r}\text { Channel } 9 \\
\text { CO2 }\end{array}$ \\
$\begin{array}{r}\text { BH Outlet } \\
\% \text { dv }\end{array}$ & $\begin{array}{r}\text { BH Outlet } \\
\% d v\end{array}$ \\
& \multicolumn{2}{c}{} \\
Servomex & \multicolumn{2}{c}{ Servomex } \\
$1420 \mathrm{~B}$ & NDIR \\
Paramagn. & $1415 \mathrm{~B}$ N \\
201170 & 203504
\end{tabular}

13.980

60

Cyllinder ID

\begin{tabular}{|c|c|c|c|c|c|c|}
\hline Zero & OK & OK & OK & OK & OK & \\
\hline Low & OK & OK & OK & OK & OK & OK \\
\hline MId & N/A & $N / A$ & N/A & N/A & N/A & $N / A$ \\
\hline
\end{tabular}

$\begin{array}{lrrrrrr}\begin{array}{l}\text { Zero } \\ \text { Low }\end{array} & \text { CC30072 } & \text { SG9134098BAL } & \text { XC012963B } & \text { CC13960 } & \text { SG9134098BAL } & \text { XC012963B } \\ \text { MId } & & & & & \\ \text { High } & \text { ALM012777 } & \text { XC012963B } & \text { SG9134098BAL } & \text { CC30072 } & \text { XC012963B } & \text { SG9134098BAL }\end{array}$

Analyzer Calibration Response ( $C_{\text {Dir }}$ )

\begin{tabular}{|c|c|c|c|c|c|c|c|}
\hline $051407 \quad 143432$ & & & 14.178 & & & 14.141 & \\
\hline & $\begin{array}{l}08: 39: 43 \\
08: 39: 58\end{array}$ & $\begin{array}{l}4.542 \\
3.810\end{array}$ & $\begin{array}{l}14.178 \\
14.182\end{array}$ & $\begin{array}{l}6.048 \\
6.044\end{array}$ & $\begin{array}{l}0.928 \\
0.830\end{array}$ & 14.141 & $\begin{array}{l}-0.122 \\
-0.122\end{array}$ \\
\hline & $08: 40: 13$ & 3.858 & 14.185 & 6.044 & 0.801 & 14.141 & -0.122 \\
\hline & $08: 40: 28$ & 3.712 & 14.188 & 6.044 & 0.732 & 14.141 & -0.122 \\
\hline & 08:40:43 & $\begin{array}{l}3.761 \\
3.858\end{array}$ & $\begin{array}{l}14.188 \\
14.191\end{array}$ & 6.044 & 0.156 & 14.139 & $\begin{array}{l}0.685 \\
3.858\end{array}$ \\
\hline & $\begin{array}{l}08: 40: 58 \\
08: 41: 13\end{array}$ & $\begin{array}{l}3.858 \\
4.103\end{array}$ & $\frac{14.191}{14.192}$ & 6.046 & 0.020 & $\frac{14.140}{14.143}$ & $\begin{array}{l}3.858 \\
5.938\end{array}$ \\
\hline & $\begin{array}{l}08: 41: 13 \\
08: 41: 28\end{array}$ & 3.712 & $\begin{array}{l}14.192 \\
14.194\end{array}$ & 6.041 & $\begin{array}{l}-0.020 \\
-0.049\end{array}$ & 14.140 & $\begin{array}{l}5.930 \\
5.940\end{array}$ \\
\hline & $\begin{array}{l}08: 41: 28 \\
08: 41: 43\end{array}$ & 3.810 & $\begin{array}{l}14.194 \\
14.192\end{array}$ & $\begin{array}{l}6.040 \\
6.041\end{array}$ & $\begin{array}{l}-0.049 \\
-0.049\end{array}$ & 14.143 & 5.940 \\
\hline & $\begin{array}{l}08: 41: 45 \\
08: 41: 58\end{array}$ & 3.858 & $\begin{array}{l}14.192 \\
14.192\end{array}$ & $\frac{6.041}{6.044}$ & -0.049 & 14.142 & 5.940 \\
\hline & $08: 42: 13$ & 3.858 & 14.193 & 6.040 & -0.052 & 14.144 & 5.940 \\
\hline
\end{tabular}

Analyzer Calibration Error (ACE) (Limit $=2 \%$, Method $25 \mathrm{~A}$ limit $=5 \%$ of gas value)

\begin{tabular}{lcccccr} 
Zzer Calibration Error (ACE) & (Limit $=2 \%$, & & & \\
Zero & $0.1 \%$ & $-0.1 \%$ & $1.1 \%$ & $0.0 \%$ & $0.0 \%$ & $0.0 \%$ \\
Low & $0.5 \%$ & $0.2 \%$ & $0.1 \%$ & $-0.6 \%$ & $0.1 \%$ & $-0.6 \%$ \\
Mid & N/A & N/A & N/A & N/A & N/A & N/A \\
High & $0.1 \%$ & $0.6 \%$ & $0.6 \%$ & $0.2 \%$ & $0.3 \%$ & $-0.1 \%$ \\
\hline
\end{tabular}

Calibration Error Status

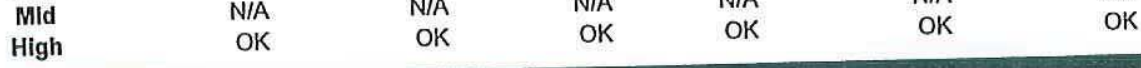

Psapares by Clean Atr Englheering Proprietary Soltware SS CEM Version 03-2004a

Copright 02004 Clean AVr Engineering Inc. 
Consol Energy

CleanAIr Project No. 10192

Dresden, New York

BH Outlet, AH Outlet

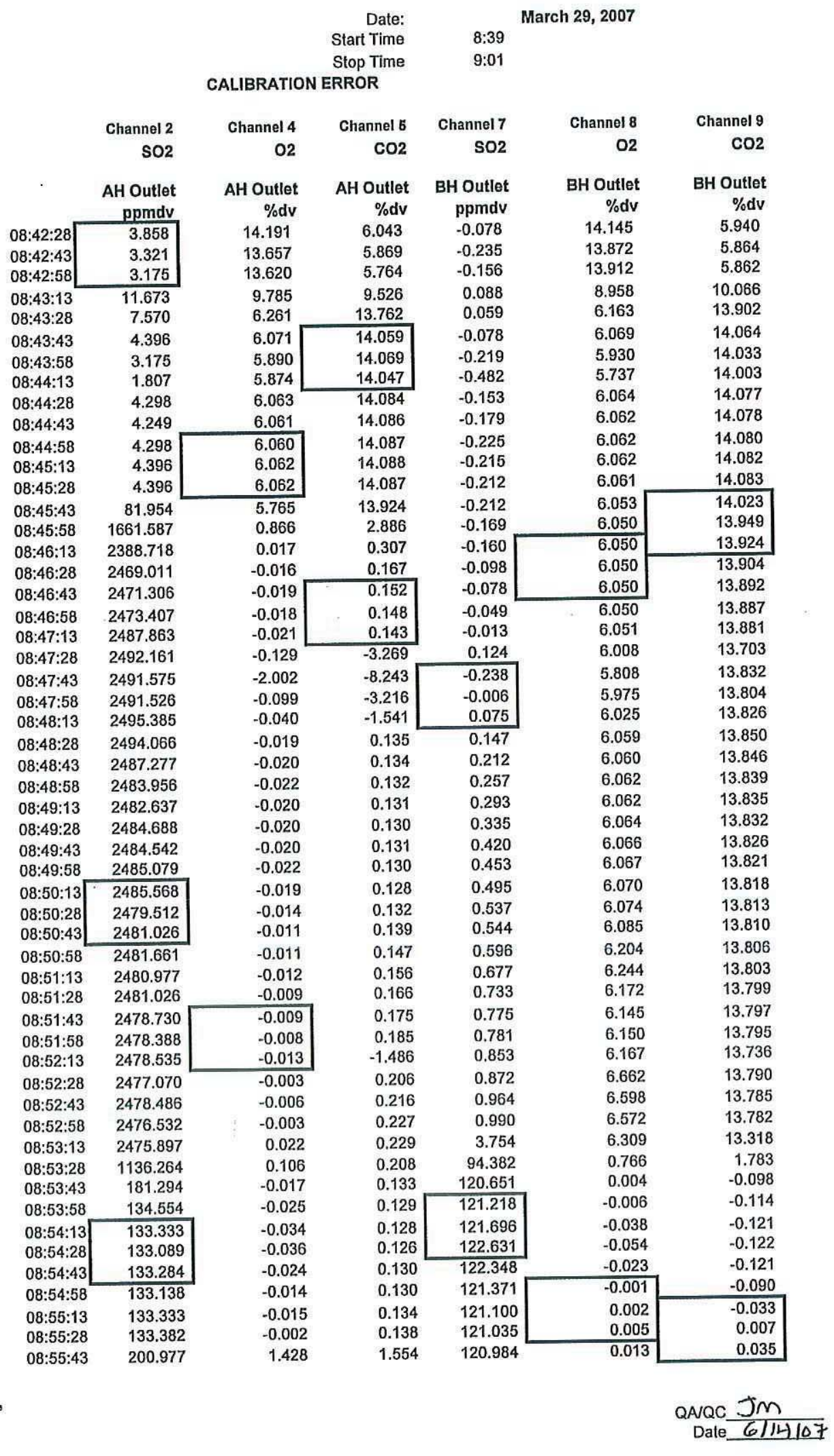


Consol Energy

CleanAlr Project No. 10192

Dresden, New York

$\mathrm{BH}$ Outlet, AH Outlet
Prepared by Clean Al: Engineering Propritary Software

SS CENA Verston 08-2004a

Copyrigh 02004 Clean Atr Englineering Inc.

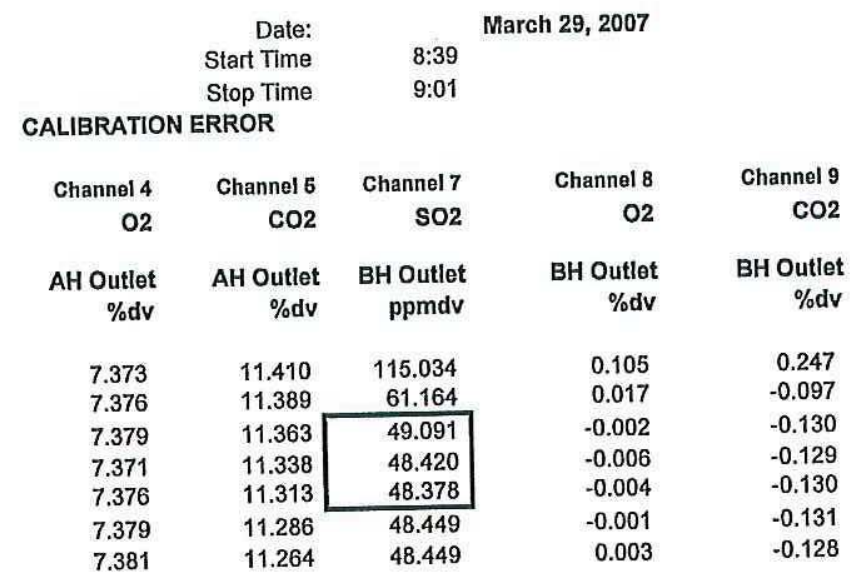

QAVC JM

Date $6 / 14 / 07$ 


\section{Certificate of Analysis: EPA Protocol Gas Mixture}

Airgas Great Lakes, Inc. 2009 Bellaire Ave.

Royal Oak, MI 48067

Ph: (248) 399-9150

Cylinder Number: SG9134098BAL Reference Number: 32-112503706-4

Fax: (248) $584-2540$

Cylinder Pressure: 2000.6 PSIG

Expiration Date: $\quad$ 9/19/2009

Certification Date: 9/19/2006

Laboratory:

MIC - Royal Oak - MI

http://www.airgas.com

\section{Certified Concentrations}

\begin{tabular}{l} 
Component \\
OXYGEN \\
CARBON DIOXIDE \\
NITROGEN \\
\hline
\end{tabular}

Concentration
$6.040 \%$
$13.98 \%$
Balance

Accuracy
$+1-1 \%$
$+1-1 \%$

Analytical Principle

Paramagnelic (Para)

Nondispersive Infrared (NDIR)

Procedure

G1

G1

Certification performed in accordance with "EPA Traceability Protocol (Sept. 1997)" using the assay procedures listed. Analytical Methodology does not require correction for analytical interferences.

Notes: CREIGHTON

Do not use cylinder below 150 psig.

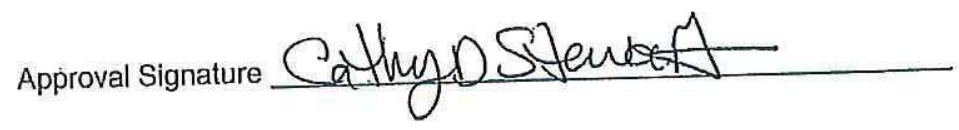

\section{Reference Standard Information}

$\begin{array}{lll}\text { TYpe } & \text { Balance Gas } & \text { Component } \\ \text { NTRiM 82745 } & \text { NITROGEN } & \text { CARBON DIOXIDE } \\ \text { NTRM 82658X } & \text { NITROGEN } & \text { OXYGEN }\end{array}$

Analytical Results 1st Component

OXYGEN

1st Analysis Date:

R 3.51 S 3.02

S $3.02 \quad Z 0.00$

09/19/2006

$\mathrm{Z} 0.00$

R 3.51

$\mathrm{Z} 0.00$

R 3.51

S 3.02
Cvl.Number Concentration

SG9183197BAL

SG9160230BAL

2nd Component

1st Analysis Date:

R $7.93 \quad S 6.99$

S6.99 Z 0.00

Conc $6.040 \%$

Conc $6.040 \%$

AVG: $6.040 \%$
$\mathrm{Z} 0.00 \quad \mathrm{R} 7.93$
$15.862 \%$

$7.015 \%$

CARBON DIOXIDE

09/19/2006

Z 0.00 Conc $13.98 \%$

R 7.93 Conc $13.98 \%$

S 6.99 Conc $13.98 \%$

AVG: $13.98 \%$ 
Certificate of Analysis: EPA Protocol Gas Mixture

Cylinder Number: XC012963B Reference Number: 32-112503706-3

Cylinder Pressure: 2000.6 PSIG Expiration Date: $\quad$ 9/19/2009

Certification Date: 9/19/2006 Laboratory:

MIC - Royal Oak - MI
Airgas Great Lakes, Inc. 2009 Bellaire Ave.

Royal Oak, MII 48067

$\mathrm{Ph}:$ (248) 399-9150

Fax: (248) $584-2540$

http://www.airgas.com

\section{Certified Concentrations}

\begin{tabular}{ll} 
Component & Concentration \\
CARBON DIOXIDE & $6.020 \%$ \\
OXYGEN & $14.10 \%$ \\
NITROGEN & Balance \\
\hline
\end{tabular}

Procedure
G1
G1

Nondispersive Infrared (NDIR)

Paramagnetic (Para)

$+1-1 \%$

Certification performed in accordance with "EPA Traceability Protocol (Sept. 1997)" using the assay procedures listed. Analytical Methodology does not require correction for analytical interferences.

Notes: CREIGHTON

Do not use cylinder below 150 psig.

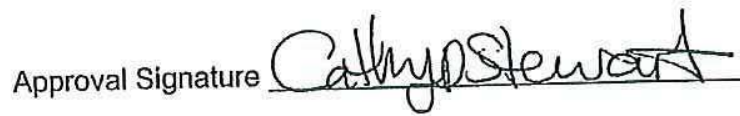

\section{Reference Standard Information}

\begin{tabular}{|c|c|c|c|c|}
\hline Type & Balance Gas & Component & Cyl.Number & Concentration \\
\hline NTRM 81674 & NITROGEN & CARBON DIOXIDE & XC018562B & $6.89 \%$ \\
\hline NTRM 82659X & NITROGEN & OXYGEN & XC024399B & $22.60 \%$ \\
\hline
\end{tabular}

Analytical Results

1st Component

1st Analysis Date:

R 6.89 S 6.02

S $6.02 \quad Z 0.00$

Z $0.00 \quad R 6.89$

\section{CARBON DIOXIDE}

09/19/2006

Z $0.00 \quad$ Conc $6.020 \%$

R 6.89 Conc $6.020 \%$

S 6.02 . Conc $6.020 \%$

AVG: $6.020 \%$ 2nd Component

1st Analysis Date:

R $4.52 \quad S 2.82$

$S 2.82 \quad Z 0.00$

$\mathrm{Z} 0.00 \quad \mathrm{R} 4.52$

\section{OXYGEN}

09/19/2006

Z 0.00 Conc $14.10 \%$

R 4.52 Conc $14.10 \%$

S 2.82 Conc $14.10 \%$

AVG: $14.10 \%$ 


\section{Certificate of Analysis: EPA Protocol Gas Mixture}

Airgas Great Lakes, Inc. 2009 Bellalre Ave.

Royal Oak, MI 48067

Ph: (248) 399-9150

Cylinder Number: CC13960 Reference Number: 32-112503706-6

Cylinder Pressure: 2000.6 PSIG Expiration Date: 9/25/2008

Certification Date: 9/25/2006 Laboratory: MIC-Royal Oak-MI

Fax: (248) $584-2540$

http://www.airgas.com

\section{Certified Concentrations}

\begin{tabular}{lllll}
\hline Component & Concentration & Accuracy & Analytical Principle \\
SULFUR DIOXIDE & 49.35 PPM & $+/-1 \%$ & Nondispersive Ultraviolet (NDUV) \\
CARBON MONOXIDE & 123.83 PPM & $+/-1 \%$ & Nondispersive Infrared (NDIR) & G1 \\
NITRIC OXIDE & 126.49 PPM & $+l-1 \%$ & Chemiluminescence (Chemi) \\
NITROGEN & Balance & & \\
\hline
\end{tabular}

Total oxides of nitrogen 126.9 PPM

Certification performed in accordance with "EPA Traceability Protocol (Sept. 1997)" using the assay procedures listed. Analytical Methodology does not require correction for analytical interferences.

Notes:CREIGHTON

Do not use cylinder below 150 psig.

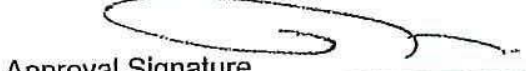

Approval Signature

\section{Type \\ NTRM 82636 NTRM $81661 X$ NTRM 81694 NTRM 81685 \\ Analytical Results 1st Component}

Reference Standard !nformation 1st Analysis Dáie: R $98.5 \quad S 19.7$ $S 19.7 \quad Z 0.0$ $\mathrm{Z} 0.0$ R 98.5

2nd Analysis Date: R $97.541 \quad S 49.227$

$S 49.267 \quad Z-0.123$

$Z-0.119 \quad R \quad 97.669$

3rd Component 1st Analysis Date: R4.89 S 2.52 $\mathrm{S} 2.52 \quad \mathrm{Z} 0.0$

$\begin{array}{ll}\mathrm{Z} 0.0 & \mathrm{R} 4.89\end{array}$

2nd Analysis Date: R 249.12 $\mathrm{S} 129.62$ Z 0.468

Balance Gas
NITROGEN
NITROGEN
NITROGEN
NITROGEN
$09 / 73 / 2000$

09/25/2006
Component CARBON MONOXIDE XC014180B SULFUR DIOXIDE SULFUR DIOXIDE NITRIC OXIDE

\section{SULFUR DIOXIDE}

$\therefore$ \&

Z 0.0 Conc 49.2 PPM

R 98.5 Conc 49.2 PPM

S 19.7 Conc 49.2 PPM

AVG: 49.2 PPM

$\mathrm{Z}-0.123$ Conc 49.57 PPM

R 97.757 Conc 49.45 PPM

S 49.273 Conc 49.50 PPM

.AVG: 49.50 PPM

NITFIC BXIDE

09/18/2006

$\begin{array}{ll}\text { Z } 0.0 & \text { Conc 126.1 PPM } \\ \text { R } 4.89 & \text { Conc 126.1 PPM } \\ \text { S 2.52 } & \text { Conc 126.1 PPM } \\ & \text { AVG: 126.1 PPM } \\ \text { 09/25/2006 } & \\ \text { Z } 0.443 & \text { Conc 127.02 PPM } \\ \text { R 249.89 } & \text { Conc 125.70 PPM } \\ \text { S 129.58 } & \text { Conc 126. } 2 \text { PPM }\end{array}$

AVG: 126.88 PPM
Concentration

246.2 PPM

246.1 PPM

$98.0 \mathrm{PPM}$

244.6 PPM

\section{2nd Component}

1st Analysis Date:

R $4.93 \quad S 2.48$

$S 2.48 \quad Z 0.0$

$\mathrm{Z} 0.0 \quad \mathrm{R} 4.93$

2nd Analysis Date:

R $248.08 \quad S 124.52$

S $124.76 \quad Z-0.124$

$\mathrm{Z}-0.204 \quad \mathrm{R} 247.63$

\section{CARBON MONOXIDE}

$09 / 18 / 2006$

Z 0.0 Conc 123.8 PPM

R 4.93 Conc 123.8 PPM

S2.48 Conc 123.8 PPM

AVG: 123.8 PPM

09/25/2006

$Z-0.032$ Conc 123.59 PPM

R 247.98 Conc 123.92 PPM

S 124.71 Conc 124.09 PPM 
Customer:

Part Number:

Cylinder Number:

Laboratory:

Analysis Date:

\section{CERTIFICATE OF ANALYSIS - Grade of Product: EPA Protocol}

E02NI99E15A0914

CC30072

MIC - Royal Oak - MI

Feb 19, 2007

\section{CREIGHTON}

Reference Number: $32-112534012-2$

Cylinder Volume: 144 Cu.Ft.

Cylinder Pressure: 2015 PSIG

Valve Outlet:
Airgas Great Lakes, Inc. 2009 Bellaire Ave. Royal Oak, MI 48067

Ph: (248) 399-9150

Fax: (248) 584-2540.

http://www.airgas.com

\section{· Expiration Date: Feb 19, 2009}

\begin{tabular}{|c|c|c|c|c|}
\hline \multicolumn{5}{|c|}{ 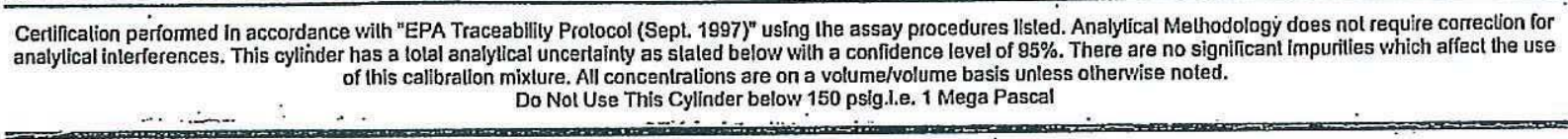 } \\
\hline \multicolumn{5}{|c|}{ ANALYTICAL RESULTS } \\
\hline Component & $\begin{array}{l}\text { Requested } \\
\text { Concentration }\end{array}$ & $\begin{array}{l}\text { Actual } \\
\text { Concentration }\end{array}$ & $\begin{array}{l}\text { Protocol } \\
\text { Method }\end{array}$ & $\begin{array}{l}\text { Total Relative } \\
\text { Uncertainity }\end{array}$ \\
\hline $\begin{array}{l}\text { SULFUR DIOXIDE } \\
\text { NITROGEN. }\end{array}$ & $\begin{array}{l}120.000 \text { PPM } \\
\text { Balance }\end{array}$ & $121.6 \mathrm{PPM}$ & G1 & $+/-1 \%$ NIST Traceable \\
\hline
\end{tabular}

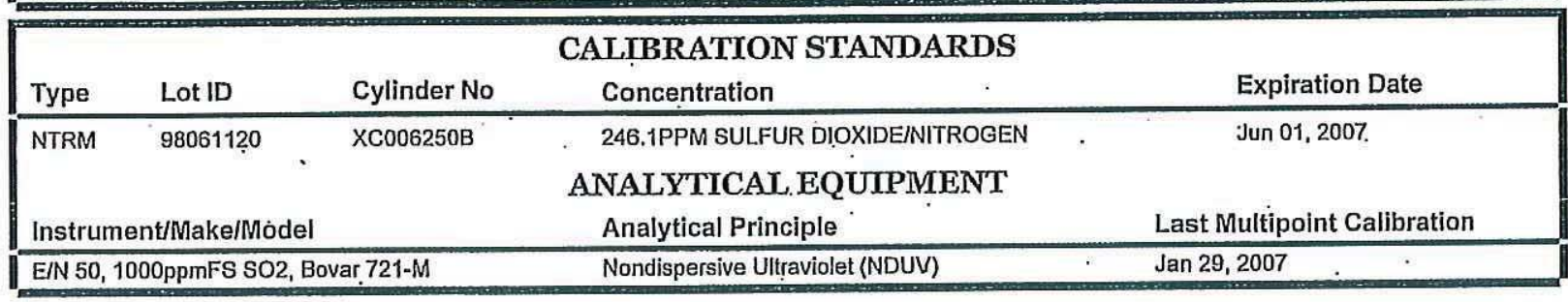

Triad Data Available Upon Request

Notes:

AFM

QA Approval 


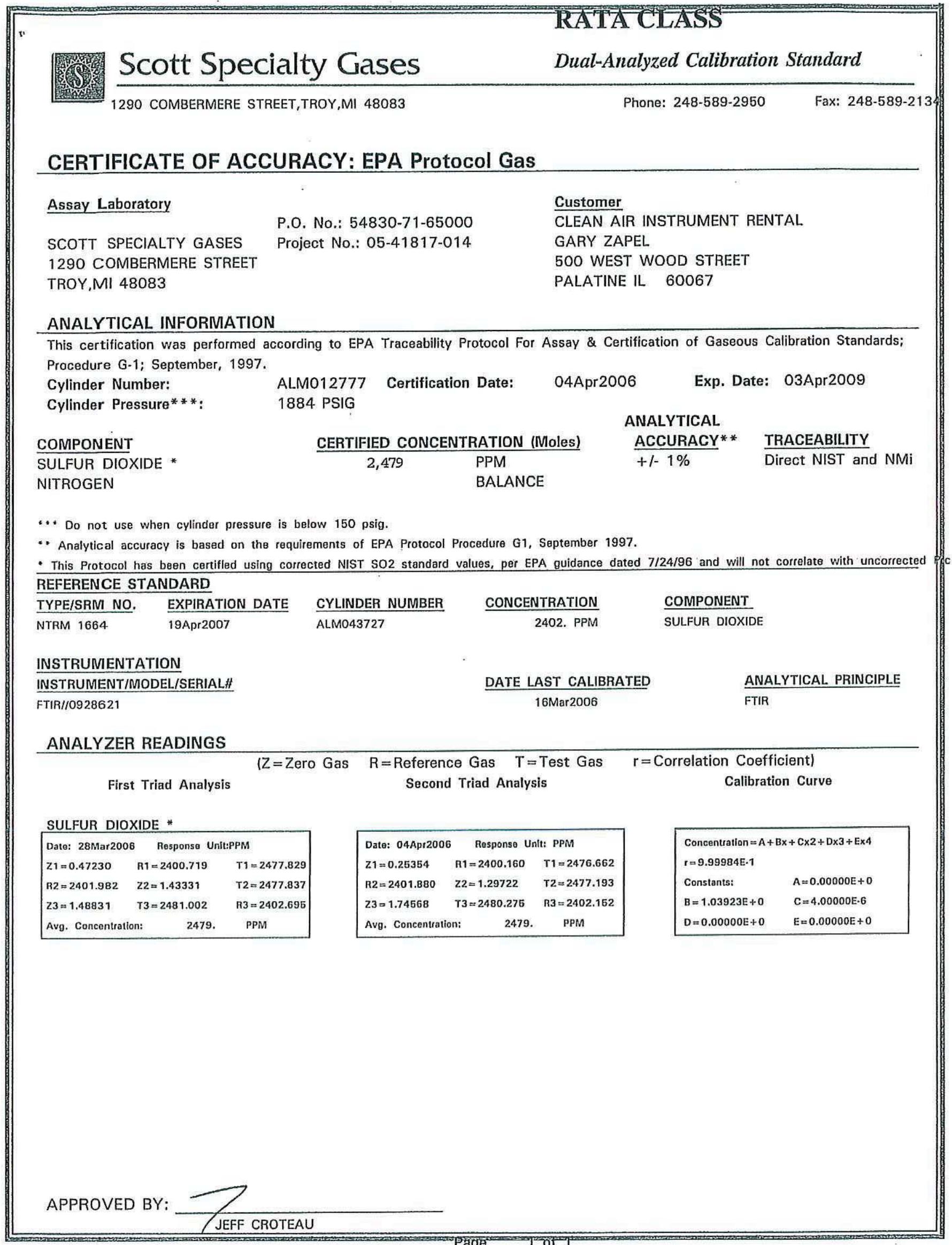




\section{CERTIFICATE OF ANALYSIS Grade of Product: EPA Protocol}

Airgas Great Lakes, Inc. 2009 Bellaire Ave. Royal Oak, MI 48067 Ph: (248) 399-9150 Fax: (248) 584-2540 http://www.airgas.com

Customer:

Part Number:

Cylinder Number:

Laboratory:

Analysis Date:

\section{AIRGAS CREIGHTION}

E04NI99E15A70B4

CC96201

MIC - Royal Oak - MI

Feb 19, 2007
Reference Number: 32-112534012-5

Cylinder Volume: $144 \mathrm{Cu}$.Ft.

Cylinder Pressure: 2015 PSIG

Valve Outlet:

Expiration Date: Feḅ 19, 2009

Certifica Certificalion performed anatytical inferferences. This cyindar of this calioralion mixlure. All concentrations are on a volume/volume basis unless othervise noted. of this calibration mixture. All concentrations are on a volume/volume basis uness
Do Nol Use This Cylinder below 150 psig.i.e: 1 Mega Pascal

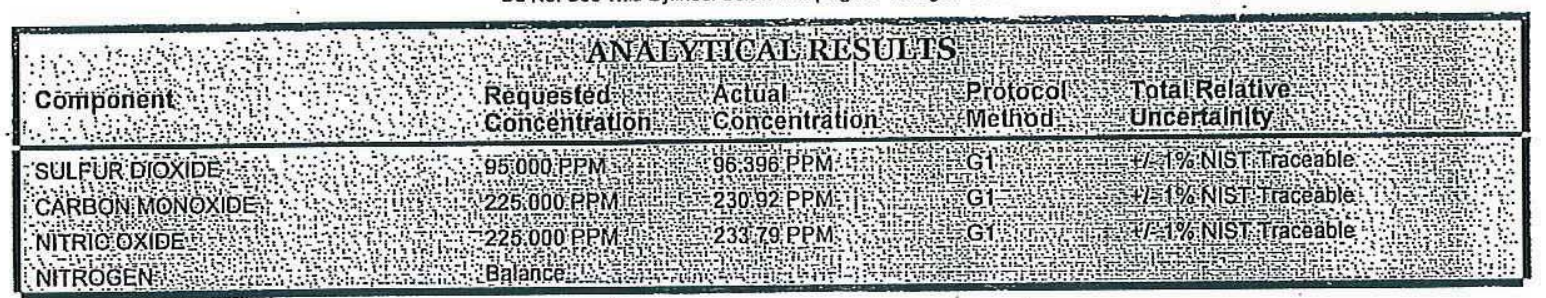

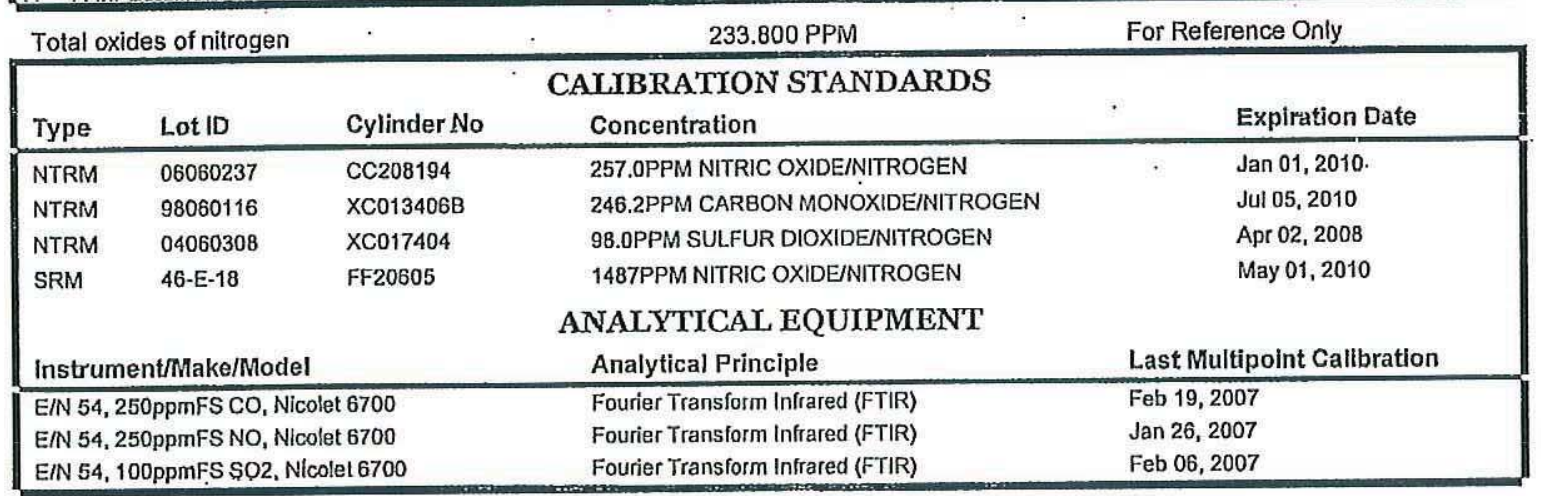

Triad Data Available Upon Request

Notes:NOX: 233.8

ORDER\# 108610

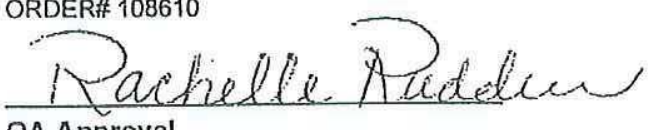

QA Approval 


\title{
CERTIFICATE OF ANALYSIS Grade of Product: EPA Protocol
}

Airgas Great Lakes, Inc. 2009 Bellaire Ave.

Royal Oak, Ml 48067

Ph: (248) 399-9150

Fax: (248) 584-2540

http://www.airgas.com

\author{
Customer: .CREIGHTON \\ Part Number: $\quad$ E02NI99E15A03D9 \\ Cylinder Number: XC023749B \\ Laboratory: $\quad$ MIC - Royal Oak - MI \\ Analysis Date: Feb 05, 2007
}

\author{
Reference Number: $\quad 32-112531795-4$ \\ Cylinder Volume: 144 Cu.Ft. \\ Cylinder Pressure: 2015 PSIG \\ Valve Outlet: $\quad 660$
}

Expiration Date: Feb 05, 2009

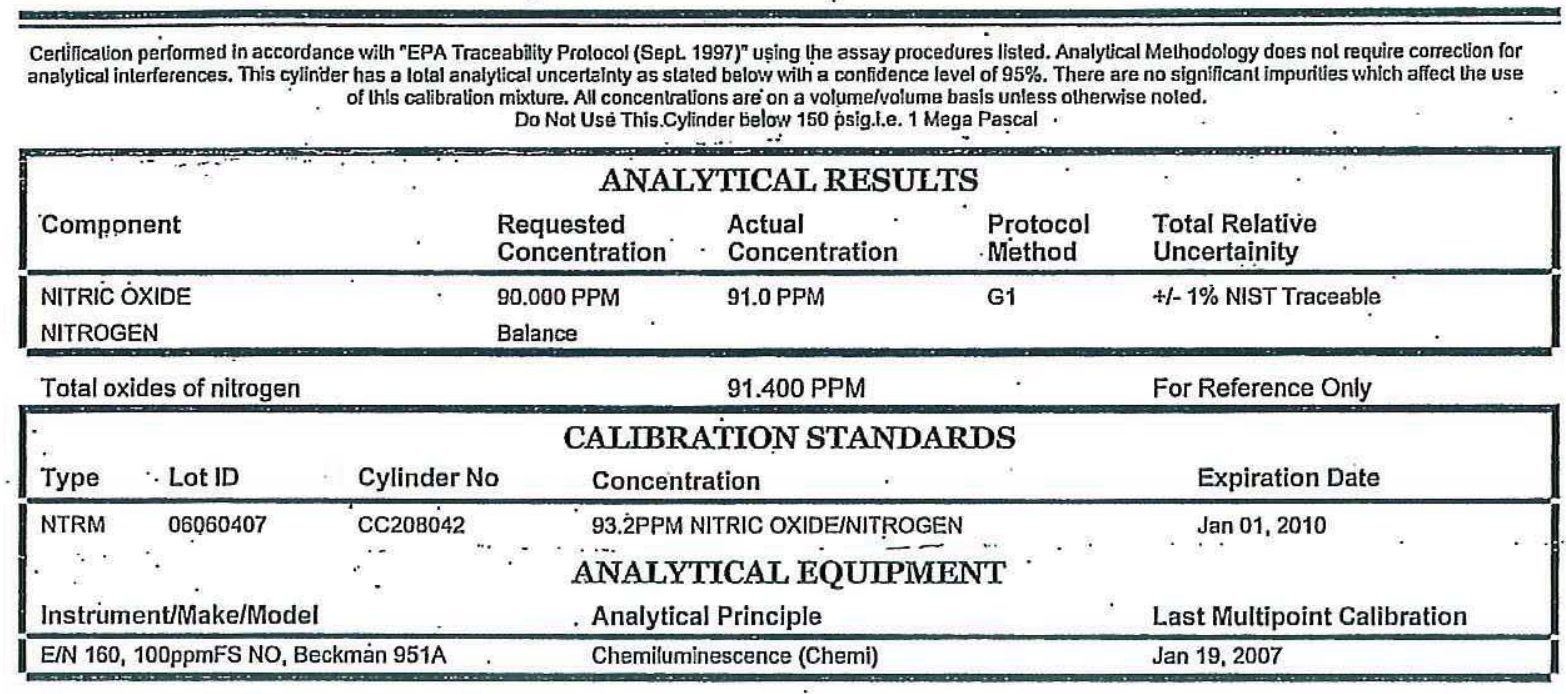

Triad Data Available Upon Request

Notes:

APAproval

Page 1 of 32-112531795-4 


\section{Certificate of Analysis: EPA Protocol Gas Mixture}

Airgas Great Lakes, Inc. 2009 Bellaire Ave.

Royal Oak, Ml 48067

Ph: (248) $399-9150$

Cylinder Number: SG9165466BAL Reference Number: 32-112441658-2

Fax: (248) 584-2540

Cylinder Pressure: 2000.6 PSIG

Expiration Date: $\quad$ 12/5/2007

Certification Date: 12/5/2005 Laboratory:

MIC - Royal Oak - MI

http://www.airgas.com

Certified Concentrations

\begin{tabular}{|c|c|c|c|c|}
\hline $\begin{array}{l}\text { Component } \\
\text { NITRIC OXIDE } \\
\text { NITROGEN }\end{array}$ & $\begin{array}{l}\text { Concentration } \\
47.4 \text { PPM } \\
\text { Balance }\end{array}$ & $\begin{array}{l}\text { Accuracy } \\
+/-1 \%\end{array}$ & $\begin{array}{l}\text { Analytical Principle } \\
\text { Chemiluminescence (Chemi) }\end{array}$ & $\begin{array}{l}\text { Procedure } \\
\text { G1 }\end{array}$ \\
\hline
\end{tabular}

Tolal oxides of nitrogen 47.8 PPM

Certification performed in accordance with "EPA Traceability Protocol (Sept. 1997)" using the assay procedures listed. Analytical Methodology does not require correction for analytical interferences.

Notes: CLEVELAND

Do not use cylinder below 150 psig.

Approval Signature Li.7. Vheromesenel

\section{Reference Standard Information}

$\begin{array}{lllll}\text { Type } & \text { Balance Gas } & \text { Component } & \text { Cvl.Number } & \text { Concentration } \\ \text { GMIS 1684B } & \text { NITROGEN } & \text { NITRIC OXIDE } & \text { XNO00401B } & 99.4 \text { PPM }\end{array}$

Analytical Results

1st Component NITRIC OXIDE

1st Analysis Date: $\quad 11 / 28 / 2005$

R 4.97

$\mathrm{S} 2.37$

S 2.37

Z 0.00

Conc 47.4 PPM

$\mathrm{Z} 0.00$

R 4.97

Conc 47.4 PPM

Conc 47.4 PPM

AVG: 47.4 PPM

2nd Analysis Date:

12/05/2005

R 4.97

S 2.37

S 2.37

$\mathrm{Z} 0.0$

Conc 47.4 PPM

$\mathrm{Z} 0.0$

$\mathrm{Z} 0.0$

R 4.97

Conc 47.4 PPM

R 4.97

S 2.37

Conc 47.4 PPM

AVG: 47.4 PPM 


\section{This Page Intentionally Left Blank}


CONSOL ENERGY INC.

AES GREENIDGE STATION
Client Reference No: 4700140111

CleanAir Project No: 10192

FIELD DATA PRINTOUTS

E

Revision 1 


\section{This Page Intentionally Left Blank}


Consol Energy

CleanAir Project No. 10192

Dresden, New York

BH Outlet, AH Outlet

\section{March 29, 2007 \\ 9.06 \\ Stop Time $\quad 9: 43$}

CALIBRATION BIAS 00

$\begin{array}{rrrrrr}\begin{array}{r}\text { Channel 2 } \\ \text { SO2 }\end{array} & \text { Channel 4 } & \text { Channel 5 } & \text { Channel 7 } & \text { Channel 8 } & \text { Channel 9 } \\ & \text { CO2 } & \text { SO2 } & \text { O2 } & \text { CO2 } \\ \begin{array}{r}\text { AH Outlet } \\ \text { ppmdv }\end{array} & \begin{array}{r}\text { AH Outlet } \\ \% d v\end{array} & \begin{array}{r}\text { AH Outlet } \\ \% d v\end{array} & \begin{array}{r}\text { BH Outlet } \\ \text { ppmdv }\end{array} & \begin{array}{r}\text { BH Outlet } \\ \% d v\end{array} & \begin{array}{r}\text { BH Outlet } \\ \% d v\end{array}\end{array}$

System Response to Calibration Gasses $\left(\mathrm{C}_{\mathrm{S}}\right)$

\begin{tabular}{|c|c|c|c|c|c|c|c|}
\hline \multirow{2}{*}{\multicolumn{2}{|c|}{$\begin{array}{ll}\mathrm{C}_{0 f} & \text { Zero gas } \\
\mathrm{C}_{\mathrm{uf}} & \text { Upscale gas }\end{array}$}} & 19.829 & -0.021 & 0.178 & 1.423 & 0.013 & 0.280 \\
\hline & & 2432.641 & 6.006 & 13.997 & 45.648 & 6.049 & 13.991 \\
\hline \multicolumn{8}{|c|}{ Analyzer Calibration Error Reponses $\left(\mathrm{C}_{\text {Dir }}\right)$} \\
\hline $\mathrm{C}_{\text {oce }}$ & Zero gas & 3.452 & -0.010 & 0.148 & -0.056 & 0.002 & 0.003 \\
\hline $\mathrm{C}_{\text {mice }}$ & Upscale gas & 2482.035 & 6.061 & 14.059 & 48.630 & 6.050 & 13.966 \\
\hline \multicolumn{8}{|c|}{ Actual Upscale Gas Value $\left(C_{M A}\right)$} \\
\hline $\mathrm{C}_{\mathrm{ma}}$ & Upscale gas & 2479.000 & 6.040 & 13.980 & 49.350 & 6.040 & 13.980 \\
\hline \multicolumn{8}{|c|}{ Calibration Span Value (CS) } \\
\hline & & 2479.000 & 14.100 & 13.980 & 121.600 & 14.100 & 13.980 \\
\hline
\end{tabular}

System Bias as Percent of Calibration Span Value (SB) $(5 \%)$

$\begin{array}{llllrll}\text { Zero gas } & 0.7 \% & -0.1 \% & 0.2 \% & 1.2 \% & 0.1 \% & 2.0 \% \\ \text { Upscale gas } & -2.0 \% & -0.4 \% & -0.4 \% & -2.5 \% & 0.0 \% & 0.2 \%\end{array}$

System Bias Status

\begin{tabular}{lllllll} 
Zerogas & OK & OK & $O K$ & $O K$ & $O K$ & $O K$ \\
\hline & OK & OK & OK & OK & OK & OK
\end{tabular}

Upscale gas
OK

$\begin{array}{cccccc}\text { Previous System Response to Calibration Gases }\left(C_{s}\right) & & & & \\ \text { N/A } & \text { N/A } & \text { N/A } & \text { N/A } & \text { N/A } & \text { N/A }\end{array}$

$\begin{array}{llll}C_{u} & \text { Upscale gas } & \text { N/A } & \text { N/A }\end{array}$

\begin{tabular}{|c|c|c|c|c|c|}
\hline Zero gas & N/A & N/A & N/A & N/A & N/A \\
\hline Upscale gas & N/A & N/A & N/A & $\mathrm{N} / \mathrm{A}$ & $\mathrm{N} / \mathrm{A}$ \\
\hline
\end{tabular}

Drift Assessment Status

\begin{tabular}{|c|c|c|c|c|c|}
\hline Zero gas & N/A & N/A & $N / A$ & N/A & $N / A$ \\
\hline Upscale gas & N/A & N/A & N/A & N/A & N/A \\
\hline
\end{tabular}

\begin{tabular}{|c|c|c|c|c|c|c|c|}
\hline \multicolumn{8}{|l|}{$061407 \quad 143432$} \\
\hline & 09:06:57 & 1330.012 & 8.243 & 11.180 & 48.840 & 0.017 & 0.234 \\
\hline & 09:07:12 & 725.568 & 10.421 & 8.557 & $\begin{array}{l}48.840 \\
48.840\end{array}$ & 0.015 & $\begin{array}{l}0.260 \\
0.281\end{array}$ \\
\hline & $\begin{array}{l}09: 07: 27 \\
09: 07: 42\end{array}$ & $\begin{array}{l}224.664 \\
102.662\end{array}$ & $\begin{array}{l}6.309 \\
6.020\end{array}$ & $\begin{array}{l}13.388 \\
13.939\end{array}$ & $\begin{array}{l}48.840 \\
48.840\end{array}$ & 0.016 & 0.299 \\
\hline & $09: 07: 57$ & 64.176 & 6.004 & 13.982 & 48.840 & 0.018 & 0.311 \\
\hline & $09: 08: 12$ & 46.154 & 6.008 & 13.999 & 48.840 & 0.023 & 0.325 \\
\hline & $09: 08: 27$ & 35.751 & 6.006 & 14.010 & 48.840 & 0.022 & 0.336 \\
\hline & $09: 08: 42$ & 29.206 & 6.004 & 13.998 & 48.850 & 0.019 & 0.344 \\
\hline & 09:08:57 & 24.762 & 6.007 & 14.012 & 48.879 & 0.026 & 0.351 \\
\hline & 09:09:12 & 21.929 & 6.010 & 14.019 & 48.889 & 0.029 & 0.359 \\
\hline & $09: 09: 27$ & 19.927 & 5.999 & 14.023 & 48.856 & 0.031 & 0.366 \\
\hline & 09:09:42 & 17.631 & 6.001 & 14.029 & 48.889 & 0.032 & 0.369 \\
\hline & 09:09:57 & 96.899 & 5.129 & 12.948 & 48.886 & 0.032 & 0.369 \\
\hline & 09:10:12 & 1457.436 & 0.515 & 2.165 & 48.886 & 0.036 & 0.370 \\
\hline & $09: 10: 27$ & 2197.069 & -0.008 & 0.374 & 48.889 & 0.041 & $\begin{array}{l}0.372 \\
0.373\end{array}$ \\
\hline & $\begin{array}{l}09: 10: 42 \\
09: 10: 57\end{array}$ & $\begin{array}{l}2336.752 \\
\end{array}$ & $\begin{array}{l}-0.026 \\
-0.030\end{array}$ & 0.267 & $\begin{array}{l}48.889 \\
48889\end{array}$ & $\begin{array}{l}0.037 \\
0.041\end{array}$ & $\begin{array}{l}0.373 \\
0.373\end{array}$ \\
\hline & $09: 11: 12$ & 2401.612 & $\frac{-0.030}{-0.035}$ & $\begin{array}{l}0.235 \\
0.217\end{array}$ & $\begin{array}{l}48.889 \\
48.889\end{array}$ & 0.042 & $\begin{array}{l}0.373 \\
0.370\end{array}$ \\
\hline & $09: 11: 27$ & 2412.210 & -0.035 & 0.204 & 48.889 & 0.047 & 0.369 \\
\hline 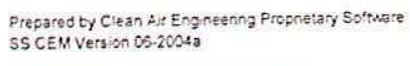 & & & & & & QAVQC. & $\mathrm{m}$ \\
\hline & & & & & & Date & $1 / 4 / 07$ \\
\hline
\end{tabular}


Consol Energy CleanAir Project No. 10192 Dresden, New York BH Outlet, AH Outlet

\begin{tabular}{|c|c|c|c|c|c|c|}
\hline & \multicolumn{6}{|c|}{ March 29, 2007} \\
\hline & & & Start Time & 9.06 & & \\
\hline & & & Stop Time & $9: 43$ & & \\
\hline & & CALIBRATIO & BIAS 00 & & & \\
\hline & Channel 2 & Channel 4 & Channel 5 & Channel 7 & Channel 8 & Channel 9 \\
\hline & $\mathrm{SO} 2$ & 02 & $\mathrm{CO} 2$ & $\mathrm{SO} 2$ & $\mathrm{O} 2$ & $\mathrm{CO} 2$ \\
\hline & $\begin{array}{l}\text { AH Outlet } \\
\text { ppmdv }\end{array}$ & $\begin{array}{r}\text { AH Outlet } \\
\% \text { dv }\end{array}$ & $\begin{array}{r}\text { AH Outlet } \\
\% \text { dv }\end{array}$ & $\begin{array}{r}\text { BH Outlet } \\
\text { ppmdv }\end{array}$ & $\begin{array}{r}\text { BH Outlet } \\
\% \text { dv }\end{array}$ & $\begin{array}{r}\text { BH Outlet } \\
\% \text { dv }\end{array}$ \\
\hline $09: 12: 12$ & 2426.667 & -0.039 & $\frac{0.188}{0.182}$ & $\begin{array}{l}48.909 \\
48.931\end{array}$ & 0.055 & $\begin{array}{l}0.368 \\
0.369\end{array}$ \\
\hline $09: 12: 27$ & 2430.183 & -0.039 & 0.178 & 48.964 & 0.057 & $\begin{array}{l}0.369 \\
0.368\end{array}$ \\
\hline $09: 12: 42$ & 2441.074 & -0.039 & 0.174 & 48.967 & 0.057 & 0.364 \\
\hline $09: 35: 03$ & 1403.468 & 7.234 & 11.643 & 93.428 & 7.268 & 11.705 \\
\hline $09: 35: 18$ & 1404.884 & 7.253 & 11.639 & 80.248 & 12.165 & 7.800 \\
\hline $09: 35: 33$ & 1402.637 & 7.192 & 11.683 & 48.104 & 6.954 & 12.344 \\
\hline $09: 35: 48$ & 1409.035 & 7.177 & 11.707 & 24.840 & 6.100 & 13.877 \\
\hline $09: 36: 03$ & 1402.637 & 7.308 & 11.600 & 14.291 & 6.062 & 13.973 \\
\hline $09: 36: 18$ & 1393.016 & 7.357 & 11.558 & 9.296 & 6.057 & 13.996 \\
\hline $09: 36: 33$ & 1394.432 & 7.270 & 11.607 & 6.535 & 6.055 & 14.004 \\
\hline $09: 36: 48$ & 1403.468 & 7.245 & 11.674 & 4.884 & 6.053 & 14.007 \\
\hline $09: 37: 03$ & 1393.065 & 7.264 & 11.617 & 3.897 & 6.053 & 14.014 \\
\hline $09: 37: 18$ & 1400.147 & 7.206 & 11.684 & 3.184 & 6.054 & 14.017 \\
\hline $09: 37: 33$ & 1406.300 & 7.145 & 11.718 & 2.716 & 6.053 & 14.020 \\
\hline $09: 37: 48$ & 1413.236 & 7.182 & 11.722 & 2.354 & 6.053 & 14.024 \\
\hline $09: 38: 03$ & 1403.175 & 7.332 & 11.573 & 2.067 & 6.050 & 14.027 \\
\hline $09: 38: 18$ & 1404.054 & 7.241 & 11.646 & 1.872 & 6.049 & 14.028 \\
\hline $09: 38: 33$ & 1405.910 & 7.264 & 11.634 & 1.693 & 6.048 & 14.029 \\
\hline $09: 38: 48$ & 1407.863 & 7.243 & 11.650 & 1.563 & 6.051 & 14.031 \\
\hline $09: 39: 03$ & 1402.979 & 7.396 & 11.516 & 1.455 & 6.049 & 14.038 \\
\hline $09: 39: 18$ & 1397.265 & 7.317 & 11.571 & 1.250 & 4.972 & 12.747 \\
\hline $09: 39: 33$ & 1395.458 & 7.282 & 11.589 & 3.487 & 0.539 & 2.009 \\
\hline $09: 39: 48$ & 1402.393 & 7.183 & 11.677 & 19.878 & 0.052 & 0.193 \\
\hline $09: 40: 03$ & 1411.478 & 7.133 & 11.717 & 30.974 & 0.028 & 0.043 \\
\hline $09: 40: 18$ & 1414.799 & 7.076 & 11.768 & 36.317 & 0.026 & 0.004 \\
\hline $09: 40: 33$ & 1408.547 & 7.246 & 11.646 & 39.108 & 0.022 & -0.018 \\
\hline $09: 40: 48$ & 1401.319 & 7.211 & 11.664 & 40.759 & 0.019 & -0.036 \\
\hline $09: 41: 03$ & 1396.532 & 7.323 & 11.579 & 41.833 & 0.019 & -0.047 \\
\hline $09: 41: 18$ & 1389.109 & 7.330 & 11.570 & 42.335 & 0.018 & -0.057 \\
\hline $09: 41: 33$ & 1388.913 & 7.277 & 11.612 & 43.054 & 0.015 & -0.063 \\
\hline $09: 41: 48$ & 1396.777 & 7.208 & 11.647 & 43.858 & 0.016 & -0.070 \\
\hline $09: 42: 03$ & 1403.272 & 7.314 & 11.606 & 44.444 & 0.014 & -0.076 \\
\hline $09: 42: 18$ & 1396.581 & 7.299 & 11.593 & 44.848 & 0.014 & -0.081 \\
\hline $09: 42: 33$ & 1404.347 & 7.309 & 11.590 & 45.180 & 0.014 & -0.085 \\
\hline $09: 42: 48$ & 1401.612 & 7.227 & 11.654 & 45.372 & 0.013 & .0 .087 \\
\hline $09: 43: 03$ & 1402.247 & 7.272 & 11.615 & 45.509 & 0.014 & .0 .089 \\
\hline $09: 43: 18$ & 1408.645 & 7.170 & 11.695 & 45.623 & 0.014 & -0.094 \\
\hline $09: 43: 33$ & 1404.738 & 7.297 & 11.615 & 45.812 & 0.013 & -0.094 \\
\hline $09: 43: 48$ & 1397.021 & 7.294 & 11.615 & 54.268 & 2.266 & 2.149 \\
\hline
\end{tabular}

Prepared by Citan Aur Engneering Propnetary Sofware SS CEM Version CB.2004a

Copnght 2004 Clean Air Engneening inc.
QAQC $\frac{J M}{6 / 4 k z}$ 
Consol Energy

CleanAir Project No. 10192

Dresden, New York

BH Outlet, AH Outlet

March 29, 2007

Start Time $\quad 9.59$

Stop time 11:00 REFERENCE METHOD RUN 1

$\begin{array}{rrrrrr}\begin{array}{r}\text { Channel 2 } \\ \text { SO2 }\end{array} & \begin{array}{r}\text { Channel 4 } \\ \mathrm{O} 2\end{array} & \begin{array}{r}\text { Channel 5 } \\ \mathrm{CO} 2\end{array} & \begin{array}{r}\text { Channel 7 } \\ \mathrm{SO} 2\end{array} & \begin{array}{r}\text { Channel 8 } \\ \mathrm{O} 2\end{array} & \begin{array}{r}\text { Channel 9 } \\ \mathrm{CO} 2\end{array} \\ \begin{array}{r}\text { AH Outlet } \\ \text { ppmdv }\end{array} & \begin{array}{r}\text { AH Outlet } \\ \% \mathrm{dv}\end{array} & \begin{array}{r}\text { AH Outlet } \\ \% \mathrm{dv}\end{array} & \begin{array}{r}\text { BH Outlet } \\ \text { ppmdv }\end{array} & \begin{array}{r}\text { BH Outlet } \\ \% \mathrm{dv}\end{array} & \begin{array}{r}\text { BH Outlet } \\ \% \mathrm{dv}\end{array}\end{array}$

Calibration Checks

\begin{tabular}{|c|c|c|c|c|c|c|c|}
\hline & per & & & & & & \\
\hline $\mathrm{C}_{a}$ & Initial zero & 19.829 & -0.021 & 0.178 & 1.423 & 0.013 & 0.280 \\
\hline $\mathrm{C}_{u i}$ & Initial upscale & 2432.641 & 6.005 & 13.997 & 45.648 & 6.049 & 13.99 \\
\hline $\mathrm{C}_{0}$ & Final zero & 13.789 & -0.017 & 0.154 & 2.554 & 0.009 & -0.00 \\
\hline $\mathrm{C}_{\mathrm{u}^{+}}$ & Final upscale & 2411.901 & 6.124 & 14.012 & 47.500 & 6.071 & \\
\hline $\mathrm{C}_{\mathrm{ma}}$ & Actual gas value & 2479.000 & 6.040 & 13.980 & 49.350 & 6.040 & \\
\hline
\end{tabular}

Analyzer Averages (concentrations)

$C_{\text {Avg }}$ Average conc. $\quad 1384.546$

$\mathrm{C}_{\mathrm{Gas}}$ Bias adjusted $\quad 1409.550$

$\begin{array}{lllll}7.331 & 11.587 & 73.817 & 7.223 & 11.530\end{array}$

Clock Time (at end of sample period)

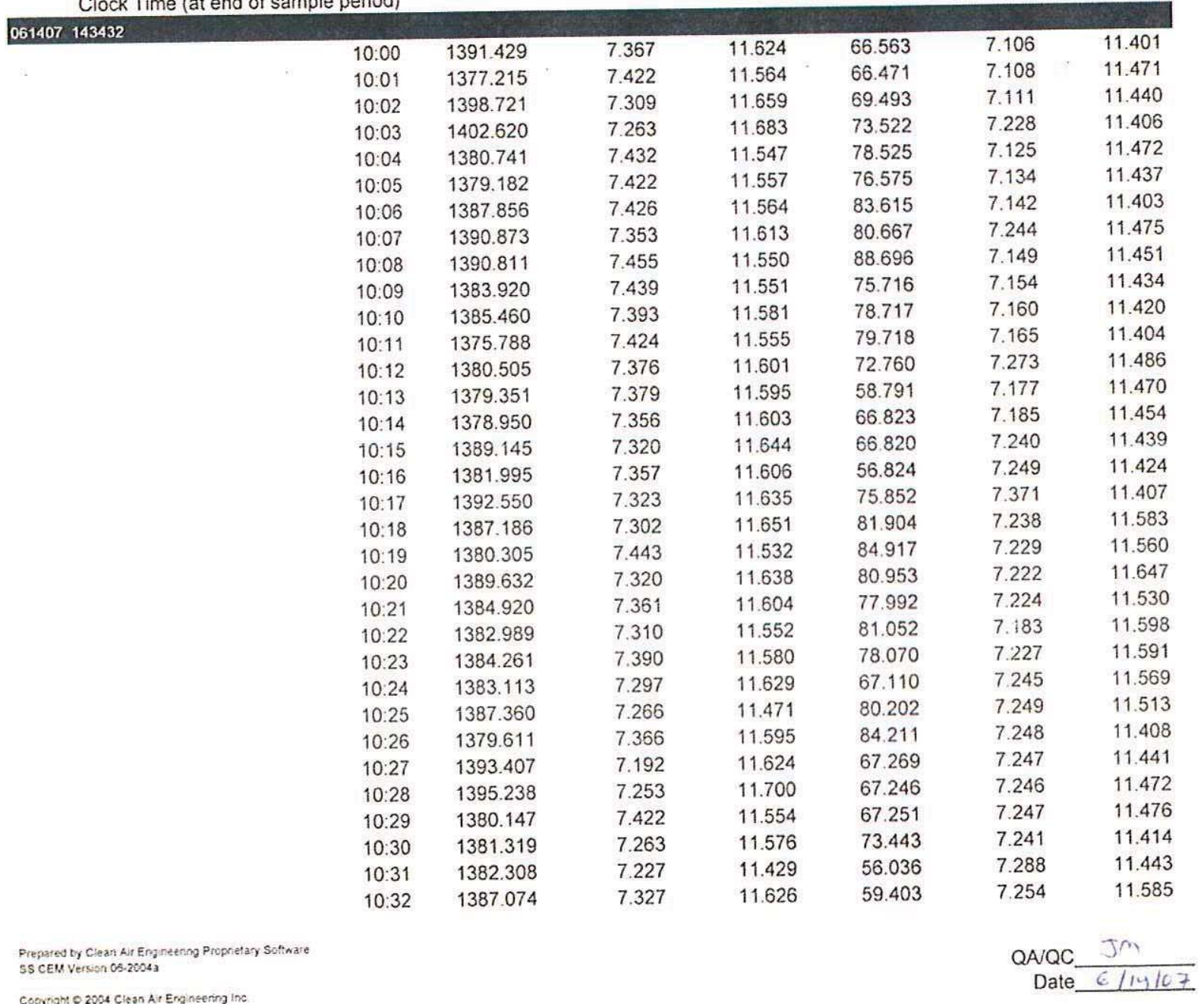


Consol Energy

CleanAir Project No. 10192

Dresden, New York

BH Outlet, AH Outlet
Piepares ty Clean Ait Enginatring Propostay Sorwate SS CEM Version OS-2004a

Coppright Q 2004 Clean Air Emg neering inc
March 29, 2007

Start Time $\quad 9: 59$

Stop time $\quad 11: 00$

REFERENCE METHOD RUN 1

\begin{tabular}{|c|c|c|c|c|c|c|}
\hline & Channel 2 & Channel 4 & Channel 5 & Channel 7 & Channel 8 & Channel 9 \\
\hline & SO2 & $\mathrm{O} 2$ & $\mathrm{CO} 2$ & $\mathrm{SO} 2$ & $\mathrm{O} 2$ & $\mathrm{CO} 2$ \\
\hline & $\begin{array}{l}\text { AH Outlet } \\
\text { ppmdv }\end{array}$ & $\begin{array}{r}\text { AH Outlet } \\
\% d v\end{array}$ & $\begin{array}{r}\text { AH Outlet } \\
\% \text { dv }\end{array}$ & $\begin{array}{r}\text { BH Outlet } \\
\text { ppmdv }\end{array}$ & $\begin{array}{r}\text { BH Outlet } \\
\% d v\end{array}$ & $\begin{array}{r}\text { BH Outlet } \\
\% \text { dv }\end{array}$ \\
\hline 10.33 & 1388.787 & 7.305 & 11.643 & 58.366 & 7.246 & 11.465 \\
\hline $10: 34$ & 1390.598 & 7.336 & 11.630 & 58.382 & 7.128 & 11.441 \\
\hline 10:35 & 1387.900 & 7.212 & 11.503 & 62.291 & 7.241 & 11.430 \\
\hline 10.36 & 1381.966 & 7.351 & 11.576 & 68.523 & 7.149 & 11.495 \\
\hline $10: 37$ & 1377.717 & 7.428 & 11.547 & 73.514 & 7.294 & 11.540 \\
\hline $10: 38$ & 1380.195 & 7.406 & 11.562 & 73.552 & 7.224 & 11.536 \\
\hline $10: 39$ & 1388.010 & 7.269 & 11.667 & 69.655 & 7.201 & 11.571 \\
\hline $10: 40$ & 1392.002 & 7.141 & 11.622 & 73.757 & 7.234 & 11.592 \\
\hline $10: 41$ & 1381.795 & 7.407 & 11.567 & 75.923 & 7.273 & 11.630 \\
\hline $10: 42$ & 1380.147 & 7.348 & 11.611 & 77.497 & 7.091 & 11.683 \\
\hline $10: 43$ & 1390.794 & 7.259 & 11.692 & 82.058 & 7.180 & 11.644 \\
\hline $10: 44$ & 1384.392 & 7.349 & 11.614 & 82.354 & 7.208 & 11.563 \\
\hline $10: 45$ & 1380.916 & 7.346 & 11.613 & 78.069 & 7.215 & 11.671 \\
\hline $10: 46$ & 1389.930 & 7.056 & 11.592 & 34.178 & 7.281 & 11.769 \\
\hline $10: 47$ & 1371.441 & 7.327 & 11.462 & 81.915 & 7.252 & 11.555 \\
\hline $10: 48$ & 1389.292 & 7.320 & 11.650 & 86.468 & 7.266 & 11.661 \\
\hline $10: 49$ & 1390.708 & 7.302 & 11.653 & 89.452 & 7.284 & 11.655 \\
\hline $10: 50$ & 1384.032 & 7.340 & 11.616 & 74.138 & 7.321 & 11.625 \\
\hline $10: 51$ & 1375.141 & 7.384 & 11.571 & 96.678 & 7.267 & 11.593 \\
\hline $10: 52$ & 1384.777 & 7.361 & 11.610 & 92.073 & 7.295 & 11.660 \\
\hline $10: 53$ & 1372.308 & 7.459 & 11.530 & 84.916 & 7.273 & 11.590 \\
\hline $10: 54$ & 1378.928 & 7.303 & 11.644 & 76.514 & 7.284 & 11.564 \\
\hline 10.55 & 1386.602 & 7.297 & 11.639 & 64.884 & 7.256 & 11.673 \\
\hline $10: 56$ & 1375.299 & 7.409 & 11.555 & 91.870 & 7.285 & 11.600 \\
\hline $10: 57$ & 1387.881 & 7.303 & 11.644 & 77.200 & 7.269 & 11.620 \\
\hline $10: 58$ & 1387.509 & 7.208 & 11.560 & 83.634 & 7.277 & 11.671 \\
\hline $10: 59$ & 1381.758 & 6.949 & 11.179 & 58.589 & 7.186 & 11.550 \\
\hline $11: 00$ & 1370.473 & 7.432 & 11.553 & 53.180 & 7.237 & 11.568 \\
\hline
\end{tabular}

QAVC $\frac{J m}{6 / 14 / 67}$ 
Consol Energy

CleanAir Project No. 10192

Dresden, New York

BH Outlet, AH Outlet

$$
\begin{array}{ll} 
& \text { March 29, } 2007 \\
\text { Start Time } & 11: 10 \\
\text { Stop Time } & 11: 22
\end{array}
$$

\begin{tabular}{|c|c|c|c|c|c|}
\hline Channel 2 & Channel 4 & Channel 5 & Channel 7 & Channel 8 & Channel 9 \\
\hline $\mathrm{SO} 2$ & $\mathrm{O} 2$ & $\mathrm{CO} 2$ & $\mathrm{SO} 2$ & $\mathrm{O} 2$ & $\mathrm{CO} 2$ \\
\hline $\begin{array}{r}\text { AH Outlet } \\
\text { ppmdv }\end{array}$ & $\begin{array}{r}\text { AH Outlet } \\
\% d v\end{array}$ & $\begin{array}{r}\text { AH Outlet } \\
\% d v\end{array}$ & $\begin{array}{r}\text { BH Outlet } \\
\text { ppmdv }\end{array}$ & $\begin{array}{r}\text { BH Outlet } \\
\% \text { dv }\end{array}$ & $\begin{array}{r}\text { BH Outlet } \\
\% \text { dv }\end{array}$ \\
\hline
\end{tabular}

CALIBRATION BIAS 01

System Response to Calibration Gasses $\left(C_{s}\right)$

\begin{tabular}{l|r|r}
$C_{0}$ Zerogas & 13.789 & -0.01 \\
\hline
\end{tabular}

$\mathrm{C}_{\mathrm{ut}}$ Upscale gas $\frac{13.789}{2411.901}$

Analyzer Calibration Error Reponses $\left(\mathrm{C}_{\text {Dir }}\right)$

$\mathrm{C}_{0-0}$ Zero gas

$3.452-0.010$

0.148

$-0.056$

0.002

0.003

$\mathrm{C}_{\text {mce }}$ Upscale gas $\quad 2482.035$

6.061

14.059

48.630

6.050

13.966

Actual Upscale Gas Value $\left(\mathrm{C}_{\mathrm{MA}}\right)$

$\mathrm{C}_{\text {ma Upscale gas }}$ Calibration Span Value (CS)

2479.000

6.040

13.980

49.350

6.040

13.980

2479.000

14. 100

13.980

121.600

14.100

13.980

\begin{tabular}{|c|c|c|c|c|c|c|}
\hline Zero gas & $0.4 \%$ & $-0.1 \%$ & $0.0 \%$ & $2.1 \%$ & $0.0 \%$ & $0.0 \%$ \\
\hline Upscale gas & $-2.8 \%$ & $0.4 \%$ & $-0.3 \%$ & $-0.9 \%$ & $0.2 \%$ & $0.3 \%$ \\
\hline
\end{tabular}

System Bias as Percent of Calibration Span Value (SB) $(5 \%)$

System Bias Status

$\begin{array}{lll}\text { Zero gas } & \text { OK } & \text { OK } \\ \text { Upscale gas } & \text { OK } & \text { OK }\end{array}$

Previous System Response to Calibration Gases $\left(\mathrm{C}_{\mathrm{S}}\right)$

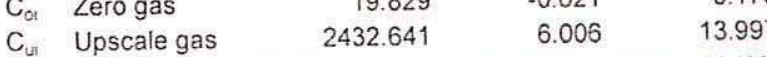

Drift Assessment as Percent of Calibration Span Value (D) $(3 \%)$

$\begin{array}{llll}\text { Zero gas } & -0.2 \% & 0.0 \% & -0.2 \%\end{array}$

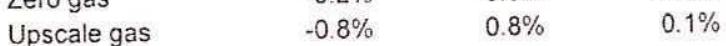

Drift Assessment Status

Zero gas

Upscale gas

$\begin{array}{llllll}\text { OK } & \text { OK } & \text { OK } & \text { OK } & \text { OK } & \text { OK } \\ \text { OK } & \text { OK } & \text { OK } & \text { OK } & \text { OK } & \text { OK }\end{array}$

061407143432

\begin{tabular}{lr}
$11: 10: 53$ & 1316.923 \\
$11: 11: 08$ & 630.965 \\
$11: 11: 23$ & 195.897 \\
$11: 11: 38$ & 90.501 \\
$11: 11: 53$ & 57.240 \\
$11: 12: 08$ & 42.002 \\
$11: 12: 23$ & 33.602 \\
$11: 12: 38$ & 28.425 \\
$11: 12: 53$ & 25.055 \\
$11: 13: 08$ & 21.831 \\
$11: 13: 23$ & 20.318 \\
$11: 13: 38$ & 19.585 \\
$11: 13: 53$ & 18.462 \\
$11: 14: 08$ & 16.606 \\
$11: 14: 23$ & 15.873 \\
$11: 14: 38$ & 14.896 \\
$11: 14: 53$ & 13.919 \\
$11: 15: 08$ & 13.577 \\
$11: 15: 23$ & 13.870 \\
\hline
\end{tabular}

9.283
12.004

10790

42.188

38.235

$12.004 \quad 7.344$

13.493

\begin{tabular}{l|l}
6.328 & 13.493 \\
& 13.983
\end{tabular}

$6 . 0 3 1 \longdiv { 1 3 . 9 8 3 }$

6.012

6.007

14.021

$6 . 0 0 5 \longdiv { 1 4 . 0 4 0 }$

6.000

14.044

$5.994 \quad 14.043$

$5.993 \quad 14.045$

$5.986 \quad 14.045$

$5.979 \quad 14.037$

5.977

5.978

5.981

5.982

5.987

5.945

5.783

\subsection{1}

14.039

14.042

14.051

14.052

13.770

13.797

23.043

14.323

10.123

7.645

6.128

5.105

4.389

3.881

3.533

3.259

3.064

2.933

2.787

2.706

2.631

2.354

2.677

\begin{tabular}{rr}
$r .295$ & 11.460 \\
11.212 & 8.182 \\
6.359 & 13.514 \\
\hline 6.101 & 13.974 \\
6.087 & 14.013 \\
6.079 & 14.026 \\
\hline 6.078 & 14.034 \\
6.076 & 14.042 \\
6.072 & 14.047 \\
6.072 & 14.050 \\
6.071 & 14.054 \\
\hline 6.071 & 14.054 \\
6.073 & 14.054 \\
6.070 & 14.054 \\
\hline 6.074 & 14.056 \\
6.078 & 14.056 \\
6.080 & 14.057 \\
6.004 & 13.996 \\
6.058 & 14.066
\end{tabular}

Prepared ty Ciean Air Engonsenng Fropnetay Sot:are SS CEN Version O5-2004a

Coprnght 62004 Cean Ait Engineenng inc

QAVC $\frac{j m}{6 / 11 / 167}$ 
Consol Energy

CleanAir Project No. 10192

Dresden, New York

$\mathrm{BH}$ Outlet, $\mathrm{AH}$ Outlet
March 29, 2007

11:10

11:22

\section{CALIBRATION BIAS 01}

\begin{tabular}{|c|c|c|c|c|c|c|}
\hline & $\begin{array}{r}\text { Channel } 2 \\
\text { SO2 }\end{array}$ & $\begin{array}{r}\text { Channel } 4 \\
\mathrm{O} 2\end{array}$ & $\begin{array}{r}\text { Channel } 5 \\
\mathrm{CO} 2\end{array}$ & $\begin{array}{r}\text { Channel } 7 \\
\text { SO2 }\end{array}$ & $\begin{array}{r}\text { Channel } 8 \\
\mathrm{O} 2\end{array}$ & $\begin{array}{r}\text { Channel } 9 \\
\mathrm{CO} 2\end{array}$ \\
\hline & $\begin{array}{l}\text { AH Outlet } \\
\text { ppmdv }\end{array}$ & $\begin{array}{r}\text { AH Outlet } \\
\% \text { dv }\end{array}$ & $\begin{array}{r}\text { AH Outlet } \\
\% \text { dv }\end{array}$ & $\begin{array}{l}\text { BH Outlet } \\
\text { ppmdv }\end{array}$ & $\begin{array}{r}\text { BH Outlet } \\
\% \text { dv }\end{array}$ & $\begin{array}{r}\text { BH Outlet } \\
\% \text { dv }\end{array}$ \\
\hline $\begin{array}{l}11: 15: 38 \\
11: 15: 53\end{array}$ & $\begin{array}{r}75.995 \\
1329.280\end{array}$ & $\begin{array}{l}5.453 \\
0.689\end{array}$ & $\begin{array}{r}13.180 \\
2.596\end{array}$ & $\begin{array}{r}2.497 \\
13.183\end{array}$ & $\begin{array}{l}6.698 \\
4.069\end{array}$ & $\begin{array}{r}13.258 \\
9.421\end{array}$ \\
\hline $11: 16: 08$ & 2145.446 & 0.001 & 0.409 & 23.010 & $\begin{array}{l}0.232 \\
0.030\end{array}$ & 0.854 \\
\hline $\begin{array}{l}11: 16: 23 \\
11: 16: 38\end{array}$ & $\begin{array}{l}2299.292 \\
2347.008\end{array}$ & $\begin{array}{l}-0.024 \\
-0.029\end{array}$ & $\begin{array}{l}0.282 \\
0.247\end{array}$ & $\begin{array}{l}33.472 \\
38.128\end{array}$ & $\begin{array}{l}0.030 \\
0.016\end{array}$ & $\frac{0.107}{0.024}$ \\
\hline $\begin{array}{l}11: 16: 53 \\
11: 17: 08\end{array}$ & $\begin{array}{l}2341.008 \\
2363.907 \\
2375.385\end{array}$ & $\begin{array}{l}-0.031 \\
-0.032\end{array}$ & $\begin{array}{l}0.227 \\
0.214\end{array}$ & $\begin{array}{l}40.573 \\
42.028\end{array}$ & $\begin{array}{l}0.015 \\
0.011\end{array}$ & $\begin{array}{l}-0.005 \\
-0.023\end{array}$ \\
\hline $11: 17: 23$ & 2381.099 & -0.036 & 0.202 & 43.116 & 0.017 & -0.039 \\
\hline $11: 17: 38$ & 2384.664 & -0.037 & 0.195 & 43.910 & 0.025 & -0.051 \\
\hline $11: 17: 53$ & 2391.600 & -0.037 & 0.191 & 44.523 & 0.030 & -0.059 \\
\hline $11: 18: 08$ & 2395.653 & -0.037 & 0.187 & 44.975 & 0.032 & -0.065 \\
\hline $11: 18: 23$ & 2397.411 & -0.037 & 0.181 & 45.395 & 0.028 & -0.070 \\
\hline $11: 18: 38$ & 2403.419 & -0.038 & 0.177 & 45.740 & 0.025 & -0.075 \\
\hline $11: 18: 53$ & 2404.493 & -0.039 & 0.174 & 46.027 & 0.019 & -0.082 \\
\hline $11: 19: 08$ & 2403.419 & -0.041 & 0.171 & 46.252 & 0.015 & -0.083 \\
\hline $11: 19: 23$ & 2403.370 & -0.037 & 0.168 & 46.411 & 0.017 & -0.086 \\
\hline $11: 19: 38$ & 2402.930 & -0.040 & 0.165 & 46.567 & 0.012 & -0.091 \\
\hline $11: 19: 53$ & 2405.372 & -0.041 & 0.165 & 46.694 & 0.010 & -0.093 \\
\hline $11: 20: 08$ & 2404.542 & -0.042 & 0.163 & 46.831 & 0.010 & -0.095 \\
\hline $11: 20: 23$ & 2406.349 & -0.041 & 0.160 & 46.912 & 0.010 & -0.096 \\
\hline $11: 20: 38$ & 2406.984 & -0.043 & 0.159 & 47.010 & 0.010 & -0.098 \\
\hline $11: 20: 53$ & 2407.619 & -0.041 & 0.159 & 47.134 & 0.022 & -0.099 \\
\hline $11: 21: 08$ & 2410.598 & -0.041 & 0.158 & 47.231 & 0.019 & -0.104 \\
\hline $11: 21: 23$ & 2410.012 & -0.042 & 0.156 & 47.297 & 0.015 & -0.107 \\
\hline $11: 21: 38$ & 2408.449 & -0.040 & 0.153 & 47.375 & 0.012 & -0.106 \\
\hline $11: 21: 53$ & 2406.789 & -0.038 & 0.154 & 47.375 & 0.012 & -0.107 \\
\hline $11: 22: 08$ & 2401.612 & -0.041 & 0.153 & 47.424 & 0.006 & -0.108 \\
\hline $11: 22: 23$ & 2405.323 & -0.042 & 0.154 & 47.476 & 0.008 & -0.111 \\
\hline 11:22:38 & 2428.767 & -0.040 & 0.155 & 47.599 & 0.012 & -0.112 \\
\hline $11: 22: 53$ & 2319.023 & 3.659 & 4.580 & 75.477 & 5.393 & 5.709 \\
\hline
\end{tabular}


Consol Energy

CleanAir Project No. 10192

Dresden, New York

BH Outlet, AH Outlet
March 29, 2007

12:16

13:17

REFERENCE METHOD RUN 2

$\begin{array}{r}\text { Channel } 2 \\ \text { SO2 }\end{array}$
AH Outlet
ppmdv


13.789
2411.901
11.005
2389.955
2479.000

Channel 4

Channel 5

Channel 7

Channel 8

Channel 9

$\mathrm{CO} 2$

$\mathrm{SO} 2$

$\mathrm{O} 2$

$\mathrm{CO} 2$

Calibration Checks

C. Initial zero

$\mathrm{C}_{\mathrm{ui}} \quad$ Initial upscale

$C_{0}$ Final zero

$\mathrm{C}_{\mathrm{b}}$ Final upscale

AH Outlet

AH Outlet

BH Outlet

BH Outlet

ppmdv $\%$ dv $\% d v$

BH Outlet

$\mathrm{C}_{\operatorname{ma}}$ Actual gas value

$\begin{array}{rr}-0.017 & 0.154 \\ 6.124 & 14.012 \\ 0.028 & 0.146 \\ 5.990 & 13.997 \\ 6.040 & 13.980\end{array}$

2554

0.009

$-0.001$

$\begin{array}{lll}47.500 & 6.071 & 14.004\end{array}$

$\begin{array}{lll}2.847 & 0.000 & -0.002\end{array}$

$\begin{array}{lll}47.711 & 6.036 & 13.987\end{array}$

$\begin{array}{lll}49.350 & 6.040 \quad 13.980\end{array}$

Analyzer Averages (concentrations)

$\begin{array}{ll}\mathrm{C}_{\mathrm{Avg}} \text { Average conc. } & 1359.48 \\ \mathrm{C}_{\mathrm{Gas}} \text { Bias adjusted } & \mathbf{1 3 9 8 . 1 0}\end{array}$

1398.106
$7.242 \quad 11.656$

$7.223 \quad 11.610$
66.122

69.699
$7.180 \quad 11.724$
7.164

$7.164 \quad 11.711$

Clock Time (at end of sample period)

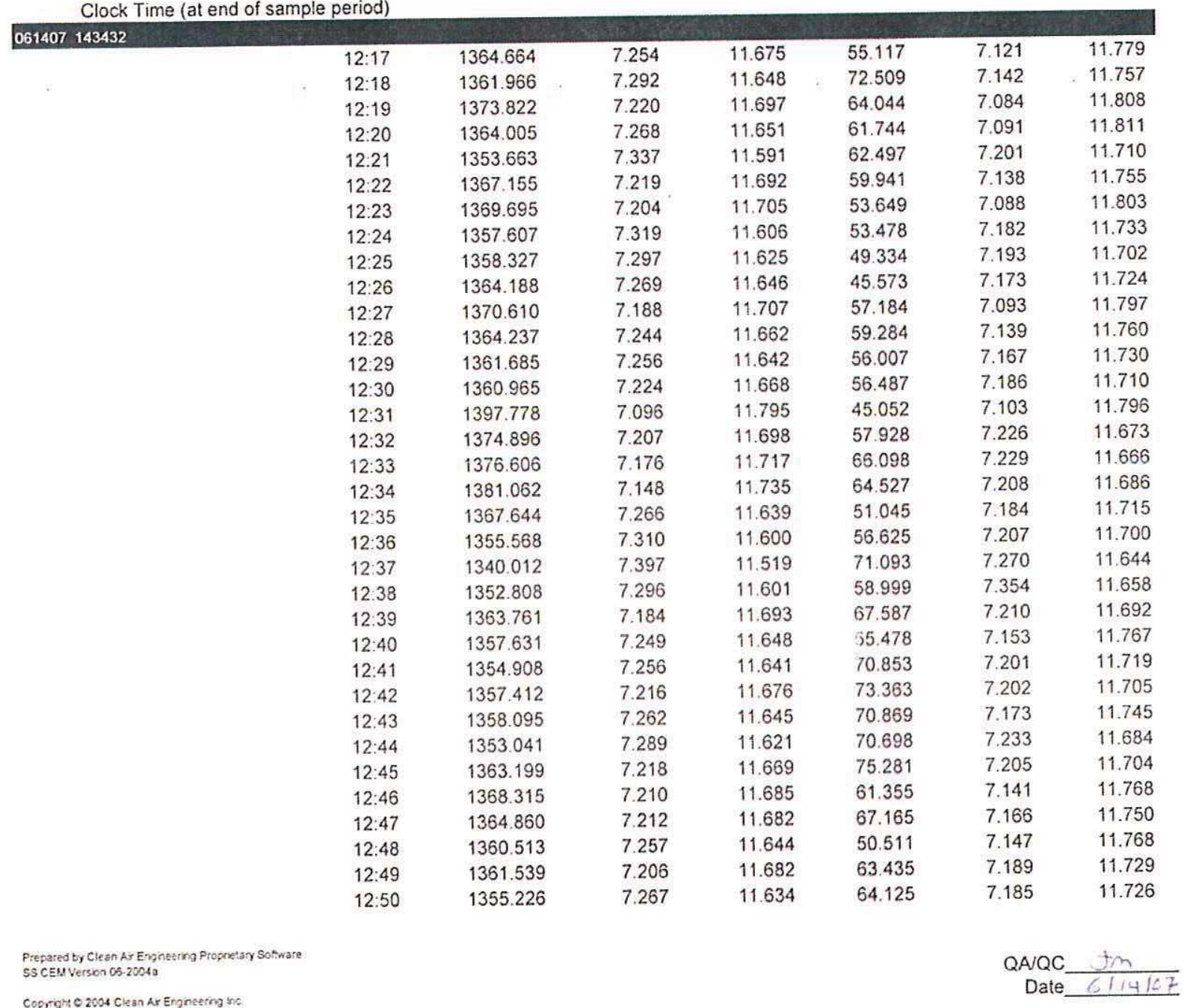


Consol Energy

CleanAir Project No. 10192

Dresden, New York

BH Outlet, AH Outlet

\section{March 29, 2007 \\ $\begin{array}{ll}\text { Start Time } & 12: 16 \\ \text { Stop time } & 13: 17\end{array}$ \\ REFERENCE METHOD RUN 2}

\begin{tabular}{|c|c|c|c|c|c|c|}
\hline & $\begin{array}{r}\text { Channel } 2 \\
\text { SO2 }\end{array}$ & $\begin{array}{r}\text { Channel } 4 \\
\mathrm{O} 2\end{array}$ & $\begin{array}{r}\text { Channel } 5 \\
\mathrm{CO} 2\end{array}$ & $\begin{array}{r}\text { Channol } 7 \\
\text { SO2 }\end{array}$ & $\begin{array}{r}\text { Channel } 8 \\
\text { O2 }\end{array}$ & $\begin{array}{r}\text { Channel } 9 \\
\mathrm{CO} 2\end{array}$ \\
\hline & $\begin{array}{c}\text { AH Outlet } \\
\text { ppmdv }\end{array}$ & $\begin{array}{r}\text { AH Outlet } \\
\% d v\end{array}$ & $\begin{array}{r}\text { AH Outlet } \\
\% \text { dv }\end{array}$ & $\begin{array}{l}\text { BH Outlet } \\
\text { ppmdv }\end{array}$ & $\begin{array}{r}\text { BH Outlet } \\
\% d v\end{array}$ & $\begin{array}{r}\text { BH Outlet } \\
\% d v\end{array}$ \\
\hline $12: 51$ & 1355.739 & 7.297 & 11.613 & 67.337 & 7.188 & 11.725 \\
\hline $12: 52$ & 1360.379 & 7.224 & 11.676 & 67.175 & 7.173 & 11.725 \\
\hline 12.53 & 1361.673 & 7.194 & 11.694 & 62.870 & 7.131 & 11.778 \\
\hline $12: 54$ & 1351.514 & 7.299 & 11.595 & 63.604 & 7.182 & 11.737 \\
\hline $12: 55$ & 1351.966 & 7.235 & 11.645 & 79.328 & 7.168 & 11.751 \\
\hline $12: 56$ & 1351.612 & 7.235 & 11.653 & 83.057 & 7.167 & 11.742 \\
\hline $12: 57$ & 1357.436 & 7.180 & 11.704 & 68.204 & 7.150 & 11.750 \\
\hline $12: 58$ & 1357.070 & 7.262 & 11.645 & 47.138 & 7.148 & 11.765 \\
\hline $12: 59$ & 1348.010 & 7.309 & 11.592 & 69.689 & 7.242 & 11.674 \\
\hline $13: 00$ & 1353.712 & 7.253 & 11.646 & 71.374 & 7.173 & 11.736 \\
\hline 13:01 & 1357.741 & 7.215 & 11.680 & 64.848 & 7.150 & 11.760 \\
\hline $13: 02$ & 1355.385 & 7.225 & 11.666 & 60.493 & 7.190 & 11.718 \\
\hline $13: 03$ & 1350.550 & 7.295 & 11.620 & 67.607 & 7.178 & 11.737 \\
\hline $13: 04$ & 1341.478 & 7.356 & 11.561 & 85.670 & 7.260 & 11.655 \\
\hline $13: 05$ & 1351.148 & 7.243 & 11.654 & 79.551 & 7.204 & 11.696 \\
\hline 13:06 & 1355.556 & 7.221 & 11.670 . & 72.598 & 7.156 & 11.755 \\
\hline $13: 07$ & 1353.443 & 7.210 & 11.667 & 71.383 & 7.190 & 11.721 \\
\hline 13:08 & 1344.957 & 7.276 & 11.602 & 71.493 & 7.243 & 11.659 \\
\hline $13: 09$ & 1342.003 & 7.331 & 11.565 & 72.107 & 7.229 & 11.683 \\
\hline $13: 10$ & 1349.255 & 7.221 & 11.655 & 89.273 & 7.222 & 11.675 \\
\hline $13: 11$ & 1350.391 & 7.253 & 11.639 & 73.191 & 7.170 & 11.708 \\
\hline $13: 12$ & 1354.591 & 7.233 & 11.652 & 61.389 & 7.141 & 11.736 \\
\hline $13: 13$ & 1338.999 & 7.318 & 11.583 & 84.348 & 7.266 & 11.611 \\
\hline 13:14 & 1341.258 & 7.295 & 11.603 & 77.016 & 7.237 & 11.626 \\
\hline $13: 15$ & 1351.990 & 7.225 & 11.652 & 85.978 & 7.198 & 11.657 \\
\hline $13: 16$ & 1390.806 & 6.985 & 11.863 & 82.170 & 7.111 & 11.737 \\
\hline $13: 17$ & 1392.161 & 7.067 & 11.806 & 85.589 & 7.104 & 11.764 \\
\hline
\end{tabular}

Prepared by Ciean Ar Engnetmp Prophetary So?ware SS CEN Verses CS-20043

Copring 02006 Clean As Engreermy the
QAVQ $\frac{317}{6 / 14107}$ 
Consol Energy

CleanAir Project No. 10192

Dresden, New York

$\mathrm{BH}$ Outlet, $\mathrm{AH}$ Outlet
March 29, 2007

CALIBRATION BIAS 02

$\begin{array}{ll}\text { Start Time } & 13: 18 \\ \text { Stop Time } & 13.34\end{array}$

13.34

\begin{tabular}{|c|c|c|c|c|c|}
\hline Channel 2 & Channel 4 & Channel 5 & Channel 7 & Channel 8 & Channel 9 \\
\hline SO2 & $\mathrm{O} 2$ & $\mathrm{CO} 2$ & $\mathrm{SO} 2$ & $\mathrm{O} 2$ & $\mathrm{CO} 2$ \\
\hline $\begin{array}{l}\text { AH Outlet } \\
\text { ppmdv }\end{array}$ & $\begin{array}{r}\text { AH Outlet } \\
\% d v\end{array}$ & $\begin{array}{r}\text { AH Outlet } \\
\% d v\end{array}$ & $\begin{array}{l}\text { BH Outlet } \\
\text { ppmdv }\end{array}$ & $\begin{array}{r}\text { BH Outlet } \\
\% d v\end{array}$ & $\begin{array}{r}\text { BHOutlet } \\
\% d v\end{array}$ \\
\hline
\end{tabular}

System Response to Calibration Gasses $\left(\mathrm{C}_{\mathrm{s}}\right)$

\begin{tabular}{|c|c|c|c|c|c|c|c|}
\hline \\
\hline & \multirow{2}{*}{$\begin{array}{l}\text { Zero gas } \\
\text { Upscale gas }\end{array}$} & 11.005 & 0.028 & 0.146 & 2.847 & 0.000 & $\frac{-0.002}{13.987}$ \\
\hline & & 2389.955 & 5.990 & 13.997 & 47.711 & 6.036 & 13.987 \\
\hline \multicolumn{8}{|c|}{ Analyzer Calibration Error Reponses $\left(\mathrm{C}_{\mathrm{Dir}}\right)$} \\
\hline $\mathrm{C}_{\text {ore }}$ & Zero gas & 3.452 & -0.010 & 0.148 & -0.056 & 0.002 & 0.003 \\
\hline $\mathrm{C}_{\text {mce }}$ & Upscale gas & 2482.035 & 6.061 & 14.059 & 48.630 & 6.050 & 13.966 \\
\hline \multicolumn{8}{|c|}{ Actual Upscale Gas Value $\left(C_{M A}\right)$} \\
\hline $\mathrm{C}_{\mathrm{ma}}$ & Upscale gas & 2479.000 & 6.040 & 13.980 & 49.350 & 6.040 & 13.980 \\
\hline \multicolumn{8}{|c|}{ Calibration Span Value (CS) } \\
\hline & & 2479.000 & 14.100 & 13.980 & 121.600 & 14.100 & 13.980 \\
\hline \multicolumn{8}{|c|}{ System Bias as Percent of Calibration Span Value (SB) $(5 \%)$} \\
\hline & Zero gas & $0.3 \%$ & $0.3 \%$ & $0.0 \%$ & $2.4 \%$ & $0.0 \%$ & $0.0 \%$ \\
\hline & Upscale gas & $-3.7 \%$ & $.0 .5 \%$ & $-0.4 \%$ & $-0.8 \%$ & $-0.1 \%$ & $0.2 \%$ \\
\hline \multicolumn{8}{|c|}{ System Bias Status } \\
\hline & Zero gas & OK & $\mathrm{OK}$ & OK & OK & OK & OK \\
\hline & Upscale gas & OK & OK & OK & OK & $\mathrm{OK}$ & OK \\
\hline \multicolumn{8}{|c|}{ Previous System Response to Calibration Gases $\left(C_{\mathrm{s}}\right)$} \\
\hline $\mathrm{C}_{0}$ & Zero gas & 13.789 & -0.017 & 0.154 & 2.554 & 0.009 & -0.001 \\
\hline $\mathrm{C}_{\mathrm{ui}}$ & Upscale gas & 2411.901 & 6.124 & 14.012 & 47.500 & 6.071 & 14.004 \\
\hline \multicolumn{8}{|c|}{ Drift Assessment as Percent of Calibration Span Value (D) (3\%) } \\
\hline & Zero gas & $-0.1 \%$ & $0.3 \%$ & $.0 .1 \%$ & $0.2 \%$ & $-0.1 \%$ & $0.0 \%$ \\
\hline & Upscale gas & $-0.9 \%$ & $-1.0 \%$ & $-0.1 \%$ & $0.2 \%$ & $-0.2 \%$ & $-0.1 \%$ \\
\hline \multicolumn{8}{|c|}{ Drift Assessment Status } \\
\hline & Zero gas & OK & OK & OK & OK & OK & OK \\
\hline & Upscale gas & OK & OK & OK & OK & $\mathrm{OK}$ & OK \\
\hline
\end{tabular}

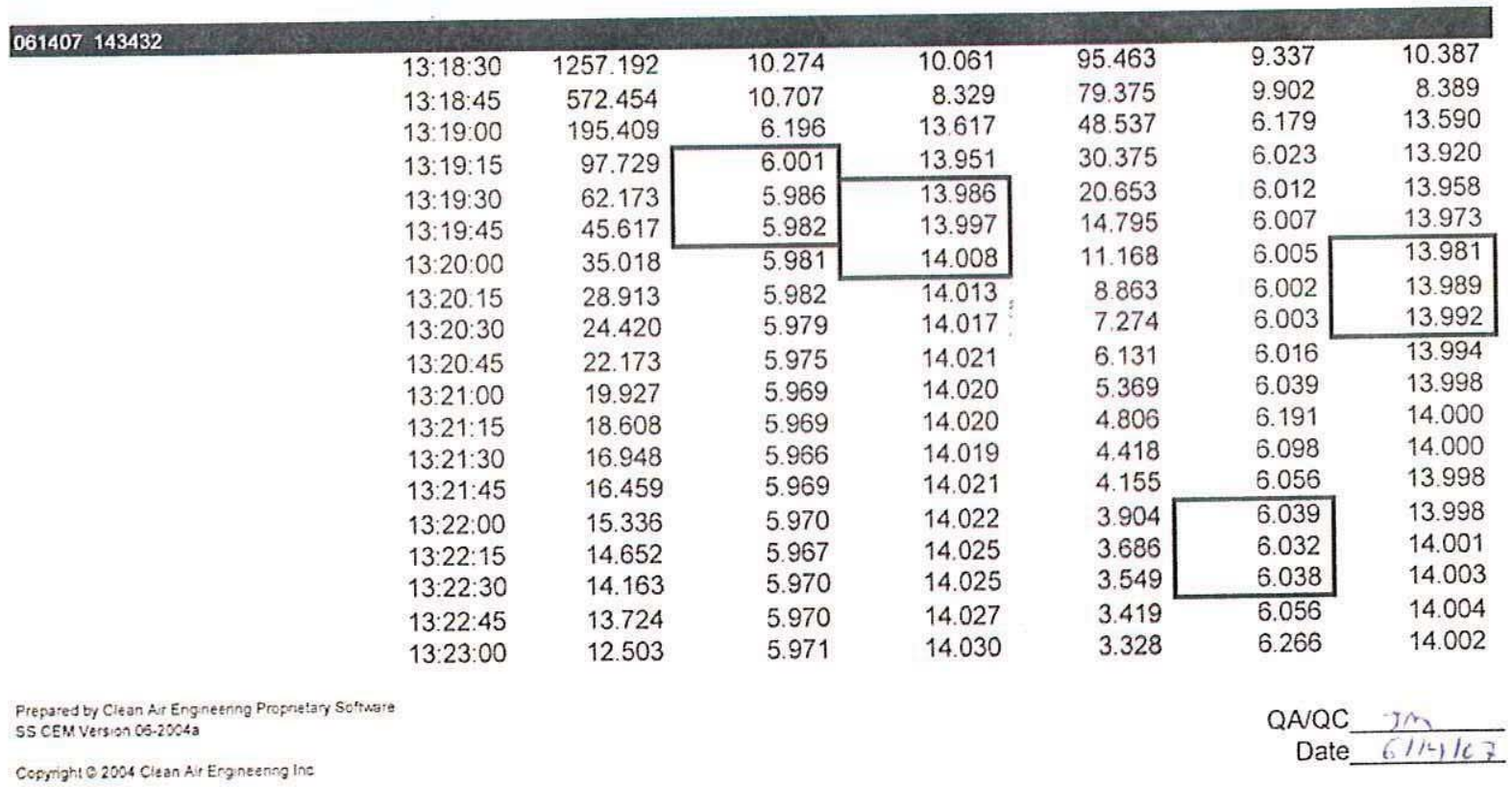


Consol Energy

CleanAir Project No. 10192

Dresden, New York

BH Outlet, AH Outlet

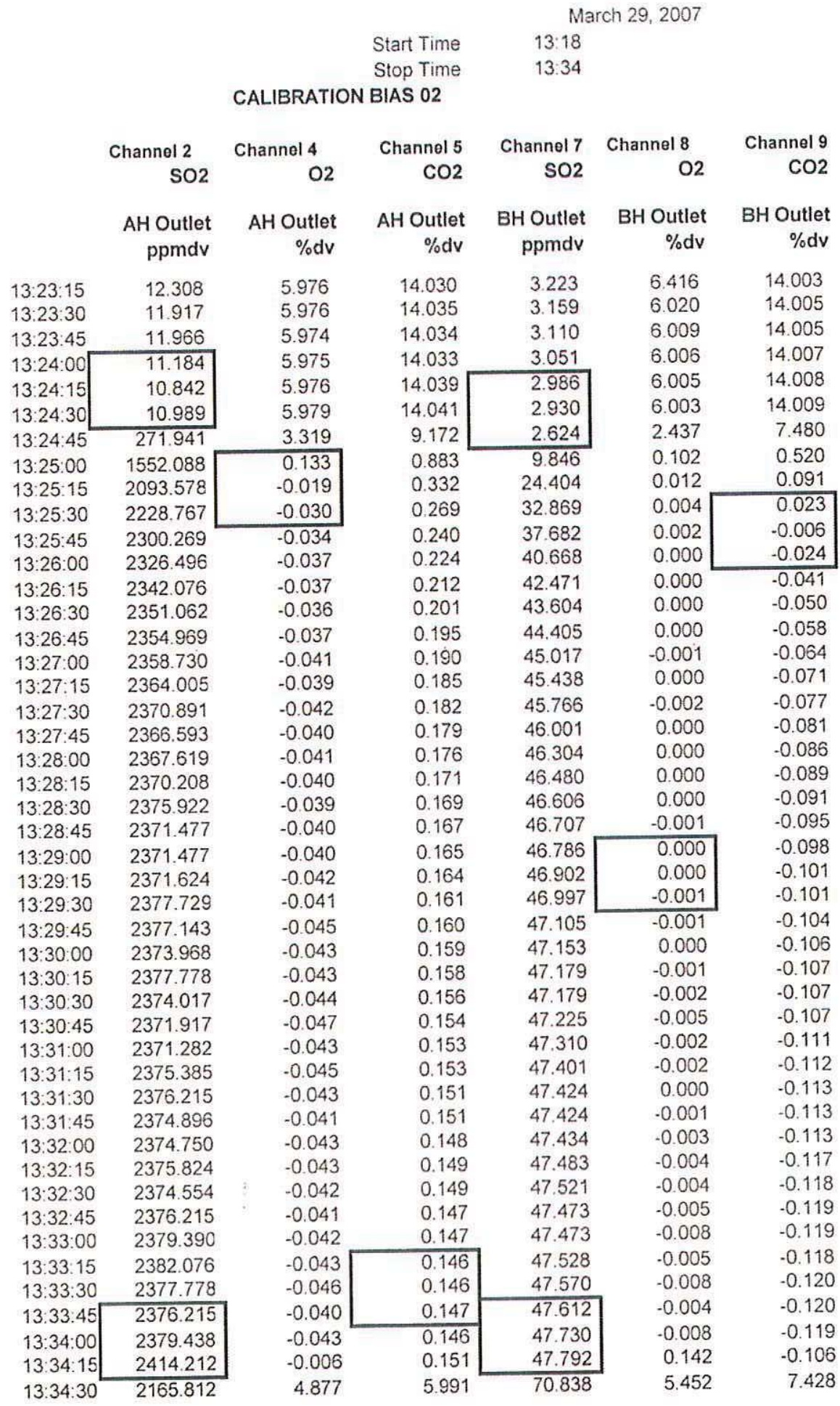

March 29, 2007

Start Time $\quad 13: 18$ 
Consol Energy

CleanAir Project No. 10192

Dresden, New York

BH Outlet, AH Outlet

\author{
March 29, 2007 \\ 15:13 \\ 16:13
}

REFERENCE METHOD RUN 3

$\begin{array}{rrrrrr}\begin{array}{r}\text { Channel 2 } \\ \text { SO2 }\end{array} & \begin{array}{r}\text { Channel 4 } \\ \mathrm{O} 2\end{array} & \begin{array}{r}\text { Channel 5 } \\ \mathrm{CO} 2\end{array} & \begin{array}{r}\text { Channel 7 } \\ \text { SO2 }\end{array} & \begin{array}{r}\text { Channel 8 } \\ \text { O2 }\end{array} & \begin{array}{r}\text { Channel 9 } \\ \text { CO2 }\end{array} \\ \begin{array}{r}\text { AH Outlet } \\ \text { ppmdv }\end{array} & \begin{array}{r}\text { AH Outlet } \\ \% d v\end{array} & \begin{array}{r}\text { AH Outlet } \\ \% d v\end{array} & \begin{array}{r}\text { BH Outlet } \\ \text { ppmdv }\end{array} & \begin{array}{r}\text { BH Outlet } \\ \% d v\end{array} & \begin{array}{r}\text { BH Outlet } \\ \% \text { dv }\end{array}\end{array}$

\section{Calibration Checks}

$\mathrm{C}_{0}$ Initial zero

$\mathrm{C}_{\mathrm{Gs}} \quad$ Initial upscale

$\mathrm{C}_{\text {of }}$ Final zero

11.005

2389.955

12.177

$\mathrm{C}_{u}$ Final upscale

2359.526

$\mathrm{C}_{\mathrm{ma}}$ Actual gas value

2479.000

Analyzer Averages (concentrations)

$\mathrm{C}_{\text {Avg }}$ Average conc

1328.389

$\mathrm{C}_{\text {Gas }}$ Bias adjusted

1381.352

0.028
5.990
-0.019
6.032
6.040

0.146

13.997

0.150

14.042

13.980

7.410

7.447

11.523
11.582

2.367

2.847

47.711

0.000

$-0.002$

3.055

47.506

6.036

13.987

$-0.006$

$-0.012$

49.350

6.040

13.980

98.811

7.512

11.509

7.513

11.507

Clock Time (at end of sample period)

061407143432

$\begin{array}{ll}15: 14 & 1341.746 \\ 15: 15 & 1329.561 \\ 15: 16 & 1335.543 \\ 15: 17 & 1338.706 \\ 15: 18 & 1336.288 \\ 15: 19 & 1334.982 \\ 15: 20 & 1325.031 \\ 15: 21 & 1325.324 \\ 15: 22 & 1344.359 \\ 15: 23 & 1338.706 \\ 15: 24 & 1352.051 \\ 15: 25 & 1349.109 \\ 15: 26 & 1347.265 \\ 15: 27 & 1342.943 \\ 15: 28 & 1336.142 \\ 15: 29 & 1334.042 \\ 15: 30 & 1338.376 \\ 15: 31 & 1333.968 \\ 15: 32 & 1322.283 \\ 15: 33 & 1316.178 \\ 15: 34 & 1325.702 \\ 15: 35 & 1327.558 \\ 15: 36 & 1325.714 \\ 15: 37 & 1323.346 \\ 15: 38 & 1327.631 \\ 15: 39 & 1340.452 \\ 15: 40 & 1340.086 \\ 15: 41 & 1326.642 \\ 15: 42 & 1339.084 \\ 15: 43 & 1332.992 \\ 15: 44 & 1328.230\end{array}$

7.394

7.383

7.301

7.300

7.289

7.311

7.409

7.384

7.265

7.340

7.387

7.337

7.324

7.276

7.344

7.368

7.598

7.392

7.379

7.454

7.401

7.393

7.418

7.463

7.390

7.351

7.386

7.449

7.341

7.448

7.441
Prepared ty Clean Ait Enginetirg Proprietay Softuare S5 CEM Version 08-2004a

Coptright $\otimes 2004$ Clean Aut Engneering inc.

\begin{tabular}{ll}
7.699 & 11.548 \\
7.758 & 11.488 \\
7.729 & 11.492 \\
7.517 & 11.577 \\
7.215 & 11.569 \\
7.205 & 11.589 \\
7.280 & 11.523 \\
7.422 & 11.454 \\
7.435 & 11.555 \\
7.329 & 11.480 \\
7.230 & 11.513 \\
7.275 & 11.534 \\
7.323 & 11.490 \\
7.294 & 11.523 \\
7.346 & 11.471 \\
7.331 & 11.455 \\
7.881 & 11.553 \\
7.790 & 11.505 \\
7.785 & 11.494 \\
7.871 & 11.420 \\
7.756 & 11.513 \\
7.757 & 11.523 \\
7.763 & 11.517 \\
7.759 & 11.492 \\
7.750 & 11.502 \\
7.494 & 11.540 \\
7.480 & 11.490 \\
7.405 & 11.425 \\
7.336 & 11.447 \\
7.244 & 11.514 \\
7.194 & 11.584 \\
& \\
\hline
\end{tabular}

QAVC $\frac{7 m}{6 / 14 / 67}$ 
Consol Energy CleanAir Project No. 10192 Dresden, New York BH Outlet, AH Outlet
March 29, 2007

Start Time $\quad 15: 13$

Stop time $\quad 16: 13$

REFERENCE METHOD RUN 3

\begin{tabular}{|c|c|c|c|c|c|c|}
\hline & Channel 2 & Channel 4 & Channel 5 & $\begin{array}{r}\text { Channel } 7 \\
\mathrm{SO}_{2}\end{array}$ & $\begin{array}{r}\text { Channel } 8 \\
\mathrm{O} 2\end{array}$ & $\begin{array}{r}\text { Channel } 9 \\
\mathrm{CO} 2\end{array}$ \\
\hline & $\begin{array}{l}\text { AH Outlet } \\
\text { ppmdv }\end{array}$ & $\begin{array}{r}\text { AH Outlet } \\
\% d v\end{array}$ & $\begin{array}{r}\text { AH Outlet } \\
\% \text { dv }\end{array}$ & $\begin{array}{l}\text { BH Outlet } \\
\text { ppmdv }\end{array}$ & $\begin{array}{r}\text { BH Outlet } \\
\% d v\end{array}$ & $\begin{array}{l}\text { BH Outlet } \\
\% d v\end{array}$ \\
\hline $15: 45$ & 1319.475 & 7.460 & 11.510 & 106.243 & 7.320 & 11.449 \\
\hline $15: 46$ & 1325.837 & 7.424 & 11.534 & 84.945 & 7.268 & 11.501 \\
\hline $15: 47$ & 1342.332 & 7.250 & 11.670 & 96.186 & 7.202 & 11.549 \\
\hline $15: 48$ & 1344.286 & 7.280 & 11.654 & 79.721 & 7.203 & 11.561 \\
\hline $15: 49$ & 1345.458 & 7.296 & 11.646 & 72.390 & 7.187 & 11.581 \\
\hline $15: 50$ & 1341.062 & 7.362 & 11.586 & 83.234 & 7.634 & 11.515 \\
\hline $15: 51$ & 1327.094 & 7.505 & 11.459 & 75.178 & 7.523 & 11.407 \\
\hline $15: 52$ & 1333.040 & 7.424 & 11.527 & 95.417 & 7.672 & 11.421 \\
\hline $15: 53$ & 1328.926 & 7.337 & 11.288 & 100.889 & 7.554 & 11.466 \\
\hline $15: 54$ & 1326.178 & 7.466 & 11.496 & 106.206 & 7.422 & 11.501 \\
\hline $15: 55$ & 1324.811 & 7.423 & 11.542 & 91.772 & 7.375 & 11.544 \\
\hline $15: 56$ & 1326.655 & 7.435 & 11.535 & 89.937 & 7.388 & 11.572 \\
\hline $15: 57$ & 1315.727 & 7.536 & 11.448 & 83.850 & 7.504 & 11.514 \\
\hline $15: 58$ & 1322.247 & 7.448 & 11.514 & 99.317 & 7.650 & 11.514 \\
\hline $15: 59$ & 1315.836 & 7.449 & 11.509 & 91.258 & 7.737 & 11.520 \\
\hline $16: 00$ & 1318.742 & 7.474 & 11.501 & 94.484 & 7.752 & 11.540 \\
\hline $16: 01$ & 1316.471 & 7.460 & 11.508 & 101.659 & 7.497 & 11.510 \\
\hline $16: 02$ & 1328.266 & 7.392 & 11.570 & 89.159 & 7.546 & 11.572 \\
\hline $16: 03$ & 1317.460 & 7.581 & 11.420 & 111.626 & 7.637 & 11.522 \\
\hline $16: 04$ & 1296.349 & 7.670 & 11.318 & 87.416 & 7.526 & 11.484 \\
\hline $16: 05$ & 1311.074 & 7.487 & 11.472 & 99.113 & 7.566 & 11.458 \\
\hline $16: 06$ & 1314.701 & 7.467 & 11.491 & 85.098 & 7.762 & 11.477 \\
\hline $16: 07$ & 1312.466 & 7.498 & 11.471 & 90.090 & 7.864 & 11.469 \\
\hline $16: 08$ & 1318.352 & 7.431 & 11.469 & 97.488 & 7.524 & 11.479 \\
\hline $16: 09$ & 1313.126 & 7.517 & 11.459 & 105.937 & 7.609 & 11.456 \\
\hline $16: 10$ & 1312.527 & 7.439 & 11.524 & 105.612 & 7.600 & 11.513 \\
\hline $16: 11$ & 1311.514 & 7.449 & 11.522 & 94.792 & 7.782 & 11.545 \\
\hline $16: 12$ & 1315.482 & 7.434 & 11.537 & 96.286 & 7.418 & 11.537 \\
\hline $16: 13$ & 1317.802 & 7.461 & 11.517 & 88.195 & 7.352 & 11.570 \\
\hline
\end{tabular}

Prepared ty Cloan Ait Engneering Proprietary Sotwate SS CEMversisn CS-2004a

Copmght 02004 Ciean Air Enginetring ine
QAVC $\frac{\text { Jn }}{6 / 14 / 67}$ 
Consol Energy

CleanAir Project No. 10192

Dresden, New York

BH Outlet, AH Outlet

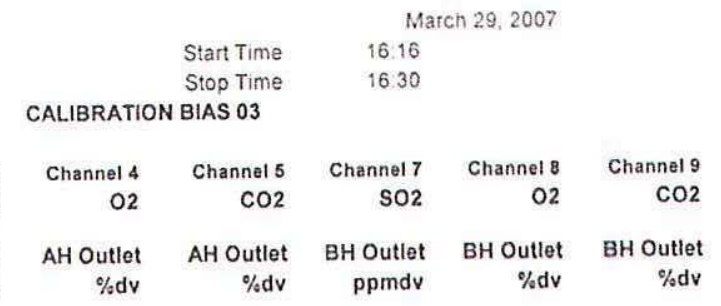

System Response to Calibration Gasses $\left(C_{s}\right)$

0.150 \begin{tabular}{ll|r|r|}
$C_{01}$ Zerogas & .00 \\
\hline
\end{tabular}

$\mathrm{C}_{4}$ Upscale gas

\begin{tabular}{r|r}
12.177 & .0019 \\
2359.526 & 6032
\end{tabular}

\begin{tabular}{|r|r|r|r|}
\hline 0.150 & 3055 & .0006 & .0012 \\
\hline 14.042 & 47.506 & 6.041 & 13981 \\
\hline
\end{tabular}

Analyzer Calibration Error Reponses $\left(C_{0 i t}\right)$

$C_{\text {oe }}$ Zerogas $\quad 3452 \quad .00$

$\mathrm{C}_{\text {mce }}$ Upscale gas $\quad 2482.035 \quad 6061$

$0.148 \quad-0.056$

$0.002 \quad 0.003$

Actual Upscale Gas Value $\left(C_{\mu A}\right)$

$\mathrm{C}_{\mathrm{ma}}$ Upscale gas Calibration Span Value (CS)

$2479000 \quad 6.040$

14.059

48.630

5.050

13966

2479.000

14.100

$13980 \quad 121.600$

5.040

13.980

System Bias as Percent of Calibration Span Value (SB) (5\%)

$$
\text { Zero gas }
$$

$0.4 \%$

$-0.1 \%$

$0.0 \%$

$2.5 \%$

$14.100 \quad 13.980$

Upscale gas

$.4 .9 \%$

$.0 .2 \%$

$.0 .1 \%$

$-0.9 \%$

$.0 .1 \% \quad-0.1 \%$

System Bias Status

Zero gas

Upscale gas

OK OK OK

OK

OK

Previous System Response to Calibration Gases $\left(C_{s}\right)$

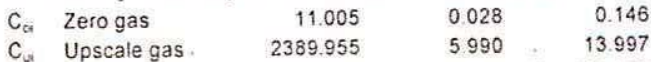

Drift Assessment as Percent of Calibration Span Value (D) $(3 \%)$

$\begin{array}{llll}\text { Zerogas } & 0.0 \% & .0 .3 \% & 0.0 \%\end{array}$

upscale gas

$\begin{array}{lll}-1.2 \% & 0.3 \% & 0.3 \%\end{array}$

Drift Assessment Status

Zero gas

Upscale gas

OK OK

$\begin{array}{llllll}O K & O K & O K & O K & O K & O K \\ \text { OK } & O K & O K & O K & O K & O K\end{array}$

OK

$0.1 \%$

OK OK OK

$2.847 \quad 0.000 \quad-0.002$

$47.711 \quad 6.036 \quad 13987$

$0.2 \% \quad 0.0 \% \quad-0.1 \%$

$-0.2 \% \quad 0.0 \% \quad 0.0 \%$

051407143432 Org

\begin{tabular}{|c|c|c|c|c|c|c|}
\hline $\begin{array}{l}16: 16: 01 \\
16: 16: 16\end{array}$ & $\begin{array}{l}23.785 \\
21.831\end{array}$ & $\begin{array}{l}6.023 \\
6.018\end{array}$ & $\begin{array}{l}14.038 \\
14.041\end{array}$ & $\begin{array}{l}7.938 \\
6.701\end{array}$ & $\begin{array}{l}6.062 \\
6.052\end{array}$ & $\begin{array}{l}13.973 \\
13.976\end{array}$ \\
\hline $16: 16.31$ & 20.513 & 6.020 & 14.045 & 5.893 & 6.053 & 13.978 \\
\hline $\begin{array}{l}16: 16: 46 \\
16: 17.01\end{array}$ & $\begin{array}{l}19.829 \\
18.706\end{array}$ & $\begin{array}{l}6.019 \\
6.019\end{array}$ & $\begin{array}{l}14.051 \\
14.054\end{array}$ & $\begin{array}{l}5.324 \\
4.835\end{array}$ & $\begin{array}{l}6.063 \\
6065\end{array}$ & $\begin{array}{l}13.981 \\
13.983\end{array}$ \\
\hline $\begin{array}{l}16: 17: 16 \\
16: 17: 31\end{array}$ & $\begin{array}{l}17.094 \\
16.019\end{array}$ & $\begin{array}{l}6.023 \\
6.024\end{array}$ & $\begin{array}{l}14055 \\
14.055\end{array}$ & $\begin{array}{l}4.497 \\
4.216\end{array}$ & $\begin{array}{l}6.061 \\
6.055\end{array}$ & $\begin{array}{l}13.982 \\
13.982\end{array}$ \\
\hline $16: 17: 46$ & 15.385 & 6.026 & 14.059 & 3.979 & 6.044 & 13.985 \\
\hline $16: 18.01$ & 13.919 & 6.026 & 14.064 & 3816 & 6.037 & 13.987 \\
\hline $16: 18: 16$ & 13.919 & 6.028 & 14.063 & 3.634 & 6.041 & 13.988 \\
\hline $16: 18: 31$ & 13.919 & 6.026 & 14.066 & 3481 & 6.034 & 13989 \\
\hline $16: 18: 46$ & 12.454 & 6028 & 14.064 & 3.350 & 6.029 & 13.990 \\
\hline $16: 19: 01$ & 12.454 & 6.031 & 14.068 & 3.252 & 6042 & 13.994 \\
\hline $16: 19.16$ & 12.356 & 6.031 & 14068 & 3.175 & 6.030 & 13.994 \\
\hline $16: 19.31$ & 11.722 & 6.033 & 14.070 & 3.133 & 6.039 & 13996 \\
\hline $16: 19.46$ & 167.424 & 3919 & 10.416 & 2859 & 3.970 & 10.754 \\
\hline $16: 2001$ & 1375971 & 0208 & 1.119 & 4005 & 0238 & 1.068 \\
\hline $16: 20.16$ & 2048010 & .0 .009 & 0350 & 14.659 & 0.011 & 0.145 \\
\hline 162031 & 2209.231 & .0 .022 & 0.275 & 25.680 & 0.000 & 0.044 \\
\hline
\end{tabular}

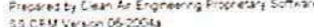

33 cEY vormos:zos

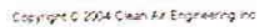

QAQC In

Date_61:4/62 
Consol Energy

CleanAir Project No. 10192

Dresden, New York

BH Outlet, AH Outlet

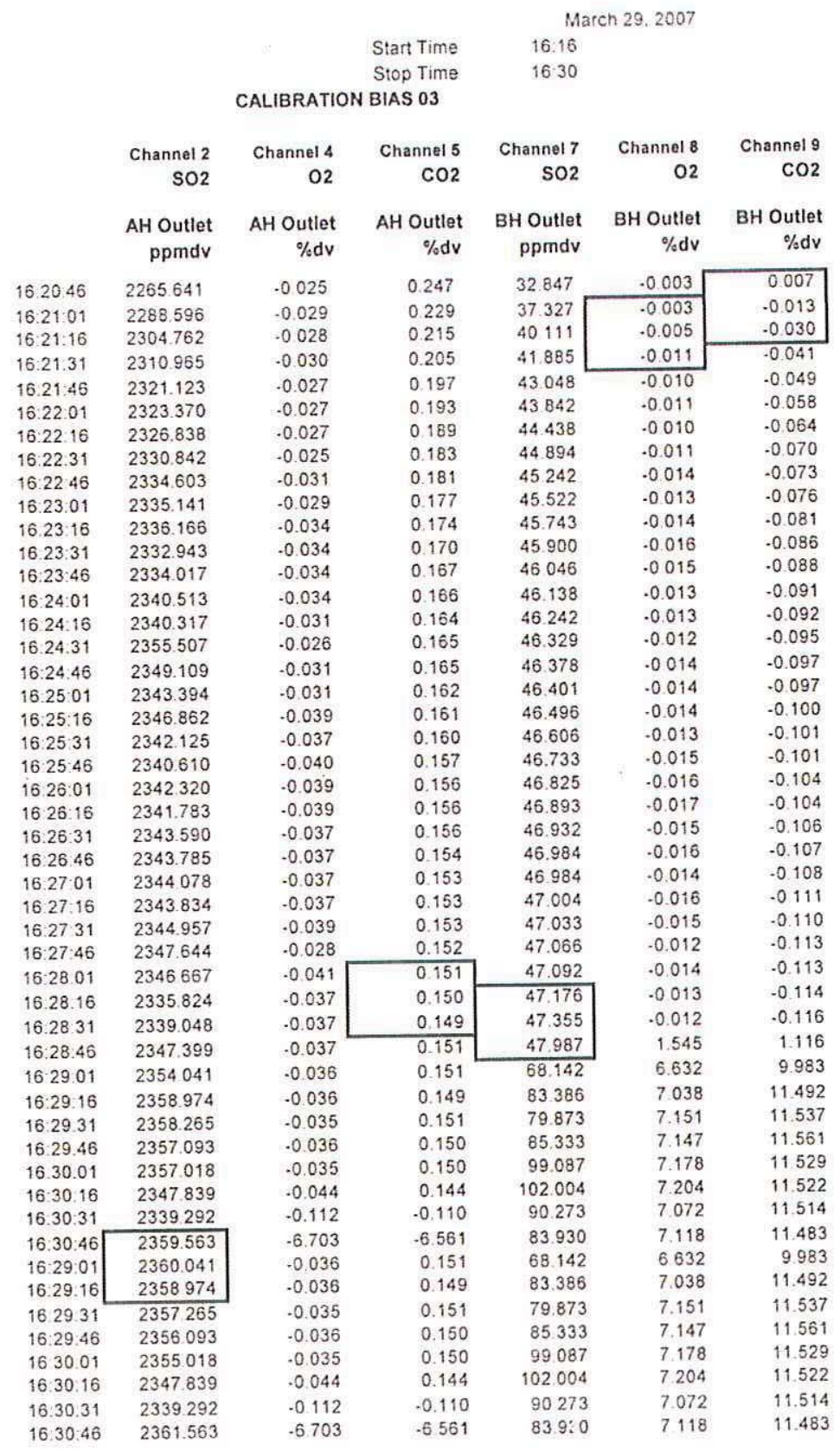




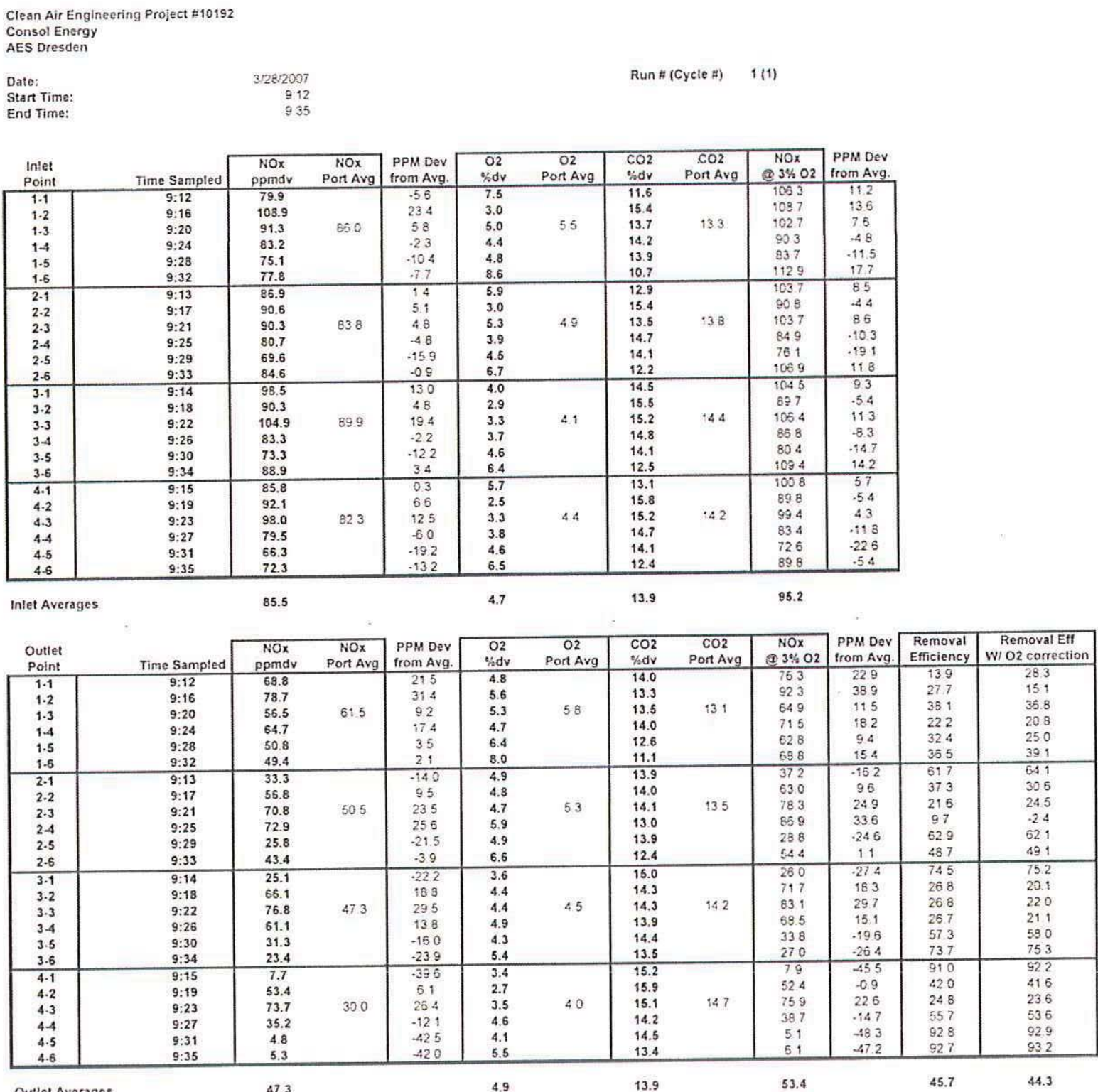

Outiet Averages

47.3

13.9

53.4 
CONSOL ENERGY INC.

AES GREENIDGE STATION
Client Reference No: $\mathbf{4 7 0 0 1 4 0 1 1 1}$

CleanAir Project No:10192

Run 1: Inlet - Set 1

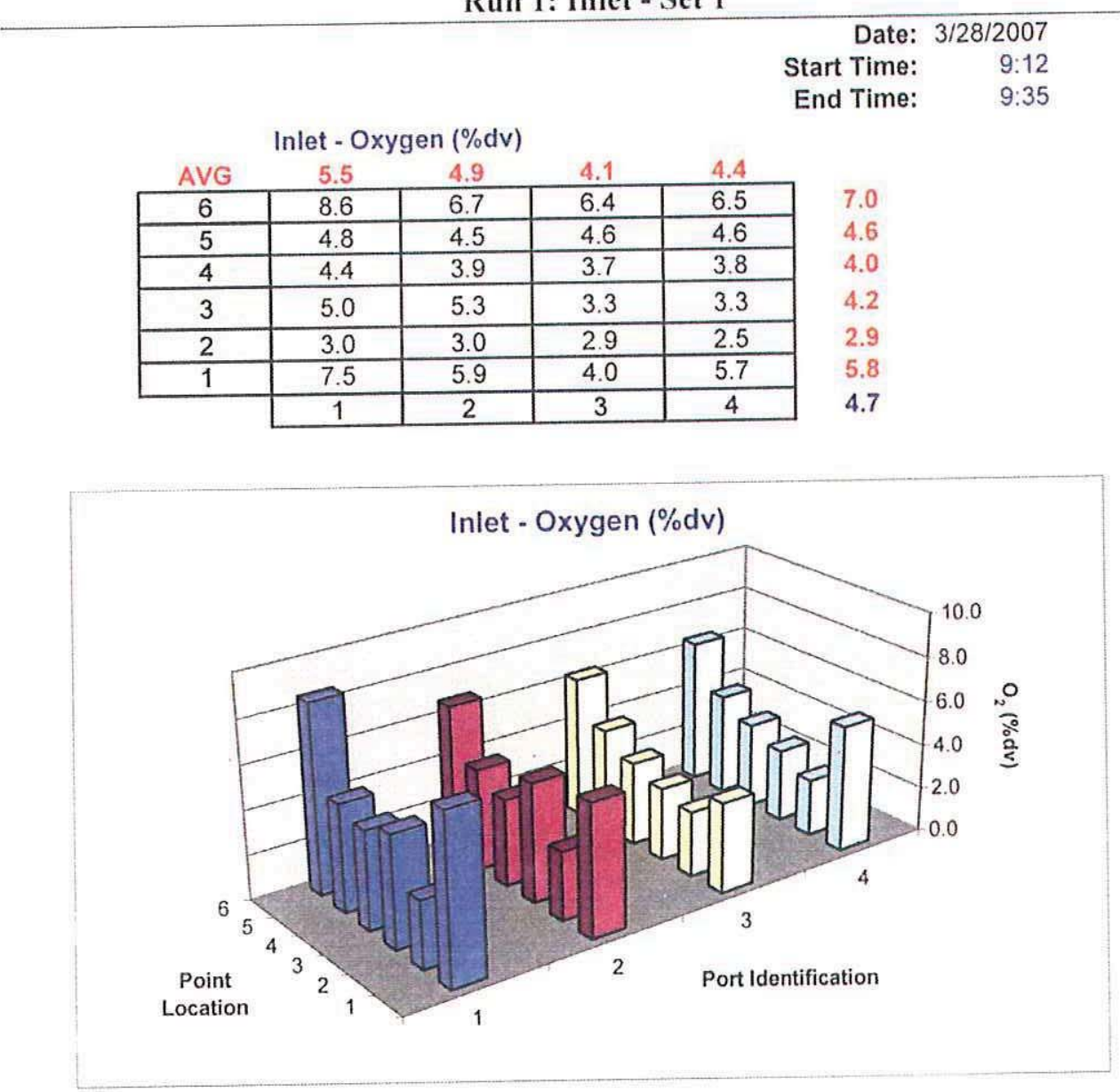


Run 1: Inlet - Set 1

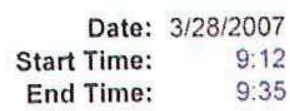

Inlet - Carbon Dioxide (\%dv)
\begin{tabular}{|c|c|c|c|c|}
\hline AVG & 13.3 & 13.8 & 14.4 & 14.2 \\
\hline $\mathbf{6}$ & 10.7 & 12.2 & 12.5 & 12.4 \\
\hline $\mathbf{5}$ & 13.9 & 14.1 & 14.1 & 14.1 \\
\hline $\mathbf{4}$ & 14.2 & 14.7 & 14.8 & 14.7 \\
\hline $\mathbf{3}$ & 13.7 & 13.5 & 15.2 & 15.2 \\
\hline $\mathbf{2}$ & 15.4 & 15.4 & 15.5 & 15.8 \\
\hline $\mathbf{1}$ & 11.6 & 12.9 & 14.5 & 13.1 \\
14.6 \\
14.4 \\
15.5 \\
13.0 \\
13.9
\end{tabular}

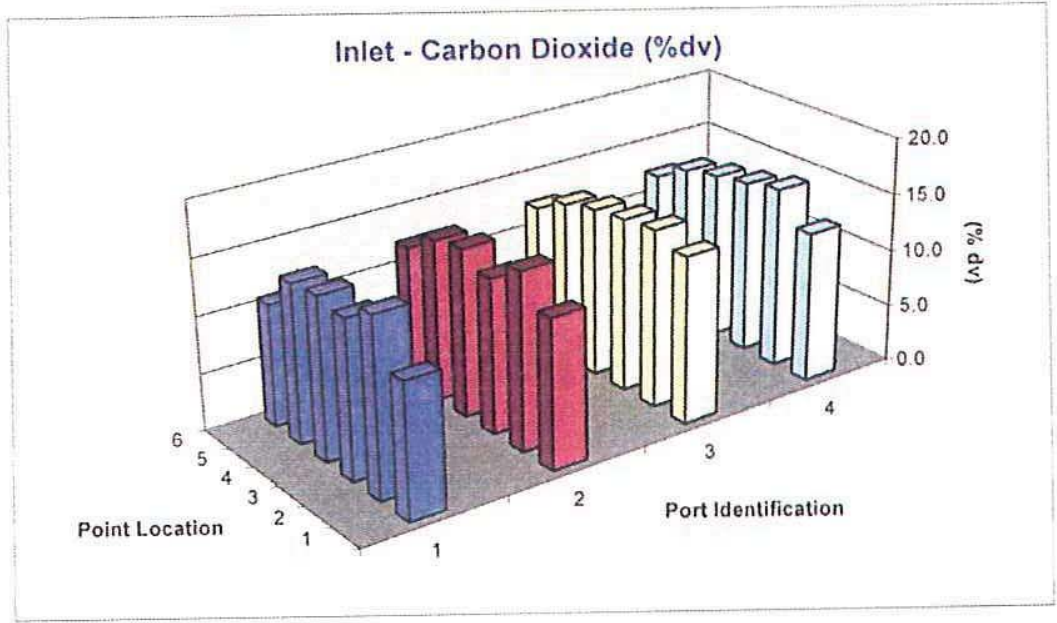


CONSOL ENERGY INC.

AES GREENIDGE STATION
Client Reference No: 4700140111

CleanAir Project No: 10192

Run 1: Inlet - Set 1

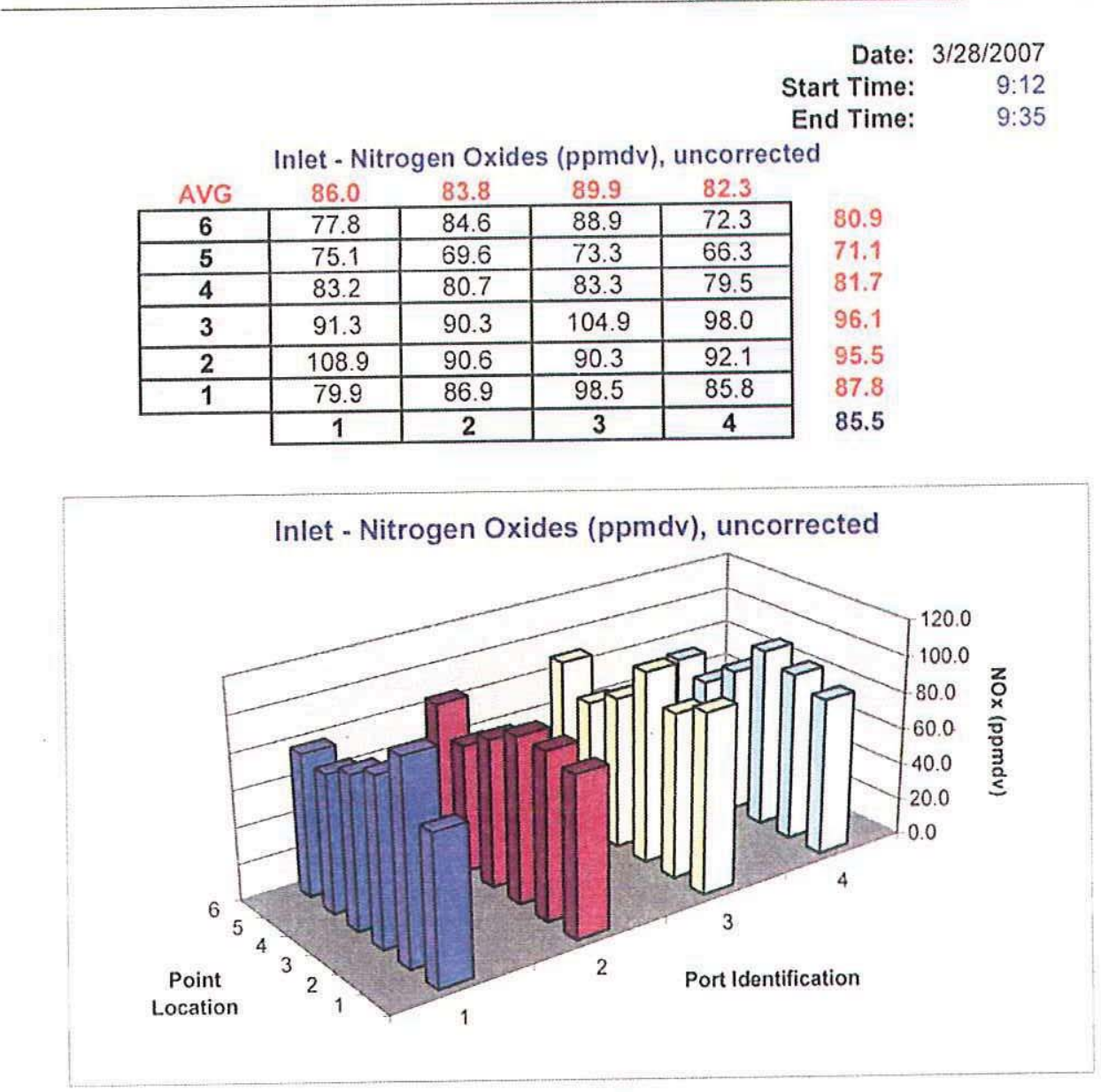


CONSOL ENERGY INC.

AES GREENIDGE STATION
Client Reference No: $\mathbf{4 7 0 0 1 4 0 1 1 1}$

CleanAir Project No:10192

Run 1: Inlet - Set 1

Date: $3 / 28 / 2007$

Start Time: $\quad 9: 12$

End Time: $\quad 9: 35$

Inlet - Nitrogen Oxides (ppmdv @ 3\% $\mathrm{O}_{2}$ )

\begin{tabular}{|c|c|c|c|c|}
\multicolumn{1}{c|}{ AVG } & 100.8 & 94.4 & 96.2 & 89.3 \\
\hline $\mathbf{6}$ & 112.9 & 106.9 & 109.4 & 89.8 \\
\hline $\mathbf{5}$ & 83.7 & 76.1 & 80.4 & 72.6 \\
\hline $\mathbf{4}$ & 90.3 & 84.9 & 86.8 & 83.4 \\
\hline $\mathbf{3}$ & 102.7 & 103.7 & 106.4 & 99.4 \\
\hline $\mathbf{2}$ & 108.7 & 90.8 & 89.7 & 89.8 \\
\hline $\mathbf{1}$ & 106.3 & 103.7 & 104.5 & 100.8 \\
\hline & $\mathbf{1}$ & $\mathbf{2}$ & $\mathbf{3}$ & $\mathbf{4}$ \\
\hline
\end{tabular}

104.7

78.2

86.3

103.1

94.8

103.8

95.2

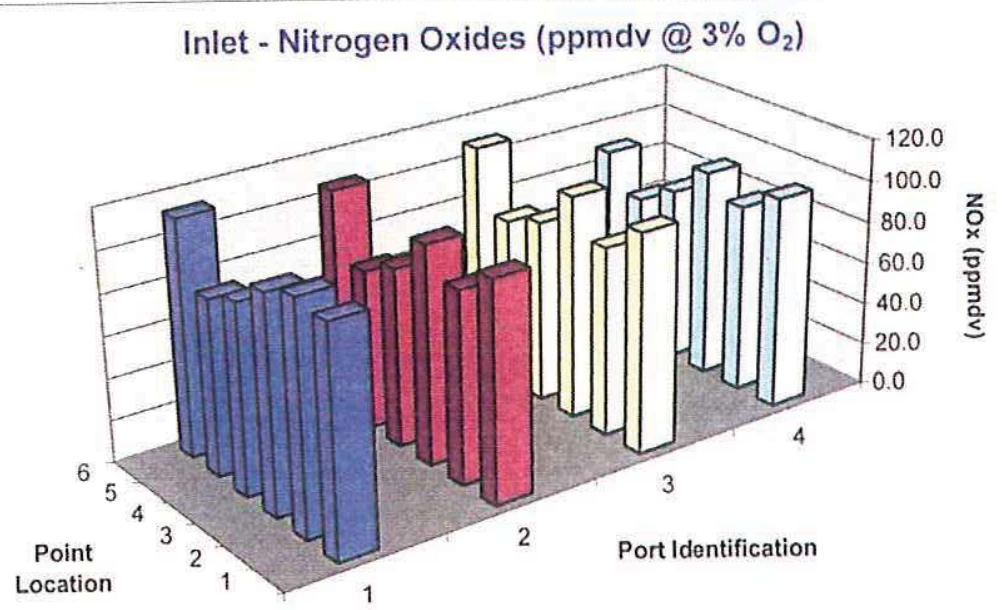


CONSOL ENERGY INC.

AES GREENIDGE STATION
Client Reference No: 4700140111

CleanAir Project No:10192

Run 1: Outlet - Set 1

Date: $3 / 28 / 2007$

Start Time: $\quad 9: 12$

End Time: $\quad 9: 35$

\begin{tabular}{|c|c|c|c|c|c|}
\hline \multicolumn{5}{|c|}{ Outlet - Oxygen ( $\% d v)$} & \multirow[b]{3}{*}{6.4} \\
\hline AVG & 5.8 & 5.3 & 4.5 & 4.0 & \\
\hline 6 & 8.0 & 6.6 & 5.4 & 5.5 & \\
\hline 5 & 6.4 & 4.9 & 4.3 & 4.1 & 4.9 \\
\hline 4 & 4.7 & 5.9 & 4.9 & 4.6 & 5.0 \\
\hline 3 & 5.3 & 4.7 & 4.4 & 3.5 & 4.5 \\
\hline 2 & 5.6 & 4.8 & 4.4 & 2.7 & 4.4 \\
\hline 1 & 4.8 & 4.9 & 3.6 & 3.4 & 4.2 \\
\hline & 1 & 2 & 3 & 4 & 4.9 \\
\hline
\end{tabular}

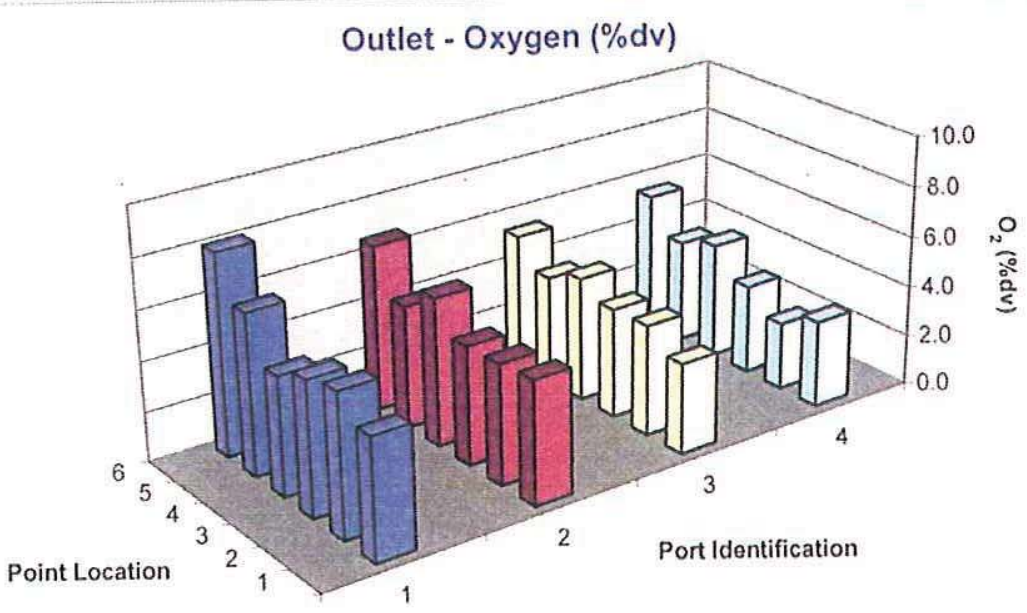


Run 1: Outlet - Set 1

Date: $3 / 28 / 2007$

Start Time: $\quad 9: 12$

End Time: $\quad 9: 35$

\begin{tabular}{|c|c|c|c|c|c|}
\hline \multicolumn{5}{|c|}{ Outlet - Carbon Dioxide (\%dv) } & \multirow[b]{3}{*}{12.6} \\
\hline AVG & 13.1 & 13.5 & 14.2 & 14.7 & \\
\hline 6 & 11.1 & 12.4 & 13.5 & 13.4 & \\
\hline 5 & 12.6 & 13.9 & 14.4 & 14.5 & 13.8 \\
\hline 4 & 14.0 & 13.0 & 13.9 & 14.2 & 13.8 \\
\hline 3 & 13.5 & 14.1 & 14.3 & 15.1 & 14.3 \\
\hline 2 & 13.3 & 14.0 & 14.3 & 15.9 & 14.4 \\
\hline 1 & 14.0 & 13.9 & 15.0 & 15.2 & 14.5 \\
\hline & 1 & 2 & 3 & 4 & 13.9 \\
\hline
\end{tabular}

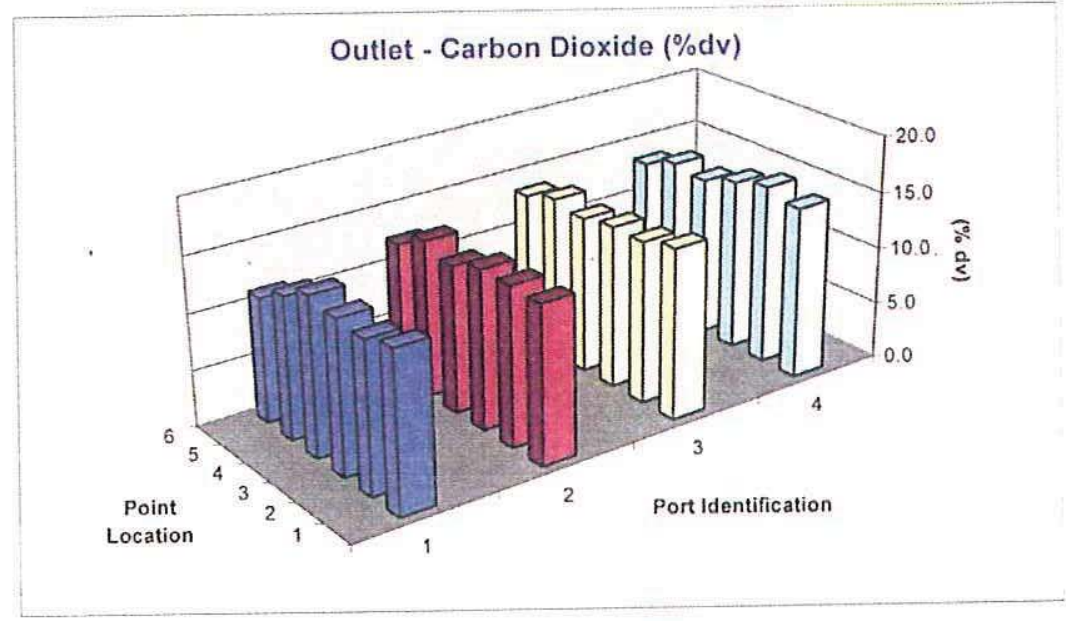


CONSOL ENERGY INC.

AES GREENIDGE STATION
Client Reference No: $\mathbf{4 7 0 0 1 4 0 1 1 1}$

CleanAir Project No:10192

Run 1: Outlet - Set 1

Date: $3 / 28 / 2007$

Start Time: $\quad 9: 12$

End Time: $\quad 9: 35$

Outlet - Nitrogen Oxides (ppmdv), uncorrected

\begin{tabular}{|c|c|c|c|c|}
\hline AVG & 61.5 & 50.5 & 47.3 & 30.0 \\
\hline $\mathbf{6}$ & 49.4 & 43.4 & 23.4 & 5.3 \\
\hline $\mathbf{5}$ & 50.8 & 25.8 & 31.3 & 4.8 \\
\hline $\mathbf{4}$ & 64.7 & 72.9 & 61.1 & 35.2 \\
\hline $\mathbf{3}$ & 56.5 & 70.8 & 76.8 & 73.7 \\
\hline $\mathbf{2}$ & 78.7 & 56.8 & 66.1 & 53.4 \\
\hline $\mathbf{1}$ & 68.8 & 33.3 & 25.1 & 7.7 \\
\hline
\end{tabular}

30.4

28.2

58.5

69.5

63.8

33.7

47.3

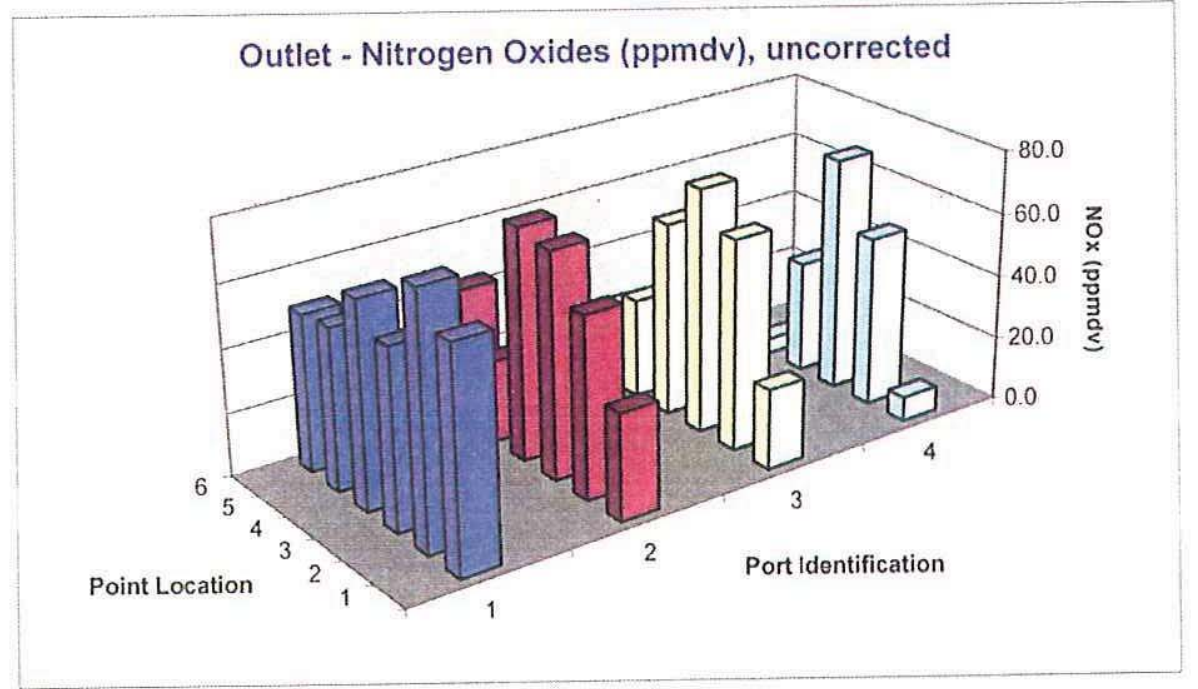


CONSOL ENERGY INC.

AES GREENIDGE STATION
Client Reference No: 4700140111

CleanAir Project No: 10192

Run 1: Outlet - Set 1

Date: $3 / 28 / 2007$

Start Time: $\quad 9: 12$

End Time: $\quad 9: 35$

\begin{tabular}{|c|c|c|c|c|c|}
\hline \multicolumn{6}{|c|}{ Outlet - Nitrogen Oxides (ppmdv @ $3 \% \mathrm{O}_{2}$ ) } \\
\hline AVG & 72.7 & 58.1 & 51.7 & 31.0 & \\
\hline 6 & 68.8 & 54.4 & 27.0 & 6.1 & 39.1 \\
\hline 5 & 62.8 & 28.8 & 33.8 & 5.1 & 32.6 \\
\hline 4 & 71.5 & 86.9 & 68.5 & 38.7 & 66.4 \\
\hline 3 & 64.9 & 78.3 & 83.1 & 75.9 & 75.5 \\
\hline 2 & 92.3 & 63.0 & 71.7 & 52.4 & 69.8 \\
\hline 1 & 76.3 & 37.2 & 26.0 & 7.9 & 36.8 \\
\hline & 1 & 2 & 3 & 4 & 53.4 \\
\hline
\end{tabular}

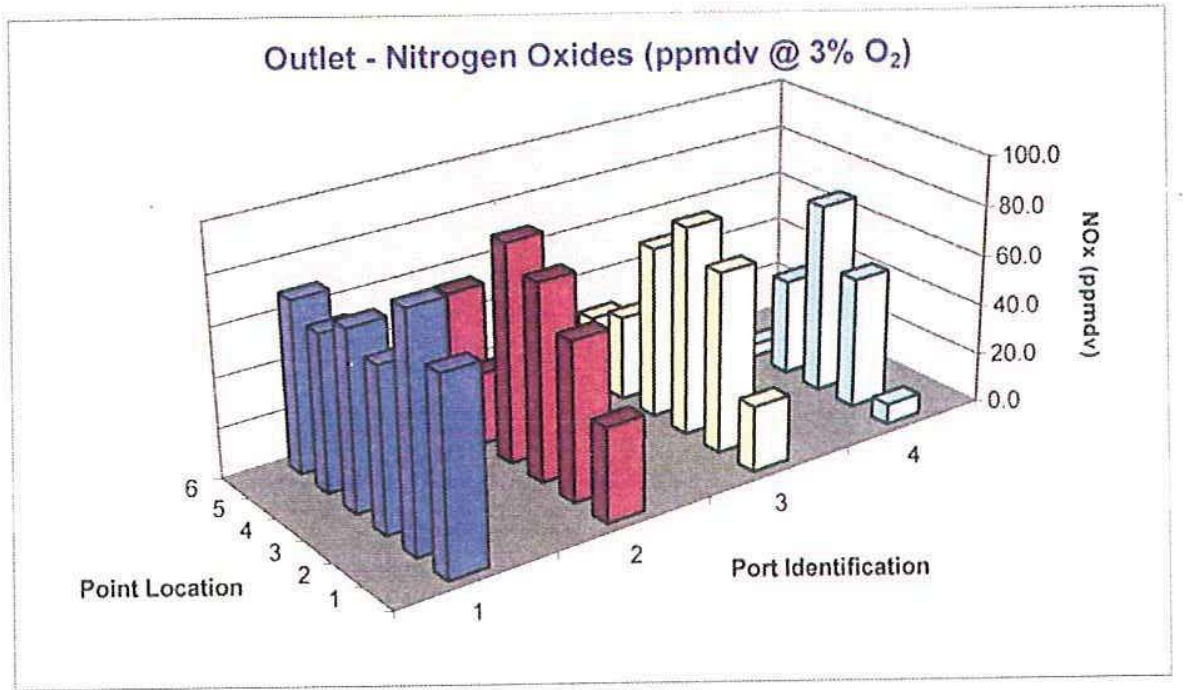


CONSOL ENERGY INC.

AES GREENIDGE STATION
Client Reference No: 4700140111

CleanAir Project No:10192

Run 1: Outlet - Set 1

Date: $3 / 28 / 2007$

Start Time: $\quad 9: 12$

End Time: $\quad 9: 35$

\begin{tabular}{|c|c|c|c|c|c|}
\hline \multicolumn{6}{|c|}{ Removal Efficiency (ppmdv@ @ 3\% $\mathrm{O}_{2}$ ) } \\
\hline AVG & $27.5 \%$ & $38.0 \%$ & $45.3 \%$ & $66.2 \%$ & \\
\hline 6 & $39.1 \%$ & $49.1 \%$ & $75.3 \%$ & $93.2 \%$ & $64.2 \%$ \\
\hline 5 & $25.0 \%$ & $62.1 \%$ & $58.0 \%$ & $92.9 \%$ & $59.5 \%$ \\
\hline 4 & $20.8 \%$ & $-2.4 \%$ & $21.1 \%$ & $53.6 \%$ & $23.3 \%$ \\
\hline 3 & $36.8 \%$ & $24.5 \%$ & $22.0 \%$ & $23.6 \%$ & $26.7 \%$ \\
\hline 2 & $15.1 \%$ & $30.6 \%$ & $20.1 \%$ & $41.6 \%$ & $26.9 \%$ \\
\hline 1 & $28.3 \%$ & $64.1 \%$ & $75.2 \%$ & $92.2 \%$ & $64.9 \%$ \\
\hline & 1 & 2 & 3 & 4 & $44.3 \%$ \\
\hline
\end{tabular}

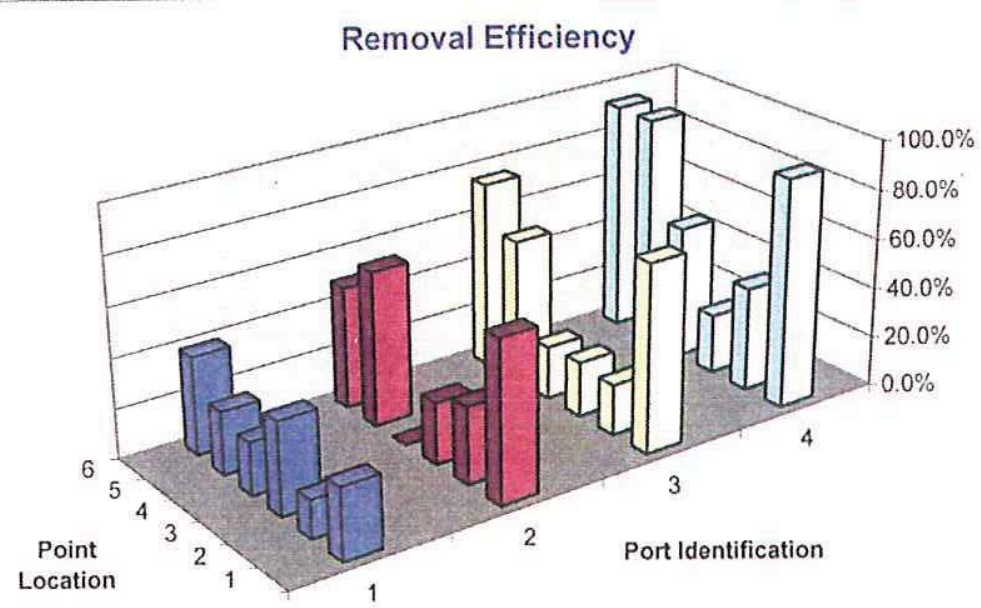


Clean Air Engineering Project $\# 10192$

Consol Energy

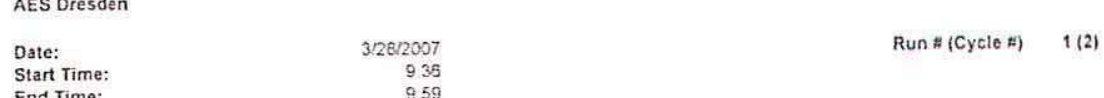

\begin{tabular}{|c|c|c|c|c|c|c|c|c|c|c|}
\hline $\begin{array}{l}\text { Inlet } \\
\text { Point }\end{array}$ & Time Sampled & $\begin{array}{c}\text { NOx } \\
\text { ppmdv }\end{array}$ & $\begin{array}{c}\text { NOx } \\
\text { Port Avg }\end{array}$ & $\begin{array}{l}\text { PPM Dev } \\
\text { from Arg. }\end{array}$ & $\begin{array}{l}02 \\
\% d v\end{array}$ & $\begin{array}{c}\mathrm{O} 2 \\
\text { Port Avg }\end{array}$ & $\begin{array}{l}\mathrm{CO} 2 \\
\% d v\end{array}$ & $\begin{array}{c}\mathrm{CO} 2 \\
\text { Port Avg }\end{array}$ & $\begin{array}{c}\text { NOx } \\
\text { (3) } 3 \% 22\end{array}$ & $\begin{array}{l}\text { PPM Dev } \\
\text { from Avg. }\end{array}$ \\
\hline 1.1 & $9: 36$ & 77.9 & & -55 & 7.6 & & 11.5 & & 1045 & 116 \\
\hline 1.2 & $9: 40$ & 105.1 & & 21.7 & 2.9 & & 15.5 & & 1045 & 197 \\
\hline 1.3 & $9: 44$ & 89.7 & 843 & 53 & 5.1 & 55 & 13.7 & 133 & 1014 & 85 \\
\hline $1-4$ & $9: 48$ & 83.2 & & .02 & 4.4 & & 14.3 & & $\$ 00$ & 2.8 \\
\hline 1.5 & $9: 52$ & 73.9 & & .95 & 4.8 & & 14.0 & & 819 & .109 \\
\hline 1.6 & $9: 56$ & 76.0 & & .74 & 8.7 & & 10.6 & & 1111 & 183 \\
\hline $2 \cdot 1$ & $9: 37$ & 83.1 & & .03 & 6.0 & & 12.8 & & 928 & 69 \\
\hline 2.2 & $9: 41$ & 85.4 & & 20 & 2.9 & & 15.5 & & 851 & .78 \\
\hline 2.3 & $9: 45$ & 88.0 & 808 & 46 & 5.3 & 49 & 13.5 & 138 & 1008 & 80 \\
\hline $2-4$ & $9: 49$ & 79.0 & & -44 & 3.9 & & 14.7 & & 83.1 & .98 \\
\hline 2.5 & $9: 53$ & 66.7 & & .67 & 4.5 & & 14,1 & & 729 & .199 \\
\hline 2.5 & $9: 57$ & 82.3 & & -11 & 6.9 & & 12.1 & & 1049 & 120 \\
\hline 3.1 & $9: 38$ & 96.2 & & 128 & 4.0 & & 14.5 & & 1019 & 90 \\
\hline $3 \cdot 2$ & $9: 42$ & 87.4 & & 40 & 2.9 & & 15.5 & & 870 & .5 .8 \\
\hline 3.3 & $9: 46$ & 102.8 & 875 & 194 & 3.3 & 41 & 15.1 & 145 & 1046 & 11.8 \\
\hline 3.4 & $9: 50$ & 81.3 & & -21 & 3.6 & & 14.9 & & 841 & -87 \\
\hline 3.5 & $9: 54$ & 70.9 & & -125 & 4.5 & & 14.2 & & 771 & .157 \\
\hline 3.6 & $9: 58$ & 86.4 & & 30 & 6.3 & & 12.6 & & 105.6 & 127 \\
\hline $4 \cdot 1$ & $9: 39$ & 83.1 & & -03 & 5.7 & & 13.1 & & 977 & 49 \\
\hline $4 \cdot 2$ & $9: 43$ & 90.6 & & 72 & 2.6 & & 15.8 & & 886 & -42 \\
\hline 4.3 & $9: 47$ & 97.4 & 812 & 140 & 3.2 & 44 & 15.2 & 142 & 984 & 56 \\
\hline $4-4$ & $9: 51$ & 79.3 & & 41 & 3.7 & & 14.8 & & 826 & .103 \\
\hline 4.5 & $9: 55$ & 65.5 & & .179 & 4.6 & & 14.1 & & 71.7 & .211 \\
\hline 4.6 & $9: 59$ & 71.2 & & $\begin{array}{r}-12.2 \\
\end{array}$ & 6.6 & & 12.4 & & 891 & .37 \\
\hline
\end{tabular}

$\begin{array}{lllll}\text { Inlet Averages } & 83.4 & 4.7 & 13.9 & 92.9\end{array}$

\begin{tabular}{|c|c|c|c|c|c|c|c|c|c|c|c|c|c|}
\hline $\begin{array}{l}\text { Outiet } \\
\text { Point }\end{array}$ & Nidt lept $T$ & Time Sampled & $\begin{array}{c}\text { NOx } \\
\text { pomdv }\end{array}$ & $\begin{array}{c}\text { NOx } \\
\text { Port Avg }\end{array}$ & $\begin{array}{l}\text { PPM Dev } \\
\text { from Avg. }\end{array}$ & $\begin{array}{l}\text { O2 } \\
\% d v\end{array}$ & $\begin{array}{c}\mathrm{O} 2 \\
\text { Port Avg } \\
\end{array}$ & $\begin{array}{l}\mathrm{CO} 2 \\
\% \mathrm{dv}\end{array}$ & $\begin{array}{c}\mathrm{CO} 2 \\
\text { Port Avg }\end{array}$ & $\begin{array}{c}\text { NOx } \\
03 \% \mathrm{O} 2 \\
\end{array}$ & $\begin{array}{l}\text { PPM Dev } \\
\text { from Avg. }\end{array}$ & $\begin{array}{l}\text { Removal } \\
\text { Efficiency } \\
\end{array}$ & $\begin{array}{c}\text { Removal Eff } \\
\text { W/ } O 2 \text { correction }\end{array}$ \\
\hline 1.1 & & $9: 36$ & 67.6 & & 201 & 4.9 & & 13.8 & & 758 & 223 & 132 & 27.4 \\
\hline 1.2 & & $9: 40$ & 79.9 & & 324 & 5.5 & & 13.4 & & 929 & 39.3 & 240 & 11.1 \\
\hline 1.3 & & $9: 44$ & 57.0 & 621 & 95 & 5.4 & 5.8 & 13.5 & 13.1 & 656 & 12.1 & 365 & 353 \\
\hline 1.4 & & $9: 48$ & 66.8 & & 193 & 4.6 & & 14.2 & & 734 & 198 & 19.7 & 185 \\
\hline 1.5 & & $9: 52$ & 52.2 & & 4.7 & 6.4 & & 12.6 & & 643 & 108 & 294 & 215 \\
\hline 1.6 & & $9: 56$ & 49.0 & & 15 & 8.0 & & 11.1 & & 582 & 146 & 355 & 387 \\
\hline $2 \cdot 1$ & & $9: 37$ & 34.8 & & -127 & 5.0 & & 13.8 & & 391 & .144 & 581 & 60.8 \\
\hline 2.2 & & $9: 41$ & 57.0 & & 95 & 4.6 & & 14.2 & & 626 & 90 & 333 & 264 \\
\hline 2.3 & & $9: 45$ & 69.6 & 500 & 221 & 4.7 & 53 & 14.1 & 135 & 769 & 234 & 20.9 & 237 \\
\hline 2.4 & & $9: 49$ & 71.5 & & 240 & 6.0 & & 13.0 & & 856 & 321 & 95 & -30 \\
\hline 2.5 & & $9: 53$ & 24.4 & & .231 & 4.9 & & 13.9 & & 273 & .25 .2 & 634 & 625 \\
\hline 2.6 & & $9: 57$ & 42.9 & & -46 & 6.7 & & 12.3 & & 540 & 05 & 479 & 485 \\
\hline 3.1 & & $9: 38$ & 25.1 & & -224 & 3.7 & & 14.8 & & 262 & .274 & 739 & 743 \\
\hline 3.2 & & $9: 42$ & 69.8 & & 22.3 & 4.3 & & 14.4 & & 752 & 217 & 20.1 & 136 \\
\hline 3.3 & & $9: 46$ & 79.9 & 479 & 324 & 4.3 & 45 & 14.4 & 142 & 852 & 326 & 223 & 17.6 \\
\hline $3-4$ & & $9: 50$ & 59.4 & & 119 & 5.0 & & 13.8 & & 687 & 132 & 269 & 20.7 \\
\hline 3.5 & & 9:54 & 30.1 & & .174 & 4.3 & & 14.4 & & 324 & .21 .2 & 575 & 580 \\
\hline 3.6 & & $9: 58$ & 22.9 & & -246 & 5.6 & & 13.3 & & 268 & .267 & 735 & 746 \\
\hline A.1 & & $9: 39$ & 7.7 & & .398 & 3.6 & & 15.0 & & 80 & 456 & 907 & 518 \\
\hline $4 \cdot 2$ & & $9: 43$ & 51.8 & & 43 & 2.7 & & 15.8 & & $5: 1$ & .25 & 428 & 424 \\
\hline $4 \cdot 3$ & & $9: 47$ & 73.8 & 299 & 263 & 3.6 & 40 & 15.1 & 147 & 761 & 22.6 & 242 & 227 \\
\hline 4.4 & & $9: 51$ & 36.7 & & .108 & 4.5 & & 14.2 & & 401 & .134 & 537 & 514 \\
\hline 4.5 & & $9: 55$ & 4.5 & & .430 & 4.1 & & 14.6 & & 48 & 488 & 931 & 933 \\
\hline 4.6 & & $9: 59$ & 5.1 & & -424 & 5.6 & & 13.3 & & 60 & 475 & 928 & 933 \\
\hline
\end{tabular}

Outlet Averages

47.5

4.9

13.9

53.6

44.3

42.7 
CONSOL ENERGY INC.

AES GREENIDGE STATION
Client Reference No: 4700140111

CleanAir Project No:10192

Run 1: Inlet-Set 2

$\begin{array}{rr}\text { Date: } & 3 / 28 / 2007 \\ \text { Start Time: } & 9: 36 \\ \text { End Time: } & 9: 59\end{array}$

Inlet - Oxygen (\%dv)

\begin{tabular}{|c|c|c|c|c|}
\multicolumn{1}{c|}{ AVG } & 5.5 & 4.9 & 4.1 & 4.4 \\
\hline 6 & 8.7 & 6.9 & 6.3 & 6.6 \\
\hline 5 & 4.8 & 4.5 & 4.5 & 4.6 \\
\hline 4 & 4.4 & 3.9 & 3.6 & 3.7 \\
\hline 3 & 5.1 & 5.3 & 3.3 & 3.2 \\
\hline 2 & 2.9 & 2.9 & 2.9 & 2.6 \\
\hline 1 & 7.6 & 6.0 & 4.0 & 5.7 \\
\hline & 1 & 2 & 3 & 4 \\
\hline
\end{tabular}

7.1

4.6

3.9

4.2

2.8

5.8

4.7

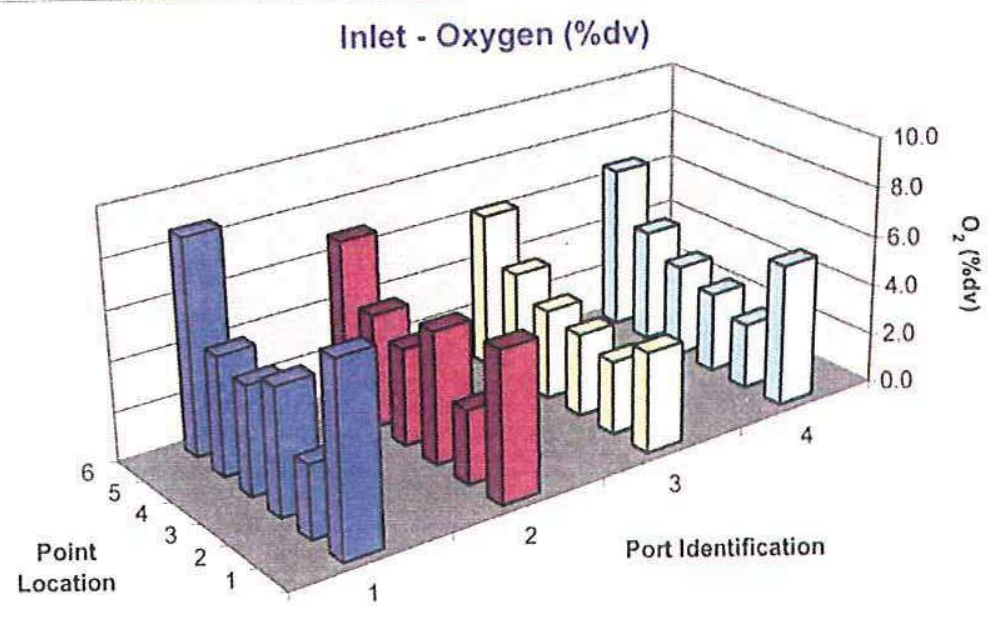


Run 1: Inlet-Set 2

$\begin{array}{rr}\text { Date: } & 3 / 28 / 2007 \\ \text { Start Time: } & 9: 36 \\ \text { End Time: } & 9: 59\end{array}$

Inlet - Carbon Dioxide ( $\%$ dv)

Inlet - Carbon Dioxide (\%dv)
\begin{tabular}{|c|c|c|c|c|}
\hline AVG & 13.3 & 13.8 & 14.5 & 14.2 \\
\hline $\mathbf{6}$ & 10.6 & 12.1 & 12.6 & 12.4 \\
\hline $\mathbf{5}$ & 14.0 & 14.1 & 14.2 & 14.1 \\
\hline $\mathbf{4}$ & 14.3 & 14.7 & 14.9 & 14.8 \\
\hline $\mathbf{3}$ & 13.7 & 13.5 & 15.1 & 15.2 \\
\hline $\mathbf{2}$ & 15.5 & 15.5 & 15.5 & 15.8 \\
\hline $\mathbf{1}$ & 11.5 & 12.8 & 14.5 & 13.1 \\
\hline & $\mathbf{1}$ & $\mathbf{2}$ & $\mathbf{3}$ & $\mathbf{4}$ \\
\hline
\end{tabular}

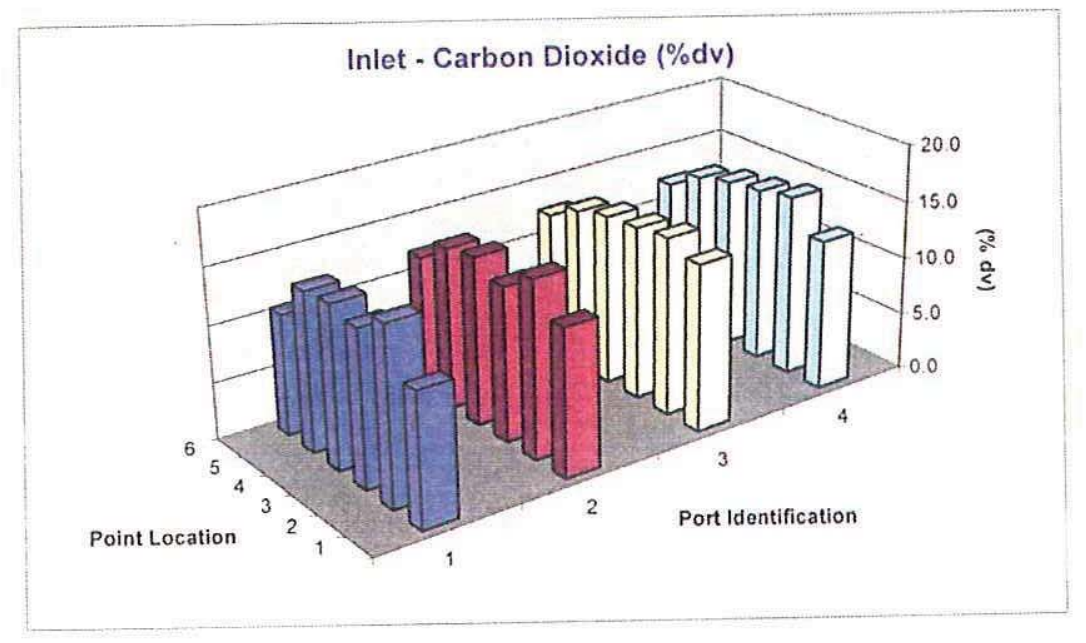


CONSOL ENERGY INC.

AES GREENIDGE STATION
Client Reference No: 4700140111

CleanAir Project No: 10192

Run 1: Inlet - Set 2

Date: $3 / 28 / 2007$

Start Time: $\quad 9: 36$

End Time: $\quad 9: 59$

Inlet - Nitrogen Oxides (ppmdv), uncorrected

\begin{tabular}{|c|c|c|c|c|c|}
\hline AVG & 84.3 & 80.8 & 87.5 & 81.2 & \\
\hline 6 & 76.0 & 82.3 & 86.4 & 71.2 & 79.0 \\
\hline 5 & 73.9 & 66.7 & 70.9 & 65.5 & 69.3 \\
\hline 4 & 83.2 & 79.0 & 81.3 & 79.3 & 80.7 \\
\hline 3 & 89.7 & 88.0 & 102.8 & 97.4 & 94.5 \\
\hline 2 & 105.1 & 85.4 & 87.4 & 90.6 & 92.1 \\
\hline 1 & 77.9 & 83.1 & 96.2 & 83.1 & 85.1 \\
\hline & 1 & 2 & 3 & 4 & 83.4 \\
\hline
\end{tabular}

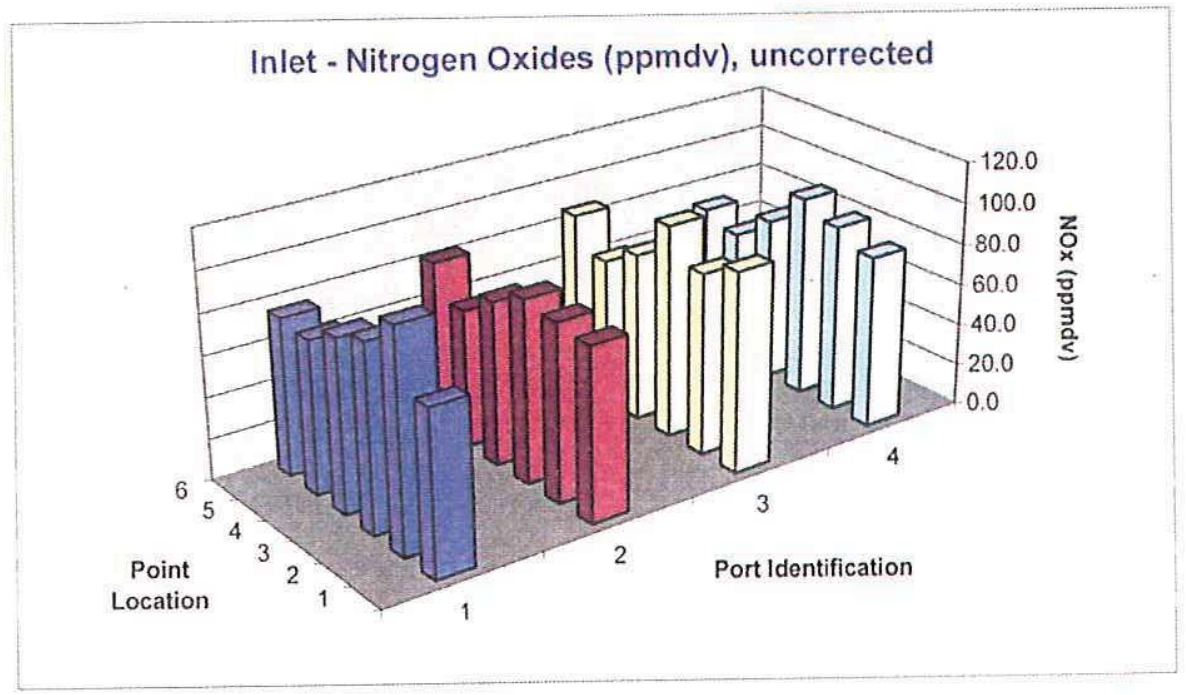


CONSOL ENERGY INC.

AES GREENIDGE STATION
Client Reference No: 4700140111

CleanAir Project No: 10192

Run 1: Inlet - Set 2

Date: $3 / 28 / 2007$

Start Time: $\quad 9: 36$

End Time: $\quad 9: 59$

Inlet - Nitrogen Oxides (ppmdv @ 3\% $\mathrm{O}_{2}$ )

\begin{tabular}{|c|c|c|c|c|c|}
\hline AVG & 98.9 & 91.1 & 93.4 & 88.0 & \\
\hline 6 & 111.1 & 104.9 & 105.6 & 89.1 & 102.7 \\
\hline 5 & 81.9 & 72.9 & 77.1 & 71.7 & 75.9 \\
\hline 4 & 90.0 & 83.1 & 84.1 & 82.6 & 85.0 \\
\hline 3 & 101.4 & 100.8 & 104.6 & 98.4 & 101.3 \\
\hline 2 & 104.5 & 85.1 & 87.0 & 88.6 & 91.3 \\
\hline 1 & 104.5 & 99.8 & 101.9 & 97.7 & 101.0 \\
\hline & 1 & 2 & 3 & 4 & 92.9 \\
\hline
\end{tabular}

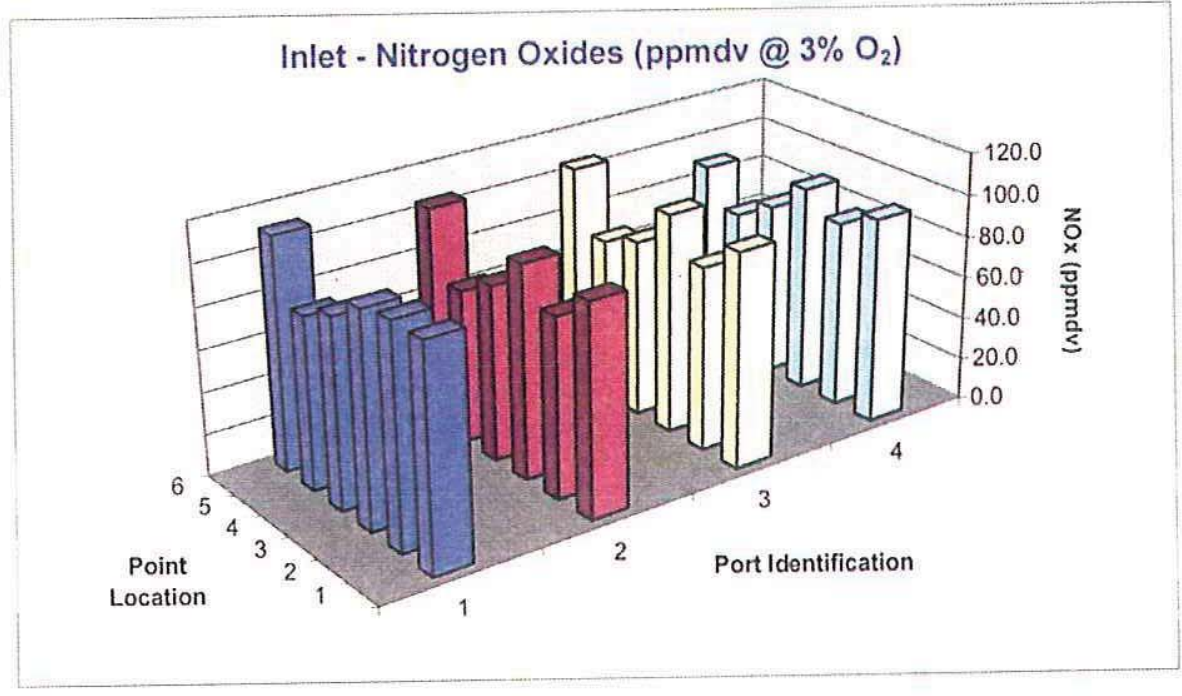


CONSOL ENERGY INC.

AES GREENIDGE STATION
Client Reference No: 4700140111

CleanAir Project No:10192

Run 1: Outlet - Set 2

Date: $3 / 28 / 2007$

Start Time: $\quad 9: 36$

End Time: $\quad 9: 59$

Outlet - Oxygen (\%dv)

\begin{tabular}{|c|c|c|c|c|}
\hline AVG & 5.8 & 5.3 & 4.5 & 4.0 \\
\hline $\mathbf{6}$ & 8.0 & 6.7 & 5.6 & 5.6 \\
\hline $\mathbf{5}$ & 6.4 & 4.9 & 4.3 & 4.1 \\
\hline $\mathbf{4}$ & 4.6 & 6.0 & 5.0 & 4.5 \\
\hline $\mathbf{3}$ & 5.4 & 4.7 & 4.3 & 3.6 \\
\hline $\mathbf{2}$ & 5.5 & 4.6 & 4.3 & 2.7 \\
\hline $\mathbf{1}$ & 4.9 & 5.0 & 3.7 & 3.6 \\
\hline
\end{tabular}

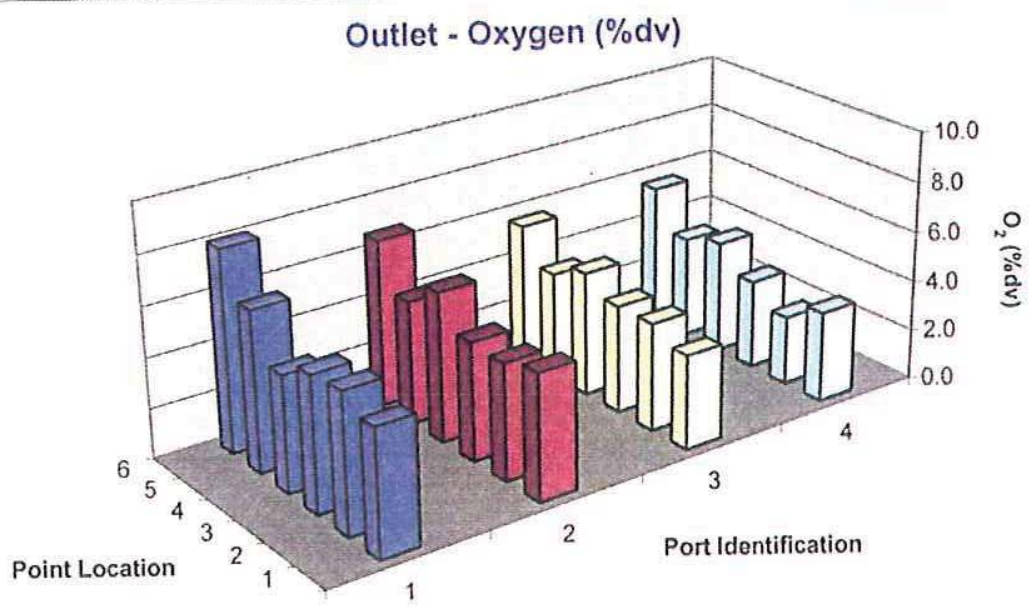


CONSOL ENERGY INC.

AES GREENIDGE STATION
Client Reference No: 4700140111

CleanAir Project No:10192

Run 1: Outlet - Set 2

Date: $3 / 28 / 2007$

Start Time: $\quad 9: 36$

End Time: $\quad 9.59$

Outlet - Carbon Dioxide (\%dv)

\begin{tabular}{|c|c|c|c|c|c|}
\hline AVG & 13.1 & 13.5 & 14.2 & 14.7 & \\
\hline 6 & 11.1 & 12.3 & 13.3 & 13.3 & 12.5 \\
\hline 5 & 12.6 & 13.9 & 14.4 & 146 & 13.9 \\
\hline 4 & 14.2 & 13.0 & 13.8 & 14.2 & 13.8 \\
\hline 3 & 13.5 & 14.1 & 14.4 & 15.1 & 14.3 \\
\hline 2 & 13.4 & 14.2 & 14.4 & 158 & 14.4 \\
\hline 1 & 13.8 & 13.8 & 14.8 & 15.0 & 14.4 \\
\hline & 1 & 2 & 3 & 4 & 13.9 \\
\hline
\end{tabular}

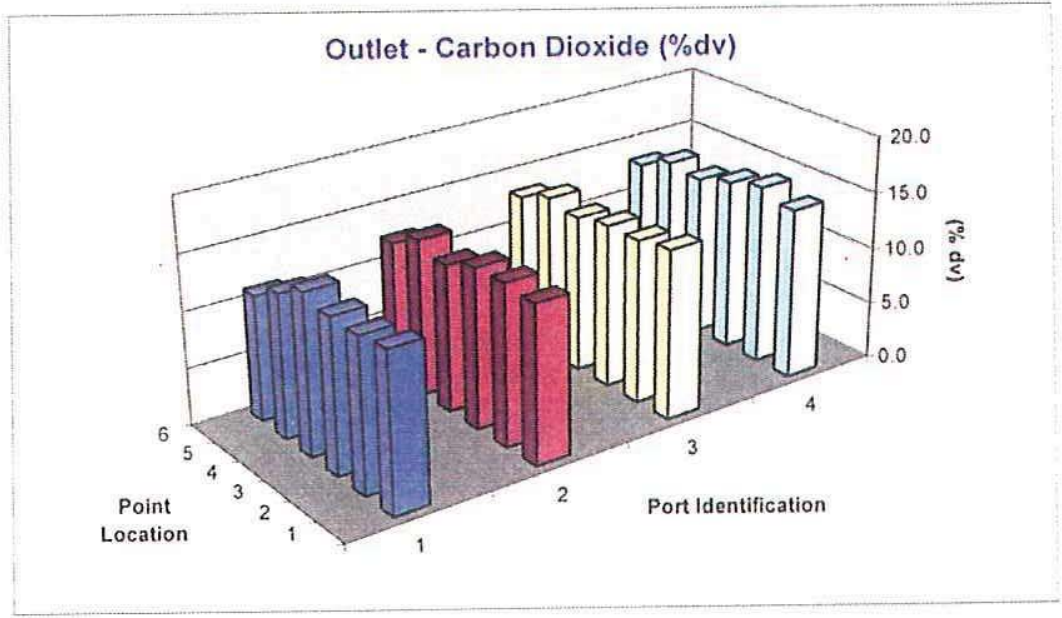


CONSOL ENERGY INC.

AES GREENIDGE STATION
Client Reference No: 4700140111

CleanAir Project No: 10192

Run 1: Outlet - Set 2

Date: $3 / 28 / 2007$

Start Time: $\quad 9: 36$

End Time: $\quad 9: 59$

Outlet - Nitrogen Oxides (ppmdv), uncorrected

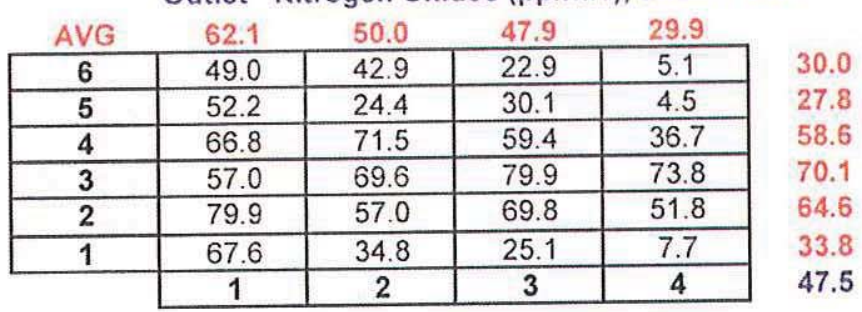

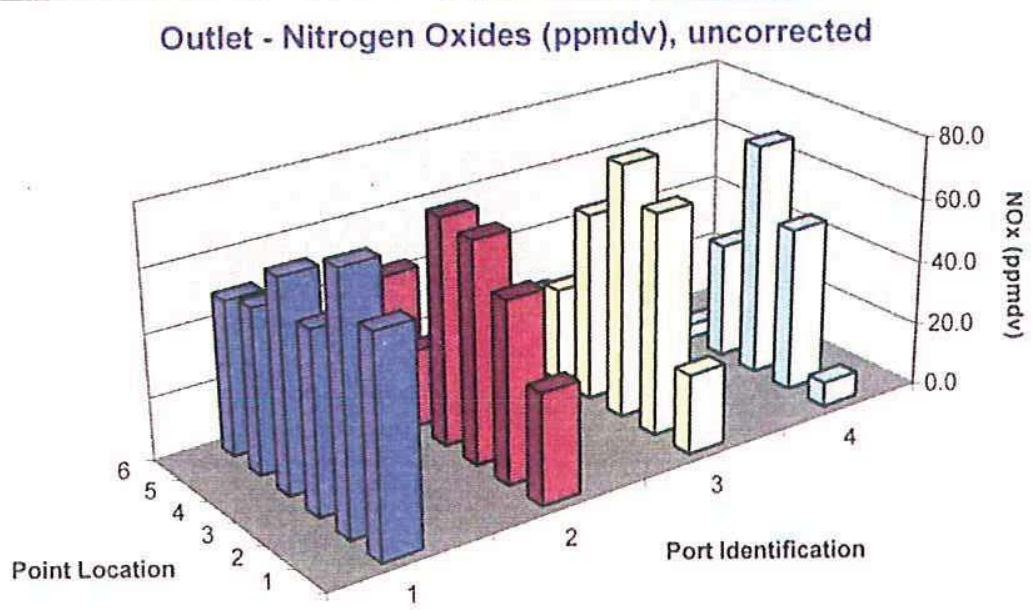


CONSOL ENERGY INC.

AES GREENIDGE STATION
Client Reference No: 4700140111

CleanAir Project No:10192

Run 1: Outlet - Set 2

Date: $3 / 28 / 2007$

Start Time: $\quad 9: 36$

End Time: $\quad 9: 59$

Outlet - Nitrogen Oxides (ppmdv @ $3 \% \mathrm{O}_{2}$ )

\begin{tabular}{|c|c|c|c|c|}
\multicolumn{1}{|c|}{ AVG } & 73.4 & 57.6 & 52.2 & 31.0 \\
\hline $\mathbf{6}$ & 68.2 & 54.0 & 26.8 & 6.0 \\
\hline $\mathbf{5}$ & 64.3 & 27.3 & 32.4 & 4.8 \\
\hline $\mathbf{4}$ & 73.4 & 85.6 & 66.7 & 40.1 \\
\hline $\mathbf{3}$ & 65.6 & 76.9 & 86.2 & 76.1 \\
\hline $\mathbf{2}$ & 92.9 & 62.6 & 75.2 & 51.1 \\
\hline $\mathbf{1}$ & 75.8 & 39.1 & 26.2 & 8.0 \\
\hline & 1 & $\mathbf{2}$ & 3 & 4 \\
\hline
\end{tabular}

38.8

32.2

66.4

76.2

70.4

37.3

53.6

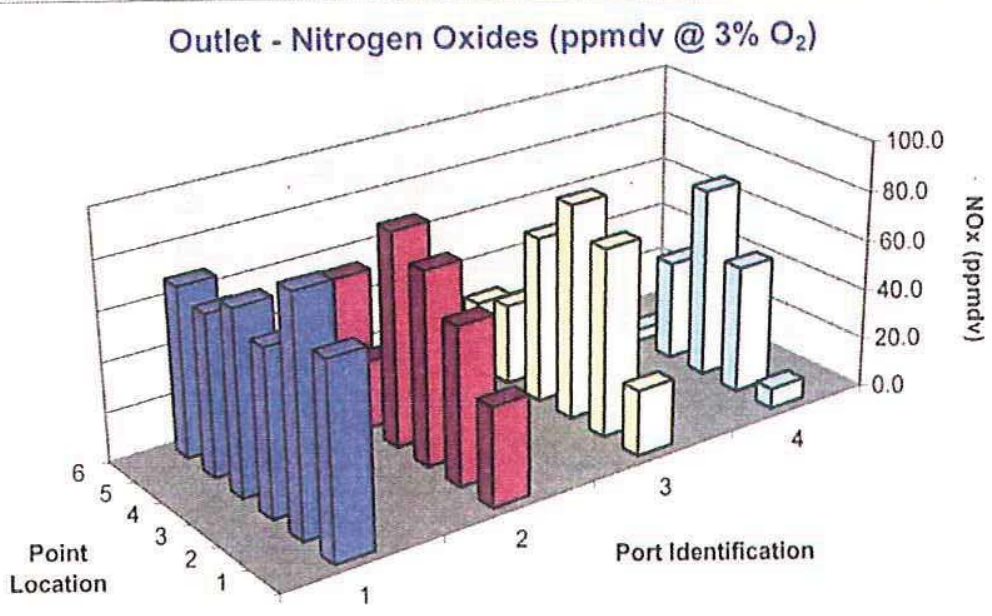


CONSOL ENERGY INC.

AES GREENIDGE STATION
Client Reference No: 470014011

CleanAir Project No:10192

Run 1: Outlet - Set 2

Date: $3 / 28 / 2007$

Start Time: $\quad 9: 36$

End Time: $\quad 9: 59$

Removal Efficiency (ppmdv @ 3\% $\mathrm{O}_{2}$ )

\begin{tabular}{|c|c|c|c|c|}
\multicolumn{1}{c|}{ AVG } & $25.4 \%$ & $36.5 \%$ & $43.1 \%$ & $65.8 \%$ \\
\hline 6 & $38.7 \%$ & $48.5 \%$ & $74.6 \%$ & $93.3 \%$ \\
\hline 5 & $21.5 \%$ & $62.5 \%$ & $58.0 \%$ & $93.3 \%$ \\
\hline 4 & $18.5 \%$ & $-3.0 \%$ & $20.7 \%$ & $51.4 \%$ \\
\hline 3 & $35.3 \%$ & $23.7 \%$ & $17.6 \%$ & $22.7 \%$ \\
\hline 2 & $11.1 \%$ & $26.4 \%$ & $13.6 \%$ & $42.4 \%$ \\
\hline 1 & $27.4 \%$ & $60.8 \%$ & $74.3 \%$ & $91.8 \%$ \\
\hline & 1 & 2 & 3 & 4 \\
\hline
\end{tabular}

$63.8 \%$

$58.8 \%$

$21.9 \%$

$24.8 \%$

$23.4 \%$

$63.6 \%$

$42.7 \%$

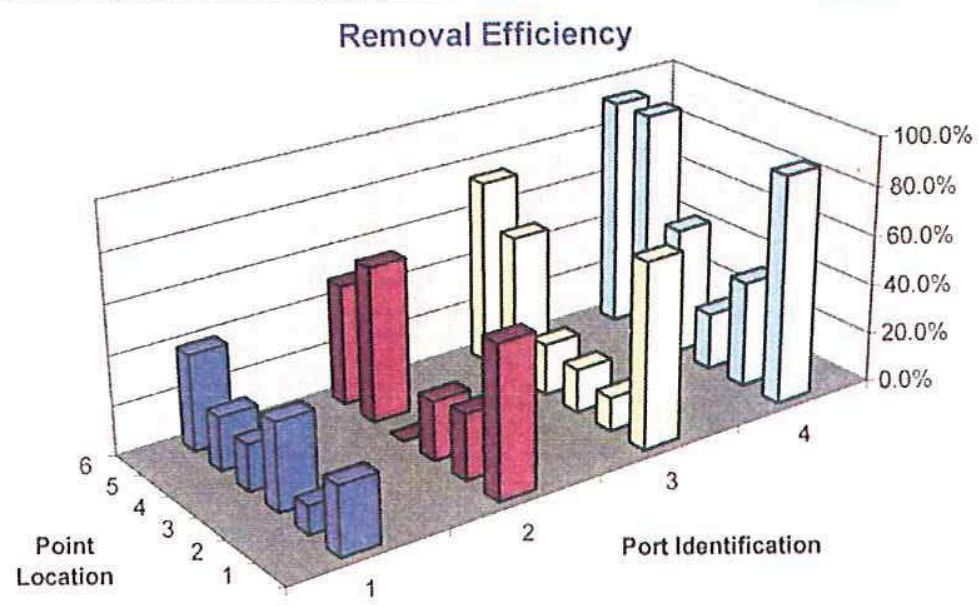


Clean Air Engineering Project $\# 10192$

Consol Energy

AES Dresden

$\begin{array}{lrr}\text { Date: } & 3 / 2822007 & \text { Run \#(Cycle \#) } \\ \text { Start Time: } & 1000 & 1(3) \\ \text { End Time: } & 1023 & \end{array}$

\begin{tabular}{|c|c|c|c|c|c|c|c|c|c|c|}
\hline $\begin{array}{l}\text { Intet } \\
\text { Point }\end{array}$ & Time Sampled & $\begin{array}{c}\text { NOx } \\
\text { ppmdr }\end{array}$ & $\begin{array}{c}\text { NOx } \\
\text { Port Avg } \\
\end{array}$ & $\begin{array}{l}\text { PPM Dov } \\
\text { from Avg. }\end{array}$ & $\begin{array}{l}02 \\
\% d v\end{array}$ & $\begin{array}{c}02 \\
\text { Port Avg }\end{array}$ & $\begin{array}{l}\mathrm{CO2} \\
\% \mathrm{dv}\end{array}$ & $\begin{array}{c}\mathrm{CO} 2 \\
\text { Port Avg }\end{array}$ & $\begin{array}{c}\mathrm{NOx} \\
93 \% 02\end{array}$ & $\begin{array}{l}\text { PPM Dev } \\
\text { from Avg. }\end{array}$ \\
\hline 1.1 & $10: 00$ & 74.9 & & -57 & 7.6 & & 11.5 & & 1005 & 108 \\
\hline $1 \cdot 2$ & 10:04 & 103.6 & & 230 & 2.9 & & 15.5 & & 103.3 & 136 \\
\hline 1.3 & 10:03 & 86.3 & 80.8 & 57 & 5.1 & 55 & 13.7 & 133 & 975 & 78 \\
\hline $1-4$ & $10: 12$ & 80.1 & & .05 & 4.4 & & 14.3 & & 86.7 & .30 \\
\hline 1.5 & $10: 16$ & 68.5 & & .12 .1 & 4.7 & & 14.0 & & 757 & .140 \\
\hline 1.6 & $10: 20$ & 71.3 & & .93 & 8.5 & & 10.8 & & 1026 & 129 \\
\hline 2.1 & $10: 01$ & 79.8 & & .08 & 6.0 & & 12.9 & & 956 & 59 \\
\hline $2 \cdot 2$ & $10: 05$ & 82.5 & & 19 & 2.9 & & 15.5 & & 820 & .7 .7 \\
\hline 2.3 & 10:09 & 84.0 & 784 & 34 & 5.4 & 49 & 13.4 & 138 & 970 & 73 \\
\hline $2-4$ & $10: 13$ & 75.5 & & .51 & 3.9 & & 14.7 & & 793 & .104 \\
\hline 2.5 & $10: 17$ & 63.3 & & .173 & 4.6 & & 14.1 & & 694 & .203 \\
\hline 2.6 & $10: 21$ & 85.4 & & 48 & 6.9 & & 12.1 & & 1093 & 196 \\
\hline 3.1 & $10: 02$ & 92.3 & & 117 & 4.0 & & 14.5 & & 979 & 82 \\
\hline 3.2 & $10: 05$ & 84.4 & & 38 & 2.9 & & 15.5 & & 841 & .5 .6 \\
\hline 3.3 & $10: 10$ & 99.4 & 854 & 188 & 3.4 & 4: & 15.1 & 144 & 1016 & 119 \\
\hline $3-4$ & $10: 14$ & 80.0 & & .06 & 3.7 & & 14.9 & & 831 & .66 \\
\hline 3.5 & $10: 18$ & 68.4 & & .122 & 4.6 & & 14.1 & & 74.9 & .148 \\
\hline 3.6 & $10: 22$ & 87.9 & & 73 & 6.3 & & 12.6 & & 108.1 & 184 \\
\hline $4 \cdot 1$ & $10: 03$ & 81.3 & & 07 & 5.7 & & 13.1 & & $\$ 50$ & 63 \\
\hline $4 \cdot 2$ & $10: 07$ & 86.5 & & 59 & 2.4 & & 15.9 & & 839 & .58 \\
\hline 4.3 & $10: 11$ & 95.4 & 77.9 & 148 & 3.0 & 43 & 15.4 & 143 & 956 & 59 \\
\hline 4.4 & $10: 15$ & 78.2 & & -24 & 3.6 & & 15.0 & & 806 & .91 \\
\hline 4.5 & $10: 19$ & 59.0 & & .216 & 45 & & 14.2 & & 642 & .255 \\
\hline $4-6$ & $10: 23$ & 67.2 & & -134 & 6.6 & & 12.4 & & 841 & .56 \\
\hline
\end{tabular}

$\begin{array}{lllll}\text { Inlet Averages } & 80.6 & 4.7 & 14.0 & 89.7\end{array}$

\begin{tabular}{|c|c|c|c|c|c|c|c|c|c|c|c|c|}
\hline $\begin{array}{l}\text { Outlet } \\
\text { Point }\end{array}$ & Time Sampled & $\begin{array}{l}\text { NOx } \\
\text { ppmdv }\end{array}$ & $\begin{array}{c}\text { NOx } \\
\text { Port Avg } \\
\end{array}$ & $\begin{array}{l}\text { PPM Dev } \\
\text { from Avg. }\end{array}$ & $\begin{array}{l}02 \\
\% d v\end{array}$ & $\begin{array}{c}02 \\
\text { Port Avg }\end{array}$ & $\begin{array}{l}\mathrm{CO} 2 \\
\% \mathrm{dv}\end{array}$ & $\begin{array}{c}\mathrm{CO} 2 \\
\text { Port Avg } \\
\end{array}$ & $\begin{array}{c}\mathrm{NOx} \\
3 \% \mathrm{O}\end{array}$ & $\begin{array}{l}\text { PPM Dev } \\
\text { from Avg. }\end{array}$ & $\begin{array}{c}\text { Removal } \\
\text { Efficiency }\end{array}$ & $\begin{array}{c}\text { Removal Eft } \\
\text { wi O2 correction } \\
\end{array}$ \\
\hline 1.1 & $10: 00$ & 67.6 & & 218 & 4.9 & & 13.8 & & 758 & & 97 & 246 \\
\hline 1.2 & $10: 04$ & 77.3 & & 31.5 & 5.6 & & 13.3 & & 904 & 391 & 254 & 125 \\
\hline 1.3 & $10: 08$ & 57.3 & 549 & 115 & 5.2 & 56 & 13.6 & 127 & 652 & 139 & 336 & 331 \\
\hline 1.4 & $10: 12$ & 55.2 & & 94 & 4.8 & & 13.9 & & 614 & 101 & 31.1 & 292 \\
\hline 1.5 & $10: 16$ & 48.1 & & 23 & 6.1 & & 12.9 & & 580 & 67 & 29.8 & 234 \\
\hline 1.6 & $10: 20$ & 23.7 & & .221 & 7.1 & & 8.8 & & 307 & .205 & 668 & 700 \\
\hline 2.1 & $10: 01$ & 31.9 & & -139 & 5.0 & & 13.8 & & 359 & .153 & 600 & 624 \\
\hline 2.2 & $10: 05$ & 56.2 & & 104 & 4.5 & & 14.3 & & 614 & 101 & 319 & 251 \\
\hline 2.3 & $10: 09$ & 68.7 & 509 & 22.9 & 4.8 & 53 & 14.0 & 136 & 764 & 25.1 & 182 & 213 \\
\hline $2-4$ & $10: 13$ & 71.3 & & 255 & 5.9 & & 13.1 & & 850 & 337 & 56 & -7.1 \\
\hline 2.5 & $10: 17$ & 23.1 & & .227 & 4.9 & & 14.0 & & 258 & .25 .5 & 635 & 629 \\
\hline 2.6 & $10: 21$ & 54.3 & & 85 & 6.7 & & 12.3 & & 695 & 174 & 36.4 & 372 \\
\hline 3.1 & $10: 02$ & 22.9 & & 229 & 3.8 & & 14.9 & & 239 & .273 & 752 & 756 \\
\hline 3.2 & $10: 06$ & 68.5 & & 227 & 4.2 & & 14.5 & & 733 & 221 & 188 & 128 \\
\hline 3.3 & $10: 10$ & 79.0 & 476 & 332 & 4.4 & 45 & 14.3 & 142 & 858 & 345 & 205 & 156 \\
\hline $3-4$ & $10: 14$ & 59.2 & & 13.4 & 4.9 & & 13.9 & & 663 & 150 & 260 & 20.2 \\
\hline 3.5 & $10: 18$ & 30.0 & & .158 & 4.2 & & 14.4 & & 322 & .191 & 55 ; & 57.0 \\
\hline 3.6 & $10: 22$ & 26.1 & & .197 & 5.5 & & 13.4 & & 303 & .209 & 703 & 719 \\
\hline 4.1 & $10: 03$ & 7.3 & & .385 & 3.5 & & 15.1 & & 75 & .437 & 910 & 922 \\
\hline 4.2 & $10: 07$ & 53.2 & & 74 & 2.6 & & 16.0 & & 519 & 06 & 385 & 351 \\
\hline 4.3 & $10: 11$ & 72.5 & 299 & 267 & 3.4 & 39 & 15.3 & 148 & 739 & 227 & 240 & 226 \\
\hline 4.4 & $10: 15$ & 36.3 & & .95 & 4.5 & & 14.3 & & 396 & -117 & 536 & 509 \\
\hline 4.5 & $10: 19$ & 4.3 & & 415 & 3.9 & & 14.8 & & 45 & -467 & 927 & 929 \\
\hline 4.6 & $10: 23$ & 5.6 & & -402 & 5.6 & & 13.3 & & 56 & .447 & 917 & 922 \\
\hline
\end{tabular}

Outlet Averages

45.8

4.8

13.8

51.3

43.2 
CONSOL ENERGY INC.

AES GREENIDGE STATION
Client Reference No: 4700140111

CleanAir Project No:10192

Run 1: Inlet - Set 3

Date: $3 / 28 / 2007$

Start Time: $\quad 10: 00$

End Time: $\quad 10: 23$

Inlet - Oxygen (\%dv)

\begin{tabular}{|c|c|c|c|c|}
\multicolumn{1}{c|}{ AVG } & 5.5 & 4.9 & 4.1 & 4.3 \\
\hline 6 & 8.5 & 6.9 & 6.3 & 6.6 \\
\hline 5 & 4.7 & 4.6 & 4.6 & 4.5 \\
\hline 4 & 4.4 & 3.9 & 3.7 & 3.5 \\
\hline 3 & 5.1 & 5.4 & 3.4 & 3.0 \\
\hline 2 & 2.9 & 2.9 & 2.9 & 2.4 \\
\hline 1 & 7.6 & 6.0 & 4.0 & 5.7 \\
\hline & 1 & 2 & 3 & 4 \\
\hline
\end{tabular}

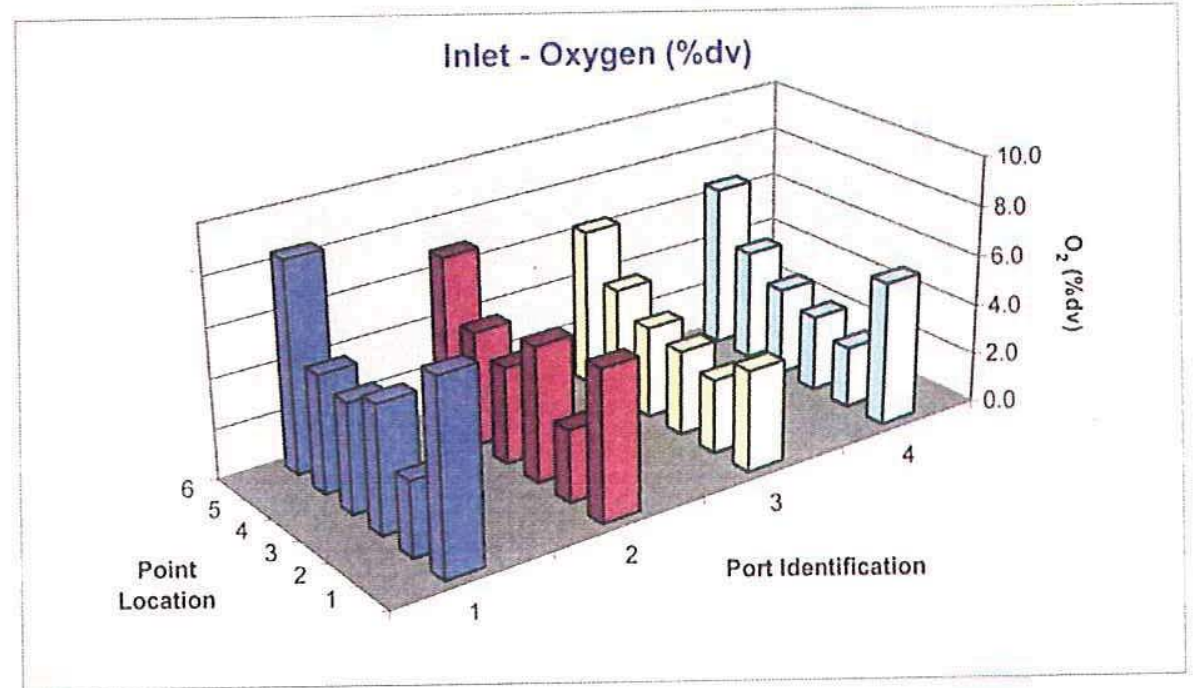


CONSOL ENERGY INC.

AES GREENIDGE STATION
Client Reference No: 4700140111

CleanAir Project No:10192

Run 1: Inlet-Set 3

Date: $3 / 28 / 2007$

Start Time: $\quad 10: 00$

End Time: $\quad 10: 23$

\begin{tabular}{|c|c|c|c|c|c|}
\hline \multicolumn{5}{|c|}{ Inlet - Carbon Dioxide (\%dv) } & \\
\hline AVG & 13.3 & 13.8 & 14.4 & 14.3 & \\
\hline 6 & 10.8 & 12.1 & 12.6 & 12.4 & 12.0 \\
\hline 5 & 14.0 & 14.1 & 14.1 & 14.2 & 14.1 \\
\hline 4 & 14.3 & 14.7 & 14.9 & 15.0 & 14.7 \\
\hline 3 & 13.7 & 13.4 & 15.1 & 15.4 & 14.4 \\
\hline 2 & 15.5 & 15.5 & 15.5 & 15.9 & 15.6 \\
\hline 1 & 11.5 & 12.9 & 14.5 & 13.1 & 13.0 \\
\hline & 1 & 2 & 3 & 4 & 14.0 \\
\hline
\end{tabular}

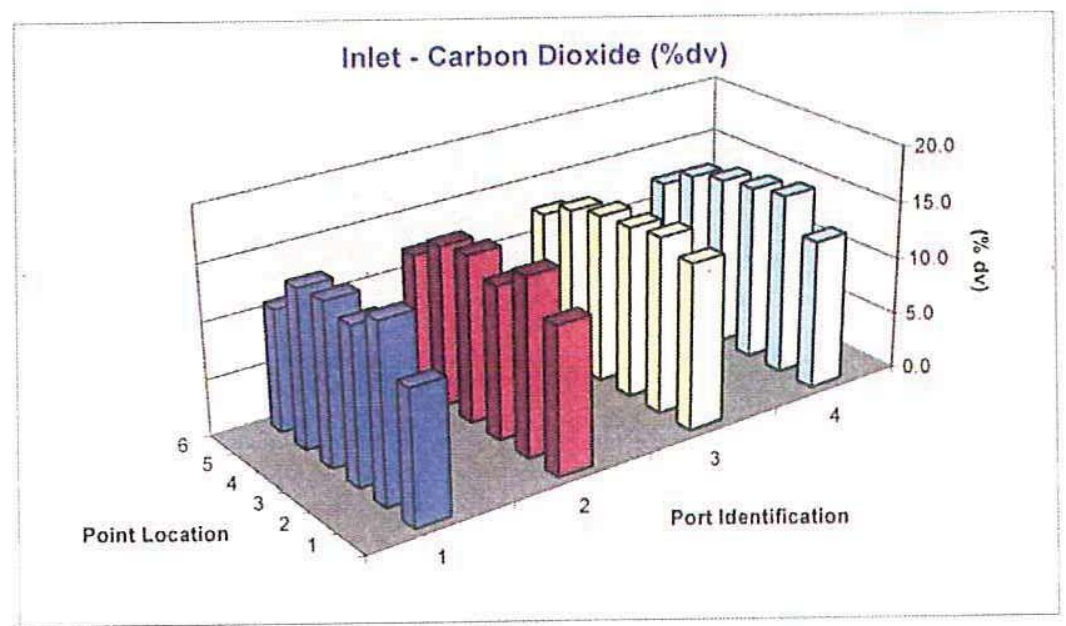

(数)

CleanAir 
CONSOL ENERGY INC.

AES GREENIDGE STATION
Client Reference No: 4700140111

CleanAir Project No: 10192

Run 1: Inlet - Set 3

Date: $3 / 28 / 2007$

Start Time: $\quad 10: 00$

End Time: $\quad 10: 23$

Inlet - Nitrogen Oxides (ppmdv), uncorrected

\begin{tabular}{|c|c|c|c|c|}
\hline AVG & 80.8 & 78.4 & 85.4 & 77.9 \\
\hline 6 & 71.3 & 85.4 & 87.9 & 67.2 \\
\hline 5 & 68.5 & 63.3 & 68.4 & 59.0 \\
\hline 4 & 80.1 & 75.5 & 80.0 & 78.2 \\
\hline 3 & 86.3 & 84.0 & 99.4 & 95.4 \\
\hline 2 & 103.6 & 82.5 & 84.4 & 86.5 \\
\hline 1 & 74.9 & 79.8 & 92.3 & 81.3 \\
\hline & 1 & 2 & 3 & 4 \\
\hline
\end{tabular}

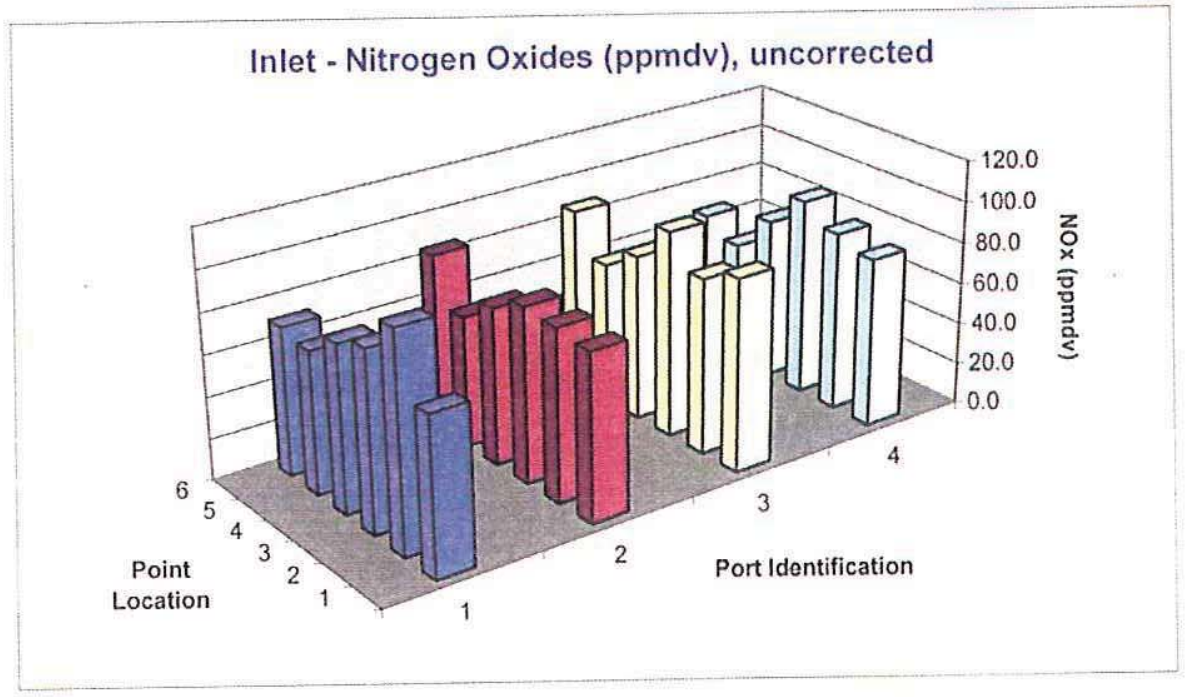


CONSOL ENERGY INC.

AES GREENIDGE STATION
Client Reference No: $\$ 700140111$

CleanAir Project No:10192

Run 1: Inlet - Set 3

Date: $3 / 28 / 2007$

Start Time: $\quad 10: 00$

End Time: $\quad 10: 23$

Inlet - Nitrogen Oxides (ppmdv @ $3 \% \mathrm{O}_{2}$ )

\begin{tabular}{|c|c|c|c|c|}
\multicolumn{1}{c|}{ AVG } & 94.4 & 88.8 & 91.6 & 84.1 \\
\hline $\mathbf{6}$ & 102.6 & 109.3 & 108.1 & 84.1 \\
\hline $\mathbf{5}$ & 75.7 & 69.4 & 74.9 & 64.2 \\
\hline $\mathbf{4}$ & 86.7 & 79.3 & 83.1 & 80.6 \\
\hline $\mathbf{3}$ & 97.5 & 97.0 & 101.6 & 95.6 \\
\hline $\mathbf{2}$ & 103.3 & 82.0 & 84.1 & 83.9 \\
\hline $\mathbf{1}$ & 100.5 & 95.6 & 97.9 & 96.0 \\
\hline & 1 & 2 & 3 & 4 \\
\hline
\end{tabular}

101.0

71.1

82.4

97.9

88.3

97.5

89.7

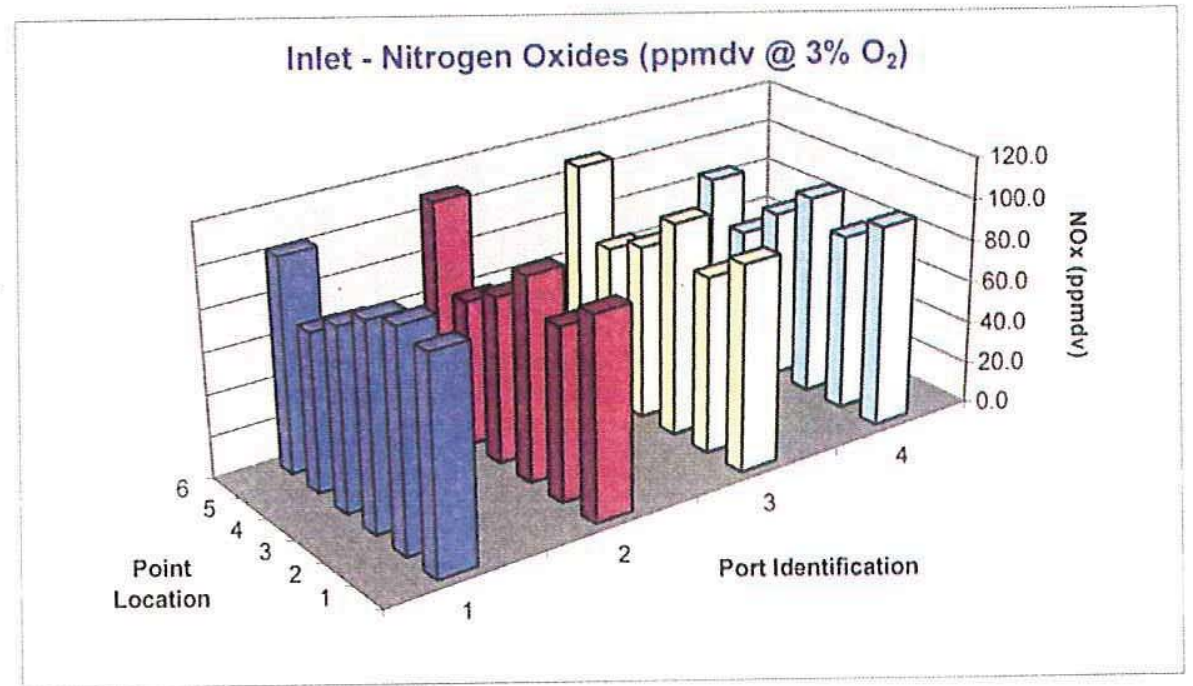

CleanAir 
CONSOL ENERGY INC.

AES GREENIDGE STATION
Client Reference No: 4700140111

CleanAir Project No:10192

Run 1: Outlet-Set 3

Date: $3 / 28 / 2007$

Start Time: $\quad 10: 00$

End Time: $\quad 10: 23$

\begin{tabular}{|c|c|c|c|c|c|}
\hline \multicolumn{5}{|c|}{ Outlet - Oxygen ( $\% d v)$} & \multirow[b]{3}{*}{6.2} \\
\hline AVG & 5.6 & 5.3 & 4.5 & 3.9 & \\
\hline 6 & 7.1 & 6.7 & 5.5 & 5.6 & \\
\hline 5 & 6.1 & 4.9 & 4.2 & 3.9 & 4.8 \\
\hline 4 & 4.8 & 5.9 & 4.9 & 4.5 & 5.0 \\
\hline 3 & 5.2 & 4.8 & 4.4 & 3.4 & 4.4 \\
\hline 2 & 5.6 & 4.5 & 4.2 & 2.6 & 4.2 \\
\hline 1 & 4.9 & 5.0 & 3.8 & 3.5 & 4.3 \\
\hline & 1 & 2 & 3 & 4 & 4.8 \\
\hline
\end{tabular}

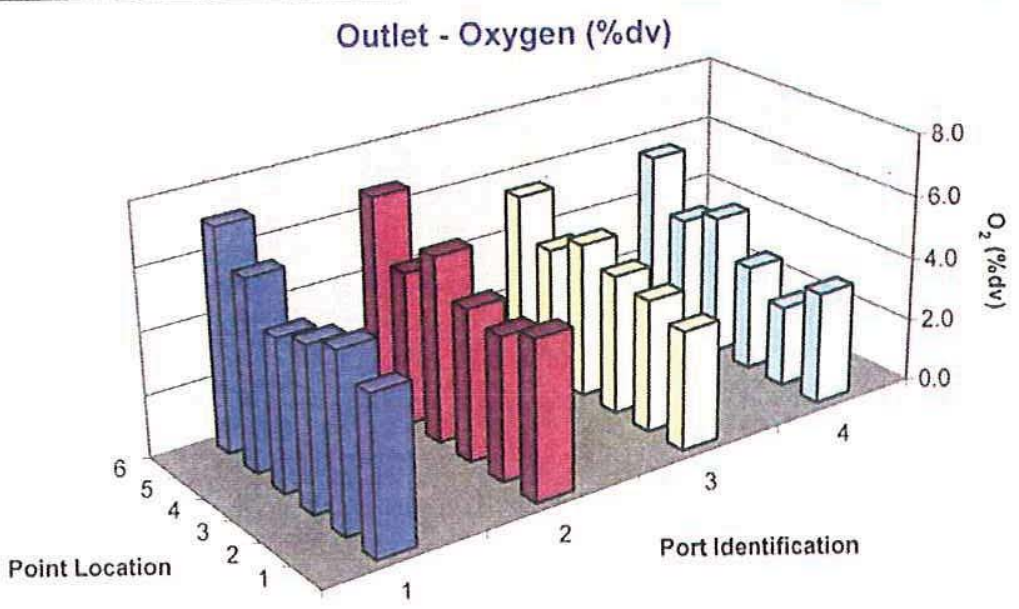


Run 1: Outlet - Set 3

Start Time: $\quad 10: 00$

End Time: $\quad 10: 23$

\begin{tabular}{|c|c|c|c|c|c|}
\hline \multicolumn{5}{|c|}{ Outlet - Carbon Dioxide (\%dv) } & \multirow[b]{3}{*}{11.9} \\
\hline AVG & 12.7 & 13.6 & 14.2 & 14.8 & \\
\hline 6 & 8.8 & 12.3 & 13.4 & 13.3 & \\
\hline 5 & 12.9 & 14.0 & 14.4 & 14.8 & 14.0 \\
\hline 4 & 13.9 & 13.1 & 13.9 & 14.3 & 13.8 \\
\hline 3 & 13.6 & 14.0 & 14.3 & 15.3 & 14.3 \\
\hline 2 & 13.3 & 14.3 & 14.5 & 16.0 & 14.5 \\
\hline 1 & 13.8 & 13.8 & 14.9 & 15.1 & 14.4 \\
\hline & 1 & 2 & 3 & 4 & 13.8 \\
\hline
\end{tabular}

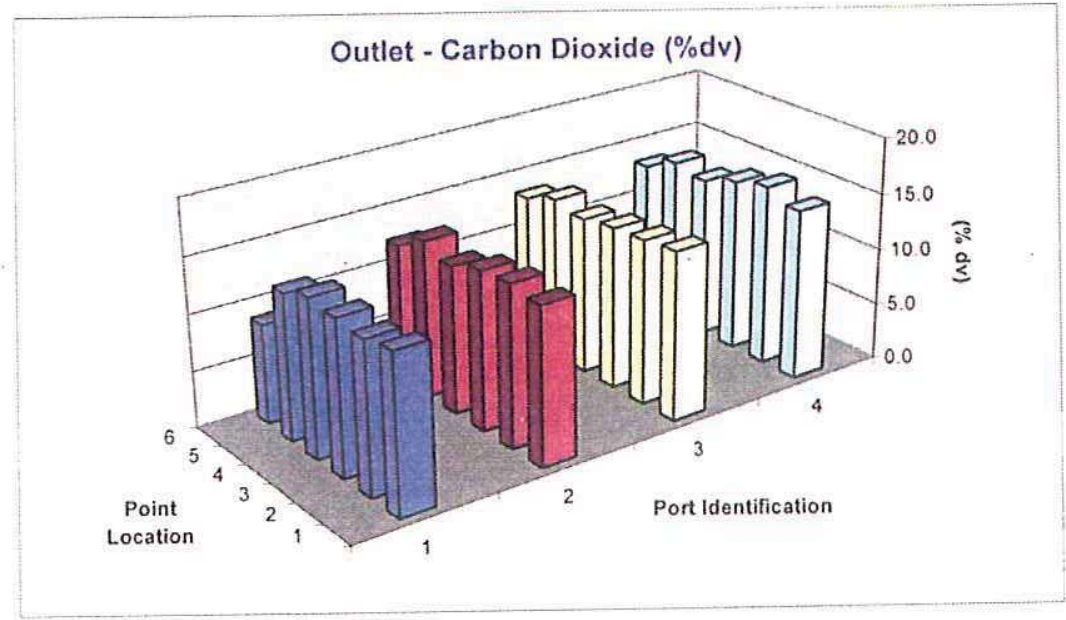


CONSOL ENERGY INC.

AES GREENIDGE STATION
Client Reference No: 4700140111

CleanAir Project No: 10192

Run 1: Outlet - Set 3

Date: $3 / 28 / 2007$

Start Time: $\quad 10: 00$

End Time: $\quad 10: 23$

\begin{tabular}{|c|c|c|c|c|c|}
\hline \multirow[b]{2}{*}{ AVG } & \multicolumn{5}{|c|}{ Outlet - Nitrogen Oxides (ppmdv), uncorrected } \\
\hline & 54.9 & 50.9 & 47.6 & 29.9 & \\
\hline 6 & 23.7 & 54.3 & 26.1 & 5.6 & 27.4 \\
\hline 5 & 48.1 & 23.1 & 30.0 & 4.3 & 26.4 \\
\hline 4 & 55.2 & 71.3 & 59.2 & 36.3 & 55.5 \\
\hline 3 & 57.3 & 68.7 & 79.0 & 72.5 & 69.4 \\
\hline 2 & 77.3 & 56.2 & 68.5 & 53.2 & 63.8 \\
\hline 1 & 67.6 & 31.9 & 22.9 & 7.3 & 32.4 \\
\hline & 1 & 2 & 3 & 4 & 45.8 \\
\hline
\end{tabular}

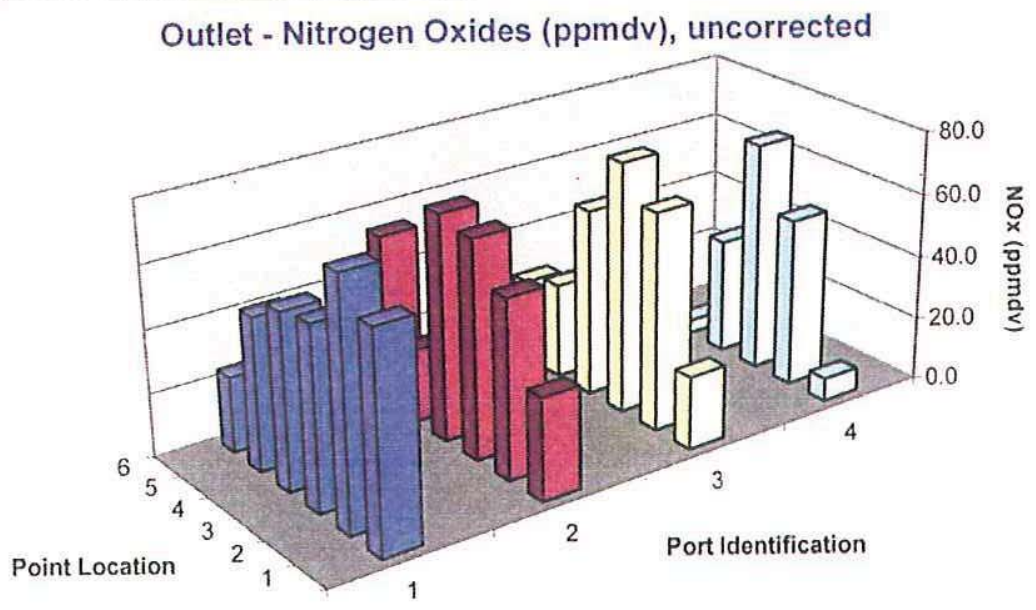


CONSOL ENERGY INC.

AES GREENIDGE STATION
Client Reference No: 4700140111

CleanAir Project No:10192

Run 1: Outlet - Set 3

Date: $3 / 28 / 2007$

Start Time: $\quad 10: 00$

End Time: $\quad 10: 23$

\begin{tabular}{|c|c|c|c|c|c|}
\hline \multicolumn{6}{|c|}{ Outlet - Nitrogen Oxides (ppmdv @ $3 \% \mathrm{O}_{2}$ ) } \\
\hline$A V G$ & 63.6 & 58.8 & 52.0 & 30.7 & \\
\hline 6 & 30.7 & 68.6 & 30.3 & 6.6 & 34.1 \\
\hline 5 & 58.0 & 25.8 & 32.2 & 4.5 & 30.1 \\
\hline 4 & 61.4 & 85.0 & 66.3 & 39.6 & 63.0 \\
\hline 3 & 65.2 & 76.4 & 85.8 & 73.9 & 75.3 \\
\hline 2 & 90.4 & 61.4 & 73.3 & 51.9 & 69.2 \\
\hline 1 & 75.8 & 35.9 & 23.9 & 7.5 & 35.8 \\
\hline & 1 & 2 & 3 & 4 & 51.3 \\
\hline
\end{tabular}

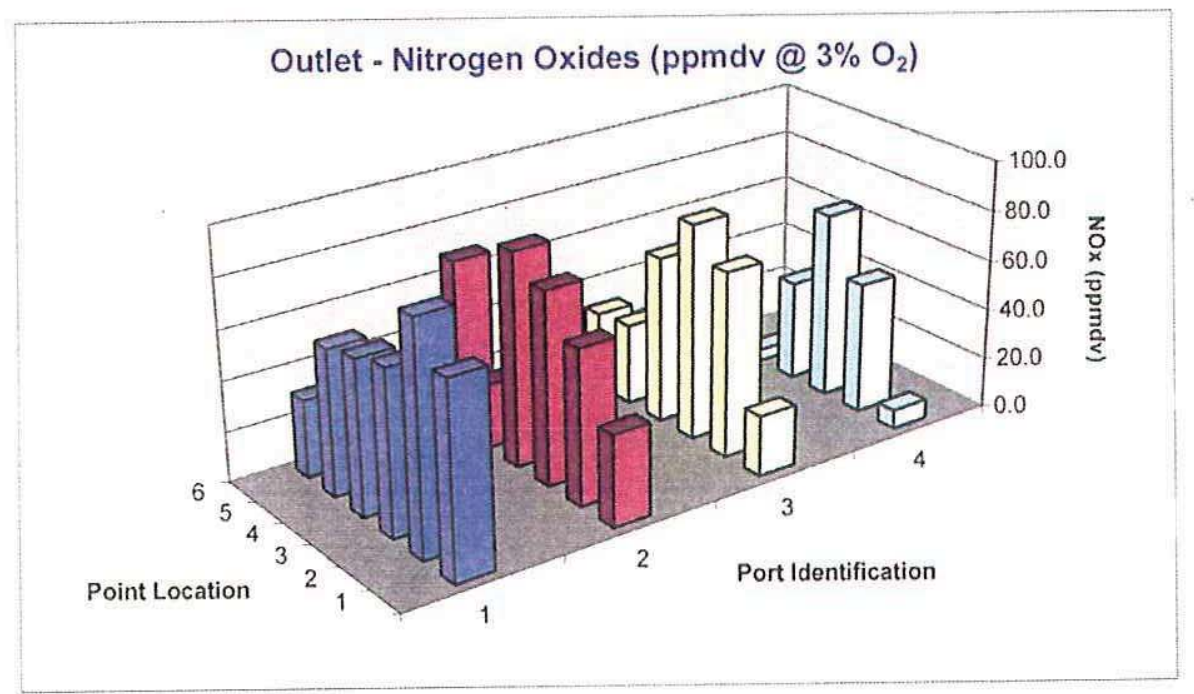


CONSOL ENERGY INC.

AES GREENIDGE STATION
Client Reference No: $\$ 700140111$

CleanAir Project No:10192

Run 1: Outlet - Set 3

Date: 3/28/2007

Start Time: $\quad 10: 00$

End Time: $\quad 10: 23$

\begin{tabular}{|c|c|c|c|c|c|}
\hline \multicolumn{6}{|c|}{ Removal Efficiency (ppmdv@ @ 3\% $\mathrm{O}_{2}$ ) } \\
\hline AVG & $32.1 \%$ & $33.6 \%$ & $42.2 \%$ & $64.8 \%$ & \\
\hline 6 & $70.0 \%$ & $37.2 \%$ & $71.9 \%$ & $92.2 \%$ & $67.8 \%$ \\
\hline 5 & $23.4 \%$ & $62.9 \%$ & $57.0 \%$ & $92.9 \%$ & $59.0 \%$ \\
\hline 4 & $29.2 \%$ & $-7.1 \%$ & $20.2 \%$ & $50.9 \%$ & $23.3 \%$ \\
\hline 3 & $33.1 \%$ & $21.3 \%$ & $15.6 \%$ & $22.6 \%$ & $23.1 \%$ \\
\hline 2 & $12.5 \%$ & $25.1 \%$ & $12.8 \%$ & $38.1 \%$ & $22.1 \%$ \\
\hline 1 & $24.6 \%$ & $62.4 \%$ & $75.6 \%$ & $92.2 \%$ & $63.7 \%$ \\
\hline & 1 & 2 & 3 & 4 & $43.2 \%$ \\
\hline
\end{tabular}

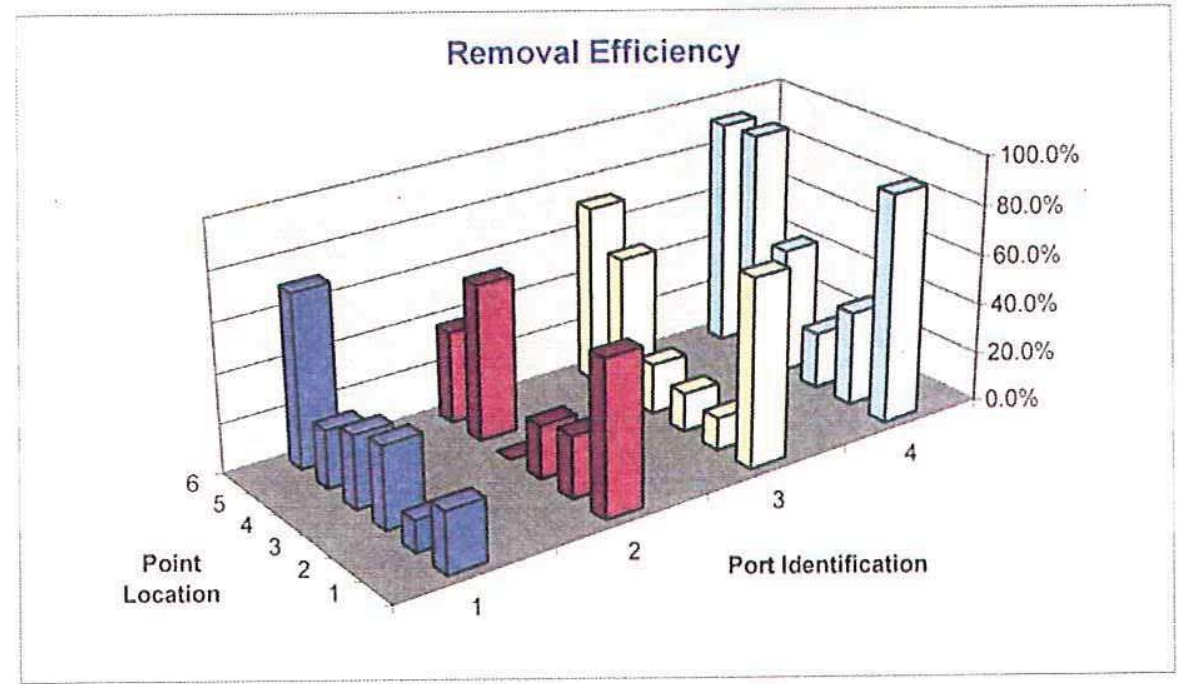

(转)

CleanAir 
Clean Air Engineering Project \#10192

Consol Energy

$\begin{array}{lrr}\text { Date: } & 3 / 28 / 2007 & \text { Run } \#(\text { Cycle \#) } 2(1) \\ \text { Start Time: } & 1112 & \\ \text { End Time: } & 1135 & 35\end{array}$

\begin{tabular}{|c|c|c|c|c|c|c|c|c|c|c|}
\hline $\begin{array}{l}\text { Intet } \\
\text { Point }\end{array}$ & Time Sampled & $\begin{array}{c}\text { NOx } \\
\text { ppmdv }\end{array}$ & $\begin{array}{c}\text { NOx } \\
\text { Port Avg }\end{array}$ & $\begin{array}{l}\text { PPM Dev } \\
\text { from Avg. }\end{array}$ & $\begin{array}{l}\mathrm{O} 2 \\
\% \mathrm{dv}\end{array}$ & $\begin{array}{c}\mathrm{O} 2 \\
\text { Port Avg }\end{array}$ & $\begin{array}{l}\mathrm{CO} 2 \\
\% \mathrm{dv}\end{array}$ & $\begin{array}{c}\mathrm{CO} 2 \\
\text { Port Avg }\end{array}$ & $\begin{array}{c}\mathrm{NOx} \\
83 \% \mathrm{O} 2 \\
\end{array}$ & $\begin{array}{l}\text { PPM Dev } \\
\text { from Avg. }\end{array}$ \\
\hline 1.1 & $11: 12$ & 78.6 & & -0.3 & 7.3 & & 11.8 & & 1031 & 155 \\
\hline 1.2 & $11: 16$ & 102.0 & & $23:$ & 2.9 & & 15.5 & & 1012 & 13.5 \\
\hline 1.3 & $11: 20$ & 84.5 & 814 & 55 & 5.0 & 54 & 13.8 & 134 & 950 & 73 \\
\hline 1.4 & $11: 24$ & 80.9 & & 20 & 4.4 & & 14.3 & & 877 & 00 \\
\hline 1.5 & $11: 28$ & 69.6 & & .93 & 4.6 & & 14.1 & & 764 & -11.3 \\
\hline 1.6 & $11: 32$ & 72.9 & & -60 & 8.6 & & 10.7 & & 1053 & 186 \\
\hline $2 \cdot 1$ & $11: 13$ & 82.3 & & 34 & 5.9 & & 12.9 & & 984 & 107 \\
\hline 2.2 & $11: 17$ & 79.9 & & 10 & 3.1 & & 15.3 & & 80.3 & .74 \\
\hline 2.3 & $11: 21$ & 84.1 & 765 & 52 & 5.2 & 49 & 13.6 & 138 & 950 & 83 \\
\hline $2-4$ & $11: 25$ & 75.4 & & .35 & 3.9 & & 14.7 & & 793 & .84 \\
\hline 2.5 & $11: 29$ & 59.4 & & .19 .5 & 4.3 & & 14.4 & & 640 & .237 \\
\hline 2.6 & $11: 33$ & 77.9 & & -10 & 6.8 & & 12.2 & & 990 & 114 \\
\hline 3.1 & $11: 14$ & 87.4 & & 85 & 4.0 & & 14.5 & & 927 & 50 \\
\hline 3.2 & $11: 18$ & 79.0 & & $0:$ & 2.8 & & 15.6 & & 783 & .94 \\
\hline 3.3 & $11: 22$ & 98.7 & 820 & 198 & 3.2 & 41 & 15.3 & 145 & 995 & 11.9 \\
\hline $3-4$ & $11: 26$ & 79.4 & & 05 & 3.7 & & 14.9 & & 825 & .51 \\
\hline 3.5 & $11: 30$ & 66.3 & & .126 & 4.5 & & 14.2 & & 724 & -153 \\
\hline 3.6 & $11: 34$ & 81.0 & & 21 & 6.3 & & 12.6 & & 994 & 118 \\
\hline $4 \cdot 1$ & $11: 15$ & 77.8 & & .1 .1 & 5.9 & & 13.0 & & 930 & 53 \\
\hline 4.2 & $11: 19$ & 81.6 & & 2.7 & 2.6 & & 15.8 & & 796 & -81 \\
\hline $4 \cdot 3$ & $11: 23$ & 95.0 & 759 & 16.1 & 3.1 & 44 & 15.4 & 143 & 954 & 77 \\
\hline $4-4$ & $11: 27$ & 76.9 & & -20 & 3.5 & & 15.0 & & 793 & 84 \\
\hline 4.5 & $11: 31$ & 60.1 & & -188 & 4.6 & & 14.1 & & 659 & .218 \\
\hline 4.6 & $11: 35$ & 63.7 & & -15.2 & 6.6 & & 12.4 & & 795 & -82 \\
\hline
\end{tabular}

Inlet Averages

78.9

4.7

$\begin{array}{ll}14.0 & 87.7\end{array}$

\begin{tabular}{|c|c|c|c|c|c|c|c|c|c|c|c|c|}
\hline $\begin{array}{l}\text { Outlet } \\
\text { Point }\end{array}$ & Time Sampled & $\begin{array}{l}\text { NOx } \\
\text { ppmdv }\end{array}$ & $\begin{array}{c}\text { NOx } \\
\text { Port Avg }\end{array}$ & $\begin{array}{l}\text { PPM Dev } \\
\text { from Avg. }\end{array}$ & $\begin{array}{l}\mathrm{O} 2 \\
\% \mathrm{dv}\end{array}$ & $\begin{array}{c}02 \\
\text { Port Avg }\end{array}$ & $\begin{array}{l}\mathrm{CO} 2 \\
\text { \%dv }\end{array}$ & $\begin{array}{c}\mathrm{CO} 2 \\
\text { Port Avg }\end{array}$ & $\begin{array}{c}\mathrm{NOx} \\
\text { (i) } 3 \% 02 \\
\end{array}$ & $\begin{array}{l}\text { PPM Dev } \\
\text { from Avg. }\end{array}$ & $\begin{array}{c}\text { Removal } \\
\text { Efficiency }\end{array}$ & $\begin{array}{c}\text { Removal Eff } \\
\text { wi } 02 \text { correction } \\
\end{array}$ \\
\hline 1.1 & $11: 12$ & 71.2 & \multirow{6}{*}{514} & 252 & 4.6 & \multirow{6}{*}{5.6} & 14.2 & \multirow{6}{*}{133} & 781 & 267 & 94 & 243 \\
\hline 1.2 & $11: 16$ & 76.7 & & 30.7 & 5.4 & & 13.5 & & 887 & 37.3 & 248 & 12.3 \\
\hline 1.3 & $11: 20$ & 53.1 & & 121 & 5.3 & & 13.6 & & 656 & 152 & 31.2 & 299 \\
\hline $1-4$ & $11: 24$ & 65.9 & & 199 & 4.5 & & 14.2 & & 72.1 & 206 & 185 & 178 \\
\hline 1.5 & $11: 28$ & 47.1 & & 1.1 & 5.8 & & 13.2 & & 556 & 4.2 & 323 & 271 \\
\hline 1.6 & $11: 32$ & 49.1 & & 31 & 7.9 & & 11.2 & & 675 & 150 & 326 & 355 \\
\hline $2 \cdot 1$ & $11: 13$ & 33.3 & \multirow{6}{*}{$\angle B 3$} & .127 & 4.8 & \multirow{6}{*}{5.2} & 14.0 & \multirow{6}{*}{136} & 369 & .145 & 59.5 & 625 \\
\hline 2.2 & $11: 17$ & 51.4 & & 54 & 4.5 & & 14.3 & & 550 & 46 & 35.7 & 302 \\
\hline 2.3 & $11: 21$ & 69.4 & & 234 & 4.7 & & 14.1 & & 765 & 251 & 17.5 & 203 \\
\hline $2-4$ & $11: 25$ & 72.6 & & 26.6 & 5.9 & & 13.1 & & 855 & 35.0 & 37 & .91 \\
\hline 2.5 & $11: 29$ & 22.7 & & .233 & 4.7 & & 14.1 & & 25.1 & .264 & 618 & 608 \\
\hline 2.6 & 11:33 & 40.6 & & .54 & 6.7 & & 12.3 & & 511 & .03 & 479 & 484 \\
\hline $3 \cdot 1$ & $11: 14$ & 24.2 & \multirow{6}{*}{457} & -218 & 3.6 & \multirow{6}{*}{44} & 15.0 & \multirow{6}{*}{143} & 250 & .264 & 723 & 730 \\
\hline 3.2 & $11: 18$ & 58.3 & & 123 & 4.0 & & 14.6 & & 618 & 104 & 26.2 & 210 \\
\hline 3.3 & $11: 22$ & 73.2 & & 272 & 4.3 & & 14.4 & & 787 & 273 & 258 & 21.0 \\
\hline $3-4$ & $11: 26$ & 67.4 & & 214 & 4.6 & & 14.1 & & 742 & 228 & 15.1 & 101 \\
\hline 3.5 & $11: 30$ & 30.5 & & .155 & 4.1 & & 14.5 & & 325 & -189 & 540 & 551 \\
\hline 3.6 & $11: 34$ & 20.7 & & .253 & 5.6 & & 13.3 & & 242 & .273 & 744 & 75.7 \\
\hline 4.1 & $11: 15$ & 6.8 & \multirow{6}{*}{28.7} & .392 & 3.6 & \multirow{6}{*}{39} & 15.0 & \multirow{6}{*}{148} & 7.0 & 444 & 913 & 924 \\
\hline 4.2 & $11: 19$ & 44.8 & & .12 & 2.5 & & 16.0 & & 43.7 & .77 & $45 i$ & 451 \\
\hline 4.3 & $11: 23$ & 73.1 & & 271 & 3.3 & & 15.3 & & 74.3 & 229 & 231 & 221 \\
\hline 4.4 & $11: 27$ & 39.1 & & -69 & 4.5 & & 14.3 & & 42.6 & .88 & 492 & 463 \\
\hline 4.5 & 11:31 & 4.1 & & -419 & 4.1 & & 14.6 & & 44 & -47.1 & 932 & 934 \\
\hline $4-6$ & $11: 35$ & 4.4 & & -416 & 5.6 & & 13.3 & & 51 & .453 & 93.1 & 935 \\
\hline tet $A$ & & 46.0 & & & 4.8 & & 14.0 & & 51.4 & & 43.2 & 42.1 \\
\hline
\end{tabular}


CONSOL ENERGY INC.

AES GREENIDGE STATION
Client Reference No: 470014011

CleanAir Project No: 10192

Run 2: Inlet - Set 1

Date: $3 / 28 / 2007$

Start Time: $\quad 11: 12$

End Time: $11: 35$

Inlet - Oxygen (\%dv)

\begin{tabular}{|c|c|c|c|c|}
\hline \multicolumn{1}{c|}{ AVG } & 5.4 & 4.9 & 4.1 & 4.4 \\
\hline 6 & 8.6 & 6.8 & 6.3 & 6.6 \\
\hline 5 & 4.6 & 4.3 & 4.5 & 4.6 \\
\hline 4 & 4.4 & 3.9 & 3.7 & 3.5 \\
\hline 3 & 5.0 & 5.2 & 3.2 & 3.1 \\
\hline 2 & 2.9 & 3.1 & 2.8 & 2.6 \\
\hline 1 & 7.3 & 5.9 & 4.0 & 5.9 \\
\hline & 1 & 2 & 3 & 4 \\
\hline
\end{tabular}

7.1

4.5

3.9

4.1

2.8

5.8

4.7

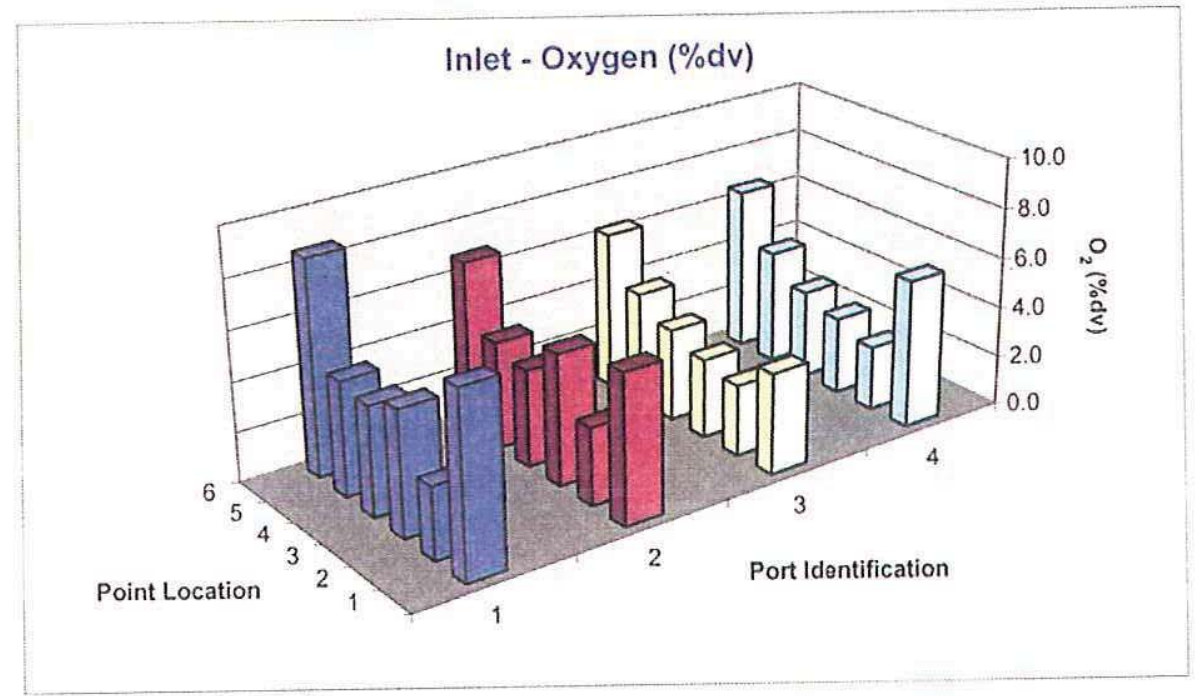


Run 2: Inlet - Set 1

$\begin{array}{rr}\text { Date: } & 3 / 28 / 2007 \\ \text { Start Time: } & 11: 12 \\ \text { End Time: } & 11: 35\end{array}$

\begin{tabular}{|c|c|c|c|c|c|}
\hline \multicolumn{5}{|c|}{ Inlet - Carbon Dioxide (\%dv) } & \\
\hline AVG & 13.4 & 13.8 & 14.5 & 14.3 & \\
\hline 6 & 10.7 & 12.2 & 12.6 & 12.4 & 12.0 \\
\hline 5 & 14.1 & 14.4 & 14.2 & 14.1 & 14.2 \\
\hline 4 & 14.3 & 14.7 & 14.9 & 15.0 & 14.7 \\
\hline 3 & 13.8 & 13.6 & 15.3 & 15.4 & 14.5 \\
\hline 2 & 15.5 & 15.3 & 15.6 & 15.8 & 15.6 \\
\hline 1 & 11.8 & 12.9 & 14.5 & 13.0 & 13.0 \\
\hline & 1 & 2 & 3 & 4 & 14.0 \\
\hline
\end{tabular}

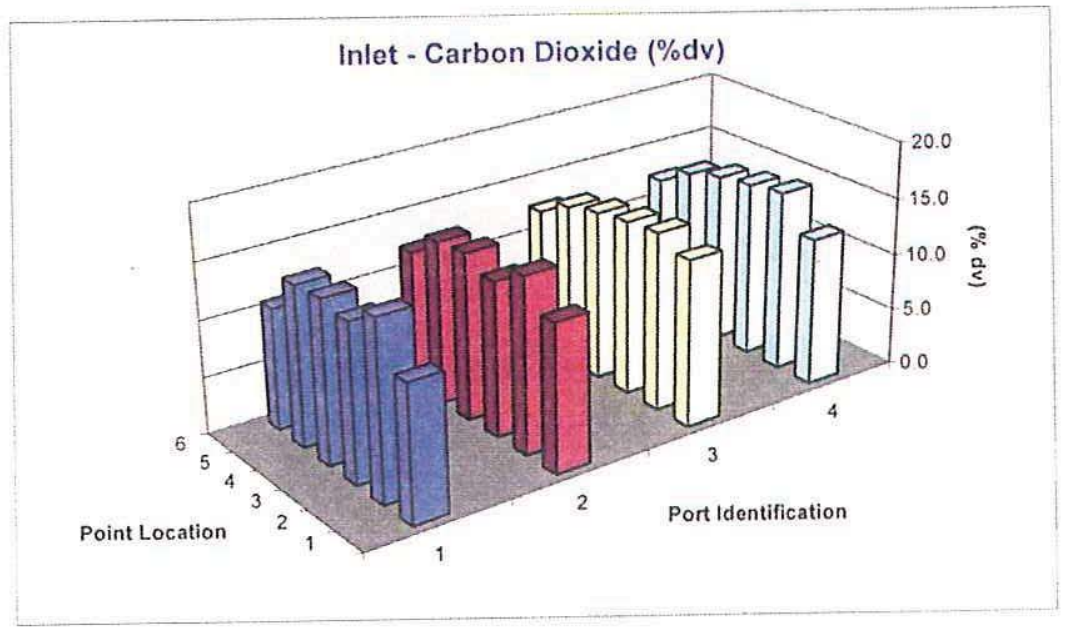


CONSOL ENERGY INC.

AES GREENIDGE STATION
Client Reference No: 4700140111 CleanAir Project No:10192

Run 2: Inlet - Set 1

Date: $3 / 28 / 2007$

Start Time: $\quad 11: 12$

End Time: $\quad 11: 35$

Inlet - Nitrogen Oxides (ppmdv), uncorrected

\begin{tabular}{|c|c|c|c|c|}
\hline \multicolumn{1}{|c|}{ AVG } & 81.4 & 76.5 & 82.0 & 75.9 \\
\hline $\mathbf{6}$ & 72.9 & 77.9 & 81.0 & 63.7 \\
\hline $\mathbf{5}$ & 69.6 & 59.4 & 66.3 & 60.1 \\
\hline $\mathbf{4}$ & 80.9 & 75.4 & 79.4 & 76.9 \\
\hline $\mathbf{3}$ & 84.5 & 84.1 & 98.7 & 95.0 \\
\hline $\mathbf{2}$ & 102.0 & 79.9 & 79.0 & 81.6 \\
\hline $\mathbf{1}$ & 78.6 & 82.3 & 87.4 & 77.8 \\
\hline & $\mathbf{1}$ & $\mathbf{2}$ & $\mathbf{3}$ & $\mathbf{4}$ \\
\hline
\end{tabular}

73.9

63.9

78.2

90.6

85.6

81.5

78.9

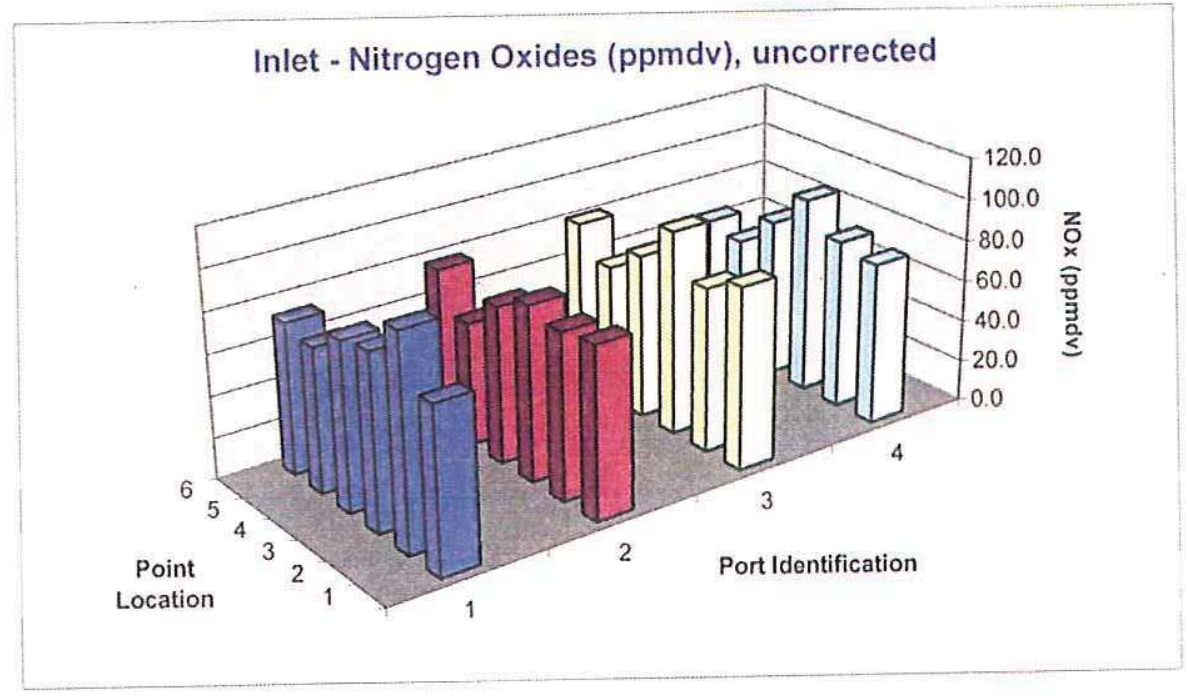

CleanAir 
CONSOL ENERGY INC.

AES GREENIDGE STATION
Client Reference No: 4700140111

CleanAir Project No:10192

Run 2: Inlet - Set 1

Date: $3 / 28 / 2007$

Start Time: $\quad 11: 12$

End Time: $\quad 11: 35$

Inlet - Nitrogen Oxides (ppmdv @ 3\% $\mathrm{O}_{2}$ )

\begin{tabular}{|c|c|c|c|c|}
\multicolumn{1}{c|}{ AVG } & 94.9 & 86.2 & 87.5 & 82.1 \\
\hline $\mathbf{6}$ & 106.3 & 99.0 & 99.4 & 79.5 \\
\hline $\mathbf{5}$ & 76.4 & 64.0 & 72.4 & 65.9 \\
\hline $\mathbf{4}$ & 87.7 & 79.3 & 82.5 & 79.3 \\
\hline $\mathbf{3}$ & 95.0 & 96.0 & 99.6 & 95.4 \\
\hline $\mathbf{2}$ & 101.2 & 80.3 & 78.3 & 79.6 \\
\hline $\mathbf{1}$ & 103.1 & 98.4 & 92.7 & 93.0 \\
\hline & $\mathbf{1}$ & $\mathbf{2}$ & $\mathbf{3}$ & $\mathbf{4}$ \\
\hline
\end{tabular}

96.1

69.7

82.2

96.5

84.8

96.8

87.7

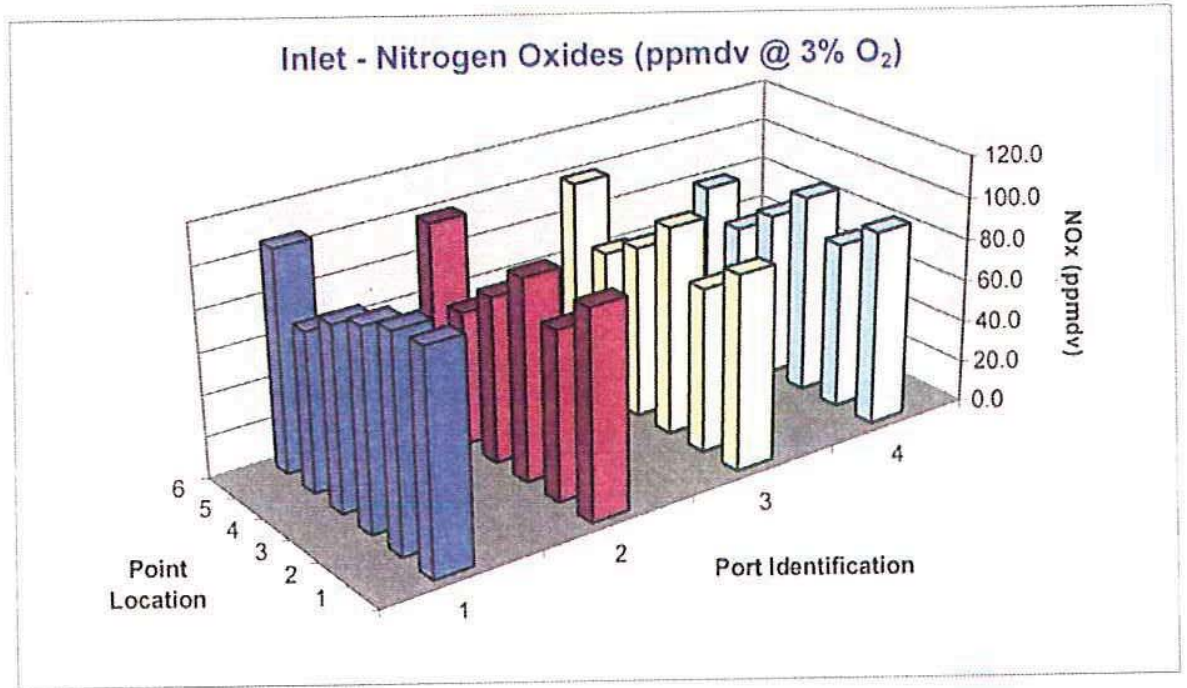


CONSOL ENERGY INC.

AES GREENIDGE STATION
Client Reference No: 4700140111

CleanAir Project No: 10192

Run 2: Outlet - Set 1

Date: $3 / 28 / 2007$

Start Time: $\quad 11: 12$

End Time: $\quad 11: 35$

Outlet - Oxygen (\%dv)
\begin{tabular}{|c|c|c|c|c|}
\hline AVG & 5.6 & 5.2 & 4.4 & 3.9 \\
\hline 6 & 7.9 & 6.7 & 5.6 & 5.6 \\
\hline 5 & 5.8 & 4.7 & 4.1 & 4.1 \\
\hline 4 & 4.5 & 5.9 & 4.6 & 4.5 \\
\hline 3 & 5.3 & 4.7 & 4.3 & 3.3 \\
\hline 2 & 5.4 & 4.5 & 4.0 & 2.5 \\
\hline 1 & 4.6 & 4.8 & 3.6 & 3.6 \\
\hline & 1 & 2 & 3 & 4 \\
\hline
\end{tabular}

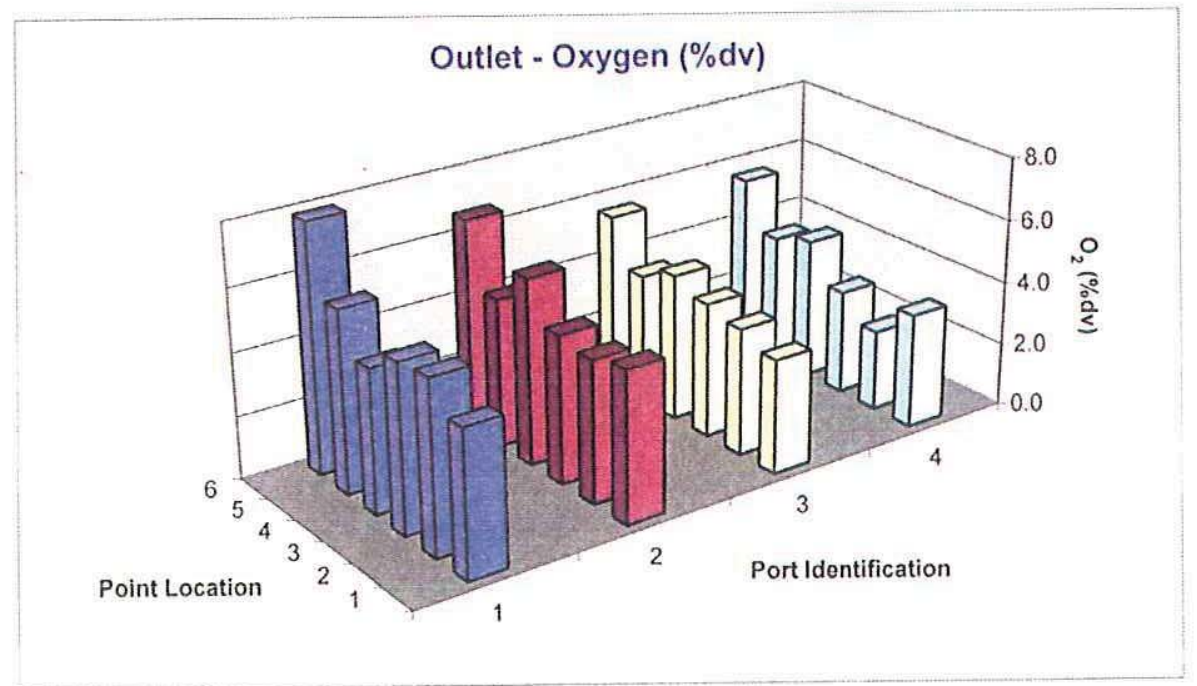


Run 2: Outlet - Set 1

Date: $3 / 28 / 2007$

Start Time: $\quad 11: 12$

End Time: $\quad 11: 35$

Outlet - Carbon Dioxide (\%dv)

\begin{tabular}{|c|c|c|c|c|c|}
\hline AVG & 13.3 & 13.6 & 14.3 & 14.8 & \\
\hline 6 & 11.2 & 12.3 & 13.3 & 13.3 & 12.5 \\
\hline 5 & 13.2 & 14.1 & 14.5 & 14.6 & 14.1 \\
\hline 4 & 14.2 & 13.1 & 14.1 & 14.3 & 13.9 \\
\hline 3 & 13.6 & 14.1 & 14.4 & 15.3 & 14.4 \\
\hline 2 & 13.5 & 14.3 & 14.6 & 16.0 & 14.6 \\
\hline 1 & 14.2 & 14.0 & 15.0 & 15.0 & 14.6 \\
\hline & 1 & 2 & 3 & 4 & 14.0 \\
\hline
\end{tabular}

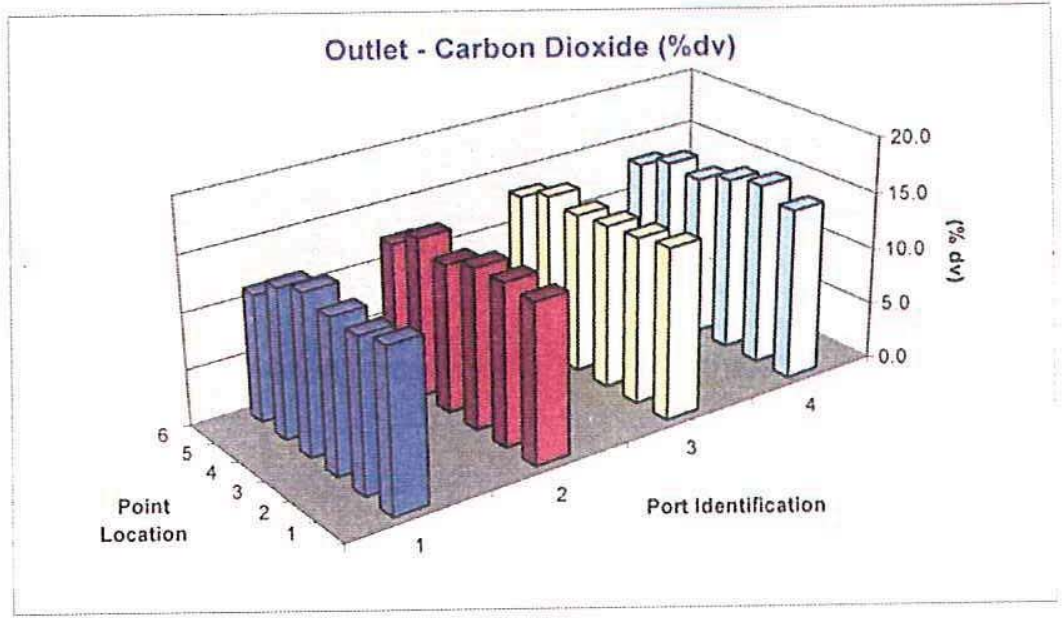


CONSOL ENERGY INC.

AES GREENIDGE STATION
Client Reference No: 4700140111

CleanAir Project No:10192

Run 2: Outlet - Set 1

Date: $3 / 28 / 2007$

Start Time: $\quad 11: 12$

End Time: $\quad 11: 35$

\begin{tabular}{|c|c|c|c|c|c|}
\hline & \multicolumn{5}{|c|}{ Outlet - Nitrogen Oxides ( $\mathrm{ppmdv}$ ), uncorrected } \\
\hline AVG & 61.4 & 48.3 & 45.7 & 28.7 & \\
\hline 6 & 49.1 & 40.6 & 20.7 & 4.4 & 28.7 \\
\hline 5 & 47.1 & 22.7 & 30.5 & 4.1 & 26.1 \\
\hline 4 & 65.9 & 72.6 & 67.4 & 39.1 & 61.3 \\
\hline 3 & 58.1 & 69.4 & 73.2 & 73.1 & 68.5 \\
\hline 2 & 76.7 & 51.4 & 58.3 & 44.8 & 57.8 \\
\hline 1 & 71.2 & 33.3 & 24.2 & 6.8 & 33.9 \\
\hline & 1 & 2 & 3 & 4 & 46.0 \\
\hline
\end{tabular}

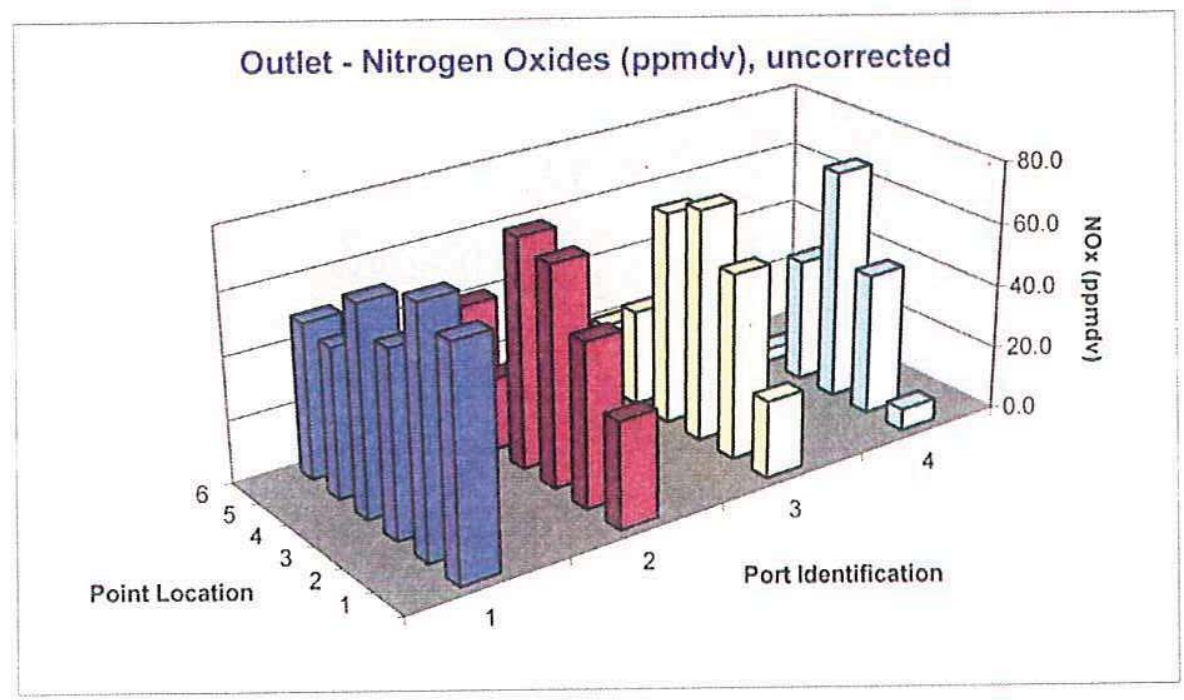


CONSOL ENERGY INC.

AES GREENIDGE STATION
Client Reference No: 4700140111

CleanAir Project No: 10192

Run 2: Outlet - Set 1

Date: $3 / 28 / 2007$

Start Time: $\quad 11: 12$

End Time: 11:35

Outlet - Nitrogen Oxides (ppmdv @ 3\% $\mathrm{O}_{2}$ )

\begin{tabular}{|c|c|c|c|c|}
\hline AVG & 71.4 & 55.4 & 49.4 & 29.5 \\
\hline 6 & 67.5 & 51.1 & 24.2 & 5.1 \\
\hline 5 & 55.6 & 25.1 & 32.5 & 4.4 \\
\hline 4 & 72.1 & 86.5 & 74.2 & 42.6 \\
\hline 3 & 66.6 & 76.5 & 78.7 & 74.3 \\
\hline 2 & 88.7 & 56.0 & 61.8 & 43.7 \\
\hline 1 & 78.1 & 36.9 & 25.0 & 7.0 \\
\hline & 1 & 2 & 3 & 4 \\
\hline
\end{tabular}

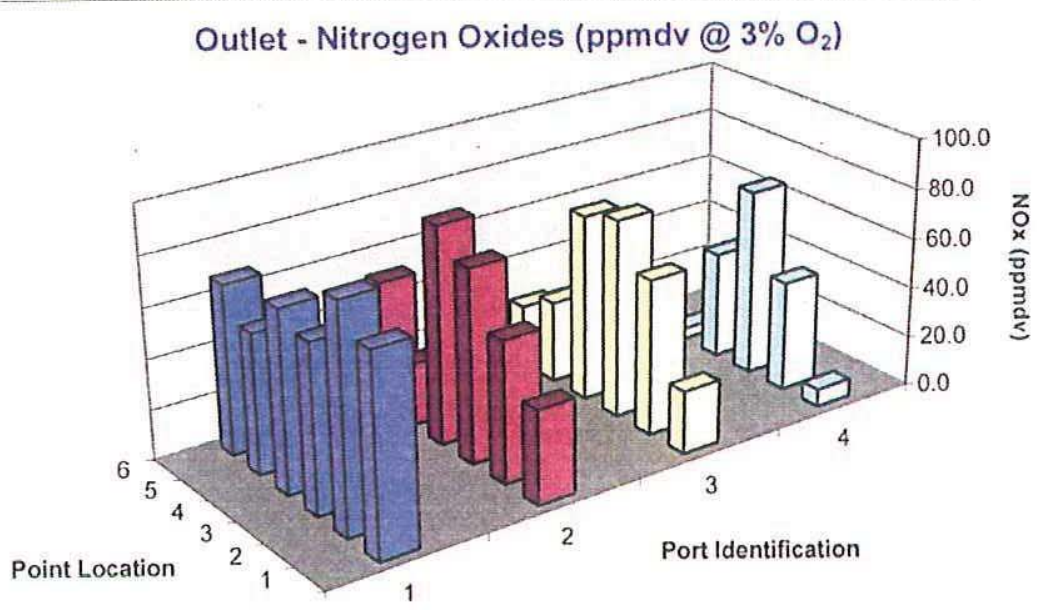

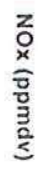

(E)

CleanAir: 
CONSOL ENERGY INC.

AES GREENIDGE STATION
Client Reference No: $\$ 700140111$ CleanAir Project No: 10192

Run 2: Outlet - Set 1

Date: $3 / 28 / 2007$

Start Time: $\quad 11: 12$

End Time: $\quad 11: 35$

Removal Efficiency (ppmdv @ 3\% $\mathrm{O}_{2}$ )

\begin{tabular}{|c|c|c|c|c|}
\multicolumn{1}{c|}{ AVG } & $24.7 \%$ & $35.5 \%$ & $42.7 \%$ & $65.5 \%$ \\
\hline 6 & $36.5 \%$ & $48.4 \%$ & $75.7 \%$ & $93.5 \%$ \\
\hline 5 & $27.1 \%$ & $60.8 \%$ & $55.1 \%$ & $93.4 \%$ \\
\hline 4 & $17.8 \%$ & $-9.1 \%$ & $10.1 \%$ & $46.3 \%$ \\
\hline 3 & $29.9 \%$ & $20.3 \%$ & $21.0 \%$ & $22.1 \%$ \\
\hline 2 & $12.3 \%$ & $30.2 \%$ & $21.0 \%$ & $45.1 \%$ \\
\hline 1 & $24.3 \%$ & $62.5 \%$ & $73.0 \%$ & $92.4 \%$ \\
\hline & 1 & 2 & 3 & 4 \\
\hline
\end{tabular}

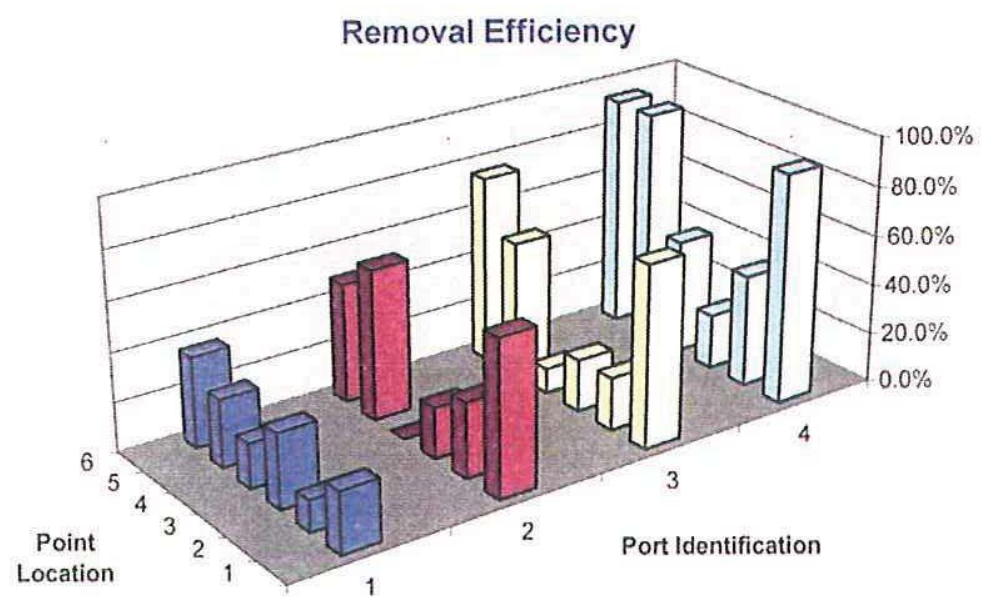


Clean Air Engineering Project $\approx 10192$ Consol Energy

Date:

Start Time:

$3 / 2822007$

Run $\#$ (Cycle \#) $2(2)$

End Time:

1159

\begin{tabular}{|c|c|c|c|c|c|c|c|c|c|c|}
\hline $\begin{array}{l}\text { Intet } \\
\text { Point }\end{array}$ & Time Sampled & $\begin{array}{c}\text { NOx } \\
\text { ppmdv }\end{array}$ & $\begin{array}{c}\text { Nox } \\
\text { Port Avg }\end{array}$ & $\begin{array}{l}\text { PPM Dev } \\
\text { from Avg. }\end{array}$ & $\begin{array}{l}02 \\
\% d v\end{array}$ & $\begin{array}{c}02 \\
\text { Port Avg }\end{array}$ & $\begin{array}{l}\mathrm{CO} 2 \\
\% d v\end{array}$ & $\begin{array}{c}\mathrm{CO} 2 \\
\text { Port Avg }\end{array}$ & $\begin{array}{c}\mathrm{NOx} \\
\text { (9) } 3 \% 02\end{array}$ & $\begin{array}{l}\text { PPM Dev } \\
\text { from Avg. }\end{array}$ \\
\hline 1.1 & $11: 36$ & 75.8 & & -10 & 7.7 & & 11.5 & & 1024 & $16 B$ \\
\hline 1.2 & $11: 40$ & 96.4 & & 196 & 3.1 & & 15.3 & & 972 & 116 \\
\hline 1.3 & $11: 44$ & 86.3 & 789 & 95 & 5.0 & 56 & 13.8 & 133 & 970 & 114 \\
\hline 1.4 & $11: 48$ & 79.0 & & 22 & 4.3 & & 14.3 & & 851 & 05 \\
\hline 1.5 & $11: 52$ & 65.8 & & -110 & 4.7 & & 14.1 & & 725 & .131 \\
\hline 1.6 & $11: 56$ & 70.1 & & 67 & 8.6 & & 10.6 & & 1023 & 168 \\
\hline $2-1$ & $11: 37$ & 77.8 & & 10 & 6.1 & & 12.8 & & 942 & 86 \\
\hline 2.2 & $11: 41$ & 79.9 & & 31 & 3.2 & & 15.3 & & 908 & -48 \\
\hline 2.3 & $11: 45$ & 82.4 & 738 & 56 & 5.5 & so & 13.3 & 138 & 950 & 104 \\
\hline $2-4$ & $11: 49$ & 73.2 & & -36 & 3.8 & & 14.8 & & 764 & .91 \\
\hline 2.5 & $11: 53$ & 56.5 & & .20 .3 & 4.4 & & 14.3 & & 612 & .244 \\
\hline $2-6$ & $11: 57$ & 72.8 & & -40 & 6.8 & & 12.2 & & 924 & 68 \\
\hline 3.1 & $11: 38$ & 88.1 & & 113 & 4.2 & & 14.4 & & 545 & 89 \\
\hline 3.2 & $11: 42$ & 78.8 & & 20 & 3.1 & & 15.4 & & 792 & .54 \\
\hline 3.3 & $11: 46$ & 99.0 & 80.9 & 222 & 3.3 & 42 & 15.1 & 144 & 1009 & 153 \\
\hline $3-4$ & $11: 50$ & 76.8 & & 00 & 3.6 & & 14.9 & & 794 & -52 \\
\hline 3.5 & $11: 54$ & 63.3 & & .135 & 4.4 & & 14.3 & & 686 & .170 \\
\hline 3.6 & $11: 58$ & 79.4 & & 26 & 6.4 & & 12.5 & & 982 & 126 \\
\hline 4.1 & $11: 39$ & 75.0 & & -18 & 6.1 & & 12.8 & & 909 & 53 \\
\hline $4 \cdot 2$ & $11: 43$ & 79.3 & & 25 & 2.7 & & 15.7 & & 780 & .75 \\
\hline 4.3 & $11: 47$ & 93.5 & 735 & 167 & 3.0 & 43 & 15.5 & 143 & 934 & 79 \\
\hline $4 \cdot 4$ & 11:51 & 74.8 & & .2 .0 & 3.4 & & 15.0 & & 767 & -89 \\
\hline 4.5 & $11: 55$ & 56.2 & & .206 & 4.2 & & 14.4 & & 602 & .254 \\
\hline 4.6 & $11: 59$ & 62.3 & & .145 & 6.4 & & 12.6 & & 767 & .89 \\
\hline
\end{tabular}

Inlet Averages

76.8

4.7

13.9

85.6

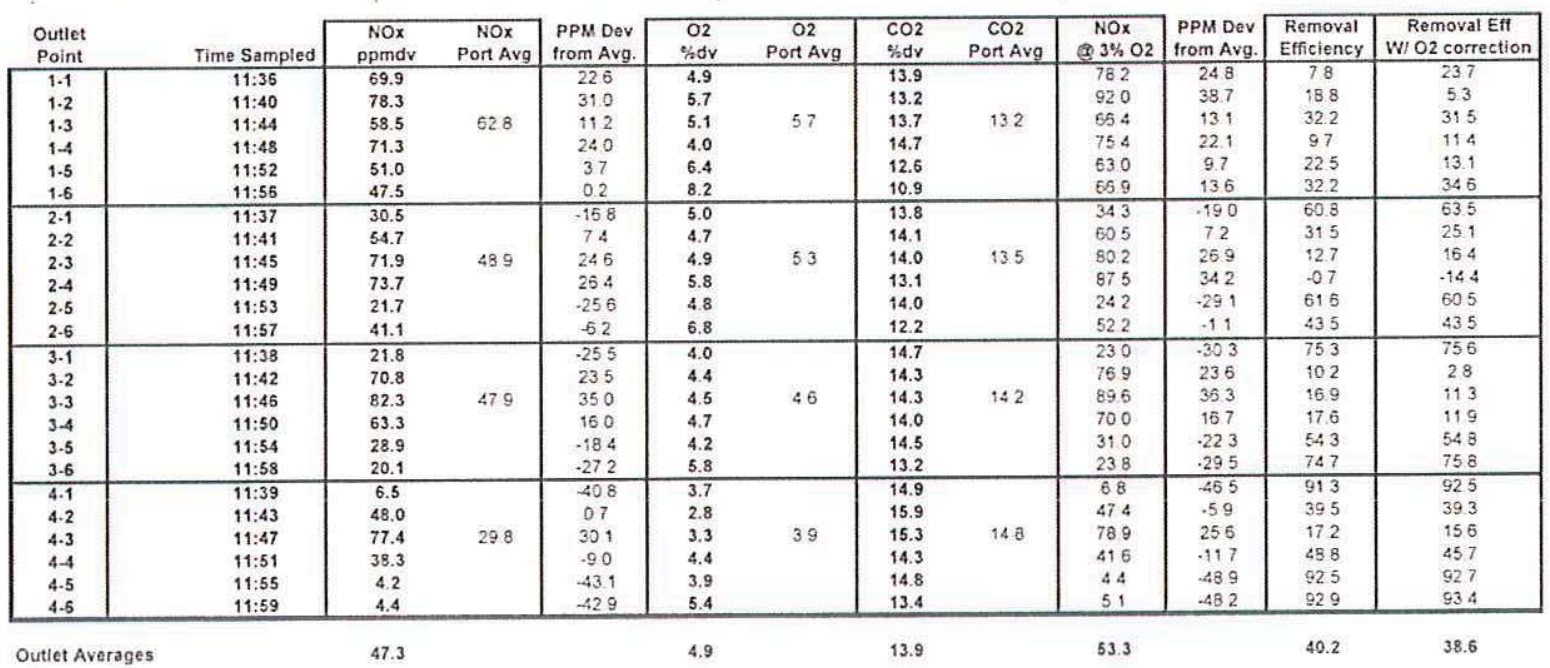


CONSOL ENERGY INC.

AES GREENIDGE STATION
Client Reference No: 4700140111

CleanAir Project No:10192

Run 2: Inlet-Set 2

Date: $3 / 28 / 2007$

Start Time: $\quad 11: 36$

End Time: $\quad 11: 59$

Inlet - Oxygen (\%dv)

\begin{tabular}{|c|c|c|c|c|}
\hline AVG & 5.6 & 5.0 & 4.2 & 4.3 \\
\hline 6 & 8.6 & 6.8 & 6.4 & 6.4 \\
\hline 5 & 4.7 & 4.4 & 4.4 & 4.2 \\
\hline 4 & 4.3 & 3.8 & 3.6 & 3.4 \\
\hline 3 & 5.0 & 5.5 & 3.3 & 3.0 \\
\hline 2 & 3.1 & 3.2 & 3.1 & 2.7 \\
\hline 1 & 7.7 & 6.1 & 4.2 & 6.1 \\
\hline
\end{tabular}

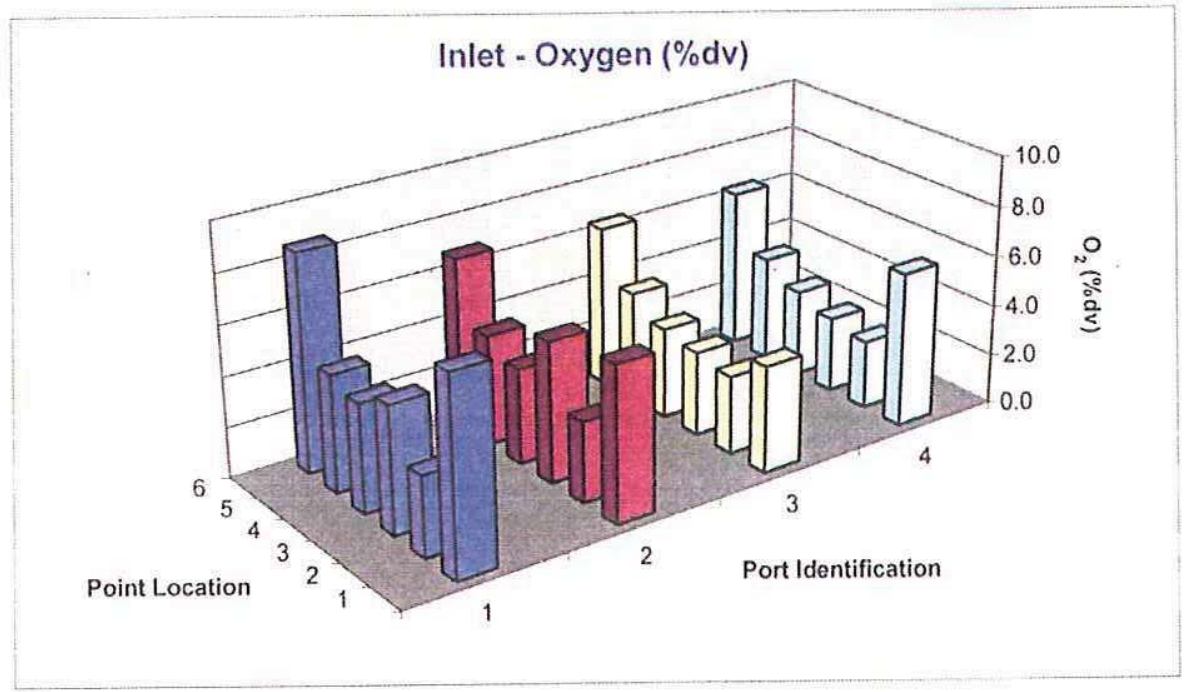


CONSOL ENERGY INC.

AES GREENIDGE STATION
Client Reference No: 4700140111

CleanAir Project No:10192

Run 2: Inlet - Set 2

Date: $3 / 28 / 2007$

Start Time: $\quad 11: 36$

End Time: $\quad 11: 59$

Inlet - Carbon Dioxide (\%dv)

\begin{tabular}{|c|c|c|c|c|}
\hline AVG & 13.3 & 13.8 & 14.4 & 14.3 \\
\hline $\mathbf{6}$ & 10.6 & 12.2 & 12.5 & 12.6 \\
\hline $\mathbf{5}$ & 14.1 & 14.3 & 14.3 & 14.4 \\
\hline $\mathbf{4}$ & 14.3 & 14.8 & 14.9 & 15.0 \\
\hline $\mathbf{3}$ & 13.8 & 13.3 & 15.1 & 15.5 \\
\hline $\mathbf{2}$ & 15.3 & 15.3 & 15.4 & 15.7 \\
\hline $\mathbf{1}$ & 11.5 & 12.8 & 14.4 & 12.8 \\
1 & $\mathbf{1}$ & $\mathbf{2}$ & $\mathbf{3}$ & $\mathbf{4}$ \\
\hline
\end{tabular}

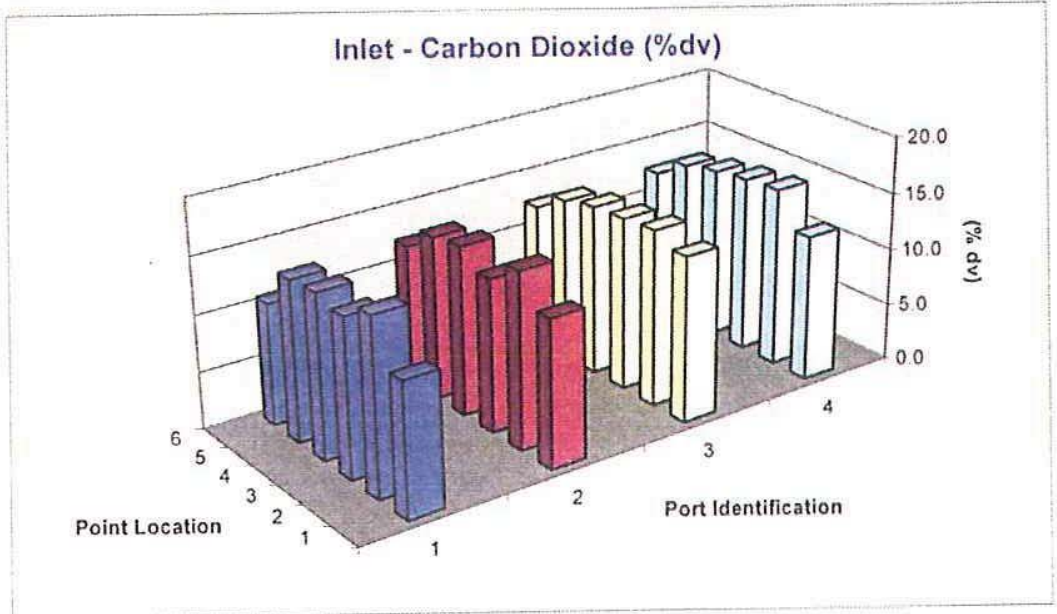

(俌)

CleanAir. 
CONSOL ENERGY INC.

AES GREENIDGE STATION
Client Reference No: 4700140111

CleanAir Project No:10192

Run 2: Inlet - Set 2

Date: $3 / 28 / 2007$

Start Time: $\quad 11: 36$

End Time: $\quad 11: 59$

Inlet - Nitrogen Oxides (ppmdv), uncorrected

\begin{tabular}{|c|c|c|c|c|}
\multicolumn{1}{c|}{ AVG } & 78.9 & 73.8 & 80.9 & 73.5 \\
\hline $\mathbf{6}$ & 70.1 & 72.8 & 79.4 & 62.3 \\
\hline $\mathbf{5}$ & 65.8 & 56.5 & 63.3 & 56.2 \\
\hline $\mathbf{4}$ & 79.0 & 73.2 & 76.8 & 74.8 \\
\hline $\mathbf{3}$ & 86.3 & 82.4 & 99.0 & 93.5 \\
\hline $\mathbf{2}$ & 96.4 & 79.9 & 78.8 & 79.3 \\
\hline $\mathbf{1}$ & 75.8 & 77.8 & 88.1 & 75.0 \\
\hline
\end{tabular}

71.2

60.5

76.0

90.3

83.6

79.2

76.8

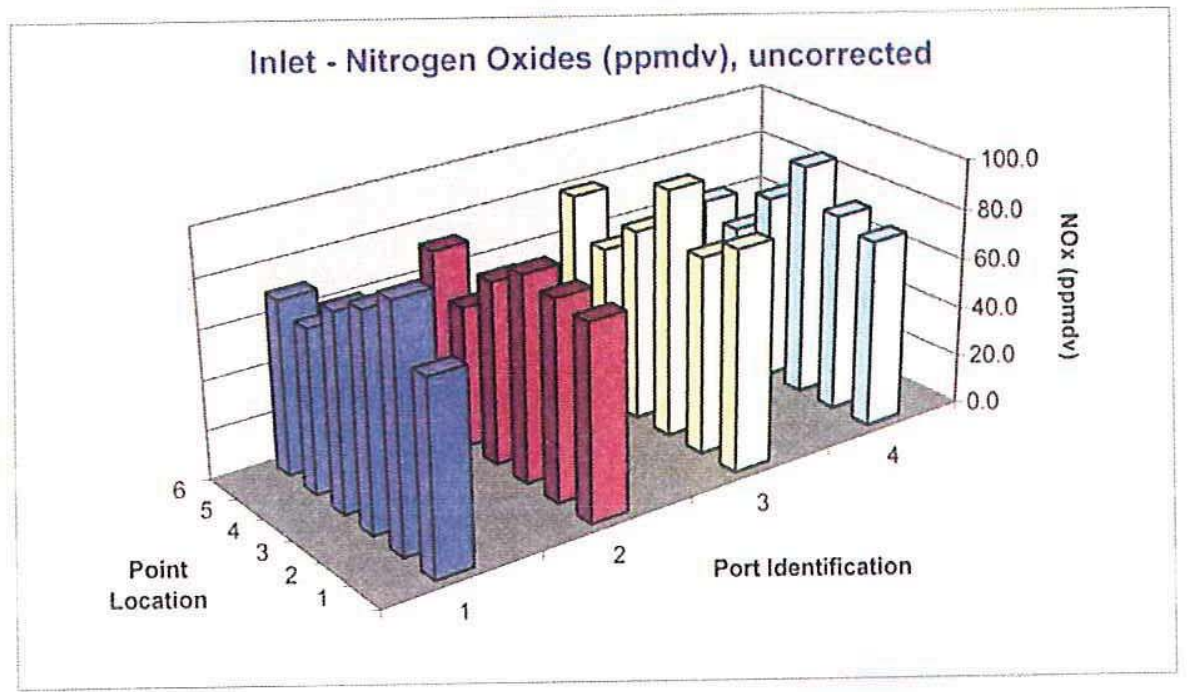


CONSOL ENERGY INC.

AES GREENIDGE STATION
Client Reference No: 4700140111

CleanAir Project No:10192

Run 2: Inlet - Set 2

Date: $3 / 28 / 2007$

Start Time: $\quad 11: 36$

End Time: $\quad 11: 59$

Inlet - Nitrogen Oxides (ppmdv @ 3\% $\mathrm{O}_{2}$ )

\begin{tabular}{|c|c|c|c|c|}
\hline AVG & 92.7 & 83.5 & 86.8 & 79.3 \\
\hline 6 & 102.3 & 92.4 & 98.2 & 76.7 \\
\hline 5 & 72.5 & 61.2 & 68.6 & 60.2 \\
\hline 4 & 85.1 & 76.4 & 79.4 & 76.7 \\
\hline 3 & 97.0 & 96.0 & 100.9 & 93.4 \\
\hline 2 & 97.2 & 80.8 & 79.2 & 78.0 \\
\hline 1 & 102.4 & 94.2 & 94.5 & 90.9 \\
\hline & 1 & 2 & 3 & 4 \\
\hline
\end{tabular}

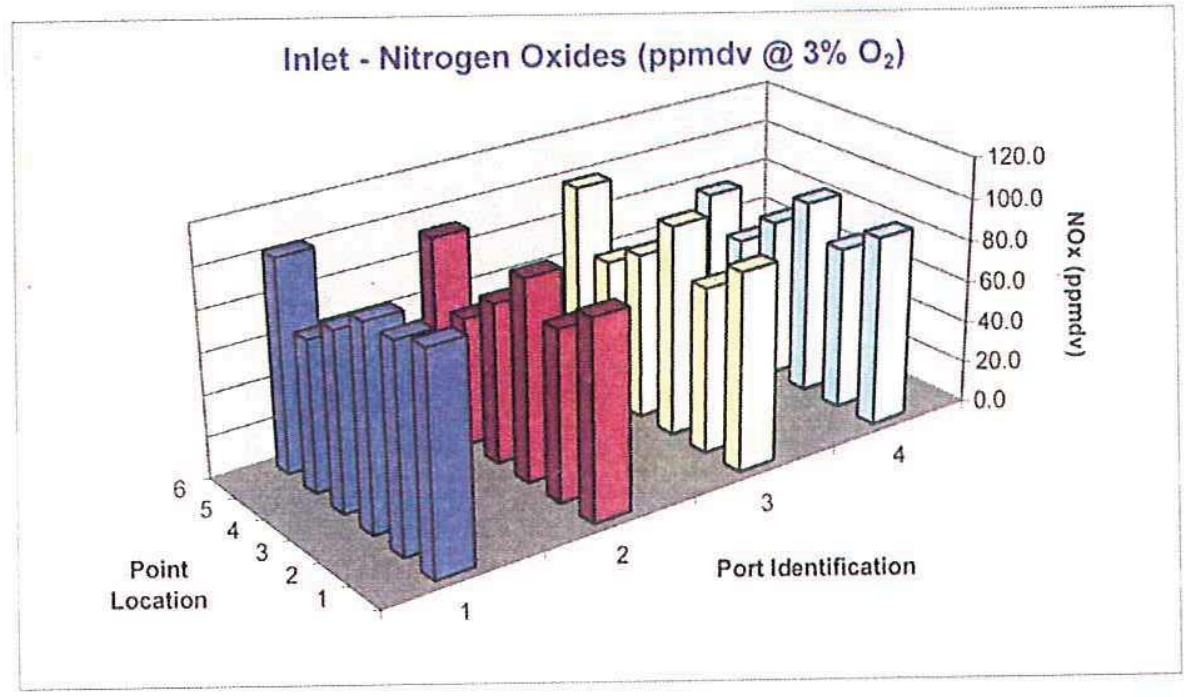


CONSOL ENERGY INC.

AES GREENIDGE STATION
Client Reference No: 4700140111

CleanAir Project No:10192

Run 2: Outlet - Set 2

Date: $3 / 28 / 2007$

Start Time: $\quad 11: 36$

End Time: $\quad 11: 59$

\begin{tabular}{|c|c|c|c|c|c|}
\hline \multicolumn{5}{|c|}{ Outlet - Oxygen (\%dv) } & \multirow[b]{3}{*}{6.5} \\
\hline AVG & 5.7 & 5.3 & 4.6 & 3.9 & \\
\hline 6 & 8.2 & 6.8 & 5.8 & 5.4 & \\
\hline 5 & 6.4 & 4.8 & 4.2 & 3.9 & 4.8 \\
\hline 4 & 4.0 & 5.8 & 4.7 & 4.4 & 4.7 \\
\hline 3 & 5.1 & 4.9 & 4.5 & 3.3 & 4.4 \\
\hline 2 & 5.7 & 4.7 & 4.4 & 2.8 & 4.4 \\
\hline 1 & 4.9 & 5.0 & 4.0 & 3.7 & 4.4 \\
\hline & 1 & 2 & 3 & 4 & 4.9 \\
\hline
\end{tabular}

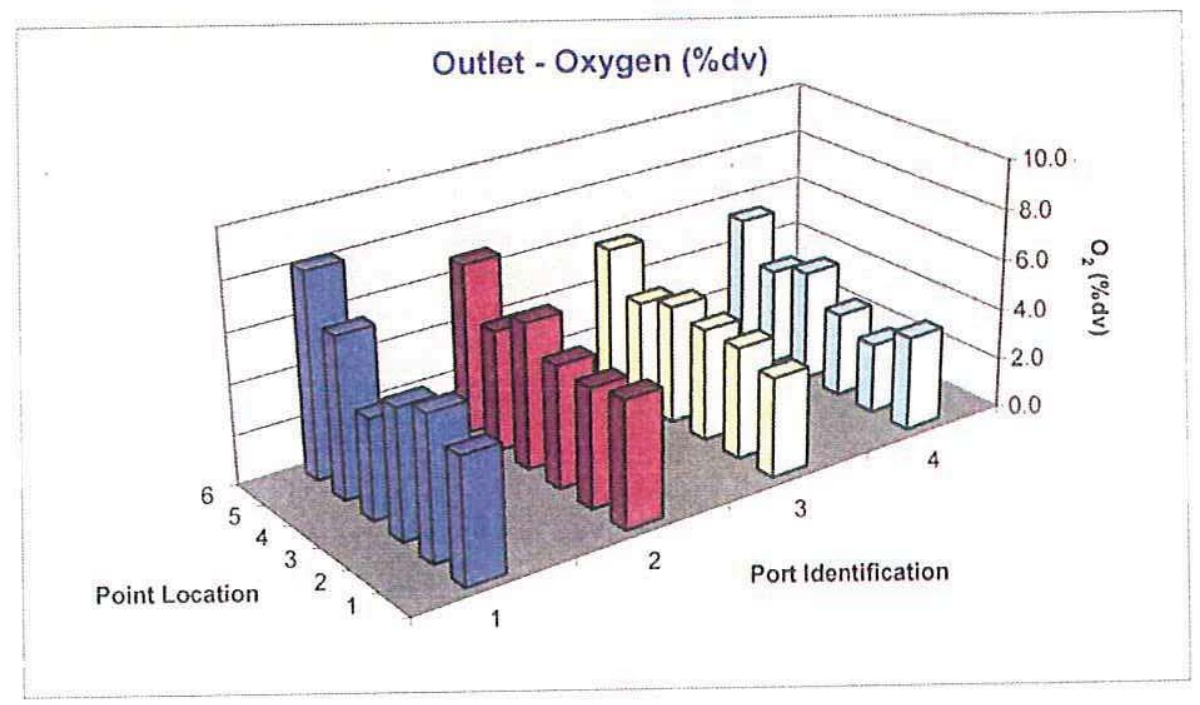


CONSOL ENERGY INC.

AES GREENIDGE STATION
Client Reference No: 4700140111

CleanAir Project No:10192

Run 2: Outlet - Set 2

$\begin{array}{rr}\text { Date: } & 3 / 28 / 2007 \\ \text { Start Time: } & 11: 36 \\ \text { End Time: } & 11: 59\end{array}$

Outlet - Carbon Dioxide (\%dv)

\begin{tabular}{|c|c|c|c|c|c|}
\hline AVG & 13.2 & 13.5 & 14.2 & 14.8 & \\
\hline 6 & 10.9 & 12.2 & 13.2 & 13.4 & 12.4 \\
\hline 5 & 12.6 & 14.0 & 14.5 & 14.8 & 14.0 \\
\hline 4 & 14.7 & 13.1 & 14.0 & 14.3 & 14.0 \\
\hline 3 & 13.7 & 14.0 & 14.3 & 15.3 & 14.3 \\
\hline 2 & 13.2 & 14.1 & 14.3 & 15.9 & 14.4 \\
\hline \multirow[t]{2}{*}{1} & 13.9 & 13.8 & 14.7 & 14.9 & 14.3 \\
\hline & 1 & 2 & 3 & 4 & 13.9 \\
\hline
\end{tabular}

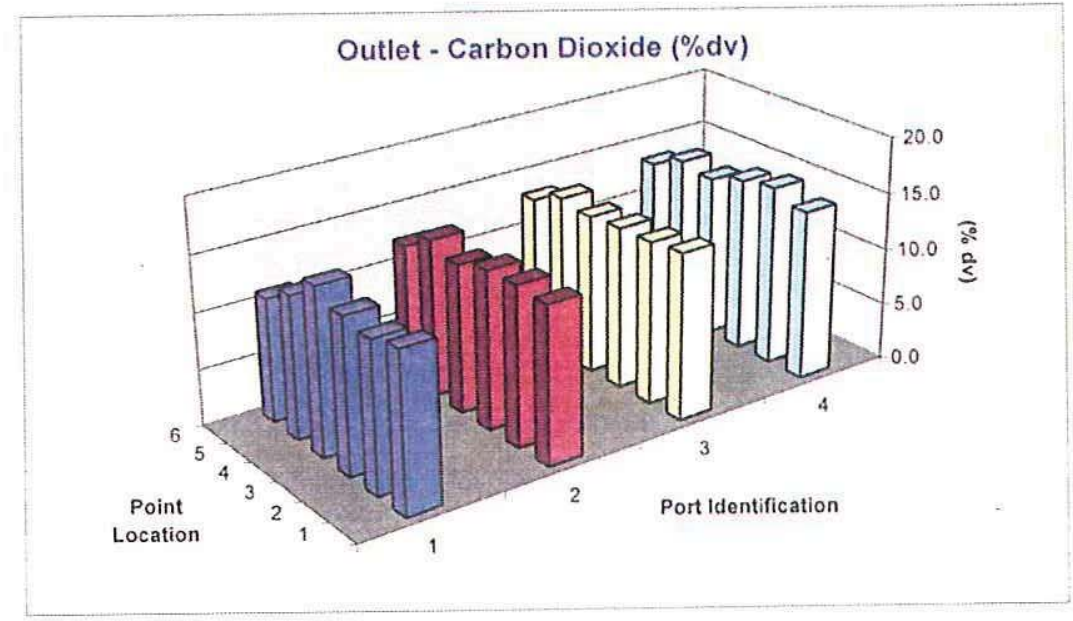


CONSOL ENERGY INC.

AES GREENIDGE STATION
Client Reference No: 4700140111

CleanAir Project No: 10192

Run 2: Outlet - Set 2

Date: $3 / 28 / 2007$

Start Time: $11: 36$

End Time: $11: 59$

\begin{tabular}{|c|c|c|c|c|c|}
\hline \multicolumn{6}{|c|}{ Outlet - Nitrogen Oxides (ppmdv), uncorrected } \\
\hline AVG & 62.8 & 48.9 & 47.9 & 29.8 & \\
\hline 6 & 47.5 & 41.1 & 20.1 & 4.4 & 28.3 \\
\hline 5 & 51.0 & 21.7 & 28.9 & 4.2 & 26.5 \\
\hline 4 & 71.3 & 73.7 & 63.3 & 38.3 & 61.7 \\
\hline 3 & 58.5 & 71.9 & 82.3 & 77.4 & 72.5 \\
\hline 2 & 78.3 & 54.7 & 70.8 & 48.0 & 63.0 \\
\hline 1 & 69.9 & 30.5 & 21.8 & 6.5 & 32.2 \\
\hline & 1 & 2 & 3 & 4 & 47.3 \\
\hline
\end{tabular}

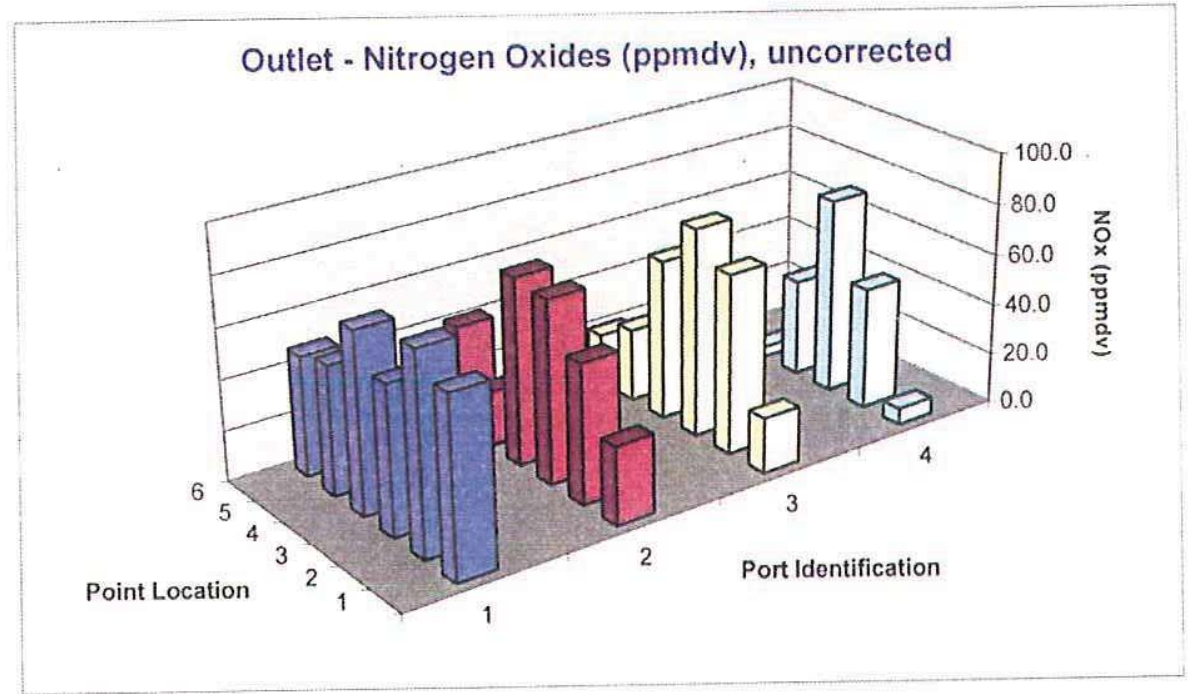

CleanAir. 
CONSOL ENERGY INC.

AES GREENIDGE STATION
Client Reference No: 4700140111

CleanAir Project No:10192

Run 2: Outlet - Set 2

Date: $3 / 28 / 2007$

Start Time: $\quad 11: 36$

End Time: $\quad 11: 59$

Outlet - Nitrogen Oxides (ppmdv @ 3\% $\mathrm{O}_{2}$ )

\begin{tabular}{|c|c|c|c|c|c|}
\hline AVG & 73.7 & 56.5 & 52.4 & 30.7 & \\
\hline 6 & 66.9 & 52.2 & 23.8 & 5.1 & 37.0 \\
\hline 5 & 63.0 & 24.2 & 31.0 & 4.4 & 30.6 \\
\hline 4 & 75.4 & 87.5 & 70.0 & 41.6 & 68.6 \\
\hline 3 & 66.4 & 80.2 & 89.6 & 78.9 & 78.8 \\
\hline 2 & 92.0 & 60.5 & 76.9 & 47.4 & 69.2 \\
\hline 1 & 78.2 & 34.3 & 23.0 & 6.8 & 35.6 \\
\hline & 1 & 2 & 3 & 4 & 53.3 \\
\hline
\end{tabular}

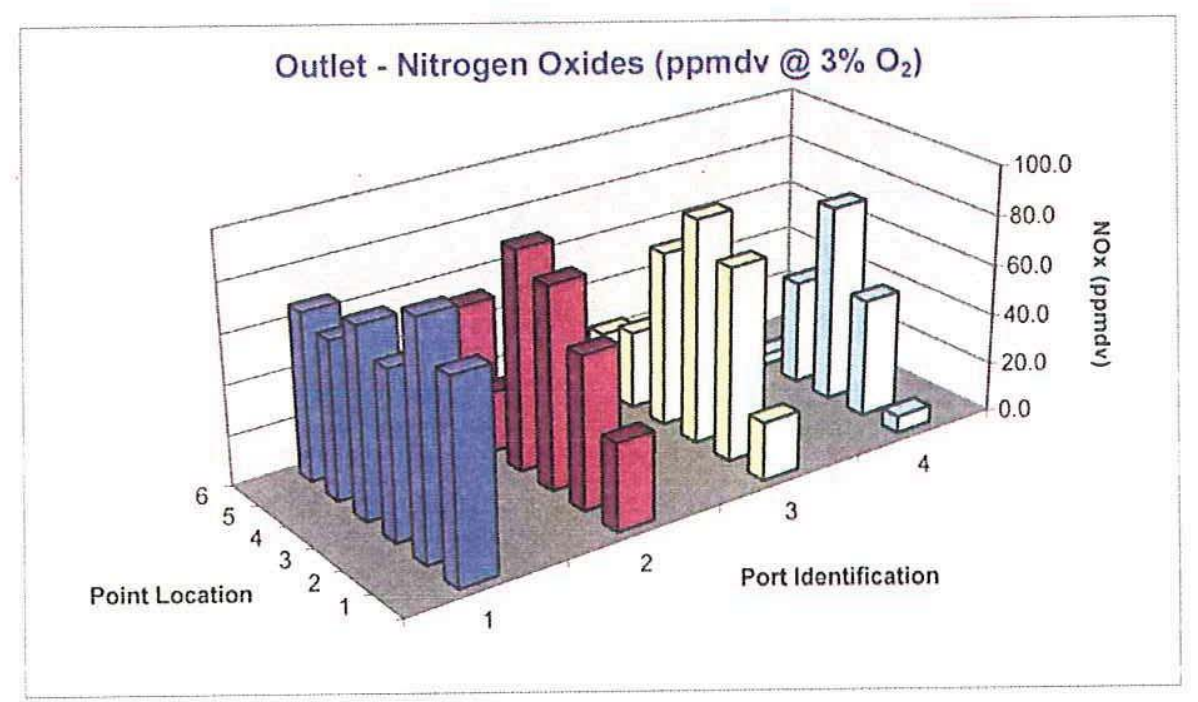

CleanAir 
CONSOL ENERGY INC. AES GREENIDGE STATION
Client Reference No: 4700140111 CleanAir Project No:10192

Run 2: Outlet - Set 2

Date: $3 / 28 / 2007$

Start Time: $\quad 11: 36$

End Time: $\quad 11: 59$

\begin{tabular}{|c|c|c|c|c|c|}
\hline \multicolumn{6}{|c|}{ Removal Efficiency (ppmdv @ $3 \% \mathrm{O}_{2}$ ) } \\
\hline AVG & $19.9 \%$ & $32.4 \%$ & $38.7 \%$ & $63.2 \%$ & \\
\hline 6 & $34.6 \%$ & $43.5 \%$ & $75.8 \%$ & $93.4 \%$ & $61.8 \%$ \\
\hline 5 & $13.1 \%$ & $60.5 \%$ & $54.8 \%$ & $92.7 \%$ & $55.3 \%$ \\
\hline 4 & $11.4 \%$ & $-14.4 \%$ & $11.9 \%$ & $45.7 \%$ & $13.6 \%$ \\
\hline 3 & $31.5 \%$ & $16.4 \%$ & $11.3 \%$ & $15.6 \%$ & $18.7 \%$ \\
\hline 2 & $5.3 \%$ & $25.1 \%$ & $2.8 \%$ & $39.3 \%$ & $18.1 \%$ \\
\hline 1 & $23.7 \%$ & $63.5 \%$ & $75.6 \%$ & $92.5 \%$ & $63.8 \%$ \\
\hline & 1 & 2 & 3 & 4 & $38.6 \%$ \\
\hline
\end{tabular}

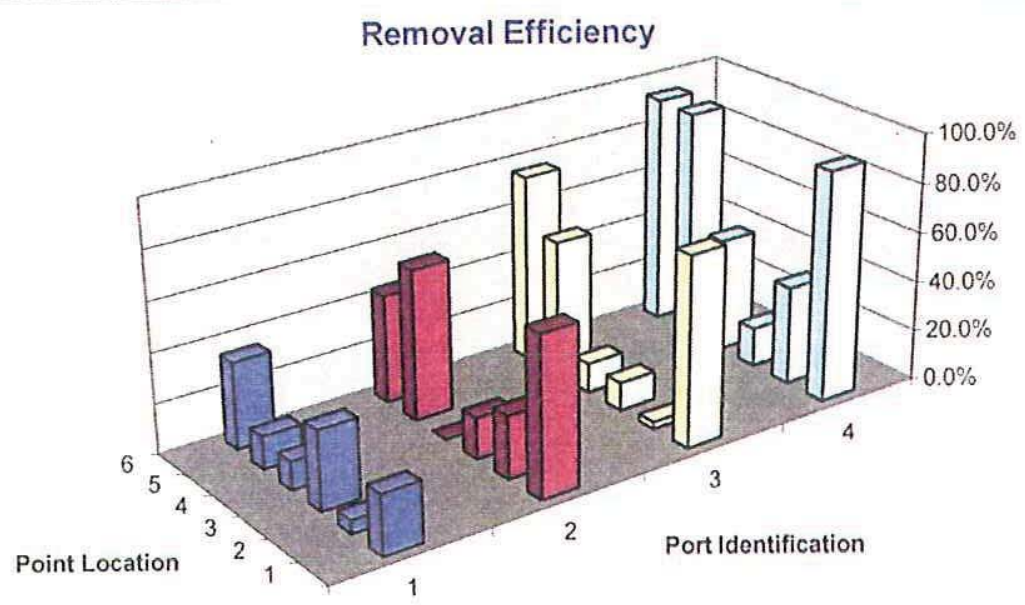


Clean Air Engineering Project $\approx 10192$

Consol Energy
AES Diesden

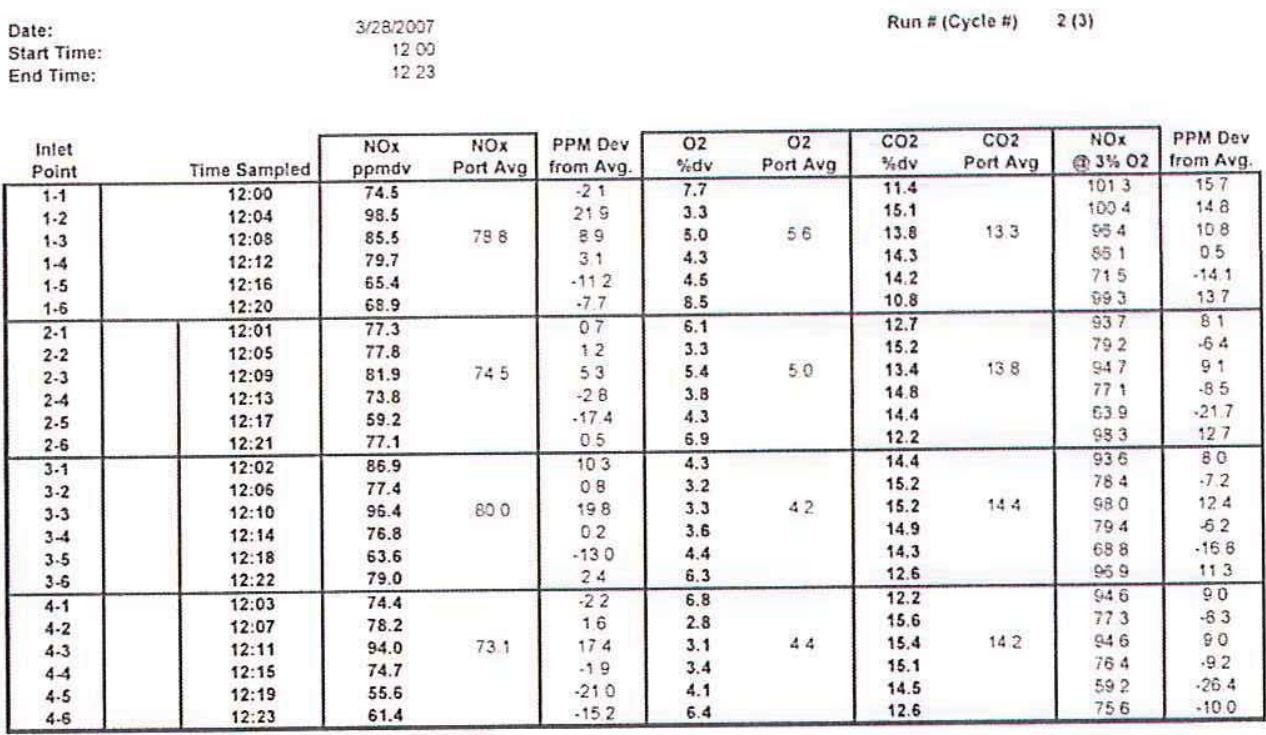

Inlet Averages

76.6

$\begin{array}{ll}4.8 & 13.9\end{array}$

85.6

\begin{tabular}{|c|c|c|c|c|c|c|c|c|c|c|c|c|}
\hline $\begin{array}{l}\text { Outlet } \\
\text { Point }\end{array}$ & Time Sampled & $\begin{array}{c}\text { NOx } \\
\text { ppmdv }\end{array}$ & $\begin{array}{c}\text { NOx } \\
\text { Port Avg } \\
\end{array}$ & $\begin{array}{l}\text { PPM Dev } \\
\text { from Avg. }\end{array}$ & $\begin{array}{l}02 \\
\% d v\end{array}$ & $\begin{array}{c}\mathrm{O} 2 \\
\text { Port Avg }\end{array}$ & $\begin{array}{l}\mathrm{CO} 2 \\
\% \mathrm{dv} \\
\end{array}$ & $\begin{array}{c}\mathrm{CO} 2 \\
\text { Port Avg }\end{array}$ & $\begin{array}{c}\mathrm{NOx} \\
\text { (2) } 3 \% \text { O2 } \\
\end{array}$ & $\begin{array}{l}\text { PPM Dev } \\
\text { from Avg. }\end{array}$ & $\begin{array}{l}\text { Removal } \\
\text { Efficiency }\end{array}$ & $\begin{array}{c}\begin{array}{c}\text { Removal Eff } \\
\text { w/ } 02 \text { correction }\end{array} \\
\end{array}$ \\
\hline 1.1 & $12: 00$ & 68.7 & \multirow{6}{*}{625} & 215 & 5.1 & \multirow{6}{*}{58} & 13.8 & \multirow{6}{*}{131} & 776 & 243 & 78 & 234 \\
\hline 1.2 & $12: 04$ & 80.1 & & 32.9 & 5.9 & & 13.1 & & 955 & 422 & 187 & 49 \\
\hline 1.3 & $12: 03$ & 57.9 & & 107 & 5.3 & & 13.6 & & 654 & 131 & 32.3 & 311 \\
\hline $1-4$ & $12: 12$ & 68.1 & & 209 & 4.6 & & 14.2 & & 746 & 213 & 146 & 134 \\
\hline 1.5 & $12: 16$ & 51.3 & & 4.1 & 6.2 & & 12.7 & & 626 & 93 & 21.6 & 124 \\
\hline 1.6 & $12: 20$ & 49.0 & & 18 & 7.9 & & 11.2 & & 674 & 141 & 289 & 321 \\
\hline $2-1$ & $12: 01$ & 30.5 & \multirow{6}{*}{493} & -167 & 5.1 & \multirow{6}{*}{53} & 13.7 & \multirow{6}{*}{135} & 346 & .187 & 50.5 & 531 \\
\hline 2.2 & $12: 05$ & 53.3 & & 61 & 4.7 & & 14.1 & & 539 & 56 & 315 & 255 \\
\hline 2.3 & $12: 09$ & 72.1 & & 249 & 4.7 & & 14.0 & & 798 & 265 & 120 & 157 \\
\hline 2.4 & $12: 13$ & 74.0 & & 268 & 5.8 & & 13.1 & & 879 & 346 & .03 & -140 \\
\hline 2.5 & $12: 17$ & 22.3 & & .249 & 4.8 & & 14.0 & & 248 & .285 & 62.3 & 612 \\
\hline 2.6 & $12: 21$ & 43.5 & & -37 & 6.7 & & 12.2 & & 550 & 17 & 436 & 44.1 \\
\hline 3.1 & $12: 02$ & 20.4 & \multirow{6}{*}{479} & .258 & 3.8 & \multirow{6}{*}{46} & 14.8 & \multirow{6}{*}{142} & 214 & .319 & 765 & 771 \\
\hline $3 \cdot 2$ & $12: 06$ & 72.6 & & 254 & 4.5 & & 14.3 & & 790 & 257 & 62 & .09 \\
\hline 3.3 & $12: 10$ & 83.6 & & 364 & 4.3 & & 14.4 & & 902 & 359 & 133 & 79 \\
\hline $3-4$ & $12: 14$ & 58.6 & & 114 & 4.9 & & 13.9 & & 656 & 123 & 237 & 174 \\
\hline 3.5 & $12: 18$ & 29.5 & & .17 .7 & 4.2 & & 14.5 & & 316 & .21 .7 & 536 & 541 \\
\hline 3.6 & $12: 22$ & 22.9 & & -243 & 5.6 & & 13.2 & & 268 & .265 & 710 & 723 \\
\hline 4.1 & $12: 03$ & 6.2 & \multirow{6}{*}{28.9} & 410 & 4.0 & \multirow{6}{*}{40} & 14.7 & \multirow{6}{*}{147} & 66 & 46.7 & 91.7 & 93.1 \\
\hline $4 \cdot 2$ & $12: 07$ & 44.4 & & -28 & 2.9 & & 15.7 & & 442 & .91 & 432 & 428 \\
\hline $4 \cdot 3$ & $12: 11$ & 74.6 & & 274 & 3.4 & & 15.3 & & 163 & 230 & 206 & 194 \\
\hline $4-4$ & $12: 15$ & 39.9 & & .73 & 4.4 & & 14.4 & & 433 & .100 & 466 & 434 \\
\hline 4.5 & $12: 19$ & 3.8 & & -434 & 3.7 & & 15.0 & & 40 & -493 & 932 & 933 \\
\hline 4.5 & $12: 23$ & 4.4 & & -428 & 5.3 & & 13.6 & & 51 & $\triangle 8 B 2$ & 928 & 933 \\
\hline
\end{tabular}


CONSOL ENERGY INC.

AES GREENIDGE STATION
Client Reference No: 4700140111

CleanAir Project No:10192

Run 2: Inlet - Set 3

Date: $3 / 28 / 2007$

Start Time: $\quad$ 12:00

End Time: $12: 23$

Inlet - Oxygen (\%dv)

\begin{tabular}{|c|c|c|c|c|}
\hline AVG & 5.6 & 5.0 & 4.2 & 4.4 \\
\hline 6 & 8.5 & 6.9 & 6.3 & 6.4 \\
\hline 5 & 4.5 & 4.3 & 4.4 & 4.1 \\
\hline 4 & 4.3 & 3.8 & 3.6 & 3.4 \\
\hline 3 & 5.0 & 5.4 & 3.3 & 3.1 \\
\hline 2 & 3.3 & 3.3 & 3.2 & 2.8 \\
\hline 1 & 7.7 & 6.1 & 4.3 & 6.8 \\
\hline
\end{tabular}

7.0

4.3

3.8

4.2

3.2

6.2

4.8

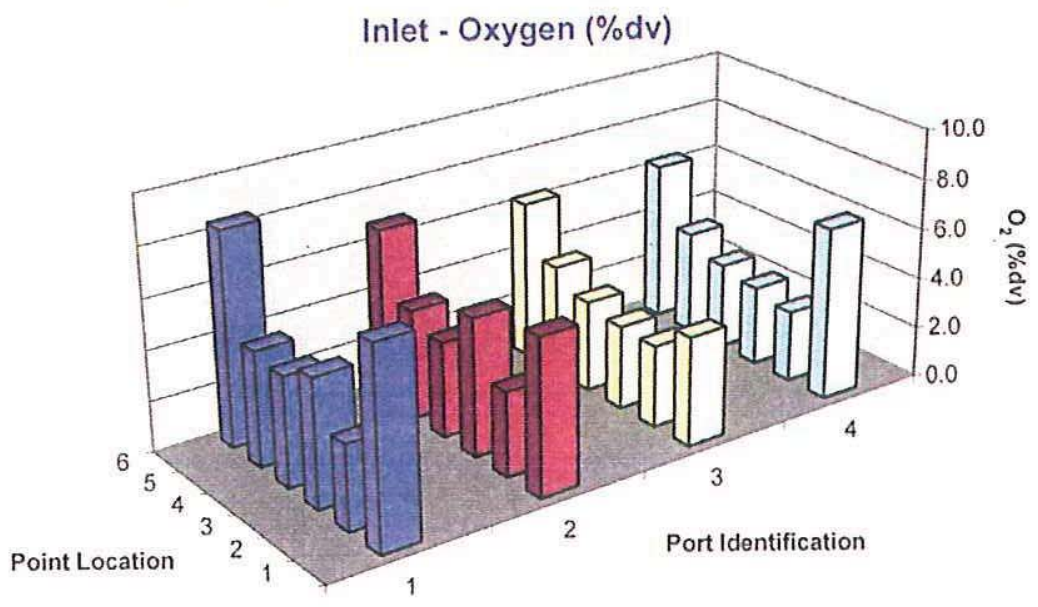

Inlet - Oxygen (\%dv) 
CONSOL ENERGY INC.

AES GREENIDGE STATION
Client Reference No: 4700140111

CleanAir Project No:10192

Run 2: Inlet - Set 3

Date: $3 / 28 / 2007$

Start Time: $\quad 12: 00$

End Time: $\quad 12: 23$

\begin{tabular}{|c|c|c|c|c|c|}
\hline \multicolumn{5}{|c|}{ Inlet - Carbon Dioxide (\%dv) } & \\
\hline AVG & 13.3 & 13.8 & 14.4 & 14.2 & \\
\hline 6 & 10.8 & 12.2 & 12.6 & 12.6 & 12.0 \\
\hline 5 & 14.2 & 14.4 & 14.3 & 14.5 & 14.3 \\
\hline 4 & 14.3 & 14.8 & 14.9 & 15.1 & 14.8 \\
\hline 3 & 13.8 & 13.4 & 15.2 & 15.4 & 14.4 \\
\hline 2 & 15.1 & 15.2 & 15.2 & 15.6 & 15.3 \\
\hline 1 & 11.4 & 12.7 & 14.4 & 12.2 & 12.7 \\
\hline & 1 & 2 & 3 & 4 & 13.9 \\
\hline
\end{tabular}

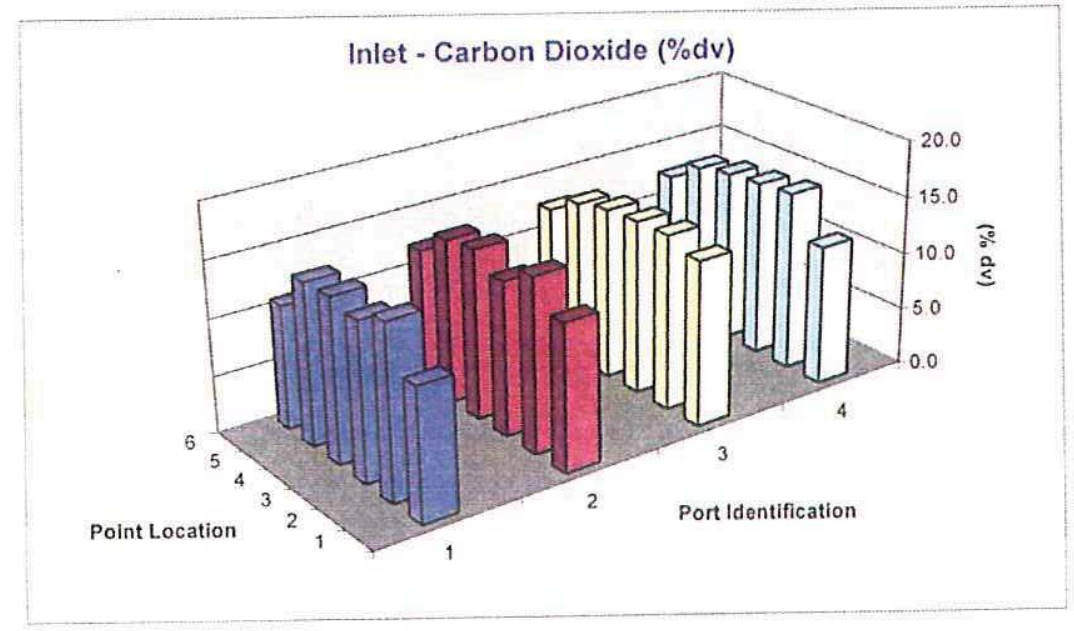

(佛)

CleanAir: 
CONSOL ENERGY INC.

AES GREENIDGE STATION
Client Reference No: 4700140111

CleanAir Project No:10192

Run 2: Inlet - Set 3

Date: $3 / 28 / 2007$

Start Time: $\quad 12: 00$

End Time: $\quad 12: 23$

Inlet - Nitrogen Oxides (ppmdv), uncorrected

\begin{tabular}{|c|c|c|c|c|}
\multicolumn{1}{c}{ AVG } & 78.8 & 74.5 & 80.0 & 73.1 \\
\hline $\mathbf{6}$ & 68.9 & 77.1 & 79.0 & 61.4 \\
\hline $\mathbf{5}$ & 65.4 & 59.2 & 63.6 & 55.6 \\
\hline $\mathbf{4}$ & 79.7 & 73.8 & 76.8 & 74.7 \\
\hline $\mathbf{3}$ & 85.5 & 81.9 & 96.4 & 94.0 \\
\hline 2 & 98.5 & 77.8 & 77.4 & 78.2 \\
\hline $\mathbf{1}$ & 74.5 & 77.3 & 86.9 & 74.4 \\
\hline & $\mathbf{1}$ & $\mathbf{2}$ & $\mathbf{3}$ & 4 \\
\hline
\end{tabular}

71.6

61.0

76.3

89.5

83.0

78.3

76.6

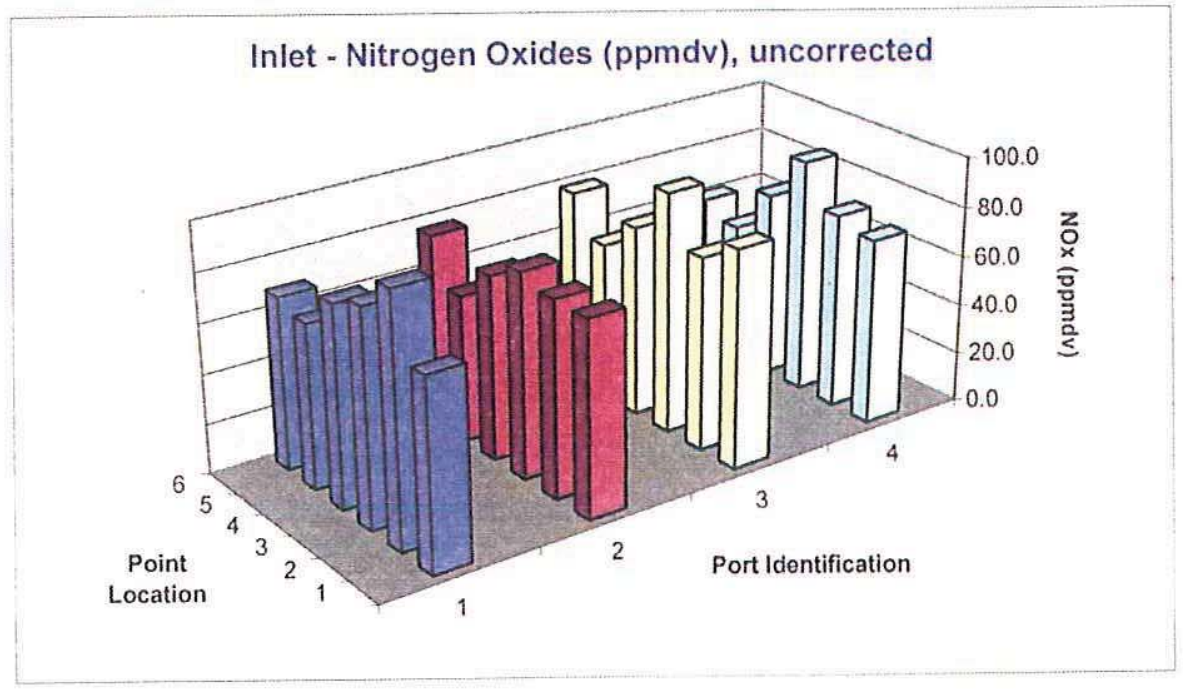

CleanAir. 
CONSOL ENERGY INC.

AES GREENIDGE STATION
Client Reference No: 4700140111

CleanAir Project No:10192

Run 2: Inlet - Set 3

Date: $3 / 28 / 2007$

Start Time: $\quad$ 12:00

End Time: $\quad 12: 23$

Inlet - Nitrogen Oxides (ppmdv @ $3 \% \mathrm{O}_{2}$ )

\begin{tabular}{|c|c|c|c|c|}
\multicolumn{1}{c|}{ AVG } & 92.5 & 84.5 & 85.8 & 79.6 \\
\hline $\mathbf{6}$ & 99.3 & 98.3 & 96.9 & 75.6 \\
\hline $\mathbf{5}$ & 71.5 & 63.9 & 68.8 & 59.2 \\
\hline $\mathbf{4}$ & 86.1 & 77.1 & 79.4 & 76.4 \\
\hline $\mathbf{3}$ & 96.4 & 94.7 & 98.0 & 94.6 \\
\hline $\mathbf{2}$ & 100.4 & 79.2 & 78.4 & 77.3 \\
\hline $\mathbf{1}$ & 101.3 & 93.7 & 93.6 & 94.6 \\
\hline
\end{tabular}

92.5

65.9

79.7

95.9

83.8

95.8

85.6

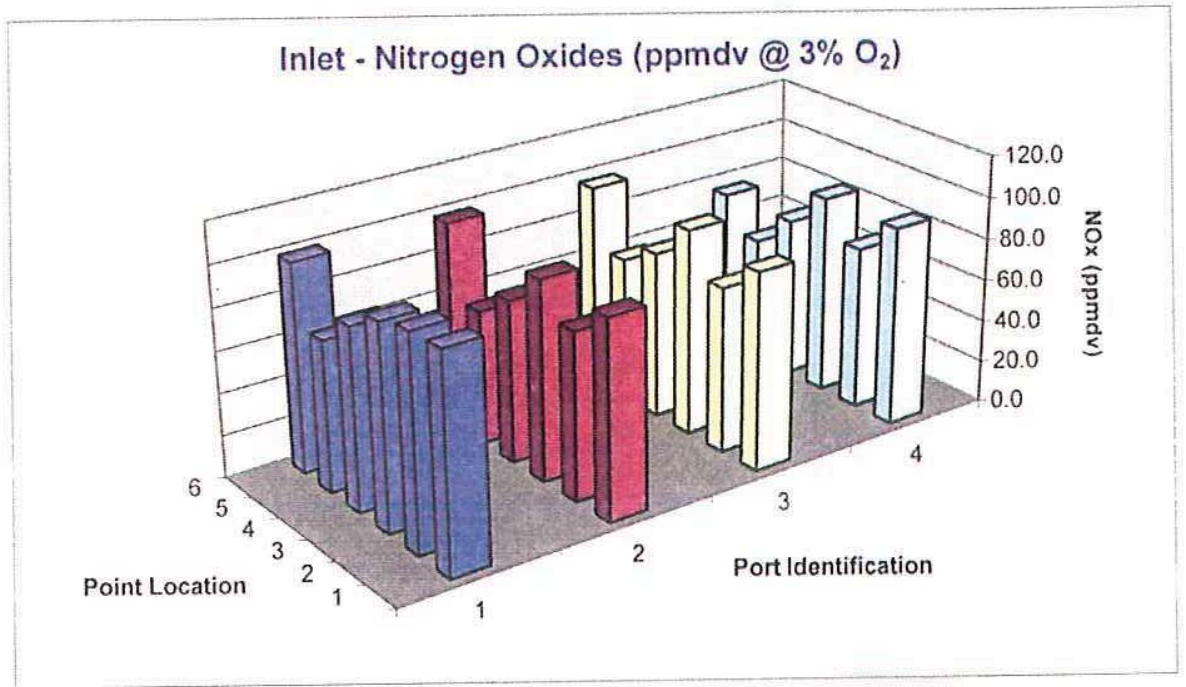


CONSOL ENERGY INC.

AES GREENIDGE STATION
Client Reference No: 4700140111

CleanAir Project No:10192

Run 2: Outlet - Set 3

Date: $3 / 28 / 2007$

Start Time: $\quad 12: 00$

End Time: $12: 23$

Outlet - Oxygen (\%dv)
\begin{tabular}{|c|c|c|c|c|}
\hline AVG & 5.8 & 5.3 & 4.6 & 4.0 \\
\hline $\mathbf{6}$ & 7.9 & 6.7 & 5.6 & 5.3 \\
\hline $\mathbf{5}$ & 6.2 & 4.8 & 4.2 & 3.7 \\
\hline 4 & 4.6 & 5.8 & 4.9 & 4.4 \\
\hline 3 & 5.3 & 4.7 & 4.3 & 3.4 \\
\hline $\mathbf{2}$ & 5.9 & 4.7 & 4.5 & 2.9 \\
\hline $\mathbf{1}$ & 5.1 & 5.1 & 3.8 & 4.0 \\
\hline & $\mathbf{1}$ & $\mathbf{2}$ & $\mathbf{3}$ & 4 \\
\hline
\end{tabular}

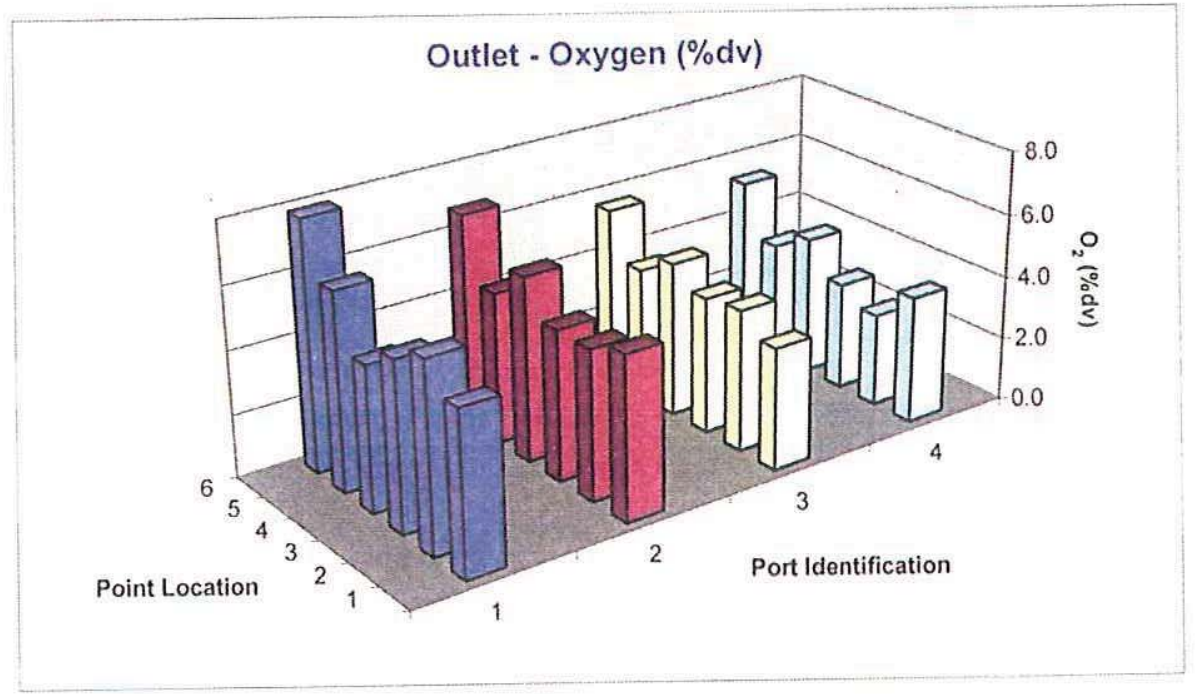


Run 2: Outlet - Set 3

Date: $3 / 28 / 2007$

Start Time: $\quad 12: 00$

End Time: $\quad 12: 23$

\begin{tabular}{|c|c|c|c|c|c|}
\hline \multicolumn{5}{|c|}{ Outlet - Carbon Dioxide (\%dv) } & \multirow[b]{3}{*}{12.6} \\
\hline AVG & 13.1 & 13.5 & 14.2 & 14.7 & \\
\hline 6 & 11.2 & 12.2 & 13.2 & 13.6 & \\
\hline 5 & 12.7 & 14.0 & 14.5 & 15.0 & 14.0 \\
\hline 4 & 14.2 & 13.1 & 13.9 & 14.4 & 13.9 \\
\hline 3 & 13.6 & 14.0 & 14.4 & 15.3 & 14.3 \\
\hline 2 & 13.1 & 14.1 & 14.3 & 15.7 & 14.3 \\
\hline 1 & 13.8 & 13.7 & 14.8 & 14.7 & 14.3 \\
\hline & 1 & 2 & 3 & 4 & 13.9 \\
\hline
\end{tabular}

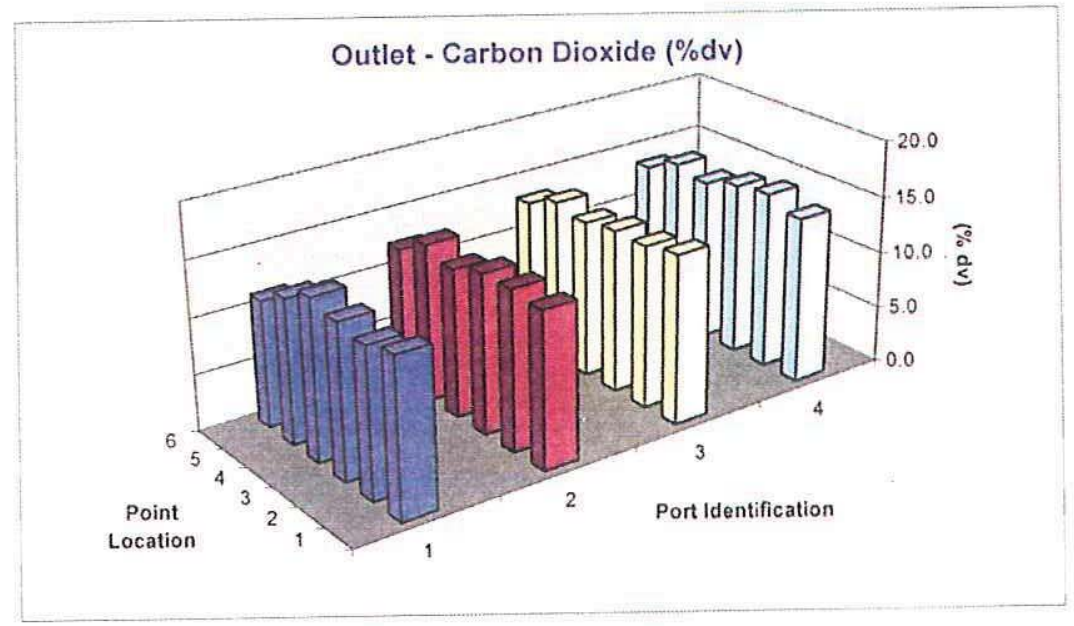


CONSOL ENERGY INC.

AES GREENIDGE STATION
Client Reference No: $\$ 700140111$

CleanAir Project No: 10192

Run 2: Outlet - Set 3

Date: $3 / 28 / 2007$

Start Time: $\quad 12: 00$

End Time: $12: 23$

Outlet - Nitrogen Oxides (ppmdv), uncorrected

\begin{tabular}{|c|c|c|c|c|}
\hline AVG & 62.5 & 49.3 & 47.9 & 28.9 \\
\hline $\mathbf{6}$ & 49.0 & 43.5 & 22.9 & 4.4 \\
\hline $\mathbf{5}$ & 51.3 & 22.3 & 29.5 & 3.8 \\
\hline 4 & 68.1 & 74.0 & 58.6 & 39.9 \\
\hline 3 & 57.9 & 72.1 & 83.6 & 74.6 \\
\hline $\mathbf{2}$ & 80.1 & 53.3 & 72.6 & 44.4 \\
\hline 1 & 68.7 & 30.5 & 20.4 & 6.2 \\
\hline
\end{tabular}

30.0

26.7

60.2

72.1

62.6

31.5

47.2

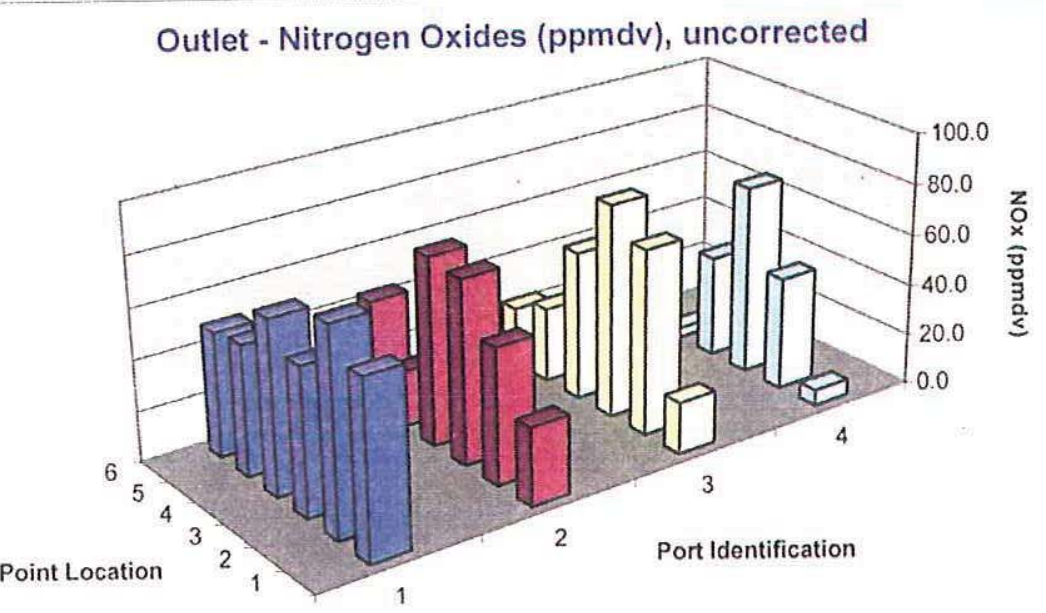


CONSOL ENERGY INC.

AES GREENIDGE STATION
Client Reference No: 4700140111

CleanAir Project No:10192

Run 2: Outlet - Set 3

Date: $3 / 28 / 2007$

Start Time: $\quad$ 12:00

End Time: $12: 23$

Outlet - Nitrogen Oxides (ppmdv @ 3\% $\mathrm{O}_{2}$ )

\begin{tabular}{|c|c|c|c|c|}
\hline AVG & 74.0 & 56.8 & 52.4 & 29.9 \\
\hline 6 & 67.4 & 55.0 & 26.8 & 5.1 \\
\hline 5 & 62.6 & 24.8 & 31.6 & 4.0 \\
\hline 4 & 74.6 & 87.9 & 65.6 & 43.3 \\
\hline 3 & 66.4 & 79.8 & 90.2 & 76.3 \\
\hline 2 & 95.5 & 58.9 & 79.0 & 44.2 \\
\hline 1 & 77.6 & 34.6 & 21.4 & 6.6 \\
\hline & 1 & 2 & 3 & 4 \\
\hline
\end{tabular}

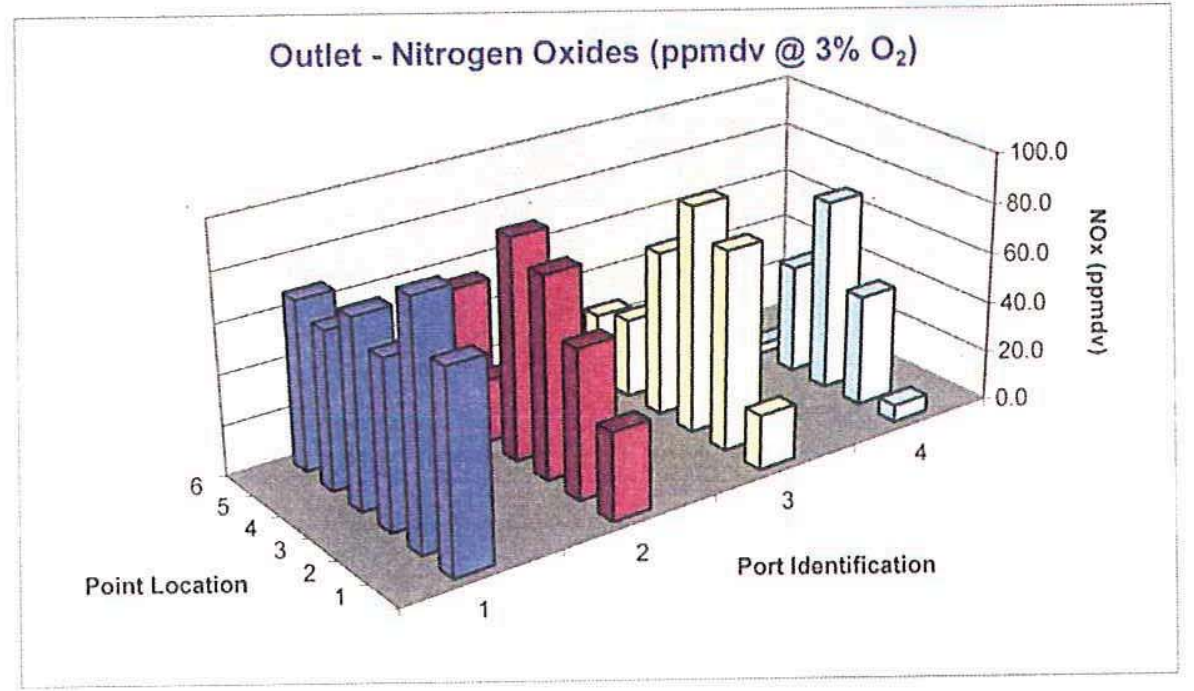


CONSOL ENERGY INC.

AES GREENIDGE STATION
Client Reference No: 4700140111

CleanAir Project No:10192

Run 2: Outlet-Set 3
Date: $3 / 28 / 2007$

Start Time: $\quad 12: 00$

End Time: $\quad 12: 23$

Removal Efficiency (ppmdv @ 3\% $\mathrm{O}_{2}$ )

\begin{tabular}{|c|c|c|c|c|c|}
\hline AVG & $19.5 \%$ & $32.6 \%$ & $38.0 \%$ & $64.2 \%$ & \\
\hline 6 & $32.1 \%$ & $44.1 \%$ & $72.3 \%$ & $93.3 \%$ & $60.4 \%$ \\
\hline 5 & $12.4 \%$ & $61.2 \%$ & $54.1 \%$ & $93.3 \%$ & $55.3 \%$ \\
\hline 4 & $13.4 \%$ & $-14.0 \%$ & $17.4 \%$ & $43.4 \%$ & $15.0 \%$ \\
\hline 3 & $31.1 \%$ & $15.7 \%$ & $7.9 \%$ & $19.4 \%$ & $18.5 \%$ \\
\hline 2 & $4.9 \%$ & $25.6 \%$ & $-0.9 \%$ & $42.8 \%$ & $18.1 \%$ \\
\hline 1 & $23.4 \%$ & $63.1 \%$ & $77.1 \%$ & $93.1 \%$ & $64.2 \%$ \\
\hline & 1 & 2 & 3 & 4 & $38.6 \%$ \\
\hline
\end{tabular}

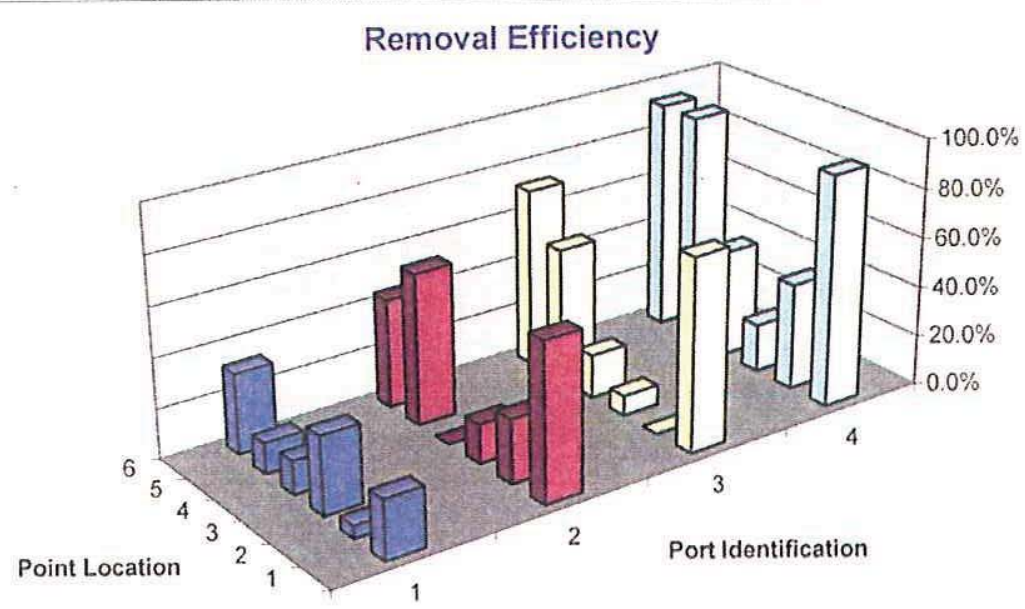


Clean Air Engineering Project $\# 10192$

Consol Energy

$\begin{array}{lrr}\text { Date: } & 3282007 & \text { Run \# (Cycle \#) } \\ \text { Start Time: } & 1248 & \\ \text { End Time: } & 1341 & \end{array}$

\begin{tabular}{|c|c|c|c|c|c|c|c|c|c|c|}
\hline $\begin{array}{l}\text { Inlet: } \\
\text { Point }\end{array}$ & Time Sampled & $\begin{array}{c}\text { Nox } \\
\text { ppmdv }\end{array}$ & $\begin{array}{c}\text { NOx } \\
\text { Port Avg }\end{array}$ & $\begin{array}{l}\text { PPM Dev } \\
\text { from Avg. }\end{array}$ & $\begin{array}{l}02 \\
\% d v\end{array}$ & $\begin{array}{c}\mathrm{O} 2 \\
\text { Port Avg }\end{array}$ & $\begin{array}{l}\mathrm{CO} 2 \\
\% d v\end{array}$ & $\begin{array}{c}\mathrm{CO} 2 \\
\text { Port Avg }\end{array}$ & $\begin{array}{c}\mathrm{NOx} \\
83 \% \mathrm{O} 2 \\
\end{array}$ & $\begin{array}{l}\text { PPM Dev } \\
\text { from Avg. }\end{array}$ \\
\hline 1.1 & $12: 48$ & 69.2 & & .5 .6 & 7.9 & & 11.3 & & 952 & 11.9 \\
\hline 1.2 & $12: 52$ & 101.3 & & 265 & 3.0 & & 15.3 & & 1013 & 180 \\
\hline 1.3 & $12: 56$ & 75.7 & 746 & 09 & 5.1 & 56 & 13.6 & 132 & 858 & 25 \\
\hline is & $13: 00$ & 70.5 & & -43 & 4.4 & & 14.2 & & 764 & 59 \\
\hline 1.5 & $13: 04$ & 61.6 & & .132 & 4.5 & & 14.2 & & 672 & .15 .1 \\
\hline 1.6 & $13: 08$ & 69.0 & & .58 & 8.5 & & 10.8 & & 999 & 166 \\
\hline $2 \cdot 1$ & $12: 49$ & 78.1 & & 33 & 6.2 & & 12.7 & & 954 & 121 \\
\hline 2.2 & $12: 53$ & 75.4 & & 0.6 & 3.3 & & 15.2 & & 766 & -57 \\
\hline 2.3 & $12: 57$ & 81.5 & 737 & 67 & 5.2 & 49 & 13.6 & 138 & 930 & 97 \\
\hline 24 & 13:01 & 72.5 & & .23 & 3.6 & & 14.9 & & 750 & .83 \\
\hline 2.5 & $13: 05$ & 56.0 & & -188 & 4.2 & & 14.4 & & 601 & .232 \\
\hline 2.6 & 13:09 & 78.7 & & 39 & 6.8 & & 12.1 & & 1002 & 169 \\
\hline 3.1 & $12: 50$ & 87.6 & & 128 & 4.4 & & 14.3 & & 949 & 116 \\
\hline 3.2 & $12: 54$ & 75.2 & & 04 & 3.1 & & 15.3 & & 757 & .76 \\
\hline 3.3 & $12: 58$ & 94.6 & 789 & 198 & 3.2 & 49 & 15.2 & 145 & 958 & 125 \\
\hline $3-4$ & $13: 02$ & 75.5 & & 07 & 3.5 & & 15.0 & & 777 & .56 \\
\hline 3.5 & 13:05 & 61.7 & & -131 & 4.2 & & 14.4 & & 653 & .170 \\
\hline 3.6 & $13: 10$ & 78.5 & & 37 & 6.2 & & 12.7 & & 958 & 125 \\
\hline $4-1$ & $12: 51$ & 74.3 & & .0 .5 & 6.1 & & 12.8 & & 899 & 66 \\
\hline 4.2 & $12: 55$ & 75.9 & & 11 & 2.8 & & 15.6 & & 751 & .82 \\
\hline $4 \cdot 3$ & $12: 59$ & 93.4 & 722 & 186 & 3.0 & 43 & 15.5 & 144 & 933 & 100 \\
\hline 4.4 & $13: 03$ & 73.0 & & -1.8 & 3.4 & & 15.1 & & 745 & .88 \\
\hline 4.5 & $13: 07$ & 54.7 & & -20.1 & 3.9 & & 14.7 & & 577 & .256 \\
\hline $4-6$ & 13:11 & 61.6 & & .132 & 6.5 & & 12.5 & & 764 & 69 \\
\hline
\end{tabular}


CONSOL ENERGY INC.

AES GREENIDGE STATION
Client Reference No: 4700140111

CleanAir Project No:10192

Run 3: Inlet - Set 1

Date: $3 / 28 / 2007$

Start Time: $\quad 12: 48$

End Time: $\quad 13: 16$

Inlet - Oxygen (\%dv)

\begin{tabular}{|c|c|c|c|c|}
\multicolumn{1}{|c|}{ AVG } & 5.6 & 4.9 & 4.1 & 4.3 \\
\hline 6 & 8.5 & 6.8 & 6.2 & 6.5 \\
\hline 5 & 4.5 & 4.2 & 4.2 & 3.9 \\
\hline 4 & 4.4 & 3.6 & 3.5 & 3.4 \\
\hline 3 & 5.1 & 5.2 & 3.2 & 3.0 \\
\hline 2 & 3.0 & 3.3 & 3.1 & 2.8 \\
\hline 1 & 7.9 & 6.2 & 4.4 & 6.1 \\
\hline & 1 & 2 & 3 & 4 \\
\hline
\end{tabular}

7.0

4.2

3.7

4.1

3.1

6.2

4.7

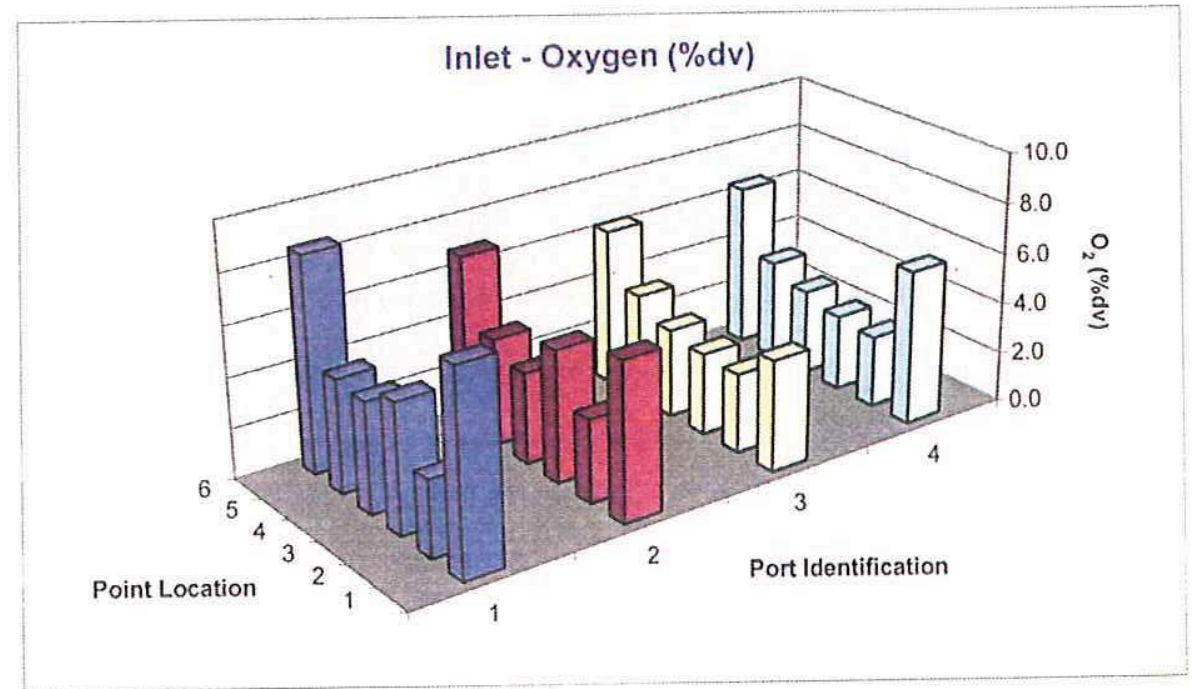


CONSOL ENERGY INC.

AES GREENIDGE STATION
Client Reference No: $\$ 700140111$

CleanAir Project No:10192

Run 3: Inlet - Set 1

Date: $3 / 28 / 2007$

Start Time: $\quad 12: 48$

End Time: $\quad 13: 16$

\begin{tabular}{|c|c|c|c|c|c|}
\hline \multicolumn{6}{|c|}{ Inlet - Carbon Dioxide (\%dv) } \\
\hline AVG & 13.2 & 13.8 & 14.5 & 14.4 & \\
\hline 6 & 10.8 & 12.1 & 12.7 & 12.5 & 12.0 \\
\hline 5 & 14.2 & 14.4 & 14.4 & 14.7 & 14.4 \\
\hline 4 & 14.2 & 14.9 & 15.0 & 15.1 & 14.8 \\
\hline 3 & 13.6 & 13.6 & 15.2 & 15.5 & 14.5 \\
\hline 2 & 15.3 & 15.2 & 15.3 & 15.6 & 15.4 \\
\hline 1 & 11.3 & 12.7 & 14.3 & 12.8 & 12.8 \\
\hline & 1 & 2 & 3 & 4 & 14.0 \\
\hline
\end{tabular}

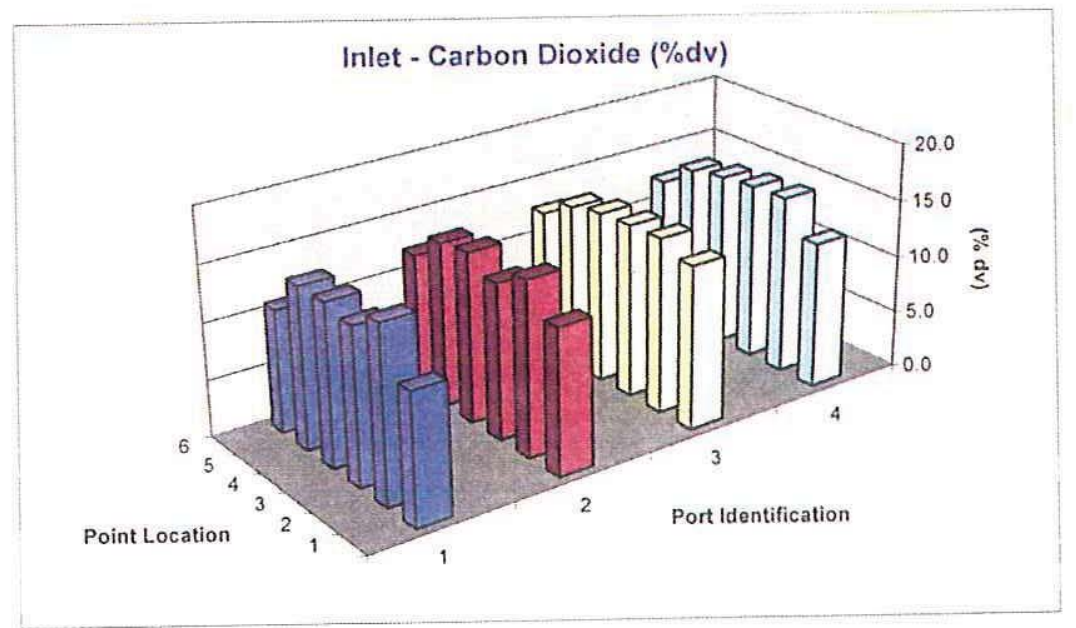


CONSOL ENERGY INC.

AES GREENIDGE STATION
Client Reference No: 4700140111

CleanAir Project No: 10192

Run 3: Inlet - Set 1

Date: $3 / 28 / 2007$

Start Time: $\quad 12: 48$

End Time: $\quad 13: 16$

Inlet - Nitrogen Oxides (ppmdv), uncorrected

\begin{tabular}{|c|c|c|c|c|c|}
\multicolumn{1}{c|}{ AVG } & 74.6 & 73.7 & 78.9 & 72.2 \\
\hline 6 & 69.0 & 78.7 & 78.5 & 61.6 & 72.0 \\
\hline 5 & 61.6 & 56.0 & 61.7 & 54.7 & 58.5 \\
\hline 4 & 70.5 & 72.5 & 75.5 & 73.0 \\
72.9 \\
\hline 3 & 75.7 & 81.5 & 94.6 & 93.4 \\
\hline 2 & 101.3 & 75.4 & 75.2 & 75.9 & 82.0 \\
\hline 1 & 69.2 & 78.1 & 87.6 & 74.3 & 77.3 \\
\hline & 1 & 2 & 3 & 4 \\
7
\end{tabular}

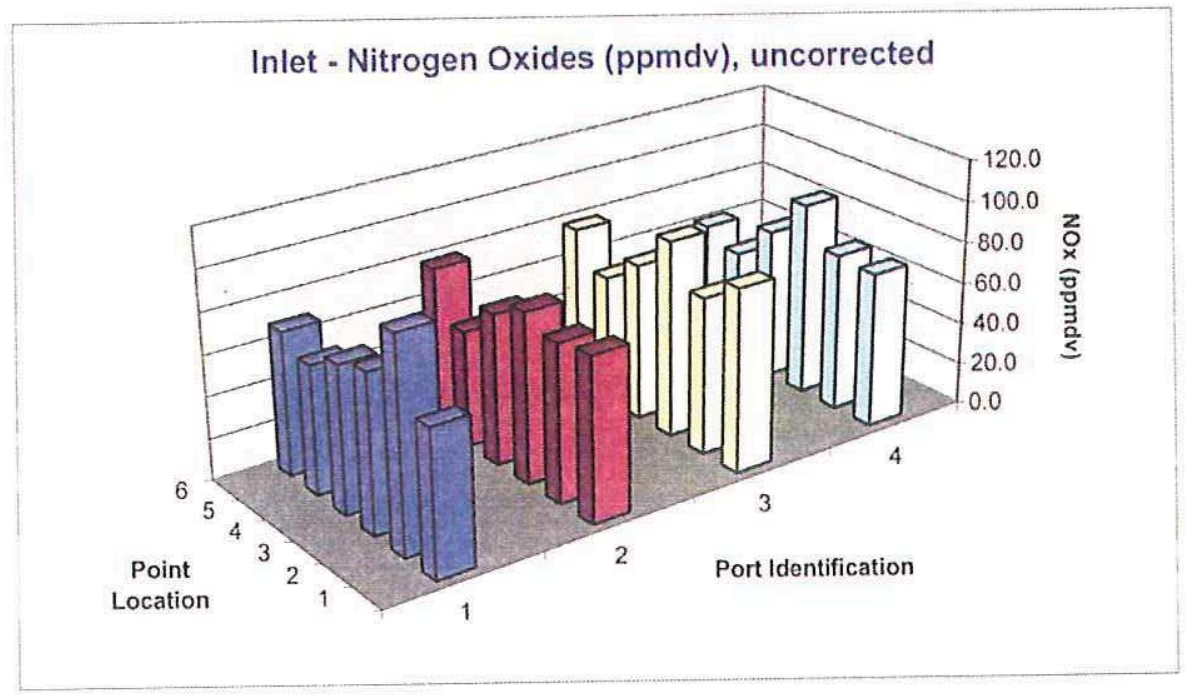


CONSOL ENERGY INC.

AES GREENIDGE STATION
Client Reference No: $\$ 700140111$

CleanAir Project No:10192

Run 3: Inlet - Set 1

Date: $3 / 28 / 2007$

Start Time: $\quad 12: 48$

End Time: $\quad 13: 16$

Inlet - Nitrogen Oxides (ppmdv @ $3 \% \mathrm{O}_{2}$ )

\begin{tabular}{|c|c|c|c|c|}
\multicolumn{1}{c|}{ AVG } & \multicolumn{1}{c}{87.6} & 83.4 & 84.4 & 77.8 \\
\hline $\mathbf{6}$ & 99.9 & 100.2 & 95.8 & 76.4 \\
\hline $\mathbf{5}$ & 67.2 & 60.1 & 66.3 & 57.7 \\
\hline $\mathbf{4}$ & 76.4 & 75.0 & 77.7 & 74.5 \\
\hline $\mathbf{3}$ & 85.8 & 93.0 & 95.8 & 93.3 \\
\hline $\mathbf{2}$ & 101.3 & 76.6 & 75.7 & 75.1 \\
\hline $\mathbf{1}$ & 95.2 & 95.4 & 94.9 & 89.9 \\
\hline
\end{tabular}

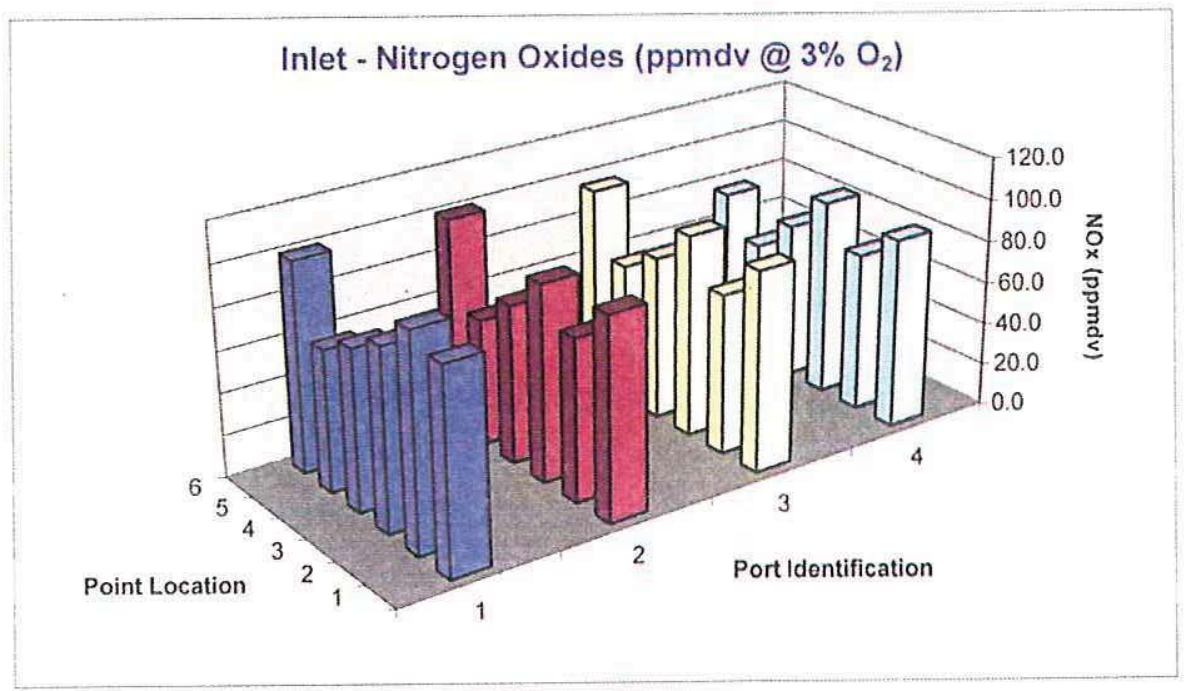


CONSOL ENERGY INC.

AES GREENIDGE STATION
Client Reference No: 4700140111

CleanAir Project No:10192

Run 3: Outlet - Set 1

Date: $3 / 28 / 2007$

Start Time: $\quad 12: 48$

End Time: $\quad 13: 16$

\begin{tabular}{|c|c|c|c|c|c|}
\hline \multicolumn{5}{|c|}{ Outlet - Oxygen (\%dv) } & \\
\hline AVG & 6.5 & 5.4 & 4.7 & 3.9 & \\
\hline 6 & 8.1 & 6.7 & 5.9 & 5.4 & 6.5 \\
\hline 5 & 5.1 & 5.0 & 4.2 & 3.5 & 4.5 \\
\hline 4 & 5.7 & 5.7 & 4.8 & 4.3 & 5.1 \\
\hline 3 & 7.3 & 5.5 & 5.2 & 3.3 & 5.3 \\
\hline 2 & 5.6 & 4.6 & 4.1 & 2.8 & 4.3 \\
\hline 1 & 6.9 & 5.3 & 4.1 & 3.9 & 5.0 \\
\hline & 1 & 2 & 3 & 4 & 5.1 \\
\hline
\end{tabular}

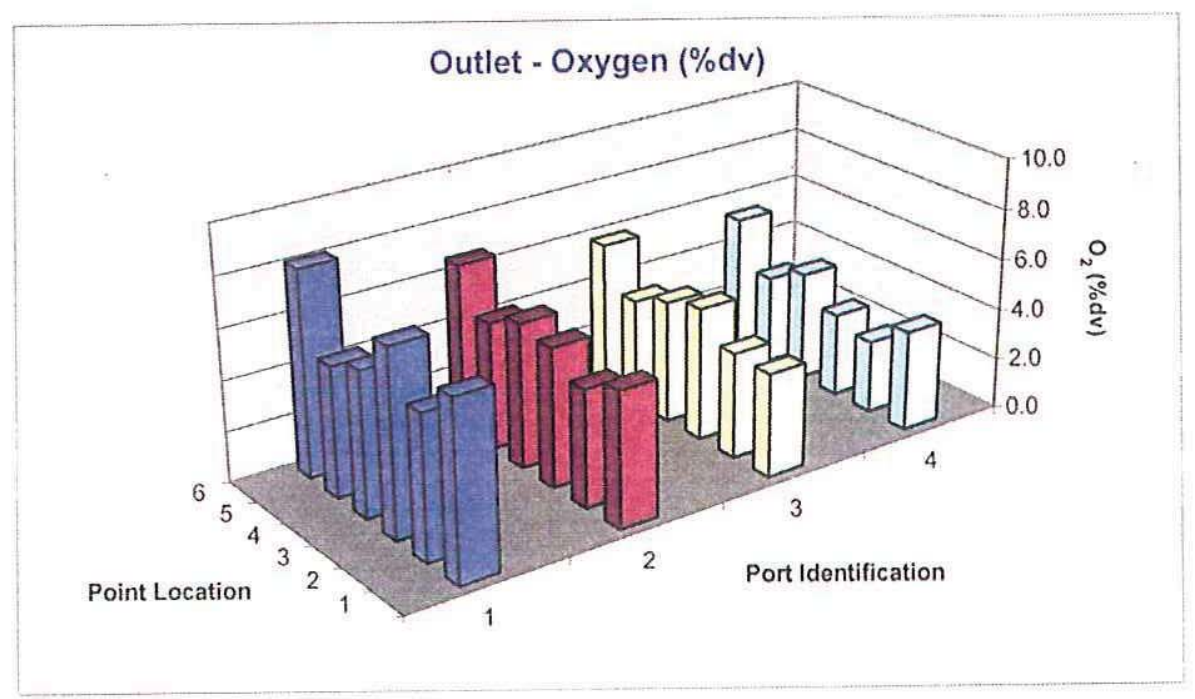

CleanAir. 
Run 3: Outlet - Set 1

Date: $3 / 28 / 2007$

Start Time: $\quad 12: 48$

End Time: $\quad 13: 16$

\begin{tabular}{|c|c|c|c|c|c|}
\hline \multicolumn{5}{|c|}{ Outlet - Carbon Dioxide (\%dv) } & \multirow[b]{3}{*}{12.5} \\
\hline AVG & 12.5 & 13.4 & 14.1 & 14.8 & \\
\hline 6 & 11.0 & 12.4 & 13.1 & 13.5 & \\
\hline 5 & 13.8 & 13.7 & 14.5 & 15.2 & 14.3 \\
\hline 4 & 13.2 & 13.2 & 14.0 & 14.4 & 13.7 \\
\hline 3 & 12.0 & 13.3 & 13.6 & 15.4 & 13.6 \\
\hline 2 & 13.3 & 14.2 & 14.5 & 15.8 & 14.4 \\
\hline 1 & 12.0 & 13.6 & 14.6 & 14.8 & 13.8 \\
\hline & 1 & 2 & 3 & 4 & 13.7 \\
\hline
\end{tabular}

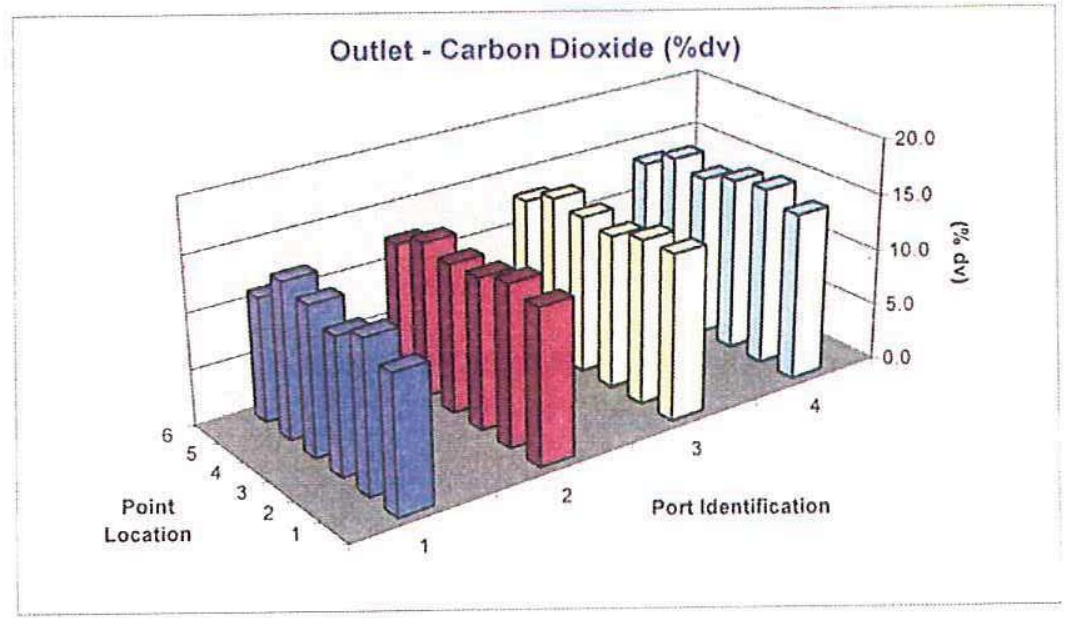


CONSOL ENERGY INC.

AES GREENIDGE STATION
Client Reference No: 4700140111

CleanAir Project No: 10192

Run 3: Outlet - Set 1

Date: $3 / 28 / 2007$

Start Time: $\quad 12: 48$

End Time: $\quad 13: 16$

\begin{tabular}{|c|c|c|c|c|c|}
\hline \multirow[b]{2}{*}{ AVG } & \multicolumn{5}{|c|}{ Outlet - Nitrogen Oxides (ppmdv), uncorrected } \\
\hline & 54.5 & 47.5 & 45.3 & 29.9 & \\
\hline 6 & 47.9 & 40.4 & 22.1 & 4.3 & 28.7 \\
\hline 5 & 54.3 & 33.1 & 30.7 & 3.8 & 30.5 \\
\hline 4 & 54.2 & 71.8 & 60.3 & 39.1 & 56.4 \\
\hline 3 & 48.1 & 56.5 & 72.3 & 78.3 & 63.8 \\
\hline 2 & 78.6 & 54.7 & 67.6 & 47.6 & 62.1 \\
\hline 1 & 43.7 & 28.3 & 18.6 & 6.3 & 24.2 \\
\hline & 1 & 2 & 3 & 4 & 44.3 \\
\hline
\end{tabular}

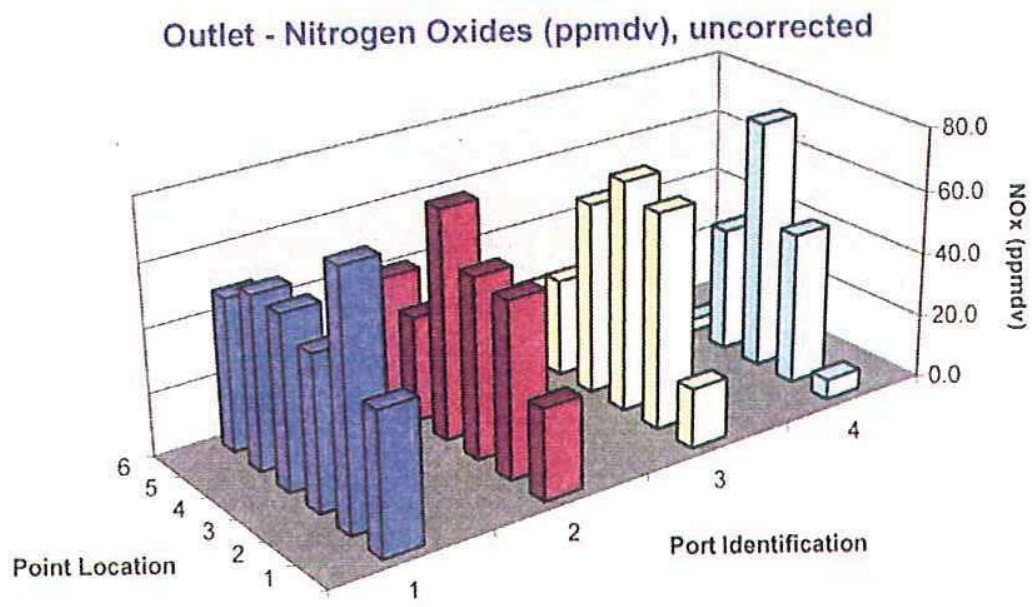


CONSOL ENERGY INC.

AES GREENIDGE STATION
Client Reference No: 4700140111

CleanAir Project No:10192

Run 3: Outlet - Set 1

Date: $3 / 28 / 2007$

Start Time: $\quad 12: 48$

End Time: $\quad 13: 16$

Outlet - Nitrogen Oxides (ppmdv @ 3\% $\mathrm{O}_{2}$ )

\begin{tabular}{|c|c|c|c|c|}
\hline AVG & 67.3 & 55.1 & 50.1 & 30.7 \\
\hline 6 & 67.1 & 50.8 & 26.3 & 5.0 \\
\hline 5 & 61.6 & 37.3 & 32.9 & 3.9 \\
\hline 4 & 63.8 & 84.6 & 67.0 & 42.2 \\
\hline 3 & 63.2 & 65.5 & 82.5 & 79.5 \\
\hline 2 & 92.0 & 60.0 & 72.2 & 47.2 \\
\hline 1 & 55.9 & 32.4 & 19.8 & 6.6 \\
\hline & 1 & 2 & 3 & 4 \\
\hline
\end{tabular}

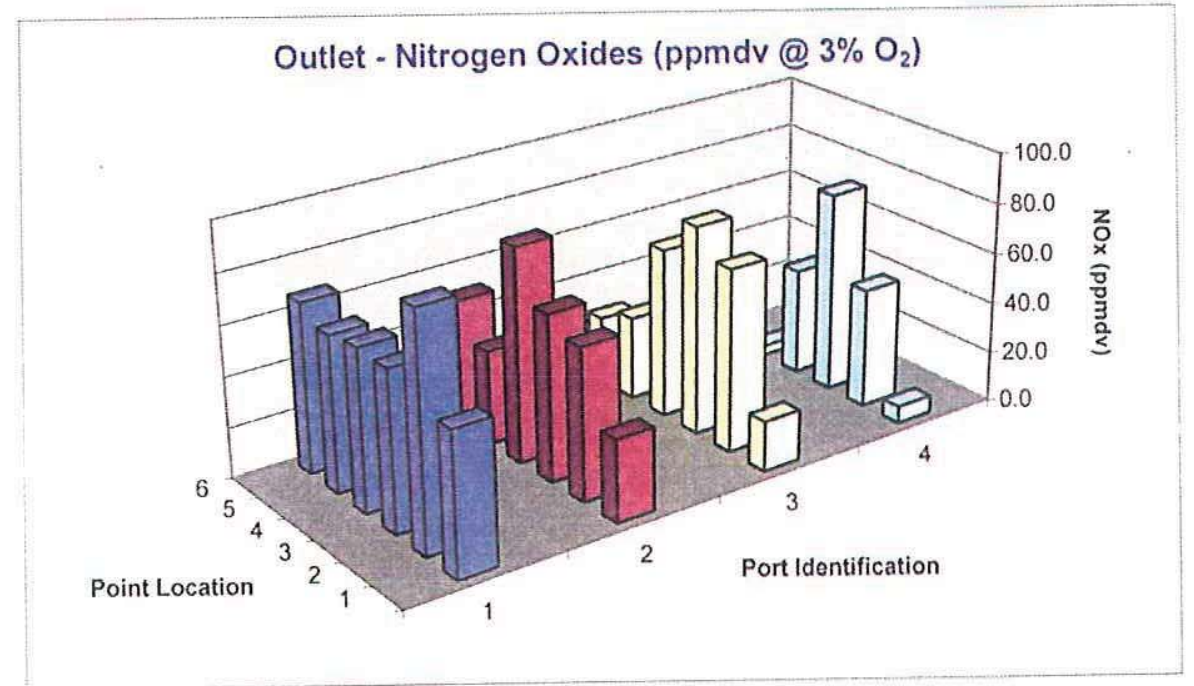


CONSOL ENERGY INC.

AES GREENIDGE STATION
Client Reference No: 4700140111

CleanAir Project No:10192

Run 3: Outlet - Set 1

Date: $3 / 28 / 2007$

Start Time: $\quad 12: 48$

End Time: $\quad 13: 16$

Removal Efficiency (ppmdv @ 3\% $\mathrm{O}_{2}$ )

\begin{tabular}{|c|c|c|c|c|c|}
\hline AVG & $22.4 \%$ & $32.0 \%$ & $39.0 \%$ & $62.5 \%$ & \\
\hline 6 & $32.8 \%$ & $49.3 \%$ & $72.6 \%$ & $93.5 \%$ & $62.1 \%$ \\
\hline 5 & $8.4 \%$ & $37.9 \%$ & $50.3 \%$ & $93.2 \%$ & $47.5 \%$ \\
\hline 4 & $16.5 \%$ & $-12.7 \%$ & $13.7 \%$ & $43.4 \%$ & $15.2 \%$ \\
\hline 3 & $26.3 \%$ & $29.6 \%$ & $13.9 \%$ & $14.8 \%$ & $21.1 \%$ \\
\hline 2 & $9.2 \%$ & $21.6 \%$ & $4.6 \%$ & $37.2 \%$ & $18.2 \%$ \\
\hline 1 & $41.3 \%$ & $66.1 \%$ & $79.2 \%$ & $92.6 \%$ & $69.8 \%$ \\
\hline & 1 & 2 & 3 & 4 & $39.0 \%$ \\
\hline
\end{tabular}

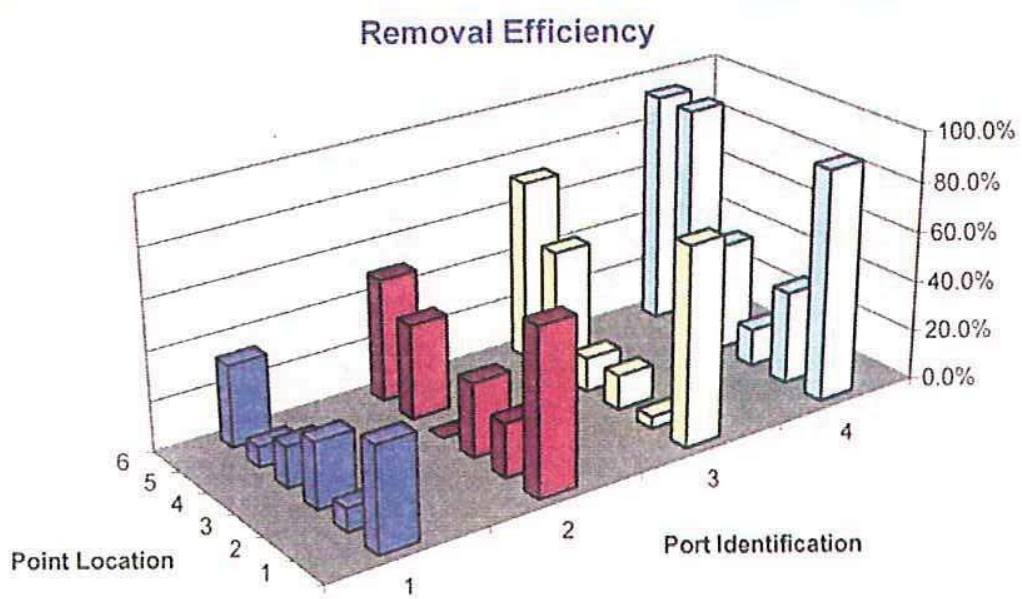


Clean Air Engineering Project $\# 1019$

Consol Energy

AES Dresden

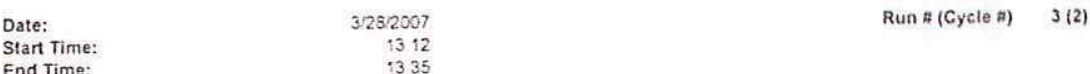

\begin{tabular}{|c|c|c|c|c|c|c|c|c|c|c|}
\hline $\begin{array}{l}\text { Inlet } \\
\text { Point }\end{array}$ & Time Sampled & $\begin{array}{c}\text { NOx } \\
\text { ppmdv }\end{array}$ & $\begin{array}{c}\text { NOx } \\
\text { Port Avg }\end{array}$ & $\begin{array}{l}\text { PPM Dev } \\
\text { from Avg. }\end{array}$ & $\begin{array}{l}02 \\
\% d v\end{array}$ & $\begin{array}{c}02 \\
\text { Port Avg }\end{array}$ & $\begin{array}{l}\mathrm{CO} 2 \\
\% d v\end{array}$ & $\begin{array}{c}\mathrm{CO} 2 \\
\text { Port Avg }\end{array}$ & $\begin{array}{c}\text { NOx } \\
3 \% 02 \\
30\end{array}$ & $\begin{array}{l}\text { PPM Dev } \\
\text { from Avg. }\end{array}$ \\
\hline 1.1 & $13: 12$ & 75.3 & & -1.3 & 7.8 & & 11.4 & & 1027 & 173 \\
\hline 1.2 & $13: 16$ & 99.3 & & 227 & 3.3 & & 15.2 & & 1008 & 153 \\
\hline 1.3 & $13: 20$ & 88.2 & 794 & 11.5 & 5.0 & 55 & 13.8 & 133 & 920 & 136 \\
\hline 1.4 & $13: 24$ & 79.9 & & 33 & 4.2 & & 14.4 & & 857 & 03 \\
\hline 1.5 & $13: 28$ & 62.9 & & -137 & 4.5 & & 14.2 & & 695 & -169 \\
\hline 1.6 & $13: 32$ & 70.6 & & 50 & 8.5 & & 10.8 & & 101.7 & 162 \\
\hline $2 \cdot 1$ & $13: 13$ & 79.2 & & 26 & 6.2 & & 12.7 & & 556 & 112 \\
\hline 2.2 & $13: 17$ & 77.4 & & 08 & 3.5 & & 15.1 & & 79.4 & 60 \\
\hline 2.3 & $13: 21$ & 86.4 & 743 & 98 & 5.2 & 49 & 13.6 & 138 & 986 & 132 \\
\hline $2-4$ & $13: 25$ & 70.1 & & .55 & 3.7 & & 14.8 & & 728 & .126 \\
\hline 2.5 & $13: 29$ & 54.0 & & .22 .6 & 4.2 & & 14.5 & & 577 & .277 \\
\hline 2.6 & $13: 33$ & 78.7 & & 21 & 6.9 & & 12.1 & & 1008 & 15.3 \\
\hline 3.1 & $13: 14$ & 86.5 & & 99 & 4.2 & & 14.5 & & 924 & 70 \\
\hline 3.2 & $13: 18$ & 76.3 & & .03 & 3.3 & & 15.1 & & 778 & .7 .7 \\
\hline 3.3 & 13:22 & 98.5 & 797 & 219 & 3.3 & 42 & 15.2 & 144 & 1000 & 146 \\
\hline $3-4$ & $13: 26$ & 76.7 & & 01 & 3.5 & & 15.0 & & 790 & .64 \\
\hline 3.5 & $13: 30$ & 62.9 & & -13.7 & 4.3 & & 14.3 & & 680 & .174 \\
\hline 3.6 & $13: 34$ & 77.3 & & 07 & 6.3 & & 12.6 & & 946 & 92 \\
\hline $4-1$ & $13: 15$ & 75.4 & & .12 & 6.1 & & 12.8 & & 914 & 59 \\
\hline $4 \cdot 2$ & 13:19 & 77.1 & & 05 & 2.9 & & 15.6 & & 767 & -88 \\
\hline $4 \cdot 3$ & $13: 23$ & 93.9 & 731 & 173 & 3.1 & 43 & 15.4 & is 3 & 942 & 87 \\
\hline $4-4$ & $13: 27$ & 74.3 & & -2.3 & 3.4 & & 15.1 & & 76.1 & .93 \\
\hline 4.5 & $13: 31$ & 57.0 & & .196 & 4.2 & & 14.5 & & 609 & .245 \\
\hline 4.6 & $13: 35$ & 61.1 & & -155 & 6.3 & & 12.7 & & 747 & .107 \\
\hline
\end{tabular}

Intet Averages

76.6

4.7

14.0

85.4

\begin{tabular}{|c|c|c|c|c|c|c|c|c|c|c|c|c|}
\hline $\begin{array}{l}\text { Outtet } \\
\text { Point }\end{array}$ & Time Sampled & $\begin{array}{c}\text { NOx } \\
\text { ppmdv }\end{array}$ & $\begin{array}{c}\text { NOx } \\
\text { Port Avg }\end{array}$ & $\begin{array}{l}\text { PPM Dev } \\
\text { from Avg. }\end{array}$ & $\begin{array}{l}\mathrm{O} 2 \\
\% \mathrm{dv}\end{array}$ & $\begin{array}{c}\text { O2 } \\
\text { Port Avg }\end{array}$ & $\begin{array}{l}\mathrm{CO} 2 \\
\% d v\end{array}$ & $\begin{array}{c}\mathrm{CO} 2 \\
\text { Port Avg }\end{array}$ & $\begin{array}{c}\mathrm{NOX} \\
\text { a } 3 \% 02\end{array}$ & $\begin{array}{l}\text { PPM Dev } \\
\text { from Avg. }\end{array}$ & $\begin{array}{l}\text { Removal } \\
\text { Efficiency }\end{array}$ & $\begin{array}{c}\text { Removal Eff } \\
\text { wi } \mathrm{O} 2 \text { correction }\end{array}$ \\
\hline 1.1 & $13: 12$ & 70.9 & & 247 & 5.0 & & 13.8 & & 800 & 278 & 58 & 222 \\
\hline 1.2 & $13: 16$ & 82.0 & & 35.8 & 5.8 & & 13.2 & & 97.2 & 450 & 174 & 35 \\
\hline 1.3 & $13: 20$ & 56.4 & 630 & 102 & 5.2 & 58 & 13.6 & 131 & 645 & 123 & 36.1 & 349 \\
\hline 1.4 & $13: 24$ & 68.3 & & 221 & 4.5 & & 14.3 & & 745 & 223 & 145 & 132 \\
\hline 1.5 & $13: 28$ & 48.8 & & 25 & 6.3 & & 12.7 & & 597 & 7.5 & 224 & 129 \\
\hline 1.6 & $13: 32$ & 51.7 & & 55 & 7.8 & & 11.3 & & 709 & 187 & 268 & 303 \\
\hline 2.1 & $13: 13$ & 30.1 & & .161 & 5.5 & & 13.3 & & 350 & .172 & 520 & 638 \\
\hline 2.2 & $13: 17$ & 51.2 & & 50 & 4.9 & & 13.9 & & 571 & 49 & 339 & 281 \\
\hline 2.3 & $13: 21$ & 64.7 & $\angle B 1$ & 185 & 4.8 & 54 & 14.0 & 134 & 717 & 195 & 251 & 273 \\
\hline 2.4 & $13: 25$ & 63.8 & & 176 & 5.5 & & 13.4 & & 742 & 220 & 90 & 19 \\
\hline 2.5 & $13: 29$ & 37.8 & & -84 & 5.2 & & 13.6 & & 43.1 & .91 & 300 & 253 \\
\hline 2.6 & 13:33 & 40.7 & & .55 & 6.7 & & 12.3 & & 51.4 & .08 & 483 & 490 \\
\hline 3.1 & $13: 14$ & 17.9 & & .283 & 4.5 & & 14.2 & & 195 & .32 .7 & 793 & 789 \\
\hline 3.2 & $13: 18$ & 41.8 & & -44 & 4.1 & & 14.5 & & 446 & .7 .6 & 452 & 427 \\
\hline 3.3 & $13: 22$ & 65.1 & 451 & 189 & 4.4 & 46 & 14.4 & 141 & 704 & 182 & 33.9 & 296 \\
\hline $3-4$ & $13: 26$ & 69.5 & & 23.3 & 4.4 & & 14.2 & & 754 & 232 & 94 & 46 \\
\hline 3.5 & $13: 30$ & 55.4 & & 92 & 4.9 & & 13.9 & & 619 & 97 & 11.9 & 90 \\
\hline 3.6 & $13: 34$ & 20.8 & & .254 & 5.3 & & 13.5 & & 239 & .283 & 731 & 747 \\
\hline 4.1 & $13: 15$ & 6.1 & & 401 & 3.9 & & 14.8 & & 64 & -458 & 919 & 930 \\
\hline 4.2 & $13: 19$ & 45.5 & & .07 & 2.8 & & 15.9 & & 449 & .7 .3 & 410 & 414 \\
\hline $4 \cdot 3$ & $13: 23$ & 75.7 & 287 & 295 & 3.3 & 39 & 15.4 & 148 & 73.1 & 249 & 194 & 181 \\
\hline 4.4 & $13: 27$ & 37.3 & & -89 & 4.4 & & 14.4 & & 404 & .118 & 49.8 & 469 \\
\hline 4.5 & $13: 31$ & 3.6 & & -426 & 3.8 & & 14.9 & & 38 & 43.4 & 93.7 & 938 \\
\hline 4.6 & $13: 35$ & 4.2 & & -420 & 5.3 & & 13.6 & & 48 & .474 & 931 & 936 \\
\hline
\end{tabular}


CONSOL ENERGY INC.

AES GREENIDGE STATION
Client Reference No: 4700140111

CleanAir Project No:10192

Run 3: Inlet - Set 2

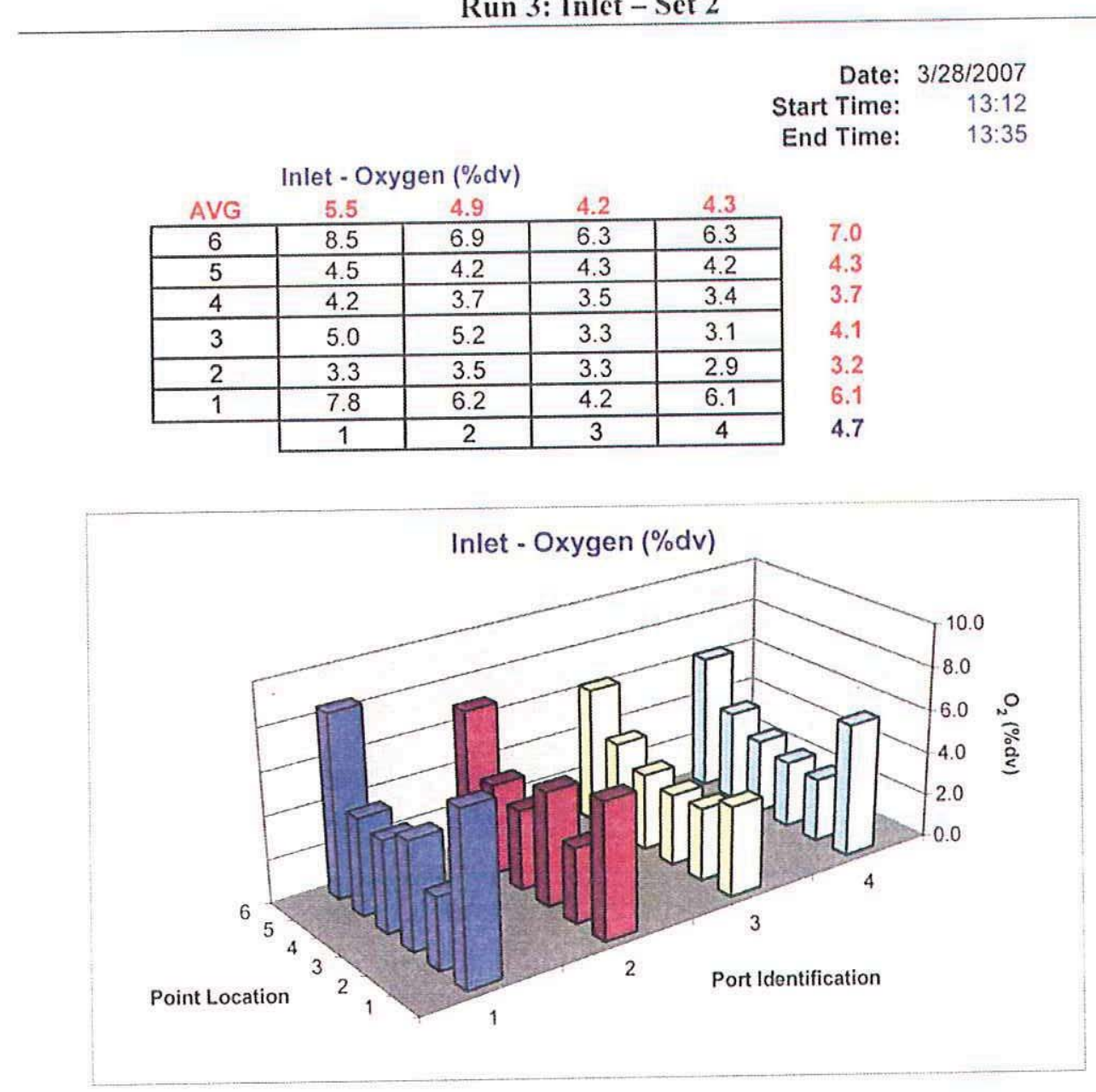


CONSOL ENERGY INC.

AES GREENIDGE STATION
Client Reference No: $\$ 700140111$

CleanAir Project No:10192

Run 3: Inlet - Set 2

$\begin{array}{rr}\text { Date: } & 3 / 28 / 2007 \\ \text { Start Time: } & 13: 12 \\ \text { End Time: } & 13: 35\end{array}$

Inlet - Carbon Dioxide (\%dv)

\begin{tabular}{|c|c|c|c|c|}
\hline AVG & 13.3 & 13.8 & 14.4 & 14.3 \\
\hline $\mathbf{6}$ & 10.8 & 12.1 & 12.6 & 12.7 \\
\hline $\mathbf{5}$ & 14.2 & 14.5 & 14.3 & 14.5 \\
\hline $\mathbf{4}$ & 14.4 & 14.8 & 15.0 & 15.1 \\
\hline $\mathbf{3}$ & 13.8 & 13.6 & 15.2 & 15.4 \\
\hline $\mathbf{2}$ & 15.2 & 15.1 & 15.1 & 15.6 \\
\hline $\mathbf{1}$ & 11.4 & 12.7 & 14.5 & 12.8 \\
\hline & $\mathbf{1}$ & $\mathbf{2}$ & $\mathbf{3}$ & $\mathbf{4}$ \\
\hline
\end{tabular}

12.0

14.4

14.8

14.5

15.2

12.8

14.0

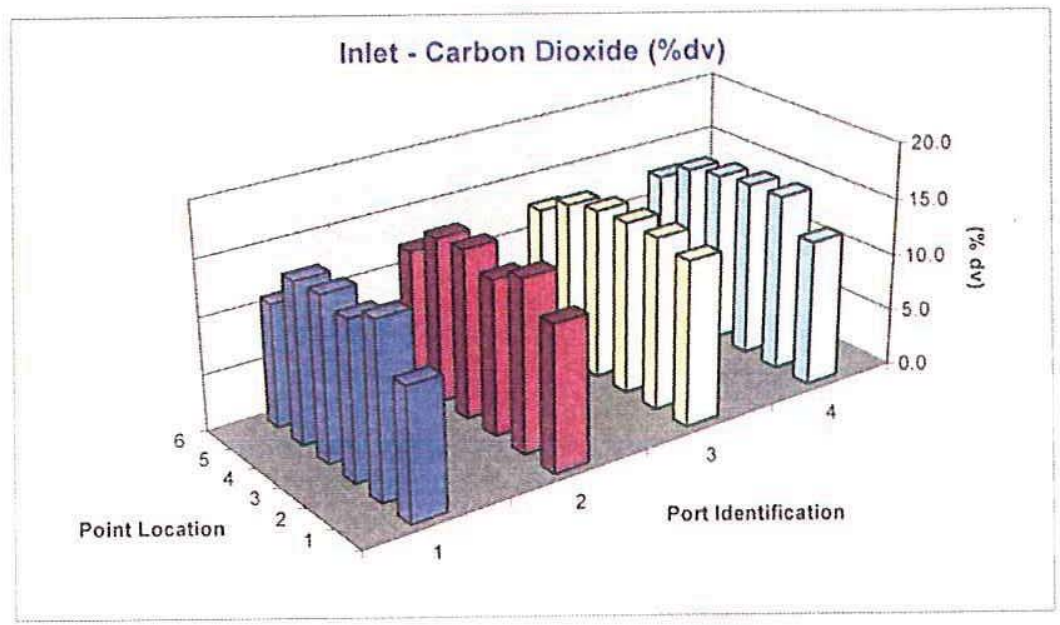

(撒)

CleanAir: 
CONSOL ENERGY INC.

AES GREENIDGE STATION
Client Reference No: 4700140111

CleanAir Project No: 10192

Run 3: Inlet - Set 2

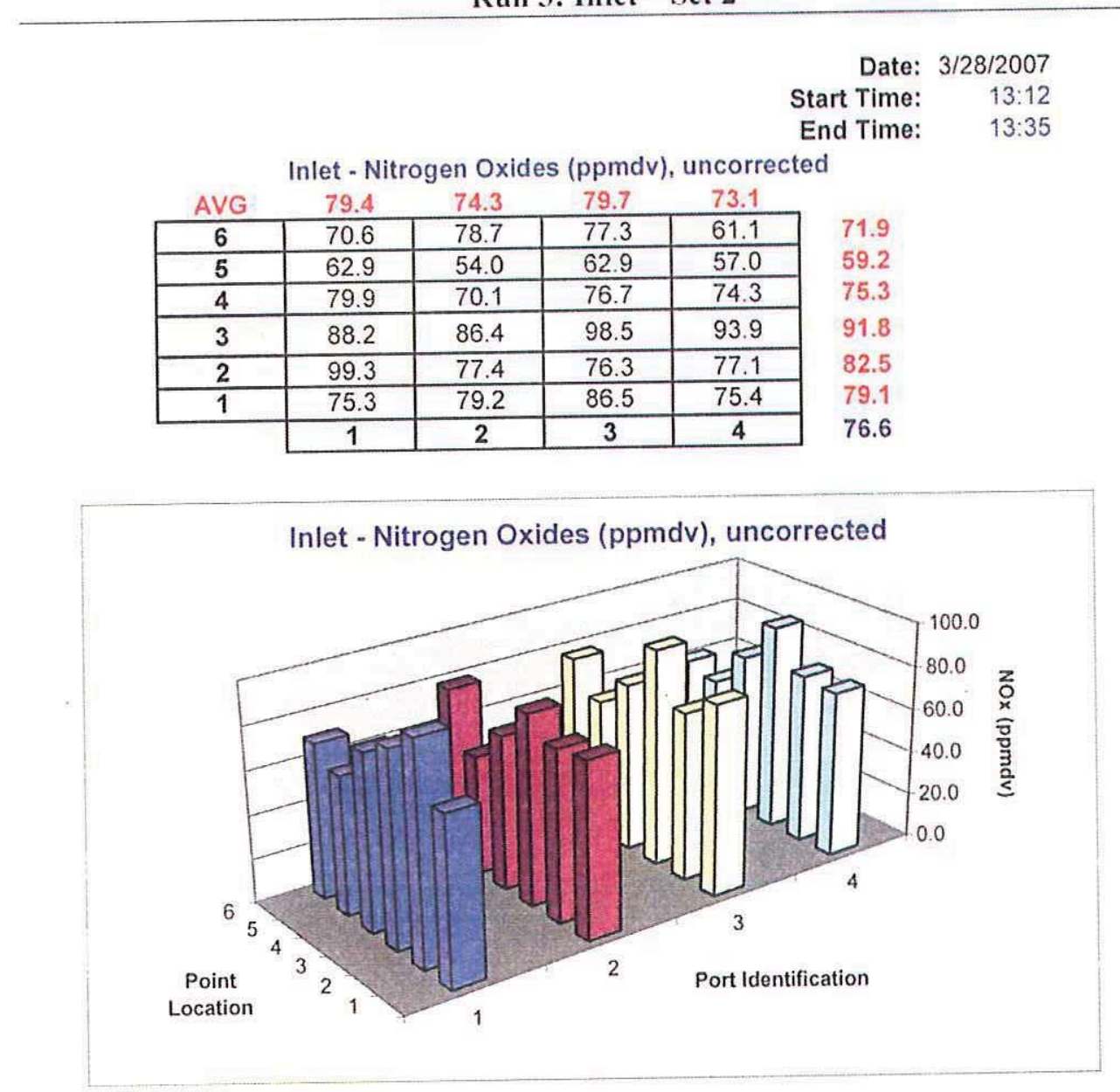


CONSOL ENERGY INC.

AES GREENIDGE STATION
Client Reference No: $\$ 700140111$

CleanAir Project No: 10192

Run 3: Inlet - Set 2

Date: $3 / 28 / 2007$

Start Time: $\quad 13: 12$

End Time: $\quad 13: 35$

Inlet - Nitrogen Oxides (ppmdv @ 3\% $\mathrm{O}_{2}$ )

\begin{tabular}{|c|c|c|c|c|c|}
\hline AVG & 93.1 & 84.3 & 85.3 & 79.0 & \\
\hline 6 & 101.7 & 100.8 & 94.6 & 74.7 & 92.9 \\
\hline 5 & 68.5 & 57.7 & 68.0 & 60.9 & 63.8 \\
\hline 4 & 85.7 & 72.8 & 79.0 & 76.1 & 78.4 \\
\hline 3 & 99.0 & 98.6 & 100.0 & 94.2 & 98.0 \\
\hline 2 & 100.8 & 79.4 & 77.8 & 76.7 & 83.7 \\
\hline 1 & 102.7 & 96.6 & 92.4 & 91.4 & 95.8 \\
\hline & 1 & 2 & 3 & 4 & 85.4 \\
\hline
\end{tabular}

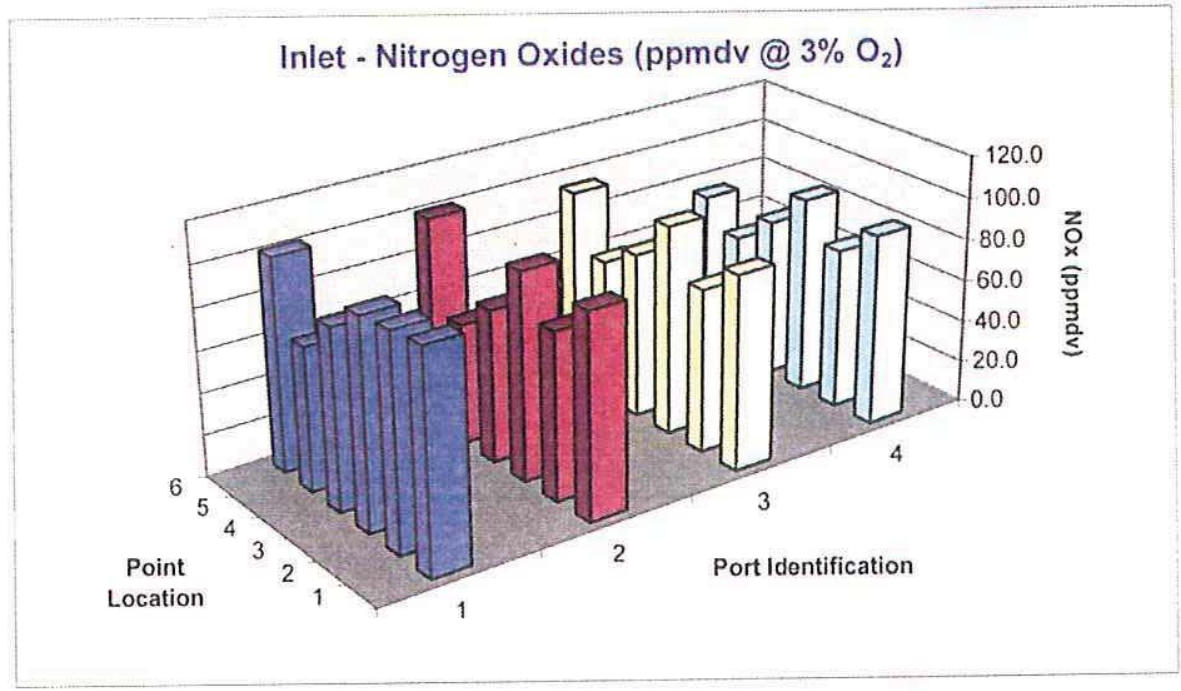


CONSOL ENERGY INC.

AES GREENIDGE STATION
Client Reference No: 4700140111 CleanAir Project No: 10192

Run 3: Outlet-Set 2

Date: $3 / 28 / 2007$

Start Time: $\quad 13: 12$

End Time: $\quad 13: 35$

\begin{tabular}{|c|c|c|c|c|c|}
\hline \multicolumn{5}{|c|}{ Outlet - Oxygen (\%dv) } & \\
\hline AVG & 5.8 & 5.4 & 4.6 & 3.9 & \\
\hline 6 & 7.8 & 6.7 & 5.3 & 5.3 & 6.3 \\
\hline 5 & 6.3 & 5.2 & 4.9 & 3.8 & 5.0 \\
\hline 4 & 4.5 & 5.5 & 4.4 & 4.4 & 4.7 \\
\hline 3 & 5.2 & 4.8 & 4.4 & 3.3 & 4.4 \\
\hline 2 & 5.8 & 4.9 & 4.1 & 2.8 & 4.4 \\
\hline 1 & 5.0 & 5.5 & 4.5 & 3.9 & 4.7 \\
\hline & 1 & 2 & 3 & 4 & 4.9 \\
\hline
\end{tabular}

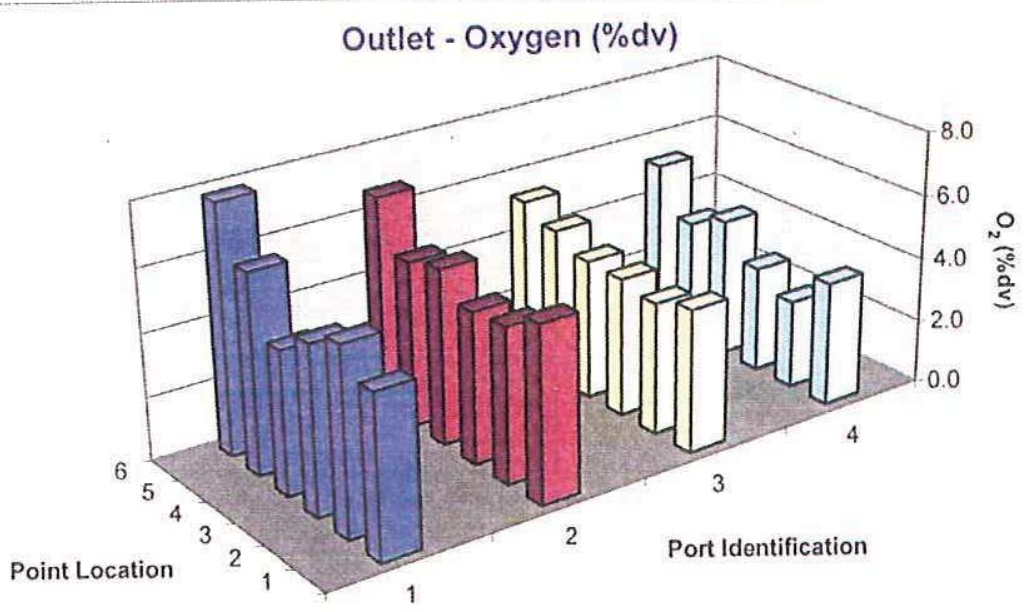


CONSOL ENERGY INC.

AES GREENIDGE STATION
Client Reference No: $\$ 700140111$

CleanAir Project No: 10192

Run 3: Outlet - Set 2

\begin{tabular}{|c|c|c|c|c|c|}
\hline & & & $\begin{array}{l}\text { Date: } \\
\text { at Time: } \\
\text { ad Time: }\end{array}$ & $\begin{array}{r}28 / 2007 \\
13: 12 \\
13: 35\end{array}$ & \\
\hline \multicolumn{6}{|c|}{ Outlet - Carbon Dioxide (\%dv) } \\
\hline AVG & 13.1 & 13.4 & 14.1 & 14.8 & \\
\hline 6 & 11.3 & 12.3 & 13.5 & 13.6 & 12.7 \\
\hline 5 & 12.7 & 13.6 & 13.9 & 14.9 & 13.8 \\
\hline 4 & 14.3 & 13.4 & 14.2 & 14.4 & 14.1 \\
\hline 3 & 13.6 & 14.0 & 14.4 & 15.4 & 14.3 \\
\hline 2 & 13.2 & 13.9 & 14.5 & 15.9 & 14.4 \\
\hline 1 & 13.8 & 13.3 & 14.2 & 14.8 & 14.0 \\
\hline & 1 & 2 & 3 & 4 & 13.9 \\
\hline
\end{tabular}

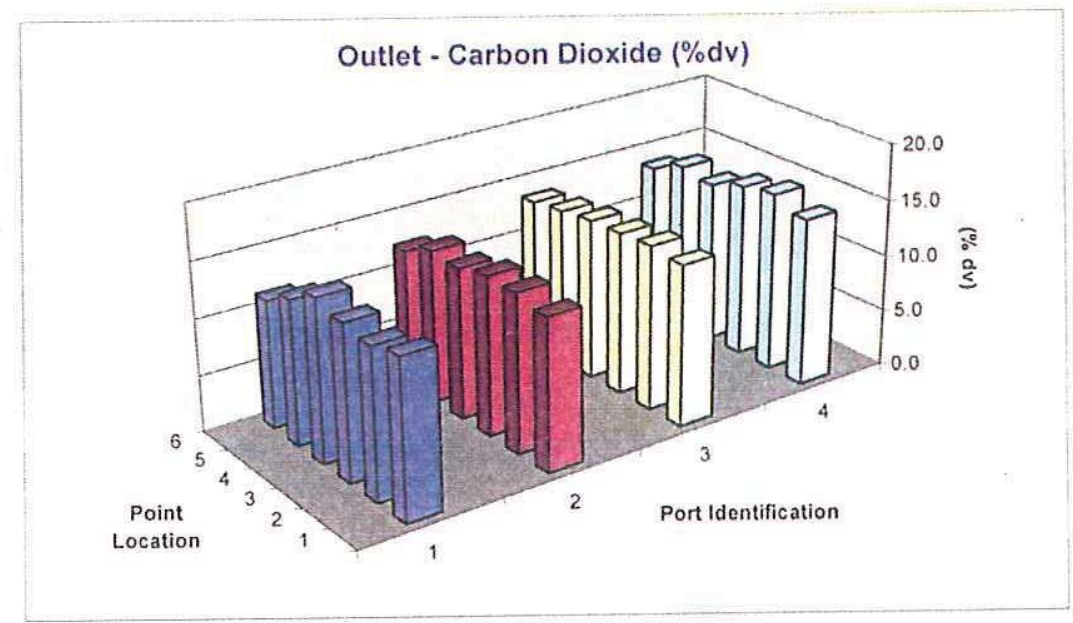


CONSOL ENERGY INC.

AES GREENIDGE STATION
Client Reference No: 4700140111

CleanAir Project No:10192

Run 3: Outlet - Set 2

Date: $3 / 28 / 2007$

Start Time: $\quad 13: 12$

End Time: $\quad 13: 35$

Outlet - Nitrogen Oxides (ppmdv), uncorrected

\begin{tabular}{|c|c|c|c|c|}
\hline AVG & 63.0 & 48.1 & 45.1 & 28.7 \\
\hline 6 & 51.7 & 40.7 & 20.8 & 4.2 \\
\hline 5 & 48.8 & 37.8 & 55.4 & 3.6 \\
\hline 4 & 68.3 & 63.8 & 69.5 & 37.3 \\
\hline 3 & 56.4 & 64.7 & 65.1 & 75.7 \\
\hline 2 & 82.0 & 51.2 & 41.8 & 45.5 \\
\hline 1 & 70.9 & 30.1 & 17.9 & 6.1 \\
\hline & 1 & 2 & 3 & 4 \\
\hline
\end{tabular}

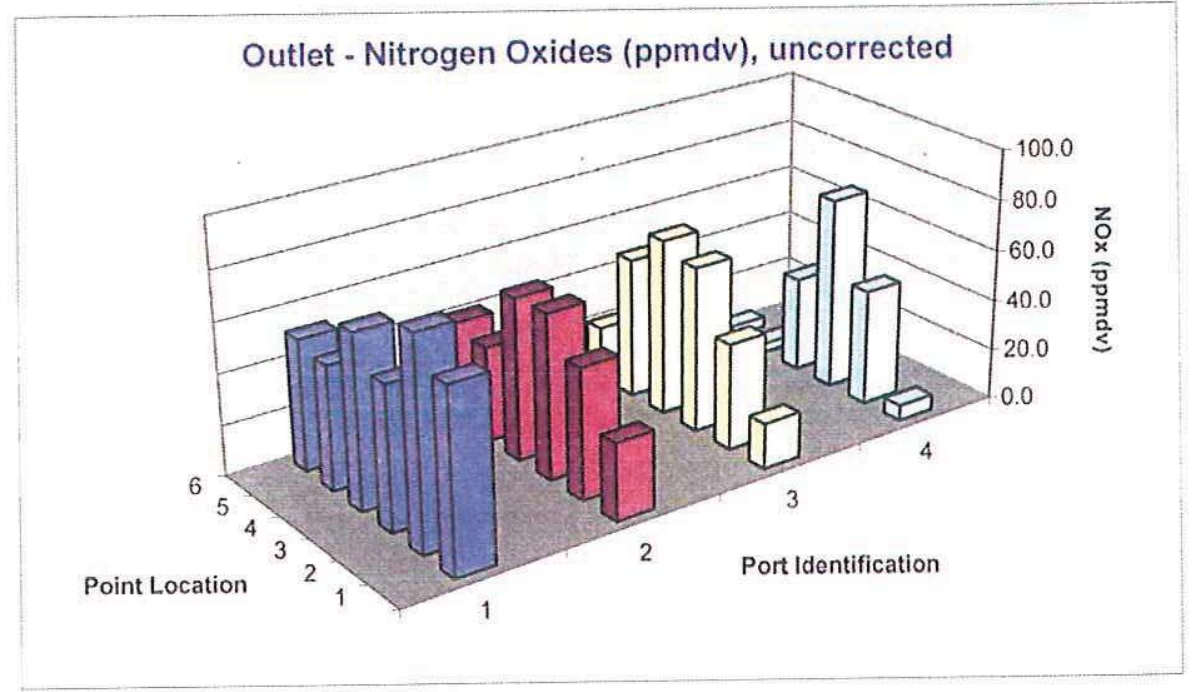

(艩)

CleanAir 